\title{
Dagmar Burkhart
}

\section{Untersuchungen zur Stratigraphie und Chronologie der südslavischen Volksepik}

Verlag Otto Sagner München · Berlin · Washington D.C.

Digitalisiert im Rahmen der Kooperation mit dem DFG-Projekt „Digi20“

der Bayerischen Staatsbibliothek, München. OCR-Bearbeitung und Erstellung des eBooks durch den Verlag Otto Sagner:

http://verlag.kubon-sagner.de

( $)$ bei Verlag Otto Sagner. Eine Verwertung oder Weitergabe der Texte und Abbildungen, insbesondere durch Vervielfältigung, ist ohne vorherige schriftliche Genehmigung des Verlages unzulässig.

«Verlag Otto Sagner» ist ein Imprint der Kubon \& Sagner GmbH. 


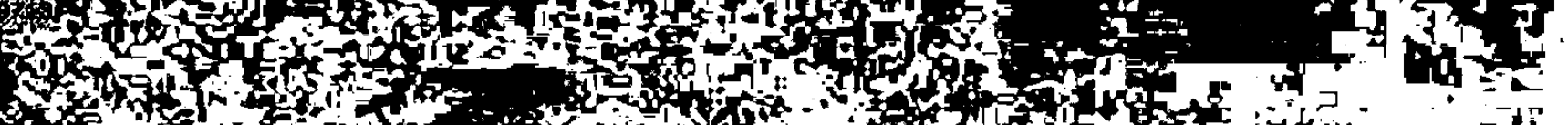

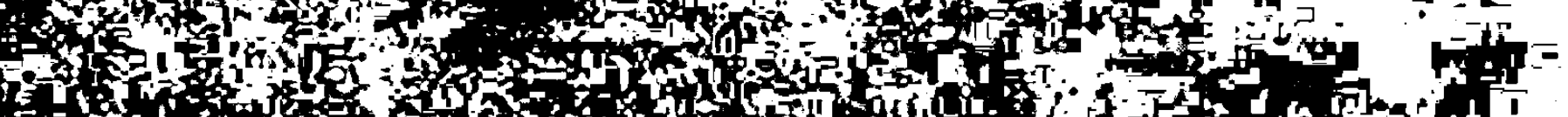

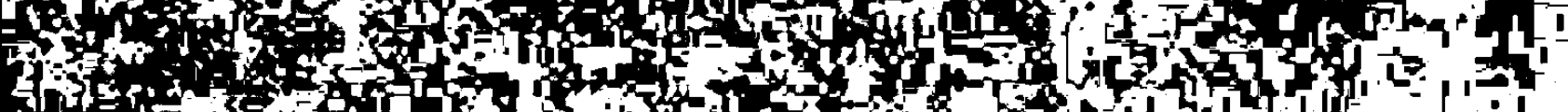

急

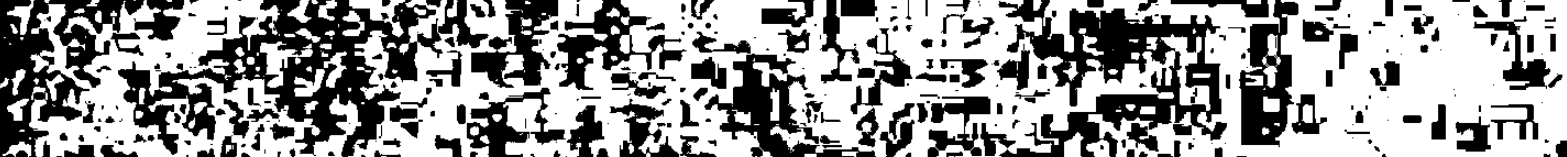

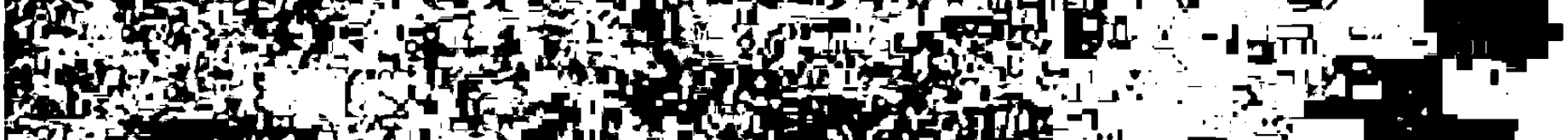

Net -

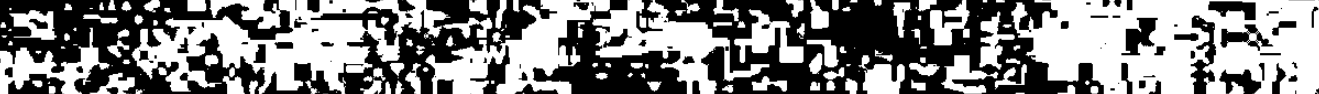

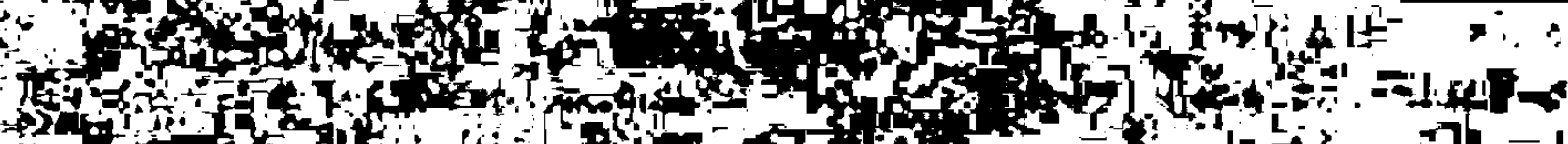

(2.)

hit -

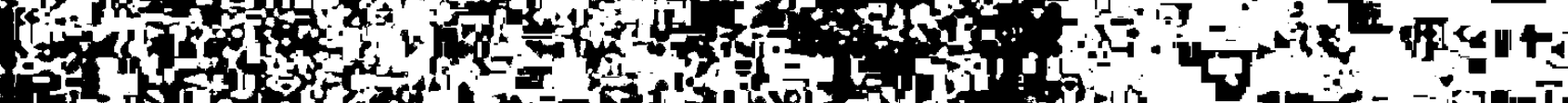

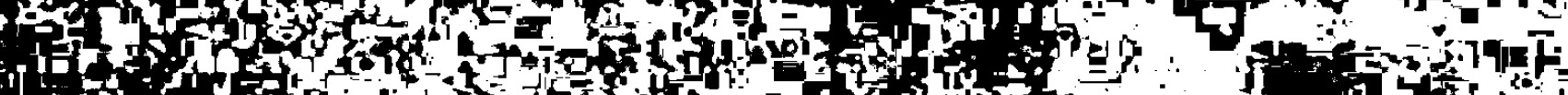

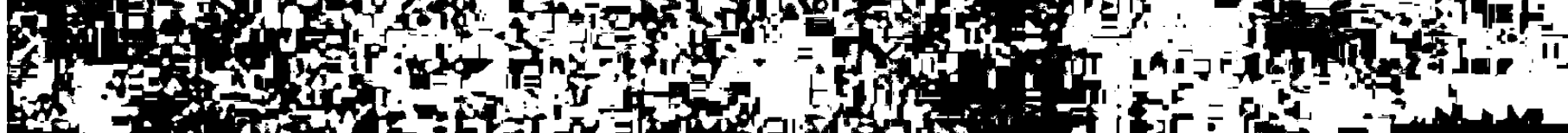

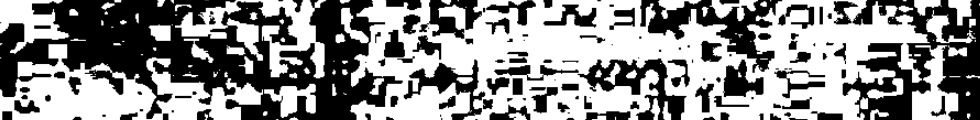

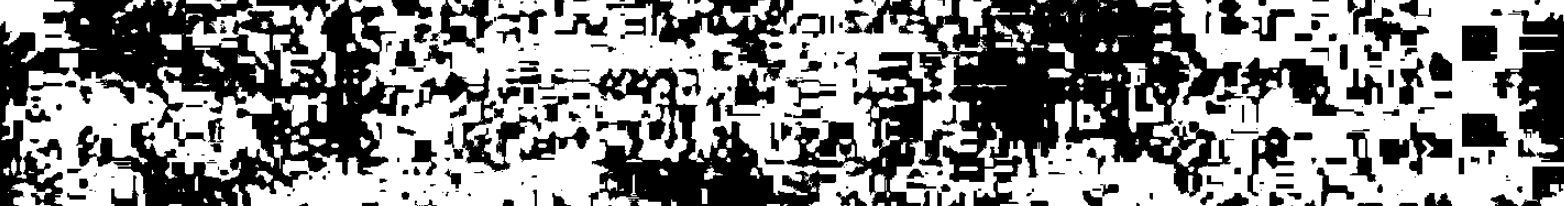

34 .

St

offor

Af

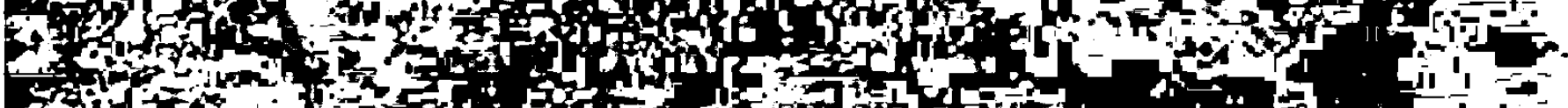

sto

St.

W

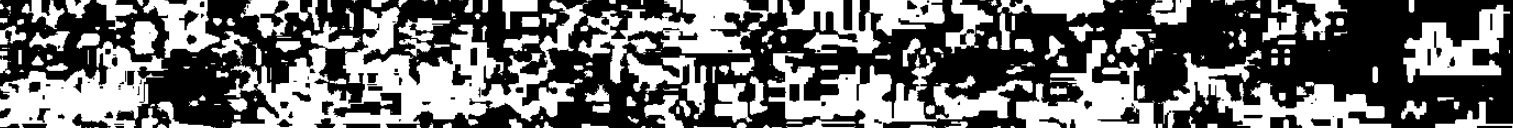

(1)

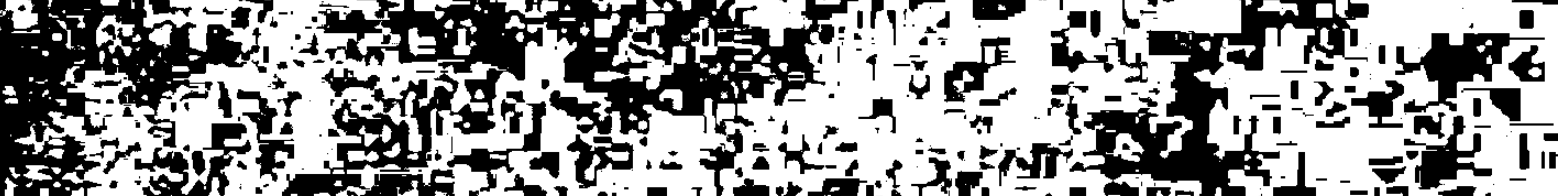

of:

$=40$ -

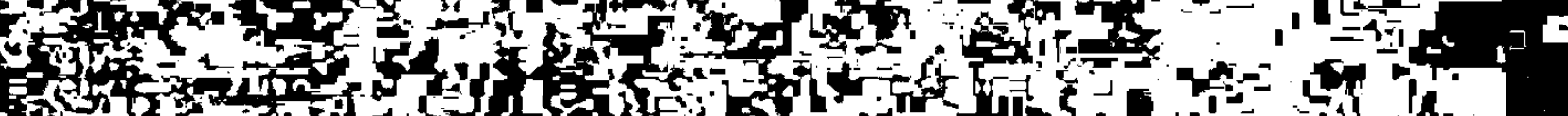

Fon

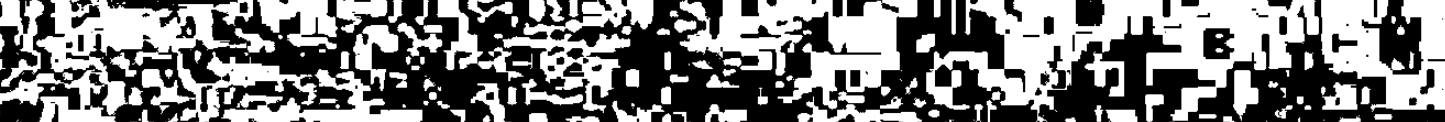

- 
$\pm 60.523(33$
SLAVISTISCHE BEITRAGE

Band 33

DAGMAR BURKHART

\section{UNTERSUCHUNGEN ZUR STRATIGRAPHIE UND .CHRONOLOGIE DER SODSLAVISCHEN VOLKSEPIK}



$z 60.523 / 33$

Dagmar Burkhart

Untersuchungen zur Stratigraphie und Chronologie der südslavischen Volksepik 


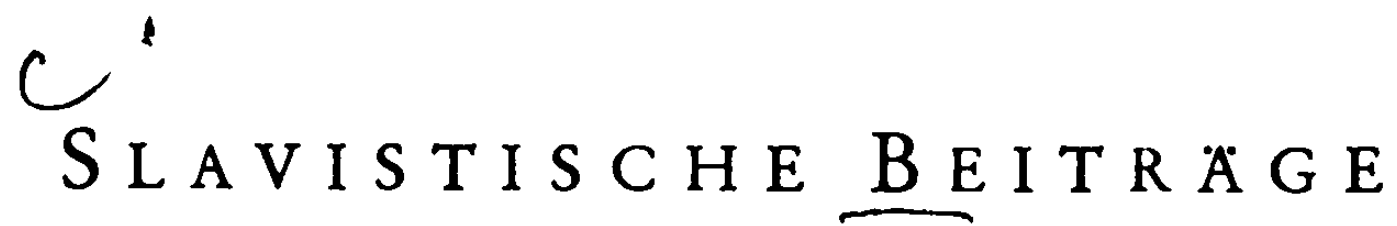

Unter Mitwirkung von M. Braun, Göttingen - † P. Diels, München - J. Holthusen, Bochum - E. Koschmieder, München - W. Lettenbauer, Freiburg/Br. J J. Matl, Graz

F. W. Neumann, Mainz - K.-H. Pollok, Regensburg - L. Sadnik-Aitzetmüller, Saarbrüdken $\cdot$ J. Schütz, Erlangen

HERAUSGEGEBEN VON A. SCHMAUS, MUNCHEN

Technische Redaktion: P. Rehder, München

Band 33 
DAGMAR BURKHART

\section{UNTERSUCHUNGEN ZUR STRATIGRAPHIE UND CHRONOLOGIE DER SUUDSLAVISCHEN VOLKSEPIK}




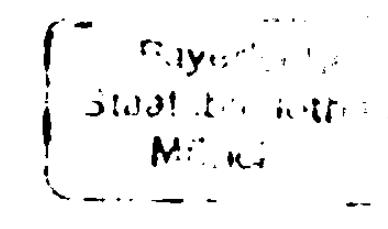

Copyright by Verlag Otto Sagner, München 1968 Abteilung der Fa. Kubon \& Sagner, München Druck: Fa. W. u. I. M. Salzer 8 München 2, Schleißheimer Straße 20 
Meinen Eltern 
00039713 
Die vorliegende Arbeit wurde 1967 von der Philosophischen Fakultät der Universität München als Dissertation angenommen.

Angeregt wurde diese Studie uber das südslavische Heldenlied im Sommersemester 1963 von Herm Prof.Dr.A. Schmaus, der mir während der ganzen Dauer der Arbeit mit wertvollen Ratschlägen zur Seite stand. Inm gilt mein besonderer Dank.

Danken möchte ich auch den Minchener Bibliotheken, vor allem der 0steuropa-Abteilung der Staatsbibliothek und der Fernleihe der Universitätsbibliothek, die mir die Beschaffung der zum Teil schwer zugänglichen literatur ermöglichten.

D. B. 


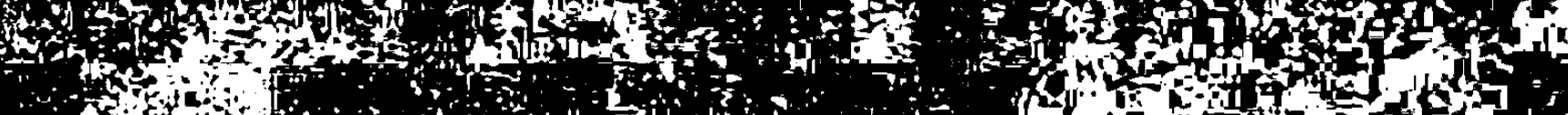

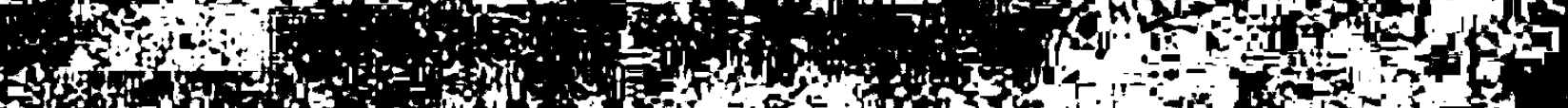

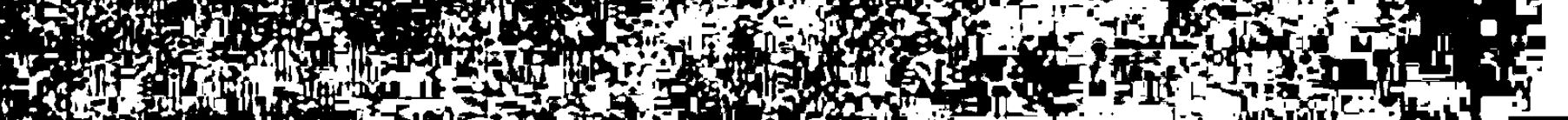

(1)

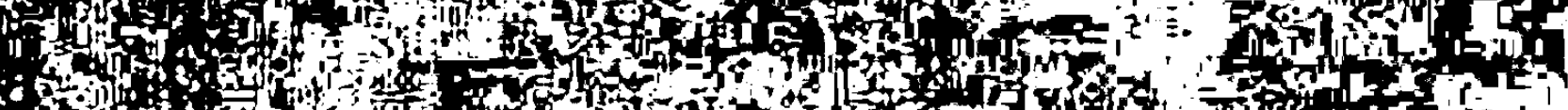

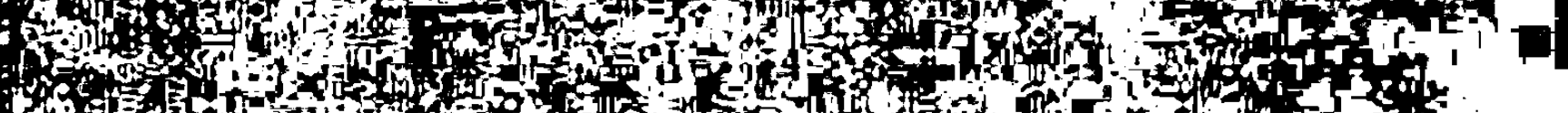

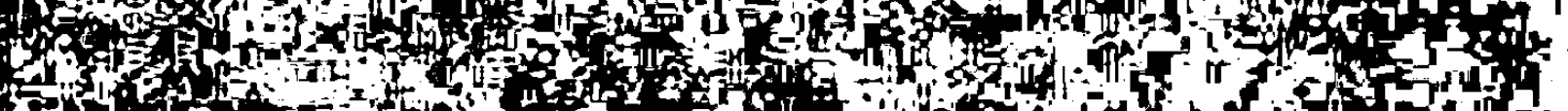

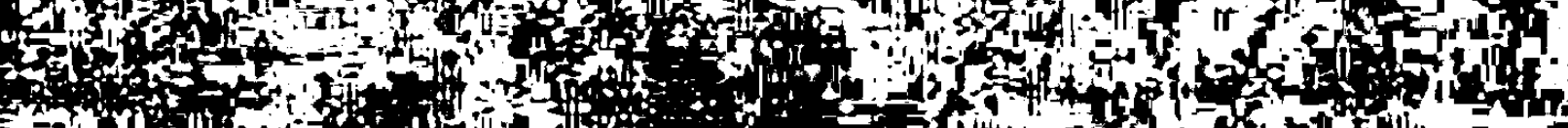

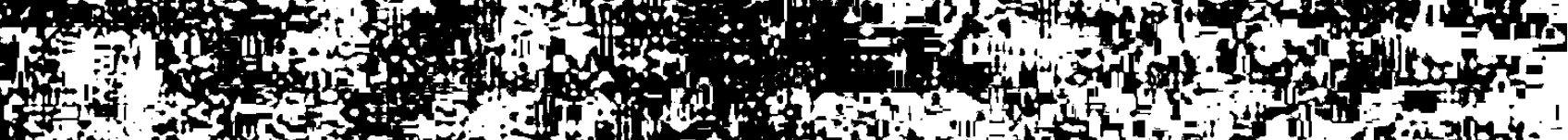

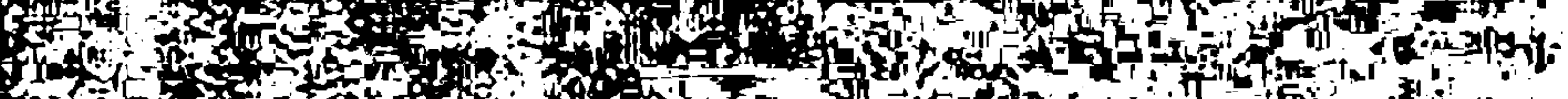

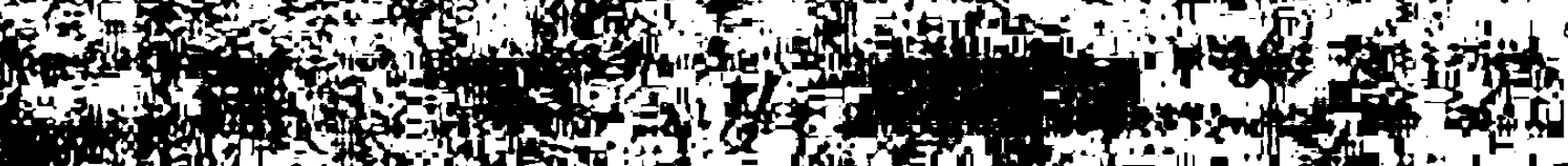

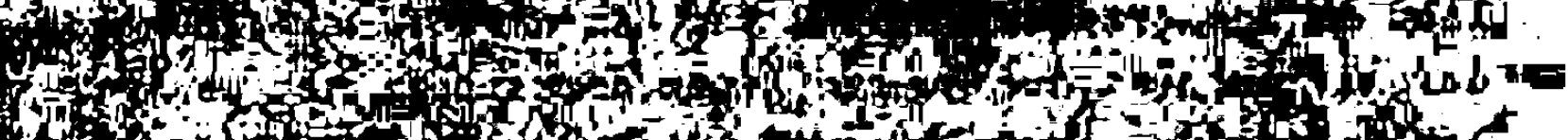

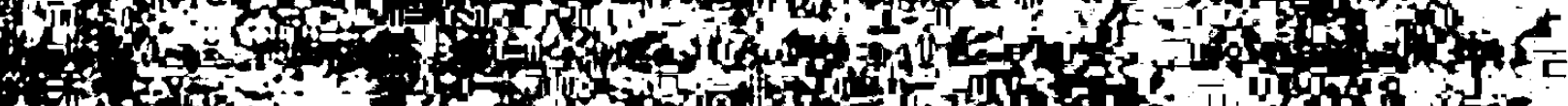

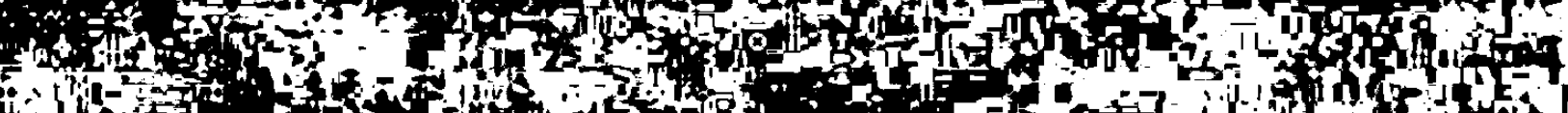

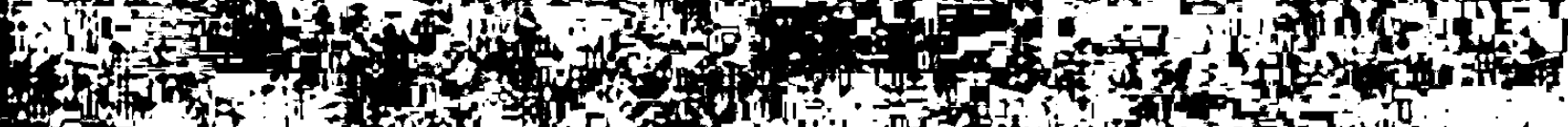
(1)

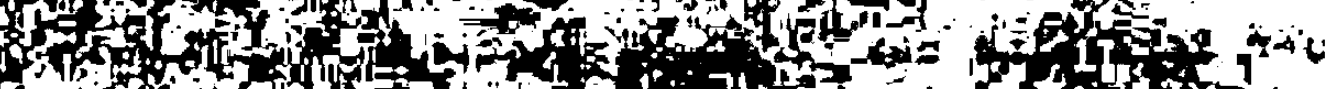
ges.

(5)

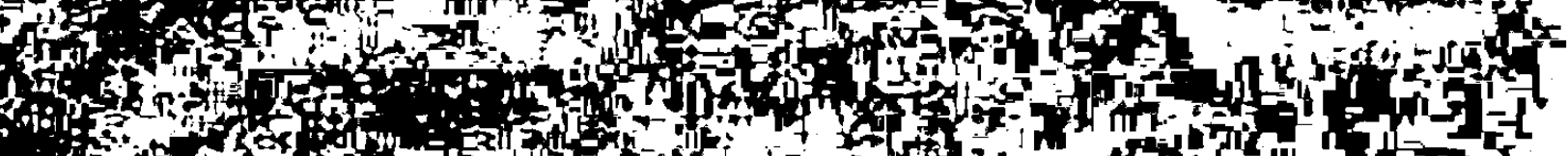

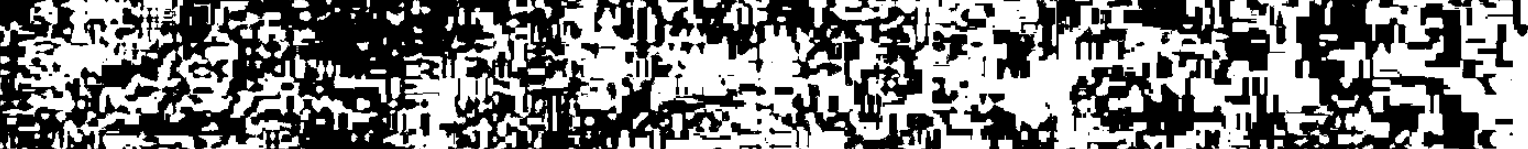

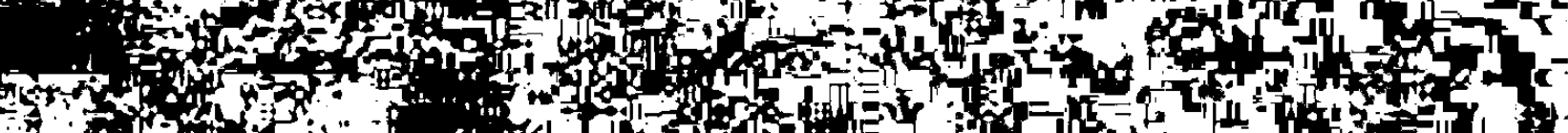

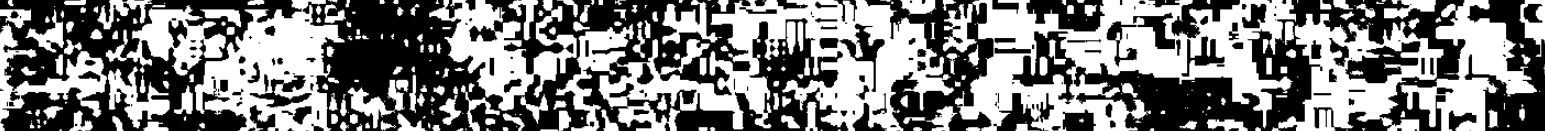

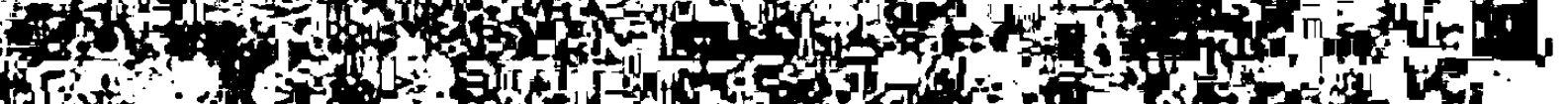

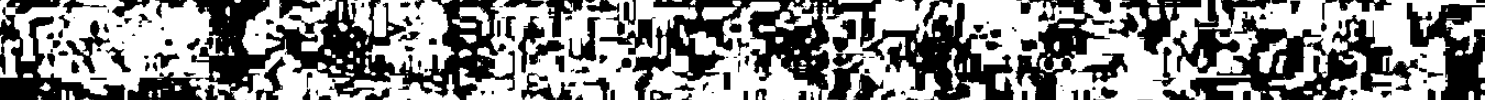

Non

7\%

(4) X. (5) ifl:

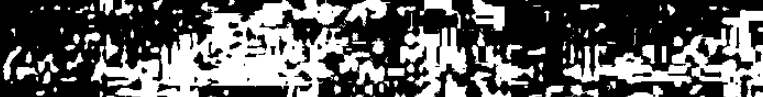

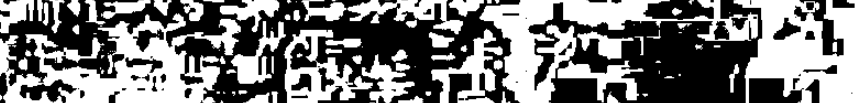

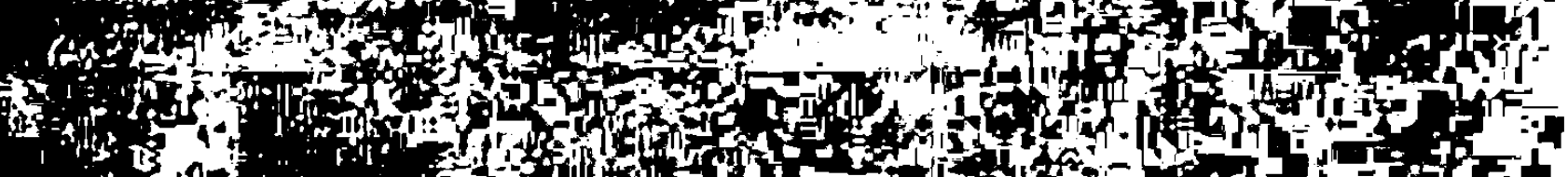
H. nne this 定;

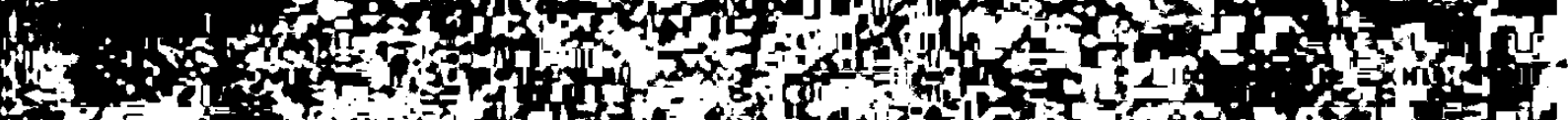

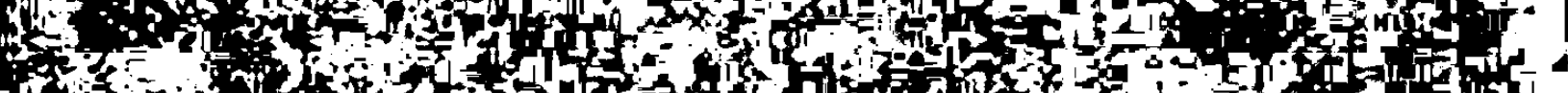
6. 3 of

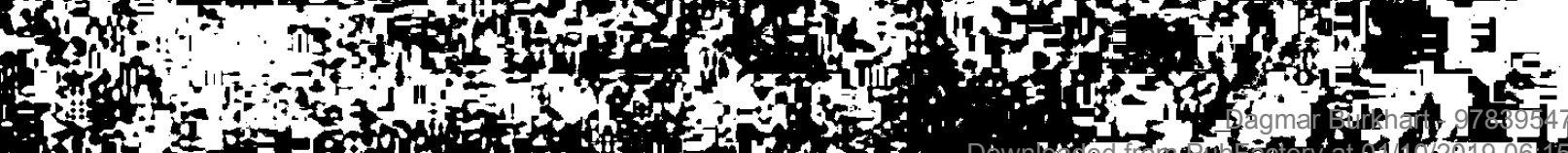


Einle1 tumg $\ldots \ldots \ldots \ldots \ldots \ldots \ldots \ldots \ldots \ldots \ldots \ldots \ldots \ldots \ldots \ldots$

1 Die serbokroatische Heldenepik - vor allem unter Berlicksicht1gung des "ugrisohen" Ante1le.......4

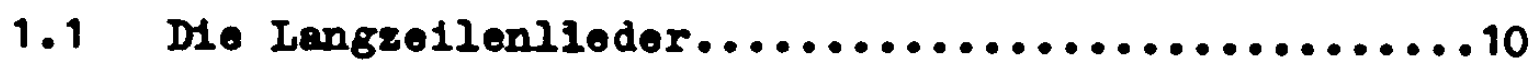

1.11 D10 dalmatinisoh-ragusan1sohen Dichter und Ka816-Miolic in thren Verhaltnis su den ugrisohserb1schen Helden..........................21

1.2 D1e Erlanger Llederhandsohrlft...............23

1.3 D1e Sammlungen Karadz16, Milutinovib und der Yat1oa Hrvatska............................31

2 Charakter1sierung der mazedonischen und west-

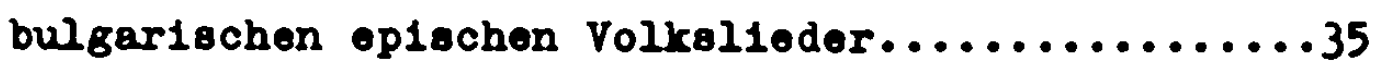

2.1 Prage des geographischen Raumes und des ep1schen Lledtype in asymetrischen Zehnsilber.......35

2.2 Charakteristik der Volksepik im mazedon1schwostbulgarlschen Raum.......................39

2.3 Bestandsaufnahme der ugrisohen Helden- und topographischen Namen an Hand der wichtigaten mazedonischen und bulgarischen L1edsammlungen....48

3 Behandlung der Sokundarschtoht in der masedonleohen und westbulgarischen Volksepik an Hand -iniger an ugriache Namen gebundener Sujeta.......59

3.1 Potir Ban und Kral Mateja...................60

3.2 Der prophetische Traum vom Fall Budims..........63

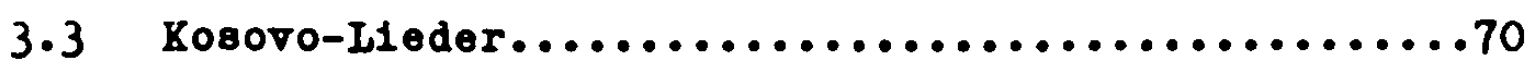

4 Untersuchung eines durch Verquickmg der Sekundar- und Primbrachicht charakterisierten Sujetfelds der sudslavischen Volksepik............88

4.1 Brautgewinnung nach Bestehon von Prelersproben....88 4.11 Brautfahrtmärchen in Lledform: Bestehon von Prelersproben durch oinen Helfer des Brăutigams...94

4.12 tbersohwimmen elnes Gewässers als vom shdchen gestellte Frelersprobe.......................150

4.13 Dberschwimen elnes Gewkssers und Drachenkamp als nicht von dem Mradchen selbst gestellte Pre1oreprobe...............................169 
4.2 Brautfahrt mit Komplikationen................228

4.21 Hochseltezug mit tberfall auf den (Rilick-) Weg und Verteldigung der Braut durch den Dever..................................229

4.22 Kampl mit dem Drachen 1. Brunnen...............291

4.3 Hocheelt mit Preleroproben und tberfall aus den Brautzug.........................302

4.4 Drachenkampf-Thenatik auBerhalb des Hoch-

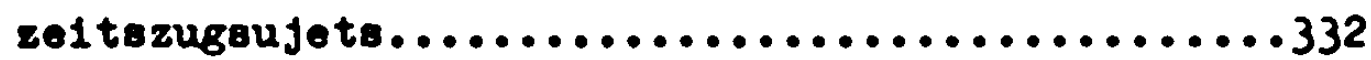

4.41 Drachenkampf-Ileder......................333

4.42 V1la Brodarlca-Lieder......................378

4.43 Bolen DojCin-Lieder......................409

4.44 Arapin-Lieder............................416

4.45 Brgebn18...............................425

5 Alter mazedoniecher und bulgarischer Liedbeotands die Primbrochicht..................429

5.1 Kampl mit einen ubernatilulichen, anthropomorphen Gegner............................430

5.2 Heldenkind-Lleder.......................451

5.3 Zmej-Lleder.............................463

5.4 (Samo-) V1la-, Samodiva- und Juda-Lleder.........479 6 Zusammenfassung und Ergebnis...............487 Anmerkungen.................................495 Abklireungen..............................518 B1bllograph10..............................519 
slaven erfreute sich die historische Schule regen $\mathrm{Zu}$ spruchs, weil man ihre Theorien im Kampf um die nationale Befreiung und Selbstbehauptung als "Beweismaterial" einsetzen konnte.

Heute ist in der Erforschung der Volksepik eine gewisse methodologische Krise zu beobachten. Von den verschiedenen Schulen scheint der sogenannte $N$ e o m $t h \circ 1 \circ g$ i sm u s (Meletinskij) die meisten Anhanger zu haben, dessen Vertreter Porscher wie F.Raglan, Jan de Vries, Ch.Autran, R.Carpenter, G.Ievy, A.B.Iord, B.Meriggi u.a. sind. Diese neue unterscheidet sich von der alten mythologischen Schule dadurch, dab keine indogermanische Grtterwelt mehr beschworen wird, sondern dab man das Heldenlied auf rituellmythologische Archetypen zurlickfunrt, den Hythos in maximale Annlherung an Magie und Ritus bringt und uberhaupt eine schon vor der Historisierung archaischer Stoffe bestehende vorhistorische, mythische liedschicht annimmt. Eine rein $p s y c h \circ a$ a $l y t i s c h$ Konzeption Jungscher Prăgung, die teilweise schon bei de Vries besteht, hat Ch.Baudouin entwickelt. Fllr das Marchen ist uns diese Methode vor allem durch die Arbeiten H.v.Beits bekannt. Treffendere Einsichten als diese extrem antihistorische kichtung liefert aber m.E. die von V.Z̈irmunskij und V.Propp angewandte Methode, die auf $h i s t o r i s c h-$ ge $n$ e $t i s c h e m$ und $h i s t \circ r i s c h-t y p \circ 10-$ g i s c h e m $V$ e $r$ g e $i$ c $h$ basiert sowie die Historizitat und das Bestehen mythischer Elemente im Heldenlied gleichernaßen berlicksichtigt. Wie leletinskij, der vor allem die Thesen propps weiterfuhrt, festgestellt hat, stimmen die Ergebnisse Zirmunskijs und Propps im wesentlichen mitoinander uboreins whrond Z1rmunskif die Existenz mythologischer Motive im Epos aus dem Heldenmarchen (der Zwischenstufe zwischen Mythos und Heldenepos) erklart,spricht Yropp von einer "vorstaatlichen" (dogosudarstvennaja) Form des Heldenlieds, deren vorhistorische !?otive durch typische Sujets wie Kampl des Helden mit Ungeheuern (entstanden aus dem ehemaligen Herm der Guter, dem "duch-chozjain") 
und heldische Brautgewinnung (nach den Gesetzen der Exogamie) bestimrt werden. Obwohl Neletinskij den westlichen Epenforschern "neomifologizm" vorwirft, kommt er doch selbst zu der Erkenntnis, dab unter den historischen Stoffen archaische, sogar zum Tell noch vorschamanistische Iledschichten mit mythologischen zllgen liegen, deren ersten primitiven Helden der namenlose "kul'turnyj geroj", der Kulturheros, darstellt.

Die vorliegende Arbeit hat sich zum ziel gesetzt, die slidslavische Volksepik - unter Berlicksichtigung der Ergebnisse der historischen und neomythologischen Schule - auf inre verschiedenen Iiedschichten und damit Fragen der Chronologie hin zu untersuchen. Die $\mathrm{F}$ a $g$ e $s$ t e l l u $\mathrm{n} g$ ist also eine $h 1 s t \circ r 18 \mathrm{c} h$ e: Es interessiert aber nicht in erster Iinie die Geschichte in der Epik, sondern vielmehr die Geschichte der Epik. Dabei werden vor allem episch periphere und damit konservativere liedraume wie Mazedonien, Westbulgarien, Sud- und Sudostserbien sowie zum Teil auch die dalmatinischen Inseln und das Kustengebiet, die bisher uber den "klassischen" last vollig entmythologisierten und dafur rationalisierten Vukschen Iiedvarianten des dinarischen Kerngebiets allzusehr vernachlassigt wurden, auf ihren liedbestand hin untersucht werden, weil hier eine noch stark archaische, vorhistorische Schicht und deren mehrmalige (allerdings jedesmal bald wieder abgebrochene) Historisierung wertvolle Aufschlusse Uber die sudslavische Liedentwicklung zu bieten vermag. Die These vom dinarischen Raum als der Wiege des slldslavischen Heldenlieds wird sich nach einem Vergleich der serbokroatischen und der mazedonischen Heldenlieder kaum mehr aufrechterhalten lassen. 



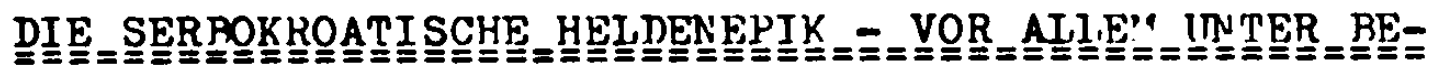

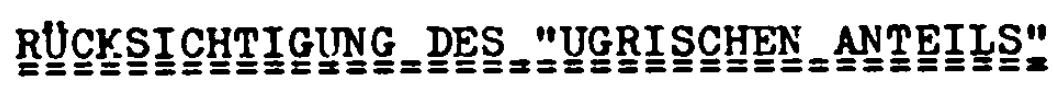

Die schon von Jakob Grimm, Goethe und Mickiewicz gerlihmte skr. Volksepik, deren friheste Zeugnisse aus dem 16., deren Hauptmasse an Aufzeichnungen aber erst aus dem 18. und 19.Jh. stammen, 1st der Gegenstand so vieler mehr oder weniger umfangreicher Untersuchungen ${ }^{2}$ geworden, dab sie somit hier, um wiederholungen zu vermeiden, nur kurz bespróchen werden soll. Dabel wird allerdings ein bestimmter Aspekt, nämlich der für die Sekundarschicht in der Volksepik der Morava-Vardar-Zone so wichtige "ugrische Anteil", besondere Berlucksichtigung erfahren. Unter dem Schlagwort "ugrischer Anteil" seien hier diejenigen skr. Liedsujets verstanden, die an historische Liedgestalten wie die ungarischen Turkenkămpfer János Hunyadi (in den blteren Liedern Janko vojevoda, ugrin Janko; in den jungeren Sibinjanin Janko), János Székely (im Lied banovió Sekula, dete Sekula), Mihály Szilágyi (im Lied Svilojeví)), König Mathias Corvinus (im Lied kralj Matijaß) und Peter Doczy (im lied Dojein Petar), also die sog. ugriliel, ugarska gospoda, und auf serbischer Seite die Despoten Eurad Brankovic (und seine Gattin Jerina, im Lied haufig "prokleta Jerina" genannt) und Vuk Grourovie Brankovic (in den glteren Liedern ognjeni despot Vuk, in neueren Liedern Zmaj-ognjeni Vuk genannt), die Brider Dmitar und stjepan Jaksic u.a. gebunden sind, d.h. es handelt sich un diejenigen skr. epischen Lieder, die im allgemeinen unter dem Oberbegriff "ciklus Brankovica" zusammengefabt werden.

Als seit dem 15.Jh. die fuhrende Rolle in den Turkenkarpien auf Ungarn Ubergeht, stehen die erwkhnten Gestalten im Mittelpunkt der ungarischen und sudslavischen Geschichte ${ }^{3}$ und gehen im sludungarisch-syrmischen Raum in die skr. Volksepik ein, und zwar in die Langzeilenlieder, die im Laufe des 18.Jh. ausstarben und endglaltig durch die Heldenlieder im asymetrischen trochaischen Zehnsilber ("deseterac", 
Zäsur nach der vierten Silbe) abgelöst wurden. Um den historischen Hintergrund der Liedgestalten kurz zu umreissen, seien einige Bemerkungen vorangestellt: János $\mathrm{H}$ u n y a d i, ca. 1387 in Siebenburgen geooren und 1456 in Semlin an der Pest gestorben, war der Sohn eines Rumänen niederer Herkunft, der aber spater Ritter wurde und von König Sigismund 1409 die Burg Vajda-Hunyad in Siebenblurgen erhielt, nach der sich Woyko und seine Familie Hunyadi nannten. 1438-39 zeichnete sich Hunyadi in Turkenkämpfen aus und wurde Banus von Severin. Weiteren Ruhm erlangte er 1441-43 nach den Turkenkämpfen in Ungarn, Serbien und Bulgarien. 1442 zerschlug er am Fuße der Karpathen zwei starke turkische fleere und wurde im gleichen Jahr Vojevode von Siebenbïrgen. 1444 fand dann die Schlacht bei Varna statt, in der König Wladislaw, waghalsig zun Sultanszelt vordringend, und der grobte Teil des christlichen Heeres fielen. Hunyadi rettete sich nach Ungarn und wurde 1446 zum Reichsverweser (Gubernator) von Ungarn fil den kleinen Ladislaus Postumus ernannt. 1448 erlebte Hunyadi, der Vergeltung für die hatastrophe bei Varna suchte, auf Kosovo mit seinem Heer eine vernichtende Niederlage gegen die Turken (Murad II.). Auf der Flucht wurde der Gubernator von den Leuten des Despoten Durad Brankovic gefangengenommen und nach Smederevo gebracht, wo der Despot von ihm Entschädigung für die lilünderungen des ungarischen Heeres in Serbien verlangte und ihn erst auf Zusicherung einer hoinen Sume durch die ungarischen Stände freilieb, zunachst aber noch Hunyadis Sohn Ladislaus als Burgen behielt. In Ungarm bildete sich indessen eine Partei gegen Hunyadi, gefuhrt von den Familien de Gara und Ijjláky, die inn fur die belden groben Katastropien des ungarlschen Heeres verantwortlich machten. 1450 entband sich Hunyadi mit Unterstutzung des Papstes Nikolaus V. von allen Verpflichtungen gegenuber dem Despoten, weil sein Eid angeblich in Gefangenschaft erzwungen wurde, und bemächtigte sich der wuter des Despoten in Ungarn. Nach der Thronbesteigung i:ehmeds II. schloß Hunyadi mit furad Frieden und 
auf dessen Vermittlung hin auch mit den Turken. Doch nach der Eroberung Konstantinopels 1453 wandte sich liehmed nach Serbien, nahm einen beträchtlichen Teil des Landes ein und lieb seine Truppen unter dem Kommando von Feriz Beg bei Krusevac zurlack. Da Uberraschte und zerschlug Hunyadi 1454 die turkischen Truppen, nahm Feriz gefangen und schickte inn dem Despoten. Er selbst aber verheerte die Umgebung von Nis und Pirot und verbrannte Vidin. Seinen Traum von der Aufstellung eines großen Heeres, das die Turken von der Balkanhalbinsel hatte vertreiben können, brachte er nicht zur Verwirklichung. Kurz vor seinem Tode trug er mit seinen Truppen und der Flotte noch dazu bei, daß 1456 die turkische Belagerung Belgrads aufgehoben wurde. Sein altester Sohn Ladislaus wurde Kommandant von Belgrad, sein zweiter Sohn Mathias Corvinus 1458 zum ungarischen König gewahlt. 1446 setzte Hunyadi seinen Verwandten (Schwestersohn?) János $\mathrm{S} z$ é $\mathrm{k}$ e $l$ y als Banus von Slavonien ein, der aber nicht lange Gelegenheit hatte, sein Amt auszullben, weil er schon 1448 in der Schlacht auf dem Kosovofeld umkam. Der jugendliche, ritterliche Banus, der sich in der Schlacht ausgezeichnet hatte, fiel im Kampl mit einem riesenhaften turkischen Zweikłmpfer, der inm die rechte Hand abschlug, obwohl Székely gepanzert war. - Mihály S z i l lá g y 1 , der Schwager (seine Schwester Jelisaveta war mit Hunyadi verheiratet) Hunyadis, war einige Jahre lang Befehlshaber von Belgrad, das er 1456 mit Unterstutzung Hunyadis und des Franziskaners Capistrano erfolgreich gegen die Turken verteidigte. 1455 war Szilágyi mit seinem Bruder von den Leuten des Despoten uberfallen und sein Bruder getötet worden, worauf Szilágyi deh greisen Despoten mit einer Reiterschar nachts bei seinem Schloß Kupinik (jetzt Kupinovo) Uberfiel. turad verlor einige Finger und wurde als Gefangener nach Belgrad geschleppt. Er mußte seine Gattin Jerina als Burgen senden und zwei Burgen sowie Lösegeld Ubergeben. Als König Ladislaus Postumus davon erfuhr, war er erbittert luber die Behandlung des Despoten und verhinderte die Guterabtretung und Zahlung des Lösegeldes. Die 
ganze Affare war symptomatisch für den Gegensatz, der zwischen der Fartei des Hunyadi und der des Despoten, des Schwiegervaters des UIrich von Cilli, herrschte.- Als 1458 Hunyadis Sohn, der funfzehnjthrige llathias, zum ungarischen König gewăhlt wurde, war Szilágyi als sein Oheim die ersten funf Jahre Reichsverweser des Königreichs, bis der junge ronig die Regiemung selbst Ubemehmen konnte. 1458 warde Szilágyi, von seinem lieffen einer Verschwörung beschuldigt, in Belgrad fur kurze Zeit gefangengesetzt. Als Szilágyi 1460 mit den Tlirken (unter Ali Beg, im Lied Berzelez Alija) bei Smederevo kampfte, wurde sein Heer geschlagen, er selbst aber gefangengenommen, nach Konstantinopel entfunrt und dort getötet. Szilágyi galt als ungezugelt, gewalttatig und grausam.

Konig $M$ a $t h i$ a 8 Corvinus (Regierungszeit 1458-90), john des Reichsverwesers und glanzenden Heerfuhrers Hunyadi. "Corvinus" genannt nach dem Raben (lat. corvas) in seinem Wappen, kan 1458 nach dem Tod des Habsburgers Ladislaus Postumus (1457) auf Betreiben des ungarischen Kleinadels (mit de Gara auf seiner Seite) auf den Thron. Als die in der ofener Burg beratenden l'agnaten mit der Verklindung des Wahlergebnisses zögerten, zog der Adel am nachsten Tag auf das Eis der Donau und rief dort Fathias zum ronig aus. l.athias mubte erst aus dem Kerker geholt werden, wohin ihn Ladislaus V. hatte werfen lassen (Hunyadis alterer Sohn war sogar hingerichtet worden, was beim Kleinadel ':isfallen erregte). ilt rfathias gelangte nach langer Zeit wieder ein natioraler Konig auf den ungarischen Thron.Die Feindschaft zwischen dem Despoten Furat und der Familie Hunyadi bestar.d weiter. Hunyadis Gegner riefen 1459 Kaiser rriedrich III. zum ungarischen konig aus, mit dem es zum Krieg und erst 1463 auf Flirsprache des Papstes (Pius II.) zum Prieden kam. Die Turken besetzten die Walachei und zosnien, wurden aber von Konig liathias in Serbien, später bei Jajce geschlagen. Nathias eroberte das nordliche Bosnien zurlick und liebs sich nach diesen Siegen 1464 zum Krnif krönen. 1468 besetzte liathias ifainren, Schlesien und 
die Lausitz; Wladislaw, 1471 nach Podiebrads Tod auf den bohmischen Thron gekommen, behielt Bobmen. 1477 und 1485 eroberte Konig Mathias, im Krieg gegen Priedrich III., zweimal Wien. 1476 nahm er persönlich an der Erojerung von Sabac teil, und 1479 siegten seine Feldherm in Siebenblrgen Uber die Tluken. Seine Truppen verjagten die Tlurken 1476 in der lioldau, worauf der walachische Vojvode ihn wieder als seinen Lehnsherm anerkannte. In demselben Verhälnis stand auch der Despot Vuk zu lathias. 1479 drang Kinizsi bis Krußevac vor, und 1481 sandte Konig "athias auch den Italienern Hilfe zur Befreiung von Otranto. - Im Landesinnerm hatte hiathias mit großen Schwierigkeiten, vor allem den Widerstand der "Iagnaten, zu kanpfen. Trotzdem fuhrte er eine Heeres-, Steuer- und Gesetzesreform durch und versammelte an seir.em Hof Schriftsteller, kirstler und humanistische iissenschaftler aus dem In- und Ausland. Das Volk und der Kleinadel sahen in :athias den gerechten und prunkliebenden König und Beschützer gegen die Magnaten, was seine Beliebtheit und sein Eingehen in das Volkslied 4 begrindete. Nach seinem Tode (er starb ohne legitimen Nachkommen) wurde Wladislaw ungarischer Konig, der durch seine Schwlyche das Reformwerk seines Vorgangers verfallen lie $B$ und den Nachtzuwachs des Adels forderte. Durch Verheiratung seiner beiden Kinder mit den Enkelkindern Kaiser Naximilians kamen später Börmen und Ungarr an Habsburg.

Von Peter $D \&$ C $\mathrm{z}$, dem Banus von Jajce und Varadin unter König Nathias, ist bekannt, daß er zusammen mit Despot Vuk, Dmitar Jaksic u.a. den turkischen Statthalter von Smederevo, Ali Beg Kichaloglu, an der Donau schlug urd 1480, wieder zusammen mit Vuk, dabeiwar, als Sarajevo von den Truppen des ungarischen Konigs uberfallen, geplundert und niedergebrannt wurde. Auch 1481/82 war Doczy an dem Feldzug unter Faul Kinizsi, dem Despoten Vuk, Dnitar Jaksic u.a. gegen die Turken beteiligt, wobei der Befehlshaber der Burg Golubac geschlagen, Branizevo besetzt und die Gegend von K.rußevac geplïndert wurde.- Vor den $J$ a $k$ s $i$ c $i$ sind vor allem die Bruder Dnitar (gest.1486) und Stjepan 
(gest.1489), Sohne des Vojvoden Jaksa, der unter tharad diente, als hervorragende Turkenkämpfer zu nennen. Nach dem endgultigen Zerfall des serbischen Staates siedelten die beiden serbischen Adeligen nach Ungarn Uber, wo sie von König Mathias 1464 das Gut Nagylak und zahlreiche andere Schenkungen erhielten, weil sie ihn bei seinen Kriegszugen unterstutzten. 1543 starben die Jaksici, die zu den angesehensten Familien Sudungarns zahlten, in mänlicher Iinie aus.

Nach dem Tode des Despoten Stefan Lazarevic, der Belgrad zu seiner Hauptstadt gemacht hatte, regierte $\rightarrow r$ a Branković (geb.ca.1375), der Neffe Stefans und Enkel Lazars, Serbien 1427-56. Despot Eurat war Sohn des Vuk Brankovic. Seine lange Herrschaft fiel in die schwersten Jahre des serbischen Staates, der drei Jahre nach dem Tod des Despoten endgultig von den Turken unterworfen wurde. turat ubergab Belgrad den Ungarn, die es mit stärkerer Streitmacht vor den Turken schutzen konnten, erhielt dafur vom ungarischen König Sigismund einige Guter in Syrmien und baute fur sich selbst das befestigte Smederevo (1430 fertiggestellt). 1414 heiratete er die Griechin Irene (Jerina), Tochter des Manuil aus der Familie Kantakuzenos, der Despoten von Morea. Ab 1438/39 erfolgten schwere Angriffe und Eroberungen von Seiten der Turken (1441 Gefangennahme und Blendung der Despotensöhne Grgur und Stefan), doch 1444 erhielt furat sein Land mit 24 Burgen, darunter auch Golubac und Krusevac, vom Sultan zurlick und nahm, um es nicht wieder zu verlieren, weder an den Schlachten 1444 noch 1448 teil. Er unterstutzte nicht König Wladislaw III. (gest.1444) und Hunyadi, sondern Ladislaus Postumus, den Enkel Siglsmunds, und die hunyadifeindliche Partel seines Schwiegersohns Ulrich von Cilli. Wahrscheinlich wird er deshalb in den meist ungarnfreundlichen Liedern als Verräter bezeichnet. $Z u$ seinem Ruf als Turkenfreund hat vielleicht auch die 1435 erfolgte Heirat seiner Tochter Mara mit Sul$\tan$ kurad II. beigetragen. Weil turads beide alteren Sohne geblendet waren, folgte inm sein jungster Sohn Lazar nach, 
der aber schon 1458 starb, worauf sein Bruder, der blinde Stefan, fur ein Jahr Despot marde. Sein Nachfolger im Amt des serbischen Despoten murde 1459 Stefan Tomasevid (bosnischer Konig 1461-63), der Schwiegersohn von Vuks Onkel Lazar, dem man die Schuld an dem Fall Smederevos (1459), durch den der Untergang des serbischen Staates besiegelt war, zuschrieb.

V u k Despot ${ }^{5}$ wurde ca. 1440 als (möglicherweise unehelicher) Sohn des blinden Grgur und Enkel des turad Brankovid geboren und trat bei Konig Mathias von Ungarn in Dienste, fir den er nicht nur gegen die Turken, sondern auch Böhmen, Polen und Osterreicher erfolgreich kampite. Fur seine Verdienste verlieh inm Konig Mathias 1471 die Despotenwlirde und schenkte inm Gilter in Syrmien und Kroatien, so dab Vuk ein Magnat des Königreichs Ungarn wurde. Er war in zweiter Ehe mit Varvara, Tochter des Zigmund Frankopan, verheiratet, die er bei seinem Tod 1485 kinderlos zurlicklieb. Sein Nachfolger in der Despotenwirde wurde Dorte, Sohn des blinden Stefan, doch bald erscheint auch Jovan, der jüngere Sohn Stefans, mit dem Despotentitel, whrhend Đorde (1496-1502) unter dem Namen Maksim als Monch lebte. Jovans Witwe Jelena heiratete den kroatischen Magnaten Ivanis Berislavic, dem 1504 der Despotentitel vom ungarischen König verliehen wurde.

Dieser kurze historische AbriB soll das Verstandnis der nun zu besprechenden skr. Lang- und Kurzzeilenlieder, vor allem inres "ugrischen Anteils", erleichtern.

\subsection{DIE LANGZEILENLIEDER}

Das Ratsel des Langzeilenliedes (bugarfitica, bugargtina, bugarkinja, pjesan bugarska), das Problem seiner Entstehung und Herkunft sowie sein Verhaltnis zum Heldenliad im epischen Zehnsilber (deseterac) ist noch immer nicht gelost, obwohl es nicht an Arbeiten aus alterer ${ }^{6}$ und neuerer ${ }^{7}$ Zeit fehlt. 
Uberliefert sind uns rund achtzig Langzeilenlieder, wovon die beiden altesten (Bog.6 und 49) von P.Hektorovic (14871572) in seinem "Ribanje i ribarsko prigovaranje" (1556) aus dem Mund zweier Fischer von der Insel Hvar aufgezeichnet sind, ein lyrisches Langzeilenlied (30g.82) in der "Vila slovinka" (Venedig 1682) des G.Barakovie (1548-1628) aus der Gegend von Zadar enthalten ist und durch das in den Schriften des Petar Zrinski (gest.1671) gefundene Langzeilenlied (Bog.46) diese Liedform im 17.Jh. auch fur Binnenkroatien belegt ist. Die Hauptmasse der Aufzeichnungen aber stamnt aus den ersten jahrzehnten des 18.Jh., und zwar handelt es sich um Lieder aus Dubrovnik, Perast und der Bucht von Kotor. Die altertumlicheren Lieder (funfzehn- bis sechzehnsilbige trochaische Langzeilen mit Zäsur nach der siebten bzw. acnten Silbe und regelmajigem secissilbigen Rerrain nach je zwei Verszeilen) befinden sich in jorm zweier Handschriften im Besitz der JAZU in Zagreb. Sie stammen aus der Bucht von Kotor und sind Anfang des 18.Jh. aufgeschrieben. Die erste HS enthalt dreiundzwanzig ( Bog . 7, 8, 11, 12, 17-19,21-25,27-29, 31, 36,43,50, $51,56,58,77,81,84)$, die zweite HS drei (Bog.5,52,83) Lar.gzeilenlieder. Eine weitere in einer Klosterbibliothek in Lubrovik aufbewahrte umfangreiche Sammel-HS aus dem Jahr 1758 enthalt drei Aufzeichnungsschichten: vierzehn Langzeilenlieder mit meist unregelmabigem oder schon fehlendem Refrain (als Aufzeichner wird der Priester Matei, gest.1728, aus Dubrovnik genannt), achtzehr. refrainlose Lanjzeilenlieder (schon vor 1750 von einem gewissen Betondic, gest.1764, gesammelt) und auBerdem sechs weitere refrainlose Langzeilenlieder von verschiedenen Sammlem (Bog.1-4,9,10,13-16,20,23,24,26,30,32-35, 37-42, 44,45, 47,48,53-55,57,76,78-80; likikl.5); zu dieser letzten Schicht gehören auch sechsundvierzig Lieder (Bog.85-130) in karzerem, Uberwiegend zehnsilbigem Versmaß, wovon elf (Bog.120130) lyrische Lieder sind. Eine ebenfalls aus Dubrornik aus den ersten Drittel des 18.Jh. stammende HS enthrit zwolf lieder, wovon elf Langzeilenlieder sind, das letzte 
aber in Zehnsilbern aufgezeichnet ist. Von den elf Langzeilenliedern sind nur zwel (Novak.ASIPh III 1 und 3 ) hier wichtig, alle abrigen decken sich mit den Iiedern (Mikl.5; Bog.14,15,9,1,10,30 zweimal, 4) aus der Dubrovniker SammelHS. In einer HS aus Perast von 1700 finden sich neun Langzeilenlieder (mit regelmabigem Refrain) lokalen Charakters (Bog-59,61,63,65,67,69,71,73,75), die - auBer dem letzten spater in Deseterac-Iieder umgewandelt wurden (Bog.60,62, $64,66,68,70,72,74)$ und sich in einer zweiten, 1775 datierten Peraster HS befinden.

Nur drei von den erwahnten Langzeilenliedern sind lyrisch (Bog.82-84), die anderen alle episch. Maretic ${ }^{8}$ halt davon nicht nur Bog.58,77 und 81 (vgl.Bog.Einleitung,S.2), sondern auch Bog.57-75 und 78-80 fur nicht volkstumlich. Soerensen ${ }^{9}$ bezeichnet aberdies Mikl.5 und Novak.ASIPh III 3 als "mehr oder weniger Kinstliche Compositionen" und Bog.77 als ein nicht volkstumliches "Machwerk", wăhrend Kravcov" der Bugarłtica generell jeden Volksliedcharakter abspricht, wozu ja auch Lalevic ${ }^{11}$ neigt.

Bei den Langzeilenliedern sind mehrere Schichten festzustellen: Whrend eine bestimate Anzahl Lieder Ereignisse des 16. und 17.Jh. behandelt und sich aup dalmatinische (z.B. Bog.76 und 77 aus Kotor; die neun Langzeilenlieder der Peraster IIS; Bog.79 und 80 aus Dubrovnik; Bog.78 aus Mitteldalmatien), bosnisch-hercegovinische (z.B. Bog.54-56: geographische Hinweise und Existenz orientalischer Elemente und Turzismen) oder kroatische (2.B.Bog.36 und 38) Herkunft festlegen l\&Bt, weisen sechsundvierzig Langzeilenlieder inrem Stoff nach keinerlei Beziehung zum Kustenland, ihrem Aufzeichnungsgebiet, auf.. Diese Iieder, die Soerensen treffend in einen "ungarserbischen" (Bog.8-35,46;ASIPh III 1 und 3) und einen kleineren "innerserbischen" (Bog.1-7,3945: Mikl.5) Iiederkreis aufgeteilt hat, weisen den oN und PN nach zum uberwiegenden Teil nach Ungarn, zum kleineren meil nach Serbien und in manchen Fallen nach Westbulgarien und lazedonien. Wenn man sich auch noch die zahlreichen orthodoxen Elemente dieser Lieder (vgl. in Bog.7,12,16,17, 
$22,23,32,35$ u.a.) $)^{12}$ und inre zum Teil sprachlichen und lexikalischen Besonderheiten ${ }^{13}$ vor Augen halt, darf man wohl mit gewisser Berechtigung vermuten, dab. die ungarserbische und innerserbische Liedgruppe nicht im dalmatinischen küstenland entstanden, sondern eben hochstwahrscheinlich aus sludungarisch-syrmischen Gegenden zugewandert ist. Der "srpski natin", in dem die beiden Fischer laut Hektorovic ihre Langzeilenlieder vortrugen, weist ebenfalls in ostliche Gebiete.

Was die Erklarung des Namens "b u $g$ a $r$ \& $i$ c a" betrifft, :so durften wohl diejenigen Liedforscher im Recht sein, die nicht auf "poesia volgare", "carmen vulgare", "bucculare", das Musikinstrument "bulgarina" bzw. "bugarija" oder soziale Begriffe wie "bugarin" in der Bedeutung "Hirte, einfacher Mann" u.u. zurluckgreifen, sondern den Liednamen etymologisch mit dem Ethnikon "bugarin" in der Bedeutung "Bulgare" in Verbindung bringen. Dabei ist zu beachten, dab mit "Bulgarien" - wie Jagic ${ }^{14}$ an Hand mehrerer humanistischer Textstellen gezeigt hat - nach Zerfall des. Dusan-Reiches meist sudserbien und liazedonien gemeint sind, - und dorthin weisen ja die gltesten Liedhelden ihrer Herkunft nach. wie vor allem Schmaus in seinen Untersuchungen uber die Bugarłtica bewiesen hat, ist diese nach ganz bestimmten "metrisch-syntaktischen Modellen" gebaut, die eine langere Liedentwicklung, d.h. einen langwierigen sprachlichen Siebungsvorgang voraussetzen. Er nimmt mit Recht eine Blute des Langzeilenliedes im unteren Donauraum an, wobei er betont, daß es sich aber "schwerlich um einen Neubeginn in den nördlichen Gebieten" handeln durfte, sondern eventuell "der Iiedtyp wenigstens in seinen Grundzlugen aus slldicheren Gegenden (Miazedonien?) hierher Ubertragen wurde"15. Diese hypothetische Annahme wird dadurch bestarkt, dab wir, wie im Laufe dieser Arbeit noch klarwerden wird, in Mazedonien und Westbulgarien tatsachlich ein sehr altes Liedgebiet mit mythologisch gefarbten Heldenliedern annehmen können. Sujets und Liedformen dieses slldostlichen Raumes sind dann wohl seit den Turkeneinfallen in letzten Drittel 
des $14 . J h$. und der damit verbundenen Fluchtbewegung nach $N$ und NW entlang des Vardar-'orava-Heges nach Sudunfarn und Syrmien gelangt, wo die suidslavische Volksepik durch Aufnahme der historischen Tükenkämpfer des 15.Jh. in das Iied einen Hochststand an Historisierung (verbunden mit einem Minimum an mythologischer. Elementen!) erreichte. Gleichzeitig zeichnet sich diese Epik durch ein Hochstmaß an feudalm ritterlicher Gesinnung, höfischem Geist und Betonung von Standesidealen aus, was sicher die heroisch-ritterliche Manier der skr. Guslarenlieder beeinflubt haben durfte.

Die Langzeilenlieder der ungar- und innerserbischen Gruppe sind geographisch an Budim (am hăufigsten), Sibinj, Smederevo, Krußevo, Kupinovo, Kosovo (sehr hăufig), Vidin, Severin, ugarska zemlja, Slovin, Srijem, Podunavlje und Bugarija (in einem Fall) gebunden. Als Liedpersonen kommen an hăufigsten vor der ungarische König (budimski, ugarski kralj), mehrmals namentlich Vladisav oder Matijas genannt, und die ungarische konigin (budimska, ugarska kraljica), um sie gruppiert die "ugarska gospoda" bzw. "ugricici", d.h. Ungarn wie Ugrin Janko (am haufigsten), Sekul sestricic, Mihajlo Svilojevic, und Serben wie die Despoten turat und Vuk ognjeni, ferner Jerina, die Gattin des murad, Barbara, die Gattin des Jespoten Vuk, und Nargarita, die Schwester des Svilojevic und Gattin Jankos. Den übergang zur innerserbischen Iiedergruppe bilden die Bruder Jakzic. Nach Suden weisen Marko Kraljevic und sein Bruder Andreas, Minja von Kostur, Novak, Banovic Strahinja und Stjepan Lazarevic, ferner die Gestalten der Kosovoschlacht: Lazar, Milica, Miloß Kobilovic, Vuk Brankovic und die Jugovici.

Eine kurze Bestandsaufnahme soll diese ungarserbische Iiedschicht verdeutlichen:

Matijas wird durch ein Gottesurteil (die dreimal hochgeworfene Krone frllt jedesmal auf das Haupt von Jankos Sohn) Konig von Ungarm (Bog.30 und 31).

Barbara, der Matija\} einst die Ehe versprochen, sie aber dann doch nicht geheiratet hat, kommt auf Einladung des Konigs nach Budim zum Gastmahl, wo sie sich als Gatten den Despoten 
Vuk erwahlt; Vuk erklart, ihm sei von Matijas alles weggenommen worden, worauf der Konig ihm die Rllckgabe des vaterlichen Besitzes zusichert (BOg.12).

Despot Vuk liegt im Sterben und beweist - gegen alle Beschuldigungen - noch im Tod seine Vasallentreue gegenuber dem ungarischen König und seine treue fllrsorge fur seine Gattin Barbara in seinen letzten Aufträgen an den Wahlbruder Mitar Jaksic (Novak.ASIPh III 1).

In der Variante dazu stirbt der verwundete Ognjen Vuk, weil seine Gattin durch ihre Neugierde die beiden dumonischen Wesen, Zmaj und Vila, die den Helden pflegen, stört (Bog.16).

Nach der Schlacht auf dem Kosovofeld beschuldigt Favao Strijemljanin vor dem ungarischen König Ognjen despot Vuk des Verrats; Vuk, gewarnt von Dnitar Jaksic, eilt herbei und klart mit Hilfe der Aussage des gefangenen Türken Hasan Pała die Situation, worauf er den Verleumder whtend schlagt; um seine Treue zu beweisen, macht Vuk viele turkische Gefangene und bringt sie dem Konig (Bog.14).

Vuk und sein Wahlbruder Dmitar Jakßic fangen Nikola Protopopic, der schon 70 ugricici getötet hat und den König von Budim an der Einnahme Wiens hindert, lebend und bringen ihn zum König; Nikola wird hingerichtet, und die stadt ergibt sich (Bog.15).

Despot Vuks betrilgerischer Wahlbruder, der Türke Alibeg, versucht ihm an der Donau seine Braut, die Tochter des Bans von Poljice, wegzunehmen, wird aber von Gredeljica Radosav daran gehindert; aus Rache plundert Vuk später Alibegs Hof $(\mathrm{Bog} \cdot 13)$.

Die Schwester des Königs Vladisav tauscht mit Ugrin Janko, ban Mihail und ihrem Brautigam Sekul Drakulovic Geschenke aus; die drei Helden ziehen mit dem Konig nach Kosovo und kommen alle um; der konig wird von seiner Schwester beweint $(\mathrm{BOg} \cdot 21)$.

In der Variante dazu berichtet ein Rabe vom Tod der Helden, worauf die Konigstochter ihren Bräutigam Sekula betrauert $(\mathrm{Bog} \cdot 32)$.

Janko, zusammen mit Mihajlo und Sekula, erbittet die Schwester des Königs von Budim als Braut fur sekula und erhalt eine Zusage; anschließend zieht Janko mit den ugricici nach Kosovo, wo Sekula zum Sultanszelt vordringt, todlich verwundet wird und stirbt; Janko teilt dies seiner Braut in symbolischer form (Sekula dem Kosovofeld argetraut) mit $(\mathrm{Bog} \cdot 20)$.

Sekulas liutter stirbt am Grab ihres Sohnes auf dem Kosovofeld. nachdem sie Jankos symbolischen Brief (Sekulas Tod = Hochzeit auf Kosovo) nicht verstanden hat und zur vermeintlichen Feier herbeigeeilt ist (Bog.22). 
Ugrin Janko ist verwundet von Kosovo geflohen und berichtet dem Konig von der Gefangenahme des Ban Mihail und der tödlichen Verwundung Sekulas; mit Gottes Hilfe (Tau und Nebel fallen) gelingt Janko und seinem Diener die Flucht vor den Turken (Bog.25).

Ban Sekula kampft in Gestalt einer Plugelschlange mit dem in einen Adler verwandelten turkischen Sultan in der Iuft; Ugrin Janko schiebt auf die Schlange, womit er Sekula todlich verwundet (Bog.19).

Janko und sein Neffe Sekula veranstalten ein Wettrennen auf Kosovo, und Sekula siegt; der Neffe schenkt Janko sein schnelles Pferd; er erhalt dafur die Stadt Sustica mit 300 turkischen Janitscharen darin (Bog.17).

Die Verlobte des Svilojevic erfährt vom kond, daß der Sultan ihren in Carigrad gefangenen Verlobten nach den drei Uberragenden Helden der Schlacht gefragt habe, worauf Svilojevic Kraljevic Marko (hier offensichtlich statt Jankol), Sekula und seinen eigenen Namen nannte; dann habe Svilojevic 300 Janitscharen besiegt und sei entkommen (Bog.46).

Ugrin Janko liegt krank im Zelt und kann nicht an der Kosovoschlacht teilnehmen; von einem Verwundeten erfahrt er den Tod König vladisavs, Sekulas und Mihajlos; er eilt auf das Schlachtfeld, sucht und findet den toten König, den er nur an seinem Ring erkennt, weil sein Gesicht so entstellt ist; Janko Uberbringt die Hand des Konigs dessen Gattin und Mutter (Bog.29).

KOnig Vladisavs Schwester, die Verlobte Sekulas, vertraut ihren Bruder Jankos Schutz an, doch Vladisav hört nicht auf Janko (der mit Sekul necak und ban Mihajlo die Truppen anfuhrt), sondern dringt waghalsig zum Sultanszelt vor, wo er den Tod findet; auf die Vorwirfe der Schwester hin schildert Janko die Situation (Novak.ASIPh III 3).

Der ungarische König ist auf Jankos Ruhm eifersuchtig und versucht ihn zu schlagen, worauf sich Janko wehren will; der Kampl wird von den ungarischen Herren verhindert: Janko reitet weg, doch die Königin bewegt inn zur Rluckkehr, wonach die Versobnung mit dem König folgt (Bog.27).

Vlatko Matenovic, der dié vom Schlachtfeld von Mohács fliehenden, verwundeten ugricici beraubt, wird von Janko getotet (Bog-24).

Ein Mädchen aus Budim sagt in einem symbolischen Traum von fallenden Gestimen dem Konig Vladisav Unheil voraus; Ugrin Janko deutet den Traum mit dem bevorstehenden Fall Budims; die Prophezeiung erfulit sich sofort (Bog.28).

Der König von Budim flieht mit seinem Diener Nikola Tomanovic vor den Turken auf dem Kosovofeld; im Waldgebirge beugt 
sich der kơnig uber einen Brunnen und trinkt, wobei ihn sein Diener aus Habgier nach seinen goldenen Kreuzen den Kopf abschlägt; der Kopf im Brunnen verflucht den Diener zu neunjührigem Siechtum; erst als Nikola nach neunjuhriger Krankheit seine Tat beichtet, erlost ihn der Tod (BOg.35).

Janko wird auf der Flucht von Kosovo vom Despoten turad in Smederevo in das Gefangnis geworfen und von seiner Gattin, die ihre beiden Söhne Lauß und Natijas als GeiBeln stellt, befreit; im Streit beim Kartenspiel tötet Matijas den Sohn des Despoten, Lazar; Janko fordert drohend seine Sorhne zuruck; als die Despotin Jerina ihren toten Sohn gefunden hat, werden Jankos Söhne verfolgt, aber vergeblich (Rog.10).

Janko vojvoda, Sekula sestricic und trurat despot sind unter den Svaten, als der Könif von Budim die Schwester des Bans von Krułevo freit; Janko allein (oder zusammen mit Svilojevic) besteht die Preiersproben, worauf die Braut ubergeben wird; auf dem Heimweg schlagt Janko (aus Rache fur seine Gefangennahme durch turad) vor den Frauen von Smederevo den alten Despoten, bis Jerina ihn aufzuhören bittet $(B 08 \cdot 9,26)$.

Despotin Jerina verspricht ihre Nichte Mara beim Gastmahl dem Damjan Sajnovic (gemeint ist sicher der Vojvode Sain des Despoten Stefan Lazarevic); dieser lehnt das Angebot $a b$, weil er schon einmal bei Maras Mutter un das itgdchen angehalten und eine Absage bekommen habe; seitdem sei lara nicht nur von ihm, sonderm auch von den Herren von Smederevo gekubt worden; Jerina labt Damjan daraufhin ins Gefangnis werfen, woraus er mit Jankos Hilfe befreit wird (Bog.11).

Janko freit die schøne Schwester des Svilojevic (Mitbewerber sind der junge, schöne Stjepan banovic und sekula) und erhalt sie, die lieber Stjepan zum Mann gehabt hatte; Janko zieht mit liargarita nach Sibinj; dort schenkt sie ihm die Sbine Laus und Matijas (Bog.23).

Despot Stjepan Lazarevic zeugt, bevor er nach Kosovo zieht und dort flall, mit dem schönsten ifladchen, yon Sibinj die Geschwister Ugrin Janko und Rusa (Bog.8) 16.

Sekul Drakulovic wirft Ban ililoz, der Sekuls Schwester gekUBt hat, auf Jankos Rat ins Gefangnis, wo inn das likdchen versorgt und schlieblich befreit; anschließend flieht sie mit Sekul in seine Heimat Ohrid (Bog.18).

Eine Vila entfacht in den Herzen der Bruder Jaksic die Eifersucht, worauf Mitar, der ältere, seinen Bruder Stjepan ersticht, dann aber aus Reue auch sich selbst totet (Bog.43).

Stjepan, von seiner Schwägerin bei seinem Bruder Mitar Jaksic verleumdet und der Untreue bezichtigt, wascht sich durch ein Gottesurteil (ein durrer Baum ergrint und aus einer Steinplatte quillt Wasser) von dem ungerechten Verdacht rein $(\mathrm{Bog} \cdot 42)$. 
Das gute Einvernehmen der Brider Jaksic wird durch die Schuld einer der beiden Schwagerinnen gestört; die Bruder stellen ihre Frauen auf die Probe, wobei sich Stjepans Gattin als die Schuldige erweist und getötet wird (Bog.41).

Die Bruder Jaksic geraten bei der Erbschaftsteilung in Streit; Dmitars Frau soll im Auftrag ihres zur Jagd reitenden Gatten ihren Schwager vergiften, tut es aber nicht, sondern verursacht durch ihren Fluch, dab Mitar der Falke davonfliegt urd sein fferd sich die Beine bricht; reuevoll kehrt Mitar heim und erfuhrt zu seiner Preude, dab seine Gattin den Befehl miBachtet hat (Bog.44).

Stjepan Jakjic holt seine Schwester liargarita, die sich als Gefangene in der Gewalt des Bans von Morinje befindet, nach Hause zurilck (Bog.45).

Novak feiert ein dreifaches Fest: die Hochzeit seiner Schwester, die Geburt seines Sohnes Gruica und den Bau seiner Hofe; Novaks Traute, eine Vila, der Novak an der Donau ihr Plugelkleid geraubt und sie dann heimgefuhrt hat, erhalt ihr Gefieder mit List (uber die gutgläubige Schwester Novaks) zurlick und fliegt davon (Bog.39).

Banovics Gattin, die Schwester der Ugovici, ist von Denalija Vlahovic entfunrt worden; von einem jungen Turken erfahrt Strahinja, daß sich Denalija mit seiner Gefangenen an der Donau aufhalte; beim Zweikampf hilft die untreue Gattin zu ihrem Entfuhrer; als Banovic Strahinja siegreich, aber von seiner Gattin verwundet nach Hause, nach Bugarija, geht und seinen Schwagern die Kunde zeigt, töten die Ugovici inre untreue Schwester zur Strafe (Bog.40).

Marko Kraljevic und sein Bruder Andrijas streiten sich bei der Beuteteilung, worauf Marko den Bruder ersticht; nach Aufträgen an die kutter und Ratschlägen fur den Bruder stirbt Andrijas (Bog.6).

Ein bosnisches Mădchen schmaht Marko und droht ihm mit dem Galgen; Marko schwört beim König von Budim, dem Madchen nichts zuleide getan zu haben (unvollendet!)(Bog.3).

Marko hat vor Budim sein Zelt aufgeschlagen und fragt die Jungste und Schönste der iladchen am Brunnen, wer sie sei, worauf das Milichen ihn beschimpft und sagt, sie sei Markos Verlobte, Banovic Pavels Schwester, und der König von Budim sei ihr Vetter; Marko kuBt das Echöne Madchen, und sie droht ihm, sie werde ihn vom König aufhangen lassen; mit Narkos Griben an Pavel und den König kehrt sie nach Hause zurluck und erfuhrt von ihrem Bruder, dab der Unbekannte ihr Verlobter l'arko war (Bog.4).

Marko erzahlt seiner Mutter, wie er mit Hilfe eines arabischen rudchens, das er zur Frau zu nehmen versprach, dann aber tötete, aus dem arabischen Kerker entkam (Bog.5). 
Minja von Kostur aus Ungarn (1) plundert in Niarkos Abwesenheit (Marko wurde vom ungarischen Konig als Kum, von Janko als Taufpate und vom Sultan zum Kriegsdienst bestellt) dessen Hofe und fluhrt ihm Gattin und lutter als Gefangene weg. Marko, als Athosmönch verkleidet, holt seine Gattin zurluck und tótet Minja (Bog.7).

Milica trifft auf dem Kosovoschlachtfeld ihren sterbenden Schwiegersohn Milos Dragilovic; ohne ihn zu erkennen, fragt sie ihn nach Lazar und Milos; da gibt liilos sich zu erkennen und beauftragt sie, seiner Braut, ihrer einzigen Tochter, sein seidenes Tuch mit 100 Dukaten und seine von dem Madchen bestickte hiltze zu bringen, sein Pferd aber nach acht Tagen mit Seide bedeckt in das Gebirge zu fluhren und dort freizulassen (Bog.2).

Milicas Tochter, mit Vuk Brankovic bzw. Milos Kobilovic verheiratet, streiten sich wegen der Herkunft (Vuk ist Sohn einer vormehmen Stgdterin, Milos Sohn einer armen "vlahinjica", die ihn an einer Stute saugte) und des Werts ihrer Gatten;in Laufe des Streits wird Miloss Gattin von ihrer Schwester geschlagen und mit dem Ring verletzt, so dab sie ihr Gatte mit tranen- und blutüberströmtem Gesicht findet; als er die Ursache erfahren hat, faßt er Vuk an der Kehle, wirft ihn zu Boden und schlagt ihm zwei Zahne aus; Lazar trennt und beschwichtigt die Kampfenden (Bog.nicht enthalten, sondern Mikl.5).

Busic Stjepan (und sein Diener oliver) zieht trotz des unheilvollen Traums und der Bitten seiner Gattin zum Hof Lazars, wo sich die "ugarska gospoda" und die Ugovici schon versammeln; purstin Nilica trăumt einen unheilvollen Traum, den ihr der Schwiegersohn Milos Obilovic so deutet, dab alie auf Kosovo fallen werden; Milica bittet, Lazar möge ihr einen der Ugovici zurlicklassen, doch vergeblich; die Helden ziehen zur Schlacht; an der Narica halt Lazar ein Abendmahl, wobei Vuk Brankovic Iazars Schwiegersohn Milos des Verrats beschuldigt, Lazar Milos beschwort, er solle treu sein, und Milos seine Treue beteuert und schwort, er werde den Sultan töten; mit seinen Dienern Ivan Milan und Nikola Kosovíc kundschaftet er das turkische Heer aus und reitet dann zum Sultanszelt: dort behauptet er, dem Sultan zu Hilfe kommen zu wollen,sticht aber mit dem Säbel auf ihn ein und flieht zu Pferd; durch eine Stimme aus den Wolken wird den Turken geraten, den gepanzerten Milos durch aufgepflanzte Schwerter zu Fall zu bringen; Milos verliert sein rechtes Bein und flieht, auf eine Lanze gestutzt, weiter, wobei er Lazar zu Hilfe ruft; Lazar hört nicht auf Vuks Einflusterungen, sondern eilt zu Milos und wird mit ihm zusammen gefangen und zum Sultan gebracht, der noch an Leben ist und anordnet, dab Milos und Lazar gekopft und zu seiner Rechten bzw. zu seinen FuBen begraben werden sollen; Milos bittet seiner Stellung gemäB um ungekehrte Grabanordnung, worauf Lazar vor Rihrming weint und Miloss sutter preist, Vuk aber als Verräter verdanmt (Vuk ist inzwischen ins Gebirge geflohen). 
Der Sultan stirbt, Milos und Lazar werden enthauptet und zu FuBen bzw. zur Rechten des Sultans bestattet; Milica bricht das Herz, als sie die Todesnachricht erhalt.

Auf eine Liedbesprechung im einzelnen muB verzichtet werden. Zusammenfassend aber lzBbt sich sagen, dab die aufgezählten Langzeilenlieder ein hohes Maß an Historizität auszeichnet, auch wenn sie die Schlacht bei Varna 1444 , die Kosovoschlacht 1448, die Gefangennahme des Svilojevic 1460 u.ä. verwechseln und zum Teil historische Namen auf balladeske oder mythologische Stoffe aufsetzen. Ferner ist festzustellen, daß die Liedgestalten zum großen Teil individuelle Zuge tragen, die der historischen Gegebenheit entsprechen: Die historisch berechtigte Dreiergruppierung Janko-Sekula-Svilojevic wird $z \cdot B$. erst in jüngeren Iiedern durch die typisch gewordene Gruppe Marko-Relja-Miloł ersetzt, die Despoten tural und ognjeni Vuk werden entindividualisiert, der Konig von Budim tritt nur noch als typische Figur auf usw. Die nghere Vertrautheit mit dem Turkentum fehlt noch in den Langzeilenliedern, ebenso echter Hajdukengeist. Statt dessen sind die Iieder von vormehmer, höfischritterlicher Gesinnung durchdrungen.

Wie Soerensen eingehend gezeigt hat, ist fur die Lieder der innerserbischen Gruppe möglicherweise Entstehung in Serbien oder Mazedonien und ein Durchgangsstadium in Slidungarm anzunehmen, wăhrend sich fur die meisten Lieder der ungarserbischen Gruppe syrmische Herkunft annehmen 1\&Bt. Bei ihrer Wanderung zum Adriaraum nahmen die Lieder zum Teil naturlich binnenserbische, bosnische und dalmatinische zuge an, die sich in sprachlicher, seltener auch in sujetmäbiger Ungestaltung zeigen. Charakteristisch fur diese Langzeilenlieder ist ein relativ starker lyrischer Einschlag und ein seltsam elegischer Ton. Die Lieder sind meist kurz und spranghaft und noch keineswegs fahig zu dem souveränen epischen Fluß der Deseterac-Lieder in der klassischen Vukschen Sammlung.

Während die meisten Liedforscher den Langvers flur älter halten, gibt es vereinzelt auch die gegenteilige Meinung 
(z.B. Puric). Seinem ganzen aristokratischen Geist nach durfte den Lengzellenlied aber die Prioritzt vor dem eplschen Zehnsilberlied zuerkannt und ein Auseterben der Bugarstica zugunsten des Kurzzeilenlieds auf Grund einer "Demokratiolerung" (Jagic) der kuberen Lage und eines wechsels der Iledtrager angenommen werden. Das soll naturlich nicht heiben, deB es vor oder glelchzeltig mit dem Langzellenvers keinen Deseterao gegeben hat (Jagic fuhrt z.B. mehrere Zehnsilber nach dem Schema $4 / 6$ bel Hektorovic an), sondern man mus auf Grund der Aufzelchnungen zu dem Schl.uB 'kommen, das berelts Anfang des 18.Jh. der Deseterac eine ausgepragte Regelmasigkelt und allgemein oudslavische Verbreitung gefunden hat, die wir vermutlich auch schon flur das 17.Jh. ennehmen durfen. Aus dem zeltweiligen Nebeneinander ging der Kurzvers alo sleger hervor, doch haben die skr. Guslarenlieder aus dem altertumlichen Sujetbestand und seiner herolsohen St1lisierung zur Genluge geschoppt bew. das Alte in achlieblich souveränerer Porm weltergefuhrt. Ob der Langvers mit seinem Versechema

$$
\begin{array}{r}
\leq-\leq-\leq--1 / \leq-\leq-\leq-\leq- \\
\leq-\leq-\leq--1 / \leq-\leq-\leq-\leq- \\
\leq-\leq-\leq-
\end{array}
$$

aus elnem anderen Versmas hergeleitet werden kann, ist bio heute elgentlich ungeklart geblieben. Mehrmale (z.B. von Chalansk1f, Miklosich, Valliant, Ibrovac u.a.) wurde die Herleitung aus dem griechischen otíxos roxitLKós mit dem Sohema $\quad-\dot{-}-\dot{-}---/ /-\dot{-}-\dot{-}-\dot{-}$ veroucht. Hoffnungelos lot melner Metnung nach das Unterfangen, den Langvers aus dem Deseterac ableiten zu wollen (Burle).

1.11 DIE DATMATINISCH-RAGUSANISCHEN DICHTER UND KACIC-YIOSIC IN IHREM VERHZ̈ITNIS 2U DEN UGRISCH-SERBISCHEN HELDEN

Das die in standiger Turkenfurcht ${ }^{17}$ lebenden dalmatinischragusanischen Dichter und auch Kac16-Hiob16, was 1hre Kennt- 
nis der ugrisch-serbischen Tlukenkampler und das Urtell Uber sie betrifft, sehr wahrscheinlich aus der durch deutliche Ungarnfreundlichkeit einerseits und Abneigung gegenuber den Turken und dem Despoten turad andererseits gepragten Volksdichtung (d.h. In diesem Pall den aus dem danuble schen Raum zugewanderten Langzeilenliedern und den sie ersetzenden Kurzzeilenliedern) geschopft haben, haben Soeren$\operatorname{sen}^{18}$ und - speziell fur Barakovic - Petravid ${ }^{19}$ deutlich gemacht, wahrend Jagi $c^{20}$ und Banovi $c^{21}$ ungekenrt zu der Erklarung neigen, die ungarnfreundliche Haltung der katholischen Dalmatiner spiegle sich in den Volksliederin und spreche fur die Annahme einer dalmatinischen Herkunft speziell dieser Lieder. Meines Erachtens durfen wir aber eher (mit Soerensen) fur einen syrmischen Ursprung der ungarnfreundlichen Lieder pladieren und ihre Entstehung in den Kreisen der unter der Pahne des ungarischen Konigo kamplenden serbischen Adligen suchen, die auf Seiten der Partei des Hunyadi, und nicht des als Turkenfreund geltenden Despoten trarạ standen. - Vor allem dem ungarischen Konig, dem Vojvoden Janko und dem Despoten Vuk, aber auch Sekula und Svilojevic als hervorragenden Turkenkampfern galten - allgemein gesagt die Sympathien von Dichtern wie Palmotić (1606-57), Barakovie (1547-1628), Lucie (1485-1553), Vetranovje (1482-1576), Zlatarie (1558-1609) und Gundulic (1589-1638) ${ }^{22}$. Am weitesten in seinem TurkenhaB und seiner Abneigung gegen den Despoten in Smederevo geht Barakovic, der turad sogar in der Holle zeigt und ihn die Ursachen seiner Verdammung selbst mit folgenden Worten schildem labt:

I ziva ognja plin, kim je duh izgarans za to bih neharan svim ki me ljubize, $i$ slugam nemaran, $k i$ za me boj bize.

I Janka vojvodu neharno uhitih

i mnogu gospodu dostojstrom obolin; Mihalj Svilajevic, omiderako zaplece, Stipan Musijevic, drug veran odvece, vitezov pak vece, kih slove slavan glas (...) Docekav prigodu na polju Kosova, da Janka vojvodu nevirnim prozovu; rekoh mu, da $n$ smin na cara udriti (...) To uvit moj bire 1 moja izdaja, da Turci robize Kosovo do kraja (...)

(aus "Vila slovinka") 
Wie stark solch ein Text inhaltlich an Iieder wie z.B. Bog. 9 und 26 erinnert, braucht wohl nicht mehr besonders betont zu werden.

Dem Franziskanerpater KaCic-Miosic lagen naturlich katholische Kampfer gegen das"heidnische" Turkentum besonders am Herzen. Daraus labt sich seine starke Sympathie fur Helden wie Skenderbeg und Janko (dem im "Razgovor ugodni" 1756 - immerhin funf Lieder, davon Nr.43 wahrscheinlich ein echtes Volkslied, gewidmet sind) erklären ${ }^{23}$.

\subsection{DIE ERIANGER LIEDER!IAN DSCHRIFT}

1913 fand der Germanist E.v.Steinmeyer in der Erlenger Universitatsbibliothek eine von einem Unbekannten geschenkte HS, die er als "Sammlung von 213 serbokroatischen lyrischen und epischen Volksliedern, auch einigen Kunstliedern, in Kurzzeilen, mit kyrillischer Schrift aufgezeichnet und mit schonen roten Initialen geschmickt" beschrieb ${ }^{24}$ und dem 18.Jh. zuordnete. Der Mnchener Slavist E.Berneker, um die Bestimmung der Sprache, der Entstehungszeit und des Inhalts der HS gebeten, gab am 7.2.1914 in der Bayerischen Akademie der Wissenschaften 25 einen Bericht Uber die Erlanger Handschrift (EH), Ubertrug aber die nahere Untersuchung und Herausgabe der HS seinem Schuler G.Gesemann, der die LiederHS 1921 kurz beschrieb ${ }^{26}$ und schlieblich 1925 mit einer 148 Seiten langen Einleitung sowie kritischen Anmerkungen und Variantenverzeichnis versehen herausgab 27 . Bald nach dem Erscheinen der EH setzte eine Flut von Besprechungen und eine Polemik über den Autor und die intstehung der Iiedersammlung ein, die in neuester Zeit schlieblich noch durch eine sprachliche Untersuchung ergänzt wurde ${ }^{28}$. Der eigenartige Mischcharakter der HS warde zwar mehrfach betont, die Sammiung aber bisher keiner eingehenden inhaltlichen Untersuchung unterzogen. Gesemann konnte auf Grund dialektologischer Eigenheiten die HS im Gebiet der ehemaligen Militargrenze lokalisieren, und zwar in dem Viereck 
Sisak-Gradiłka-Virovitica-Križevci. Als Entstehungszeit bestimmte er die ersten Jahrzehnte des 18.Jh., d.h. alsc die Z3it, der auch die Lieder bei Bogizic entstammen. Hinter dem Sammler und Schreiber (in einer Person) vermutet Gesemann auf Grund der orthographischen Fehler einen der skr. Sprache machtigen suddeutschen (laut Reiter wird man die Heimatmundart des Sammlers "an der Nordgrenze des Mittelbairischen oder im sudlichen Nordbairischen" vermuten durfen), moglicherweise einen Militar- oder Kanzleibeamten in der Verwaltung der Militargrenze.

Die Iieder müssen von den verschiedensten Skngern vorgetragen worden sein, denn die Sammlung enthalt ein Gemisch von Iiederm christlicher (katholischer und orthodoxer Konfession; laut Gesemann stammen Nr.27,28,30,190 und 210 eindeutig aus orthodoxer Umgebung) und mohammedanischer (İaut Grge $\bar{c}$, S.175 f. sind folgende Iieder der EH mohammedanisch: Nr.6. $24,25,54,55,57,58,61,68,77,85,86,88,91,93,95,99,101,103$. $104,108,126,130,140,158,159,161,162,184,191,193,200$; Gesemann nennt hier Nr.9,54,57,93,102,130,145,191,193,195 als Sevdalinke Iyrischen Charakters und Nr.6,24,25,55,58,61,65, $68,82,85,86,95,99,101,103,104,142,158,159,162,173,183,184$. 193,200,204 als Sevdalinke mit Balladencharakter) Provenienz, außer den skr. auch Lieder bulgarischer Herkunft (laut Gesemann durften Nr.33,48,198 und 13 ziemlich sicher und Nr. $19,22,23$ und 32 wahrscheinlich bulgarischer Herkunft oder von bulgarischen Elementen durchdrungen sein) und, verstreut in der Hauptmasse der echten Volkslieder, auch einige Iieder vermutlich nicht volkstumlichen Ursprungs (laut Gesemann die Nr.1,2,20,37,38,39) 29 .

Besonders interessant sind die Lieder, in denen christliche Kämper von Turken bezwungen (z.B. in Nr.88 und 138) oder Uberlistet (z.B. in $\mathrm{Nr} \cdot 74,77,83$ und 126) werden. Wie Schmaus. 30 gezeigt hat, scheinen die Martolosen (christliche FuBsoldaten in turkischen Diensten, die als Wachmannschaften in den Grenzfestungen und als Kundschafter dienten, aber auch im "feindlichen" christlichen Gebiet tberfalle und Plunderungen verubten) in ungarnfeindlichen und tlur- 
ken-, marko- und martolosenfreundlichen Liedern wie EH 83 , Bog.88, EH 124, EH 204 u.a. als Liedträger gewirkt zu haben. In Liedern wie EH 64,80 und 156 werden christliche Sldslaven in der Rolle von Martolosen auf der einen und Hajduken und Uskoken (Senjani) als Vertreter der nationalen und christlichen Sache auf der anderen Seite einander feindlich gegenubergestellt. Eine ausgepragte Martolosenepik konnte deshalb nicht entstehen, weil die Institution der Martolosen immer mehr degenerierte (Martolose und Räuber werden schlieblich Synonyme!) - im 18.Jh. finden sie nur noch selten Erwahnung - und nun den christlichen Hajduken und Uskoken regelrechte mohammedanische Grenzklmpler (krajißnici, serhatlije) als Vertreter der osmanischen Staatsmacht und des Islam gegenuberstehen, womit sich zwei deutlieh geschiedene Fronten erkennen lassen. Wie Gesemann (Einleitung zur EH,S.CXXV f.) und Schmaus ${ }^{31}$ (gegen D.Kostid ${ }^{32}$, der EH 51 und 116 fur Langzeilenlieder halt) bewiesen haben, gibt es in der EH keine einzige Bugarstica,nur Kurzzeilen-, vorwiegend Deseterac-Lieder. Diese Lieder im epischen Zehnsilber, die mit den epischen Deseterac-Iiedern der Dubrovniker HS von 1758 (Bog.85-119) große Ähnlichkeit aufweisen, zeigen uns erstens, daß in den nordostlichen Landschaften flir das $17 . \mathrm{Jh}$. mit DeseteracIiedern zu rechnen ist, whyrend sich die Bugarstica in den westlichen klustengebieten noch bis in das 18.Jh. hielt, und dab zweitens, gemessen an dem realistischen Bild der keineswegs Uberragenden Lieder in der EH, die etwa hundert Jahre jungeren "klassischen" Vukschen Lieder den Höchststand und Endpunkt einer langdauernden Liedentwicklung darstellen. Aupfallenderweige findet aich in der EH kein einziges Lied uber die Kosovoschlachten. Nur einmal in EH 124 wird Kosovo lediglich erwahnt. Sollte das Fehlen jeglicher Kosovolieder in der EH kein Zufall sein, so durfen wir vielleicht aus dieser Tatsache schließen, daB die Kosovotradition mehr in dem dinarischen und klistenlandischen Raum zu suchen sei. Die EH ist von mehreren Liedschichten geprägt: Einerseits 
sind da die jungeren Lieder, voll von echtem Hajduken- und Uskokengeist, dem Ausdruck einer verkinderten sozialen Umwelt, andererseits aber findet sich noch eine bestimnte Anzahl alterer lieder der ungarserbischen Liedgruppe, die an die ritterlich-feudale Gesinnung der Langzeilenlieder erinnern. Was den Stil der epischen Lieder in der EH betrifft,

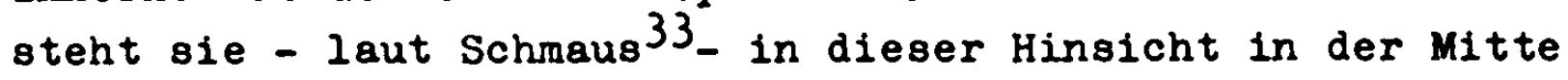
zwischen dem Bugarstica-Stil und dem Liedstil der Vukschen Sammlung. Wharend 2.B. der Gebrauch des doppelten Epithetons (dabei an erster Stelle "lijep" in der Bedeutung "vornehm") fur die Bugarstica charakteristisch ist und die EH noch deutliche Spuren der fruheren Verwendung zeigt, ist "lijep" in den Vukschen Liedern im allgemeinen durch das jungere "beo" ersetzt. Diese Tatsache durfte ein weiterer Beweis fur eine kontinuierliche Liedentwicklung und ein höheres Alter der Bugarstica sein.

Uns sollen hier, wie bei den Langzeilenliedern, vor allem die Lieder der ungarserbischen Gruppe interessieren, die oft genug die Einwirkung späterer Sangergenerationen zeigen, die zu Anachronismen in den "Heldenkatalogen" (wobe1 altere Helden wie Janko und Sekula sich in der Gesellschaft von Hajduken und Uskoken befinden) u.k. Puhren. Wahrend bei Bog. (insgesant 130 Lieder) Janko noch in 23, Sekula in 14, Svilojevic in 9, Despot ognjeni vuk in 6, Despot turat in 4, Jerina in 3, Matijas in 6, Vladisav in 3, budimski kralj in 20, budimska kraljica in 7, die ugricici (ugarska gospoda) in 15 und die Jaksici in 8 Liedern vorkommen, lauten die Vergleichszahlen flir die EH (bei insgesamt 217 Liedern) 9-4-0-3-2-3-6-2-4-1-2-2, also schon bedeutend weniger. Die Zahl dér Marko-Lieder ist etwa gleich (13:12), ebenso die haufige Erwähnung Budims (16:12). In der EH tauchen dafur Hajduken wie Novak (8mal), Gruica dete (6mal), Radivoj (5mal), Aleksa (3mal), Tatomir (1mal) und Uskoken wie (Senjanin) Ivo (5mal), Vuk Mandusic (3mal), uskok Radovan (2mal) und Turken wie Balibeg (2mal; der histo rische Baly Beg Malqod-oghlu, zweite Halfte 15.Jh.) usw. auf 
Dooh nun su einer kurgen Bestandsaufnahme der Iledgruppe in BH, In der ungarserb1sche Helden vorkonmens

Auf briefliche Aufforderung durch Vuk Mandusic sammelt oein Wahlbruder Ivan Sand16 d1e "arambabe" Branko, Vuk, vojvoda Janko, Petar latinin, Sekola (Jankos Neffen) und stelit 1hnen einen Bannertrager voran; nachden die Schar ("druzina") vom Georg8- b18 zum Michaeletag vergeblich in Otres (Dalm.) aue bosn18che Spah1s und uberseelsche "Cehaje" gewartet hat, wagt Vuk Mandusic oinen Voratos im Alleingang, macht tuchtig Beute und teilt anschlieBend mit seinen Gefahrten (BH 17).

M1lo8 "Oricanin" dient neun Jahre lang belm Vojroden Janko wegen dessen Schwester Jana, die thm Janko aber nlcht geben wili mit Hilfe einer Sklavin dringt Milos in Janas Gemach - in und verbringt dort eine Ilebesnacht; nach sechs Monaten flleht dea Paar in Richtung Obrid, verfolgt von Janko und se1nen Diener Mihajlo: Janko abchte Milob erachleBen, aber au Bitten Mlhajlos findet oine Versobnung atatt, und Janko laBt Mllos mit Jans ziehen (BH 50).

Der Vojvode Nikola fordert seine echone Schwester, um die sioh als Bewerber Mehmed und Usein aus Konstantinopel, zwel Herren aus Senj, namlich Ban Nikola und Vojvode Janko, cowle der Lateiner Herceg Stipan streiten, aur, sie solle sich endlich rur einen entschelden, sonst tote or sies nach dem miBgluckten Verouch, olch in Garten aufuhingen, fordert das Madchen Herceg StIpan aus der Hercegovina auf, or solle mit seinen Svaten kommen (EH 76).

Vojroda Voin aus Vucitrn frelt Jelica, die Schwester des serbischen Zaren Stefan, und erhalt die Aufforderung, ind Svaten su kommen; Voin sammelt daraumin die Helden Jugovic Bogdan, Kral jevi6 Marko, Janko von S1binj, Radivoj, Novat, dete Grulca, die drel Brader Kozatovi6, die neun Jugov161, Mersan Brdar16, uskok Radojca, Stefan Musojevio und harambasa Pavle, nit denen or seine Braut in Prizren abbolt (BH 92).

Vojvoda Janko w11l gegen den Rat seiner Gattin, die einen unbelivolien Traum getrlumt hat, oelne belden sihne gleichzeit1g verhelraten auf dem Rluckeg nach Elnholung der Briute wird der Hochzeitazug von Hajduken uberfallens Jankos Sohne werden get8tet und die BrEute entrihrt; Janko bringt oliner Gattin die abgeachiagenen Kopfe Ihrer sohne (EH 109).

Vojroda Janko, der bel Morgengrauen in seinem Zelt beim Wein sitzt, wird von einem "seidenhaarigen Ungarn" benachrichtigt, das sein Heer faot aufgerioben und Sekula schwer verwundet (d1e rechte Hand und das I inke Bein abgeschlagen) selen; Janko stlust auf das Schlachtfeld, ormutigt selne Druzina und besiegt die Turken im Sturn (EH 133).

Vojvoda Janko aus Sibinj, der von zwel Henkersknechten im Veleb1t-Geblrge verbrannt werden soll, bittet seine Schwe- 
ster Jelica, sie moge ihren Sohn opferm und statt des Oheims verbrenren lassen; Jelica Uberlabt daraufhin ihren Jungsten (Vukosav) den Henkern und wird zur Strafe von der Vila erschossen (EH 134).

Vojvoda Janko nimmt seinen Neffen Sekula gegen den Widerstand seiner Nichten mit sich, um ihn zum Harambasa auszubilden; urterwegs, als Janko vor den Toren der Stadt Branicevo mit riadchen wegen Zeltstoff verhandelt, wird Sekula von der Stadt aus erschossen; Janko bestattet seinen Neffen und antwortet seinen Nichten, die inren Bruder zurluckfordern, weil sie eine Braut fur inn gefunden hätten, er habe Sekula längst mit der schwarzen Erde und dem grinen Gras. vermahlt (EH 157).

Crnojevic Ivo freit die Tochter des klstenländischen Bans und holt sie mit einem großen Hochzeitszug ab, in dem sich Relja von Budim, Milos Kobilic, Kraljevic Marko, Kaica Radonja, Sekula und Janko, flinfzehn aus Udbina "entsprungene" Uskoken, die beiden Novakovici, Novak und Radivoj, Janko Zekaranin, Sima Samohod als Svaten und Aleksa als Wegfllhrer befinden; auf dem Rluckweg wird der Zug von einem dreikopfigen Araber uberfallen, den die Brauteltern nachgesandt haben; Marko als Dever aber verteidigt die Braut und totet den Araber (EH 188).

Konig lailutin verlobt sich mit einem Madchen aus Janok, erkrankt aber dann und stirbt; vor seinem Tod tragt er seiner Mutter auf, sie solle seiner Braut schwarze Trauerkleider aus Seide senden; sei die Braut aus vornehmem Haus ("roda gospodskoga"), dann werde sie inn ein Jahr lang betrauern; die Braut trägt die Trauerkleider sogar drei Jahre lang und heiratet nach dieser Frist Konig Matijas (EH 53).

Konig Matijas belagert Split drei Monate, ohne es einnehmen zu konnen, weil inm ein Spliter Protopope namens Zlotopop siebzig seiner besten Helden getotet hat; der konig fordert seinen Wahlbruder Zmaj despot Vuk in Srem brieflich auf, ihm mit 6000 Mann zu Hilfe zu kommen; Vuk sammelt das Heer und hat damit schon die Drina uberschritten, als er sich Sorgen um Srem macht: Er schreibt einen Brief an seinen Wahlbruder Peter von Varadin und einen zweiten an seinen hahlbruder Mitar Jaksic, die er seine Stadt vor dem Tlirken Bali-beg in Smederevo zu schutzen bittet; in einem dritten Brief an seinen Diener Vaistina leǵt er diesem den Schutz seiner Hofe in Kupinovo ans Herz; dann zieht Vuk mit seinen Leuten vor Split, wo er Zlota protopop im Zweikampl besiegt; die Stadt wird eingenommen und geplundert; Vuk aber nimmt die Gattin Zlotas, die Schwester des Dogen von Venedig, als Sklavin mit (EH 59).

Der König von Budim wird in der Schlacht von den Turken besiegt und sein Heer bis auf einen Mann, den Diener Matijaz, aufgerieben; Matijaz bringt der Konigin von Budim die traurige Botschaft, worauf die konigin inn zum Gatten nimmt und Matijaz Konig von Budim wird ( $\mathrm{EH} 73$ ). 
Die Herren von Budim wollen durch Hochwerfen der goldenen Krone einen König wăhlen und bitten Gott um schones Wetter fiur diese Zeremonie; die Gattin von Vojvoda Janko trăumt und sieht ihren Sohn Matijas mit einem goldenen, bis zum Seidengurtel reichenden Zopf; auf dieses gute Vorzeichen hin fuhrt Janko seinen Sohn zur Königawahl nach Budim, wo die Krone tatsächlich auf latijass Haupt fallt und ihn 80 zum König bestimmt (EH 75).

Dreibig Martolosen trinken Wein im schonen Smederevo, unter ihnen auch Kaica Radonja; da kommt der alte Balibeg zu ihnen und erklärt, er suche einen Helden, der nach seinem im Lager von König Matijas im Zelt von Zmaj despot Vuk gefangenen Sohn Ajdar-beg sehe; Kaica Radonja erkiart sich zu dieser Tat bereit, fordert aber den Schecken Alibeg8, einen Abkömmling des Sarac von Kraljevic Marko; er reitet nach Srem ins Lager des Konigs, wo der junge Turke das Pferd seines Vaters erkennt und weint; der Konig schickt Ajdarbeg mit einer goldenen Keule hin zu dem unbekannten Reiter, um seine Herkunft zu erfragen: Kaica packt den Jungen, setzt inn hinter sich aufs Pferd und flieht; Vuk verfolgt inn, muB aber an der Sava aufgeben; sein Pferd scheut nämlich vor dem Wasser, worauf Vuk nicht so sehr den Verlust des Gefangenen als den der goldenen Keule beklagt (EH 83).

Ban Yetar von Varadin wird von dem Landesherm, König Matijas, getadelt, weil er 300 Dukaten, seinen Rappen und seinen goldenen Streitkolben an einem Tag vertrunken hat; $\mathrm{Pe}-$ tar rechtfertigt sich und meint, der konig hatte noch mehr Geld und dazu ganz Pest sowie halb Budim vertrunken, wenn er bei der schönen Schenkwirtin gewesen wäre (EH 178).

Die Turken fallen uber Budim her und reiBen Wohnturm fur Wohnturm ab, weil sie die schöne Mara suchen und nicht finden; endlich entdecken sie die Schöne, die mit Ban Petar Wein trinkt; Petar wird erhangt, die schone Mara aber ubers Meer entfuhrt, wo sie sich ins Wasser sturzt und den Tod sucht (EH 11).

Die Bruder Jaksic, Ninko und Nikola; fliehen mit Pferden und Geld vom Hofe des Osman-beg, wo sie neun Jahre lang umsonst dienen muBten; mit Hilfe der listigen und ihnen wohlgesinnten Schankwirtin gelingt die Flucht, und Osman-beg kehrt erfolglos zu seinem Hof zurluck (EH 111).

Jerina gent in Smederevo epazieren und trifft Damjan Sajnovic, den sie auffordert, ihr Geliebter zu werden; Damjan lehnt ab mit Hinweis auf den Treueschwur, den er ihrem Gatten, dem Despoten turad, geleistet habe; Jerina racht sich damit, daB sie bei einem Gastmahl Damjan mit einem Goldbecher zutrinkt, und zwar auf die Gesundheit seiner Trauten Jana, die den Despoten liebe; gekrankt eilt Damjan nach Hause und ersticht im Zorn die unschuldige Jana; als er die Despotin trifft und diese ihn nach Jana fragt, verflucht er Jerina (EH 18). 
Anlelija, die Gattin des blinden Stefan, den seine Schwester blenden ließ, belauscht ihre Schwiegermutter Jorina, die ihren Freunden, den Wesiren, erzählt, Stefans Söhnchen habe ein wunderbares Geburtszeichen, ntmich goldene Haare, was darauf hinweise, dab er das Reich einnehmen werde; die Wesire sollten ihn also fangen und toten; Stefan labt seine Gattin einen Brief an den Kơnig von Budim schreiben, in dem er den kleinen Maks unter seinen Schutz stellt; Iiener des Königs holen den Jungen nach Budim, wo er grobgezogen wird (EH 21).

Der Sultan (Suleiman) schreibt aus Mostar an den Vojvoden Presta (Priezda) von Stalac einen Brief, in dem er von inm seine Traute Vidosava, sein Pferd und sein Schwert fordert; gebe der Vojvode die drei Guter nicht freiwillig her, komme er, der Sultan, mit seinem Heer;dies geschieht, und der Sultan belagert Stalac drei Jahre lang vergejlich; als er schon nach Mostar zurluckkehren will, rat inm Papas-pała, der erllher Protopope in Smederevo war, aber unte= der Tyrannei von Burad und Jerina sich verturkte, er solle Minen graben und so in Stalac eindringen; drei Jahre lang wird gegraben, doch der Sultan erhält die Guter nicht, weil Presta, als er das vom Erdreich trube Wasser der Morava sieht und yein Geschick ahnt, das Schwert zerbricht, das Pferd totet und schlieblich mit Vidosava in cen FluB springt; dem Sultan bleibt nur die Leiche der Frau (EH 70).

Jerina ("plemenita gospoja") aus Budin lockt den jungen Miklin zu einem Stelldichein in ihr Haus, weil Ban Erko auf der Jagd ist; als aber der Hausherr unerwartet zurluckkehrt, versteckt Jerina ihren Iiebhaber in einer Truhe und entschuldigt ihre Blasse mit Fieber (EH 186).

Die Diener von turat melden ihrem Herm, daß der Held Ivan auf dem Weg zu seiner Schwester sei und auf einem wunderbaren feurigen Pferd vorbeireite, worauf Ivan auf turads GeheiB zum Wein eingeladen wird; Ivan schluft, vom vielen Wein mude, ein, sein Pferd jedoch weckt inn und meldet, das man sich anschicke, Ivan zu toten und ihm das Pferd zu rauben: Ivan entkommt rechtzeitig, und Burad verflucht ihn, denn er sei der erste, der ihn Uberiistet habe (EH 216).

Ein Madche: zieht drei Falken groß und schenkt sie dem König von Budim, dem Konig von Erdel $j$ und dem erlauchten "cesar"; sie erhalt von dem ersten und zweiten Perlen und Stoffe als Gegengabe, woflur sie sich bedankt, gleichzeltig aber betont, daß sie beides schon selbst besitze; am meisten Freude bereiten inr die Geschenke des"cesar" namlich Pferde und Helden: Die Pferde werde sie gut futtern, die Helden klssen (EH 215).

Der Konig von Budim trinkt Wein mit seinen Vojvoden und Hauptleuten und sucht einen Helden, der inm Kraljevic Marko aus Prilep lebend oder tot herbringe; es meldet sich Pilip Dragilovic, der sich rihmt, dreibig Martolosen und ihren Anfuhrer Nikola getotet und deren Frauen als Sklavinnen wegge- 
fuhrt zu haben; Momeilo, Markos Wahlbruder, warnt Pilip und meint, Marko werde selbst dorthin kommen, wo man BOses gegen ihn sinne; dann reitet Momcilo zu Marko und berichtet ihm alles; harko reitet rasch von Prilep uber Belgrad nach Budim, wo er sich nach dem Hof Pilips durchfragt; dort trifft er Pilips Gattin, die meint, erhabe auf ihrem Hof nichts zu suchen; daraue schlagt Marko ihr mit einer Ohrfeige drei zahne aus und reitet zur Schenke; Pilip kehrt nach Hause zurlack und erfährt von seiner Gattin alles; er weiB, daB es sich nur um Marko handeln kann, reitet zur Schenke, fordert Marko durch Keulenschlage zum Kampf heraus und wird von Marko durch einen Schlag auf die Brust get8tet; Marko reitet unbehelligt nach Prilep zurick (EH 124).

Wie aus dieser kurzen Bestandsaufnahme hervorgeht, ist der ungarserbische Anteil in der EH im Vergleich zur Sammlung Bog. bereits zurulckgegangen, obgleich er immer noch relativ hoch ist. Die meisten ugrischen Helden haben schon ihre Individualitat verloren und können in beliebige sujets eingesetzt werden; der konig von Budim ist bereits eine typische Figur geworden. Nur in relativ wenigen Liedern schimmerm die historischen Bezlige noch durch. Wahrend noch eine kleine Anzahl dieser Lieder (z.B. EH 59) den alten vornehmen, hrfisch-ritterlichen Geist bewahrt hat, herrscht in den meisten anderen bereits echter Hajdukenund Uskokengeist, dem sich auch die alteren Helden beugen mussen 34 .

\subsection{DIE SNALINGGE KARADŽIC, MILITINOVIC UND DER NATICA HRVATSKA}

Von den zahlreichen jungeren skr. Heldenliedsammlungen können und sollen hier nur die meiner Ansicht nach wichtigsten kurz beaprochen werdens Band II ("u kojoj ou pjesme junarke najstarije") der Sammlung von Vuk S. Karadzic (I.Ausgabe in 2 Bänden, Wien 1814-15; II.Ausgabe in 4 Bänden, Leipzig 1823-33, Nachdruck Belgrad 1958; Staatsausgabe in 9 Bänden, 1887-1902) mit Iiedern vor allem aus dem hercegovinischen Raum, aber auch aus Srem und Montenegro; die Sammlung montenegrinischer und hercegovinischer Heldenlieder von Sima 
Milutinovic, Pjevanija cernogorska i hercegovacka (Ofen 1833 und Leipzig 1837); und die beiden ersten Bände (Junacke pjesme $I_{1-2}$, Zagreb 1896 und 1897) der von der Matica Hrvatska unter dem Titel "Hrvatske narodne pjesme", Zagreb 1896-1942 herausgegebenen kroatischen Volkslieder.

Auf eine eingehende Liedbesprechung der drei Sammlungen mub hier natïrlich verzichtet werden; sie erübrigt sich fur Milutinovic und Vuk, die von Soerensen auf vergleichendem Weg genau untersucht wurden (allerdings vielleicht unter zu starker Betonung der Priorität der Milutinovićschen Lieder). Die Sammlung MH wurde bisher zwar nicht monographisch behandelt, wird aber immer zum Variantenvergleich herangezogen.

Allgemein labt sich sagen, dab der berihmte Band Vuk II (100 Lieder) serbische Heldenlieder enthalt, die sich durch ein hohes Maß an ksthetischem Geschmack, psychologischer Durchdringung des Geschehens, epischer Stilisierung und Typisiserung sowie einen souverun fließenden Deseterac auszeichnen, mythologische Elemente nur noch ganz sparlich enthalten und uberhoupt in ihrer klinstlerischen vollendung die jungste Liedstufe darstellen. Demgegenuber sind die Lieder der Sammlung Milut. (175 Lieder, davon Nr.48,55, 61-64,165 und 166 auf Zeitereignisse bezugnehmend und sehr wahrscheinlich nicht volkstilmich) zwar ästhetisch weniger wertvoll, da sie einen zu nuchternen und breitspurigen Eindruck erwecken, sie zeichnen sich aber meist durch altertilmlichere Zuge aus und, wie Soerensen sagt: "in der Regel steht Milutinovic einer aus Bogisic (resp. aus einem diesem ganz nahestehenden Text) hervorgegangenen Grundlage nicht allzufern, whhrend bei Vuk eine durchgreifendere, kunstlerischer gestal tete Umarbeitung einer gleichen Grundlage vorliegt" 35 . Die gegen die Sammlung Milut., die vom Vukschen "Kanon" abweicht, verschiedentlich erhobenen Bedenken ${ }^{36}$ konnten bisher nicht präzisiert oder durch Beweise erhartet werden. Da Milutinovic fur seine Lieder fast immer den Sanger nach Beruf und Herkunft genannt hat und die Texte m.E. einen durchaus volkstumlichen Eindruck ma- 
chen, glaube ich nicht an die Stichhaltigkeit der gegen den Sammler erhobenen Vorwlirfe. Eventuelle kleinere sprachlich Änderungen könnten zwar möglich sein, ließen sich abez nicht beweisen. - Der gröBere Tell der Lieder (105 Nummern) gehbrt stofflich ausschlieblich dem Westen an (davon 65 Mo tenegro, 25 BH und 16 dem bosnisch-dalmatinischen Grenzland) und reicht nicht uber das Jahr 1600 zurlick, während nur 56 Lieder allgemein serbische und ungarserbische Themen behandeln. Hierbei fallt auf, daß die Sammlung Milut. auch in der Bewahrung des ungarserbischen Liedanteils wesentlich konservativer als Vuk II ist: Whahrend bei Vuk Gestalten wie Janko vojevoda und Sekula fast völlig uber Haj duken- und Uskokenhelden wie Stojan Jankovic, Ivo von Senj Janko von Kotari u.a. (vgl. vor allem die 89 lieder von Vuk III) in Vergessenheit gerieten, so wie im 15.Jh. zur Zeit der ungarisch-turkischen Kriege die Taten eines Vuk despot, Hunyadi, Szilágyi und Székely die eines Milos Kobilovié, Lazar und Vukasin in den Schatten stellten, ist bei Milut. der ugrische Anteil relativ hoch geblieben. Die Zahlen sprechen für sich: Janko kommt bei Vuk II in nur 8 ( $\mathrm{Nr} .40,61,78,80,84-86,95)$, bei Milut. in 14 ( $\mathrm{Nr} .2,26,32$, $72,74,75,79,95,109,145,148,151,158,159)$ Liedern vor, Sekula bei Vuk 2mal ( $\mathrm{Nr} .84,85)$, bei Milut. 8mal ( $\mathrm{mr} .2,26,32,72$ $74,79,148,159)$, Despot turad kommt in beiden Sammlungen etwas gleich oft vor (Vuk II 35,78,80,82,85; Milut. 71,74, 152,158), König vladislav schlieblich nur bei Milut (Nr.77, Die Lieder der $\mathrm{MH} \mathrm{I} \mathrm{I}_{1-2}$ (82 und 72 Nummerm ohne die Variante im Anhang) fuhren uns vom dinarischen Raum weg in die Land schaften der kroatischen Peripherie, vor allem zu den dalmatinischen Inseln und in das adriatische Kustenland. Hier, wo das Heldenlied vorwiegend von Frauen tradiert wir (vgl. Mazedonien und Bulgarienl), haben sich manche archai schen, mythologisch gefarbten Sujets, die im dinarischen Raum einer rationalisierenden und psychologisierenden Auffassung weichen muBten, bewahrt. Auch der ugrische Anteil hat sich in diesen konservativeren Liedern, die allerdings die "deutlichen Spuren des Durchgangs durch den dinarische 
Raum" 37 tragen, besser als bel Vuk erhalten: Janko kommt in 18 Liedern ( $M H I_{1} 33,67,70,72,76,78$; $M H I_{2} 5,8,20,29$, 46,50-53,61-63) vor, Sekula in 12 (MH I $160,72-78 ; \mathrm{MH}_{1} \mathrm{I}_{2}$ 8,51,53,63), Kralj Matijas in 3 Liedern (MH I, 67; MH $\mathrm{I}_{2}$ 44,67); Svilojevic taucht in 1 Lied ( $\left.M H I_{2} 44\right)$ - wie bel Vuk II (Nr.51) - auf.

Auffallend ist der auggepragte Hang zur Bewahrung mythologischer Sujets, die wir bei Vuk nur noch rudimentar finden. Hier sind vor allem die Lieder $\mathrm{MH} \mathrm{I} \mathrm{I}_{1} 53, \mathrm{MH} \mathrm{I}_{2} 69,70$. (Kampl eines Freiers mit einem Wasserungeheuer beim Uberschwimmen eines Gewassers), MH $I_{1} 74,75$ (Sekula wird von einer Vila in einen $\mathrm{Zmaj}$ verwandelt bzw. verfolgt als $\mathrm{Zmaj}$ eine Vila), $\mathrm{MH} \mathrm{I}_{2} 2$ (Marko und die Vila brodarica), $\mathrm{MH} \mathrm{I}_{2}$ 20 ( Vila, die einen Hochzeitszug uberfallen und die Braut entfuhrt hat, wird durch Gefangennahme ihrer seelentiere gefugig gemacht), MH $\mathrm{I}_{2} 49$ (Kampl mit einer Riesin), $\mathrm{MH} \mathrm{I}_{2}$ 50 (Kampl mit einem Zmaj, der einen Hochzeitazug uberfallen hat) zu nennen, wobei aber gesagt werden muB, daB auBerdem auch in anderen Liederm der Sammlung MH I $1-2$ Vilen und Zmajs eine Rolle spielen. Erwähnt wurden die obigen Sujets vor allem deshalb, weil keines von ihnen in Vuk II eine Parallele pindet.

Von allen drei genannten Liedsammlungen haben die ugrischen Helden m.E. bei Milut. noch am meisten individuelle zuge bzw. historische Beziuge bewahrt, obwohl auch hier - wie bei Vuk und $M H$ - der Hang zur stereotypen Verwendung dieser Heldennamen schon sehr grob ist. Auffallend ist in diesen jungeren Liedsammlungen ferner der hohe Anteil an Marko-Liedern (im Vergleich $\mathrm{zu} \mathrm{Bog}$. und $\mathrm{EH}$, wo er noch nicht so hoch, aber auch schon bedeutend ist), d.h. Marko ist langst zum "Universalhelden" geworden, an dessen Namen beliebige Sujets geknupft werden können.

Alle drei Iledsammlungen, die nicht ausfunrlicher besprochen werden konnten, werden im Laufe dieser Arbeit standig zum Variantenvergleich herangezogen werden. 


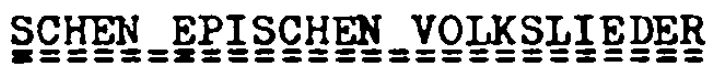

Mit dem schon eingangs betonten mazedonischen und westbulgarischen Raum ist kein politischer oder ahnlicher Begriff gemeint, sondern hier soll der relativ homogene epische Volksliedraum darunter verstanden werden, der den größten Teil Mazedoniens, Sud- und Sudostserbien sowit Westbulgarien (bis etwa Koprivitica als östlichstem Punkt) umfaßt 'und epische Lieder in vorwiegend zehnsilbigem Versmaß mit heldenliedhaften Zligen aufzuweisen hat. Um sich uiBdeutungen zu entziehen, ware es laut Schmaus 38 "fast ratsam, von einer Vardar-Morava-Zone zu sprechen". Die Bedeutung dieser flur die geschichtliche Entwicklung der sudslavischen Volksepik offenbar so wichtigen Liedzone wurde auch von Gesemann 39 erkannt und gewlurdigt. Er spricht, außer der westbalkanischen "dinarischen" Heldenliedzone, von einer zweiten epischen Zone "der zentralbalkanischen Gebiete mit dem Kernpunkte in Mazedonien" und von einer dritten, schlagwortartig "schopisch" genannten Zone, wobei es sich um die "startich zu Jugoslavien und Bulgarien gehörenden Iandschaften 0stserbiens, des heutigen Moravabanats, un die West- und Osthinge der Stara Planina und um das sog.Schopluk um Sofia herum" handelt. Heiner Meinung nach lassen sich diese zweite und dritte Zone $z u$ e $i \mathrm{n} m$ Liedraum zusammenfassen, dessen Erforschung zwar mehrert kleinere monographische studien ${ }^{40}$, aber noch keine umfassende Arbeit gewidmet wurden, - wahrscheinlich deshalb, weil die maz.-wbulg. Volksepik immer allzusehr im Schatten der epischen Heldenlieder des dinarischen Raumes otand.

\subsection{FRAGE DES GEOGRAPHISCHEN RAUMES UND DES EPISCHEN LIED- TYPS IM ASMMETRISCHEN ZEHNSILBER}

Wie schon Penco Slavejkov ${ }^{41}$ bemerkt hat, läbt sich der bulg. und maz. Liedraum in mehrere Zonen einteilen:"Nord- 
und Sudbulgarien sind das Hauptgebiet der Hajdukenlieder, die Rhodopen (bis zum Vardar) hauptsăchlich der Liebeslieder und Westbulgarien und Mazedonien jenseits des Vardar vornehmlich der epischen Lieder. Ich sage vornehmlich, weil in diesen drei Gebieten nicht nur die genannten liedtypen, sondern auch viele andere in diesen drei Gebieten ebenfalls vertretenen gesungen werden, - aber charakteristisch fur sie sind eben nur die oben erwahnten". Dinekov ${ }^{42}$ hat recht, wenn er die Meinung Slavejkovs, vor allem was die uberall verbreiteten Liebeslieder betrifft, nicht widerspruchslos akzeptiert. DaB die epische Heldenliedtradition sich aber auf die wbulg.-maz. Gebiete konzentriert, darin stimnt Dinekov dem Dichter zu, und gerade dieser Punkt ist ja der entscheidende fur unsere Untersuchungen. Wharend 0stbulgarien die Wiege eines selbständigen jungeren Liedtyps mit stark realistischen Zugen, knapper Diktion und dynamischem achtsilbigen Versmaß, nämlich des bulgarischen Hajdukenliedes, wurde, blieb im maz.-wbulg. Liedraum die alte epische Heldenliedtradition mit inrem ausgeprägten Hang zur Stilisierung, Mythisierung und teilweise phantastischen tberhohung infer Lieblingshelden bewahrt. - Auch M.Arnaudov trennt in seinem Buch "Baladni motivi $v$ narodnata poezija.I.Pesenta za delba na drama bratja" (Sofia 1964) eine deutlich geschiedene wbulg. und maz. Liedsphare ab, wo die Lieder sich durch starkere episch-heldenliedhafte Zuge auszeichnen.

Dieses Festhalten an der alten Liedtradition in Mazedonien und Westbulgarien durfte nicht zuletzt das Verdienst der b $I$ i $n$ d e $n$ (oder mit Gebrechen anderer Art behafteten) Berufssänger gewesen sein, die uberhaupt in der Liedvermittlung entlang der Vardar-Morava-Tuler eine groBe Rolle gespielt haben milssen. Zentren dieser blinden sanger epischer Lieder waren regelrechte "Sängerschulen" vor allem in Bito1a, Prilep und in der Gegend von Razlog 43 , die der beruhmten sangerschule in Irig (Srem $)^{44}$ entsprechen.

Wie es schon im Vorwort der Liedersammung der Bruder Miladinovi ${ }^{45}$ heiBt, ist das zehnsilbige VersmaB im maz.-wbulg. 
Raum neben dem achtsilbigen das gebruuchlichste, wobel betont wird, daß die "zehnsilbigen Verse der heldischen (epischen) Epoche angehören". Ob dieses fur die Heldenlieder in Mazedonien und Westbulgarien fast ausschlieblich verwendete epische Versmaß des asymmetrischen Zehnsilbers mit Zusur nach der vierten Silbe (im Gegensatz zu dem besonders in 0stbulgarien verwendeten symmetrischen Zehnsilber), der dem skr. Deseterac entspricht, in diesem Raum wirklich autochthon ist, "ist eine kaum gestellte, jedenfalls noch nicht beantwortete Frage" ${ }^{46}$. Whinrend in skr. Arbeiten die A $u t \circ c h t h \circ n i e$ des epischen Zehnsilbers im Raum der Vardar-Morava- Zone meist in Abrede gestellt wird, nimmt man von maz. und bulg. Seite den Zehnsilber in diesem Raum ebenso selbstverstandlich als autochthon an. Hier kann und soll nun naturlich nicht die ganze schwierige Problematik der in den slidslavischen Volksliedern gebrauchlichen Versmaße aufgerollt werden 47 . Die auf skr. Seite herrschende Meinung bringt Jagic ${ }^{48}$ zum Ausdruck, wenn er vorsichtiger als Soerensen - sagt, "daB ja auch in der bulgarischen Volksdichtung der achtsilbige Vers das am meisten ubliche Versmaß der epischen Lieder bildet. Daneben finde ich zwar auch den zehnsilbigen Vers sehr haufig, doch scheint er mir hauptsachlich in solchen liedern vorzukommen, die dem Inhalte nach den serbischen sehr genau entsprechen, so dab ich nicht sicher weib, ob das Vorkommen dieses Versmaßes in der bulgarischen Volksepik nicht auf einer juingeren Strömung beruht, welche, wenn man sie nicht geradezu als Entlehnung aus dem Serbischen aupfassen will, so doch unter glelchen Bedingungen wie in der serbischen Volksepik zum Durchbruch kam (...). Unstreitig ist jedoch in der bulgarischen Volksepik vieles aus der serblschen entlehnt; das entlehnte, wie ich schon oben sagte, hat auch den zehnsilbigen Vers angenommen". - Inwieweit Jagic und andere verfechter der Entlehnungstheorie recht haben, kann hier nicht entschieden werden. Ich möchte aber doch darauf hinweisen, da man bei dem maz.-wbulg. asymmetrischen Zehnsilber relativ haufig beobachten kann, wie durch Einschieben eines zwei- 
silbigen bzw. zwei einsilbiger Pullsels, durch Wortverdoppelung und Anhangen von Vokalen am Wortende die notige

Silbenzahl erreicht wird, z.B.

Katodete tova rujno vino..

Salte ne $e$, male, nae pokanil..

I tova li, sinu, griza beres...

Tovo si je, bre, vĭrla pomamka..

I se belo, belo premenete..

Mene mlado, mlado $k$ 'e pogubi..

Nazad, nazad, dva curmi ciganje..

Otka sam si se jaze uglavil..

Si otide vo Kamnena grada..

Sto ja docul 1 ja je poznalo..

Sal te Gorum zivo ostanalo...

Sto je bilo o Gorum k'esedzija,

Razljutilo na svoja druzina..

Sxo retalo tri dni 1 tri noci

Popitalo vice od vixica..

Sum setalo zemja pokrajina..

Si pratilo pała Kamenezki..

S1 pratilo silna tebabija..

Red je doxlo Markoti junaka

Ono bilo po-junak ot site..

Da ja sŭm gi malko pregrerillo...

Koga zulo Marko kralevik'e...

Sto 티 zelo zdravica $\nabla$ raka..

Se napilo 1 sfadba porestilo...

I pomal dever ona mi stanalo...

I túrgnalo na svadba da odi.. 49

Auffallend ist hier vor allem die beliebig zu erweiternde Anzahl Beispiele, die ein (gegen die Regeln der Grammatik) auf -10 statt -1 endendes maskulines Partizip Prateritum Aktiv zeigen, das dem skr. maskulinen Partizip Präteritum Aktiv auf -o (silbenschlieBendes -1 vokalisiert $2 u-01$ ) nachgebildet $z u$ sein scheint, wodurch eine Silbe gewonnen wird. Uberhaupt ist interessant, dab sich die Zahl der durch Fullsel u.ä. gewonnenen Silben sehr haufig auf zwei 
beläuft, so dab man beinahe vermuten könnte, daB der asymmetrische Zehnsilber im maz.-wbulg. Raum nicht autochthon, sondern aus einem wahrscheinlich autochthonen Achtsilber (nach dem Schema $4 / 4$ oder $3 / 5$ bzw. 5/3) gewonnen ist ${ }^{50}$. Doch dieser Gedanke muBte durch umfassende Untersuchungen bewiesen werden und soll an dieser Stelle lediglich als Beobachtung am Rande gewertet werden.

\subsection{CHARAKTERISTIK DER VOLKSEPIK IM MAZEDONISCH-WESTBUL- GARISCHEN RAUM}

Der erste namhafte Liedforscher, der sich uber die wbulg. Heldenepik äuBerte, war kein Geringerer als Vuk Karadžic. Er schreibt in seinem "Dodatak"51:"Die Bulgaren haben auch Heldenlieder, die zur Gusle-Begleitung gesungen werden, genau wie die Serben, und der grobte Teil davon sind offensichtlich serbische Lieder, die bulgarisiert wurden". Diese Meinung ist aber keineswegs auf genauere Untersuchungen, sondern eher auf einen mehr oder weniger fluchtigen ersten Eindruck begrindet. Wenn Vuks vornehmlich intuitive Urteile auch meistens erstaunlich richtig sind, so ist doch seine Beurteilung der bulgarischen Heldenepik in dieser strengen form abzulehnen.

Als P.Bezsonov 1855 in Moskau seine "Bolgarskija pesni iz sbornikov Ju.I.Venelina, N.D.Katranova i drugich bolgar" herausbrachte, hatte er der Sammlung eine 135 Seiten lange Einleitung mit dem Titel "Épos serbskij $i$ bolgarskij vo vzaimnom otnołenii, istoriceskom i topograficeskom" vorangestellt, worin er die erst zu einem geringen Teil gesammelten und veroffentlichten bulg. mit den damals schon wohldekannten und bewunderten serb. Heldenliedern vergleicht und zu einem ahnlichen Urteil wie Karadżit gelangt. Auch er behauptet, die Bulgaren hätten hauptsachlich Hajdukenlieder: "Chajducestvo - vot glavnaja certa bolgarskago éposa". Was die echten Heldenlieder der Bulgaren betrifft, so meint Bezsonov, sie seien dem Sujet, dem Inhalt und der Ausfuh- 
rung nach den serb. unterlegen; auBerdem habe das bulg. Epos altertumliche und historische Erinnerungen mit wenigen Ausnahmen verloren und besinge hauptsächlich die Taten der Helden nach den Ereignissen von Kosovo, wobei es sich vorwiegend um serb. Helden handle, d.h. die Bulgaren hätten vieles vom serb. Epos übernommen und bulgarisiert. Was jedoch die schöpferische seite, die Form, den Vers und die Sprache betreffe, erklärt Bezsonov, "v étom otnosenii serbskij $i$ bolgarskij épos nachodjatsja meždu soboju $v$ svjazi bližajłej, drug druga raznoobrazjat, odin drugomu ne ustupajut" 52 .

Diese Ansicht wurde in ihren Hauptzligen von A.Yypin in seiner "Istorija slavjanskich literatur" (I-II, St.Peterburg 21879-81) Ubernommen und verbreitete sich von hier aus wie ein wissenschaftliches Dogma.

Ganz radikale Äuserungen in dieser Richtung hat dann A.Soerensen 53 getan, der bei den Bulgaren jeglichen Besitz an eigenen Heldenliedern in Abrede stellt, wenn er sagt:

"Ich brauche hier wohl kaum zu bemerken, dab alle diese sogenannten bulgarischen Heldenlieder bei Miladinov, Kacanovskij, im Sbornik bei Sapkarev usw. nichts genuinbulgarisches an sich haben. Meines ilissens gibt es bloB bulgarische Haidukenlieder, wie sie Dozon herausgegeben(...). Alle bulgarischen Lieder von Marko Kral jevic, der Kosovoschlacht und dgl. sind nichts weiter als serbische Lieder, die auf bulgarischem Boden - eigentlich wohl nur in den Gebieten mit Ubergangsdialecten, mir ist wenigstens von Aufzeichnungen aus Donaubulgarien und Ostrumelien nichts bekannt gesungen und - grindlich verdorben worden sind. Verdorben ist zunzchst die reine und durchsichtige serbische Sprachform; die sprache dieser Lieder ist weder serbisch noch bulgarisch (...); Hsthetisch wirkt sie durchaus abstobend (...). Die Cardinalfrage ist natürlich die, wann die Verpflanzung dieser Lieder auf bulgarischen Boden stattgefunden hat. Zunachst kennzeichnet ihr unfertiger Zustand (...) ihr unzweifelhaft junges Alter. Da indessen ihre metrische Form auch keine andere ist als der gewöhnliche serbische Zennsilber (...), hängt diese Frage natürlich mit der nach dem Alter des Zehnsilbers selbst zusammen(..). Die Hauptsache aber ist und bleibt, dab Serben und Bulgaren nicht nur sprachlich und historisch geschiedene, sondern auch ihrem Charakter nach 
so durchaus verschiedenartige volker sind, das schon deswegen ihre ganze Volksdichtung in Form und Inhalt verschiedenartig sein muB (...). Die bosnisch-serbischen Haiduken bleiben doch noch immer Helden, der bulgarische hajdutin ist aber nach Ausweis der Lieder ein einfacher Morder und StraBenrauber gemeinster Art, nur vielfach (...) mit stark ausgeprägten sentimentalen Anwandlungen $(\ldots)$. Neben diesem Element des Haidukenthums tritt uns in der bulgarischen Volksdichtung ein ganz verschiedenartiges, wenn auch vielfach damit eng verflochtenes Grundelement entgegen, das wir wohl auf eine gemeinslavische Wurzel zurluckfuhren durfen (...). Ich möchte dafur die Bezeichnung Liebes- und Familientragodie verwenden (...). Kamen wir nun bereits, indem wir die serbische Heldendichtung bis auf ihre ersten Wurzeln zurlackzufuhren bestrebt waren, $z u$ dem Resultat, daB derselben eine Epoche der Liederdichtung voraufgegangen sein mus, wo ausschlieblich solche im Familienleben wurzelnden Stoffe behandelt wurden, das ferner die erwachsende Heldendichtung aus solchen bereits vorhandenen Liedern die Farben und Tone entnahm, womit sie die aus der historischen Wirklichkeit entstammenden Stoffe zu umkleiden begann $(\ldots)$ - 80 sehen wir hier diese Liedergattung bei den Bulgaren bis auf den heutigen Tag erhalten, ohne dab hier der weitere Schritt gemacht ware, durch Ubertragung dieser Motive auf historische Personlichkeiten zur Entwicklung einer wirklichen Heldendichtung fortzuschreiten (...). Da indessen die Serben nach dem Zeugnis der Uberlieferung in ulterer Zeit - etwa rom XIV.bis XVI.Jh. eine ahnlich geartete Liederdichtung besessen haben - auch die Kurelac'sche Sammlung dirfte vielfach auf eine solche zurlickweisen -, so wage ich zur Erklarung dieser Erscheinung die Vermuthung. daB diese Gattung von Liedern zu den Serben von den Bulgaren gekommen sein konnte. Sollten nicht z.B. Bog. 6 und vor allem $49 \mathrm{mit}$ seiner bulgarischen Localisierung (...) auf bulgarische Vorlagen zurlickgehen? Sollte fermer nicht die Bezeichnung bugar\$tica, resp. pjesan bugarska, (Bog.27,29) so ihre einfachste Erklarung finden, wenn wir annehmen, daß eine derartige Liederdichtung wirklich bulgarischen Ursprungs war? (...). Ist meine Vermuthung und damit die Deutung des rithselhaften Namens uberhaupt annehmbar, dann wirden wir wohl nicht allzu sehr fohlgreifen, wenn wir einen solchen bulgarischen Einflus in erster Linie dem XIV.Jh. zuschreiben wirden, einer Epoche, wo die serbische Machtsphare auch weithin uber bulgarischen Sprachboden sich ausbreitete und dadurch einen solchen Einflus Thilr und Thor gerfenet sein muste. Lage es nun aber nicht auch nahe, die Entstehung 
einer solchen bulgarischen Liederdichtung mit griechischen Einfilssen in Verbindung zu bringen?"

Dieses ausfuhrliche zitat war m.E. deshalb nötig oder zumindest berechtigt, weil hier alle auch aus spateren Arbeiten bekannten und zum groBen Teil ungerechten Vorwlirfe gegen die bulgarischen und mazedonischen bei soerensen als "tbergangedialect" bezeichnet!) Heldenlieder und die Betonung der allein als eigenstänig betrachteten bulg. Hajdukenlieder und Balladen in gedrangter Form enthalten sind, womit sich uns ein willkommener Ausgangspunkt fir die Diskussion bietets

Wenn Soerensen behauptet, alle Lieder vcn.Marko Kraljevib, der Kosovoschlacht usw. hatten nichts echt Bulgarisches an sich, so muB dieser Meinung zum Teil widersprochen werden. DaB die Lieder von der ersten und zweiten Kosovoschlacht in der maz.-wbulg. Epik nicht autochthon sind, sondern zur Sekundarschicht gehoren, ist richtig und wird in Kap. 3.3 behandelt werden. $\mathrm{DaB}$ aber alle Lieder von $\mathrm{Kraljevid} \mathrm{Marko}$ nichts weiter als serbische Lieder sein sollen, die auf bulgarischem Gebiet mit thergangsdialekten gesungen und grindlich verdorben worden sind, ist eine bei den heute bekannten Liedern unhaltbare These Soerensens. DaB nur in Hestbulgarien und Mazedonien Heldenlieder gesungen und aufgezeichnet wurden, stimit nicht; ich erinnere nur an die Sammlungen Bonlev (Varna 1884), Jankov (Plovdiv 1908), Arnaudovs "Folklor ot Elensko" (SbNU XXVII) und "Severna Dobrudza" (SbNU XXXV) u.a., die die Existenz epischer Lieder auch in den bstlichen Gegenden Bulgariens beweisen. Soerensen hat natirlich z.T. recht, denn das Hauptgewicht der epischen Lieder liegt zweifellos in Westbulgarien und Mazedonien, wo ja auch der epische asymmetrische Zehnsilber sein Verbreitungsgebiet hat. Wenn Soerensen diese Volksepik als "grïndlich verdorben" bezeichnet, so ist dies zweifellos ungerecht, denn wir finden in den maz.-wbulg. Sarmlungen, ich denke nur an Miladinovi, Kacanovakif und Vater (SbNU XIIII), zum Teil sehr gelungene und zum groBen Teil mindestens Lieder von anerkennenswerter Qualität. 
Soerensen hat aber offenbar erstens das maz.-wbulg. Liedmaterial zu wenig gekannt und es zweitens an der klassischen Norm der ästhetisch zweifellos hochstehenden Lieder der Vukschen Sammlung gemessen. Diese Vukschen Lieder stellen aber sicher die Endstufe einer langen Liedentwicklung im dinarischen Raum dar, und ihre ästhetisch vollkommene Form ist ein Zeichen ihres jungen Alters, nicht umgekehrt, wie man automatisch immer angenommen hat. Hätte Soerensen die 1925 veroffentlichte Erlanger Liederhandschrift aus der ersten Hälfte des $18 . \mathrm{Jh}$. gekannt, so hätte er seine Ansichten revidieren müssen, denn sie spiegelt den ästhetisch zwar weniger wertvollen, aber gerade in seiner Unvollkommenheit realistischen stand der skr. Volksepik in den nördlichen Räumen wider. Ein ähnliches Bild bietet eben auch der periphere maz.-wbulg. Liedraum, der zwar durch die an den Vukschen Liedern orientierten ästhetischen Normen in ein ungunstiges licht geruckt wurde, darur aber fur eine historische Liedbetrachtung, - und um diese geht es ja hier, wertvolle Anhaltspunkte gewährt. Bei genauer Untersuchung des Liedmaterials aus hazedonien und Westbulgarien stellt sich nänlich heraus, dalb in diesem Liedraum eine ganz a $r$ c h a i s c h e primäre Liedschicht mit stark m $\mathrm{y} t \mathrm{~h} \circ \mathrm{l} \circ \mathrm{g} i \mathrm{~s} \mathrm{c}$ e $\mathrm{n}$ Zugen erhalten geblieben ist, wie wir sie wohl noch in den Heldenliedern des griechischen Nachbarraumes finden, die im dinarischen Raum aber nur noch rudimentär oder ganz verdeckt erhalten ist. Vielleicht meint Jagic das, wenn er sagt" Volksepik, welche von der turkischen Herrschaft keinen so mächtigen Impuls zu neuem Aufschwung erhielt wie die serbische, weil die Zertrümerung ihres staatlichen Lebens nicht so erschllternd auf sie wirkte wie die Kosovo-katastrophe auf die serbiscne Epik - scheint im ganzen mehr alterthümliches bis auf die Gegenwart fortgepflanzt zu haben". - Dieses archaische Liedgut, das sich vermutlich schon vor dem 14.Jh. im griechisch-slavischen Grenzbereich, also im heutigen :iazedonien und Viestbulgarien, bildete, war wainrscheinlich vorepischer, mythologischer oder balla- 
desker Natur, gespeist aus einem Reservoir von "rohem" Volksglaubensmaterial, mythologischen stoffen in bereits strukturierter Form sowie Zauber- und Heldenmarchen. Eine klare Differenzierung in Gattungen ist fllr diese frlbe Zeit noch unmbglich und meistens auch nicht von vordringlicher Wichtigkeit. Soweit wir das heute noch feststellen konnen, gehoren dieser frlhen mythologischen Schicht die maz.-wbulg. Lieder an, die mythische Ungeheuer noch (im Sinne Meletinskijs) als urspringliche Herren der Guter erkennen lassen ( $\mathrm{ggl}$. das Hervorbrechen von drei Stromen Ernteglitern aus dem Leib der Lamja), die Drachentoter mit den archaischen Zeichen des Kulturheros (besondere Geburt, Bastard, Nachgeborener, Zwilling) auftreten und auf märchenhafte Weise eine Braut gewinnen lassen (Heldenkind gewinnt Braut nach Uberschwimmen des Meeres, Besiegen von Wasserdrachen und Erringen von drei goldenen Äpfeln; Heldenkind besteht Kampf mit Drachen im Brunnen auf dem Weg zur Braut; Heldenkind totet Drachen, der die Braut aus dem Hochzeitszug entfuhren will), die den Kampf eines Helden mit einem ubernaturlichen Gegner (Iamja, Riese, Riesin, Heldenkind mit mehreren Herzen, Samovila, Zmej) oder den Kampf zweier damonischer Machte (Zmej gegen Lamja, Samovila gegen Lamja) behandeln. Ein interessanter Zug in solchen Liedern, den wir auch in der griechischen Epik antreffen, ist der Gedanke einer magischen Verwandtschaft zwischen mythischem Wesen und Mensch. Der alteste Helfer des archaischen Helden ist zweifellos das Pferd. dessen Rolle erst später zum Teil von der hilfreichen Fee Ubernommen wird (der urspringliche Charakter der Samovila oder Juda ist jedoch sicher der einer bosen Schicksalsmachtl). Deshalb sei hier die Gestalt des sprechenden und ratgebenden Streitrosses, wofur die maz.-wbulg. Volksepik unzählige Beispiele bietet, besonders hervorgehoben 55 . Diese archaische, halbmythologische Iiedschicht in Mazedonien und Westbulgarien hat nun - genau wie die griechischen Akritenlieder im 10.Jh. - im 14.Jh. einen ProzeB 
der $H 1$ s $t$ o $r$ i $i$ e $r$ u $g$ mitgemacht, in dessen Verlauf einheimische Helden wie der Konigssohn Marko. Momiilo, Hrelja, Konstantin Dejanovic u.a. in das Iied eingingen und die stelle alterer, wahrocheinlich namenloser Helden einnahmen. Ähnlich wie bei den Akritenliedern, wo der HistorisierungsprozeB schon in byzantinischer Zeit schwächer wurde und schlieblich ganz aufhrrte, kam auch bei der maz.-wbulg. Volksepik der Prozeß der Einbeziehung historischer Gestalten in das Iied relativ fruh zum Stillstand, whurend die Liedgestalten offensichtlich eine N-NW-Wanderung mitmachten und zu den Lieblingshelden der skr. Epik wurden. Zum Teil wurden Liedsujets wieder nun in veränderter Form - in ihr Ursprungsgebiet zurluckgetragen, wie dies von. Schmaus 56 und Dinekov 57 z.B. fur die Mombilo-lieder angenommen wird, sicher aber auch fur zahlreiche Lieder mit der jungen Ireiergruppierung MarkoRelja-Milor gilt.

Eine zweite Historisierungswelle erfaßte die maz.-bulg. Volksepik, als im 15.Jh. den Turken an der beinahe hundert Jahre lang umkämpften Donaulinie von den berilhmton ungarischen und serbischen Turkenkänpfern wie Hunyadi,Székely, König Mathias, Despot (Zmaj-ognjeni) Vuk, Dmitar und Stepan Jakzic u.a. Widerstand geleistet wurde und bei den Christen durch Teilsiege der "ugrilici" neue Hoffnung erwachte. Finde des 15. und im Laufe des 16.Jh. mussen der maz.-wbulg. Epik topographische Namen wie Budim (bald stereotypisiert zu dem Inbegriff der reichen königsstadt), Slankamen, Temesvar, Kosovo usw. und Heldennamen wie Janko, Sekula, kralj Matijas, kralj budimski, Zmaj-ognjeni usw. zugeflossen sein, die in dem neuen Iiedraum spezielle Namensformen annahmen (Jankula, dete Selcula, kral Mateja, Ognen bzw. Ognjance). Diesen "importierten" Iiedgestalten kbnnen nur zum geringsten Teil wirkliche historische Reminiszenzen zugeordnet werden; im uberwiegenden Teil der Fulle handelt es sich aber um eine Loslosung der Helden von den mit ihnen verbundenen Ereignissen (die natbrich zum Teil schon vor der Zuwanderung erfolgt sein kann) und 
Stereotypisierung der Namen, so dab die neu zugewenderten Iiedhelden, vor allem Jankula, beliebig in gegebere Sujets eingesetzt und der typische Name Marko oder Stojan mit Jankula vertauscht werden kann. Weiter wurde der Historisierungaprozeb teilweise dadurch aufgefangen bzw. sogar rilckgangig gemacht, daß sekundar zugewanderte und auf Grund spezifischer Eigenschaften dazu pradestinierte (jugendliches Alter, Zmej-Charakter) Helden (Sekula, Zmaj-ognjeni Vuk) in den Sog der eigenstandig mazedonischen Heldenkindtradition geraten und vollig adaptiert werden (Sekula detence, Ognjance).

AuBer der Ubernahme topographischer und Heldennamen erfolgte offenbar auch die Zuwanderung an ugrische Namen gebundener Sujets im ganzen. Davon wird in Kap.3 die Rede sein. Wit dem turkischen Sieg bei Mohács 1526 brach die sludungarische Abwehrfront zusammen, und damit horte wohl auch die Aufnahme von Nacen historischer Turkenkbmpfer in die Volksepik vorlaufig auf. Far den maz.-wbulg. Raum kam so der zweite Historisierungsproze $B$ zu einem relativ frahen $A b-$ schluB. Die somit entstandene $s$ e $u$ n $d r s c h i c h t$ wurde spater, d.h. wahrscheinlich ab Ende des 17. und im 18.Jh., durch den Zustrom neuerer und stkrker episierter Sujets (z.B. Todor von Stalać, Dušans Hochzelt, KosovoLieder u. . $_{\text {) }}$ uberlagert.

Ein auffallender Zug der maz.-wbulg. Volksepik ist die deutlich zu beobachtende Tendenz, archaische heidnische Sujets mit mythologischem Inhalt durch nachtraglich beigefugte $\mathrm{Zu}$ gaben c h $r$ i 8 t l i c h e $r$ Natur quasi zu "entschirfen", als ob der fromme christliche sänger (wohl zum Grosteil Blinde) sein Gewissen damit beruhigen wollte, daB er das Unheimliche, Heidnische mit frommen Attributen belegte und dadurch milderte. Nur aus solchen Bestrebungen heraus ist es zu erklaren, dab Heilige ( $h l$. Georg, hl. Elias) die Rolle urspringlich kulturheroenartiger Drachentoter abernehmen, eine Stimme vom Himmel zum Drachenkampf ermutigt, der Held vor dem Kampl betet, die Sanovila als Sonntagsbeschutzerin auftritt, die Riesin zum Abendmahl geht, der 
Held auf dem Weg zur Kommunion Sklaven befreit und und mit zur Kirche nimmt, das fur den Zarenthron bestimmte Heldenkind im Kerker auf wunderbare Weise von Engeln beschlutzt wird usw. Im dalmatinischen Raum sind zum Teil ahnliche Versuche der Abschwachung des mythologischen Gehalts durch verchristlichende Zusktze zu beobachten.

Ein relativ hohes Alter scheinen - nach den mythologischen liedern - auch die $V \circ I k 8$ b a l l a d e n mit entweder mehr mythologisch-schicksalhaftem ("Die Fee entzweit die Bruder", "Stojan holt Wasser von der Samovilenquelle" u. k.) "oder mehr familizrem ("Der tote Bruder", "Bauopfer", "Der heimkehrende Ehemann auf der Hochzeit seiner Frau", "Bestrafung der untreuen Frau" usw.) Inhalt aufzuweisen, die in Mazedonien, West- und 0stbulgarien gleichermaßen verbreitet sind. Wahrscheinlich ging den ersten epischen Heldenliedern im maz.-wbulg. Raum eine Phase lyrisch-epischer, d.h. wahrscheinlich balladenghnlicher Gestaltungsweise voraus, und Soerensen hat vielleicht sogar in gewisser Weise recht, wenn er die Bezeichnung "pjesan bugarska" und "bugarstica" mit dem gerade in Mazedonien und Bulgarien 80 stark vertretenen lyrisch-epischen Iiedtyp in Verbindung bringt und den "bulgarischen" Ursprung von Liedern in der Art der Langzeilenlieder erwägt.

Auffallend ist die Tatsache, daB wir in Mazedonien und Westbulgarien, also dem zweiten großen Verbreitungsgebiet der epischen Heldenlieder, wenig $\mathrm{H}$ a $j \mathrm{~d} u \mathrm{k}$ e $\mathrm{l}$ i e d e r ${ }^{57 a}$ finden. Diese Erscheinung läßt sich sicher damit erklären, daß wir Ostbulgarien als die Wiege des bulgarischen Hajdukenliedes ansehen konnen, eines im Vergleich zum Heldenlied mit seiner epischen Stilisierung jungeren, realistischeren Liedtypa im dynamisohen aohtailbigen VoramaB. Wrhrend, wie Schmaus 58 aufgezeigt hat, im skr. Raum kein Kontinustztsbruch eingetreten ist und das Hajdukenlied dort keinen jungeren Liedtyp vertritt, sondern die durch das Heldenlied geschaffene Tradition einfach weiterfuhrt, ist in dem bulgarischen Hajdukenlied (uhnlich dem griechischen Klephtenlied und dem albanischen historischen Iied) "eine neue Iied- 
form jungeren Ursprungs", ein anderer Liedtyp, entstanden. Insofern hat Soerensen recht, wenn er diesen Liedtyp als echt bulgarisch bezeichnet. Unsachlich aber wird seine Argumentation, wenn er den bufgarischen hajdutin als einfachen "Mrorder und Straßenrüuber gemeinster Art", den bosnischen und serb. Hajduken aber immer noch als Helden bezeichnet. Soerensen hat dabei ubersehen, daB der Typ des Hajduken sich wohl in beiden Fallen sehr shnlich ist, das Lied aber in dem einen (bulg.) Fall mit neuen, realistischeren, in dem anderen Fall jedoch mit den al thergebrachten Mitteln des Heldenliedes arbeitet. Denn ware nach der Soerensenschen Auffassung dann nicht auch Kraljevic Marko in dem von Hektorovic aufgezeichneten Langzeilenlied Bog. 6 als "Morder und Straßenräuber" anzusehen?

\subsection{BESTANDSAUFNAHME DER UGRISCHEN HELDEN - UND TOPOGRAPHI- SCHEN NAMEN AN HAND DER WICHTIGSTEN MAZEDONISCHEN UND BULGARISCHEN LIEDSAMMCUNGEN}

Die Existenz ungarserbischer Heldennamen wie Jankula, Sekula, kral Mateja, ban Petúr, ban Michail, Budimka Jana, budimski kral, budimska kralica, Gjuro, Ognjan, Dmitŭr und Stefan sowie topographischer Namen wie Budim, Temiłvar, Slankamen, Smederevo und Srem in der maz.-wbulg. Heldenepik und zum Teil auch in Brauchtumsliedern usw. weist eindeutig darauf hin, daB diese Namen aus dem $N$, vermutlich aus der stark historisierten Volksepik in Sudungarn, "importiert" worden sind. Diese Zuwanderung dürte fruhestens Ende des 15., wahrscheinlich aber im Laufe des 16.Jh. erfolgt sein, d.h. seit dieser zeit lagerte sich uber die einheimische maz.-wbulg. Epik eine $s$ e k u n d ä $r e$ $\mathrm{s} c \mathrm{~h} i \mathrm{c} h \mathrm{t}$ ugrischer Namen bzw. einzelner, an ugrische Namen gebundener Liedsujets. Schmaus vor allem hat mit Nachdruck auf diese für die Chronologie und Stratigraphie der südslavischen epischen Lieder so wichtige Erscheinung hingewiesen ${ }^{59}$ und dafur meines Wissens als erster den 
Terminus "Sekundarschicht" gebraucht. Nach thm griff Cv. Romanska ${ }^{60}$ das Thena auf und diskutierte es allgenein beim Volkskundekongres in Budapest. S1e weist darauf hin, das naz. und bulg. Helden- und historische Lieder uber Personen der ungarischen Geschichte schon allgemein auch von J.Ivanov, P.Dinekov, Ch.Vakarelak1 und I.Burin 61 behandelt wurden. DaB alch schon uber oin Jahrzehnt frlaher J.Bodej 62 von ungarischer Selte mit dem Problem befaste, scheint weitgehend unbekannt zu sein. Erwahnt sel noch, das sich bereits in der Arbe1t Banaderics ${ }^{63}$ uber den Marko-2yklus der aufschlubrelche Hinwels findets mogla je doci neka peena na Jug, kao to ou dosle pesme o Janku, Sekul1 1 drugin Junacina sa severa, koj1 su narodito popularni u macedongkim peemana": D1e Vermittiung des fremden Liedgutes bzw. der ugrischen Namen erfolgte wahrscheinlich durch wandernde Sunger entlang der Morava-Vardar-Tkler.

W1e W. Werner in 1hrer Studie uber die munnlichen PN in den bulg. Volksliedern lestgestellt hat, sind heute die Heldennanen Jankula (rumbin. lancula; Hunjadi soll rumän. Herrunft gewesen sein und wird in der rumkn. Porm selnes Namens auch in den serb., poln. und rech. Urkumden erwahnt) und Sekula (einfache Bulgarisierung des Nanens Szókely) in West- und 0stbulgarien, vor allem aber in Mazedonien und Westbulgarien im Lied verbreltet 64 .

Nur mehr in den seltensten pallen sind an die ugrischen Namen historische Reminiszenzen oder zuge einer ehemal1gen Individualitat gebunden ${ }^{65}$. Vielmehr aind die zugewanderten fremden Namen meistens aller individuellen $2 u_{g}$ ontkleldet und darur $t$ g 1 s 1 \& $t$ und schablonlsiert worden. Hierbel erhebt sich allerdings die Prage, Inwiewo1t die ungarserb1schen Lledhelden schon vor lhrer Zuwanderung enthlotorisiert waren, denn der Prozes der Entind1vidualisierung splegelt sich zwelfellos zum Tell schon in den Langzeilenliedern.

D1e Bestandsaufnahme der ufrischen Namen in der maz.-wbulg. Volksep1k kann und soll naturlich nicht vollstindis durchgefuhrt, sondern wuß aus das Wesentliche beschrlinkt werden. 
Als Hilfamittel dienten hier vor allem drei Indices fur den maz. und bulg. Iiedbestand: fur die altere zeit Stoilov, A.P.: Pokazalec na peđatanite prez XIX vek bülgarski narodni pesni I (1815-60) und II (1861-78), Solia 1916-18; fur den bis ca. 1928 veroffentlichten Liedbestand "Pregled na bülgarskite narodni pesni" (uriter der Redaktion von $S$. Romanski) in ISSP V(1925) und VI(1929); und schlieBlich, riach PN geordnet, Dimitrova,A. und M.Janakiev: Predanija za istoriceski lica $v$ bulgarskite narodni umotvorenija, in ISSF VIII/IX (1948), S.411-606. Beracksichtigt werden die wichtigsten maz. und bulg. Iiedsammlungen wie Mil., Kac., Il., Drag., Bonc., Jank., Mich., Sapk., Doz. und SbNU.

Von den ugrischen Namen steht an der Spitze Jankula (Jankul, Janko) mit 55 Indexnummern ${ }^{66}$ in ISSF V/VI und 60 Indexnummern in ISSF VIII/IX; dann folgt Sekula mit 18 bzw. 37, budimski kral mit 13 bzw. 7, budimska kralica mit 3 bzw. 2 und kral Mateja (Matias, Matlija) mit 3 in beiden Fallen; die ubrigen ungarserb. Helden finden nur selten Erwahnung. Von den ON steht Budim mit 24 Indexnummern in ISSF V/VI an der Spitze und wird nur noch von dem typischen Flußnamen Dunav ubertroffen, der in ISSP V/VI mit 125 Indexnummern vorkommt.

Die wichtigsten Sujets, in denen $J$ a $n$ u $l$ a eine Rolle spielt, sind folgendes

Ein Held feiert Hochzeit und ladt Jankula als Svaten ein (SbNU I, 59; IX,20; XIII, 91; XIII,95; Yer.Spis.XUV, 459; Kad.,237; KaX.,484; Mil.273; Sapk.366; Mich.,203).

Jankul rojroda und Sekula detence toten hinterlistig dete Dukatince, weil sie nicht zu seiner Hochzeit geladen wurden (SbNU VI,53).

Jankul und sein Bruder Nikola (Mirco) streiten bei der Teilung des väterlichen Erbes; Jankul möchte seinen Bruder vergiften, sieht aber dann ein, wie teuer ihm der Bruder ist, und versobnt sich mit inm (Mil.182 und 159).

Ban Jan'ul baut unter Anweisung eines "verto pile"(weissagenden Vögelchens) ein Kloster; danach erschlagt er Kara Korun, der seire neun Bridder versklavt hat (Drag.,83).

Jankul und Sekula sind Im Gefkngnis von Solun eingesperrt; 
Jankul befreit sich mit List (SbNU II,112; Sapk.,71). Jankul totet mit anderen Helden zusammen den Araber, der keine Hochzeiten stattfinden läBt (Rod.Napr.VIII 2,54 ).

Der junge Jankul heiratet nichtsahnend seine Schwester; als die beiden erfahren, daß sie Geschwister sind, sterben sie (Stoil.II, 10; Drag.,97).

Ijutica Bogdan raubt die Schlussel der Stadt legen und ein Madchen; Jankul und andre Helden versuchen ihm beides wieder wegzunehmen, aber ohne Erfolg (Kad.,466).

Ban Jankul wettet mit einem Juden, in einem Tag das Land zu umfahren, und gewinnt (SbNU IX,71).

Jankul und andere Helden kämpfen mit Arvatka devojka, werden besiegt und in ein Verlieb gesperrt, woraus sie mit is entkommen (SbNU $X, 80$ ).

Die Könige versammeln sich, um die Abgaben unter sich aufzuteilen: Jankul erhält drei "stranici" (halbe Pferdelasten) mit Goldstucken (Sapk.,143).

Janko von Janina und andere Helden schutzen Solun vor den Tirken (Mil.156).

Džordže Kastrioti liefert durch list ein turkisches Heer an Sibinjanin Janko aus (Drag.,102).

Jankul vojvoda halt ein Gelage mit seinen neun Brudern (Drag.,99).

Jankul ist auf der Suche nach seinem Bruder Bogoj; die Brulder begegnen sich im Wald und Bogoj totet seinen Bruder, ohne ihn zu erkennen (SbNU VIII, 103).

Der Araber wartet auf Jankuls baldigen Tod, damit er dessen Frau nehmen kann (Sapk.,308).

Jankul heiratet seine Nichte und trennt sich erst von ihr, als Gott ihn durch schlimme Zeichen warnt (Drag.,93;I1.,273).

Jankwl und Janinka heiraten; hernach stellt sich heraus, daB die beiden Geschwister sind und als Kinder von Tatarbeg und Bogdan vojvoda entfuhrt worden sind (SbNU XIII,221).

Jankul, Markos Neffe, tötet König Madzarin, der ihm seine Tochter nicht gegeben hat, obwohl Jankul verschiedene Freiersproben bestand (Drag.,66).

Jankul nimmt Milica Kraleva aus Legen zur Frau (Per.Spis. $\mathbf{I X}-\mathbf{X}, 94)$.

Janin Janko Sibin raubt mit List ein Mädchen (Drag.,96). 
Jankul vojvoda und seine Gefahrten schlagen das Heer des Mehmed Ali-pała (Drag.,95).

Korun Kesedzija totet hinterlistig die søhne von Jankul rojroda (SbNU XIII,88).

Heldenkind totet Lamja und befreit die Braut seines Oheims Jankul; anschliebend wird das Kind von Jankul getauft (Mil.59).

Jankul findet sein Kind Sekula krank im Gebirge liegend (II.,119).

Jankul rojroda holt seinen Neffen Sekula detence in sein "vilajet", das Land Arbanałka; Sekula raubt Altün-zvezda als Braut (Mil.60).

Stefan, der jungste Sohn Jankos von Sibin, erringt aup Grund seines Heldenmuts die Tochter des Pałas von Kamnen zur Frau (I1.,125).

Korman Kesedzija und Janko von Kosovo wollen Ivan Popovid und seine Frau töten, doch der Anschlag miBlingt (SbNU XXXVIII,86; Kax.,482).

Korun Kesedzija nimmt PopoviC Ivan mit Hilfe von dessen Frau Mujruna gefangen; Jankul Ban aber totet Korun und Mujruna (Drag.,79).

Jankul macht mit List und Heldenmut ein ganzes feindliches Heer nieder, das seinen Hof umzingelt hat (Mil.96).

Die Turken beschweren sich beim Sultan, daß Jankul vojvoda keine Ruhe gebe; der Sultan schickt Isak-pasa aus, um Jankul töten zu lassen (Drag.,82).

Der kranke Jankul wird von einem Vögelchen versorgt (I1,,118).

Jankul liegt neun Jahre lang krank, gepllegt von seiner treuen Schwester, die er um Wasser wegschickt; das Madchen Pindet nicht mehr zu dem Bruder zurlick und verwandelt sich in einen klagenden Kuckuck (SbNU X,15).

Jankul zieht nach Kosovo zum Kampl mit den Tlirken; als er gerade sein Schwert ziehen will, geht jäh eine Flinte los und totet ihn (Mil.97).

Die Thrken - mit dem hl.Elias an der Spitze - erobern das Reich von Konig Jankul und seinem Bruder Stefan; um nicht den Tlirken in die Hande zu fallen, ertränken sich die Bruder in der Morava (Stoil.II,20).

Nigrica funrt Jankula Frau als Gefangene weg, woraup Jankul und Dzan GruiCe ihn ţten (SbNU VII,99;Sapk.,95,253; Drag.,86) 
Der Sultan schickt einen Araber, der Marko, Jankula und andere Helden gefangen nimmt; Sekula (Grulca) dete endlich totet den Araber und befreit die Gefangener. (SbNU XIIII, 118; KaC.,377; KaC.,386; Mil.143).

Marko lydt Gaste ein und will ihnen Fische aus Ohrid holen; unterwegs fallt er den Turken in die Hande, aber Janko von Kosovo befreit ihn $(\operatorname{Kac} ., 294)$.

Jankula, Sekula und Marko toten "evrejze" (den kleinen Juden) mit List und nehmen ihm drei Lasten Schztze weg (SbNU XIIII,58).

Krali Marko und sein Oheim Jankula toten "evrejee", das den Heiligen Berg kaufen will (Rod.Napr.VIII 3,89 ).

Marko, Jankula und Sekula detence trinken Wein, konnen ihn aber nicht bezahlen; Marko und Jankula verkaufen daraufhin Sekula an eine vlachin und bezahlen den Wein (SbNU XIII,90).

Marko, Janko von Kosovo und der König von Kraleva bewerben sich um ein und dassel be Madchen; liarko raubt die Schone, tötet sie aber dann, als sie ihn mit dem Kum betrogen hat (KaC.,271).

Marko findet sein von Derwischen geraubtes Sohnchen wieder (Sapk.,89).

Marko und sein Neffe Jankula kämpfen miteinander, und Marko wird besiegt (SbNU II,133; Ikon.,135).

Janko von Kosovo lHBt keinen Tliken das Kosovofeld Uberqueren; Narko, als Tarke verkleidet, nimnt Janko gefangen, läbt ihn aber wieder frei (Kac.,356).

Andreasko verkleidet sich auf Anraten Jankuls als Madchen und totet den scharzen Araber (SbNU X,84).

Jankuls Frau befreit ihren Mann aus Sultan Murads Gefangenschaft; danach toten Jankul und Sekula detence den Sultan und rauben seine Schätze (SbNU VI,50).

Litre Pomorjance raubt in Jankuls Abwesenheit dessen Gattin, doch Jankul, von Sekula benachrichtigt, gewinnt sie mit List zurlack (Ikon., 108).

Janko von Kosovo ladt Guste ein, darunter auch Grujo dete, das verschiedene Aufgaben erfulit und dadurch Angelina erringt (KaC.,471).

Jankul rojroda raubt Magda Arbanaska fur Stari Novak (SbNU 1,64; Sapk.,314).

Konig Nikola, Marko und Janko von Kosovo m8chten alle dasselbe Madchen; Konig Nikola bekommt es schlieblich, weil 
er ihm einen Ring geschenkt hat (Kad.,264).

Jankul findet aeinen Bruder Nikola mieder (SbNU III,110; XIIII, 255;Mil.152).

Die wichtigsten Sujets, worin $S$ e $k$ u $l$ a vorkommt, sind - außer den schon bei den Jankula-Liedern aufgezählten folgende:

Sekula raubt sich ein schönes Madchen (Drag.,219).

Sekula freit ein Mádchen aus Albanien; auf dem Weg verletzt er sich ungewollt mit der Lanze, wird aber von seiner Wahlschwester, der Samodiva, wieder geheilt (Mil.60).

Sokula tummelt sein Pferd auf dem Samovilentanzplatz; Dimka Samovila bittet Sokwla, er möge sie verschonen, und schenkt inm dafur einen BlumenstrauB, der ihn gegen Schwerthiebe gefeit macht (SbNU XIIII,167).

Seko dete und seine junge Frau sind unterwegs zum ersten Elternbesuch und werden Uberfallen (II., 123; Sapk.,116,344).

Sekul vojroda verheiratet sein Kind ("godinale") mit einer Erntearbeiterin (Drag.,58).

Sekula detence und Radul beg gehen als Grate zu dem hinterlistigen Konig Latin und toten ihn (Mil.181).

Sekula detence wird als Hochzeitsgast geladen (SbNU XIII, 91,104; Per.Spis.XIV, 459).

Sekul besteht ungeladen die Freiersproben fur seinen Oheim (SbNU XIIII, 135).

Sekula detence traumt einen unheilverklindenden Traum (Šapk. 387).

Sekula detence liegt krank im Waldgebirge und wird von Stojna Samodiva gepflegt (Il.,119).

Sekula frult auf dem Kosovofeld; ein Vogel bringt die traurige Botschaft (Sapk.,289).

Sekula kommt durch Verrat seiner Gattin ums Leben (Sapk.,99).

Sekwlas Mutter Pragt Fuhrleute nach Sekulas Grab (Mil.245).

Suliman verheiratet seine Tochter mit Markos Neffen Sekula (Sto1l.II, 18).

Sekula, Marko, Milos u.a. toten den Araber, der keine Hochzeiten atattfinden laBt, mit List (SbNU VII,95).

Sekula detence wird von den anderen Helden an eine Judin 
verkauft, damit die Zeche bezahlt werden kann (Drag.,56; SbNU XIII, 90; XIV,92).

Sokula besteht schwierige Freiersproben, un die Tochter von Konig Latin (Michail) zu erringen (SbNU XLIII,162;Mil. 145).

Marko, Sekula u.a. toten auf Bitten der "nemska kralica" die Araber, die in ihrem Land keine Hochzeiten zulassen (Mil.126).

Sekula, Marko u.a. ziehen nach "Nemska zemja", schlagen sich mit den dortigen Helden und rauben die Braut von Dimo Cernogorce (SbNU XIV, 87).

Sieben Konige ziehen zum Ende der Welt; unterwegs holt Sekula Wasser aus einem Brunnen, wird aber von einer Lamja halb verschlungen und erst von der Samovila befreit (Mil. 142; SbNU IV, 64;XIII, 160;KaC.,329).

Sekula wird von Marko. aus der Gewalt der Lamja gerettet (Sapk., 126).

Wie aus dieser Sujet-Aufzkhlung ersichtlich ist, sind Jankula und Sekula in alle möglichen Lieder des breiten maz. und bulg. Sujetspektrums eingesetzt und (mit ganz wenigen Ausnahmen) aller individuellen Zuge entkleidet. Auffallend ist bei beiden ihr haufiges Auftreten beim Hochzeitszugsujet, bei Sekula außerdem beim Drachenkampf. Das sehr oft zu beobachtende Vorkommen in einer größeren Heldengruppe ist ein Beweis fur relativ junges Alter dieser Sujets in der vorliegenden Form.

Der in den Langzeilenliedern hăufig mit Jankula und Sekula in einer Dreiergruppe verbundene Ban $M$ i h a $i$ (Svilojevic) findet sich in der maz.-wbulg. Epik selten, und dann bestehen zum Teil noch Zweifel, ob er gemeint ist; der Banus-Titel könnte aber als Hinweis dienen: Ban Michail kämpet mit Sultan Murad (SbNU X,90). Furstin Milica träumt einen sonderbaren Traum, den ihr Flirst Michail zum Guten deutet (SbNU XJ.III,518).

Ein Turke versucht auf Befehl Sultan Sjulejmans Ban Michail zu fangen und zu toten, findet aber selbst den Tod (Per.Spis.XIVII,814; Mich.,205).

Michail vojvoda wird vor den Mauern Belgrads getotet (SbNU IV,71). 
Ban Michailco von Edrene wird mit anderen Helden zur Hochzeitafeier von Filip Madzarins Tochter geladen (Per.Spis. XIV, 459).

Kral Budim labt fur die Hochzeit seines Sohnes Michail und seiner Tochter Irina Tauben und Pfauen zuchten (II.104).

König M a $t h i$ a sommt ebenfalls nur selten vors Ein mit wanderbaren Zeichen geborenes Kind nimmt dem Zaren von Vidin, Matias, den Thron weg (Karav.,120).

König Mateja rugt den trinkfreudigen Ban Petŭr (SbNU XI,33; Col.92; Sapk.337).

König Matlija wird von den Tlaken dazu verurteilt, entweder den "turkischen" Glauben anzunehmen oder zu sterben; der König erbittet sich Rat von seinen drei Schwestern; die jungste rät ihm, er solle lieber sterben, als sich zu verturken, doch Gott rettet inn (Mil.73).

$\mathrm{P}$ e $t \mathfrak{u} \mathbf{r}$ ban und $J$ a $n$ a von Budim werden in Kap.3.1 und 3.2 behandelt. Fir den $K$ o $n i g$ und die $k$ o $n i g$ i von Budim erubrigt sich eine Sujetaufzahlung, denn die beiden Figuren werden vollig stereotyp immer dann eingesetzt, wenn eine Königsfigur in einer reichen Königsstadt gebraucht wird. Von den serbischen Helden, die mit den ugrischen Helden in Bezlehung stehen, sind eigentlich nur die Despoten Burad und Zmaj-ognjeni Vuk und die Brider Dmitar und Stepan Jaksic zu nennen.

$\mathrm{Z} m a j-0$ g $n j$ e $n i$ u $k$ tritt offenbar in der Form $0 \mathrm{~g} n \mathrm{j}$ a $n$ ( $(0)$, meist als Heldenkind, auf:

Filip Madžarin möchte sich mit Marko schlagen, der Filips Tochter fur seinen Sohn Ognjanco geraubt hat, doch die Samovila labt den Kampf nicht zu (Karav.,58).

Markos Sohn Ognjan`o vertritt den haßlichen Schwiegersohn von König Latin beim Hochzeitszug (SbNU XIIII, 139; XVI-XVII, 175; Mil.84; Maleళ.159; Sapk.389).

Marko verheiratet seinen Sohn mit Mara (Mich.,199).

Krali Marko verheiratet seinen Neffen Ognjan (SbNU XLIII, 134; III, 15;XلIV,46; Jastr.,276; Males.161).

Marko findet seinen Bruder Ognen wieder (SbNU XVI-XVII, 179). Ognjan befreit seinen von den Turken hinterlistig gefange- 
nen Oheim Xavdar (SbNU XIII,49).

Despot $\exists u r$ a verbirgt sich offenbar hinter dem maz.wbulg. Liednamen $G j u r o$ Temizvarin bzw. Smederevec: Temizvar Gjuro nimmt dete Golomese zum Dever, und "dete" totet den schwarzen Araber, der den Brautzug uberfalit (Mil. 59 und 173; SbNU I,59; Sapk.366; KaX.119).

Gjuro vojvoda weilt gerade in Vlakko, als ihm die Tlirken seine Gattin rauben (II.,343).

Gjuro vojvoda kehrt nach neunjuhriger Abwesenheit im Krieg zur Hochzeit seiner Prau zurluck (SbNU XXI,34;XIII,201; XIIII,205; Sapk.,225).

Gjuro Smederevec ist einer der zahlreichen zur Hochzeit von Pilip Madzaring Tochter geladenen Gaste (Per.Spis. $X(1,459)$.

Die Brider $J$ a $k$ i $c$ sind in den maz.-wbulg. Heldenliedern nur sehr schwer zu erkennen, weil sie nur unter ihren Vornamen auftreten. Deutlich erkennbar sind sie m.E. nur in dem Lied bei Amaudov, Baladni motivi, 341 vom Streit der Bruder bei der Erbschaftsteilung, wo sie als Dimitri und Stefan auftauchen (vgl. die skr. Varianten Bog.44; Vuk II 97 und 98), und in To8ev,27, wo sie als "Stefan dobar junak" und "mlado DimitriCe" erscheinen. Moglicherweise ist z.B. auch mit Stefan, dem Sohn Jankos, in Il.125, mit Stefan als Jankuls Vetter in Verk.-Lavr.47 oder mit Stefan als Jankuls Bruder in Stoil.II,20 Stjepan Jakric gemeint, doch labt sich diese Vermutung nicht beweisen.

Was die topographischen Bezeichnungen betriff, ist die Qberaus haufige Verwendung der typisch gewordenen stadt B u d $1 \mathrm{~m}$ auBer Konkurrenz. T $e$ m e $v$ a und $s$ m ed e $r$ e $v$ werden selten, und wenn, dann meist in Zusammenhang mit Gjuro genannt. AuBerdem kommt Smederevo in der ontotollten Form "Sminderevo" in To8̌v,176 und alo "Semender grad" in Sapk.159 und Mj.1.565 vor. S $r$ m taucht zu "Struem" entstellt in Per.Spis.XIV,459 und S 2 a $n$ k m e $n$ als "Kamen grad" in Il.125 oder "Slamankin" in Mich.362 aup. 
Kurz zusammenfassend labt sich also sagen, das wir in der maz.-wbulg. Volksepik (aber daneben auch in lyrischen und Brauchtumgliedern) eine relativ starke sekundare Schicht wahrscheinlich im $15 . / 16 . J h$. aus der auffallend historioierten skr. Epik des sulungarischen Raumes zugewanderter ungarserbischer Helden- und topographischer Namen feststellen konnen, von denen die Namen Jankula, Sekula und Budim am häufigsten auftreten und allgemein fast nur noch in typisierter Form Verwendung finden. 
 \\ UND $==$ WESTBUUGARISCHEN

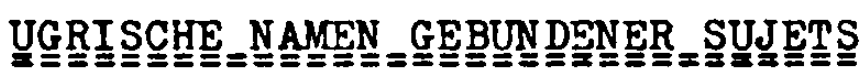

Nachdem im vorhergehenden Kapitel eine Bestandsaufnahme der zur sekundären Liedschicht im maz.-wbulg. Raum geh8rigen ugrischen Helden- und topographischen Namen versucht wurde, soll dies nun auf ganze Sujets ausgedehnt werden, denn m.E. erfolgte zur Zeit der ungarischen Fihrung in den Turkenkämpfen nicht nur eine SW- und SO-Wanderung berihmter ugrischer Heldennamen, die in der maz.-wbulg. Volksepik eine zweite Historisierungswelle auslosten, sondern es wanderten anscheinend auch an ugrische Namen gebundene Lieder im ganzen entlang der Morava-Vardar-Linie nach so (und anscheinend auch nach $S W$ an die Adriakllste, wo sie erstmals aufgezeichnet wurden).

Von all diesen nach Mazedonien und Westbulgarien zugewanderten Sujets, deren Zahl sich naturlich nicht genau bestimmen labt, kann hier nur eine gewisse (bewubt heterogene) Auswahl von Liedern besprochen werden, numlich das Scherzlied von dem verliebten und trinkfreudigen Ban Petar aus Varadin, das Sujet, worin durch einen prophetischen Traum der Fall Budims vorausgesagt wird, und schlieblich Lieder, die die zweite, an Jankula und Sekula gebundene und die erste, an Lazar gebundene Kosovoschlacht behandeln.

Ein weiteres wichtiges sekundäres Sujet, namlich die Brautgewinnung nach dem Bestehen von Preiersproben durch einen Helfer des Brăutigams, wird in Kap.4 zu untersuchen sein. Uberlegenowert soheint mir ferner die MutmaBung, daB möblicherweise auch das Sujet von dem Streit zweier Brider bei der Erbschaftsteilung ${ }^{67}$ in den maz.-wbulg. Raum zugewandert ist und sich dann nach Mittel- und 0stbulgarien verbreitet hat, auch wenn Arnaudov der tberzeugung ist, das "Urlied" stamme aus der Gegend von Türnovo. M.E. weisen jedoch die an die Bruder Jaksić gebundenen Varianten die altertumlich- 
sten und feudal-ritterlichsten Zuge auf, die sich gerade im maz.-wbulg. Raum spiegeln; auch Namen wie Dimitri und Stefan bzw. Jankula und Nikola, Jankula und Sekula sowie Jankula und Murco konnten elne Zuwanderung aus dem slidungarischen Raum vermuten lassen. - Auf ähnlichem Wege durften auch die Todor von Stalak-Lieder nach Mazedonien und Westbulgarien gewandert sein.

Auch die in Mazedonien und Bulgarien verbreiteten MomiloLieder sind vermutlich in der hier erhaltenen, episch voll. entfalteten Form aus Gebieten des NW oder $N$ zugewandert, d.h. in diesem Fall ruckgewandert ${ }^{68}$, weil sie sich sicher in ihrer urspringlichen, uns unbekannten Gestalt (noch keine Bindung an König Vukazin usw.) in Herkunftsland des Helden (SW-Bulgarien) formierten.

\subsection{PETUัR BAN UND KRAL MATEJA}

Das bekannte Lied von Petar Dojzin, dem Ban von Varadin, der bei der schonen Schenkwirtin 300 Dukaten, sein Pferd und die goldene Streitkeule vertrinkt, deshalb von Kralj Matijas getadelt wird und sich rechtfertigt, findet sich bereits in EH $178(13 \mathrm{~V} . ; 4 / 4 / 5)$ und ist also in seiner frihesten Aufzeichnung schon Anfang des 18.Jh. fur den Bereich der ehemaligen Militärgrenze bezeugt, d.h. es ist wahrscheinlich in dieser Form schon im 17.Jh. oder noch friher im Umlauf gewesen. Weitere skr. Aufzeichnungen dieses kurzen Scherzliedes, das Entwistle als "a rather jolly drinking-song" 69 bezeichnet, stehen uns in folgenden Liedern zur Verfugung:

Vuk I 633 (12 V.; 4/4/5); Vuk V 538 (17 V.; 4/4/5; davon aber nur die ersten drei $V$. hier relevant); Kuhac IV 1472 aus Slavonien mit dem Hinweis "stara popievka"(15 V.;4/4/5) und eine Variante ( $10 \mathrm{~V} \cdot ; 4 / 4 / 5)$; Kuhac IV 1473 aus Bisag mit dem Hinweis "stara pjesma" (10 V.; 4/4/5) sowie eine Variante" aus Medjumurje (10 V.; 4/4/5) und eine weitere aus der Steiermark (?)(10 V.;4/4/5); Kuhat IV 1474 aus der 
Backa (12 V.; 4/4/5) und dazu eine Variante aus Kroatien (10 V.; 4/4/5).

Alle Varianten zeigen einen mehr oder weniger gut erhaltenen Endreim, was sicher dazu beigetragen hat, daß die lieder in der Hauptsache nicht allzusehr voneinander abweichen. Als Beispiel sei EH 178 ganz zitiert:

Vino pije Tuci Petar, varadinski ban; Popio je trista dukat, sve za jedan dan, Jos $k$ otome vrana konja $i$ zlat buzdovan. Karao ga kralj Matijas, zemlji gospodar: "Kurvo jedna, Tuci Petar, varadinski ban, Jer ti popi trista dukat ave za jedan dan, Jos $k$ otome vrana konja $i$ zlat buzdovan." N jemu veli Tuci Petar, varadingki ban: "Ne karaj me, kralj Matijas, zemlji gospodar! Da si bio u krimara u koga sam ja, Popio bi vise dukat' nego to sam ja, Jos $k$ otome celu Pestu $i$ pol Budima, Jer su lepe pestankinje, bog in ubiol"

Der trinkfreudige Held heiBt in Vuk I 633, Kuhad IV 1472 b und 1474 a Dojein Petar, in Kuhad IV 1474 b Duci Petar, in Kuhad IV 1472 a Dulci Petar, in EH 178 und Kuhad 1473 b Tuci Petar und in Kuhad IV 1473 a sogar ljuti Peter. Hinter all diesen Namensformen verbirgt sich zweifellos $P$ e $t$ e $r$ D 6 c $z$ y, der unter Konig Mathias Corvinus, dem kralj Matijał bzw. Mateja unserer Lieder, "Ban" von Jajce und Varadin war und als Tlirkenklkmpfer zusammen mit Despot Vuk, Dmitar Jaksic u.a. genannt wird ${ }^{70}$. Die Namenserklkung in ISSF VIII/IX,466 unter "Peturr ban, vlaßki ban" ist sicher falsch. Hier wird numlich behauptet, unter kral Mateja sei der walachische Konig Matei Basarab (1632-54) zu verstehen; fur Petur ban wird keine Erklarung gefunden, weil keiner der sechs moldauischen Voevoden namens Peter den Zeitgenossen von Konig Matei angehrre.

Dieses Sujet, das seinen Liedfiguren nach fruhestens in der zweiten Hzlfte des $15 . \mathrm{Jh}$. entstanden sein kann, wanderte m.E. In den maz.-wbulg. Raum, wo wir es in der sekundaren Iiedschicht in vier Varianten aufgezeichnet finden: Sapk.337 (13 V.;4/4/5) aus Ohrid; Jastr.,385 (14 V.;4/4/5) aus der Gegend von Prizren; Col.92 (18 V.34/4/5) aus dem Sopluk; und SbNU XI,33 (15 V.;4/4/5) aus Krivorecna Palant 
ka in NO-Mazedonien. Der Liedheld heiBt hier Peter ban, Dojxin Petar, Petre bane und - in entstellter Form - auch Pejzin Petŭr, der Kơnig immer kral Mateja. Das Sujet hat zum Teil sekundare Veränderungen erfahren:

Ban Petŭr trinkt nicht nur einen Tag lang wie in den skr. Iiedern, sonderm drei (SbNU XI,33) oder flinf Tage lang (Col.92); er vertrinkt nicht nur seine Dukaten und sein Pferd, sondern auch seine Waffen (Streitkeule, Plinte, Pistolen) der Reihe nach. Vor allem aber der Iiedschlus ist umgestaltet:

"Ej tiseka, kral Mateja, zemski gospodar, Ti da znais, ja zto ljubim, i Bosna bi dau,, Da vu vidis belo lice, i Vama bi day, Da vu brúner u pazuki, kralevstro bi dax, Da vu legnes u postelja, i duşa bi daux.

(SbNU XI, 33)

Noch ausfuhrlicher und sogar auf Wortspielereien bedacht ist Jastr., 395:
"Ne karaj me, kralj Mateja, zemski gospodar
Da ti vidiz kr Xmaricu, hiljadu bi dao!
Da joj vidis belo lice, Beograd bi daol
Da joj vidis ruse kose, Rusiju bi daol
Da joj vidis altun celo, Venedik bi dao!
Da joj vidir crne oxi, Crnu gor' bi dao!
Da joj vidiz bele dojke, do duse bi dao!
Da ti legne pored tebe, i dušu bi dao!

In Col.92 erfolgt die Ruge und die Rechtfertigung sogar brieflich.

Petar ban, der auch in anderen Liedern (z.B. EH 11 und 59; Vuk II 80; Maz.,202; Mil.184; SbNU II,86; Per.Spis.XJV, 459; SbNU XVI-XVII, 156; KaC.200; SbNU XIV, 66;XXXI,209;XIIII, 128;XIIII,483), und zwar mit anderen ugrischen Helden zusammen, vorkommt, scheint noch in einem andren Sujet nach $S$ gewandert zu sein: Das Iied EH 11, das die Eroberung Budims, die Gefangennahme und den Selbstmord der schonen Mara und den Tod von Ban Petar durch die Janitscharen schildert, taucht namlich im maz.-bulg. Raum in verschiedenen Versionen wieder auf ( $\mathrm{ggl}$. ISSF VI, 181(21b) und VI,232(125g) und VIII/IX,467(441): SbNU XI, 36; XXVI, 158; XLIII,408; Sapk. 181 und 384; Stoin SSB 169 und 170; Col.40; Mil.107; Drag., 126; Il.248; uv. sind Mil.167; Il.325; Jastr.,83), nur 
heibt hier die heldin bela Rada, bela Jana, Budim Jana oder tünka Stana, auf die wir noch zurückkommen werden. Das Motiv wird in mehreren maz.-bulg. Varianten dahingehend erweitert, daB Eltern und Geschwister (erfolglos) von den Turken gefoltert werden, damit sie Janas Versteck preisgeben, und daB Janas Schwagerinnen sofort den ort verraten, wo sich Jana aufhält. In manchen Liedern flieht Jana, von den Schwägerinnen verraten, in den Wald, wo sie sich als Baum verstellt. Als die Türken nach Anraten der Schwggerin den ganzen Wald abholzen und die Bäume wegtragen, sturzt sich : Jana in die Donau, um den Turken nicht in die Hände zu fallen.

\subsection{DER PROPHETISCHE TRAUM VOM FALL BUDIMS}

Wie $Z_{i r m u n s k i j}{ }^{71}$ richtig bemerkt, tritt das Motiv des prophetischen Traumes "bei allen volkern, die den Traumen eine Bedeutung beimessen", - und das ist ja eigentlich bei allen volkern der Fall, "als epische Schablone" auf. Als eines der berlhmtesten Beispiele sei hier das Nibelungenlied genannt, das bekanntlich mit Kriemhilds prophetischem Traum (ein Falke wird von zwei Adlem zerfleischt) beginnt. Wie Gesemann 72 gezeigt hat, stellt die epische Schablone I.Traum - II.Traumdeutung - III.Traum wird Wirklichkeit - eines der vielbenutzten und gut ausgearbeiteten Kompositionsschemata (neben der Rabenbotschaft und dem Vilenruf) der skr. Volksepik dar. Wichtig ist dabei die zwischen Ende von II und dem Anfang von III eingeschobene Formel "Er (sie) hatte noch nicht ausgeredet, als schon...", d.h. der Traum wird augenblicklich nach der Traumdeutung Wirklichkeit. In unserem falle handelt es aich um einen unheilvollen prophetischen Traum, in dem der Fall der Stadt Budim symbolisch vorhergesagt wird. Das Sujet in dieser speziellen Form durfte sich also frihestens nach 1541 (dem Jahr, in dem ofen beim funften Zug Suleimans II. nach Ungarn von den Turken eingenommen wurde ${ }^{73}$ ) ausgebildet haben, und zwar ziemlich sicher in Sudungarn. Tatsăchlich stamt ja unsere alteste 
Aufzeichnung aus der Sammlung Bog., d.h. das Liedsujet des prophetischen Traumes vom Pall Budims 1st m.E. in dem epischen Ballungszentrum an der unteren Donau in Form eines Langzeilenliedes gestaltet worden und trat dann seine SWVianderung an die Adriakliste an, wo es Anfang des 18.Jh. erstmals aufgezeichnet wurde. Das Lied Bog.28 (28 Langverse mit 6silbigem Refrain nach je 2 Zeilen: insgesamt 42 V.) hat folgenden Inhalt:

Ein schönes junges Mádchen aus Budim ruft den ruhmvollen König Vladisav, er möge, wenn er gerade seine Traute kusse, aufhören zu kussen, wenn er gerade seine Schatze zähle, aufhören zu zahlen, und wenn er gerade im Schlaf trăume, aufhören zu schlummern, denn es habe einen sonderbaren Traum geträumt:

Đe no ti se bjese vedro nebo r.ad Budimom prelomilo, A drobne ti zv'jezde padahu pod polace od Budima, I te ti bjełe jasan mjesec potamio! Te lijepe zv'jezde,

Niemand kann diesen Traum deuten auBer dem Vojvoden Ugrin Janko, der das Mädchen ob seines Traumes verflucht, den er so auslegt: DaB der heitere Himmel uber Budim zusammensturzt, bedeute, dab die verfluchten Tlurken die weiBen Mauern Budims ersturmen werden; dab die leuchtenden Sterne auf die Königsburg niederfallen, bedeute den Tod der ungarischen Helden durch die verfluchten Turken; und daß der helle Mond sich verfinstere, deute den Tod des ruhmreichen Königs Vladisav voraus.- Janko hat noch nicht ausgeredet, als schon die Turken die weiBen Mauern von Budim umstellen, die ungarischen Helden unter die sabbel nehmen und dem Landesherm, König Vladisav, das Haupt abschlagen.

Der Anachronismus, daß im Lied der 1444 in der Schlacht bei Vama gefallene ungarische König Wladislaw und János Hunyadi (1456 gestorben) die Einnahme Budims (1541) erleben, soll uns hier nicht interessieren, denn Anachronismen sind in der sudslavischen Volksdichtung an der Tagesordnung. Wichtig ist vielmehr die Tatsache, daß dieses Sujet 74 offenbar nach Mazedonien und Westbulgarien gewandert ist, wo wir es in mehreren relativ heterogenen Aufzeichnungen antreffen: Jastr.,49 (10 V.;4/6; Debar;Weihnachtslied); Sapk. 364 (uv.; Prilep); Maleł.150(106 V.;4/6; Malełevo); SbNU 
XII.77 (113 V.;4/6; Blagoevgrad); Drag.68 (98 V.;4/4; KrivoreCna Palanka); Il.248 (45 V.;4/4; Blagoevgrad).

Das kurze lied Jastr.,49 z.B. beginnt mit der Feststellung:

Son sonila Budimska kraljica,

Se razbudi Budimska kraljica.

Dann folgt der Bericht der Königin von Budim uber ihren

Traum:

Beš mi se nebo otgrnalo,

A since mi krvavo ogreja,

Vo dvor padna zvezda vecernica,

$\mathrm{Na}$ divani jasna meserina.

Der Konig, dem seine Gattin dies erzahlt, deutet nun nicht, wie Janko in Bog.28, die einzelnen Symbole, sondern fugt

nur die lapidare Feststellung an:

Aj ti tebe, moja gospodarke!

Vexe ni se-kraljstvo dovrsilo.

Aus dem namenlosen Mädchen aus Budim in Bog.28, dessen Funktion fast an den Vilenruf erinnert, ist hier nun die stereotype Konigin von Budim geworden. Diese ist es auch, die in den einander sehr ahnlichen, erweiterten Varianten Maler. 150 und SbNU $X I I, 77$ trăumt:

Zagina mi jasnoto sŭn ${ }^{2} i c e$, Jasnoto sindice od planina, Pa ogrea jasna mesedina, Popadaa dzvezdi od neboto, Zarosi si sitna Zeêka rosa, Pobegna si dzvezda vecernica

Pokraj more $\nabla$ Srübinskata zemja, Bezom bega soz dve malk' 1 dzvezdi (SbNU XII,77).

Der Konig legt diesen Traum so aus: Das Untergehen der Sonne bedeute seinen eigenen Tod; das Aufleuchten des Mondes bedeute die Ankunft des Sultan Murad; das Herabfallen der Sterne vom Himmel bedeute den Tod und das Fallen von Tau die Trinen der Untertanen; die Plucht des Abendstems mit zwei kleinen Sternen bedeute die Flucht der K8nigin und ihrer beiden Szhnchen in das serbische Land. - Er, der Kon1g, werde nun zur Kirche gehen und seine Sunden beichten. Wenn Sultan Murad eintreffe, solle inm die konigin wertvolle Geschenke und die Schlussel ihrer zwolf Stadte Ubergeben und ihn bitten, er moge ihre Srhnchen am Leben lassen. - Der König wird mit einem großen Teil seiner Leute beim Verlassen der Kirche von einem starken turkischen Heer geţtet, worauf die Konigin zu Sultan Murad geht und alles ausfuhrt, wie 
der Konig es ihr aufgetragen hat. Da der Sultan ihrer Bitte um Schonung ihrer Kinder unentschlossen begegnet ("oni sa si kralevo koleno,/kuga da je maka k'e me macat"), elieht die königin mit ihren zwei sobnchen in das oerb.Land. Hier wachsen die beiden Prinzen auf, lernen lesen und schreiben und erfahren schileBlich aus dem Vermächtnis ihres Vaters, das sie ihr vaterliches Erbe verloren haben.- Inzwischen versammeln sich die "odzi $i$ efendil" und tadeln den Sultan, das er die Königin fliehen lieB und die Prinzen nicht totete. Eine nun eingeleitete Suchaktion bleibt erfolglo8. Die Königs8రhne haben ein 50000 Mann starkes Heer gerlistet und fordern ihren veterlichen Besitz mit Gewalt zurlick. Nach einjuhrigem Kampf sind vom Zarenheer 100 000, vom Heer der Prinzen aber nur 1000 Mann gefallen, worauf der Sultan den Konigsebhnen ihr vaterliches Erbe ("tatkovina") zurluckgibt. Sie fordern aber auch den Besitz der Vorfahren ("stara dedovina") zurlack, klmplen drei Jahre darum und vernichten das ganze turkische Heer, wofur sie von Sultan Murad verfluoht werden.

In diesem erweiterten Sujet ist das legendare Motiv von den Heldenkindern, in diesem Fall den Königs8bhnen, die ihren Vater rächen und das vaterliche Reich zuruckerobern, sekundar angehängt und bietet damit einen positiven Iiedschluss

Od deca pesna je ostanala.

Da se alavi, da se prikazuva,

den es natlurlich in der damaligen Wirklichkeit nicht geben konnte. Zar Murad deutet aber, statt auf den Fall Budims, eher auf die beiden Kosovoschlachten (1389 und 1448) hin. die unter den Sultanen wurad I. bzw. II. otattfanden. Das Moment der Flucht nach Serbien ist naturlich erfunden, könnte aber vom sunger aus der neueren Perspektive, als Serbien sich bereits vom Turkenjoch befreit hatte (Volksaufstände 1804-12,1815-17; 1878 selbständigkeit), hinzugefugt worden sein (vgl. das Kosovolied SbNU III,85, das ja auch mit der Einbeziehung Karadortes, des Fuhrers des ersten aerbischen Volksaufatandes, endet).

Ferner sind die belden zusammengehörenden, ebenfalls sekundur erweiterten Varianten Il.248 und Drag.68 zu nennen. Im einen Fall traumt Budim Jana folgenden prophetischen Traum: 
Zadade se teven oblak, Niz oblako sitna rosa, Niz rosata maten poroj, Kara durvje i kamenje.

Janas Vater deutet den Traum so: Die dunkle Wolke seien die verfluchten Tlrken, der feine Tau die Tränen der Bewohner von Budim, der trube, reissende Regenbach deren Blut und die angeschwemmten Baumstämme und Steine deren Leichname und Kopfe. - Jana verbirgt sich, als die Tlurken gleich nach dieser Traumdeutung kommen, in dem weiben Wohnturm. Der Reihe nach werden Janas Vater, Mutter und Brider von den Eroberern gefoltert und dann getötet, als sie Janas Versteck nicht verraten wollen. Erst Janas Schwägerinnen geben das Versteck preis, worauf Jana gefangengenommen wird.

In Drag.68 traumt lepa Jana - abweichend von dem bisherigen Motiv - folgenden Traum:

Dotekau mi ti'i Dunav

U nasite rami dvori

I doneseu do tri kitki:

Dvete kitki stratarovi,

A ednata bosil'kova.

Ihr Bruder, Petŭr ban, deutet die Donau mit den verfluchten Tlirken, die beiden (sic!) Basilienkrautsträuße mit den Tränen und den Tausendschönchengtraub mit dem Blut der Bewohner von Budim.Als gleich darauf die Türken eintreffen, foltern und verstummeln sie Janas Eltern, weil diese Janas Versteck nicht preisgeben wollen. Janas Schwagerin aber verrat schon nach drei Schlagen, wo Jana sich verborgen hilt. Die Turken dringen in den eisernen Wohnturm ein, toten Janas Bruder und nehmen Jana gefangen. Nach einem rihrenden Abschied von ihren gemarterten Eltern labt Jana sich abfihren, springt aber beim Uberqueren der Donau in das Wasser, um sich lieber das Leben zu nehmen, als den Turken ausgeliefert zu sein.

Beide Varianten sind sekundar mit dem am Ende von Kap.3.1 genannten und in seinen Varianten aufgezahlten Sujet von "Bela Jana ot Budim grada" kontaminiert. Hinter der Liedgestalt "bela Jana" möchte Ivanor 75 mit Trifonov" 76 die ungarische Konigin Isabella (gest.1559), Gattin des János Zapolya (gest.1540) und Tochter des polnischen Konigs Sigismund, sehen. Ivanov schreibt:

Boevete na avatrijci, madžari 1 turci za Buda, stradanijata na kralicata-vdovica Izabela 8 a dali chrana na motiv 8 dosta varianti 1 o pre- 
plitanija, na elementi ot drugi motivi. Imeto na budimskata kralica Izabela e minalo $v$ bülgarskija folklor kato bela (Iza-bela) Jana ili Rada. Auch Cv.Romanska 77 schliebt sich dieser Meinung an und fugt noch hinzu, dab die Entfuhrung der "bela Jana" im lied die der Konigin von Sultan Suleiman auferlegte Verbannung in die Stadt Lippa wiedergebe.

Das Motiv des prophetischen Traumes vom Fall Budims wurde naturlich wegen der Affinität der Thematik auch auf Lieder, die den $\mathrm{Pall}$ des bulg. oder byzantinischen Reiches ${ }^{i 8}$ bzw. die Kosovoschlacht behandeln, Ubertragen. Dieses Motiv steht im Palle der maz.-bulg. Lieder gleichberechtigt neben dem in vielen Varianten vertretenen Sujet von der den Untergang des Reiches ankïndigenden Vogelbotschaft, vgl. "Ptica nosi predizvestie za padane na carstvoto" in ISSF VI, 233(126b) 79 und "Carica sunuva prokoben sŭn" in ISSP VI,232(126a). In diesen Iiedern träumt meist die Zarin den unheilvollen Traum vom Untergang des Reiches, und Zar Kostadin deutet ihn; nur in zwei mir bekannten liedern, Sapk., 388 und SbNU II,129 träumt der Zar selbst, was naturlich eine sekundare Veranderung bedeutet. - Unter Zar Kostadin ist wahrscheinlich der bei der Eroberung Konstantinopels 1453 gefallene letzte byzantinische Kaiser Konstantin XI., kaum aber der 1394 zusammen mit Marko in der Walachei ungekommene Konstantin Dejanovie, Herrscher von Kustendil, gemeint.- Die Hauptpersonen des kurzen Liedes Mil.62 sind ein nicht weiter benannter "car" und die ebenso namenlose "carica". Das "carstvo", dessen Fall im Traum vorhergesagt wird, ist ebenfalls unbenannt. - In Il.139 kindigt sich die Eroberung des Reiches, der Tod des Zaren und die Gefangennahme der Zarin im Traum von "Risanu carice,/Mada vizirice" an, wobei man hinter "Risana" vielleicht den sudslavischen Liednamen Roksanda (vgl. Vuk II 28 usw.) vermuten darf. Als Variante zu dem letztgenannten Lled sei Boǵorov 39 erwhrnt. - In Drag. 65 klindet schlieblich der unheilvolle Traum der als "budimska kralice" bezeichneten Konigin Milica (gemeint ist naturlich Lazars Gattin) dem Zaren Kostadin 
an : "Ke nastane nǎ̧e Bugarsko carstvo". - "Carica Elena" dagegen sieht in Kad.117 den Untergang des Reiches von Zar Kostadin voraus, und das lied schlieBt, ahnlich den oben erwahnten Varianten, mit den Satzens

Sinove im dalek prebegnaa,

Dalek, dalek u slavna Rusija.-

Dva mi sina carstro zemat.

In KaX.112 ist das Sujet von dem unheilvollen Traum der "kralica kmetica", worin die Eroberung des Reiches durch die Turken und der Tod des Königs vorhergesagt werden, durch das Motiv der ungetreuen Frau, gebunden an die aus Budim hergeholte Gattin des Königssohnes, erweitert. - Karav.86 ist sekundar erweitert durch das Motiv, dab die Zarin nach dem im Traum vorhergesagten Zusamenbruch des Reiches und Tod des Zaren allein mit ihrem Sohn Nikola zurickbleibt und von den Kmeten und Corbadzis betrogen wird: Sie labt namlich auf Anraten der Kmeten nicht, wie zuerst geplant, Kirchen, Klöster oder Brlicken, sondern ein Gefängnis bauen, in welches die verraterischen Ratgeber ihren eigenen Sohn werfen und dort umkommen lassen, trotz der Loskaufversuche der unglucklichen Zarin.

In den Liedern Sapk.387 und Stoin TV 2366-68 schlieblich ist das Motiv des unheilvollen Traumes von den fallenden Gestimen in die rein familiare Atmosphare transponiert:
Aj ti, sinko, Sekula detence!
Mesedina tfoja stara majka;
Jasno solnce, tfojata nevesta;
Dremi dzvezdi, tfoite decina;
Taja dzvezda, na nebo zro stoit,
Taja mi je tfoja mila sestra

lautet die Traumdeutung in Sapk.387.- In Stoin TV 2366 traumt Rada:

$$
\begin{aligned}
& \text { Slünceto padna vĩv doma, } \\
& \text { Meseca padna } 1 \text { zidovi, } \\
& \text { Zvezdite redom na is selo. }
\end{aligned}
$$

Die Mutter deutet den Traum als ein gutes Vorzeichens Mond und Sonne bedeuten Schwiegervater und -mutter und die Sterne die Brautfunrer, d.h. also, Radas Hochzeit steht bevor. - Stoin TV 2367-68 sind ganz ahnlich. 
Zusammenfassend labt sich also sagen, dab die Schablone des unheilvollen prophetischen Traumes, der den Fall Budims oder den Untergang eines Reiches anklindigt, wahrscheinlich auf der Morava-Vardar-Straße nach Mazedonien und Bulgarien gelangt sein durfte. Das alteste, vielleicht schon in der zweiten halfte des 16.Jh. zugewanderte Sujet mit dem Motiv der herabfallenden Gestirne ist das Lied, das den prophetischen Traum vom Fall Budims zum Inhalt hat, nach dessen Muster dann andere Sujets (Untergang des Reiches; Kogovo), in seltenen Fällen sogar mit sekundär positiver Traumdeutung (bevorstehende Hochzeit), gebildet wurden.

\subsection{KOSOVO-LIEDER}

Aus der relativ reichen Kosovo-Liedtradition sollen hier nur die im maz.-wbulg. Raum zugewanderten und damit sekunduren Lieder behandelt werden, die sich auf die eintagige Schlacht auf dem Kosovofeld am 15.Juni 1389 (zwischen Serben und Bosniern mit knez Lazar an der Spitze auf der einen Seite und dem turkischen Heer unter Sultan Murad I. auf der anderen Seite) und die zweite dreitagige Kosovoschlacht von 17.-19.0ktober 1448 (zwischen dem Heer des ungarischen Reichsverwesers János Hunyadi und dem von Sultan Murad II.) beziehen. Beide Schlachten brachten fur die christlichen Heere eine Niederlage. 1389 fanden sowohl der Sultan wie auch Furst Lazar den Tod, - ein Ereignis, das diese erste Kosovoschlacht besonders in das Gedachtnis des Volkes eingepragt hat. AuBerdem erregte die Heldentat deg Milos Kobilic Aufsehen, der im feindlichen Lager bis zum Sultanszelt vordrang, Murad tötete und gleich darauf selbst den Tod fand. Diese Tat (verbunden mit der vorhergehenden Verleumdung des Milos durch Neider und Bezichtigung beim Abendessen durch den Firsten) dirfte wohl in den ersten Kogovo-Iiedern besungen worden sein, und diese bildeten den Grundstock fur eine zunkchst selbständige Milor-Sage. Erst etwa der zweiten Halfte des 16.Jh. dürften die Ver- 
suche entstammen, eine Synthese der bisherigen Milos-Sage und der schon fruh einsetzenden und von kirchlicher seite forcierten Lazar-Ubberlieferung herzustellen, die wahrscheinlich im 17./18.Jh. zu einem epopöenhaften Kosovo-Lied fuhrten, dessen wesentliche Elemente in der Bugarstica Bog.1, in Petran.II 26, in der Povest ${ }^{80}$ und dem Tronoski rodoslov 81 enthalten sein durften. Vuk Karadzic hat bekanntlich in seine Liedersammlung kein zusammenhängendes Kosovo-Lied, sondern nur Bruchstucke eines sicher frither epopöenartigen Liedes aufgenommen. In seinen Nachlaßschriften in Leningrad befindet sich allerdings ein Kosovo-Lied mit uber $2000 \mathrm{~V}$. , das aber (wahrscheinlich wegen mangelnder Qualitat) von Vuk nicht veroffentlicht wurde. Der historische Sachverhalt der ersten Kosovoschlacht ist von Racki ${ }^{82}$ grundlegend dargestellt worden. Uber die historische Entwicklung der Kosovotradition in den skr. Liedern informieren am besten Novakovic $c^{83}$, Maretic ${ }^{84}$, Chalanskij ${ }^{85}$, Soerensen ${ }^{86}$, Kostic ${ }^{87}$, Popovic ${ }^{88}$ und Schmaus ${ }^{89}$. Soerensen und Kostic haben dabei zum erstenmal auf die Wechselwirkungen, d.h. gegenseitige Beeinflussung und Motiventlehnung, zwischen den Liedern der ersten und zweiten Kosovoschlacht hingewiesen. - Fllr die zweite Kosovoschlacht stehen uns mehr und zuverlassigere historische Quellen 90 zur Verfugung als fur die erste. Die wichtigsten Momente sind hier der Versuch von christlicher Seite, in einem Uberraschungsangriff bis zum Sultanszelt vorzustoBen und Murad II. zu t8ten, der Verrat durch den walachischen Voevoden Dan und der Tod von János Székely, dem Banus von Slavonien. Die skr. lang- und kurzzeiligen Lieder Uber die beiden Kosovoschlachten mussen hier als bekannt vorausgesetzt werden, denn sie kơnen wegen der fulle des Materials unmöglich im einzelnen behandelt werden. AuBerdem sind sie ja 2.B. bei Soerensen und Kostič Gegenstand der Untersuchung. Was uns aber im Rahmen unserer Fragestellung zu interessieren hat, sind die im maz.-wbulg. Raum zugewanderten, sekundaren Kosovolieder. An erster Stelle sind hier diejenigen 
Lieder zu nennen, die das Motiv des unheilvollen prophetischen Traumes - auf Kosovo Ubertragen, wie in dem Langzeilenlied Bog.1 - enthalten:

Kac.175 (27 V.;4/6; KUstendilsko); SbNU II,90 (102 V.;4/6; Sofijsko); Stoil.II 12 (156 V.;4/6; Mariovo); BNTV III, 142 (69 V.;4/6; Dimitrovsko); SbNU I,51 (163 V.;4/6; Sopijsko); XIV,90(153 V.;4/6; Kopriv3tica); XIIII,268 (175 V.;4/6; Sofijsko); XUIII,271 (82 V.;4/6; Sofijsko).

In Kac.175 träumt Königin Milica Polgenden Traum:

Jasno mi se nebo razdvoilo, Jasni dzvezdi po zemi padnali, Vlachci( + ) dalek prebegal1, Denicata kervo ogrejala, A meejaco na nasi dvorove. (t) "viachci" = nazvanie zvezd, Anm.Kad.

Der Zar (gemeint ist knez Lazar) erklart seiner Gattin die Bedeutung des Traumes: Das Reich werde untergehen, die Untertanen ("nasi mili deca") fliehen, Milica Witwe werden und er, der Zar, seinen Kopf verlieren. Er hat kaum ausgeredet, als die Twrken alles Uberrennen, den Zaren t $8-$ ten und Milica als Witwe zurlucklassen.

Varianten hierzu sind die beiden Lieder SbNU XIII,268-73, worin Königin Milica von den fallenden Gestimen träumt und ihr Traum von Zar Lazar so ausgelegt wird, daB er getotet und das Reich von den Turken erobert wirde. Gleich daraup fallt Lazar gegen die Thriken auf dem Kosovofeld und Milica bleibt als Witwe zurluck. In dem ersten der beiden lie$\operatorname{der}(\mathrm{Nr} .114)$ kommt dann Golovin, einer der drei Brider Milicas, auf Lazars Thron.

Wie Soerensen 91 bewiesen hat, beruht Milicas unheilvoller Traum in dem als ein "Resultat fortschreitender Amplification" erklarten Langzeilenlied Bog.1, das in der vorliegenden Form wahrscheinlich dem 17.Jh. entstammt, "aus Nachbildung des gleichen Motivs in Bog.28". Was in Bog.28, gebunden an den Fall Budims, noch als kunstvolles Motiv wirkte, ist in Bog.1 zu trivialen Vergleichspaaren geworden:

Der Himmel zerspringt in vier Stlucke, was gekinstelt von Milos dahin gedeutet wird, das das Herz Milicas vor Schmerz zerspringen werde. Wie die Sterne vom Himmel sturzen, werden auch die 
K४pfe der Ungarm fallen; und wie sich der Mond verfinstert, so werde sich auch das Antlitz Lazars verdustern.

Milicas Traum in Petran.II 25 macht einen noch jungeren Eindruck ${ }^{92}$.

Unser vorher wiedergegebenes wbulg. Lied Kac.175 dagegen zeigt anscheinend eine gltere Version des Traumotivs als Bog.1 und halt sich offenbar mehr an das urspringliche Lied, dem Bog.28 weitgehend entsprechen durfte. Die Version Kac.175 könnte also bereits Ende des 16./Anfang des 17. Jh. von Studungarn auf der Morava-Vardar-Iinie nach So ge"wandert sein, wo es in erstaunlicher "Originaltreue" bewahrt wurde. - In Stoil.II 12, das ansonsten mit dem Todor von Stalac-Motiv kontaminiert ist und einen ziemlich verderbten Eindruck macht, trăumt die junge (namenlose) konigin, Jankulas Gattin, daß der Himmel zusammensturzt und die Sterne, Sonne und Mond herabfallen. Jankula, der, wie wir wissen, auch in Bog.28 dem Mädchen von Budim den Traum deutete, erklart das unheilvolle Vorzeichen sinngemab wie in dem alteren Langzeilenlied:

\footnotetext{
Neboto e, veli, ja k'e padna, Dzvezdite se vera risjanstia, Sunceto e Stevo po-mal bratok, Mesecina turdin ' ${ }^{\prime}$ 'e otkine, K'e ni zeme našata dưržava, Nałata düržava na Kosovo!
}

Anscheinend ist das Traummotiv hier auf die von Hunyadi (Jankula) gefuhrte zweite Kosovoschlacht Ubertragen und der Held sogar zum König gemacht worden.- In SbNU II,90 ist das Motiv des unheilvollen Traumes so abgeandert, daB G'urica kral'ica auf dem Kosovofeld (!) liegend trăumt:

Se Kosovo zeleno livag'e,

Nasret livag'e toj güsta trünica,

U trŭnica zmija trojoglava.

Nach der Deutung des Königs bedeute die grine Wiese Elend und Kummer, das dichte Dorngestrupp großen Hader auf dem Kosovofeld und die dreikypfige Schlange die baldige Einberufung auf das Schlachtfeld. In weiteren Verlauf schliebt sich das Sujet von der untreuen Prau an, die nach neunjahrigem Warten auf ihren aus dem Kampf noch nicht zurlackge- 
kehrten Mann einen neuen Gatten nimmt, die beiden Söhne vertreibt und von dem als Bettler verkleidet heimkehrenden rechtmbBigen Gatten mit dem Tod bestraft wird (so z.B.auch in der Variante SbNU XIIV, 68, wo aber das Traummotiv fehlt; in SbNU II, 90 findet die untreue Gattin, als sie ihre Tat, numlich die Untreue, bereut, wieder Gnade ).

Unter "G'urica vojvoda", wie der Konig in der Variante SbNO XUIV, 68 heiBt, möchte Vakarelski 93 "Georg Stracimirovic (1385-1403), den Herrn der ganzen Zeta und des Kustenlandes" sehen, "der, um vor den Turken verteidigt zu werden, Schutz bei Furst Lazar suchte, indem er dessen Schwester Elena heiratete". Wahrscheinlich hat in SbNU II,90 die klangliche Ähnlichkeit der Namen G'urica - Milica zur Ubernahme des Traummotiva von der Schlacht auf dem Kosovofeld gefunrt. - In SbNU I.51 traumt Enica - lautlich ebenfalls an Milica anklingend -, als "Sofijska kralica" bezeichnet:

Nasred se e nebo propuknalo,

Sitni zvezdi po zemja padnale,

Jasen mesec kưrvav e izgrejal.

A po nego - zvezdica-dennica,

I ona e kurvava izgrela.

Konig Sizmanovic Jane deutet den Traum so, daB das bulgarische Reich untergehe und alle fallen whrden. Kaum hat er ausgeredet, da ruft ihn Zar Sizman, umzingelt von Tlirken, nach Kostenec zu Hilfe. Enica, die Griechin, iabt ihren Gatten nicht ziehen. Da trifft eine zweite Nachricht ein: Der Konig moge Michail Vasilic zu Hilfe eilen, dem Gefangennahme durch die turkischen Verfolger drohe. Wieder lzBt die Konigin Jane nicht fort. Als schlieblich die dritte Nachricht, die die Belagerung des Michael und den Tod Sismans meldet, eintrifft, eilt Jane gegen den Willen seiner Gattin auf das Feld von Ichtiman. Der Iskúr fliebt blutig und tragt Kappen und abgeschlagene Heldenarme mit sich. Ein MBdchen sucht seine drei Bruder und bittet Jane um Unterstutzung. Dieser nimmt eine Hand und erkennt an dem Ring, daß es sich um die Hand des Zaren Sizman handelt. Daraufhin eilt Jane nach Stupen, wo Michail belagert wird. Jane schlagt das turkische Belagerungsheer auseinander und dringt in die Stadt ein. Michail aber verzeiht inm seine Verspktung nicht und lehnt Janes Hilfe ab. Enttascht schlagt sich Jane zum zweitenmal durch die Turken. Eine alte Frau rat den Jani- 
tscharen, ihre Sabel an der Iskür-Brllcke aufzustellen, damit Janes Pferd stolpere und der Held in die Schwerter sturze. Dies geschieht, und Jane wird von den herbeieilenden Turken geköpft.

Obwohl in diesem Lied weder von Kosovo noch serb. Helden die Rede ist, sondern der Untergang des bulg. Reiches und bulg. Helden beschrieben werden, muß es hier doch erwahnt werden, weil es eindeutig mit den Elementen der skr.Kosovotradition gestaltet ist: offensichtlich ist namlich hier das aus Vuk II 46 bekannte Motiv des zur Schlacht zu spät kommenden Helden (Musić Stjepan, Vasojević Stevan), der auf dem Schlachtfeld ein Madchen (Kosovska devojka) mit Furst Lazars Mutze in Händen trifft, und das Motiv der "Kosovska devojka" (Vuk II 50), die auf dem Schlachtfeld die drei Wahlbrluder Miloz Obilić, Kosancí Ivan und Toplica Milan, von denen der letzte ihr Verlobter ist, sucht, ausgenutzt und kann daher nicht alt sein. Das Motiv der abgehauenen Hand finden wir bereits in Bog.20 und 29 und auch in dem berlihmten Vukschen Lied "Smrt majke JugoviCa"(Vuk II 47). Was die in unserem lied genannten Personen betrifft, möchte Vakarelski 94 hinter "Michail Vasiliz" Michail, den Sohn Aleksandurs, sehen. Weiter schreibt er:

Unter Si fmanine Jane, Sizmanoviz Jane ist vielleicht Ban oder Vojvode Janko, vom Volk Jane genannt, der Verteidiger Sofijas zu verstehen, der betragerisch zur Jagd in die Gegend von Ichtiman und Kostenec gelockt und von den Tüken gefangen murde, woraufhin die Einnahme Sofijas erfolgte. Es kann sich aber auch um ein und denselben $\mathrm{Na}-$ men handeln, der auf Grund des dichterischen Vergessens der Tatsachen (poradi poetiCeska zabrava) zweigeteilt wurde.

Mir scheint die zweite Deutung wahrscheinlicher zu sein. Gemeint ist das Nebeneinander der Namen Ivan Silman und Sismanovid Jane.

Die kurze Variante BNTv III, 142 verbindet schlieblich das typische Motiv der Vorhersage der Kosovoschlacht im Traum der konigin Milica auf kuhne, aber unsinnige Weise mit dem Untergang des bulg. Zarenreiches zur Zeit des Ivan Sizman und mit der Schlacht bei Kostenec:

krnigin Milica, deren Traum nicht von inrem 
Gatten, dem Zaren, sondern von den Klostermónchen gedeutet wird, sieht in symbolischen Bildern von fallenden Gestimen den Untergang des bulg. Reiches und des Heeres, die Flucht des bulg. Zaren nach "Vlazko" und den Tod von Mil1cas Sohn voraus. -Gleich darauf wird der Zar durch einen Brief nach Kostenec gerufen, wo Zar Sirman in Bedrangnis geraten sel und die Tlurken die Stadt belagem. Der Zar eilt mit einem starken Heer 108. Er findet den Iskrr trube und blutig und voll von Heldenmutzen und - handen. Der Zar stelgt vom Pferd, holt eine Hand aus dem Wasser und erkennt an dem goldenen Ring, dab es sich um Sirmans Hand handelt und das bulg.Reich nun verloren ist.

Das Moment der Flucht und des Todes des Zarensohnes werden nicht mehr beschrieben, obwohl sie im Traum vorhergesagt wurden.- In SbNU XIV,90 triumt Marko auf dem Weg nach Anatolien ("Anadola"), wo er sich mit den Plirken schlagen will, folgenden Traum:

Ce 8 a razdeli tova jasno nebe, Sicki zvezdi na zemja padnale.

Dadurch beunruhigt, reitet Marko nach Prilep zurlick und erzahit seiner hutter den Traum, die ihn dahingehend deutet, dab Marko mit den turkischen Janitscharen kampfen werde. Marko erfahrt von seiner Mutter, die Tlirken hutten inzwischen das ganze bulg. Reich eingenommen und verlangten nun von Marko nur noch die Schlussel seiner Stadt Prilep. Daraufhin reitet Marko zum Kosovofeld. Auf dem Weg trifft er drei Turken, die die Stadtschllussel holen wollen. Marko gibt sich zu erkennen, weigert sich aber, die Stadt zu ubergeben, und totet die Tlurken. Dann setzt er se1nen Weg zum Kosovofeld fort, wo er ein unermeBlich starkes turkisches Heer vorfindet, sturat sich in die Reihen der Peinde und totet drei Tage und drei Nachte lang Turken, bis gein peerd bis zum Knie im Blut steht. Da erscheint der hl. Elias mit drei Engeln und erklurt Marko, er schlage sich umsonst, denn das bulg. Reich sei zum Fall bestimmt. Marko fugt $81 \mathrm{ch}$ in den willen Gottos und kehrt nach Prilep zurluck, wo er Prau, Sohn, Mutter und Pferd totet, damit sie den Turken nicht in die Hande fallen. Er gelbst flieht mit unbekanntem ziel.

Dinekov95 meint, in diesem SchluB liege "etwas ebenso Tragisches und Rilhrendes wie Mannhaftes und Heroisches" und erinnert an das Lied Vuk II 73 vom Tod Marko Kraljevics, 
wo aber die Tragik des Geschehens einen persönlichen Charakter trage, wahrend es sich in dem bulg. Lied um das Schicksal des ganzen Volkes, den Untergang des Staates und die Versklavung des Landes handle.

Das Motiv des prophetischen Traumes ist hier nicht mehr voll entwickelt; es scheint in diesem zwar eigenwilligen, aber sicher relativ jungen Lied gleichzeitig an die Kosovoschlacht und den Fall des bulg. Reiches gebunden zu sein. Markos Teilnahme an der Schlacht auf dem Kosovofeld aber ist - historisch gesehen - kußerst fragwhrdig. Markos vage Flucht am Liedende ist m.E. alles andere als heldenhaft, denn im Sinne der episch-heroischen Stilisierung des Heldenlieds hatte Marko sich mit seiner Familie - vgl. Todor von Stalacl - das Leben nehmen mulssen.

Weitere maz.-wbulg. Kosovo-Lieder, die - unabhangig von der Traum-Motiv - von der Schlacht im Jahre 1389 hardeln, sind: Sapk.286 ( 14 V.;4/6/4; Prekudrim); KaX.176 (119 V.;4/6; Radomirsko); KaX.177 (601 V.j4/6; Samokovsko); KaX.178 (21 V.; 4/6; Türnsko); KaX.180 (75 V.; 4/6; Blagoevgrad); SbNU XIIII, 264 (348 V.;4/6; Sofijsko); XIIV,101 (31 V.;4/6; Sofijsko); XIIII,272 (94 V.;4/6; Breznik); XIIII,261 (203 V.;4/6; Sofijsko); III,85 (850 V.;4/6; Razlozko); Drag.5 (160 V.; 4/6; Debar).

Erinnerungen an die Ereignisse von 1448 zeigen kil.97 (53 V.;3/5; Mazedonien); Mil.245 (20 V.;6/6; Struga); Sapk.441 (116 V.;3/3 bzw.2/4; Samokov); Mil.115 (14 V.;4/6; Mazedonien).

In Drag.5, einem offenbar erst in jüngerer Zeit nach Mazedonien zugewanderten lied, wird praktisch nur der Inhalt von Vuk II 44 "Car Lazar i carica Milica", und zwar fast mit demselben wortlaut (aus dem Diener Milutin 1st allerdings Miladin und aus Vuk Brankovic Vujko Branikov geworden!), nacherzahlt, was naturlich den Verdacht einer Einwirkung der gedruckten Vukschen Sammlung hervorruft. SbNU XIII, 272, das laut Anmerkung Vakarelskis in BNTV III, 612, "unter den bisher veröffentlichten Liedern keine Va- 
rianten hat", behandelt die verspatete Ankunft des Vasoevik Stevo mit seinem Diener Voistina auf dem Kosovofeld, wo sie an der trube und blutig fließenden Sitnica ein Madchen treffen, das eine Heldenmutze aus dem Wasser geholt hat.- Bis hierher handelt es sich offenbar um eine wiedergabe des Sujets von Vuk II 46 "Music Stefan", während im nun folgenden Handlungsverlauf eine miblungene Kontamination mit dem Sujet Vuk II 50 "Kosovaka devojka" eingetreten ist, wobel das Lied sekundar verundert wurdes

Nach dem Gesprach mit dem Madchen (wobei die Mutze nicht - wie in Vuk II 46 - als die Pederkappe des gefallenen Zaren Lazar identifiziert und damit das Motiv zerstort wird) machen sich Stevo und sein Diener auf den Weg zum Schlachtfeld, als ihnen der schwer vermundete orlovikju Pavle ("desnu ruku u levutu nosi,/vita sa mu rebra polomeni") begegnet. Von Pavle erfahren gie, Lazar krmple schon seit dem vergangenen Abend mit den Tirken und habe bereits Schwert und Lanze verloren; in dieser Bedrungnis habe der Zar Vasoevik Stevo und Vukovike Branko verflucht, weil die beiden dem Schlachtfeld ferngeblieben seien und damit Verrat gellbt hatten. - Stevo und sein Diener ellen auf das Kosovofeld zu Zar Lazar, dem Stevo die Hand kast und um Verzeihung flir seine Verspatung bittet. Lazar verzeiht ihm, verlangt aber, er solle Branko rufen und mit inm auf Kosovo weiterkamplen. Zusammen mit Vukovike Branko und seinem Diener reitet Stevo auf das Schlachtfeld und vertrelbt die Turken. Das Lied schliest mit happy end: "I togaj se umiri surbija".

Schwerwiegende sekundare Veränderungen der urspringlichen tberlieferung fuhren hier schlieblich soweit, daB furst Lazar an Leben bleibt, Vuk Brankovic, der Kosovo-Verrater (ein Rest dieser Vorstellung blieb wahrscheinlich in dem Motiv seines Fernbleibens vom Schlachtfeld erhalten) der skr. Liedertradition, hier zum tapferen Turkenkbmpfer wird, und die Schlacht sich zugunsten der Serben entscheidet (wahrend Music Stefan in Vuk II 46 naturlich den Heldentod sucht und findet (). - Eine ebenso starke Verknderung des uberlieferten Todes von Miløళ, dessen besondere Tat doch das Attentat auf Sultan Murad war, finden wir in Kac.180. Hier ist von dieser Heldentat Uberhaupt keine Rede mehr, sondern Miloz, der die Turken schon zweimal auf Kosovo zuruckge- 
schlagen hat und sich trotz Zar Stefans (gemeint ist naturlich Lazarl) Warnung noch ein drittes Mal allein vorwagt, findet unter den turkischen sabeln den Tod. - In diesem allein gefuhrten Kampf durfte noch die Erinnerung an Miloss allein gewagten VorstoB zum Sultanszelt erhalten sein. - In dem bruchstuckartigen Lied Kad.178 berichtet Marko, von seiner Druzina nach dem Verlauf der Kosovoschlacht befragt, dab, als die christlichen Helden bis zum Knie im Blut wateten, ihnen Gott erschienen sei und sie zur Flucht aufgefordert habe, weil es so beschlossen sei; darauf hatten sich Relja Krilatid, Musa kesedzija, MomXilo, dete Gmujanic und dete Mijaille zur plucht gewandt und sich getrennt. - Hier spielt, wie schon oben in SbNU XIV,90, der Gedanke eine Rolle, dab der fur die Christen negative Ausgang der Schlacht und Untergang des Reiches eine von Gott schicksalhaft beschlossene Sache war und sich deshalb auch der heldenhafteste Kampf als nutzlos erweisen mußte. Vielleicht hat auch die in Il.103 zum Ausdruck kommende Vorstellung einer gottlichen Strafe fur die Glaubenslosigkeit der Menschen eingewirkt. - In SbNU XIIV,101 mit dem Titel "Majka i ubitijat 1 sin" ist praktisch nur das Lied vom Tod der Mutter der Jugoviken (Vuk II 47), kombiniert mit dem Thema aus Bog.2, daB der sterbende Held Milos seiner Schwiegermutter Milica Geld fur inre Tochter mitgibt, nacherzahlt, doch wurde es inhaltlich und in seiner ganzen urspringlichen Dramatik verstimmelt:

Ein Rabe bringt an den Hof des Damjan die Nachricht von dessen Tod auf dem Kosovofeld. Die Mutter, versteinert vor Schmerz und unfuhig zu weinen, fuhrt ein Pferd aus dem Stall und reitet auf das Schlachtfeld. Sie watet bis zum Knie im Heldenblut und dreht 3000 KOpfe um, bis sie endlich die Leiche inreo Sohnes Pindet. Sie greift unter sein Wams und zieht drei Gurteltaschen voll Gold hervor. Damit nimmt sie sich, nach Hause zurlackgekehrt, einen Knecht:

Pa ucani rataj da ja slusa -

Sedem godin za sedem kesii.

Die Realistik des Alltagslebens hat diesen so unheldisch anmutenden Schluß geprägt, während Vuk II 47 damit endet, 
daß das Herz der Jugovicen-Mutter endlich vor Schmerz zerspringt, als zwei Raben die abgehauene goldberingte Hand ihres Sohnes Damjan vom Schlachtfeld zum Hof bringen. SbNU XIIII,261 mit dem Titel "Izgraždane na DeCanskija manastir" stellt offensichtlich eine Kontamination der Sujets Vuk II 45 "Propast carstva srpskoga" und Vuk II 34 und 35 "Zidanje Ravanice" dar:

Auf Anraten des hl. Elias läBt Zar Lazar das Kloster Decani erbauen (das in Wirklichkeit 1327-35 von Konig Stefan Uroß "Decanski" gebaut wurde), weil er so "car nebesen" werde und ein "carstvo dưlgovedno" gewinne. Die Bauleute werden im Auftrag Lazars von Juže Brankovic ausbezahlt, doch nur sechs Jahre lang, denn das Geld fur die lubrigen drei Baujahre behält Juže betrugerisch fïr sich. Nach Fertigstellung des Baus wird das Kloster im Beisein Lazars eingeweint. Als der Zar von dem Betrug Južs erfuhrt, verteilt er sein ganzes Vermógen unter die Leute. Der hl. Elias sendet Lazar einen Brief, in dem er ihm mitteilt, Lazar werde am nuchsten Morgen auf Kosovo den Tod finden, die rurken werden sein Reich erobern und Lazar werde Zar im Himmel werden.

Vielleicht hat die Vorstellung vom Verrat des Vuk Brankovic bei der Kosovoschlacht seine negative Rolle in diesem Lied beeinfluBt. - Kad.176 scheint Elemente verschiedener Kosovo-Liedbmachstucke (Vuk II 49) zu enthalten, die sekundar umgestaltet wurden:

König Lazar ladt seine vier Schwiegersobne, namlich "ajduk" Brankovic, Milos Kobilic, Milana Toplika und Ijutica Bogdan, zu sich ein. Als sie an der Tafel sitzen, trifft von Sultan Murad ein Brief ein, worin er Lazar auffordert, entweder mit einem Heer gegen die Turken in die Schlacht zu ziehen oder freiwillig die Hauptstadt Prizren zu ubergeben und Steuer fur sieben Jahre zu entrichten. Lazar ist in groBer Bedrängnis und weib sich keinen Rat, doch seine Gattin rät ihm, Hilfe von Seiten der vier Schwiegersöhne, nämlich ein Heer von viermal 1000 Mann, zu verlangen. Lazar befolgt den Rat seiner Gattin, und bald treffen die gewlinschten Krieger ein. Einer der vier Schwiegersohne jedoch, Brankovic, Ubt Verrat: Er fordert von Lazar 6000 gepanzerte Soldaten und geht samt diesem Heer zu den Turken Uber. Da zieht Milos mit dem ubrigen Heer gegen die Tirken und Brankovic zu Felde und macht den 
grobten Teil des turkischen Heeres ohne Schwierigkeiten nieder, die gepanzerten Truppen aber bezwingt er nicht, sondern wendet sich an sie mit den Worten:

Cuete 11 zes iljadi oklopnikal

Kojto u vas bel Mechmet,

Bel Mechmet 808 bel mustak?

Da izlezne bitka da pravime.

Mechmet mit dem weiBen Bart tritt gegen Miloz auf, doch dieser will nun nicht mehr kämplen, weil er vorher einen Traum gehabt hat, worin ihm bedeutet murde, daß die Turken laut höherem beschlub sein Land unterwerfen werden. Deshalb sagt er zu Mechmet:

Sverbava se naseto carstrol

I vi Cete carstro da derzitel

Der Iiedschlus ist offenbar von dem Sanger in neuester Zeit angefugt worden:

Milor legt seine "Uniform" ab und fugt sich in sein Schicksal. Die Turken nehmen ganz Bulgarien und Serbien ein, un volle 500 Jahre darin zu herrschen. - Und schlieblich:

Eve stana dve godini vreme, Odkak se e Bügarija izbavila.

Izbavil e car Alesandrija,

Car ne stara Rusija.

In diesem Lied sind die Motive der Rivalitat zwischen Lazars Schwiegersohnen (hier allerdings durch Einbeziehung eines Milos-Wahlbruders sowie Ljutica Bogdans auf vier erhöht!), des Sultansbriefes, des Gastmahles vor der Schlacht, des Verrats von Brankovic und der Heldentat des M1loz (hier allerdings als enorme Kampfleistung dargestellt) miteinander verbunden, wobel der AbschluB des Liedes wieder, wie oben, dadurch bestimnt wird, daB der Hauptheld auf christlicher Seite, durch einen Traum dazu aufgefordert, resigniert und sein Land den Eroberem Uberlabt. - Das kurze Lied Sapk.286, eine mehr lyrische Hinwendung an den Vogel des Schlachtfeldes, den Raben, der sich von Aas ernahrt, enthalt nur die Aufforderung an den "schwarzen Vogel", er möge nicht vor Hunger und Durst - auf dem Stein sitzend krächzen, sondern auf das Kosovofeld fliegen und seinen Hunger an weibem Heldenfleisch und seinen Durst an schwarzen Heldenaugen stillen. 
Langere, epopbenartige Lieder Uber die erste Kosovoschlacht im maz.-wbulg. Raum sind SbNU XIIII,264, Kad.177 und SbNU III,85, die alle drei einen relativ jungen Eindruck machen, d.h. Irluhestens im 18.Jh. zugewandert sein durften. Das Lied SbNU XIIII,264, worin die urspringlich Ubernommene Handlung sekundar an manchen Stellen gezundert wurde,kann wegen seines Umfangs - genau wie auch die beiden anderen Lieder - nicht in seinem genauen Inhalt, sondern nur in seiner Motivfolge wiedergegeben werdens

Car Lazar, der mit Milica beim Abendessen aitz $t$, wird durch eine Falkenbotschaft vom tberfall des zahllosen Turkenheeres, dem Untergang des Reiches und seinem bevorstehenden eigenen Tod unterrichtet; Milica bittet darum, Lazar mbge ihr vor dem Wegreiten nach Kosovo einen ihrer neun Brlder (worunter außer Jugovidi Bozko falschlich auch Milus Kobilidin und Janko Kosanovid genannt werden1) dalassen, worauf der Zar meint, Milica solle die Helden am nuchsten Morgen selbst darum bitten; keiner der Bruder erfult Milicas Bitte, 80 daB die Zarin weinend zurlakbleibt; Ritt des Zaren mit seinen sieben Wahlbrlidern und dem Heer zum Sohlachtfeld; Aufruf des Zaren, einer der Helden moge mit 12000 Mann den Tlirken Einhalt gebieten; Juze Brankovide erklart aich dazu bereit, liefert jedoch das Heer den Tlirken aus; nach der bis zur Abenddrmmerung dauernden Schlacht halt Lazar ein Abendmahl ab, wobel Juze Brankovide Lazars Wahlbruder Milus des Verrats bezichtigt, worauf milus schwort, er werde dem tirkischen Sultan Schweinespeck in den Nund stecken (eine aus der skx. Tradition bekannte Geschmacklosigkeit des Sungers(), ihn toten und dann selber den Kopf verlieren; Juxe unterrichtet den sultan heimlich vom Kommen viluss und rat ihm, nicht die Hand, sondern den Stiefel zum KuB hinzuhal ten; Milus dringt in das Sultanszelt ein, verletzt den Sultan todilich, flieht, kehrt zurlkck, um Murad Schweinespeck in den mund zu stecken, und plieht erneut, verfolgt von den Turken auf Anraten eines alten Weibes stellen die Verfolger auf der Brlacke Schwerter auf, Milo fullt vom Pferd, verflucht die Ratgerin der Thiken, worauf diese versteinert, und wird in das Sultanszelt gebracht; der Sultan ist noch am Leben, laBt $81 \mathrm{ch}$ von Milus die Hand kllssen und rihmt ihn als "junak nad junaci"; Milus wird von zwei Mohren getötet und stirbt gemeinsam mit Murad; inzwischen tobt der Kampe zwischen dem christlichen und dem turkischen Heer; ein Mohr tötet Zar Lazar und wird 
von Bozko Jugovili niedergemacht, worauf der Verräter Juže Brankovice Bozko, Janko und seinen Wahlbruder Ivan totet; das serb. Heer wird vernichtend geschlagen; ein Falke bringt Milica die schriftliche Nachricht vom Ausgang der Schlacht; der Diener Gulabina kommt toddich verwundet $z u$ Milicas Hof, berichtet von der Schlacht und dem Verrat des Juze Brankovice, ryt der Zarin zur Verkleidung und Flucht und stirbt, bevor ihm Milica noch die Wunden waschen konnte.

Wie aus diesem Handlungsverlauf ersichtlich ist, sind hier fast alle neueren, aus der serb. Uberlieferung ab dem 18.Jh. bekannten Motive der Kosovotradition enthalten, nur fehlt die Konfrontation von Lazar und Milos (hier fäschlich in der Rolle von Wahlbrüdern, und nicht Schwiegervater und -sohnl) im Sultanszelt, ihre Hinrichtung und ihr gemeinsamer Tod mit Murad, verbunden mit Miloss Bitte um eine seiner Vasallenstellung angemessene Bestattungsordnung (Lazar neben Murad und Milos zu FuBen seines Herm). Dies gilt auch fur SbNU III,85, das folgendes Handlungsschema zeigt:

First Lazar sitzt mit seinen vier "Dienern" Kubiliki Milus aus Prizren, Kusace Ivana, Toplica Milana und Banu Gulebanu an der Tafel, als ein Brief von Sultan Murad eintrifft, worin Lazar zum Entocheidungskampe aufgefordert wird, damit das verarmte Volk nicht langer zwei Herm Steuer zahlen mllsse; Lazar gibt Milus die Schuld an diesem Brief : er, der von einer Stute gegkugt worden sei (ein Vorwurf, der in der serb. Uberlieferung von der Gattin des Vuk Brankovic gemacht wird!), habe den christlichen Glauben verraten und werde den Zaren an die Tlirken ausliefern; Milus schwort daraufhin, er werde niemals Verrat am chriatlichen Glauben uben, sondern zum Zelt des Sultans vordringen und ihm Schweinespeck in den Mund stecken; als Milus losreiten will, wird er von Ivan Kusače davon abgehalten mit der Begrindung, Milus verstehe die turkische Sprache nicht und solle daher lieber ihn zu Murad gehen lassen; Ivan Kusace erreicht das Zelt, wird zu Murad vorgelassen, stellt sich als Gesandten aus Anatolien ("Anadola") vor und fragt, ob der Sultan noch Truppen brauche, was Murad bejaht; im Sultangzelt befindet $81 \mathrm{ch}$ Vuk Brankovic, Lazars Schwiegersohn, als Verbundeter Murads; Ivan berichtet Milus, das tiurkische Heer sel unvorstellbar groB, und Brankovic mit all seinen Leuten befinde sich - als Janitgcharen verkleidet - darunter: Lazar lbBt geine vier "Diener" mit Panzern ("ut tel upleteni") ausstatten und schickt sie in den Kampf, 
wo sie so viele Turken niedermachen, dab der Sultan den Mut verliert und sich zurluckziehen will; die vier Helden sind auf dem Rlckweg, als Milus sich plotzlich seines Schwurs erinnert: Er eilt zum Sultan zurlack, schlagt ihn in zwei Teile und steckt inm Schweinespeck in den Mund verfolgt von den Turken flieht Milug, wird aber auf Anraten eines alten Welbes durch aufgepflanzte Schwerter auf der Brlucke zu Fall gebracht und nach Kosovo geschafft; dort graben ihn die Turken bis zu den Knien in die Erde und schlagen drei Tage und Nachte auf ihn ein, ohne inm schaden zu kónnen; schlieBlich labt Milus sie seinen Panzer mit einem unter dem Schnurrbart. verborgenen Schlussel offnen; Milus wird get8tet und zur Rechten des Sultans begraben, doch wird eine Mauer zwischen den beiden errichtet; Miluss drei Wahlbruder kehren zu Lazar zuruck und raten ihm, ein moglichst grobes Heer zu sammeln, um Serbien befreien zu können; Lazar bittet daraufhin unter anderm Stefan von Uslik, er moge zur Schlacht kommen; Stefan macht sich mit seinem Diener Purvozor auf den Weg, gelangt zur Sitnica, die er vom Blut der gefalienen Krieger Lazars rot und voll von Heldenmitzen, darunter auch Lazars Mutze, findet; in heldenhaftem Kampl schlagen sich Stefan und Purvozor zum Zelt der turkischen Befehlshaber durch, wo der Diener von einem Pfeil des verruterischen Brankovid getroffen wird; Stefan verlabt daraufhin das Schlachtfeld und flieht mit lazars Witwe, ihren beiden sohnen und der Furstenkrone in das "deutsche Land" nach Wien ("ViJana") zu Kaiser Joseph; mit Unterstutzung des Kaisers schlagen die herangewachsenen Flirstensohne die Tlirken und nehmen den vaterlichen Thron ein; die endglitige Befreiung Serbiens von der Tlirkenherrschaft gelingt aber erst mit Hilfe Kara G'orges.

Unter Stefan von Uslik ist nicht, wie Vakarelski 96 meint, Lazars Sohn Stefan Lazarevic zu verstehen, sondern es handelt sich eindeutig um des Motiv des zur Schlacht zu spat kommenden Stefan Musio ( $\nabla g l$. Vuk II 46), dessen Name eben in Stefan von Uslik geandért wurde. Interessant ist der LiedschluB, wo der sanger eine Brlicke zwischen der schlacht vom Jahre 1389 und dem ersten serb. Volksaufstand 1804-12 unter Karadorde geschlagen hat. Mit Kaiser "Josif" lat wahrscheinlich Maria Theresias reformfreudiger Sohn Joseph II.(1765-90) gemeint. - Das letzte umfangreiche wbulg. Kosovolied 1st Kac.177. Es hät sich in seinem Handlungsab- 
laue sehr stark an die Motivfolge in SbNU III,85 und mus daher nicht nacherzahlt werden. Am Schlub heibt es, ohne einen Bezug zu Kaiser Joseph von Osterreich oder Karatorde herzustellen, die beiden Sohne Lazars lebten funfzis Jahre im "deutschen Land" und eroberten dann ihr Vaterland Serbien zurlick.

Wie wir aus den bisher behandelten Liedern uber die erste Kosovoschlacht ersehen konnten, 1st der gröbte Tell der Sujets erst in jungerer Zeit nach Mazedonien und Westbulgarien zugewandert, denn hier treffen wir solche Motive an, wie sie in der skr. Uberlieferung erst seit dem 18.Jh. bestehen; ulter durfte allerdings das mit Kosovo verbundene Motiv des prophetischen Traumes von Königin Milica sein. vielleicht wurde das Kosovo-Sujet zu der Zeit in Mazedonien und Westbulgarien ubernommen, als in der skr. Uberlieferung noch ein zusammenhängendes, epopöenartiges lied bestandz die drei zuletzt behandelten umfangreichen ifieder aus Westbulgarien sprechen fur diese Vermutung. Die Erinnerung an die zweite Kosovoschlacht 1448 18t ofLenbar schwächer als die Uberlieferung zu 1389. Schon Soerensen 97 machte (die Langzeilenlieder Bog.17, 19-20,25, 32 und 46 betreffend) die Beobachtung:

Die wirklichen Erinnerungen an die ungarische Kosovoschlacht sind sehr durftig, sie beschränken sich darauf, dab dort helden gefallen, andere geschlagen und fluchtig geworden sind, am ehesten bieten sie noch Erinnerungen an Sekul's Heldentod auf Kosovo $(\ldots)$. Alles macht einen zufallim gen fragmentarischen Eindruck; nirgends wird ein zusammenhingendes Bild vor uns entrollt.

Motive dieser Kosovolieder, gebunden an Jankula und Sekula, sind wahrscheinlich schon Ende des 15. Oder im Laufe des 16.Jh. nach Mazedonien und Wostbulgarien gelangt, als die Erinnerung an die berihmten Turkenkampfer noch ganz lebendig war. Eine Reminiszenz an János Székelys Tod auf dem Kosovofeld ist z.B. in Sapk.441 und Mil.245 erhalten. Sapk.441 hat folgenden Inhalt:

Es tanzen die Madchen in drel Reigentanzen: Der erste wird von Sekulas Gattin Nevenka und die 
beiden anderen von Sekculicas Schwagerinnen gefuhrt. Da ruft die Schwiegermutter Sekulas junge Prau naoh Hause, weil ein sprechender und klagender Vogel angekommen se1, den sie nicht verstehe. Nevenka kehrt nach Hause zurlick und erfuhrt aus der Vogelbotsohaft, das Sekwla auf Kosovo gefallen 1st. Sekulica melnt darauf, sie werde zwar unter Umotinden einen besseren Gatten und eine bessere Schwiegermutter bekommen, wenn sie wieder heirate, Sekulas Mutter aber keinen Sohn mehr. - Gemeinsam reiten die beiden Frauen auf das Schlachtfeld, holen Sekulas Le1che heim und bestatten ihn. Nevenka aber nimmt einen anderen Mann.

Eine Ghnliche Vogelbotschaft, nur hier auf die Gattinnen dreier Helden bezogen, finden wir in Mil.245:

Vor den Toren Budims werden drel Reigentunze, gefuhrt ron Angelina, Jankulica und Sekulica, getanzt. Da kommen dre1 Adler vom Schlachtfeld hergeflogen: Der erste trugt das abgeschlagene Haupt Bogdans und setzt sich damit Angelina aus die Schulter; der zweite bringt Jankulica Jankuls hand und der dritte tragt fur Sekulas Gattin Sekwlae Bein in einem gelben Stiefel herbel.

Obwohl Jankula nicht auf Kosovo gefallen 18t, wohl aber eine achwere Niederlage erlitten hat, ist er hier mit Sekula und einem (unhistorischen) Bogdan zusammen als einer der 1448 Umgekommenen vorgestellt. Das Motiv der von einem Vogel uberbrachten Hand des toten Helden kennen wir schon aus Vuk II 47, dem Lied rom Tod der Jugovićen-Mutter. Auch in Mil.97 fall Jankula auf Kosovos

Jankula futtert sein plerd mit dem feinsten Stroh und Weizen, gibt inm guten Wein zu trinken, last es beschlagen und striegeln, zkumt es mit goldenem Zaumzeug auf und sattelt es mit einem seldenen Sattel, was das. Pferd zu der Prage veranlast, ob Jankula es verkaufen oder tauschen wolle. Jankula aber erklart, er habe aus der Walachel einen Brief erhalten, worin er zur Teilnahme an der Schlacht auf dem Kosovofeld gerufen werde. - In Kampf wird Jankula von einer Xugel getroffen und stirbt, worauf sein treues Pferd die Totenwache halt:

Konja zastana nad nego, Konja divan da mu rine. S grita mu senka dinere. S opaske muhi branese, Bin drobnl suldzi roneše, Tam 1 on do nego padna, 
Do nego duša predade.

Ein ähnlich rlihrender und schmerzlicher Ton wird in Mil. 115 angeschlagen, wo sich Sekulas Mutter bei einer Gruppe junger Fuhrleute erkundigt, ob sie Sekulas Grab bei Kŭpina (Kupinovo?) gesehen hatten. Die Fuhrleute kennen das Grab und beschreiben es der Mutter so:

A na glava kurstetna bajraka, Na bajraka dvanaeset kưrsti, A na kirsti kamni besceneti.

Zusammenfassend läßt sich also sagen, daB sowohl die Lie.der von der ersten wie auch der zweiten Kosovoschlacht in der maz.-wbulg. Volksepik unbedingt zur Sekundarschicht gehören, wobei die blinden sanger in der Vermittlung des Liedgutes eine wichtige Rolle gespielt haben durften. Zur alteren, vielleicht schon Ende des 15. bzw. im Laufe des 16.Jh. zugewanderten Liedachicht gehören offensichtlich die Lieder, die Erinnerungen an die zweite Kosovoschlacht enthalten. Der mittleren (16./17.Jh.) Liedschicht gehören wahrscheinlich die Lieder an, die das Motiv des prophetischen Traumes von den fallenden Gestimen, urspringlich an den Fall Budims gebunden, auf die Kosovoniederlage ubertragen haben ( $v$ gl. dazu als Vorbild die Lieder Bog.28 und Bog.1, V.71-83). Die zum Teil kurzen, zum Teil aber auch epopónhaft langen Lieder, die die Thematik der ersten Kosovoschlacht beinhalten, durften erst in der zweiten Halfte des 17., wahrscheinlich aber im 18.Jh. in den maz.-wbulg. Raum gelangt sein. 
Nachdem im Vorhergehenden einige typische Sujets der Sekundarschicht in der maz.-wbulg. Volksepik besprochen wurden, soll nun ein sehr umfangreicher sujetkreis behandelt werden, bei dem wir m.E. eine mehr oder weniger enge Verquickung der Sekundärschicht mit einer angenommenen archaischen maz. Primärschicht feststellen können.

Die Hauptschwierigkeit liegt hier methodisch gesehen darin, daß ein Uberaus reiches gesantsüdslavisches Liedmaterial fur dieses Sujetfeld zur Verfugung steht, dessen verschiedene Motivketten häufig in so enger Beziehung zueinander vorliegen, daß sich gewisse Uberschneidungen bei der Untersuchung kaum vermeiden lassen. Ältere, weniger alte und jungere Elemente sind hier verzahnt, und es soll der versuch gewagt werden, fur das weitverzweigte Material eine - wenigstens relative - Chronologie aufzustellen und damit gewisse gltere und jungere Schichten in den maz.-wbulg. und skr. Erzahlliedern zu trennen.

Thematisch gesehen handeit es sich hier vor allem um zwei große Motivkreise, namlich un Lieder, die die Hochzeit eines Helden nach dem Bestehen von Freierspröben beinhalten, und um Lieder mit Drachenkampethematik und deren zahlreichen Ableitungen.

\section{1 BRAUTGEWINNUNG NACH BESTEHEN VON FREIERSPROBEN}

Wenn Žrmunokij behauptet, "die epischen Sagen uber die Brauterwerbung gehoren bei den meisten volkem auf allen Entwicklungsstufen des Epos zu den beliebtesten" 98 , so können wir inm - auch was den sudslavischen Raum betrifft voll beipflichten. Brautwerbung, Brautfahrten und damit eventuell verbundene Wettkampfe oder sonstige Brauterrin- 
gung nehmen in den oldslavischen Liedern einen breiten Raum ein. Das Sujet ist sittengeschichtlich besonders interessant, weil sich hierin die verschiedenen Entwicklungsphasen der Ehe und Familie widerapiegeln. Die ultere Porm der Brautgewinnung durfte der Brautraub sein, der haufig so vonstatten geht, daB der Held ein Madchen am Brunnen um Wasser bittet, sle aber statt des dargebotenen Bechers selber packt und hinter sich aufs Pferd wirft, um mit ihr loszureiten (vgl. Vuk II 81; VII 8; Mil. 147; Bog.117; Jastr.,79; Verk.-Lavr.23; Kad.125,179; SbNU 'II,116; XIVIII 22 usw.); oder aber er entfuhrt das Madchen im Auftrag eines anderen, der sich zu diesem Unternehmen selbst nicht befuhigt fuhlt ( $\nabla$ gl. Vuk III 23; SbNU I,64 usw.); oder aber die Braut wird - in novellistischer Manier - auf die Weise entfluhrt, dab der Brkutigam oder eine von ihm bestimmte Person bzw. ein "Ruckentfuhrer" sich als Kaufmann auf einem Kaufmannsschiff bzw. -wagen auf den Weg zu dem madchen macht und sie durch ein besonders attraktives Warenangebot auf sein Gefkhrt lockt und mit seiner Beute losflahrt ( $\nabla$ gl. Vuk I 580; II 100; V 709; Bog.38,117; aH I, 82; $I_{2}$ 87; Nikolie I 46; Mil.116; Il.71,88; Sapk. 435; Jank.255; Verk.314; Jastr.,59; Stoin TV 78; SbNU XXI, 47; Rod.Napr.II,268 usw.) ${ }^{99}$. Hierzu gibt es eine besonders reiche Iiteratur 100 .

Eine Brautentfunrung mit Einverstandnis der Braut 1st sehr wahrscheinlich eine jungere stufe (z.B. Vuk III 22) und kommt in alteren Iledern weitaus seltener vor.

Neben diesen Formen des Brautraubs, dessen Blemente in die archaischen Zeiten der Raubehe zurlickreichen durften und aus den exogamen Verhaltnissen der patriarchalischen Gent1lordnung ( $v$ gl. Zirmuskif,41) resultieren, gibt es eine jangere Art der Brautgewinnung in der Porm, daB der Preier beim Brautvater oder -bruder in Diensten steht, $\dot{d} . h$. eigentlich eine gemabigte Porm des Brautkaufs ( $\mathrm{gl}$. EH 50; Vuk II 95; III 22; Stojad.I 7; Petran.II 54-56; Horm.I 18 usw.) 10 !

Neben diesen Brautgewinnungssujets gibt es den weltaus um- 
fangreicheren Kreis der Iieder, in denen die Hochzelt des Helden nach dem Bestehen von $F r$ e 1 e $r$ p $r$ b e $n$ erfolgt. Hier handelt es sich um Typen der Brauterwerbungssagen, die "das Epos mit dem Helden- und Zaubermärchen verbinden" 102 . Der Held hat in diesem Sujet marchenhaft-phantastische Hindernisse auf der Brautfahrt zu uberwinden bzw. - bei der Braut angekommen - schwierige Freiersproben zu bestehen, wobei er allein oder mit Hilfe anderer unlbobar Anmutendes 188t. Kravcov charakterisiert diesen Tatbestand treffend, wenn er sagt: "Als Grundlage fast jeden Sujets dient die heroische Tat des Helden. Sel es die Hochzelt des Helden, d.h. ein novellistisches Sujet, oder sei es ein phantastisches Sujet: immer ist es heroisch" 103 . AuBer dem schon erwahnten Werk von Frings und Braun Uber Brautwerbung bespricht Zirmunskif (S.39/40) noch Iobodas Untersuchung uber das Brautgewinnungsoujet in den russischen Bylinen und Geisglers als blober Motivkatalog bzw. symchronische Gegenuberstellung zu wertende Arbeit uber die Brautwerbung in der Weltliteratur ${ }^{104}$ und fordert glelchze1tig eine "historisch-typologische Beschreibung und Brforschung der epischen Sagen uber die Brautwerbung in breiter historisch-vergleichender Sicht," - und zwar "unter notwendiger Hinzuziehung des vergleichend-ethnographischen Materials der Hochzeitsbrauche und -sitten sowie der gesellschaftlichen Sippen- und Pamilienverhaltnisse"105. Diese Maxime kann in dieser Arbeit nicht erfullt werden, we1l es sich hier ja nicht un eine Monographie uber Brautwerbemarchen und -lieder handelt, sondern in erster Iinie die Prage der Chronologie in der sudslavischen Epik beleuchtet werden 8011 .

Es moge der Hinweis gentrgen, daß sich tatskchlich zahlreiche Parallelen im hochzeitlichen Brauchtum der Sudslaven und Ihren Brautwerbeliedern finden. So ist z.B. das Brauthaus gewbhnlich verschlossen, wenn der Brkutigam mit den Svaten die Braut heimruhren will, urspringlich wohl deshalb, damit "den nachdrangenden Damonen der Eintritt verwehrt werde" 106.

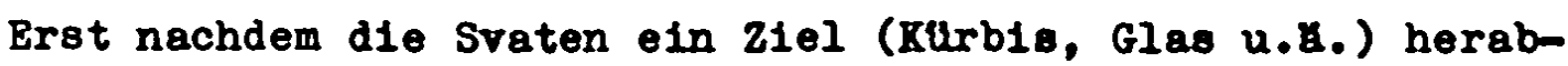


geschossen haben oder eine Ablösung an der Tür (Reminiszenz an die Kaufehe?) gezahlt haben, wird von innen geoffnet. Schneeweis vermutet Dämonentäuschung in dem Brauch, dab zunächst eine falsche Braut vorgefuhrt wird, wăhrend Volkov an "verojatno razni chitrosti pri purrvobitnata prodažba $i$ kupuvane na nevjastata" 107 , also an verschiedene Listen beim urspringlichen Brautkauf, denkt. Ich m8chte mich hier der Meinung von Schneeweis anschließen, denn auch der Brauch, daß die Svaten die Ausrede vorbringen, sie wollten in dem Haus ein geflohenes Wild oder verirrtes Schaf suchen, spricht für Dämonentäuschung. - Dämonen halten sich dem Volksglauben nach mit Vorliebe an Brlicken auf, deshalb ist hier besondere Vorsicht geboten ${ }^{108}$. Wir werden spater sehen, welch wichtige Rolle in den Erzahlliedern mit Brautfahrtthematik das Passieren von Bricken hat. Der im Gebiet der ehemaligen Militargrenze vorkommende Brauch, dab der Hochzeitszug durch ein quer uber den Weg gespanntes Seil aufgehalten wird und erst nach Abgabe eines I8̈segeldes passieren darf ${ }^{109}$, bezweckt sicher urspringlich das Aufhal ten von Dämonen; dafur sprechen die apotropłische rote Farbe des Bandes und die haufige Maskierung der Aufhaltenden. - Hier vergleiche man das spätere Kapitel, in dem die Rede von epischen Liedern mit Brautfahrtthematik sein wird, in denen der Hochzeitszug auf dem Weg durch irgendein Ereignis (Uberfall eines oft drachenahnlichen Arabers, Drachenkampf, Vilenschub u.u.) unliebsam aufgehalten wird.

Lieder mit Brautfahrtthematik, in denen weder Freiersproben bestanden werden mussen, noch ein Uberfall oder sonstige Komplikationen unterwegs erfolgen, sind in der slldslavischen Volksdichtung in der Minderzahl und scheinen in den meisten Fallen verderbte Varianten zu sein (vgl. EH 92; SbNU XLVI, 7; XUVI 5 u.a.). In der uberwiegenden Mehrheit der Fälle ergeben sich verschiedene Schwierigkeiten bei der Brautgewinnung, sei es daB die Braut sich tot stellt und in balladesk-schwankhafter Weise (durch drei Proben, indem der Brłutigam der "Toten" zuerst Eis, dann eine 
Schlange auf die Brust legt und ihr schlieblich in den Halsausschnitt fabt; danach gesteht das Madchen seiner Mutter, die dritte Probe sei am schwersten auszuhalten gewesen) vom Brautigam gepruft wird (vgl. Bog.95; Vuk I 727; III 78,79; V 499; MH II 13 ; Mil.69; Sapk.459; Mich.255; Mich.132; SbNU II,59; XIIV,57 usw.) ${ }^{110}$ oder daB der Brautigam nach der Ruckkehr des als Werber Pungierenden prahlerischen Vaters inzwischen durch Krankheit entstellt ist und durch einen anderen, schönen jungen Mann ersetzt wird, woraus sich naturlich Streitigkeiten ergeben ( $v g l$. Typ AaTh 855: Substitute Bridegroom - ISSF VI,181,Nr.20b;Vuk II 88; III 80; MH I 68; Mil.84; Males. 159; Milut.70; Kad. 130; Šapk. 389; SbNU XVI-XVII, 175; XLIII, 139,142; XLIX, 35 usw.), und andere Sujets mehr.

In den meisten Fullen jedoch bestehen die zu uberwindenden Schwierigkeiten in Freiersproben ${ }^{111}$, die entweder von Brautvater, Brautmutter, Brautbridern oder schlieblich von dem Madchen selbst gestellt werden. Kennzeichnend fur diese Brautgewinnungslieder ist die bewußte Werbung des Helden, also nicht die mehr zufallige oder unfreiwillige Brauterringung. Der Brauterwerb bildet das Hauptthema der Erzahlung, so daß wir unsere Lieder mit Lutz Mackensen ${ }^{112}$ als "eigentliche Brauterwerbungsmärchen" - allerdings hier in Form epischer Lieder - bezeichnen kornnen. Eine relativ alte Iledstufe scheint in den Liedern vorzuliegen, wo der Brautvater einen Dreikampf als Freiersprobe zur Bedingung macht, dem Brautigam aber aus den Reihen der Hochzeitsgăste ein Helfer zur Seite steht, der die drel Proben fur ihn besteht. Solche epischen Lieder atmen echten hofischen Geist, ihr Verhaltnis zum Heldenmärchen jedoch durfte schwer zu bestimmen sein. Mackensen meint, die hrfischen Epenstoffe haben mit ihrem feststehenden Brauterwerbungsschema und inrem Motivschatz die Marchengruppe stark beeinflußt. "Andererselts bilden diese Epen keinen Ausgangspunkt schlechthin fur unsere Brautwerbungsmarchen, sondern stellen im wesentlichen Sammelbecken fur bltere Motive und Motivketten dar, die zum Tell aup diese Welse 
nach Deutschland gekommen sein mbgen"113. Und weiter : "Die Brautwerbungsmarchen sind also an eich ulter als jene deutechen Epen, die zunkchst von ihnen gespeist murden ( $O b$ sie in Deutschland als volkstumliche Marchen blter waren, ist eine zweite Frage); die Wahrscheinlichkeit von Fllckwirkungen wurde bereits angedeutet und ware naher zu untersuchen. Jedenfalls handelt es sich bei diesem Typ von Brautwerbungsmarchen um Marchennovellen, bel denen literarischer Ursprung geargwbint werden muß".

Der alteste Typ des Wettkampfs ist sicher der zwischen Werber und Braut, wobel sich die Braut als Heldenjungfrau erweist. Solche fulle finden wir nicht nur im germanischen Epos (Siegfried - Gunther - Brinhild), sondern auch im asiatischen Epos (z.B. in der ogusischen Redaktion des Heldenepos "Alpamy") und Marchen (z.B. Im baschkirischen "Nlpamy und Barsyn-chyluu") ${ }^{114}$. Diese Art des Kampfes zwischen Werber und Braut 1st mir aus dem sludslavischen Bereich nicht bekannt.

Im germanischen Bereich besteht der Dreikampl meist aus Steinwure, Speerechleudern und Sprung, bei den Turkv8lkerm aus Pferderennen, BogenschieBen und Ringen, wobel aber ein Ersatz durch primitivere sportliche Splele wie z.B. Steinmurf, Wettlaue, Springen erfolgen kann. - In den slldslaviechen Heldenliedern besteht der der Brautgewinnung vorausgehende Wettkampl meist darin, daB ein Mitglied des Hochzeitszuges stellvertretend flir den Brlutigam die rom Brautvater gestellten Aufgaben l8sts Er beklumpft und besiegt einen vom Brautvater gestellten Recken; er schieBt einen Apfel oder Ring von einem Turm, einer Mauer oder einer Lanze herunter; er uberspringt mehrere (meist neun) nebeneinandergestellte Pferde, auf deren Rluken manchmal noch Lanzen oder Schwerter aufgerichtet sind, um die Gefahr des Uberspringens zu erhohen; und er findet schlieblich die Braut aus einer Anzahl (meist neun bzw. drei) gleichaussehender und -gekleideter madchen durch listiges Vorgehen heraus, - d.h. wir haben hier wahrscheinlich einen urspranglichen Dreikampf (Ringkampf, Schus, Sprung) vor uns, dessen 
erster Bestendteil hkuf1g wegflel und dafur durch olne zusatzliche Preieraprobe - Herausinden der Braut - wettgemacht wurde.

Diese Wettkumple werden, w1e aus dem Polgenden hervorgehen eoll, vor allem im maz.-bulg. Berelch zum Tell stark verindert, d.h. dem mehr buluerlichen M1l1eu angepast ${ }^{115}$ bzw. zum reil durch MArchenmotive erweitert.

Den folgenden drel Unterkapiteln (Bowle mehreren weiteren Kapiteln) sind Varlantenverzelchnieee und Karten vorangeotellt. Die jedem Iled vorangehende arabische iffer lot auf der $\mathrm{K}$ a $\mathrm{I}$ - neben dem Aufzelohnungsort in einem kleinen Quadrat elngetragen: sie bestimit glelchzeltig die Reihenfolge, nach der die Varianten in dem jeweiligen Kap1tel behandelt werden. In Variantenverzelchnis sind nech den Varianten in Klammern, fallo bekannt, das Versmas, die Verszahl und der Aufzelchnungeort der Ileder angegeben. Lleder, deren Aufzelchnungsort unbekannt 18t, fohlen also aue der Karte. Haben mehrere Ileder denselben Aufzelchnungsort, so sind sie in einem enteprechend groben Rechteck zusammengelabt. Ist von einem Iled nur die Aufzelohnungegegend, aber kein bestimmter Ort bekannt, so 18t das numerierte quadrat etwa im Zentrum der betreffenden Iandschaft eingeze1chnet.

4.11 BRAUTPAHRTMÄRCHEN IN IIEDPORY BESTEHEN VON FREIERSPROBEN DURCH EINEN HELFER DES BRT̈UTIGAMS

Bel den olldelavischen Brautfahrtmarchen in Iledforn, bel denen meist ein ungeladener Neffe unerkannt die schwierigen Aufgaben flur eeinen Ohein, den Brautigam, erfullt, handelt es sich melnes Wissens un folgende Varienten ${ }^{116_{8}}$

1 Bog.9 (7/8, 0.R.\& 111 V.8 Dubromik)

2 BOg.26 (7/8, 0.R.\& 74 V.8 Dubrovnil)

3 Kad1C-Miost6 43 (4/6, 112 V.8 Zadar)

4 Jow1t8ch,92 (4/6, 142 V.; Slavonien)

$5 \mathrm{MH} I_{1}, 584$ (Bizcan 26, 4/6,? Karlovac) 
IH $I_{1}, 584$ (Bunjevac $44 ; 4 / 6 ; ?$; Zrinj)

? MH $I_{1}, 584$ (Klaric 16;4/6;?; Karlovac)

8 MH $I_{1}, 584$ (Kovacevic 54;4/6;?; Severín)

9 MH $I_{1}, 585$ (Markovic $82 ; 4 / 6 ; ? ;$ Prozor)

10 MH I $I_{1}, 586$ (Strohal II 15;4/6;?; Stativo)

$11 \mathrm{MH} \mathrm{I}, 586$ (Pericic 49;4/6;?; Sukozan)

12 Istarske 18 (4/6;96 V.s Istrien)

13 H8rm.I 13 (4/6;119 V.; Sarajevo)

14 Strekelj I 245 (4/6;61 V.; Krain,von der kr.Grenze)

15 Nikolic I 42;4/6;?; Syrmien)

16 Vuk II 78 (4/6;298 V.; Gacko)

17 SbNU XII,71 (4/6;215 V.; Blagoevgrad)

18 SbNU XVVI $.2,11$ (4/6;84 V.; Karlov8ko)

19 SbNU II, 130 (5/3;112 V.; Asenovgrad)

20 SbNU XIIX,77 (4/6;398 V.; Graovo)

21 Bezs.I 5 (6-Silber; $110 \mathrm{~V} . ;$ 8stliche MA)

22 SbNU XUIII,178 (5/3;113 V.; Sofijsko).

23 Mich.365 (4/6;52 V.3 Mazedonien)

24 Vurb.359 (6-Silber;227 V.; Berdjansk)

25 SbNU XXXIX,, 64 (5/3;86 V.; mittlere Rhodopen)

26 Malez.158 (4/6;208 V.; Maleževo)

27 SbNU XU,389 (4/6;110 V.; Kamenica)

28 Jank.1 (5/3;97 V.; Jambol)

29 SbNU' VII,112 (4/6;124 V.; Razlozko)

30 Verk.-Lavr.5 (8-17-Silber; $117 \mathrm{~V} . ;$ Mazedonien)

$31 \quad$ M11.57 (4/6;184 V.; Struga)

32 Sapk.516 (6/6;24 V.: Gabrovo)

33 SbNU II, 132 (5/3;58 V.; Smol jansko)

34 SbNU XXXV,251 (6/6;99 V.; nOrdl.Dobrudza)

35 BonX.92 (6-Silber;73 V.; Razgradsko)

36 SbNU XIII, 137 (4/6;155 V.; Sop1jsko)

37 Mich.297 (4/6;17 V.; Mazedonien)

38 Verk.-Lavr.192 (8-14-Silber;95 V.; Mazedonien)

39 SbNU VI.55 (4/4;82 V.; Demir-Hisarsko)

40 SbNU XIII, 135 (3/5;143 V.; Sofij8ko)

41 SbNU XXXV,254 (6/6;uv.; nordl.Dobrudza) 


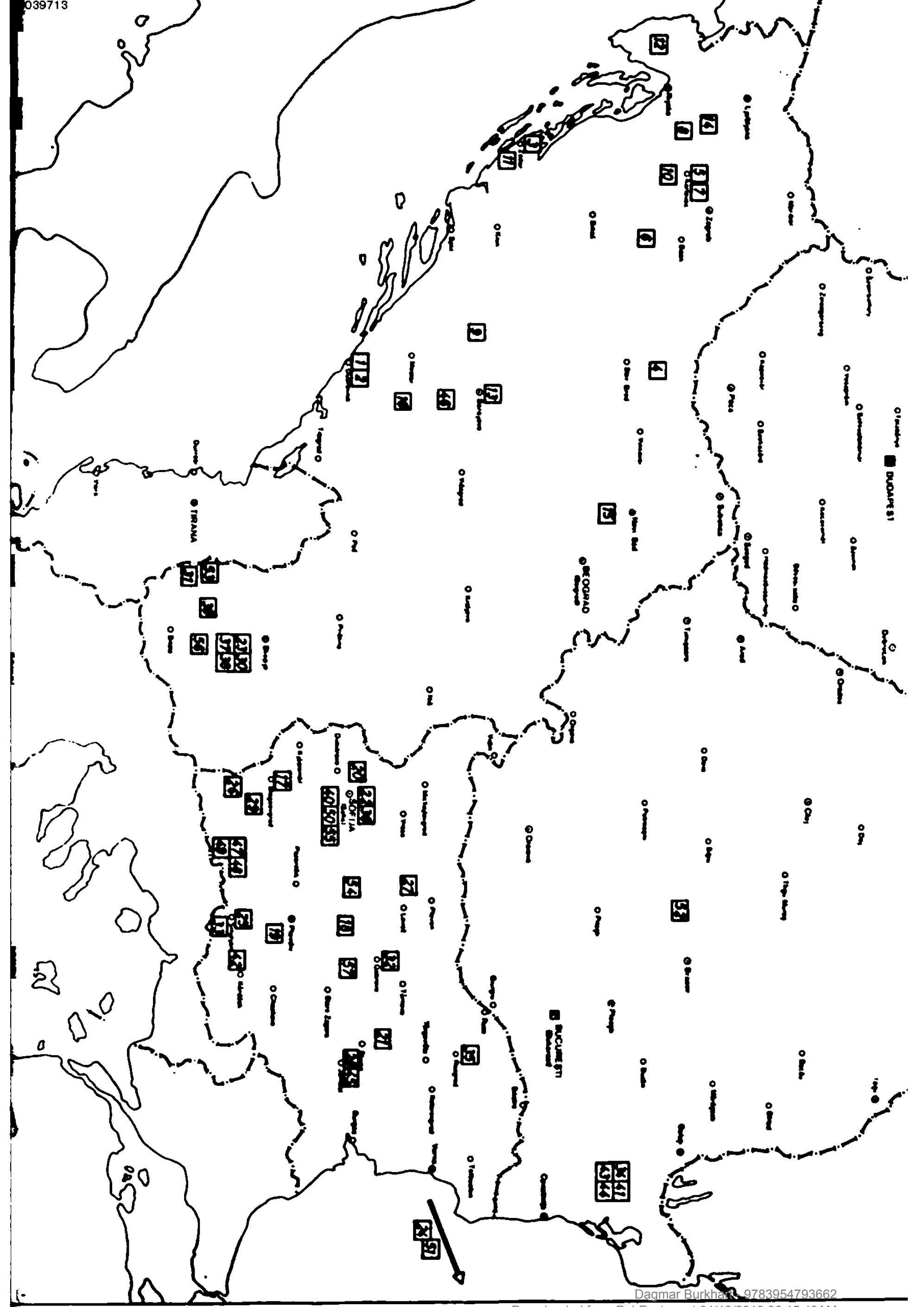


$\because$

Dagmar Burkhart - 9783954793662 


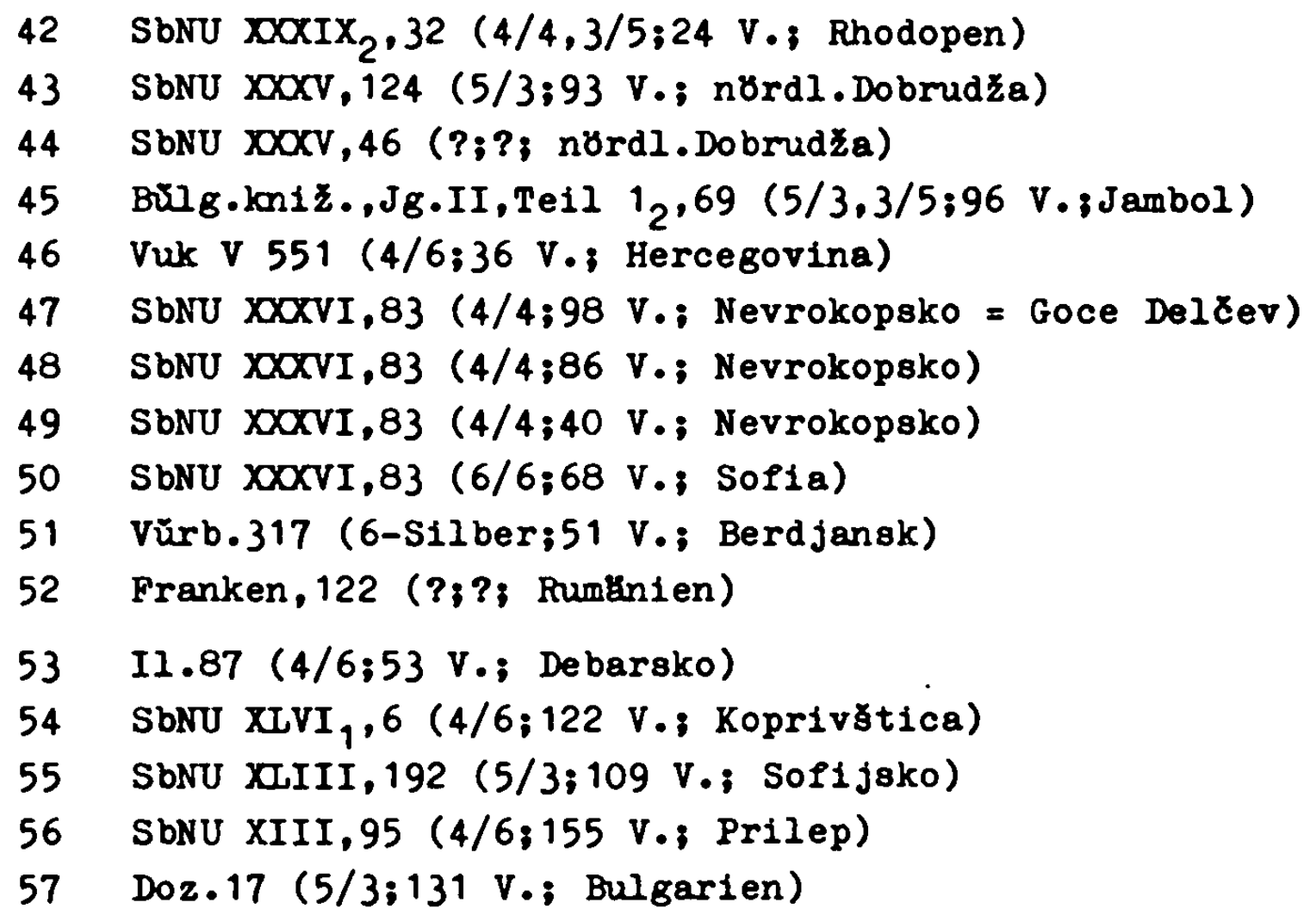

Das ursprlingliche Sujet bzw. die Motivreihe, wie sie aus den besten Varianten $2 u$ rekonstruieren ist, lautet im wesentlichen so:

Ein Held, der Uberall nach einer passenden Braut gesucht hat, findet sie schlieblich in Gestalt der Tochter eines Premdikndischen Herrschers, der haupig als "Lateiner" bezeichnet wird. Der Held halt um die Hand des Madchens an und erhalt vom Brautvater eine Zusage, die mit der Aufforderung verbunden ist, die Braut binnen einer festgesetzten Prist heimzuholen, wobei er aber bestimmte Helden (meist die Neffen) nicht mitfuhren soll, weil diese angeblich starke Trinker und Raufbolde seien. Betrubt sammelt der Held die Svaten und zieht ohne seine Neffen 108. Die Neffen jedoch wundern sich, daB ihr Oheim sie nicht eingeladen hat, und Pragen inre Mutter diesbezuglich. Diese gibt ihren Sohnen den Rat, sie sollten entweder selbst mitziehen oder den dritten Bruder, der schon jahrelang im Gebirge als Hirte lebe und den der Oheim nicht kenne, durch einen Brief(mit der Aufforderung, rasch zur sterbenden Mutter zu kommen) heimzuholen, auszustatten und verkleidet dem oheim nachzusenden, damit er ihn vor eventucllen Intrigen und Anschlagen schützen konne. Dies geschieht. Der Neffe schliebt sich dem Zug 
an und gelangt mit den Svaten zur Stadt, in der die Braut wohnt. Dem Hochzeitszug wird der Ein-tritt verwehrt, weil zuerst schwierige Freiersproben bestanden werden sollen. Keiner der Hochzeitsgäste erklurt sich dazu bereit, nur der Nef$f e$, der allein fur die Lbsung der Aufgaben befuhigt ist, setzt sich unerkannt flur seinen Oheim ein. Die urspringlichen Aufgaben sind Kampf mit einem vom Brautvater gesteliten Recken (dieser Punkt fillt allerdings haufig weg), Sprung luber mehrere Pferde, Schuß auf ein Ziel und Herausfinden der Braut unter mehreren Madchen. -Nachdem alle Proben glucklich bestanden sind, wird das Madchen lubergeben, und die Heimfahrt kann beginnen. Zu Hause angelangt, offenbart sich der hilfreiche Neffe seinem geruhrten Oheim, wobei hbufig eine moralische Schlubsentenz uber den Wert der Verwandtentreue angefugt wird.

Von sekundaren Veranderungen dieser wohl urspringlichen Motivkette wird in Folgenden die Rede sein.

Bel dem flur eine Analyse unumganglichen Variantenvergleich sollen zuerst die skr. Lieder behandelt werden, die zwar verglichen mit dem maz.-bulg. Material - in der Minderzahl sind, dafur jedoch das Liedsujet besser bewahrt habens Die drei gltesten Varianten sind Bog.9, Bog.26 und KadicMiosic 43. Alle drei warden wahrscheinlich vor 1750 aufgezelchnet; alle drei bewegen sich in der Zeilenzahl um 100, sind also kurze Lieder. Die beiden Bog.-Ileder stammen aus der Dubroviker HS vom Jahre 1758 und sind in refrainlosen Langzeilen im Kustengebiet aufgezeichnet, durften aber ihrem Sujet nach - genau wie das Deseterac-Iied bel KacicMiosic - aus dem ungarserbischen Raum zugewandert sein, wofur sowohl die PN wie auch topographische Details sprechen. Bog. 9 und 26 nehmen insofern eine Sonderstellung ein, als sie mit einer Rahmengeschichte versehen sind, die mit dem Brautwerbesujet nichts zu tun hat. AuBerdem besteht hier Janko als Kum (bzw. In Bog.26 eine der Aufgaben ein zwe1ter Hochzeitsgast) die drei Preiersproben fur den Brăutigam, den Konig von Budim, whrend in fast allen ubrigen skr. Varianten, angefangen bel Kacic-Miozic, Janko der Brăutigam 1st und sein Neffe Sekula unerkannt die Aufgaben fur den Oheim erfullt. Doch zunkchst der Inhalt von Var.1,die den den Iledinhalt schon lurz zusammenfasgenden Titel trägts 
"Kad je Janko vojroda udarao Eurla despota buzdohanom"

Der Konig von Budim freit ein Mkdchen aus dem schonen Krubevo. Als Svaten sammelt er seine "ugarska gospoda", als Belstand (vjencan1 kum) nimmt er Janko vojvoda, fur die Nachhut den alten (starac) Despoten turad und Sekula sestricic als Brautfuhrer (djever). Die versammelten Hochzeitsguste sind lustig bis auf einen: Ugrin Janko. Auf die Prage des Konigo nach der Uraache seines Mibmuts erklärt Janko, er konne nicht Prohlich sein, wenn er seinen und des Konigs Feind, den Verrater turad, vor Augen sehe, und er habe gute Iust, sein Schwert zu ziehen. Der Konig befiehlt ihm, davon abzulassen, rat Janko aber gleichzeitig, am nachoten Tag beim Vorbe1ziehen des Hochzeitszugs an den Mauern Smederevos, wo die Despotin Jerina herunterblicken werde, den Despoten am Bart zu packen und ihn mit dem vergoldeten Streitkolben zu achlagen, wodurch Schande mit Schande vergolten se1.- Jankos Laune bessert sich auf diesen Vorschlag hin, und er zieht mit den Svaten nach Krusevo. Die Stadtore sind verschlossen, und von der Mauer ruft die Wache, weder durfe der konig die stadt betreten, noch werde die Braut herausgefuhrt, wenn $81 \mathrm{ch}$ nicht ein Held in Hochzeltszug finde, der den goldenen Apfel von der Stadtmauer herabschiebe. Ratlos sieht der Konig den alten tural an, dieser aber blickt auf Janko, der Pfeil und Bogen nimmt und die Aufgabe erfulit. Janko besteht auch die zweite Probes Er uberspringt zwölf gesattelte Pferde und sitzt dem letzten auf. Die dritte Aurgabe, aus zwolf gleichaussehenden Madchen die Braut herauszufinden, verwirrt Janko zunkchst; er lost das Problem aber dann dadurch, daB er seine seidene Dolama auf den Rasen breitet, zwole goldene Ringe darauf hinstreut, seinen sabel in die Hand nimmt und der richtigen Braut befiehlt, die Ringe anzustecken; wenn eine andere das wagen solite, werde er ihr die Hande abschlagen.Da tritt die Richtige vor, sammelt die Ringe aue, wird von Janko zum Konig gefuhrt und als Braut vorgestellt, dann aber dem Dever Ban Sekula ubergeben mit dér Weisung, er moge die Braut ja gut behuten. Sekula hebt die Braut aufa Pferd, und der Hochzeitszug setzt sich in Bewegung. ile Smederevo mit den Frauen auf der stadtmauer in Sicht kommt, reitet Janko nach hinten, packt murad beim Bart und ochlagt ihn vor den Augen Jerinas mit dem Streitkolben. Jerina klagt um ihren Gatten und schickt Diener zu seiner Rettung. Diese bitten Janko un Schonung flur ihren Herm, die Janko auch gewkhrt, worauf gurad zu Jerina gebracht wird. Die Svaten aber ziehen nach Budim weiter, 
wo ein großes Hochzeitsfest statfindet.

Var.2 mit dem Titel "Zenidba kralja budimskoga od Bana od Kruseva i vojevoda Janko" unterscheidet sich nur unwesentlich von der ersten:

Der Konig von Budim hat um die Schwester des Bans von Krusevo geworben und kommt mit einem großen Hochzeitszug, un die Braut abzuholen. Die Stadttore sind verschlossen, weil die Svaten zuerst einen aus ihren Reihen stellen sollen, der neun Pferde Uberspringt und dem zehnten aufsitzt, was Ugrin vojroda Janko gelingt. Weiter soll ein goldener Apfel von der Stadtmauer geschossen werden, was Mihajlo Svilojevic ausfuhrt. Und schlieblich soll aus zwolf gleichen Madchen die Braut herausgefunden werden, was Janko dadurch 1ost, daß er der Palschen, die sich die Ringe anzustecken versuche, droht, er werde ihr den Kopl abschlagen. Die Braut wird gefunden, die Feier kann beginnen. Janko flult dem Konig durch seine Uble Laune auf und, nach deren Ursache befragt, beklagt sich Janko daruber, dab der Konig ihn neben seinen grobten Feind, den alten Despoten Burad, gesetzt habe. Der Konig tröstet inn mit dem Vorschlag, Janko solle turad vor Smederevo unter den Augen der Frauen schlagen. Nachdem die Feier beendet ist und der Hochzeitszug heimkehrt, geschieht dies wirklich, und Jerina verflucht Janko von der Mauer herab, worauf Janko whtend auch gegen die Despotin die Keule schleudert, die auf der Mauer liegenbleibt. Janko droht, er werde Jerina an den Haaren und tural am Bart ziehen, sollte ihm der streitkolben nicht ungehend zurllckgesandt werden.

Pormal gesehen ist Bog.9 die bessere Variante, weil hier die Rahmengeschichte vollständig (in Bog.26 nur der zweite Teil) erhalten ist und die Aufgaben von einem Helden erfullt werden (in Bog.26 die zweite Aufgabe von einem anderen Hochzeitsgast). Was den Inhalt der beiden lieder betrifft,kommt in der Rahmengeschichte der alte $\mathrm{HaB}$ der politischen Gegner Purad Brankovic und János Hunyadi zum Ausdruck, indem daran erinnert wird, daß Janko auf der Flucht nach der Niederlage von Kosovo 1448 von Burad in Smederevo ins Gefangnis geworfen wurde ${ }^{117}$; was die Mißhandlung turats anbelaingt, könnte sich hier eine Erinnerung an die Mißhandlung von Seiten Szilágyis erhalten haben, an deren Folgen der greise Despot gestorben sein soll ${ }^{118}$. Daß hier eine Erinnerung an das alte 
serbische Furstentum in Krusevac, also an Furst Lazar, dessen Enkel, und Stefan Lazarević, dessen Neffe turad war, erhalten blieb, ist ein Anachronismus angesichts der gleichzeitig angedeuteten Herrschaft des Despoten furad in Smederevo, der hier unter den ugrischen Herren (ugarska gospoda) mitzieht. - Soerensen ist der Meinung, daB die "romantische Einkleidung", die Brautwerbegeschichte, mit dem "eigentlichen Inhalt des Gedichtes nichts zu tun" hat und erst später hinzugefugt wurde. - Dies beweist aber m.E. gerade, daB das Brautgewinnungssujet bereits vorher $z u$ den verfugbaren Liedschemata gehort haben mußte, damit es hier eingesetzt werden konnte.

Die Prage labt sich schwer beantworten, ob es sich aus der Rahmengeschichte erklären laBt, daß Janko hier (wahrscheinlich aus Vasallentreue seinem konig gegenuber) die schwierigen Aufgaben erfullt, wăhrend er in den anderen skr. Liedern meist selbst der Bräutigam ist und sein Neffe aus Verwandtentreue fur inn die Freiersproben besteht. Feststeht jedenfalls, dab es sich bei dem Brautgewinnungssujet um ein Wandermotiv handelt, das im ungarserbischen Raum historisiert, d.h. mit historischen Namen aktualisiert wurde, wobei es im h8fischen Milieu durchaus denkbar war, dab der konigliche Vasall zum Haupthelden des Liedes wurde. Der tbergang von der Betonung der Vasallentreue zur Betonung der Verwandtentreue scheint schon bald erfolgt zu sein, d.h. Janko als Brăutigam und der Neffe Sekula als Helfer und Held des Geschehens ersetzten den König von Budim und Janko in diesen Rollen. In dieser Form bietet sich uns die Handlung in der Mehrheit der skr. Varianten dar.

Die alteste Variante dieses Typs - Var.3 - ist das bei Kacic-Miosic aufgezeichnete, allem Anschein nach echte Volkslied, das dieser als eines der "pisme vojvode Janka, koje općenito pivaju Dalmatini, Bornjaci, Li cani $i$ ostali od slovinskoga jezika narodi" charakterisiert, die "lipe su slusat1, ako i nije moguce, da su posve istinite". Das Iied hat folgenden Irihalt: 
Sibinjanin Janko findet weder in Bosna und Hercegovina, noch in Dalmacija, Lika und Krbava ein Madchen zum Heiraten, wohl aber in Gestalt der schönen Janja Temišarka. Er verlobt sich mit ihr und erhalt nach kurzer Zeit einen Brief vom zuklunftigen Schwager mit der Weisung, Janko solle nun Svaten sammeln und das Madchen abholen, Sekula "netjak" aber nicht mitbringen, weil er als streitsuchtig beim Wein gelte. Janko gehorcht und zieht ohne Sekula mit den Svaten los. - Sekulas Mutter, Jankos Schwester, wundert sich, dab ihr Sohn nicht eingeladen wurde, und befurchtet fur ihren Bruder das Schlimmste, wenn er ohne verwandtschaftliche Unterstutzung zu dem Schwager gehe, mit dem er ohnehin in Streit lebe. Sie rat also Sekula, das beste Pferd im Stall und bulgarische Kleider (bugarske aljine) zu nehmen und in Abstand hinter der Hochzeitsgesellschaft herzureiten, was Sekula auch tut. Beim Hof der Braut angelangt, werden die Gaste empfangen; Diener nehmen ihnen Pferde und Waffen ab, Sekula aber wird nicht beachtet. Die Gäste setzen sich an die Tafel, nur Sekula bleibt an der "klhlen Wand" sitzen. Als die Gesellschaft genug Wein getrunken hat, schlagt der Bruder der Braut (sura) dem zuklinftigen Schwager (zet) Wettspiele vor (igre zametnuse). Man holt einen auf eine Lanze gespiebten Apfel herbei und befiehlt Janko, ihn herabzuschieben, andernfalls werde er weder lebend davonkommen noch die Braut wegfuhren. Janko schlagt sich aufs Knie und bedauert, Sekula nicht mitgebracht zu haben. Diese Worte hort der als Bulgare verkleidete Neffe und trobstet den Brăutigam mit dem Hinweis, er werde den Apfel schießen. Er springt auf sein Streitrob, fliegt "wie ein grauer Falke" heran, zielt und trifft den Apfel.Ebenso souverän lost er auch die zweite Aufgabe: Er fliegt "wie eine Schwalbe" und uberspringt neun Pferde, wobei er sich dem zehnten in den Sattel setzt. Auch die dritte Aufgabe, aus neun gleichaussehenden Mudchen die Braut herauszufinden, lost Sekula, indem er seine bulgarischen Kleider auszieht, "strahlend wie die heiße Sonne" seine scharlachrote Dolama vor den Madchen ausbreitet, goldene Ringe daraufstreut und der Braut befiehlt, den Schmuok aufzulesen; einer Fulschen werde er die Hande abschlagen. Die anderen Madchen weichen angstvoll zurick, die Braut sammelt die Ringe auf und wird von Sekula dem Brăutigam mit den worten zugefuhrt: "Oheim, hier hast du das schone Madchen, deine Traute, meine liebe Tantel" Nachdem Sekula sich somit als Neffe zu erkennen gegeben hat, weint Janko vor Freude und Ruhrung und sagt: "Schwer ist es dem Oheim ohne Neffen und dem Nef- 
fen ohne Bruderl" - Danach ziehen die Svaten mit der Braut fröhlich nach Hause zum Hochzeitsfest.

In diesem Iied tauchen - abgeseren von der veränderten Personenkonstellation - einige neue Elemente auf: Der Brautbruder bittet den Bräutigam, er möge seinen als trink- und streitsuchtig geltenden Neffen nicht mitbringen:

Kupi, Janko, gospodu svatove,

Kupi svate, odi po divojku,

Al ne vodi Sekula necaka,

U vinu ga kabgadijom kažu.

Mit dieser listigen Ausrede will der Schwager den Bräutigam seines besten Helden berauben, um ihn, Janko, dann bel Nichtbestehen der Freiersproben töten zu können. Neu ist auch das Gespräch des ungeladenen Neffen mit seiner uutter und deren Rat, sich mit bulgarischen kleidern ${ }^{119}$ zu verkleiden, dem Oheim unerkannt zur seite zu stehen und damit seine Verwandtentreue zu beweisen.- DaB die Neffen-Oheim-Beziehung möglicherweise auf sehr alte matriarchale Verhältnisse zuruckweist, wird in einem spateren Kapitel noch zu besprechen sein. - Anders als in den beiden Bog.-Iiedern finden die Svaten hier die Stadtore nicht verschlossen, wobel mir aber das Element des zunkchst geschlossenen Tores - wie sich aus dem Variantenvergleich ergeben wird - als das archaischere erscheint, das ja auch ( $v g l$. obenl) in den Hochzeitsbrauchen noch in Resten zum Ausdruck kommt. - Darin, daB der Helfer des Brăutigams sich als Hirte verkleidet, liegt m.E. vielleicht der Anfang fur die Weiterentwicklung in anderen (jungeren) Varianten, wo der Neffe namlich wirklich als Hirte vom Gebirge geholt wird, um unerkannt mit dem Brautigam zu ziehen. Ein wirkungsvoller Kontrast wird dann ausgespielt, wenn der Helfer seine armliche Verkleidung ablegt und als strahlender rarchenheld erscheint:

Skide sebe bugargke aljine,

Sinu Sekul kano sunce zarko.

Marchenhaft ist Uberhaupt diese Gestalt des "verkannten Dummlings"120, des "torichten Schufers" (ovcar budalina, vgl.Mich.365), der schlieblich alle durch Kraft, Geschicklichkeit und Schonhe1t luberrascht. Daß der Schufer bel einem 
ehemaligen Hirtenvolk wie den Bulgaren sich besonderer Beliebtheit erfreut, darf nicht verwundern ${ }^{121}$. In bulgarischen Varianten des spater zu behandelnden Themas vom Hochzeitszug mit einem Uberfall auf dem Heimweg wird das Motiv des verkannten Dhimalings sogar so weit getrieben, dab der Brautigam ein Kind, das er im Sand spielend vorfindet, zum Dever nimmt, vor dessen Starke und Heldenmut schlieblich alle weichen mulssen.- Nun zu den Personen des Liedes: Das Heldenpaar Sibinjanin Janko und sein Neffe Sekula ist uns schon aus den vorhergehenden Kapiteln vertraut. Interessant ist die Braut, die uns als Jana Temisvarka, also Jana von Temesvar, vorgestellt wird. Es handelt sich hier möglicherweise um eine erfundene Schwester von Durat Brankovic, der im skr. bzw. maz.-bulg. Lied nicht nur als Duro Smederevac bzw. Gjuro Smederevec (als Erbauer von Smederevo), sondern auch als Gjuro Temizvar oder Temiłvarin auftaucht ${ }^{122}$ - vielleicht deshalb, weil turat in Ungarn zahlreiche Stadte, Burgen und Guter besab, durch die er einer der reichsten Magnaten von Ungarn wurde ${ }^{123}$. Sein Enkel, Despot Vuk, hat zusammen mit Dmitar Jakßić und dem Befehlshaber von Belgrad, Ladislaus Rozgonyi, 1481 nach der Besetzung von Branilevo und Plunderung bei Kruševac mehr als 50000 serb. Flüchtlinge mitgebracht, die König Mathias Corvinus bei Temesvar ansiedelte ${ }^{124}$. Die Brankovici stehen also zweifellos in einer gewissen Beziehung zu Temesvar.- tura besab keine Schwester namens Janja. Er hatte Tochter namens Jelena, Mara (1435 mit Murad II. verh.) und Katharina (verh.mit Ulrich von Cilli, Sohn Friedrichs II.), von Katharina eine Enkelin namens Jelisaveta, die in zweiter Ehe mit König Mathias verheiratet war ${ }^{125}$. Daß eine dieser Prauengestalten wahrscheinlich die Vorlage fur die Janja Tomibrarka im lied gebildet hat, geht vielleicht auch daraus hervor, dab auf die Peindschaft zwischen Janko und dem zuklinftigen Schwager (turad?) hingewiesen wird, wenn Sekulas Mutter ihre Besorgnis uber Jankos Schicksal mit den Worten ausdrickt:

Straho mi je, poginuce ludo,

Jer je bio u zavadi zurom. 
Moglicherweise wird auch hier das bei Bog.9,10 und 26 schon behandelte Thema des bitteren Hasses zwischen den belden Mannern berihrt.

Die deutsch bei Jowitsch wiedergegebene Var.4 von der ehemaligen slavonischen Militurgrenze entspricht der Personenkonstellation nach vollig der dritten Var., ist aber in der Handlungsfinrung etwas reicher (142 gegenuber $112 \mathrm{~V}$.). Bel Jowitsch warnt der Schwiegervater (nicht der Schwager) Janko davor, Sekula mitzubringen, "well man mir als Lanker inn beschrieben"126. Sekulas Mutter meint besorgt, als sie Janko ohne den Neffen ziehen sieht:

Mir ist un sein theures Leben bange, Denn er war mit seinem Schwiegervater

Vor nicht langer Zeit in offner Pehde.

Sie rat dem Sohn:

Darum sattle, Sohn, dein bestes R8Blein,

Das du immer sonst gehein gehalten.

Hille dich in bulgarische Klelder.

Folge, wie von Ungefuhr, der Hochzeit, Daß, wenn Janko etwa sich in Noth sieht,

Er an dir doch Hilf und Beistand finde.

Die Beschreibung, wie sich Sekula zum Hochzeitszug ribstet, ist reicher und schoner als in Var.3, verrat aber damit bereits langere Tradition:

Erstlich $20 g$ er an ein feines Hemde,

Bis zum Glurtel von gedieg'nem Golde,

Und vom Glartel an von weiber Seide.

Uber's Hemde eine feine Weste.

Einen Dollman dann mit gold'nen Knopfen,

Und ein Beinkleid noch mit gold'nen Hefteln.

Dann umschnallte er den schweren Kurab,

Welcher viele Marken Gold gewogen,

Und darluber einen Bulgar-Mantel.

Daß der Glanz den Helden nicht verrathe:

Und auf seinem allerbesten KampfroB

Polgte er der Hochzeit aus der Perne.

Die erste Preiersprobe ist wie bei Kadic-Miobic. Neu iot, wie Sekula eich mit seiner Treffsicherheit bristet, was in jungeren Liedem noch starker ausgebaut erscheinen wird:

Laß mich zielen, Siebenbilrger Jankol

Eine Schwalbe kann im Flug 1 ch schieBen,

Warum nicht den Apfel von der Lanze?

Die zweite Preiersprobe 1st, im Gegensatz zu der Kacib- 
Miosid-Variante, dadurch erschwert, dab auf den neun zu Uberspringenden Pferden:

Jedes trägt am Sattel einen Säbel,

Dessen Spitze himmelwärts gekehret.

Von diesen auf den Pferdericken aufgerichteten Schwertern werden wir in spateren Varianten, vor allem in maz. und bulg. Liedern, zahlreiche Ableitungen erleben.- Als Sekula die zweite Freiersprobe erfullt, ruhmt er sich wieder:

Hab' im kihnen Spiele mit den Hirten Ungeheure Klufte ubersprungen;

Warum sollt ich diesen Sprung nicht wagen?

Als Erweiterung kommt hier noch dazu, dab der Bräutigam Sekula zum Ablegen des schweren Bulgarenmantels auffordert, der ihn doch nur beim Sprung hindere, worauf Sekula entigenet:

Weh dem Vogel, den die Federm irren!

Als Sekula sich anschickt, die dritte Aufgabe, namlich das Herausfinden der Braut unter neun gleichen Madchen, zu $28-$ sen, gibt er sich als Hirte zu erkennen, dem solch eine Aufgabe keinerlei mhe bereite:

Sei du ohne Sorge, Brăut'gam Janko!

Hab' zu Hause an zwoll fausend Schafe, Die mir viele hundert Lammer geben; Jedes Lamm ich nach der Mutter kenne, Will die Braut auch nach dem Vater kennen.

Sekula findet die Braut mit der bekannten List heraus und Ubergibt sie dem Oheim mit den Worten:

Nimm dir Onkel jetzt das schöne Mädchen, Deine Braut und meine liebe Tante!

worauf Janko mit Freudentranen sagt:

Wohl mir, dab ich solchen Neffen habe,

Dir verdank ich Sieg und Braut und Leben.

Mit der frohlichen Hochzeitsfeier in der Heimat des Brăutigams schliebt das lied, das schon in so vielem auf das später zu behandelnde, meisterhafte skr. Lied von Dusans Hochzeit hinweist.

In der Sammlung $\mathrm{MH} I_{1}, 584-587$ werden sieben Lieder aus Kroatien erwähnt, die mir im Wortlaut leider unzugänglich waren. Wir sind daher auf die zum Teil sehr durftigen Anmerkungen angewiesen. Es handelt sich zunächst um Var.5 mit 


\section{folgendem Inhalt:}

Janko vojvoda freit das schöne Madchen Misirki nja Jana. Die Herren von Misir sagen ihm, er solle Sekula junak nicht zu den Svaten muen, denn der trinke nicht eher Wein, als Heldenblut geflossen sei. Sekula folgt den Svaten, unter denen sich Kraljevic Marko, Milor Kobilic und mali Reljica befinden, als "mlado Vugarine" verkleidet. In Misir uberspringt er neun Pferde und setzt sich auf das zehnte. Dann schieBt er einen Apfel von einer Lanze und findet die Braut unter neun Mădchen heraus.

wie wir sehen, wurde hier Janja aus Temesvar durch Jana aus Ägypten (Misir) ersetzt. Misir wurde wahrscheinlich deshalb gewählt, um die Fremdartigkeit des Brautlandes und dessen eigenartige Sittei zu erklären. Uberhaupt werden Heldenfahrten durch Überbruckung großer Entfernungen interessanter : Misir, das ferne, reiche Land als Ziel einer prunkvollen Brautfahrt. - Fur die Svaten wird einer der in jungeren Liedern so beliebten "Heldenkataloge" angefuhrt, eine Tatsache, die bei den vorhergeheilder altaren Varianten noch fehlte. $\mathrm{DaB}$ bei salclien Heldenkatalogen Anachronismen unterlaufen, ist cire fast selbstverständliche Feststellung. Marko (1394 yest.), Miloł (1389 gest.) und Relja (1343 gest.) sind zwar Zeitgenossen, passen aber nicht zu dem um mehrere Generationen späteren Janko (1156 gest.).

In Var.6 gewinnt Sibinjanin Janko ebenfalls Misirkinja Janja als Braut. - In Var.7 kommt zum erstenmal ein neues Element ins Spiel:

Vojvoda Janko freit ein Mädchen von weither, drei Tagereisen durch die Ebene, vier durchs grine Waldgebirge, nämlich das lateinische Mădchen (latinska djevojka). Bevor Janko sich auf den Weg macht, sagt ihm der schlaue Lateiner (mudri Latinin), anscheinend der Brautvater, er solle seinen Neffen Sekula nicht mitbringen. Die Schwester (wessen?) fertigt darauphin Monchskleider und einen Bart an, Sekula zieht als " $\chi_{i} \chi_{a}$ kaludjer" verkleidet mit den Svaten und löst die Freiersaüfgaben für Janko.

Die anschließende Var.8 wird nur mit dem Prädikat "nizta osobito" versehen und scheint sich somit im wesentlichen mit der vorigen zu decken.- In Var.7 tauchen zum erstenmal das lateinische Mädchen und der schlaue Lateiner auf, die 
vermutlich darauf hinweisen, daB das genannte lied rit diesem Element nicht im katholischen Kroatien entstanden sein kann, sondern höchstwahrscheinlich aus orthodoxem serbischen Gebiet zugewandert ist. "Lateinisch" bedeutet ngmlich hier die Konfessionszugehörigkeit zum katholischen Glauben. Die Hervorhebung der Schlauheit der Lateiner ist im skr. Volkslied Wandergut, vgl. die Stelle in einem kroatischen Prauenlied:

Vesela je Alaj-begovica, Gdje udaje kcerku i pastorku:

Kcerku daje u modre Latine, 127

A pastorku u b'jele Cernike.

Die Verkleidung Sekulas mit Monchskleidern ist sicher nicht urspringlich, sondern ein Ersatz fur die Verkleidung als Hirte. Die Mönchsverkleidung ist vor allem aus den Minja von Kostur-Iiedern bekannt und durfte vielleicht von dorther ubernommen sein.- Als Var.9 ist ein Lied zu nennen, das davon handelt, daB Sibinjanin Janko in der Gegend von Sibinj freit und schlieblich:

on izabra za sebe djevojku,

Sibanjkinju, lijepu djevojku.

Weiter ist nichts erwahnt (ob Sekula die Freiersproben erfullt usw.). DaB Janko von Sibinj nicht in einem fernen Land, sondern in seiner nachsten Umgebung eine Braut sucht, ist eine sekundare Umbildung.- In Var.10 freit Janko die kluge "Latinjanka". Der Neffe, der die Freiersproben besteht, ist hier "Mikula sestricak", was natirlich nur eine falsche Wiedergabe von "Sekula sestrilic" sein kann. - In Var.11 freit Vojroda Janko die Sultanstochter Ajka Desniarka, wobei es sich vielleicht um eine falsche Bildung aus Temnicarka" handeln könnte. - Var.12 unseres Sujets scheint

\section{Var.7 zusammenzuhängen:}

Sibinjanin Janko gedenkt zu heiraten und schickt zu diesem Zweck einen Brief an Latinka divojka mit der Prage, ob sie Janko zum Mann nehmen mochte. Es antwortet aber nicht Latinka, die den Brief offensichtlich gar nicht gesehen hat, sondern die lateinischen Herren (latinska gospoda) schreiben in betrligerischer Absicht an Stelle des Madchens, sie werde seine Prau werden. Janko sammelt nun alle seine Svaten. Zum Kum bestimmt er 
Kraljevic Marko. Seinen Neffen Sekula aber ladt er nicht ein, weil der beim Wein sich immer ungehorig benimint. - Als der Hochzeitszug vor die weibe Stadt kommt, in der Latinka divojka wohnt, sind die lateinischen Herren schon vor der Stadt versammelt und fragen Janko, was ihn hierher gefuhrt habe. Da zeigt Janko seinen Brief mit der positiven Antwort des Madchens vor. Die Herren erklären, der Brief sei falsch und Janko werde das Mudchen nicht eher wegfluren, ehe er drei Proben bestanden habe. Die erste Aufgabe sei, einen Apfel von einer Lanze zu schieBen. Gelinge ihm das nicht, komme er weder allein heil davon, noch werde er das Madchen erhalten.

Die alte Mutter fragt Sekula, warum er nicht unter den Svaten des Oheims sei, worauf Sekula ihr gesteht, der Oheim habe inm brieflich mitgeteilt, dab er Sekula wegen seines schlechten Benehmens nicht zu den Svaten rufe. Sie zuBert sich darauf besorgt uber das Schicksal Jank08, der von den schlauen Iateinern sicher betrogen werde. Sie rat Sekula, er solle dem Onkel verkleidet zu Hilfe eilen. Sekula gehorcht, zieht seine schonsten Kleider an, daruber die gríne Dolama, in die er dreissig Ringe steckt, zuoberst schlieblich Monchskleider und reitet mit seinem besten pferd 108 . Noch hat Janko keinen Versuch gemacht, die Aufgabe zu 18sen, als Sekula schon neben ihm erscheint und fragt, ob er nicht die Probe flir den Bräutigam bestehen könne, was Janko freudig bejaht. Nachdem Sekula den Apfel mit der Flinte herabgeschossen hat und damit die Herren in Erstaunen versetzt, bristet sich der junge Held, er schiebe die Schwalbe in Flug, wie solle er also einen aufgespiebten Apfel verfehlen. Sekula erfullt auch die zweite Aufgabe: Er Uberspringt dreibig pferde, zerbricht dem letzten den Sattel beim Aufitzen und bristet sich anschließend damit, er uberspringe drei Mauern, wieso also nicht dreiBig "Pferdchen". Als dritte Aufgabe soll Janko aus dreibig ganz gleichen Mädchen die Braut herausfinden, was ihm nicht gelingen will, weil er das Madchen nie gesehen hat. Da bietet sich wieder Sekula als Helfer an, zieht die Monchskleider und die grline Dolama aus, streut darauf die Ringe und fordert diejenige, die seine Tante sei, auf, die Goldringe zu nehmen: sollte eine andere dies wagen, werde er ins den Kopf abschlagen. Die Richtige sammelt die Ringe auf. Sekula packt die Braut und wirft sie hinter sich aufs Pferd. Er reitet fluchtartig davon und ruft zu Hause seiner alten Mutter $2 u$, er habe seine "liebe Tante" mitgebracht.

Zunächst stort bel dieser Variante der schlechte Aufbau. Der 
Sanger war anscheinend nicht in der Lage, die beiden Handlungsstränge simultan ablaufen zu lassen und schlieblich zu verbinden. Statt dessen behilft er sich mit einer plumpen Rllckschaltung von einer Sujetlinie zur anderen. Als neues Element ist hier zu nennen, daB die lateinischen Herren den an das wadchen gerichteten Brief hinterlistig beantworten und dann als falsch erklaren, um Janko zu den Proben zwingen zu konnen. Ein Versehen des Sangers durfte es sein, $d a b$ er an der Briefstelle nicht gleich das Verbot, Sekula mitzubringen, anknupft, sonderm dies als Entschlub Janko in die Schuhe schiebt und noch dazu Sekula brieflich mitteilen läbt. Neu ist in diesem Iied auch, dab Sekula eine grine Dolama trägt, die hier - was die Farbe anbelangt - sicher nicht urspringlich ins lied gehort und in diesem Zusammenhang auch sinnlos ist, sondern wahrscheinlich aus Liederm des Typs "Marko Kraljevic pije uz ramazan vino, nosi zelenu dolamu i igra uz Turkinje uz prkos carevoj zabrani" (Bog.90; vgl. auch SbNU III,107 u.a.) Ubernommen ist, wo eben eine grine Dolama (Griln als Farbe des Propheten!) laut Sultansbeschlus flur Christen verboten ist.- Auch daB betont wird, Sekula habe vor dem Wegreiten dreibig Ringe zu sich gesteckt, ist eine ungebuhrliche und ungeschickte Vorwegnahme und damit Abschwkchung des Motivg der dritten Preiersprobe. Weiter ist dem Sanger anzukreiden, dab er Sem kula hier den Apfel mit der Flinte, und nicht mit Pfeil und Bogen, herunterholen 18Bt. DaB Sekula sich ruhmt, drei Mauerm uberspringen zu können, war vielleicht der AnlaB fur das Motiv des Maueruberspringens in spater zu besprechenden maz. und bulg. Varianten. Die SchluBpointe ist dadurch zerstort, dab Sekula sich dem Onkel nicht direkt zu erkennen glbt, oondorn nur zu den dreibig Madchen sagt:

Sada beri, ka 81 ujna moja, Ako bi se koja pomamila, Odsic bu joj glavu do ramenal

Unsinnig mutet das Iiedende an, wo Sekula wie bei einer Entm fuhrungsizene mit dem Madchen auf dem Pferd zu seiner Mutter zurikcreitet, die ja eigentlich mit der Braut Jankos 
nichts zu tun hat, und sie ihr mit den Worten ubergibt: Oro ti je verma ujna moja!

Diese Formel, die wir aus Brautraubliedern kennen, hatte doch nur Sinn in diesem Zusammenhang, wenn sie lautete: ovo ti je verna 1 j u b a moja!

Nach diesem verderbten lied wenden wir uns nun der mohammedanischen Var.13 zu, die folgenden Inhalt hat:

Latinin Dujo schreibt Aga Hasan-aga einen Brief mit der Aufforderung, 1000 Svaten zu gammeln, die beiden Neffen Ujunovici aber nicht einzuladen, denn sie seien trink- und streitsllchtig. Hasan-aga befolgt die Weisung.- Wharenddessen fragt die Mutter der beiden Neffen, was sie dem Oheim (dajo) nur angetan haben mbgen, dab er sie nicht zu den Svaten lade. Die sohne befolgen den anschliebend gegebenen Rat der Mutter, ziehen Derwisohkleider an, reiten dem Oheim nach, um ihm bel der Brautfahrt beistehen zu können, und erreichen den Hochzeitszug nach der ersten Tagesreise. Sie werden gut aufgenommen und gelangen mit den Svaten nach zwei weiteren Tagen bel Morgendummerung zu der Stadt, wo die Braut wohnt. Der Schwiegervater Latinin Dujo komnt heraus und fordert den Schwiegersohn Hasan-aga auf, einen goldenen Apfel von der Lanze zu schieBen, denn andernfalls komme er weder selbst mit heiler Haut davon, noch erhalte er das Madchen.- Da schlagt sich Hasan-aga jammernd aufs Knie, dab das Tuch platzt, und beklagt sein MiBgeschick, seine zwei Neffen nicht mitgebracht zu haben. Die beiden, Mujo und Alija, sehen sich an, Alija springt auf und schiebt den Apfel in zwei Teile. Bei der zweiten Aufgabe (mudrost) wiederholt sich die obige Szene, und wieder springt Alija auf, nimmt Anlauf und lberspringt die neun nebeneinandergestellten Rappen. Auch die dritte Probe besteht Alija auf die Ubliche listige Weise: Nachdem er seinen blutroten Mantel ausgebreitet, Ringe daraurgestreut und den Madchen mit dem Schwert gedroht hat, tritt Anda Latinina vor und sammelt die Ringe auf, worauf die Svaten das Madchen mit Musik wegflunren.

Diese nicht verderbte, wohl aber etwas karg anmutende Variante ungeres Sujets enthalt alle Motive in der richtigen Reihenfolge, nur sind hier uberflusgigerweise zwei Neffen als Retter des Oheims aufgeboten. Hauptheld ist Alija, hier der handelnde Part des im mohammedanischen lied so beliebten Briderpars Mujo und Alija. Es ist nicht einzusehen, war- 
um zwei Neffen mitziehen, wenn dann doch nur einer die Freiersproben auf sich nimmt. Doch da der Sănger sich nun einmal fur das Briderpaar als Retter des Oheims entschieden hatte, mußte er die "Unzertrennlichen" beide ins Lied ubernehmen. Hasan-aga, am bekanntesten aus dem berlhmten Lied "Hasanaginica" (Vuk III 81), ist eine historisch nicht nachzuweisende Figur ${ }^{128}$. Sollte Dujo Latinin der in anderen Liedern dieses Typs mehrmals agierende Doge von Venedig (Duzd Mletaka) sein?

Anzufuhren ist weiter die slovenische Var.14, die wahrschein'lich die Vorlage zu den in Hauffens Werk uber die Sprachinsel Gottschee unter Nr.74 mit den Varianten A,B und $C$ angegebenen deutschsprachigen Brautwerbeballaden bildete ${ }^{129}$. Sie lst "Modri Sekol junak" betitelt und hat folgenden Inhalt:

Janko vajevoda freit ein Madchen von weither, aus dem lateinischen Land. Da schreibt der schlaue (modri) Latinjane an Janko, er solle Svaten sammeln, aber nicht den Helden Sekola einladen, weil dieser maBlos sei im Essen und Trinken und "svakojake sege sobriałe" 130. Janko gehorcht.- Sekol fragt indessen seine Nutter, was sie dem Oheim wohl angetan haben moggen, dab er sie nicht zur Hochzeit einlade. Die Mutter rät ihm, ein dem Oheim unbekanntes Pferd und Schwert zu nehmen und mit den Svaten zu ziehen. Sekol gelangt mit dem Hochzeitszug ins lateinische Land, wo der schlaue Latinjane gleich die erste Preiersprobe auferlegt, und zwar mit der hohnischen Bemerkung, Janko habe sicher keinen Helden bei sich, der drei Lanzen Uberspringen könne. Sekol jedoch tritt vor und besteht die erste Probe. In derselben hohnischen Art wird die zweite Aufgabe gestellt, namlich einen Apfel von einer Lanze zu schießen, was wieder nur Sekol meistert. Bei der dritten Probe (sega) breitet Sekol seinen seidenen Mantel hin, streut drei goldene Zechinen (cekine) darauf und droht, allen neun Madchen den Kopl ybzuhauen, wenn eine andere als die Braut sich nach den Goldstlucken blucke.- Da springt die Braut nach vorn; sammelt die Zechinen auf und gibt Sekol den Mantel zurlick.- Als sie in ihre weibe Heimatstadt zurlackkommen, berichtet Sekol triumphierend seiner Mutter, dem schlauen Lateiner habe er Staunen eingeflöBt, der dachte, Janko habe keinen Helden bei sich, der solche Proben bestehen könne. 
Diese slovenische Variante, die bestimmt aus dem skr.Raum ubernommen wurde, zeigt sekundare Verfallserscheinungen. Sie lot kurz und sprunghaft und verzichtet auf jeden erzahlerischen Aufwand. Der hofische Geist ist verlorengegangen und des Lied mehr zur prägnanten Episode einer Familiengeschichte geworden. Anstatt sich zu verkleiden, nimmt Sekola lediglich ein Pferd und Schwert, die dem Onkel fremd sind, - als ob der Oheim den Neffen dann nicht erkennen wurdel Die in anderen Liedern vorkommenden neur. Pferde mit aufgerichteten skbeln auf dem Rlicken sind hier zu drei aufgerichteten Ianzen reduziert worden. Die goldenen Ringe wurden durch einfache Geldstücke ersetzt. Die Szene, wo Sekola sich als Neffe Jankos zu erkennen gibt, fehlt v8lisg. Statt dessen endet das Lied mit der Prahlerei Sekols vor seiner Mutter und seiner Genugtuung luber die gelungene Heldentat.

Var.15 war mir leider nicht zugänglich.- Bevor wir zu den maz. und bulg. Varianten Ubergehen, soll hier noch ein lied angefunrt werden, das unserem Sujet nicht ganz, wohl aber in großen Zugen entspricht. Es handelt sich um Var.16 "Zenidba turaa Smederevca" mit folgendem Inhalt:

Buro Smederevac freit in Dubrovnik die Tochter Jerina des Konigs Mihajlo und erhalt eine Zusage, allerdings mit der hinterlistigen Bedingung, keine Serben, die als trunk- und streitsluchtig bekannt seien, zum Hochzeitszug zu laden, sondern lauter Griechen und Bulgaren zu sammeln. Als turo nach Hause aufbricht, erreicht inn schon unterwegs ein Brief seiner vuklinftigen Braut, in dem sie Buro auffordert, nicht auf die Anweisung inres Vaters zu hören, sondern Serben als Svaten zu rufen, und zwar Debelic Novak als Gevatter (kum), Novakovic. Gruja als zweiten Gevatter (prikumak), Sibinjanin Janko als Obersvaten (atari svat), Kraljevic Marko ala Brautfuhrer (dever), Relja Krilatica als SpaBmacher (Caus), Obilic Milos als Anflurer (vojvoda) und Kosancil Ivan als Beistand (privenac) sowie andere Siraten nach Belieben, im ganzen aber 1000.- Als turo nach Hause kommt, fragt ihn seine Mutter nach seinen Erlebnissen, worauf er ihr (in epischer Wiederholung) alles Obige erzthlt und sie zugleich Iragt, ob er auf das Madchen oder den Konig hören solle. Die Mutter rät ihm davon ab, dem Ko- 
nig zu gehorchen, denn die Lateiner seien alte Betriger. Daraufhin schreibt turo allen von Jerina empfohlenen Helden Briefe und fordert sie mit ihren Leuten zum Kommen auf, so daB er schlieblich 1000 Svaten unter Fuhrung des Wahlbruders Marko nach Dubrovnik entsenden kann. Als sich die Svaten der Stadt nahern, befiehlt Marko sēinen Leuten, die Pferde den Dienern zu Uberlassen, die Waffen aber nicht herzugeben. Er werde dem Konig dlese Mabnahme schon erklaren. Als es wirklich dazu kommt, sagt Marko, es sei bei den Serben Sitte, bewaffnet Wein zu trinken und sogar bewafenet zu schlafen.- Die Grste Ubernachten in Dubrovnik und werden am nuchsten Morgen dadurch geweckt, daß ein Lateiner (Latince) von der Festungsmauer herab den Kum zum Kampl mit zwei Lateinern, zwel gestellten Kampfern, aufruft; finde sich kein Kumpfer auf serb. Seite, 80 konne das Madchen nicht ubergeben werden. Grujica wagt den Kampl und besiegt die beiden Gegner. Da wirft ihm Jerina einen goldenen Ball zu mit der Bemerkung, nun wisse er, wo sie sitze. Als Grujica an seinen Platz zurluckkehrt, wird schon zur zweiten Preiersprobe aufgerufen, nimlich drei pferde mit aufgerichteten Lanzen auf dem Rlucken zu Uberspringen. Diese Aufgabe wird von Relja gelbst, und die perde werden Starina Novak zugefuhrt. Die dritte Prifung, einen goldenen Apfel von dem Turm hemunterzuschieben, besteht Milos und bringt die Trophke zum Kum. Da wird Marko witend und sagt zu Starina Novak, wenn er wiste, wo die Braut sitze, wllrde er nicht langer un die Auslieferung des Madchens bitten. Grujica erklärt, er wisse, wo das Madchen sei, und finrt Marko zu Jerina, die sie gemeinsam wegfuhren. Da ruft der Lateiner von der Mauer, 77 Tore seien vor ihnen verschlossen. Marko nimmt aber seinen Streitkolben und sagt, das sei der Schlussel zu den 77 Toren. Er zertrllmmert in seiner Wut alle bis auf das Stadttor, das jedoch unter seinen Schlugen so erzittert, das der Wohnturm des Konigs schwankt. Der König gebietet Marko Einhalt und refnet selbst das letzte Tor. Da fordert Marko den König zum Nahertreten auf, damit man sich versobhnen und beschenken kơnne. Der König fallt auf diese list herein und wird von Marko erschlagen. Der Hochzeitszug kehrt heim und wird von turo freudig emplangen.

Der Bräutigam in diesem Lied ist offensichtlich Burad Brankovic, der tatsachlich 1414 in zweiter Ehe Jerina (die beruhmte "prokleta Jerina" des skr. Volkslieds) aus der Familie der Kantakuzenos heiratete, die aus Thessalonike 
nach Serbien kam"31. "Konig" Mihajlo von Dubrovilk tat erfunden, wird uns aber als lateinischer konig von Venedig wieder begegnen. Es handelt slch hier um den Prototyp des betrügerischen Iateiners, d.h. das Lied ist somit oerb.Ursprungs und daher serbenfreundlich, whrend Griechen und Bulgaren in diesem Iled nicht sehr hoch eingeschatzt werden. Wle M.Braun annimmt, hat das Lled einen historlschen Kern, der sich nach den Akten des Archlv8 von Dubrovnik so darstellt:

Durde ist der letzte Herrscher des mittelalterlichen Serbiens, Despot Durad (Georg) Brankovic, hier nach seiner Residenz Smederevo benannt. Er Preite 1446 Helena, die Tochter des Herrschers von Morea, Thomas Palaiologos, fur seinen Sohn Lazar. Die Ragusaner stellten ihm Schiffe zur Verfligung, um die Braut aus Griechenland abzuholen; eine grobere Anzahl serbischer Vojvoden wartete inzwischen in Dubrovnik. Ste warden nicht in der Stadt aufgenommen, sondern in Privathausern ausserhalb der Stadtmauern untergebracht. Die griechische Braut blieb einige Tage als geehrter und wohlbewirteter Gast der Regierung in Dubrovnik und reiste dann nach Serbien ab. In der Zwischenzeit kam es zwischen den einheimischen Adligen und den serbischen Gasten zu Streitigkelten, die von der Reglerung untergucht und bereinigt werden musten. Dabel wurden einige Ragusaner gerligt und sogar bestraft; die Schuld durfte also auf ihrer Seite zu ouchen sein. Im Ubrigen ist noch zu erwähnen, das die Stadt in der Tat von der Begleitung der fremden Besucher das Ablegen der Waffen verlangte, und daß Markos Auftreten in Dubrovnik allem Anschein nach ebenfalls nicht aus der Luft gegriffen 1st: 1361 war ein "Gesandter Marko" des serb1schen Zaren Uror in Dubrovnik und es lst zum mindesten sehr wahrscheinlich, daß es sich um den Sohn des Konigs Vukarin Krmjavcevic, ebenso den berlihmten Konlgs8ohn, handelt (Tadic 49-50). So 18t also, trotz alier Ausschmllckung und Umgestaltung, immer noch vieles vom tatskchlichen historischen vorgang stehengeblieben. 132

Ob dies wirklich der historische Kern fur unser. Iisd ist, mochte ich dahingestelit sein lassen. Ich glaube eher, dab es sich um eine blobe Belegung des inzwischen gentugend vertrauten alten Brautfahrtliedes mit hlotorischen Namen handelt, wobel die Anachronismen im Heldenkatalog besonders 
Prappierend sind: Starina Novak (gest.1601) als Kum von turat, der ein Jahrhundert friher lebte, und als Svaten Helden des 14.Jh. - Einleuchtender wäre vielleicht der allgemeine Hinweis auf die Tatsache, daB furad sich oft in Dubrovnik aufhielt und ihn mannigfaltige Beziehungen (er hatte z.B. sein Vermögen dort deponiert) mit dieser stadt verbanden. Wenn man schon eine historische Reminiszenz in unserem Lied suchen will, könnte man vielleicht auch auf die Beziehung von Starina Novak, dem Hajdukenführer aus der zweiten Hälfte des 16.Jh., zu dem siebenbürgischen Vojvoden Michael hinweisen, dem er in seinen kamplen gegen die rurken und Sigismund Báthory beistand ${ }^{133}$. Der bulg. Zar Michailo, Sohn des Vidiner Fursten Sisman, der mit seinen Bulgaren 1330 bei Velbuzd (Küstendil) die beribnte Niederlage gegen die Serben erlitt, scheidet hier wohl aus, weil es sich ausdrucklich um einen katholischen (lateinischen) bzw. romanisch-klistenländischen Flirsten handelt. Auch Michael Paläologos, der byzantinische Kaiser (1261-82), und Michael IX. (1295-1320), Sohn und Mitregent des Andronikos, kommen hier aus denselben Grinden vermutlich nicht in Frage.Der Könif der Zeta, Mihailo (1050-80), liegt wahrscheinlich zeitlich zu weit entfernt. D. Kostic möchte unter dem Namen Mihailo mehrere Mitglieder der venezianischen Familie Michiel, nămlich die Dogen Vitale I., Domenico und Vitale II. aus dem XI./XII.Jh. bzw. Giovanni (13.Jh.) oder die Heerfuhrer Marco (13.Jh.), Domenico (14.Jh.), Fantino (15.Jh.) bzw. Salomon (15.Jh.), Marccio (16.Jh.) und Marino (17.Jh.), die den Posten eines "provveditore" innehatten, verschmolzen sehen ${ }^{134}$, womit er möglicherweise recht raben könnte, weil der Doge von Venedig ebenfalls häufig in Liedern dieses Typo genannt wird.- Vielleicht iat der Name Mihailo auch nur ein stehender, stereotyper Name fur einen "lateinischen", d.h. katholisch-romanischen Herrscher, - eine Annahme, die auch in den Anmerkungen zu Vuk II 27 und 28 betont wird. Das Lied iat wahrscheinlich relativ jung (der Heldenkatalog, die komplizierte, umgestaltete Handlung u.a. sprechen dafur), 
hat aber die Freiersproben gut bewahrt, nur werden diese hier von verschiedenen Helden auggefuhrt, woflur wir aber in Bog.26 schon Ansatze haben. Die beiden lateinischen Ringkłmpfer (dvoje Latincadi), die als erste Probe zu besiegen sind, erfillen hier die gleiche Aufgabe wie in anderen Liedern der schwarze Araber als vom Brautvater gestellter Gegner. Diese Beobachtung hat auch Kravcov gemacht, wenn er schreibt:"obraz latinca imeet to ze znacenie kak $v$ drugich pesnjach obraz Arapina. Stolknovenija Serbil s latinskim, katoliceskim (u serbov latinec = katolik) Zapadom byli pricinoj sozdanija etogo obraza, analogicnogo Arapinu"135. - Die dem aus einem Kampl gegen gestellte Gegner, Sprung und Schub bestehenden Dreikampl in Dusans Hochzeit noch angefugte vierte Probe, das Herausfinden der Braut, ist hier m.E. madimentar darin erhalten, daB die Braut selbat Grujica einen goldenen Apfel (vgl. die Goldoder Schmuckstucke in den anderen Varianten, wo sie allerdings von dem Helden geworfen werden) zuwirft, um inm damit zu zeigen, welches der Madchen sie sei.- Neu ist in diesem Lied, daß das Verbot, bestimmte Gäste mitzubringen, sich nicht auf einen oder zwei Neffen, sonderm auf die als gute Kampfer gefurchteten Serben allgemein bezieht, wobei wieder die scheinheilige Ausrede gebraucht wird, die Serben seien trunk- und streitglichtig:

Ti ne zovi Srba u svatove, Jer su Srbi terke pijanice, A u kavge l jute kavgadżje (...)

Vec ti zovi Grke $i$ Bugare.

Ein Iied mit diesem Motiv kann also nur von einem serb. Sanger stammen und auf serb. Boden entstanden sein. Zum erstenmal tritt hier der Fall ein, daB dem Brăutigam von einer anderen Person (hier der Braut) ein Brief nachgesandt wird mit der Warnung, die Anweisung des Brautvaters ja nicht $z u$ befolgen, sondern erstklasige serb. Helden mitzubringen, andernfalls mlisge das Schlimmste befurchtet werden. In anderen, später zu behandelnden Liedern ist es u.U. die Brautmutter, die den warnenden Brief nachsendet.- Auf 
den Rat seiner Mutter hin richtet sich turad nach den Brief des Madchens, denn die Kutter meint:

Latini su varalice stare, Hoce tebe, sinko, prevariti.

Diese Warnung vor, den Lateinern, den alten Betrigern, ist im orthodoxen Liedraum anscheinend schon so zur stereotypen, sprichwortlichen Wendung geworden, daß es in einem maz. Hochzeitslied aus Debar sogar heibt (hier allerdings mit der Verbotsformel kombiniert):

Budimdziji kleti kavgadziji.

A na vino tezki pijanici. Na rakije ljuti kavgadiji. Ce ni storit golema sramota,

Ce ni vratit nazad bez nevesta. 136

Bedingt dadurch, daB sich das Verbot des Brautvaters auf Serben allgemein (und nicht nur auf einen einzelnen Helden) erstreckt, werden die Aufgaben dann auch folgerichtig von mehreren Helden, und nicht nur von einem (die urspringliche Version) erfullt. Es fallt auf, daB der Brautigam selbst nicht zur Braut mitkommt, sondern die Svaten zu Hause erwartet. Die Weigerung, die Waffen abzulegen aus Furcht vor einem moglichen Uberfall, ist eine "in unmuhigen Zeiten ganz naturliche Vorsichtsmaknahme" (Kirmunskij), die auch in der Edda schon dem in fremdem Land weilenden Krieger angeraten wird, so daß Simonovit sicher unrecht hat, wenn er diese stelle in Vuk II 78, V.152-163,173-181 als auffallende Ufbereinstimmung mit dem vermeintlichen Vorbild, numlich dem Nibelungenlied, bezeichnet ${ }^{137}$.- DaB 77 Tore vor Marko verschlossen werden, mutet marchenhaft an, ebenso die Tatsache, dab er 76 davon mit dem streitkolben zerschlagt. Die Schlubszene, wo der Brautvater getbtet wird, weil er das Madchen immer noch nicht freiwillig ausgeliefert hatte, erinnert an die im folgenden Kapitel behandelten Lieder,wo der Brautvater vom Preier deshalb erschossen wird, weil er die Braut nicht ereigibt, sondern immer unzumutbarere Forderungen stellt.

Soweit die skr. Varianten dieses Brautfahrtaujets. Bevor wir zu den maz. und bulg. Varianten ubergehen, soll schon 
jetzt auf die mutmaßliche Prioritat des Sujets im skr. Raum hingewiesen werden, das im maz. und bulg. Raum in dieser Form sicher zur Sekundarschicht gehört, was aus augenfäligen Details ersichtlich sein wird: Das Sujet wird zum Teil $m i t$ den urspringlichen ungarserbischen Heldennamen ubernommen, zum großen Teil aber setzt man stereotype, meist unhistorische Namen ein. Die urspringliche Abfolge der Freiersproben ist in keiner einzigen maz.-bulg. Variante erhalten. Die Motivkette ist meistens stark verbauerlicht worden; sie wurde einerseits erweitert, andererseits - und das ist noch huufiger der Fall - aber verstummelt. Nun zu den Liedtexten. Der Inhalt von Var.17 lautet:

Seit die Mutter ihren Sohn "mlado Crŭnogorce" verlobte, hat sie inn nicht mehr fröhlich gesehen. Er ist betribt, tragt ein schwarzes Tuch bis zu den Augenbrauen, redet und scherzt nicht. Schlieblich fragt inn die Mutter, ob inm die drei Fuhren Wein, die Fuhre Schnaps und der Wagen voll Mehl leid tuten, die er flur die Feier aufbringen mulsse, was der Sohn alles verneint. Der Grund fur seine uble Laune sei vielmehr, das er an vorhergehenden Tag einen Brief von Mildo, seinem klnftigen Schwiegervater, erhalten habe, in dem er aufgefordert werde, Svaten aus drei Stadten zu sammeln, und zwar alles Leute, die reiten und den "dzirit" (dzilit= Kurzspeer) werfen können, seine beiden Neffen solle er aber fernhalten.- Crünogorle klagt, seit seiner Verlobung zuchteten die Neffen gute Pferde mit feinem Klee, auserlesenem Weizen und dreijührigem Wein, und das alles fur die Hochzeit des Oheims! - Die Mutter rat ihm, die Svaten zu sammeln, wie gewinscht, doch solle der zug mit Trommeln und Gesang am Hof der beiden Neffen vorbeiziehen. Crünogortes Schwester sei schlau und schicke die Sbhne sicher ungeladen nach.- Crünogorde folgt dem Rat seiner Mutter. Als die Svaten am Hof der Neffen vorbeizichen, fragen diese inre Mutter, warum sie nicht geladen murden. Die Mutter meint, bei der ganzen Sache handle es sich um einen groBen Betrug: Der Bruder sei noch nie im lateinischen Land gewesen und kenne die dort geltenden Gesetze nicht. Er werde sicher ohne die Braut zurückkehren müssen. Sie backe also Brot flur die Reise, die Srhne aber sollten die Rappen satteln, Wein aufladen, sich die schönsten Kleider anziehen und den Svaten folgen.- Die beiden brechen auf und holen die Svaten ein, werden aber von 
ihnen verjagt, weil sie, die "schwarzen Zigeuner", die "schmucken Svaten" störten. Die Bruder lassen sich aber nicht abweisen, denn sie hatten fur sich selbst Proviant dabei, fielen also niemandem zur Last, und gingen im ubrigen nicht mit den Svaten, sondern nur denselben Weg.- Der Hochzeitszug gelangt ins lateinische Land, wo ein dreitägiges Festgelage stattfindet. Schlieblich fordert der Kum die Bruder der Braut auf, endlich das Madchen herauszufluren, damit es den Svaten die Hand kusse. Die Bruder weigern sich, das Madchen auszuliefern, bevor nicht einer der Svaten neun Pferde Ubersprungen habe; wer das fertigbringe, erhalte die Braut. Alle Svaten blicken zu Boden, Crúnogorce ringt die Hände und weint. Nur die beiden Neffen sind furchtlos und erklaren dem Oheim, er brauche keine Angst zu haben, sie wirden die Aufgabe losen. Und wirklich Uberspringt der jungere der beiden muhelos die Pferde. Die Braut wird jedoch nicht ausgeliefert, sondern man fordert das Bestehen einer zweiten Freiersprobe, numlich das tberspringen von neun mit Dorngestrupp gefullten Wagen. Es wiederholt sich die gleiche Szene wie vorher, nur daß nun der bltere Bruder die Probe besteht. Der Kum fordert erneut das Madchen, erhalt aber die Antwort, dab noch eine dritte Probe zu bestehen sei: Aus zwei gleichen Mudchen musse die Braut herausgefunden werden. Da sagen die beiden jungen Helden zu den Svaten und dem Brăutigam, der Hochzeitszug könne ruhig schon abreisen; sie beide wollten die dritte Aufgabe auch noch lösen.-Die Svaten reiten los. Der altere der beiden Bruder greift in die seidene Tasche, zieht Perlen hervor, streut sie vor die Mädchen hin und fordert die Braut zum Aufheben auf. Sollte die andere sich auch nur bewegen, so schlage er ihr den Kopf ab.- Die Braut gehorcht und sammelt die Perlen auf. Da wirft der altere Neffe die beiden Madchen zu sich aufs Pferd, reitet mit seinem Bruder 108 und holt mit ihm die Svaten ein. Der Neffe ubergibt dem Oheim die Braut und sagt, das andere madchen behalte er fur sich. Eine Doppelhochzeit krónt die Uberstandenen Muhen.

Dieses im allgemeinen gut gelungene lied steht noch ganz in der Tradition des vom skr. Raum zugewanderten Sujets. Die meisten Elemente sind bewahrt geblieben, wenn auch manches verandert wurde. Erhalten blieben das lateinische Land (Latinska zemja) als Reiseziel und die Bedenken wegen der betrugerischen Lateiner: 
On ne je odil u Latinska zemja,

On ne znae Latingki zakon'e,

$K^{\prime} e$ go vrünat nadzat bez nevesta.

Erhalten blieb auch der im skr. Iled häufige Name des kunftigen Schwiegervaters Mihajlo, hier anklingend in der leicht veranderten, bulgarisierten Form Milco. AuBerdem blieb die Drelzahl der Freiersproben bewahrt, nur wurde der pfeilschus durch das Ubberspringen von neun Wagen mit Dorngestrupp ersetzt. Ich sehe in diesem Dorngestrupp, das als Gefahrdung fur einen schlechten springer gedacht 1st, eine sekundzr verbkuerlichte Abwandlung der in skr. Iiedern haufig auf den Pferderücken aufgerichteten Schwerter, so dab wir in unserem wbulg. Iied also die Aufspaltung dieses Motivs in Pferde und Schwerter hatten, wobei die Schwerter aber durch Dornen ersetzt murden. Erhalten blieb auch das Motiv der nicht eingeladenen Neffen, dem aber sekundar die Stelle hinzugefugt wurde, dab die Mutter des Bräutigams meint, seine Schwester sei schon selbst klug genug, die sobne nachzusenden. Neu ist auch der Ifedeingang, wo Crunogorces schlechte Laune geschildert und der Grund fur sie angegeben wird. Die yutter spielt hier, wie so haufig in maz. und bulg. Iiedern, eine groBe Rolle. $S 1 \mathrm{e}$ hat den Sohn verlobt, sie fragt ihn nach dem Grund fur seine Verstimmung, sie weis Rat und behalt auch recht.- Ein schones sekundures Motiv enthalt die Stelle, wo Crinogorce beschreibt, wie seine Neffen schon Pferde flur die Hochzeit des Oheims vorbereitet haben.- Der Sangerin ist ein Fehler unterlaufen, wenn sie einerseits sagt, Crünogorce sei schon seit drei Jahren, also seit dem Tag seiner Verlobung, miBgestimmt, andererseits aber wegen des am Vortag erhaltenen Briefes. Ein weiterer Fehler besteht darin, dab sie vergessen hat zu sagen, das sich die beiden Neffen als 21 geuner verkleidet haben, denn anders lot der Widerspruch nicht zu erklaren, daB sich die Neffen einmal "belo, belo prementil", und andererseits als "curni cigan'e" von den Svaten abgewiesen werden. Eine sekundare Verkinderung und Entstellung besteht darin, dab der Neffe seinen Onkel schon zu frlih, namlich bel der er- 
sten Prufung, als "Oheim" anredet und sich so vorzeitig zu erkennen gibt. Damit fallt die Erkennungsszene am Iiedende naturlich weg. Statt dessen ist ein neues Motiv hinzugekommen: Die Neffen schicken die Svaten voraus, und erst jetzt löst der gltere die dritte Aufgabe, wirft die beiden Madchen zu sich auf das Pferd und reitet mit seinem Bruder den Svaten nach. Diese Stelle ist besonders wirkungsvoll:

Ta $a i$ fana do dve malki momi,

Ta gi furrli zad nego na kone,

Ta pripusti nis pole siroko.

Ni go veter, veter doduvjase,

Ni go sŭnce, sưnce dogrevjał̌e,

$\mathrm{Ni}$ go rosa, rosa dorosuva,

Ta si stigna kiteni sfatove.

Nun ubergibt der Neffe seinem Oheim die Braut und erklart, das andere Madchen werde er für sich behalten:

Cekai, vuk'o, crunogorce mlado, Ja ti poznach tfoe purvno l'ubne, Edna k'e mene, drugata tebe.

Der Oheim ist einverstanden; eine Doppelhochzeit schliebt das Lied ab. Nun wird auch klar, warum der Neffe den Brăutigam und die Svaten voraussandte: damit hermach der Madchenraub umso reibungsloser vonstatten gehen konnte.- Die Neffen werden in diesem Iied nicht beim Namen genannt, wohl aber der Brautigam, der in der typischen maz.-bulg. Deminutivform als "mlado Crünogorce" bezeichnet wird. Gemeint ist damit sicher die beliebte skr. Liedgestalt, namlich der historische Ivan Crnojevic (1465-90), Sohn des Stefan Crnojevic, "Herr der Zeta" (gospodar zetski), ein Vasall Venedigs, der vergeblich die Selbstandigkeit anstrebte. Er wurde Vojvode der Oberen Zeta und wegen seiner Verdienste im Kampf Venedigs gegen die Turken sogar in den Adel von Venedig aufgenommen. Nach dem Turkeneinfall in Montenegro floh Ivan nach Italien, kehrte aber 1481 nach dem Tod von Mohummed II. wieder in seine Heimat zuruck, wo er turkischer Vasall wurde. Den Venezianem galt er forthin als "homo de animo inquieto et scandaloso". Seinen altesten Sohn durfte Ivan mit Erlaubnis des Sultans mit Elisabeth, der Tochter des venezianischen Patriziers Antonio Erizzo, verloben ${ }^{138}$. Doch die- 
se Tatsache hat sicher nicht auf unser lied eingewirkt, sondern das beliebte Wandersujet wurde einfach mit Hilfe des historischen Namens historisiert. Uberhaupt entspricht von alledem, was uber die Crnojevici in Iiedern gesungen wird, kaum etwas der historischen Wahrheit. Ivan Crnojevic ist eine bekannte sudslavische Liedfigur. Er tritt in den skr. Ilederm als Ivan und, von dort lubernommen, in den maz. und bulg. Iiederm als Ivo Cernogorle, Ive curmogor oder Ivo dobŭr junak auf ${ }^{139}$.

In Var.18, einem mittelbulg. Koledalied, ist unsere Normalreihe "SchuB - Sprung - Herausfinden der Braut" noch durch eine Trinkprobe erweitert:

Jankul junak freit ein Madchen aus Adrianopel (divojkŭ drejnupolkŭ). Er ladt Krali Marko als Gevatter (pubastim) ein und zieht mit vielen Svaten nach Adrianopel ( $v$ Drejnopoli). Dort kommt den Gasten eine Abordnung junger Manner aus der Stadt entgegen. Sie reichen Jankul peil und Bogen und sagen, er werde das Madchen nur dann bekommen, wenn er Adrianopel und das Peld von Çorlu (Corl jư krru) Uberschiebe. Janko, der sich die Erfuliung dieser Aufgabe nicht zutraut, erhalt Beistand von Seiten Markos, der fur ihn die Preiersprobe besteht. Als zweite Aufgabe Uberspringt er neun Pferde, als dritte Aufgabe trinkt er ein neun Oka schweres Glas aus und zuletzt erkennt er schlieblich Jankulica aus zwe 1 glelchaussehenden Mädchen dadurch heraus, daß er Ihnen gelbe "Zejl1" (Goldstlucke?) und Perlen (bisir margir) vorlegt, die Richtige zum Nehmen auffordert und dabei mit dem blanken Schwert droht. Die Braut gehorcht und verrat sich somit.

In dieser gerafften und sehr kargen Variante ist der SchuB zwar erhalten, gilt aber hier keinem bestimmten Ziel, sonderm muß nur weit und hoch sein. Der Sprung geht - wie in den skr. Varianten - Uber neun Pferde. Die Trinkprobe ist ein neuer Faktor, der uns vom ritterlichen Milieu des Dreikampfs wegfunrt. Das Herausfinden der Braut ist ohne jeden Prunk und nur in kmappen Worten beschrieben. Die Neffenepisode und die Warnung vor den betrugerischen Ieuten im fremden Land fehlen, wodurch das Iied seine Spannung verliert. Marko ist als Gevatter offiziell beim Hochzeitszug und erfullt die Aufgaben fur den Preier in seiner Eigenschaft als Helfer des 
Brautigams. Die reizvolien Verkleidungs- und Offenbarungsszenen fallen also weg.- DaB dieses Lied nicht auf bulg. Boden entstanden ist, durfte - nach einem Vergleich mit dem skr. Variantenmaterial - wohl ziemlich klar sein. Das Handlungsgerippe ist noch einigermaßen bewahrt; auch Janko als Brăutigam blieb erhalten. Ein bulg. Zusatz ist offenbar die aus einer Trinkprobe bestehende Aufgabe.

Var. 19 hat folgenden Inhalt:

Zar Milos verlobt sich mit der Tochter des Zaren und erhält vom Schwiegervater die Welsung, beliebige Leute als Svaten einzuladen, nur nicht die beiden Neffen, die als trink- und streitslichtig bekannt seien. Milos gehorcht. Da erklären die Neffen ihrer Mutter, sie habe die roten Festkleider (cocha Cervena) umsonst genkht, denn vom Oheim komme keine Einladung. Die Mutter solle die Stute satteln, weil einer von ihnen ins Gebirge reiten und sich den vorbeiziehenden Svaten anschlieben werde.- Dies geschieht, aber der Bräutigam will den Neffen zuruckschicken, weil man ihn nicht eingeladen habe; außerdem sei die ganze Gesellschaft in Rot gekleidet, er aber trage Grin und falle dadurch unliebsam auf. Der Neffe (wobei er Miloz mit "Oheim" anspricht) sagt, er denke nicht daran umzukehren, denn die Mutter habe inn zum Schutz ihres Bruders gesandt.- Sie reiten tagelang und gelangen endlich zur stadt, in der die Braut wohnt. Man fragt Miloz, ob er einen helden im hochzeitszug dabeihabe, der einen Silberring treffen und die Stadt uberschießen konne. Solite sich niemand dazu bereit finden, wirde Miloz getbtet werden: "zda ti ziomim glavona". Als sich keiner der Helden meldet, klagt Milo8, er hatte doch seine Neffen einladen solien; die wilden nun die Aufgabe losen.- Da tritt der Neffe vor und besteht die Probe. Als zweite Aufgaba soll ein Held die Stadtmauer uberspringen und das Tor von innen offnen, damit die Hochzeitsguste in die Stadt einziehen können. Der Neffe besteht auch diese Prufung mit Ieichtigkeit:

Na dvaz ja nadripna. prüripna. und die Svaten betreten die Stadt. Als drittes besteht der Neffe eine schwierige Trinkprobe:

S stovna vinu piezi, 1 gulema mako kiogl'arŭ, und als vierte Aufgabe findet er schlieblich die Braut aus 300 verschleierten Madchen heraus. Er wirft den Mudchen Geldstucke (altonü) hin, die sie aber nicht aufsammeln, dann "rupkovú" (rup= Groschen), die sie ebenfalls liegenlassen, und end- 
lich Goldmilnzen (zolti altoni) mit der Mahnung, sie sollten diese schleunigst auflesen, sonst werde er ihnen die Hande abschlagen. Nun erst schlagen die Madchen die Ärmel zurluck, un die Goldstlicke aufzulesen. Der Neffe erkennt die Braut an ihren Fingerringen und fuhrt sie dem Oheim zu mit den Worten:

Ujkoljo, ujko Miluડ̌, ja suva ti i bulcŭnu, worauf der Brautigam antwortet:

Vodi ja, vodi Rambule, da ti $i$ chalal bulcŭno, Cimi chariza dušosal

Dieses Angebot lehnt der hier zum erstenmal als Rambul angeredete Neffe jedoch ab.

Auch diese bulg. Variante fält qualitativ gegenüber den skr. Liedern ab und erweist sich als zugewandert und sekundar. Das urspriingliche Sujet ist zum Teil zerrütet: Einerseits ist zwar das Moment, die Neffen auf Rat des Brautvaters nicht einzuladen, erhalten, andererseits aber dadurch verdorben, daB der Neffe nicht verkleidet mitzieht (sondern nur andersfarbig gekleidet) und den Bräutigam gleich als "Oheim" anredet, also sich zu früh zu erkennen gibt, worauf der Oheim bei der ersten Freiersprobe unverständlicherweise trotzdem um seine uneingeladenen Neffen klagt. Der "klassische" Sprung uber mehrere Pferde wurde hier durch einen Sprung uber das Stadttor ersetzt, was natürlich als sekundärer Zug zu werten ist. Die Trinkprobe fanden wir schon in der vorhergehenden Variante. Neu ist die Art, wie der Neffe hier das richtige Mädchen herausfindet: Beim Aufsammeln der Goldstilcke verrät sich die Braut durch ihren bei aufgeschlagenen ärmeln sichtbaren Fingerschmuck. Dieses Motiv ist zwar sehr reizvoll, aber sekundär an stelle des in den skr. Varianten ublichen eingesetzt. Daß der Neffe Rambul erst an Ende des Liedes beim Namen genannt wird, ist ein Versehen der Sängerin. W.Werner mochte "Rambul" aus dem Turkischen erklären, närlich als Ableitung von dem männlichen PN Ramo (+bul), den sie aus turk. Ramadan bzw. aus Avram herleitet ${ }^{140}$.- Mit "Zar" Milos ist hier entweder Milos obilic gemeint, der 1389 Sultan Murad I. auf Kosovo tötete, oder aber der serb. Fibrat Miloß Obrenovic, der nach Karadoraes Flucht nach Österreich 
in Serbien regierte (ab 1815). Wahrscheinlich ist aber der erstere gemeint, der stereotyp ins lied eingesetzt wurde; die zweite Möglichkeit wäre vielleicht als Aktualisiemungsversuch zu betrachten. Mit dem "Zaren" (Car'an), dem Brautvater, ist der turkische Sultan gemeint. Das Lied könnte in pomakischer Umgebung tradiert worden sein, weil auch der Hinweis auf die betrugerischen Leute am Hof des Brautvaters fehlt.

Var.20 folgt in der Personenbesetzung und Handlungsfuhrung deutlich dem ersten Teil von Vuk II 28, das noch zu besprechen sein wird, und erweist sich dadurch sowie durch die Abwandlung der Freiersproben als relativ junges sekundäres lied im maz.-bulg. Raum:

Konig Stefan von Serbien entsendet seinen Diener Todor nach Leden ins kroatische Land zu König Mikailo, um auskundschaften zu lassen, ob sich das Madchen Rosanda als serb. Konigin eigne. Todor kommt mit positiver Antwort zurick, berichtet jedoch gleichzeitig, der Brautvater habe die Bedingung gestellt, dab Stefan seine beiden Schwestersohne Petmasin und Vukasin aus der Stadt Trünc (moglicherweise entstellt aus Vucitrn, wie die Stadt in Vuk II 28 heiBt) nicht zur Hochzeit einlade, weil sie Trinker und streitsuchtig seien. Stefan gehorcht und zieht mit einer Menge Svaten, aber ohne die Neffen 10s. Die beiden Brlder erblicken den Hochzeitszug und verstehen, was geschehen ist. Ihre Mutter, Stefans Schwester, ahnt, dab ihr Bruder in eine Falle geht, und beschwort ihre Sorhne, heimlich zu seiner Unterstutzung mitzuziehen, was die beleidigten sohne aber ablehnen. Darauf wird der im Sar-Gebirge lebende dritte Bruder, der Hirte Milan, verstandigt, er solle nach Hause kommen. Als er eintrifft, erzahlt man ihm alles und verwandelt ihn durch entsprechende Verkleidung in einen schwarzen Bulgaren, der aber unter seinem Hirtenmantel prachtige Festkleider trägt. Er zieht mit den Svaten, die ihn zuerst vertreiben wollen. Der Konig bestimmt aber, daB dor Bulgare beim Hochze1tszug bleiben darf.- In Leden fordert vilan die Schankwirtin auf, ihm Wein zu verkaufen, worauf sie ihn verspottet und dafur von Milan geschlagen wird. Da erkennt sie Milan, von dem seine Bruder ihr schon viel erzählt haben, und schenkt ihm Wein ein, soviel er will. Der Held eilt zu den Svaten zuruck und kommt gerade noch rechtzeitig, um die drei Freiersproben, die niemand bestanden hätte, erfỉlen zu können. Die zun 
Uberspringen bereitgestellte Lanze fegt Milan mit seinem Streitkolben weg. Dann Uberspringt er neun mit Dorngestrupp gefullte Wagen und findet mit der bekannten List aus drei gleichaussehenden Mädchen die Braut heraus, fluhrt sie dem Brăutigam zu und nimmt flir sich selbst eines der Madchen, das sich als die Schankwirtin von vorher entpuppt.

Statt den auf einer Lanze aufgespieBten Apfel zu schieBen, wird hier - wahrscheinlich daraus abgeleitet und gleichzeitig mit der năchsten Probe vermengt - ein Sprung uber die Lanze gefordert. Statt des Sprungs uber neun Pferde verlangt man hier die verbäuerlichte Form des Sprungs uber neun Wagen mit Dorngestrüpp. Das ganze Sujet erweist sich also in dieser Form als sekundär. Die Veränderung der Freiersproben und die Erweiterung durch die Episode mit der Schenkwirtin (krürmara) erfolgten im neuen Liedraum. Die Erkennungsszene zwischen Oheim und Neffen fehlt. Var.21, mit der Bemerkung "ostliche Mundart" versehen, hat folgenden Inhalt:

Vülko verlobt sich mit der Zarentochter, und der Zar gibt dem Bräutigam die Weisung, alle Verwandten einzuladen, nicht aber seine Schwestersöhne Marko "malko dete" und vullean vojvoda, denn die beiden seien zankslichtig und würden nur die Hochzeitsfeier stören. vullko gehorcht und macht sich mit den Svaten, aber ohne die Neffen auf den Weg zur Braut. - Marko hort davon und fragt seine Mutter, warum der Oheim sie nicht eingeladen habe; ob er sie vergessen habe oder ob er sie beide nicht dabeihaben wolle? Die Mutter solle ihm seinen Pelzmantel aus drei Bärenfellen, die Zobelmitze sowie die "kleine", 100 Oka schwere Eisenkeule herrichten. Er werde namlich uneingeladen mit den Svaten ziehen.- Marko kleidet sich an und schmllckt sich, reitet dem Hochzeitszug nach und erreicht inn am Tor des Zarenhofes. Der Zar labt das Stadttor schließen und fordert vǔlko zum tuberspringen und Öffnen des Tores auf; nur so könne er die Braut erringen.- Vülko senkt den Blick und weiB sich keinen Rat. Da meint Marko, er sei zwar vom Oheim nicht eingeladen worden, werde aber dennoch die Aufgabe lösen. Er tummelt sein Pferd, uber. springt das Tor und offnet es fïr die Hochzeitsgäste. Die Braut wird wieder nicht Ubergeben, sondern man ladt drei Fuhren Dorngestrüpp im Hof ab und fordert den Bräutigam erneut zum Ubersetzen auf. Wieder besteht Marko die Probe für Vŭlko. 
Dann werden drei gleichaussehende Madchen herbeigefuhrt und vulko aufgefordert, die Braut herauszufinden, denn wenn ihm das gelinge, konne er sie endlich fur sich nehmen.- Marko tritt fur den ratlosen Oheim vor, zieht einen goldenen Ring aus seiner Tasche und sagt leise zu den drei gleich furstlich gekleideten Mädchen, die Braut solle den Ring nehmen; sollte eine der beiden anderen es wagen, erschlage er sie mit seiner Keule. Die Zarentochter streckt daraufhin die Hand aus und nimmt den Ring, worauf Marko sie dem Oheim zufuhrt. Das zweite Madchen behult er fur sich und das dritte Ubergibt er seinem Bruder. Dann zieht der Hochzeitszug glucklich nach Hause.

In dieser Variante blieb der Dreikampl zwar erhalten, wurde aber nach einem uns schon bekannten Schema abgewandelt: An die Stelle des Sprungs uber mehrere peerde trat der Sprung Uber das Stadtor. Der Schuß fiel aus, statt dessen folgt ein Sprung uber drei Fuhren hingeschuttetes Dorngestrupp (wobei die Wagen wegfielen), was naturlich nur ein sekundarer, in bäuerlicher Umgebung entstandener Zug sein kann, vielleicht aber, wie schon erwahnt, als Rluckbildung der in skr. Varianten auf den Pferderucken aufgestellten Schwerter oder Lanzen aufzufassen ist. Beim Herausfinden der Braut droht der Neffe nicht damit, der Falschen nur die Hande abzuhauen, sondern sie mit der Keule zu erschlagen,- wieder eine sekundure, rohe fbertreibung und Verzerrung des urspringlichen Motivs. Bewahrt blieb das Motiv der nicht eingeladenen Neffen; die Begrindung aber, warum Marko doch mitreitet ( $n$ amlich aus Besorgnis wegen der betrugerischen Leute an Hof der Braut), fiel weg. Ferner wird die Verkleidung Markos durch Barenfellmantel und Pelzmitze zwar angedeutet, dann aber nicht ausgenutzt. Auch die Selbstoffenbarung des Neffen erfolgt viel zu fruh, nämlich schon bei der ersten Freiersprobe, so daß die in den skr. Varianten so wirkungsvolle Schlubszene dieses Inhalts entfallt. Auch hier wieder werden drei Madchen weggefuhrt. Vülko ist ein "gewohnlicher" und sehr häufiger Name ${ }^{141}$. Es wurde also kein Versuch gemacht, einen moglichst beruhmten, furstlichen Brautigam fur das Iied zu wahlen. Umso klangvoller lst der Name des hilfreichen Neffen: Es handelt sich un den beliebten Konigssohn 
Marko, hier nach Art der maz.-bulg. Heldenkinder "mlado dete" genannt. Als sein Bruder wird vullean erwänt, hinter dem sich vielleicht König Vukazin, der Vater des historischen Marko, verbirgt.

Der Inhalt von Var.22 lautet so:

Gruica verlobt sich in einem fermen Land mit einem Madchen. Zum Hochzeitszug lädt er alle seine Verwandten ein sowie Svaten aus drei Stadten. Die Hochzeitsgăste treffen vollzählig ein, und zu ihnen geselit sich der junge Nikola, in Tatarentracht verkleidet, doch unter seinem "pandzak tatarski" in seidenen Kleidern. Die Svaten fragen den "schwarzen Tataren", ob er sein Pferd tauschen oder verkaufen wolle, was Nikola verneint und sagt, er werde lieber zu Pferd mit den Svaten ziehen. Diese aber wollen ihn wegjagen, weil er ihnen Schande bereiten könnte. Er ikBt sich jedoch durch nichts beirren.- Sie gelangen zu dem großen Dorf, wo die Braut wohnt, und machen davor halt, worauf man ihnen als erste Freiersprobe auferlegt, daB einer der Svaten die Blatter eines Maulbeerbaums zăhle und dann den Baum uberspringe. Keiner der Svaten ist dazu in der Lage, Nikola aber lost die Aufgabe. Er besteht auch die zweite Probe: Er Uberspringt das verschlossene Tor, yffnet es und labt die Svaten in das Dorf herein. Da werden drei gleichaussehende Madchen vor die Gaste gefuhrt und gefordert, dab einer die Richtige herausfinde (koja je moma godena). Wieder ist Nikola der einzige, der die Probe besteht: Er zieht seinen Tatarenmantel aus und breitet ihn auf den Boden, worauf der Held in glanzenden Seidenkleidern erstrahlt, streut Perlen (biser margari) auf den Mantel, zluckt sein frankisches Schwert (sablja frengija) und fordert die Braut auf, die Perlen aufulesen; weigere sie sich, schlage er ihr den Kopf ab.- Die Braut gehorcht und wird dem Bräutigam zugefuhrt, worauf die Svaten nach Hause ziehen und am Hofe Gruicas eine Woche lang Hochzeit feiern. Nikola, der die Svaten daran erinnert, dab sie ohne seine Hilfe Uberhaupt nichts erreicht häten, wird mit einem goldenen Hemd (zlatna kosulja od zlato) und einem Goldglurtel (zlaten kolanec) beschenkt. AuBerdem schließt man Wahlbruderschaft mit ihm.

Das Auffallendste an diesem Lied ist, daß der sänger das Motiv der nicht eingeladenen Neffen völig fallengelassen hat, wodurch das ganze Sujet eine Veränderung erfährt: Irgendein Nikola gesellt sich völlig unmotiviert zu den Svaten, noch dazu verkleidet, d.h. der Sanger bcsab wohl noch 
eine blasse Erinnerung an die Verkleidung, in der der uneingeladene Neffe unerkannt und ungern geduldet mit den Svaten zieht. Erhalten blieb auch bei der dritten Freiersprobe die hubsche Szene, wo der "schwarze Tatare" seinen Tatarenmantel ablegt, in strahlender Seide gekleidet dasteht und nun die Braut mit Hilfe von Perlen und Schwert herausfindet. Weil also am Liedende keine Erkennungsszene stattfinden kann und damit kein Anlab zur Verherrlichung der Verwandtentreue besteht, wird hier dadurch Ersatz geschaffen, dab Nikola zum Wahlbruder erklärt wird. - Die Variante ist stark verbauerlicht. Gruica freit ein namenloses Madchen, dessen Vater gar nicht in Erscheinung tritt (wodurch das Motiv der Warnung naturlich hinfullig wurde), in einem weit entfernten Dorf (1). Wenig ritterlich ist auch das Blutterzählen und Baumuberspringen, die sekundär - zusamen mit dem Torlberspringen und -öffnen - fur die urspringliche Sprung- und SchieBprobe eingesetzt wurden. Das Sujet ist also (wie alle bisherigen und erst recht die weiteren maz. und bulg. Varianten) sicher aus dem skr.Raum ubernommen und nachträglich umgestaltet und verderbt worden.- Gruica ist ein sehr häufiger sudslavischer Liedname. An ihn ist auch das Motiv der untreuen Prau geknupft. Er wird häufig als Sohn (dete Grujo, Grujica, Grujco) des Hajdukenanfuhrers Starina Novak aus dem 16.Jh. aufgefaBt ${ }^{141 \text { a }}$ (vgl. die Lieder Bog.39; EH 66,92,112; Mil.122 u.a.) und im Lied sehr haufig als Neffe seinem Oheim Marko zugesellt. Oft ist Gruica als Heldenkind (dete, detence) aufgefaßt.Var.23 unseres Sujets mit dem Titel "Ovðar budalina i carevata dústerja" hat folgenden Inhalt:

Ive Curmogorte freit die Tochter des Zaren. Er ladt Bekannte und Unbekannte ein und zieht mit 300 Leuten zum Hop seiner Braut. Ive hat viele Neffen (nogu sestrixnici), die aber trink- und streitslichtig sind und mit dem zaren streit beginnen wlirden, worauf der Zar das Mädchen nicht hergabe. Die 300 Svaten ziehen also ohne die Neffen 10s. Da tritt ein "torichter Schüer" mit einem schwarzen Mantel auf und schliebt sich dem Zug an. Die Hochzeitsgäste versuchen ihn zurlickzutreiben, weil der schwarze Hirte (cüma ovca- 
rino) den schmucken Svaten Schande bereite.Sie gelangen zum Zarenhof, wo schon eine Pesttafel vorbereitet ist. 300 Herolde (teljali) treten auf und verklinden, das nur derjenige die Zarentochter erhalte, der Kiefern und Pappeln uberspringen könne. Alle Svaten blicken zu Boden, nur der torrichte Schafer hat Mut und besteht die auferlegte Freiersprobe. Als nächste Aufgabe müssen neun Wagen Dorngestrlipp Ubersprungen werden, was wieder nur der Schufer vermag. Zuletzt labt der Zar seine Töchter und Schwiegertochter in einer Reihe aufstellen, und Herolde fordern den Freier auf, die Braut herauszusuchen. Keiner der Svaten traut sich das zu, nur der Schafer schwingt sich aufs pferd, hängt sich seinen schweren Mantel um, nimmt seine flinte, umgurtet sich mit dem Schwert, tummelt sein Pferd und ruft den Madchen bei drohend gezlucktem Sabel zu, wenn sie am leben bleiben wollten, solle sich die Zarentochter zu erkennen geben.

In dieser offensichtlich stark gerafften und verderbten Variante ist zum zweitenmal Ivo Curmogorle der Bräutigam. Die Braut ist wieder einmal die Tochter des Zaren, also die Sultanstochter. Es handelt sich erneut um eine (Pseudo-)Historisierung des episch-märchenhaften Sujets.- Verderbt ist die Stelle, wo von den vielen Neffen des Bryutigams die Rede ist. Man weib nicht, ob Ivo hier seine Meinung aubert, wenn es heibt:

Oni sa si nogu kavgalii,

Oni sú caro kavga da naprava

Ok'e caro moma da ne dava,

oder ob dies nur ein Kommentar oder eine Erklärung des Sangers ist. Das wichtige Motiv der uneingeladenen Neffen wird also nicht klar formuliert. Die Besorgnis wegen der Sitten im fremden Land ist ebenfalls nicht ausgesprochen, weil die Figur der Mutter des Brautigams bzw. der Mutter des Neffen vollig fehlt. Auch die Stelle ist verderbt, wo der törichte Schafer einfach zu den Svaten stobt und trotz inres Protests mitzieht. Es geht mit keinem Wort aus der Situation hervor, ob das der verkleidete Neffe des Brăutigams ist, - was er aber wohl sein soll, wie wir bereits aus dem Variantenvergleich wissen. Deshalb fallt auch die Erkennungsszene am Liedschluß weg. Die Freiersproben sind wieder sekundar verbauerlicht worden und schlieBlich dazu abgesunken, daß Kie- 
fern und Pappeln sowie neun Wagen mit Dorngestrupp Ubersprungen werden sollen, was allein der verkannte Dummling, der "törichte Schafer", in murchenhafter Weise schafft.Das Lied hört abrupt damit auf, dab der Schufer sich unsinnigerweise seinen schwarzen Mantel (cŭma gunja) anzieht, aufs Pferd steigt, seine Flinte (1) nimmt und sein Schwert schwingt, um dann nur den Mädchen zuzurufen:

Koj si saka zivo da ostane, Da 8 i kaže carevata kerka!

Var.24 (vgl. später Var.51) hat folgenden Inhalt:

vil. co $_{0}$ Preit jenseits der Donau in der Stadt Kotljan die Konigstochter Margita, soll aber auf GeheiB seines Schwiegervaters seinen Neffen Ivanto nicht einladen, weil inm dieser mit Trinken und Streit die Hochzeit store.- Ivanco erfuhrt, davon und geht auf den Rat seiner Mutter ungeladen mit den Svaten, verkleidet mit einem Mantel aus neun Burenfellen und einer Wolfspelzmutze. Als der Hochzeitszug am Hof der Braut angelangt ist, wird die Braut nicht Ubergeben, sondern den Svaten nur inmitten anderer, vollig gleichaussehender Mädchen im Hof gezeigt. Als erste Preiersprobe mllssen neun $\mathrm{MaB}$ Wein und ein Maß Schnaps ausgetrunken werden, was nur Ivanco gelingt, um den der Oheim jammert, weil er den Verkleideten ja nicht erkennt. Als nuchste Probe besteht Ivanto den Kampl mit einem Bären und findet als letzte Preiersprobe durch List die Braut heraus. Nun wird die Braut endlich Ubergeben, und die Svaten konnen mit dem uadchen nach Hause ziehen.

Auch hier wurde der einfache, volkstumliche Name vullo als Name des Brăutigams eingesetzt und damit die urspringliche Historisierung ruckgängig gemacht. Das Ziel der Brautfahrt ist Kotljan, hinter dem sich vielleicht die Stadt Kotel verbirgt. Dagegen spricht allerdings, das die Stadt uber der Donau liegen soll.- Die Trinkprobe hat auf bulg. Boden die urspringliche ritterliche SchuBprobe ersetzt. Der Kampl mit dem Baren ist typisch ostbulg. und murde hier vielleicht sekundar flur einen Kampf des Helden mit einem Zweikämpfer des konigs gesetzt.

Var.25 ist ein Tischlied (trapezna pesen) und hat folgenden Inhalt:

Kornig Milos verlobt sich mit der Zarentochter und erhalt vom Brautvater die Anweisung, beliebige 
Gkste einzuladen, nicht aber die beiden Neffen, die als trink- und streitsuchtig gelten. Milos gehorcht und lkdt aus neun Dorfern Svaten ein, aus dem zehnten die Kume, - die beiden Neffen aber Ubergeht er.- Da weint Malecko und fragt seine Mutter, wozu sie nun Kleider genäht und Pferde gezluchtet hatten, wenn der Oheim sie doch nicht einlade, worauf die Mutter r\&t, er solle ungeladen mitgehen.- Malecko tut dies, wird aber vom Oheim erkannt, der ihn zurickzutreiben versucht, damit er die Svaten nicht bedrohe (da mi ne grozis svatove). Malecko antwortet, der oheim solle nur mit den Svaten vorausziehen; er werde in einigem Abstand folgen, um niemanden zu belastigen.- Als sie zum Zarenhof gelangen, sind die Tore verschlossen. Der Zar ruft, ob der Schwiegersohn Milos einen Helden bei sich habe, der die Tore offnen könne. Milos bricht in Trünen aus, Malecko aber tröstet ihn und sagt, er werde die Aufgabe lösen. Er tummelt sein Pferd, Uberspringt die Mauer und offnet die Tore.Als nächstes besteht Malecko stellvertretend flur den Bräutigam eine Trinkprobe mit dem Zaren. Aufgefordert, endlich die Braut herauszufluhren, l\&Bt der Brautvater drei gleichaussehende Madchen auftreten, aus denen die Braut herausgefunden werden soll. Wieder weint Milos. Von Malecko befragt, ob die Braut ein Verlobungsgeschenk (menana) erhalten habe und daran zu erkennen sei, antwortet Milos, sie trage einen Silberring. Da streut Malecko Goldminzen (jalture) auf den Boden und ruft, Svaten und Kume sollten sie auflesen; wer sich nicht an dem Aufsammeln beteilige, dem schlage er die Hände $a b$. Nun erblickt Malečko den besagten Ring an der Hand eines Madchens, nimmt die so erkannte Braut an der Hand und fuhrt sie dem Oheim zu.

Uber Konig Milos und den Zaren als Liedfiguren wurde oben schon gesprochen. Der Name "Malecko" ist aus malecŭk, Deminutiv zu mal(ük) "klein", und -ko gebildet und - laut Werner"142 - "sehr selten". Es handelt sich hier um die Rolle eines Heldenkinds, das Unmogliches zu leisten imstande ist. Falsch ist in diesem Lied, daß der Neffe unverkleidet mitzieht und von seinem oheim sofort erkannt wird. Verderbt ist auch die Stelle, aus der hervorgeht, daß Malecko nur aus materiellen Erwägungen mit dem Oheim zieht, damit die kostspieligen Vorbereitungen fir die Hochzeit nicht umsonst waren:

Zašto sme şili, bǔrzali, Zarto sme kon'e chranili, 
Kuga na vujco ne vika,

I ni svatove da idem?

Es fehlt deshalb auch die Stelle, wo die Mutter Besorgnis Uber das Schicksal ihres Bruders in der unbekannten Fremde ausdruckt. Sie sagt nur lakonisch:

Idi mi, sinu Malecko,

Idi, sinu, ne kalesan!

Von den urspringlichen Preiersproben ist nur die letzte erhalten geblieben, doch auch sie nur in entstellter Form:

Es bleibt unverständlich, weshalb die Madchen sich am Aufsammeln der Goldmunzen betelligen, wenn Malecko sich nur an Svaten und Kume mit seiner Aufforderung wendet: '

Svatove, stari kumove,

Zbirajte zulti jaltŭne,

Kojto jaltune nezbira,

Rak'ina ga mu jots'eka.

Anscheinend sammeln nun alle Anwesenden Munzen auf, auch

die Zarentochter, denn:

Vid'e Malecko menana

In car'uvana dǔster'a.

Var.26 mit dem Titel "Zenidba na Stari Novakina" fällt durch Erweiterungen auf. Es mlssen z.B. nicht weniger als funf Proben bestanden werden:

Stari Novadina verlobt sich mit einem Madchen aus dem lateinischen Land und verspricht, Grste aus zehn Stadten einzuladen, nicht aber die beiden Brider Asik-Dimo und Asik-Nikola, die starke Trinker und daher unerwlinscht seien.- Die beiden Neffen horren davon, daß sie nicht geladen sind, und beschließen daher, ihren jungsten Bruder (malo bratce), der in der Stara Planina Schafe hutet, dem Onkel mitzusenden; er düfte nämlich, nachdem sie ihn sieben Jahre lang nicht mehr gesehen haben, Inzwischen ein großer Held (junak nad junaci) geworden sein und konne sich wirkungsvoli flur den Oheim einsetzen, damit dieser des Kidchen erhalte.- Sie gehen Im "Petersmonat"(Juni) ine Gebirge, finden die Herde an elnem Brunnen grasend und den Bruder schlafend. Seine Atemzluge sind 80 mächtig, dab der Wald sich jedesmal neigt und das Gebirge fast auseinanderbricht. Der Hirte erwacht, und die Brilder begriken aich. Dann fragen ihn die beiden, wieviel er trinken konne, wenn es darauf ankomme. Da antwortet der Jingste, wenn er an Ostern seine Schafe melke, trinke er neun Eimer Milch auf einmal aus und habe damit immer noch 
nicht genug. Weiter fragen ihn die Brider, wie weit er notfalls springen konne, worauf der Hirte meint, neun Taler konne er leicht uberspringen. - Wie weit er werfen könne?- Wenn er die Herde zum Heimkehren sammle, werfe er einen 300 Oka schweren Stein uber neun Thler.- Ob er eine Quitte dem Alter nach erkenne?- Selbstverstandlich, denn er erkenne ja auch jedes seiner zahlreichen frisch geworfenen Lammer sofort nach der Mutter.Nach diesen befriedigenden Antworten rucken die beiden blteren Brluder endlich mit ihrem Anliegen heraus: Der Oheim heirate ein Madchen aus dem lateinischen Land, die Lateiner seien aber Schurken und wiluden das Mädchen auf keinen $\mathrm{Fall}$ ohne Bedingungen ubergeben. Deshalb solle er, der Hirte, mit nach Hause kommen, sich bereit machen und dem

Oheim zur Unterstutzung nachreiten.- Der schwarze Schafer (crna ov carina) geht sofort nach Hause mit seinen Brudern, legt seinen schwarzen Hirtenmantel (crna kabanica) ab, verkleidet sich als "schwarzer Monch", nimmt Waffen und reitet den Svaten nach. Als er sie eingeholt hat, machen die Svaten den Bräutigam darauf aufmerksam, was fur ein schrecklicher Mensch (aro) sich ihnen da zugeselle. Der Brăutigam meint jedoch, er konne ruhig mitreiten; es kamen ja allerlei Leute ins lateinische Land, sie wiirden also mit ihm nicht unangenehm auffallen.- Als sie ans Meer gelangen, weicht das Wasser zurück und schleudert einen $\mathrm{Pisch}$ aufs Trockene. Die Svaten wollen sich auf ihn stiurzen, werden aber von dem Schäfer mit blankem Schwert zurlukgetrieben, weil der Pisch (riba= Pemininum!) seine Wahlschwester sei.- Als sie zu den Lateinerm kommen, werden sie schon erwartet. Man stellt ihnen die erste Freiersaufgabe: Wenn jemand neun Wagen mit Dorngestrupp Uberspringe, werde das Mudchen ausgeliefert. Alle Svaten blicken zu Boden, nur der Schbfar zeigt keine Furcht und Uberspringt die neun Wagen, und zwar so hoch, dab er noch neun weitere leicht ubersprungen hätte. Er besteht auch die zweite Probe: Er iBt neun Kessel Speise und trinkt neun Eimer Wein leer. Als dritte Aufgabe soll ein 300 Oka schwerer Stein aus dem Meer heraufgeholt und herbeigeschafft werden. Nur dem Schafer gelingt dies, und zwar mit Hilfe seiner dankbaren Wahlschwester,dem Fisch ('riba',fem.1), der ihm den Stein aus dem Wasser herauswirft. Die vierte Aufgabe bestent darin, die zehn stadtore, von denen das letzte aus Stahl ist, zu uberspringen, die lateinischen Schlosser aufzubrechen und die Svaten einzulassen, was wieder der Schafer vollbringt. Die Svaten ziehen in die Stadt ein. Da fuhrt man drei gleichaussehende Mädchen herbei und erklät, die Braut musse erst herausgefunden werden, bevor man sie (armasnica) mitnehmen dirfe. 
Als sich niemand das zutraut, tritt wieder der Schbfer vor. Er zieht seinen schwarzen Hirtenmantel aus, worauf er sich in seiner ganzen Heldenschonheit und -kraft zeigt und wie die Sonne strahlt. Dann schwingt er sich aufs Pferd, zluckt sein Schwert, holt aus seiner seidenen Tasche eine Handvoll Gold und eine zweite Silber,streut es vor die Mädchen hin und sagt, die Braut solle das Gold, die beiden anderen Mädchen aber sollen das Silber auflesen; gehorchten sie nicht, werde er sie alle t8ten. Die Mittlere sammelt das Gold auf und gibt sich darit als Braut zu erkennen. Der Held steigt vom Pferd, setzt das Madchen darauf und führt es zum Bräutigam hin. Dann setzt er die beiden anderen Mädchen hinter und vor sich aufs Pferd und ruft dem Oheim zu, es sei nun Zeit zu fliehen: die Beute sei erjagt. Das eine Mádchen behalte er flur sich, das andere gebe er den Gefahrten (na drugare) als Belohnung (bakłił).

Die vorliegende Variante ist ein ausgesprochen schones und fehlerfreies Lied, doch auch sie ist erst sekundär zu dem geworden, was sie nun darstellt. Das urspringliche Sujet wurde geschickt modifiziert und erweitert, neue Motive märchenhafter Art kamen hinzu, z.B. die Beschreibung des schlafenden Helden:

Dremka dreme $i$ silno si disa,

Od disanje gora se zanisa,

Dip za malo gora k'e ispada.

Er kann wirklich als Märchenheld gelten: Er ist der jüngste von drei Brudern, schoner und stärker als die beiden anderen; er wird als armer und törichter Schäfer verkannt, verblufft aber dann alle durch seine wunderbare Kraft und strahlende Schonheit. Mrarchenhaft ist auch das Motiv des dankbaren Tieres: Der Fisch, dem der Schafer auf dem Weg zum hof der Braut das Leben gerettet hat, erweist sich spater als dankbar und hilfreich.- Das Gerïst des Sujets ist im allgemeinen gut bewahrt worden. Das Motiv der uneingeladenen Nefren blieb erhalten, auch die bedenken wegen der betrugerischen Lateiner:

Latini sa kurvi i kavpeji,

$\mathrm{Pa}$ bez kaul moma ne davar.

Bewahrt blieb auch die Verkleidung mit einem schwarzen Bulgarenmantel und das wirkungsvolle Ablegen dieses Mantels 
bei der letzten Preiersprobe sowie das Motiv, daß der verkannte und unerkannt agierende Neffe sich erst an Liedende zu erkennen gibt.- AuBer den schon erwahnten Marchenmotiven kamen noch weitere sekundäre Veränderungen hinzu: Nicht einer der beiden uneingeladenen Neffen macht sich auf den Weg, sondern der dritte, jungste, schon lange im Gebirge lebende heldenhafte Bruder, den der Oheim nicht kennt, wird von den älteren Bridern zur Unterstlutzung des Brăutigams mitgesandt, - ein Motiv, das wir schon aus Var.20 kennen.. Neu ist die Art, wie die Brider den Schäfer durch gezielte Pragen auf seine Heldenhaftigkeit hin prufen, wodurch gewissermaßen schon eine Vorwegnahme der Preiersproben erfolgt, was nicht unbedingt positiv zu werten ist, weil dadurch die Liedspannung gemindert wird. Bei mehreren skr. Varianten sohen wir dieses Motiv, daß der Held sich mit seinen groben Leistungen brilstet, an passenderer stelle, nämlich bei den jeweiligen Freiersproben, eingefugt. Von den urspringlichen drei Freiersproben ist nur die letzte erhalten geblieben, doch wurden vier neue Proben vorangestellt, die uns - bis auf die Tauchprobe - schon aus anderen Varianten bekannt sind. Das Tauchermotiv ist im griechiachen Iiedbestand anzutreffen (vgl. Llubke,20) und gtammt vielleicht von daher. Die Iiedgestalt Stari Novak, hier als Stari Novacina auftretend, wurde bereits erklart. Die beiden Brider Dimo und Nikola (beiden arab.-tluk. "asik" vorangeetellt, d.h. TrautDimo und Traut-Nikola,einander in bruderlicher Liebe zugetan) konnten vielleicht als Mitglieder der Familie Jaksió erklärt werden, von denen an anderer stelle schon vermutet wurde, dab ihre Namen sekundar im maz. Raum auftreten. Im 16.Jh. lebten wirklich zwei Bruder Jakăit Dmitar (gest. 1539) und Nikola (gest.1539). Finkel des aus der Bugarstica so bekannten Dnitar Jaksic (gest.1486), des Wahlbruders des serb. Despoten Vuk Grgurovio ("Zmaj-ognjeni Vuk", gest. 1485). - Als Var.27 ist folgendes Lied zu nennen:

Vuce Saratlijex verlobt sich mit einem Madchen weit weg in der Stadt Legen. Die Kmeten (Stadtaltegten) von Legen tragen inm auf, er solle 300 
Svaten sammeln, nicht aber seinen Neffen sowie Perozikosano als ersten Kum und Janko Simijanko als zweiten Kum einladen. Vuce kehrt betrubt nach Hause zurick und wird von der Tante (strina) nach der Ursache seiner Verstimmung gefragt, worauf Vuce - in epischer Wiederholung - erzahlt, was die Kmeten von ihm verlangt haben. Die Tante empfiehlt inm, die verbotenen Leute doch einzuladen; sie willen ihm auch die 300 gewinschten Svaten herbeischaffen. Vuce hort auf den Rat und lädt den Neffen sowie Perosikosano und Janko Simijanko ein, die ihm wirklich 300 Svaten zufuhren. Inzwischen verkleidet sich der Neffe. Er zieht einen langen, graubräunlichen Mantel (sura gun'etina) an, ungurtet sich mit einem schwarzen Strick (crüna popražina) und setzt eine Bärenfellmilze (kapa mecetina) auf. Die Svaten ziehen 108. Auf offenem Feld stoßen sie auf einen Zug Ameisen. Der Neffe hält die Svaten zurilck, damit die Tierchen nicht zertreten werden, weil er meint, sie konnten ihnen vielleicht noch von Nutzen sein. Die Hochzeitsgäste erreichen die Stadt Legen, wo sie von den kmeten schon erwartet werden. Als erste Preiersprobe soll ein Kubel Wein ausgetrunken werden, was nur der Neffe, der verkleidete, "unbekannte Held" (nepoznat delija), vermag. Das Madchen wird aber noch nicht ubergeben, weil zuerst noch eine zweite Aufgabe zu losen ist: Drei Rappen sollen übersprungen werden,-eine Prurung, die wieder nur der "Unbekannte" besteht. Als dritte Probe soll ein Kessel Hirse (kutel proso) ausgelesen werden. Wer diese Aufgabe 1ose, erhal te das Mkdchen zur Frau.- Da ruft der Neffe, der auf dem Weg zur Braut die Ameisen beschutzt hat, die Tiere zu Hilfe, die fïr ihn die Hirse in gelbe und schwarze Körner aussortieren. Die Kmeten sind zwar uber die rasche Lbsung dieser schwierigen Aufgabe erstaunt, liefern das Mädchen aber immer noch nicht aus, sondern lassen es - zusammen mit zwei weiteren ganz gleichaussehenden Madchen - herbeifuhren und verlangen, dab man die Braut herausfinde. Da legt der unbekannte Held Mantel und Pelzmitze ab und steht strahlend in goldenen Kleidern (ruo sŭnðogledo) da. Er nimmt sein Schwert, wirft Perlen vor die Mädchen hin und sagt drohend, die Braut solle oioh danach bucken, andernfallo fielen drei blonde Krpfe. Daraufhin beugt sich das in der Mitte stehende Madchen nieder und liest die Perlen auf. Der Held ubergibt die-Braut triumphierend seinem Oheim Vuce Saratlijke.

In dieser Variante sind - ahnlich wie in den vorhergehenden - die urspringlichen Motive teils erhalten, teils verlorenE€ jangen bzw. geändert oder durch neu hinzugekommene erwei- 
tert worden. Bewahrt blieb z.B. das Motiv des gegen bestimmte Personen gerichteten Einladungsverbots, doch sind der Sängerin hier Fehler unterlaufen: Die beiden Kume, die auf den Rat der Tante doch eingeladen werden und bei denen es sich anscheinend um besondere Helden handelt, deren Kommen die Kmeten von Legen verhindern wollen, spielen dann im Iied Uberhaupt keine Rolle. Warum der Neffe nicht eingeladen werden soll, wird von den Kmeten Uberhaupt nicht begrindet, d.h. hier fehlt die schon bekannte fadenscheinige Entschuldigung, es handle sich un einen streitsuchtigen Trunkenbold. An die Stelle der ratgebenden Mutter ist hier unsinnigerweise die Tante getreten, die ihrem Neffen Vuce empfiehlt, die drei unerwinschten Personen doch einzuladen, wobei sie dazu aber nicht aus Besorgnis wegen der zu erwartenden Intrigen in der fremden Stadt rat, sondern nur meint:

Ti gi kani, selo da ne znae:

Oni $k^{\prime} e$ ti raja pokan'iti,

Oni k'e ti svati pokan'iti.

Man fragt sich, warum der Neffe, wenn er schon vom Oheim eingeladen warde, eigentlich verkleidet auftritt. Die Sangerin hat anscheinend die Verkleidungsszene beibehalten, um das Iiedende, wo der Neffe die Verkleidung ablegt und die Braut herausfindet, wirkungsvolier gestalten zu können. Die Erkennungsszene am Schluß ist Uberflussig. Von den urspring. lichen drei Freiersproben sind zwei erhalten geblieben: der Sprung Uber die Pferde und das Herausfinden der Braut. Die beiden neuhinzugekommenen Proben sind deutlich dem bauerlichen Milieu entsprungen: Ein Eimer Wein muB ausgetrunken und ein Kessel voll hirse ausgelesen werden. Bei dieser Auslesearbeit wird wieder - wie im vorhergehenden Iied - das Marchenmotiv der dankbaren Tiere als Helfer des Helden ausgenutzt (vgl. Aschenputtel, dem Tauben beim Auslesen von Linsen helfen).- Die Rolle des Bråutigams spielt hier vuce Saratlijce. Vuce ist die im Volkslied gern verwendete Vokativform von Vuk, die Deminutivform Saratlijke ist anscheinend von "seratlija" in der Bedeutung "Grenzkämpfer" (skr. 
krajiznik) abgeleitet. Damit konnte der berihmte Turkenkämpfer Despot Vuk Grgurovic (Zmaj-ognjeni Vuk) gemeint sein. Sein Name gehört in der maz. Epik selbstverstandlich zur Sekundarschicht, ebenso wie die beiden hier als Kume auftretenden Helden Peroßikosano und Simijanko Janko, hinter denen sich wahrscheinlich dis Liedhelden Pletikosa Pavle (historisch nicht zu identifizieren, gehort aber vielleicht auch zur ungarserb. Liedschicht, vgl. die fruhesten Belege in EH 26 und 80 sowie das Auftreten eines Pavao Banović in Bog.4 und 47, eines Pavao Strijemljanin, d.h. Pavao aus Srem, in Bog.14 und eines Vojvoda Pavle in Bog.95; ferner tritt ein Platokos Pavle auf in Mil.88, $t$ in Plitokos Pavle in Mil.181, ein Jane Pletikosa in Sapk.,114, ein Pletikosa Pavle in SbNU XIV,74 und XIIII,239 sowie ein 2latokosic Pavle in Vuk II 82 und III 10) und Sibinjanin Janko verbergen. Was die Stadt Legen anbelangt, so gibt es dazu bereits eine ganz stattliche Liste Sekundärliteratur, uber die in Kap.4.3 zu sprechen sein wird. Erwahnt sei hier nur, daß Legen-grad in den maz. und bulg. Liedern zum Prototyp der fermen lateinischen Stadt geworden ist (vgl.Mil. 30,84,341,493,512; Per.Spis.IX-X(1882),94; SbNU IX,81; XLIII,241 usw.), sehr wahrscheinlich aber aus der skr.Epik Ubernommen wurde.- Var.28 ist klirzer als die vorhergehende und Uberhaupt stark geraff:

König Petŭr verlobt sich mit der Tochter von Pirin-Pop, der Enkel in von König Bejko. Er trägt seiner Mutter auf, sie solle einladen, wen sie fur richtig halte, nur durfe sie seine beiden Schwest,ergöhne nicht rufen, denn:

Tij sa grozni, omrazni,

Da mi svatbata ne grozjat.

Die Mutter befolgt die Anweisung.- Gruil, der Neffe, erzahlt inzwischen selner Mutter, der Oheim habe ihn nicht zur Hochzeit eingeladen: wenn $e r$ aber nicht mitziehe, werde der Brăutigam die Braut nicht erhalten.-Die Mutter versucht Gruil zurlakzuhalten, doch der Held zieht einen Mantel aus neun Bärenfellen an, setzt eine Mutze aus Wolfspelz auf und zieht hinter den Svaten her. Als der Hochzeitszug ans Ziel gelangt, hat Pirin-Pop die Tore geschlossen und erklurt 
den Svaten, nur wer die Tore Uberspringe und offne, erhalte das Mtdchen.- Gruil, der Neffe, besteht diese schwierige Probe. Er erfillt auch die nkchste Aufgabe, eine schwere Trinkprobe, und prahlt sogar, er könne noch weit mehr trinken.Als dritte Freiersprobe werden drei gleiche Mädchen hergefuhrt, von denen eine als Braut erkannt werden soll. Gruil streut "siten margarit" vor die Madchen und befiehlt der Braut, die Perlen aufzulesen, was diese auch gehorsam tut.

Dieses Lied hat zwar die Dreiheit der Freiersproben bewahrt, von den urspringlichen ist aber nur noch die letzte erhalten, allerdings in verderbter Form, weil das Motiv der Drohung mit dem gezückten Schwert weggefallen ist. Falsch ist, daB nicht der Brautvater, sondern der Bräutigam selbst die Neffen nicht dabeihaben will, noch dazu mit der vagen Begrundung, die beiden seien schrecklich und verhabt. Aus dem liedtext geht nicht hervor, ob der Neffe unerkannt die Proben besteht. Negativ zu bewerten ist auch der abrupte Iiedschluß. Die Liedpersonen sind sekundär eingesetzt und historisch schwer zu identifizieren.- Var.29 steht noch etwas starker unter dem EinfluB der skr. Uberlieferung. Es hat folgenden Inhalt:

Marko verlobt sich in der Stadt Alatin mit einem Mädchen (Alatinska moma), Es vergehen drei Jahre. Marko hat drei Schwestersohne, die in dieser Zeit Festkleider, schwarze Pferde, blaue sattel und goldenes Zaumzeug hergerichtet haben, um wohlgerustet an der Hochzeit des Oheims teilnehmen zu können. Doch die Lateiner (Latinci) sind "verfluchte Teufel"(prokleti $g^{\prime}$ avole) und erklaren Marko kurz vor der Hochzeit, wenn er die drei Neffen einlade, werde man inm das Mädchen nicht zur Frau geben. Marko lädt also die Neffen nicht ein. Die drei jungen Helden beklagen sich bei ihrer Mutter, dab sie nun alle Vorbereitungen umsonst getroffen hätten. Der jungste Bruder, ein Hirte, kommt nach Hause, erfährt den Sachverhalt und erklärt sich bereit, den Svaten in Monchskleidern zu folgen. Er tut das, holt die Svaten ein und wird von Marko abgewiesen, worauf er trotzdem denselben Weg zieht. Als der Zug zur lateinischen Stadt kommt, haben die Lateiner, die "verfluchten Kerle" (prukleti gidii), die Stadtore geschlossen und fordern einen Helden zum Überspringen und öffnen der Tore auf, sonst werde das Madchen nicht herausgegeben.- Der schwarze Mónch tummelt seinen Rappen und besteht die Sprungprobe. Als nächste 


\begin{abstract}
Aufgabe erfullt er eine EBprobe, wobei "slatki blagi mandž" mit "dǔzi lažici" (mit einem Dutzend Löffeln?) zu essen sind. Zuletzt soll die Braut aus zwei gleichaussehenden Mädchen erkannt werden. Gelinge das nicht, whrden alle Svaten den Tod finden.- Da packt der Mónch das eine Mădchen, setzt es hinter sich aufs perd und erklärt, das sei Markos Braut. Das zweite Madchen setzt er vor sich aufs pferd und sagt, nun habe auch er eine Frau gefunden. Dann reitet er los, gefolgt von dem Zug der Svaten.
\end{abstract}

Bewahrt blieb hier das Motiv der betrlggerischen Lateiner, die Markos gefährliche Neffen nicht bei der Hochzeit dabeihaben wollen. Die Begrindung dafur fehlt allerdings. Die Bezeichnung "Alatin grad" ist anscheinend verderbt aus "Latin grad". Falschlicherweise ist hier von drei und einem Neffen die Rede. Erhalten blieb auch das Verkleidungsmotiv, doch fehlt die Selbstoffenbarung des Neffen an Liedende. Von den drei Freiersproben ist in unserem Lied nur die letzte zum Teil bewahrt, doch wurde die richtige Lösung vergessen, so daß der Iiledschluß nun unsinnig erscheint. Die zweite Aufgabe, namlich die Art und Weise der geforderten EBprobe, wirkt lächerlich. Marko als Bräutigam ist naturlich sekundär eingesetzt.- Var.30, deren vollig unregelmäßiges Versmaß vielleicht weniger die Schuld des Sängers als des Aufzeichners sein durfte, hat folgenden Inhalt:

Krali Marko verlobt sich mit Ilena aus der Stadt Budim. Er lädt eine große Zahl Svaten ein und zieht mit ihnen zum Hochzeitstermin nach Budim. Da treten siebzig Helden aus der Stadt heraus und reihen siebzig schwere Streitkolben nebeneinander auf, die als erste Freiersprobe ubersprungen werden sollen. Die Svaten, von denen keiner den geforderten Sprung wagt, machen nun Marko Vorwlirfe, daß er viele Gäste geladen, seine drei Neffen aber Ubergangen habe, die zwar beim Wein- und Schnapstrinken trunk- und streitslichtig, trotzdem aber ausgezelchnete Kumpfer seien. Da weint Marko und gesteht beschbint, dab ihm seine Mutter verboten habe, die drei Neffen eirzuladen.- Die Trommler fangen zum Zeichen der Niederlage an zu trommeln und die Blaser begleiten sie mit einer traurigen Melodie. Dies hört der jungste der drei ungeladenen Neffen im Gebirge und deutet die klagenden Tơne richtig: Die Bewohner von Budim bereiten dem Oheim Schwierigkeiten, die keiner der Helden im Hochzeitszug zu meistern vermar.- non 
Neffe beschliebt, dem Oheim zu Hilfe zu eilen, tauscht mit einem Mönch die Kleider und macht sich auf den Weg nach Budim. Unerkannt fragt er Marko, warum dessen Neffen nicht eingeladen wurden, und erfährt, dab Markos Mutter dies verboten habe. Nun erst schurzt der Neffe die Mönchskleider, uberspringt die 70 streitkolben und verlangt, dab man ihm noch auBerdem siebzig Wagen voll von schwarzem Dorngestrupp ("Cali1", von turk. çall) bringe, die wieder nur er allein uberspringen kann. Als zweite Freiersprobe werden neun verschleierte Mädchen vorgefuhrt, von denen eine die Braut ist. Um sie herauszufinden, streut der als Mónch verkleidete Neffe Perlen vor die Mädchen hin und befiehlt, seine Tante (moja vujna) solle stehenbleiben, alle lubrigen aber die Perlen auflesen. Dies geschieht, und der Neffe fuhrt die Braut dem Oheim zu mit den Worten:

Na ti a vujko Ilena nevesta.

Da erkennt Krali Marko den Neffen und gibt seiner freudigen Uberraschung Ausdruck, wăhrend der Neffe meint, inm gebuhre das Heldentum, dem Oheim aber die Braut.

In dieser Variante haben wir eine nicht uninteressante sekundäre Abwandlung des ursprïnglichen Sujets vor uns. Neu ist hier z.B., daB Marko Vorwlurfe von Seiten der Svaten erhält, als niemand die erste Aufgabe lösen kann. Neu ist auch, dab Markos Mutter - motiviert als Angst vor Familienschande - verboten hat, die streit- und trunksuchtigen Neffen einzuladen. Als weiteres neues Motiv ist die gelungene Stelle hinzugekomnen, daß der juingste der ungeladenen Neffen durch die klagende Musik, die von Budim herubertónt, sich zum hilfreichen Eingreifen veranlabt fuhlt. Auch der Kleidertausch mit dem Monch ist in diesem Zusammenhang neu. Gut bewahrt blieb das Motiv des unerkannten Helfers, der sich erst am Schlub wirkungsvoll zu erkennen gibt und in echt episch-heroischer Gesinnúng "nur" den Heldenruhm fur sich beansprucht. Von den ursprunglichen Freiersproben ist allein die letzte erhalten, allerdings ohne das wichtige Teilmotiv der Drohung. Der Sprung uber Pferde wurde in unserem Lied sekundär zu einem Sprung uber eine große Anzahl Streitkolben. Wenn der Neffe in anderen Varianten bei der bloßen Prahlerei blieb, so setzt er sie hier in die Tat um: Er for- 
dert zusätzlich siebzig Wagen zum Uberspringen, um zu zeigen, dab ihm die als erste Probe verlangte Leistung noch zu gering war, d.h. von den drei Freiersproben ist die mittlere eigentlich selbst gewählt.- Die Lateinerstadt ist hier Budim, die typische -Stadt der sekundären Iiedschicht im maz. und bulg. Raum. - Var.31 mit dem Titel "Kral Siłman, Kral Latin i ovcar Tabarina" hat folgenden Inhalt:

König Siłman verlobt sich mit der Tochter von König Iatinin, der bei diesem AnlaB die Bedingung stellt, daß der Brăutigam zur Hochzeit seine beiden Neffen, die als trink- und streitsuchtig verrufen seien, nicht einlade. König Sišman willigt ein. Als der Hochzeitstermin naht, lädt der Bräutigam Svaten aus dem ganzen Land ein, seine Neffen aber ubergeht er. Die beiden fragen verärgert ihre Mutter, warum der Oheim sie nicht geladen rabe; sie häten ihm zur Hochzeit 300 Kilogramm Weizen (cejnca), 300 Fuhren Trauben und 300 Schafe geschenkt. Die Mutter meint darauf, die Söhne sollten im Morgengrauen ungeladen mit dem Hochzeitszug gehen, denn der verfluchte König Latinin habe die Einladung nur vereitelt, um den Brăutigam ungehindert blobstellen zu können.- Da bitten die beiden, die Mutter solle den Sohn, den sie filr den besseren Helden halte, mit den Svaten schicken. Darauf meint die Mutter, wenn es um heldische Fähigkeiten gehe, sei der jungste (dritte) Sohn, Mirco, der grobte Held von allen, denn sie habe einmal, als sie ihm das Essen ins Waldgebirge brachte, beobachtet, wie sich die Äste der Erle, unter der MirCo schlief, im Rhythmus seines mächtigen Atems hoben und senkten.-Die Söhne fragen, wie sie Mirco am besten herholen könnten, worauf die Mutter rät, einen Falken mit der brieflichen Nachricht zu Mirco zu senden, dab die Mutter im Sterben liege.- Der mutterliche Rat wird befolgt, und Mirco "po-malexek" erhält die traurige Nachricht. Er weint beim Lesen des Briefs, verlabt sofort seine neun Schafherden und erreicht den Hof noch vor dem Falken. Er trifft die Mutter gesund an und macht inr Vorwlirfe wegen des Briefs, doch sie erklart ihm, dab man ihn dringend brauche, um ihn ohne Wigeen des Oheime mit den Svaten zu eenden. Mirlo zieht seinen schweren Mantel an, nimmt sein Pferd und reitet zum Hof des Oheims, wo er von den Svaten nicht aufgenommen wird. Bei Morgendämerung zieht der Hochzeitszug zur Braut. Der Brăutigam reitet nur schweren Herzens ohne seine drei heldenhaften Neffen 10s, denn er weiB, daB schon viele Freier ohne die Braut zurickkamen.Am Hof von König Latinin wird zuerst eine dreitä- 
gige Feier veranstaltet, dann stellt der Brautvater die erste Aufgabe: Wer die Braut erringen wolle, mulsse mit dem Pfeil durch einen goldenen King treffen. Keiner der Svaten wagt den SchuB. Der Brăutigan ist verzweifelt und klagt, daß nur seine Neffen inm jetzt helfen konnten. Er wird von dem heimlich mitgezogenen Schafshirten getröstet, der auch wirklich die Freiersprobe glänzend besteht. Als zweite Freiersprobe sollen drei Äpfel dem Jahr nach unterschieden werden. Die Svaten sind ratlos, Mirco aber läßt sich ein GefuB mit Wasser bringen, wirft die drei Âpfel hinein und erklart, der oben schwimme, sei vom vorvorigen, der halb abgesunkene vom vorigen und der am Grund liegende Apfel von diesem Jahr.- Danach erkennt er die Braut aus drei gleichgekleideten Mädchen dadurch heraus, daß er Goldstucke vor die Mädchen wirft und der Braut drohend verbietet, sich danach zu bucken, den beiden anderen aber das Auflesen befiehlt. Nachdem die List sich bewährt hat, fuhrt er die Braut zu Konig Sisman und heiBt ihn mit den Svaten losreiten. Er selbst wirft eines der beiden anderen Mädchen zu sich aufs pferd und reitet den Svaten nach zum Hof des Brăutigams, wo man den heldenhaften Hirten feiert. Nun erst gibt sich Mirco als Neffe zu erkennen und eilt nach Hause, um die eigene Hochzeit zu feiern. Als die Autter ihn mit dem Madchen kommen sieht, verflucht sie ihn, weil sie glaubt, er habe dem Oheim die Braut geraubt. Nachdem Mirco die Situation aufgeklärt hat, beginnt er mit der Hochzeitsfeier, die volle drei Monate dauert.

In dieser gelungenen Variante sind einerseits viele urspringliche Motive bewahrt geblieben, andere aber verbauerlicht worden. Erhalten blieb das gegen die gefährlichen Neffen gerichtete Einladungsverbot von Seiten des betriggerischen "lateinischen Königs", die Entsendung des als Schafhirten verkleideten Neffen auf Rat der klugen Mutter und die Erkennungsszene nach der glücklichen Heimkehr. Von den Freiersproben bleiben die erste und letzte bewahrt, wăhrend die mittlere sekundăr in bäuerlichem Milieu fur den Sprung eingesetzt wurde. Typisch fur die bauerliche Umgebung sind $z . B$. auch die erwähnten Hochzeitsgeschenke der Neffen. Die Szene, wo der Baum durch den mächtigen Atem des schlafenden Mirče bewegt wird, ist uns bereits aus Var.26 bekannt und als maz. Zusatz erklärt worden. Mirðe "po-malecek" ist ein typisch maz. Heldenkind. König Sił̆man wurde sekundür als Brăutigam 
eingesetzt, um das lied für bulg.-maz. Verhăltnisse zu "aktualisieren".

Die restlichen bulg. und maz. Varianten unseres Sujets sind so stark verändert, verstümmelt oder verderbt, dab es sich m.E. nicht lohnt, sie ausfuhrlich zu besprechen. Statt dessen sollen hier lediglich die wichtigsten Momente dieser Lieder angefüht werden. Bei den Var.32-38 sind nur noch zwei Freiersproben übriggeblieben, in Var.39-46 ist es schlieblich nur noch eine einzige Probe, die bestanden werden muB. Var.47-50 sind als hierher gehörig in SbNU 'XXXVI,83 kurz erwähnt; diese vier Iieder waren mir aber leider nicht zugänglich. Var.51 ist unvollständig. Var.52 beweist die Zuwanderung unseres Sujets von Bulgarien nach Rumänien. Var.53-57 enthalten schlieblich nur noch Reminiszenzen des besprochenen Liedsujets.

Var.32: Brăutigam ist Gojce, Braut die Zarentochter; die hilfreichen Neffen sind Grujč und Michalco; zwei Freiersproben: aus dreibig Mädchen die Braut herauszufinden und ein Tor zu Uberspringen.

Var.33: Brăutigam: König Milos; Braut: die Zarentochter; Neffe: Stojan; zwei Freiersproben: Sprung uber das Tor und Herausfinden der Braut aus drei gleichen Mädchen.

Var.34: Brăutigam: Vŭlč; Braut: Kotlenka devojka; Neffe: Ivanč Kozarčo ("Ziegenhirtchen"); zwei Freiersproben: Sprurig liber neun Wagen mit Dorngestrupp und Erkennen der Braut unter neun Madchen.

Var.35: Brăutigam: vŭlko bajraktar (Bannertrăger); Braut: die Zarentochter; Neffen: Grujco und Michalðo;zwei Freiersproben: Schub durch einen Ring und Erkennen der Braut aus zwei Hadchen.

Var.36: Bräutigam: Marko; Braut: das lateinische Mädchen; Neffe: Ilija Kozarðe; zwei Freiersproben: Sprung uber eine hohe Mauer und Trinknrobe.

Var.37: Brăutigam: "momðe sedmak (7 Jahre alt?)junak";Braut: die Tochter Kostadins; kein Neffe, Bräutigam erfullt selbst zwei Freiersproben: Mähen von neun Fuhren Dorngestrupp und Sprung luber die neun Wagen.

Var.38: Bräutigam: "Sarbinsko delijðe" (serb."Heldchen"), auBer ihm noch vier "rumelische Freier"; Braut: Jankulas Tochter; Bráutigam besteht selbst die beiden Freiersproben: Erklettern eines glatten Baumstamms und Erkennen der Braut aus fïnf gleichen Mädchen. 
Var.39: Bräutigam: Krali Marko; Braut: Latincanka (Lateinerin); Neffe: namenlos; eine Freiersprobe: Herausfinden der Braut aus drei Mädchen.

Var.40: Bräutigam: namenlos; Braut:"vlachinka"; Neffe: Sekul "kozarce"; eine Freiersprobe: wie Var.39.

Var.41: Bräutigam: vullco; Braut: Tochter von König Marko; Neffe: Ivanco Kozarco; eine Freiersprobe: wie Var. 39.

Var.42: Brăutigan: Zar Milos; Braut: "beligratsko momice" (Madchen aus Belgrad); Neffe: Nikolce; eine Freiersprobe: wie Var.39.

Var.43: Brătigam: Jaula (entstellt aus Jankula); Braut: Tochter des Paschas von Gjaur selo (d.h. die turk. Entsprechung fur "lateinisches Land" in anderen Var.); drei Neffen: Kirč, Strachilco und Belju; eine Trink- und EBprobe: neun Fässer Wein, neun Fässer Schnaps und neun Kilhe.

Var.44: Bräutigam: namenlos; Braut: Zarentochter; zwei Neffen: Gruscu und Michalcu; eine Freiersprobe: Kampf mit dem Ringkämpfer (pechlivan) des Zaren.

Var.45: Bräutigam: Stefan; Braut: Donjana, Tochter der Boljarenwitwe Dona; statt zweier Neffen die Onkel Sevila (vielleicht aus Sekula entstellt) und Strasila; eine Freiersprobe: Kampf mit dem Bären der Brautmutter.

Var.46: Bräutigam: Xobanin Jovo; Braut: Zarentochter ("sultanija"); eine Freiersprobe: Uberschießen einer Zypresse; Liedschluß: Zarentochter preist den Hirten als Liebhaber.

Var.47-

50: Einzelheiten sind bei diesen vier HS-Var. nicht bekannt, sondern nur das allen vier gemeinsame Moment, daß der Bräutigam Krali Marko seine Neffen nicht zur Hochzeit einladd: "Krali Marko ne kanil na svatba sestrincite si".

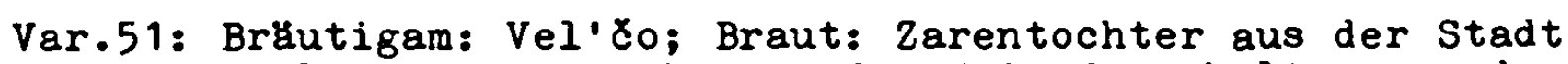
Kotlin; uv.: nur bis zu der Episode erhalten, wo der Neffe Ivanco ungeladen und unerkannt mit dem Oheim zieht.

Var.52: Diese rumänische Var. ist allem Anschein nach aus der benachbarten bulg. Liedtradition ubernommen, was schon aus der bulg. Version der drei Freiersproben hervorgeht, deren zweite sekundär allerdings wieder etwas abgeändert wurde; erste Probe: Sprung uber das Stadttor und Öffnen des Tores; zweite Probe: Sprung Uber Tuchballen; dritte Probe: Erkennen der Braut aus drei Madchen; Bräutigam: Bogdan, Sohn des Alexander Läpusnean (wahrscheinlich die historische Figur des moldauischen Vojvoden Alexander IV. Lǎpuşneanŭ aus dem 16.Jh., vgl. Jir.GdS,228); Braut: 
Tochter Iiteans, eines reichen Renegaten; kein Neffe, Brututigam selbst erfillt die Aufgaben.

Var.53: In diesem Lied durfte noch eine Reminiszenz an die Sprung-Probe erhalten sein: Stefo, der jungste und einzig ledige von neun Söhner: des Janko von Sibin sieht den Pascha von Kamnen grad (Slankamen?) mit Gattin und Tochter in drei goldenen Kutschen auf der Straße fahren, tummelt sein Pferd und uberspringt die drei Wagen. Der Pascha ist zunuchst daruber verargert, gibt Stefo aber spater sogar seine Tochter zur Frau.

Var.54: In diesem Lied ist noch eine Reminiszenz an das von den Brauteltern gestellte Gebot hinsichtlich der Svatenwahl sowie das Oheim-Neffen-Verhaltnis (nur hier ungekehrt) erhalten: Dimo Cernogorte freit die Kaisertochter "v grada Belonemska" (Wien?) und erhalt von der Brautmutter die Bedingung gestellt, er musse genau 3000 Helden als Svaten mitbringen. Dimo kann diese Auflage nur mit Hilfe seines Oheims Krali Marko aus Prilep erfullen, den er als "pobastim" beruft.

Var.55. In dieser Var. ist noch eine Reminiszenz an das gleiche Aussehen der Mudchen, aus deren Mitte die Braut herausgefunden werden soll, erhalten, hier allerdings auf den Bruutigam ubertragen Die Konigin sucht fur ihren Sohn Stojan eine Braut und findet sie in der Stadt Irin (Edirne?). Man stellt jedoch die Bedingung, der Brëutigam musse 300 Junggesellen, alle seines Namens und Aussehens, sowie drei "chora" junge Madchen mitbringen. Der Brăutigam erfullt die Aufgabe und erhalt geine Braut.

Var.56: In diesem kontaminierten lied ist fúr uns nur das Mittelstuck wichtig, wo vielleicht eine Reminiszenz an die gleichaussehenden Mydchen erhalten ist: Die Witwe von Konig Resula (Sekula?) will ihre sechs Söhne verheiraten und läd als Svaten u.a. sechs Konige ein: Marko Kralevik'e, Relo Sestokri10, Obilik Hiloß, Jankula vojvoda, bolen Dojlin und Duka Semsoik'a. Die Königin möchte, daß ihre Sohne mit sechs ganz gleichen Madchen verheiratet werden, eine Bedingung, die nur Marko erfullen kann.

Var.57. In diesem Hajdukenlied ist eine Romintezenz an dio urspringliche Schub- und Sprung-Probe erhalten: Das Mädchen Bojana wird Anfuhrerin von siebzig Hajduken, weil sie im dreiteiligen Wettbewerb siegt: Sie erhblt durch einen glucklichen Zufall das im Kuchen eingebackene Geldstluck, sie trifft durch einen Ring hindurch und springt schlieblich uber neun aufgestellte Schwerter. 
Wie olch aus dem Variantenvergleich ergeben hat, otcmmen die ultesten, urspringlichen und am besten erhaltenen sidslavischen Iieder von der Brautgewinnung nach dem Bestehen von Frelersproben (durch elnen Helden aus dem Gefolge des Brăut1gams; erst in wenigen sekundar verunderten Var.durch den Bräutigam selbst) aus dem skr. Raum, von wo aus sie in den maz. und bulg. Raum zugewandert sind und dort also der Sekundarschicht angehrren.

Hinsichtlich des zielorts der Brautfahrt sind bel den Var. verschiedene Moglichkelten festzustellen. DIe ulteste Lokalisierung der Braut-Stadt scheint im serb.-ungarischen Raum zu liegen, die erst opkter durch die zur Schablone gewordene "lateinlsche Stadt" (m1t 1hren Bewohnern, den "betrugerischen Lateinern") abgelobt wurde, ein Motiv, das natlurlch im serb.-orthodoxen Bereich entstanden sein dirfte. Was den Helfer anbelangt, der die Frelersproben fur den Brăutigam besteht, ergibt sich fur die skr. Lieder eine vierstufige Entwicklungsreihe: In den altesten Var.(Bog.) ist der Helfer des Brăutigams eln besonderer Held aus der Rethe der Svaten, nicht aber ein Verwandter (Neffe) des Brautigams, wobel auch noch nicht davon die Rede 18t, daB der Brautvater ein Verbot hinsichtlich der Einladung bestimmter Helden ausspricht. Dann entwickelte sich ansche1nend das feste Schema, daB ein Held zu seiner Hochzelt auf GeheiB des Brautvaters den angeblich trunk- und streitsuchtigen Neffen nicht mitbringen soll, dieser aber verkleidet mitzieht und die drel Prelersproben erfolgreich fur den Oheim besteht. D1eses Iledschema murde urspringlich an das beribnte und bellebte Ohelm-Neffen-Paar Jankula-Sekula (be 1 zehn von funfzehn skr. Var.1) geknupft, von Kacic-M1 ortc angefangen. Aus dem anfanglich nur als Hirten verkleideten Neffen wird schlieblich ein wirklicher Hirte, der - und das lot nun die dritte Stufe - haufig als der jingste und starkste von drel Brlidern geschildert wird und erst aus dem Waldgebirge herbelgeholt werden muB, um (verkleldet) zur Hochze1t des gefahrdeten Oheims entsandt werden zu können. Diese Stufe 18t im skr. Raum allerdings nur in der zusammenge- 
setzten Form unseres Liedsujets (vgl. Kap.4.3 - Typ: Vuk II 28 "Dusans Hochzeit") erhalten, in maz. Liedern (namlich in Mil.57 und Maler.158) aber schon in der hier besprochenen einfachen Iledform, d.h. ohne den Zusatz "therfall auf den Hochzeitszug" wie im Typ "Dusans Hochzeit". Daraug konnte die Vermutung entstehen, daß speziell dieses Teilmotiv aus dem maz. Bereich stammt, was wieder nur ein weiterer Beweis fur das Hin- und Herwandern der liedmotive und -sujets ware. Maz. mutet das Motiv an wegen seines marchenhaften Charakters einerselts (der verkannte Dtimmling, der jungste von drel Brudern, erwelst sich als ein Held von marchenhaften Frhigkeiten) und seiner offensichtlichen BeeinPlussung durch den Heldenkind-Typus andererseits.

Die vierte Stufe der Entwicklungsreihe besteht darin, da $B$ der Brautigam durch einen Brief der Braut oder Brautmutter davor gewarnt wird, das gegen jestimnte Helden gerichtete Einladungsverbot des Brautvaters zu befolgen. Der Brăutigam hort, beraten von seiner Mutter, auf den warmenden Brief und nimmt die besten Helden mit, die fur inn die Freiersproben bestehen (Typ "Die Hochzeit des Durad Smederevac", Vuk II 78).

Beweise fur den im maz.-bulg. Raum sekundaren Charakter des Iledsujets von der Erfullung mehrerer Frelersproben durch den vom Oheim nicht geladenen Neffen sind m.E. folgende: 1. Die im skr. Iied aus dem ritterlich-feudalen kilieu stammenden drei Freiersproben (Sprung luber Pferde, Schuß auf ein Ziel und Herausfinden der Braut) sind im maz.-bulg. Lied nur zum Teil erhalten geblieben (zwei oder nur eine davon) bzw. sekundar durch dem bäuerlichen Milieu entstamende neue Proben ergunzt oder ersetzt worden (Sprung luber Mauer, Tor oder mit Dorngestrupp gefulte Wagen, EB- und Trinkprobe, Aus1esen von Hirse, Altersbestimmung von Äpfeln u. $\left.u_{.}\right)$. 2. Die im skr. Liedsujet vorkommenden (meist ungarserb.) PN und topographischen Bezeichnungen wurden in den maz.-bulg. Liedern teils beibehalten, teils aber auch sekundär "umhistorisiert" (tbertragung der Bräutigamsrolle aup Konig కisman, Krall Marko, Konig Miloz usw.) oder enthistorisiert, 
d.h. durch unhistorische (z.B. Vriko, vullco, Stojan,Gruica) oder sogar namenlose Helden (momce sedmak junak, mlado crnogorle i crno kalugerce, crna ovcarina) ersetzt.

3. Wichtig ist auch noch die Pestatellung, das die maz.Var., die dem skr. Herkunftsgeblet des Sujets am nachsten lokalisiert sind, meistens besser erhalten sind und weniger verderbte Zlige als die Var. aus Bulgarien aufweisen.

\subsection{UBERSCHWIMMEN EINES GET/ZSSERS ALS VOM MODDCHEN GESTELi- TE FREIERSPROBE}

whrend fur die Var. Im vorhergehenden Kapitel typisch war, dab die Freiersproben von einem Helfer des Brkutigams erfult murden, handelt es sich nun um lieder, in denen der Brkutigam selbst die gestellte schwierige Aufgabe 18st. Unberlucksichtigt bleiben hier jedoch solche lieder, in denen Brautrater oder Brautmutter dem Freler Bedingungen stellen, 2.B. maz.-bulg. Lieder wie SbNO XIIII,134 (Brautrater labt Brautigam die Blatter eines Baumes zahlen), SbNU IX,20(Brautvater laBt Brautigam-Schlangeneohn - AaTh 433, vgl, auch MH: I, 32-34 und vuk II 11,12 - eine goldene Straße zum Haus der Braut bauen), SbNU XXV,121 (Freier muß fur die Brautmutter einen Mantel aus Pfingstrosen und ein Tuch aus Moos herstellen sowie im Meer Trauben und Quitten an einem Tag pplanzen und am nachsten Tag emten), SbNU VIII,25 (Brautigam muB fur die Brautmutter inmitten des Meeres Weinreben pflanzen) usw. Behandelt werden nun vielmehr solche Lieder, in denen das Madchen selbst eine schwierige Aufgabe stellt und nur demjenigen Preier die helrat verspricht, der die Probe besteht. Dadurch, das die Initiative nun von dem Madchen (statt von dem Brautvater wie im vorhergenden Kap.) ausgeht, wird eine Simplifizierung der Handlung erreicht: Die Beschreibung einer umstandilchen Rllstung des Hochzeitszugs, die Schilderung der Einladung und des Eintreffens der Svaten u.a. fallen hier neturlich weg. Der Held kgmpft allein um den Preis 
des Madchens. Durch solche Vereinfachungen wirkt die nun, zu besprechende Liedgruppe "wesentlich unliterarischer"143 als die vorhergehende vielgliedrige. Das Ganze ist episodisch zugespitzt; die Werbung besteht allein in der glucklichen Lboung der gestellten Aufgabe. Die Vermutung liegt nahe, dab eher der nun zu untersuchende Iiedtyp sich aus dem in Kap.4.11 besprochenen Sujet - durch Isolierung des Abenteuerkerns und erzahltechnische Vereinfachung "unter gleichzeitiger Motivvariation und Motivhuufung"144 - entwickelt hat als umgekehrt ( $\nabla$ gl. Bond.113: Freier muß als vom Madchen gestellte Aufgabe drei Wagen mit Domgestrupp Uberspringen).

Von den zahlreichen slldslavischen, vor allem maz. und bulg. Freierwettbewerbsliedern, in denen die Umworbene den Freiern eine oder mehrere schwierige Aufgaben stellt ${ }^{145}$ und unter Umstanden sogar getరtet wird, well sie immer unmenschlichere Anforderungen stellt ${ }^{146}$, soll hier das Sujet herausgegriffen werden, wo ein Madchen demjenigen Freier die the verspricht, der ein von ihr bestimmtes Gewässer uberschwimmt. Es handelt sich dabel um folgende sudslavioche varianten:

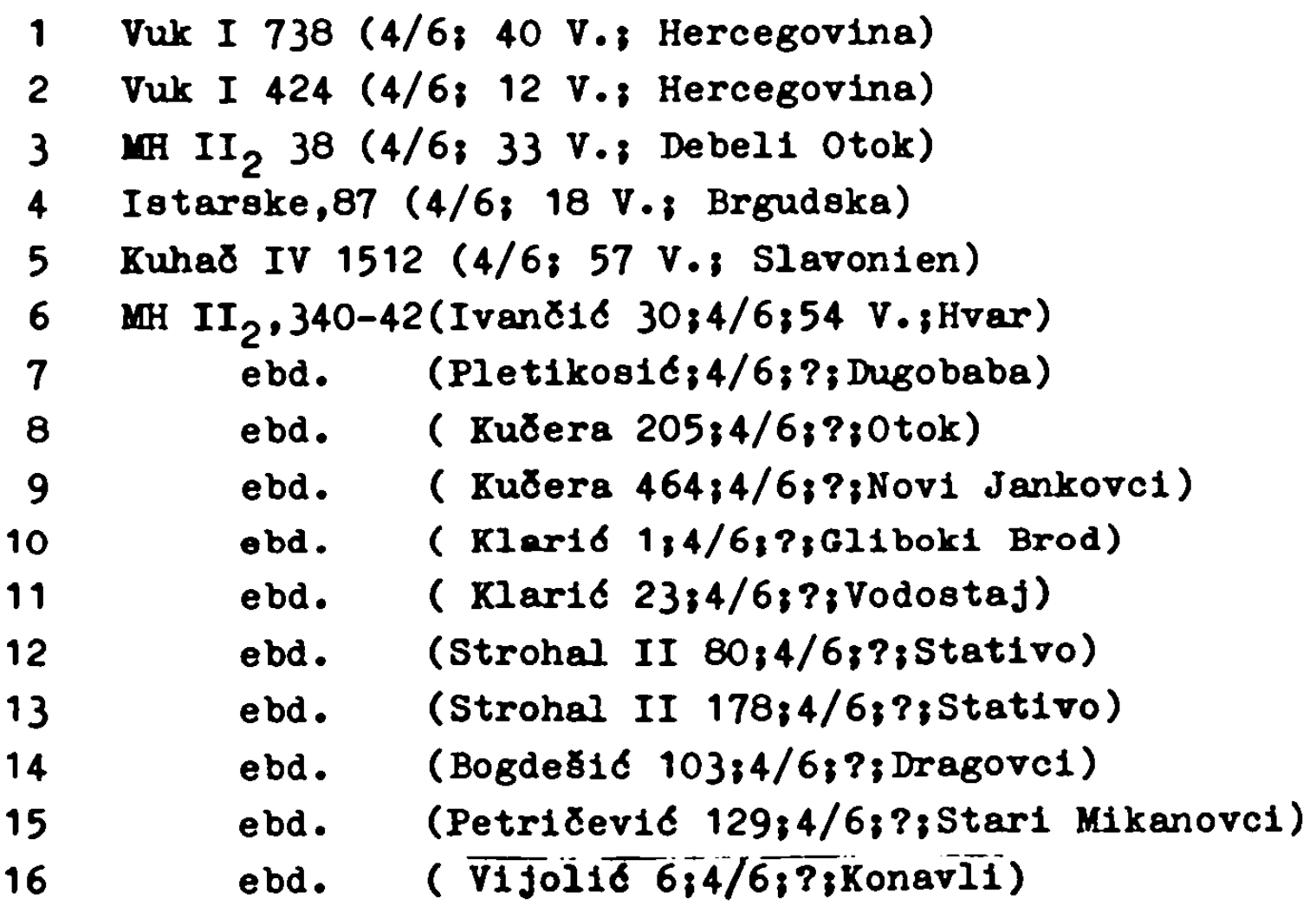


Don

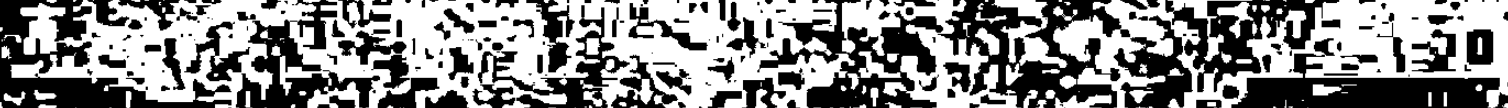

$f=0$ of

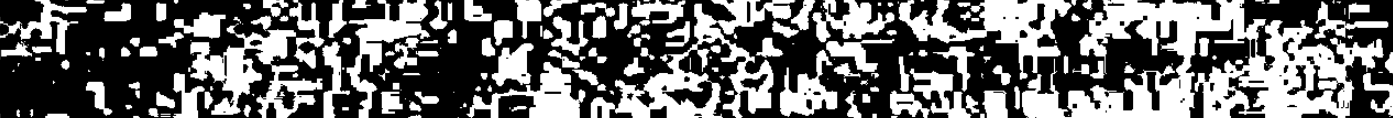

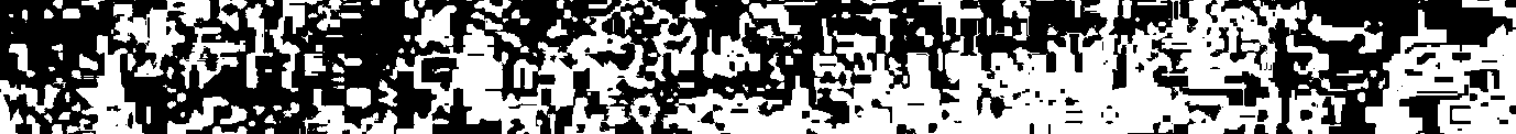

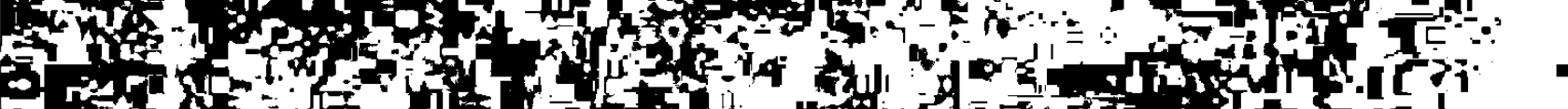

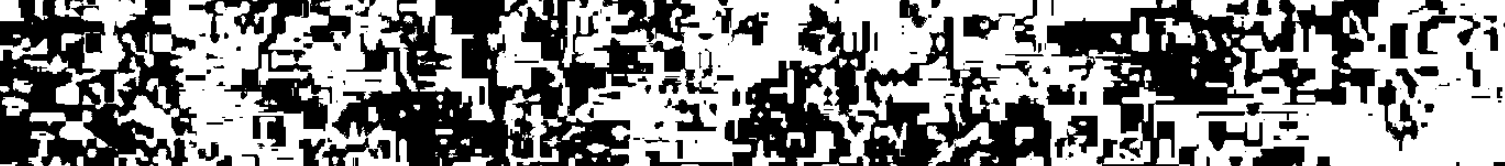

(1)

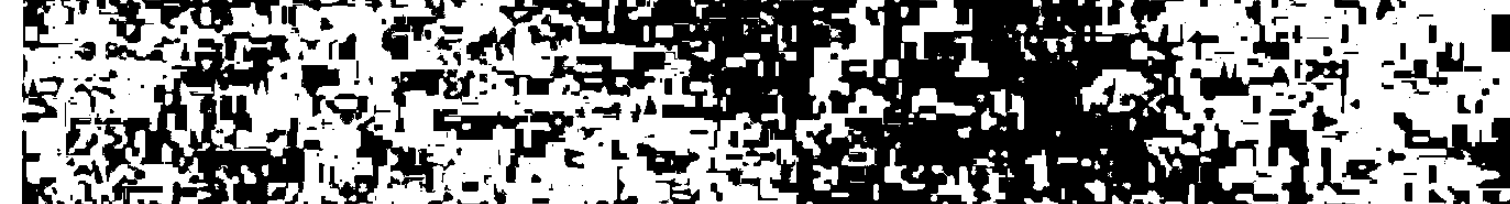

5 Fily

कर

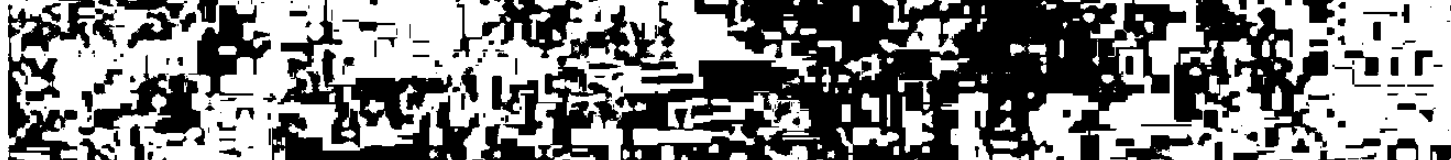

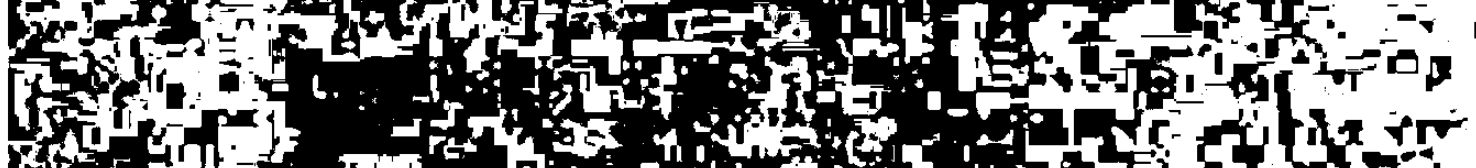

Riting

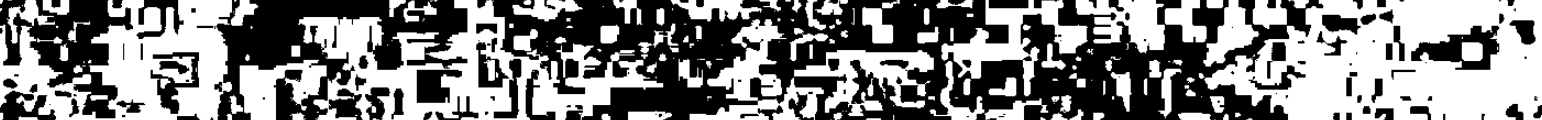

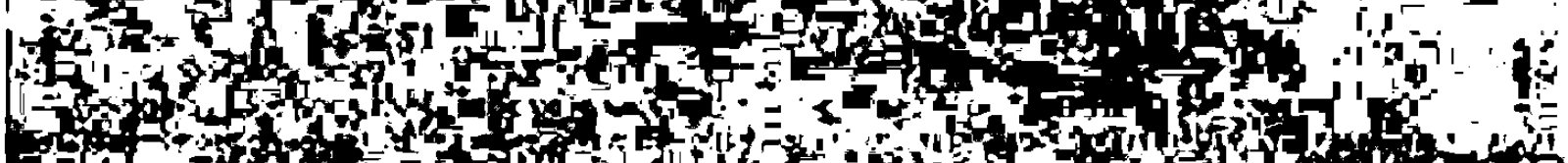

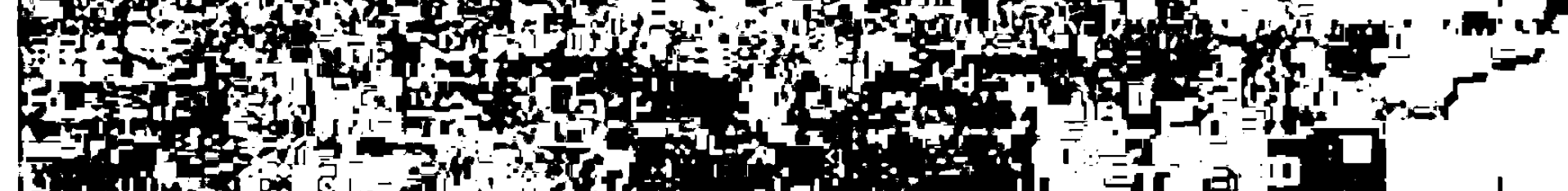

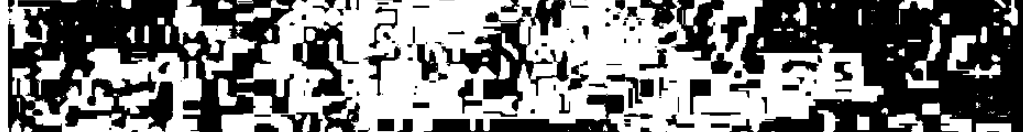

Gitis

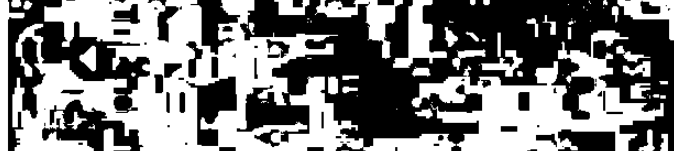

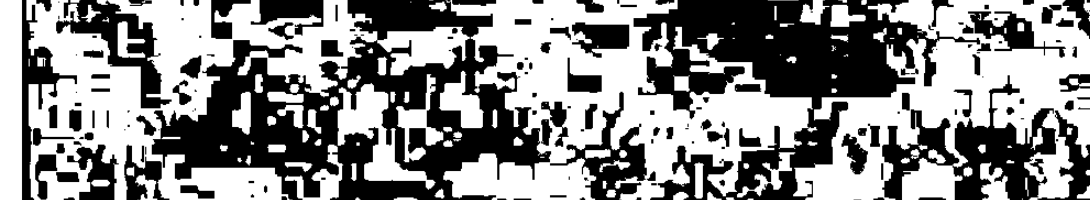

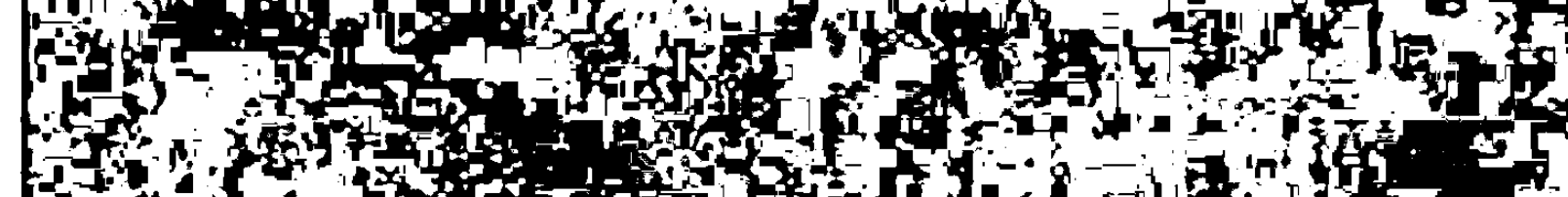

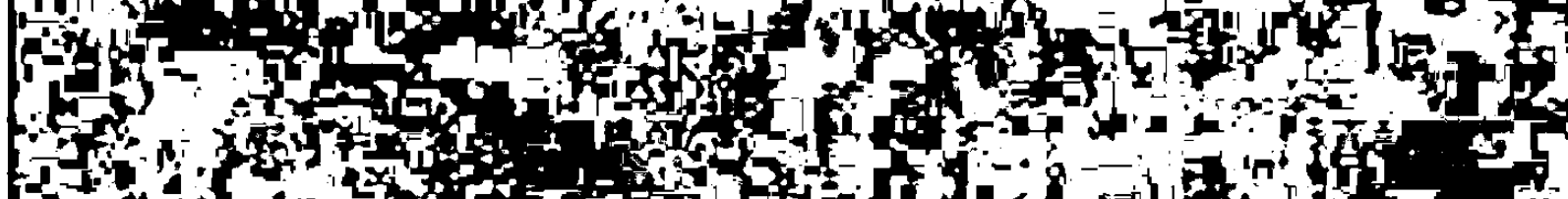

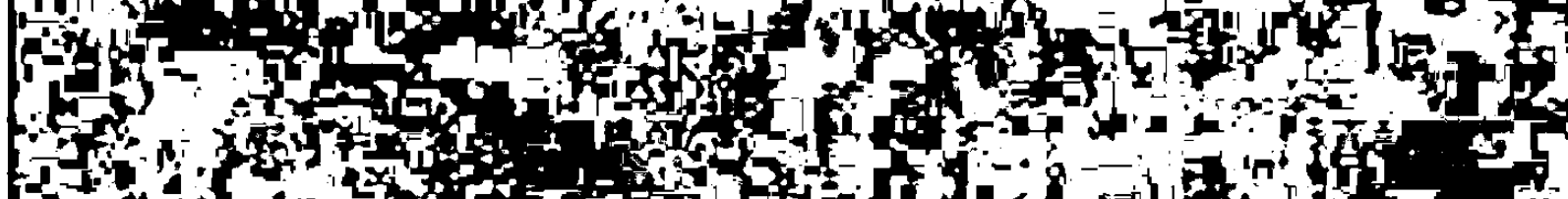

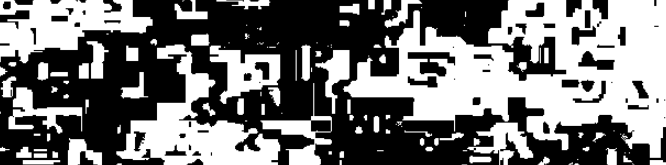

II

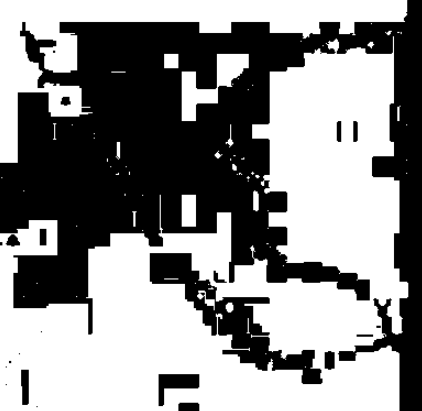

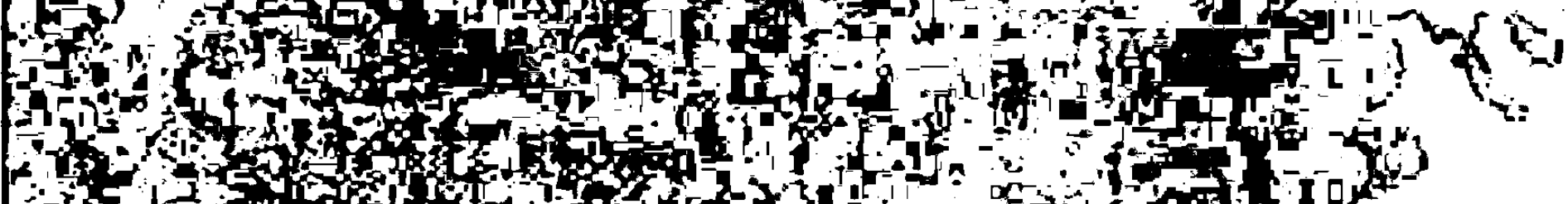

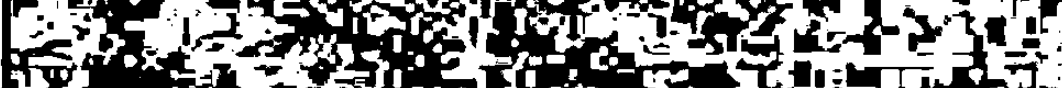

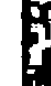

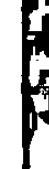

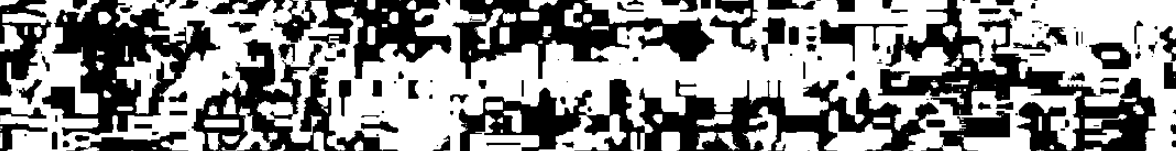

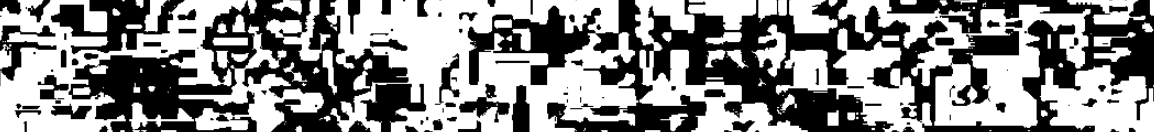

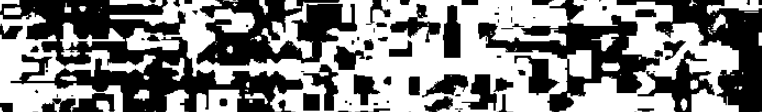

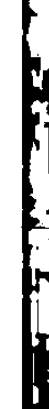

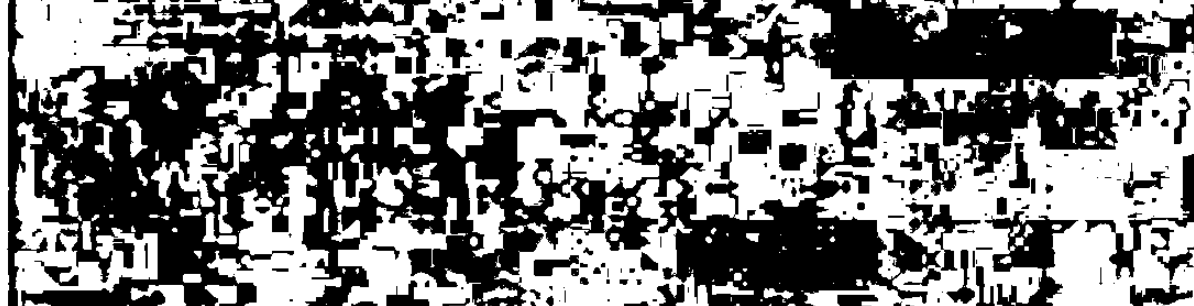

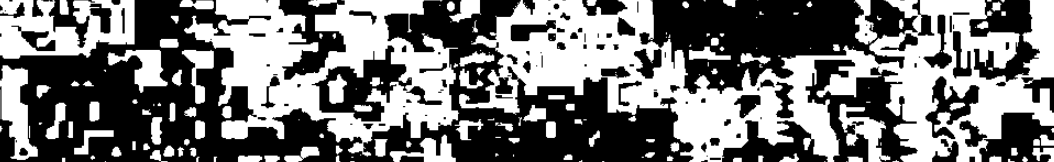

to.

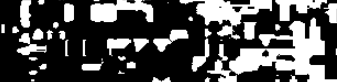

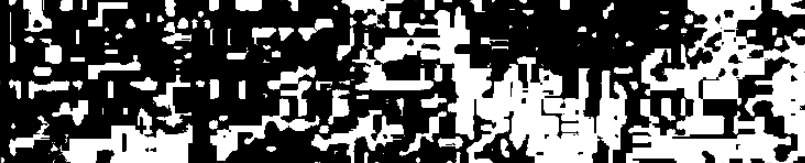
1

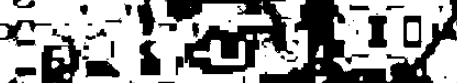

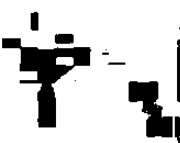




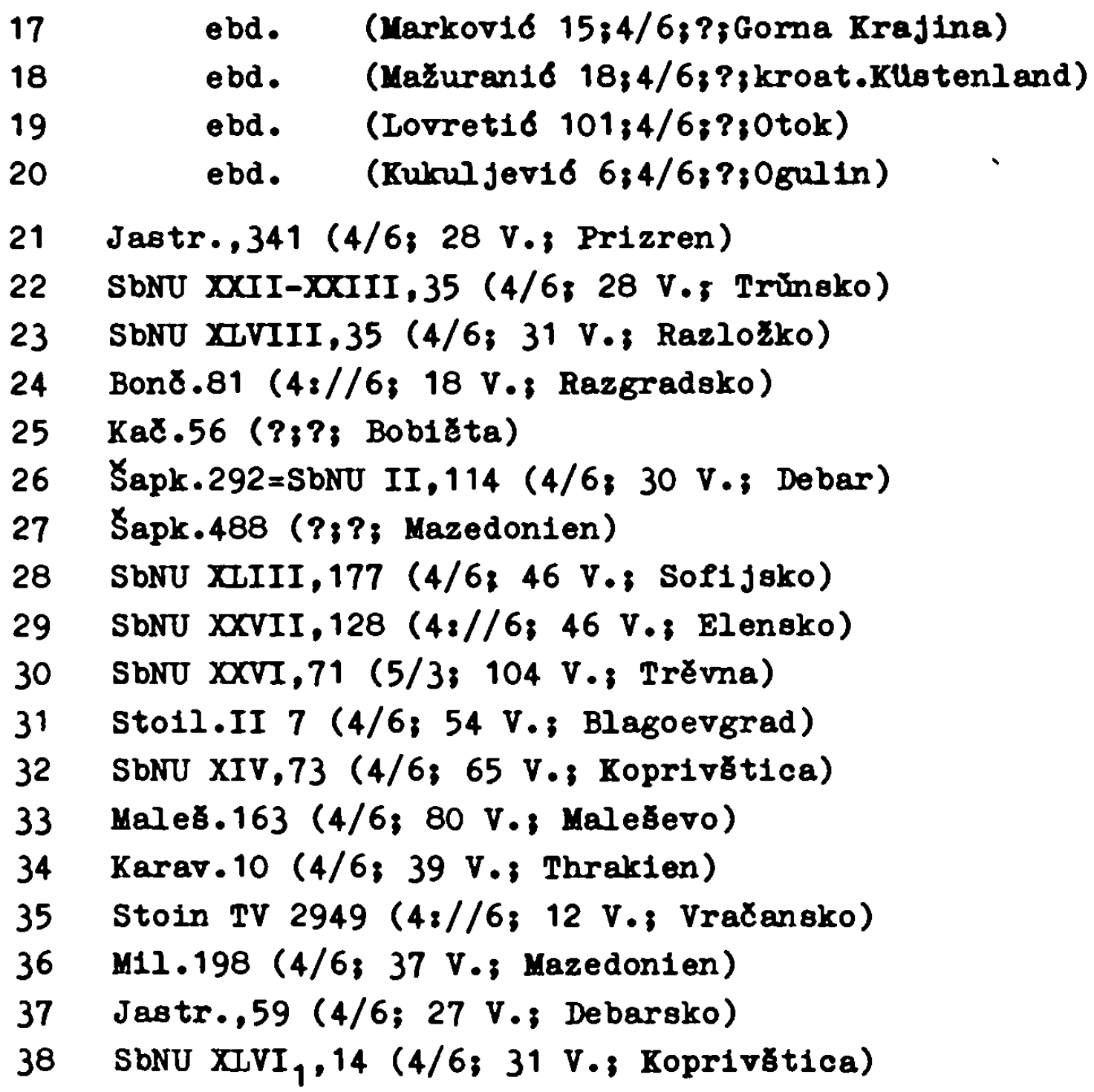

Var.1 18t bel Vuk unter den Frauenliedern aufgezelchnet, im Vorwort (der vierbandigen Ausgabe von 1953, S.XVIII) abor als eines der Lieder bezeichnet, die Vuk Karadzic zwischen die Helden- und Frauenlieder einordnen wollte, wenn er sagt: "Dekoje ou pje日me tako na medi izmedu zenskije 1 junadkije, da Covek ne zna medu koje bi 1 uzeo (...).ovake su pjesme nalioñ je na junarke nego na zenske; all b1 se tesko culo da 1 ljudi pjevaju uz gusle (vec ako, Zenama), a zbog dužine ne pjevaju se ni kao zenske, nego se samo kazuju".- Der Inhalt des kurzen Liedes mit dem Titel "Cetinfka 1 mali Radofica" 1st folgender:

Dreibig Helden aus Cetinje trinken Wein "'am kinlen . Cetinja-Flus (Ist hier die Cetina ge- 
meint, die bei Omis in die Adria flieBt? Warum aber dann Bildungen wie "Cetinjka" und "Cetinjanin", die offensichtlich von Cetinje abgeleitet sind?). Es bedient sie Cetinjka devojka.Sie wird von jedem, dem sie das Glas nachfulit, derb angefaBt, so dab sie schlieblich erklart, sie konne zwar allen dreiBig Helden Bedienung, aber nur einem einzigen die liebste sein; sie werde den zum Mann nehmen, der voll bekleidet und bewafinet den FluB Uberschwimme.- Da blicken alle bis auf Radojica zu Boden. Radofica aber kleidet sich an, nimmt seine Waffen und zieht sogar den schweren Hirtenmantel (divan-kabanicu) uber. Er schwimmt uber die Cetinja und kommt gut am anderen Ufer an. Auf dem Rllckweg will er seine Zukunftige auf ihre Treue hin prufen und tauscht deshalb Ertrinken vor. Als das Madchen inn untergehen sieht, steigt es sofort ins Wasser, um Radojica zu helfen. Er aber schwimmt nun rasch ans Ufer, nimmt Cetinjka an der Hand und finrt sie heim.

Die stereotype Eingangsformel

Vino pije tridest Cetinjana,

Kraj Cetinje, tihe vode ladne,

vino sluzi Cetinjka devojka

findet sich - in jeweils abgewandelter Porm - in fast all unseren Iiedern, ebenso eine zweite formelartige Liedstelle mit Endreim, wo das Madchen erklart:

Nko mogu svima biti sluga, Ja ne mogu svima biti ljuba.

Interessant 18t, daB der Schwimmer hier den Charakter des Madchens erproben will, whirend er in anderen Var. die kameradschaftilche Treue seiner Gefkhrten (druzina) praft.Bei Var.2 handelt es sich offensichtlich um unser sujet in verstummelter Forms

Eine Gruppe von Helden hat an Donauufer ihre Zelte aufgeschiagen. Die jungen Manner trinken Wein und werden von einem schonen Madchen bedient, dem alle an den Busen greifen, bis das Madchen sagt, es konne zwar allen Schenkwirtin, aber nur einem, den sie liebe, die Traute seins

Ako svims mogu biti sluga, Ja ne mogu svima biti ljuba, Nego jednom - kog mi srce l jubi.

An dieser Stelle bricht das Iied ab, ohne das Sujet zu Ende zu fuhren.- Var.3 dagegen ist vollstandig erhalten:

Wein trinken die jungen Manner von Cetinje am 
klhlen Ufer der Cetina. Sie werden von der jungen Cetinjka bedient, der jeder der Männer an den Busen faBt, bis sie sich das verbittet und erklürt, sie kónne zwar alle bedienen, nicht aber allen die Liebste sein, sondern nur dem jlingsten Helden namens Ive Grlovic oder demjenigen, der das Wasser Uberschwimme.- Da blicken alle feige zu Boden, nur Ive nicht. Er springt vielmehr auf und sturzt sich in die Cetina. Als er zur PluBmitte geschwommen ist, ruft er plotzlich seine Kameraden zu Hilfe. Alle blicken wieder zu Boden, nur Cetinjka nicht: Sie schurzt ihr Kleid und schlagt die Armel hoch, um Ive zu Hilfe zu eilen. Ive bemerkt dies und ruft, sie brauche inm nicht zu helfen, er habe namlich nur die Treue seiner Gefuhrten erproben wollen, ob er bei ihnen notfalla Beistand finden wïrde.

Auch hier wieder die Lokalisierung in Cetinje bzw. an der Cetina sowie die stereotypen Iiedstellen am Anfang:

Pije vino kita Cetinjana

$\mathrm{Na}$ Cetini na vodici hladnoj,

Sluzi jim ga Cetinjka divojka

und in der Mitte, als das Madchen erklärt:

Ako svima mogu biti sluga,

Al ne nogu svima virna ijuba.

Neu ist hier, daß der Schwimmer seine Kameraden zu Hilfe ruft, weil er ihre Treue priben will, und von ihnen enttauscht wird, während das Mádchen sich als hilfsbereit erweist. Die Stelle, wo das Madchen schon vor dem Probeschwimmen Ive als ihren moglichen Iiebsten nennt, ist von der sangerin sicher verdorben. Gelungen ist dagegen die parallele, daB einmal Ive als einziger nicht feig zu Boden blickt und das andere Mal Cetinjka als einzige sich zu seiner Rettung anschickt. - Var.4 hat folgenden etwas abweichenden Inhalt:

Kita Cetinija schenkt Wein aus am Donauufer. Als Guste kommen die jungen Cetinjaner, von denen jeder, wenn er das Glas hebt, dem Mädchen zutrinkt. Daraup meint Cetinija, sie könne nur dem die Liebste sein, der in voller Bewaffnung die Donau uberschwimme:

Koji hoce Dunaj preplivati

Pod skornjama i pod ostrugama

I pod pusku veliku i malu

I pod cordu rickoga kovaca.

Als die Helden vom Wein angetrunken sind, beginnen sie Streit untereinander und verlieren dabei den besten Helden. Sieben Jahre beweint ihn das 
Mădchen, trägt keinen Pelz mehr und hört auf damit, Wein zu verkaufen:

Sedam ga je godin narekala, Da ni lipa krzna spronasala, Nit' junakom vina sprodajala.

In diesem lied wird nicht gesagt, der Held sei beim Überschwimmen des Flusses umgekommen, sondern er wird anscheinend bei dem allgemeinen Streit und Handgemenge getötet. Dieses Fehlen der Schwimprobe und des happy ends sind natörlich sekundäre Veränderungen, genau wie die Verlegung der Handlung an die Donau erst nachtrăglich erfolgt sein :durfte, was ja auch die Beibehaltung des Kadchennamens Cetinija beweist. - In Var.5 ist Senjkovic Ivan einer von sechzig Hajduken, die von Cvetkinja (sicher falsch abgeleitet aus Cetinjka und umetymologisiert als Ableitung aus "cvet" in der Bedeutung Blume, Blite) bedient werden, und der einzige, der das Uberschwimnen der Donau in voller Ausrlistung wagt:
U Zizmama i u Zakirirama,
U dolani i prsluku svilnom,
I pod perjem $i$ pod kalpatinom,
I pod svojih sedam sanokresa,
Sedam pari noža i korica.

In der FluBmitte ruft er die Kameraden zu Hilfe, weil ein Fisch ihn bis zum Gurtel verschluckt habe. Als das Mădchen allein inm helfen will, halt er sie zurlick und erklät, er habe sie nur auf ihre Treue hin prufen wollen:

Nije mene riba ni vidila,

Već te kußam, duß̌, kako b' bila,

U nevolji, kano dobroj volji.

Hier wird ein neues Moment eingefuhrt: Der Schwimmer tauscht kein "gewöhnliches" Ertrinken mehr vor, sondern behauptet, von einem $F$ i s $c h$ gepackt worden zu sein,- ein Motiv, das sich noch als wichtig fur den Liedvergleich erweisen w1rd. - Die Var.6-20 sind im Anhang zu Var.3 (MH II $2,340-$ 342) nur kurz erwăhnt und können demzufolge nur den mehr oder weniger ausfuhrlichen Angaben entsprechend behandelt werden. Var. 6 stimmt im wesentlichen mit Var. 3 uberein, nur fehlt das Motiv der Treueprobe bzw. ist sekundar abgeăndert worden: 
Das Madchen Mare kommt dem schwimmenden Helden zu Hilfe, der hier wirklich zu ertrinken droht und das Madchen fur einen Fisch halt, der ihn $z u$ verschlingen suche. Das Mädchen macht ihm jedoch klar, daß kein Fisch, sondern sie, seine Verlobte (vjerenica), ihn gefabt habe. Sie zieht Ivo an das andere Ufer der Cetina und ruft höhnisch zu den feigen Kameraden hinluber:

Vama bora, devet Cetinjana!

Sada l jub'te b'jelo lice moje.

Var.7 deckt sich anscheinend fast mit Var.3. - In Var.8 ist (sekundär eingesetzt) von einem ägyptischen Madchen (Misirka djevojka) die Rede:

Misirka stellt die Bedingung, daß der Held, der sie erringen wolle, dreimal die Donau Uuberschwimmen musse. Allein der junge Radojica wagt dies und stlurzt sich ins Wasser, worauf das Madchen, das anscheinend nur seinen Mut erproben wollte, ihm sofort nachspringt und ruft:

K meni, k meni, mali Radojica!

Ne gub' glave radi moga lica!

Ja sam tvoja, vjera ti je moja!

In Var.9 springt Seljanin Ivo (sicher aus Senjanin Ivo abgeleitet) in die Cetina und ruft in der Flubmitte dem Mădchen $z u$, ein Fisch halte seine Beine fest. Als Cetinka inm helfen will, halt er sie zuruck und erklart, er habe nur ihre Treue erproben wollen. - Var.10 ähnelt Var.5, weil hier auch Senkovic Ivan und Cvijetkinja djevojka die Hauptpersonen sind und Ivan ebenfalls, wh die Treue des Madchens zu erproben, vorgibt, ein Fisch verschlinge ihn. - Var.11 behandelt das Motiv etwas anders:

Das Madchen aus Senj (Senjkinja), die Schankwirtin, stellt den Freiern die Aufgabe, die Donau zu Uberschwimmen, worauf der Jüngste (najmlajłi junak) den Strom freiwillig sechsmal (zest Dunaja) uberquert, noch dazu in voller Ausrustung:

Pod barjakom $i$ pod sivim perjem,

Pod Cizmami i pod mamuzami

Za ̧eకirom pero paunovo,

I $u$ peru zrno gjungjerovo

I u zrnu oko divojacko.

Var.12 ist unvollendet. Hier will das Mädchen demjenigen die Liebste sein.

Ki no more Dunaj preplivati,

I na glavi kołulju prenesti. 
In Var.13 ist Senjkinja djevojka die Umworbene, fur die Sekula die Donau uberschwimmt und dabei seinen Kopf leicht untertaucht, um das Madchen, das sich auch wirklich als hilfsbereit erweist, damit zu erproben. - In Var.14 uberschwimmt allein Mato fur Cetinjka djevojka die Donau. In Var.15 ruft der Held inmitten der Cetina um Hilfe, um Liebe und Treue des Madchens zu erproben. - In Var.16 pruft Ivo Senjanin die Treue seiner Gefahrten, doch nur das Madchen ist bereit, ihm ans rettende Ufer $z u$ helfen.In Var.17 erringt ein junger Held "tanku Talijanku" (also sekundar eine Italienerin), weil er die Donau mit "Cakomkapom i pod telecakom" Uberschwommen hat. - In Var.18 springt der Held in die Donau, um die Treue seiner Gefuhrten zu erproben:"ote $l i$ hoke li mu u pomoke dojti". - In Var.19 sturzt sich Ivo Senjkovic "u Xizmama i u Eaksirama" ins Meer, Uberschwimnt es und ruft auf dem Rllckweg seine Gefuhrten zu Hilfe, die sich aber nicht um ihn klumern. Da versucht Seljanka (wahrscheinlich statt Senjanka) djevojka ihn zu retten, wird aber von Ivo zurluckgehalten. Als er an Land kommt, setzt er das Madchen vor sich auf das pferd und zieht mit seiner Braut zu seinem Hof, und zwar: Pivajuci, puske hitajuci.

In Var.20 gewinnt Mijat, der Hajduken-Harambasa, die Wirtin, weil er als einziger wagt, mit Mantel und Flinte die Donau zu Uberschwimmen. - Var.21 ist ein sudserb. Hochzeitslied mit folgendem Inhalt:

Dreibig Freunde trinken Hein, bedient von Sevdali, die von allen handgreiflich belkstigt wird, bis sie schlieblich erklurt:

Ako sam ja svima vama sluga, Ja ne mogu svima biti ljuba.

Sie werde den heiraten, der Sava unj Donau uberschwimme und vom anderen Ufer als Beweis eine (uitte und Apfelsine (dunju i nerandzu) bringe. Alle blicken beschamt zu Boden. Ivo Crnogorde aber lost seine silbermen Beinschienen und springt in die Dor.au. Als er in der Strommitte angelangt ist, ruft er, ein Fiscn habe inn bis zum Gllrtel verschluckt:

Do pasa me riba progutala. 
Die ganze Družina blickt furchtsam zu Boden, Sevdali aber schickt sich an, dem Schwimmer zu Hilfe zu kommen, der sie aber zurlickhalt mit den Worten:

Vrat' se natrag, Sevdali devojko!

Neje mene riba progutala,

Vec ja gledam kakva je družina.

Nachdem Ivo sich von der Treulosigkeit seiner Kameraden liberzeugt hat, holt er die gewinschten Frlichte vom anderen Ufer und erringt dadurch Sevdali zur Frau.

Ivo Crnogorce, der Hauptheld dieses Iieds, ist uns schon aus dem vorhergehenden Kapitel als beliebte liedgestalt bekannt. Durch Einsetzen seines Namens sollte eine Historisierung des Sujets erreicht werden. Sevdali, der Madchenname, ist von tilrk. "sevda" (Liebe) bzw. "sevdall" (verliebt) abgeleitet.- Wie im vorhergehenden Lied will auch hier der Held durch seinen Hilferuf (allerdings schon auf dem Hinweg!) die Druzina prifen. Doch damit, daß der Schwimmer nicht mehr Ertrinken vortäuscht, sonderm behauptet, von einem Fisch bis zum Gurtel verschluckt zu sein (vgl. auch Var.5 und 10), steht das sudserb. Iied ganz in der maz.-wbulg. Tradition, auch damit, dab der Freier Frilchte als Beweis vom anderen Ufer mitbringen soll. Dab hier die Donau zu uberqueren ist, entspricht ebenfalls der maz.-bulg. Iieduberlieferung, wo die Donau - noch ausgepragter als in den skr. Liedern - der typische FluB schlechthin geworden $18 t^{147}$.

Den maz. und bulg. Varianten sollen zwei Iieder vorangestellt werden, die unser Sujet jeweils nur zum Teil realisieren. Es handelt sich zuerst um Var.22 mit dem Titel "Gưrkinja si izbira libe izmeżu petdeset drugari", wo nur der Iledanfang aus unserem Sujet stammt, dann aber eine andere Preiersprobe verlangt wird:

Finfzig Helden sind auf dem "sovisko polje" versammelt und trinken roten Wein. Sie werden von einer Griechin bedient, die allen die Gläser einschenkt (doljevuje), dem jungen Griechen aber soviel einglebt, daß sein Glas uberläuft (preljevuje). Dies bemerken die anderen und fragen:

Gürk' in'o le, Gŭrk' in'o devok'o,

Kưko možer na svi sluga da si, Da li možer na svi libe da si? 
Die Griechin antwortet, sie könne zwar allen Bedienung, aber nur dem Traute sein, der aus dem Vitoßa-Gebirge Quellwasser nach Sofija leite und einen Brunnen mit zehn Rohren baue. Da senken alle bis auf den jungen Griechen ratios den Kopf. Gürce aber erklärt, er werde die Bedingung erfullen.

Var.23 enthylt zwar unser Sujet im ersten Teil, geht dann aber in den Liedtyp uber, wo bei der Freiersprobe ein dem Madchen unerwinschter Bewerber siegt:

Dreißig Helden sitzen in der kỉhlen Schenke und trinken Rotwein, den ihnen Denica serviert. $\mathrm{Da}$ schlägt das Mädchen den dreibig Männern vor, sie soliten einen Wettbewerb veranstalten: Nur der konne Denica erringen, der die "weiße Donau" uberschwimme und als Beweis vom anderen Ufer Quitten und Orangen mitbringe. Keiner wagt die Schwimmprobe auber einem schwarzen Araber (cŭma arapina). Er besteht die Probe, worauf Denica ihre Schónheit verflucht, die der Araber nun "verderbe" (kerdosa).

Man vergleiche Sapk.499, wo das Mudchen ebenfalls seine Schönheit verflucht, weil ein "latince" im Freierswettbewerb - hier Uberwerfen eines Ahombaums und Blatterzahlen gesiegt hat. - Die nicht ganz vollstundige Var.24 hat folgenden Inhalt:

Siebzig Männer essen und trinken in der Schenke und werden dabei von Denica bedient, die sie alle an der Hand zu fassen suchen, wenn sie die Gluser nachfullt. Da sagt das Madchen schlieblich:

Brej! $0 j$ va vazi :// sidimdise ljudi, Ja sa ku sŭm :// na sinca vi sluga, Brej! Ce va ne súm :// na sinca vi żina.

Denica fährt fort, sie werde nur dem gehoren, der die Donau Uberschwimme (primini priz bjal Dunav) und vom anderen Ufer Quitten und Orangen (duli $i$ niranzi) herhole.

Die Var. bricht hier $a b$, so daß man nicht erfuhrt, wer von den siebzig Bewerbern das Überschwimnen des Stroms gewagt hat. - Var.25 war mir leidor nicht zuglinglich, doch iot ihr Inhalt in etwa aus der Erwähnung in ISSF V,536-37 (Nr.491) zu entnehmen:

Eine Gruppe Helden wird beim Wein von Rusalena bedient. Alle Männer suchen sie zu fassen, aber nur einer, Djura Skendelija, fragt sie, ob sie ihn zum Mann nehmen wolle, worauf Rusalena erklart, sie heirate nur denjenigen, der die Donau 
überschwimme und ein Zeichen vom anderen Ufer bringe. Djura erfullt diese Bedingung.

Eine sekundüre Veränderung besteht hier darin, dab einer der Helden das Madchen fragt, ob sie inn heiraten wolle, während in den anderen Var. das Mädchen gleich selbst die Vorbedingung fur eine Hochzeit verklndet.- Mit Djura Skendelija ist sehr wahrscheinlich der berlihmte albanische und südslavische Liedheld, der Turkenkämpfer Skenderbeg, der historische Georg Kastriot (gest.1468) gemeint ${ }^{148}$. Durch Eirsetzen seines Namens wurde unser Liedsujet (pseudo-)historisiert. - Mit der kurzen Var.26 schließen wir dort wieder an, wo wir mit der Var.21 aus Prizren die skr. Var.verließen:

200-300 Helden versammeln sich im Gebirge und ziehen dann hinunter in die kilhle Schenke, wo sie von Denika bedient werden. Alle Männer nehmen sie bei der Hand, wenn sie die Gläser nachschenkt, worauf das Madchen meint, Händefassen sei noch keine Leistung:

Ne je uner za roka fak'an'e.

Sie nehme nur den zum Mann, der die Donau überschwimme. Alle blicken beschämt zu Boden bis auf Stojan, der erklärt, er werde den Strom uberqueren. Er schwimmt bis zur Flußmitte und ruft dann seiner Družina zu, ein Fisch habe ihn bis zu den Knien verschluckt:

Me pogoltna riba do kolena!

Die Männer lachen nur über ihn, während Denika aufspringt, um ihm zu helfen. Stojan halt sie zuriuck mit den worten:

Aj ti tebe, Denik'e devojk'e,

$\mathrm{Ne}$ me pogol tna riba do kolena,

Da vidime mojava družina,

Da vidime $\mathrm{g}_{0} \mathrm{o}$ vera imaet.

Dieses lied ist nur däurch etwas entstellt, dab die gereimte Erklurungsformel dés Madchens aufgelöst und veründert ist und dab der Held schon auf dem Hinweg um Hilfe ruft. Ein Beweis vom anderen Ufer wird noch nicht verlangt, oder aber die stelle ist im Lied ausgelassen, was angesichts der beiden jeweils durch Beispiele belegten Moglichkeiten schwer zu entscheiden sein dürfte. - Var.27 war mir leider nicht zugänglich. Sie scheint sich aber inhaltlich an die vorher- 
gehende zu halten, weil sie dort (bei Sapk.292) als Liedvariante vermerkt wird. - Der Inhalt von Var.28 lautet:

Dreibig Helden versammeln sich an der Morava und werden von Mara Belogratka mit dreijuhrigem Wein bedient. Da fragen die Mănner das Mädchen:

Kako,-Maro, ret junaci sluzis, Moz li, Maro, ret junaci ljubiz?

Mara antwortet, sie könne nur den lieben, der die weibe Donau uberschwimme und aus den Garten (bach$\left.{ }_{i} i\right)$ auf der walachischen Seite "dunki i neramdżi" mitbringe. Allein Grujo malo dete erfullt diese Bedingung. Als er auf dem Rllckweg sich in der Plußmitte befindet, ruft er die Druzina zu Hilfe, weil ein Pisch ihn bis zu den Knien verschluckt habe:

Gurltna mene riba do kolena!

Die Kameraden antworten, er solle nur nicht aufgeben, sondern weiterschwimmen, denn als Lohn winke der Besitz von Mara Belogratka. Mara springt darauf ins Wasser und will zu Grujo hinschwimmeh, wird aber von ihm zurickgehalten mit den Worten:

Nadzat, nadzat, Maro Belogratko, Ja 1 i nexem Dunar da preplivam?

Ja druzina izpitija cinim.

Grujo schwimmt ans Ufer und fuhrt Mara heim.

Hier ist die gereimte Erklurungsformel falschlich den Mannerm als Frage in den Mund gelegt. Held dieses Liedes ist das Heldenkind Grujo, das uns im nächsten Kapitel als Protagonist beschäfigen wird. Neu ist hier, dab die Druzina den Schwimmer auf seinen Hilferuf hin hohnisch zum Durchhalten auffordert, was uns auch in den folgenden Iiedern begegnen wird. - Var.29 mit dem Titel "Nikola Bosnak vaima Dennica devojka" hat folgenden Inhalt:

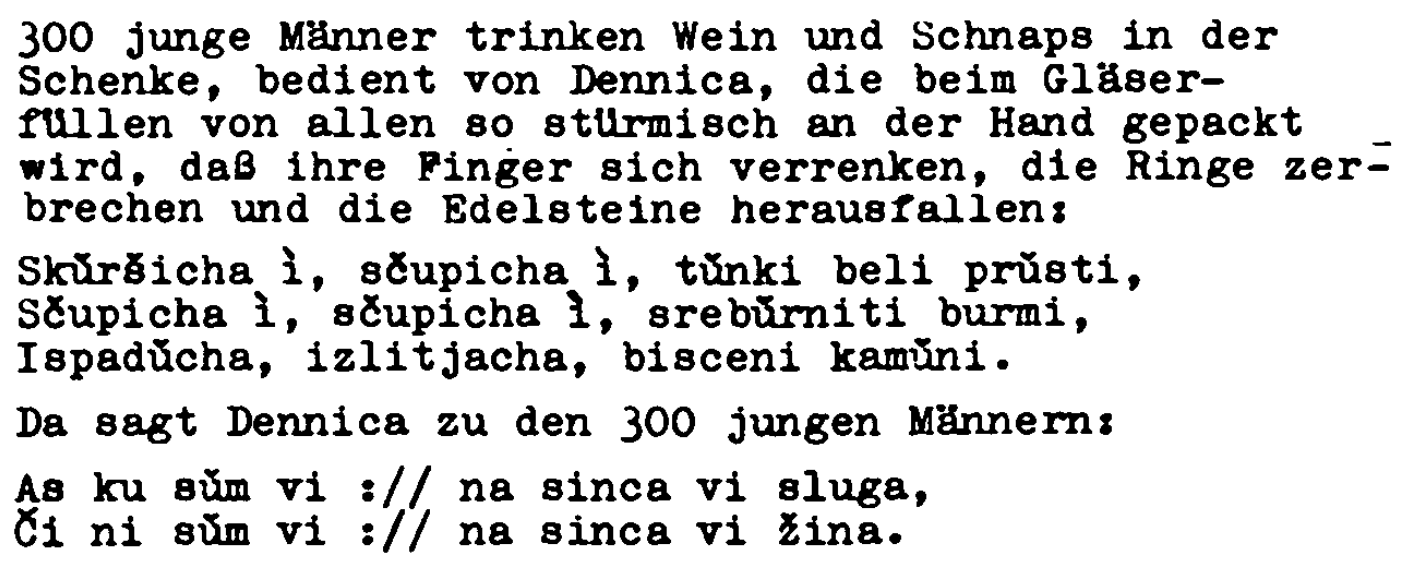


Wer sie heiraten wolle, sagt Dennica, der musse die Donau uberschwimmen und "djuli i mirandzi" vom anderen Ufer heruberholen. Nikola Bosnak schwimmt hinuber und holt die geforderten Fruchte. Auf dem Rulckweg ruft er die Kameraden zu Hilfe, weil ein Fisch ihn bis zu den Knien gepackt habe:

Nŭgưl ta ma:// riba muruniŭna (Morăne?)

Nưgŭlta ma:// cak du kuliǔnetja!

Seine Gefahrten erwidern darauf:

Plavrj, plavrj :// Nikola gidio, Ti sa zŭmniz :// Dinica divojka.

Der Schwimmer wiederholt seinen Hilferuf und erhält wieder die gleiche Antwort. Da springt das Madchen ins Wasser, schwimmt hin zu Nikola und fabt ihn an der Hand.

An diesem Iied ist auszusetzen, daß der Hilferuf zwar wiederholt, nicht aber gesteigert wird. AuBerdem fehlt die Auflösung am Liedende, daß es sich namlich nur um ein tauschungsmanöver des Schwimmers handelte, womit die Freundestreue gepruft werden sollte. - Beide Bedingungen sind in Var.30 erfullt, deren Inhalt kurz so wiedergegeben werden kann:

Momce Troence (Junge aus Trojan) wagt als einziger von siebzig Helden das Überschwimmen des plusses, das die junge Schenkwirtin Dennica als Bedingung fur eine Heirat mit ihr gestellt hat. Auf dem Rlickweg behauptet der Schwimmer zuerst, ein Fisch (riba muruna) verschlinge ihn bis zum Knie, dann - als die Freunde lhm nicht helfen wollen - bis zur Taille. Dennica will inm zu Hilfe eilen, wird aber zurickgehalten mit den Worten:

oj ta tebja bre Dinnico,

Nidej plava tich bjal Dunŭf!

As si laža moj družina,

$\chi_{i}$ da vidja, $\chi_{i}$ da vidja

Koj za si menja až́disa.

Die wirkungsvollste Art des Hilferufs, nämlich in dreimaliger Steigerung, wird in den folgenden drei Varianten realisiert. Var. 31 hat folgenden Inhalt:

Denica bedient eine Druzina von dreibig Mannern und wird von ihnen gefragt:

Site ne naret sluga posluzi, Mozez le ne site zaljubiti?

Dennica antwortet darauf, sie konne allein die Liebste von Jovan seimen (sejmenin = tlukk. Soldat im Polizeidienst) sein. Da senken alle den Kopf 
und weinen. Dennica fahrt fort, der könne sie gewinnen, der die Donau uberschwimme und von der Walachei (Kara-Vlaška zemja) Quitten und Orangen heriberhole. Jovan springt auf und erklart sich zu der Schwimmprobe bereit. Als er den Strom uberquert hat und wieder auf dem Ruckweg ist, versinkt sein Pferd an der ersten tiefen Stelle (rastoka) bis zum Knie, an der zweiten bis zum Steigblugel, und an der dritten schlieblich reicht das Wasser Jovan bis zur Schulter, worauf er ruft:

E vieka, triese druzina, Pogŭna me riba do ramenja.

Die Družina ermahnt ihn zum Weiterschwimmen. Allein Denica will ihm helfen, wird jedoch von Jovan zuruckgehal ten:

Nadzat, nadzat, Denice devok'o,

Jaze laža moite družina, Da li si drǔžat zgovorna duma.

Negativ ist an dieser Var. nur, daß das Mådchen den Namen des Schwimmers vorwegnimmt und daß Jovan nur einmal um Hilfe ruft, während der dreimaligen steigerung des Einsinkens auch ein dreimaliges Rufen entsprechen wildde. - In Var.32 sind diese Schwächen vermieden:

Hier Uberschwimmt Pavel dobar junak die Flusse "Sava $i$ Morava, toz tich bjali Dunav" und holt aus den Gärten in Kara-Vlaska die gewlinschten Frluchte. Auf dem Ruckweg erfolgt dann die dreimalige Steigerung des Hilferufs:

Ej vi vaze, trieset delie, Jobzina me riba morunova, Jobzina me dur do kolenete!

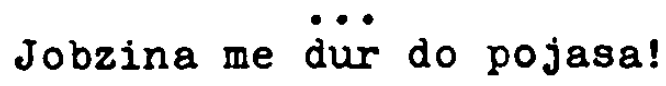

Jobzina me dur do ramenata!

Hier schwimmt der Freier, nachdem die Družina ihm nicht geholfen, das Mădchen aber seine Bereitschat't dazu gezeigt hat, an Land und fuhrt das Mådchen heim, während Var.33, wo die dreimalige steigorung genau so wie in Var.32 erfolgt, noch dadurch erweitert ist, dab der Held blutige Rache an den treulosen Gefährten nimmt:

Razljutilo na svoja družina, Istrgna si taja ostra sabja

I iseče trijese družina, Sal zaljubi Denica devojka,

Oti go je ona požalila. 
Neu ist hier, daß der Held nicht mehr blob Frlichte holen sol1, sondern einen Rosenzweig, aus dem sich ein Kranz winden läbt, einen vergoldeten Apfel, eine Quitte und Orange sowie einen Rosenstrauß:

Da otkryi pracka od trendafilj,

$\mathrm{Da}$ izvijem tove zelen venec;

Da otkine pozlat'na jabaka,

Da otkine duna i nerandža,

Da nabere kitka ruzinovo.

Var.34 gehört nur bedingt zu unserem Sujet, enthklt aber eindeutige Reminiszenzen daran und soll der Vollständigkeit halber erwahnt werden:

Der Fluß Tundža (oder Tundželija). tat Hochwasser und trägt einen Olivenbaum heran, der goldene Wurzeln, einen silbernen Stamm und Perlenblatter aufweist und an jedem Zweig mit einem goldenen Apfel geschmilckt ist. Auf dem Baum sitzt Angelina, die in der Rechten einen vergoldeten Becher mit dreijährigem Wein und in der Linken einen Basilienstraub halt. Da versammeln sich junge Manner an Ufer, die den Wein trinken und das Mădchen klissen möchten. Angelina aber erklärt, nur der konne sie erringen, dem es gelinge, einen goldenen Apfel zu pflücken und ihr den Becher mit Wein aus der Hand zu nehmen.- Ein junger Schzfer (mlado ovčerče) zieht darauf seinen Mantel aus, nimmt seine Flote und spielt ein so einschmeichelndes Iied, daß das Mädchen ganz versunken zuhört. Der Hirte watet nun ungehindert ins Wasser,leert den Becher, pfluckt den goldenen Apfel, nimmt den Blumenstrauß und kaßt das Madchen.

Hier sind m.E. deutliche Reminiszenzen an die goldenen Äpfel und Blumen, die der Held Uber dem Wasser pelucken soll, un das Mädchen zu erhalten, bewahrt geblieben, nur ist die Handlung sekundar umgestaltet worden, was zu einem sehr gelungenen neuen Sujet führte. - Var.35 ist unvollendet und unsinnig:

Marko sagt zu den dreibig Helden in der Schenke. die alle nach der Hand der Schenkwirtin Dennica haschen,

Ce ako e na svekima sluga, Ceva ne e na svekima zena, Stroß̧ijte 1 , skŭrక̧ijte 1 tŭnki beli prǔsti, worauf die Männer dem Madchen wirklich die Finger quetschen:

Istroßicha zlatnite prüstene, 
Ispadacha besceni kamūne. Abschliebend sind noch drei Var. zu besprechen, die eine Sonderentwicklung aufweisen. Zuerst Var.36 mit folgendem Inhalt:
DreiBig junge Manner halten am Schwarzen Meer ein Trinkgelage $a b$, bedient von Ruzica, die vor- schlagt, derjenige könne sie zur Frau gewinnen, der die Seidenkleidung ablege, dafur sein Pan- zerhemd anziehe, eine stählerne Platte nehme und in dieser Ausristung das Meer uberschwimme, wobei er von dem goldenen Apfel baum am anderen Ufer drei goldene Äpfel zu pflucken habe.- Alle Männer bis auf einen senken mutlos den Kopf. Der Mutige aber ristet sich, Uberschwimnt das Meer und fin- det den goldenen Apfelbaum. Er pfluckt jedoch nicht erst die drei gewlinschten Äpfel, sondern reibt den ganzen Baum mit den Wurzeln aus, uber- quert wieder das Meer und bringt den Wunderbaum hin zu der.Tafel, wo die Druzina beisammensitzt. Ruzica springt auf und kuBt dem Sieger die Augen- lider. Der klinne Schwimmer nimmt das Madchen und funrt es, gefolgt von den Helden, nach Hause, wo drei Monate lang Hochzeit gefeiert wird.

In dieser schonen Var. finden wir zwar die bekannten stereotypen Stellen wie den Liedeingang

Sednale mi tri'eset momcina, Sednale mi pokraj cưmo more, Sluga slużit Ružica devojka

und die gereimte Erklarung des ladchens

$$
\begin{aligned}
& \text { Ako možem 'sem sluga da Cinam, } \\
& \text { Ja ne možam' sem l jubov da bidam, }
\end{aligned}
$$

doch fallt hier ein besonderer episch-marchenhafter ton auf, der in den anderen Varianten, die sich dafur durch starkere Realistik auszeichneten, nicht zu bemerken war. In diesem Lied nun 8011 das weite Meer - kein FluB mehr - uberschwommen werden, eine unlobbare Aufgabe, die nur ein marchenhafter Held, ein "junak ot junaka roden", erfullen kann, von dem das Mudchen uberdies verlangt:

$$
\begin{aligned}
& \text { Da si slecit rubo koprineno, } \\
& \text { Da oblexit ot pandzur kosulja, } \\
& \text { Da si zemit stica celiko'a. }
\end{aligned}
$$

Er soll auch nicht mehr schlicht "Quitten und Orangen", also naturliche Frlichte, als Beweis vom anderen Ufer bringen, sondern drei goldene Äpfel von einem goldenen Apfelbaum, dem beliebten goldenen Baum des Märchens. Der wunderbare 
Held aber will seine Fuhigkeiten dadurch noch unterstreichen, $d a b$ er den Baum entwurzelt und im ganzen herschaft:

Jabolinica ot koren otkorna;

Si prepliva preku Curno more,

Ja donese na Cesna türpeza.

Hier ist keine Rede von Ertrinken bzw. einer Prüfung der Mădchen- oder Druzinatreue. Das ware ein Stilbruch in dem marchenhaften Ton dieses liedes, den die Sangerin (vor allem im Mittelstuck) meisterhaft durchzuhalten verstand. Es fehlt auch die Erwähnung eines Fisches, der den Schwimmer angeblich zu verschlingen droht. Episch - wie der Anfang ist auch der Liedschluß:

$$
\begin{aligned}
& \text { Ko' go vide RuZica devojka, } \\
& \text { I si stana na junacka noga, } \\
& \text { I se spusti v ozi go celiva. } \\
& \text { Si ja fati za desna rúcica, } \\
& \text { Si povede tri eset momXina, } \\
& \text { Si otide pri svojata majka. } \\
& \text { Zafati'e svadba da mi zinet, } \\
& \text { Malu svadba tokmu tri meseci. }
\end{aligned}
$$

Die beiden folgenden lieder stehen dadurch, daß nicht das Meer, sondern zwei Flusse zu uberqueren sind, den bisher besprochenen Var. noch naher als Var.36. - Var.37 hat 1olgenden Inhalt:
Dreibig Helden versammeln sich im Waldgebirge und steigen dann zur klhlen Schenke hinunter, wo ihnen Danica Wein und Schnaps kredenzt. Sie meint, sie könne zwar alle bedienen, aber nur den einen lieben, der mit einem Panzerhemd (pan- cirli dolama) gerlistet das Flugelpferd (konja krilatnjego) besteige, Sava und Donau uberquere (prefrlit) und von einem goldenen Apfel baum, der druben auf einer stählemen Platte (Stica Celi- Cena) wachse, einen goldenen Apfel mitbringe.- Die Druzina blickt feige zu Boden, nur ein Held tut, wie Danica gesagt hat, d.h. er bringt so- gar den ganzen Baum mit (ja otkorna zlatna ja- blknica) und erringt dadurch das Madchen.

Var.38 ist ganz ahnlich:

Dreibig Helden trinken Wein aus Solun und Rakija aus Demir Kapija. Drei Tage und drei Nachte lang bedient sie Danica, bis es ihr schlieblich lastig wird, dab alle sie zu fassen suchen, und sie erklart:

Ej vi vazi, trideset delija, Ako sam vi sluga na sickite, 
Ta ne sam vi libe na sickite.

Sie werde allein den zum Mann nehmen, der Sava und Morava luberschwimme und vom anderen Ufer drei goldene Äpfel hole, die an dem Baum (drvo keferezno) auf einem weiBen Stein (na kamik belica) zu finden seien.- Nur ein siebenjăhriges Heldenkind (dete sedemgotze) erfullt diese Aufgabe und bringt sogar den ganzen Baum entwurzelt her an die Tafel (na Cesna trapeza), worauf das Mädchen ihm gehört.

Obwohl diese beiden Lieder große Ähnlichkeit mit Var.36 aufweisen, fehlt ihnen doch der episch-märchenhafte Anstrich des vorhergehenden Liedes. Sie wirken geraffer und schmuckloser als Var.36. Inhaltlich nehmen sie quasi eine Zwischenstellung zwischen den vorher besprochenen Liederm und $\operatorname{Var} .36$ ein, d.h. sie spiegeln eine thergangsphase wider, wobei sich jedoch die wichtige Frage erhebt, in welcher Richtung die Entwicklung erfolgtes

Entwickelte sich das Schwimmproben-Sujet von der epischmärchenhaften Stufe (drei goldene Äpfel uber dem Meer; vorgetauschtes Ertrinken und Treueprobe fehlen) uber die halbmärchenhafte (drei goldene Äpfel am anderen Flußufer; Entwurzeln des Wunderbaums wie in der vorigen Stufe; Treueprobe durch vorgetłuschtes Ertrinken fehlt) zur halb-realistischen (natürliche Früchte am anderen Flußufer; fingierter Riesenfisch dient zur Treueprobe) und schlieblich realistischen Stufe (Uberschwimmen des Flusses mit oder ohne Frlichteholen; Treueprobe durch vorgetäuschtes Ertrinken) oder eher in umgekehrter Richtung?

Die realistischen Var. stammen alle aus dem skr. Raum. Sie stehen einer etwa gleich großen Zahl maz. und bulg. Lieder in halb-realistischem bzw. märchenhaften Ton gegenuber, so dab sich die Vermutung aufdrangt, unser sujet habe sich im maz.-wbulg. Raum ausgebildet, und zwar in seiner dort vertretenen marchenhaften Spielart, die bei ihrem Vordringen in den skr. NW immer mehr realistische Zuge annahm. Diese Hypothese wird dadurch gestuitzt, daß wir schon in Kap.2.2 auf die Vorliebe der maz. Lieddichtung fur archaisch-märchenhafte und mythologische Motive hinweisen konnten. Die 
vor allem in den skr. Var. ausgeprägte Psychologisierung des Geschehens mit Hilfe der Treueprobe ist vermutlich ein relativ neues Element.

Wăhrend wir bei den in Kap. 4.11 besprochenen vielgliedrigen Iiedern (ungeladener Neffe erfullt fur den Oheim Freiersproben, die der Brautvater stellt) zu der Vermutung gen langten, daß die im ersten Teil von Kap. 4.12 erwähnten, meist eingliedrigen Iieder (Mädchen stellt einem Bewerberkreis eine schwierige Aufgabe, die einer der Freier löst) durch Vereinfachung und Zuspitzung auf das Episodenhafte aus den 4.11-Liedern entstanden sind, liegt der Fall bei den Iiederm, die das Schwimmproben-Motiv gestalten, wahrscheinlich komplizierter. Im nüchsten Kap. ist nămlich ein Variantenkreis zu besprechen, dessen mehrgliedriges Sujet wie eine Weiterentwicklung aus dem hier behandelten, relativ einfachen Schwimmproben-Motiv anmutet. Zur Untermauerung dieser möglichen Entwicklung stïnden uns sogar aufschlubreiche 2 wischenglieder zur Verfugung, die beweisen könnten, daß die Glieder der angenommenen urspringlichen Motivkette zum Teil unregelmäBig an der Weiterentwicklung teilnahmen. So konnte z.B. das Madchen als Aufgabenstellerin beibehalten werden - bei gleichzeitiger Motivkettenerweiterung durch die Pferdetausch- und Meeresungeheuer-Episode - oder aber im Laufe der Entwicklung eine Ablösung durch ein "Heldengremium" bzw. schlieblich den Brautvater als Aufgabensteller erfahren; oder aber das Überschwimmen der Donau und die Treueprobe blieben bewahrt, während sich nun gleichzeitig der (fingierte) Fisch zu einem oder mehreren Meeresungeheuern (Drachen, Schlange, Meeresjuda) weiterentwickelte.

Ob diese hier als Moglichkeit angedeutete Entwicklung tatsächlich in der angegebenen Richtung verlief, soll im nächsten Kap. untersucht werden, wo auch die erwahnten Zwischenglieder die ihnen geblhrende Behandlung erfahren. 


\subsection{3 ÜBERSCHWIMMEN EINES GEWÄSSERS UND DRACHENKAMPF LLS NICHT VON DEM MÄDCHEN SELBST GESTELLTE FREIERSPROBE}

Wie im vorigen Kap. abschließend erwănnt wurde, könnte es sich bei dem nun zu untersuchenden Sujet um eine Weiterentwicklung aus dem relativ einfach strukturierten 4.12Sujet handeln, wo durchweg die Rede von kurzen Iiedern war (Durchschnittslänge $42 \mathrm{~V} .1$ ), in denen ein Mudchen (Schankwirtin) eine Freiersprobe stellte, die im Uberschwimmen eines Flusses oder des Meeres bestand. Obwohl eine Entwicklung vom einepisodigen zum komplizierter gebauten Sujet theoretisch möglich wäre, spricht m.E. mehr flur eine umgekehrte Liedentwicklung (vom mehrepisodigen zum eingliedrigen Sujet), die ubrigens in den 4.11-Liedern und deren Reduktion zu einepisodigen Sujets eine Parallele hatte.

In den nun zu untersuchenden liedern geht die Initiative der Aufgabenstellung entweder von einem "Heldengremium" bzw. einem Vertreter aus dessen Mitte oder einem Gastgeber aus, wahrend das Madchen eine passive Rolle spielt. Dem Helden, der die gefuhrliche Schwimmprobe zu bestehen vermag, winkt als Belohnung die Hochzeit mit dem Mädchen, das die Helden bedient. Die Freiersprobe - drei goldene Äpfel von einem Baum im Meer zu holen - wird dadurch besonders erschwert, daß der Held unterwegs mit dämonischen Wesen (Drachen, Schlangen) kämpfen bzw. ihren (Samovilen, feenartige Wesen) Verlockungen widerstehen muß. Dieses Sujet, das stark an die Sage der griechischen Mythologie erinnert, wo Herakles als elfte Aufgabe fur seinen Vetter Eurystheus, den Konig von Mykene, die drei goldenen $\ddot{A}$ p $f$ e $l$ der H $_{\text {e }} \mathrm{s}$ pe$r i d e n$ von dem durch den mehrköpfigen, ewig wachsamen D $r$ a $\mathrm{c}$ e $\mathrm{n}$ Ladon bewachten Baum im Göttergarten am Westrand der Welt holen muß ${ }^{149}$, scheint zum Ausgangspunkt einer Liedentwicklung in mehrere Richtungen geworden zu sein.Einerseits ist eine Reduktion $z u$ beobachten, so daB entweder nur noch vom Herholen goldener Äpfel uber dem Meer ohne Drachenkampf oder dem Ubberschwimmen eines Gewässers und Herholen na- 
türlicher Früchte die Rede ist, wobei in einem (fingierten) Riesenfisch die Erinnerung an den ursprunglichen Drachen weiterlebt bzw. als neueste Entwicklung in einem "ErtrinkManöver" rein psychologisiert und vollig entmythologisiert wurde:

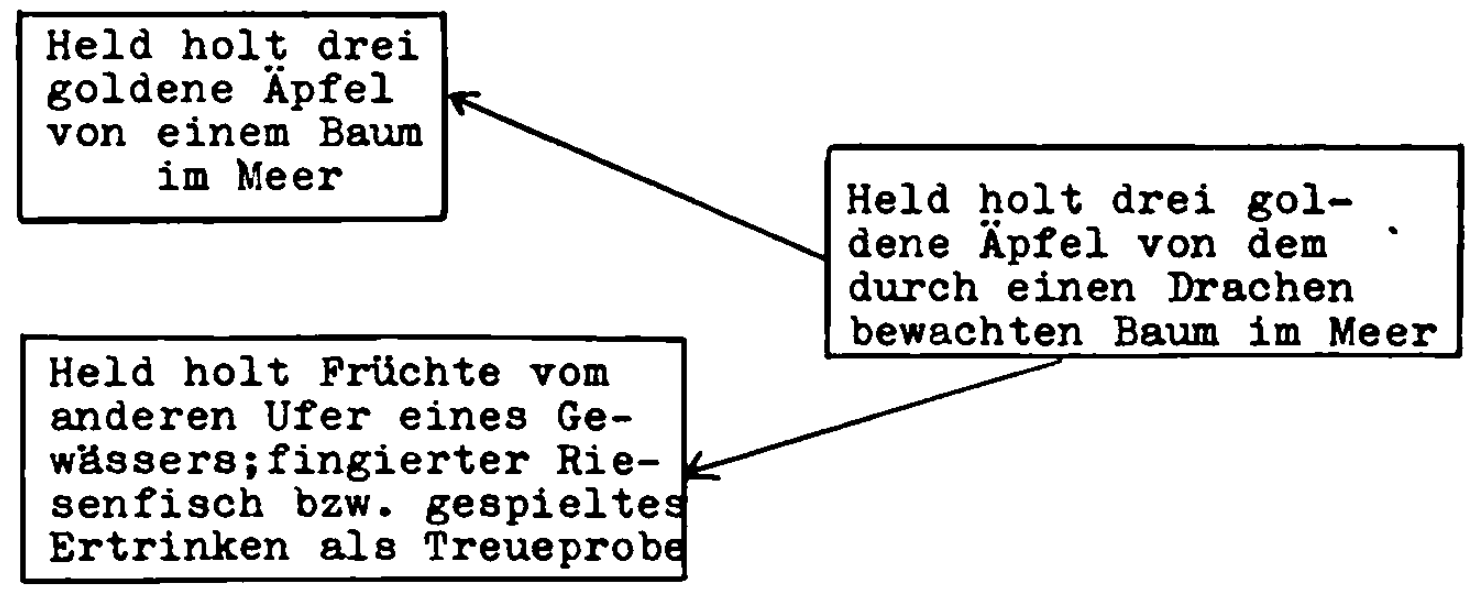

Andererseits kam es von unserem Sujet ausgehend zu zahlreichen Amplifikationen und Motivanderungen, die z.B. unter dem EinfluB der Lieder vom Typ 4.11, 4.21, 4.22 und 4.3 oder durch Episodenanreicherung (z.B. Erweitemung durch "Handschuh"-Motiv, Schicksalafrauenepisode, Oheim-NeffenKampf-Episode usw.) entstanden.

Da einer erdrulckenden Mehrheit vọ maz.-wbulg. Varianten nur einige wenige ostbulg. bzw. sudserb. und sluddalmatin. Lieder gegenuberstehen, darf man vermutlich mit einer Ausbildung des Sujets im maz.-wbulg. Raum rechnen, also dem slavisch-griechischen Berluhrungsbereich, wo die Vermittlung von Kulturglitern und somit auch alter Mythen am ehesten stattfinden konnte. Das Sujet gehort also im maz.-wbulg. Liedbestand zur altertumlichen Primarschicht. Es handelt sich meines Wissens um folgende Varianten: ${ }^{150}$

1 SbNU II,91 (4/6; 59 V.; Sofijsko)

2 SbNU XIIX,39 (4/6; 156 V.; Brezniłko).

3 Kad.143 (4/6; 74 V.; Sofijsko)

4 Drag.36 (4/6; 70 V.; Kumanovo)

5 SbNU XIIII, 176 (4/6; $46 \mathrm{~V}$.; Sofijsko)

6 SbNU XXV,34 (6-Silber; $241 \mathrm{~V}$.; Vracansko) 
sings

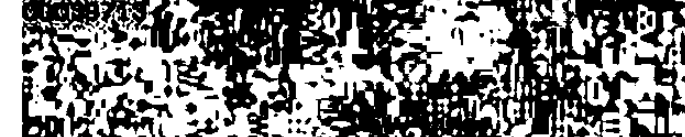

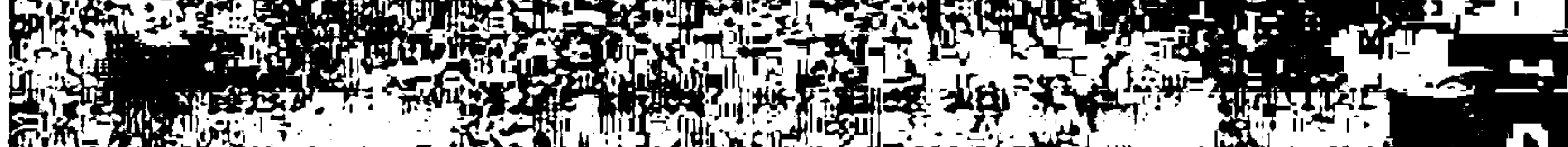

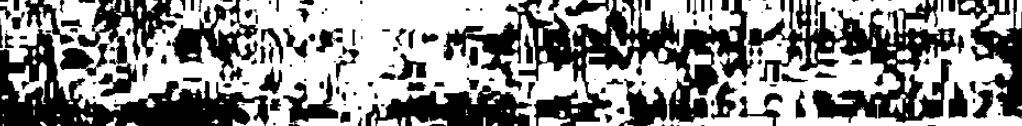

(1)

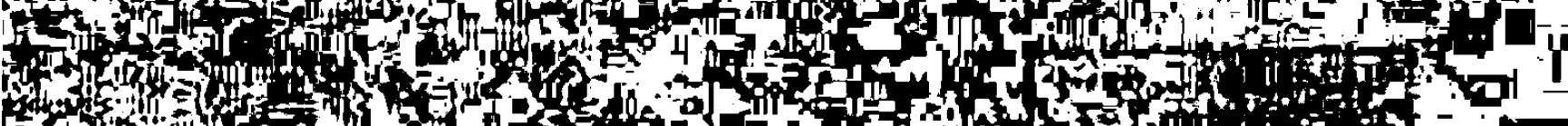

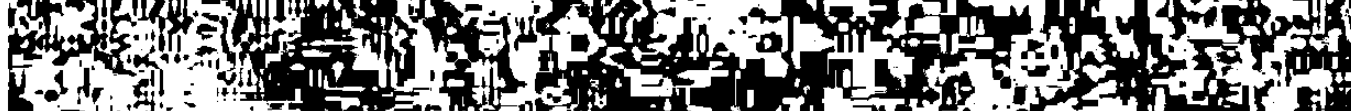

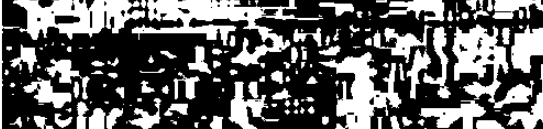

The

(2)

3ital

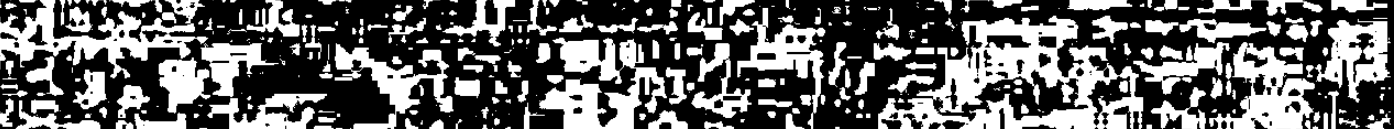

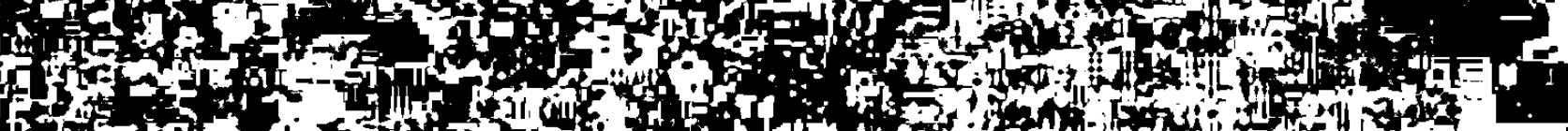

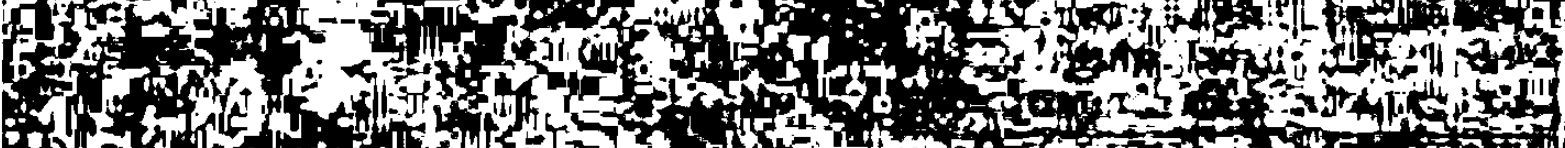

int

格

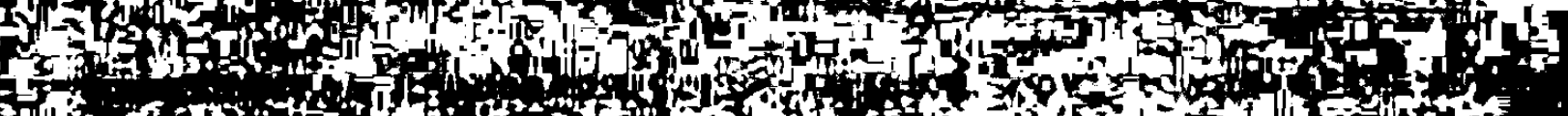

1

PIf

a

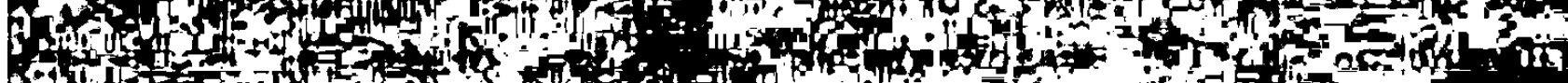

ty

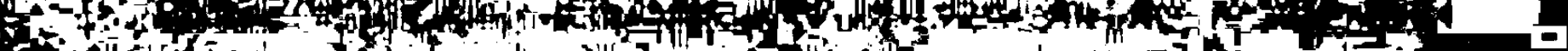

if

and

4 in

-

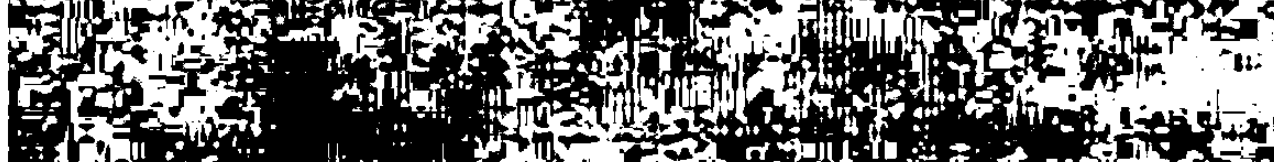

40

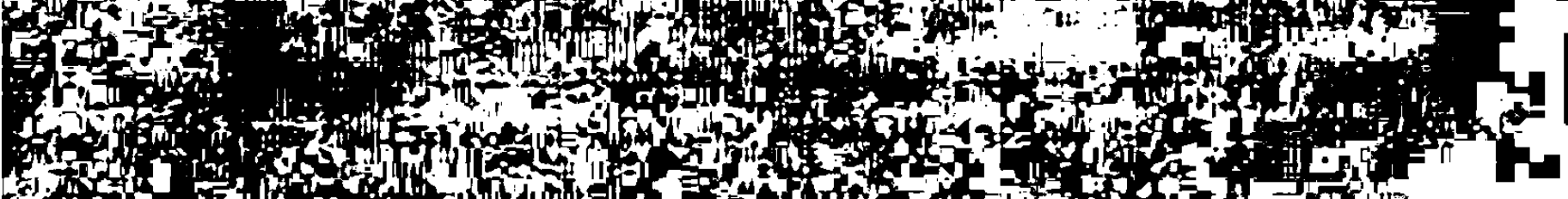

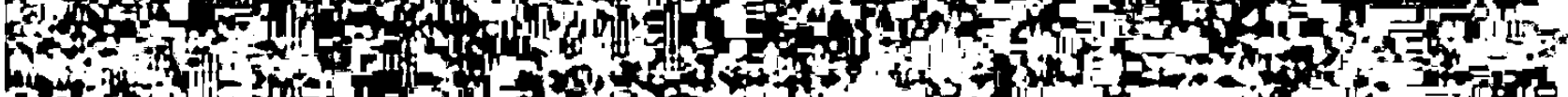

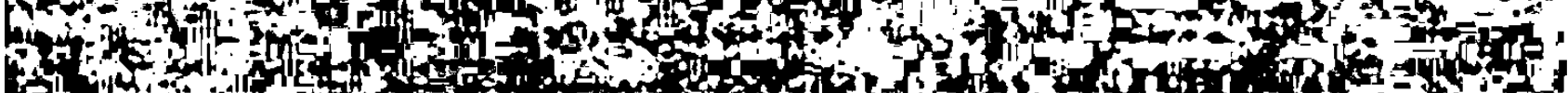
Sh

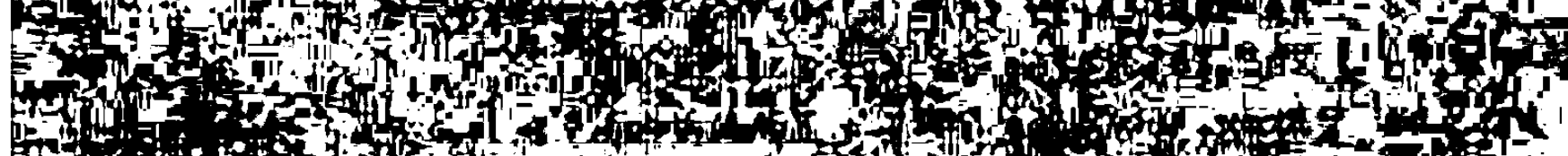

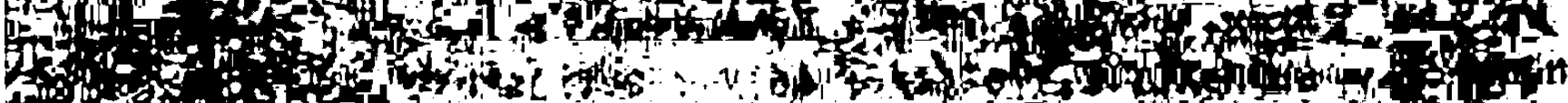
i.t4h

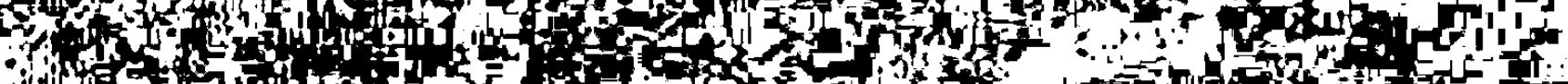

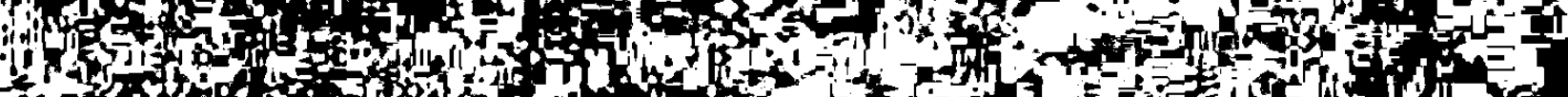
L.

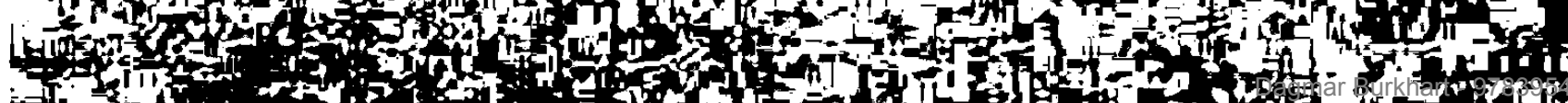


SbNU XXV,10 (4/6; 18 V. Uv.; Vraca)

8 Mich.360 (4/6; 53 V.; Mazedonien)

9 SbNU XIIII, 170 (4/6; $179 \mathrm{~V}$.; Sofijsko)

10 Verk.-Lavr.7 ( $5 / 5$ ur.; 30 V.; Mazedonien)

11 Stoin TV 3698 (4/6; 35 V.; Vidinsko)

12 Kar.191 (4/6; 70 V.; Samokovsko)

13 Drag.30 (4/4; $177 \mathrm{~V}$.; Solunsko)

14 KaX.137 (4/6; $104 \mathrm{~V}$; Radomirsko)

15 SbNU XXVII,122 (6/6; 79 V.; Elensko)

16 SbNU XXVII, 124 (6/6; 102 V.; Elensko)

17 SbNU XXXIX, 88 (4/6; $37 \mathrm{~V}$;; mittl.Rhodopen)

18 SbNU VIII,91 (4/6; $163 \mathrm{~V}$; Kopriv8tica)

19 SbNU IXII, 114 (5/3; $46 \mathrm{~V}$;; Kolarovgrad)

20 Verk.-Lavr.8 (6/6 ur.; $153 \mathrm{~V} . ;$ Mazedonien)

21 Sapk.372 (4/6; $170 \mathrm{~V} \cdot ;$ Sofijsko)

22 SbNU XIIV,49 (4/6; 64 V.; Sopijsko)

23 Mil.145 (4/6; 203 V.; Mazedonien)

24 SBNU XIIII,162 (4/6; $412 \mathrm{~V}$;; Sofijsko)

25 Per.Spis.XLV,459 (4/6;608 V.; Blagoevgrad)

26 Drag.31 (ur.; $88 \mathrm{V.;}$ Solunsko)

27 SbNU XIJIII,51 (4/6; $83 \mathrm{~V}$;; Razložko)

28 SbNU XIIV,46 (4/6; 322 V.; Sopijsko)

29 Maleక.161 (4/4; $49 \mathrm{~V} . ;$ Maleževo)

30 Jastr.,276 (4/6; $200 \mathrm{V.;}$ Sirinic)

31 SbNU IX, 12 (4/4; 150 V.; Iskrecko)

32 Stojk.,396 (4/6; 102 V.; Toplica)

33 SbNU XIIII,173 (4/6; $285 \mathrm{~V}$.; Solijsko)

34 vurrb.323 (5/3; $184 \mathrm{~V}$; Preslav)

35 BNTv.I,348 (4/4;93 V.; ?)

36 BNTv.I, 687 (3/5; ur.,uv.; ?)

37 IAH $I_{1} 53=I_{2} 69$ (4/6; $549 \mathrm{~V}$.; Dubrovnik)

$38 \mathrm{MH} \mathrm{I} \mathrm{I}_{2}, 444$ (Markovic 12; 4/6; ?; Luka)

$39 \mathrm{MH} \mathrm{I} 270(4 / 6 ; 486 \mathrm{~V}$; Luka)

$40 \mathrm{MH} \mathrm{I}, 569$ (Ikic 2; 4/6; ?; Derventa) 
Nun zum Liedvergleich. Var.1 hat folgenden Inhalt:
Finfzig Helden sind in der kühlen Schenke ver- sammelt und streiten sich beim Wein um Nedel'i- ca, die sie bedient. Das Madchen macht dem Streit dadurch ein Ende, daß es den Bewerbern die Be- dingung stellt, die Donau zu überschwimmen und aus dem Meer von dem "drŭvo sevdelijevo" (Liebes- baum) drei goldene Äpfel herzuholen. Kaum hat das Mädchen ausgeredet, da springt Gruica ergen- $\mathrm{Ce}$ (Junggesellchen) auf und holt seinen Rotfuchs (konce dorejance) aus dem Stall. Darauf meint Marko Kral'evice, Gruica solle nicht dieses un- erfahrene Pferd (adžamija) nehmen, das mitsamt dem Reiter ins Verderben gehe, sonderm seinen eigenen erfahrenen Schecken (sargalija), der das Meer schon dreimal uberschwommen habe. Gruica gehorcht, setzt sich auf Markos Pferd, steckt den rechten FuB in den Steigbligel und ist, bevor er noch den linken Steigbligel berihrt hat, bereits an der Donau und gleich danach im blauen Meer. Er findet den Baum, den er im ganzen ausreiBt, und macht sich sofort auf den Rlickweg. Da begeg- nen ihm zwei "morski prelübnici", also verfuhre- rische Meereswesen, die Gruica gebannt anstarrt, bis das Pferd den jungen Helden auffordert, das Schwert zu ziehen und die beiden Zauberwesen zu toten. Gruica leistet dieser Aufforderung Folge und kehrt glucklich zur Schenke zurlick. Er nimmt den Baum mit den gewlinschten goldenen Äpfeln von der Schulter und pelanzt ihn auf der Tafel (na Cesni trapezi) auf, worauf Nedel'ica seine Frau wird.

In diesem von wunderbaren Elementen erfullten lied hat sich der Hesperiden-Mythos relativ gut erhalten, nur peluckt hier der Held nicht erst die Äpfel, sondern entwurzelt den Baum - zum Beweis seiner märchenhaften Stärke ${ }^{151}$ - und trăgt ihn im ganzen mit sich fort. Eine Reminiszenz entweder an die (vier) Tochter des Atlas, die Hesperiden, oder aber an den wachsamen Drachen Ladon blieb in Gestalt der beiden "morski prelŭbnici" erhalten, die in der FN zu dem lied erklärt werden als "njako1 morsk1 sútestva, kolto mogat da se predvarjat $i$ pravjat pakosti po moreto: te sa se pretvorili na chubavici momi i sa iskali da go omajat ili omag' osvat za da se udavi u moreto, ili pak druga vrjada da mu stane". Man könnte bei diesen bose gesinnten Meereswesen, die sich hier in sch bne Mädchen verwandelt haben, auch an eine Fortsetzung der antiken Sirenen bzw. Nereiden oder an 
eine Umschreibung der slavischen Vilen bzw. der griechischsudslavischen Lamja denken.- Neu ist hier das Erweiterungsmotiv des Pferdetauschs zwischen Marko und dem jungen Gruica, deren Verwandtschaftsverhaltnis (Oheim-Neffe, seltener Vater-Sohn) in diesem lied nicht angedeutet wird, aus anderen Liedern aber klar hervorgeht. Typisch fur die maz.wbulg. Volksepik lot die Gestalt des erfahrenen Streitrosses, das - gefragt oder ungefragt - dem Helden mit guten Ratschlagen und konkreten Anweisungen beisteht. Dieses spre-

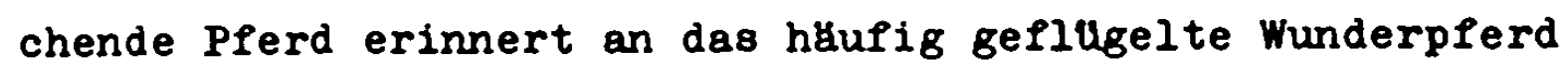
der vorepisch-murchenhaften Stoffe, aus denen oder gleichzeitig mit denen sich vielleicht die ersten stark mythologischen Lieder des maz.-wbulg.-griechischen Liedzentrums entwickelten.- DaB in unserem lied das Madchen den Freiern die Aufgabe stellt, verweist dieses Sujet in eine 2 wischenstellung, zwischen Typ 4.12 und 4.13. - Die diesem ersten Lied sehr ăhnliche Var.2 wirkt in der Ausfunrung mancher Motive praziser und gleichzeitig ausfuhrlicher:

Denica verspricht Grujo, der mit seinem Oheim Marko von Prilep in einer Trinkversammlung von dreissig Männern sitzt und sich um das Madchen bemluht, die Heirat, wenn er, "malo dete", das Schwarze Meer Uberschwimme und den dort wachsenden Apfelbaum (durvo jabukovo) herschaffe. Grujo, der sich seines "musko sứce" ruhnt, will sich sofort mit seinem Rappen auf den Weg machen, wird aber von seinęm Oheim zurlickgehalten und mit dessen Schekken Sarko ausgestattet, weil "iz more lose srexe ima, sto se sluxi, Sarko de te uri". Grujo reitet mit Sarko 108, und als sich Pferd und Reiter mitten im Meer befinden, verschlingt eine Meeresschlange (morska zmija) Sarko bis zum Knie. Das Pferd wiehert und sagt zu Grujo, er solle sein Schwert ziehen und zu Sarkos Knien hinunterstoBen, um Pferd und Schlange voneinander zu trennen: Ja izvadi sabiju is pod sebe, Ta ju spusti mene do kolena, Ega možes̆ zmiju da rasporiš, Ega mozes dvama da kurtalis.

Grujo befolgt die Anweisung des klugen Pferdes und gelangt so glucklich und ungehindert zu dem Baum, den er aber nur mit Hilfe Sarkos entwurzeln und wegschaffen kann. Auf dem klickweg "nach Bulgarien" (u Bugarsko), als sie schon fast das Ufer erreicht haben, taucht vor innen ein dreikbp- 


\begin{abstract}
figer Drache, eine "ala trojoglava", auf und verschlingt. Sarko bis zur Schulter. Das Pferd bittet Grujo, es von dem Ungeheuer mit dem Säbel zu befreien, was Grujo auch tut, worauf alle Helden, die Denica schor fruher nach dem Baum entsandt hatte, mit Getose dem Leib des toten Drachen entsteigen:
\end{abstract}

Silno se e voda razl'jul'jala, U Bugarsko zeml'ja primrǔdala, I krǚme se silno razniłale, Pred junaci Całe popadale.

Marko deutet diese Zeichen lachelnd positiv und erklärt, glucklicherweise habe Grujo eben heil das Meer verlassen und sei auf dem Weg zu ihnen. Die Gefunrten aber glauben ihm nicht. Am Mittag des nachsten Tages jedoch erscheint Grujo auf Sarko, tritt vor Denica hin und pelanzt den gewinschten Baum vor ihr auf. Alle begluckwinschen den Helden, Denica aber erklärt, sie bereue, dab sie so geringes Vertrauen in die Leistungen Grujos gehabt hatte, der sich nun als der grobte Held (junak nad junaci) entpuppt habe, während alle vorher entsandten Freier im Meer ertrunken seien.Darauf gelobt das Madchen Grujo ewige Treue.

Auch hier wieder stellt das Mudchen die schwierige Aufgabe und unterstutzt Marko Grujo, doch wird er hier als Oheim des Heldenkinds bezeichnet, was sicher die altertumlichere (weil matriarchale) Form des Verwandtschaftsverhaltnisses ist, whrend das Verhältnis Vater-Sohn flur patriarchale Familienordnung spricht und daher sicher erst spater eingetreten ist. Die uns aus anderen Liedern (vgl.Kap.5.2) bekannte Kombination Oheim(Marko, Jankula)-Neffe (Heldenkind) muBte schon vorher bestanden und eine gewisse Tradition gehabt haben, um in unserem vorliegenden lied eingesetzt werden zu können.- Auch hier wieder spielt das kluge Heldenpferd als Helfer und Ratgeber eine wichtige Rolle. Vergessen wurden jedoch die urspringlichen drei goldenen Äpfel. Der sangerin war offensichtlioh nur noch der zu entwurzelnde Baum im Geduchtnis. Auch bei dieser schwierigen Kraftprobe wird der Held von dem erfahrenen StreitroB seines Oheims unterstutzt. Statt der im varigen lied auftretenden "morski prelŭonici", in aenen wir entweder eine Reminiszenz an die Hespériden oder eine Weiterbildung aus dem Drachen (nach dem später noch zu besprechenden Schema Drache 
$\longrightarrow$ Wasservila) sehen wollten, tauchen hier auf dem Hinweg eine Meeresschlange und auf dem Rlickweg ein dreik8pfiger weiblicher Drache auf, die das Pferd bis zum Knie bzw. bis zur Schulter verschlingen,- eine Steigerung, die uns ja schon aus dem vorhergehenden Kapitel (Motiv des Riejenfischs) bekannt ist und die hier wahrscheinlich wi rkungsvoller gewesen ware, wenn es sich dabei um ein, und nicht zwei verschiedene Ungeheuer handelte. In der Wasserschlange ist man versucht, eine Erinnerung an die antike Hydra von Lerna zu sehen, eine mehrkopfige Wasserschlange, die Herakles als zweite seiner Aufgaben töten muBte, wobei ihm Jolaos, sein Waffengefuhrte und Wagenlenker, mit brennenden Ästen half ${ }^{152}$. Diese Helferrolle spielt nun quasi das pferd. Der dreikbpige Drache konnte aus dem mehrkopfigen Drachen Ladon, dem Huter der Hesperidenapfel, oder aber ebenfalls von der Hydra oder sogar dem sechskbpfigen Seeungeheuer Skylla abgeleitet sein ( $v g l$. auch das siebenköpfige Ungeheuer, das Gilgamesch totet). Ein altes Motiv, dab namlich die von dem Ungeheuer fruher Verschlungenen seinen leib lebend verlassen, schlielst sich an. Das Motiv, daß der Oheim Marko zuversichtlich auf die Rlickkehr des jungen Helden wartet und von seinem Sieg fest uberzeugt ist, auch wenn alle anderen nicht daran glauben wollen, wird uns in spateren Var. noch mehrmals begegmen.

2u der "ala trojoglava" 1st eine Erklurung notig. "Hala", "chala" bzw. "ala" (aus turkisch 'ala'; vgl. neugriech. $x \alpha ́ \wedge \alpha \zeta($ in der Bedeutung "Hagel") ist der sludslavische Gewitterdrache, auch "aždaha, aždaja, aždava, aždaa" (aus avestisch "azdaha", persisch "azdeha, azder" in der Bedeutung "Drache") genannt, eine Bezeichnung, die wohl durch türkische Vermittlung zu den Sudslaven gelangte. Von diesem Gewitterdrachen glaubt man, er kornne fliegen, die Wolken bewegen, Hagel auf die Ernteguter niedersenden und Durre verursachen. Ein Gewitter wird als Kampf solcher geflugelter, feuerspeiender Ungeheuer gedeutet. Der Tanz dieser Drachen labt den Wirbelwind entstehen, der beim Menschen 
zu Irrsinn und Tod flihren kann. Auch die Mondfinsternis wird als eine Bedrohung von Seiten der Drachen erklart. Aus christlicher Sicht ist der hl. Elias, der Blitze von seinem feurigen Wagen schleudert, der Bekämpfer der Gewitterdrachen. Dem heidnischen Aberglauben nach erwächst dem Menschen aber im "zmaj, zmej" ein Helfer, der aufsteigt und in den Wolken mit dem Drachen kämpft, um die Vernichtung der Ernten in dem unter dem Schutz des Zmej stehenden Gebiet zu verhuten ${ }^{153}$. Vom Zmej wird in Kap.5.2 noch ausfunrlich die Rede sein.

Die "chala, ala, hala" wird im Volksglauben der Bulgaren, Mazedonier und sudserben huufig vermischt mit der "lamja" (maz.,bulg. "lamja", sudserb. "lamnja" aus griech. $\lambda \alpha \mu(\alpha)$ ), einem weiblichen Drachen in der Gestalt einer Riesenechse mit einem oder mehreren Köpfen (manchmal als Hundsköple vorgestellt), riesigen Kiefern, schuppenbedecktem gelben oder roten Korper, einem oder mehreren Schwänzen, vier klauenbewehrten Beinen, hautbespannten Fligeln und feuerspeienden Nustern, - ein Ungeheuer, das Menschen und Tiere verschlingt, Emten vernichtet und Quellen versiegen labt. Es haust in Höhlen, im Meer, in Seen oder an Quellen ${ }^{154}$. Die suldostlichen Sudslaven haben diese Lamia von ihren Nachbarn, den Griechen, ubernommen. Im neugriechischen Volksglauben spielt die Lamia einerseits die Drachenrolle wie bei den südslaven, andererseits aber tritt sie als anthropomorphes weibliches Wesen auf (vgl. die Lieder Lubke,264-270 bzw. Lubke,246-249; Kind,95; Passow Nr.525 usw. ) das junge Männer zu unermudlichem Flotenspiel auffordert oder in die Meerestiefe ziehen will und Schiffe durch Wirbelwind zum Untergang funrt. Diese letztere Vorstellung der Lamia als verfuhrerisches weibliches Wesen labt eine Vermischung mit den Neraiden oder Sirenen vermuten. Diese Annahme findet sich auch bei Schmidt (S.131-135), der uberdies anfuhrt, daß die Lamia nach elischem Volksglauben sogar als Königin der Neraiden gedacht wird.- Die Lamia kann auch als häßliches, dummes, schmutziges, gefräßiges und blutgieriges Riesenweib auftreten, dessen Beine (zwei oder 
mehr an der Zahl) haufig deformiert oder ungleich (ein Bein kann aus Bronze oder ein Tierbein sein) sind ( $v g l$. die Äinlichkeit mit der antiken Empusa). Diese Lamia, die vor allem im Marchen vorkommt, lebt geworhnlich in Ehe mit

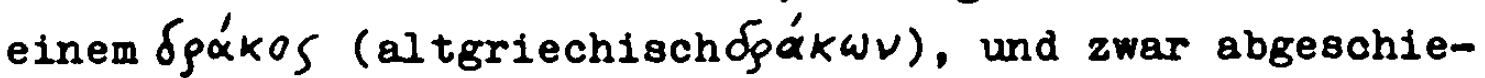
den in Höhlen oder Einßden. AuBer den typischen Eigenarten der Laszivität und des Hungers nach Menschenfleisch hat die komplexe Lamia des neugriechischen Volksglaubens mit der antiken Lamia nicht viel gemeinsam ${ }^{155}$. Die antike Sa-

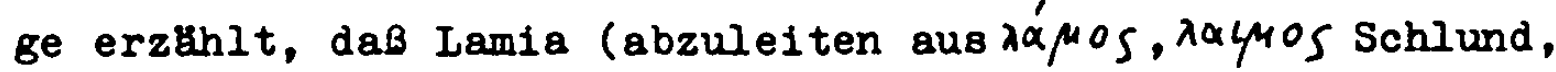
also Lamia etwa in der Bedeutung "Verschlingerin") die Tochter des Belos und der Libye war, mit der Zeus Umgang pflegte. Die eifersilchtige Hera aber brachte Lamia dazu, die Kinder, die sie von Zeus auf die Welt brachte, zu torten, oder Hera selbst besorgte dies, worauf Lamia sich in eine einsame Grotte inmitten dusterer Felsen zurlakzog und dort $z u$ einem tllckischen und gefrabigen Ungeheuer verwilderte, das mitern aus Verzweiflung und Neid die Kinder raubte und umbrachte. Hera hatte sie schlaflos gemacht, damit Lamia ihren Schmerz nicht vergessen konnte, doch Zeus verlieh inr die Gabe, die Augen herausnenmen und sich in beliebige Gestalten verwandeln zu können.- Spater verstand man unter Lamien schorne, gespenstische Prauen, die jungen Männern das Blut aussaugten, also Inkuben gleich den Empusen. Im Mittelalter wurde Lamia huufig mit Hexe gleichgesetzt. In Westeuropa lieB man im fruhen Mittelalter die Lamien in Fllussen wohnen.- Nur in einem Fragment von Stesichoros gibt es einen Hinweis auf die Verbindung der Lamia mit dem Meer. Hier heiBt es nämlich, das Meeresungeheuer Skylla sei die einzige von Hera nicht get8tete Tochter der Lamia. Nach einer anderen Version ist Lamia eine Tochter des Meeresgotts Poseidon und von Zeus Mutter der libyschen Sibylle. Nikander behandelt die Sage von einer Lamia bei Kirrha, die den Namen Sybaris fuhrte. Sie raubte Kinder und erhielt Menschenopfer, bis ein Held,der sich freiwillig zum Opfer erbot, sie vom Pelsen hinabsturzte ${ }^{156}$. Bei Horaz (Ars poetica 340) wird das echt 
marchenhafte Motiv erwahnt, daß aus dem Bauch der Lamia die von ihr verschlungenen Kinder lebend herausgeschnitten werden konnten ${ }^{157}$. Diesen Zug fanden wir ja auch in unserem letztgenannten wbulg. Lied, wo die von der Ala verschluckten Helden nach Tötung des Ungeheuers wieder lebend zum Vorschein kommen.- Bei Gertrude Jobes (in Dictionary of Mythology, Folklore and Symbols, New York 1961,II,967) finden wir außer den bereits erwähnten Hauptzugen der Lamia interessanterweise noch einen Hinweis auf den schlangenartigen Korper des Ungeheuers, wenn es heiBt: "A Lamia 'had the face and breast of a beautiful woman and the body of a serpant. Probably originally orgiastic priesteress of the Libyan snake goddess Lamia, who had been adopted by the Greeks. In Aristophanes's time they were emissaries of Hecate" (leider ohne Iiteraturangaben!).

Nach dieser notwendigen Abschweifung nun zurilck zum Variantenvergleich. Var. 3 hat folgenden Inhalt:

Dreibig Helden trinken Wein in der Schenke bei Demir-Kapija, bedient von Denica. Marko, der bemerkt, dab Pavel von Denica bezaubert ist, erklurt diesem, er könne das Madchen nur dadurch erringen, daß er die "weiße Donau" Uberschwimme und vom walachischen Ufer die zwei goldenen Äpfel von einem Lorbeerbaum (dervo dafina), Blumen, Weintrauben, Quitten und Orangen herbringe. Die Fruchte seien allerdings von einem dreiköpfigen Drachen bewacht:

Ta gi vardi ala troeglava.

Pavel zieht trotzdem 108 und springt in die Donau. Schon auf dem Hinweg ruft er die Druzina zu Hilfe, worauf ihn Marko zum Weiterschwimmen auffordert. Da erwacht die dreikbpfige Ala und greift Pavel in der Plubmitte an. Pavel zieht sein scharfes Schwert, dessen Scheide mit neunzig Spiegeln bedeckt ist, und schlkgt die Ala in drei Teile, worauf sich die Donau von dem schwarzen Blut des Ungeheuers dunkel furbt. Danach sciwimmt Pavel ans Ufer und ruft Denica und die Drużina herbei, denn sie sollen sehen, was er gebracht habe: den Lorbeerbaum mitsamt den Wurzeln. - Pavel tötet die treulosen Kameraden und nimmt Denica zur Frau.

In diesem gerafften und ziemlich kunstlosen Lied, wo z.B. die Stelle des Prüchtepfluckens bzw. Baumentwurzelns ein- 
fach ausgelassen ist, das Pferd vergessen wurde, Pavel schon auf dem Hinweg die Gefahrten zu Hilfe ruft und der Schlub ganz abrupt lautet:

Ta izgubi negova druzina,

Ta zalibi Denica devojka,

ist interessant, das der dreikopfige Drache zunlachst im Schlaf liegt und erst beim Ngherkommen Pavels erwacht und dab Pavels Sabelscheide mit vielen Spiegeln bedeckt ist, ein Motiv, das im Lied zwar nicht weiter ausgebaut wird, aber doch wie eine ferne Reminiszenz an Perseus' Abenteuer bei den schlafenden Gorgonen anmutet: Da deren schrecklicher Anblick jeden versteinerte, fing Perseus ihr Bild nur in seinem spiegelblanken schild auf, um dann das eine der drei mit Drachenschuppen bedeckten, mit Schlangen an Stelle von Haaren, groBen Hauzkhnen, ehernen Hunden und goldenen Plugeln ausgestatteten Ungeheuer, die allein sterbliche Medusa, zu töten ${ }^{158}$. - Das nachste Lied ist Var.4 mit folgendem Inhalts

Dinica bedient dreiBig Helden und stellt die Bedingung (als sie von allen dauemd an der Hand gefaßt wird), sie werde dem gehoren, der Sava und Donau Uberschwimme und vom deutschen Land Quitten und Orangen bringe.- Allein Ivo Curmogorde wagt die Schwimmprobe und holt die gewinschten Frlichte. Auf dem Rlickweg ruft er in drei Etappen seine Gefuhrten zu Hilfe, weil eine Ala ihn bis zum Knie, zum Gurtel und schlieblich bis zum Hals verschluckt habe. Nur das Madchen ist bereit, ihm zu helfen, und besteht damit die Treueprobe. Ivo bestraft die treulose Druzina blutig mit nach allen Seiten auggeteilten Schwerthieben.

Dieses Lied steht den 4.12-Varianten besonders nahe, konnte aber wegen der nötigen Vorbemerkungen zur "ala" erst an dieser Stelle besprochen werden. - Bei Var.5 handelt es sich un ein ganz kurzes lied mit folgendem Inhalt:

Siebzig Konige sind in der Schenke versammelt, unter ihnen auch Marko Kralevidi und Gruju "malo dete". Sie werden von Sokolica bedient; die der junge Held Gruju an der Hand faBt und zu klissen versucht. Als die siebzig Könige Marko lacheln sehen, sagen sie warnend:

Nemoj nełto maskara da stanel worauf Marko meint, warum die beiden jungen Leute 
nicht Gefallen aneinander finden sollten. Die KOnige antworten, sie guben Sokolica nur demjenigen, der das Schwarze Meer durchschwimme und vom Samovilenbaum drei goldene Äpfel hole. Daraufhin besteigt Grujo sein sechsflugeliges Pferd (konde SestokrilCe), schwimmt lbers Meer, findet den Samovilenbaum (samovilsko dürvo) und pfluckt die drei goldenen Äpfel, ohne daB die den Baum bewachenden Samovilen aufwachen. Siegreich kehrt Grujo zu der Schenke zurlick und erhilt das Maddchen.

In diesem sehr gerafften Lied begegnen uns die in der maz.wbulg. Epik so beliebten stereotypen siebzig konige, die immer als Einheit auftreten und deshalb nicht im einzelnen aufgefuhrt werden. Das Verwandtschaftsverhaltnis von Marko und Grujo ist in diesem Lied nicht angegeben. Der Drachenkampf ist weggefallen, deshalb fehlt auch die helfende Funktion des Pferdes. Statt von Drachen wird der Wunderbaum von Samovilen bewacht, die nicht einmal erwachen, als der Held die goldenen Äpfel pfluckt. Der Baum wird hier nicht entwurzelt. Bei den Samovilen, den komplexen Feenoder Elfengestalten der maz. und bulg. Volksdichtung, die den Menschen gut $u n d$ brse gesinnt sein kbnnen ${ }^{159}$, darf man im Fall der obigen Var. vielleicht einerseits an die Hesperiden denken, andererseits aber, was ich fur wahrscheinlicher halte, eine Ableitung aus der Drachengestalt vermuten, von der spater noch die Rede sein wird. Es handelt sich hier offenbar um eine fortschreitende Anthropomorphisierung des urspringlichen Drachen, deren Ergebnisse dann Gestalten wie die Samovila, die dümonische Figur des oft dreiköpfigen schwarzen Arabers oder Musa Kesedžija 160 bzw. unter Umstunden die Schankwirtin mit dumonischen Zugen oder sogar der Hajduke sein konnen. - Var.6, ein längeres Lied, hat folgenden Inhalt:

Siebzig Konige sind bei einem Trinkgelage versammelt und zu ihnen gesellen sich Marko "deli baš" und das siebenjuhrige Heldenkind Grujo mit seinem dreijuhrigen Pferd. Den Konigen ist diese Gesellschaft nicht sehr willkommen, denn Marko gilt als Trunkenbold, Grujo aber als streitsluchtig:

¿e je Marko mlogo,/ Mlogo vinopiec; A je Grujo mlogo,/ Mlogo kavgadzia. 
Sokolina bedient die Helden mit Wein aus Budim und Schnaps aus Demir Kapija in einem zwolf Oka schweren Larmorkmug. Alle lassen sich die Glaser fullen, nur Grujo halt das Madchen fest, worauf die siebzig Könige die Bedingung stellen, Grujo misse, um das Madchen zu erringen, von dem Baum Tafericno mitten im Meer ïpfel (jabŭlki tafericni) herholen.- Grujo erhalt von seinem Onkel ( $\left.Z_{i} \chi_{0}\right)$ Marko dessen erfahrenes Pferd (stara Sargalija), worauf er seinen Braunen (konce Doralija) stehenlabt. Bevor er noch richtig im Sattel sitzt, ist Markos Pferd schon uber neun Gebirge geflogen. Sie schwimmen zu dem Wunderbaum, und Grujo pfluckt nicht erst die Äpfel, sondern entwarzelt den Baum und legt ihn sich uber die Schulter. Auf dem Rluckweg begegnen inm drei feurige Drachen (do tri mi kucki, do tri ljuti lamii), die inn listig damit zum Halten bringen, daB sie inm angeblich Gruße an die Konige auftragen wollen. Das unerfahrene Heldenkind halt an, wird von den Lamien eingeholt, die das Pferd bis zu den Vorderbeinen verschlingen. Da fordert das Pferd Grujo auf, er solle es mit seinen silbernen Sporen in die Rippen stoßen, dann werde es sich seiner Jugend erinnern und mit neuer Kraft die Lamien an Land ziehen.- Dies gelingt, und Grujo bindet die Ungeheuer mit Ketten hinter sich ans Pferd.- Die Kơnige verspotten indessen Marko, weil er sich mit Grujos Heldenstärke gebrlistet habe. In diesem Moment aber kommt Grujo mit dem Wunderbaum uber der Schulter und den drei Dram chen hinter sich und lost bei den Konigen groBes Erstaunen aus. Marko muB hingehen und Grujo davon abhalten naherzukommen, weil beim Anblick der drei Ungeheuer Leute zu Tode erschrecken und schwangere Frauen vorzeitig gebaren kbnnten.

Dab Marko hier als Skufer und Grujo als streitsluchtig hingestellt werden und deshalb nicht germ gesehen sind bei dem Trinkgelage, ist als Motiv ganz offensichtlich aus den 4.11Liedern ubernommen, wo der oheim die Neffen aus solchen Grinden nicht einladen 8011.- Der Wunderbaum heiBt hier "dürvo Taferično", wahrscheinlich abgeleitet von arabischturkisch tafra "schön, schmuck". Was die drei Drachen anbelangt, könnte man fast an eine Vermischung der. Erinnerung an den Hesperiden-Mythos mit der Erzahlung von der letzten Aufgabe des Herakles - den Hollenhund Kerberos aus dem Hades heraufzuholen - denken. Kerberos hatte nämich drei Hundekrpfe, einen Drachenschwanz und Schlangen an Stelle 
von Kopl- und Fuckenhaaren. Man vergleiche damit nun die drei "kucki (Hundsfotte) lamil". Herakles legte dem drachenartigen H8llenhund Fesseln an, bevor er ihn vor Konig Eurystheus hinbrachte ${ }^{161}$, und auch Grujo tut dies:

Izvadil mi Grujo/ Drebni mi sindzire,

Vurzal do tri kucki,/ Do tri l juti lamii.

Die Angst der Konige vor dem Anblick der Lamien entspricht allerdings mehr dem Entsetzen, das die Betrachter des Hauptes der Gorgo-Medusa erfabte und sie versteinern $11 \mathrm{eB}{ }^{162}$, wenn Perseus das schlangenumzingelte Haupt hochhob. Auch an die Hydra mit ihrem hundeähnlichen Korper und den neun Schlangenkbpfen ließe sich denken ${ }^{163}$. Interessant ist die Parallele zur russischen Byline, wo der furchterregende Solovej Razbojnik von dem Helden Il'ja Muromec auch nicht in Hof des k8nigspalastes, sondern auBerhalb der Mauern getytet wird. - Von Var.7 ist nur der Liedanfang erhalten:

Marko hat siebzig Konige zu einem Trinkgelage eingeladen, wo das Mudchen Sokolina bedient. Narko als Gastgeber stellt die Aufgabe, daB derjenige das Madchen erhalte, der das Schwarze Meer uberschwimme und von dem Lorbeerbaum im Wasser goldene Äpfel herhole.

Dieser Liedanfang ist eigentlich nur deshalb interessant, weil hier zum erstenmal der Liedtyp vorliegt, wo der Gastgeber die Aufgabe des Äpfelholens stellt, eine Version des Sujets, die m.E. am altertimlichsten wirkt (und ubrigens auch dem Hesperidenmythos am besten entspricht). Von dem Gastgeber als Auftraggeber ging die Aufgabenstellung dann wahrscheinlich auf ein "Heldengremium" (siebzig konige, dreibig Helden u. .) bzw. einen Vertreter aus dessen mitte oder auf das Mädchen selbst uber. - Zu dem altertumlicheren Liedtyp gehbrt auch Var.8:

Kon1g Kostadin gibt ein Fest und ladt dazu viele Gruste ein, unter anderem auch Marko und seinen Gefuhrten Gruizo detence, seinen kleinen Bruder (bratance). Die Königstochter Angelina bedient die Gaste. Marko beobachtet, wie das Madchen ausgerechnet beim Nachschenken von Gruikos Glas zittert und danebengieBt, woraus er sehr richtig schließt, "dek mladi sa asik". Marko bittet also den Konis fur Gruico um die Hand des Mädchens. Der Konig stellt aber die Bedingung, dab der Frei- 
er von einem vertrockneten Baum im Schwarzen Meer ein Zeichen bringen musse.- Da sagt Marko zu Gruico, er solle den Streitkolben (bozdugan) mitnehmen, denn dort im Meer sei kein vertrockneter Baum (ne e pusto su'o drüvo), sondern eine grimme Schlange mit drei Köpfen. Diese werde sich trilgerisch in eine schöne junge Prau verwandeln, seine rechte Hand fassen und klissen wollen. Dann solle er ihr die Iinke geben und mit dem Streitkolben in der Rechten die Schlange erschlagen, und zwar mit einem Schlag, sonst wirden numlich noch neun weitere K४pfe hervorwachsen:

Da ubies zmija so tri glavi, Ama, nemoj, dete, da povtores, Ke se stvorat joste devet glavi!

Gruico zieht von der Festtafel weg zum Meer und findet alles bestutigt, was Marko itm gesagt hat. Als er die Schlange mit dem Bozdugan geschlagen hat, fordert sie inn listig auf, ein zweites Mal zuzuschlagen:

Ja si ma'ni, dete, joste ednaž!

worauf das Heldenkind nur lakonisch antwortet:

Mene majka ednaz me rodila.

Da verflucht die Schlange denjenigen, der ihm die guten Ratschlage gegeben hat:

Proklet da e koj te tebe uxi.

Grujo bringt die tote dreikopfige Meeresschlange dem König und erhalt nun dessen Tochter zur Frau.

Auch in diesem Iied haben wir wieder die Konstellation, daß Marko und Grujo zu einem Fest gcladen sind und der Gastgeber die Freiersaufgabe stellt. Altertumlich mutet an, dab dabei als preis die königstochter, und nicht irgendeine gewöhnliche Schenkwirtin winkt. Auffallend an die Hydra-Episode erinnert die Stelle unseres Liedes, wo Marko rät, die Schlange mit einem Schlag zu töten, weil sonst neun neue Köpfe hervortreiben wïden. Herakles wurde der immer neu hervorwachsenden Köpfe der neunköpfigen Hydra bekanntlich dadurch Herr, daß er mit Hilfe seines Freundes Jolaos die Halsstlimpfe mit brennenden Baumstämmen versengte ${ }^{164}$. Auch die Keule-als Waffe ist beiden Helden (Grujo und Herakles) gemeinsam. Erst das neunte, das unsterbliche Haupt der Hydra schlug Herakles mit dem Schwert ab. Daß das Ungeheuer den jungen Helden hinterlistig zu einem zweiten Schlag auffor- 
dert, dieser aber von Grujo mit der formelhaften Wendung, seine Mutter habe ihn auch nur einmal geboren, abgelehnt wird. finden wir als Schablone auch im griechisch-sudslavischen Marchenbestand. Doch davon an anderer Stelle mehr. - Das nächste Iịed unseres Sujets, Var.9, hat diesen Inhalt:

Pilip Mažarin (sicl) veranstaltet ein groBes Gelage, zu dem er Helden aus allen Gegenden,unter anderem auch Marko und Grujo,"malo dete", einlkdt. Als die Gaste an der Tafel sitzen, schlagt Marko einen Wettbewerb vor: Es soll ein Held gefunden werden, der gleichzeitig bedienen und (aus sich selbst) leuchten könne.- Pilip fragt seinen Vater um Rat und erhalt die Antwort, er solle das Madchen Dobrens in goldene Kleider kleiden, mit Edelsteinen schmucken und in den Pestsaal schikken: sie werde gleichzeitig bedienen und (in ihrer strahlenden Schonheit) leuchten.- Pilip tut, was sein Vater ihm geraten hat, und gewinnt damit die Wette.- Grujo hat nur noch sugen fur das Mădchen, so dab Pilip (auf den Rat seines Vaters) vorschlagt, Grujo konne das Madchen dadurch erringen, daB er die weibe Donau uberquere und von einem Wunderbaum inmitten des Meeres (durvo zerdelija) drei goldene Beeren herhole.- Grujo will sofort mit seinem Pferd losreiten, erhalt aber von Marko dessen erfahrenen Schecken Sarajana. Grujo gelangt.zu dem Baum inmitten des Meeres, unter dessen Ästen er drei Drachen ("ali") schlafend antrifft, entwurzelt ihn, wirft ihn auf seine Schulter und tritt den Rluckweg an. Da erwachen die drei Drachen, eilen inm nach und versprechen inm der Reihe nach feines Tuch (Xocha), Silber (surma, eigentlich "Silberdraht") und andere Schrtze (imanje), wenn er anhalte und ihnen den Baum zurickgebe. Das kluge Pferd aber warnt Grujo davor, und sie schwimmen schnell an Land. Nls sie die Donau Uberqueren wollen, taucht eine Meereslamja (morskana lamija) auf und packt das Pferd an der Brust. Auf Anraten des Pferdes labt Grujo das Schwert am Hals des Tieres hinunter und t8tet auf diese Weise den Drachen. Da taucht eine zweite Ala ouf und hingt eich dem Pferd "za eanata" (vielleicht verdruckt statt "za sapata" in der Bedeutung 'an die Kruppe'), worauf Sarko rkt, scharfe Haken (Cengele) zu nehmen, die Ala daran aufzuspießen und ans Trockene zu ziehen. Grujo befolgt den Rat. Dann tragt Sarko dem Reiter auf, scharfen Galopp zu reiten (pokaraj me malko na sürdito), was Grujo auch tut, so dab Pilip Marko darauf aufmerksam macht, was fur ein seltsamer Nebel, Staubwirbel, Tau und Peuer in der Ferne auf der Straße 
zu sehen seien. Marko erklurt, es handle sich um Grujo, der die Ala heranschleppe, worauf Pilip Marko bittet, dies zu verhindern:

Nemoj ala tuka da dokara:

Koj je bolno, po-bolno $\overline{c e}$ stane,

Koj je zdravo, bolno de da stane.

Pilip kann aber kaum ausreden, als Grujo schon da lat, um Baum und Ala vorzuweisen. Nun endlich erhklt der junge Held Dobrena.

Hier fallt im ersten Teil des Iieds die Erweiterungsepisode auf, daß jemand gesucht wird, der gleichzeitig bedienen und leuchten könne. Nur dem geschmllckten, strahlenden Madchen Dobrens gelingt dies, d.h. es handelt sich hierbel um eine Verherrlichung der atachenschonhe1t, die uns auch in anderen Iledern in annlicher Porm begegnet. Auch das Motiv im zweiten Teil, wo sich die Ankunft des Helden in einer nebelartigen Staubwolke ankindigt, kommt in mehreren weiteren Varianten vor. Die Drachenepisode warde hier willklurlich erweitert, indem der sunger insgesamt funf Drachen auftauchen labt.- Gastgeber ist hier Pilip Madzarin, der bekannte slidslavische Iledheld, hinter dem man wahracheinlich Pipo Spano (abgeleltet aus ungarisch "18pán"= zupan) bzw. Pipo von Ozora, den historischen Pilippo de Scolari (1369-1426), der aus Florenz stammte und als Temesvarer Vojvode unter König Sigismund sich als Turkenkumpfer auszelchnete, vermuten darf ${ }^{165}$.

Bevor wir zu einem etwas erweiterten Sujet ubergehen, sollen noch zwel Lleder zur Sprache kommen, in denen unser sujet verstummelt bzw. mit negativem Ausgang vorliegt. Nun zuerst Var.10:

Iudo ermenlijte wettet mit Kadija Efendi, daß er in dre1 Tagen und dre1 Nachten das Schwarze Meer Uberschwimme. Als Preis der Wette verspricht ihm Kadija Efendi selne Tochter und Schwester. Iudo ermenlijce geht daraufhin zu seiner Mutter und bittet sie bel der Milch, mit der oie ihn einst nuhrte, um ihren Segen, den ihm die alte Mutter auch gewahrt. Erst dann begibt sich der Junge zum Meer und beginnt zu schwimmen. Plotzlich erhebt sich ein Sturm, der das Meer aufwhilt und den Schwimmer ertrinken labt.

In dem Sturm 1st vielleicht eine Reminiszenz an den Dra- 
chenkampf erhalten. Sekundur ist das Fehlen des happy end.Bei Var.11 ist der Anfang unseres Sujets, allerdings in veränderter Form, bewahrt:

Filip Madzarin heiratet das Mädchen Resimka und lädt seinen Wahlbruder Grujco nicht zur Hochzeitsfeier ein. Von seinem Oheim Marko in echt epischer Manier nach dem Grund seines Kummers gefragt:

Zaso places, Grujč, ukevoto, Da li si gladen, ukev, ili zaden,

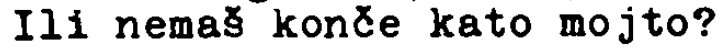

antwortet Grujco (in epischer Wiederholung), nicht solche Grinde lugen vor, sonderm sein Wahlbruder Filip habe ihn enttäuscht, weil er Marko und Gruj¿o nicht geladen habe.- Auf Markos Vorschlag hin gehen die beiden ungeladen zur Hochzeit Filips. Als Filip die beiden kommen sieht, tritt er mit der Braut heraus, um die Gaste zu begruben. Marko grubt, Grujco aber schweigt. Filip läBt neun Kubel voll Wein herbeischaffen und ladt Grujco zum Trinken ein, doch Grujco schweigt weiter.Sie (das Brautpaar) wollen ihm die Hand klssen, doch Grujco läBt dies nicht zu und schweigt. Da beginnt Filip fur den beleidigten Grujco mit der Hochzeitsfeier ganz von vorne, um ihn zu versöhnen. Doch erst nach drei Tagen und Nachten beginnt Grujco einzulenken und mitzufeiern.

In diesem jürgeren Lied ist das Motiv, dab der Wahlbruder bei der Hochzeitseinladung vom Brăutigam ubergangen wird, zum selbstänigen Liedsujet geworden, das in seiner psychologisierten Form naturlich nicht sehr alt sein kann.

Die nun folgenden Varianten (Var.6 zeigte schon Anklänge daran) enthalten alle als sekundäres Erweiterungsmotiv die Stelle, dab das Heldenkind und sein Oheim bzw. Vater zu dem Fest nicht geladen werden, weil sie als trink- und streitsuchtig gelten und daher unerwinscht sind. Dieses Motiv wurde zweifellos - wegen der Affinitut der lied themen - von den 4.11-Iiedern her ubernommen und der situation entsprechend abgewandelt, so dab nun Oheim $u^{-} n d$ Neffe nicht eingeladen werden. Als erstes Lied dieses Typs ist Var.12 zu nennen, wo das Motiv des Einladungsverbots allerdings weiter abgewandelt erscheint:

Janko von Kosovo veranstaltet ein Fest, zu dem er 
siebzig Könige sowie Marko Kralevic einludt. Er stellt Marko die Bedingung, dab dieser seinen Sohn Grujo zu Hause lasse, damit sie beide nicht durch eine mögliche Heirat ihrer Kinder (Grujo und Vida) gegen das Gesetz der Wahlbruderschaft verstieben und aus alten Wahlbrudern zu jungen Schwägern wïrden:

Ti da dojdes, Grue nedovodi;

Dode bechme staro pobratimce, Da ne stanem mlado svakostino;

Aze imam Vida malka moma.

Da erwidert Marko, er könne nicht ohne Grujo kommen:

Bez se moga, bez Grue ne moga, Ono mi e armo sluzba.

Die Guste sitzen vollzălig an der Festtafel und feiern, nur dete Grujo trinkt nicht, weil er den Blick von Vida, die bedient, nicht losreissen kann.- Wer Vida erringen will, erfahrt Grujo,muB aber von einem weiBen Apfelbaum im Meer drei goldene Äpfel herholen. Als Grujo diese Bedingung angenommen hat, springt er augenblicklich auf und will mit seinem dreijăhrigen pferd davonreiten, wird jedoch von Marko aufgehalten, der ihm sein Pferd ("Pfüzenwater") leiht. Als Grujo unterwegs an einen Strom kommt, taucht eine dreijährige Ala auf, die das Pferd verschlingen will. Das Tier baumt sich aber auf, un die Ala zu zertreten. Diese Szene spielt sich noch zweimal ab,als an zwei weiteren Stromen jeweils noch schrecklichere Drachen auftauchen. Ärgerlich fordert das Pferd jedesmal den Reiter auf, den Sabbel zu ziehen und die Ala zu töten, was Grujo auch gelingt. Endlich erreichen Pferd und Reiter schwimmend den Baum im Meer. Grujo fragt, ob er den Baum entwurzeln solle, worauf ihm das pferd aber rät, nur die Âpfel zu pflucken. Glucklich kehrt Grujo zu dem Fest zurick und erhält das Madchen zur Frau.

Janko von Kosovo (als Ungar!) ist hier wahrscheinlich sekundăr für Filip Madzarin eingetreten. Sonst ist die bekannte Motivkette beibehalten. Nur am Schluß hat die Sängerin dem Motiv des Baum-Entwurzelns die Pointe genommen. - Der Inhalt von Var.13 lautet so:

König Martin veranstaltet anlublich der Hochzeit seines Sohnes ein großes Festgelage und ladt dazu 300 Konige und 200 Adelige (boleri) ein, nur Kral Marko mit seinem Neffen Gruica Ubergeht er. Wahrend die Gäste schon mit dem Festmahl beginnen, beschwert sich Marko bei Gruica Uber die MiBachtung von Seiten König Martins und fordert 
den Neffen zum Pferdesatteln und Mitkommen auf. Als sie zur Peier gelangen, die inzwischen schon auf dem Hobnepunkt angelangt ist, werden sie vom Gastgeber freundlich emplangen und auf den Ehrenplatz gesetzt. Da fordert Marko Iicht (edno cvetilo), um sehen zu können, wer alles an Gasten da sei. Konig Martin bittet ihn um Geduld und l\&Bt dann seine mit Edelsteinen reich geschmluckte Tochter Rusana auftreten, die durch eine unvergleichliche Schönheit den Saal in Licht erstrahlen l\&Bt. Gruica beachtet weder Essen noch Trinken, sondern starrt nur noch auf das Madchen. Da schlagt Marko vor, die beiden jungen leute miteinander zu verheiraten. Konig Martin otellt jedoch die Bedingung, daB Gruja vorher von einem durch drei Lamien (tri kuðki lami) bewachten Granatapfelbaum (durvo kalinkovo) mitten im Meer drei Prlichte bringe. Gruica springt sofort auf und zieht mit Markos erfahrenem Pferd zum Meer. Dort erblicken ihn die drei lamien, die ihm zurufen, sie hitten ein Geschenk filr Rusana.Gruica labt sich aber nicht beirren und reibt den Baum aus. Auf dem Rickweg versuchen inn die Drachen wieder mit Versprechungen aufuhalten, in.. dem sie inm nimlich 300 Oka feinen Seidenstoff (birendzuk), 300 Oka pures Gold und drei kostbare Steine flur Rusana versprechen. Da labt Gruica sich tuuschen und halt an, worauf die Lamien das Pferd sofort bis zu den Knien verschlingen. Das Pferd fordert Gruica auf, die Sporen anzulegen und es damit in die Seite zu stoben, dann werde es sich an seine Jugend erinnern, mit neuer Kraft hochspringen und so von den Lamien loskommen. Gruica st8Bt das peerd mit den Sporen, worauf das Tier Feuer aus dem Maul und Nebel aus den Nustern blust und hochspringt, dab das Meer aufschulumt, und sich auf diese Weise von den Drachen befreit. Gruica bindet die drei Ungeheuer mit Ketten und reitet zurluck zur Peier, den Baum Uber der Schulter und die drei Lamien hinter sich nachzerrend, so dab der ganze Weg erschuttert wird. Marko hort das Gepolter und fordert die Gäste zum Emplang des siegreichen Helden auf. Alle staunen, als Gruica ankommt, und Rusana reicht inm den Ring. Konig Martin bittet, Gruica solle die drei "kuzk1 lami satanovi" Im Geb1rge toten, was Gruica gleich erledigt. Anschliebend folgt die Hochzeit zwischen Rusana und dem siegreichen Preier.

König Martin, der Gastgeber in diesem lied, ist meines Wissens historisch nicht zu identifizieren.- Die auch hier gegebene Metapher "Licht, Leuchten" fur Madchenschonheit 1st in den sudslavischen Liedern relativ haufig anzutreffen. 
Der Name Rusana klingt an Roksanda ( $\nabla g l$. Vuk II 28), den haufig fur furstliche Madchengestalten verwendeten Iiednamen, an. Zum zweitenmal erscheint hier das Motiv, das das Pferd nicht rat, die Lamien mit dem Schwert zu töten, sondern die Sporen zi spliren verlangt, weil es sich dann mit jugendlicher Kraft selbst befreien könne. Die in Ketten vor den Konig gebrachten Lamien erinnern wieder sowohl an die Hydra wie auch den Hollenhund. - Der Inhalt des nuchsten Iledes unserer Sujetkette, Var.14, lautet so:

Konig Vukazin hat alle moglichen Gaste eingeladen, nur Marko und Grujo "malko dete" nicht, weil sie angeblich trunk- und streitsthchtig sind:

Deka su se mogi p'janici.

Vino zaodili, u rakija neznajali,

A na noževe djurejacil,

A na kone binekdii.

Grujo beschwert sich bei Marko, dab sie Ubergangen murden, worauf beide ungeladen zu dem Pestgelage hinreiten. Die Gaste wollen ihnen die Pferde abnehmen, doch Marko erklart, das bltere rier finde selbst seinen Weg (on e uXen, sam Ze seta) und das jungere werde von dem ulteren angeleitet:

Ne vatajte konce troegodce, Ce go uci uxiva kon.

Sie sitzen an der Tafel, wo das MBdchen Roselin die Glaser der Reihe nach fullt, Grujo aber Ubergeht. Da erkundigt sich Marko, ob es einen Wettbewerb um das Madchen gebe, worauf die Gkste antworten, nur der bekomme Roselin, der zu einem der drei Seen im Bior-Gebirge gehe und von dem im See wachsenden Baum drei goldene Äpfel hole.- Grujo zieht daraufhin mit Markos erfahrenem Streitros in das Abenteuer. Am See angelangt, rit das Pferd (auf Grujos Prage), den Baum mitsamt den Wurzeln mitzunehmen. Als Grujo den Baum mit den goldenen Äpfeln entwurzelt hat und sich auf dem Ruckweg befindet, tauchen plotzlich drei Samovilen auf:

Izleznali do tri vili-samovilj., Samovili tija jašni kucki,

fordern Grujo zum Anhalten auf und versprechen Thm der Reihe nach "taja zlatna forma" (goldene Kleider?), "taja zlatna tepsija, u tepsija zlatne pilista" (eine goldene Schlissel mit goldenen Vogeln) und sogar einen goldenen Tisch mit Edelsteinen, die ihm zum Abendessen leuchten krnnten (taja zlatna sofra, na sofra tova bezcani kamenis kad veceras, sami te da svéta). Die Vilen spannen 
ein Netz, um das Pferd damit anzuhalten, woraus das Tier den Rat gibt, Grujo solle ihm einen Sabel zwischen den Vorderbeinen hinablassen, so wirden die Netze zerrissen und die Vilen getotet werden.- Die Ausfihrung dieses Plans gelingt, und, als sie an Land gekommen sind, ryt das erfahrene Pferd dazu, zwei der Samovilen an die Steigbigel und die dritte an den Pferdeschweif zu binden und so zum Konigshof zu ziehen. Grujo gehorcht und wird bei seiner Ankunft von den erstaunten Gasten gefeiert. Zur Belohnung fur seine Heldentat erhalt er das versprochene Madchen zur Frau.

Konig Vukasin ist sicher sekundur als Gastgeber eingesetzt. Roselin (auch eine Ableitung aus "Roksanda"?), die dem mutigen Freier als Preis winkt, scheint die Königstochter zu sein, obwohl dies nicht ausdricklich gesagt wird. Die IichtMetapher fehlt in diesem Lied. An Stelle des dreikópfigen Drachen bzw. der drei Drachen treten hier drei Samovilen auf, doch werden sie als "kucki" (wie die Lamien!) bezeichnet, so daß die vermutung naheliegt, daß sie fur urspringliche Drachen eingesetzt warden. Interessant ist die Art von Versprechungen, die sie Grujo machen. Was das Motiv der Schüssel mit den goldenen Kuchlein anbelangt, so taucht dies ofter im sudslavischen Liedschatz auf ${ }^{166}$. Die aufgespannten Netze der Samovilen lassen andererseits wieder eher an das Werk von Neraiden als von Drachengestalten denken. Die Begrlindung fur die Einladungsverweigerung am Liedanfang ist, wie schon gesagt, stereotyp aus den 4.11-Varianten entlehnt. - Die nachsten zwei Lieder stammen aus 0stbulgarien. Zunkchst zu Var.15, deren Inhalt im Prinzip dem vorhergehenden Lied entspricht:

Filip Madzarin heiratet und läd eine groBe Anzahl Gaste zu dem Fest ein, nur Marko nicht.Grujo "malko dete" fragt den Vater nach der Ursache seiner mibstimmung und meint, als er den Grund erfahrt, das Beste sei, das Einladungsverbot zu ignorieren und einfach ungeladen zu erscheinen. Marko geht auf den Vorschlag ein und zieht mit seinem Sohn zu der Hochzeitsfeier. Dort schlagt Grujo den versammelten 300 Zaren vor, derjenige solle die schone Zarentochter Angelina erhalten, der den von drei graubrkunlichen Iamien (tri suri lami) und drei Samovilen bewachten Baum mit den 
drei goldenen Äpfeln Uber der Donau entwurzle und herhole.- Keiner der Helden wagt dieses gefahrliche Unternehmen, nur Grujo selbst,der den Baum wirklich herbeischafet, obwohl ihn die damonischen Wesen unterwegs mit Versprechungen aufzuhalten und dann zu toten versuchen.

Das Motiv des Pferdetauschs und der Hilfeleistung durch das ratgebende Pferd wurde in diesem lied ausgelassen. In sekundarer Abanderung des Sujets warde hier der mutige Preier (Grujo) selbst zum Aufgabensteller. Die Nktivitat der Drachen und Wasserfeen beschrankt sich in Var.15 auf. Verlockingsversuche; das Pferd wird in diesem Pall nicht festgehalten oder verschlungen. Auch das Motiv, die Ungeheuer zu der Pesttafel hinzuschleppen, fehlt hier. Var.16 ist deshalb verderbt, weil die sangerin, wie vom Aufzeichner erklürt wird, das lied vorher nur einmal gehort hat. Falschlich holt hier nicht Grujo, sonderm Marko (noch dazu freiwillig, denn ein Aüftraggeber fehlt!) für Sokolina, die Nichte der Hochzeit feiernden "moma Bosnjakinja", von der Rujo dete und Marko Kralevic nicht eingeladen wurden, den Wunderbaum llber der Donau. Er bringt auch die drei den Baum bewachenden Lamien und die drei verfuhrerischen Lamien mit und erhalt fur seine Heldentat Sokolina als Braut. - In den nachsten beiden Liedern fällt als sekundare Besonderheit auf, dab die Samodiva, Markos Wahlschwester, den Helden darauf aufmerksam macht, dab Pilip Madzarin ein Pest veranstalte und ihn sowie Grujo "malo dete" nicht eingeladen habe. Während von Var.17 eigentlich nur der Anfang erhalten ist, stellt Var.18 ein besonders schones Iied dar, dessen erste Zellen schon den Bindruck einer gelmgenen epischen Porm vermitteln, die das ganze Iied hindurch aufrechterhalten wird:

Selnik (= veselba) pravi Filip Madzerina,

Ce godjava sestra Sokolina,

Ta kalesa naj-otbor junaci,

Sedemdeset kralja, osemdeset bana,

Ala ne te Marko da kalesa,

Ce e Marko mnogo vinopiec,

A pak Grujto, sestrino mu cedo,

Ce e mnogo kavgadzija.

Kak gi zacu vila samodiva, 
Vila samodiva, Marku posestrima,

Lekom letja $v$ polunos utide,

Pa na Marko tichom govori: usw.

Als Oheim und Neffe, von der Samodiva unterrichtet, ungeladen an der Festtafel erscheinen, macht ihnen niemand Flatz, so dab sie die schlechtesten Plutze einnehmen mussen:

Koga na trapeza pristignacha, Nikoj ne si stava, mjasto da im Xini. Marko sedna na kraj mi trapeza, Grujčo sedna duri kraj vratata.

Als Grujco auch noch das bedienende Madchen Sokolina an der Hand faßt und ihr die Finger so sehr prebt, daB die Steine aus ihren Ringen fallen, stellen die versammelten Könige und Bane die Bedingur.g, der Freier müsse den goldenen Apfel von dem "drŭvo kefericno" im walachischen Land holen. Grujo gelingt die Lösung dieser schwierigen Aufgabe mit Hilfe von Markos klugem Pferd, das ihm die notigen Anweisungen zur Unschadlichmachung der drei "lami-kucki", die den Baum bewachen,gibt. Die drei Iamien werden hier - eine Motivvariation - an drei Haaren às der Pferdembhne abgescinleppt. Wahrend die Gäste schon an Grujos Sieg zu zweifeln beginnen, glaubt Marko unerschutterlich an den Erfolg seines Neffen und behält auch Recht.

Da die Motivkette dieses gelungenen Lieds vollständig urd mit den schon bekannten Mitteln gestaltet ist, erubrigt sich jeder weitere Kommentar. - Eine verstiumelte Var.liegt in $\mathrm{Nr} .19$ vor:

Hier reitet Grujo, verägert über die MiBachtung seines Vaters liarko, ungeladen in so scharfem Galopp zur Hochzeit des "car madžerin", daß das Wegpflaster zerspringt und der Himmel sich von Staubwolken verfinstert. Zur Strafe fur diesen Übermut schickt der Zar in. seinem Ärger Grujo un die golGenen Äpfel fort in der Hoffnur.g, daß die Lamja ihn verschlinge:

As ̧̌e i, cholŭn, provod'ŭ. Dor na zlatata abŭlka, Da i lam ata izedo.

Als die Lamja Grujo erblickt, sperrt.sie ihre neun Rachen auf:

Devet si gürla utori.

Grujo aber erschlagt das neurköpfige Ungeheuer, bindet es an das pferd und schleppt es zum Zaren:

Izgŭna muždr'ak pozlaten, 
$\checkmark$ devet ja gürla udari,

خe jŭ na kon'o privŭrza,

Ce si vŭs car'u otide.

Grujo will den Zaren mit seiner Leistung in Erstaunen versetzen und erhofft sich eine Belohnung.

Von einem Mäachen ist in dieser verstümmelten Var. keine Rede mehr. Das urspringliche Motiv ist dahingehend abgeändert, daß der Held zur Strafe, weil er den Zaren verärgert hat, den goldenen Apfel unter Iebensgefahr herholen muß. Die Lamja hat in diesem Lied neun Köpfe wie die antike Hydra. - Die nun folgenden sechs Varianten zeichnen sich dadurch aus, dab ihre Motivkette jeweils durch ein oder mehrere Glieder erweitert wurde. Es handelt sich zunächst um Var.20 mit folgendem Inhalt:

König Sirbin halt ein Festgelage und ladt dazu siebzig Könige ein, nur Marko und dessen Neffen aus Solun vergibt er. Da fordert Marko seinen Neffen Gruju auf, zwei Pferde zu satteln und mit ihm zusammen ungeladen loszureiten. Gruju hat alles Nötige eingepackt, nur Kerzen hat er vergessen, die Marko aber am Zielort zu bekommen hofft. In der serbischen Stadt (u sirbinska grada) tummeln die beiden Helden inre Pferde so, dab die erstaunten Guste das pflaster zerspringen hören, aus den Fenstern sehen und llarko mit Neffen erkennen. Die beiden kommen in den Festsaal, wo man sie herzlich willkommen heiBt und ihnen platz macht.Marko verlangt Licht, um die anwesenden Gäste sehen zu können. Daraufhin geht die serbische königin hinaus und holt ihre schöne Tochter, die wie die helle Sonne strahlt und alles erleuchtet:

J)a ja ukadi gore na divanchanata, Deka ugrjala katu jasno slince, I prosvetila sickata divanchana,

I na site vidilo si cinila.

Gruju flustert seinem Oheim $z u$, daß̉ er das schöne Mădchen gern zur Frau nähme. Marko prostet daraufhin dem Gastgeber (nun "Sarbin" genannt!) zu und grubt ihn als Svaten, worauf der konig meint, der Freier seiner Tochter musse, um das kiddchen zu erringen, einen Apfel von dem Granatbaum inmitten des Schwarzen Meeres holen. Dann erst könnten sie beide, nümlich Marko und Sirbin, Svaten werden.Nach dem Pferdetausch ("adžamia" gegen "akilija") schnallt sich Gruju mit funfzehn Kiemen an Markos Pferd fest und reitet zum Keer. Auf dem Weg zu dem Baum taucht eine "kucka lamja katu stara baba" 
auf und verspricht Gruju ein M\&dchen, doppelt so schön wie König Sirbins Tochter, sowie neun Fuhren Seide als Mitgift. Das kluge Pferd warnt den jungen Helden vor dem Anhalten, das fur sie beide den sicheren Tod bedeuten wïrde. Sie gelangen zu dem Baum, den Gruju im ganzen ausreibt. Auf dem Rllckweg ist wieder die Lamja zur Stelle. Sie puhrt Graju drei wie die Sonne strahlende M\&dchen vor, von denen er sich eines aussuchen soll; dazu wirde er dreibig Lasten Goldstlucke als Mitgift erhalten.- Gruju erliegt dieser Täuschung der Lamja, hylt an und beschworrt damit das Ungluck herauf: Die Lamja offnet den schrecklichen Rachen und verschlingt das Pferd bis zum Sattel, Gruju bis zum Knie. In dieser gefährlichen Lage fordert das Pferd den Helden auf, ihm die Sporen fuhlen zu lassen, worauf es mit frischer Kraft hochspringt und im Plug ans feste Ufer gelangt. Marko, der handeringend und in starker Besorgnis um Grujus Schicksal das serbische Peld (sarbinsko ramno pole) Uberblickt, sieht Gruju mit dem Pferd halb in der Lamja stecken und ruft dem Neffen zu, er solle das Ungeheuer schleunigst mit dem Sabbel töten, aher ja nicht zum Königshof herbringen, weil der schreckliche Anblick des Ungeheuers nur Schaden anrichten whrde:

Oti, koja Zena netrudna da ja vidi, trudna da si rini,

I koja Zena e trudna, da ja vidi, malko ki si metni.

Da zieht Gruju sein Schwert und t8tet die Lanja drauben auf freiem Peld. Dann kommt er an den Konigshof, uberreicht dem Brautvater den wunderbaum, pflanzt ihn als Schattenspender auf den Hof und fordert das Mädchen. Als Gruju mit seiner Braut auf dem Weg nach Solun ist, singen die v8gel:

Taja nevesta ima na sirceto zmija, Ga ki si legni Gruju s nea, ki go izjadi.

Marko, der die Vogelsprache (ot pile jazik) beherrscht und wohl verstanden hat, daß der Braut eine Schlange auf dem Herzen liegt, die den Brăutigam tלten werde, wendet eine list an. Er sagt, Gruju solle die Braut links, er werde sie rechts an der Hand nehmen. Dann zuckt er sein scharfes Schwert und erklärt, nun werde er die Braut teilen: die eine Häl te nehme er selbst, die andere sei fur Gruju. Gruju ist sprachlos vor Schreck, das Mädchen aber bekomm t vor Angst den Schluckauf, wodurch die dreiköpfige Schlange aus ihrem Mund herausgeschleudert wird. Marko totet die Schlange und ubergibt die Braut seinem glucklichen Neffen.

Wer sich hinter dem Namen "Sirbin kral" verbirgt, ist m.E. 
unklar. Das Ethnikon wurde hier zun Eigennamen. Gemeint ist mit diesem "serbischen Konig" vielleicht Stefan Dusan oder Stefan Lazarevic, mit dem "serbischen Feld" moglicherweise das Kosovofeld. Auf diese Frage wirc an anderer Stelle (Kap.4.21) noch zurlakzukommen sein. Neu ist in diesem Lied das Motiv, dab die Lamja als altes Weib auftritt und dem Helden zuerst ein schones Mădchen mit Mitgift verspricht, dann aber sogar drei Madchen vorfluht, un inn zu ubertolpeln. Hinzugekommen 1st auBerdem das Motiv, daB Marko vom Söller aus bis zum Meeresufer blickt und seinem Neffen rät, sich durch Schwerthiebe des Ungeheuers zu entledigen,- ein Rat, den urspringlich das pferd zu geben hat. Der Aberglaube, daB der Anblick des schrecklichen Drachen Schwangeren schade, findet sich auch in dieser Var. wieder. Ganz neu ist die Motivkettenerweiterung durch die Schlangenepisode, in der Marko durch eine fast salomonisch zu nennende Weisheit besticht und mit List zum Erfolg gelangt. Die sprechenden und allwissenden v8gel, die "vesti pili" oder "vesti (p)tici" des sludslavischen Volkslieds, sind uns z.B. auch aus den Liedern vom toten Bruder bestens bekannt. Marko versteht deren Sprache (vgl. die Erzahlung "Nemusti jezik" in der Vuksehen Marchensammlung), whhrend Gruju dem Handeln des Oheims verständnislos und erschrocken folgt. Die Schlange auf der Brust oder in Mund eines Madchens ist ein beliebtes Mrrchenmotiv. - Die nachste, um eine Messer-Episode erweiterte Var. mit negativem Ausgang ist Nr.21 mit folgendem Inhalt:

G'ine ladt eine groBe Gesellschaft ein, Arme und Reiche, dazu sieben Könige aus sieben Königreichen und sieben Bane von "Banevo pole", nur an Marko und Gruica detence ergeht keine Einladung. Die beiden aber satteln inre pferde und reiten uneingeladen 10s. Unterwegs erteilt Marko dem Jungen VerhaltengmaBregeln, wie er sich bei der Peler zu benehmen habe. Auf dem ebenen Peld kommt ihnen G'ine "ot Latine" entgegen, entschuldigt sich filr seine Vergeblichkeit und sagt, er wollte sie beide eben holen. Zu dritt gelangen sie zu der Feier, wo G'ine erklurt, er habe eine Tochter, deren strahlende Schonheit innen das 
Iicht ersetze. Das Mädchen bedient die Gaste.Als die Reihe an Gruica kommt, vergibt dieser vor Verwirrung den Wein und hat nur noch Augen fil die Schone. Marko macht lachelnd G'ine darauf aufmerksam, der fur eine mogliche Heirat folgende Bedingung stellt:

Neka ide u sin'i ezere, U ezere dürvo dafinovo, U durrvoto dve zlatni jabizlki. Da g'i zeme, tuka da donese, Ce mu dadem moja milna Cerka.

Gruica macht sich sofort mit Markos erfahrenem Pferd auf den Weg, gelangt an den See und erblickt den Baum. Nachdem das Pferd den jungen

Helden zum Festhalten aufgefordert hat, schwimmt es mit Gruica auf dem Rucken zu dem Baum hin, den sie gemeinsam entwurzeln und fortschaffen. Auf dem Heimweg tauchen plotzlich drei Drachenkopfe auf :

Pa si dojde po ramni drumove, Po detence tŭ́rca 'ali-trojoglava.

Das Pferd sagt, wenn der Drache es an den Beinen packe, solle Gruica den mittleren Kopf mit dem Streitkolben zerschmettem, und zwar mit einem einzigen Hieb. Gruica gelingt es aber, mit einem Schlag gleich zwei Kopfe zu zertrlimmern, worauf die dritte "ala" lebend mitgenommen wird. G'ine sieht Gruica mit dem Baum Uber der Schulter und der lebenden Ala kommen und beauftragt Marko, das Ingeheuer zu toten. Gruica belehrt ihn, dab dies mit einem Hieb gelingen musse, eine Bemerkung, Uiber die sich Marko Grgert.-Gruica pflanzt den Baum auf; das M\&dchen pfluckt die goldenen Äpfel und wird Gruica Ubergeben.- Auf dem Heimweg im Waldgebirge sagt Marko zu Gruica, er habe sein Messer bei G'ine vergessen; Gruica moge es holen. Gruica tut das, doch als er zurluckkommt, lauert Marko ihm auf, schlagt ihm den Kopf ab und nimmt das l.! \&dchen fur sich selbst.

Mit Gine ot Latine ist möglicherweise der historische Georg Balfic gemeint ${ }^{167}$, der Herrscher der Zeta in der zweiten Halfte des 14.Jh., der im Lied auch als Gino Latinin, Gine Arnautce, Bela ot Kostur u.k. auftritt ${ }^{168}$ - Auffallend ist in diesem Lied die Unentschiedenheit des Sangers hinsichtlich der Drachenerscheinung. Es wird nicht klar, ob es sich dabei um einen dreiköpfigen oder drei einköpfige Drachen handelt. Die ursprungliche Version durfte m.E. ein dreioder mehrköpfiger Drache gewesen sein, aus dem dann sekun- 
där arei oder mehr einzelne vrachen bzw. sogar Samovilen wurden. - Die nachträglich angefugte Messerepisode, psychologisch motiviert durch Gruicas belehrende und damit beleidigende Worte Marko gegenluber, erinnert an die Lieder von Marko und Dete Dukadince ${ }^{169}$, wo Marko das inm Uberlegene Heldenkind ebenfalls hinterlistig und feige totet,indem er es von hinten mit dem Schwert in zwei Teile schlagt. Vielleicht ist die liotiverweiterung sogar auf den EinfluB dieses Iiedtyps zurlickzufuhren. - Das nächste Lied,Var.22, ist durch das Motiv des Araber-Kampfes in seiner Grundstruktur beträchtlich verändert worden:

Dete Dukatince heiratet und ladt zu der Peier siebzig Konige sowie Marko von Serbien (Sürbia) ein, nicht aber Gruju Silegara ("Ifmmerhirte"). Gruju beauftragt seine Gefihrten mit der Wartung der Lammer, weil er beabsichtigt, ungeladen zur Feier Detes zu gehen und die Hochzeit zu storen. Diese Absicht verkindet er auch seinem Oheim Marko, der ihm jedoch einen "besseren" Rat gibt: Gruju solle in die arabische stadt gehen und den schwarzen Araber toten; dadurch wiurde sein Kummer leichter werden:

Otidi si u arapska grada, Ta utepaj cruna arapina, Ega bi ti zalbi uminali.

Gruju befolgt den Rat und geht zur arabischen Stadt, wo er den schwarzen Araber aus seinem Hof herausrufen will. Er erfährt aber von dessen Gattin, dab der Araber sich in der Schenke aufhalt. Gruju geht dorthin und fordert den Araber zum Zweikampl auf dem Kosovofeld heraus:

Ajde dime na Kosovo polje, Dvata da si ď̃ilit igraeme.

Sie stellen sich zum Kampf auf, und der Araber wirft als erster den Streitkolben (terka topuzina), den aber Gruju mit der bloben Hand auffangt. Dann schleudert Gruju seine Keule, trifft den Araber mitten auf die Stim und schmettert ihn dadurch drei Ellen (lakti) tief in den Boden. Gruju kehrt zu den Svaten zuruck und teilt Marko das Kampfergebnis mit; sein Kummer sei aber dadurch nicht kleiner geworden.- Bevor Marko ihn zuriakhalten kann, erschlagt Gruju den Brautigam Dete Dukatince und "stört" damit die Hochzeitsfeier, wie er es vorausgesagt hat.

Von der Liedgestalt Dete Dukatince wird spater (in Kap.5.2) 
noch die Rede sein. Unser lied ist offenbar sekundär mit den Liedern vom Typ "Marko und Filip Madžarin" (vgl. Vuk II 58 und ISSF VIII/IX Nr.217-219) verschmolzen, wodurch das eigentliche Preiersproben-Sujet verlorenging und auch der negative Ausgang des Geschehens bedingt warde. Kosovo ist hier wieder einmal die typische Walstatt fur Kämpfe mit Arabern und Turken. - Der Kampf mit einem Araber opielt auch in den nachsten erweiterten Varianten eine Rolle. Es handelt sich zunkchst un Nr.23 mit folgendem Inhalt:

Marko sitzt auf dem hohen Divan. Da fliegt inm ein Brief zu, den er lächelnd liest. Von Markovica nach dem Inhalt befragt, erklurt Marko, Konig Latinin habe ihm geschrieben, ob er damit einverstanden sei, wenn man ihre beiden Kinder, d.h. Markos Sohn Sekula und Latinins Tochter, miteinander verheirate. Marko beauftragt seine Gattin, Sekula flur die Freiersfahrt zu risten:

Aj vlezi si vo łarena oda,
Do ntkljucis łarens kovéga,
Da izvadis rubo koprineno,
Da promenis Sekula deteto, I da zgotvis do dva burzi konja.

Marko reitet mit seinem Sohn, der wie die lichte Sonne strahlt, 108. Konig Latinin sieht dieses Strahlen von weitem und und trägt seiner Tochter Angelina auf, sie solle im bunten Gemach die Truhe offnen, die darin aufbewahrten Festkleider anziehen und sich schmllcken, die Gaste am Tor emplangen, Marko die Hand klissen und Sekula Geschenke Uberreichen. Nachdem Angelina dies alles getan hat, empfangt Konig Latinin die beiden Helden, setzt sie auf den Ehrenplatz im hohen Divan und bewirtet sie eine Woche lang. Marko meint, nun sei genug gefeiert worden und Konig Latinin solle endilch seine Tochter ubergeben. Der Konig erklart, dies könne erst geschehen, wenn Sekula sich als Held bewhirt habe:

Kak ke ti dam kerka Angelina, Dur' ne atorit dete junastina?

Er besitze einen schwarzen Araber, den er schon sieben Jahre im dunklen Verlieb halte. Mit ihm moge Sekula kampfen.- Marko befragt sein Pferd, was zu tun sei, und erhalt den Rat, Sekula detence solle ein fränkisches Messer in seinem blonden Zopf verstecken, dem Araber im Kampf die Hosengurte ( (cintjani) durchschneiden und ihn so bewegungsunfahig machen, un ihn besiegen zu konnen.Der schwarze Araber kåmpft mit Sekula drei Tage 
und drei Nkchte unentschieden. Dem Araber läuft s.hwarzes Blut herab, Sekula stoßt weiBen Schaum aus. Als Sekula schlieblich zu unterliegen droht, schreien die anwesenden Frauen und Madchen auf; das treue Pferd wiehert. Da endlich erinnert sich Sekula an den Rat von Markos StreitroB, den er nun befolgt. Der schwarze Araber sturzt, Sekula hebt ihn hoch, schlagt ihn bis zum Gurtel in die Erde und köpft ihn mit seinem Säbel. Er trägt das abgeschlagene Haupt zum Konig und wird weitere drei Tage und Nachte gut bewirtet. Marko fordert erneut die Herausgabe des Madchens, worauf der Konig eine zweite Probe auferlegt: Sekula solle in einen drei Tage und Nächte geheizten Ofen springen.- Markos Pferd rät dieses Mal, Sekula solle das Tier neben den ofen hinführen; es habe drei Brunnen ausgetrunken und werde den gluhenden Ofen 18schen.- Dies gelingt; Sekula betritt den ofen und verläBt ihn wieder heil. Nach drei weiteren Tagen Feiem fordert König Latinin eine dritte Heldentat: Sekula soll uber das Meer schwimmen und von dem inmitten des Wassers wachsenden Apfelbaum drei goldene Frichte bringen.Sekula schnallt sich mit neun Riemen an dem Pferd fest und fliegt mit ihm zum Schwarzen Meer. Da taucht plotzlich ein Meeresdrache (morskana lamia) auf und versperrt dem Pferd den Weg. Das Pferd rat dem Reiter, der Lamja die Haare abzuschneiden:

Aj zemi si sabja potajnica,

Da presecís kosa na lamia.

Sekula tut dies und verstreut die Haare in alle Himmelsrichtungen. Bald darauf gelangen sie zu drei Samovilen-Reigen. Das Pferd gibt Sekula den Rat, sich nicht in die drei Reigen hineinziehen zu lassen und nichts zu sprechen. Die Samovilen fordern Sekula zum Mittanzen auf. Sekula schweigt Sie gelangen zu dem Apfelbaum, von dem Sekula zuerst die drei goldenen Äpfel pflucken will, ihn aber dann auf Rat des Pferdes samt den Wurzeln ausreibt und schultert. Daraufhin schwimmen sie zum Ufer zuriuck.- Der König hat inzwischen die Hoffnung auf Sekulas Rluckkehr aufgegeben und fordert deshalb Marko auf, mit ihm fur Sekulas Seele zu trinken. Er hat noch nicht ausgeredet, als Sekula siegreich eintrifft, nicht erst lange am Tor um Einlaß bittet, sondern mit dem Pferd uber die Mauer setzt, um den goldenen Apfelbaum zu uberbringen. Der Konig bewirtet den Helden festlich und Ubergibt ihm dann seine Tochter, die unzahlige Schätze als Mitgift erhält.

In diesem offenbar kontaminierten Lied ist unser sujet eigentlich nur noch eine von mehreren Episoden, nämich die dritte 
von drel Preiersproben, die der Brautvater stellt. Somit ergibt sich elne gewisee Thnlichkeit bzw. Vermischung mit den Iledern vom Typ 4.11, nur das hier der Preler selbst die schwierigen Aufgaben 168t. AuBer dieser aktiven Rolle des BrEutigams lot auch die Vater-Sohn-Konstellation (Marko und Heldenkind Sekula) sowie das Eingrelfen des hilfreichen, klugen Pferdes charakteristisch fur die Motivkette von 4.13. Bel den Freiersproben sind Elemente aus anderen Iledeujets eingeflochten. Das Motiv des versteckten Messers z.B. scheint aus den Iledern ubernommen zu sein, wo Marko unbewaffet zur Kirche reltet, unterwegs auf den schwarzen Araber st8Bt, der drel Ketten Sklaven fuhrt, und diesen nur mit Hilfe des von Markos weitblickender Gattin in der Pferdemanne versteckten Messers toten kann,- oder aber aus den Musa Kesedżjja-Liedern, wo Marko im Ringkampl mit Musa zu unterliegen droht, von selner Wahlschwester, der Vila, auf sein verstecktes Messer aufmerksam gemacht wird und mit Hilfe dieser Waffe den Uberlegenen Gegner besiegt ${ }^{170}$. Der Trick, den Gegner beim Ringkampe ${ }^{171}$ durch Zerschneiden seines Hosenbands in den heruntergleitenden weiten Hosen zu fesseln, lot auch aus dem Banovie Strahinja-zyklus bekannt, wo allerdings die untreue Prau lhrem Mann damt

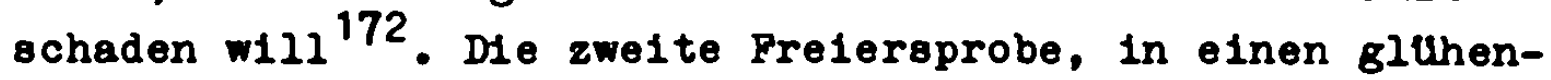
den ofen zu springen, durfte dem marchenhaften Berelch entstammen 173. Sehr interessant 18t die Lamja-Eplsode, wo anscheinend das Samson und Del1lah-Mot1v 174 Verwendung fand, wenn namlich Sekula die Lamja durch Abschneiden ihrer offensichtlich Starke verleihenden Haare unschadlich macht. Oder aind mit diesen "Haaren" vielleicht Schlangenlelber (wie bel der Hydra, der Medusa oder dem Kerberos) auf dem Kope des Ungeheuers gemeint?- Auch in diesem lied findet eloh wieder das Motiv, daB der Gastgeber an dem Gelingen der Schwlmmprobe zweifelt, Marko aber voll Zuversicht 18t. ob in dem tberspringen der Mauer durch den siegreich heimkehrenden Sekula ein Anklang an die Sprungprobe in den 4.11Lledern zu sehen 18t? Moglich wäre dies, well ja in der ganzen Iledanlage eine Ahnlichke1t mit dem andren sujet aue- 
fallt. In ganzen gesehen lat dieses lied wohl ein Glanzstuck der Miladinovichen Sammlung. Es besticht durch se1nen ep1sch-marchenhaften Stil, der melsterhaft durchgehalten wird und in den Paralleliamen ( $v$ gl. die fast gleichlautenden Aufträge an die Gattin Markos bzw. Angelina, in das bunte Zimmer zu gehen, die Truhe zu ofinen usw.), den epischen Wiederholungen (z.B. gibt das Pferd einen Rat, dann wird dessen Inhalt in der Schilderung der Ausfuhrung wiederholt uaw.), der Betonung der Dreizahl (dre1 Prelersproben, dre1 Tage und dre1 Nachte, drei goldene Apfel, dre1 Reigentknze usw.), den altertimlichen hrfisch-ritterlichen Sitten (festlicher Emplang der Grste, Kussen der Hand, Uberreichen von Gastgeschenken, großzllgige Bewirtung der Glate auf dem Ehrenplatz, Bedingung ritterlicher, fur den jungen Helden als Bewhinrungsprobe gedachter Preiersproben usw.) u.k. zum Ausdruck kommt. Es konnte sich hier wohl urspronglich um ein Heldenmarchen gehandelt haben, das in maz. Raum zu einem mythologisch-märchenhaften lied urgestaltet murde und spater in den Bannkreis der skr. ep1schen Lieder vom Typ 4.11 geriet. - Das folgende Lied,die large Var.24, 1at dem Miladinovichen Sujet in vielem 80 ahnlich, daß sich eine ausfunrliche Inhal tsangabe eribrigt. Auch hier erhblt Marko vom lateinischen Konig (Michail) einen Brief, in dem er Marko eine Heirat ihrer Kinder Angelina und Sokula (a Sekula) vorschlagt. Bevor der Konig die Tochter ubergibt, mus Sokula (volksetymologisch mit "sokol" d.h. Palke, in Verbindung gebracht!) mit einem schwarzen Araber kamplen, drel Stunden in einem geheizten ofen ausharren und dre1 goldene Ápfel aus der Gewalt von dre1 Samovilen 1m Schwarzen Meer holen. Bei der Lbsung dieser Aufgaben opielt Markos erfahrenes Pferd Sarko die Ubliche Helferrolle. Nur manche Einzelheiten sind hier anders als in Var.23: Es fehlt z.B. die Episode des Hosenbanddurchtrennens; statt dessen schneidet Sokula mit seinem versteckten Prankischen (frußko) Messer dem Araber den Kopf ab. Bel der ofeneplsode Uberspringt Sarko, der vorher drel Brunnen ausgetrunken hat und nun "das Herz einer Samovila besitzt", 
dreimal den gluhenden ofen und loscht das Feuer mit seinem leuchten Atem. Der Kampl mit der Lamja ist hier ausgelassen, dafur aber die Samovilenepisode breiter augefuhrt. Auf dem Hinweg versuchen die verfuhrerischen Feen, Sokula zum Mittanzen zu bewegen. Auf dem Rllckweg entfessein sie, als sie den Raub des Baumes bemerkt haben, einen gewaltigen Sturm auf dem Meer:

$$
\begin{aligned}
& \text { Ka vidoa, ce im durvo nema, } \\
& \text { Izlitnaa duri kod neboto, } \\
& \text { Ta fanaa vetri } 1 \text { virulki, } \\
& \text { Ponesoa durrje i kamene } \\
& \text { Tolko sa go ga gila gonili. }
\end{aligned}
$$

In dieser Bedrangnis, in die Sokula durch die Winddamonen geraten ist, folgt wieder der schon bekannte Rat des Pferdes, der Held solle thm die Sporen zu fuhlen geben, damit eo mit jugendlicher Kraft an Land springe. Auch hier, wie schon in anderen Varianten, klindigt eine Wolke in der Ferne die Ankinft des slegreichen Frelers an. Das Mitbringen der damonischen Wesen zum Krnigspalast Pehlt in beiden Liedern. - Var.25 ist ein stark erweltertes, langes lied, in dem einige Heldenkindlieder kontaminiert sind und unser Sujet nur eine von mehreren Episoden darstellt:

Ein Kind wird am Nachmittag geboren, am Abend spricht es schon und verlangt von seiner Mutter ein gesatteltes dreijuhriges pferd und einen Taufpaten. Die Nutter erkikrt dem Kind (dete Maliande), es habe keine Verwandten außer seinem Oheim Marko, der es sicher taufen werde. Dete $\mathbf{M}$. Pragt, wo dieser Oheim wohne, worauf die Mutter meint, das sei leicht zu finden. Der Hof Markos befinde sich in der Stadt Dukat, wo er schon von Perne vor lauter Metall und Spiegeln glunze. Das Kind möge von weitem rufen, Marko solle herauskommen und seinen Neffen taufen.- Dete Maliande mus mit seinem Aufbruch noch etwas warten, weil die Mutter 1hm noch eine Stahlplatte als Schutz gegen alle moglichen Angriffe und drohenden Gesahren schmiedets

Da ti skova daska ot bliznica.

Po pat lma sekfa $g^{\prime}$ avolina.

Schlieblich macht das Heldenkind sich auf den Weg und gelangt zunächst nach Struem (= Sreml), wo es ein Madchen beobachtet, das einen Hof legt und dabel Rajko verflucht, weil seit seiner Vojvodenschaft die rurken ihr Unwesen treiben, wăhrend al- 
les in bester Ordnung war, als Marko noch in Struem reglerte. Dete 4. hort diese Klagen, opornt sein peerd an und reitet in dae Waldgebirge, wo die Btume oich vor ihm verneigen und die vogel the als "Helden uber allen Helden" preisen. Auf offenem Peld begegnen ihm drel alte Prauen. die des Kind freundilich gruben und inm erklaren, ole beten beine Sohtckealefrauen (narecnici).Die erste hilt das Pferd an Zlugel, die zwelte hebt das Heldenkind herunter und die dritte setzt es auf einen Teppich. Dann prophezelt die erste, das Kind werde rasch heranwaohsen und zum tapfereten Helden aller Iander werden, die zwelte, es werde durch seinen Heldenmut ein radchen erringen, und die dritte, es werde, von einer Schlange zwischen die Augen gebissen, den Tod Pinden.- Nach diesen Prophezelungen zieht das Heldenkind weiter und befrelt den Vojvoden Detelin aus der Gewalt des Schwarzen Arabers, woraue die Druzina $81 \mathrm{ch}$ herz$11 \mathrm{ch}$ bel Dete $M$. bedankt, denn alle Wege selen von dem Gewalttkter (ot zoluma) bedroht gewesen. Das KInd zleht seinen Weg weiter, und kein Wetter cann inm etwas anhaben:

Ni go veter, veter zadurjare,

N1 go eúnce, sưnce dogrevjase,

N1 go rosa, rosa dorosuva.

Inzwischen beklagt $81 \mathrm{ch}$ Markos Skbel, er habe, oeitdem er in Markos Besitz sei, weder Fleisch zu essen nooh Blut zu trinken bekommen. Marko nimmt sioh diese Klege zu Herzen und will mit dem Stabel auf dae offene Feld ziehen, wo immer 18glichke1t zum Kampl gegeben 18t:

Tamo minat denja k'1radzi1.

A nozteska viril k'esadzil.

Dort begegnet ihm Dete Maliande. Marko zieht oein Schwert und holt aus, Dete M. jedoch zerschllagt Ihm die Waffe, bindet Marko an den Pferdeschwanz, schleift ihn nach Dukat vor den Hof seines Oheims und verlangt lautstark nach Marko: Er m8ge herauskommen, um den Neffen zu taufen und zu sehen, welchen Teufel ( $g^{\prime}$ avolina) dieser gefangen habe:

Snaga mu je düga devet arăina,

Noze mu 8 a kato poteglica,

Racete mu 8 a kato Jazika (jasika "Espe"?).

Zablte mu 8 a kato dik'elje,

odite mu a kato kladence.

Ustata mu je kato kosara,

Noso mu je kato buck'1 cifun.

In diesem Augenblick kommt Markos Gattin heraus, begreift die mibliche Lage und erklart, Oheim Marko halte sich oben Im Wohnturm aup und beobachte die Umgebung, un die Rajah jederzelt vor 
feindlichen Angriffen schutzen zu können. Markovica fahrt fort, sie werde das Pferd des Neffen versorgen und Marko Bescheld sagen, whrend Dete M. Inzwischen schon nach oben gehen solle. In Wirklichkelt aber bindet ole Marko von dem Pferdeschwelf 108, Glbt Ihrem Gatten frische Klelder und fuhrt ihn zu Dete $M$. in den Turm hinauf. Des KInd erkennt Marko nioht als selnen Gefangenen, sondern begrust inn freudif als seinen Oheim und uuBert die Bitte, von ihm getauft zu werden. Marko lkBt daraufhin Popen kommen, die die Zeremonle vollziehen. Dann schenkt Marko seinem heldenhaften Neffen den Braunen Dora Malena mit neun starken Gurten als "treues Streitrob". Als Oheim und Neffe gutgelaunt belsammensitzen und trinken, kommt ihnen das Gerlucht zu Ohren, das Pilip Madzarin aus Budim seine Tochter Magdelena verheirate und $2 u$ der Peler lauter beruhmte Gaote einlade:

Ot Bukures Bedzelej Dubedze,

Ot Silistria I'utica Bogdan.

Ot Pokrovnik Dete Magdalence,

ot Tưnovo Bugarsk' 1 car Sizman.

Ot Vidima G'orgia Stragjmir.

Ot Krajkova Krajkovak' 1 vojvoda,

Ot Krupnik Jovanco dobar Junak.

Ot Krubumlia Junak Juk Bogdan,

Sos nego devet sina Jugovi,

ot K'upria Dete Golomese.

Ot Nig Leven Stojan vojvoda,

Ot Alekeinec Savak' in Todor,

ot Jagudin Sekula Detence,

Ot Krußica sứpck'1 car Lazar.

Ot Sumadia oǔrpck'1 kral Stefan,

ot Smenderevo G'uro Smenderevec,

Ot Varadin Petre Varadince,

Ot Stalatin Stalatin Todor.

Ot Beligrat Petre 1 Orlo.

ot Arbanazka zemja G'ino Arbanasce,

Ot Veles Marenko vojvoda,

ot Dolenc1 Tole vojvoda,

ot Pelister Mome1l vojvoda,

Ot Solum grada Bolen Dojein.

ot Samokof Leko Kapitan ¿e,

Ot Umlena $K \cdot 1$ tan vojvoda,

Ot Tetovo Avram Gostol'uboo,

Ot Radomir Sirace Jovance,

ot Malesevo Pelifan Pedin,

Ot K'0stendil Kostadin vojvoda,

Ot Kratovo mlado Kratoviance,

ot Kacane otari ajduk Novak.

Ot Vinica Gruica vojvoda,

ot Nevrokop N1los dobar junak,

ot Leg'ena grada Ieg'enck' 1 kral,

Ot Kosoro Jankula vojvoda, 
Ot Edrene Bano Miailde,

ot Novi-pazar II'o vojvoda,

ot Novo Brirdo Rajko vojvoda,

Ot Stambol grada car Kostadin,

Sos sestra ol carica Elena,

dazu alle Helden, die reiten, mit dem Wurfopeer umgehen, Stein schleudern und wein trinken konnen, nur Marko und seinen Neffen hat Pilip vergessen einzuladen. Marko 18t darluber emport, doch auf Dete Maliandes Vorschlag sattein sie ihre Pferde Pelifan (turk.pehlivan "Ringklampfer") und Dora Malena und reiten ungeladen zu dem Peot nach Budim. Als filip die beiden Helden erblickt, begrubt er sie als seine Glate und befiehlt dann seiner Tochter, s1ch mit Edelsteinen zu schmllkken, damit sie wie die Sonne leuchte, wenn sie den Glaten Wein serviere. Auf Markos Vorwlerfe wegen der verskumten Einladung antwortet Filip, Marko und sein Neffe seien herzlich willkommen; er habe sie zu seinem Bedauern nioht einladen konnen.- Magdelena bedient die Glate. Dete M. verliebt sich in sie und bittet Marko, flir ihn, seinen Neffen, bei Pilip um die Hand des Mrdchens anzuhalten. Als Marko diese Bitte erfulit, stellt Pilip die Bedingung. Dete M. mllese alle Ubrigen Helden im athletischen Dreikampf, bestehend aus Speerwurf, Steinschleudern und Reiten, besiegen:

K'e mu dadam Sterka Magdelena, Ako Detence nadigra o dzilit, Nadigra : dzilit, kamen naterurla, $S$ kon natjas site dobr1 gosje.

Als der Junge Held diese Probe glunzend bestanden hat, will Pilip seine Tochter noch nicht Ubergeben, oondern fordert weiter, das der preier thm von der Samovilentenne Stroh (Strohblumen?) bringen mllose:

Ja ne davam terka Magdelena,

Dur ne Ide Dete Maliande,

Dur ne ide na samovilcko gurno,

Deka samovili ol virizat smil,

Ot smil da donése, ja da vida.

Marko rat seinem Neffen, auf den Berg Begulica zu steigen. Dort werde er die Samovilentenne finden.- Dete $K_{\text {. macht }}$ sich mit Markos Pferd auf den Weg und ruft den Samovilen schon von weitem $2 u$, sie sollten seine Wahlschwestern werden und 1 hm von ihrem Stroh eine Probe mitgeben, damit er Pilips Tochter erhalte. Die Samovila G'urg'a erklurt, er durfe von ihrem Stroh etwas nehmen, well er den Schwarzen Nraber getotet habe, der alle jungen Mudchen raubte, $80 \mathrm{daB}$ die 
Vilen ihre Burgen oben in den Wolken nioht mehr bauen konnten, weil ihnen das "Baumaterial" pehlte.- Dete nimmt eine Probe von dem Stroh, bringt ole Pilip und fordert das Madchen. Filip verlangt aber noch eine dritte Freiersprobes Dete M. 8011 den Stamm elnes von drei schrecklichen Lamien bewachten Ahornbaums, der mitten im Schwarzen Meer wachse, herschaffen.- Marko ristet den Neffen mit seinem Schwert und Pferd aus und laBt ihn so in das gefuhrliche Abenteuer ziehen. Dete $\mathrm{u}$. gelangt um Mitternacht, als die Lamien schlafen, zu dem Baum im Meer, entmurzelt ihn und bindet Ihn dem Pferd an den Schwanz. In diesem Augenblick erwachen die Lamien und verschlingen das Pferd bis zu den Steigbligeln. Pelifan rut, Dete M. Bolle das Schwert ziehen, zum rechten Steigblagel hinunterstoßen und die Lamien so lostrennen, was dem Helden auch wirklich gelingt. Er bindet eine Lamje an die Pferdemähne, die zweite an den Pferdeschweif und nimt die dritte in die Hand, um int ihr sein Pferd anzutreiben.- Am nachoten Mittag geht Marko handeringend am Hor auf und ab und halt Ausschau nach Beinem Neffen. $P$ ilif kusert die feete therzeirging, daB Dete $M$. lunget von den Lamien verschlungen se1. Als Marko aber die Nebelwolke in der Perne erblickt,die das Herannahen eines Reiters verklindet, weiB er, das dies nur sein siegreich zurlickkehrender Neffe sein kann. Als er weiter ungeduldig den Blick in die Perne richtet, opottet Pilip uber ihn. Marko ruft aber triumphierend, er sehe seinen Neffen schon heranreiten, einen Wunderbaum mit wunderbaren Dingen daran (Cudesa) tragend sowle eine Lamja als Reitpeitsche in der Hand haltend, whrend er die belden anderen Ungeheuer an den Sohwelf und die Mahne des Pferdes gebunden habe. Da ist Dete $M$. auch schon angelangt und ubergibt Filip den Baum und die Lamien. Marko fordert nun zum letzten Mal die Herauggabe des Mädchens und als Mitgift neun Rappen mit neun Lasten Seide. Als Filip diese Forderungen erfult hat, zieht Marko mit dem Brautpaar zu seinem Hor, wo die Trauung stattfindet. Gemeinsam goht es dann zu Dete Maliances Mutter, die das Brautpaar schon erwartet. Die junge Prau klist der Schwiegermuttor dio Hand und beschenkt ole, worauf dio Nite der Schwiegertochter den Schleier hochhebt und den Sohn zu seiner schonen Frau begluckwinscht. Dre1 Tage und dre1 Nuchte lang dauert die Hoohzeltsfeler, zu der die ganze Verwandtschaft geladen 18t.- Dete M. wird berluhmt durch seinen Heldenmut und seine Schonheit.- Eines Tages reitet der junge Held aus und legt $81 \mathrm{ch}$ in der Sonne zum Schlafen nieder, als eine Schlange (pepelava zmija) herankriecht und den Schlafenden 
zwischen die Augen beiBt, worauf des Heldenkind so stirbt, wie die dritte Schicksalofrau thm prophezeit hat.

Dieses kontaminierte Lied, das im allgemeinen weniger durch Qualitat als durch Quantitat Uberrascht, hat mehrere schwache Stelien. Zuerst fullt das blinde Motiv der von der Mutter geschmledeten Stahlplatte auf, das spater nicht mehr aufgegriffen wird. Sinnlos flur das Iledganze lat auch die Episode, wo Dete M. das Madchen in Srem Rajko vojvoda 175 verfluchen und Marko preisen hort. Der oN Srem ist in der maz. Volksepik sekundar und deshalb auch entsprechend (zu "Struem") verungtaltet worden. Schlecht bzw. unklar 1st auBerdem die Iledstelle, wo Dete M. mit dem an den Pferdeschwanz gebundenen Oheim vor Markos Hof ankommt und den Oheim zu sprechen winscht, um Ihm das "Ungeheuer" zu zeigen, das er gefangen habe. Die MaBe dieses Gefangenen (Augen wie Brunnen, Mund wie ein grober Korb usw.) passen aber eher zur Beechreibung eines Ungeheuers (vgl. ganz ähnllche Beschreibungen in den russischen Bylinen "Aljoza Popovid und Tugarin", "Il'ja und Idolizce" und anderswo, siehe Bowra, Heldendichtung, 185-194) als zu dem 80 schmăhlich unterlegenen Marko, um den es sich doch offensichtlich hier handelt. Ich halte die Beschrelbung an dieser stelle fur falsch plaziert, wahrend ale eventuell nanh dem Kampf mit dem Schwarzen Araber bzw. mit der Lamja angebracht gewesen ware.Etwa dreiBlg Verse vorher erweist sich die sangerin als unfuhig. die beiden Handlungsstrange mit Dete $M$. einerseits und Marko andererselts sinnvoll miteinander zu verbinden. Nachdem gerade noch geschildert wird, wie das Heldenkind durch wind und Wetter reitet, setzt ganz unvermittelt der zweite Handlungsstrang mit der Klage von Markos sabel um Flelsch und Blut ein. Ungeschickt ist ferner die Stelle in Iled, wo PiIIp auf Markos Vorwlirfe lediglich antwortet, er habe Marko nicht einladen konnen; eine Begrlindung wird nicht gegeben. Des "Hesperiden-Motiv" wird auf das Holen des Baumstamms beschrankt, doch scheint die sangerin noch eine blasse Erinnerung an die drel goldenen Apfel gehabt zu haben, wenn 
es namlich heiBt, Dete 4 . habe einen Wunderbaum mit Wunderdingen daran hergebracht.- Andererselts zelchnet olch das Iled durch mehrere sehr poetische Stellen aus. Schon der Lledeingang otellt einen langen negativen Vergleich dar:

Pala Bogu, za cudo gulemol

Da-11 gürmi, 11' se zemja trese,

Il1 ot visoko voda tece,

Ill atado $2 a$ jagnenca blee,

Ili oftar 8 meden kafal afiri.

Ill zmija u gramada afirl.

Ill momi zalni pesni pojat.

Il oka (= ohka,stene) ot Solun Bolen Dojein,

Il1 mramor ( = zivotno) pod bel kamen duma,

Il mak'a za milna aina place.

Ili junak za druzina vika,

Il1 samovill oro igrat?

N1to grmi, ni se zemja trese.

Nito voda. ot visoko tede,

Nito stado za jagnenca biee, usw.

$(\ldots)$

Tuku se je dete porodilo

(Interessanterwelse ist hier der Liedzyklus vom "siechen Dojcin" als bekannt vorausgesetzt und zu einem einzeiligen Vergleichsglied innerhalb der Vergleichsanhaufung abgesunken, was naturlich ein Beweis fur die relativ junge Form oolcher kontaminierter Ileder 18t.) Sehr poetisch 18t auch die Beschrelbung der Hole Markos in Dukat, ferner die Schilderung der Art und Welse, wie die Natur dem jungen, strahlenden Helden huldigt (die BHume vernelgen sich vor thm, die vögel singen ihm ein loblied). Die bildhafte Vorstellung, daB Markos Schwert nach blutiger Nahrung verlangt, eindet sich auch in anderen Iledern (vgl. Stoll.II 1; Istarske,40 u.a.). Eindrucksvoll in 1hrer murchenhaften Ubertreloung lst auch die Beschrelbung der Ankunft des Heldenkinds an Plilps Hof mit zwel an das Pferd gebundenen lamien und der dritten alo Peiteohe in der Hand (vgle die vila mit einer

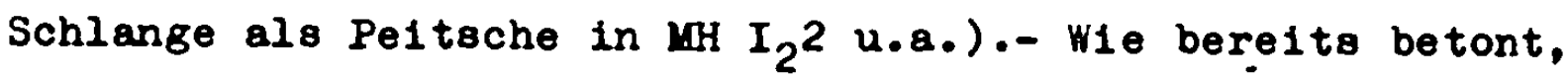
besteht Var.25 aus mehreren Einzelliedern bzw. Episoden. Die Rahmengeschichte bildet die Eplsode mit den SchicksalsIrauen, deren Prophezelungen alle in Erfullung gehen ${ }^{176}$. Die Vorstellung dieser sudslavischen Schicksalsfrauen (narečnici, narǚnici, recenic1, orisnic1) wurde moglicher- 
weise durch die Volksglaubenevorstellungen in den griechischen Nachbargegenden beeinflubt, wo die Moiren eich schon seit der Antike behaupten ${ }^{177}$. - Dem fur uno wichtigen Sujet "Uberschwimmen des Meeres, Baumentwurzelung und Drachenkampf als Freiersprobe" geht ein weiterer Kontaminationsbestandtell voran, den wir als Binzellied mit dem Thema "Oheim-Neffen-Kampl ohne gegenseltiges Erkennen und Taufe des Neffen durch den Oheim" kennen ( $\nabla$ gl. ISSP VII/IX 323 Stoil.II 1; Vuk VI 19). Die Sangerin hat hier fluechlioh Marko in Dukat lokalisiert, wo richtig dae Heldenkind wohnen mabte ( $\nabla g l$. Dete Dukatince in Stoil.II 1). Dete Mal1ance lat ein typischer Vertreter der Heldenkinder, von denen spater (in Kap.5.2) noch ausfuhrlich die Rede sein wird. Die Stelle, wo Dete M. den Vojroden Detelin aus der Gewalt des die ganze Gegend terrorisierenden Schwarzen Arabers bePreit, lst ein zur bloßen Bpisode reduzlertes Araber-KamplLied.- In dem uno in erster Iinie interessierenden sujetteil sind wieder ganze Lieder eplsodisch geraft zusammengefabt. Die erste Frelersprobe z.B., die in einem athletiochen Dreikamp ${ }^{178}$ (Speerwurf, Steinschleudern und Reiten) besteht, wirkt wie ein komprimiertes Lied des Typs 4.11. Be1 der Schilderung der zweiten Frelersprobe 1st ebenfalls ein zur bloBen Erwghnung recuziertes Lled festzustellen. Wenn die Samorila dem Heldenkind nłmlich fur die Trtung des Arabers deshalb dankbar lst, weil dieser den Samovilen die zu ihrem Burgbau benbtigten jungen madchen vorenthalten hat, so lat darin eine Reminiszenz an die Lieder zu sehen, wo die Vila eine Burg aus Menschen verschiedenen Geschlechts und Alters bzw. aus Menschenknochen verschledener GroBe in den Wolken baut. Zu diesem wahrscheinlich orientalischen und urspringlich an den griechischen Charos gebundenen Motiv vergleiche man die ausfuhrlicheren Bemerkungen in Kap. 5.4.- DaB der Held zu der Tenne im Gebirge, dem Samovilentanzplatz, reiten und von dort eine Probe "smil" mitbringen muB, wirkt marchenhaft und erinnert an das Marchen vom Teufel mit den drel goldenen Hearen ( $\mathrm{ggl}$. Bolte-Polfrka I,267 f1., 276 ff.).- Interessant lst der umfangreiche, aus 41 
Gliedern bestehende Heldenkatalog, der elgentlich eher flur die skr. Lieder, nicht aber flur die maz.-bulg. typisch $18 t$. Man vergleiche nur die zahlreichen Heldenkataloge in der skr. Volksepik, angefangen von der EH, vor allem aber das Lied Vuk III 10, das einen 37 Namen umfassenden Heldenkata$10 g$ enthglt. Ein genauer Vergleich dieses Iieds mit Var.25 ware speziell fur die Heldenkataloge interessant, doch scheint das maz. Iied auch in manchen anderen Punkten in direkter Bezlehung zu dem Vukschen Iied zu stehen. Man vergleiche z.B. die Eplsode in Var.25, wo das Madchen flucht:

Da b1 Bog dade, Rajko vojvoda,

Ot tebeka grobnika da nema, $(\ldots)$

Ot ka je u tebe vojroctfo, Turci nis dvorove prosetas, Stari otarci pesok prozobaa, Setrek'1 turck'ite atovel Kuga bese niarko na Struema, Xisto kehmo hlebes najaderi, Cisti behme drei nanosent. Cisto carcteo togaj oaruvahme,

mit der entaprechenden Stelle in Vuk III 10:

$$
\begin{aligned}
& \text { Bog t'ubio, Rajko vojevodal } \\
& \text { Cim ti nasta na Srijem vojroda, } \\
& \text { Tako name Turci dodijase. } \\
& \text { A dok bjese vojevoda Mirko, } \\
& \text { Mi Turtina nigde ne Cujasmo, } \\
& \text { Akamoli oxima vieasmo. } \\
& \text { A danas nam dodijare Turci, } \\
& \text { Turaki konjl noge iskidaze, } \\
& \text { Setajuci jutrom } 1 \text { vecerom. }
\end{aligned}
$$

Mit Mirko ist wahrscheinlich Mirce (1386-1418) gemeint,der 1394 das Heer Sultan Bajazids, in dem auch Marko kamplte, in der Walachei schlug (vgl. Anm. Vuk III,595 zu Vuk III 10). Die Sangerin, der das serb. Lied anscheinend bekannt war, hat Mirko durch den ihr vertrauteren Marko ersetzt, obwohl dieser in keinerlel Bozlehung zu srem otand. D1ese Episole sowie der Heldenkatalog zum Teil gehorręn also vermutlich zur Sekundarschicht in unserem maz. Lied. Interessanterwelse sind die ugrischen Helden Jankula (ot Kosovo) und Selcula detence (ot Jagudin) in Var.25 erwahnt, in der Vukschen Fassung des serb. Lieds aber nicht mehr, wobel jedoch anzunehmen $18 t, d a B$ sie in einer blteren liedversion 
(die viellelcht das Vorbild unseres maz. Lledes darstellte) noch enthalten waren. Mit Bano Miallce (ot Edrene) in dem maz. Iled und dem Vojvoden Mijajlo (na Kosovu ravmu) in Vuk III 10 (hier in der Anm. als "erfundene Iledgestalt" erklart) lot wahrscheinlich der uns aus den Iangzellenliedern vertraute ugrische Held kichael Szilágyl (Svilojevie) gemeint, der von den Tluken nach Konstantinopel (nicht Edirne) verechleppt und dort getötet murde.

Die nun folgenden vier Varianten 26-29 sind alle durch ein Motiv erweltert, das wir in Kap.4.12 in Anlehnung an Schillere Romanze mit dem Schlagwort "Handechuh-Motiv" umschrieben. Wurde in Kap.4.12 das Madchen als mablose Aufgabenstellerin von dem Preier erschossen, so endet in diesen vier Varianten der Brautvater durch einen Schuß oder Hieb des Frelers. Es handelt sich also um Ileder vom Typ Kac.24 (wo ein Preier zwel Gebirge durchstechen, Meereswasser herleiten. Weinreben und Quitten in der Donau pelanzen und schl1eBlich noch die Sonne mit dem Pfell treffen 8oll, worauf der Freier aber die Brautmutter, die solche unerfullbaren Aufgaben otellt, zur Strafe selbet erschieBt, vgl. ISSP V,15), nur das unsere vier Varianten zunachst die mit dem Appelholen verbundene Schwimmprobe als Preiersaufgabe enthalten, bevor ole mit dem Handschuh-Motiv enden. - Neu 18t bel Var.26 die Personenkonstellation. Marko 18t hier der Oheim und "mladi" Jankula der Neffe, was die These Matovs ${ }^{179}$ otutzen konnte, daB Maliance (vgl. das Heldenkind in Var.25) aus "mall" und "Jance" (abgeleitet von Janko) entstanden 18t. Jankula, der sonst im allgemeinen die Oheimrolle (gegentuber Sekula als Neffen) eplelt, wre hier moglicherwelse aus Unkenntnis der Alters- und Verwandtechaiftsverhaltnis8e selbst in die Heldenkind- und Neffenrolle gedrkngt worden. Doch daruber mehr In Kap.5.2.- Dem Preler treten in Var.26 vier Meeressamovilen mit Servierplatten in Handen entgegen, aue denen sie Inm Goldstucke, Kaffee und Ẍpfel anbieten. Des Pferd warnt den jungen Jankula davor, von diesen listig fellgebotenen Apfeln zu nehmen. Er solle vielmehr moglichst schnell den bezeichneten Apfelbaum ausreiseen und damit den Rackweg an- 
treten.- Die Vierzahl der Samovilen erinnert an die vier Hesperiden, die den Baum der Hera bewachten.

Nun das Schlubmotivi Filip Madzarin otellt nach der erfolgrelch bestandenen ersten Probe noch elne weitere Aufgabe unl8sbarer Natur und wird dafur von dem erzlurnten Preier getrtet:

I mu kazal osce edno kaul:

"Jasna zvjazda ot neboto da svalil"

Koga mu velit mladi Jankula

$\mathrm{Na}$ Krali Madzarinas

"Ne sưm Gospud zvjazda da sval jam!

T1 s mene se podigravasl"

Madi Jankula Izvadil sabjata

I mu ja secal glavata

Na Krall Madzarina.

Var.27 zelgt einen sekundar kontaminierten Iledanfang, mit dem motiviert werden soll, warum Sultan (car) Murad-beg, der Gastgeber, Marko nicht zu seinem Fest eingeladen hat:

Tembich cini care Murad-bego,

Tembich Zinl po olCkata zemja,

De ne jaaa konje ajgrrli1,

Da ne nosi kapi kamburli1,

Da ne nosi zelent dolami.

Da ne pija prez ramazan vino.

In epischer Wiederholung wird dann erzählt, wie Marko all diese Verbote der Reihe nach mibachtet, ein Motiv, das uns von dem berunmten Iled Bog.90 "Marko Kraljevic pije uz ramazan vino, nosi zelenu dolamu 1 igra uz Turkinje uz prkos carevoj zabrani" u.a. her bekannt $18 t$.

Der Sultan, der zu seinem Pest 77 Bane, 88 Kön1ge, 99 Vlachen und zwe1 Zarensobne eingeladen hat, libergeht bewubt den ungehorsamen Marko, der jedoch mit Gruju "maloj dete" ungeladen bel der Feier erscheint. Das junge Madchen, des den Gasten Wein einschenkt und gleichzeitig mit seiner otrahlenden Schonhelt leuchtet, wird demjenigen versprochen, der drel goldene Apfel von dem Samovilenbaum im Meer hole. Gruju macht aioh auf den Weg und besteht des geflhrliche Abenteuer, ohne sich von den verfuhrerischen Feen beirren zu lassen. Als Gruju siegreich zurackkehrt, fordert der Sultan noch als zusatzliche Frelersprobe, daB der Held einen Stern vom Himmel herunterschieBe. Gruju zielt aber auf den Sultan und totet lihn init elnem Pfeilschub.

Var.28 ist ein gelungenes langeres Lied, das am Anfang 8e- 
iroundar etwas umgestaltet murdes

Pilip Madzarin verheiratet seinen Sohn mit der Tochter des Konigs von Latine und ledt zu der Hoohzeitsfeier Königo, Bane und eine groBe Zahl weiterer Helden ein, die die Befluchtung BuBern, Marko werde, wenn er nicht eingeladen sel, ungeladen erscheinen und die Peler storen. Pilip macht sich daraufhin auf den Weg nach Prilep, um die verskumte Elnladung nachzuholen. Unterwegs erblickt er in der Perne ein Ieuchten, das $1 \mathrm{hm}$ sein Pferd so erklarts Marko komme auf SarkanIlja und Detence Ognjanco auf Dzvezdanl1ja herangeritten, und das Leuchten gehe von dem Stern auf der Stim von Ognjancos Pferd aus.-Als Pilip die beiden Helden ntherkommen 18Bt und bemerkt, deb sie drohend mit ihren Streitkolben opielen, mochte or vor Angst am liebsten umkehren. Sein Pferd rit ihm jedoch, den beiden entgegenzutreten und thnen zu erkiaren, dab or gerade aur dem Weg nach Prilep sel, un die Einladung naohzuholen. Marko $1 \mathrm{BBt}$ sich versohnlich stimmen und reitet mit Filip und Ognjanco zu dem Fest. Die weitere Handlung libuft nach dem bekannten Schema ab, nur dab hier, bevor des Heldenkind inmitten des Meeres von einer siebenköpfigen Ala, abwechselnd auch "morska samodiva" genannt, bedroht wird, an der Kuste schon "morski piavioi" (Meeresblutegel) und eine "riba sestokrila"(ein secheflugeliger Fisch) zuatzliche Geflhrdungen des mutigen Freiers darstellen. Das Iled schliest $r$ damit, daB Ognjanco auf Anraten des Mrdchens P1lip erschieBt, als dieser auch noch den Abendstern heruntergesohossen haben mochte.

Das Heldenkind heibt hier Ognjanco (wie auoh in den folgenden Varianten), abgeleitet von "ogun" (Feuer) Uber das Adjektiv "Ognen" (feurig). Hinter diesem Namen verbirgt olch vielleicht der Despot Vuk Brankovic, der Zmaj-ognjeni Vuk des skr. Volkelieds. Doch davon wird im Kapitel uber die Heldenkinder noch ausfuhrlicher die Rede seln. - Die letzte der vier genannten Varianten 18t Nr.29. Sie wirkt verotummelt; inr Anfang funrt gleich in medias res:

E t1 Marko, pobratime,

Ajde da se osvatime.

$K^{\prime} \Theta \mathrm{mi}$ dader tanka Vida,

Za Ognana, Ognan sina.

Darauf antwortet Marko oeinem Wahlbruder Novak:

Jas k'e dadam tenka Vida

KoJ 81 ide $\nabla$ eredi Dunav:

$\checkmark$ sredi Dunar drvo ime. 
Drvo ima ognenovo,Da otkrsi ot drvoto, Da donese $\nabla$ moji drori.

Ognan erfullt die Aupgabe, den "Peuerbaum" herzuholen, mit Hilfe von Novaks klugem Yferd. Das Iled endet damit, daB der junge Held den betrifgerischen Brautvater Marko erschieBt, als dieser zusatzlich noch verlangt, Ognan solle "Gott ins Auge treffen".

Ein etwas verknderter Sujetrahmen tritt uns in den drei folgenden Varianten entgegen, wo Marko und sein Neffe nach erfolgloser Jagd bei einem Wirt oder Freund einkehren und der Neffe sich in die Tochter des Gastwirts oder Gastgebers verliebt, flur den er - um das Mudchen zu erringen - ein gefuhrliches Abenteuer bestehen muß. Die Varian- . ten dieses Typs sind anscheinend so entstanden, dab sich unser urspringliches Sujet mit Liedern wie SbNU III, 15 "Vitec Janko 1 dete Grujo otivat na lov" (Nach erfolgloser Jagd kehren Janko und Grujo bei dem Gastwirt Novak in Novo Selo ein. Grujo verliebt sich in dessen Tochter, erhalt sie aber erst nach Bestehen einer Trinkprobe) oder SbNU XLIII, 134 "Ognjan 1 vujco mu Marko" (Als Uber Nacht im Dospat-Gebirge Rauhreif und Schnee fallen, fluchten sich Marko und sein Nefle Ognjan in das Gasthaus von Golemo-selo, wo ihnen ein Madchen den Wein serviert und ein zweites dazu leuchtet. Ognjan verliebt sich in das zweite Madchen und nimmt es mit nach Hause.) kontaminierte. Das erste Lied dieser Art, Var.30, hat folgenden Inhalt:

Kraljević Marko und sein Neffe Ognjan jagen im Sar-Gebirge, ohne Erfolg zu haben. Als der sechzehnte Tag anbricht und aich das Jagdgluck immer noch nicht eingestellt hat, erklkirt ognjan, sie hatten nun lange genug ihre zeit vergeudet und sollten besser heimkehren. Marko gibt ihm recht, meint aber, nach Hause sel es zu we1t; oie konnten jedoch zu Konig Mijail, dem "Poluaki kralj", gehen und bei inm ubernachten. Der Konig sei ein alter Freund Markos und werde sie sicher aufnehmen.- Der Konig sieht die Glste kommen, geht ihnen entgegen und begrubt sie sehr herzlich. Dann labt er ihnen von seiner Tochter Schnaps servieren. Ognjan nimet nicht das gefulite Glas, das das Madchen ihm relcht, sondern das Mrdchen bei der Hand. Marko rlest das unge- 
horige Benehmen seines Ieffen, worauf Ognjan beschint zu Boden blickt. Beim Abendessen, als der Konts oich nach dem Grund flur die Verlegenhelt Ognjans erkundigt, erzahlt Marko, daB Ognjan in seiner Verliebtheit das MBdchen an der Hand gefast habe und deshalb von Marko gerilgt worden se1. Da stellt der Konig die Bedingung, der Preier musse zuerst einen Orangenzweig aus dem Schwarzen Meer herholen, dann werde er das MEdchen zur Prau erhalten.- Mit Markos Pferd und Schwert ausgerlstet zieht Ognjan 108. Marko ermahnt ihn vorher, ja nicht vom Pferd abzusteigen und den Versprechungen der beiden schonen Madohen zu erliegen, die er unterwegs an dem Brunnen unter einer groBen Elche treffen werde. Es handle sich namlioh um "dve ala goleme", die lhn sofort fressen whrden. Wenn er ans Meer komme, solle er aue dem Pferd sitzenblelben, denn Sarac kơnne schwimmen. Da es im Wasger aber viele gefthrliche Pische gebe, die Sarac beim Schwimmen hindern konnten, solle er dem Pferd sein Schwert an die Knle binden, damit es sich auf diese Weise freie Bahn schaffe. Dann solle er den Orangenzweig brechen und $81 \mathrm{ch}$ sofort auf den Heimweg machen.- Alles kommt 80, wie Marko es vorausgesagt hat. Mit Hilfe der Ermahnungen von Selten des Pferdes melstert Ognjan die gefuhrl1chen Situationen und kehrt siegreich zum Hof des Gastgebers zurlick. Marko emplangt seinen Feffen voller stolz und fuhrt ihn zum Konig. Ognjan lubergibt den gewlinschten $\mathrm{Zwe1g}$ und erhylt daflr das Midchen, dazu noch drel Lasten Schktze. Nach elner elnwochigen Hochzeltsfeler am Konigahof begleitet Marko das Brautpaar nach Hause.

Statt der urapringlichen drel goldenen Äpfel muß der Preler hier einen Orangenzweig im Meer holen. Interessanterwelse treten die belden Drachen, als verfuhrerische Mädchen getarnt, hier an einem Brunnen, und nicht im Meer auf, was vielleicht schon auf die Lieder vom Typ 4.22 verwe18t. M1t "Polusk1 kralj Mijail" 18t wahrscheinlich der une aus den 4.11-Liedern bekannte tjpisierte latein1sohe Konig Mthajlo gemeint, der hier anscheinend nach Po$\log$ ( = Tetovo pole in Mazedonien) verlegt murde. Var. 31 behandelt das glelche Sujet, nur daB hier der Neffe namenlos als Heldenkind ("malko dete") auftritt, "Vlakkl ban" der Brautvater lot und die Tanne im Schwarzen Meer von einer "zmlja tojoglava" bewacht wird. Dieses Ungeheu- 
er wird von dem Heldenkind nicht mit Hilfe des Schwerte, sondern durch einen Pustritt getitets

On 81 opne desna noga,

Ta rascesna ljuta $2 \mathrm{mija}$.

In der Anm. zu diesem Lied schreibt der Aufzeichners"Taka 1 v edna novogr. prik. u Smidta razkekva edin junak edna zmija", d.h. unser Lied steht mit diesem Teilmotiv durchaus in der griechischen Volkadichtungstradition, von der an Ende dieses Kapitels noch die Rede sein wird.- Var.32 weicht hinsichtlich der Aufgabenstellung etwas von den vorigen Liedern abs

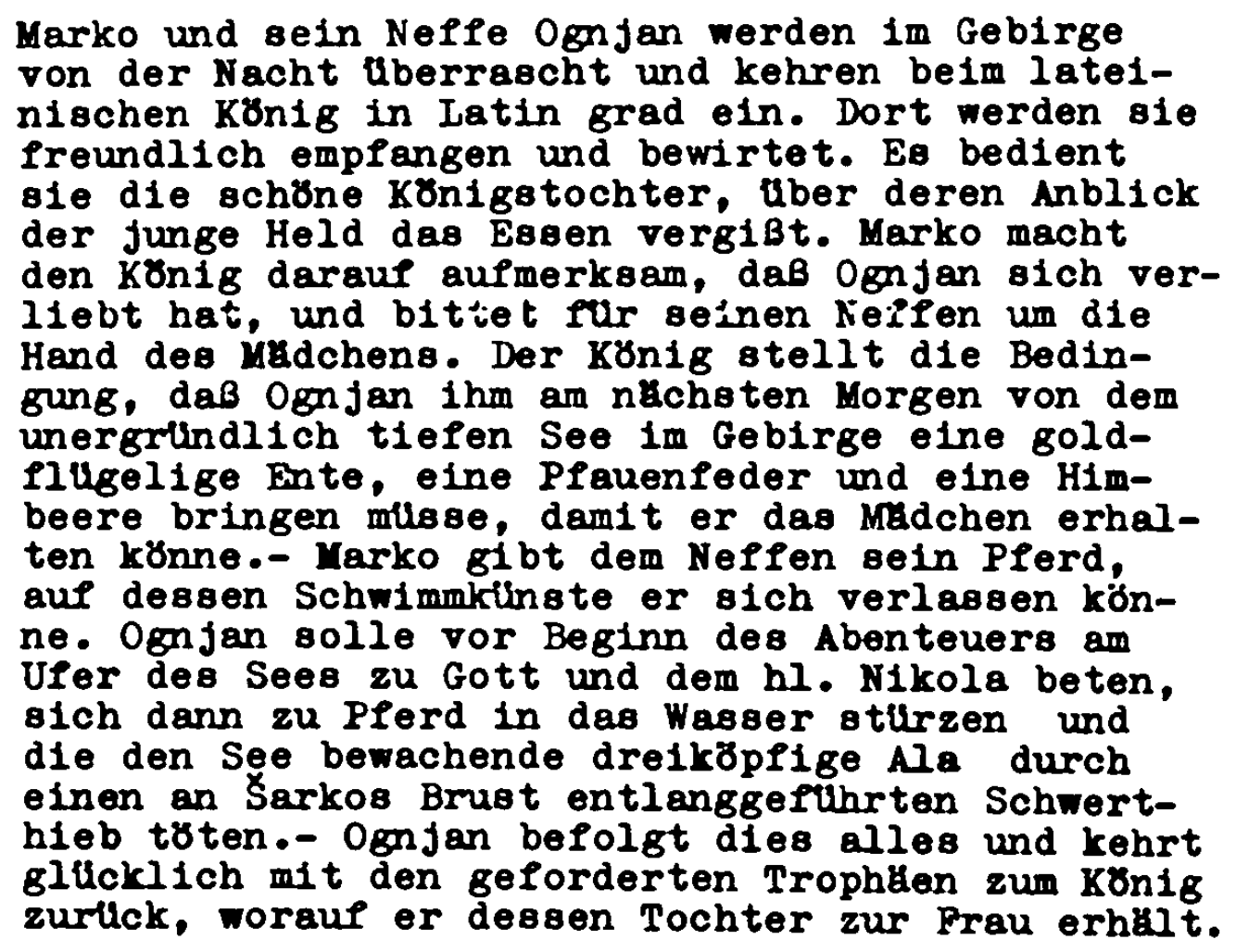
Die drei goldenen Āpfel sind hier sekundur durch die murchenhafte goldflugelige Ente, elne Plauenfeder und eine Himbeere, das Meer durch einen Gebirgssee ersetzt worden. Sonst entspricht die Handlung im wesentlichen unserer Sujetlinie. - Die nun folgende Var.33 steht dadurch 18oliert, das hier eine sekundare Synthese unseres Sujets mit dem von Kap.4.11 vorliegt:

Pilip Madzarin verlobt sich mit der Tochter des lateinischen Kornigs. Er sammelt Svaten und zieht 108, um das Madchen zu holen, wobel er Marko und Grujo "malo dete" einzuladen vergessen hat. Wenn 
auch ungeladen, ziehen Marko und Grujo trotzdem mit dem Hochzeitszug, um zu sehen, ob man auch ohne sie zurechtkomme. Und wirklich erhklt P1lip die Braut echlieblich nur dank des Elngre1fens von Grujo, der die vier vom Brautvater gestellten Frelersproben flr den Brautigam erfilit. Grujo bricht als erste probe mit Hilfe von Pferd und Keule das stahlerne stadtor auf und uberspringt als zweite Prelersprobe dreibig Schluchten, durchmiBt sechzig Engplsse und Uberschwimmt auf Markos Pferd das Schwarze Meer, un von dort etatt der von drel Samovilen bewachten goldenen Äpfel den ganzen Wunderbaum zu holen, ungeachtet des von den Samovilen entfesselten Unwetters.Die dritte Prelersprobe besteht darin, daß Grujo drel Stunden lang in einem gluhenden ofen ausharren 8011, was thm mit Hilfe des vlugen Pferdes gelingt, das das Peuer mit seinem feuchten Atem loscht. Nls vierte Probe 8011 der Held aus drel gleiohgekleideten Madchen die Konlgstochter herausfinden, was Grujo mit der aus 4.11 bekannten I1st gelingt. Grujo behalt an Ende jedoch die Braut flur sich, worauf P1lip das zweite und Belo Kosturjance das dritte Midchen nehmen.

Nach diesem mit dem 4.11-Sujet kontaminierten Iled nun zu Var.34, die mit ihrer Handlungsfunrung etwas auBerhalb des bisher lublichen Schemas oteht:

N1koldo hat mit Zar Kostadin gewettet, das er die Donau uberschwimmen und nach viakka gehen werde, um dort von einem silbernen Beum einen goldenen Apfel zu pilucken. Gelinge thm das, erhalte er die Schwerter des Zaren sowie die Halfte des Reiohes, gelinge es ihm aber nicht, so verliere er seinen Kopf.- Kummervoll kommt Nikoldo nach Hause und erzahlt seiner wutter von der verhangeniovollen Wette. Die Mutter rat ihm, er solle su seinem Ohsim Trifon gehen und $81 \mathrm{ch}$ von ihm ein erfahrenes Pferd ausleihen, das thn sicher luber das Wasser bringe. Nikoldo sucht seinen Oheim auf und wird von thm ereundlich empeangen und bewirtet. Dem Onkel frilt Nikolcos Niedergeschlagenhelt auf, die der Neffe als Polge seiner ungluckseligen Wette erklart. Nachdem Nikol 80 alles erzkhlt hat, darf er olch das beste Pferd im Stall des Oheims ausbuohen. Nit der ausgewahlten Stute macht sich der junge Held auf den Weg zur Donau, wo thm das Pferd die Anweloung gibt, die Riemen etwas lockerer zu schnallen und sich selbst die Augen zu verbinden. Am anderen Ufer des Stromes nimmt Nikoldo die Augenbinde ab und erblickt den silbernen Baum mit den goldenen îpfeln daran. Unter dem Baum jedoch windet sich eine schreckliche Lamja, die dem 
Helden erklart, ele habe schon neun junge Männer verschlungen und werde nun thn als zehnten fressen. Es gelingt NikolCo aber, das Ungeheuer zu töten und den Baum mit den goldenen Appeln auszureissen und wegzuschaffen.- Die Schwester des Zaren sieht den Helden von weitem und weckt ihren Bruder, um mit $1 \mathrm{hm}$ das "Wunder" anzuschauen.-N1koldo hat somit die Wette gewonnen. Er erhalt Elenka als Braut sowie die Hzlfte des Zarenretchs.

In diesem Iled ist der Handlungsablauf in seinem guBeren Rahmen sekundur etwas getndert worden, das Motiv des Äpfelholens von dem durch einen Drachen bewachten Baum, ein Abenteuer, das dank des beim Oheim entliehenen Pferdes gelingt, blieb jedoch erhalten. - Wle Var.33 offensichtlich mit den Liedern von Typ 4.11 kontaminiert war, so ist die num folgende Var.35 mit den erst noch zu besprechenden Iledern des Typs 4.22 vermischt:

König Madžarin versammelt 200 Bane und 300 Könige sowie Kral Marko und dessen Neffen Grujca zu einem Pest, wo Grujca zunkchst die Glste bedient, denn aber zum großen Ärger aller Anwesenden einschläf. Die Gaste fordern von Konig Madzarin eine bessere Bedienung. Nun fuhrt der Gastgeber das schbre Mudchen Angelina herbel, woraue Grujca sofort seine Mudigkeit vergibt und das Mrdchen umwirbt. Konig Madzarin stelit dem Jungen die Bedingung, er mlis8e, um Angelina zu erringen, von dem Brunnen Bul1kovo Wasser holen und weibe Apfelbluten mitbringen.- Marko glbt Grujca sein eigenes Pferd und rat dem Neffen, ja nicht zu graßen, wenn er unterwegs zwel ardchen treffe, sondern sein Pferd anzuspornen und rasch vorbeizureiten. Wenn er zu dem Brunien gelange, solle er sich am Gurtel mit einem Tau festbinden, das Seilende dem Pferd ins Maul geben und sich in den Brunnen hinunterzulassen beginnen. Sel es ihm gelungen, Wasser zu schopfen und von den Bluten zu pfiucken, solle er sich von dem Pferd wieder hinaufziehen lassen, weil thn sonat die siebenkbplige Lamja verschlinge.- Des treue Pferd zieht Grujca wirklich hereus, aber mit thm auch die Lamja, die den Helden bis zum Seldenglirtel veroohlungen hat. Wutschnaubend zertritt das Pferd die sieben Kopfe des Ungeheuere und zieht Grujca aus einem der Rachen der Lamja heraus. Grujca schlkgt die Lamjaköpfe ab und bringt sie - zusammen mit den gewinschten Trophren - zum Konig, worauf er als Belohnung Angelina erbilt.

In dieeer Variante fallt negativ auf, das ein Teil der Hand- 
lung, der durch Markos theoretische Anweloungen glelchsan vorweggenommen 18t, prakt18ch aber erst von dem Helden ausgefuhrt werden mubte (epieche wiederholung), elnfach fehlt. Die beiden Madchen, die Grujca unterwege nicht gruben soll, sind wahrecheinlich Samovilen, doch wird dies filschlich nicht geklurt. Wenn in den 4.22-Varianten die hilerelche Wahlschwester, die Samovila, den Helden aus dem Rachen der Lamja zieht, so tut dies in unserem Iled des Pferd, der uropringliche Helfer des Helden, wortn olch olcher die altere Version offenbart. - Var.36 war mir lelder nicht zuging11ch. Sie ist jedoch in BNTv $I, 687$ als unvollotindig bezelchnet.

Im Anschlus an die erdrlickende Mehrheit von 36 Varianten dieses Sujets aus dem maz., bulg. und sudserb. Raum oind noch dre1 kroat. Varianten aus Dubrovnik und Umgebung und eine Variante aus dem dinariechen Zentralgebiet zu besprechen, in denen unser Motiv zwar nur verblaßt, aber von bre1tem epischen Bolwerk umranmt erhalten 18t. Das erste Iied dieser Gruppe, Var.37, hat folgenden Inhalts

Noch vor Sonnenun tergang verlabt Kral jevio Marko mit seinem Neffen (Bestrib) Marijan Prilep, um Im Kunar-Gebirge zu jagen. Die Jagd verlauft ergebniel08. Plotzlich wird Marijan von heftigem Durst taberfalien und will schon sein Pferd erstechen, um dessen Blut zu trinken, als Marko ihn davon abhblt und thm verspricht, er werde thn nach Krojan an den Hof des Bang fluhren, wo er seinen Durst I8schen krnne.- S1e machen sioh aue den Weg. Der Ben emplangt die Glate freundlich und setzt thnen Kaffee und Schnaps vor, labt ein prachtvolles Abendeseen auftischen und seine Bchone Tochter Zlatija Wein Bervieren. Markos Neffe lot von dem MBdchen 80 bezaubert, daB or es unverwand ansieht und seinen oheim zweimal bittet, er moge Zlatija zu seiner Verlobten machen. Marko tut zweimal 8o, als habe er nichte gehort. Ale Marijan ihn aber zum drittenmal um das Madchen bittet, droht er dem Ohe1m glelchzeitig. 1hm den Kopp abzuschlagen, wenn er nicht endlich auf die Bitten des Neffen eingehen sollte. Ale der Ben diese Worte hort, schlkgt er dem Jungen vor, er solle am nkchsten Morgen oein Pferd besteigen, die Bukovica-, Orahovica-, Jabuka- und Vuk - Gebirge uberqueren, den Vuk - See uberschwimmen, dort in der Hohle einer roten Felewand vergoldete 
Blumen (cr'jeca pozlacena) pelucken und sie als Troph⿱e nach Krojan mitbringen, dann werde er Zlatija erhalten.- Marijan verspricht, die Wunderblumen zu holen. Marko aber warnt den Neffen eindringlich vor den Gefahren im Gebirge, wo es keine Wege gebe und Wrlfe und Bären im Dickicht hausten.- Marijan läBt sich jedoch nicht von seinem Vorhaben abbringen. Er bricht mitten in der Nacht auf und reitet 108. Marko erwacht kurz darauf, reitet Marijan nach und gibt ihm wenlgstens seinen erfahrenen Schecken, wenn er den Neffen ochon nicht zurikckhalten kann. Marijan gelangt glucklioh durch die drel ersten Gebirge ins vierte, wo er schwer mit wrleen und Buren zu kumplen hat. Nach diesen gefuhrlichen Mutproben funrt Sarac inn olcher zu dem See. Dort taucht eine Gebirgafee auf und fragt Marijan, wer er sel. Als sie hrrt, daB es sich um Markos Neffen handelt, erkundigt sie sich nach Markos Belinden. Als oie ochlieblich erfluht, zu welchem Zweck der junge Held hergekommen 18t, warnt ole thn vor dem See, der schon viele Schwimmer verschlungen habe. Die Vila rat dem Jungen, der oich nicht auphalten l\&Bt, auf dem Hinweg zur Hohle dom Pferd das Zaumzeus und die Riemen fest anzuziehen, auf dem Rluckweg aber lockerzulassen und mit dem Schwert am Pferdekorper entlang ins Wasser zu schlagen. Marijan befolgt die guten Ratachlage, gelangt glucklich zu der Hohle und peluckt die Goldblumen. Auf dem Rluckweg tut er wieder, was die Vila Ihm geraten hat. Das Wasser dee Sees trubt oich plotzlich und schlägt blaue und blutigrote Wellen. Sarac beginnt zu oinken und Yarijan mit ihn. Zum Gluck hat die Vila das alles beobachtet. Sie ruft ihre dreiBig Wahlschwestern, die sie das Pferd herausziehen heibt, whirend sie selbst den Helden rettet. Pferd und Reiter, die beide halbtot sind, werden von den mitleidigen vilen wiederhergestellt und mit vielen guten winschen verabschiedet. Marijan gelangt glucklich b1s kurz vor Krojan, als ihm plotzlich Musa Arbanasa den Weg verstellt und ihm die Blumen wegnehmen will. Es kommt zum 2weikampl mit dem Schwert, dann zu einem otumdenlangen Ringkampe, In dem Marijan zu unterliegen droht. Er lenkt Muses Aufmerksamke1t durch olne list auf den Himmel; Mag lockert Be1nen Griff, Marijan springt dem Gegner auf die Brust und belBt $1 \mathrm{hm}$ den Kehlkopf durch. Daraue zleht er Musas Klelder an, schlägt dessen Kopf $\mathrm{ab}$ und steckt $1 \mathrm{hn}$ auf die Lanze, bestelgt Musas Stute und reitet 80 , mit Sarac neben $81 \mathrm{ch}$, nach Krojan zurlick, wo thn der Ban von weltem kommen sieht und thn flir Musa blit. Marko aber erkennt in dem Reiter seinen Neffen und empeiehlt dem Ban, Yarijan gleich seine Tochter zu geben, denn der 
Nefle sel sicher mude und relzbar und könne mbgIlcherwe18e Strelt beginnen.- Marljan ubergibt dem Ban die gewlinschten Blumen, worauf dieser ihm rat, nun nach Prilep zu reiten, Svaten su sammeln und dann die Braut absuholen. Marljan aber verlangt das Madchen sofort und drobt. er werde den Ban tbten, wenn dieser nlcht gehorche. Daraufhin erhalt der junge Held seine Braut, reltet mit ihr und seinem Oheim Marko nach Prilep und felert in der Kirche Ruzica Hochze1t.

Das Kunara-Gebirge $179 a$ (auch Namensformen wie Kunar,Kunor, Kunarica, Kunovica und Kunovo kommen vor) eplelt sonet vor allem in Uskokenliedern ( 8 gl. Vuk III 20 u.a.) ethe Rolle. Bukovica und Orahovica oind (laut Rjecnik JAZU) Geblrge in Bosnien. Jabuka 18t im Jugoslavischen Nkademiewbrterbuch nur als serb. ON, nicht aber als Gebirgename verselchnet.Das Iled schllest elch,was die Komposition betrifet, an die Var.30-32 an, die ebenfalls eine Jagdszene nt Marko und dessen Neffen zum Ausgangepunkt haben. In unserer Var.37 erinnert die Eingangsezene mit dem Durat-Mot1v an die Vila brodarica-Ileder, die noch su besprechen sind (vgl. Kap.4.42). Um die Tochter des Bans zu erringen, mus der Held hier nicht das Meer, sondern nur einen see uberschwinmen, su dem er eloh allerdings unter schwierigsten Bedingungen vorkämpfen muB. Der Preler soll auch keine goldenen Äpfel von einem durch Wasserdrachen bewachten Baum, sondern vergoldete Blumen aus einer Hoble am See holen. AuBerdom sind die Lamien ausgefalien. An ele erinnert nur noch, das der Held auf Anraten der vila neben dem Pferdekörper mit dem Schwert ins Waseer stoBen soll, daB die Wellen des Sees sich plotzlich blutig farben und daB Pferd und Reiter unter dem Einwirken einer unsichtbaren Macht plotelich zu sinken beginnen. Sekundar $18 t$ die Helferrolle von der Heldenpferd auf die Vila und ihre Wahlechwestern ubergegangen. Der zweite rell des Iledes stellt eine Kontamination nit den Kusa Keeedz1 Ja-Lledern (Typ Vuk II 66; vgl:. Kap. 5.1) dar, nur das hier die Szene der rotung des uberlegenen Gegners mit dem versteckten Messer und die Auffindung von drei Herzen im Körper Musas fehlt. Das Motiv, daß der Held in den Klelderm seines Gegners belmreitet und rur diesen ge- 
halten wird, erinnert an das Lied Vuk III 56 "Ivo Senkovi6 1 Aga od Ribnika", wo das Motiv mit tragischen Akzenten ausgestaltet wird.

Im ganzen genommen scheint unser sujet in den slldwestkroat. Raum aus Mazedonien zugewandert zu sein. Es macht einen relativ jungen Eindruck und lot sekundar umgestaltet und erweltert worden, wobel das urspringliche Kermmotiv sehr verblabte. Dieses Urteil gilt auch fur die folgenden drel Lleder. - Var.38 18t dem vorhergehenden lied ganz ähnlich, nur heibt der Neffe hier Miljenko, Sohn des Bans von Sibinj, und als Brautvater fungiert der Kontg von Budim. In Var.39 18t wieder Marko Kraljevit der Oheim, Miljenko Vojinovib der Neffe und der Konig von Budim der Brautvater. Das Lied lot episch breit ausgesponnen. Es beginnt wie Var.37 und 38 - mit der Jagdszene und der Einkehr beim Konig von Budims

Um die schöne Schwester des Konlgs zu gewinnen, Uberschwimmt Miljenko in voller Ausrlatung und Bewaffnung den See unter der Adlerwand (pod Orlove St'jene), um die gewlingchten Blumen (Petrovo cvijede = Ochsenauge bzw. Turkenbundlilie) zu pllucken. Dabel ertrijkt der Junge. Marko, der inm nachgeritten 18t, zieht thn aus dem Wasser und bringt inn weder zu Bewubtsein. Der Konig labt den Jungen in elner Kutsche an den Hof nach Budim bringen. Das Gerlucht vom Tode des Miljenko lst bis zu dessen Nutter gedrungen, die in Trauerkleidung herbeleilt, ein Motiv, das besonders breit ausgemalt ist (Sturz der Mutter vom Pferd usw.). Nach einer Woche Aufenthalt in Budim verlast Marko mit Schwester und Neffen die Stadt. Miljenko sammelt in Karlovac Svaten und holt die Braut ab, die er bekommen hat, obwohl er die geforderten Blumen nicht bringen konnte.

Die Vilen- und ile Musa-Szenen fehlen in diesem Lied, des sich noch weiter als die beiden vorhergehenden Varianten von dem urspringlichen maz. Motiv entfernt hat. - In der letzten, sehr verderbten Var.40 18t wieder der konig von Budim der Brautvater, dieses Mal aber Despotovi6 Vuk der Preier. Mit Deepotovie Vuk ist sehr wahrscheinlich Zmajognjeni Vuk gemeint, den man wohl auch hinter dem MarkoNeffen Ogajan in Var. 30 und 32 vermuten darf. Der Inhalt von Var.40 lautet nun 80 s 
Despotovic Vuk soll einen vergoldeten $\mathrm{Zweig}$ mitten Im Meer holen, wenn er die Konnigstochter gewinnen will. Auf dem Weg zur Kuste warnt den Reiter "etwas" aus dem Waldgebirge, den Wiesen und dem Wasser heraus, er solle umkehren, wenn ihm sein Leben lieb se1. Vuk Uberlegt lange, was zu tun sel, ruft Jesus und Maria an und besteigt dann doch (mit verbundenen Augen) seinen Rappen, um olch von ihm zu der Tanne mitten im Meer tragen zu lassen. Dort angelangt, otreokt er seine Hand aus, um den vergoldeten Zweig abzureiBen. Da mufen plötzlich Kinder von der Tanne herab, er oolle ihr vom Vater und den Vorfahren ererbtes Gut in Ruhe lassen; solange sie noch ihren Kopf auf den Schultern trilgen, gelinge es inm nicht, den Zweis zu pelucken:

Povikate djeca sa jelices

"Ostav' granu, Despotovic-Vuðel

Ti ne nosi nare oxevine,

orevine, a 1 djedorine,

Dok je na nam nase crne glave,

Ne Ces Vuce odnijeti grane.

Vuk klimmert sich nicht um diese warnenden Worte, sondern pfluckt den Zweig und macht eich auf seinem Pferd auf den Rlickweg. Da springen samtliche Kinder hinter ihm ins Waseer und verfolgen ihn. "Etwas" veroucht, Vuk vom Pferd herabzuziehen und das Tier zu ertrkinken. In Kustennahe kann das Pferd plotzlich nicht mehr weiterschwimmen, weil es von "1rgend etwas" an der Mahne festgehalten wird.Als Vuk dies bemerkt, nimmt er den erbeuteten Zweis in die linke Hand, die seidenen Zugel zwischen die Zähne und des Schwert in die Rechte, ruft Jeous und die heilige Jungfrau Maria an und schlkgt dann mit der Waffe dem Pferd so lange um den Kopf, bis das Tier loskommt und ihn sicher ans rettende Ufer trkgt.

Die weitere Handlung wird in MH $I_{1}, 570$ nicht mehr angefuhrt. Der angegebene Teil genugt uns aber schon, um eine seltsame Veränderung der urspringlichen Handlung feststelien zu können, wobel vor allem ein starker Hang zum GeheimnisvollMirchenhaften aufalit: Geleterhafte Stimmen in der Natur warnen Vuk davor, zum Meer hinzureiten und zu der Tanne zu schwimmen; der Baum, von dem er den goldenen Zweig peluckt, lot die Wohnstatte ratselhafter Kinder, die den Helden, als er trotz ihrer Warnung den Zweig abreibt, durch die Wellen verfolgen; elne geheimiovolle, unsichtbare Kraft will ihn mit dem peerd ertranken und halt das Tier an der Mahne fest. 
Vom urepringliohen Sujet lot erhalten geblieben, dap der Freier eine Trophle von einem Beum inmitten des Meeres holen mus, um die Konlgstochter zu erringen. Die goldenen Xpfel sind jedoch durch einen vergoldeten zweig ersetzt worden. Die urspringlichen Lamien sind anscheinend in die ratselhaften Kindergestalten ubergegangen, die den Helden offensichtlich unsichtbar verfolgen. Nicht mehr das Pferd glbt hier den Rat, der Held solle mit dem Schwert um oloh echlagen, oondern Vuk kommt selbst auf diesen Gedanken. Des chrietliche Moment ist durch die wiederholten Heiligenanrufungen relativ stark betont. Es dient viellelcht als Gegengewlaht gegen das heldnisch-dimonische Moment dieses Ileds.- Von einem Oheim 18t in dem angefuhrten Iledtell kelne Rede.

wie der Variantenvergleich ergeben hat, handelt es olch be1 dem besprochenen Sujet hochstwahrscheinlich um ein Mot1v, dessen Brennpunkt in Mazedonien liegen dirfte und das, wie wir bel der Iledbesprechung gesehen haben, im 0 b18 Elena und im $W$ bis Dubromik ausgestrahlt hat. Was das "Hesperiden-Motiv" anbelangt, sollen hier noch die sudslavisohen Iledvarianten erwahnt werden, die das Motiv, goldene Apfel von einem durch Drachen bewachten Baum zu holen, in Zusammenhang mit dem Mot1v AaTh 590 II "The Treacherous Mother" und NaTh 315 "The Palthlese Sieter" behandeln. Dieses Sujet labt sich kurz so beschreiben, das eine Nutter (bzw. Schwester), die durch ihren heldenhaften Sohn (brw. Bruder) in Ihrem Ilebesverhaltnis zu einem Riesen, Hajduken usw. geetort wird, dem Sohn (bzw. Bruder) auf Anraten des Liebhabers die Aufgabe stellt, Xpfel, die von einem Drachen bewacht werden, flur ale herzuholen, um ibn dadurch aus dem Weg zu raumen; der junge held besteht jedoch das gefahrliche Abenteuer und nimmt blutige Rache an dem Ilebespar. Be handelt sioh hier meines Wiseens um folgende slldslavisohe Iiedvarianten: Vuk II $7^{180}$; MH $I_{1} 45$ s SauI16 I 1; SbNU XIX,41; XXXI, 521; XIII,11; Sapk.422; M11. 90 und SbNU $\mathrm{XV}, 106$. 
Zusammenfassend laBt oich num zu dem in diesem Kapitel besprochenen Sujet sagen, daB es mit aller Wahrscheinlichkeit dem maz. Raum entstammt und m.E. eine deutliche Einwirkung des griech18chen Hesperiden-Mythos zelgt. Ferner durfte sioh aus dem stark mythologischen Iledsujet 4.13 durch fortsohre1tende Entmythologisierung und Paychologielerung der Lledtyp 4.12 entwickelt haben. Das Sujet 4.13 gehort - Im Gegensatz zu dem sekundären sujet 4.11 - in seiner Reinform der maz.wbulg. Primarliedschicht an. Diese aber durfte einen bedeutenden Tell ihrer Motive aus dem griechischen Mythen- und Marchenschatz ubernommen bzw. mit ihm gemelnsam haben, so dab der maz. Lledheld sich, um mit Meletinskif und Zirmunskij zu sprechen, aus dem Protagonisten des Heldenmarchens (bogatyrakaja ekazka) entwickelt hktte, der wiederum eine We1terentw1cklung des "Kulturheros" (kلl'turnyj geroj), des hauf1g demiurgischen, vaterlosen oder durch munderbare Geburt aue die Welt gekommenen ultesten Helden der Folklore ${ }^{181}$ daratellt.

Wie sehr das maz.-wbulg. Iled mit seiner archaisch-marchenhaften Thematik in der griechischen Marohentradition verankert lst bzw. mit ihr zusammen aus elnem nach Gattungen noch nicht geschiedenen Stoff- und Mot1vreservolr geschrpft hat, oollen folgende Beiplele zelgens Motive wie z.B. das Auslesen von Hirse und das Bestehen einer EBprobe, die wir be1 der Besprechung des 4.11-Sujets als sekundare maz.-bulg. Mot1ve bezelchneten, finden wir tatskchlich im griechlachen Kärchenschatz wieder. In Hahn 37 ("Der Kon1g8sohn und der Bartlose") z.B. muB der Prinz, un die Goldgelockte zu gewinnen, u.a. "vier untereinander gemengte Pferdelasten We1zen, Gerste, Spelt und Más" an elnem halben Tag auseinanderlesen, was ihm - genau wie in dem oben behandelten lied nur mit Hilfe dankbarer Tiere (auch hier Amelsenl) gelingt. Er muB auBerdem aus elner Anzahl verschlelerter Madchen die Braut herausfinden, eine Aufgabe, bel deren Iroung ihm wieder dankbare Tiere, dieses Mal Bienen, helfen. In der bel Hahn, 243 angepuhrten Varlante zu Hahn 37 muB der Held (vgl. den Stein in unserem oblgen Iledl) einen Ring aus dem Meer 
heraufnolen, wobet inm (wie in unserem maz. Ited) ein dankbarer Fisch hilft. In Hahn 63 ("Der junge Jager und die Schöne der Welt") muß der Held, um die Schöne zu gewinnen, genau wie in manchen unserer maz.-wbulg. Iieder eine EBprobe bestehen, namlich 100 gebratene Ochsen und 500 Brote aufessen, was inm allerdings nur mit Unterstutzung eines hilfreichen Riesen gelingt. Anschliebend muB er (wie in den Liedern vom erweiterten Typ 4.13) in einem gluhenden ofen bis zu dessen Erkalten ausharren, wobel ihm ein zweiter Riese, der Wasser in groben Mengen trinken und dann ausspeien kann, beisteht, d.h. die Rolle spielt, die in unseren Liedern das Pferd, der archaische Helfer des Helden, innehat. AuBerdem muB der Held noch einen Apfel von einem vieraig Tagereisen entfernten Baum in einer Viertelstunde herbeischaffen, was der hilfreiche Mohr fur ihn ausfunrt. In Hahn 114 ("Die heirathsscheue Prinzessin") holt der Prinz flur die Prinzessin als Freiersprobe drei "lachende Äpfel" aus einem von 100 wachsamen Drachen bewachten, 600 pagereisen entfernten Garten und drei "weinende Quitten" aus dem verschlossenen Drachenpalast. Eine Reminiszenz an die einem wachsamen Drachen zu raubenden (Hesperiden-) Äpfel ist möglicherwelse auch in Hahn 70 und Var. ("Der Goldapfelbaum und die Hollenfahrt" = Kretschmer 59) erhalten, das Kretschmer (S.339) kurz als das "Marchen vom Drachentöter, seinen neidischen Brldern und den drel geretteten Prinzessinnen, Aarne Nr.301 A" beschreibt. Hier wird aus dem Garten eines Königs jeden Abend ein goldener Apfel geraubt, was sich niemand erklkaren kann, bis nicht der jüngste Königssohn unter dem Baum wacht. Der Prinz bemerkt numlich plötzlich eine schwarze Wolke, die sich auf die goldenen Äpfel niedersenkt, ochioßt in die goheimnisvolle Wolke und folgt schlieBlich der Spur des in der Wolke verborgenen verwundeten Drachen in die andere Welt, wo er drel Prinzessinnen aus der Gewalt des Ungeheuers befreit. Hier finden wir sogar zum Teil wortliche Entsprechungen zu unseren Iiedern, z.B. wenn der mit einem Hieb niedergestreckte Drache den Helden listig bittet: 
"Gib mir noch einen Schlag, damit ich rasch verende", antwortet der Held: "Meine Mutter hat mich nur einmal geboren." Darauf zerplatzt der Drache, weil thm der Held bewußt einen weiteren Schwerthieb verweigert. In dem maz. Marchen Cepenkov I 39 ist es eine Lamja, die die Goldäpfel holt und von dem jungsten der drei Brllder in die andere Welt verfolgt wird ${ }^{182}$, wo der Held die unter der Lamja leidenden Ieute, denen sie das Wasser sperrt und nur gegen Menschenopfer freigibt, von dem Ungeheuer erlost. Ein albanisches Beispiel dieses Marchentyps ist Lambertz, Die geflugelte Schwester,37-49 ("Der jungste Bruder und der Send-eGjă"), wo ebenfalls das Andromeda-Motiv eine Rolle opielt. Der Drache, der das Wasser bewacht und Menschenopfer fordert, ist hier die Kutschedra.- In Hahn 32 ist die Lamja Besitzerin eines Apfelbaums.- Auch das sprechende und den Helden beratende Pferd (vgl. Hahn 6,37,45,58 usw.), das so typisch fur die maz.-wbulg. Ileder und opeziell fur das zuletzt besprochene Sujet ist, findet eine ausgeprägte Parallele im griech.-maz. Marchenschatz.- Vielleicht atammt auch das Motiv aus dem griech. Mrrchen, dab der Held einen Gegner (den Drakos im griech. Märchen, z.B. Hahn 32,64 usw. und den schwarzen Araber im sludslavischen Heldenlied) tief in die Erde stöBt und inm erst dann das Haupt abschlagt. In Hahn 22 ("Die Zwillingsbruder") muB der Held, um die "Schöne des Landes" zu erringen, wie in mehreren erwelterten Iledern des Typs 4.13 mit einem Hohren kämplen, der in dem Fall des griech. Murchens allerdings die verwandelte Prinzessin selbst verkorpert. Zum Thema Araber-Kamps im slldslavischen Iied und seine eventuelle Beziehung zum griech. Märchen sel auf das folgénde Kapitel verwiesen.

Abschließend soll eine treffende Formulierung Meletinskifs unsere Gedanken uber die Marchen-Iied-Beziehung im griech.slavischen Folkloreraum abrunden:

Voznikaja $v$ period razlozenija pervobytnoobzdinnogo stroja, geroiceskij épos opiraetsja na tradiciju povestvovatel'nogo fol'klora doklassovogo obrcestra. Vyjasnente roli doklas8ovogo fol'klora 
kak važnejgego 1stoðnika formt rovanija épikogeroiceakogo zanra 1 znacenie pervobytnoobzinnogo nasledija $\nabla$ geroideskom épose bylo osnovnym $\nabla$ nasem 18sledovanil (Proischoźdenie,425).

Mit dieser Aussage wird die Tatsache unterstrichen, das das Heldenepos, entatanden in der Zerfalloperiode der Urgesellschaftsordnung, sich aue die Tradition der archalschen erzahlenden Polklore, die ein Produkt der Sipponordnung darstellt, stutzt.

\subsection{BRAUTPAHRT MIT KOMPLIKATIONEN}

War im 4.1-Sujet das Zustandekommen einer Hoohzeit dadurch gefuhrdet, dab der Freier selbst oder ein Stellvertreter ochwierige Freieraproben zu bestehen hatten, so handelt es aich nun darum, daß der Brautzug durch einen tberfall aufgehalten und bedroht wird. Diesen tberfall - und das wird das Hauptsujet von Kap.4.21 sein - veranstaltet in den meisten Fullen ein mit damonischen zugen ausgestatteter, meist dreiköpfiger achwarzer Araber (in obulg. Var. auch ein Bar). der allein vom Brautflunrer (dever) bekămpft wird, während die Ubrigen Svaten feige fliehen und die Braut allein laseen. Dieser dumonische Mohr mit drachenartigen Zugen wird opäter zum Teil zu einem an der Furt bzw. im Waldgebirge lauernden Turken entmythologiaiert.

Weltere Komplikationen der Brautfahrt können bich daraus ergeben, das der Hochzeitazug unterwegs von vilen beschossen wird oder der Brautigam ein auf dem Rluckweg plotzlich angeachwollenes Gewksser erproben muß. Nebenthemen behandeln das Sujet, das ein Brautzug oder ein Bhepar, das gerade zum oreten Boouch bol den Brauteltern unterwogs iot, von elnem abgewiesenen ehemaligen Freier der Frau uberfallen wird, wobel die Handlung melat $\overrightarrow{i m}$ Hajdukenmilieu spielt, oder aber ein Brautpaar, das unterwegs von Neldern beobachtet wurde, wegen der Schonhelt der Braut einen fberfall erleiden muß, nachdem das Paar kaum in dem neuen HeIm angekommen 18t. Nicht behendelt werden hier jedoch die Ileder, 
wo während der Brautfahrt von Seiten des Kums oder Devers ein Verfuhrungeversuch gegenluber der Braut gewagt (vgl. Vuk I 742 und 743; Vuk II 55; Vuk III 82; Milut.119; Vien. uzd.1; Marj.1 und 2; Kad.130 u.a.) oder von Seiten der Svaten ein Uberfall auf den Brkutigam unternomen wird ( $\nabla$ gl. SbNU XIII, 91 u.a.).

4.21 HOCHZEITSZUG MIT UBERFNLL AUF DEM (RUCK-)WEG UND VERTEIDIGUNG DER BRAUT DURCH DEN DEVER

Bei diesem Sujet handelt es sich meines Wissens um folgende sudslavische Varianten:

1 EH 188 (4/6;145 V.; Gebiet der ehemal.M1litägrenze)

2 MH I 2,411 (Ilic 23;4/6;?; Velika)

3 Petr.II $33(4 / 6 ; 724$ V.; Hercegovina)

4 MH $I_{1}, 584$ (Marjanovio 13;4/6;?; Gorna Krajina)

5 MH $I_{1}, 586$ (Rakovac $88 ; 4 / 6 ; ? ;$ Gorńa Krajina)

6 Vuk VI $36(4 / 6 ; 233 \mathrm{~V} . ;$ Sabac)

7 MH $I_{1}, 586$ (Tommaseo 8;4/6;?; Dalmatien)

8 Vuk VI $37(4 / 6 ; 570$ V.; Hercegovina)

9 Milut.72 (4/6; 341 V.; Gacko)

10 Pilip.12 $(4 / 6 ; ? ; ?)$

11 MH $I_{1}, 587$ (Vrbanic 10;4/6;?; Gospi6)

12 Vuk II $86(4 / 6 ; 187$ V.; Gacko)

13 Petr.III $36(4 / 6 ; ? ; \mathrm{BH})$

14 Petr.III $54(4 / 6 ; ? ; \mathrm{BH})$

15 Petr.III $6(4 / 6 ; ? ; \mathrm{BH})$

16 Petr.III $34(4 / 6 ; ? ; \mathrm{BH})$

17 Petr.III 45 (4/6;?; BH)

18 MH I, 585 (0stojic II 596;4/6;?; Grabovac)

19 Vuk VI $34(4 / 6 ; 262$ V.; Hercegovina)

20 Petr.II 22 (4/6; $271 \mathrm{~V}$; Sarajevo)

21 Petr.II 21 (4/6; 864 V.; Sarajevo)

22 H8rm.I 1 (4/6; 863 V.; Sarajevo)

23 H8rm.HS $15(4 / 6 ; ? ; \mathrm{BH})$

24 H8rm.HS $20(4 / 6 ; ? ; \mathrm{BH})$ 
1

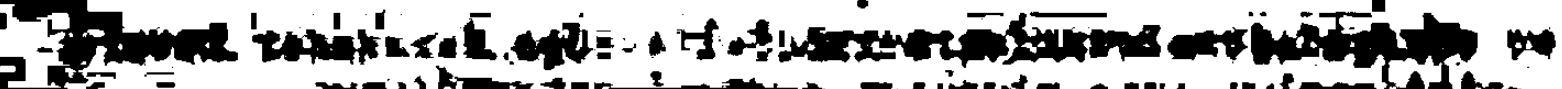

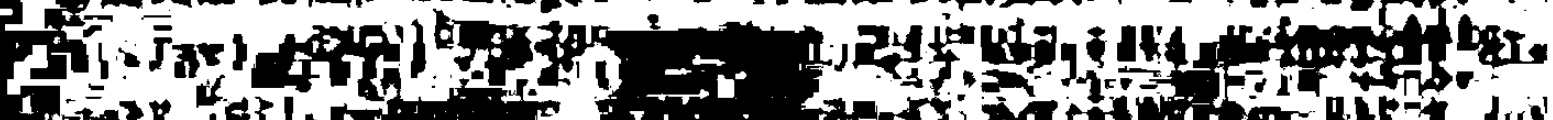

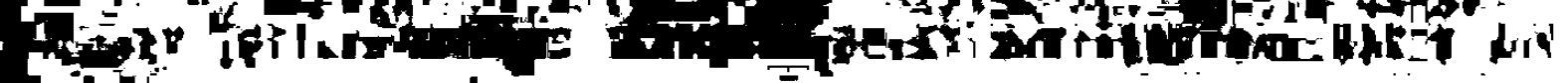

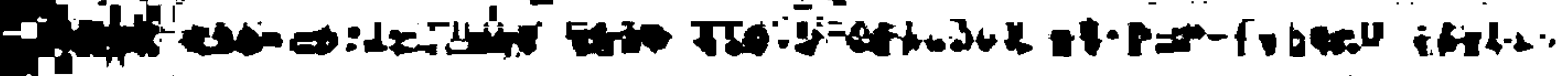

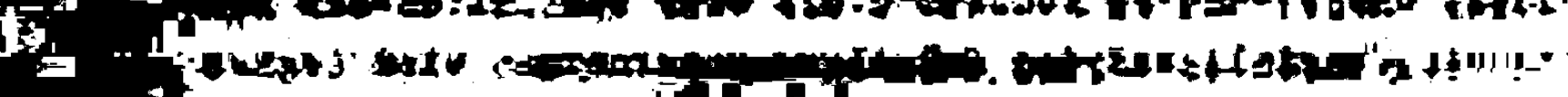

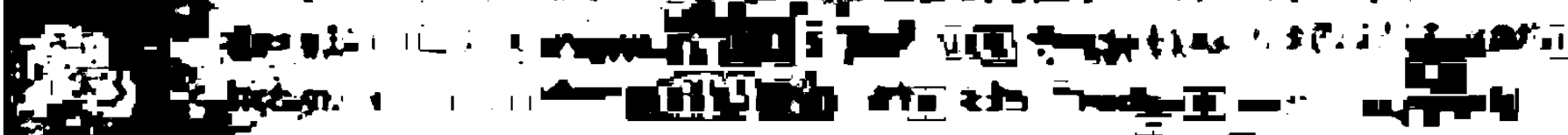

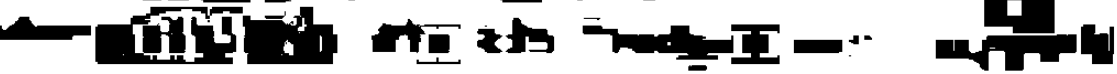

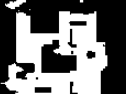
I

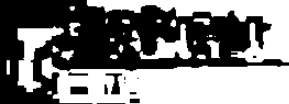

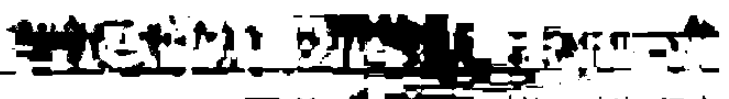

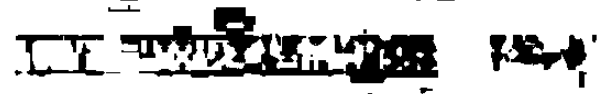

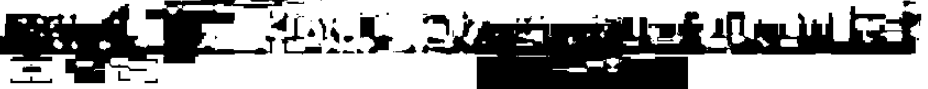

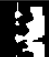
1

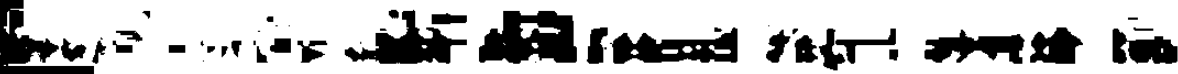

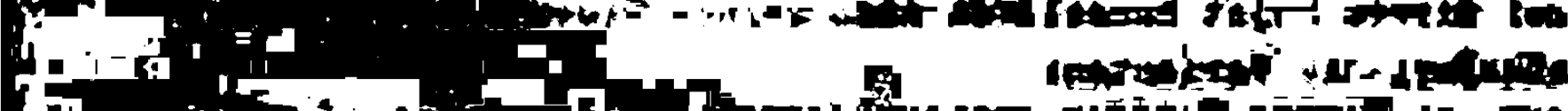

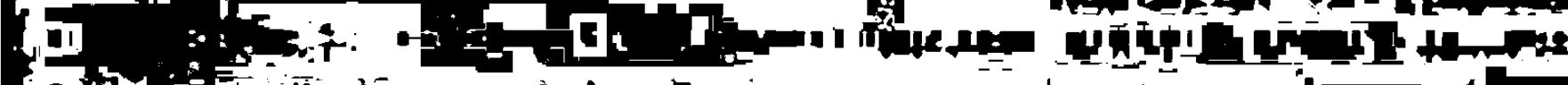
Fip

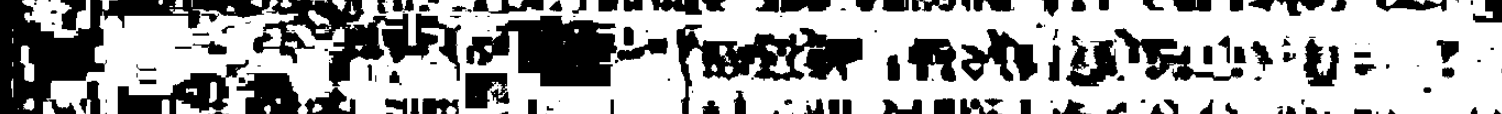
id ir to

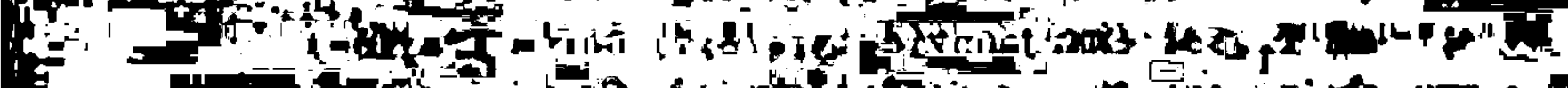

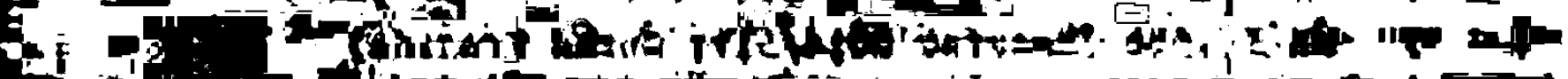
b.

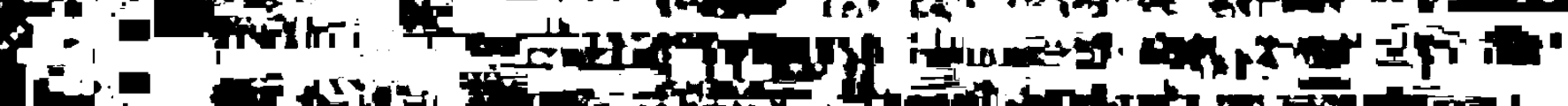

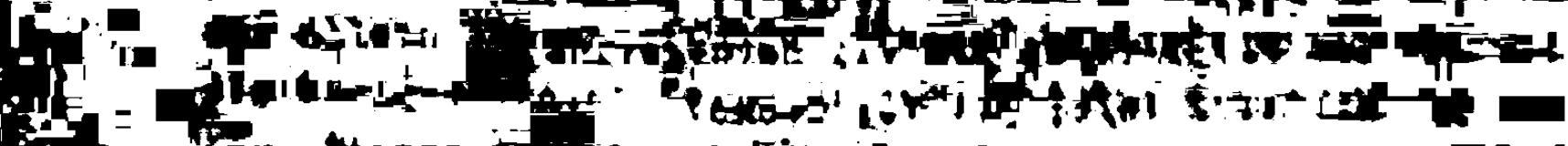

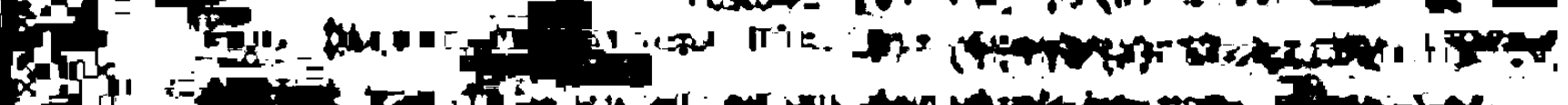

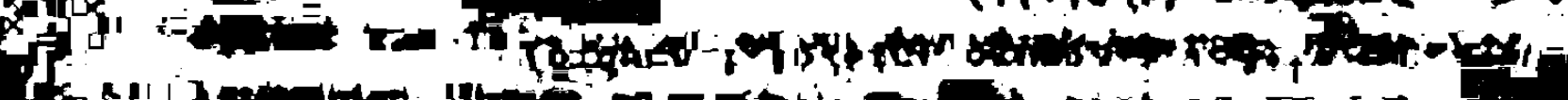

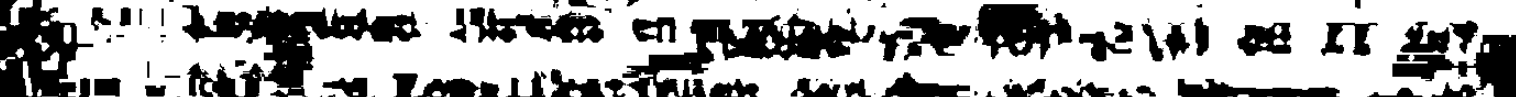

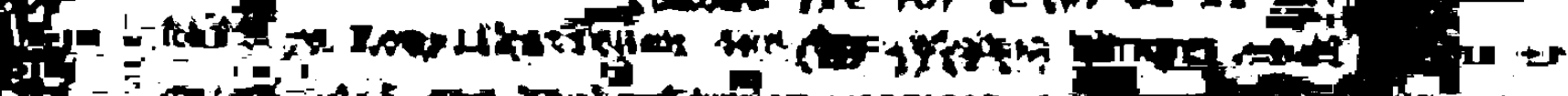
Lev a

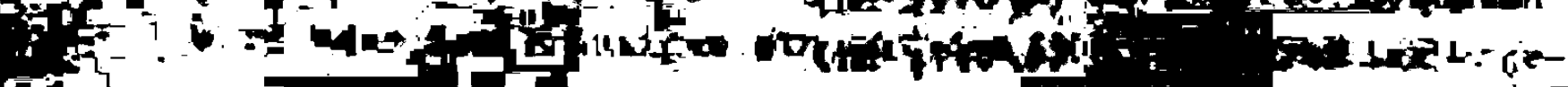

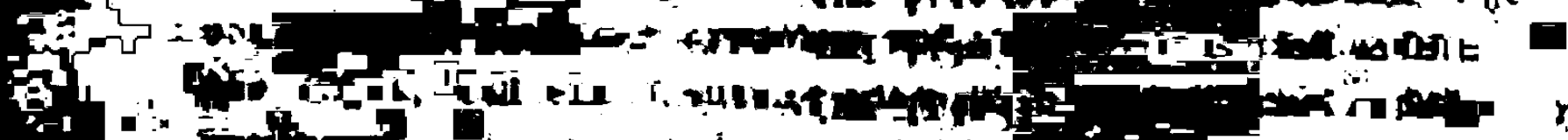

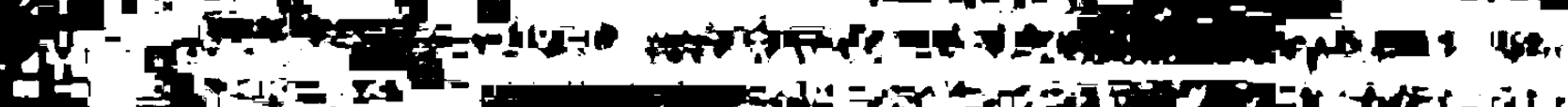
AL

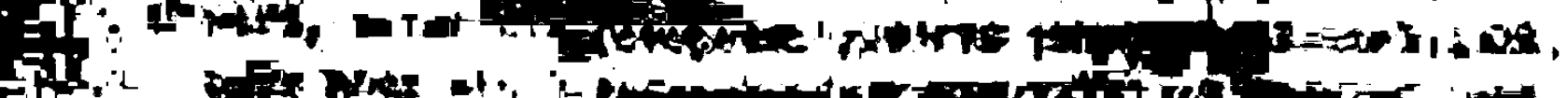

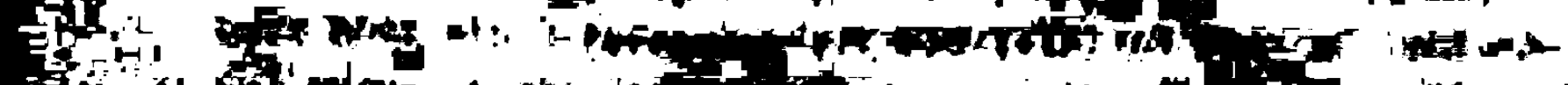
F.

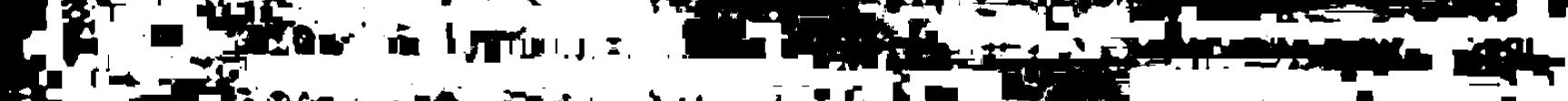

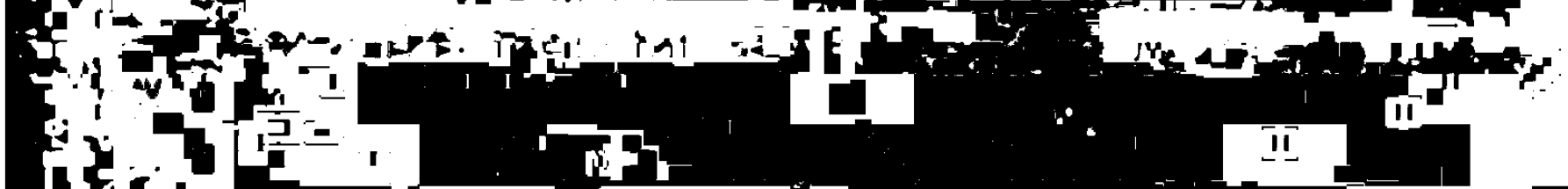




\section{a}

n n- II -

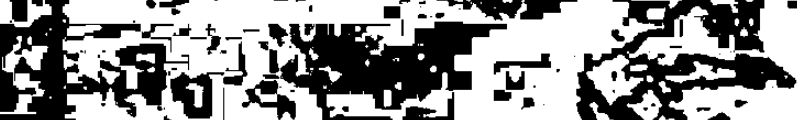

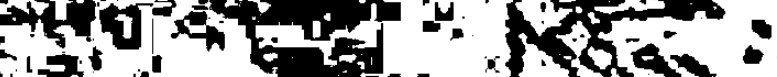

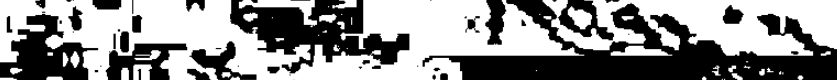

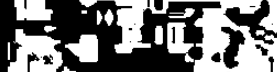

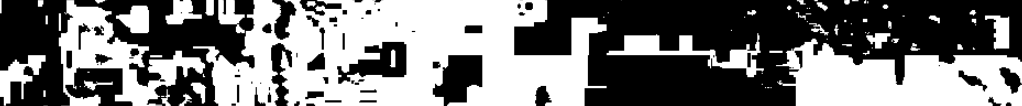

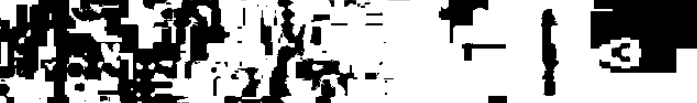
1. 1) ind (a) atis itos

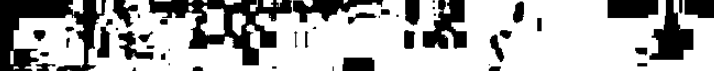

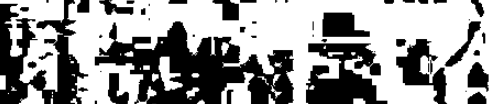
H \&f

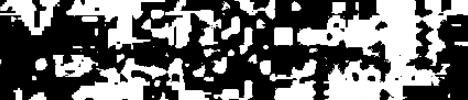

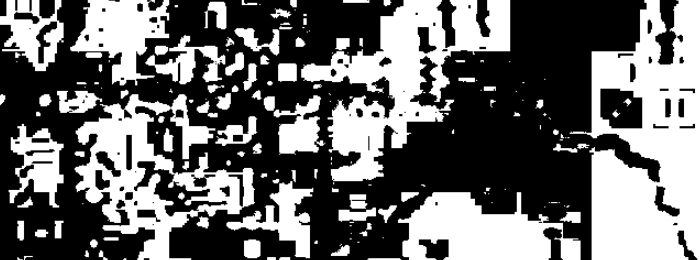
$\rightarrow$ If

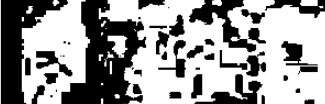

a c 1) It

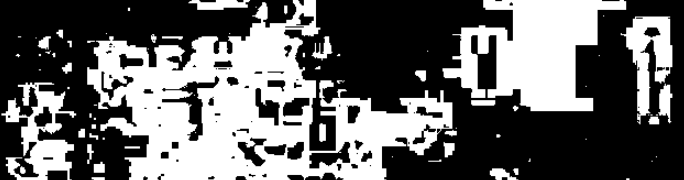
aty $i^{2}$ ind $f^{2}-2-16$

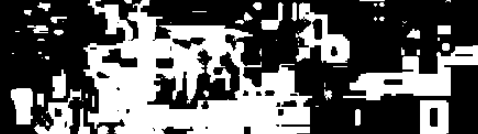
Find

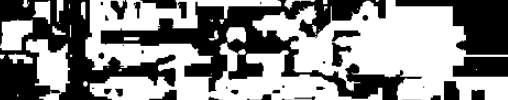

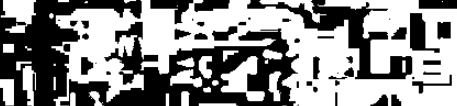
1)

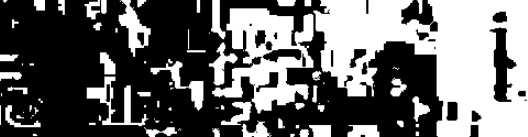

1, Hi $q=0$ fot 8 is 1

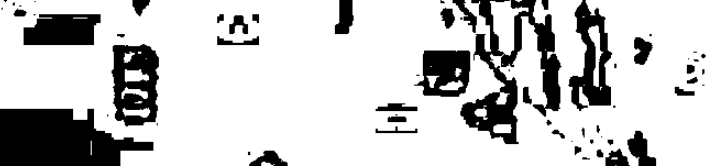

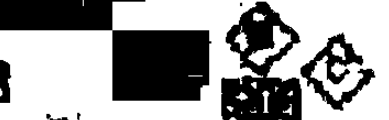
at

西 ' i: TI 11

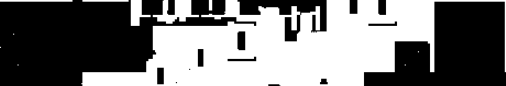


M11.59 (4/6, $110 \mathrm{~V}$. : Mazedonien)

26 M1I.173 (4/6, 349 V.; Mazedonten)

27 SbNU I.59 (4/6; 359 V.; Sol1 jako)

28 Sapk.366 (4/6; 160 V. uv.; Gost1var)

29 SbNU XIIII, 180 (4/6; 358 V.; Sol1 jako)

30 SbNU IX,79 (4/6; 155 V.; Sol1 joko)

31 SbNU XUIII, 169 (4/6; 123 V.; Sol1j8ko)

32 Mch.362 (4/6; 42 V.; Mazedonten)

33 SbNU XVI-XVII, 177 (4/6, 258 V.: Pr1lep)

34 Tosev,27 (4/6; 335 V.: Blagoevgrad)

$35 \mathrm{MH} \mathrm{I} 50(4 / 6 ; 77 \mathrm{~V} \cdot 3$ Makarska)

36 Stojk.,399 (4/6; 81 V.; Presevo)

$37 \mathrm{KaC} .160$ (4/6; $71 \mathrm{~V} . ; \mathrm{Vranj8k0)}$

38 SbNU VIII.95 (4/6; 158 V.; Kopriv8t1ca)

39 P111p.36 (4/6;?;?)

40 Vuk VI $39(4 / 6 ; 217$ V.8 Hercegovina)

41 Vuk VI 38 (4/6; $344 \mathrm{~V} \cdot$; Hercegovina)

42 Caregr.Vestn..Jg.9(1859),Nr.414 (?; 67 V.;88tl.kA) ( = 8to1l.Pokaz.I 415)

43 SbNU XXV,98,Nr.7 (5/3; 118 V.; Rueensko)

44 SbNU XXV,130,Nr.47 (5/3; 40 V.: Gabroveko)

45 SbNU XXVI, 47,Nr.23 (5/3; 48 V.uv.; Gabroveko)

46 SbNU XaVI, 66,Nr.44 (5/3; 136 V.8 Gabroveko)

47 SbNU XXXV,260,Nr.264 (5/3; 76 V.8 Severna Dobrudza)

48 SbNU XXXV,261,Nr.265 (5/3,64 V.uv.8 Sev.Dobr.)

49 SbNU XXXV,262,Nr.266 (5/3; 51 V.; Sev.Dobr.)

50 SbNU XXXVII, 123,Nr.205 (5/3;43 V.iBjala Cerkva)

51 SbNU XII, 95,Nr.23 (5/3; 42 V.; Kolarovgrad)

$52 \mathrm{SbNU}$ XII, 16,Nr.11 (5/3; $88 \mathrm{~V} \cdot 3$ Novopazarsko)

53 Vurb.275 ( $3 / 5 ; 52$ V.; Berdjanek)

54 Vurb.276 (5/3; 54 V.: Berd jansk)

55 Vuk I 718 (4/6, 24 V.; Heroegovina)

56 Petr.III $2(4 / 6 ; ? ; \mathrm{BH})$

57 Petr.III 3 (4/6;?; BH)

Um die unterschiedlichen Iledtypen auf der Karte zu trennen, wird flur Var.1-34 das Ze1chen 0 , flur Var.35-42 das Ze1chen $\Delta$. Fur Var.43-54 das Zelchen Ound flur Var.55-57 das Ze1cheno verwendet. 
Nun zum Variantenvergleich. Mit Var.1 steht uns immerhin ein Beleg aus der ersten hulte des 18.Jh. zur Verfugung. Das Lied hat folgenden Inhalt:

Crnojevic Ivo ereit drei Tagereisen ubers ebene Feld, vier Tagerelsen durch die schwarzen Berge und dreibig Tagereisen lubers blaue Meer entfernt ein Mädchen, die Tochter des klistenländischen Bans ( $u$ onoga bana primorskoga), und erhalt eine Zusage, woraue er Selde und einen Ring als Verlobungsgeschenke hinterläBt, heimreist und Svaten sammelt. Zum Kum bestimnt er Relja von Budim, zum eraten Svaten Milo\} Kobilic, zum Dever Kraljevic Marko, zum Bannertrkger Kalca Radonja; auBerdem ladt er Sekula und Janko, funfzehn Uskoken aus Udbina, die beiden Novakovici sowie Novak und Radivoj, schlieblich Zekaranin, die "grimme Sohlange" (ijutu zmiju) aus der Stadt Zekar, mit 1hm Samohod Sima, der mit den Vilen Im Gebirge Umgang pelegt, und als Finrer (kalauz) Aleksa Primorac, der zu Wasser und zu Land den richtigen Weg weib und außerdem zwolf Sprachen versteht.- Als alle versammelt sind, setzt aich der Zug mit Nleksa an der Spitze in Bewegung. Ar Meer angelangt, er.. tellt Aleksa den Svaten den Rat, sie sollten, wenn ale nach Venedig kämen, die Pferde abgeben, die Waffen aber behalten, denn die Lateiner seien schlau und zu jedem Betrug fuhig.- Die Svaten gehorchen und behalten, als sie in Venedig angekommen und vom Konig empfangen worden sind, ihre Warfen und setzen sich sogar bewaffiet an die pesttafel. Nach dem Gelage fordert der Kum Marko in seiner Elgenschaft als Brautfuhrer auf, die Braut zu holen, damit sie die Svaten beschenke und ihnen die Hande klisse. Marko geht darauf zum Konig von Venedig und tragt sein Anliegen vor.Der Brautvater beschenkt nun die Gaste mit kostbaren Geschenken (Helmschmuck, Seidentucher, Pferde, Waffen) und fluhrt dem Dever die Braut zu, worauf die Svaten mit dem Mädchen Venedig verlassen und uber das Neer in thre Heimat zuruckkehren. Als der Hochzeitszug das Meer schon uberquert hat, kommen ler Konigin plotzlich Bedenken, ob sie nicht voreilig gehandelt hutten, als sie ihre pochter diesen Leuten mitgaber, von denen sie gar nicht wuBten, ob es sich wirklich un Helden handelte. Sie schiägt deshalb dem König vor, dem Hochzeltszug thren Araber nachzusenden, der, wenn ihm das Gluck hold se1, allein das Madchen zurluckholen k8nne. Er möge das geraubte viudchen behalten, den Elterm jedoch sollen die erbeuteten Geschenke gehbren.-Der Konig läBt den Mohren kommen und legt ihm den Plan dar: Er, der treue Diener von heldenhaftem Geblut, sel dazu ausersehen, mit Hilfe seiner "drel Feuer" 
den Svaten die Braut und die Geschenke wieder abzunehmen und herbelzuschaffen, dann konne er das Madchen behalten.- Der Araber, der auf eine eolche Gelegenhe1t schon lange gewartet hat, willigt ein und macht sich sofort auf den Weg. Er lauert den Svaten in einem Hinterhalt im Wald aue, nachdem er drel Elefantenkbple aufgesetzt und einen Wolfopelz ungehangt hat. Er verlust das Dickicht und labt aus dem Kund Peuer stromen, aus der StIm Donner rolien und aus den Nusterm Regenglisse opruhen, wodurch das Waldgebirge vernebelt wird. Nis die Svaten dies alles sehen, fliehen sie in den Welds nur die Braut und ihr Beschltzer Marko ble1ben zurlick. Als der schreckl1che Araber aue den Dever losgeht und Marko schon fliehen will, beschwort inn die Braut, er moge sie doch nicht dem Mohren aueliefern. Nachdem Marko gehort hat, das es sich nur um den Araber des Konigo handelt,zleht er sein Schwert und schlagt dem Angreifer den Kopp ab. Da sagt der Kopf, wenn er gemut hitte, daB Marko unter den Svaten se1, hatte er den fberfall nicht gewagt.- Das Midchen fordert die Svaten auf, Gott zu danken, denn ohne die Schonheit von Ivo Crnojeric und Markos Heldenmut hitten sie weder das Madchen errungen noch ihren Kopl gerettet.Die Svaten danken Marko fll seine mutige Tat und ziehen dann trommelnd und peeifend mit der Braut zu Ivoe Hofen.

Dieses Lied macht eine ganze Relhe von Bemerkungen notig. Ivo Crnojevic (1456-90), der Braut1gam in unserem Iied, war Herrscher der Zeta und Vasall Venedigs. Wahrscheinlich deshalb lot das Ziel seiner Brautfahrt im Iled die "weibe stadt Venedig" . Der Brautvater wird einmal als "klistenlundischer Ban", dann wleder ale "Konig von Venedig" bezelchnet, womlt allgemein der Prototyp des "lateinischen Herrschers" gemeint 18t, dessen Tochter das beliebte "Objekt" der Brautfahrten In sudslavischen Heldenlledern darstellt. Auch der Gemelnplatz von den betrugerischen Lateinern, der uns schon von Kap.4.11 her bekannt tot, taucht nun wieder auf:

Konje dajte, oruzje ne dajte, Jer su mudra gospoda latinska, Ja 8 e bojim da nas ne prevare, Pod oruzjem pijte 1 jedite.

Interessant lat der Heldenkatalog, in dem Helden aus verschledenen Jahrhunderten anachronistisch gemischt werden, was ein Beweis fur die relativ spate Zusammenstellung sein durfte ${ }^{183}$. An erster stelle stehen dabel die drel bekannten 
Wahlbrider Relja von Budim (sonst auch Relja von Pazar bzw. Relja Bosnjanin genannt), Milos Kobilic (hier noch in der ulteren Namensform, sonst meist in der jungeren Form Ob1116, einer euphemistischen Umbenennung statt Kobilic "Stutensohn") und Marko Kraljevic, das typische jungere Heldentrio, das die Hltere Dreiergmupe Janko-Sekula-Svilojevic abgelöst hat. Kaica Radonja lot eine historisch unbekannte Liedfigur, die dem christlich-vorturkischen Heldenkreis ${ }^{184}$ angehort, in EH 83 aber in turkenfreundlicher Martolosenungebung auftaucht und in Vuk II 80 sich im Gelolge des thrat Brankovic, des historischen Gegners der Hunyadi-Partel, befindet. Sekula und Janko gehbren dem 15.Jh. an, whrend die ubrigen Personen in Var.1 anscheinend Hajdukengestalten des 16. und $17 . \mathrm{Jh}$. sind. Die glteren Helden sind diesen Hajduken und Uskoken hier ebenso selbstverstindlich zugesellt wie Sekula den jungeren Helden in EH 17 und anderswo.

Der Uberfall durch den w h $r$ e $n$ (crni Arapin) ist in unserem lied mit der Habgier der Eltern der Braut und ihrer Besorgnis un das Schicksal der Tochter in der unbekannten Fremde motiviert. Der schwarze Araber wird als "treuer Diener" des Konigs von Venedig bezelchnet,der den Mohren an seine sturkste Waffe, seine drei Peuer, erinnert:

I u tebi tri vatre imaju.

Der schwarze Araber macht sich durch Umhangen eines Wolfsfells (vucje kozuhine) und Aufsetzen von drel Elefantenkopfen (tri filjeve glave) 185 unkenntlich und versetzt in dieser Aufmachung die Svaten in todliches Entretzen:

Iz usta mu sipa zivi oganj.

A iz Cela gromovi puoaju,

A na nos mu ljuta kisa ide,

Zamagli se ona crna gora.

Wie der Mohr diesen bffekt erzlelt, wird nicht gesegt. Das ihm aber "drei Peuer" zur verfugung stehen und er aus dem Mund Peuer lodern lassen und wie Donner grollen kann, das sind typische $D$ r a h e n eigenschaften, die ein geworhnlicher Mensch nicht haben kann. Aus diesem Grund mochte ich olcher annehmen, dab an der Stelle des schwarzen Arabers ur- 
opringlich ein drachenartiges Ungeheuer atand, das im Zuge der Entmythologisierung zu einem Mohren mit drmonischen pranlgkeiten bzw. nur noch maskenartigen Hilfomitteln abgewertet murde. $\mathrm{DaB}$ der schwarze Araber in der sudslavischen Volksdichtung draohenartige zuge aufweist, die gerade in den Hochzeltszugliedern besonders auffallend sind, hat unabhangig von dieser Arbeit A.B. Lord ${ }^{186}$ festgestellt, wenn er sagt: "Another human figure with dragon characteristics in South Slavic tradition is the Black Arab". Auch das aind m.E. typische Drachenelgenschaften, wenn der schwarze Araber in den Liedern vom Typ "Marko Kraljevio 1 Arepin" (Vuk II 65) 81ch an Meer (die Bezlehlir.o des Drachen zum Wasser, vgl. vor allem die Lamja, muB imer wleder betont werden () elnen Turm baut und der Zarenstadt schweren Tribut in Form von Madchenopfern und riesigen Mengen an EBwaren und Wein abverlangt, wenn der achwarze Araber in den Lledern vom Typ "Marko Kraljevió ukida svadbarinu" (Vuk II 68) den Bewohnern des Kosovofelde auferlegt, inn zu ernkhren und inm schwere Helratssteuer zu entrichten, und wenn sohlleblich der schreckliche Mohr in den Bolen Dojzin-Lledern ganz Solun dadurch in Angst und Schrecken versetzt, daB er taglioh ein Madchen fordert. Es hendelt $81 \mathrm{ch}$ also um typische Drachenzage, wie wir sie von der Georgslegende her kennen, wo ein Drache die Wasserquellen einer Stadt besetzt hrlt und nur gegen trgliche Menschenopfer frelgibt.

Der typische D r a h e n k m p $f$ e lst das Heldenkind (hkufig ein Witwensohn), wie wir es in den maz. und bulg. Varianten des hier zu besprechenden Hochzeltszugoujete (Mil. 173 u.a.) Pinden. Wenn in den skr. Varianten melotens Marko als Sleger uber den drachenartigen schwarzen Araber auftritt, so lst er - wie Ubrigens in den meisten anderen Plulen auch sicher erst spater eingesetzt worden und an die Stelle eines vermutlich heldenkindartigen Drachentöters getreten. Vorwegnehmend sel gesagt, dab man m.E. mit gewisser Berechtigung annehmen dare, das hier zu behandelnde Liedoujet habe sioh im maz.-wbulg. Raum in seiner ursprlinglichen Gestalt geformt - worauf die archaischen Zuge dieser Varianten hinwelsen! -, 
1m skr. Raum aber seine breite eploche Ausgestaltung und auch eine weitgehende Entmythologisierung erfahren. Den Iledern, die den tberfall elnes dumonischen schwarzen Arabers auf elnen Hochzeitezug achilderm, liegt vermutlich das Sujet zugrunde, das wir von der griechlechen Mythologle (Perseus und Andromeda, Herakles und Heelone) und der chrletlichen Georgelegende her kennen, daB namlich ein Held eine Jungfrau davor bewahrt, von einem Ungeheuer, dem taglich Menschenopfer gebracht werden mllseen, verschlungen zu werden. In enteprechender Modifizierung let dieses archal ache Kermmotiv vermutlich im maz.-wbulg. Liedraum zu einem Hochze1tezugeujet umgeeteltet worden, whrrend ein eolches Sujet im Griechischen Nachbarraum fehlt. Gefordert murde die Ausbildung dieese (maz.?) Iledsujete viellelcht durch die Volksglaubensvorstellung, das eine Braut bel der Wegelihrung vom Elternbaus und Heimfunrung in das Haus des Briutigams der Macht von Damonen und Gelsterm besondere ausgeeetzt 18t, und diee vor allem an Plububergangen, weil dimonische Wesen (im Iled die Lamja, der schwarze Nraber, die Vila) Gewkseer als Aufenthaltsort beeondere schktzen. W $r$ dieeer o r $n 1$ A a $p$ in ee1, daruber wurden verechledene Meinungen geluBert. Penev ${ }^{187}$ vermutet, es hand10 81ch um den Typ dee im 16.Jh. zur Ze1t der Inquiaition In Theeselonike und Konstentinopel angesiedelten spanischen Mauren.- Diese Anelcht durfte etwas Wahres enthalten auch die Iokalioierung in den Iledern eprkche darur (Solun,Car1grad). Burin ${ }^{188}$ dagegen meint, in dem ochwarzen Araber komme eine viel ultere Gestalt der Volkemythologie zum Ausdruck, die das Bbee symbolisiere. Sohwarz bedeute das B88es auch der Teufel oel schwarz. Der schwarze Araber stelle dae distere Symbol der tlurkischen Unterdrlackung dar, wie oie in den Iledern von der Befrelung der drel Ketten Sklaven aus der Gewalt des Arabere an besten zum Ausdruck komme. It dem turkischen Heer aeten auoh Neger gezogen, die die Phantasie des Volkes beeondere anregten und zum Symbol der turkisohen Peudalgewalt warden. An anderer Stelle ${ }^{189}$ sohrelbt Burin 
sehr richtig. "der Araber lot eine uralte Kraft, ein archa1sches Symbol der Gewalt, das spater mit dem Bild des turkischen Feudalismus in Verbindung gebracht wurde". Ähnlich uuberm sich die Verfesser des "Trem ne bulgarskata narodna eplCeska poezija"190, wenn ale sagen, beim schwarzen Araber durfte es sich keum um eine konkrete Person handeln, sondern er sel die metephorische Verkorperung der türkischen Mecht, der Helfershelfer des turkischen Sultans.

Die Bezelchnung "Arapin" wurde m.E. vielleicht auch deshalb gewahlt, weil "Turein", das glelchzeltig als Ethnikon und als Bezelchnung fur die mohammedanische Religionszugehorigkeit diente, eine Beleidigung flr die zum Islam ubergetretenen olldslavischen Landsleute gewesen ware.

De die Griechen ebenfalls unter turkischer Herrachaft standen, wundert es nicht, daB auch in ihrer Volksdichtung,d.h. allerdings nur im Marchen, der Arápis ('AgánクS), wortlich "Araber", worunter aber wie unter Mohr, lat. Maurus der Heger verstanden wird, als dimonischer Gegner des Helden erscheint. Kretschmer ${ }^{191}$ gibt hierzu interessante Anmerkungen:

Als Unhold, als Verkorpperung des bobsen Prinzips begegnet der Mohr, der Schwarze schon frlhzeitig. Bei den Romern galt die Begegnung mit einem Neger Gbvius Aethiops Plor.IV,7,7) als boses Omen. Vom "Wilden Mann" sagt Hartmann von Aue im Iwein 425: er was eim Môre gelich. Als Versucher an Stelle des Teufels oetzt die mittelalterliche Iegende(..) ofter einen hyBlichen Nohren (Ethyopem teterrimum). Der Arap18 des griechischen Marchens otammt indessen aus dem Orient, zunkchst von den Tlirken, in deren Murchen der Rlesenaraber oder der schwarze Perl dieselbe Rolle spielt; auch der Name 'Afódins = Mohr geht offenbar auf das ebenso betonte und glelchbedeutende tlurkische aráb 'Neger' zurlak. Daraus erklart sich auch das $\pi$ von i jaints fur das zu erwartende $\beta$ ( $\lambda \rho \propto \beta \varepsilon S$ ); denn das turkische Wort wird aráp geoprochen. Auch ruman. aráp, al ban.aráp, oerb.Arapin 'Mohr, Neger' weisen durch Laut und Bedeutung auf turkischen Ursprung. Das bulg. und serb. Marchen kennen gleichfalis den Araber als BOsewicht.

D1e Tliken wieder haben den schwarzen Unhold aus den arab. Merchen Ubernommen, wo er uns als boser Damon in den Erzahlungen aus 1001 Nacht (..) nicht seltien entgegentritt. Wenn der Arápis daneben auch als hilfreicher Geist erscheint (..), so spiegelt 
dies nur die doppelte Rolle wider, die der Neger als dienstfertiger Sklave und als unheimlicher Henker und Soldat im Orient spielte. Drittens tritt der Mohr auch als Huter von Schatzen und als Gespenst, das in Schlossern und alten Gebruden umgeht, im Marrchen auf (..), was Politis,

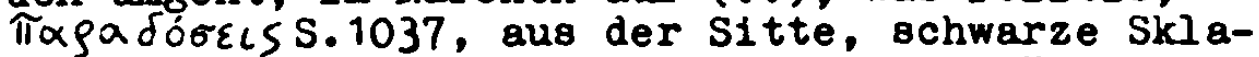
ven als 808 . Bauopfer einzumauern, erklärt.

Dieses aufuhrliche Zitat war m.E. notig, weil es uns die Herkunft der sudslavischen Wortform "Arapin" (mit Betonung auf der zweiten Silbe) aus dem Turkischen erklart und eine eventuelle fruhe tbernahme dieser negativen Gestalt aus dem uárchen ins lied vermuten labt.

$\mathrm{DaB}$ der schwarze Araber im oudslavischen Iied meist eine Substitution des Drachen darstellt, wurde bereits betont und findet vielleicht noch Unterstütung darin, wenn es in Wachsmuths Untersuchungen 192 uber die neugriech. Volkskunde heiBt: "Auch Draken hausen in Brunnen (..). Ebenso erzahlt man $8 i \mathrm{ch}$ von Negern, die dort sich aufhelten urd ofters neben dem Brunnen erblickt werden". Wieder ist der Bezug zum Wasser gegeben. Auch von "unterirdischen Gembchern" ist die Rede, Uber die der Neger verfugt, was gleichermaBen vom Drachen gesagt werden kann. Uber den Brunnen als Eingang zur Unterwelt wird spater noch zu sprechen sein. Ähnlich wie Wachsmuth schreibt Schmidt (Volksleben der Neugriechen, 188):

Die in Brunnen waltenden Ortsgeister werden ge-

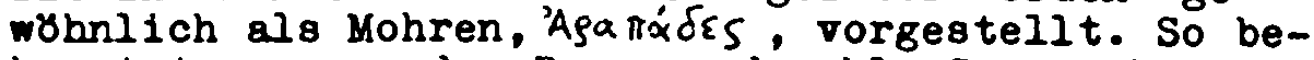
hauptet man von dem Brunnen des hl. Symeon bel dem Dorfe Steiri am Parnasos, daß ihn ein riesengrober, flrchterlicher, menschenfressender Mohr bewohnes derselbe besitzt einen großen Schatz von Thalern, die er huufig, wenn er aus seinem Brunnen hervorkommt, an eine Schnur gereint mit sich funrt, und die Bewohner jenes Dorfes wollen ofters den Larm der auf der Erde fortgeschleiften Geldstucke vernommen haben.

wie dio Lamja im oudelavischen Heldenlied uglert also hier der Mohr als schatzhutender Brunnendämon, wobei.jedoch m.E. eine Drachengestalt in dieser Funktion archaischer anmutet. Arnaudov schildert in seinem Aufsatz "Kukeri 1 Rusali1"(SbNU XXXIV, 30,37,40,58) Kukeri-Maskenzlige, wo zum Teil Leute mit geschwärztem Gesicht als Araber, Mohr auftreten, d.h. es handelt sich hier um eine Nachbildung der dumonischen We- 
sen, vor denen man sich durch diesen Abwehrzauber schlltzen möchte.- Cajkanovic sieht (vgl. seine Aufsatzsammlung "O srpskom vrhovnom bogu", 58-65) den dreiköpfigen schwarzen Araber als eine chthonische Gottheit (ähnlich dem Kerberos oder der Hekate) an, denn die Dreiköpfigkeit sei in der Regel Kennzeichen der Gottheiten der Unterwelt.- Dieser Ansicht möchte ich mich aber nicht anschließen, sondern den meist noch damonischen schwarzen Araber in den sudslavischen

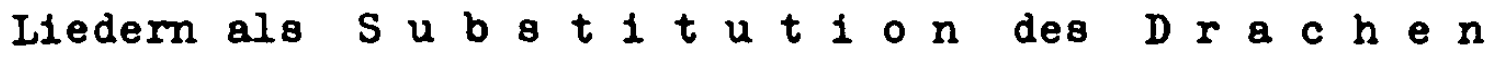
ansehen, eine These, die im Laufe der Arbeit ihre Bestytigung erfahren wird.

Der Mohr unserer Hochzeitszuglieder wird hkueif durch einen mit Namen benannten Helden ersetzt, wobei aber zum Teil dzmonische Eigenschaften beibehalten werden. Namen fur diesen Brautentfuhrer sind BATABAN, BALACKO, BALACKA, BALESA, BALE, BALASIN, BELAVER usw. Hinter Balaban verbirgt sich sicher Sultan Lurads Peldherr gleichen Namens, der bei der Schlacht auf dem Amselfeld eine wichtige Rolle spielte 193 und dadurch wohl zum Prototyp der bösen Macht wurde. Werner ${ }^{194}$ erklart den Namen mit turk. balaban 'stattlicher, groBer Mensch". Bale durfte eine Koseform von Balaban sein. Belaver ist vielleicht dem Bilaver aus Gundulics "Osman" nachgebildet. Balacko möchte P.Popovic (Pregled, 91931,61) von Majer Blaz, dem 1470 emannten Ban von Kroatien, Slavonien, Dalmatien und Bosnien, oder von Balaban ableiten.- Diesen und die anderen Namen will Nodilo" aus "ala, hala" ableiten, so dab Balaban, Balacko usw. direkte Verkörperungen eines Drachenwesens waren. Dieser Ableitungsversuch wurde jedoch schon von Chalanskij 196 als unmoglich verworfen. Ebenso lehnt Chalanskij die Deutung van Ruvarac ${ }^{197}$ ab, der Balacko aus dem Veda-Dbmonen Valas = Vritra-Ahi abzuleiten versucht und die Reihe Balacko- ${ }^{+}$alas-Valas-Vritra-Ahi aufatellt. Beide Herleitungen sind etymologisch unhaltbar. Chalanskij, der mit den beiden Forschern so streng ins Gericht geht, fugt aber selbst einen nicht minder unwahrscheinlichen Erklärungsversuch be1, indem er nämich Balacko mit einer Parallele aus dem Wolfdietrich-Epos, mit Bimrock von Palacker, zu deuten 
versucht, was thm besonders wahrscheinlich erscheint, weil das serbische epische Iled gerade mit diesem Epos auch sonst zahlreiche Gemeinsamkeiten aufweise.

Auffallend 18t die den oben aufgezbhlten Namen gemeinsame erste Silbe BAI-, die vielleicht etymologisch mit dem skr. băljota, bêljast, bal jar 'schwarzkopfig' (bel Ziegen, Rindern usw., vgl. Vuk Rjecnik und im Akademiewörterbuch)verwandt sein könnte und damit etwes Dunkles, Schwarzes bezelchnen wirde. Alban. baloz 'der Schwarze, Drache' 198 durfte zu derselben Wurzel gehoren, moglicherwelse auch ruman. balaur 'Drache, Iindwurm' und bala 'Untier' ${ }^{199}$, von dem skr. blävôr 'Schlange' abgeleitet $18 t^{200}$, das mit griech. $\pi \varepsilon$ in Ung $^{\prime}$ Ungeheuer, Riese' in Verbindung gebracht wird. Tatskchlich finden wir. in der bulg. Volksdichtung (z.B. MI. 158) den mannlichen PN Baljur, eine Verklirzung aus Balaur, also von rumbin. balaur 'Drache' abgeleitet 201 , das wort fur Drache wird also als Eigenname benutzt, was uns ja von dem Beinamen "Zmaf" her nichts Neues lat (wo das Wort "Drache" allerdinge positive Bedeutung hat; nur ein groBer Held wird als Zmaf bezelchnet).- Vuk Karadzic erklart in seinem Rfedn1k 'Balacko vojvoda' kurz und ohne weitere Bemerkungen als "Name eines Riesen, nomen propr." Mareti6 (NNE, 186) bezelchnet Balacko (nach Danicic) als "18tovetan o Balabanom": "Balacko je ime od mila kao i Ivacko, Stojacko". Wie mir Dr. Martin Camaj (Mlnchen) mlindlich mitteilte, mochte er alban. Baloz $1 \mathrm{zl}$ 'der schwarze Baloz', wie er in alban. Volksliedern haufig vorkommt, mit dem maskulinen $P N$ Bale (ahnlich wie ital. Bruno) in Verbindung bringen, denn bale als Adjektiv bedeutet 'schwarz' oder 'mit schwarzen Plecken', z.B. dele bale 'schwarzgeflecktes Schaf' ivgl.auch balbsh 'brandrot' (bei pferden), das in bal-und das Suffix - bsh zu trennen ware; Ghnlich besteht Baloz aus bal- und - $6 z$ (zu dem Suffix -oz vgl. A.Xhuvani und E.Çabej: "Prapashtesat e Gjuhës shqipe, Tiranë 1962, S.79), wobei -oz aue dem Griech. stammt, und zwar aus der Findung des Aorists -wsa, vgl. zioz (z1- und -0z) 'schwarzer Mensch' usw. Baloz ist laut Camaf etymologisch nicht verwandt mit rumern. balaur und okr. bla- 
vor, blavur, blavoruera, blor, bloruea, alban.bole (große Schlange'; zur Btymologie vgl. Jokl,N.: Vulgarlateinlsches im Albanischen, in: ZfRomPh1l XII,1921,S.228-233, wo die latein. Form tbola vorans der ganzen Gruppe zugrunde gelegt wird), könte aber in der Volksvorstellung die Assoziation "groBe Schlange - Dunkles, Unheimliches - schwarzer Baloz" hervorgerufen und so eine volksetymologieche Verbindung geschaplen haben.

Nach diesen m.E. notwendigen Vorbemerkungen nun zurlick zum Variantenvergle1ch. Bel Var.2, die uns leider nur auszugsweise zur Verfugung steht, wird lediglich gesagt, Marko (vermutlich auch hier der Dever) habe den von der Dogengattin dem Hochzeltszug nachgesandten Araber getotet; Briktigam lat in diesem Lied Stevo Ajmanovic.

Der Araber ristet oloh zu dem tberfall, indem er sein Pferd mit einem Barenfell bedeckt, oelbot einen Wolfopelz uberwirlt, sich mit drei Schlangen girtet und dre1 Zmaj-Kopfe aufsetzt.-Marko warnt die Hochze1tsgkste davor, Im Wald laut zu oingen, denn:

Ova gora nigda nije sama,

N1t bez vuka, niti bez hajduka,

N1t bez zmije, zmaja neristoga, woraue Marko von Kilos Kobille als angetlich verspottet wird. Als aber gleioh darauf der schreckliche tberfall des Drachen erfolgt, der Peuer ape1en und Blitz und Donner erzeugen kann, da verteidigt allein Marko die Braut vor dem Araber, whhrend alle anderen fliehen:

Al eto ti 12 gore azdaje. Kako ona 1 juto kurva aiva, Iz kopita vatru kremen krese,

Iz usi ju munje 1 gromovi,

Iz praa joj zelen plamen liza, Iz zuba joj 8 vitrom kiza pada.

Auoh hier sehen wir m.E. wleder deutlich, das die Rolle des urspranglichen leuerapeienden Drachen mit drel schrecklichen Kopfen von dem Araber ubernommen murde, wobel eine real1st1sche Erklarung mit Hilfe der geschilderten furchterregenden Vermummung des Brautraubers versucht wird. Interessant 18t hier auch das Teilmotiv des Umglirtens mit dre1 Schlangen, das uns bel den vila brodarica-Iledern wieder begegnen wird. 
$D a B$ der Arapin hier drei Zmaj-Köpfe aufsetzt, ist der urspringlichen Gestalt des brautraubenden Ungeheuers (wahrscheinlich eines dreikoppigen Drachen) sicher nther, als wenn der Brautentfluhrer aich mit Hilfe dreier Elephantenkopfe (vgl.Var.11) unkenntlich macht. - Var.3 hat folgenden Inhalt:

Sibinjanin Janko freit eln Madchen weit weg in der Stadt Bozun, libergibt seine Verlobungsgeochenke und vereinbart flur den Hochzeitstermin eine Monatafriat, um Svaten sammeln zu können. Der Brautvater warnt Janko vor dem dreikbpfigen Araber, der an der Grenze zwischen dem tilrkischen und dem arabischen Land sein Unwesen tre1be und das Madchen zu rauben versuchen werde. Der Araber sel ein Drache (azdaja) und besitze drel Kopfe, wie die leute erzbhlen. Aus elnem blase er Wirbelwind, aus dem zweiten blaue Flammen und aus dem dritten schlieslich ertone seine Stimme.- Janko ist sehr niedergeschlagen angesichts dieser Gefahr. Als er nach Hause kommt und von seiner Mutter empeengen wird, berichtet er von dem dreikopfigen Araber, der die Wege und Furten besetzt halte, Schktze wegnehme und Mudchen raube. Als die Mutter dies hort, rat sie Janko, auf alle Falle Marko aus Prilep einzuladen, fermer Relja Boßnjanin aus Pazar, den Vojvoden Milos aus Prizren, Milan Toplica aus Toplik und Ijutica Bogdan aus Ungarn, weil er mit Hilfe dieser Helden den Araber besiegen konne. Janko schrelbt darauf Relja einen Brief, in dem er ihn von der bevoratehenden Hochzelt in Kenntniseetzt und uber den schwarzen Araber berichtet, der an der turkisch-arabiachen Grenze Furten und Wege sperre. Deshalb sel er, der tapfere Held Relja, als erater Svate berufen.-Janko ladt ferner Milos als Anfuhrer des Zuges, Milan als Bannertrager, Ljutica Bogdan als Kum und Marko Kraljevic als Brautfunrer ein. Kaum hat er die Briefe abgesandt, als sich auch schon von allen Se1ten Staubwolken zelgen und die Ankunft der Giste anklindigen. Marko entschuldigt sich, daß er seinen Neffen Banovic Sekula mitgebracht habe, doch der Jungo Held solle dus slcher sehr ocheue Mudchen fluhren, das alch vor einem "alten Helden" vielleicht geniere. Er, Marko, werde dafur die Verteidigung der Braut lbernehmen.- Sie ziehen nach Bozun zum Hof der Braut, und Sekula nimmt das Madchen in Emplang. Dann folgt die reiche Beschenkung der Gaste (Helmschmuck, sil berne Brustplatten usw.). Danach ziehen die Svaten frohlich mit husikbegleitung ab. Sie reisen drei Tage, bis ole zur Grenze gelangen, wo der dreikbpfige Araber 
mit selner geschmlickten Stute Wache hält und dabei Wein trinkt. Als der Hochzeitszug herankommt, fordert der Araber die Helden der Reihe nach zum Zwelkampf oder Ablieferm der Geschenke auf, worauf die Svaten die zweite Moglichkeit vorziehen und anschließend fliehen. Sekula ergreift erst dann die Flucht, als sein Oheim Marko ihn dazu auffordert. Marko bleibt schlieBlich allein be 1 der Braut zurlick und labt den Araber mit seinen dre1 schwarzen Kopfen, blutunterlaufenen Augen und gefletschten Zuhnen auf sich zukommen. Das Mädchen flustert dem Dever zu, das Schwert, das ihr Vater thm geschenkt habe, konne Helm und Panzer des Gegners durchtrennen. Durch diese Worte ermutigt, erbffnet Marko den Kampl, indem er den Araber provoziert. Der Araber schleudert seine int 300 Schellen geschmllckte Lanze, doch Marko und sein Pferd schrecken nicht davor zurlick. Whinrend der Schecke in die Knie geht, fungt der Held die Waffe auf und zerbrioht sie. Als Marko seine Ienze schleudert, packt der Araber sie in der luft und bricht sie auseinander. Um Marko einzuschlichtern, blust er anschließend wind und sprunt Feuer aus seinen K8pfen. Doch der Zweikampl geht weiter. Der Kampl mit der Keule verlauft unentschieden, doch beim Kampl mit dem Schwert gelingt es Marko, seinem Gegner alle drei Kople abzuhauen. Nun, da der Araber tot 18t, ruft Marko die Peigen Sraten einzeln zurluck. Es dauert drel Tage, bis alle vollzkinlig versammelt aind und aus Markos Hand beschamt ihre Geschenke wieder in Emplang nehmen. Mit den zahllosen Schatzen des Arabers kehrt der Hochzeitszug nach Sibinj zurlick, wo die Hochzeit otattindet.

In dieser Variante lst der Bräutigam schon vorher von dem Brautvater vor dem schwarzen Araber gewarnt worden und kann daher bewubt die berlhmtesten und besten Helden als Svaten einladen. AufschluBreich lat wieder die Verbindung des drachenartigen Arabers mit dem Wasser: er sperrt nämich die Furten (bogazi, okele), d.h. er bewacht FluBläufe und labt die Hochzeitszlige nicht passieren. Er ist wieder dreiköpeig und verfugt uber furchtbare Abschrechungemittel, die er allerdings nicht gegen die Svaten in der Masse, sondern allein gegen Marko einsetzt: "vjetar otisnuo", "vjetar izdusio", "plamen otianuo", "oganj 1zdusio". Was seine Drachennatur betrifft, sagt der Brautvater uber den schwarzen Araber (und wiederholt danit ein Gerlucht, das er von den Leuten gehrrt hat ): 
Azdaja je, pak tri ima glave, Kažu l judi, vidio ni jesam, Iz jedne mu vihor vjetar puse, A iz druge maven plamen lize, A treća mu progovara glava.

Von einer Maskierung des Arabers lat hier keine Rede, d.h. fur seine Dreik8ppigkeit murde keine rationale Erklarung (Aufsetzen dreier kyple) versucht. Der Mohr wird in diesem Lied auch nicht von den Eltern der Braut ausgesandt, um das Madchen und die Geschenke zurluckzuholen, sonderm er lat ein Madchenrauber aus eigenem Antrieb. Diese Form ist wahrscheinlich ulter als die andere Verion, wo der Mohr im Auftrag der Brauteltern handelt. Die archaischeren maz. Varianten werden dies bestatigen.- Mit Bozun grad 1st mbglicherweise Pozun, PreBburg gemeint. Der Heldenkatalog ist hier ghnlich anachronistisch wie in EH 188. Interessanterweise tritt Marko in Var.3 mit oeinem Neffen Sekula auf. Es handelt sioh um das beliebte Oheim-Neffen-Paar, wobel Marko sicher Janko aus der Oheim-Rolle verdrangt hat. Var.4 ist bel MH I, $I_{1} 58$ lediglich in sehr geraffer Form vermerkts

Vojroda Janko freit beim Dogen von Venedig (od onoga duzda mletađkoga) das Müdchen "Misirkinju Janju" und erhult eine Zusage. Daraufhin bestimmt der Brautigam Kral jeric Marko zum ereten Kum, M1lo8 Obilic zum zweiten Kum und "mall Radojca" zum Dever. Sekula "nebak" aber wird nicht eingeladen. Als die Sraten das Mudchen weggefuhrt haben, ruft der Doge von Venedig seinen Diener Mllaver, dem er das Madchen als Braut verspricht, wenn er es zurlickholen konne. Milaver setzt nun neun Elephantenkrple auf:

Mece na se devet Cudnih glava, Ama devet vilovikijeh glava,

lauert den Svaten auf und laBt aus dem Mund Wind, aus den Nasenlochern Flammen und aus den Augen Blitze entweichen:

Iz usta mu plaovit vjetar puse,

Iz nozdrva modar plamen $118 \mathrm{~s}$,

Iz odiju munje sijevaju.

Sekula uberrennt diesen schrecklichen Angreifer zu Pferd und schlkgt inm furchtlos die neun Köpfe ab.

In dieser Variante erschlaggt nicht der Dever den neunkoppi- 
gen, feuerspeienden Angreffer, sondern der ungeladene Neffe (wessen?) Sekwla, der helmlich mit den Sraten gezogen ist, beweist hier seinen Heldenmut, indem or den Anschlag auf den Hochzeltezug vereitelt. DaB Sekula, ohne eingeladen zu sein, den Svaten folgt, lat natirlich ein aus den 4.11-I1edern ubernommener Zug, der dem 4.21-Sujet elgentlich nicht entspricht. Der im Auftrag des Brautvaters handelnde Diener setzt sich hier neun Kopfe (die endere, neben der Dreizahl beliebte Version der Mehrkopfigke1t, vgl. die Lamja-Ileder) auf, d.h. es handelt sich hier - in Zelchen der fortschre1tenden Rationalialerung - wieder nur um eine Maskierung, whrend in den ursprlinglicheren, noch starker in Mythologiochen verhafteten Liedern ein wirklich mehrkoplig gedachter schwarzer Araber bzw. sogar Drache auftritt.- Die Ungereimtheit, dab Janja von Misir (= ̈̈gypten) in der vorliegonden Variante die Tochter des Dogen von Venedig sein soll, laBt sich wahrscheinlich daher erklaren, das der sanger anscheinend bellebige (typlache) Namen, die ihm aus Hochzeltezugliedern gellueig waren, elngesetzt hat. - In der aus derselben Gegend stammenden, nur zum Tell erwhinten Var. 5 hat der schwarze Araber noch ausepragte Draohenzliges Er erhebt sich auf riesigen Plugeln, sffnet seine schrecklichen Kiefer, wobel der oberkiefer in die Wolken ragt und der Unterkiefer auf der Erde schleift, etreckt zwrlf zungen heraus und labt aus der Brust Blitze fahren, worauf s1ch der bisher hel tere Himel bewrikt:

$$
\begin{aligned}
& \text { On se dize na velika krila, } \\
& \text { On rasklopi a evoje zeljustis } \\
& \text { Gorna Keljust ode u oblake, } \\
& \text { A dolna se bas po zemlj1 vude. } \\
& \text { I 1eplaz1 dranaest jezika, } \\
& \text { Od praa mu el jeraju munje, } \\
& \text { Bilo redro, pak oe naobladi. }
\end{aligned}
$$

Uber die Zusammensetzung des Hoohreitszuge und die Umstrinde der Brautfahrt erfuhrt man in dieser kurzen Angabe leider nichts. - Der Inhalt von Var. 6 mit dem Titel "Yenidba Ivana Crnojerica" lautets

Cmojerie Iro freit im fernen Venedig Ruzica, die Tochter des Dogen, und vereinbart eine zweiwochige 
Priet zum Sammeln der Svaten. Der Brautvater rat ihm, nur wenige und vor allem keine jungen Svaten einzuladen, weil die besonders streitallchtig seien. Doch auf inraten seiner Mutter hin lidt Ivo Sibinjanin Janko als Kum, Konig Vukarin als obersten Svaten, Kraljevic Marko als Brautfuhrer, Milos obilid als Anfunrer, die beiden KosanCiC1 als Spaßmacher und Relja von Pazar als Bannertrkger sowle alle angesehenen Helden, die er noch erreichen kann.- Als alch die Svaten Venedig nkhern, gibt Vukasin die Anweisung, alle Tellnehmer des Zuges sollten sioh in Zweierreinen aufstellen, laut singen sowie die streitkolben in die luft werfen und wieder auffangen, damit die schlauen Lateiner staunen konnten (nek se Cudi mudra Lat1n1 ja). Als der Doge den Zug kommen sieht, argert er sich uber die Mibachtung seiner Anweloungen und beschliest, dem Brtutigam nicht Ruzica, sonderm eine Sklavin zu ubergeben. Marko rat inzw1sohen den Svaten, die Pferde herzugeben, die Waffen aber zu behalten:

Konje dajte, oruzja ne dajte.

Als elch der Doge Hber das Verhalten seiner Giste wundert, erklkit Janko, bel den Serben se1 es Sitte, bewafinet zu trinken und zu schlafen. Denn zwingt Marko den Dogen mit gezlucktem Schwert, Ruzica unverzllglich herbeizufuhren. Dies geschieht, und die Svaten ziehen ab, nachdem sie auch noch Geschenke erhalten haben. Kaum sind sie auBer Sicht, da IBBt der Doge einen Helden suchen, der thm die Tochter zurluckhole; gelinge dies, so erhalte der Held nicht nur zahlreiche Schktze, sondern gewinne auch das Madchen als Braut. Es meldet $81 \mathrm{ch}$ allein der drelkbplige Araber, der sofort loszleht und die Svaten einholt. Um den Hochzeltezug zu erschrekken, sprint der Mohr aus einem Kope blaue Flammen, blist aus dem anderen kalten wind und labt aus dem dritten seine Stimme ertbren. Die Svaten pliehen, und Marko bleibt mit dem kadchen allein zurluck. Der Dever zllckt zwar sein Schwert, zittert aber vor Furcht, weil er denkt, es handle sich un einen Meeresdrachen. Ruzica klüt den Helden auf, das der Angreifer lediglich ein Diener ihres Vaters sei. worauf Marko dem Mohren sofort zwel Kople abtrennt. Der dritte Kopf fleht um Gnade, doch Marko ochlagt auch thn ab. Darauf muft der mutige Dever die Svaten zurick und sammelt sie, doch er "sammelt" sie mit seiner Keule; jeden Svaten "zuhlt" (d.h.echlagt) er einmal, seinen Vater Vukasin aber zwe1- und dreimal. Das Madchen meint, es sel allein Iv0s Schonheit und Harkos Heldenmut zu verdanken, daB sie, die Braut, noch bel den Svaten sei.-Der Hochzeitszug kehrt nach Senj zurluck, wo die grobe Feler 
etettrindet.- Die Ehe wird mit zwel Tochtern und vier Sohnen gesegnet.

Hier lot der Brüutigam wieder einmal Ivan Crnojevib, der jedoch falschlich in Sonj (und nicht in Zabljak oder Cetinje) lokalisiert wird, was wohl auf elner Verwechslung mit Senjanin Ivan beruht. Auch hier finden olch wieder die Pormeln von den echlauen Lateinern und von der Welgerung, die Warfen abzulegen, otereotype Wendungen, die offensichtlich aus dem 4.11-Sujet stammen und zu Wandergut geworden sind. Ein Hinwele auf die angenommene ureprlingliche Drachennatur des Brauträubers ist wohl darin zu sehen, das Marko den dreiköpligen Araber zunkchet flur einen Meeresdraohen halt: Jer mifijase, moraka je azdaha.

Durch die Erklarung der Braut, es handle sich nur um einen Diener Ihres Vaters, wird das Motiv entmythologisiert. Zum erstenmal taucht hier des Motiv der Bestrafung der felgen Svaten durch den mutigen Dever auf, das wir in den maz.und bulg. Varianten noch mehrmale antreffen werden. - Die um das Motiv des Vilenschusses erwelterte Var.7 hat folgenden Inhalts

Milin "mlado mombe" Preit die Tochter des Dogen von Venedig (duzd Mecenin). Dever 1ot Kral jev16 Marko, Kum Sibinjanin Janko, Beletand (prvijenac) Vuk Brankovib, zweiter Kum Relja Bornjanin, oboroter Svate Milos obilic und Brautbegleiterin (jena) eine Bohwarze Nebelkrähe (crna vranetina). Unterwego im Velebit-Gebirge uben die Svaten Sprung und Stelnwure, wobel der Brelutigam $81 \mathrm{ch}$ als der beste Kampler ermelot. Dies beobachten die vilen und wandern sich, das uilin oogar Ihren Wahlbruder Marko Ubertreffen konnte. Da bietet die oberete V1la derjenigen, die Milin zur Strafo erschieBe, die Halfte ihres "staresinstvo" (Äl testenwlurde, hochoter Rang) an. Den anderen Vilen aber tut il $_{-}$ In leid; or sel auBerdem der einzige Sohn oeiner Mutter, die bel Miline Tod ganz allein blelbe. Da schie日t die oberste Vila selbst einen Prell ab und trifft Niln, 80 das diesem der Stein aus der Hand falit und or zu selnem Onkel, dom alten Radoolar sagt, etwas spitzes habe ihn ins Herz getrolPen; es gehe zu Ende mit 1hm. Der Onkel melnt aufmunternd, Milin habe sich nur uber irgend etwas aufgeregt oder sel viellelcht erschrocken. Er, der Onkel, werde bel der Hochze1t rir $1 \mathrm{hn}$ die Gleser leeren, wenn Milin nicht lmotande sel gu felerm.- 
Die Svaten holen die Braut in Venedig ab und fuhren ole zu einem Kloster, wo die Trauung etattfindet. Beim Abschied von den Sohwlegereltern sagt Milin, der weis, das die Vila ihn t8dlich getroffen hat, zu der Brautmutter, sie werde inm wohl flur immer Lebewohl sagen mussen. Da zischt die Prau wie eine Schlange auf und verflucht ihren Gatten, der die Tochter einem elenden Unbekannten zur Frau gegeben habe.Als der Hochzeltszug abgezogen 18t, muft der Doge seinen Diener Belaver und befiehlt ihm, zwel Luchs- und zwel Barenfelle luberzuziehen und den Kopf eines feurigen Drachen (glavu zmaja ognjenoga) aufzusetzen. In dieser Vermummung solie er auf seinem Braunen losreiten, den Svaten an einer Kreuzung auflauern, mit den Zahnen knirschen, dab es blitze, und aus dem Kopf Donner rollen lassen. Gelinge es thm, das wadchen zurickzuholen, erhalte er eine ganze Last Schatze.- Der Diener fuhrt alles aus, was der Doge ihm befohlen hat, und jagt die Svaten in die plucht. Nur Marko bleibt bel dem Mudchen, totet Belaver, ruft die Svaten zurack und entsendet zwel Pajken, die die Vj.la herholen sol.len, damit Milin von ihr geheilt werde. Als die vila gefangen und hergebracht 18t, schlagt Marko ale mit seiner Keule und befiehlt ihr, Heilkriuter fir den von ihr getroffenen Brkutigam zu sammeln. Die Vila heilt Milin und verflucht alle Schmiede, die gefiederte Keulen herstellen und sie solchen Narren (budalinam), wie Marko einer sel, in die Hand geben und so zulassen, dab damit "girote" im Gebirge geschlagen werden.

In dieser kontaminierten Variante ist des Motiv des Vilenschusses und der erzmungenen Heilung des Getroffenen naturlioh sekundur von den Iledern Ubernommen worden, wo Markos Wahlbruder wegen seines Singens im Waldgebirge von der Vila erschossen und auf Markos Drohungen hin wiederbelebt wird.Der urapringliche Drache ist hier zu einem nur noch drachenuhnlich verkleideten Diener des Brautvaters entmythologisiert worden. - Der Inhalt des nuchsten Liedes, der weitschweifigen Var.8, lautet folgendermaßen:

Der Ban von Ledan wirbt weit entfernt-in der weiBen Stadt Janok um Ijubica, die Tochter des Bans von Janok, teilt reichlich Geschenke aus und erhalt schlieBlich eine Zusage. Binnen Jahresprist soll der Briutigam Svaten sammeln, und zwar 300 an der Zahl. Preudig gestimmt macht sich der Ban von Letan auf den Heimweg. Auf dem Feld vor Krubevo erblickt er 300 Araber mit dem dreik8peigen 
Anfuhrer an der Spitze. Ein junger Serbe (erpsko momce mlado) gibt dem Ban Auskunft daruber, wie der Araber mit seinen Leuten plotzlioh aufgetaucht sel und nun von der Rajah sohweren Tribut forderes jeden Tag eine Kub, elnen Ofen voll Brot, ein $\mathrm{FaB}$ WeIn sowie ein Mrdchen, das inn bedienen wlisse und das er nach einer Ilebesnacht wieder den El tern zurlioksende. Auberdem berichtet der Junge, dem Araber sei zu Ohren gekommen, das der Ban von Ledan helrate, und er habe beschiossen, den Hoohzeitszug zu Uberfallen und das Midchen samt den Geschenken ou rauben. Nach dieser Meldung otrkuben sich dem Ban die Heare vor Angst. Br entlohnt den Jungen und w1ll weiterziehen, doch der Araber hat thn echon erblickt und ruft, allein durfe der Ban dieses Mal voruberziehen, schwerer werde er es aber haben, wenn er mit den Svaten und der Braut vorbelwolle.- Zu Hause berichtet der Ban oeiner Nutter von dem Unhell, das thm drohe, und wagt volle drel Jahre nicht, Svaten zu sammeln und das ifdchen abzuholen. SchileBlich trifft eln Brief von eeinem kinftigen Schwiegervater ein, in dem der Brăutigam aufgefordert wird, das Madchen entweder abzuholen oder frelzugeben. Daraue antwortet der Ban nit einem Brief, in dem er erklart, das or aus Angst vor der grimmen Schlange, dem dreikópligen Araber (l juta guja troglar Arapine). das Madchen bisher nioht abgeholt habe. Der Brautvater schrelbt daraue, der Brautigam 80lle olch nicht unnotig oorgen, sondern mit erprobten Helden losziehen, dann werde ihm nichte zustoBen.Er solle Marko von Prilep zum ersten Svaten und Relja Bosnjanin zum Kum ernennen. Die belden wlirden den Araber sicher t8ten.- Der Ban von Lelan schlckt num einen Brief an Marko und einen zweiten an Rel ja und erhalt von Marko die Nachricht, er konne aus Anget vor dem Araber nur dann am Hochzeltszug telinehmen, wenn der junge Held "dijete" Grujlca, der Sohn des Starina Novak, zum Dever berufen werde. Der Brautigam schlckt darauf einen Falken mit einem Brief zu Novak und bittet um dessen Sohn als Brautruhrer. Grujioa wird heimgeholt. Er zieht Festkleider und darliber einen Panzer an und otelgt ouf sein SchlachtroB. Der Vater erteilt ihm noch Ratschlage, ermahnt inn zu ritterlichem Benehmen und warnt inn vor dem Araber, dem gegenuber er die Braut unter allen Umstanden verteldigen musse.Grujica zieht 108. Wohin er kommt, strahlt der Weg und 18t das Waldgebirge heiter. Er wird Uberall bestaunt und beschenkt unterwegs die Armen. Findlich gelangt er nach Ledan, wo er von der Gattín des Bans erfahren muB, daB die Svaten schon am Morgen losgezogen selen. Er mbge lhnen, so rasch er kbnne, folgen. Grujica macht sich auf den Weg und 
trifft aue dem Peld von Krubevo einen Burschen und ein Madchen, die thm weinend erzahlen, oie seien Geschwister und der Bruder mllsse gerade die Schwester dem Araber als Tribut zufunren.Grujica verhindert dies und st8Bt daraup mit dem Araber zusammen, der ihn vor weiteren Mutproben warnt und droht, er werde beim Vorbeiziehen des Hochzeitszugs "Kraft" aus seinen Kopfen stromen lassen (pustio bih ollu iz tri glave). Grujica reitet verargert nach Janok, wo er herzlich emplangen wird. Nach dreitugigem Peiern werden den Gasten Geschenke sowie die Braut Ubergeben, worauf sich der Hochzeltszug, von dem Brautvater nochmals eindringlich vor dem Araber gewarnt, auf den Heimweg macht. Kurz vor dem Peld von Kruaevo mahnt Marko die larmenden und singenden Svaten, sie sollten besser zu singen aufhören und auf Seitenwegen weiterziehen, um BlutvergleBen zu vermeiden. Relja ist aus Angst vor Spott und Schande dagegen und meint, wann habe man je gehort, das a1ch 300 Helden vor einer gleichen Zahl Gegner geflrchtet hatten. Grujo fragt nun, wer gegen wen kämpfen solle, worauf Marko vorschlagt, er selbst werde zusammen mit Relja gegen die 300 Araber antreten, whhrend Grujica die Braut vor dem dreik8pfigen Anfuhrer beschutzen solle. Nls der Brautzug auf das Krusevo-Peld kommt, sitzt da der Araber mit seinen Leuten. Er fordert von den Svaten die in Janok erhaltenen Geschenke und bekommt sie widerstandslos. Auf das Plehen der Braut hin schlagt Grujica dem Araber zwei seiner Kopfe ab, worauf der Mohr aus dem dritten Peuer sprint (oganj popustio) und Grujica Verbrennungen erleidet. AnschlieBend klmpfen Grujlca und der Mohr zwel Stunden lang unentachieden miteinander, beiBen sich gegenseitig mit "Wolfszahnen" und ver wunden einander. Grujica flult plotzlich seine Krafte schwinden und ruft Marko und Relja zu Hilfe. Die beiden Helden aber kamplen mit den 300 Arabern und hören thn nicht, whihrend die anderen Svaten elle geflohen aind. Da fordert Grujica die Braut auf, seinen Handzar aus dem Gurtel zu ziehen und sich fur einen der beiden Kumpeenden zu entscheiden, worauf das Madchen mit der Waffe auf den Mohren einsticht. Grujica kommt auf diese Weise loo und oohlagt ooinom Gegnor den dritton Kopl ub. Marko und Relja haben inzwiachen die 300 Araber niedergemetzelt. Die Braut versorgt die Vermundeten. Dann kehrt der Hochzeitszug heim, wo eine einwochige Peier stattindet.

Von der Stadt Lelan wird in Kap.4.3 die Rede sein. Hinter Janok vermutet man die ungarische stadt Gyór (Ráb). Das Peld von Krugevo (womit das maz. Krušovo oder das serb.Kru- 
Sevac gemeint sein k8nnen) steht hier wahrscheinlich statt des Kosovofelds, das sonst den mehr oder weniger stereotypen Schauplatz fur kample mit Turken und Arabern abgibt. Die vorliegende Variante ist durch Kontaminationen ziemlich stark erweitert und scheint relativ jung zu sein, weil in ihr Lieder wie "Marko und der Araber"(vgl. unsere Variante ab Vers 42), "Bolen Dojein" ( $v g l$. hier ab Vers 336) und Banovié Strahinja" ( $v$ gl. hier ab Vers 539) episodenhaft verwendet bzw. in modifizierter Form verarbeitet sind. Der schwarze Araber erscheint hier noch als wirklich dreiköpfiger (und nicht nur vermumeter) Mohr mit drachenahnlichen Eigenschaften: Er kann aus seinen drei Koplen Peuer sprinen, er zwingt die Bewohner des Krusevo-Feldes zu schweren Tributleistungen (vor allem Madchenopferl) usw. Der als Brautbeschutzer fungierende Grujica hat in diesem Iled heldenkindartige zuge. Var.9 18t das Lied Milut.72, von dem Soerensen 202 zu Unrecht gesagt hat, es handle sich um "nichts weiter als eine wirre Zusammenhăufung bekannter Namen alter und neuer Llederdichtung". Der Inhalt 1st folgender:

Novak und sein Sohn Gruica trinken Wein. Da beklagt sich Gruica, daB er schon seit geraumer Zeit weder einen der Helden aus Srem noch Marko Kraljević gesehen habe. Novak erkiärt seinem Sohn, der Konig von Ledan hate die Tochter des Konigs von Furdija gefreit und eine Zusage erhalten. Nach seiner Rlickkehr nach Letan habe der Brkutigam aus Angst vor den den Hochzeitszug bedrohenden Arabern folgende serbische Helden zu sich gerufen: Relja, Miloz, Marko aug Prilep, Musié Stevan, Ivan Kosan¿ic, Mitar und Śépan Jakzić, Milan Toplica, die Brider Mijzo und Śépan Volnovié, Vuk aus Srem 80wie Janko aus Sibinj und Sekula und noch 1000 andere Svaten. Gruica brauche also nur nach Letan zu gehen, dort werde er alle namhaften Helden versammelt finden.- Novak hilft seinem Sohn beim Ankle1den und fuhrt ihm dann seinen Rotfuchs aus dem Stall. Er ermahnt Gruica, unterwegs weder auf das Rufen noch Winken der turkischen Madchen von Sarajevo zu achten, sondern ohne Anhalten durch Bosnien zu reiten und Uber Banja Iuka und Split in die "vlabke Kotare" zu ziehen, wo er Novaks Wahlbruder Bijelić Jovan aufsuchen und sich von thm nach Ledan fuhren lassen solle.- Grutca befolgt die Anweisungen seines Vaters und gelangt zu Jovans Hof, wo er aber von der Gattin erfahren muß, daB Jovan von 
dem Konig von Duralja gefangen genommen worden sel, und zwar schon vor drei Jahren. Grulca mbge also jetzt, da er an den Hol des Konigs komme, Jovan von seiner Gattin grluben und inm bestelien, das sie $1 \mathrm{hm}$ in seiner Abwesenheit Zwillinge geboren habe, und fragen, ob ale den verwaisten Hof verkaufen oolle.-Grutca schlieBt mit Jovano Prau Gevatterschaft, blelbt uber Nacht und reitet am nacheten Morgen nach Ledan, wo or $81 \mathrm{ch}$ nach den Svaten erkundigt und erfihrt, das diese schon seit einem halben Jahr in puralja weilten und noch immer nicht gurlickgekhrt seion. Gruica erbittet sich elnen Fuhrer und gelangt uber "Lecka und Poljacka", durch "Turska und Kaurska" an die Sitnioa, wo er eine vergoldete Kutsohe mit einem nackten Lateiner (Latince) darin antrifft, der inm erzbhlt, or habe einen Brief der zwolf in Duralja gebliebenen Vojvoden zu befordern. Er meint, Gruica werde den PluB nicht uberqueren konnen, we1l an anderen Ufer 1000 Araber lagerten: Grulca konne ja sehen, wie sie ihn, den Lateiner, behandelt hatten.-whinrend der junge Held noch uberlegt, was zu tun sei, lauft inm angesichte der drohenden Gefahr sein Finrer davon. Gruica reitet also allein zum $P I u B$, uberquert ihn und bahnt sich einen Weg durch die arabische tbermacht, Indem er 100 Araber mit dem Schwert totet. Er reitet weiter Richtung ourdija, wo er schon von weitem von den zwole Vojvoden erblickt wird, die sich darluber mundern, wie der Held trotz der 1000 Araber nach puralja gelangen konnte. Grulca stellt sich als Novaks Sohn vor und erzkhlt von seinem Durchbruch durch die Reihen der Araber.Als er erkikrt, or wolle Jovan befreien, will thm Marko davon abraten, denn der Konig von pural ja verfuge uber 1000 Kanonen und 100000 Soldaten. Mit Hilfe elner List gelingt Gruloa aber doch die BePrelung des Gelangenen. Durch diesen Vorfall umgestimmt, labt der Konis Geschenke verteilen, die Braut, seine Tochter, herbelfuhren und den Svaten Ubergeben. Der Brautzug verlabt num endlich puralja und macht sich auf den Heimweg nach Letan. Als die Svaten an die Sitnica kommen, stehen ihnen 3000 Araber, angefuhrt von dem dreikopelgen Araber (troglar Harapin), gegenuber. Der Dreikopeige spraht aus einem Kopf Peuer, blkst aus dem zweiten Wind und laBt aus dem dritten oolno stimme ortonon. M1t Markos Pferd und Schwert ausgerlstet ellt Gruioa auf das Ungeheuer zu und schilgt zwel seiner Kopfe ab und, als der Araber um Gnade fleht, auch noch den dritten. Marko ruft die Svaten zusammen und bricht mit ihnen durch die Reihen der Peinde, von denen 1000 getstet werden. Der Hochzeitszug erreicht glucklich Letan, wo dem Kontg geine Braut ubergeben wird. Grusca ist witend auf den Briutigam, der die Svaten verräterisch in so grobe Go- 
fanren brachte, und will inm den Kopf abschlagen. Der Konig beschwichtigt aber Gruica und die librigen Svaten und beschenkt sie mit drei Lasten Schutzen, die die Vojvoden unter alch aufteilen, wobei sie aber Gruica den Vorrang einruumen ( 1 Gruici dare staresinstro). Gmuica begleitet anschliebend Jovan nach Hause und muß sich dann durch drei von Aga Sarajlija aufgestellte Wachmannschaften den Weg zum heimischen Romanija-Gebirge freikumplen, wo ihn sein Vater schon ungeduldig erwartet.

Bei dieser Variante fält, was den Handlungsaufbau betrifft, eine gewisse Ähnlichkeit zum vorhergehenden lied auf. Wieder spielt der konig von Letan die Rolle des Brautigams und wieder lat Gruica der Hauptheld des Geschehens, der sich durch besonders mutiges Vorgehen auszelchnet und vor allem den drachenartigen dreikopfigen Araber totet. Auch in dieser Variante trifft Gruica schon auf dem Hinweg zur Braut mit dem Mohren zusammen, whihrend der Entscheidungskampe und der Sieg Uber den dreiköpligen Araber in beiden liedern erst auf dem Rluckweg stattinden. Die Episoden des Besuchs bei Jovans Gattin und der Befreiung des in Duraija gefangenen Jovan sowie des Kamplo mit den Leuten des Aga sind naturlich erst sekundăr in dieses relativ junge lied (vgl. die anachronistische Heldenlistel) eingefugt worden. Dals der Mohr hier wieder dreikopfig vorgestellt wird, Feuer sprihen kann und sich außerdem an einem Gewasser (hier der past als stereotyp zu bezeichnenden Sitnica) aufhult, sind sichere Hinweise auf seine ehemalige Drachennatur. Das Motiv, dab Gruica mit Markos Pferd und Schwert den Araber besiegt, erinnert an die 4.13-Iieder, wo das Heldenkind Grujo mit Hilfe von Markos, seines Oheims, peerd (manchmal auch Pferd und Schwert) die Meereslamja uberwaltigt. Daß in der vorliegenden Variante der Brautigam als Betruger dargestellt wird, lakt sich daraus erkluren, dab der sanger mehr oder weniger gedankenlos die (negative) Pigur des Koniga von Ledan eingesetzt hat, der sonst in Hochzeltazugliedern die Rolle des betrugerischen Brautvaters zu opielen hat, der die Svaten haufig durch seinen Diener (Araber) uberfalien labt. Interessant sind die beiden von Grulca unternommenen Reisen, deren Routen Aufschluß uber die mangeln- 
den geographischen Kenntnisse bzw. Willklur des spaten Săngers geben. So reitet Gruica einmal vom Romanija-Gebirge bei Sarajevo im Dreieck Uber Banja Iuka nach Split und weiter zu den "vlakke Kotare", wo aich Jovans Hof befindet. Mit diesen "vlaski Kotari" ist das Hinterland von Zadar mit seiner orthodoxen ("vlaski") und katholischen Mischbevolkerung gemeint. Von dort aus reist Gruica weiter nach Ledan, das der Sanger vielleicht als im Kustenland lokalisiert gedacht hat, weil auffallenderwelse zwischen Jovans Hof in ger Nahe von Zadar und der sagenhaften Stadt Ledan keine Zwischenstationen mehr angegeben werden. Die Route der zweiten Reise Gruicas dagegen verwelst flr die Lokalisierung Ledans eher in den polnischen Raum (was gut zu unserer These in Kap.4.3 passen whrde!), denn der Held reitet nun durch Polen (laut Akademieworterbuch bedeutet sowohl Poljacka wie auch Lexka = lerka zemlja, 'Land der Lechen', Po $l$ e n! in das christliche (Kaurska) und turkische (Turska) Land und gelangt von dort aus an die Sitnica, den berlhnten FluB des Kosovofelds. Durch das arabische Land (kroz zemlju Harapsku) reist Gruica endilch nach Purdija, hinter dem man - der ungefuhren Reiserichtung nach - vielleicht Georgien vermuten konnte, obwohl mit ebenso großer wahrscheinlichkeit mit einer Ableitung des (fiktiven) Ländernarens turaija aus dem männlichen YN irurad (BrankoviC?) zu rechnen wäre.

Var. 10 war mir im Hortlaut leider nicht zuginglich. Sie ist jedoch inhaltsmaBig aus den Angaben bei Chal.RFV 31,S.141 zu entrehmen:

Ivo Senjanin freit die Tochter des Konigo von Tokaj und ruft Relja von Budim, Vuk Brankovic und Novak ala Svaten; Dever iat Kraljevic Marko. Die Svaten holen die Braut in Tokaj ab und treten den Kllkweg an. Da eondet ihnen dor Brautvater seinen Diener V1lovnjas nach, der die Braut zurlickholen und dann zur Frau erhalten soll. Vilovnjar besteigt sein dreiköpfiges Pferd Bama, aus dessen Hufen Feuer spribt, dessen Maul Regen entströmt, aus dessen NGstern Flammen zlingeln, dem aus den Augen Blitze fahren, aus den Ohren Donner rollt und auf der Mhne elne weibe Lilie blunt. Als die Svaten vilovnjas auf seinem unheimlichen Pferd erblicken, fliehen alle, nur Marko bleibt bel der Braut zurick und meint, wenn er wisite, daB 
diese schreckliche Erscheinung von Gott gesandt se1 (od Boga otrahota), wirde er den Weg freimachen; wenn es sich aber nur um eine Ilst des Brautvatere handle, whrde or su Gott beten und sich bekreuzigen, sein Schwert zlicken und "zwel aus einew machen". Katica erklart Marko, daB e8 aich nur um besondere Ränke (velike mudrine) ihres Vaters,namlich um den Diener Vilovnjax handle, der ele euf seinen Wunderpferd schon dreinal zurlickgeholt habe und dem sie jetzt versprochen se1. Sie aber konne Ihn vor Fkel nicht einmal ansehen, geschweige denn Zunelgung empfinden.- Nach dieser Erklarrung schlägt Marko den Angreifer in zwel Telle, setzt sich aur des Pferd Barne, fuhrt sein eigenes Pferd nebenher und sammelt die Pferde der geflohenen Svaten zu elner Herde. Nach und nach kommen die Svaten wieder herbel, und der Hochzeltezug kehrt nach Hauee zurlick, wo eine groBartige Peler atattindet. Die Svaten konnen be1 dieser Gelegenhe1t ihre Pferde fur je acht Dukaten bel Marko zurlickkaufen.

Auch in dieser Varlante lot ein anachronistischer Heldenkatalog zusammengestellt, allerdings mit geringerer svatenzahl. Senjanin Ivo, der Brautigam in diesem Lied, ist eine bellebte skr. Iledfigur, die als historische Gestalt dem 16.Jh. angehort. Man vermutet hinter Senjanin Ivo einen 1551 und 1578 erwahnten gleichnamigen Unteroffizier ("wachmeister") aus Senj bzw. Oinen 1612 als "Rłuber" zum Tod verurteilten Anfuhrer der Senjer Uskoken namens Ivan Novakovic-Vlatkovic ${ }^{203}$. Die Braut wird hier wieder aus einer "lateinischen" Stadt, numlich aus rokaj, geholt. Der Brautraujversuch liegt in seiner jingeren Version - Entrendung eines Dieners durch den Brautvater - vor. Im Zeichen der fortschreitenden Entmythologisierung bzw.sekundären Ungestaltung hat hier nicht mehr der Brauträuber Drachenattribute, sondern sein Pferd, von dem es heibt:

Iz kopite kremen vatru daje,
Iz zuba mu tiha kiba pada,
Iz nozdrva modar plamen lize,
Iz odiju gtrałna munja j jeva,
Iz ubiju gromovi pucaju,
Na grivi mu b' jeli liljan crate.

Der Name Vilovnjas let elne ăhnliche Wortbildung wie skr.vilovnjak 'Hexenmeister' und will besagen, daB der Besitzer des Zauberpferds selbst uber magische Mittel verfugt. Das den Svaten von Marko auferlegte Zurlickkaufen der eigenen Pferde 18t als Geldotrafe (anstatt der sonst vom Dever praktizierten Korperstra- 
fe) fur inre feige Flucht während des Uberfalls aufzufassen. - Var.11 18t be1 MH I, 587 erwahnt. Aus der kurzen Angabe geht jedoch nicht klar hervor, ob das Lied vielleicht eher zu Kap.4.3 zu rechnen ware. Es hat folgenden Inhalt:

Vojvoda Janko freit drei Tagereisen auf dem ebenen Land und vier Tagereisen durch das Gebirge entfernt die Tochter des Zaren Ladomir. Jankos Neffe Milos Voinovic schließt sich (ungeladen?) dem Hochzeitszug an. Als die Svaten das Waldgebirge durchqueren, werden sie von Hajduken uberfalien, an deren Spitze Musa Vrbanusa steht. Milos, der Hirte (Coban), schlagt aue Musa ein, worauf aus diesem Feuer sprint, aus Hilos aber eine "tija godinica" (wortlich: "Unwetter') niedergeht, die die Flammen ausloscht. Dann trennt Milog mit seinem Schwert den Gegner durch "bis zu den seidenen Persen". In Musas Korper befinden sich aber drei Herzen: Das erste ist ermllet, das zweite ist voller Kampliust, und das dritte ist noch nicht erwacht:

Jadno se je srce umorilo, Drugo se je srce razigralo, Trece arce 1 a boj ne znade.

Als Milos erkennt, welch einen Helden er getbtet hat, beklagt er sein Ungluck, denn er, der elnen inm Uberlegenen Gegner erschlagen habe, werde nun von der Hand eines schlechteren fallen:

Ala 81 mi uda, sréo mojal

De pogubi 1 boljeg junaka,

Od gore cu rdje poginut1.

Zar Ladomir, der Brautvater, lot sicher eine vom sanger erfundene Figur, die mir aus keinem anderen lied bekannt ist. Der Hirte Milos Voinovic in der Rolle des (ungeladenen) hilfrelchen Neffen des Bräutigams sieht wie eine Entlehnung aus den 4.3-Iledern aus. Die Stelle des dreiköpligen schwarzen Arabers vertritt in diesem Lied sekundar Musa mit den drei Herzen, ein Ersatz, der wahrscheinlich aus der Affinitat der beldon mit ubernaturilohen zugen (drol koppo - drol Horzon) ausgestatteten Gestalten zu erklaren sein durfẹ. Obwohl es sich offensichtlich um eine Kontamination mit den Musa-Liederm von Kap.5.1 handelt, aind in dem vorliegenden Iled jedoch kleine Änderungen zu beobachten. Wahrend Karko in den 5.1-Liedern den uberlegenen Musa mit Hilfe eines Ablenkungsmanovers und eines versteckten Messers besiegen kann, verfugt 
Nilos hier - wie sein flammensprihender Gegner Musa - Lber eine ebenfalls ubernaturliche Elgenschaft: er kann einen Gewitterregen entfeseeln und damit die Plammen löschen,d.h. er lat dem nur mit Hilfe listiger Praktiken alegenden MusaGegner Marko überlegen. Zu der Ubernaturlichen Eigenschart, bei Schlägen Plammen zu eprihen, vergleiche man Bog.86, wo N.inja von Kostur im Kampl mit Marko diese Elgenart zeigt (vgl. dazu auch die Bemeriongen in Kap.5.1). - Var.12 mit dem Titel "Zenidba Popovis Stojana" hat folgenden Inhalts Popovic Stojen freit die Tochter von Konig M1jallo Im "lateinischen Venedig", erhalt eine Zusage des Brautvatere und verteilt deraufhin Geschenke. Bevor stojan abzieht, gibt thm der Konig noch die Anweisung, keine Serben als Svaten zu nehmen, denn die seien Trinker und Raufbolde, sondern lauter Griechen und Bulgeren. Als Stojen noch unterwegs 18t, erreicht inn ein Brief der Konigin, in dem er davor gewarnt wird, Griechen und Bulgaren einzuladen; or oolle daftur lieber Serben als Svaten nehmen. Die Lateiner beien namlich "alte Betrliger":

Latini ou stare varalice.

Von Ihnen oel olcher irgendein Betrug zu erwarten.Zu Hause berichtet Stojan seiner kutter von der Anweloung des Konigo und dem Brief der Konigin und bittet die Mutter um Rat, wem er gehorchen solle. Die Mutter meint, er solle auf die Konigin horen, denn die Lateiner seien wirklich al te Betrliger. AuBerdem solle er den Konlg von Budim als Kum, Mandusic Vuk als obersvaten, Janko von Sibinj als Vojvoden, Relja Krilatica alo Spaßmacher, Milos Ob1Iic als Bannerträger, Marko Kraljevic als Dever und flur den Rest der Svaten bellebige Leute einladen, dann werde alles gut gehen. Stojan befolgt die mitterlichen Ratechlage und ladt die genannten Helden sowie 1000 andere Svaten ein. Der Hochzeitazus zieht nach Venedig, wird dort drel Tage lang freundlich bewirtet und erhalt echlieBlich wertvolie Geschenke. Nach Obergabe der Braut ziehen die Svaten heimwarts. Als oie zu einem Berg im Waldgebirge gelangen, oitzt da ein Held am Weg, ganz in Silber und Gold gehilit, mit einem riesigen Pederbusoh bis zum Boden, den Streitkolben neben oich, die Lanze auf den Inien und das Schwert an der Selte. Er trinkt roten Wein, bedient von der Bergoila, die ihm den goldenen Becher kredenzt. Als sich die Svaten nkherm, opringt der Unbekannte auf, fordert die Herausgabe der Geschenke und erhalt diese widerotandsios. Als er schlieblich von Marko die Braut und das Pferd verlangt, meint Marko, er werde thm 
lieber das dritte Geschenk, den Streitkolben, geben, und schlagt darauf den "lateinischen Riesen" (dzin od Latina) so auf die Stirn, daB diesem die Augen herausspringen. Dann kbpft er ihn. Nachdem alle Svaten ihre Geschenke wieder zurluckerhalten haben, setzt sich der Zug in Bewegung und zieht zum Hof des Brăutigams, wo die Hochzeitsfeier stattindet.

Stojan Poporio ist eine historiach whbekannte Pigur. Der Heldenkatalog stellt wieder eine anachronistische Liste von Helden verschiedener Jahrhunderte dar, deren ermeute Besprechung sich hier exlbrigt. Hingewiesen sei nur auf Vuk Kandusic, einen in venezianischen Diensten stehenden Uskokenanfuhrer des $17 . J$ J $^{204}$. Die sprichwortliche Redensart von den betrugeriechen Lateinern findet sich auch in diesem Lied, d.h. sie wird hier sogar zweimal angefunrt. Wie in Vuk II 91 wird auch in diesem Lied der Brăutigam brieflich davor gewarnt, die Anweisungen des Brautvaters zu befolgen. Statt der in 4.11 verbotenen (angeblich rauf- und trinkslichtigen) Neffen ist nur. das Mitbringen von Serben Uberhaupt untersagt, ein Verbot, das vom Brăutigam zum Gluck lubertreten wird. DaB es sich bei dem Helden in Gebirge auf jeden Pall un einen besonderen (ubernaturlichen) Gegner handelt, darauf weisen die Bezeichnung "dzin" in der Bedeutung 'Riese', die Bedienung durch die Gebirgsilia und die prunkvolle Ausstattung des Unbekannten hin. Die Benennung "dzin od Latina" lat vielleicht ein Hinweis darauf, daß der Riese von dem betrligerischen (lateinischen) Brautvater ausgesandt worden ist, um das Mädchen zurickzuholen. Der drachenthnliche dreiköpfige Mohr ist also hier sekundar durch einen ursprunglich wohl zhnlich damonischen, nun aber weitgehend entmythologisierten Riesen ersetzt worden. -

Die nachsten funf Varianten, numlich Nr.13-17, die alle aus Petr.III otamen, waren mir leider nioht zuganglioh. Ich fand sie be1 Chal.RPV 31,S.145-150 erwähnt.

Grundsatzlich ist zum dritten Band der Petranovicschen Iledsammlung zu sagen, daß die dort aufgezelchneten lieder (mit Ausnahme von Nr.6, einem Abdruck aus "Kralj Milutin u srp.n. p.", Novi Sad 1884) hier nur bedingt in Frage kommen können (der Vollotändlgkelt halber aber angefluht werden sollen), 
weil der Sänger Illja Divjanovie kein Anal phabet mehr war, sondern aus allen je gelesenen und gehorten Lledern oder Erzăhlstoffen mit großem Geschick und einem hohen Maß an Phantagie sofort eigene Liedprodukte verfertigen konnte.Petranovic selbst sagt im Vorwort (S.XIII) Uber Ilija, er sei einer der "begabtesten und klugsten" Sänger gewesen, die er je getroffen haber

Neka mu ko samo jednom ma kakav dogadaj 18prica, on je odma gotov preliti ga u narodnu pjesmu onako zivo i kitno, kao sto drugi ne moze. Maretic ${ }^{205}$ urteilt m.E. sehr richtig uber diese Lieder, wenn er sie als ganz persönliche Erzeugnisse des Divjanovió, aus den verschiedensten Quellen gespeist, bezeichnets

Gotovo sve ou te pjesme a kraja na kraj lilni proizvod reCenoga Divjanovica, t.j. on in nije onakovih, kako su tampane, ni od koga cuo, već ih je sam spjevao uzeví za osnovu sadrzaj drugih narodnih pjesama, to in je od drugijeh pjevaca cuo ili u Ztampanijem knjigama ditao (na pr. u II. knjizi Vukovoj), a ova je prilika, da je predmete za ovoje istoridke pjesme uzimao i 12 kojekakvih tampanih popularnih knjiga, u kojima se govorilo to o orpekoj lotoriji.

Die erste dieser funf Varianten ist Nr.13 mit dem Titel "Zenidba Leke Kapetana":

Kapetan Leka aus Prizren Preit die Tochter des kastenlundischen Bans:

U Primorju gradu bijelomu.

Auf dem Rlickweg uberfullt den Hochzeitszug ein "divaki starjes̆ina" (Riesengl tester), der die Braut pur seinen Sohn rauben mochte. M1los obilió besiegt den Riesen und rettet dadurch den Hochzeitszug.

Kapetan Leka ist ein Zeitgenosse von Georg Kastriot. Nach dem Zeugnis Orbinis war er mit Voisava, der Tochter des montenegrinischen Vojvoden Stefan, "di Stefano duca di Montenegro" (Ende 15.Jh.), verheiratet ${ }^{206}$. Man konnte aber auch an den ebenfalls historischen Leka Dukagjin denken, der um 1378 herrschte und in Lesh (Ljer, Alessio) residierte. Kapetan lot eine spätere Benennung, die aus dem Klistenland stammt und sich auch in Bosnien und Hercegovina verbreitete (vgl. Jir.GdS,112). Der schwarze dreiköplige Araber lot hier wieder durch einen 
Riesen, aleo einen ebenfalla Ubernaturlichen Gegner, ersetzt worden. - In Var.14, "Ženidba sa Zmijana Rajka", dagegen tritt er zusktzlich zum schwarzen Araber auf:

Rajko auszmijanjeerhblt die Tochter des Bars von Bozun, Ruzica, zur Frau. Im Gebirge Uberfallt den Hochzeitszug zuerst ein "divaki starjesina", also der Riesenkiteste, und dann der schwarze Araber. In beiden pallen werden Svaten und Braut von dem Heldenpaar Marko und Sekula verteldigt.

Von Rajko und der Stadt Bozun war schon fruher die Rede. Leider sind mir keine Einzelheiten des Liedes bekannt; eine Besprechung ist damit unmoglich. - Var.15 mit dem Titel "Zenidba kralja Milutina" hat folgenden Inhalts
Milutin aus der weiben Stadt Prizren freit die Tochter Jovanka des Konigs Milovan aus der weiben Stadt Malt1ja. Auf Wunsch der Braut werden Marko Kraljevib, Milos, Relja, Zmaj Ognjeni Vuk, Sekula, Strahllo und Ivan Kosandic als Svaten eingeladen, weil Jovanka weis, dab dem Hochzeltszug ein tber- fall von Seiten des dreikópligen Arabers droht, der mit seinen Gefahrten ein Lager am Rosula-FiuB aufgeschlagen hat.-Als Konig Milutin die berlhmten Helden einladen will, stellt sich heraus, das sie geschlosien am hof der russischen Zarin weilen. Milutin zieht also mit den Ubrigen Svaten nach Mal- ti ja und holt dort das Madchen ab. Aup dem Rllickweg wird der Zug von den Arabern Uberfallen: Die Sva- ten werden vertrieben, Milutin gefesselt und die Braut geraubt. Gerade noch rechtzeitig trifft Mar- ko mit seiner Druzina ein, um den Arabern eine Schlacht zu lieferm, in deren Verlauf der Flub sich von dem Heldenblut rot furbt. Marko macht den Kump- fen dadurch ein Ende, daB er dem dreikbpligen Ara- ber seine Krpfe abschlagt. Dann bindet er Milutin 108, befrelt das Madchen aus der Gewalt der Araber und ruft die geflohenen Sraten zurlick. Gemeinsam zieht man nach Prizren, wo die Hochzeitsfeier statt- findet.

Mit Maltija 18t mbglicherwelge Malta gemeint. Konig Milovan lot eine erfundene Liedgestalt. Konig Milutin (Stefan Uros II., 1282-1321) als Brautigam ist natirlich willklarlich eingesetzt. Den anachronistischen Heldenkatalog kennen wir schon aus den anderen Iledern. Das Liedsujet wurde durch die Nebenhandlung der am Zarenhof weilenden und rechtzeltig zurlackellenden Helden sekundar geteilt und erweitert. Typisch lat auch hier wieder der Aufenthalt des dreikopfigen Arabers am Wasser (der Na- 
me Rosula durfte erfunden seinl). Auch hier wird der Bräutigam - wie schon in einem der frluher besprochenen Lieder von dem Madchen, das von dem geplanten fuberfall etwas ahnt oder weib, zum mitbringen der besten Helden aufgefordert. DaB die russische Zarin als Liedperson eine Rolle opielt, lat ein Beweis für das junge Alter des Liedes in dieser Form.Fur Var.16, "Ženidba Voinovic Mía", gibt Chalanskif folgenden Inhalt an:

Zar Stepan freit fur seinen Nelfen Voinovic Mico die Tochter des Bane von Bozun. Die Svaten holen die Braut ab und werden auf dem Rlickweg am Fluß Usura von dem dreikopfigen Mohren Uberfallen, den Marko, der Dever, totet.

Der Sanger hat wahrocheinlich Vuk II 28 (Dusang Hochzeit) gekannt und Elemente daraus ( $\nabla$ gl. dle Lledpersonen Zar Stepan und den Neffen Milos bzw. Mibo Voinovib) entnommen. Auch hier halt aich der drachenartige,dreikopfige Araber an einem PluB (der Name Usura durfte ebenfalls - vgl. die Rosula im vorhergehenden Iied- erfunden sein) auf. - Var.17, das letzte der funf hier zu besprechenden Lieder aus Petr.III, "Zenidba vircete vojrode" betitelt, hat laut Chalanskif diesen Inhalt:

Mirceta Preit die Tochter des Bans von Karlovac. Als die Svaten die Braut abholen, werden sie auf dem Heimweg vom ochwarzen Araber uberfallen, den Milos obilic aber totet. Das Iled echliebt mit einer Prelsung des Helden und der Druzina :

Verela mu do vijeka majka, N jemu majka, a nama druzina!

Wie aus den zuletzt angefunrten funf varianten zu ersehen ist, hat der Sänger Divjanovio zwar das Liedaujet vom Uberfall auf einen Hochzeitezug geataltet, dabei aber willklulich solche Eingrifle und, Änderungen vorgenommen, daB er als echter Volkeliedeănger, d.h. al wahrer und Trager der liedUberlieferung, fragwlirdig erscheinen mus.

Das nachste Lied in unserem Variantenvergleich,. Nr.18, zeigt Polgenden Inhalt:

Ea jagen drel wrlfe: der erete im Romanija-Gebirge, der zweite an der Bosna und der dritte an puB des Gebirges. Des alnd aber kelne wrlfe, sondern die Hajduken Gavranovic BoZe, Komlen "kaurin" und Senjanin Ivan. Die drei Wahlbruder treffen oloh in der 
Schenke, wo Komlens Sohn Demetrije die Männer bedient und jedem ein volles Glas relcht, nur selnem Vater nicht. Demetrije hat sich namlich uber ihn geärgert, weil er dem Sohn keine Heldenkle1der gibt, damit Demetrije bei der Hochzeit se1nes Wahlbruders Zadranin Nikola nicht als Dover auftreten könne. Nikola wird die Tochter des Begs von Leden heiraten. Demetrije hat aber geträumt, auf einer Holzbrucke bei Leten lauerten 1000 Araber - mit einem dreikbpfigen Anflihrer an der Spitze - dem Brơutigam auf, um ihn auszurauben und zu toten.- Demetrije erklürt nach diesem Traum, wenn der Vater ihn nicht ziehen lasse, werde er unter die Hajduken gehen, einen eigenen Trupp (ceta) samineln und sich auBerdem vertbrken.- Auf diese Drohung hin labt der Vater ihn gehen. Den Weg nach Leden zeigt inm Milutin, der Diener des Smiljanic Il1ja. An einer Holzbrlacke in der Nthe der Stadt erwarten sie tatsachlich 1000 Araber, die schweren Tribut fordern: kein Gold und keine Dukaten, sonderm blonde Heldenkopfe. Vor den 1000 Arabern sitzt, die Beine gekreuzt und das Schwert auf den Knien, der dreiköplige Mohr. Milutin besiegt den Dreiköpfigen im 2weikampl, wahrend Demetrije die Araber vertreibt. Als sie nach Leden gelangen, stoBen ele auf Tadija von Senj, der mit noch vier Gefahrten gefesselt daliegt. Tadifa berichtet, der Beg von Leden habe eine grobe Anzahl Serdaren und andere Anfuhrer aus Zadar ermordet.-Nachdem die Gefesselten losgebunden sind, brechen sie mit ihnen zusammen das Gefangnistor auf und befreien 500 gefangene Uskoken. Dann fallen alle zusammen plundernd und brennend uber Ieten her, wo nur der Beg Widerstand leistet. Er labt weder seine Wohnturme in Brand aetzen, noch liefert er die Gefangenen aus; er tötet vielmehr Zadranin Nikola sowie 200 weitere Helden aus Zadar. Dann erst labt er sich in seinem Turm verbrennen.- Die Uskoken kehren gemeinsam nach Bosnien zurilck, plundern unterwegs zahlreiche Dörfer und Stzdte und bringen Schatze und Gefangene sowie viele schöne Turkenmadchen mit nach Hause.

Bei dieser erweiterten und veranderten Variante handelt es sich um ein Junges Uakokenlied, in dem der Kampl mit dem dreiköpligen Mohren eine nur noch episodische Rolle spielt. Wichtig erscheint mir wieder die Lokalisiemung des Arabers am Vasser. Das alte Handlungsschema ist fast vollstgindig verlorengegangen. Die Hochzeit scheitert daran, daß der Brăutigam ar Hof des Brautvaters in Leaen den Tod findet. Deshalb muBte die Araber-Episode schon auf den Hinweg nach Leten verlegt 
werden. Das Hauptgewicht der Handlung verlagerte sich auf die Gefangenenbefreiung und den erfolgreichen Plinderungszug der Uskoken aus Zadar und Senj. - Der Inhalt von Var.19 mit dem Tltel "Zenidba ban-vojrode Janka" lautet 808

Ban-vojvoda Janko freit die Tochter des Konigo von Leâan, doch Murat-beg versucht das Madchen mit rasch gesammelten Svaten wegzufreien, worauf die Braut Janko brieflich bittet, er möge $8 \mathrm{chnell}$ einen Hochzeitszug mit Relja Bosnjanin, Kraljevid Marko und Nilos oblile sowie den beiden vojinovicl als Brautfuhrem aufstellen und herbeiellen.-Janko sendet den genannten Helden Briefe, in denen er sie bittet, mit je 300 Svaten zu ihm zu kommen,was auch geschieht. Der Hochzeltszug eilt nach Ledan, wo die Svaten eine Woche lang bewirtet werden. Dann fordert man die beiden Brautfuhrer auf, die Braut zu holen. Gegen die beiden ist jedoch ein Anschlag vorbereitet: Sie werden von zwei Zigeunern gepackt, auf große SpieBe gesteckt und gebraten. Als sie dann den Svaten als Speise vorgesetzt werden, merkt noch niemand, was geschehen ist. Als die Svaten aufbrechen wollen und nach der Braut und den Brautfuhrem rufen, erklurt der K8nig,die Vojinovicl wlirden gerade von seiner Tochter durch die stadt gefthrt.Daraufhin durchotreifen die Svaten die ganze Stadt, ohne die Brautflunrer mit dem Madchen zu treffen. Statt dessen mlssen sie aber feststellen, daB man die Stadttore geschlossen hat. Als es Marko gelingt, eines der Tore zu zerschmettern, strömen die Svaten ins Preie. liarko, Relja und Milos kumplen mit den 600 Wachsoldaten auf der Mauer und schlagen sie in die Flucht. Dann dringt Marko in den Wohnturm des K8nigs ein, raubt und totet dessen zwei kleine sohne und zwingt den Konlg, von dem Fleisch zu essen, wie die Svaten von den gebratenen Brautflurern gegessen hätten. Darauf schlagt er dem Konig das Haupt ab, ruft die Konigstochter herbel und fordert sie zum Kitkommen auf. Gemeinsam fliehen sie aus der stadt. Die Königin ruft nun ihren Diener, den dreiköpligen Araber, herbe1 und fordert ihn auf, das likdchen zurilckzuholen und Marko zu töten.- Als es zum Kampl kommt, besiegt aber líarko den Araber und schlkgt ihm seine dre1 Kopfe ab.- Nach diesem Zwischenfall kehrt der Hochzeitszug sicher zu Jankos Hof zurluck.

In dieser ebenfalls sekundur erweiterten Variante ist das Kernstuck der Handlung der bestialische liord an den beiden Brautflihrem und die Rache dafur, narlich die nicht minder Grausame Ermordung der S8hnchen des Konigo. DLe Araber-Episode lot nur kurz und ohne Schilderung der Einzelheiten darge- 
stellt. Man erfährt also - genau wie in den vorhergehunden Varianten - nicht, ob der Araber noch drachenahnlich, mit drel feuerspeienden koppen gedacht ist oder sich nur mit Hilfe von drei furchterregenden Kopfen vermummt. Der dre1köpfige Araber 18t hier offensichtlich zur Schablone erstarrt, um die man sich keine Gedenken mehr macht und die in ihrem mythologiachen Gehalt schon vollig verblabt ist. Auch hier wieder steht der Araber in Diensten des Brautvaters und wird nach dessen Tod den Svaten von der Konigin nachgesandt. Marko totet den Angreifer, weil die beiden toten Brautfinrer diese Aufgabe nicht mehr erfillen konnen. Auf Grund der sekundären Sujetanderungen spielt also hier Marko, und nicht der Dever, wie es in der urspringlichen Version der Fall ist, die Hauptrolle. - Nun zu Var.20 mit folgendem Inhalt:

Eine Gruppe Vojvoden trinkt Wein, unter ihnen Banovic Strahinja, die neun Jugovici, die beiden Vojinovici (Petrasin und Vukasin), die drei serb. Vojroden Kosancic, Obilic und Topilca, die beiden Ugrezic1, Relja Boßnjanin aus Pazar,Ijutica Bogdan aus Zagorje, Janko aus Sibinj, Misirlija Mato aus Misir und Bogdan aus Solun. Die Vojvoden trinken Strahinja zu und Pragen ihn, warum er immer noch nicht geheiratet habe. Er sel - nach Ijutica Bogdan - der beste Held von allen; deshalb moge er sich jetzt von einem aus ihrer Mitte die Tochter oder Schwester als Braut erwkhlen. Strahinja wehrt dieses Lob bescheiden ab und meint dann, es gebe eine Rose unter neun Äpfeln, mit der er sich liebend gerne schmllcken mochte; wenn die neun Jugovidi inm Ikonija gaben, whrde er sie sofort zur Prau nehmen. Die Jugovici erwidern, mit Freuden gaben sie thm die Schwester. Da klabt Strahinja die zuklinftigen Sohwlger der Relhe nach, uberreicht dem altesten neun Ringe und einen goldenen Apfel mit einem Edelstein und erklkrt, er werde nun nach Hause ellen und 3000 Svaten sammeln. Die Brlder oollten olch um die Sohwostor kelne Sorgen machon, denn solange er das Schwert in der Rechten und se1nen treuen Hund Karaman zur Selte habo, sei nichts zu befluchten. Allerdings mllsse Ikonija damit rechnen, dab sie haufig blutverschmierte Hemden zu waschen habe, weil er, Strahinja, jeden Turken, den er treffe, kopfen misse.- Nach einem herzlichen Abschied trennen sich die Helden. Die Jugovibl teilen zu Hause die Neuigkelt mit, woraue der Vater JugBogdan seinen Schwiegersohn Lazar zu dem bevorste- 
henden Fest einlädt. AuBerdem schickt er dem zuklinftigen Schwiegersohn einen Brief mit der Aufforderung, er moge nicht 3500, sondern nur 700 Svaten sammeln, dafir aber lauter junge Serben, ja keine Griechen. Er solle die Brluder Stjepan und Dimitar Jaksic einladen und ferner Janjo aus Srem zum Kum, Vuk aus Srem zum zweiten Kum, Janko aus Sibinj zum ersten Svaten, Banovic Sekula zum Bannerträger (mit Rajko aus Zmijanje zusammen), die BanoviC1 Marko und Milinko zu Brautfuhrern und Miloz Obilic zum SpaBmacher bestimmen.- Als der Brautigam dieses Schreiben erhalt, sendet er unverzluglich Briefe in alle Himmelerichtungen, um die Svaten zusammenzurufen. Als der Hochzeitszus vollzbhlig versammelt ist und gerade aufbrechen will, trifft noch ein Brief der Schwiegereltern ein, in dem der Bräutigam vor Balaban, dem Zwe1kampfer des Königs von Venedig, gewarnt wird. Balaban, der sich ebenfalls un das Madchen beworben habe, werde den Svaten auflauern und den Bräutigam zum Zweikampl fordern.- Als der Hochzeltszug einen Teil des Weges zurukckgelegt hat, erblickt Strahinja plotzlioh das zelt des widersachers und fordert ihn zum Kampl heraus. Sie kämplen zuerst mit der Lanze, dann mit dem Schwert. Wienn Strahinja seinen Gegner trifft, opriht dieser Funken:

Sve mu ziva vatra posipase.

Zuletzt tragen die belden einen Ringkampl aus. Der Bräutigan droht schon zu unterliegen, als er sich plotzlich an seinen Handzar erinnert und den uberlegenen Gegner danit totet. Er ruft, die Svaten soliten sich freuen, denn er habe eben Balaban mit der schwarzen Erde vermahlt. Strahinja bringt seiner Braut den abgeschlagenen Kopl und gibt dann das Zelchen zum Aufbruch des Zuges.

Am Anfang dieses jungen Liedes, in dem vermutlich der Konig vun Venedig der uropringliche Brautvater war, wird von einer Gruppe anachronistisch zusammengewirfelter serb. Heiden ein Trinkgelage abgehalten und so die Ausgangsituation flur die Werbung geschaffen. Hinter Banovic Strahinja (hier auch Strahinin genannt) vermutet man den Herm der Zeta Burad $s(t) r a-$ cimirovic Balsic (1386-1404)207, der in diesem Iied aber schon als ein Iiedheld mit bekannter Physiognomie behandelt wird, denn die Hinweise auf das berlunte Iled von Banovic Strahinja, seiner untreuen Frau und seinem treuen Hund Karaman (vgl. Vuk II 43, Bog.40 u.a.) sind nur zu deutlich.Auch Strahinjas Turkenfeindschaft wird unterstrichen. Die Vojinovic-Brider Vukazin und Petrasin werden auch in Vuk II 28 ge- 
nannt. Historisch sind aber nur ein Altoman und Voislav Voinovid aus dem 14.Jh. als serb. Adlige bekannt ${ }^{208}$. Die Namen Kosandic und Toplica erklärt Maretic als nicht historisch, sondern von den Flußnamen Kosanica und Toplica abgeleitet ${ }^{209}$. Mit den beiden Ugresici sind vielleicht zwel namenlose ungarische Helden (ugridibl) gemeint. Misirlija Mato (Mato aus Ägypten) kann m.E. nicht erklurt werden.Mit Vuk aus Srem ist vielleicht Zmaj-ognjeni Vuk (Despot Vuk Brankov16, 1440-1485) gemeint. Janjo konnte Jovan Brankovic (gest.1502), der Enkel des Despoten furat Brankovic, seln. Whe man sieht, wurden vom Sanger alle berluhmten serb. Helden aufgeboten, un die Hochze1tszugthematik moglichst heldisch gestalten zu konnen. Auffallend lst wieder die positive Bewertung des serbischen und die Ablehnung des griechischen Elements. Das Lied erweist sich auch dadurch als relativ jung, daß es schon weitgehend entmythologisiert ist. Balaban (hier abwechselnd auch Balesa und Bale genannt) ist kein schrecklicher drelköpliger Mohr mit dämonischen Zugen mehr, sondern eln naturlicher, gefuhrlicher Gegner wie jeder andere gute Held. Die einzige blasse Reminiszenz an ehemalige Drachenzluge sehe tch darin, daß Feuerfunken aus ihm schlagen, wenn sein Gegner ihn mit dem Schwert trifft. Eine weitere sekundäre Voränderung besteht darin, da $B$ der Bräutigam hier selbst mit dem Brauträuber kämpft, und nicht mehr der Dever. Von einer Flucht der Svaten 1st keine Rede. -Die năchste Var., Nr.21, soll nur kurz erwhhnt werden, well sie alo ein aus Vuk II 28-Elementen zusarmengesetztes Lied jungen Datums erscheint und die Rolle des dreikopfigen schwarzen Arabers hier offenbar nicht mehr verstanden wurde:

Milos Obilic, der Wahlbruder Markos und Milans von Toplica, erschlägt den dreiköppigen Araber und erhalt durch Erpressung - Mil an halt nümlich den Kठnigssohn gefangen - Roksanda, die Tochter des K8niga Mihajlo von Letan, zur Frau.

Die drittletzte skr. Var., das sekundär erweiterte mohammedanische Lied Nr.22, soll ebenfalls nur kurz erwähnt werden. Von einem drelkbpfigen Araber lst keine Rede mehr, sondern der urspringlich damonische Brauträuber wurde hier zur Ge- 
stalt eines gewissen Idris-arap entmythologisiert, dem nicht mehr drel Kopfe, sondern nur die Ohren abgesohnitten werden. Das Iled mit dem Titel "Gazl Husrev beg vod1 svatove u Stambol" hat folgenden Inhalts

Gazl Husrev-beg aus Sarajevo zieht mit berzelez Alija und Beg Ijubovic nach Istanbul, un die Braut des Hajdar-alaj-beg abzuholen. Nach verschiedenen Abenteuern, die die Bezlehungen der tilkiechen Beamten untereinander und das Verhyltnis des Sultans zu seinen Untergebenen oharakterioleren, gelangen die Svaten nach Istanbul, wo sie die Sympathie des Sultans erringen und auf Betreiben des Wesirs Cuprilic die Braut erhalten, mit der ale sich auf den Rliokweg nach Bosnien machen. Dreibig andere Wesire aber, die ales miBglinstig und neidisch beobachtet haben, schicken den Svaten Idris-arap mit einem 12000Mann-Heer entgegen. Der Araber uberfullt die Svaten, doch Berzelez All ja verjagt die Angreifer. fungt den Araber Idris und schneldet thm die Ohren ab. Nach diesen Zwischenfullen erreichen die Svaten gllucklich Bosnien und ubergeben dem BrkutIgam die Braut.

Die stark erweiterte mohammedanische Var.23 enthalt den "dreikbpligen" Araber (Troglav-Arapin), hier einen Feind des Konige von Neapel (napuljski kralj), dessen Tochter er erfolglos umirbt, nur noch entmythologisiert als EpisodenIi gur:

Der junge Held Omer wird von Troglav-Arapin, ale er $1 \mathrm{hm}$ seine Absicht, die Konigotochter helraten zu wollen, kundtut, zum Zweikampl aufgefordert. Omer schlagt dem Araber den Kopp (elnen?) ab und setzt seinen Weg zum Königahof fort.

Obwohl der Araber hier noch Troglav-Arapin genannt wird, sieht man deutlich, wie der sanger inn schon vollig entmythologisiert und den Begriff der Dreikbpelgkelt sinnentleert hat, denn im Zweikampl wird der Araber wie ein "normaler" Gegner behandelt, dem Omer einfach "den Kopf" abschlagt. Der "dreiköplige Araber" lot in dieser Spatphase offensichtlich zu einem otereotypen negativen Iledhelden geworden. - In der ebenfal1s mohammedanischen Var.24 ist der Ubernaturliche Charakter des dreikopeigen Mohren noch zum Tell erhalten. Dieses Iled hat auch das Hochzeltszugsujet von den drel zuletzt genannten Varianten am beeten be- 
wahrt:

Der dreiköpfige Araber (Troglavi Arapin) Uberfallt den Hochzeltszug des Brăutigams Bojlib Delalija. Marko, dem Brautfuhrer, gelingt es, den Angreifer zu besiegen und ihm seine drei Kopfe abzuschlagen. Die Svaten setzen ihren Weg fort und fluren die Braut, die Tochter des Memed-Arapin, glucklich zum Hof ihres Brautigams.

Von den in den letzten drei Iledern genannten mohammedanischen Helden 18t der bekannteste Berzelez Alija210, in dem vermutlich zwei historische Piguren des 15.Jh. zusammengeflossen sind: Alibeg, der erste Beg des Sandžaks Smederevo, - der sich 1437-1470 in den Kämpfen gegen Ungarn und Serben besonders hervortat, und der ab 1472 erwahnte Statthalter von Smederevo Alibeg Michaloglu, der die kumple gegen die Ungarn, den Despoten. Vuk und die Jaksici fortsetzte.

Damit sind wir mit den skr. Varianten am Ende angelangt und wollen nun zu den maz. und bulg. Itedern ubergehen, an deren erster Stelle die vor allem wegen ihrer archaischen Zuge interessante Var.25 stehen soll:

Eine junge Witwe bringt ein sohnchen zur Welt, das sofort zu reden anflingt und verlangt, man solle es, "dete maleckovo", drel Tage schlafen lassen. Als das Kind nach dieser Frist aufwacht, verlangt es Waffen, Pferd und Kleider des verstorbenen Vaters. Die Mutter gibt ihm das Gewinschte. In der Ausristung seines Vaters reitet das Heldenkind zu seinem Oheim Jankula, der ein Mådchen gefreit hat und nun sohon seit drei Monaten mit den Svaten untatig hemmsitzt, weil der Hochzeitszug aus Furcht vor einem unterwegs drobenden Drachen (kuckana lamia) die Braut nicht ab-

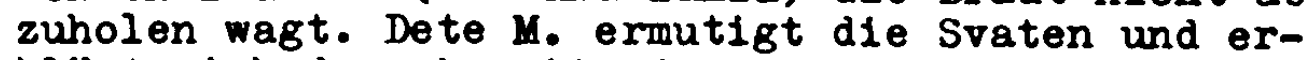
klart sich dazu bereit, den Drachen zu toten.Mit dem Heldenkind an der Spitze macht sich der Hochzeitszug auf den Weg. Als ihnen wirklich der schreckliche Drache den Weg versperrt, schneidet Dete $M$. dem Ungeheuer den Kopf $a b$ und erschlagt es mit seinem Streitkolben. Als das Heldenkind die Lamja auf den Leib trifft, platzt dieser aue, woraue drei ganze Hochzeltszlige zum Vorschein kommen.- Die Svaten ziehen zum Hof der Braut, um das rädchen endlich abzuholen. Dete $\mathrm{H}$. entwurzelt elnen auf dem Hof der Brauteltern wachsenden goldenen Apfelbaum mit drei goldenen äpfeln daran und nimmt ihn mit zu Jankulas Hof, wo alle das Heldentum des Kindes bewundern. Nach dreimonatigem Feiern fordert Dete $M$. die Svaten auf, nun seine 
Taufe zu feiern, worauf Jankula und seine Grste zu dem Hof der Witwe ziehen und dort dre1 Wochen lang die Taufe des Kindes feierm.

In dieser sehr altertumlichen maz. Variante ist nun zum erstenmal wirklich ein $D r$ a $\mathrm{c}$ e derjenige, der den Hochzeitszug aberfält, womlt also unsere These von der Ableitung des dreik8pfigen schwarzen Arabers aus einem urspringlichen Drachen gestärkt wäre. Sehr archaisch mutet auch die Gestalt des Heldenkinds ("dete malezkovo" ist hergeleitet aus maz. maleckav, malecok 'klein, jung'), eines naohgeborenen Witwensohns, in der Funktion des Drachent8ters an, wovon in Kap.4.41,4.43 und 5.2 noch ausfunrlich die Rede sein wird. Der Name Jankula fll den Oheim 18t naturlich erst opater einem urspringlich wohl unhistorischen und namenlosen ( $\nabla g l$. die ubrigen Iledgestalten, die alle namenlos bleibenl) Helden aufgepfropet worden, als eine Historisierungawelle uber die primäre maz. Iledschicht hinwegging. Sekundär ist auch das Motiv des von dem Heldenkind entwurzelten Goldapfelbaums, das wohl von den 4.13-Liedern her in unser Sujet eingedrungen ist (Affinitat der Thematikl) und hier seinen Sinn verloren hat. Altertimlich durfte das vielleicht an matriarchale Verhalthisse erinnernde Oheim-Neffe-Paar sein. Der jungeren Tendenz zur Verchristlichung heidnisch-mythologischer Sujets zufolge lot das Motiv der Taufe des Heldenkinds in unserem Lied besonders hervorgehoben. Nur dem erst wenige Tage alten Kind gelingt die Trtung des die ganze Umgebung terrorisierenden Ungeheuers, von dem der Oheim sagt:

Da t1 kažime cudo golemo:

Bog je ubil kuckana lamia. Mi padnala na ramni putizta, Sto pominvit, kurtulia nemat, Straf imame d'ojme po ne'esta.

Dem Lied lot eine 19 Zeilen lange Einleitung vorangestellt, in der von einer Wette zwischen Sonne und Mond, die nicht zusammenkommen k8nnen, we1l der Mond wegen des von ihm beobachteten "Wunders" (uner; gemeint 1st die Geburt von Dete $M_{\bullet}$ ) zurluckbleibt, berichtet wird.- Als Var.26 folgt nun das "Temisvar Gjuro, Marko Kralevike, Jankula vojvoda 1 dete Golomese" betitelte maz. Iied mit folgendem Inhalt: 
Temifvar Gjuro sucht drel Jahre lang eine passende Braut und besucht zu dem Zweck 77 stzdte, b18 er endlich in Slankamen ein Hidchen nach seinem Geschmeok findet.Br hinterlabt elnen Verlobungsring sowle drel lasten Schatze und vereinbart mit dem Brautvater, daB die Hochzelt in einer Woche statteinden soll. Gjuro bestelgt sein treues Pferd Karaman und macht alch auf den Weg nach Prilep, um Kralevik Marko al s Kum und den Vojvoden Janko als zweiten Dever elnzuladen. Die beiden wilIIgen ein. Gjuro hat aber num noch immer keinen ereten Dever, der thm die Braut fuhren konnte. Auf den Rat der ihtter hin macht sich Gjuro wieder auf den Weg, entschlossen, dem erstbesten, den er treffen solite, die Wahlbruderschaft und das Amt des Brautfuhrers anzubieten. Er reitet lange auf den weiBen Straßen umher, ohne jemanden zu treffen. Am Meeresetrand endlich findet er ein nacktes, im Sand halb vergrabenes und mit Steinohen spielendes Kind namens Dete Golomese. Gjuro will schon an thm vorbelreiten, da fkllt inm der mutterliche Rat ein. und er ladt das Kind als Dever zu seiner Hochzeit ein. Das Kind wird zornig, weil es glaubt, einem Scherz zum Opfer zu fallen, und droht, es werde Gjuro die Aueen aus dem Kopf springen lassen. Erst als Gjuro schwort, keinen SpaB zu maohen, laBt sich das KInd aufs Pferd heben und $2 u$ Gjuros Hof bringen, wo es sich Kleldung, Keule und Schwert 8owie ein Pferd (es whilt ausgerechnet Gjuros Pferd Karaman) aussuchen darf. Mit dre1 Paar Tromeln und drel seldenen Bannerm setzt sich der Hochzeltszug unter Fihrung von Dete Golomese in Bewegung. Als die Svaten im Gebirge angelangt oind, stoben ole aue elne "hala-haletina", einen ochwarzen Araber, dem die Unterlippe ouf die Brust hangt, die Oberlippe an die Stim st8Bt und der einen Kopl hat 80 groB wie zwel Trommeln, Augen wie Schllsseln, einen Mund wie ein kleines Tor, Zthne wie Hacken und Beine wie Masten. Wenn er den Mund zuklappt, opruhen Punken, so daß die Baume versengt werden. Er droht den Svaten, wenn sie nicht sofort unkehrten, werde die Braut thm gehbren, wenn sie auf dem Rlickweg wieder durch das Gebirge klmen.- DIe Svaten lassen sich nicht von ihrem Vorhaben abbringen, ziehen zu den Brauteltern und werden dort gut aufgenommen und großzug1g beschenkt. Deto Golomese aber bekommt statt eines Geschenke die Braut anvertraut. Trommelnd machen sich die Svaten auf den Kllckweg. Im Waldgebirge werden sie schon von dem schwarzen Araber erwartet und aufgefordert, die Geschenke hinzuwerfen, wenn sie mit dem Leben davonkommen wollten. Der Reihe nach lieferm die felgen Sraten tatskchlich alle ihre Geschenke ab und fliehen, b18 nur noch Dete Golomese mit der Braut zurluckbleibt. Da verlangt der Araber auch sein "Ge- 
schenk", namlich die Braut, weigere or 810h, werde er verschlungen werden. Darauf fordert Dete G. den Araber zum Zweikanpl auf. Sie werfen zuerst die Streitkolben. Der Araber zielt auf den Kopf des Gegners, doch Dote G.8 Plerd geht in die Knie, so das die Keule uber den Reiter hinweglilegt. Der Araber möchte den Wure wiederholen, doch Dete G. erklart, selne kutter habe thn auch nur einmal geboren. Obwohl das Pferd des Arabers ebenfalle in die Knie geht, trifft Dete G., well er tiel genug gezielt hat, den Gegner mitten auf die Brust, woraue der Araber vom Pferd otlurzt und von Dete G.gekopet wird. Der Dever ellt zum Zelt dee Arabers und Pindet dort dreibig Maultierlasten Schatze, die or mit der Braut zusammen vor das Tor von Gjuros Hof schaff. Dort hort er, wie Narko auf sein (Dete G.8) Seelenhell trinkt, weil man inn verloren glaubt. Daruber gerat der Dever in itut, zerschlagt das Tor, dringt in den Hof ein und wiret den Kopl des Arabers auf den T18ch. Dann bestraft er die felgen Svaten, Indem er ole der Reihe nach mit der Keule schlagt, und zwar Marko 15mal, Jankula 16mal und Gjuro 20mal, die ubrigen Svaten jedoch nur dre1- b18 funfmal. Des Nidchen erklkrt, er tue recht daran, denn sie sel schon dreimal von dem Araber zurlickgeholt worden und whre nun ein viertes Mal geholt worden, was nur dank der Tapferkeit dee Devers vereltelt werden konnte, whinrend die Svaten felge flohen.- Die Hoohzeltsfeier dauert drel Wochen. Danach zieht Dete G. mit seinen erbeuteten Schatzen nach Hause, wo ebenfalls eine Hochze1t, nimlich die Dete G.8, bevorateht.

Auch diese Varlante macht einen archalscheren Eindruck, als er bel den akr. Iledern entatand. Hier lot der Dever ein Heldenkind, was alcher die kltere stufe des Sujets wiedergibt, das m.E. aus dem Drachenkanpl-Sujet abgeleitet 18t, wo gerade Heldenkinder den typischen Drachentoter darstellen. Das Motiv, daß der erstbeste, dem der Brautigem begegnet, als Dever geladen wird, lot sicher alt und erscheint in ahnlicher Form Im Mrarchen. Alt 1st auch das Motiv, das wir schon in Kap.4.11 behandelten, das namlioh der M1Bachtete oder nur mit Geringschatzung Betrachtete, der Dummling - hier ein im Send aplelendes Kind -, sich als der grobte Held erwelot. Der schwarze Araber, hier sogar ausdricklich "hala, haletina" ( also 'Drache, grober Drache') genannt, wirkt noch gehr drachenthnlich, wenn er folgendermaben besohrieben wirds

Dolna usta na grude mu bie, Gorna usta $\nabla$ celo go udara, 
Glava ima kolku dva tưpũna,

O丈i ima kolku dve panici,

Usta ima kolku mala vrata,

Zubi ima Eetiri dikeli,

Nodze ima solunski direci.

Koga klapat taa pusta usta,

Dur' ot usta ogin izfürljuva,

Irux' na gora listovi obliva.

An einen Drachen erinnert auch, dab der Araber droht, er werde Dete G. verschlingen (ke te goltnam). Der Zweikampf allerdings verlauft ganz nach heldischen Regeln. Hier ist der Araber anscheinend wieder anthropomorph gedacht. Auch

- In dieser Variante flienen die feigen Svaten und werden vom Dever mit Keulenschlägen darlur bestraft. (Dete) Golomese ist von golem 'groB' abgeleitet, $\mathrm{d} . \mathrm{h}$. es handelt sich um ein besonders groBes. und kräftiges Kind, womit der Heldenkindcharakter im Namen schon angedeutet ist. Slankamen gehort - genau wie Temiśvarin Gjuro und Jankula - zu der PN und ON betreffenden Sekundarschicht in der maz. Epik. In der, was Namen und Einzelheiten betrifft, sehr ahnlichen Var. 27 ist der Araber so beschrieben:
Izleznal e curma arapina, Arapina straśna chaletina. Ustata mu kato mall vrata, oðite mu dva mali pendžeri, Nozete mu solunski direci, Kucete mu kato dva direci.

Hier ist noch keine Rede davon, daB der Araber das Mudchen schon ofter zurlickgeholt hat, was sicher - vom Drachenkampf her gesehen - die bltere Form sein durfte. In dieser Variante kehrt Dete G. am Liedende wieder zu dem Sandstrand zurlick, von wo das kind an Anfang weggeholt wurde. - Sehr nahe steht diesen beiden zuletzt besprochenen liedern die unvollendete Var.28, die nur bis zu dem Zweikampl zwischen dem Araber und dem eiebenjuhrigen Heldenkind reicht. - In der ebenfalls sehr thnlichen Var.29 18t der Araber so beschrieben:

Izleznal je curma arapina, Arapina, strasna chaletina. Ustata mu kato mali vrata, Orite mu dve mali pendzari, Nodzete mu solunski direci, Rúcete mu kato dva direci.

Diese Beschreibung ist also, abgesehen von geringfligigen 
dialektbedingten Unterschieden, praktisch identisch mit der von Var.27, was die gegenseitige Abhangigkeit der sonst nicht gleichlautenden Ileder beweist. Typisch drachenkhnlich iot in allen vier Varianten, daß der Araber, der jedesmal ausdricklich "Drache"(hala, augmentativ haletina) genannt wird, Schätze besitzt, die der siegreiche Dever erbeutet. Der Drache als Schatzhuter ist bekanntlich ein altes und beliebtes Motiv der Folklore. - In Var.30 18 t Marko Kralevice der Brautigam:

Marko freit ein Madchen aus Solun und findet den fehlenden Dever in Gestalt des an WelBen Meer spielenden Heldenkinds Dete Golomese. Dete G. beweist seine Stkrke zunkchst damit, w 1 e er oich sein Pferd aussucht. Er schwingt ein Pferd nach dem andern am Schweif umher und nimmt schlieBlich dasjenige, bel dem $1 \mathrm{hm}$ dies nicht gelingt. Ein zweites $\mathrm{Mal}$ liefert Dete G. dann einen Beweis se1ner heldenhaften Sturke, als der Hochzeitszug auf dem Rluckweg von einem Araber (o1la Arapina) Uberfallen wird, den Dete G. besiegt und tötet. Beim, drittenmal erweist oich diese Starke als sehr unheilvoll, als das Heldenkind namlich die Svaten zur Strafe flir ihre Peigheit mit der Keule ochlagt und alle bis auf Marko erschlkgt:

I avi ovatove a dusa razdeli.

Das folgende Lied, Var.31, lat im Handlungsablauf verändert:

Marko beschlkgt sein Pferd, und Sarko fragt inn, ob es verkauft werde. Marko erklkrt, es werde ke1neswegs verkauft, sondern habe eine Braut bel der Hochzeit zu tragen. - Als olch der Hochzeitszug von dem Hof der Braut fortbewegt hat, macht das Madchen die Svaten warnend darauf aufmerksam, daB der Zug vom richtigen Weg abgekommen sel. Doch zu oputl Schon dringen dre1 "arvat1" und ein schwarzer Araber auf die Svaten ein und machen alle nieder. Das Madchen weint und antwortet, nach der Ursache befragt, es bedaure so sehr, daß es dem Kum und dem ersten.Svaten die Hand nicht mehr klisien und sie nicht un Verzeihung dafur bitten könne, daß die Braut nun einem anderen Traute sein werde. Da erlaubt der Araber, dab das Madchen mit dre1 Bewacherm zu den Toten zurlackkehrt, ụ das Versaumte nachholen zu können. Das Kädchen geht aber nur zum Brautigam hin und beklagt ihn oo herzzerre1esend, dab Gott Mitleid hat und den Toten wieder lebendig werden labt. Der Bräutigam tötet die drei Wachposten und fuhrt die Braut auf dem richtigen Weg nach Hause zu seinem Hof. 
Hier 18t der Araber schon v81118 entmythologlolert und auBerdem sind thm drel "arvat1", d.h. wahrscheinlich Kroaten ( $\nabla g l$. das felndliche "kroatische Kudchen" in Kap.5.1), zugesellt worden. Die Handlung lot ganz neu gestaltet und mit zunkchst negativem Verlauf, dann aber doch positivem Ausgang versehen. Die Feinde fallen auf die list des Madchens herein, was sich sofort bitter rkcht. Die sonst meist passiv wirkende Braut der Hochzeltszuglieder wird hier zur aktiv Handelnden, ja Hauptperson. Unsinnig wirkt, daß die Svaten und das Madchen anonym bleiben, Marko aber, der nur ein Pferd liefert (eine andere Funktion wird nicht erwahnt), beim Namen genannt wird. Das Iled macht einen relativ jungen, verderbten Eindruck. Es ocheint nicht nur andere Liedelemente, sondern auch ein Legenden- bzw. Marchenmotiv (Belebung des Toten) verarbeltet zu haben. - Vie nachste Var., Nr.32, 1st sekundar mit elnem negativen Schlus versehen:

Ivan "dobar junak" eindet nach langem Suchen endlich in der Stadt Slamankin eine passende Braut und holt sie binnen einer Woche mit seinen Svaten $a b$, unter denen Dete Golomese, Jankula vojvoda und Pillp Madzarin sind. Auf dem Rllckweg raubt ihnen ein schwarzer Araber mit einem "Kopf so groB wie zwe1 Trommeln" und einem Mund "wie ein Tor" des Madchen.

Slamankin 18t natlirlich entstellt aus Slankamen. Der Araber lot in diesem sehr kurzen und ungestalteten Iled zwar noch wie ein Ungeheuer beschrleben, neu 18t jedoch, dab er nicht besiegt und getitet wird, sonderm erstmalig wirklich die Braut raubt. - Var.33 hat durch eine sekundar angehangte Rahmengeschichte eine starke Erweiterung erfahren. Das Iled trägt den Titel "Marko spored narúbata na narúnicite precupva kost1te na basta 81" und hat folgenden Inhalt:

Volkalin lot abergluoklioh, als Jevrosima thm einen Knaben schenkt, und tauft das Kind auf den Namen Marko. Volkasin ladt zahlreiche Gaste ein, um mit Ihnen die Geburt seines Sohnes zu felern. Um Mitternacht erscheinen drei Schicksalsfrauen (narednici), die das Schicksal des Kindes vorhersagen. Die dritte Narecnica propheze1t, das Kind werde zu elnem starken Helden heranwachsen und seinem Vater die Knochen "zerscilagen" (preXupva). Daraufhin labt Volkasin das Kind in einen geteerten Korb le- 
gen und in den Vardar werfen. Ein Schkfer findet das Kind, zleht $e 8$ auf und stellt es ale Hirten an, b1s es eines Tages die thm anvertrauten T1ere heft1g schlagt (1etepa). Der Sohkfer verflucht den Pindiling und jagt thn zum Vardar zurlick, der ihm von nun an wieder Vater und wutter ersetzen muB. Marko setzt sich am Vardar in den Ufersand und spielt. - Rela Sestokrila heiratet und ladt dazu KOnlge, Bane und viele andere eohmucke Svaten ein. Zum Kum bestimmt er Volkasin und zum eraten Dever Gruica. Er braucht aber noch einen zwe1ten Dever, der die Braut fuhren soll, und schickt daher Gruica aus, um den erstbesten, der thm auf der Straße begegne, als Brautfuhrer herholen zu lassen. Gruica trifft den Im Sand spielenden Marko, der zuerst nicht glauben will, daß er wirklich die Leverrolle ubernehmen 8011 , dann aber freudis einwilligt. Rela Seetokrila kieidet ihn ein und gibt thm Waffen und ein Pferd. Dann zieht der Hochzeitszug zu den Brauteltern, um die Braut abzuholen. Auf dem Hilkogreg im Gebirge tritt ihnen ein dreik8pIlges Ungeheuer (eigentlich 'großes wildes Tier') entgegen (dzveretina so tri glava), das von den Svaten die Geschenke und vom Dever die Braut verlangt. Die Braut bittet die Brautfuhrer, oie nicht dem Unt1er auszuliefern, worauf der erste Dever aus Purcht flieht, Marko aber kelne Angst ze1gt und an der Selte des Madchens bleibt. DLe Svaten fliehen inzwischen zurluck an Relas Hof, wo sie auf Markos und der Braut Seelenhe1l trinken. Marko klmpet dre1 Stunden lang mit dem Ungeheuer, totet es, schlagt ihm die drel $\mathrm{Kbpfe}$ ab und befreit drel Ketten Sklaven (Junge Manner, Madchen und alte Leute). Dann kehrt er mit der Braut zu Relae Hof zurllck, wo er die drel abjeschlagenen Hzupter auf den Tisch wirft. Alle erschrecken sehr, loben Markos Heldentat und setzen Ihn auf den Ehrenplatz. Doch Marko fangt an, die Svaten mit Keulenschlagen fur Ihre Untreue zu bestrafen. Den ersten Dever schlagt er sechsmal, Volkasin 15mal, den ersten Svaten auch 15mal, Rela zwolfmal und die lubrigen eln- b18 zwe1mal. Als die Svaten dann wieder beim Feiern oltzen, fragt Volkasin Marko nach seinen Elterm, woraue Marko antwortet, der Vardar sel thm Vater und Mutter und der Sand sein Haus gewesen. Als Volkasin dies hort, versteht er, das or seinen gleich nach der Geburt ausgesetzten Sohn vor sioh hat, und erzkhlt ihm die ganze Geschichte. Da springt Marko auf und bittet seinen Vater wegen der Keulenschlyge um Verzeihung, worauf sich die wiedergefundenen umarmen und frohlich weiterfeiem.

Die sekundure Rahmengeschichte erlnnert stark an die PerseusSage, wo Pereeus mit selner Mutter Danae von dem Konig von Argoe, seinem Grobvater Akr18ios, dem ein Orakelspruch vor- 
hergesagt hatte, dab ein Enkel ihm Leben und Thron rauhen wlirde, in einen Kasten eingeschlossen und ins Meer geworfen murde 211 . Ferner finden wir dieses Motiv in der Mosesgeschichte (zweites Buch Moses,1.2), wo Moses vor seiner Mutter aus Furcht vor dem Pharao in einem Schilfkästchen in den Strom gelegt und von der Tochter des pharao gefunden und großgezogen wird.- Von den Schicksalsfrauen ist auch in anderen bulg. Iiedern die Rede, vgl. BNTv 4,277 ff.u.a. Auch hier wieder spielt das Kind im Sand und wird von dort weg zum Deveramt berufen. Marko wurde hier wahrscheinlich sekundăr fur Dete Golomełe eingesetzt. Das damonische Wesen, das fur den Drachen steht, ist nun anscheinend theriomorph (dzveretinal), doch mit drei kopfen gedacht. Daß Niarko die drei (Drachen-)Köpfe abschlagt und zum Erschrecken der Anwesenden den Hochzeitsgusten vorlegt, erinnert an Perseus mit dem Haupt der Gorgo Medusa. Dais Marko ferner mit der Totung des Ungeheuers drei Ketten Sklaven befreit, scheint aus den Liedern Ubernommen zu sein, wo Marko den schwarzen Araber totet und dadurch drei Ketten Gefangene freiwerden. Hier ist die Stelle wahrscheinlich so zu verstehen, dab die jklaven im Bauch (vgl. die drei Hochzeitszluge in Var.25) oder mindestens in der Gewalt des Untiers waren und durch den Helden befreit werden. Am Schlub des Iiedes erfullt sich die Vorhersage der Schicksalsfrau, als Marko nănlich seinen Vater - ebenso wie die anderen untreuen Svaten - mit der Keule schlagt. - Var.34 gehörte eigentlich auch hierher, weil darin der Araberkampf eine Rolle spielt, doch ist die Zugehörigkeit dieses Liedes zum nächsten Kapitel noch ausgepragter, so dab seine Behandlung dort zweckmaBiger erscheint.

Die nëchsten acht Varianten sollen gesondert besprochen werden, weil hier sekundar ein einheitliches Handlungs- und Kompositionsschema verwendet wird dergestalt, daß Marko mit seiner wutter beim Abendessen sitzt und sie ihren Sohn fragt, ob er sich je im Leben geflurchtet habe, worauf Marko den Uberfall auf einen Hochzeitszug schildert, an dem er als Dever teilgenommen und dabei den Angreifer, meist einen schwar- 
zen Araber, get8tet hat. Damals habe er sioh zum erstenmal in seinem Leben gefurchtet. - Das erste Lled dieser Gruppe, Var.35, trägt den Titel "Kraljević Marko 1 zmaj" und hat folgenden Inhalt:

ilarko sitzt mit seiner Mutter beim Abendessen, und die Mutter fragt inren heldenhaften Sohn, ob er sich je im Leben gefurchtet habe, worauf Marko antwortet, er habe ein einziges Mal Angat gehabt, und zwar be1 der Hochze1t des Sibinjanin Janko, der ihn als Dever berufen habe. Damals selen sle an Hof der Braut reich beschenkt worden, und die Brautmutter habe die Svaten vor der Abreise vor dem dreikbpfigen und sechsflugeligen Zmaj gewarnt, der beim ersten Flugelschlag alle Svaten zu Boden schleudere, beim zweiten tote und beim dritten das Mudchen entfuhre.- Die Svaten seien im Waldgebirge tatskchlich auf den Zmaj gestoBen, der mit dem ersten Plugelschlag die Svaten zu Boden warf, mit dem zweiten flugelschlag alle Svaten totete (svi ou svat1 listom izginuli) und beim dritten Flugelschlag Marko das Bein bio zur Hifte peitschte, 80 daB er starke Schmerzen versplurte. Da habe er, Marko, sein Schwert genommen und dem Zmaj drei Flugel abgeschlagen. Als inm das Schwert entglitten sei, habe er den neugeschenkten Sabel gepackt und damit den Zmaj geto tet. Vom Kampl mit dem 2 maj sel er aber nicht so mude geworden wie danach vom Sammeln der verstreuten Svaten. Eine ganze Woche hatten sie dann an Jankos Hof Hochzeit gefelert.

In dieser Varlante erfolt der therfall auf die Svaten durch einen Zmaj, der aber in der Art einer Lamia mit drei kbpfen und sechs Plugeln beschrieben wird, wahrend ein $2 \mathrm{maj}$ doch sonst meist anthropomorph (wenn auch mit einem Paar plugel) gedacht wird. Widerspruche ergeben $81 \mathrm{ch}$ daraus, dab der Zmaj einerseits alle Svaten mit dem zweiten Flugelschlag trtet, daß Marko, die Braut und schlieblich alle Svaten dann andererseits doch lebend gedacht sind; Marko allerdings wird "gepeitscht", wahracheinlich mit dem Plugel oder Drachenschweif des $2 \mathrm{maj}$. Die anscheinend besonders weit geflohenen Svaten milsen nach der therwaltigung des Zmaj minsam gesammelt werden. - In Var.36, wo wieder Marko berichtet, ist Janko kußetlija der Brăutigam, Braut die Tochter des Konigs Mikail, Kum Milo Kobilic, erster Svate Relja von Pazar und Brautfuhrer Marko Kral jeviç 
Die Svaten ziehen Uber das Heer zur Braut und werden von den Brauteltern gut aufgenommen und reich beschenkt. Auf dem Rlckweg uberfilit sie im Rumenlifa-Gebirge der dreikbpfige echwarze Araber, der aus einem der Kopfe spricht und sagt, die Svaten sollten ihre Geschenke der Reihe nach ablieferm. Alle tun dies, und schlieblich soll Marko das Madchen auf dem Pferd hergeben. Da ermahnt ihn die Braut, or moge jetzt sein Heldentum beweisen und sie nicht dem ochwarzen Araber ausliefern. Darauf uberwindet Marko seine Furcht und totet den dreikbpligen Angreifer.

Hier ist otatt des urspringlichen Drachen wieder der dreikopfige damonische Araber eingesetzt. Mit Janko Rusetlija lot vielleicht Janko von Sibinj gemeint; Rusetlija ist mbgIlcherwelse von rusiti 'zerstoren', musenje 'Zerstorung' abgeleitet. Der Brautvater Konig Mikail ist naturlich identisch mit dem lateinischen Krnig Michael in den 4.11-Iiedern. Das kumenlija-Gebirge ist olcher der Gebirgezug Romanija in Bosnien. - In Var.37 erzunlt Marko seiner Mutter folgendes Erlebnis:

Der junge Rad1voj habe gehelratet und Duka Iatinin zum Kum, Relja von Pazar zum ersten Svaten, Milor KobiIic zum zweiten Kum und Marko zum Dever berufen. Sie seien in das lateinische Iand gezogen und hrtten die Braut abgeholt. Dann sei im verfluchten Romanlija-Gebirge der dreikbplige Rapin aufgetaucht und habe allen Svaten die Geschenke abverlangt. Nur Marko habe zunkchst noch dem Angreifer getrotzt und das Madchen beschlitzt, sel aber dann vor Anget in den Wald geflohen. Durch den Pluch und Hilferuf des Lizdchens wieder zurlickgerufen, habe Marko den Rapin getrtet und inm seine drel Drachenhupter abgeschlagen. Drei Tage lang habe er anschliebend die geflohenen Svaten wieder zusammensuchen mussen.

Brăutigam iot hier Radivoj, ein Hajduke, der in den Volksliedern meist mit Novak zusammen genannt wird. Das Romanija-Geb1rge finden wir auch in diesem Iied wieder. Die Braut atammt schablonengemas aus der latelnischen Iand. Arapin wurde hier zu "Rapin" und einmal sogar zu "Rap" verkllrzt. Erhalten blieben jedoch die drei schrecklichen Kopfe des Arabers, von denen es ausdrucklich heibt, es seien Drachenkopfe (ajdzerske glave) gewesen, $d . h$. hier bietet sich uns wieder ein direkter Anhaltspunkt fur unsere "Drachen-Theorie". - In Var.38 berichtet Marko seiner Mutter: 
Bilinko Bilincin habe geheiratet und Georgi Despotidin als Kum geladen sowie weitere $70 \mathrm{Konige}$ und 80 Bane als Svaten und Marko als Dever. Sie seien nach Nikatan gezogen, dort gut bewirtet und relchlich beschenkt worden und hatten dann die Braut weggefuhrt. Sie selen glucklich durch Gebirge und Felder Eekommen, doch an elnem See habe sie der schwarze Araber uberfallen und aupgefordert, ihre Geschenke abzuliefern. Zuerst hatten die Svaten versucht, den Araber mit ple1len zu treffen, was aber nicht gelungen sel, worauf die Svaten alle die Flucht ergriffen hatten und nur Narko bel dem likdchen geblieben sei. Dann habe der Araber einen Zweikanpl um das N.ädchen vorgeschlagen, worauf Karkos Pferd seinem Herrn geraten habe, er solle sich mit Gurten festschnalien und dann den Kampl zuerst. mit der Keule, dann mit dem Schwert wagen. Marko habe den Araber mit der Keule vom peerd gerissen, ihm dann mit dem Schwert die Augen ausgestochen, Arme und Be1ne abgehauen und inn $80,2 u$ einem Torso verstilumelt, als "Wächter des Sees" zurlickgelassen.Dann habe er die Geschenke gesammelt und sel mit der Braut zu der nuchoten Schenke geeilt, wo er die geflohenen Svaten getroffen habe, die sich uber seinen mutmaßlichen Tod unterhalten hatten. Als sie Marko erblickten, sel er stiumisch und herzlich emplangen worden. Dann habe er dem Brautigam die Braut zugefunrt und fur seine Heldentat besonderes Lob geerntet.

In dieser Variante lot der Araber an einem See lokalisiert, was wieder fur seinen drachenartigen Charakter spricht. Neu lot hier, dab Marko den Araber ?von drel kopfen ist in dieser entmythologioierten Version nicht die Rede) nicht totet, sonderm - ein sekundăres Motiv - "nur" verstummelt und völlig hilflos zurlicklzBt. Bilinko Bilindin ist vermutlich ein errundener Name. Mit Georgi Despotidin konnte burat Brankovic gemeint sein. - In der bel Chal.RFV 31,S.143 kurz angegebenen Var.39 erzahlt Marko seiner Mutter folgende Begebenheit:

Kurz nach seiner Freiersfahrt habe Janko von Sibinj einen Hoohzeltszug veranstaltet, un die Tochter des Konigg von Budim heimzufuhren. Er, Marko, sei damals Dever gewesen. Auf dem Heimweg seien sie von dem schwarzen Araber Uberfalien worden, der, um sie einzuschllchtern, den blanken skbel hoch in die Wolken geworien und mit den Zähnen aufgefangen habe. Er habe von allen Svaten die Geschenke gefordert und erhalten, nur von Marko nicht, an den sich das lakdchen geklammert und thn beschworen habe, er solle sie nicht dem Araber ausliefern. Karko habe dar- 
aufhin - allerdings mit angstlich geschlossenen Augen - den Araber in zwel Telle gespalten, inm den Kopl abgeschlagen und die Geschenke an sich genommen. Dann habe er die geflohenen Svaten zurllokgerufen und mit ihnen die Braut zu Janko geellhrt.

Hier hat der Araber seine drachenartigen Zluge schon v8lilg verloren, so das ein Ubbergang zu den drel folgenden Varianten gegeben 1st, wo der Drache bzw. dämonische Araber ganz entmythologisiert und durch die Gestalt eines $T$ U $r e n$ ersetzt wurde. Das Handlungsschema lat aber sonst erhalten geblieben. In Var.40 ist der Angreifer ein "turako momce" an einem See (1), In Var.41 Aga Belll-aga mit 300 Janitscharen und in Var.42 schlieblich ein "Turince bosnjace". In Var.41 erinnert noch die Tatsache, dab Marko duratig ist und sich von dem Tluken an einen See fluhren läbt, an das Sujet von dem Drachen am Wasser; man vergleiche damit den Turken an see in Var.40.

Da dieses Spezialschema - Marko berichtet seiner Mutter von dem Uberfall auf den Hochzeitszug und seiner eigenen Heldentat - fast nur im okr. Raum verbreitet ist, darf man vermutlich annehmen, das es sich in der vorliegenden Form dort gebildet hat, und zwar in jungerer zeit.

Das nun zu besprechende Sondersujet dagegen gehort eindeutig dem obulg. Raum an. Es trägt einerseits sehr altertumliche Zuge, die aber andererseits mit jungeren, schon mehr dem "b1t" (dem durch Brauchtumspelege gepragten Alltagsleben) entstammenden Elementen durchsetzt sind ${ }^{212}$. Der Inhalt dieses Handlungsschemss ist folgender:

Stojen wird bei der Hochzeit seiner ehemaligen Geliebten als Dever bestimmt und erklart sich damit einverstanden. Seine Mutter warnt ihn vor einer in der Gegend umherstreifenden Burin, die Menschen anfalle und zerrelese. Stojan abor ochlugt die Warnung in den wind und zieht mit den Svaten zu der Braut. Aus dem Rluckweg wird der Hochzeitszug tatsachlich von der blutgierigen Barin (mexka strünica) Uberfallen, worauf die Svaten die Plucht ergreifen. Allein Stojan bleibt bel der Braut und kümpet mit dem wilden, blutrinotigen Tier. Als er zu unterliegen droht, ruft er die Svaten zu Hilfe, erfahrt aber von dem Mädchen, daß alle geflohen 
seien. Da ermuntert die Braut den Kampfer mit dem Versprechen, das er naoh einem Sieg uber den Buren nicht mehr Dever, sondern Brlutigam sein werde. Dank dieser Ermutigung gelingt Stojan der Sieg Uber das wildg, Tier, wodurch er das Madchen fur sich erringt. 213

Es handelt sich hier um die Var.43-54, die alle aus M1ttelund 0stbulgarien, also aus der Wiege des Hajdukenlieds stammen. Deshalb nimmt es auch nicht munder, dab der Hieblingeheld des bulg. Hajdukenlieds stojen (abgeleitet von bulg. stoja 'stehen'; also Stojan in der Bedeutung 'der Aufrechte') hier die Protagonistenrolle spielt. Das Hendlungegefuge nach dem Schema "flberfall auf einen Hochzeltszug, Flucht der Svaten und Verteldigung der Braut durch den Dever" $18 t$ noch ziemlich gut erhalten, nur wurde der zehnsilber durch den dynamischen Achtsilber und, was den Inhalt betrifft,der Drache bzw. dreikbpfige Araber durch einen blutgierigen BHren ersetzt. Dies könnte man als ein Zeichen der zunehmenden Annaherung an die Realitat und danit als letzte Stufe der Entmythologisierung ansehen. Moglicherwelse schwingen aber auch noch alte totemlstische Vorstellungen mit, in denen der Bar (wie andernorts der Wolf usw.) das Totemtier oder mindestens das dimonische Tier war, man verglelche den "Burentag" (mexicin den) in Mazedonten und Bulgarien und die "meckina povojnica" in 0atserbien und Mazedonien, wo man der Barin am Abend des Andreastags bzw. am ersten Januar gekochte Malskolben oder sogar einen Kindbettbrel ins Freie otellte 214 . well sie angeblich um diese Ze1t ihre Jungen bekommt. Der Andreastag wurde deshalb gewahlt, weil der Heilige das Vieh vor dem Angriff der Bären schützen sollte. - Neu 1 st der sekundă verlinderte Lledausgang, daß der Dever als Belohnung flur seinen siegreichen Kaimpl die Braut bekomnt, was schon in der Iledeinleitung vorbereitet wird, wo es heiBt, die Braut sel die ehemalige Geliebte Stojens geweren.

EIn anderes Sondersujet 1st serb. Ursprungs und sioher jungen Alters. Hier lst die Hochzeitszuggeschichte mit tberfall in eine Vogelhochzeit verwandelt. Es handelt alch hierbel vor allem um Var.55, ein Frauenlied mit folgendem Inhalts 
Der Sperling (vrabac) Podunavac frelt eine Melse (sjenica) drel Tagereisen ubers ebene Peld und vier Tagerelsen lubers Gebirge entfernt und erhalt die Einwilligung der Brauteltern. Er beruft die langschwinzige Elster (zvraka) als Kum, die Lerche (Bevrljuga) als zweiten Kum, den Grinspecht aus dem Norden ( $z u n j a$ ) als ersten Svaten und die Schwalbe (lastavica) als Dever. Auf dem Helmweg, als die Svaten zun Kosorofeld kommen, meint die Braut, man solle sich besser lelse verhalten, andernfalls werde der Raubvogel Sperber (kobac avanica) auf den Hochze1tszug aufmerksam und sie, die Braut, zu entfuhren versuchen. Das Madchen hat kaum ausgeredet, als der Sperber schon angeflogen komit und die Braut entfuhrt. Alle Svaten aind in das Dorngebüsch geflohen, der Brăutigam aber in des Hirsestroh und der Kum aue den Schlehdorn.

In diesem dem Heldenlied nachgestalteten Frauenlied mit dem Sujet einer Vogelhochzeit lot bezelchnenderweise wieder einmal Kosovo die Kampetztte, deren Name aber hier viellelcht auch deshalb eingesetzt wurde, well eben das "Amselfeld" besonders gut zu der Vogelthematik paßt. Ein Kampl zwischen dem Dover und dem Brautrauber fehlt hier, 80 daB das Ifed ohne happy end schlleBt. - Der Vollotundigkelt halber sollen noch zwel Lieder aus Petr.III angefuhrt werden, deren volkstumlicher Charakter aber, wie schon erwahnt, berechtigten 2weifeln unterliegt. Es handelt sich zunkchst um Var.56, "Zmaj 1 azdaha", mit folgendem (be1 Chal.RFV 31,S.152) kurz zusammengefabten Inhalts

Ein Palke freit die Tochter der Vila auf dem hohen Zvijezda-Gebirge und Uberreicht thr den Ring und elnen goldenen Apfel. In zwel Wochen soll die Hochzelt stattfinden, eine Prist, in der der Falke 1000 graue Palken und goldene Tauben als Svaten sammelt sowie Hirsche und Hirschillhe, mit goldenem Zaumzeug vereehen und mit Edelatelnen geschmuckt. als Reittiere bereitstellt. Nachts ziehen die Svaten zur Braut. Sie otrahlen 80 hell, das des ganze Gebirge aufleuphtet, als ob die Sonne schiene. Bel den vilen werden ele gut aufgenommen und erhalten die Braut. Als ole auf dem Rlckweg ins Kaldak-Gebirge gelangen, werden sie von elnem feuerspeienden, gierigen Drachen (nesita azdaha) Uberfallen, der alle Svaten in die Plucht schlkgt. Er entfunrt die Braut zu einem See (1), setzt sie ins Gras und entschleiert sie, woreuf die Vila bitterlich zu weinen anflingt. Der Draohe verschlingt das Reittier der Braut, was die Vila zu einem Hilferuf nach ih- 
rer sutter veranlabt. Die Mutter hort ole nicht, wohl aber der Held Zmaj Oenjenl, der auf elnem Tannenest im Waldgebirge sitzt. Hr breitet seine feurigen Plugel aus, wobel or Blatter und Griser versengt, und kommt herbeigellogen. Dann flunt or die Vila, die wie die Sonne strahlt, belseite und beginnt mit dem Drachen einen Kampl aue Leben und Tod. Die belden kgmpfen vier stunden lang und be1Ben sich mit ihren schareen Zahnen, b18 schlieBlich der Zmaj siegt, den Draohen tótet und in den See wirft. Er sammeit die geflohenen Svaten,nimmt die Braut und ruhrt den Hochzeltszug zur Behausung des Falken oben auf dem Gebirge, wo eine frobliche Hochzeltsfeler beginnt. Zum Dank fur seinen heldenharten Belotand schenkt die Braut Ihrem Retter eln von Vilenhand geschmiedetes Schwert, dem 810 seinen Namen eingraviert hat.

Le1der 18t der Volksliedcharakter dieser Varlante mehr als eragwlird18, sonst ware das Iled wirklich srotaunlich. Obwohl es deutlich als Produkt der Phantasie des Skngers zu erkennen und einzustufen 18t, enthrit es doch wesentliche Sujetelemente, die dem Berelch der echten Volkslieder entstammen. Hier Uberfallt statt des schwarzen Arabers wirklioh ein Drache den Hochzeltszug, was zu der auch sonst mythologlolerenden Art (eine Vila als Braut, eln Zmaj als Retterl) des Iledes past. Interessanterweise lot hier Zmaj Ognjent, der in dieser Variante tatskchlich als feuriger Zmaj aufgefast 18t, der Gegenspieler des Drachen, eine Vorstellung. die dem Volkgglauben entepringt, dab der Zmaj als wohlgeoinnter lokeler Schutzgelet den erntevernichtenden Gewitterdrachen bekámplt. Doch daruber mehr in Kap.4.41. Der Kampl der beiden dimonischen Wesen wird in dem Iled so beschriebens

Zmaj ognjevit, a Azdaha ljutas

Iz Azdahe vihor vjetar puse,

A od Zmaja maven plamen suxe.

Der Zmaj funglert hier nicht als Dever im Hoohreitszug, sonderm grelft, veranlast durch den Hilferuf der Pee, von auBen ir. das Geschehen ein. - Var.57 stammt ebenfalls aus der ob1gen Sammlung:

Hier mus der Palke olch erst ein Jahr lang alo Freier bemlihen, bis er endlich die Vila als Braut veroprochen erhylt. Er sammelt Palken und Tauben als Svaten, Irwen als Relttiere. Auf dem Rluckweg werden die Svaten im Otres-Gebirge von Turken Uberfallen, wobel die Braut fur den Anfuhrer "delibara 
Ibro" entfuhrt wird. Rajko von Zmijanje, der heldenhafte Wahlbruder der Vila, befreit die Braut. Hier oind Drache und Zmaj zu einem Tlirken und seinem serb. Gegner entmythologisiert worden, whicend die anderen phantagtischen Blemente - eine Vila als Braut, ein Falke als Bräutigam, Tauben und Falken als Svaten und Löwen als Reittiere - erhalten blieben.

B1s hierher reicht eigentlich unser Sujet, doch soll nicht verskumt werden, noch Ileder anzufunren, wo ein Hochzeltszug von elnem Turken oder einem abgewiesenen Freier uberfallen wird. Entweder ist hier der drachenkhnliche Araber sohon v81118 zu einem Turken entmythologlsiert worden, das urspringliche Handlungsechema aber noch intakt (vgl. Vuk II 91. Petr.II 42 u.a.), oder aber es handelt sich um neuere (Hajduken-)Ileder, in denen ein Uberfall auf einen Hochzeitszug, durch den abgewiesenen ehemaligen Preier der Braut verubt, geschildert wird, wobel das urspringliche sujet aber so abgeändert 18t, daß der Anschlag mit Hilfe einer Verkleidung der Braut und damit Irrefuhmung des Brauträubers vereitelt wird (vgl. Vuk II 93, III 72 und 73, Radov.13 u.a.). Zwischen diesen Möglichkeiten gibt es fließende Ubbergange, $80 \mathrm{daB}$ die belden Liedkomplexe nur schwer voneinander getrennt werden konnen. In vielen Fallen erfolgt der fberfall noch an einem Gewksser (vgl. Bog.13, Vuk II 93 u.a.), was vielleicht eine Reminiszenz an das alte Sujet, vielleicht aber auch nur zufall sein kann. Es handelt sich hier vor allem um die Iieder Vuk II 91 und 93, III 72-76, VI 24 und 35, Bog.13, Milut.87, Patr.II 42, III 43, 46, 50 und 57 ; Jastr., 287, Male8.169, M11.144, Bez8.I 32, SbNU XII,70, XIIII, 167. Oder aber es dreht sich um reine Hajdukenlieder, die zwar an der Sujetlinie und Komposition der zlteren Heldenlieder Pesthalten, den dämonischen Brautrauber aber durch eine Hajdukenbande ersetzt haben, wie es in Bog.118, Horm.I 6, Vuk III 67 und 68, Milut.130 und 144 u.a. der Fall ist.

Eine weitere Komplikation beim Hochzeitszug kann dadurch entstehen, daB die $V I l$ a den Bräutigam ins Herz sohieBt 
(vg1. Maz.,81 und Boßk. NEP II 15 ohne und MH $I_{1}, 586=$ Tommaseo $8 \mathrm{mlt}$ happy end) oder aber die Braut entfuhrt und die Svaten erblinden labt ( $v g l$. wH $I_{2} 20$ und die var. MH $I_{2}, 364-368$ mit happy end). Bei dem Iled aH $I_{2} 20$ und Var. 1st interessanterwelse das (Märohen-) Motiv AaTh 302 ("The Ogre's [ Dev11'8] Heart in the Egg", vgl. Vuk Pripov. $\mathrm{Nr} .8$; Hahn Nr.26, Nr.64 und Var.1 + 3, Nr.65 Var.1, Nr.70 Var. usw.), das Motiv der AuBenseele (external soul), die hier im Falle der vila in den goldflugeligen Enten auf der Donau und den Gebirgatieren (uva?) mit dem goldenen viles eingeschloseen 1st, mit der Hochzel tezugthemat1k verbunden. roglicherwelse lat die vila - genau wie der dumonische Araber - erst sekundar für ein Drachenwesen eingetreten, woflur auch das Motiv der "Seele außerhalb" spricht, ein Motiv, 215 das eben sonst fast ausschlleblich in Verbindung mit drachenartigen Ungeheuern oder Riesen, also auf jeden Fall dgmonischen Wesen, vorkommt. In dem Lied MH $I_{2}, 366$ 18t sogar von elner "vila troglavkinja", also einer dreikbpligen vila die Rede, was ebenfalls auf eine etwalge Substitution des dre1k8ppigen Drachen oder dämonischen Arabers durch die v11a hinweist. Noch drachenahnlicher verhalt sich die Samovila Angelina in dem kurzen maz. Iled Mil.179, wo sie die belden Söhne der Janovica, die sich als Brautigame auf dem Rllckweg von der Brautfahrt befinden, mit Haut und Haar verschlingt. In all diesen Fullen handelt es sich sicher um eine altertilmiche Substitution, namlich um eine Ersetzung des Drachen durch die vila zu einer zelt, als die vila noch als ein dem Menschen kuberst gefuhrliches dumonisches Wesen mit grausamem Charakter aufgefabt wurde, whrend die spatere Zelt die Feen zu Wahlschwestern, Helferinnen und manchmal sogar Dienerinnen des eplschen Helden gemacht hat.

Eine andere Komplikation des Hochzeltszugs kann dann elntreten, wenn der Broutigam unterwegs ein Gewksser auf seine Tlefe und Strömung hin erproben mub, bevor der lug sich hindurchbewegt. Diese Lleder, die das Motiv der E r p r o b u n $g$ eines $G$ e w $a_{\text {s }}$ e $r$ o enthalten, konnen mit oder ohne happy end angelegt sein, vgl. dle Var. Males.156, 
M1ch.220, Bezs.I 9, Kad.198, Bulg.kn1z.I, 199; Jastr.,299; SbNU XXXV,140 u.a. War das liotiv der Strrung eines Hochzeltszugs durch die vila vor allem skr., so handelt es sich nun bei dem llotiv der Gewsssererprobung ausschlieblich um bulg. und maz. Varianten. Auffallend ist dabei, daB der Bräutigam - ahnlich wie in den 4.12-Liedern - häufig in drei Etappen untersinkt und in einigen Liedern das Madchen inm helfen will. Es konnte sich also um eine sekundarre Motivvermischung von 4.12 und 4.21 (wobel mit 4.21 hier naturlich nur die Lieder mit dem Motiv der Erprobung eines Gewässers durch den Brăutigam gemeint aind) handeln. DaB die Svaten darauf bestehen, daß allein der Brătigam das Gewasser erprobt, erinnert andererseits an die 4.22-Ileder, wo ebenfalls der Brkutigan gezwningen wird, Hasser aus dem durch einen Drachen bewachten Brunnen heraufuholen. Vielleicht war auch in den Liedern mit dem Notiv der Gewbssererprobung ursprunglich ein Drache vorhanden ( $\nabla g l$. das Untersinken des Brautigams in drei Etappen), der dann zunehmend entmythologisiert wurde und schlieblich ganz wegfiel. Zwischenstufen der angenommenen Entmythologisierung sind moglicherweise in anderen (meines Wissens nur skr.) Liedern, die ebenfalls das notiv einer PluBuberquerung enthalten, zu erkennen. So wird Narko in Milut.153 z.B. von einer Schlange im Wasser angegriffen, als er den Jabuka-Fluß uberschreiten will.Eine Var. hierzu bildet $\mathrm{HH} \mathrm{I}_{2} 66$, wo die Schlange (eigentlich die[!] hl. Sonntag - sveta Nedelja - in Gestalt einer Schlange)aus einer Wolke auf liarko niederfallt und sich $\mathrm{inm}$ um den Hals windet (weil er am Sonntag gejagt hat). In Horm.I 3 bleibt litars peord plotzlich in der Drina stehen und lst nicht mehr zum Heitergehen zu bewegen. Da stellt sich heraus, daß die "bjelogorka vila" dem Tier unter Wasser die Vorderbeine mit ihren Haaren unwickelt hat, um Mitar zu ertranken. In einem Hochzeitszuglied, wo "herceg Stjepan" seinen altesten Sohn Viaisav mit der Tochter des Konigs von Venedig verheiratet ${ }^{216}$, versuchen zwei vilen, den Brautigam dadurch zu ertränken, daß sie sich seinem fferd an die Hufe hägen, als es die Tara uberschwimmen will. In dem jungeren Lied MH I,65 
versucht die von dem Brautigam turo Smederovac verschmbhte Vila Ana aus Indien (1) einige seiner Svaten in der Donau zu ertranken, indem sle sle unter Wasser mit ihren Haaren fesselt. Auch in der russischen Byline finden wir eine vergleichbare Episode. Hier lot es in dem Lied "Dobrynjas Kampe mit der Schlange" die Schlange Goryndirze, die den Helden Dobrynja im Pucajflub ertranken will 217 .

Wie wir gesehen haben, handelt es sich bel dem zuletzt Beoprochenen um voneinander wahracheinlich abhlingige Iledkomplexe, in denen vermutlich verschiedene Mrglichkeiten und Stufen der Substitution eines ursprlinglichen (Wasser-) Drachen realisiert wurden.

Den Iledern, wo ein Hochzeitszug Uberfallen wird, steht ein anderes Sujet nahe, wo auf ein $E h$ e a a $r$ beim ersten Elternbesuch ein $U$ b e $\quad P$ a $I l$ ausgeubt wird:

Ein Held schlagt seiner jungen Frau vor, ele zum ersten Besuch (pohod) seit ihrer Helrat zu ihren Eltern zu bringen. Die junge Prau hat Angat davor, durch das Waldgebirge zu reiten, weil sie dort einen abgewiesenen Freier vermutet. Ihr Mann aber meint, sie solle sich nur auf seinen Heldenmut verlassen. Sie machen sich auf den Weg. Im Gebirge wird der Mann plotzlich von kudigkeit uberfallen. Er bittet deshalb selne Prau, lhm etwas vorzusingen, damit er nicht auf dem pferd einschlaPe. Die Frau verwelot wjeder auf den Feind, dooh der Held beharrt auf seiner Bitte, so daB die Frau schlieblioh zu singen anfangt. Der im Wald versteckte Vojvode erkennt sie an der Stimme, verkleidet sich als Bettler und taucht plotzlich an einer Wegkreuzung auf. Die Prau, die in dem angeblichen Bettler den feindlichen Vojvoden erkannt hat, warnt ihren Mann davor, dem Verkle1deten etwas zu geben. Der Mann hort nicht auf sie, beugt $81 \mathrm{ch}$ rom Pferd he runter und wird von dem "Bettler" gepackt und gePesselt. Fntweder bittet nun die listige Frau mit geheuchelter Preude Qber das unverhoffte Wiedersehen mit dem ehemaligen Geliebten um das Schwert des Vojvoden, um damit Ihrem Mann den Kopp abechlagen zu können, trennt inm aber dann vielmehr die Fesseln durch, worauf ein Zweikampl entbrennt, oder aber die Frau bittet den Vojvoden, ihren Mann heimgehen und Geschenke holen zu lassen, worauf der Mann aber mit dem Schwert zurlickkommt und den "Bettler" samt seiner Druzina niedermacht. Dann setzt das Ehepaar seinen RAtt fort. 
Es handelt $81 \mathrm{ch}$ hierbel um die Varlanten ${ }^{218}$ Il.86, Kax. 184 und 196, M11.114 und 161, Sapk.336 und 360; SbNU II, 104; IV, 65; XIV,80; XXV,15; XIII,23; XIVII,234. In den I1edern Bezs.I 40 sowie Vrrb.339 und 493 sind statt elnes Ehepara Bruder und Schwester elngesetzt.- In den Iledern EH 71 , Male8. 154, Drag.42, Doz.34, Jastr.,69, SbNU Xل,388 fordert der Ehemann belm Zwelkampe selne Prau auf, entweder ihm oder seinem Widersacher zu helfen, worauf sie threm ehemaligen Geliebten belsteht und wegen dieser Treulosigke1t von Ihrem trotzdem olegrelchen Mann schwer bestraft wird. Dieser Zug durfte aus den Iledern von der untreuen Frau ubernommen worden und hier sekundar sein. Sekundar let sicher auoh das Sonderschema, daß die Prau bewubt durch Singen den Hajduken hervorruft, um thn unschadlich machen zu können ( $\nabla g l$. SbNU XIII Nr.55 und die dort angegebenen Var.). Da den zahlre1chen maz. und bulg. Varianten nur ein einziges akr. Iled (EH 71) gegenubersteht, dare man wohl vermuten, das es sich um ein aus dem maz.-bulg. Raum atammendes Sujet handelt. DaB der Widersacher duroh Singen hervorgelockt w1rd, erinnert an die sudslavischen Ileder, wo zwel Wahlbrlider durch das Waldgebirge reiten und der eine, weil er die vila durch sein Singen gestbrt hat, von der Fee erschoseen wird, woraue der Uberlebende (Marko) die V1la zwingt, den Getroffenen durch Helikräuter wieder Ins Leben zurlokzurufen, was auch wirkl1ch gelingt (vgl. die Var. Vuk II 37, MH I $I_{2}$, Jastr.,218, SbNU I, 55; I,58; XIII,96; XIIII,97 u.a.). Auffallenderweloe gibt es nun ein kurzes wbulg. Iled (SbNU XIV,62 "Marko 1 zinifa troeglava"), In dem statt der vila oder des Hejduken ein $D r$ a $h$ e dae Ehepaar flur die durch das Singen der Prau verursachte Störung bestrafen will \&

Marko 18t mit oeiner jungen Prau zu einem Verwandtenbesuch unterwegs. Plbtzlich wird der Held von starker Mudigkeit erfabt und bittet Elena, seine Prau, ole möge ihm etwas vorsingen, sonst schlafe or ein. Die Frau gehorcht, oingt aber so laut, daß der ganze Weld widerhallt. Da kommt ein dre1köpe1ger Drache mit neun Zungen (ala trooglava sù tri glav1 $1 \mathrm{z}$ devet ez1c1) hervor und fragt, ob er flur dlese St8rung lieber Marko oder Elena das Leben nehmen solle, woraue Marko der Mla sein Sbhnchen an- 
bietet mit der Begrlindung, ohne elnander konnten Marko und Elena nicht leben, ein S8̈hnchen aber wirde Ihnen Gott in einem Jahr schon wieder schenken.

Leider fand ich zu diesem fllr unsere Substitutionstheorfe so wichtigen wbulg. Lied, wo ein Drache sich durch Singen gestort fuhlt und die Storenfriede verschlingen will, ke1ne weiteren alldelavischen Varianten, was aber nicht unbedingt heiben soll, das es nicht doch noch Lieder dieser Gruppe gibt oder gegeben hat. Bel den griech. Volksllederm dagegen at1eB 1ch, ohne systemat1sch gesucht zu haben, gle1ch auf zwe1 Varianten (Kind XIII; Kind XIV = Ilabke,250), wo ein

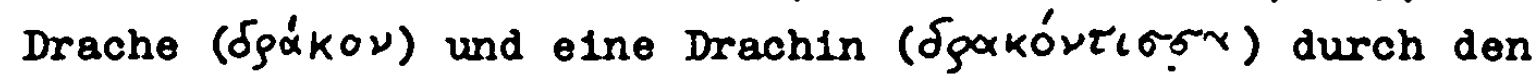
Gesang eines Helden (Jannis) gestort werden und den sanger verechlingen wollen, was aber im elnen Pall durch eine Drohung ("Der Sohn des Blitzes bin 1chl"), im anderen Fall mit Hilfe eines Geschenks verhindert wird.

Das heibt vermutlich, dab wir flir das wbulg. Iled und die griech. Varianten wahrscheinlich eine genetische Verwandtschaft bzw. gemeinsame Tradition annehmen durfen.

Nach all dem Gesagten konnte man viellelcht eine Entmythologlolerungareihe $\mathrm{Dr}$ a c he $\rightarrow \mathrm{V} 1 \mathrm{l}$ a $\rightarrow \mathrm{H}$ a j d uke aufatellen, die bel dem vorher behandelten Hauptsujet 4.21 (Uberfall auf einen Hochzeltazug) den Reihen D r a $\mathrm{h}$ e $\rightarrow$ dumontscher achwarzer A $r$ a b e $\rightarrow$ T U r ke bzw. abgewiesener $F$ e 1 e $r$ oder $H$ a $f d u k$ a oder aber D ra $\circ \mathrm{h}$ - V 1 la (Vila im Gebirge bzw. Vila Im FluB) enteprache.

vielleicht handelt es sich aber bel dem obigen Motiv (singende Prau lockt ehemaligen Freier hervor) um ein reines Hajdukenmotiv, das unabhlingig von den anderen Liedkomplexen entstanden 1at. Diese Prage durfte jedoch achwer zu entschelden sein.

Einen.weiteren unserem Hauptsujet 4.21 nahestehenden Liederkreis sehe $1 \mathrm{ch}$ in den Varianten, die den fo ber 1 a 11 auf ein $B r$ a $u$ p a a (nicht unterwegs, sondern zu Hau8e) zum Thema haben, wobel das Sujet aber ganz anders als in den Hauptrarianten zu 4.21 aufgebaut 1st, namlich sos 
Ein Held (melet Surbin) Ireit die schone Vida aus Ohrid. Auf der Brautfahrt (von Svaten ist keine Redes das Brautpaar reltet offensichtlich ohne Begle1tung zu Surbins Hof!) erblickt ein versteckter Beobachter (Markos Nefle Grujo; Detelin vojvoda; Kosul kesedzija; Jankula und Sekula) das Antlitz der schonen Braut, der der Wind den Schleler weggeweht hat, und entbrennt in Leidenschaft zu ihr. Er sammelt eine Schar Krieger und zieht zu surbins Hof, un das Brautpaar zu uberfallen und die Braut zu rauben. Die Braut, auf deren Schob der ochlafende Brbutigam seinen Kopf gelegt hat, sieht das Heer kommen, beginnt zu weinen und weckt den Schlafenden mit ihren Tranen. Der Brăutigam stellt olch sofort zum Kampl und metzelt alle bis auf eine kleine Schar Leute nieder, die ihn aber dann nach Anwendung einer List ("Wir sind gekommen, un air Geschenke zu Uberreichen") meuchlings umbringen. Entweder opringen nun die Braut und thre Schwagerin in den Flus und ertrinken oder aber der Anfunrer der Schar t8tet die Braut,um die sich die Munner erbittert otreiten,- weil nur durch Totung des "Streitobjekts" die Auseinandersetzung beendet werden kann.

Als Varianten 219 aind vor allem folgende lieder zu nennen: Verk.-Lavr.6; Drag.28 und 63; Jastr..75; M11.96; SbNU IV,69; VI,53; XII,62; XIV,66; XIIII,235; XIIV,50; XIVI,Nr.7; XIVIII, 56. - Interessant ist der Name $S$ u $\mathbf{r}$ b $1 \mathrm{n}$, der be1 Mil.,653 unter den "sobstren1 narodni 1mina" genannt und von Sapk. In Anm.1 zu Nr.291 mit der Bemerkung "Srrbin, sobstveno 1me, koeto u nasite mesta redko se upotrebjava, osobito po selata" versehen wird. Bel Werner 220 wird Surbin als mannlicher $P N$ In Mazedonien und Westbulgarien lokalisiert und von dem Ethnikon surbin 'Serbe' abgeleltet. Fest steht jedenfalls, daß dieoer Namenform kein allzu hohes Alter zugeschrieben werden dare, well im uittelalter die Bezelchnung "Srbin, Surbin" kelne Rolle eplelte und daher nicht verwendet wurde. Der Name kommt auch außerhalb unseres Sujets relativ haufig in der maz. Sammlung Verk.-Lavr. sowie in Kac.119, SbNU XIII,235 u.a. (vgl. ISSP VIII/IX 285, 327, 439, 525, 590-96, 642) vor. Die Frage 18t, wer mit surbin gemeint sein konnte. vielleicht verbirgt elch hinter diesem Namen Jankula, der hkuf18 Janko von Kosovo, das Kosovofeld aber in elner Reihe von Iledern (vgl. Verk.-Lavr.6 und 149 usw.) "gurbsko" oder "sirbinsko pole" genannt wird. Wahrochelnlicher lot aber die Deutung. 
daB Milos (Milos Ohrinjanin) gemeint 1ot, der alo Milos von Ohrid auch in Bog.18, EH 50 und Mil.143 vorkommt und in einigen Liedern 221 eogar Milo Surbin genannt wird.Daß ein schlafender Held angesichts der nahenden Gefahr durch die auf sein Geolcht niederfallenden heiben Tränen der Prau geweckt wird, lot ein altes Motiv, das z.B. auch in den Drachenkampliledern, wo der hl. Georg durch die Tränen des dem Drachen augelieferten Madchens aus dem (maglochen) 222 Schlaf geweckt wird, vorkommt. - Der Meuchelmord an dem. Brautigam erinnert an die Lieder, wo Dete Dukatince, des Heldenkind, von Karko meuchlinge ermordet wird, und tatskchlich heibt der Brkutigam in Verk.-Lavr.6 "Birbinoko dete", in Drag.28 und SbNU XII,62 "dete oúrbijance", In Jastr.,75 "dete sirotence" und in SbNU VI,53 sogar "Dete Dukatince". Surbin lat also vermutlich ein den maz. Heldenkindern angepabter serb. Iledheld (kiloz?). Da das zuletzt behandelte Sujet nur in Mazedonien und Westbulgarien aufgezelchnet wurde, dürte es wohl in diesem Iledraum entetenden sein.

Zusamenfassend labt sich Uber die 4.21-Ileder mit dem Hauptoujet "Hochzeltezug mit therfall auf dem Rllckweg und Verte1digung der Braut durch den Dever" und den Nebenthemen "thberfall auf ein Ehepaar beim ersten Elternbesuch" und "Uberfall auf ein Brautpaar nach beendeter Brautfahrt" agen, daB es a1ch um Iledkomplexe handelt, die m.E. In Bezlehung zueinander otehen, wobel eine Tendenz zur fortechreitenden Entmythologielerung - vom Draohenkampleujet ausgehend - zu beobachten 18t. Wie aus dem Iledvergleich erolchtlich wurde, stammen die Var. entweder ausschlieBlich aus Mazedonien und (West-) Bulgarien (d1es gilt fur die Nebenthemen), oder aber die archalochsten Var. des Sujets (gemeint 18t des Haupteujet) oind dem maz. und bulg. Raum zuzuordnen, so dab wir mit gewiseer Berecht1gung die 4.21-Ileder 1hrer Entetehung nach dem maz.-wbulg. epischen Ballungszentrum zuordnen können. D1es gilt m.E.,wie schon betont, auch fir die 4.12- und 4.13-Lieder, whrend die 4.11-Ileder in ihrer opezifischen Porm wahrocheinlich im okr. Raum entatanden sind. $\mathrm{Da}$ in den neurriech. Heldenliedern ein 
Sujet, in dem Hochze1tszug- und Drachenkampfthematik kombinlert sind, meines Wissens nicht existiert, scheint es sich bel den 4.21-Iiedern um rein slldslavische Sujets zu handeln.

\subsection{KAMPP MIT DEM DRACHEN IM BRUNNEN}

War die eine Mrglichke1t der Komplikation eines Hoohze1tezuges ein therfall auf die Svaten, verubt von elnem melst dämonischen Wesen, so handelt es $81 \mathrm{ch}$ nun um einen Drachenkampl des Bräutigams bel dem Versuch, Wasser fur die Svaten aus einem Brunnen, in dem eine Ala bzw. Lamja haust, heraupzuholen. Es hat den Anschein, daB hier ein rein maz.-wbulg. Iledeujet vorllegt, 'denn die mir bekannten Var. stammen alle aus Mazedonien und dem westlichen Bulgariens

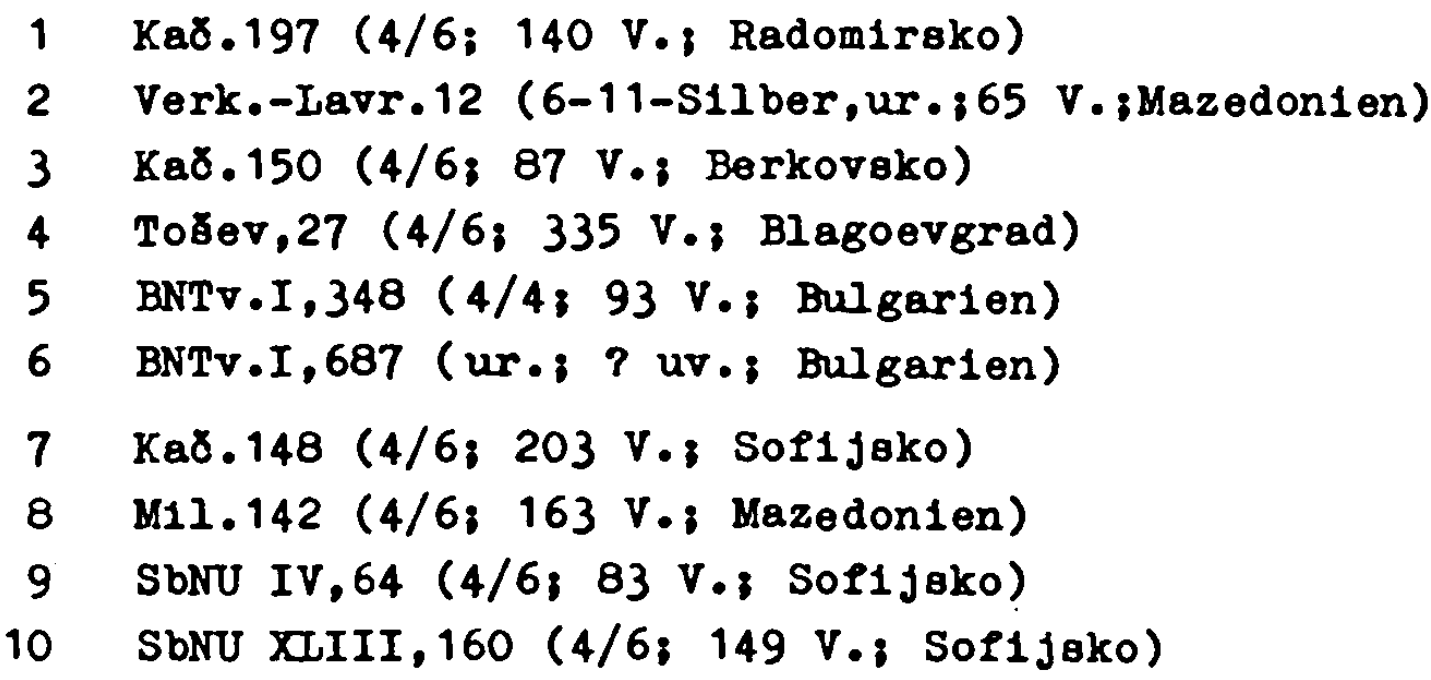

Die Var.1-6 sind mit dem Ze1chen $\square$, die Var.7-10 mit $\Delta$ in die Karte elngetragen.

Var. 1 hat folgenden Inhalts

Der Junge Held Todor freit ein fiddchen von welther, ntalich aus der Stadt Negrit.Als Todor kaum zu Hause angekommen 1st, erhalt er einen Brief von den Brauteltern mit der Anweloung, der Brăutigam solle 900 Svaten sammeln. Todor 1at verzwe1felt, bekommt aber von seiner Mutter den Rat, Marko Kralevik ale Kum, Janko von Kosovo als Dever und Relja Krilatica als ersten Svaten einzuladen, denn diese dre1 Helden könnten mit Leichtigke1t je 300 Sraten aus 1h- 


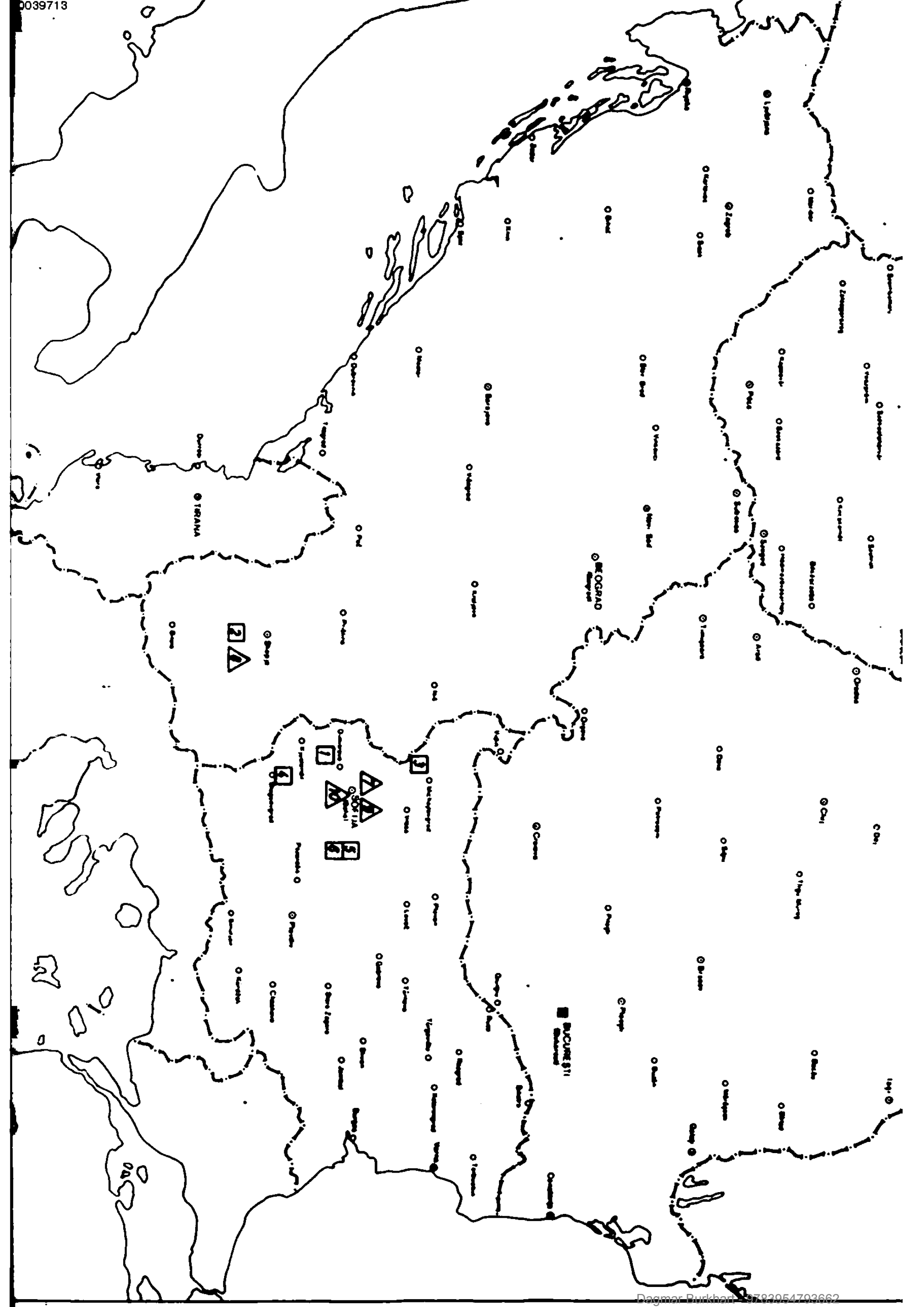




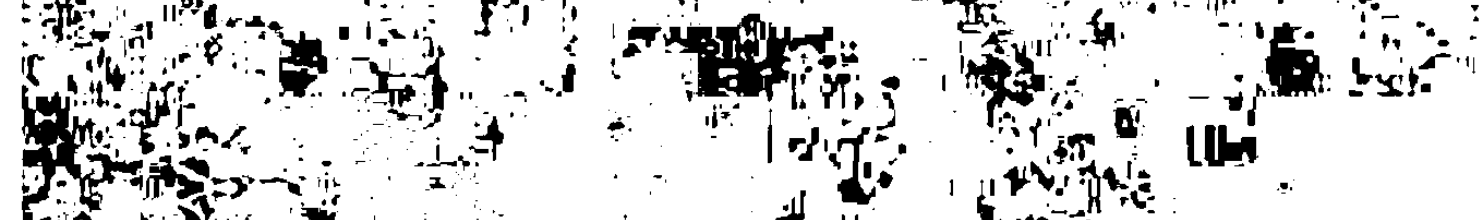

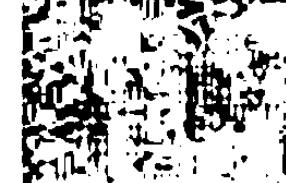

and

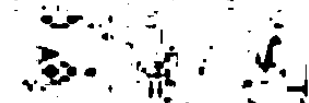

$$
\begin{aligned}
& \text { (n) }
\end{aligned}
$$$$
\text { 年 }
$$

$$
\text { Not }
$$

on

and

$$
\text { At }
$$

tor

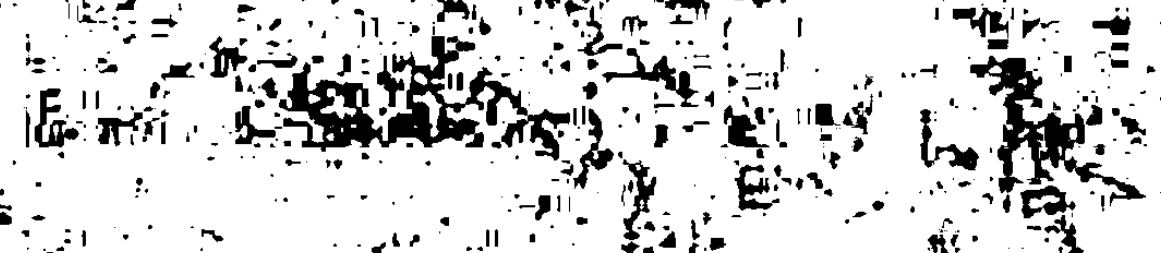

ond

fit

$$
\text { 7t }
$$

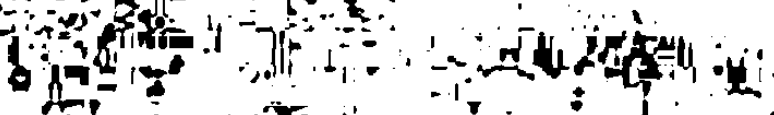

(1)

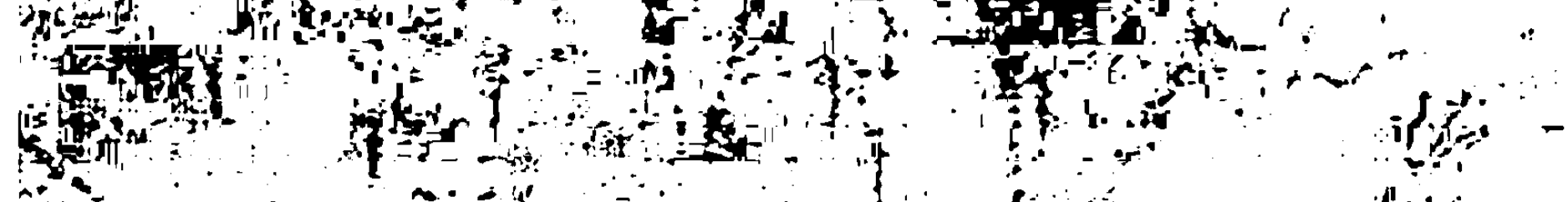
Af a ard sis $+!$

:

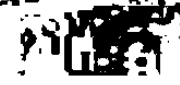

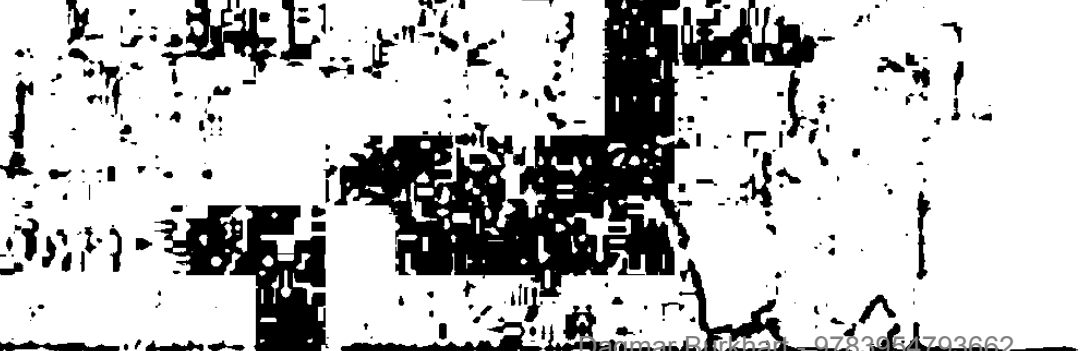




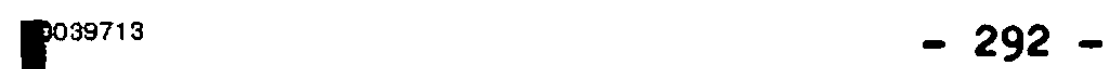

ren Stzdten mitbringen. Todor gehorcht den Rat der kutter und errelcht so die erforderliche Svatenzahl. Die Reloevorbereltungen dauern zwolf Tage. Man stollt ew6lf Wagen zusammen, auf denen Trinkwasser transportiert werden ooll, denn in Porlm-Geblrgo, das die Svaten uberqueren nllseen, glbt es kein Wasser. Marko jodoch let dagegen. das Wasser attzunehmen, woraue auoh die ubrigen Svaten melnen, wenn sio we der Jagd selen, tranken sie ja auch drel Wochen lang kein Waeser. Nach diesen tberlegungen lassen sie die Wagen zurlick, zlehen durch des Perim-Geblrge zur Stadt Negrit und holen das Madchen ab. Auf dem Richweg Uberfallt die Svaten in Goblrgo plotzlich hert1ger Duret, worauf ale Todor eragen, ob ale die Pferde ochlachten und deren Blut trinken sollten. Todor verbletet dies und segt, er wis8o einen 70 Bllen tiefon Brunnen mit Irischem Wasser.- 110 d1e Svaten an dem Brunnen angelangt ind, weigern 81ch alle hinunterzustelgen. Da fordert Marko den Brautigam aue, Waseer heraufzuholen. Welnend legt Todor seine Hochzeltskleider ab. Dann wird or an seinem Seldenglirtel festgebunden und in die T1efo gelaseen. Br let kaum unten angelangt, als er auch schon verewelfelt ruft, an Grund des Brmnens 110ge elne Rieseneohlenge, die Ihn b1s zum Inte, num b18 zum Glurtel verschlungen habe.- Marko, Janko und Relja versuchen der Relhe nach, Todor heraurzuziehen, was aber nicht gelingt. Erst als Marko sein Plerd zlehen laBt, kommt Todor aus dem Brunnen zum Vorschein, allerdings mit der Schlange. Marko zleht sein Schwert, un die Schlange zu toten, schneldet aber aus Versehen den Glirtel durch, worauf die Schlange und ihr Opfer wieder in den Bminien zurlakfalien. Da muft Todor, die Svaten sollten 1hm, wenn sie wogzogen, wenigitene sein Pford dalasson und thn daran festblinden.- D108 goeohleht, und die Sraten breohen als. D10 Braut fragt Narko, wem or 810 denn nun zufuhre, wenn Todor im Brunnen zurlakbleibe. Marko olbt dareuf ke1ne Antwort.- Todor schrelt aus der T1efe, und das Pferd wiehert am Brunnenrand so lange, bis sie von der Samovila gehrrt werden, die unverzbglioh herbeleilt und Todor fragt, warum er im tiefon Brunnen l1ege. Todor antwortet, die Schlange habe 1 hn halb verschlungen. Darauf stalgt die Samovila in den Brunnenschacht hinumter, schlitzt die Schlange auf, zieht Todor heraus und bringt $1 \mathrm{hn}$ naoh oben. S1e fordert zuerst Todor auf, die Svaten zurluckrurufen, tut es aber dann selbst, als Todor dazu noch zu schwach 18t. Marko hort d10 Stimme, kehrt mit der Braut um und sieht Todor mit der V118 am Brunnen sitzen. Da vernelgt sich Marko von veitem und Wust, an Brunnen angelangt, der Samovile die Hand und beschenkt e1e mit Goldmonzen, whrend die Braut 
der hilfrelchen Fee ein seidenes Gewand Uberrelcht. In dieser Var. ist ein unbekannter Todor (oder ist Todor von Stalac gemeint?) der Brăutigam, die Anfuhrer der Svaten aber alnd die bekannten Helden Janko, Marko und Relja. Die Braut stammt aus der Stadt Negrit, hinter der man weniger die rumanische Stadt Negreģti als vielmehr eine Ableitung aus bulg. negur 'Neger' vermuten darf (vgl. Misir 'Ägypten' als Ziel der Brautfahrt in anderen Iiedern). Mit "Perim" durfte wohl das Pirin-Gebirge gemeint sein. Das Motiv "Durst im wasserlosen Waldgebirge" ist m.E. alt; es kommt vor allem in den 4.42Liedern vor, wo allerdings das Wasser von der vila bewacht und nur gegen schweren Tribut freigegeben wird. Hier ist es nun eine Riesenschlange mit Drachencharakter (pogolema zmija jalovita; "jalovit" ist wahrscheinlich von ala, hala abgeleitet, vgl. halovit), die das Wasser im Brunnen bewacht und jeden verschlingt, der sich ihr nthert.

Ich möchte nun sowohl die hier zu besprechenden lieder vom Drachen im Brunnen wie auch die Vila brodarica-Iieder (4.42) von den Drachenkampfliedern des Typs 4.41 ableiten, wo ein Drache das Wasser bewacht und Menschenopfer verlangt (Andromedanotiv; Georgslegende). DaB der Drache an das Wasger gebunden ist, konnte bisher schon oft an hand der Ileder festgestellt werden. Interessant ist hier der Brunnen als Aufenthaltsort des Drachen, well der Brunnenschacht bekanntlich als elner der möglichen Eingange zur Unterwelt gedacht wird, vgl. das Grimmsche Mërchen "Prau Holle" usw. Die Vorgtellung, daß der Unterweltseingang in einer Grube, Höhle oder einem Brunnen liege, halt Cajkanovic $\mathrm{C}^{22}$ fur möglicherweise gemeinindogermeniech. - Var.2 unseres sujete maoht einen ziemlioh verderbten Eindruck:

Svaten sitzen belsammer, und felern, bevor sie sich auf den Weg machen, um die Braut abzuholen. Sie kuBerm Bedenken daruber, ob es unterwegs wohl Wasser gebe, doch Marko zerstreut ihre Angst und sagt, er wisge im Gebirge einen tiefen Brunnen mit frischem Wasser, allerdings von einer verdammten Lamja (kucka lamja) bewacht.- Als die Svaten unterwegs zu dem Mădchen (nigriCanka) sind, kommen sie zu dem Brunnen. Stefan wird angebunden und als erster in die Tiefe gelassen, dann aber unverrichteter Dinge 
wieder hochgezogen, weil inm das bloBe Geheul des Drachen schon zuviel Angst einflobt. Jankul ist mutiger: Er wird bis zu dem Ungeheuer hinuntergelassen, titet es und holt Wasser herauf. Als alle getmunken haben, setzen die Svaten inren Weg fort, holen die Braut ab und bringen sie glucklich zum Haus der Bräutigammutter (na dilber Stanovata majka).

In dieser Var. wird zunkchst gar nicht gesagt, wer der Bräutigam ist (am Liedende stellt sich heraus, dab es sich um einen gewissen Stan handelt) und was flur Svaten eingeladen oind. Mit Stefan ist vielleicht Stefan Jakbic, ein Held der sekundaren maz. Iledschicht, gemeint. Jinger ist sicher das Motiv, daß mehrere Helden (nicht aber der Bräutigam) den Abstieg in den Brunnen versuchen. Flischlich sind in dem stark verderbten Lied die Episoden des Gurtel-Iurchschneidens und der Hilfeleistung der Samovila weggelassen. Das Brunnenungeheuer wird hier ausdrucklich "lamja" genannt. Das Mudchen "nigricanka" erinnert an die Stadt Negrit im vorhergehenden lied. - Var.3 ist der ersten sehr ähnlich:

Hier 1st Polugun Specen der Brăutigam, der Wasser aus dem durch einen dreiköpligen Drachen (ala troeglava) bewachten Brunnen holen soll, von Marko, dem ersten Svaten, mitsamt der Ala heraufgezogen und aus Versehen am Gurtel abgeschnitten wird, so daB die Ala und ihr Opfer in den Brunnen zurlickfallen. Die Wahlschwestern Vela und Jona Samovila horen Poluguns Schreie und das Wiehern seines Pferdes.Vela verlangt von dem Drachen die Herauggabe ihres Wahlbruders, doch die Ala meint darauf, sie sitze nun schon 300 Jahre in 300 Artin Tiefe, aber solch ein Held sel ihr noch nie zugefallen. Sie wolle lieber Ihren Kopf verlieren, als thre Beute herauggeben. Da fangt die Vila an mit den Flugeln zu schlagen und sich zu drehen und erzeugt dadurch einen solchen Wind, dab das Brunnenwasser hochgewirbelt und die Ala mit ihrem Opfer herausgeschleudert wird. Die Vila totet den Drachen und zieht aus ihrem wideraacher den halbverschlungenen polugun mit so zerschundenen und zerbrochenen Gliederm heraus, dab der Held erst mit Heilkräutern behandelt werden muB, bevor er den Svaten nacheilen kann.

Neu lat hier die Art, wie die Wahlochwester des Brlutigams, die Samodiva Vela, die Ala aus dem Brunnen herauf- und herauswirbelt, womlt sie sich unmittelbar als Sturmaamonin erwelst. Dieses Motiv erinnert an ein Ghnliches in dem Lied Jastr.,208, 
wo Sultan Suleiman mit Hilfe des hl. Georgs und eines durch sein Gebet hervorgerufenen starken Hindes mitsamt dem feindliehen Heer in das Meer geschleudert wird, ein lied also, das ziemlich eindeutif aus dem Drachenkamplmotiv abgeleitet 18t, wobei hier der turkische Sultan den Drachen ersetzt und der hl. Georg die Rolle des Drachentoters spielt. - In Sapk. VIII.53 ( $\mathrm{Nr}$.45) werden die Samovilen als Windgottheiten (boZestra na vetro'ite) bezeichnet. Es heiBt dort ferners"Koga da se storit nekoja vetrußka (vichrułka), veleet: se terale samovilite ill viulicite". Erwahnenowert scheint mir außerdem, daß auch der babylonische konig liarduk den weiblichen Chaos-Drachen Tiamat und Gilgamesch das Ungeheuer Chumbaba mit Unterstutzung der Winde toten. - Der liame Polugun laBt sich vielleicht mit ISSP VIII/IX,424 so erklaren, daß der Held "polovin guna", also einen Halbmantel trug, eine Erklaummg, die in ISSF fur Kosta Lera Pologun gegeben wird, hinter dem Kazon den historischen Relja sehen mochte. Var.4, auf die im vorigen Kap. bereits hingewiesen murde, hat folgenden Inhalt:

Milor futtert drel Jahre lang ein gutes pferd mit feinem Heu, goldgelbem Heizen und dreijuhrigem Wein. Als Milos zum erstenmal damit ausreitet, zertritt das Pferd das Steinpflaster und labt die Mauern erzittern. Da meint die Druzina, Mllos habe dieses wur dervolle Pferd sicher nicht umsonst herangezlichtet. Er solle es beschlagen, mit Silberplattchen schmikken und seine alte lutter damit in allen Iandern eine passende Braut flur den Sohn suchen lassen. Die hutter macht sich tatsachlich auf den Weg und zieht erfolglos durch alle mbglichen Itander, bis sie endlich in Budim ein passendes Madchen fur ihren Sohn findet. Sie erfuhrt aber, dab ein schwarzer Araber jedem Preier das lfadchen streitig mache. Die Mutter schliebt die verlobung trotzdem ab, und die Bruder der Braut, die die Alte ein Stlick begleiten, tragen ihr auf, Milos solle binnen einer Woche Svaten sammeln, und zwar lauter leute, die relten und den wurfspeer schleudern konnen, sowie als Dever seinen trevesten Preund nehmen.- Die Mutter macht sich auf den Heimweg. Sie zieht neun Tage lang durch das Waldgebirge und acht Tage lang ubers offene Feld, findet aber nirgends Trinkwasser auser in einem tiefen Brursnen, den eine Schlange (zmija nebesnica) bewacht, die jeden, der sich ihr nuhert, verschlingt. Die Mutter gelangt nach Hause und berichtet ihrem Sohn uber alles, was sie erlebt hat.-Mloy sammelt nun schmucke 
Svaten aus drel Studten, lauter wehrfkhige Leute. Al Kum nimmt er Stefan und als ersten Svaten den jungen Dimitrice. Er hat aber noch keinen Dever und zieht deshalb betrubt durch alle mbglichen Lander, b1s er schlieBlich Dete Golomese trifft, der 81ch fur dieses Amt anbietet, daflur aber K11088 Pferd, Klelder und Waffen verlangt.-Als andlich alle Svaten versammelt oind, kann der Hochzeitazug aufbrechen. Hilos vergiBt, Wein und Schnaps mitzunehmen. Nach neun Tagen werden d1e Svaten durst18 und verlangen vom Brautigam etwas gum Trinken. Milos berlchtet von dem Brunnen mit der Schlange, und die Svaten verlangen nun, dab der Brautigam sie zu dem Brunnen hinfuhre und Wasser heraurhole. Als der Hochzeltszug an der Wasserstelle angelangt 18t, wird H1los am Gurtel festgebunden und in den Schacht hinuntergelaseen, wo thn die Schlange 80fort b18 zu den Inien verschlingt. D1e Svaten binden ihre 300 Pferde und Mioss Yrachtplerd aneinander und ziehen 80 , wobel die Pferde der Svaten b1s zum Knie und MAlose Pferd b1s zum Sattel einsinken, den Brautigam samt der Schlange heraus. Stefan wili das Ungeheuer toten, trennt aber aus Versehen den Gurt durch, 80 daß 4108 mit der Schlange in den Brunnen zurickfillt, wo er b1s zum Glurtel verschlungen wird. Mllos ruft, er werde hier sterben; man mbge deshalb seine Lanze zerbrechen und sein Pferd am Brunnen festbinden.- Nachdem dies geschehen 1st, bleibt nur der Dever zurlck, um auf Hiloss Tod zu warten und dann dessen Pferd flur sich zu nehmen. D1. Svaten aber achlagen den Weg eln, auf dem sie gekommen sind.- Miloss Pferd wiehert den Pferden naoh und der Held im Brunnen weint so laut um die Druzina, das ihre beiden Stimmen sogar zu Gott dringen. SchlleBlich hort cile Juda Samovila die Klageschreie, obwohl sie drel Gebirge weit entfernt im Relgentanz (oro) tanzt. Sie vermutet ihren Wahlbruder H1los in dem von der Schlange bewachten Brunnen und ellt herbel, un thm zu helfen. Sie ruft der Schlange zu, sie solle Mllos loslassen, doch die Schlange meint, sie denke gar nicht daran, denn so eine gute Beute oel thr nie zugefallen. Da pleht die Sanovila zu Gott um Wind, in dem ole, als Gott ihre Bitte erh6rt hat, tanzt, Wirbelwind erzeugt und so das Hasser sant der Schlange und ihrem Opfer aus dem Brunnen springen 18Bt. Sie totet das Ungeheuer, befreit Milos und hellt seine zerquetschten Glieder mit Helikriutern. Der Dever holt inzwischen die Svaten zurluck, die nun endl1ch Wasser trinken konnen. Dann zieht der Hochzeltszug zur Braut, deren Bruder den Svaten schon entgegenkommen. Nach dreitagigem Pelern machen ole $81 \mathrm{ch}$ mit der Braut aue den Heimweg. In Waldgebirge lauert den Svaten der 8chwarze Araber auf, vor dem alle auBer dem Dever, der die Braut beschutzt, fllehen. Der Araber 
verwickelt den Dever in einen Zweikampf, wobei Dete Golomese zunzchat den von dem Araber geschwungenen sabel mit dem Steigbugel abwehrt. Der Araber fordert Dete G. auf, noch einmal stehenzubleiben, damit er ihn treffen konne, worauf Dete G. meint, nur einmal habe inn die Mutter geboren und nur einmal der Kum getauft. Der Dever schleudert seinen eisernen Streitkolben auf den Gegner, treibt diesen drei Arsin tief in den Boden und tötet ihn.- Als die Svaten wieder zurlickkommen, versetzt Dete G. Jedem einen Keulenschlag zur Strafe fur das Verlassen der Braut; den Kum aber schlugt er noch dreimal, den ersten Svaten zweimal und den Brăutigam sogar neunmal. Milos schreit unter den Schlägen, worauf die Samovila wieder herbeieilt, um zu sehen, was ihrem Wahlbruder dieses Mal geschehe. Sie wird von der Braut mit einem Seidengewand beschenkt und gibt dieser als Gegengabe drei Edelsteine.

Wie deutlich zu ersehen ist, wurde das Sujet dieser Variante sekundar mit dem 4.21-Sujet (Uberfall auf einen Hochzeitszug und Verteidigung der Braut durch den Dever) kontaminiert. Auch hier wieder holt die Juda Samovila die drachenartige Schlange ("nebesnica" iat von nebo 'Himmel' abgeleitet) mit Hilfe eines von ihr erzeugten Wirbelwinds herauf und befreit und heilt ihren Wahlbruder. Daß in diesem lied die shutter fur den Sohn auf Brautschau geht, ist ein altes, typisch maz. Motiv, das vielleicht noch eine Reminiszenz an die Zeiten des Matriarchats enthalt.- Wahrschelnlich ist die Vermutung richtig, daß das Pferd, bevor das Motiv einer Wahlbruderschaft zwischen Held und Vila aufkam, die urspringliche und alleinige Helferrolle spielte, vgl. BNTV I,348, wo das pferd allein dem Helden aus dem Brunnen hilft, wahrend es in den jungeren Liedern zwar am Gurt zieht, die Rettung des Helden aber der vila Uberlaseen mub. - Die zwel letzten Varianten, numlich Nr.5 und 6, die eine Kontamination von Sujettyp 4.13 und 4.22 darstellen, wurden schon in Kap.4.13 besprochen.Es handelte sich darum, daB Gruica, Harkos Neffe, flur Kral Madzarin, um Angelina zu erringen, Wasser aus einem von einer siebenkopfigen Lamia bewachten Brunnen holen muBte.

Unser bisher behandeltes Sujet steht einem anderen sehr nahe, aus dem es vielleicht - durch Erweiterung mit der Hochzeitszusthematik - entstanden ist. Dieses nahverwandte sujet weist 
ein den vorhergehenden Varianten sehr Hhnliches Handlungsschema auf, das flur Var.7 so lautets

Sieben Konige begeben $81 \mathrm{ch}$ auf Wanderschaft duroh alle moglichen Itunder, um bis zum Ende der Welt vorzudringen. Mit Ihnen zieht Sekula Detenoo. Nach dre1 Wochen Relse bekomnt Sekula Durat. Sein Ohe1m Harko fuhrt ihn zu einem Brunnen, den eine dreik8pfige Schlange bewaoht. Siebenmal wird Sekula in den Brunnen hinunterselassen, um Wasser flir die Kontge heraufzuholen. Als er schlleBlich fur sich selbst Wasser holen will, erwacht die Schlange und versohlingt $1 \mathrm{hn}$ bis zu den Knien. Sekula bittet um sein Schwert, das man thm sofort hinunterlabt. Als er damit ausholt, zerschneldet er aus Versehen das Sell, an dem er angebunden 1st, und flult auf den Grund des Brunnens, worauf thn die Schlange bis zu den Schultern versohlingt. Aup Sekulas Bitten ziehen die Konlge welter, nachdem s1e $1 \mathrm{hm}$ noch sein Pferd am Brunnenrand festgebunden haben. Das Wiehern des Pferdes wird von den Samovilen Djurga, Vela und Magda gehort, die 1hrem Wahlbruder Sekula zu Hilfe ellen. Nachdem Magda die therwindung des Ungeheuers nicht gelumgen 1st, totet Djurga die dreikopfige Schlange und rettet damit Sekula, der sofort sein Pferd bestelgt und den sieben Konigen nachellt.

Dieses archaisch-mythologisohe lied mit marchenhapt anmutenden Zugen behandelt eine Wanderschaft der im maz.Lied stereotypen sleben Konige ans Ende der Welt, - und ans Ende der Welt paBt dieser von elnem Drachen bewachte Brunnen, gle1chsam der Eingang zur Unterwelt. Da dieses Sujet 224 einen noch altertimlicheren Eindruck maoht als das mit dem Hoohze1tszugmotiv verbundene ( $\operatorname{Var} \cdot 1-6)$, möchte $1 \mathrm{ch}$ es als den Ausgangspunkt fur das erweiterte Sujet aneehor. Die Verkoupfung mit dem Hochzeltszugoujet lot eben - wie wir wissen - eine beliebte Methode der Episierung des allein nicht sehr erglebigen Drachenkampfoujets. - Die nkchote Var., Nr.8, 18t dadurch erweitert, daß Marko von'seinem peerd auf den von den vilen aus dem Brunnen geretteten und nun dcch nachkommenden Sekula mehrmals aufmerksam gemacht wird und die freudige Nachricht zuerst unglaubig, dann aber mit Erleichterung aufnimmt. Die hilfreichen Samovilen heiBen hier Gjurgja und Erina. - In Var.9 bewacht eine "ala trojoglava" den Brunnen. Hier trennt Marko aus Versehen den Rlemen, an dem Sekula hangt, durch. Sekulas Retterinnen sind die Samovilen Gjura und Dena. Auf 
Anraten der Samovila Dena erschlagt Sekula alle oleben Könige wegen ihrer Untreues

Site sedúm pot nos je turilo.

In der letzten Var., Nr.10, werden fur den Relseweg der sieben Konige 15 Lunder aufgezahlt, namlich "zemja Turatinska", "Arbanaska", "Karam Vlazka", "Rus1 jaka","Prus1 jaka", "K1taj8ka", "Amer18ka", "Ital1 joka", "Crrmogorska", "Grürka", "Masŭrska"(M181r?), "Anadolska", "Persijska", "Anglijska" und "Vrensǔska"(Frankreichl). Dies lst natülich ein Zug aus jungster zelt, in dem der sanger seine geographischen Kenntnisse beweisen wollte. Die Samovila heibt hier wieder Gjurga. Sie halt sich im Pirin-Gebirge auf.

Interessanterweise stieb ioh auf mehrere griechische Iieder, in denen ebenfalls der Drache im Brunnen eine wichtige Rolle spielt. Im ersten Lied, Kind Nr.11 (32 V.) mit dem Titel " $O$

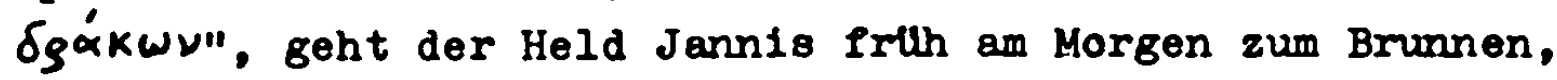
um Wasser zu holen:

Er weckt den im Brunnen hausenden Drachen, der inn zur Strafe fressen will, von Jannis aber 1mmer wieder vertrostet wird. Schlieblich nahert sich Jannis dem Brunnen mit oeiner klagenden Familie und seiner froblichen Schönen ( $\dot{\eta} k \alpha \lambda \dot{\eta})$, die dem Drachen Angat einjagt, indem sie sagt: Vom Himmel steigt der Vater mir, die Mutter von den Wolken,

Zu Brudern hab' ich Donner und Blitz, und fresse selbst die Drachen.

Daraufhin verzichtet der Drache auf sein opfer. Jannis' Schöne, auf deren Drohung hin der Drache den Helden Preigibt, 1st anscheinend selbst ein dumonisches Wesen (khnlioh dem, Zmaj), das Draohen trten kann. 224a In dem zweiten Brlech. Iled, Lubke,264 (28 V.) mit dem Titel "Der Quellgelst", das unserem maz. Sujet noch uhnlicher 18t, ziehen neun Bruder auf kơniglichen Befehl hin fur zwölf Jahre in Peindesland:

Vierzig Tage leiden die Brider unterwego Hunger und Durst, bis sie endilich in einer einsamen Gegend auf einen tiefen Brunnen stoBen. Durch Los wird entschieden, das Konstantin, der Jingste, in die Tiefe steigen und Wasser holen muB. Die Brider senken thn an einem langen Tau vierzig 
Klafter tief hinab. Inm dunkelt vor den Augen und or ruft angetvoll, man moge lhn hinaufziehen. und zwar mit Hilfe seines Rappen.- Der Versuch miBlingt: 1rgend etwas hilt Konstantin im Brunnen fest. Schließlich ruft er nach oben, die Brlder soliten Ihn im Brunnen zurlacklassen und der Mutter zu Hause sagen, Konstantin habe in der Premde eine Braut gefunden, "ein Konigokind, elne Zaubermaid", die inn fir allezelt mit ihren benden gefeseelt habe.

In dem von Llubke mit der Uberschrift "Der Quellgelot" versehenen Lied hendelt es sich offensichtlich um einen Drachen Im Brunnen, obwohl dies nicht ausdrlicklich gesagt wird. "Etwas" halt den Helden im Brunnensohacht fests Gemeinbalkanisch und wahrscheinlich alt 18t des B1ld, in dem der Tod Im fermen Land als Vermbhlung mit einer fremdlandischen Schonen umschrieben wird. - Mit diesem Iled 18t die inhaltich fast glelche Var. Sakellaridis Nr.7 (17 V.) von der Insel N18yros zu vergleichen. Hier met Mikrokonstandis aus dem Brunnen herauf, das dort "wilde Tiere"( $\theta \varepsilon \rho\llcorner\dot{\alpha})$ und auf dem Grma

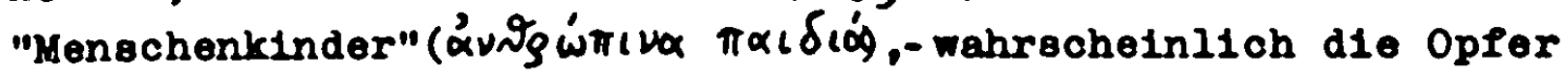
der "wilden Tiere", selen. - Drel weitere griech. Var. aus Kastoria, Epiros und Pontos fand 1ch in der Sammlung Ellinika unter den Nm. $\Gamma^{\prime}\left(25 V_{\bullet}\right), r^{\prime} \alpha\left(25 V_{\bullet}\right)$ und $\Gamma^{\prime} \beta\left(20 V_{\bullet}\right)$. Davon $18 t$ vor allem die erste Var. Intereseant, well hier das Brmnenungeheuer, des in den anderen liedern melot nur als ein gehelmnisvolles "etwas" bezelchnet wird, ausdrucklich ale "kinderfreseende Lamia" beschrieben wird. In alien Griech. Var. eplelt das Pferd (zusammen mit den Brudern) die Helferrolle, wobel die griech. Lleder aber ohne happy and schlieben. Von elner Fee let hier kelne Rede, d.h. wir haben damlt wahrocheinlich einen Beweis fur das relativ opute Elntreten der hilfreichen Samovila in den maz. und wbulg. Lledern. Angesichts der auffallenden Ähnl1chkelt zwischen den griech. Iledern und dem maz.-wbulg. Sujet 18t - geatutzt duroh die geographische Nahe - mit groBer Wahrecheinlichke1t genet1sche Verwandtechaft enzunehmen, wobel das griech. Sujet das urspringliche sein dirfte. Das vermatlich dem grieoh. Raum entstammende Sujet scheint nach N vorgedrungen zu sein, wofur Drag.180 (63 V.), ein maz. Iled aus Dojran, den Bowe1s 
liefert. Der Inhalt dieser Var. lautet numlich so:

Eine Mutter hat neun Sbhne, die zum Militurdienst elnberufen werden, wobel sich der jungste, der neunjuhrige Gjurgil, als Bannertrager meldet. Als die Truppe auf dem Weg nach Anatolien dre1 Tage lang kein Wasser findet, endlich aber doch auf einen tiefen Brunnen st8Bt, ruft der Herold, ein Mutiger werde gesucht, der den Abstieg in den Brunnen wage. Es meldet oich Gjurgil, der an ein Seil gebunden und so oft in den Schacht hinuntergelassen wird, bis er die ganze Truppe samt den Pferden mit Wasser versorgt hat. Als er zum letztenmal in den Brunnen hinabsteigt, um selbst zu trinken, kommt er nicht mehr herauf, weil ihn eine neunkoppige schlange verachlungen hat:

Go lapna zmija u a devet glavi.

Der Junge ist nicht zu retten, obwohl seine Brider ihn immer wieder heraufzuziehen versuchen. Schlieblich binden ale ihm das Pferd an den Brunnen und ziehen weiter. Als ole nach dreijăhrigem Kriegsdienet heimkehren und der lifuter die Todesnachricht bringen, stirbt die Alte vor Schmerz.

Aus dem ritterlichen lilileu stamt das schon aus den skr. Langzellenliedern bekannte Motiv, daB das Pferd beim Tod seines Herrn mit ihm zugrundegehen soll (und daß die Waffen des Helden zerbrochen werden, vgl. die obigen maz. Var.), ein Motiv, das in den griech. Iledern dieses Sujets nicht erscheint. Im Vergleich zu den balladesk und sprunghaft wirkenden griech. Varianten lot das zuletzt genannte maz. Iled nach den Grundsatzen der slldslavischen epischen Lieder gestaltet; der Liedausgang ohne happy end gilt fur beide Seiten, whrend die zehn oben besprochenen maz. Heldenlieder mit happy end, $d . h$. der Rettung des Drachenkumpfers,enden. Dieser positive Schluß lst, wie wir noch sehen werden, ein typisches kerkmal der maz. und wbulg. Drachenkamplileder, in denen der Held gegen das Ungeheuer niemals unterliegt.

Statt der oben angenommenen genetischen Verwandtschaft der griech. und maz. Varianten des Sujets vom Drachen im Brunnen und der mutmablichen Prioritat der griech. Ileder ware als andere Hbglichkeit zu erwägen, daß auch im Falle dieses Sujets wie achon an anderer Stelle bei thnlichen mythologiachen IIedern angedeutet wurde - die sanger wahrscheinlich aus einem archaischen, fur den griech., maz. und wbulg. Raum gemeinsamen 
und urspringlich wohl gattungsmalis noch undifferenzierten Stoff- und Rotivreservoir schopften, wodurch sich die offensichtlichen Parallelen erklaren ließen. Diese Frage mußte aber in größerem Rahmen an Hand des gesamten einschlagigen hiaterials behandelt werden.

\subsection{HOCHZEIT MIT FREIERSPROBEN UND UBERPALI AUP DEN BRAUT- $\underline{\text { ZUG }}$}

Das nun zu behandelnde Sujet ist m.E. ganz offensichtlich eine Kontamination aus zwel urspringlich getrennt voneinander existierenden Sujets, die - wie wir sahen - gleichzeitig auch unabhangig bestehen. Es handelt sich nämlich um den Zusammenschluß der Sujets 4.1 (Brautgewinnung nach dem Bestehen von Freiersproben) und 4.2 (Uberfall auf einen Hochzeitszug), woraus dann das neue Sujet 4.3 (Hochzeit mit Freiersproben $u n d$ tberfall auf den Brautzug) entstand, zu dem so berlinmte Lieder wie z.B. Vuk II 28 "Dusans Hochzeit" gehoren. Das Sujet ist im skr., maz. und bulg. Raum bekannt und umfaBt meines Wissens folgende Varianten:

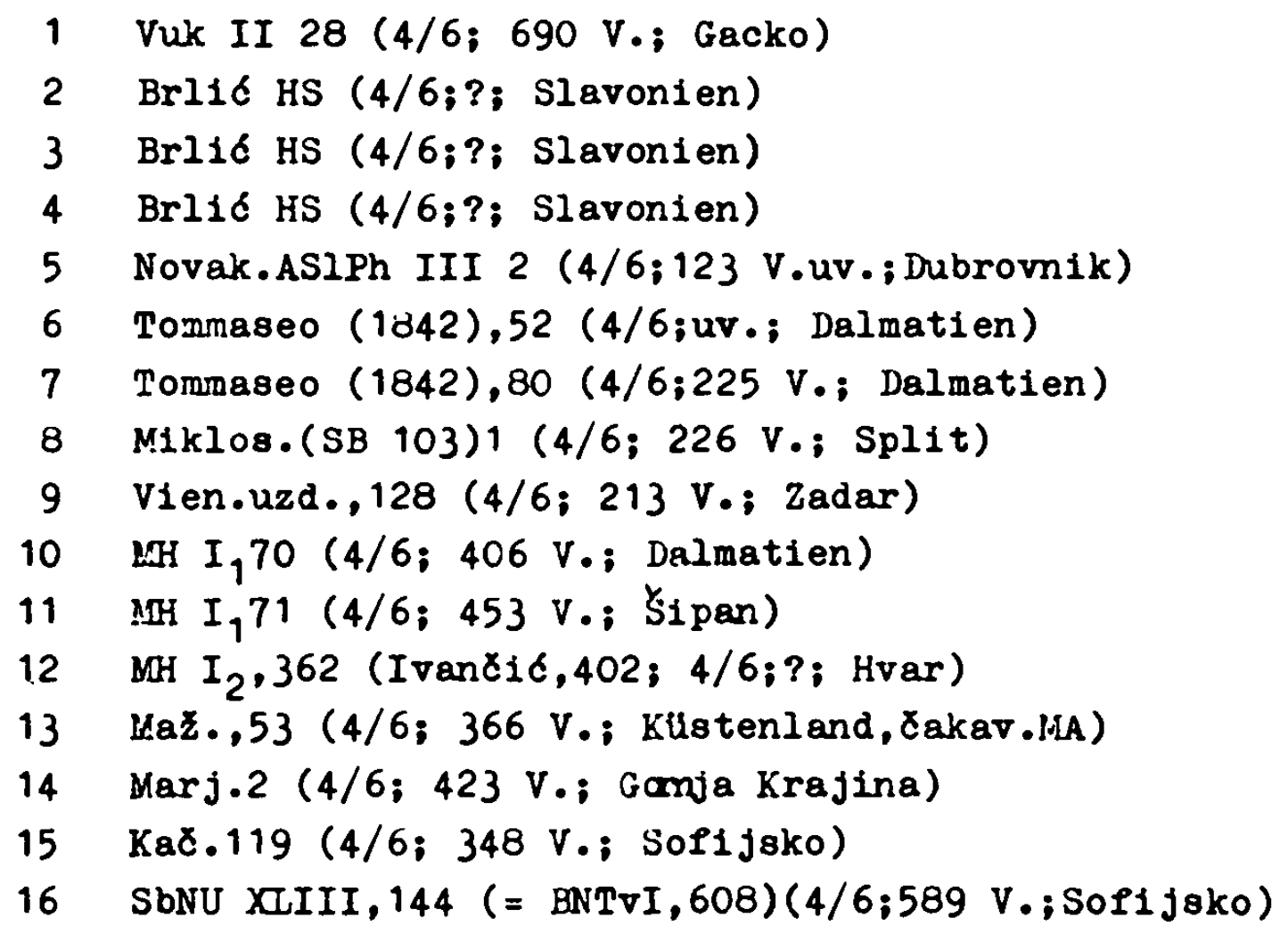


(1) the

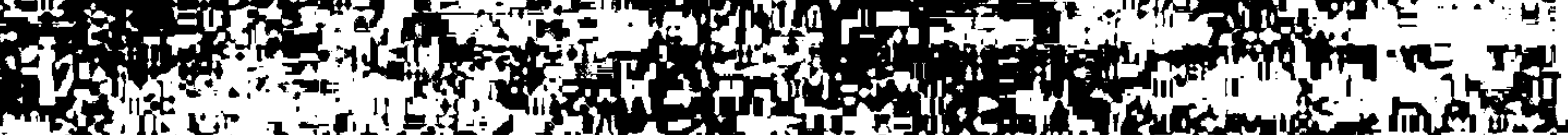

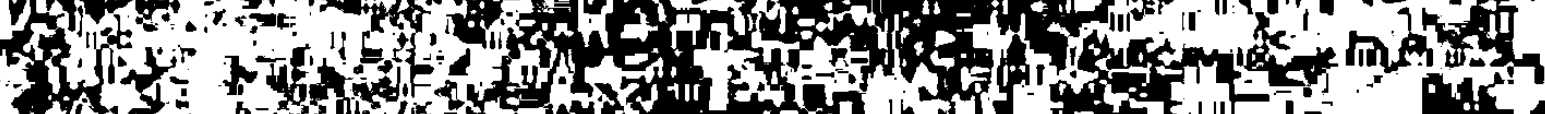

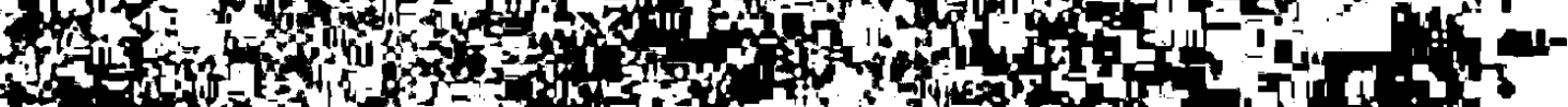

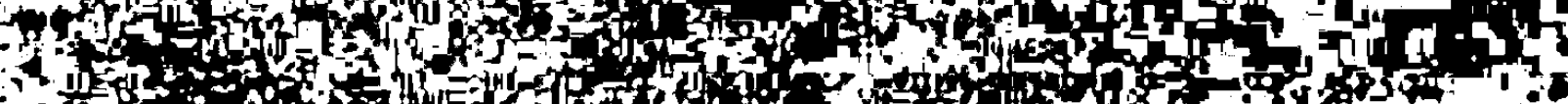
infor of a :10 (t) then

Fis

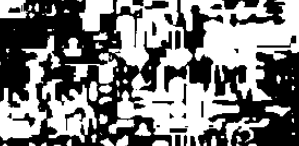

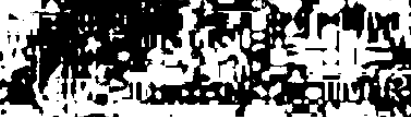

ind int

(1)

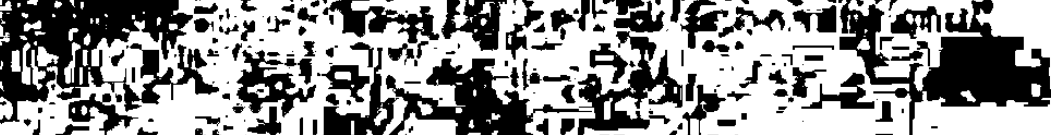
- 1 d

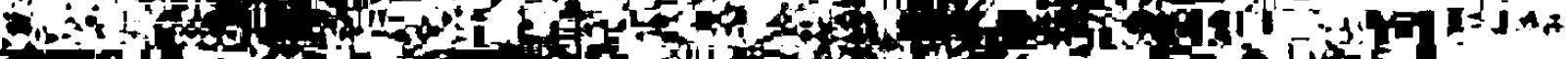

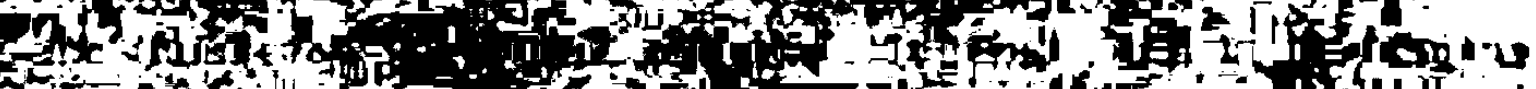

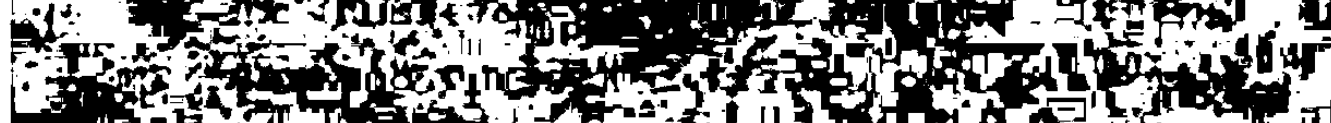

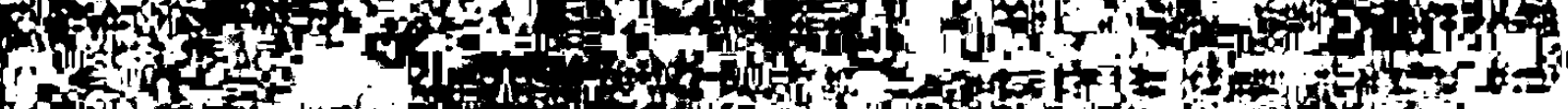

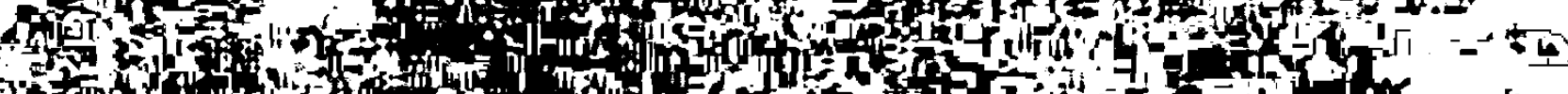
Fon

\section{If}

Nor Ar-

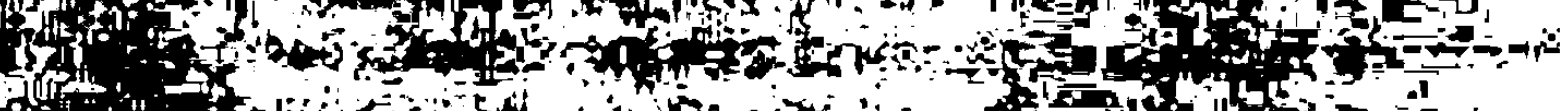

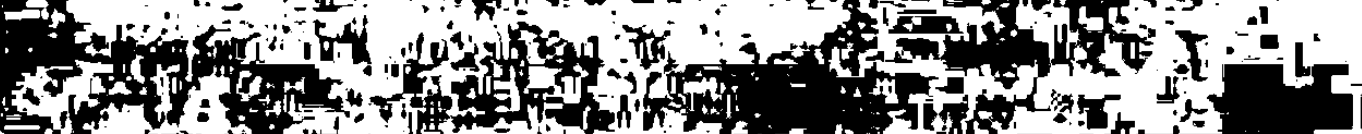

ats 3 an

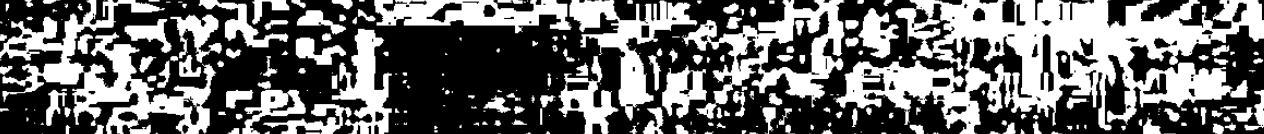
if

(10)

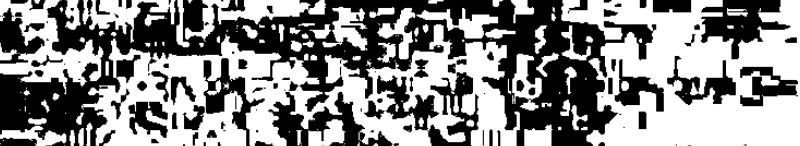

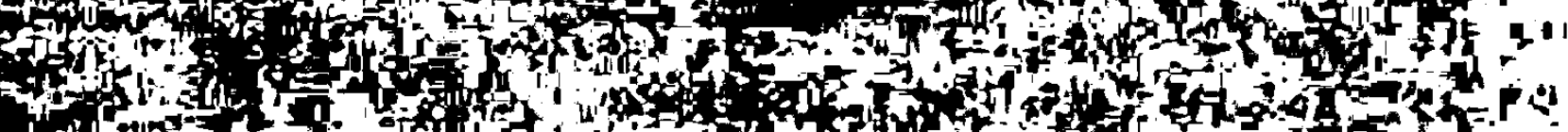
a whe 1) 6. SAl 


$\begin{array}{ll}17 & \text { SbNU XIII,104 (4/6; } 299 \mathrm{~V} . ; \text { Mariovsko }) \\ 18 & \text { SbNU XIIII,164 (4/6; } 467 \mathrm{~V} . ; \text { Sofijsko }) \\ 19 & \text { SbNU XIIII,190 (4/6; } 184 \mathrm{~V} . ; \text { Sofijsko }) \\ 20 & \text { Karav.BNP 80 (5/3;256 V.; Jambol) } \\ 21 & \text { SbNU XIV,87 (4/6;289 V.; Kopriv3tica) }\end{array}$

Al a Var.1 soll Vuk II 28, wohl das schönste Lied des Sängers Podrugović und der Vukschen Sammlung uberhaupt, ein unfangreiches, vom Sänger sehr individuell gestaltetes episches Iiedbeispiel, besprochen werden. Der Inhalt dieser Var., uber die bereits eine beträchtliche Sekundärliteratur besteht, ist folgender:

Der serb. Zar Stjepan freit brieflich die Tochter Roksanda des Konigs Mijailo in Letan, der lateinischen Stadt, und erhallt vom Brautvater eine $\mathrm{Zu}-$ sage. Er entsendet nun Todor, seinen Wesir, nach Ledan zu seinen klinftigen Schwiegereltern, um die Hochzeit verabreden, das Madchen beurteilen und den Verlobungsring ubergeben zu lassen.Todor wird freundlich emplangen und bewirtet und vereinbart einen Hochzei tstermin. Was die Neffen Petras in und Vukaßin betrifft, bittet Mijailo, Stjepan, ihr Oheim, möge sie nicht einladen; die beiden seien nämlich trunkslichtig und Raufbolde. - Bei Einbruch der Dunkelheit flunrt man Todor die Braut zu. Mit Hilfe des edelsteinbesetzten Goldrings beleuchtet Todor das dunkle Gemach und sieht, dab die Braut schöner als eine Vila 1st. Am nächsten Morger. kehrt Todor zu seinem Herm zurlick und erstattet dem Zaren Bericht. Stjepan argert sich, dab der schlechte Ruf seiner Neffen schon bis nach Ledan vorgedrungen ist, und ladt die beiden nicht zur hochzeit ein. Mit 12000 Svaten macht aich der Brautigam am vereinbarten Termin auf den Weg. Bei Vucitrm erblicken die Neffen Vukaßin und Petrasin, die Voinovibi, den Brautzue und wundern eioh, daß man sie beide bei der Einladung ubergangen hat, befurchten aber gleichzeitig, die schlauen Lateiner konnten ihrem Oheim schaden oder 1hr, sogar toten, wenn er keinerle1 verwand tschaftlichen Be1stand habe. Die Mutter rat ihnen den jungsten Bruder, den Helden Milos, der im Sar-Gebirge Schafe hite, zu benachrichtigen, daß die Mutter todkrank sei und man sein Kommen fur unerläblich halte.- Als die beiden alteren Brlider diesen lat befolgen und Milos einen Brief mit der Nachricht von der schweren Erkrankung der Mutter senden, eilt der Hirte sofort nach Hause und erfährt dort, dab man inn 
mit Hilfe der fingierten Krankheitsmeldung besonders rasch helmholen wollte, weil er unerkannt im Hochzeitszug des Oheims mitziehen solle. Er wird prachtig ausgestattet, erhalt jedoch zuletzt einen langen Hirtenmantel (bugar-kabanicu) Ubergeworfen und eine Bulgarenpelzmitze (bugarsku gubaru) aufgesetzt, so dak er wie ein "schwarzer Bulgare" aussieht und inn seine elgenen Bruder kaum mehr erkennen. Man rat ihm, auf die Pragen der Svaten zu antworten, er habe seinen Dienst bei Radul-beg in Karavlazka quittiert, da dieser ihn nicht mehr entlohnt habe, und hoffe nun, von den Svaten ein Stluck Brot und einen Becher Rotwein zu erhalten.- Milos holt die Svaten ein und wird von ihnen bereitwillig aufgenommen. Um die Mittagszeit Uberkomnt liflos nach Hirtengewohnheit der Schlaf und Ubermannt inn schlieblich (wovor seine Brlider inn ausdricklich gewarnt haben), so rab sein Pferd, das neben dem Pferd des Zaren zu reiten gewohnt ist und nun von dem schlafenden ililos nicht mehr zurlickgehalten wird, nach vorne an die Spitze des Hochzeitszuges draingt. Nur mit Muhe kann der Zar seine Vojvoden davon abhalten, daB sie den Hirten verprugein. Als Milos erwacht, reibt er sein peerd herum und gibt inm die Sporen, worauf es drei Ianzen welt nach vorm und vier in die Hohe springt und aus Maul und Nüstern Feuer sprüh. Drei Strauchritter, Đakovica Vuk, Nestopoljče Janko und "Prijepoljče mom če", wollen ihm das Prachtpferd abhandeln, schlieblich sogar mit Gewalt wegnehmen. Sie erhalten jedoch von billos solche Keulenschluge, daß sie sich Uberschlagen. Als die Svaten vor Ledan angelangt sind, schlagen sie ihre Zelte auf und erhalten Futter fiur ihre Pferde, nur Milor nicht. Als lillos noch dazu vom Schankwirt keinen Wein bekommt, schlygt er dem Mann drel Zuhne aus und bedient sich selbst. Am nachsten Horgen verkïnden die Herolde des Konigs, Zar Stjepan misse mit einem gesteliten Kumpfer (zatodnik) aus Ledan einen Zweikampf bestehen, wern er heil heimkehren und die Braut heimfuhren wolle. Da klagt der Zar un seine abwesenden Neffen, die ihm in dieser Situation allein helfen konnten, worauf der wegen seiner uuberen Aufmachung verspottete und vom Zaren nicht erkannte Milos den gefährlichen Kampf wagt, den Gegner (Latince, 'Latelnerchen') in die Plucht schlygt und verfolgt, an stadttor aufspießt und schließlich köpet. Fur diese Tat erhalt er vom Zaren Wein und Schäze. Als zweite Aufgabe wird gefordert, drel Pferde, die auf dem Rlucken aufgerichtete Schwerter tragen, zu Uberspringen. Wieder ist allein Milor, dessen Sprungvermögen wegen seines schweren Nantels angezweifelt wird, in der Lage, den schwiertgen Sprung erfolgreich auszufuhren. Als dritte Aufgabe wird verlangt, einen auf dem hochsten Gebrude der Stadt auf einer Lanze aufgespieBt.en goldenen Apfel herabzuschteBen, wobel noch dazu 
durch einen Ring getroffen werden muB, ein Schuß, der nur Nilos gelingt. Anschließend fuhren die beiden sobne des Konigs drel Madchen gleichen Aussehens und gleicher Kleldung herbel, aus deren Mitte der $\mathrm{Zar}$ die Braut herausfinden soll. Er fordert Todor auf, diese Aufgabe zu lösen, weil er das Nudchen wenigstens einmal gesehen habe, worauf der Wesir sich entschuldigt, das gei im halbdunkel gewesen. Da erbietet sich wieder sillor zur Lbsung der Aufgabe und erklärt, er kenne jedes einzelne seiner 20000 Schafe, also werde er auch die Braut aus drel Mudchen herausfinden. Er tritt vor die Madchen hin, wirft Hirtenmantel und -mutze ab und bietet nun, mit seinen prachtigen Kleidern und dem Netallschmuok wie die Sonne strahlend, einen glanzenden Anblick. Er breitet seinen Purpurmantel auf den Boden, streut Ringe, Perlen und Edelsteine darauf und fordert die Braut zum Aufsammeln auf, wage dies aber eine andere, 80 werde ihre Kunnheit dadurch bestraft, daB er ihr die Arme abschlage. Da blicken die belden außen stehenden Madchen das mittlere an. Dieses, Roksanda, blickt zu Boden, schlirzt die Rokkke, krempelt die Ärmel hoch und sammelt den Schmuck auf. Darauf funrt Milos die drel Madchen dem Zaren zu und nimmt dann eine der beiden Begleiterinnen der Braut fur elch.- Die Svaten machen sich auf den Heimweg. Miloz berichtet dem Zaren, Konig Mijailo halte schon sieben Jahre lang den Vojvoden Balacko bei sich, der die Svaten auseinandertreiben und Roksanda zurickholen solle. Er, Hilos, kenne Balacko und dieser ihn. Der Vojvode habe drei Köple, von denen einer blaue plammen sprilhe und einer kalten Wind ausstoBe:

Iz jedne mu modar plamen bije. A 12 druge ladan vjetar duva.

Auf Milore Vorschlag hin bleibt er mit 300 Svaten zurlick, um Balacko zu erwarten, whirend die ubrigen weiterziehen. - Konig Mijallo hat sofort nach dem Abzug der Svaten Balacko zu sich gerufen und ihn aufgefordert, Roksanda den Serben wieder abzunehmen. Gelinge dies, werde er das Nïdchen als Braut erhalton. Bol don Svaton ool nur oin oinzigor Hold, ein junger Bulgare.- Balacko versteht sofort, von wem die Rede 18t, und erklkrt, des ge1 kein gewbinlicher Hirte, sondern MIlos, der Neffe des Zaren, den dieser nur noch nicht erkannt habe.- Mit 6000 Beglelterm zieht Baladko dem Hochzeltszug nach, st8Bt auf die von Milos gefunrte Gruppe und beginnt mit dem Neffen des Zaren einen Zweikampl, in dessen Verlauf alch Hilog mit einem Burenfell vor den Flammen und dem kalten Wind, die der Gegner erzeugt, schutzt. Milos schlagt den Vojroden mit der goldenen Keule nieder, kbpft ihn und bringt die drel abgeschlagenen Krpfe zum Zaren, der inm 1000 Dukaten 
daflr schenkt. Bel Vucitrn verabschiedet er aich von dem Zaren, wobel er ihn zum erstenmal als Oheim anredet. De endlich wird Stjepan klar, wer eigentlich sein Helfer und Retter ist, und er preist die Mutter, die einen solchen Sohn geboren hat.

Brăutigan ist in diesem lied der serb. Konig Stefan Duran (1331-1355), der sich 1346 in Skopje zum "Car Srba, Grka 1 Bugara" krönen 11eß. Unter Dusan dem Mkchtigen erreichte der serb. Staat seine bisher grobte Ausdehnung.- Der Name Stjepan durfte in Var.1 sekundär fur andere, urspringlichere Braut1gansnamen, mbglicherwelse aus dem ugrischen Bereich, eingesetzt worden sein, woflur die uberwiegende Mehrhe1t der 4.1Lieder den Beweis liefert. Der Brautname Roksanda, der aus dem Alexanderroman stammen dürfte, wo die Gattin Alexanders des Großen Roksanda (griech. Rhoxáne) heiBt ${ }^{225}$, 18t der bel aldslavischen eplachen Sangern beliebte Name fur Frauengestalten hoher Herkunft (vgl. Vuk II 28,29,32,26,39,91; Petr.II $16,21,56$ u.a.). S.Stanojevic $e^{226}$ hat den kaum uberzeugenden Versuch gemacht nachzuweisen, daß $81 \mathrm{ch}$ in dem Iled "Duranova zenidba" gewisse Erinnerungen an Ereignisse bel der zweiten Vermahlung des Kaisers Manuel von Byzanz (1060) splegeln. DaB D.Kostic in dem lateinischen Konig Hijallo mehrere Vertreter der venezianischen Pamilie Michlel verschmolzen sehen mbchte 227 , wurde bereits erwahnt. Auch Miletic setzt sich in seinen "Sitnij1 prilozi"228 mit dem Iled Vuk II 28 auseinander und vergleicht es mit Kadic-Mioric 43 und Strekelf II,299. P.Yopovic stellt in seinem "Pregled srpske knjizernosti"(91931, 61) fest, daB Ähnlichkeiten in der Motivwahl bel Lang- und Kurzzeilenliedern bestehen, und verweist dann auf das Iied "Dusans Hochzeit" Im Verglelch zu Bog.9 und 26. Uber Balacko meint Popovic, das es alch entweder um Majer Blaz handle,der 1470 zum Banus von Kroatien, Slavonien, Dalmatien und Bosnien ermannt wurde, oder aber un Balaban, den an der ersten Kosovoschlacht beteiligten turkischen Heerfuhrer. Chalanskij zeigt in Kap.XI "N1belungenlied 1 olavjanskij geroiceskij épos"229 seiner umfangreichen Arbeit uber Kraljevic Marko Parallelen zwischen den skr. Hochzeltszugliedern und dem Nibelungenlied auf, wobel er vor allem die Abenteuer 
VI-VIII heranzieht, die von der Hochzeit Gunthers mit Brinhilde berichten:

1. König Gunther zieht mit den Helden Siegfried, Hagen und Dankwart Uber das Meer nach Island, wobei sich ihnen 1000 iilbelungen anschließen.-In den skr. Iledern entsenden Dus̆an, Furad Smederevac u.a. Svaten oder ziehen selbst mit innen in die ferne Stadt Iedan, Dubrovnik usw. Unter den Svaten sind hervorragende Helden wie Milos, Marko, Relja usw.

2. Sowohl die germanischen wie auch die serb. Helden kommen in ein Land mit feindlicher, betrligerischer Bevölkerung ( $\nabla g l$. - "Latini su stare varalice" in Vuk II 28 und 78), weshalb Vorsicht geboten ist.

3. Die Diener Brlinhildes wollen den Ankömmlingen die Haffen abnehmen, Hagen aber. erklart, man werde sie nicht hergeben. Erst als Siegfried sagt, das Ablegen der Waffen sei hier ub1ich, geben die Hochzeitsgăste ihre Waffen her. Im XXVIII. Abenteuer weigern sich die Burgunder am Hofe Etzels, ihre Bewaffnurg abzulegen.- Auch in Vuk II 78 liefern die Svaten auf Markos Anraten hin ihre liafen nicht ab, was sich dann als großer Vorteil erweist.

4. Sowohl im Nibelungenlied wie auch in den skr. Iiederm werden dem Bräutigam bzw. seinem Stellvertreter aus den Reihen der Hochzeitsgäste schwierige Freiersproben auferlegt. 5. In beiden Fällen ist nicht der Brăutiean der Hauptheld, sondern sein Helfer Siegiried bzw. Milos, Marko usw.

DaB Chalanekif das Nibelungenlied und die skr. Lieder mit ghnlicher Thematik auf eine gemeinsame Quelle zurlickfuhrt, woraus die bestehenden Parallelen erklart werden, wird sowohl von Maretic ${ }^{230}$ wie auch von Simonovic ${ }^{231}$ akzeptiert. Gegen diese m.E. fragwlirdige These wendet sich erst V.Zirmunskij ${ }^{232}$, der die typologische vor die genetische Verwandtschaft der Epen stellt, wenn er sagt:

Ungeachtet dessen, daß hier die Werbungsfahrt als gemeinsames Thema vorliegt, laBt sich kaum eine Ubereinstimmung in der Bearbeitung dieses Themas erkennen, es sei denn der sowohl im deutschen als auch im slldslawischen Epos auftretende Helfer bei der Brautwerbung und den Wettkämpfen, die allerdings ganz unterschiedlich sind; diese sind aber, wie wir 
gesehen haben, uralte Motive des Heldenmarchens, die bei verschiedenen vilkem begegnen. Sonst wird Im südslawischen Epos im Gegensatz zum Nibelungenlied keine List angewandt, der Brautwerber tritt hier in seiner rechtmbiligen, duroh das Brauchtum geheiligten Rolle als Helfer des Preiers auf; es gibt auch keine Heldenjungfrau wie in der deutschen Sage.

Hie Chalanskij behauptet, stellt die Verwendung von skr.sablja 'sabel' in der Bedeutung 'Recke' eine Lehnubersetzung aus dem Mittelhochdeutschen dar, wo das Wort 'degen' sowohl 'sabel" als auch 'Ritter' bedeutet habe, wogegen sich Zirmunsij (S.85) wendet. Er betont sehr richtig, skr. sablja als 'skbel' und 'Recke' sel eine gewornnliche Metonymie und 'degen' in der Bedeutung 'Recke' ein altes germanisches und indoeuroparsches Wort (vgl. angloschottisch 'thane', einen feudalen Titel, und griech. TÉkvOV). Im volkstümlichen Heldenepos des 12.-13.Jh. sei es noch häufig anzutreffen, verschwinde aber im weiteren Verlauf zusammen mit der altertumlichen Dichtung heroischen Stils. Dagegen stelle das in der mittelalterlichen Dichtung unbekannte Wort Degen im Sinne von Stichwaffe eine bintlehnung aus dem Romanischen dar, die erst im 15./16.Jh. aufgetaucht se1 (vgl. Pranz.dague 'Klinge'). Von einer doppelten Bedeutung des Wortes Degen könne folglich damals nicht die Rede sein.- Auch Maretic (NNE,208) wendet sich dagegen und funrt (NNE,46-47) weitere Metonymien wie skr. kruna 'Krone' fur 'Konig' oder 'Zar' und skr.džeferdar 'Danaszenerflinte' fur 'Held an. Dem ware hinzuzufugen, daß in heutigen Sprachgerrauch skr.buzdovan 'Keule: in der Bedeutung 'schwerfalliger Mensch" verwendet wird ("On je pravi buzdovanl").

Chalanskijs Versuch, die Stadt I e a n als "Eisotadt", urspringlich "Eisland, Iśland", zu deuten 233 , ist von slaviotischer seite verworfen worden und darf houte als uberholt gelten. Andere Porscher verwiesen bel Leatan auf Iitauen, Polen, Italien, Rumänien, den Glasermen oder Eisberg, das Dorf Lerko bel Tetovo usw. 234 . N.Nodilo vermuteto sogar, mit Ledan sei die holle gemeint ${ }^{235}$, v.Cajkanovic dachte, mit Ledan sei Lesh (Alessio) in Albanien und mit den Lateinem seien nicht die venezianischen, sondern die albanischen Katholiken ge- 
deint ${ }^{236}$. Dieser dieinung schliebt sicn T.tordevic (NNZ VI, 78-79) an, der eine von einem Albaner aus Ulcinj (1931) genörte Erzählung anfuhrt, in der es heibt, die alten Leute erzahlen, Skadar sei einst serbisch und Ljes italienisch gewesen; damals Preite der serb. Zar aus Skadar die Tochter des italien. Zaren in Ljeß; als die Svaten das Mädchen abholen wollten, verlar.gte der Brautvater vom serb. Zaren,dab er zuerst eine ganze Reihe von Hindernissen uberwinde, bevor er das l:adcinen bekommen konne.- Darllber, sagte der Gewahrsmann, gebe es auch ein Lied in albanischer Sprache. \#ortevic vermutet nun eine Verbindung von dieser alban. therlieferung in Prosa und Lied zu unserem serb. Lied dergestalt, dab I etan aus Ijes (lesh) abgeleitet wurde. Ich möchte aber eher umgekehrt annehmen, dab die skr. Liedüberlieferung dieses Sujets in Albanien bekannt war und man dort fur Letan einen uhnlich klingenden ON, eben Lesh, einsetzte ( $v g l . z . B$. analoge in den skr. Iiedern bekennte "Ersatzpaare" wie Solun-Solin oder Peritheorion-Pirlitor).- A.Soerensen 237 morchte in Ledan Litauen sehen, weil in der bei 4.11 angegebenen rumänischen Variante bogdan, der Sohn des Lăpuģnean, die Tochter "de Iitean cel bogat ģi din lege lepadat" preit und "litean' (hier zwar als PN) "bekanntlich die rumanische Bezeichnung des Ii thauers" ist. Soerensen glaubt, das Liedsujet sei bereits frilh von den sudslaven zu den Rumbinen gelangt und dort sei als ziel der Brautfahrt, den vielfachen Beziehungen zwischen Kumänen und Iitauern entsprechend, Iitauen fixiert worden, und - mit diesem neuen Element ausgestattet - sei das Lied schlieblich k:itte des 18.Jh. zu den Serben zurlickgewandert. Wenn nun "der liame Ledanin auch oonot in Hiteror oerbiocher Literatur vorkommt, dann haben wir die Rumänen und nicht die kagyaren als Yermittler desselben arzusehen". Leider macht sich Soerersen keine Gedanken darluber, wie aus 'Iltean' Letan werden konnte, was m.E. lautlich nicht zu rechtfertigen ist. Zütreffender scheint mir die Deutung von S.Novakovic $e^{238}$ zu sein, der in Letan irgendeine polnische Stadt sehen mochte. Unterstutzung fur diese These Pindet Novakovit in der 80g. Chronik des Brankovic (Brankovicev letopis), gedruckt im "Arkiv za po- 
vjestnicu jugoslavensku" III (Zagreb), wo es an einer Stelle heiBt: "Anno 1440 constitutus est in Ungaria rex Vladislav Ledianin". Das Wort 'Ledianin' bedeutet zweifellos 'Pole', weil historisch sicher ist, dab der ungarische Konig, von dem hier die Rede ist, Pole von Geburt war. Das wort Ledanin ist also synonym zu Poljak, einem Ethnikon, das von dem hort 'polje' (Feld) abgeleitet ist. Analog durfte ledanin von dem Wort 'ledina' (ebenes, unbearbeitetes Land) hergeleitet werden. Die Ledani wären daher Bewohner der 'ledina'. Ledina ist entstanden aus 'lędina' mit Nasalvokal in der ersten Silbe, daher wurde auch ledanin einst mit Nasalvokal ausgesprochen. Wahrend dieser Zeit, als Nasalvorale noch gesprochen wurden, Ubernahmen die Ungarn das Wort und bewahrten es in der Form 'lengyel" (Pole), während die Serben und Kroaten das Wort verloren. Als aber im skr. Raum das Wort Ledanin als Volksbezeichnung noch existierte, war es leicht, daraus durch kllckbildung das Wort ledan abzuleiten, womit die Stadt oder das Land der Letari bezeichnet wurde. Novakovic funrt fir eine solche Ableitung Ledanin-Ledan eine Parallele aus dem Volkslied ans

Dvorbu dvori Jakšic Dimitrije

U Madzaru gradu bi jelome

U onoga bana Madzarina.

Niaretic ${ }^{239}$ ergunzt dieses Beispiel, wo aus Madzarin (Madjar) der Stadtename Madžar abgeleitet wurde, durch weitere Parazlelen aus Milut.,160:

Vino pije Mitar od Udvarja

U Madzam gradu velikome

Sa onijem Filip Madzarinom

und Milut.,190:

Nadaleko u Hrvatu gradu
U onoga Hrvat dizdar-age.

Dem morchte 1ch noch die Stadtebezeichnungen 'Madžar' aus KaC. 147 und SbNU IV,66, 'Arap' aus Sapk.814 und 'Latin' aus SbNU VII,112 als Beispiele fur den maz. und bulg. Raum hinzufligen. Maretic meint, dab sich Ledan deshalb im "lateinischen"(katholisohen) Land befindet, weil die Polen als eifrige Katholiken bekannt waren. Aus dem gleichen Grund werden im lied auch ale 
Bewohner von Dubrovnik "Lateiner" (wie die Venezianer) genannt. Ich glaube, daß vielleicht auch die Polenbegeistemang zur Zeit Gundulics, als die Polen als tapfere Turkenkämpfer gefelert wurden, dazu belgetragen haben durfte,daß man damals auch im epischen Iled von diesem Volk sprach. Novakovic (S.129/130) äußert sich zu diesem Problem mit weiteren wichtigen Argumenten, wens er schreibt:

Die Entlehnung des Namens "Legjan" von "lengyel", der magyarischen Bezelchnung fur die Polen, fuhrt unzwelfelhaft auf den Konig Vladislav "Legjanin" zurlick (...). Wenn dem so 1st, so kann die Beziehung der serbischen Sagen und vï̈rchen auf eine Stadt namens Legjan - Legen nicht alter sein als aus dem Anfang des XVI.Jh. Es 1st nicht unmöglich, dab auch Dusan erst um diese leit herum in die Zahl der poetischen Yersonlichkeiten der serbischen Volksdichtung Autnahme fand, da Uber thn bekanntlich nichts Geschichtliches in der serbischen Volkspoesie Uberliefert 18t. Sein Name ware demnach um diese Zeit an die Stelle anderer blterer Namen getreten. Ysychologisch läb sich der Anfang des XVI.Jh. gerade als ein sehr geeigneter Zeitpunkt flur diesen thergang hinstellen. Um diese Zeit hatten sich die Erinnerungen an die alten geschichtlichen Verhaltnisse in den Schatten der Poesie gehullt und die Generation der Augenzeugen jener Erelgnisse war ausgestorben.

An dieser Stelle möchte lch das Z1tat mit der Bemerkung unterbrechen, daß man die Ubernahme des Namens Dusan in unser Iiedsujet m.E. noch spater (wahrscheinlich 1m 18.Jh.) ansetzen darf, well im 16.Jh. slcher noch die ugrischen Helden im Vordergrund des Interesses standen und die Haupthelden der sudslavischen Volksdichtung stellten.-Novakovic fuhrt fort:

Endlich bin ich bereit anzunehmen, daB auch fur die Ankoupfung der Sage von der Helrat Dusans an die Stadt leejan kein Zeitpunkt eeeigneter war ale der Anfang des 17.Jh., in welchem die Sympathien der Sudslaven fur die Polen der Muse Gundulics so herrliche Töne entlockten.

Und schlieblich zu der Frage der Vermittlung des Wortes Ledan an die Bulgaren:

Ich bin der Ansicht, dab dieser Name den Bulgaren von den Serben zugefuhrt worden 1st. Beachtenswerth 18t es jedenfalls, dab die Lieder, worin der Name vorkommt, alle aus dem nordilichen Macedonien herstammen; diese Gegend aber hat seit jeher die meisten Beziehungen zu den Serben gehabt. 
Auch in diesem letzten Punkt dürte Novakovic recht haben. A.P.Stoilov ${ }^{240}$ möchte das bulg. Legen aus $\wedge \in X \in H^{2}<\wedge \in X 6 H^{6}$ $<\wedge A \times 6 H Z$ wegen der Ähnlichkeit des gutturalen -ch- und - g("zamjanata na gŭrlenata ch s sŭotvetnata $i \mathrm{~g}$ ") herleiten und damit serb. Vermittlung ausschlieBen.Das Zagreber Akademiewörterbuch schließt sich Novakovic an, zitiert aber auch I.Perwolf (ASIPh IV,70-71), der Ledani von (latein.) "Lendizi", Iȩdici, einem poln. Stamm, der seit dem 9.Jh.erwähnt wird, von dem auch das ungar. Wort herstamme, ableitet. Das skr. Letani sei aber nicht aus dem Madjarischen ïbernommen, sondern habe sich aus der alten Tradition erhalten.

Nach dieser langen Abschweifung nun zurück zum Variantenvergleich. - Var.2 findet sich laut I. Ruvarac 241 in der HS-Sammlung von Ignjat Brlic und ist mit der "Hochzeit Du§ans" bei Vuk Karadžic "u glavnom jednog sadržja". Laut A. Zivaljevic"242 ist in diesem slavonischen Lied "car Stepan iz Udbina" der Bräutigam; der hilfreiche Neffe, der die Freiersproben für den Oheim besteht, heibt "Cobanin Mile"; Stepans Schwiegervater, ein Festungskommandant ("dizdar"), schickt seinen dreiköpfigen Zmaj (troglavit zmaj) aus, der das Mädchen zurückholen 80ll, was dank Miles mutigem Eingreifen verhindert wird.- Man sieht also, dab in dieser Vuk II 28 sehr ähnlichen Fassung, die mir leider nicht zugänglich war, das mythologische Element in Form des dreiköpfigen Zmaj noch besser als bei Vuk bewahrt blieb. Eine sekundäre Änderung ist natürlich darin zu sehen, daB der Brautvater hier vom König zum "dizdar" degradiert wurde.In dem zweiten bei Zivaljevic angegebenen, von Brlic in Slavonien aufgezeichneten Lied, Var.8, ist Sibinjanin Janko der Bräutigam (also eine ältere Liedstufe!), Braut die Tochter des lateinischen Königs; der hilfreiche Neffe heiBt "Nine Cobanin". vom Kozara-Gebirge und der vom Brautvater entsandte Mädchenentführer, den Nine mit "Wahlbruder" anredet, Irizanka Planinka.- Hier liegt also die gleiche Vorstellung wie in Vuk II 28 zugrunde, daß der hilfreiche Neffe des Bräuti- 
gans und der dumonische Angreifer sich kennen, ja sogar Wahlbrider sind, was auf das Phanomen der mythischen Verwandtschaft (2wischen dumonischem Hesen und Helden) hinweist, die wir auch in den griech. Heldenliedern antreffen. In Var.4, dem dritten Brlic-lied, ist der Brăutigam Senkovic aus dem lateinischen Land; er wird unterstutzt "od svog sestrica u gore Cobana", d.h. wieder einem Hirten, der spater im Iied "Ugor Cobanin" genannt wird. Das dämonische liesen, das den Hochzeitszug luberfullt, wird als "Plamena devojka"(Flammenmädchen) bezeichnet, d.h. es handelt sich wahrscheinlich um eine dünonische weibliche Gestalt, die Feuer spruhen kann, also möglicherweise eine sekundare Ableitung aus dem Zmaj. Da mir das Lied nicht zugänglich war, kann ich leider'nichts raheres Uber das geheimnisvolle Flammenmadchen aussagen. - Var.5 ist die Nr.2 der von S.Novakovic in einem'Beitrag zur Iiteratur der serbischen Volkspoesie' (ASIFh III,640-653) veroffentlichten drei Volkslieder einer aus dem ersten Drittel des 18.Jh. stammenden ragusarischen HS mit insgesamt zwollf Volksliedern in Lang- und Kurzzeilen. Var.5 ist ein (leider unvollendetes) Kurzzeilenlied mit folgendem Inhalt:

Der serb. Zar Stjepan freit die Tochter des Konigs von Iedan und erhält von dem Schwiegervater einen Brief, in dem er aufgefordert wird, Svaten aus allen Himmelsrichtungen zu sammeln, die beiden Neffen, die Voinovici, aber nicht einzuladen, weil sie trunk- und streitsuchtig seiens

Neg do po dne hladno vino piju, $A$ od po dne terku kavgu cine.

Dieses Verbot bedrlickt den Zaren, doch er muB die Anweisung des Königs von Letan befolgen. Als er mit den Svaten an dem Hof der Nerfen vorbeizieht, erblicken ihn die beiden und berichten ihrer Mutter ganz verwundert, dab der onkel (dundo) heirate und sie bei der Einladung ubergangen habe; irgend jemand habe sie sicher bei ihm verleumdet.-Da rat ihnen die Wutter, den dritten Bruder, der seit seinem siebenten Lebensjahr im Gebirge die weiBen Schafe hute und den der Onkel nioht kenne, durch einen Boten aus dem Gebirge herbeizuholen und ihn mit dem Onkel reiten zu lassen.- Die beiden sobne befolgen den mutterlichen Rat und schicken einen Jungen los, der noch vor Tagesanbruch nach Horija kommt, wo er 
die Hirten bei Wettrpielen, Sprung und Steinwure, antrifft. Milos Voinovid besiegt alles Er wirft drei Arsin weiter als die anderen und springt viermal so weit wie sie. Seine Keule aus Kornelkirschenholz ist mit Silber beschlagen und in der Mitte mit Gold ummunden.- Der Bote teilt 1hm mit, er solle die Schafe im Gebirge lassen und sofort zu seinem weiBen Hof kommen; die Brider ließen ihn rufen.- Milos vertraut seine Herden der Obhut seiner Kameraden an und erreicht in drei Tagen seinen Hof, wo ihm die Brtuder alles erkluren und ihn bitten, er moge in einigem Abstand hinter dem Hochzeitszug herziehen und dem Onkel im Notfall beistehen, denn es sel Verrat zu befürchten.- Sie ziehen inm bulgarische Klelder an, setzen ihm elne Mitze auf, werfen ihm einen schwarzen Vantel uber, gllirten inm ein scharfes Schwert um, satteln ihm ein gutes perd und bedecken es mit einem Barenfell. Bevor Milos aufbricht, warnen ihn die Brider davor, auf dem Pferd einzuschlafen, denn das Tier sei daran gewornnt, unter dem Banner neben dem Zaren zu gehen, und werde nach vorne drängen, wenn er im Schlaf die Zugel lockerlasse.- In drei Tagen holt Hilos die Svaten ein, obwohl sie sechs Tage Vorsprung hatten. Sie laden den "ludi Bugarin" ein, sich ihnen flur ein Stluck Brot und ein Glas Wein anzuschließen. Er zieht hinter den Svaten her, schluft aber schlieblich ein und wacht erst auf, als sein Pferd schon neben dem des $\mathrm{Za-}$ ren 18t. Er zieht es leicht an Zugel und bewirkt dadurch, daß es 100 Ellen zuruckspringt. Die Svaten bewundern insgeheim das Streitrob des Unbekannten und beschließen, es Milos wegzunehmen. Ein Spahi verlangt das perd und wird von Milos aufgefordert, es am Steigbligel zu fassen, dann erhalte er $\notin 8$ geschenkt. Der Spahi kommt heran, faBt an den Steigblugel und wird von lillos so heftig mit der bloBen Hand geschlagen, daB er tot zu Boden fillt.

Diesem leider unvollendeten Lied aus dem Anfang des 18.Jh. ist das etwa 100 Jahre jungere Lied Vuk II 28 in allen Einzelheiten 80 zhnlich, dais wir darin eine direkte Anboüpoung sehen durfen. Wahrend in Kacic-Miosic 43 noch Sibinjanin Janko der Brătigan und Temesvar das Ziel der Brautfahrt waren, finden wir in Var.5 schon Zar Stefan als Brăutigam und das sagenharte Letan als Zielort, wie wir es ja dann in Vuk II 28 u.a. wieder antreffen. Var.5 konr.te also als Mittelglied zwischen Kacic-Miozic 43 und Vuk II 28 betrachtet werden.- sist dem on Morija ist (laut Akademiewbrterbuch) 
Morea (neugriech. fur Pelopornes) gemeint. - Var.6 mit der Uberschrift "Ie nozze dell'imperatore Dusciano" entspricht Vuk II 28. - Var.7 ist bruchstuckhaft, Vuk II 26 aber sehr ghnlichs

Auch hier ist der serb. Zar Stevan der Brautigam, Braut die Tochter des Bans von Legjan. Der hilfreiche Neffe Mio, der von seinen Bridern Nicolica und lifhailo aus dem Sar-Gebirge geholt wird, reitet mit Festkleidung und darüber einem langen Hirtenmantel (divan kabanica) unerkannt hinter der Hochzeltsgesellschaft her und schliebt sich ihr an. Als er einschlaft und sein fferd nach vorne zum $\mathrm{Za-}$ ren drangt, wollen die Wesire ihn toten, was aber vom Zaren verhindert wird. Das pferd springt mit drei Sprïngen, neun Lanzen weit bei jedem, zurlick, worauf die liesire dieses lunderpferd fiur neun normale Streitrosse und neun Iasten Schätze erwerben wollen. Da sagt Mio zu seinem Streitkolben:

Buzdovane, moje perje svjetlo,

Dok je nami perje jedinoga,

Ne damo mi vranca velikoga.

Die Svaten werden im Gebirge von dem Einbruch der Dunkelheit uberrascht. Da fragt der Zar, wer von den Svaten den Hochzeitszug trotz Dunkelheit flhren konne, worauf sich Mio, der schwarze Bulgare, dazu erbietet. Er schlägt den langen Hirtenmantel hoch, so dab das licht, das die drel Edelsteine an seinem Sattel ausstrahlen, so hell leuchtet, daB die Svaten muhelos den Weg nach Ledan finden, wo sie in der Morgendammerung ankommen und vor den verschlossenen Toren haltmachen. Wieder bietet sich der Bulgare an, das Tor zu bffnen. Er ruft mit lauter Stimme, der Ban von Leatan solle das Stadttor offnen lassen, denn andernfalls werde er, Mio, mit seinem Rappen die Mauer Uberspringen und den Ban an seinem grauen Bart durch die ganze Stadt schle1fen. Daraufhin bffnet sich das Tor und die Svaten ziehen in die Stadt hinein. Allen werden die pferde abgenommen, nur um den schwarzen Bulgaren kilmmert sich niemand. Whihrend die Svaten sich setzon und zu schmausen anfangen, bedient sich Mio selbst beim Fleischer und beim Schankwirt, die inm zuerst nichts geben wollen, dann aber von dem Helden dazu gezwungen werden. Dann beginnen die Freiersproben. Zuerst soll ein Apfel von einer Lanze heruntergeschossen werden, was nur Nio gelingt. Danach solien neun Pferde, die auf dem Kucken aufgerichtete Schwerter tragen, ubersprungen werden. Wieder erklurt sich der Hirte bereit, die Aufgabe zu lösen, wird aber von larko Kraljevic wohlmeinend aufgefordert, zuerst seinen liantel abzulegen, worauf lijo erklät, im Gebirge werfe man alle Schafe in eine Grube, die ihre 
eigene wolle nicht tragen konnen. Er werde also seinen Mantel nicht ausziehen.- Mio pliegt heran "wie eine Schwalbe" und uberspringt die Pferde spielend leicht. Als dritte Freiersprobe soll die Braut aus neun gleichaussehenden Mädchen herausgefunden werden. Mit dem aus den 4.11-Iiedern bekannten Trick erkennt Mio die Braut und fuhrt sie dem Bräutigam zu, worauf der Hochzeitszug solort aufbricht. Im Waldgebirge aggt Zar Stevan, die Svaten möchten nun zu singen aufhorren, weil sie sonst der dreikopfige Hajduke Juris Uberfalle. Der schwarze Bulgare erklart, Juris sei sein Wahlbruder und werde deshalb dem Zug nichts zuleide tun. - Als der Uberfall aber doch erfolgt, fliehen alle, nur Mio bleibt zurlick und verteidigt die Braut. Als alle sioh nach Mios siegreichem Kampl und dem Tod des Widersachers wieder einfinden, auBert der Zar Bedenken, ob Mio nicht das Alleinsein mit der Braut ausgenutzt habe, woraus sich Mio als sein Neffe zu erkennen gibt und damit uber jeden Verdacht erhaben iat. Der Zar umarmt Mio und dankt inm flir seine grobe Hilfe.

Diese jungere, etwas erweiterte Variante (zusktzliche Motive: der Neffe fuhrt die Svaten aus dem dunklen Gebirge heraus und offnet das Tor zur Stadt) folgt sonst der Vuk II 28-Variante. Leider fehlt gerade an der Stelle ein Textstuck, wo der tberfall durch den dreiköpligen Hajduken geschildert wird. Hier finden wir einerseits schon eine Entmythologisierung des uropringlich damoniachen Angreifers zu einem bloßen Hajduken, andererseits aber noch die Beibehaltung der drei koppe. Auch hier kennt der Hirte den Hajduken und nennt ihn seinen Wahlbruder, wird aber von ihm schmahlich enttauscht, als Juris wider Erwarten uber den Hochzeitszug herfallt. - Var.8, das erste der drei von F.Miklosich in seiner Abhandlung "fber Goethes "Klaggesang von der edlen Prauen des Asan Aga'" in den Sitzungsberichten der Kaiserlichen Axademie der Wissenschaften (Wien 1883, Bd.103,413-489) abgedruckten Lieder aus der sog. Spalatiner HS, die wahrscheinlich aus der Mitte des 18.Jh. stamnt,ist in der Porm des Originale angefunrt, das durch eine vom Italienischen ausgehende Umschrift des skr. Textes auffallt. Das Lied ist Tommaseo, 80 und Vuk II 28 sehr ahnlichs

Der Brautigam heibt auch hier Zar Stipan; Braut ist das Kadchen Rosanka aus Iegen; als hilfreicher Neffe Pungiert Milos Voinovic. Im dunklen Waldgebirge labt der Zar mit zwei Edelsteinen aus den mitgefuhrten Schätzen leuchten. Milos bedient sich hier schon 
selbst beim Esseneverwalter und Schankwirt des Zaren, und nicht erst in Legen am Hof der Braut. Die drei Freiersproben bestehen aus einem Kampl mit elnem gesteliten Gegner (zatačnik), einem Schuß auf einen Apfel, der an der Spitze einer - Lanze steckt, und dem Erkennen der Braut airs neun gleichaussehenden Madchen. Alle drei Proben werden von Mllos bestanden. Er fuhrt die Braut dem Zaren zu und gibt sich schlieblich als Neffe zu erkennen, als der Zar ihn zum Dever ermennen will. Auiserdem klindigt er dem Brautigam an, dab oie nun auf dem Kllckweg von dem Vojvoden Palaso uberfalien wirden, der mit ihm zusammen Schafe gehutet habe und ein noch besserer Held als er, Miloz, sei.

Leider fehlt hier der LiedachluB, wo der Kampl mit dem AnEreifer Palało (vgl. Balacko bei Vuk II 28) geschildert ware. Auch in diesem Iied kennen sich die beiden von fruher her. Inwieweit yalało noch damonische zuge trăgt, geht aus der unvollotindigen Iied nicht hervor. - In der folgenden Var., Nr.9, heiratet der serb. Zar Stevan die Tochter des lateinischen Dogen, das lateinische Mrdchen (Latinku djevojku):

Alo Kum lat Relja von Budim, als erster Svate Zmaj Despot Vuk und als Dever Kraljevic Marko elngeladen.- Stevans Schwester Jelica sendet ihrem Sohn Milos ins Gebirge einen Brief, in dem sie ihn uber die bevorstehende Hochzeit des Oheims unterrichtet und auch dartuber, dab er weder die Schwester noch ihn, den Neffen, eingeladen habe. Er moge jedoch ungeladen mit Stevan ziehen:

Da car ima koga rollenoga.

Narko erteilt den Svaten die Anweisung, am Hofe des Dogen die Waffen nicht herzugeben, nur die Pferdes Konje dajte, oruzje nedajte!

Der Brautvater wundert sich Uber diese sitte und funlt oloh voropottet, doch Marko beschwichtigt inn und bittet um die Herauggabe des Mladchens. Der Doge fordert aber zuerst das Bestehen dreier Freiersproben. Wer die Proben bestehe, werde zum Brautfuhrer emannt. Zunächst 8011 ein Apfel, der auf einer Lanze steckt, Ubersprungen werden. Dann mus Uber eine Kirche geworfen und die Braut aus drei Hadchen herausgefunden werden. Alle drei Aufgaben erfullt der schwarze Bulgare, Milos, der sich erst dann als Neffe zu erkennen gibt, als man ihn zun Brautfuhrer erklaren will. Der Zar ist uber die Verwandtentreue des jungen Kilos so gerunrt, daB er sagt: 
Bog ubio svakoga na avjetu, Ko nezove svoje u svatove.

Die Svaten machen alch auf den Heimweg und werden vom Dogen bis zur Donau begleitet. Ne der Brautvater heimkommt, schlckt er sofort selnon "feurigen Araber" (ognjan Arapin) hinter den Svaten her, lim die Braut rauben zu lassen. Der Araber zieht Drachenkleider (halovike haljine) an und bestelgt sein Drachonpferd (konja halinoga). Er reitet den Svaten nach, laBt die Erde erzittern und st8Bt Feuer aus, so das die Baume zu brennen anfangen. Die Braut welot Marko darauf $h i n$, daB es sich um den feurigen Araber handle, der sie schon mehrmals zuriakgeholt habe. Die Svaten zittern vor Angst, Larko aber fleht zu Gott um Regen, der die plammen loschen moge, und wird erhort. Darauf ziehen die Svaten frónlich zum Hof des Zaren, wo die Hochzeltefeler mit Milor auf dem Ehrenplatz otattindet.

Den IledachluB bildet elne Lobpreloung der Verwand tentreue.

Wie man sleht, lot diese Var. in manchen Punkten verderbt. Hier lot von den belden alteren Neffen uberhaupt nicht die Rede, sondern nur von Milos und seiner kutter. Auch des EInladungsverbot fehlt. Mlloss Verkleidung wird ebenfallo nicht beschrieben. Er taucht plotzlich als "crn1 Bugarin" auf.Aus dem SchuB auf den Apfel an der Lanzenspitze wurde hier ein Sprung uber die Lanze; statt des Sprungs uber die Pferde lot als zweite Frelereprobe sekundar ein Wure uber die Kirohe $242 a$ eingesetzt. Neu und schwach ist das Motiv, daB der feuerspeiende Araber nicht getotet, sondern sein Feuer durch einen von Gott gesandten Regen gelobcht wird. DaB der Araber "halovske haljine" anzieht, bewelot, das er im Zelchen der Rationalisierung schon weltgehend entmythologisiert lat und nur noch verkleidet gedacht wird. An dieser Var. let noch deutlich zu erkennen, daß.es sich um eine Kontamination handelts Im ersten Teil ist Milos die Haupteigur, im zweiten Te1l aber Marko, der Dever. - Var.10, ein umfangreiches kroat1sches Iled, hat folgenden Inhalt:

Janko von Sibinj preit ein Madchen von weither, namlich die Tochter des lateinischen Konlge. Er lust oelne Mutter die Hochzeitsvorbereitungen treffen, macht sich selbst auf den Weg zum alten Cidovin und ladt diesen zur Hochzelt ein. Der entschuldigt sich aber, dab er die Einladung nicht annehmen k8n- 
ne, weil sein Brauner lahme; auBerdem sei er, Cidovin, mit Marko verfeindet. Janko geht weiter zu Musa "arambasa", der es ebenfalls ablehnt zu kommen, weil er mit Marko in Feindschaft lebe. AuBerdem lahme sein Rappen. Marko Kraljevic, $z u$ dem Janko weiterzieht, deutet dasselbe von seinem Sarac an; auBerdem könne er, Marko, der Einladung nicht folgen, weil er mit Musa verfeindet sei.Janko kehrt nach Hause zurisk und klagt seiner Mutter sein Leid: Alle Vorbereitungen seien umsonst gewesen, weil keine Svaten kämen.- Wider Erwarten kommen am nachsten Morgen aber doch der alte $X_{i d o v i n}$ und Musa mit je 300 Svaten, Marko jedoch allein. Als sich die Svaten aufstelien, fragt Marko, ob Janko seinen Neffen Nine eingeladen habe, was von Janko vermeint wird. Der Konis habe ihm das verboten, weil Nine trunk- und streitsuchtig sei. - Nines Mutter schreibt inzwischen einen Brief und schickt ihn mit einem schnellen Boten ins KozarGebirge zu Nine, der dort Ziegen hutet. Als Nine den Brief gelesen hat, vertraut er seine Herden den anderen Hirten an und macht sich auf den Veg nach Hause. Als er dort angekommen ist, fragt ihn seine sutter, was sein Ohein gegen inn habe, weil er ihn nicht zu den Svaten mue. Nine ist sich keiner Schuld bewußt, glaubt aber, die Lateiner hatten den Oheim belogen und wirden ihm vielleicht sogar das Leben nehmen. Deshalb schlagt die liutter vor, Nine solle ungeladen zum Schutz des Oheims mitreiten, was Nine auch - ausgerlistet mit einem bulgarischen Hirtenmantel (bugar-kabanica), einem 60 Oka schweren Bronzestreitkolben und einem Kornelkirschenholzstock - auf seinem feurigen Rappen tut. Obwohl die Mutter ihm geraten hat, ja nicht aup dem peerd einzuschlafen, weil sonst das Pferd nach vorn dränge, schläft Nine doch zur gewohnten Mittagsstunde ein, worauf das Pferd sofort an die Spitze des Zuges eilt. Marko fragt, was das flur ein "schwarzer Araber" sei, doch Janko meint, man solle ihn ruhig bei den Svaten behalten.- Als der Hochzeitszug ins lateinische Land kommt, wird er von den Lateinern gut aufgenommen. Man nimmt allen die Pferde ab und weist jedem Gast ooinon Platz an, nux Nine nioht, der ungeladen kam, sich aber selbst an die Tafel setzt und drei Tage lang mit den anderen schmaust. An vierten Tag wird die erste Freiersprobe gestellt: Ein Apfel soll von einer Lanze geschossen werden, was allein Nine gelingt, der sich rihmt, schon mit sieben Jahren in der Dammerung eine Milke getroffen zu haben. Die zweite Aufgabe besteht darin, neun pferde zu uberspringen und sich dem zehnten in den Sattel zu setzen. Wieder blicken alle auf Janko, der aber seinen Blick auf den ersten Kum Cidovin richtet; dieser blickt aur den zweiten Kum viusa, der aut den Dever Harko und Barko schlieblich auf die ubrigen Svaten, 
bis sich endilch Nine meldet und den Sprung wagt, wobei er sich brüstet, schon im Alter von sieben Jahren von Berg zu Berg gesprungen zu sein und neun Gebirge sowie die Donau Ubersprungen zu haben.- Nach drei weiteren Tagen Festgelage soll als dritte Aufgabe die Braut unter neun gleichen M.Hdchen herausgefunden werden, was allein Nine mit $\mathrm{Hilfe}$ der bekannten Iist von den hingeworfenen Schmuckstlucken gelingt, wobel er sich ruhmt, er habe seit seiner Jugend 100 Schafe und 100 Ibimmer zu betreuen und wisse doch genau, welches Lamm zu welcher sutter gehore; wie solle er also die eigene Tante nicht aus neun wädchen herausfinden. Nine wirft die Braut hinter sich aufs pferd, bindet sie fest und ruft den Kum zum Aufbruch, worauf die Svaten den Rilckweg antreten.- Kurz darauf meldet sich Iizanka Planinka beim König und fragt,ob er nun endlich dessen Tochter erhalte, wenn er sie ein zehntes Mal zurickhole. Der Konig gibt ihm das Versprechen. Darauf zieht Iizanka einen Holfspelz an, wirft ein Barenfell daruber und folgt den Svaten. Als diese ihn erblicken, fliehen sie vor Angst in alle Richtungen, nur Nine bleibt bei der Braut zurick. Er halt den so schrecklich verkleideten Iizanka zuerst fur ein von Gott gesandtes lingeheuer, erkennt ihn aber plotzlich und sagt, er furchte keinen lebenden Wolf oder Bären, wie sollte er also die Ubergeworfenen Felle seines Vahlbruders Lizanka furchten. Er erinnert den Angreifer daran, daB sie beide in ihrer Jugend Sprungubungen gemacht hatten, wobel er, Nine, zum SpaB Berge und die Donau ubersprungen habe, Iizanka aber nur bis zur Stromitte gekommen sei und ertrunken whre, wenn Nine thn nicht gerettet häte. Iizanka möchte inn darauf kủssen, doch Nine wehrt ab, weil er furchtet, sein Schnurrbart werde versengt. Iizanka gelingt es aber doch, den Wahlbruder zu kuissen und dessen Bart zu versengen, worauf $N$ ine ihn packt und witend gegen eine Tanne schleudert, so daß Iizanka die Augen herausspringen. Nine funrt dem Brăutigam das Mädchen zu und gibt sich als Neffe zu erkennen, worauf Janko Gott dankt fur seinen treuen Verwandten. - Nine eilt zurick ins Gebirge zu seinen Herden.

In dieser sekundär veranderten Var. ist an alten Elementen erinalten, daß Janko als Brătigam fungiert und der uneingeladenes verkleidete Neffe fur inn die schwierigen Freiersproben besteht. An Sekulas Stelle trat ein gewisser Nine, der sich historisch nicht identifizieren labt. Sekundar ist auch die Erweiterung an Liedanfang. Die beiden blteren Neffen, die Bruder Nines, sind auch hier wieder ausgefallen. Auch die Episode,wo man Nines Pferd wegnehmen will, fehlt. Statt des "crni bugarin" 
wurde in diesem Iled der dem Sanger ebenso gelaufige "crni Arapin" eingesetzt, der hier natlurlich fehl am Platz ist. Ilzanka Planinka, dem Nine von Jugend an in Wahlbruderschaft verbunden ist (interessant ist dabel das agonale Element in ihren gemeinsamen Jugenderlebnissen!), ist insofern noch etwas drachenähnlich, daß er in seiner Verkleidung einem Ungeheuer gleicht und den Bart seines Wahlbruders zu versengen vermag, d.h. er muB irgendwie Feuer ausstoßen können, was im Iled aber nicht beschrieben wird. Auch der Name "Lizanka" könnte auf die Elgenschaft des Peuerspeiens hindeuten, weil man ihn wohl von skr. lizatl 'lecken, lodern, zlingeln" ableiten darf. "Planinka", vermutlich aus skr.planina 'Gebirge' herzuleiten, weist auf die Herkunft des Brautrüubers hin. Etwas lächerlich wirkt der Iiedschluß, wo der urspringliche heldische Zweikampl dadurch ersetzt 1st, dab aer von Ilzanka (durch Versengen des Schnurrbarts) gereizte Nine den Gegner einfach hochhebt und gegen einen Baum schleudert. - Var.11 weist folgende Besonderheiten auf:

Mato von Srijem ist der Brăutigam, der Bar von Letan der Brautvater und Milos "cobanin", der Jingste der drei Voinovidi, der hilfreiche Neffe. Milošs prëchtige Ausrlustung wird ausflunrlich beschrieben. Uber seine Festkleider schlieblich zieht er "ugurske haljine", nie sie der "crni Ugarin" (der schwarze Ungar bzw. Bulgare) trkgt. Er $8 \mathrm{chll} \in B \mathrm{t}$ sich unerkannt den Svaten an, bleibt aber in einiger Entfermung hinter dem Zug. Einer der Svater will ihn toten (warum?), wird aber von M1los ungebracht (vielleicht eine Reminiszenz an den versuchten Pferdehandel in anderen Var.). In Iedan besteht Miloz fll seinen Oheim die Freiersproben: Er schießt einen Apfel von einem Becher mit Wein herunter, ohne diesen zu verschlitten, und trinkt den Becher leer; er uberspringt, gestutzt auf se1ne Lanze, zwolf Pferde und setzt sich dem dreizehnten in den Sattel; er findet schlieblich die Braut aus dreibig gleichaussehenden lidchen heraus. Als die Svaten sich auf den Heimweg rachen, reitet $\mathrm{MI}_{-}$ los voraus und stöbt an einem See auf dreizehn Monche, die inm sagen, sie warteten auf Mato und seine Svaten, um inm das lädchen zu rauben. Da erkennt liilo8, daß die "r.onche" in Wirklichke1t verkleidete Gebirgshirten sind, die inn aber nicht wiedererkennen. Er sagt, Nato und die Svaten kämen glelch, das l:adchen aber habe wegen Krankheit zurlickbleiben misssen.- Wharend die "lönche" ihrer Enttäuschung Aus- 
druck geben, zieht Miloz plotzlich das Schwert, kopft die dreizehn als lionche Verkleideten und reint ihre Kopfe auf Steinen am Seeufer auf.Die Svaten treffen ein und bewundern seine Heldentat. In der Nahe von Srem ("Srijem") eragt Mato den Hirten nach seiner Pamilie und seinem Namen, worauf lilio\} sich als lieffe zu erkennen gibt. Mato weint vor Rihrung und mochte Milo\} das Madchen uberlassen, was der Neffe aber ablehnt und statt dessen den goldenen Apfel fordert und erhalt. Mato will seinen heldenhaften leffen noch mit weiteren Schatzen belohnen, Nilos aber kehrt sofort zu seinen Herden ins Gebirge zurluck.

In diesem Iied dirfte statt Janko ein anderer ugrischer Held, nämlich König Mathias Corvinus, hier in der Namensform "Mato von Srem", die Brăutigamrolle spielen. Wahrers die drei ireiersproben noch fast in ihrer urspringlichen Form erhalten sind, wurde die tiberfallszene sekundar v81118 verandert und entruythologisiert. An einen urspringlichen Drachen konnte noch die Tatsache erinnern, daß sich die als Monche verkleideten Gebirgshirten (auch hier wieder eine Beziehung zu Milő, dem Hirtenl) an einem See aufhalten, um dem Hochzeitszug aufzulauern. - Das nkchste Lied in unserer sujetkette, Var.12, ist in MH I, 362 mit nur wenigen Worten mitgeteilt: Marko freit die Tochter von Milan, dem Serbenfursten. Dieser schreibt ihm, er solle beliebige Svaten sammeln, nicht aber seine beiden Neffen Milovan "Cobanin" und Sekula mitbringen.- Sekula, als schwarzer Bulgare verkleidet, zieht mit den Svaten, schiebt den Apfel, uberspringt neun Pferde und erkennt die Braut aus neun viadchen heraus. Auf dem Rluckweg erschlägt er seinen Bruder Milovan, als dieser die Svaten im Waldgebirge Uberfallt. Als Sekula die geflohenen Svaten wieder eingeholt hat, möchte Marko ihn toten, was aber die Svaten verhindern, indem sie Marko erkiüren, Sekula habe ihnen allen das Leben gerettet.

In dieser Var. ist Marko wahrscheinlich sekundar fur Janko eingesetzt, eine Vermutung, die dadurch gestutzt wird, daß Sekula in der Neffenrolle erhalten blieb. Das Motiv der beiden uneingeladenen Neffen ist hier vollig durcheinandergebracht mit der Episode von den beiden Wahlbrudern in anderen Var., wo einer der beiden im Auftrag des Brautvaters als Anereifer auftritt. Das Ergebnis ist, daß in unserer Var. einer der beiden uneingeladenen Neffen den Hochzeitszug uberfallt 
und von seinem eigenen Bruder (nicht Wahlbruderl) getötet wird. Damonische Eigenschaften besitzt dieser Angreifer naturlich keine. - Var.13, ein gelungenes Lied mit dem Titel "Zenidba Jankovic Stojana", hat folgenden Inhalt:

Stojan Jankovic freit Janja, die Tochter des Königs von Misir. Erster Kum wird Kraljevic liarko, zweiter Kum Milos obilic. Brautfuhrer der junge Relja, wahrend die beiden Vojinovibi (hier fehl am Platzl) als Spaßmacher und die zehn jungen Jugovibi (sonst immer neun Brider und inr vater Jug Bogdan!) als gewohnliche Svaten eingeladen sind. Sekula "djete", der ungeladen und unerkannt zur Unterstutzung des Oheims mit den Svaten gezogen ist, gibt den Ieuten den guten Rat, sie sollten den 300 Mudchen, die sie vor der Stadt Misir empfangen wirden, nur die Pferde geben, die Waffen und Mántel aber behalten.- vies geschieht. Um Sekula klimmert sich niemand, als alle an der Tafel sitzen und schmausen. Da bedient er sich selbst bei der Brotverwalterin, dem hietzger und dem Weinschenk, und zwar mit Gewalt. Die Brautmutter verspottet inzwischen die Svaten, die in ihren Nignteln und schwer bewaffnet Wein trinken. Marko weist sie zurecht mit der Bemerkung, daB ja auch einem Hammel sein Pell nicht zu schwer zu tragen sei.- Dann erfullt Sekula die drei Freiersproben, die in der Reihenfolge Mrdchenerkennen, Sprung und Schuß ablaufen. Als sich die Svaten auf dem Heimweg befinden, schickt innen der König seinen Diener Vide Zeravica nach, der neun Vilenkipfe (devet vila glave) aufsetzt, nachdem er sie mit gluhender Kohle gefullt hat ( $u$ nje siplje zivu zeravicu), und hoch in den Wolken den Svaten nachfliegt. Beim Hochzeitszug angekommen, wirft er Glut ab, stobt aus den Nlstern Peuerregen, aus den Ohren Plammen und aus dem Mund Blitze.- Die Svaten pliehen und eilen zu Stojans Hof, wo sie das traurige Schicksal des zuruckgebliebenen Bulgaren und der Braut beklagen. Sekula aber tötet inzwischen den neunkopfigen Žeravica, als das Kadchen ihm gesagt hat, dab es sich nur um einen Diener ihres Vaters handle. Dann bringt Sekula die Braut olcher zu Stojans Hof und gibt sich schlieblich als Neffe zu erkennen, wobei am Liedende aber unklar bleibt, ob 5tojan ihn verstanden hat.

Stojan Jankovic ist eine historische Pigur und eine beliebte Iiedgestalt, ein in venezianischen Diensten stehender Turkenkämpfer des 17.Jh.(vgl. Maretic NNE,132; Vuk III,616, die Anm. zu Vuk III 21). Sein Name warde in unserem Sujet vermutlich fur den alteren Sibinjanin Janko eingesetzt, wofur auch Sekula in der Neffenrolle spricht. Der Diener und Angreffer Zeravica, 
dessen Name 'Glut, gluhende Kohle' (vgl. Lizanka!) bedeutet, hat einergeits noch Dracheneigenschaften (er fliegt hoch in den Wolken!), arbeltet aber andererseits - ein realistischer Erklärungoversuch des Sangergl - mit einem Trick: Er setzt neun mit Kohlenglut gefullte Kopfe auf, sprint dadurch Feuer und erweckt den Eindruck eines mehrkopfigen Drachen. He "V1lenköpfe" entstanden vielleicht aus den "viljeve, filjeve glave' (Elefantenköpfen) anderer varianten durch Fehldeutung und Volksetymologie. - Die letzte skr. Var. ist Nr.14:

Hier Preit Kraljević larko (der fur einen alteren Helden wie Janko eingesetzt wurde) die Tochter des "kralj Graorsk1" (vielleicht eine Entstellung aus skr. daurski, dem Adjektiv zu Giaur, analog zu dem "lateinischen König" in anderen Var.). Er schickt seine beiden Neffen Luka und Ilija als Freier zu dem Konig, wo sich die Brlder so trunk- und streitsuchtig benehmen, daB der Brautvater Marko brieflich bittet, die beiden Neffen nicht zu seiner Hochzeit einzuladen.

Hier wurde also sekundär eine Motivierung fur die Ausschaltung der beiden Neffen des Brautigans versucht, die aber fehl am Platz lst, well es aich ja nur um elne listige verleumdung des Brautvaters handeln soll. Doch weiter in der Inhaltsangabes

Der hilfrelche Nefle, der aus dem Geblrge geholt wird, verkleidet und unerkannt mit den Sraten zieht sowle die bekannten drel Prelerproben besteht, heiBt Mile (aus Milo8) "Zobanin". Als die Svaten auf dem Heimwee sind, lauert innen des Konigs Diener Milovan auf, der schon neunmal die Braut zurlickgeholt hat und sie nun beim zehnten Mal selbst zur Braut bekommen soll. Er hat sich Bären-, Wolfs-, Hasen- und Fuchspelze ubergeworfen, labt aus den Nasenlbchern Regen, aus den Ohren Feuer und aus dem Mund Blitz und Donner entweichen.

Der Diener lat hier noch mit drachenahnlichen zugen ausgestattet (er kann Peuer usw. speien!), die aber schon weitgehend entmythologisiert aind (Vermumung durch verschiedene Pelzel).

Mile bleibt als einziger bei dem Mudchen und verteldigt es gegen den Angreifer, den er schon lange kennt und schon oft beslegt hat.

Am Schlus geht das Lied in das Sujet vom Typ Vuk II 55 und Marj.1 uber, wo namlich der kum versucht, die Braut, deren blendende schønheit er unter dem durch einen WindstoB hochgehobenen Schleler erblickt hat, durch Bestechung des Devers ausgeliefert zu bekommen und zu verfuhren. Der Braut gelingt es aber dank einer 
Iist, in das zelt zu Marko zu fliehen, der den untreuen Kum und auch den mitschuldigen Deves: am nächsten Morgen tötet. Bei der Trauung will Marko den jungen Mile zum Kum machen, erfahrt aber nun, daB es sich um seinen Neffen handelt.

Wo unser 4.3-Sujet, das aus 4.1 und 4.2 kontaminiert ist, sich formiert hat, labt sich nicht mit Bestimmtheit sagen. Wahrscheinlich hat es sich im skr. Raum herausgebildet und wanderte in der neuen, kontaminierten Form nach Mazedonien und Bulgarien zurlick, wo es namlich im ganzen gesehen sekundure Zuge trägt. So ist z.B. Var.15 (aus liestbulgarien) m.E. eindeutig an skr. Ileder vom Typ Vuk II 28 angelehnt, auch wenn im zweiten Teil bei den Preiersproben einige typisch bulg. Elemente hinzutraten:

Der König von Misir möchte heiraten und findet endlich in der Stadt Roksana eine passende Braut. Man verlangt aber von inm drei Lasten Schatze und einen goldenen $\mathrm{Ring}$ und spricht gegen seine Neffen ein Einladungsverbot aus, weil die beiden trink- und streitsllchtig seien. Der Konig kehrt nach Hause zurlack und berichtet alles seiner Mutter, die ihm rkt, er solle den Freunden seines Vaters, nälich Kraleviti Marko, Janko von Kosovo, Relja von Reljovo und Serbin, schreiben, sie sollten die Rolle des Brautfuhrers, Obersvaten, Kums und Bannerträgers Ubernehmen.- Nachdem der Brautigam Botschaften weggesandt hat, versamme in sich an seinem Hof schlieblich 600 Svaten, die mit Marko an der Spitze aufbrechen.- Die liutter der ungeladenen Neffen Vukasin und Petrusin labt inzwischen Milo\}, den Jungsten, der als Hirte im Gebirge lebt, hermfen. Schnelier als der Palke, der ihm die Botschaft brachte, kommt Milos nach Hause und erfahrt von seiner Nutter, daB er unerkannt mit dem Oheim nach Roksana ziehen soll, um ihm in gefuhrlichen Situationen beizustehen.- Nilos zieht goldene Kieider an, wirft ein Barenfell uber und reltet den Svaten auf dem rferd seines vaters nach. Cbwohl der Hochzeitszug drei Tage Vorsprung hat, holt Milos ihn nach kurzer zeit ein und reitet mit den Svaten. Als er auf dem Pferd zur gewohnten Mittagszeit eingeschlafen ist, wollen ihm drei Svaten sein pferd nehmen. Sie zielen und werfen nach hilloz, der davon aufwacht und die drei wie steinchen vor seiner feurigen Peitsche tanzen labt.Nach der Ankunft in Roksana stellt man dem Broutigam finf Aufgaben, die alle Milos besteht: Er Uberspringt drei nebeneinanderstehende Pferde, auf deren Rlucken Lanzen mit sechszackigen Pfeilen darauf aufigestellt sind, wobei er sich ringt, schon 
neun Hugel ubersprungen zu haben. Er trinkt neun Kruge Wein aus und brikstet sich, zur Zeit der Sommerschur inmer 9000 Schafe gemolken (und deren liilch getrunken?) zu haben. Er schiest mit dem Yfeil durch einen Ring auf einen Apfel und trifft ihn. Er Uberspringt zu Pferd das eiseme stadtor und rffnet es fur die Svaten. Zuletzt findet er die Braut aus drei gleichen Madchen heraus.- Die Svaten sagen erleichtert, nun hatten sie mit Hilfe des schwarzen Bulgaren alle Prelersproben und Prifungen uberstanden. Miloß klät sie aber auf, daß ihnen noch ein Kampf mit dem dreikbpigen Balasin bevorstehe. Wirklich labt nach der Abreise der Svaten der Konig Balasin kommen und schickt linn dem Hochzeitszug nach. Balasin hat aber erfahren, dab lílos unter den svaten ist, und fluchtet nun um sein Ieben. Er lauert den Svaten auf, blyst Sturmwind und sprint helles peuer, worauf die Helden von den peerden fallen und fliehen. Der schwarze Bulgare aber nimmt den leichten Streitkolben und die schwere Keule und fordert Balasin zum Wurf, flingt aber dann dessen keule mit der Rechten auf und treibt ihn mit einem gezielten Keulenwure neun Ellen tief in die Erde. Hilos kehrt zur stadt zurlick und holt die beiden Mädchen, die bei der Braut waren, fur sich, ur die eine zur Schafehuten und deren Gefahrtin zun Wassertragen anzustellen. Er holt die Svaten ein und gibt sich seinem Oheim als Neffe zu erkennen, indem or meint, ungeladen sei er gekommen, ungeehrt werde er wieder gehen.

Hier sieht man m.E. deutlich, daß das kontaminierte sujet als Ganzes im wbulg. Raum Aufnahne fand, gleichzeitig aber - was vor allem die Freiersproben betrifft - von der bereits vorhandenen Tradition beeinflubt wurde. Wie das einfache Sujet 4.1 als im maz. und bulg. Raum sekundär erklärt warde, so gehört offenbar auch das aus 4.1 und 4.2 kontaminierte sujet 4.3 der maz.-bulg. Sekundarschicht an. Die Sujetubermittlung aus dem skr. in den maz. und bulg. Raum erfolgte also vermutlich in zwei Schuben: 4.1 wanderte aus dem skr. in den maz.-wbulg. kaum, whihrend 4.2 den ungekehrten $\mathrm{Keg}$ eingeschlagen haben durfte. 4.1-Iieder, im skr. Raum mit dem zugewanderten 4.2Sujet kontaminiert, fanden später in Form von Sujet 4.3 zum zweitenmal in Kiazedonien und Bulgarien Eingang. Statt Stefan, dem Serbenzar, ist in Var.15 sekundur der Konig von Misir, also der Gyptische konig, als Bräutigam eingesetzt. Der Brautvater und der Name des Mudchens werden gar nicht genannt. Aus dem urspringlichen Brautnamen Roksanda 
(vgl. Vuk II 28 u.a.) murde hier falschlich der ON Roksana; Balacko wurde in Balazin abgeandert. Der Angreifer ist dreikbpfig und feuerspeiend gedacht, hat also noch echte Drachenzlige. - In Var.16 wird er sogar als "chala Balacka vojvoda", also als 'Drache' bezeichnet:

Hier freit der serb. Konig Stefan durch seinen Wesir Todor Roksandra, die Tochter des lateinischen Konigs Michail, und zieht mit 12000 Svaten nach Legen. Er kommt dabei durch Turnovo (wahrscheinlich fur vucitrn wegen Namensähnlichkeit eingesetzt), läd aber seine beiden Neffen Vuk Vukasin und Petre Petrusin nicht ein, weil die Lateiner inm das wegen der angeblichen Streitsucht der beiden untersagt haben. Die Mutter der Neffen lickt inren dritten Sohn, den irunderhelden Milos "Cobanin", aus dem Gebirge holen, um ihn dem Oheim, weil sie eine Palle vermutet, zur Unterstützung mitzugeben. Wirklich erhblt der König in Legen seine Braut nur deshalb, weil lifilos fur inn neun Fैasser Hein austrinkt, neun mit Dormgestrupp beladene Vagen uberspringt, einen Vorkampfer der Lateiner ("dambelo" Latince) im Zweikampf besiegt, Roksandra aus drei gleichaussehenden Madchen herausfindet und schlieblich einen drei Stunden entfernten goldenen Apfel durch einen Ring trifft.- Auf dem Heimweg uberfallt die Svaten der vom Brautvater entsandte "Drache" Balacka:

Koga pojde Balacka vojvoda, Koga pojde chala sŭs tri glavi: Niz ednata laden vetur duchna, Niz drugata jasen ogin seva, $\mathrm{Niz}$ trekjata sitni rosi rosa.

Diesem drachenähnlichen, dreiköpfigen Balacka, der Wind wehen, Feuer sprihen und Tau fallen lassen kann, tritt kilor allein entgegen und antwortet auf die Frage, wo denn die Svaten seien, der Wind aus Balackas Kopf habe sie zu den Wolken emporgeweht. Durch Anwendung dieser list bringt Milos das Ungeheuer dazu, daß es zum Himmel emporblickt. Im gleichen Augenblick schlkgt inm Milos die drei Köpfe ab und reitet den Svaten naoh. Er gibt eioh dem Oheim als Neffe zu erkennen und macht ihm Vorwïrfe, daB man inn nicht eingeladen habe.

Auch hier ist wieder - genau wie in der vorhergehenden Var. Anlehnung an die Handlungsfuhrung und Namen in Vuk II 28 festzustellen, nur sind die Freiersproben jetzt nach bulg. und maz. Muster ungestaltet. Roksanda wurde zu Roksandra, Letan zu Legen und Balacko zu "chala" Balacka, einem noch echt drachenahnlichen Ungeheuer (also keine bloße Vermummung!). Das Motiv der listigen Ablenkung des Gegners scheint aus den Kusa kese- 
dżija-Iiedern Ubernommen zu sein. - Var.17 erzuhlt folgendes Geschehen:

Zar Kostadin sucht eine passende Braut fur seinen Sohn Ognenin, findet aber keine, bis ihm drei Schiffsleute berichten, daß uber dem lieer in leg'en König Smeletin eine heiratsfahige Tochter namens Angelina habe. Zar Kostadin setzt daraufhin uber das lieer und schlagt seine Zelte vor Leg'en auf. Die Königstochter hat dies bemerkt und schickt ihre Kutter zum Viasserholen vor die Stadt; gleichzeitig aber soll sie den Helden fragen, was ihn hierher Eefunrt habe.- Als die Alte von seinen Heiratsplanen erfahren hat, nimit sie der. Zaren mit an den Königshof und verlobt ihre pochter mit seinem Sohn. Als Zar Kostadin aufbricht, erhlilt er die iieisung, mit 3000 Svaten wiederzukominen, seine Neffen Stanka und Jankula aber nicht mitzubringen. Verärgert gelangt kostadin zu Hause an und berichtet seiner Gattin von der ungehörigen Bedingung, worauf die Prau inm rat, er solle liarko von Prilep mit 1000 Svaten, den jungen (malecok) Sekula als Dever mit 1000 und den alten sovak mit weiteren 1000 Svaten eirladen. Dies geschieht, und die svaten machen sich auf den Vieg.- Die Weffen befurchter einen Verrat urd holen auf Anraten ihrer lutter den dritten Bruder, den Hirten Velko, aus dem Gebirge herunter.Sie erkizren inm die sachlage, statten ihn prachtig aus und schicken inn auf dem lange gezuchteten fferd G'oka hinter den svaten her. Nur wit Velkos Hilfe, weil er die gestellten freiersproben besteht, erhalt der Oheim die iraut: Velko kann von drei Äpfeln 8agen, aus welchem Jahr sie stammen, kann zwei Buffelkihe als hiutter und Tochter unterscheiden, uberspringt zwei Pferde und findet die Braut aus drei gleichaussehenden radchen heraus. Fr ruhrt die Braut dem Schwiegervater lostadin zu, und die Svaten treten die Heimreise an. $\mathrm{Nm}$ lieer werden sie von einem schwarzen fraber uberfalien, der die reichen Geschenke fordert, von Velko aber getötet wird, während die Svaten Eeflohen sind. Als Velko den Svaten mit dem l.Zdchen und den Schätzen nachreitet, halt ihn Duka Dukatince aur und fordert die Braut, wird aber von Velko im Zweikampf getortet. Velko erreicht die Svaten und nimmt mit wutter und Bruderm drei Wochen lang an den Hochzeitsfeierlichkeiten teil.

In diesem Iied sind sekunär ganz andere Namen eingesetzt, nur Leg'en als Ziel der Brautfahrt blieb erhalten. Das Sujet wurde nachtraglich um die Episode mit den drei Schiffsleuten und am Iiedschluß durch den Zusammenstoß Velkos mit Duka Dukatinde erweitert. Ebenso wurden auch die rreiersproben vermehrt und gleichzeitig nach maz. und bulg. ¿uster verbauerlicht. iine ir- 
innerung an ehemalige Drachenzluge des Angreifers könnte man noch darin sehen, da!3 der schwarze Araber die Svaten am lieer, also an Wasser, Uoerfältt. Hinter Smeletin verbiret sich möglicherweise eine Sntstellung von skr. Illeci 'Venedig' oder eine Ableitung aus bulg.smel 'klhn'. Die Episoden mit dem versuchten perderaub und der Selbstoffenbarung des keffen fehlen. Neu ist, daß König Smeletin und der Bräutigam Ognenin in diesem Lied Uberhaupt nicht in Erscheinung tretens Zar Kostadin geht fur seinen Sohn auf Brautschau und die Königin von Leg'en verlobt ihre Tochter Angelina mit dem unbekannten Zarensohn. - Var.18 zeigt inhaltliche Abweichungen:

f.onig Dimitrija freit die Tochter des "deutschen" königs. kum ist Aiarko kralevicin, erster Svate könig Miludin und Brautfuhrer l)ete Golomese, den der Bräutigam erst aus dem Sand hervorgeholt und zum Dever gemacht hat, wofur er ihn vortrefflich ausristet. Die 3000 svaten ziehen zu der Stadt, in der die Verlobte von könig Dimitrija lebt, erhalten das liadchen jedoch erst dann Ubergeben, als Dete G. zwei Preiersproben bestanden hat: Er zerschiägt das stählerne stadttor urd erkennt die Braut unter drei gleichgekleideten! ädchen heraus. Daraufhin wird die Braut Dete G. arvertraut, und die Svaten ziehen nach Hause. Unterwegs uberfallt sie der schwarze Araber, "arapina strasna chaletina", also ein Drache, dem die Oberlippe an die Stim schlägt, die Unterlippe aber auf die srust hängt. Die Svaten fliehen vor diesem Scheusal, nachdem sie inm ihre Geschenke abgeliefert haben. Jer Araber erklärt, er sei schon seit sieben Jahren nit dem tiadchen verlobt und hole es nun endeilitig zurick.- Nach einem heldenhaften Zweikampf besiegt der Dever, der allein bei der Braut geblieben ist, den gefuhrlichen Angreiler und schneidet inm den Kopf ab. Er eilt mit der Braut zum Hof des Brătigams, wo er hört, wie man gerade sein Geschick bedauert. Dete G. schlagt daraufhin alle Svaten der Reihe nach mit der keule zur Strafe flur ihre Feigheit. Der Brăutigam ist Dete G. fllr alles oo sohr denkbar, deb er ihn zu seinem jungeren Bruder eriklurt.

Diese Var. gehört eigentlich in die Gruppe der 4.21-Lieder, in denen der Dever (in den maz. und bulg. Iiedem Dete Golome ${ }_{\theta}$ ) die Braut vor einem Ingeheuer beschutzt und später die treulosen Svaten bestraft. Sekundär sind hier anscheinend die beiden "reiersproben eingetuft worden, die eine Behandlung des Iiedes in Kap.4.3 fordern. liit dem "deutschen" Könif ist sicher der Kaiser von Oisterreich gemeint. Dimitrija könnte Dmitar Jakłic 
sein, honig Miludin ist sicher Kornig filutin aus dem mittelalterlichen Serbien, - also alles in allem eine ganz willklirliche Zusammenstellung. Weil das Lied eigentlich dem Typ 4.21, und nicht 4.11 argehört, fehlt naturlich die Episode mit den uneingeladenen Neffen am Anfang und die iiedererkennungsszene zwischen Oheim und Neffen am Schluß. Var.19 folgt im wesentlichen der Handlung des vorhergehenden Liedes:

Dete SedmogodXe (also ein siebenjühriges Heldenkind) ist hier der Bräutigan, Latinka devojka (ein Lateinermädchen) die Braut, Marko Delibała der Kum, Ivan Černogorec der Obersvate und jillus Kobilicin der zweite vever. Dete Sedmogodke findet aber unter den svaten keinen, der ihm ebenburtig ware und die Rolle des ersten Devers Ubernehmen könte.Deshalb ernennt er Dete Golomese, den wunderbaren Helden, zum ersten Brautflinrer.Allein Dete G. besteht die 'reiersproben ia lateinischen Land: Er ilst neun Backofen mit Brot leer, trinkt reun plisser vein aus und findet die Braut aus drei Eleichaussehenden 1. Hadchen heraus. Auf dem Rllckweg tötet er schlieblich einen schrecklichen schwarzen Araber mit einem Kopf, so grow wie eine Tonne, urd Augen wie $\mathrm{KaB}-$ kriegen.

Deutlich erkennbar ist in dieser 4.3-Var. das fiberwiegen des 4.2-3estardteils, wobei sogar zmei jeldenkinder (in der Bräutigam- und Deverrolle) aie Protagonisten sind, die mit den Ubrigen Svaten $z u$ einem ziemlici anachronistischen Heldenkatalog zusammengestellt sind. Der Angreifer ist mit den Ublichen schablonenhaften Vergleichen als Ungeheuer gekennzeichnet. Die Freiersproben sind nach maz.-wbulE. Muster modifiziert worden. - Var.20 berichtet folgendes Geschehen:

Königin lilica verlobt ihren Sohn Ivanco mit dem Mudchen Kotlenka und mub die Bedingune annehmen, daß sie ihre Neffen, den Schafhirten Ivanco und den Schweinehirten Michaldo, nicht einludt, weil die beiden angeblich Streit verursachen wurden. Die Svaten brechen auf, um die Braut abzuholen. Als zwei, drei Tage vergehen und die Leute immer noch nicht zurlickgekehrt sind, wendet sich die Tante an Ivanco, den Hirten, mit der Bitte, er möchte den Svaten nacheilen und nach dem Rechten sehen, was Ivanco aber unter Hinweis auf den schrecklichen Hadzarin und den nicht minder gefährlichen Marko Kralevic ablehnt. Michaldo jedoch wagt das Unternehmen, wirft sich Bären- und Wolfsfelle lber und zieht nach Kotel, nachdem man inn nocn vor liadża- 
rin und iarko gewarnt hat. Wirklich wollen ihm die beiden sein Pferd abnehmen, was ihnen aber nicht gelingt, weil Ivanto sie abzuwehren vermag. Ir kommt gerade noch rechtzeitig nach Kotel, um flur den Bräutigan die b'reiersproben bestehen zu können: Er Uberspringt neun wagen, dann neun Pferde, und findet die Braut unter drei gleichen 1.kdchen heraus. Er ubergibt die Braut dem Bräutigam und nimmt die beiden anderen !iädchen firr $81 \mathrm{ch}$ und seinen Bruder Ivanco.- Ais die Svaten auf dem Heimweg sind, senden ihnen Pilip liadzarin und ilarko den schwarzen Araber nach, der sich vergewissert, ob nicht die beiden Neffen unter den Svaten seien, was vermeint wird. Darauf zieht der Araber dem Hochzeitszug nach, Uberfallt inn und wird von Michalco mit der Keule in drei Teile zerschmettert.

In diesem lied wuraje das Sujet sekundär stark verändert. Y.onigin lilica (typisch bulgarisch, dab die liutter den Sohn verlobt1), in diesem iled natbrlich willibirlich eingesetzt, geht selbst zu den Neffen, uber die ein inladurigsverbot verhangt wurde, und bittet den einen der Hirtenbrider, er möge den Svaten beistehen. Als Ivanco aus Furcht ablehnt, erfullt richalco die Bitte der Tante. Pilip ladzarin und krarko Kralevid, sonst imuer Gegner, sind hier Spiebgesellen und spielen gemeinsam eine negative Kolle: Sie sind diejenigen, die den Pferderaub versuchen, was in anderen Var. doch drei der Svaten tun, und sie schicken den Svaten den schwarzen Araber nach, was sonst die Aufeabe des Brautvaters ist. Der Araber ist hier vollig entmythologisiert. Fine Erkennungsszene zwischen Ivanco, dem Brăutigam, und lichalco fehlt. Var.21 gehort nur bedingt hierher, weil die Neffen-Episode fehlt, die Freiersproben indirekt gestellt werden (einer der svaten fordert die Helden auf, die liauer zu Uberspringen und das Tor zum "Yohnturm des likdohene zu offnen) und ferner nicht der schwarze Araber, sondern ein ganzes Heer die Braut zurlickholen will. :ieil das Lied aber noch deutliche Reminiszenzen ar uriser 4.3-Sujet enthalt, mußte es hier wenigstens erwikhnt werden.

liit dieser letzten Var. ist das Brautgewinnungsthema in seiner vielfíltigen Gestalturg abgeschlossen. Yir kanen zu dem Ergebnis, das das Hochzeitszugsujet mit Preiersproben, aber ohne fiberfall oder sonstige Komplikationen, also Typ 4.11. 
primar dem skr. Raum zugeoranet werden muls, wahrend Typ 4.2 (iberfall auf den Brautzug und Verteidigung der Braut durch den Dever, ein Heldenkind), sowie Typ 4.13 (Der Brkutigam holt drei goldene Äpfel von einem durch Lamien bewachten Baum im Meer) und 4.22 (Kampf mit dem Drachen im Brunnen wahrend der Brautfahrt) dem maz.-wbulg. I,iedraum entstammen.Das jungere Sujet 4.3, eine Kontamination aus 4.1 und 4.2 , durfte dem skr. Raum angehören und wäre daher im maz. und bulg. Gebiet seikundar (worauf auch die IN und ON hinweisen), wo es aber Verghderungen gemas der im Zuwanderungsgeblet bestehenden Tradition erfuhr.

Fin tragender Gedanke in diesem Kapitel war, daß die moglichen Komplikationen, durch die der Hochzeitszug in den 4.2und 4.3-Liedern gestört wird, alle auf den vrachenkampl zurickzufuhren sind. Der schwarze Araber, aer dreikopfige Balacko, die vila und vielleicht auch der bür wären also vermutlich nur verschiedengestaltige Substitutionen des urspringlichen Drachen, wie er in einigen archaischen maz. Varianten roch am deutlichsten zum Ausdruck kommt.

\subsection{DRACHENKAMPP-THERATIK AUSSERHALB DES HOCHZEITSZUGSUJETS}

Der eine große Pol unseres Sujetkreises 4, bei dem Primarund Sekundärschicht in der maz.-wbulg. Heldenepik verquickt aind, war Typ 4.11, das Sujet der Brautgewinnung nach dem Bestehen von Freiersproben, das wir als primär dem skr. und als sekundur dem maz. und bulg. Raum zuordneten. Der andere grobe Pol des sujetkreises 4 ist das wahrscheinlich dem maz.-wbulg. Liedraum entstamende Drachenkampfoujet. Aus dem Ineinandergreifen der beiden umfangreichen, zu den Polen I und II Eehorigen Liedfelder ergaben sich die Miechsujets 4.13, 4.12, $4.21,4.22$ und 4.3, bei denen Hochze1tazugaujet und Drachenkampfthema miteinander verbunden aind. In den folgenden Kapiteln 4.41 - 4.44 soll nun die Drachenkampf-Themat1k außerhalb des Hochzeltszug- bzw. allgemelner Brautgewinnumgseujeto, also der zweite groBe Pol unseres Schemas behandelt werden, 
des sich so daratellen labt:

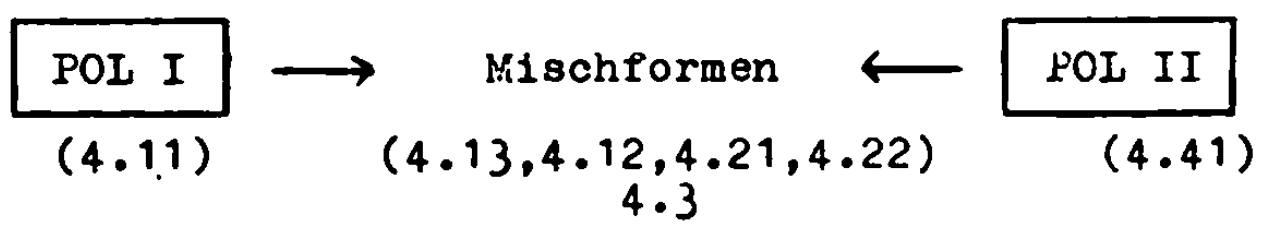

\subsection{DRACHEAKAMPFLIEDER}

Liedsujets, in denen ein Held allein oder zusammen mit anderen einen Drachen bekampft und tötet, sind im slidslavischen Raum, und da vor allem wieder auf maz.-wbulg. Boder, reich belegt. ther diese Dracherkampf-(bzw. zum Tell Georgs-)Lieder besteht eine umfangreiche Literatur 243 . Is handelt sich vor allem um Lieder vom Typ ISSF V,294-297 (Nr.170-172) "Sv.Georgi (junak) ubiva triglava lamja, ta poticat tri reki: ot zito, ot mljako 1 ot vino", "Sv.Georgl osvobozdava samodivaki robi" und "Sv.Georgi porubva lamja, kojato gulta chora". In der Volkserzahlung bzw. in kikrohen ist dieser Typ reichlich, und zwar international, belegt ${ }^{244}$, vgl. AaTh 300 (FFC 184) "The Dragon Slayer" und Hahn, Griechische und albanesische M.7urchen (Leipzig 1864), I,49-50 "Andromedaformel", vertreten beispielsweise durch die hellenischen Sagen von Andromeda und Pereeue sowie Hesione und Herakles, anklingend in der SiegPriedsage von der Befreiung Brinhilds und deren Vermahlung mit Gunar in der nordischen Form und Befreiung der von einem Drachen geraubten Königstochter und Veriählung Siegfrieds mit ihr in der Volksbuchform, wo allerdings die Auslieferung an das Ungeheuer Pehlt.

Literatur zur "lamja" bzw. "(ch)ala, hala, azdaja" wurde bereits in Kap.4.13 genannt. Eine mindestens ebenso reiohe Sekundurliteratur 245 informiert uber den Drachen, die Georgslegende und berlinmte Drachenkampfer wie Perseus, Herakles, Kadmos, Apollo, liarduk, Ansar, Yu, Susano, Indra, Horus, Gilgamesch, Digenis Akritas, Dobrynja, Beowule, Siegfried,Dietrich von Bern, lie Helligen Demetrios, Konstantin, Theodor, Michael u.a. Laut Keletinskij 246 let der K u l t u r her o s (kul'turnyj geroj) - die alteste Gestalt der Folklore - der typische 
D r a c h e n $t$ o $t$ e $r$, namlich derjenige, der die Welt von Ungeheuern befreit, die sich aus den urspringlich noch nicht negativen Gestalten, den Herren der verschiedenen Gllter, entwickelt haben. Meletinskij morchte die Herausbildung der Gestalt des haufig noch theriomorphen Kulturheros dem Ausgarg der matriarchalen Epoche zuordnen. Typisch rur den "kwl turnyj geroj" sind vor allem seine wunderbare Geburt und sein Auftreten in Zwillingsgestalt. Beide Merkmale finden wir auch bei den Drachenkamplem im sludslavischen Raum. Es handelt sich hier vorwiegend um archaische maz.-wbulg. Lleder, in denen ein Held von besonderer Geburt (z.B.ein nach dem Tod des Vaters geborener Witwensohn; auch der hl. Georg wird entweder als Witwensohn und sogar Heldenkind oder als unehelich geboren und an einem Freitag gezeugt 247 gedacht), haufig ein Heldenkind, oder ein Zwillingspaar 248 den Drachen bezwingt.

Ein typisches Lied dieser Art ist Verk.-Lavr.86, ein $78 \mathrm{~V}$. langes Lied aus Hazedonien mit folgendem Inhalts

Ein kind wird am Abend geboren, langt bel Morgengrauen schon an zu gehen, liuft am Tage wher und beginnt mittags bereits zu schreiben. Die erstaunte vutter hrlt das Kind fur ein Wunderwesen:

Ti 81 halis Juda samovila!

Worauf das kind inr aber entgegnet:

Jaze nesam juda samovila,

Tuku sam halis Cendo ( $=\mathrm{K}$ ind)

und erklart, es werde nach Solun ziehen, wo eine schreckliche Iamja aufgetaucht oe1 und se1t dre1einhalb Jahren dort wite, thglich ein vadchen freose und schon neun ganze Hoohzeltszllge sowle neun Karawanen Fuhrleute verschlungen habe. Dieses Ungeheuer werde es nun t8ten.- Die Mutter rkt $1 \mathrm{hm}$ besorgt davon ab, doch das Heldenkind verlangt die Waffen seines Vaters: den Stre1tkolben und das scharfe Schwert. Nachdem das Kind die vaterlichen Waffen erhalten hat, bestelgt es das Streitros des Vaters und zieht in Riohtung Solun. Da taucht unvermittelt ein Stern auf, und aus dem Sterm ertont eine Stimme, die das Heldenkind auffordert, nicht vom Weg abzuweichen und keine Furcht zu zeigen, denn es atehe von nun an unter dem Schutz der hl. Gottesmutter und der hl. Nedelja ("oveta nidel ja". hl. Sonnta8). Darauf tritt das Kind furchtlos dem brillenden Drachen entgegen, streckt ihn zuerst 
mit dem Streitkolben nieder, steigt vom perd und sohlagt dem Ungeheuer den Kopf ab, worauf neun Karawanen Fuhrleute, neun Hochzeitszllge und neun junge Brâte zum Vorschein kommen.

In diesem Iied ist das Heldenkind offensichtlich ein Hitwensohn, denn der Vater tritt uberhaupt nicht in Erscheinung; die Waffen aber, die er hinterlassen hat und die das Heldenkind von der thutter fordert und erhklt, spielen eine wichtige Rolle. Vit ihnen und dem perd des Vaters zieht das Kind gegen den schrecklichen Drachen in den Kampl. Der Drachentoter ist also hier ein durch auBergewohnliche Geburt und wunderbares Viachstum sowie Ubernaturliche Stbrke ausgezeichnetes Heldenkind. Zu diesen ganz archaischen Elementer ist der christliche Zusatz, namlich das Auftreten der beiden Heiligen als Beschutzerinnen des Drachenkămpfers, selbstverständlich erst spgter hinzugekommen. DaB aus dem Drachen ganze Hochzeitszluge und Karawanen hervorstrómen, darUber wird noch zu sprechen sein. - Eine ähliche Mischung aus Heidnischem und Christlichem finden wir in Stoil.II 13, einem 85 V. (epische Zehnsilber) langen maz. Lied aus der Gegend von hariovo mit folgendem Inhalt:

Die junge "itwe Ververica geht drei Jahre lang schwanger, bis sie den Tag der Geburt ihres Kindes nahen fuhlt und neun Geburtshelferinnen kommen laBt. Als die alten Frauen an der Ture stehen, kommt das Kind gerade ohne ihre Hilfe zur Welt: jamo dete masko se rodilo, und heibt die irauen zurucktreten, denn es konne alles Notige selbst erledigen:

Sam se rodi, sam se izbabuva.

Das kind labt sich nicht in Windeln wickeln, sondorm beauftragt oeino Mutter, s10 solle ihm, whirend es schlafe, inzwischen das pferd des Vaters aufzumen. Vom Schlaf erwacht, fordert das Kind noch die "iaffen selnes Vaters und erklart, es werde nun im vaterlichen Reich (tatkova durzava) nach dem Rechten sehen, denn das sel drel Jahre ohne einen Herm gewesen. Des Kind reitet in Richtung Solun und gelangt dabei an einen tiefen See, an dessen Ufer ein Greis sitzt, der das Kind vor dem im See hausenden menschenfressenden Drachen, der "Líndin Lamja" (hucetina lamia), warnt. Das Heldenkind aber tritt der auftauchenden Iamja furchtlos ertgegen, schiebt mit peilen auf sie, zieht sie 
mit eisermen Haken aus dem See und erschlagt sie mit dem Schwert, worauf aus inrem Leib junge Manner, junge Frauen und kleine Kinder hervorquellen, die dem Heldenkind fur ihre Befreiung danken.- Die Nutter halt inzwischen Ausschau nach ihrem Sohn und sieht ihn, gefolgt von den Befreiten, des Weges kommen. Sie weint und klagt, ihr 80 lange erwarteter Sohn se1 nun ein käuber geworden:

Su nosila dete tri godini, I toa nekoj ajdut k'e izlezi.

Doch Dete "malečkavo" klärt seine hutter auf, daß es nur seine Aufgabe erfulle, nublich das Reich seines Vaters zu huten.- Die hutter fragt nun, auf welchen Namen es getauft werden wolle, worauf das Kind erklart, es habe schon einen Namen: es heiBe Zmejce Anostolce. Die shtter fragt weiter, aus welcher Richtung sie den Sohn erwarten solle:

Ani ot kade da te, sinko, Ceka?

und das Heldenkind antwortet ihr etwas ratselhaft:

K'e 81 oda po viłnoto nebo:

Koa k'e si, majko, progovara,

Seta zemja k'e si odgovaral

Auch hier wieder ist das auffallende fromme Element ein späterer (vielleicht durch blinde sanger hinzugekommener) $\mathrm{Zu}-$ satz zu einem archaisch-heidnischen Drachentoterlied,dessen Protagonist nach wunderbarer Geburt, außergewohnlichem Wachstum und einem magischen Schlaf mit der Ausrlistung seines Vaters zum Drachenkampl gegen dic im See hausende Iamja auszieht und die Opfer aus dem Schlund des Drachen befreit.DaB das Kind sich ApostolCe ${ }^{249}$, also 'kleiner Apostel', nennt. ist ein christlicher Zusatz zu dem sicher urspringlichen "Zmejče", also 'kleiner Zmej", wobel festzuhalten ist, daß der Zmej im sudslavischen Volksglauben d a $s$ dämonische Wesen darstellt, das zum Kampf gegen die Lamja pradestiniert ist (vgl. Kap.5.2). Weitere der Tendenz zur Verchristlichung entspringende Elemente sind die Motive der (von der Mutter vorgeschlagenen) Taufe und der "Himmelfahrt" des dem hl. Georg oder dem "Donnerer" Ellas ("koa k'e 81, majko, progovara, seta zemja k'e 81 odgovara!") so ahnlichen Zmejce Apostolðe.An dieser Stelle ist ein geeigneter Anknupfungspunkt fur vier bulg. und maz. Ileder gegeben, in denen nun tatsächlich Zmejs ("zmejove"), also die prädestinierten damonischen Drachento- 
ter, allein oder - in sekundarer Abwandlung - zusammen ult einem Helden oder Heiligen eine Lamja bezwingen.

Der Inhalt des ersten Liedes, Doz.,133 (= Suppl.Nr.8), einer 40 V. (ur. 7- bis 12-Silberl) langen Var. aus Bulgarien, lautet folgendermaben:

300 Zmejs ("zmeja") versameln sich im Gebirge am Ufer eines Sees, um mit der großen Lamija um den Besitz des Gewkssers zu kămpfen. Die Zmejs schleudern inre rfelle, die der Lamija in die goldenen Schuppen dringen. Die Lamija wirft jedoch die Pfelle zurluck und totet so viele $\mathrm{Zmejs}$, dab nur noch sieben Ubrigbleiben. Diese stehen kumervoll da und Uberlegen, wie die schreckliche Lamija zu bezwingen se1. Da tritt eine "zmijnica" (= weibliche Porm des "zmej") zu innen und fordert sie auf,nicht langer untutig zu sein, sondern, whrend sie selbst die Ianija durch ein Gespräch ablenke, mit yelilen und Blitzen (suie orelite 1 gromovete) unter dem UnEeheuer einen Graben zu schaffen und Feuer zu legen, um die Lamija auszurauchern (lanija da 1zcurite); durch einen Pfeilschus solle man sie, die Zmijnica, warnen, sobald das Feuer gelegt sel, damit sie rechtzeitig fliehen konne.- Die Zmeje horen auf den Rat, graben elnen Graben, legen Peuer und zllinden es an. Da stohnt die Lamija "wie ein Berg" auf, zerstluckelt Blume und verschlitet damit den See. Dieser tritt uber die Ufer, und das Wasser fließt zu den Huusern der Zmejo, wo die Zmej-Prauen damit waschen und ihre Kinder baden.

Aufschlubreich an diesem Text erscheint mir, dab "lamija" und "zmejove" um den Besitz des Sees, d.h. des Fassers, klupfen. Die Kamplmittel aind dabel l'elle, Blitze und Feuer, was der Tatsache entspricht, daß man sich im balkanischen Volksglauben das Gewitter als Kanpl zweier einander feindlicher likchte, namlich des Gewitterdrachen (skr. hala, ela; bulg.-maz. chala, hala, ala, lamnja, lumilja; alban. kulshedra) und des damonisohen Drachentoters (skr. zmaj; bulg.,maz. zmej; alban. drangue) voretellt. Der Drachentbter wird dabel als den Henschen elner bestimnten Geeend und ihrer Ernte Preundlich gesinrit und hilfrelch gedacht, whrend der feindliche Gewitterdrache versuoht, das Wasser zu operren und durch Durre, verheerende Gewitter oder Hacelsturme die Ernten zu verniohten. Dabel durfte der Zmej oder Zmaj der uropringliche Drachenklimpfer gewesen und in der Volksdichtung und Volksglaubens- 
vorstellung erst spyter durch einen Helden (urspringlich wahrscheinlich ein Heldenkind) oder Heiligen (Georg oder Elias) ersetzt worden sein. - Noch deutlicher erwelst sich der Zmej im folgenden Lled SbNU $x, 9$, einem $76 \mathrm{~V} .(5 / 5)$ langen griech.-maz. Lled aus der Gegend von Seres (Serrat), alo ein lokaler Schutzdämon:

Mirce vojvoda geht im ebenen Peld auf Hirechjegd. Er erlegt jedoch keinen Hirsch, sondern fangt einen kranken $Z m e j$. Hirce tumelt sein Pferd.und zieht oein Schwert, um den Zmej zu toten. Der aber fleht Mirde an, inn am Leben zu lassen, denn or sei keine "verfluchte Iamja", onderm nur ein kranker Zmej. Er erzbhlt, sie seien dre1 Brlder, von denen der erste Mirces Dorf und Umgebung, der zwe1te das Peld von Kostur und er, der dritte, das P1rin-Gebirge ("Yerineko virse") beschutze. Von elnem Kampf auf dem Peld von Kostur Bei er vermundet zurickgekehrt. Hirle solle ihm nun helfen, die verPluchte Lamja ("lamé"), die das Pirin-Gebirge verheere, mit Hilfe seiner Brider zu besiegen. Die Lamja komme bei Regen hervor und vertilge "we1Be Trauben" sowle "weiBen Weizen" und fuge den Louten groBen Schaden zu. Un die Lamja hervorzulocken, werde der eine Bruder donnerm (ke gurmne, grimne 1 trjasne), der andere eine Wolke feinen Taus entstehen und der dritte dunklen Nebel fallen lassen. Wenn die Lamja dann hervorkomme, um wieder Weizen und Weintrauben zu Pressen, solle Mirde sein Sohwert ziehen und sie töten.- Nit den dre1 Zmej-Bruderm gelangt Mirde zum Pirin-Gebirge, wo die Lamja hervorgelockt und von Mirte mit dem sabel erschlagen wird. Denach zerstreuen die Zmej-Brider den Nebel und die Wolken und lassen so die Sonne wieder etrahlen. Mirce bringt den verwundeten Zmej in eine Sennhatte, wo er inn mit frischer Milch heilt und wahlbruderschaft mit inm ochlieBt, damit er auch weiterhin das Peld von Kostur (Kastoria) beschutze.

Hier lat die Lamja eindeutig alo Gewitterdrache und Erntevernichterin bestimmt, die, von den lokalen Schutzakmonen durch ein inszeniertes Gewitter hervorgelockt wird. Dab ein Mensch, der Held kirte, die Lamja trtet und nicht der Zmej, lot aicher sekundär. - Die dritte Var., SbNU XVI-XVII,54, eln 64 V. (4/4) langes Iled aus Pazardik, hat folgenden Inhalt:

lunkler Nebel senkt sich auf des Peld hernieder,verweilt da dre1 Tage und dre1 Nachte und raubt den ganzen Grannenweizen ("Cenica zagari ja"). Dann l1eg1 die dunkle Nebelwolke drei Tage und dre1 Nuchte uber der Viehweide und nimmt die ganze gelbe Hirse weg. 
Zuletzt fallt sie auf die Sennereien (mandrite) nieder und plundert die Vorrate an weiBer Milch und gelber Butter.- Es handelt sich aber nicht um eine dunkle Nebelwolke, sondern eine graubrăunliche (sura) Lamja mit drei Kopfen, die sich wie eine Wolke niedersenkt. Sie beludt eine Karawane mit der Belite und treibt sie zur Donau. Dies beobachten zwei Zmej-Bruder, von denen der jungere zun alteren sagt, er solle aufsteigen und kräftig donnern: Sei dies ein Handler, so werde er anhalten und beten; sei es aber eine Lamja, so werde sie sich zum kampf stellen.- Jer ältere Bruder donnert, worauf die Iamja anhält und Kampfstellung einnimat. Die beiden Bruder treiben das Ungeheuer zur Donau, an deren Ufer ein schwarzaugiger Hirte sitzt. Das ist der hl. Georg (sveti G'orgi), der Lummer weidet. Als er die Lamja erblickt, rollt er die ïrmel auf, zieht sein Schwert und schlagt ihr die Kopfe ab, worauf diese Nilch und Butter, dann Hirse und Trauben urd schlieblich Grannenweizen ausspeit, und zwar in solcher lienge, dab man damit neun Distrikte ("kazi") häte ernähren können.

In aieser sekundar mit christlichen Elementen versehenen Var. ist die Lamja wieder die Ernte- und Vorratvernichterin, wăhrend das Zmej-Briderpaar, unterstutzt vom hl. Georg, dem Schafhirten, als Drachentoter fungiert. Interessant ist die Vorstellung der Lamja in Gestalt einer durklen Nebelwolke, was wieder auf ihren Gewitterdrachencharakter hinweist. Pehl am Platz ist die Stelle, wo die Lamja eine Karawane mit den geraubten Gutern beladt, denn an Liedende wird gesagt, dab die Guter aus dem Leib der Lamja hervorquellen, als der hl.Georg inr die drei kopfe abschlagt. Diese Vorstellung von den (drei) aus der toten Lamja hervorbrechenden Strömen wird uns bei den Georgsliederm noch ofter begegnen. Vielleicht wurde das Noment der Karawane aus anderen Drachenkampf-Liederm Ubernommen, wo es heibt, dab dem Leib der Lanja ganze Karawanen und Hochzeitszluge, die sie verschlungen hatte, entstromten. Der hl. Ge or g (sv.Georgi, turat, Juraj), dessen Fest am 24. April (bzw. $7 . \therefore$ ?ai) gefelert wira, ist als Drachenkampfer der Legende auch ins Lied eingegangen. Sein Festiag gilt als Prinlingsbeginn und Georg deshalb als Patron dieses Zeitabschnittsfestes, als "ErdaufschlieBer", Schutzheiliger der Herden und des gesundheitsspendenden Vassers. Das balkanische Brauchtum in seinen mannigfachen Formen des Grinzaubers ( $\nabla$ gl. 
den "zeleni Juraj" der Kroaten) trügt kaum kirchlichen Charekter, sondern wird von altem agrarischen Denken und Hirtenriten getragen ${ }^{250}$. Im balkanischen (skr.,bulg.,maz. und griech.) Volkslied ist Georg einerseits der Drachentoter, andererseits (im bulg. und maz. Lied) auch derjenige,der an seinem resttag die Felder begeht, um zu sehen, ob das Getreide schon Ähren angesetzt hat und eventuell Regen braucht (vgl. die Lieder Mil.42; Kac.34-37 und 54; SbiU I,13;III,35; IV,22;XII, 10;XXVIII, 440; I1.260,268,306,318,321; Sapk.28, 30, 29 usw.) und der die herden besucht, um nachzusehen, ob sie den lifnter gut ujoerstanden und sich vermehrt haben (vgl. die Lieder SbliU XI,6;I,13; II.164; I!il.42 u.a.). Diese Eigenschaft des hl.Georg als Beschützer der Herden soll in unserem Liea wohl darin zum Ausdruck komen, dais der Heilige als Schafhirte vorgestellt wird. - Die vierte Var., worin der Zmej gegen die Lamja kămpt, ist SbNU IX,7 (Nr.6), ein $46 \mathrm{~V}$. (4/4) langes Lied aus der Gegend vor. Dobric (nördlich von Chaskovo), mit folgendem Inhalt:

Ein dunkler Nebel fallt herab und bleibt drei Jahre lang liegen, so deß bei den Ackerbauern ( $c$ if$x_{i i}$ ) Hunger, bei den Weinbauern ("kupali" von bulg. kopaja 'hacken, graben') Durst und bei den Schafhirten ("uvcari") Seuchen herrschen. Da versammeln sich alle Heiligen und beratschlagen, was zu unternehmen sei, um diese ciunkle Ṇebelwolke zu beseitigen. Der hi. Elias rät innen, sie sollten ins schwer zugängliche Gebirge ziehen, dort den zwei Zmej-Brudern, den beiden "Yfeilchen" (dve strelceta), auflauern, sie fangen und donnernd auf die liebelwolke. loslassen: Senke sie sioh noch mehr, sei es wirklich Nebel; steige sie aber höher, so handle es sich um eine Lamja. - Die Heiligen befolgen den Rat des hl.Elias und stellen mit Hilfe der donnernden Zmej-Bruder fest, dab es sich um eine Lanja handelt, die sie sofort tôten. Darauf fließen drei stróme (teknŭli sŭ du tri reki), ein Strom Weizen (zito) für die Ackerbauern, ein Strom Rotwein für die Weinbauern und als dritter Strom Honig und Butter fur die Schafhirten.

Ganz ahnlich wie im vorhergehenden lied ist auch hier die Lamja in Form einer dunklen Nebelwclke vorgestellt, die die Ernteguter der Bauern, Winzer und Schafer vernichtet. Und wieder wird die Alternative (Wolke oder Lamja; im vorigen Lied Hundler oder Lamja) mit Hilfe der donnererzeugenden Zmej- 
Brider entschieden und die Lanja getrtet (dieses lial von allen Heiligen, nicht von einem einzelnen). Statt des hl. Georg 1st hier der hl. E I i a s (sv.Ilija; Pesttag am 20.Juli bzw. 2.Aueust), der "Donnerer" (skr. Eromovnik, bulg. gurmodolec, grimolomnik, erimornik), einzesetzt, an dessen Felertag nach skr. und bulg. Volksglauben deshalb Arbeitsverbot herrscht, weil der Hellige sonst verheerende Gewitter und Blitzschlag sendet. In Ostserbien und Bulgarien schlachtet der Hausherr am Eliastag den alten Hahn, sonst muBte er selbst argeblich sterben. "Als Verklnder des Tageslichts wurde der Hahn schon bel den alten Griechen Attribut des Sonnengottes Helios (spatgriech. Ilios) und ist in christlicher Zeit mit dem ahnlich klingenden Namen des Vietterheiligen Ilija verbunden worden, zumal man aus seinem Krähen Schlusse auf das lietter zieht", meint Schneeweis 251 und steht damit der Ansicht von Nachsmuth 252 sehr nahe, der ebenfalls von einer Ablösung des Sonnengottes "Helios (oder wie man damals schon sagte Ilios)" durch den "auf feurigem liagen gen Himel fahrenden, auch lautlich nahe stehenden تlias (Ilias)" spricht und weiter meint: "So blieb unter Vertauschung des Namens die Grundbedeutung des zu verehrenden Wesens meist dieselbe, und lange genug mag halb unbewust das Volk unter den neuen Namen seine alten Gottheiten angebetet haben". Diese lieinung mag richtig sein, kann aber m.E. vorerst nicht bewiesen werden. Genau wie der hl.Georg im vorhergehenden lied ist auch der mit ganz ghnlichen Funktionen bedachte Elias in unserem letzten Lied nur ein christlicher "Zusatz" zu dero urspringlich wohl allein fur das Gedeihen der brnten sorgenden Zmej. Dals in den beiden letzten Iiedern ein Brluderpaar als Drachenkämpfer auftritt, erinnert an eine besonders archaische Form des Kulturheros in $2 w i l l i n g s g e s t a l t^{253}$.

So wie wir vorhin an den Beinazen "Zmejče" des Heldenkindes in Stoil.II 13 anknlpften und vier Zmej-Lamja-Lieder anfugten, soll nun an den Heldenkindcharakter angeknupft und ein ganz uhnliches Ifed behandelt werden, in dem das kind nicht mit einem Drachen, sondern mit einem Bären küpft. Dieser 
stellt aber, wie aus der ganzen Formulierung hervorgeht, eine Substitution des Drachen dar. Es handelt sich um SbNU XXVII, 133 (Nr.9), ein $58 \mathrm{~V} \cdot(5 / 3)$ langes Iled aus der Gegend von Elena mit folgendem Inhalt:

So strahlt der Abendstern in der Nacht von Sonnabend auf Sonntag. Das ist aber kein Abendstern, sondern ein blutgieriger Bar (mexka krürnica), der neun Wege so absperrt, daB kein Vogel hindurchfliegen kann, und im zehnten auf der Lauer liegt. Da kommt Marijka mit ihrem Sbhnchen Ivanco des Weges, als sich gerade Zaren und Konige aus je neun Landern versammelt haben, um mit dem Baren zu kanplen. Der Kanpl dauert drel Tage und dre1 Nachte, doch der Bur bleibt unbesiegt. Da bittet das Kind seine Mutter, es zu stillen und ihm ein Hemdchen anzuziehen, denn nun werde $\in$ it mit dem Untier kampfen. Die Mutter tut, wie befohlen, und das heldenhafte Kind k\&npet dres. Tage und dre1 Nichte mit dem Tier, und zwar unentschieden. Da laBt sich das Kind erneut nuhren, wirft den Baren neun Korperlangen (boja) in die Hohe und schleudert ihn so auf den Boden, dab das Tier zerplatzt. Triumphierend preist sich das Kind daraue selbst als den grobten aller Helden:

Slorajti chori seljani, Ce as sưm junak nad Junak, Az1 81 mexkŭ mŭspŭdich.

Bemerkenswert ist hier die Anfangsszene - ein Bar sperrt die Straßen ab -, die genau der gleichen Szene in zahlreichen Drachenkampfliedern und den Liedern von liusa Kesedzija, einer weiteren Substitution des Drachen, entspricht, vgl. Vuk II 668

Pozatvara skele oko mora,

I drumove okolo primorja.

Un die wunderbare K.raft des lieldenkindes zu unterstreichen, laßt der Sanger zuerst Zaren und k.8nige erfolglos mit dem lntier kbupfen, während es dem Salugling, nachdem er sich zwe1mal bel der Mutter Kraft geholt hat, gelingt, den Baren zu Uoerwinden. Allem Anschein nach wurde hier ein wropringliches Drachenkampelied vom Typ Sto1l.II 13 nach den in 0etbulgarien beliebten BArenkamplifedern (vgl. In Kap.4.21: Bar statt Drache oder Araber Uberfallt einen HochzeitszuE) ungestaltet. Der Bur wurde wahrscheinlich oeim Versuch, das Iledsujet mehr der Realitkt anzunghem, fur den urspringlichen Drachen eingesetzt. In einer zanzen Anzahl oetbulg. Iieder 1 st dann das Su- 
jet weiter entmythologisiert worden:

Protagonist ist hier Stojan, der Iieblingsheld der bulg. Hajdukenlieder, der trotz der Warnung seiner Mutter nach Carigrad geht und am Sultanshof drei Tage und drei Nachte mit dem Baren, der bisher jeden verschlungen hat, kämpft. Whahrend des unentschiedenen Kamples bittet der Held die uružina um Wasser, findet aber bei seinen treulosen Ger bhrten kein Gehorr. Entweder mit Hilfe seines treuen Hundes oder angespornt durch eine vom Sultan ausgesetzte Belohnung besiegt der Held schließlich das lintier.

Hier hat sich die Motivierung des Kamples volilg verändert. Der Held kampft in der Mehrzahl der lieder nicht mehr um die Befreiung einer von einem Untier bedrohten Stadt, sondern aus reiner Kampliust oder un eine Kraftprobe zu bestehen und die versprochene Belohnung zu erhalten. Es handelt sich dabei um Lieder 254 wie SbNU XXVII,133(Nr.8);XIII, 18(Nr.24);XXXVIII,33; XNXV, 262 (Nr .267); XXV , 97; XXV, 114 ; XUVII , 17;XIVII , 231-232-233; XXII,74;VII,83;XII,96; Jank.47 u.a., lauter kurze (50-60 V. lange) Iieder in achtsilbigem Versmaß.

Bei den folgenden Sujets handelt es sich jeweils um zwei oder mehr Helden, die zum Drachenkampl antreten. Zunachst ist da ein Heldenkind, dem sein Oheim (Marko) beim Kampf mit dem Ungeheuer zu Hilfe eilt. Das erste Lied, SbNU V,6(Nr.6), 57 V. (4/4) lang, aus der Gegend von Sofija, hat folgenden Inhalt: Zwei Helden, ntmich "Vitec" Marko und Grujco dete, sitzen in der Schenke und trinken roten 'Vein. Da taucht eine grimme Schlange mit drei kopfen auf, die drei Gebirgspasse sperrt und neun Dorier entvolkert. Davon horen die beiden Helden, und Grujco erklkrt seinem Oheim Marko, er werde in den Wald ziehen und die Schlange toten. Er besteigt sein Pferd und reitet in den Wald, wo er versucht, die dreikbpfige Schlange mit der Lanze zu toten, dann aber selbst von dem ungeheuer gepackt wird. Grujco ruft larko $z u$, er werde sterben, wenn der Oheim inm nicht zu Hilfe komme. Marko hört den Hilferuf drei Dörfer weiter, schmiedet eine dreigehornte Kamplianze, besteigt sein Streitroß, zieht gegen die dreikopfige Schlange zu Felde und totet sie. Darauf entsteigen dem Korper der Drachenschlange ein ganzer Hochzeitszug sowie der ebenfalls verschlungene Grujco. l!arko schultert die tote Schlange und fordert die Dorfbewohner triumphierend auf, in ihre verlassenen Häuser zurluckzukehren, denn das geflurchtete Ungeheuer sei nun tot. 
Altertlumich mutet hier und im nuchsten Iied die an matriarchale Verhältnisse erinnernde Neffe-Oheim-Konstellation an. Verwunderlich scheint allerdings das Versagen des Heldenkindes, das doch sonst immer d e $r$ siegreiche brachentöter ist. Das Motiv in der vorliegenden Form ist deshalb vielleicht nicht urspringlich. Wie in den Liedern Mil.59, Verk.-Lavr.86 u.a. entstromt auch in diesem Lied dem Drachen bzw. der dreikopfigen Schlange ein ganzer Hochzeitszug. den sie verschlungen hat. Möglicherweise wurde dieses Moment aus den Liedern ubernommen, wo ein Drache den Hochzeitszug uberfallt: Bei der Totung des Ungeheuers entstromen seinem Leib alle bisher verschlungenen Brăute und svaten. - Eine Var. zu dem vorhergehenden Lied 1st Sapk.362, ein 67 V. (4/6) langes Lied aus lazedonien mit diesem Inhalt: Sekula fragt sein Pferd im Stall, warum es wiehere. $\mathrm{Ob}$ es nicht genugend Wasser oder weiBen Heizen bekommen habe. Beides verneint das Pferd; es wiehere vielmehr, weil es oben im Gebirge ein Feuer, eine mächtige Flamme bis zum Himmel lodern sehe. Darauf besteigt Sekula das Pferd, bewaffnet $81 \mathrm{ch}$ mit dem schweren Streltkolben und dem scherfen Schwert und reitet ins Gebirge zu dem Feuer hin. Es ist dies aber kein Feuer, sondern eine sechsflugelige Schlange, die gerade einen gefleckten Hirsch verschlingt. Die Schlange begrust Sekula und verspricht ihm eine hohe belohnung (golem baksis), wenn er dem Hirsch das Geweih abschneide, damit sie ihn ungehindert hinunterschlucken konne. Sekula läbt sich täuschen und tut, wie gewinscht, worauf die Schlange nicht nur das Beutetier, sondern auch Sekulas l'ferd bis zun Sattel verschilingt. In seiner Not ruft Sekula seinen Oheim Marko zu Hilie; er moge ins Gebirge eilen und den in Todesgefahr schwebenden Neffen retten.- Marko hort die Schreie, reitet ins Gebirge, findet Sekulas Pferd bis zum Sattel verschluckt und zieht sofort den Streitkolben, wo die Schlange zu toten. Diese fordert liarko auf, er solle sie lieber mit seinem "frankischen" lesser ins Herz stechen als mit der Keule erschlagen, weil er sonst auch den Hirsch, das Pferd und - nicht zuletzt - Sekula zerschmettere. Harko sticht die Schlange also mit dem Hesser ins Herz, worauf die beiden Tiere und Sekula lebend ihrem Schlund entsteigen. Aus Dankbarkeit folgt der Hirsch Marko an seinen Hof.

Hier ist statt liarko-Grujica das andere beliebte Neffe-OheimPaar Sekula-liarku eingesetzt, wodurch eine Historisierung des alten Drachenkampfthemas argestrebt wurde. Irspringlich 
stand an deren stelle sicher entweder ein namenloses oder zumindest nichthistorisches Heldenpaar, das im Zuge der Historisierungsbestrebungen zunächst wahrscheinlich durch das Paar Janko-Sekula ersetzt wurde; spater erst trat larko filr Janko ein.- Falsch an dieser Var. durfte sein, dả die Drachenschlange selbst die Anweisung gibt, wie sie am besten zu töten sei. Statt dieser Losung ist wohl anzunehmen, dab der Rat urspringlich von dem in der maz. Volksdichtung so beliebten sprechenden Pferd ausging. Das Noment, daB die geflugelte Schlange ihr Opfer, den Hirsch, wegen seines Geweihs nicht ganz verschlingen kann, finden wir in ahnlicher Form auch im rumbin. Volkslied, wo die Schlange den Helden Mistricean wegen seiner ungehangten Waffen nur bis zur Taille verschlucken kann und der Iiedheld schließlich aus dem Schlund des ungeheuers gerettet wird. ${ }^{25}{ }^{2}$ Ein aus dem vorhergehenden abgewandeltes Iied scheint mir die nächste Var., Japk.15,57 V. (4/6) lang, aus der Gegend von lirilep, zu sein. Hier ist die altertumlichere Oheim-Neffe-Beziehung in eine jungere Vater-Sohn-Konstellation ungewardelt. Der Iiedinhalt ist folgender:

Die Huridin Ianja (kuXka lamja) kommt aus dem tiefen seer hergekrochen zum ebenen Peld von Solun, um Markos Hofe zu Uberfallen und sein Sobnchen zu verschlingen. Die Samovila Erina wamt Marko vor der drohenden Gefahr, worauf llarko sich von seiner Gattin das kind in seidene windeln wickeln, mit einem goldenen Wickelband versehen und in eine silberne liege legen labs, um dann damit in den Wald auf die Jagd zu reiten. Im lialdgebirge in einer dunklen Schlucht schlagt Marko sein Zelt auf, legt sein sohnchen hinein und geht mit den Jagdhunden und - falken auf die Jagd, worluber er das Kind vollig vergibt. Inzwischen hat die Lamja das Kind aufgesplurt und verochlingt es. Ale Marko zurliokkohrt und die Viege leer findet, sendet er die Jagdhunde aus mit dem Befehl, der Lamja die Beine zu zerfleischen, whyrend die Falken ihr die Augen aushacken sollen. vie Hunde und Falken verfolgen die Lamja, holen sie auf dem Peld vor Solun ein und fluhren-karkos Befehle aus. Marko kommt herbeigeeilt, schlitzt die Lamja auf und holt sein sohnchen unversehrt aus ihrem Leib heraus.

Junger durfte an diesem Lied der Zug sein, daß die Lamja epeziell deshalb aus dem lieer in die Gegend von Thessalonike her- 
kommt, un Markos Søhnchen zu fressen. Die Iokalisierung in Solun 18t Ubrigens dieselbe wie in den Bolen DojCin-Iiederm. Unverstaindlich blelbt, warum Marko, der doch zum Schutz vor ler Lamja sein Kind fortschaff, es dann im Wald allein zurucklubt. Dies konnte jedoch auf ein Versehen der sangerin zurlickzufihren sein. Besser erhalten scheint die Var. Tomic, 181, ein 95 V. (4/6) langes Lied aus dem Yorecki Kraj (einem Talkessel sudlich von Skopje), zu sein:

Die Lamj3 vom Ohrider See brlstet $81 \mathrm{ch}$, sie werde Marko Kralevićs Sobnchen lebend verschlingen. Als Marko beim Abendessen betrubt aussieht, fragt ihn seine thutter nach dem Grund und erfahrt nun von der Absicht der Lamja. Sie rat Marko, er solle im Mimus-Gebirge sein seidenes Zelt aufschlagen, das Kind ins Gras legen und es beauftragen, die drei Falken des Vaters mit Peigen und Kichererbsen zu futtern. Den Falken aber solle er die Bewachung se1nes Sbhnchens auftragen. Die v8gel mußten dauernd gefuttert werden, damit gie nicht wegflogen und das Kind der Lamja preisguben.- isarko befolgt die Ratschlage seiner Mutter und fuhrt alles so aus, wie sie ihm geraten hat.- Die Lanja hat inzwischen den See verlassen und sucht den Westen und osten nach dem Kind $a b$, doch vergeblich. Schlieblich erfährt sie vom Abendstern, wo sich das Kind aufhalt und dab es von hungrigen Falken bewacht wird, die die Lamja zerreissen wirden, wenn sie sich naherte.Die Iamja macht sich dennoch auf ins Mirus-Gebirce und scheucht unterwegs vier Rebhuhner auf. Diese fliegen an Markos ?elt vorbel und locken die Palken hinter sich her. Nun verschlingt die Iamja das Kind und zieht sich in den See zurlick. Als die Falken von ihrer Verfolgungsjagd zuruckkommen und das Zelt leer finden, bleibt ein Falke dort zurlick als ilache; der zweite fliegt hoch in die luft und der dritte zum See, wo er die Lanja entdeckt und mit lauter Stimme Marko herbeimuft. Als Marko am See eintrifft und die Lamja im Wasser erblickt, ruft inm der Palke zu, er werde Wind wehen und Regen fallen lassen, dann verlasse die Lamja den See und könne von liarko getotet werden. Dem Palken gelingt es, die Ianja aus dem Viasser zu treiben. Sie kommt gerade auf Niarko $z u$, der wie gelthmt ist und erst auf die Aufforderung des Palken hin das Ungeheuer mit dem Streitkolben zwischen die Augen schlagt. Die Iamja fordert Narko zu einem zweiten Schlag auf, doch der Held meint, die kutter habe inn nur eirimal geboren und er werde nur eirmal sterben. Da eilen zwei der Palken herbel und zerreissen die Lamja, aus deren Leib liarko sein Sbhnchen sowie drei Hochzeitszlige ("tri rala svatoi", eigentlich 
- drei Reihen Svaten') mit drei Bräuten herausholt.

Neu ist in diesem Zusammenhang das lotiv, daß die Lamja sich an den Abendstern wendet und von ihm, aer aus seiner Hohe alles beobachten kann, Auskunft über den Aufenthaltsort von Markos Søhnchen erhält. Daß Niarko auch in diesem Lied auf der Jagd ist, wird zwar nicht ausdricklich gesact, geht aber aus der Situation hervor. Deshalb sind hier die Falken, die typischen Jagdtiere, die Helfer des Felden. viellelcht haben aber die Falken einen urspringlichen Zmej ersetzt, denn fur einen Zmej ware es charakteristisch, Wind wehen und Regen fallen zu lassen und die Lamja zu bekămpfen, nicht aber fur einen ialken. Uberhaupt scheinen sich hier das larko-Falkenjagd-lotiv und ein alteres einfach strukturiertes Iamja-Zmej-Sujet uberlagert zu haben. Wie schon aus anderen Iiedern her bekannt, fordert auch in dieser Var. die Lamja karko zu einem zweiten Schlag auf, den der Held ihr aber nicht gibt, wobei er inre Aufforderung mit der formelhaften Viendung von der Iinmaligkeit seiner Geburt und seines Sterbens abtut. Auch in diesem Lied verlassen den Leib der toten Lamja mehrere Hochzeitszige.

Die folgende Variantengruppe durfte aus der vorhergehenden abgeleitet sein, weil die Dreiergruppierung der Helden und ihre "iette darum, wer den Kampf gegen die Lanja gewinne, auf ein weniger hohes Alter hinweisen. Das erste Iled dieser Gruppe ist SbNU II,7 aus der Gegend von Sofija, eine $80 \mathrm{~V} .(4 / 4)$ lange Var. mit diesem Inhalt:

Eine grimme Schlange (ljuta zmija) mit drei Köpfen, sechs flugeln und zwollf Schwänzen (trooglava, gestokrila, dvanaeseopasita) haust im Gebirge in einer Hohlo und operrt drel Gebirgsechluchten, entvolkert neun Dörfer und drei Stadte und halt neur. Hochzeitozlice auf.- In einer Schenke in Adrianopel (mechana Drenopolska) sitzen drei Helden beim Wein und wetten, dab derjenige Gold, Silber und Wein erhalten solle, dem es gelinge, die dreiköpfigé Schlange zu töten. Der eine Held ist Gruica, der zwe1te Andreaska und der dritte der große Held ("Baban banko") liarko. In Trinklaune erkikrt sich der junge Gruica zum Kampf mit der Lamja bereit:

Nael se e mlad Gruica, Ne nae se u junakstvo, No se hae u pijanstro. 
An nachsten liorgen futtert er sein perd mit feinem Re1s, träkt es mit Rotwein und klhlem Wasser, bewaflnet sich, steigt weinend aufs Pferd, bekreuzigt sich und macht sich auf den Weg ins Gebirge. Dort ruft er den Drachen zum Kampl: Er wolle sehen, wer "junak nad junaci" und wer "ala nad alite" sel. Als die Schlange diese Herausforderung hort, kommt sie mit wassersprlhendem Atem hervor (a dusata si poroj nosi), labt mit ihren Flugelschlagen Berge bersten und tragt sie mit ihren FuBen ab. Wo sie vorbeizieht, verwelkt alles, und wo sie stehenbleibt, verdorrt die ganze Umgebung. Als Gruica dieses Ungeheuer erblickt, flieht er, doch die Schlange holt thn ein und packt mit einem ihrer KOple das Pferd, mit einem zweiten Kopf Grulca und mit einem dritten will sie ihn fressen. Da ruft Grulca seinen Onkel (ZiCo) Marko zu Hilfe, als thn die Schlange zu verschlingen droht.

Das Lied ist zwar unvollendet, aber es geht klar daraus hervor, daB liarko seinem Neffen - wie in den obigen Iiedern zu Hilfe ellen wird. Interessant und sehr wirkungsvoll ist die Schtlderung der ungeheuren Drachenschlange mit thren riesigen Ausmaßen, ihrem landverheerenden und menschenfressenden Vesen und ihrem entsetzlichen Aussehen, vor dem der junge Held flieht. Sekundar durfte das psychologisierende Moment sein, daB Gruloa in Veinlaune das Versprechen zum Kampl glbt, seinen EntschluB aber am nkchsten Morgen weinend bereut. Mit Andreaska ist wohl Markos historischer Bruder gemeint. - Die nkchste Var., KaC.163, ein $100 \mathrm{~V} .(4 / 4)$ langes Lied ebenfalls aus der Solloter Gegend, weist einen sehr thnlichen Inhalt auf:

Drei Gefghrten treffen sich beim Wein in der Schenke zu Adrianopel: Marko, Favel und Branko. Sie h8ren von der grimmen Schlange, die im Balkan-Gebirge neun Dorrer entvolkert und drei Schluchten gesperrt hat. Da erklyrt sich Branko bereit, mit der Schlange zu kămplen,. whrrend die belden anderen Helden auf ihn warten sollten. Er reitet ins Gebirge und fordert die Schlange zum Kampl heraus, rettet $81 \mathrm{ch}$ aber mit Muhe durch rasche Plucht, als das Ungeheuer zischend und bergezerstampfend auf thn zukommt. Branko kehrt zur Schenke zurlick und erzahlt, die dreiköplige und sechsflugelige Schlange sel nicht zu besiegen. Da macht $81 \mathrm{ch}$ Pavel auf den Weg ins Gebirge und erlebt die glelche Niederlage. Schlieblich zieht Marko in den Kampl, läbt die Schlange auf sich zukommen und erwartet sie, auf Sarko sitzend, mit ,dem blanken Schwert in der Hand. Die Schlange packt 
mit einem Kopf Sarko, mit dem zkeiten Niarko und will inn mit dem dritten fressen. Marko weint zuerst, als or sein Blut flieBen sieht, doch dann ermannt er sich und totet die Schlange. Triumphierend kehrt der Held zurlick und verklundet seinen Sieg. Die neun Dörfer können nun wieder besiedelt und die drei Schluchten wieder begangen werden.

Neu ist an dieser Var., dab alle drei Helden den Kampl versuchen, der Sieg aber nur Marko zufillt. Die Abhängigkeit von dem vorhergehenden Lied ist offensichtlich. - In der folgenden Var., SbNU XIIII,103, einem $110 \mathrm{~V} .(4 / 4)$ langen KoledaIjed aus der Gegend von Sofija, wird ein ganz ähnlicher Inhalt berichtet:

Drei Helden, nămlich Dete Gruju, Vitec Marko sowie Deli Janko, die miteinander eine Wette abgeschlossen haben, gehen der Reihe nach aui die dreiköpfige Schlange los, die der ersten (Gruju) packt, dann loslubt, als diesem der zweite (Janko) zu Hilfe eilt, dann den zweiten halb verschlingt, der wiederum den dritten (Marko) herbeiruft, der schlieblich der sieg Uber das Ungeheuer gelingt.

liie wir sehen, differiert die handlung dieses Liedes nur geringtugig gegenüber den vorhergehenden varianten. Immer erweist sich der dritte Held, llarko, als der stärkste Held, dem aer Sieg luber das Ungeheuer gelingt. Die Dreiergruppierung, besonders wenn Marko darin vorkomnt, kann nicht sehr alt sein. Die vierte Var., Hil.113, ein $80 \mathrm{~V} .(4 / 4)$ langes Iied aus Panagjuriste, hat folgenden Inhalt:

Es taucht eine grimme Schlange mit drei Köpfen und drei Schwänzen, die die Sonne meidet ("osojnica" = im Schatten lebend), auf, sperrt die Straßen des Sultans und labt seine Schatzfuhren nicht passieren. Schlieblich sucht der Sultan einen Helden, der die Drachenschlange bezwingen könne. Davon hören die drei Gefkhrten Yetar, Nlarko und Groica "malo dete" und beschließen den Kampf zu wagen. Zuerst zieht Petar aus und lockt die Schlange mit einem Kampflied hervor. Als das Ungeheuer aber seine drei Kopfe nach ihm ausstreckt und mit dem ersten die Beine des Pferdes, mit dem zweiten die Hande des Helden und mit dem dritten seine schwarzen Augen packen will, ergreift Petar die Plucht und warnt unterwegs Marko vor der Schlange. Marko labt sich aber nicht abhalten, doch ihm ergeht es wie Petar. Er flieht ebenfalis und warnt unterwegs den zum Kampl ziehenden Groica. Die Schlange packt mit einem Kopf Groicas Fferd, mit dem zweiten ihn selbst bei der Taille und mit dem dritten seine Hände. Der Held aber reibt 
sich 108 und schlagt dem Ungeheuer die dre1 $\mathrm{Kop}-$ fe $a b$, die er zum Sultan bringt, worauf dieser thm die gebluhrende Ehre bezelgt:

oj ta tebe, Gruju, malo dete,

Irosto tebe stolninata,

Az da stana, t1 da sedner.

Diese sehr gelungene Var. halte lch fïr das alteste der vier zuletzt behandelten Lieder. Bezeichnenderwelse ist närlich nicht liarko, sondern das Heldenkind Gruica der Drachentöter, was sehr wahrscheinlich die urspringliche Version des Sujets sein durfte. Neu 1st, dab die Helden in Auftrag des Sultans den Drachenkampl wagen und der sieger von thm belohnt wird, d.h. es handelt sich un eine spatere Ubertragung in "episches" Lilleu, wie wir sie auch in den griech. Heldenliedern mythischen Inhalts feststellen konnen. - In den nächsten belden Lledern 1st Branko der Drachenkampler, der sich am Brunnen vor Burschen und Kädchen rlhmt, er werde das Ungeheuer bezwingen. Von zwel welteren Helden 18t keine Rede mehr. Die beiden Varianten scheinen aus den obigen durch Reduktion entstanden zu sein. SbNU XIV,74, ein $54 \mathrm{~V} .(4 / 4)$ langes Iled aus der Gegend von Sofija, berlchtet folgende Begebenhe1t:

Im Gebirge in einer Hohle haust eine dreikoprige, sechsflugelige und zwblfschwanzige grimme Schlange, die dre1 Gebirge bewacht, neun lorfer und drei studte entvolkert sowie neun Hochzeltszlige auflost. Der Held Branko rühmt $81 \mathrm{ch}$ abends an Dorfbrunnen vor Bursohen und Madchen, er werde die schreckl1che Drachenschlange toten. Er futtert sein Pferd mit we1Bem Reis, glbt inm Rotwein zu trinken, legt ihm einen blauen Sattel aus Seide auf und zăumt es mit goldenem Zaumzeug. Dann reitet er ins Gebirge und ruft die Schlange aus ihrer Hohle zum Kampl heraus. Das Ungeheuer kommt angeflogen, zertrimmert mit se1nen Fuben und Flugeln das Gebirge und hinterlibt einen tiefen Graben als Spur. Wo es voruberzieht, verdorrt alles. Aus seinen Nlotern sturzt ein Wasserfall hernieder. Als Branko dieses grabliche Ungetum erblickt, flieht er ohne Z8gern, wird aber von der Schlange eingeholt. Diese packt mit einem Kopl das Pferd, mit dem anderen den Helden und versucht ihn mit dem dritten aufzufressen. Branko aber tzuscht das Ungeheuer, Indem er es bittet, Ihm elne Hand frelzugeben, damit or nach seinem Pferd tasten und es ein letztes Mal tatscheln konne. Alo or wirklioh eine Hand Ireibekommt, sieht er sein Messer und ersticht die Schlange.

Die Ableitung aus den obigen Iledern let ziemlich eindeutig. 
HInzu kamen Elemente des "bIt", des brauchtumgebundenen Alltagslebens, daß namlich bel der abendlichen Versammlung der Dorffugend am Brunnen aus agonaler Motivierung heraus das Versprechen zum Drachenkampf gegeben wird.- Die Var. dazu, SbNU II, 19, ein 139 V.(4/4) langes Iled aus derselben Gegend, lot dadurch erweitert, daß dem Helden Branko im Falle eines Sieges luber die Schlange das Madchen Magdelena als Preis versprochen wird. AuBerdem tzuscht hier der Held die Schlange dadurch, daß er behauptet, er habe nur seine Schwester besuchen wollen und sei vom Weg abgekommen. Die Schlange moge ihn ereilassen, denn:

N1 sam dozel da te liba,

Ni sam dosel da te guba.

Die Schlange glaubt der Versicherung des Helden, daß er ke1nen Kampl mit ihr beabsichtigt habe, und gibt Branko frei, worauf dieser sein Schwert zieht und das Ungeheuer in zwei Teile schlagt. Damit ist ihm Magdelena sicher.- Eine weitere Var. 1st SbNU XIII,104, ein $87 \mathrm{~V} .(4 / 6)$ langes Lied ebenfalls aus der Sofioter Gegend, das in seinem Sujetablauf sekundar den Iiedern von Kap.4.12 angenahert wurde:

Marko versamelt dreiBig Helden und erklart ihnen, er habe ole nicht hergebeten zum Wein oder zur Unterhaltung, sondern um mit innen gemeinsam die dreikopfige Schlange zu toten, die die Sultansotraben (corevi drumove) und Engpässe (tesni klisuri) sperre und keinen Vogel, geschweige denn einen Menschen passieren lasse. Die dreibig Helden machen sich mit Marko an der Spitze auf den Weg ins Gebirge. Marko lockt die Schlange hervor, die mit dem einen Kopf in die Wolken ragt, mit dem zweiten am Boden schleift und den dritten dazwischenhält. Sie geht auf Marko 108, un thn zu verschlingen. De fliehen die Gefkhrten und lassen Marko allein mit dem Uneeheuer in der Schlucht. Marko erklärt seinem Yferd Sarko, es werde nun wohl keine Rettung geben, doch der Schecke ermutigt ihn und sagt, er werde den oberen Schlangenkopf zerbelssen und den unteren zertreten, wahrend Marko den mittleren mit dem Schwert abschiagen solle. Dies alles geschieht, und Marko kehrt siegreich in die Schenke zurick, wo er die treulosen Gefährten in einer Reihe antreten labt und sie dann mit Keulenschlagen schwer bestraft.

Wie in den 4.12-Iiederm, mehr aber noch in den 4.13-Iiedern, handelt es sich auch hier um eine Druzina in der Schenke, aus 
deren lifte ein Held den Kampf mit dem Drachen wagt, von seiner treulosen Umgebung keine Hilfe erfährt und die Gefährten fur ihre Untreue bestraft. Ähnlich den 4.13-Liedern, wo der Held Äpfel von dem durch Lamien bewachten Baum im Heer holt, ist auch in dem obigen Sujet das sprechende Pferd der treue Berater und Helfer, ohne den der Feld nicht zum Sieg gelangt ware. Diese Sujetannaherung an die 4.12- und 4.13-Licder erfolgte bei der zuletzt behandelten Var. sicher sekundar, und zwar auf Grurd der Affinitzt der Thematik. Das nächste Lied, Verk.315, $63 \mathrm{~V} .(3 / 5)$ lan€, aus der Gegend von Titov Veles hat folgenden Inhalt:

Auf dem ebenen Feld von Vidin taucht eine Riesenschlange auf, zwei Pappeln hoch, wenn sie sich aufrichtet, und zwei Tennen lang, wenn sie sich windei. Sie verlangt und erhalt als tägliche Nahrung (tain) drei Backöfen frisches Brot, drei Fässer Rotwein und drei schöne lï̉dchen. Da teilt die Schlange eines Tages mit, die ihr gesandte tagliche Ration genlige ihr nicht mehr, worauf der Pascha voll Vidin einen Herold umhersendet, der demjenigen eine große Schenke, neun Laden (duk'ani) und neun Schiffe (gemii) verspricht, dem die Totung des Ungeheuers gelinge. Allein Dimo, der oberate Hirte ( $k$ 'echaja), moldet sich zu diesem gewagten Unternehmen.Er zieht neun Seidenhemden und neun violette Dolamen an, umglirtet sich mit neun roten Girteln, neun silbernen Pistolen und neun goldenen Schwertern und besteigt sein Pferd. Die Mutter warnt ihn davor, in den Kampl zu ziehen, denn:

Turci su chitri, razumni, $K^{\prime} e$ da te tebe izmanat.

Dimo hort aber nicht auf die warnenden Horte seiner Mutter, sondern fordert die Schlange auf herauszukommen, denn er habe ihr die tägliche Speiseration gebrachts neun silberme pistolen und neun goldene Skbel. Die Schlange kriecht heraus und wird von dem Helden mit einem einzigen Schlag getstet.

Bemerkenswert erscheint mir an diesem Lied, daß die Riesenschlange einen taglichen Tribut fordert, was einen durchaus typischen Zug in den Liedern von der Belingerung einer stadt durch einen Drachen (vgl. z.B. die Georgsliederl) darstellt. Nachdem sich der Held besonders prächtig ausgerlstet hat (Betonung der epischen Neunzahll), zieht $\in \mathrm{r}$ trotz Warnung aus und besiegt die Schlange, die er mit einem ironischen zurue hervorgelocit hat. Das Motiv der Harnung vor den betrigeri- 
schen Turken (vgl. die aus anderen Lledern bekannte stereotype Wendung von den betrigerischen Lateinernl) und die P1stolen als Tell der Bewaffnung sind naturlich jungere $\mathrm{Zu}-$ satze. Das Lied weist eine gewisge Ähnlichkelt mit Mil.113 auf, wo auch ein Herrscher, allerdings der Sultan selbst, eine Belohnung fur die rytung der schrecklichen Schlange veropricht. Der Protagonist in unserem Lied 18t ein Hirte, eine der Ileblingsifuren der sudelavischen Volksdichtung.- Eine kurzere, aber sehr ahnliche Var. zu unserem lied stellt Drag. 163, ein 36 V.(4/4) langes Lied ebenfalls aus Titov Veles,der:

Eine riesige Hala taucht aue und bewacht und sperrt die Wege, so daß niemand passieren kann. Ein Herold verkindet, derjenige werde neun Laden sowie dre1 Arsin weiBes Tuch ( $\left.\delta^{\circ} a\right)$ erhalten, der die Hala tote. Es meldet sich der Held Dimo und erklkrt sich zur Totung. des Drachen bere1t. Er zieht neun Seldenhemden, neun violette Westen (eleka) und neun grine Dolamen an, umglirtet eich mit neun roten Gurtein und setzt neun grine Mutzen auf. Er zieht der Hala entgegen, und als diese inn erblickt, fordert sie Ihn zum Umkehren auf, denn er sei doch der einzige Sohn seiner Mutter. Dimo aber geht furchtlos auf den Drachen zu und totet ihn. Als er die Hala aufschlitzt. atromen naun Hochzeitazlige aus inrem Leib heraus. Dimo kehrt siegreich heim und erhalt die ausgesetzte Belohnumg.

Der Herrscher, der seinen Herold auegesandt hat, lst in diesem Lied falschlich nicht erwahnt. Die Art der Belohnung epricht hier noch mehr fur eine zunehmende Verbluerlichung als im vorigen Lied. DHe Warrung aus dem Mund der Hala ist fehl an Platz; sie mubte naturlich von der Mutter des Helden auggehen. Das Motiv der Hochzeitszluge im Bauch des Drachen 1st zu vergleichen mit demselben Motiv in Liedern wie Mil.59 und Jerk.-Lavr.86.Die nkchste Var.. Stoin TV 1401, ein 90 V. (5/3) langes Lied aus der Gegend von Vidin, zeigt eine eigenwillige Behandlung des Irachenkamploujets:

So donnert und blitzt, und Gott labt einen Brief auf den HUgel von Borovan fallen, in dem er die Bauern auffordert, aich zu versammein, eine Geltkuh zu schlachten und allerle1 Speisen aufzutischen, denn die "chala Semendra" werde zu ihnen kommen. Alle Bewohner versammeln sich und tun, wie belohlen, nur N1kolo "kopile" (Bastard) wird nicht gerufen.N1kolo geht ungeladen zu der Versammlung, wird aber von den Anwesenden doch begrubt und sogar zum Trinken eingeladen. 
Nach kurzer Ze1t schon erscheint der Drache, der, Butume und Felsen unter sich zermalmend, auf die Versammelten zukommt. Alle Bauern erheben 8ich, nur Nikolo bleibt sitzen. Da Pragt die Chala, ob das "Kind", das ihr als elnziges nicht die nótige Ehre erwlesen habe, entweder jung und unverstandig oder alt und toricht (1) oder besonders heldenhaft sel:

Selent selekl kmetove,

Kato me vie vidochte, Siciri do edin stanachte, liene cest da napravite. $A$ tova Dete ne stava, Dal1 e mlado gluparo, Il1 e staro bezumno, Jl1 e tvirdo junace?

Die Bauem antworten auf diese Prage, das Kind sel lediglich jung und unverninftig. Da meldet sich N1kolo selbst zu Wort und erklart der Chala, der "mome semendra", er sel weder jung und unverstandis noch alt und toricht, sondern besonders heldenhaft. Deshalb fordere er sie jetzt zum Zwelkampl heraus: Beslege sie ihn, konne sie seinen Kopl nehmen, beslege aber or 81e, werde er thr alle drel Kopfe abschlagen.- Die Chala nimmt die Aufforderung zum Kampl an. Sie ringen von morgens bis mittags miteinander und sind schon bis zum Knie in die Erde eingesunken und uber und uber mit Schaum bedeckt, die Chala mit weiBem, Nikolo aber mit we1Bem und rotem. Da bittet N1kolo selne Stiefmutter un Hasser, damit er, dadurch gestrikt, den unentschledenen Kanpl zu se1nen Guneten entscheiden konne. Die Stiefmutter fullt ein GefkB mit Wasser, glbt aber Gift hinein, um N1kolo zu toten. liskolo halt den Krug an den kund, doch die Chala schlugt $1 \mathrm{hm}$ das Gefab aus der Hand. Der Krug flilt auf einen Stein und zerspringt, worauf das vergiftete Wasser den Stein in vierzig Stlucke zerbersten labt. Da wird Nikolo von Wut ubermennt und totet den Drachen. Arschliebend richtet er an eeine Stiefmutter, deren Hordabsicht er durchechaut hat, die Ironische Prage, welche "Belohnung" sie num von ihm erwarte.

Altertlimlich mutet an dieeem Iled an, dab ein duroh besondere Herkunft Ausgezelchneter, nallch ein Bastard, Uberdies ein Heldenkind, zum slegreichen Drachentoter wird. Der wenig Geachtete, ja sogar Ausgestoßene, der "Dammling", erwelst sich als der grobte Held. Die brse Stiefmutter 18t, genau wie in vorhergehenden $\mathrm{Pall}$ die untreue Druzina, selbstverstindlich ein sekundares Zusatzelement. Auch dae fromme Element - Gott eelbst kundigt die Ankunft dee Drachen an - 1st nachtraglich auf dae heldnische Sujet aufgeeetzt worden. Der Name "Semen- 
dra" fur die Chala dürfte von Salamander (bulg."salamandra"; vgl. BNTv.IV,640 die Ant. zu S.271, wo es heiBt, daB der Salamander als bobser Geist betrachtet wird, der im Feuer lebt, und $d a b$ er in den magischen Vorstellungen und kiten zur Goldgewinnung eine Rolle spielt) abgeleitet sein. Interessant ist die konkrete Lokalisiemung des Geschehens in Borovan in liordwestbulgarien. Das Notiv, daß beim Zweikampe von dem Ubernaturlichen Gegner nur weiBer Schaum, von dem Helden aber blutiger tropft, kehrt in anderen Liedern, 2.B. in den Liedern von Marko und Musa Kesedzija, wieder. - Als Viehtbterin bzw. per- sonifizierte Viehseuche (morija) zeigt sich Samandra in SbNU $\mathrm{XXXI}, 219$, einem $43 \mathrm{~V} .(5 / 3)$ langen Lied aus der Gegend von Teteven:

Samandra tötet dem Helden Stojan von seinen 77 Stluck Vieh siebzig Tiere. Stojan jedoch nimmt im Kloster von Carigrad Kredit "na faide"(ouf Zinsen) zuf, ergunzt seine Herde auf die alte $Z$ ahl und dient seine Schulden in Drei jahresfrist ab, worauf die boswillige Samandra ihn zu ihrem großen Ärger wieder mit der vollstandigen Viehherde ziehen sehen muB.

Die Rolle einer Zmeica oder Samovila dagegen ubernimmt die "chala semendra" sekundur in dem Lied Stoin TV 3627, $48 \mathrm{~V} .(5 / 3)$ lang, aus der Gegend von Vidin, wo sie dem Schafer Stcjan regelmabig nachtliche Besuche abstattet und inn durch ihre liebesbezeugungen so schwächt, dais dies Stojans liutter auffullt. Diese kocht, nachdem sie alles erfahren hat, ein blindel Zauberwurzeln und labt Stojan in dem Absud baden, was zur Folge hat, dais die Chala inre Besuche bei dem Schafer sofort einstellt.Das Iied SbNU XIIV,62, in dem das Singen ron Elena, Narkos junger Frau, die dreikopfige Ala stört und diese das sohnchen des Ehepaars fordert, wurde bereits in Kap.4.21 besprochen. - Das folgende Drachenkanpflied, Stoin TV 1112, ist $20 \mathrm{~V} .(5 / 5)$ lang, stammt aus der Gegend von Teteven und hat folgenden Inhalt:

Eine dreikbpige Chala, die in einem See haust, terrorisiert die Ortschaft Izvorsko, indem sie von jedem Haus ein menschliches Wesen als Tribut fordert. Nun ist die Reihe an Elena, die Schwester von drei Brüdem, gekommen, die die Bruder weinend anfleht, sie mochten zu dem Drachen hingehen und ihn bitten, daß er sich an Stelle des madchens mit einem Unterpfand zufriedengebe. Die Brider kommen zurlick und berichten, die Chala verlange mindestens die "s'viti 
paskule"(Plechten?) der Schwester.

Dieee Var. enthalt ale archaische Elemente, daB der Drache in einem See haust und taglich Menschenopfer fordert. Neueren Datums jedoch dỉrte der lug sein, dab die Chala mit sich ver handeln laBt und sich mit einem pfand zueriedengibt. - Die beiden einander eehr ahnlichen Var. SbNU XIIV,61 und SbNU XIIV, $62(\mathrm{Nr} .46)$, worin die Ala das Wasser sperrt und Tribut fordert, sollen lieber in Kap.4.42 behandelt werden, wo sie zur Erhellung der vila brodarica-Lieder beltragen kbnnen.- In der Var. SbNU XIVI, $5(\mathrm{Nr} .4)$, einem $52 \mathrm{~V} \cdot(4 / 6)$ langen Iled aus Koprivetica, wird Marko - genau wie in den mbglicherweise daraus abgeleiteten Marko-lihsa-Iiedern, vgl. Vuk II 66 - aus dem Gefungnis dee Sultans geholt und gepflegt, damit er die goldflugelige Schlange ("zmija zlatokrila", vgl. die "utva zlatokrila" zahlreicher slidslaviecher Heldenlieder) tote, die die Handelestraßen nach Edirne ("Odrin") unsicher macht. Als Marko den Kampl siegreich besteht, erhalt er als Belohnung drel Lasten Schatze, zwei Hofe und die Herrschalt uber das Prileper Gebiet.

Be1 der Besprechung dieser Lleder, wo ein oder mehrere Helden einen Drachen beklmplen, fiel auf, daB es eich ausschlieslich um maz. und bulg. Ileder handelte, ekr. Lieder aber fehlten. Es findet eich lediglich ein $260 \mathrm{~V} .(4 / 6)$ langes ekr. Drachenkampliled, leider jedoch in der Sammlung Petr.III (ale Nr.14), die wir bereito an anderer Stelle ale wenig vertrauenewlidig bezelchneten, weil der Sanger der Ileder "Ispod Javorine" den Vorstellungen von echten epischen Volkeliedsungern nicht entopricht. Der Liedinhalt let kurz folgender:

Der dreikbpige echwarze Araber baut am Heer einen 300 Ellen breiten und 500 Ellen hohen Turm und darunter ein 300 Stufen tiefse Verlies, in dem Wasser steht, Schilf wächet und Schlangen hausen. In dieeee Geflungnie wirft er noch einen glerigen Drachen (nesitu azdahu), den er mit den Helden, die er am Meer fungt, futtert. Eines Tages erklärt der Araber seiner 300-k8pfigen Družina, nun fehle inm nur noch der Christenhund (kaurin) Kraljević Marko, den er zu germ in dieees Verlieb wille, aus dem $1 \mathrm{hm}$ auch die Vilen nicht mehr heraushelfen könnten. Kurz daraup kommt der dre1kbplige schwarze Araber zur Schenke der Wirtin Rosa, wo er Karkos Sarac auBen angebunden findet. Er ruft die Wirtin heraue und erfuhrt, Marko 
liege drinnen und ochlafe, denn sie habe ihm einen Schlaftrunk verabreicht, well er lmmer grobe llengen trinke und nicht bezahlen konne - Der Araber ergreift diese Elinstige Gelegenhe1t und legt dem schlafenden Marko Pesseln an. Dann wirft er ihn in das Verlieb in dem Glauben, der glerige Drache wer de Karko sicher toten. Marko aber uberwaltigt das Ungeheuer mit den bloBen Hunden. Nach dre1 Tacen kommt die Schenkwirtin Mara, eine Gefangene des Arabers, mit Kerzen und Weihrauch in das VerlieB, um den vermeintlich toten larko zu ehren. Sie findet aber Marko lebend und bringt ihm von nun an drel Jahre lang heimlich Essen. Als der Araber elnes Tages beschließt, gegen die Serben ins Feld zu ziehen, klagt er un den heldenhaften Marko, den er jetzt gut gebrauchen könnte. Er willde $1 \mathrm{hm}$ auch das Leben schenken und Schktze dazu, Ihn aber nach dem Kampp wieder ins Gefkngnis werfen. Mara lkBt $81 \mathrm{ch}$ den Gefangnlsschlussel geben und holt Marko, der thr baldige Befrelung veropricht, lebend herauf. Marko erhait Waffen und sonstige Kamplausristung und reitet gegen die Serben, verbindet sich aber sofort mit ihnen und sturmt nun gegen die Araber, die alle lebend gefangen werden. Nur dem dreiklpfigen Araber schlkgt Narko die Krpfe ab. D1e Serben plundern den Hof des schwarzen Arabers und befreien die Wirtin Mara. Rosa aber w1rd von Larko zur Strafe verbrannt.

Pur dieses lied aus der Samalung Petr.III gilt das berelts an anderer Stelle Gesagtes Der Sanger Divjanovic verwendet zwar Volksliedelemente fur seine Phantasieprodukte, verkonupt sie aber in einer solchen Welse und mit solchen individuellen $\mathrm{Zu}$ sktzen miteinander, daB die Lieder sich unwelgerlich als nicht echt volkstumlich erweisen.

D $r$ a $h$ en $k$ a m $p l$ - Lieder in Verbindung mit dem $h l$. $G$ O $\mathrm{r} g$ finden $81 \mathrm{ch}$ sowohl im skr. wie auch im bulg. und maz. Raum. Das erste zu besprechende Iled dieser Art 1st Vuk V 248, eln 30 V.(7-silber) langes Iled aus der Hercegovina, mit folgendem Inhalts

Traurig steht ein Madchen, die elnzige Tochter des Konigs, an Ufer des tiefen Sees. Da kommt ein Held auf einem weiben Pferd des Wegs. Das 1st aber kein gewornlicher Held, sondern der hl.Georg (evetitely Dora1ja). Er fragt das Madchen nach der Ursache selnes Kumbers, worauf die K8n1g8tochter antwortet, er solle rasch fliehen und sein Ieben retten, denn heute sel die Reihe an sie gekommen, von dem im See hausenden Drachen verschlungen zu werden:

Red je mene dopao,

Da me prozdre azdaja. 
Die Konigetochter hat kaum ausgeredet, da wird der See aufgewhihlt und der Drache komit hervor, we sein Opfer zu verschlingen. Das Madchen beginnt zu weinen, wird aber vom hl.Georg getrobtet, der seine Lanze zllckt und dem Ungeheuer das Herz durchbohrt. Er funrt dem Kon1g das gerettete Midchen zu, woraue der gluckliche Vater zum Dank KIrchen erbauts

De 8 poju molitve,

Bogu falu 1 Bordu.

Ganz Innliche Georgslieder glbt es im Briechischen Raum,z.B. das Iled Lubke,267-270 (man vgl. auch Sakellarid18 17), das dadurch erweltert 18t, daß von dem Drachen gesagt wird, er sperre die Quelle, wenn man thm kein Mensohenopfer darbringe, und daB der hl.Georg vor dem Drachenkampl im Schos des Mkdchens schlaft, das seine Iocken strelchelt (wahrscheinlich $254 \mathrm{~b}$ eine Umschrelbung flr das urgpringliche Iausen, vgl. AaTh 300) und thn durch helBe Tranen zum Kampl weckt. Auch hier baut der dankbare kơnigliche Vater eine Kirche zu Ehren des Rettere.

Der hl. Georg in seiner Rolle als Drachent8ter "18t eine literarische Neubildung des 11.Jh., gearbeltet nach dem Vorb1ld anderer altchristlicher Drachent8ter wie Konstantin, Theodor, Demetrius, deren Taten formelhaft von griechlochen Haglographen aue den Großmärtyrer Georg ubertragen wurden und vom byzantinischen Kulturkre18, in dessen Kunst sie se1t dem 12.Jh. dargestellt werden, s1ch nach Mitteleuropa verbreiteten (deutsche Wanderesken mit Georgs Drachenkampl se1t dem 13.Jh.)"255. Auch Krumbacher guBert olch in seiner Arbeit uber die griech. Georgstexte, die vom 5. b18 15.Jh. relchen, ganz ähnlich:

Zu den spatesten Wundern gehort gerade das, welches gle tandläue1ge helnung als das Georgswunder $k \alpha \tau^{\prime}$ Ejoxyv betrachtet, die munderbare Besiegung des Drachen und die, Befrelung der ihm ausgelieferten Konlgotochter, die in Lasia, spater in Berytos 10kallolert wird. Kirpicnikov ( 5.50$)$ behauptet, das Drachenwunder sel in Griechenland schon Iange vor den Kreuzzligen bekannt gewesen die Matlunder Handechrift oel wahrscheinlich der griechloche Originaltext. In Wahrhelt 1 st das Wunder durch 11 terarische Denkmaler bel den Griechen nicht vor dem Jahre 1315 , Im Abendland und bel den Slaven nicht vor dem $12 . \mathrm{Jh}$. bezeugt. 256

Bevor thm die Rolle des Drachent8ters ubertragen wurde, war der hl.Georg ein lartyrer, der unter dem sagenharten Konig 
Dadianos bzw. dem historischen Christenverfolger Kaiser Diokletian Martern erlitt, Wunder wirkte und viele in der Umgebung des Kaisers zum Christentum bekehrte.

Es ist anzunehmen, daß die auf dem Balkan verbreiteten Lieder von Georg, dem Drachentöter, in ihrem Kern auf literarische (haglographische) Vorlagen zurickgehen, als Folge der mundlichen Tradiemung aber Veränderungen verschiedener Art erfuhren. - liăhrend in den Liedern Vuk V 248 und Lübke,267 der König und seine Untertanen schon Christen sind und dem hl.Georg bereitwillig huldigen, handelt es sich in den folgenden Liedern um Heiden und Götzendiener,- also die vernutIIch altere Version. Die beiden Lieder IMS (1840)III,70 und IMS (1848)I,81 berichten folgende Begebenheit:

Ein Drache (aždaja), der in einem nahen see haust, verheert die Stadt Trojan, indem er sich tëglich Menschenopfer bringen labt, weil die Bewohner der Stadt - unter kihrung aes Konigs - einem silbernen Gotzen, und nicht dem wahren christlichen Gott dienen. Als die Tochter des Königs an der Reihe ist, dem Ungeheuer geopfert zu werden, rat ihr der Konig, sie solle zu dem silbermen Gott, die Königin aber, sie solle zum christlichen Gott beten. Das Madchen gehorcht seiner Mutter, worauf inn der hl. Georg zu Pferd erscheint und von seiner Not erfuhrt. Er beruhigt das kikdchen und legt seinen Kopf schlafend in ihren Schoß. Als der Drache aus dem See aufsteigt, weint die Konigstochter vor Angst und weckt durch die niederfallenden Tranen den Heiligen, der aufspringt und den Drachen mit der Lanze totet. (In IMS III, 70 erhalt der Heilige sogar von einem Engel die lanze Christi, ein Element, das aber kaum aus dem Volkslied stammen durfte.) Dann fuhrt er das Madchen dem Konig zu, worauf sich Trojan und seine Bewohner zum christlichen Gott bekehren.

Dle Georgslieder Petr.II 1 ("Anaeli blago dijele"), Saulic,21 ("Svetitelj Đoraije ubio aždaju") und Saulic,23 ("Bezakonje u Trojanu gradu") sind offensichtlich mit dem Sujet "Die Heiligen teilen die Guter auf" kontaminiert. Es handelt sich dabei um Iieder wie Vuk II 1 und 2 , MH I, 5 (und Var.MH I, 477-481), Mil.30 und 53, Verk.218; SbNU III, 35;II,26;X,12;X,24;XIIV, $164 ; X I V I I I, 43$ und XXXVIII,9, in denen erzahlt wird, wie die Heiligen (Elias, Nikolaus, Johannes, Petrus u.a.) die Guter (Donner und Blitz, die Schiffe auf dem Meer, die Taufe, die paradiesesschlussel usw.) untereinander aufteilen und die hl. 
Maria sich ihnen anschliebt, un von der Glaubens- und Sittenlosigkeit in "Indija" bzw. "zemja Iegenska" zu berichten. Die Jeiligen beschlieben nun, die Ungläubigen und Sittenlosen durch verheerende Gewitter, Dïrre und Seuchen wieder auf den christlichen Weg des Heils zuruckzufihren,- was auch gelingt.- Hie S. Natic in der Anmerkung zu Vuk II 1 betont, ist das alteste Zeugnis der christlichen Iiteratur fur dieses Thema die biblische srzăhlung von der Sintflut. Die altserbische Iiteratur kenne ähnliche Erzählungen wie z.B. "Vaprosi Bogorodice o sedan grehova" und "Slovo Epifanija za Hrista urodivago". "Iz te dve price", meint latic, "postala je velikim delom ova narodna pesma". Indien sei dem sanger ebenfalls aus der altserbischen Iiteratur, nämlich aus der Erzählung von den Ieiden des Apostels Thomas bekannt gewesen. - Die "zemja Iegenska" in der Miladinovschen Var. wurde sicher erst später auf Grund des Namens des typischen, weit entfernten und legendären Landes (bzw. der Stadt) Iegen (Letan) eingesetzt (vgl. die Typisiemung des Namens Iegen in Iiedern wie $1: 11.84$ u.a.). Wegen der Affinităt def beiden Themen lag es nahe, dabs der Sänger auf die Idee kam, dieses Thema mit dem Georg-Drachenkampf-Sujet zu verbinden. In den Liedern letr.II 1, Saulic,21 und Saulic,23 lyst sich also folgender Handlungsablauf - als Ergebnis der erwăn ten Kontamination - feststellen:

Der Konig der slindigen und glaubenslosen Stadt Trojen formt einen silbernen Gotzen, dem alle Bewohner huldigen. Zur Strafe dafur lassen die Heiligen neben der Stadt einen See entstehen und die Stadt von einem in dem hisser hausenden Drachen schwer heimsuchen. Als die Reihe an die Konigstochter gekommen ist, daß sie von dem Ungeheuer verschlungen werden soll, taucht der hl.Georg auf, rettet das Mächen und bekehrt die Gotzendiener.

Interessanterweise berichtet nun A.Hilferding 257 von einer Kuine in der Nihe von Novi Pazar, die das Volk "Trojanov grad" nennt. Daneben befindet sich ein kleiner See, von dem man im Volk erzahlt, daß einst ein Drache daraus aufgetaucht sei, der die Madchen im ganzen Umkreis verschlungen habe. Als die Reihe an die Tochter des Bans gekommen sei, sei der hl.Georg erschienen und habe den Drachen getrtet.- Jedes Jahr am Georgstag versammeln sich deshalb muslimische flbaner und christliche Serben 
gleichermaßen an diesem See und bringen dem hl. Georg ein Opfer: Sie schlachten einen Widder und gieBen sein Blut in den See. - Daraus, dab dieser Brauch von Hoslems und Christen gleichzeitig geubt wird, schlieBt V. Cajkanovid ${ }^{258} \mathrm{zu}$ Recht, dab er alt sei, d.h. noch aus der Zeit vor dem Turkeneinfall stamme. Er meint weiter, dab das Opfer ursprir.glich nicht Georg, sondern einem Seedumonen oder -gott, nkmlich der chthonischen Gottheit Trojan, dargebracht worden se1. Was den silbernen Gotzen im Lied anbelangt, so weiat Cajkanovic (op.cit.S.64) aup die silberne Ferun-Statue (Nestorchronik flur das Jahr 980) und den silbernen dreikoppigen Stettiner Triglav hin.- Auch der indische Gott Kubera, der Herr der Erzschatze (1), wird in einem indischen worterbuch des 12. Jh. als "trifiras", 'Dreiköpliger', bezeichnet, d.h. die Dreikopfigkeit ist eine Eigenschaft, die mit Vorliebe chthonischen Gottheiten beigemessen wird $258 a$.

Laut Vuk Karadz1ćs Wörterbuch s.v. "Trojan" bezeichnet das Volk mit diesem Namen bzw. mit "Trojanov grad" eine Ruine auf dem Cer-Gebirge (sluwestlich von Sabac), wo einst ein König Trojan gelebt haben soll, der jede Nacht nach Srem ritt und eine Ilebesnacht ait einem vädchen oder einer Frau verbrachte. Er ritt nashts, weil ihr die Sonne am Tag geschmolzen hatte. Wenn er bei seiner liebsten ankam, fullte er dem peeri den Futtersack und blieb jeweils so lange, bis dieser leer war und die Hahne krahten. Als eines Tages ein Ehemann (oder Bruder bzw. untreuer Diener) Sand in den Futtersack gepult und den Hahnen die Zunge herausgerisgen hatte, verspatete sich der Konig und zerflob in der Sonne.- Bei M. Milićevic, Kneževina Srbija, S.423 (zitiert nach Cajkanovic, op.cit.s.60) wird dieselbe Geschichte mit kleinen Abweichungen berichtet:

Trojan hat hier drel Kopfe: Mit einem friBt er Nienschen, mit dem zweiten Herdenvieh und mit dem dritten Fische. Er geht nachts in die Stadt Sirin an der Sava, um dort jeweils mit einer anderen Frau eine liebegnacht zu verbringen. Der $h l$. Demetrius entlockt inm durch geschickte Fragen das Geheimnis, daB Trojan sich einzig vor der Sonne furchtet, worauf der Heilige entsprechende Maßnahmen trifft.

Cajkanovic (op.cit.S.60) halt den sonnenscheuen König Trojan 
wohl mit Recht fur eine nachtliche Gottheit und vergleicht ihn mit Hades und Triglav. Daß der Konig jede Nacht ein anderes kadchen verlangt, $d a B$ er lienschen und Tiere verschlingt sowie drei kopfe hat, erinnert m.E. stark an eine Drachengestalt. Fur diese Vermutung spricht auch der Brauch, daB man bei Novi Pazar Opferblut in den See giebt, wobel wahracheinlich der Gedanke, den Drachen damit zu besunftigen, zugrundeliegt.- Wie in der oben angefuhrten Volksluberlieferung das Geheimnis Trojans darin besteht, daB er sich vor der Sonne huten muß, so kennen wir andererseits eine Reihe skr.(z.B. Vuk, Pripovetke Nr.39), maz. und bulg. Volkserzahlungen, in denen Trojan seine Ziegenohren (Eselsohren) zu verheimlichen sucht,d.h. es handelt sich wohl um eine sekundäre Ubernahme des in anderen (mythischen) Traditionen schon verwurzelten Trojan in die Midas-Sage (in griech. Var. heibt der Herrscher melst Alexanders Trajan mit Bocksohren wird schon bei einem byzantinischen Schriftsteller des $12 . \mathrm{Jh}$. erwahnt) 259.

Neben den Rumbnen, die Trojan als einen Gott des Winters bzw. Gott der Vegetation verehrten, liefern auch die Russen Zeugnisse fur eine Aufnahre Trojans in die Reihen ihrer heidnischen Gotter. In einer masischen HS des 16.Jh. ("Slovo $i$ otkrovenie ovjatych apostol") mit kompilatorischem Charakter wird an einer Stelle, die sich offenbar auf das Heidentum im allgemeinen bezieht, Trojan - neben Perun, Chors und Dyj (< $\Delta L C ́ S$;Zeus)-als heidnische Gottheit erwahnt, wobei er gleichzeitig als zum Gott erhobener römischer Kaiser verdammt wird. AuBer in dieser apokryphen "Offenbarung" taucht Trojan als heidnischer Gott - (zusammen mit Chors, Veles und Perun)- in einer slavischen Interpolation auf, die in die alteste slavische tjbersetzung des "Chozdenie Bogorodicy po mukam" (Gang der luttergottes durch die H8llenqualen) aus dem 12.Jh. eingefugt 18t $259 a$. Im altrussischen Igorlied ("Slovo o polku Igoreve") aus dem 12.Jh.(?) wird Trojan an vier verschiedenen Stellen erwahnt, namlich "vs tropu Trojaní" (auf der Fahrte Trojans), "byli veci Trojani" (vergangen sind die Zeiten Trojans), "na zemlju Trojanju" (in das Land Trojans) und "na sedomoms vece Trojani" (im Zeitalter VII bzw. im giebten Zeitalter des Trojan), worluber eine umfang- 
relche Sekundärliteratur besteht ${ }^{260}$,- das Ergebnis einer heute noch andauernden D1skussion, die aufurollen hier nicht der Platz 1ot.

Was die Gestalt des T $r$ o f a $n$ betrifft, so handelt es sich sehr wahrscheinlich um eine Divinisation des romischen Kaisers ("divinus") Trajanus, der 101-105 n.Chr. die Daker nordlich der Donau unterware. Der Name Trojan wurde den 0otslaven vermutlich durch die Sudslaven und Rumbinen, in deren Polklore er - unter Anknupfung an altere mythologioche Traditionen, also "Historisierung" der vorhandenen tberlfeferung durch den Naren Trojan - fortlebt, vermittelt. Nlo "Ableitung" von dem Namen des heldnischen Herrschers Trojan lat wohl die in der slidslavischen Volksuberlieferung auftretende Bezeichnung "Trojan" fur eine gotzendienerische Stadt (2wischenstuLe: Trojanov grad) aufzurassen ( Trojan etymologisch von aksl. troj6nz und skr. trojan 'dre1faoh' herzuleiten, was Vyncke versucht hat, der Trojan als trikephale Gottheit, ale "dieu triple" Interpretieren will, ist unmblich in Nbetracht des beweglichen -a- in skr. trojan,fer. trojna (wăhrend der gen.8g. von Trojan doch 'Trojana' lautetl). Es lat eher umgekehrt anzunehmen, dab der Name Trojan - in volksetymologlscher Auslegung als "der Drelfache" - elnem dre1-

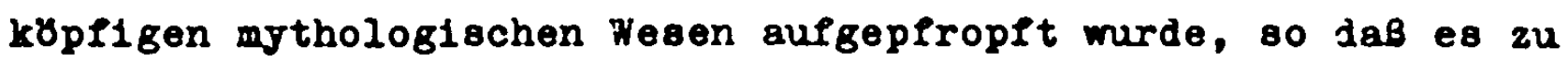
der Vorstellung des dreikbpigen Trojan komen konnte.

Nach dieser Abschwelfung nun zu den maz. und bulg. Varianten der Georgsileders Mil.31, ein 159 V.(ur.) langes Iled aus Kukus, und Mil.38, ein 152 V.(4/6) langes Lled aus Mazedonien, stehen ebenfalls in der Tradition des gotzendienerischen Krn188 von Trojan:

Als der König von Trojan nicht aufhort, mit seinen Untertanen einem Gotzen zu dienen und den ohriatlichen Glauben zu verleugnen, flleBen zur Strafe aus allen Quellen der Stadt nur noch Gold und S1lber, whinend sich die einzige Wasserquelle in der Gewalt elnes Drachen ("gura lanja" bzw. "zm1ja halovita") befindet, der taglich Menschenopfer verlangt. Als die Konigatochter von dem Drachen verschlungen werden soll, betet sie in 1hrer Angst zu Gott, der Brbarmen zelgt und den hl. Georg zu 1 hrer Rettung ontsendet. Der Heilige zieht den Drachen aber an elner 
Kette noch lebend vor den Konlg der Stadt ("Troem" b2w. "Trojan"), so dab eich angesichte dleeer Bedrohung der Konig und alle selne Untertanen zum Chrietentum bekehren und den ollbernen Gotzen zerstören. Nun eret totet der hl. Georg den Draohen, worauf alle Wasserquellen wieder zu flleBen beginnen.

Auch bel dieeen belden Liedern sind die Spuren haglograph1scher Vorlagen nioht zu Ubersehen, auch wenn eie durch lange mindliche Tradierung einen "AbechlelfungeprozeB" durchmachten.D1e einfachere Form der Georgelieder, ntmlich ohne Begrindung fur das Auftauchen dee Drachen und ohne Bekehrung des Krnigs, aleo Typ Vuk $V$ 248, ist in folgenden maz. und bulg. Varianten vertreten: Sapk.19; SbNO I, 30; IX, 154; XXXV Nr.408; XVI-XVII, 206 (etatt des hl.Georg rettet hier ein "neznajna delija" d1e Zarentochter); XXXVIII,22; Stoin SrSB 59; Per.Sp1s.XIII,147; Spie.BAN XXI, 160; Ob8t trud III,79; Bulg.kn18.I(1860), 198 und SbNU XlVIII,43,Nr.14 (in belden Iledern let der hl.Geors durch den hl.Ellae ersetzt); SbNU XII,39,Nr.154 (hier 18t zwar von keinem Gotzen die Rede, wohl aber devon, dab die Stadt Carlgrad "se ne prekristil" und Gott ele dadurch beetrafte, daB er alles Wasser auBer einer Quelle versiegen 11eB, an die er eine menBchenfreeeende Lamja setzte); Mil.11 (der hl.Georg wird nicht erwhint; die Lamja verschlingt den Zaren eamt seiner Tochter), SbNU XXXV Nr.113 (der Drache nimmt eine Kuh als Ersats fur die Zarentochter; der hl.Georg wird nioht genannt); SbNU $\mathrm{XIVI}_{2} \mathrm{Nr}$. 61 (der Hellige lehlt; dem Zaren tut seine Tochter le1d, ale ole von des Drachen verechlungen werden eoll, nloht aber der Zarin, die in dem Madchen doch nur eine "curda otmjana" sieht, d.h.d1e Toobter wird auBer Haus gehen und elne andere, namlich die zuklnftige Sohwlegermutter, in der Arbelt ablösen).

Es gibt im bulg. und maz. Raun aber noch andere Sujets, in denen der $\mathrm{hl}$. Geors allein oder mit Helfern ale Drachent8ter auftritt. In dem L1ed Virb.44 aus Berdjansk $2 . B$. he1.Bt eor

Bin dunkler Nebel hat elch herabgesenkt und drel Landerelen verwlatet. $D a$ vereammeln s1ch alle betropfenen "Zorbadz1" und beraten, was zu tun ee1, damit der Nebel wieder verschwinde. Der hl. Goorg erklart den Louten, das sei kein Febel, sondern eine dreikoplige Lamja, und fragt, wae man ihm eohenke, wenn or den 
Drachen totete. Man verspricht inm drei Fässer Wein, doch Georg verlangt nur ein Iamm und totet dafir die Lamja.

Indem Georg ein Lamm fordert, erweist er sich als Beschutzer der Herden, eine Funktion, auf die wir schon oben hingewiesen hatten. Bemerkenswert ist hier wieder die Vorstellung der Lamja als dunkler Nebelwolke und Erntevernichterin. Hatten wir bisher schon den nachgeborenen witwensohn bzw.den Bastard, also auf auBergewohnliche Art Geborene, als Drachentoter par excellence genannt, 80 sind diesen nun noch die gleichermaBen prädestinierten Zwillingsbruder hinzuzufugen. In dem Lied SbNU XII,4,Nr.5, $23 \mathrm{~V} .(4 / 4)$ lang, aus der Gegend von Burgas, heiBt es z.B.:

Ein dunkler Nebel senkt sich herab.- Das ist aber keine Nebelwolke, sondern eine graubrkunliche Lamja mit drei kopfen, die drei lander heimsucht und die Ernteglter vernichtet. Davon hören zwei Zwillingsbruder ("dvama bratja, dva bliznaka") und verfolgen die Lamja. Der jungere Bruder erreicht sie, zieht sein Schwert und schlagt ihr die drel Kopfe ab,worauf drei Strome fließen: gelbes (Weizen-)Gold flur die Ackerbauern, Honig und Butter fir die Schafhirten und roter Wein fur die Weinbauern.

Das Iled, dem der Aufzeichner den aufachlubreichen Titel "Lamja 1 plodorodie" gegeben hat, ist einerseits so interessant, weil ein namenloses Zwillingsbruderpar in der Punxtion des Kulturheros in den Drachenkampl zieht, und weil andererseits die Iamja - wie schon in oben behandelten Liedern - als Erntevernichterin dargestellt wird, nach deren Tod der Erntesegen wieder reichlich fließt, vom Sunger bildich als drei offenbar dem Korper des Ungeheuers entspringende Ströme von Erntegutern fur die "cifeil", "kupali" und "ufcari" vorgestellt. - In der Var. SbNU IX,6,Nr.4, einem $30 \mathrm{~V} .(4 / 4)$ langen Iled aus Dobridko, wo ebenfalls Zwillingsbruder das von der Lamja drei Jahre lang heimgesuchte Dorf ("selu Trojanuvu") befreien, flieben "gelber Weizen", "roter Wein" und "weiBe Milch" fur die Bauern. Winzer und Schafer.- In der Var. SbNU XVI-XVII, 15 totet ein namenloser Held ("dobur junak") die dreiköpfige Schlange uber der Romanija, worauf die drei Ströme Erntegiter fließen.Diesem altertumlichen Liedsujet wurde ein christlicher stempel aufgedrluckt dergestalt, daB zuerst den zwillingobrldern vom hl. 
Georg geholfen wird ( $\nabla g l$. die Var. Vürb.440, 49 V. [4/4] lang, aus Berdjansk: Hier wird die erntevernichtende dreikopeige Lamja von den $\mathrm{Zw1llingen}$ auf Anraten des hl. Georgs mit Haken vom Grund des Schwarzen Meeres heraufgeholt und in dre1 Telle zerachlagen, aus denen die drei Strome Ernteguter entspringen, oder $\nabla g l$. weiter die bereits behandelte Var. SbNU IX,7, wo der hl.Elias und zwei Zmej-Bruder die Lamja ţten), dann aber das Sujet volllig auf den hl. Georg Ubertragen wurde und die 2 willingsbrider wegfallen. Dies ist der Pall in den Varianten Doz.14; SbNU XXVIII,441; Stoilor, Lamite, S.160; Bulg.ten1z.II (1858),78; Vurb.51; Naudno sp1s.IV Nr.7 und 8; Kar.Pam.,212.- In dem 38 V.(3/4) langen Lled SbNU VIII, 12 aus Varnensko 1st dieses Sujet groteskerweise sogar mit dem Sujet von der Erbtellung kontaminiert:

Eine Mutter teilt den Besitz unter ihren beiden Söhnen auf. Der altere, mit dem Ergebnia unzufrieden, erschlagt die thutter, aus deren Leichnam die genannten drei Ströme Pließen.

Das nachste Glied in unserer Sujetkette bilden Lieder mit folgendem Inhalt:

Am Georgstag begeht der hl. Georg die Felder und Wiesen, um nach dew Rechten zu sehen. Da begegnen inm drei Ketten Sklaven ("tri aindzira robi"), gepunrt von einer Samodiva bzw. Juda: Die erste Kette besteht aus Ackerbauern, die zweite aus Winzern und die dritte aus Schafern. Sie bitten Georg, er mbge sie befreien, und bieten ihm dafiir $300 \mathrm{Kilogramm}$ Weizen bzw. 300 Mab Wein bzw. 300 widder an der Hellige - und hier 18t wieder ein Element des Volkebrauchtums eingefloseen - winscht sich aber nur einen Gebarckkringel (kravaj), ein $M a B$ Wein und ein Lamm,- bescheidene Gaben, die inm mit ehrlichem Herzen am Georgatag dargebracht werden sollen.

Die drei kotten Sklaven konnen auch aus jungen Frauen, Jungen Mannern und Mädchen bestehen, die plur den Fall der Befrelung durch den hl.Georg einen Pladenkuchen, ein Lamm und Blumenkranze versprechen, d.h. also Gaben, die naturlich an das Brauchtum am Georgatag erinnern. Als Varianten olnd - Plur beide Palle zusammen - Polgende Lieder zu nennen: SbNU IX,6; VIII, 15; XXVII,36; VI,75; IV,8; XI,44; XV,9; Ziva etar.I, 149; obrt trud III,67; Stoin TV 134; Virb.441; II.20,44,63 und 276 . Auffallende verknderungen gegenuber den vorhergehenden Liedern 
bestohen nun darin, daB die Lamja durch oine andere mytholo61sohe Plgur, namlich die $S$ a a o d 1 a, ersetzt warde und dab die Ackerbauern, Schufer und Welnbauern, flir die in den anderen Varianten die drel Strome von Brntegatern floeeen, h1er ale drel Ketten Sklaven in der Gewalt der Poe aufgefabt sind, wodurch anschoinend wleder d1e Geflurdung der Ernten durch das dzmon1sohe Wosen zun Ausdruck gebracht werden ooll.

Intereseanterwe10e gibt so num ein Sujet, dae ron der Befre1ung dreler Ketten Sklaven, beetehend aus Jungen Frauen, Mannern und Madchen, aus der Gewalt dee $A$ r b e r e bew. dee T $r$ o $n$ handelt. Ale Befreler runglert der Konlgseohn Marko, hier Krall Marko genannt.- Zwlechen diesen und den vorher genannten Iledern gibt os nun Zwlechenglieder, die die Ilucke in der Sujetrette echl1eBen, nimlich die maz.-wbulg.Varlanten Drag.17 und 18 eowle Tonic 2, wo Marko dre1 Ketten Sklaven (Junge Prauen, Jinglinge und Madchen) aus der Gewalt der Samorila befre1t. Dabel lot ou beachton, daB - wio in den Iledern ron der Sklavenbefrelung aue der Gewalt dee Arabere oin sueltelichee Notir auftaucht: Marko fragt den Wald, warum or so verwelkt eel, worauf ihn der wald erklkit, die Samovila bew. der Mohr hitten dre1 Ketten Sklaven durch ihn hindurchgotrieben und inn 00 zum Wolken gebracht. In einzelnen Fulion kommt d1esee Zusatemotiv allerdinge auch echon bel Georgelledern (z.B. SbNO IV,8) ror.

D1. Innlichke1t und eventuelle gegeneeitige Abhunglgkelt der b1sher gonannten Sujete, wo so olch um dae Plieben dreier strome bew. Pahren dreier Kotten sklaven handelt, cohoint nir augenfullig ziu eein. Bel dem ereten Llederkrele, wo der hl. Georg olne Lamja totet und aue den abgesohlagenen xopfen Strome ron Weisen, Wein und kich (bew. Hon18 und Butter) rur die Bauem, Winzer und Schufor flleBen, let der Hell1ge (abgeklaret HII) wohl eret im Zuge der Verehrietlichung alter heldniecher Sujete fur einen uteren namenloeen Helden beeonderer Art,z.B. elnen Zmej, Nachgeborenen, Bastard oder Zwilling, aloo den archalechen Drachentoter (abgeraret DT), eingetreten. V1ellelcht murde der Drache uropringlich ale Herr der Gater (Korn, Velntrauben, Milch; Trinkwaecer) aufgefabt, die lha ron dem Kul- 
turheros mit Gewalt oder list geraubt werden musten. Das Hervorbrechen der Ernteguter aus dem Leib der Lamja (abgekurzt I) spricht in gewiseem Sinn fur diese Vermutung. Laut Meletinsikif wurden diese Herren der Guter erst im laufe der Ze1t zu Ungeheuern, und von da an gehort die Ongeheuerbeklmpfung zu den vordringlichsten Aufgaben des archalsoben Helden.- Nachdem die Lamja von der Huterin und Herrín der Guter zum Prototyp des erntevernichtenden Ungeheuers geworden war und das Iledsujet von der Totung des Drachen und dem PlieBen dreier Erntestrome sich formiert hatte, entwickelte oich daraus offensichtlich ein anderes, wonach die Samodiva (bzw. Juda) die Ackerbauern, Weinbauern und Schafer (abgekurzt $N / W /$ $\mathrm{SCH}$, die im vorigen Sujet von der Lamja durch Vernichten der Ernte geschadigt worden waren, als aneinandergekettete Gefangene fuhrt. Aus der Vorstellung der drei Ströme (abgekurzt 3 S) von Erntegltern, die nach dem Tod der Lamja flr die Bauern, Winzer und Schafer flieBen, durfte wohl die gestaltmkBig ahnliche Vorstellung der drei Gefangenenzuge oder Ketton (abgekluzt $3 \mathrm{~K}$ ), bestehend aus Bauern, Winzern und Schrferm, entsprungen sein. In beiden Fullen sind Pruchtbarkeit und Erntesegen durch ein dumonisches Wesen bedroht: Im ersten Fall 1 at dies die Lamja, im zweiten Fall ein schon mehr anthropomorphes Wesen, nämlich die dem Menschen borggesinnte Fee. Solche Prlle der Substitution des Drachen durch die Fee, also eine zunehmende Anthropomorphisierung, sind uns aus mehreren anderen Sujetkreisen (z.B. dem Hochzeltezugsujet) bekannt und werden vor allem im nachsten Kapitel (4.42) von der Vila brodarica zu behandeln sein. Es ist anzunehmen, daB sich das Sujet von der Samovila (abgekfrat SV) als Sklaventreiberin frihestens zu Beginn der Tlukenzelt gebildet hat, als Sklavenzluge wirklich zu beobachten waren. Anfang8, als nooh der Gedanke einer Gefahr fur die Emteertrage von dem Lanja-Sujet her lebendis war, wurden die Gefangenen als Bauern, Winzer und Schafer vorgestellt, dann aber mehr der Realitat anger.bhert: In einigen Liedern trelbt die Juda bereits junge Prauen, Manner and Madchen (abgeklirzt $P / M / M$ ).

Erwahnt sel noch, daB wir in einem Iled aus SW-Bulgarien, nam- 
lich Stoin $\mathrm{Tr}, 133$, ein Sujet vertreten finden, worin die Lamja, nlcht die Juda, drel Ketten Sklaven trelbt, dle von Krail Marko (abgekinzt $\mathrm{KM}$ ) befreit werden. Wir besitzen somit ein entscheidendes Zwischenglied zwischen Sujet I: Aus der toten Lamja eließen drel Strome" und Sujet II: "DIe Juda bzw. der Araber Ifhren drel Ketten Sklaven", d.h. die Juda (Samovila) und der "curmi Arapin" (abgekbrzt $C A$ ) alo Sklaventreiber waren also sehr wahrscheinlich von der Lamja als Sklavenhalterin abzuleiten. Moglicherwelse hat auf diese letzte Vorstellung das aus der maz. Volksdichtung wohlbekannte Motiv der Iamja als Verschlingerin dreier Hochzeltszuge eingewirkt. Der Drache als mythologisches Wesen, das Menschen gefangen halt, 18t z.B. auch aus den Bylinen von Dobrynjas Kampl mit der Drachenschlange her bekannt. 260 a

Als in der Turkenzelt auf dem Balkan Araber eine immer wichtigere Rolle alo Sklavenhandler oplelten, erfolgte offensichtlich die Substitution der Fee durch den ochwarzen Araber und ochlieblich durch den Vertreter der Unterdrickermacht oelbot, namlich den Turken (abgeklirzt $T$ ). Sklavenbefreler 1at in dieoen P\&llen Immer Krall Marko.- Zur Verdeutlichung der blaher behandelten Sujetkette möge das folgende Schema dienen, das in Plelirichtung die fortschreltende Entmythologisierung und die gleichzeltig zunehmende Hiotorisierung widersplegelt:

\begin{tabular}{|lll}
$\mathrm{DT}$ & $\mathrm{I}$ & \\
$\mathrm{DT}+\mathrm{HL}$ & $\mathrm{I}$ & \\
$\mathrm{HL}$ & $\mathrm{I}$ & $\mathrm{S}(\mathrm{A} / \mathrm{W} / \mathrm{SCH})$ \\
$\mathrm{DT}$ & $\mathrm{I}$ & $3 \mathrm{~S}(\mathrm{~A} / \mathrm{W} / \mathrm{SCH})$ \\
$\mathrm{DT}+\mathrm{HI}$ & $\mathrm{I}$ & $3 \mathrm{~S}(\mathrm{~A} / \mathrm{W} / \mathrm{SCH})$ \\
$\mathrm{HL}$ & $\mathrm{I}$ & $3 \mathrm{~K}(\mathrm{~A} / \mathrm{W} / \mathrm{SCH})$ \\
$\mathrm{HL}$ & $\mathrm{SV}$ & $3 \mathrm{~K}(\mathrm{~F} / \mathrm{M} / \mathrm{M})$ \\
$\mathrm{HL}$ & $\mathrm{SV}$ & $3 \mathrm{~K}(\mathrm{P} / \mathrm{M} / \mathrm{M})$ \\
$\mathrm{KM}$ & $\mathrm{SV}$ & $3 \mathrm{~K} / \mathrm{M} / \mathrm{M})-(+\mathrm{R})$ \\
$\mathrm{KM}$ & $\mathrm{CA}$ & $3 \mathrm{~K}(\mathrm{~F} / \mathrm{M} / \mathrm{M})-(+\mathrm{R})$ \\
$\mathrm{KM}$ & $\mathrm{T}$ & $3 \mathrm{~K}$
\end{tabular}

Auf die belden letzten Glieder dieser schematisierten Sujetkette, die ohne bzw. in jungerer form mit einem Raimen ( $\mathrm{R}$ ) 
vorkommen, werden wir in Kap.4.44 noch nuher eingehen. In der obigen Sujetkette bietet sich uns ein Musterbeispiel dafur, wie aus den ursprlinglich wohl neutralen Naturkrkften bzw. Herren der Guter dumonische Ungeheuer (Drache, bosartige Pee) werden, die man schlieblich im ProzeB der fortBchreitenden Entmythologielerung und damit verbundenen H1storlsierung durch die historischen Peinde ersetzt. Diese Beobachtung, am konkreten Liedmaterial gewonnen, wird ron Meletinskij 261 bestatigt, wenn er allgemein sagt:

Die epischen Feinde in den archaischen Denkmblern des Heldenepos sind in der Regel Damonen, Riesen und mythische Ungeheuer, in denen eich - genau wie in den Gestalten der urspranglichen Folklore - ein Synkretismus von Vorsteliungen uber Naturkrafte und uber historische Stammesfeinde widerspiegelt... DLe epischen Feinde verlieren im klessischen Heldenepos Schritt flir Schritt den Charakter mythischer Ungeheuer und gewinnen dafir die Zuge historischer Foinde.

Whihrend im Vorhergehenden me1st der hl.Georg als Drachentoter funglerte, sind nun noch einige lieder erganzend anzuruhren, in denen der hl.Ellas, der Donnerer und fllr das Wetter verantwortliche Hellige, diese Rolle spielt. Das erste Lied dieser Gruppe, M1l.40, 18t $53 \mathrm{~V} .(4 / 6)$ lang, stammt aus der Gegend von Struga und hat folgenden Inhalts

Neun hundische ("kucki", elgentlich 'HUndinnen') Lamien suchen das Feld von Ohrid heim und fallen uber die Vorratskammern ("kladenc1", elgentlich 'Brunnen') des Zaren her, wo sie den weiBen Weizen aufressen. Der hl.Elias uberlegt, wie man die gefrabigen Lamien toten könnte, findet aber keine Lobung. Da rat ihm der hl.Nikolaus, er solle nach Kaneo gehen; dort lebe elne Wi twe mit ihrem nachgeborenen Sohnchen ("muisko dete po tatka posmurce"); diese Prau solle er mit einem Pladenkuchen und einer Plasche Schnaps bewirten und, wenn die Witwe - vom Schnaps ermldet - in Schlaf gesunken se1, das Kind nehmen, zu den Vorratskammern des Zaren bringen, wit thm ine Pirin-Gebirge steigen und die Lamien ausfindig machen.- Der hl. Elias fuhrt alles so aus, wie Nikolaus inm geraten hat, und das unverstkndige ("ludo") Bind spurt wirklich die Lamien auf, empfangt sie mit dem Schwert in der Rechten und totet acht davon, whrend die neunte Lamja in die Erzengelkirche 1lieht. Da kommt der hl. Ellas herbel und erkundigt sich bel dem "Wlegenkind" (dete ot ruleka) nach dem Hergang des Kampfes. Als er von dem "Wickelkind"(dete povojnile) erfuhrt, das 
ein Drache olch in die Erzengelkirche gefluchtet habe, totet er diesen eigenhandig. Dann bringt er der schlafenden Witwe das Kind zurluck und weckt sie mit der Aufforderung, sie solle das ermudete Sobnchen otillen.

In diesem Iled labt sich noch ein alter Kern feststellen,woneoh das durch besondere Geburt ausgezelchnete Heldenkind wohl der uropringliche und alleinige Drachentoter war. Der archaloche Kern wurde von elner Schicht chriotlicher Elemente uberlagert, so das nun der hl.Nikolaus als Ratgeber und der hl. Elias als zusktzlicher Drachentoter fungieren und schlieBlich sogar eine Lamja in der Kirche Zuflucht oucht. Die konkreto Lokalisierung des Geschehens am Ohrider see und die Einschluferung der Witwe durften ebenfalls neuere Elemente sein. Die Lamien oind wieder deutlich alo Emtevernichterinnen gekennzeichnet. - In dem $75 \mathrm{~V} .(4 / 6)$ langen Lied Jastr., 254 aus Sudserbien wird folgender Inhalt behandelt:

Drel Jahre lang hat es schon nicht mehr geregnet, 80 dab den Acker- und Welnbauern alles verdorrt ist. Die hl.Maria fordert deshalb den Donnerer Ellas aue, die Plugelpferde anzuspannen, Donner und Blitz 108zulassen, damit endlich der ersehnte Regen falle. Der hl.Elias verlangt, Maria solle thm den Neffen Sava schicken; der solle numilch zum Meer gehen, wc zwolf Drachen (hale) hausten, die die schwarzen Regenwolken nicht aufoteigen lieben.- Alo Sava eintrifft, gibt thm der Ohelm die Anweisung, er solle oich mit dem Damaszenerschwert bewaflnen, zum Meer ziehen und dort den zwoll Drachen, die er, Elias, durch Blitzochlige bettuben werde, die Kopfe abachlagen.- Als Oheim und Neffe gemeinsam die Ungeheuer getotet haben, kommt plotzlich noch ein zwolfköpliger Drache ("aźda") hervor und will Sava mit aufgerisoenem Rachen verschlingen, worauf das Kind vor Schreck den sabel fallen luBt, zu dem obeim in den Himmel plieht und inm von dem Ungeheuer berichtet. Da lachelt der hl.Elias und melnt, er werde auch diesen Drachen durch Blitze betkuben, und Sara solle ihm die Kopfe abschlagen, wenn das Ungeheuer ans Ufer treibe. - Als auch die Totung dieses letzten Drachen gelungen 18t, oteigt sogleich eine dunkle Wolke auf, die den 80 lange entbehrten Regen bringt.

Auch in dieser Var. lot offenbar ein Heldenkind der urspringliche Drachenkampler, der jedoch opater durch den hl.Sava ersetzt und in die bellebte Oheim-Neffe-Beziehung mit einem anderen Helligen, namlich dem Donnerer El1as, gebracht warde. 
Wie im vorhergehenden Iled ist auch hier der letzte Drache nur unter besonderen Schwierigkeiten zu tóten (Element der Steigerung!). Aufschlubrelch ist die Vorstellung, dab die Drachen die Regenwolken Im Neer festhalten und so Durre verursachen. Damit ist wieder die Bindung des Gewitterdrachen an das Wasser betont. Wie Helios mit seinem Sonnenwagen uber den Himmel puhrt, so spannt in unserem Lled Ellas seine Plllgelpferde an, lenkt sie durch die Wolken und sendet Blitze aus,- eine aus zahlreichen bildilchen Darstellungen wohlbekannte Vorstellung.- Als Wetterhelliger erwelst olch der hl. Elias auch in dem Koledalied SbNU IV, 11 aus Dobricko, das $40 \mathrm{~V} .(4 / 4)$ lang ist und folgenden Inhalt aufweist:

Neun Jahre lat weder ein Wind gegangen, noch eine Regenwolke aufgetaucht, well der hl.El18s krank 11egt. Aup Anraten der Muttergottes bringt die besorgte Schwester des Helligen frische Hirschkuhmilch herbel und heilt damit den Kranken, wonach endlich wieder Regen fallt.

Von einem Drachen, der das Wasser sperrt und damit Durre verursacht, ist hier zwar nicht die Rede, doch könnte dieser uropringlich in dem lied eine Rolle gesplelt haben und nur durch ein Versehen des Sangers weggefalien sein.- In den Iledern SbNU IV,6,Nr.7 und SbNU XII,40,Nr.155 kunpet der hl.El1as mit einem "mlado zmejce", das er dadurch besiegt, daß er es hochhebt und dann in die Erde stobt. Die Polge des flur Elias siegreichen Kampfes, das namlich der ersehnte Regen fallt, ist hier ausgelassen, wird aber erwahnt in der Var. zu SbNU XII. 40 ( = Blǔskov, "Elcha" 1887) und in SbNU XV,6,Nr.9, wo allerdings ein gewisser Bogdan mit dem ZmeJ kamplt. In Stoin TV,26 besiegt - ein Versehen des Sangers? - das "zmejce" den hl.El1as.

Damit ist das ganze im oludslavischen Raum gegebene Spektrum des Drachenkamples behandelt, sowelt wirklich von einem Drachen die Rede 18t. "Verkappte" Drachenkampllieder dagegen werden noch in den folgenden Kapiteln zu besprechen sein. Bel der Behandlung der aldalavischen Drachenkampelieder fiel auf, das es sich past durchweg um kurze, melst Brauchtumslieder handelte. Dies laBt sich damit erkluren, daB das Drachen- 
kamploujet allein, ohne historischen Hintergrund, ohne breit zu beschrelbende gegnerische Lager, Kamplvorbereitungen usw. sich nicht fur umfangreichere Ereahllieder heldischen Charakters eignet. Erst - wie wir sahen - durch Kontamination mit anderen Sujets, z.B. dell Hochzeltszugthema, kann es epische Breite gewinnen.

Bemerkenswert war ferner die starke Verbreitung der Drachenkampflieder im maz. und bulg. Raum und ihr auffallendes Fehlen im skr. Raum, von den wenigen Georgslegenden-Liedern abgesehen. Die maz. und bulg. Lieder mit Drachenkampp-Thematik stehen vorwiegend auf einer ganz archaischen Stufe, haufig mit ganz altertlumlich anmutenden Drachenkampfern als Protagonisten und aufallend gut erhaltenen "agrarischen Akzenten" ausgestattet, whrend wir es in skr. Raum im wesentlichen nur noch mit "Indirekten" Drachenkampfliedern (Substitution des Drachen durch den Arapin, die Vila usw.) zu tun haben.

Auf eine $K$ a $r$ e murde in diesem Kapitel verzichtet, weil die Lieder einen zu heterogenen Charakter aufwiesen, d.h. in diesem Fall, dab es sich nicht um Varianten eines allen gemeinsamen Sujets handelte.

In der russischen Byline lot das Drachenkampethema in den Liedern von Dobrynjas Kampf mit der Schlange 262 relativ gut vertreten. Bemerkenswerte Parallelen aind dabel, das die Drachensohlange auch an das Wasser (den Puraj-PluB) gebunden lst,daB sie wie eine Wolke dahergebrauet kommt, daB sie Gefangene bel sich halt, das der Zweikampl mit dem Ungeheuer nach epischer Pormel dre1 Tage und drel Nachte dauert, das die Schlangenbrut dio Belno des peordes umringelt und das Stroitros sioh nach einem Peitschenhieb durch einen Sprung rettet (was wr in Kap. 4.13 in ghnlicher Porm angetroffen haben, wo das pferd durch einen SporenstoB zum Sprung und damit zum Abschutteln der Lamien getrieben wurde), das es sich bel Dobrynja um einen Witwensohn handelt und daB schlieblich dem Drachenkampe durch die Stimme aus den Wolken ein christlicher Anstrich gegeben wurde.

Naber llegt unserer elldslavischen tberlieferung jedoch der 
B r 1 e c b. Ilederschatz, mit dem wir noch auffallendere Ubereinstimmungen finden, - vermutlich aus der sogenannten Balkangemeinschaft resultierend. Die griech. Sujets von dem Drachen im Brunnen, der den Helden beim Wasserholen festhalt, und das Sujet,worin den Drachen das Singen des Helden stort, warden berelts in Zusammenhang mit den suldslavischen Iledern dieser Sujets behandelt. Nls weitere griech. Drachen-

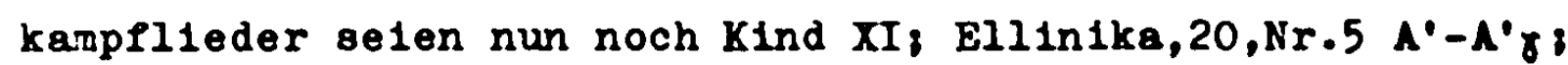

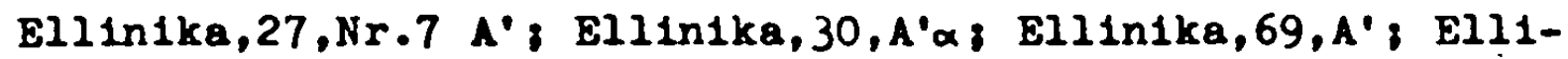
n1ka,70, $A^{\prime} \alpha_{8}$ und Ellinika, 341, $H^{\prime}$ genannt, deren Besprechung aber in einem separaten Artikel ( $Z$ Balk $V$ ) erfolgen wird. Parallelen zwischen diesen griech. und den oben behandelten maz. und bulg. Drachenkampfliedern lassen sich vor allem auf folgende Punkte reduzieren: Die Drachentoter sind me1st Bruder, Uberdies hkue1g Witwensohne; sie werden von einem Herrscher zum Kampl gegen das Ungeheuer aufgefordert; der Drache haust am Wasser (bzw. hat sich des Wassers bemkchtigt) und verschlingt Menschen; er besitzt mehrere kopfe und weist ungeheure AusmaBe auf; zwischen dem Helden und dem Ungeheuer besteht eine mythische Verwandtschaft aufellend 18t schlleBlich die Tendenz zur Verchristlichung des heidnisch-mythologischen Themas: u.U. greift ein Engel hilfreich in den Kampl ein. An dieser stelle sei daraup hingewiesen, daB auch im byzant1niochen Digenis Akritas-Epos, das in flinf Versfassungen und einer Prosaversion erhalten $18 t^{263}$ und von dem auch zwe1 altruss. Passungen existieren, ein Drachenkanpl des Helden Uberliefert 18t. Die altrussischen Versionen des Epos (unter dem ritel "Dergenievo dejan1e"), die anschelnend nach elner uns nlcht uberlieferten griech. Passung des 12./13.Jh.angefert1gt wurden und gew18se Z48e des griech. Archetypus besser bewabrt haben ${ }^{264}$, bringen den Drachenkampl als wirkungovollen Abschlus der Jugendabenteuer des Digenis Nkr1tas. Nachdem der junge Held bel seiner ersten Jagd mit Vater und Onkeln eine Bärin, elnen Bären, einen Elch und elnen Iobwen getötet hat, funrt inn der Vater an eine Quelle, damit Digenis alch von Blut, Schweis und Staub reinige. In dem ersten rekonetruierten russischen Text bel Kuz'mina 265 folgt dann die Stelle, wo Dige- 
nis an der Quelle mit dem dreikoppigen, geflügelten Drachen kampet:

Vo 1stornice bo tom siet, a roda jako svesca svetitsja, 1 ne smejase bo $k$ vode to 1 ot chrabrych priltti nikto, poneze bjachu mozi cudesa: v vode toi $z$ m e 1 velik zivjase.

I priredsi im ko latorniku, 1 sedora okolo Dergenija, 1 nacara myti lice ego 1 ruce, on ze rece: 'Ruce moi umyraete, a erce im kalatisja.' I togo slova junora ne okoncav, able $z \mathrm{me} 1$ velik prilete ko istodniku, jako celovek javis' troeglavoi, 1 chotjaşe ljude1 pozret1. I uzre Dergeni1, 1 vborze med svol pochrati, 1 protivo zmija poide, 1 tri glavy emu otsece, 1 nacat ruki umyvati.

wichtig lat auch hier die Vorstellung, dab der Drache an der Quelle haust oder sogar Huter und Herr des Wassers lot, was wir filr den sudelavischen irachen schon mehrfach betonten. AuBerdem hat dieser "zmei" - genau wie die Lamja, Ala oder Zmija in den sudslavischen Drachenkamplifedem - drei kople, mit denen er seine Opfer an der Quelle verschlingt. Er ist gePlugelt (wie Zmej und Lamja) und hat menschenähliches Aussehen ("Jako Celovek javis""), wie wir es nicht von der Lamja, wohl aber vom slldslavischen Zmej oder Zmaj her kennen. Im griech. Epos steht ja auch "drakon" (altruss."zme1"), und nicht "lamia". Das Leuchten der Quelle laBt auf Peuriges Aussehen des Drachen schließen ( $\mathrm{g}$. den südslavischen "zmaj ognjeni" bzw. "ognen zmej"). - In dem zweiten rekonstrulerten russischen Text bel Kuz'mina lautet die entsprechende Stelle:

- Poidem ko istorniku, eot' $v$ sei pustyni istocnik vody, $\nabla$ nem aki svesta sijaet, ot prostych ljudei ne mozet $k$ nemu nikto prilti. Nyne, cado, sam tebe svoima rukami omyju lice 1 ruce 1 noze.' Videv ze to grazdane poidoşa zret1 predinnago togo cudese. Prildoza ze oni ko lotocniku, naca otec lice 1 ruce 1 noze omyvat1.

Reze im Devgeni1:'Ruce mol moes', a erce ze im kalnym byt1'. Po male ze vremjani prilete $z \mathrm{~m} i \mathrm{i}$ ko istorniku tomu, imejai u sebja jako Celovezeski glavy Zetyre. Videv ze preslavny Devgeni1 1 vaja med 1 poskoti protiv zmija, 1 udari ego mezem, 1 otnjal emu voe glavy prod'. 266

In diesem Text besitzt der Drache vier Kðple "wie Menschenkopfe", was vielleicht eine etwas jungere Abänderung sein durfte, denn die typische Kopfzahl beim Drachen ist drei. whrend der Drachenkamp des Digenis in den russiachen Pas- 
oungen m.E. als effektvolle Stelgerung das letzte Jugendabenteuer des Helden aue der Jagd bildete und damit an der "richt1gen", d.h. wohl urspringlichen Stelle otand, warde er in den griech. Passungen auf ein opateres Kapitel verlagert. In der Grotta Perrata-Version z.B. ist in Buch IV in Er-Form die erste Jagd des Helden Digents beschrieben, in deren Verlauf der Held zwei Baren, eine Gazelle und einen Irwen totet. Der Drakon als Stelgerung und Hobepunkt (von den naturlichen Jagdtieren aufwarts zum dumonischen Wesen an der Quelle) fehlt hier. Erst in Buch VI berichtet Digenis in IohPorm von dem Abenteuer mit dem Drachens

Er sel einst whbrend der Mittagezeit eingeschlafen,

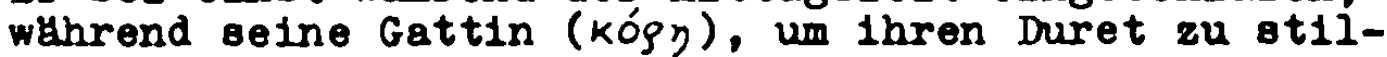
len, eine Quelle aufgesucht habe. Dort sel vor thr ein Drakon in Gestalt eines schonen Jungen Mannes aufgetaucht und habe versucht, ole zu Uberfalien. Durch ibre Schreie geweckt, sel Digents augenblicklich zur Quelle geeilt und habe den Gewalttuter. der sich während des Kamples in einen dreikoppigen Drachen zurlackrerwandelte, oein Schwert fluhlen lassen und thm sumtliche Krpfe abgeschlagen. Danach sel er, Digents, wieder in tiefon Schlal geounken. Da sel ein Lówe aus dem Waldesdiokicht gesprungen und uber die Gattin des Digents hergefalien. Er sel erneut erwacht und babe den Irwen getotet.

In der Version aus Trapezunt wird die Jagd in Buch IV, das Abenteuer mit dem Drakon aber erst in Buch VII geschildert 267 . Auffallend let hierbel 268 der Schlap des Digenis vor dem Drachenkampe, was naturlich an die Georgolleder und die Marchen vom Typ AaTh 300 erinnert, wo der mag18che Schlaf vor dem Drachenkampl und das Wecken durch die helBen Tranen des dem Ungeheuer ausgelleferten Mudchens, In deren SchoB der Held ruht, eine wichtige Rolle spielen. Es ware zumindest denkbar, daB dieses Motiv von der Befreiung eines Madchens aus der Gewalt elnes Drachen auf das'urapringliche Digenis-Drakon-Abenteuer eingewirkt und es dergestalt verandert hatte, das der Kampl mit dem Drachen olch nun folgerichtig von den Jugendabenteuerm des Digenis in die Zelt nech Digenis' Helrat verlagerte, well zur Verwirklichung des genannten Motive eine Prauengeetalt notig war. Jlinger lot vermutlich auch die Vorstellung, dab der Drakon der Jungen Prau in Gestalt eines ochönen Jinglings erschelnt und erst in Kampfrerlaue wieder seine dreikopelge Dram 
chengestalt annimmt.

Weder A.B.Lord ${ }^{269}$ noch M.Budimir 270 , die in Aufsatzen das Digenis Akritas-Epos und die skr. Volksepik bzw. Digenis und Marko Kraljevit miteinander verglichen haben, sind auf den Drachenkampf elngegangen. Dabei ware gerade eine vergleichende Untersuchung der Drachenkampp-Sujets in den griech. Akritenliedern, dem Digenis-Epos und der sudslavischen, vor allem maz.-wbulg. Volksepik auberst lohnend und interessant, konnte aber in der vorliegenden Arbeit, deren Themenetellung dies nicht erlaubte, nur angedeutet werden.

Wie aus dem bisher Gesagten hervorgeht, darf man wohl annehmen, das der griech. und maz.-wbulg. Volksdichtung eine nach Genres wahrocheinlich noch nicht differenzierte gemeinsame Unterschicht zugrunde liegt, bei deren Ausbildung die griech. Selte wahrscheinlich mehr die gebende war, we z.B. der LamjaGlaube bel den sludichen sudglaven eindeutig aus dem griech. Raum Ubernommen wurde und auch die Zmej-Vorstellung der Sudslaven aus dem griech. Drakon-Glauben entwickelt zu sein scheint. Von dieser Grundschicht mit anscheinend stark mythologischen Zugen ausgehend, erfolgte dann bei den Griechen und sudslaven eine Sonderentwicklung in zwei zwar getrennten, aber doch benachbarten Volkedichtungarkumen, die durch eine groBe Zahl gemeinsamer (wenn auch oft abgewandelter), aber auch unterschiedlicher Zlige gekennzeichnet sind. Gemeinsam ist z.B. die Vorliebe fur eine (Pseudo-)Historisieming mythologischer stoffe durch nachtragliches Einsetzen historischer Namen; und gleich ist in beiden Pallen die Tendenz zur Verchristlichung alter heidnischer Sujets. Gemeinsam sind weiter zahlreiche Motive und sogar Pormeln. Ein untorachiodlicher zug - um nur oln Bolopiel zu nonnon ist die maz. und bulg. Charakterisiemang der Lamja als Gewitterdrachen und Erntevernichterin, deren Hauptgegner der Zmej darstellt, wahrend die griech. Lamja im Lied mehr dazu neigt, mit den Peengestalten der Neraiden zu verschmelzen (im griech. Marchen lat dagegen eine Annaherung der Lamja an die Riesen zu beobachten!), und sie ihre Rolle als Menschenverschlingerin und Wasserhuterin dem Drakon abgetreten hat. 


\subsection{VILA BRODARICA-LIEDER}

Wie zu zeigen sein wird, etellen die lieder von der wasseroperrenden Fee, der Vila brodarica, allem Aneohein nach olne Ableltung aus dem Drachenkampf-Sujet dar. Es hondelt soh dabel un folgende othdelavische Variantens

1 EH 176 (4/6,34 V.;Geblet der ohemal.Militärgrenze)

2 Vuk VI $23(4 / 6 ; 41 \mathrm{~V} .3$ Srem)

3 II 30 (4/6; 36 V.8 Makarsko Primorje)

4 Maz..32 (4/6; $43 \mathrm{~V} .3$ Vrhovine)

5 PPNP IV,270 (4/6; 58 V.8 Serbien)

6 Stojk.,182 (4/6;56 V.i Gegend von Budapest)

7 M116.,254 (4/6; $56 \mathrm{~V} .8$ Gegend von P1rot)

8 Istarske, $16(6 / 6 ; 41 \mathrm{~V} .8$ Istrien)

9 PPNP IV,284 (4/6; 52 V.3 HVar)

10 Pilip.10 (4/6;?;?)

11 Kuhad IV 1498 (4/6; 55 V.: Srem)

12 LH $I_{2} 2(4 / 6,112 \mathrm{~V} \cdot 3$ Suddalmation)

13 MH I $I_{2}, 328$ (Aladeví II 340a; 4/6;?3 Brad)

14 KH $\mathrm{I}_{2}, 328$ (Ciganovic $94,4 / 6, ?$; Gegend von 2 rinj)

15 MH I $I_{2}, 328$ (Dolid $46,4 / 63$ ?; Gornja Kraj1na)

16 MH $I_{2}, 329$ (Marjanovid $5 ; 4 / 6 ; ? ;$ Zavaljo)

17 MH $I_{2}, 330$ (Merjanovic 6, 4/6,?, Zavaljo)

18 MH $I_{2}, 330$ (M.Markoví $21 ; 4 / 6,9 ;$ Otodac)

19 MH $I_{2}, 331$ (Trnski 6; 4/6;?3 Banska Krajina)

20 Chal.RPV 29,331 (4/6;? Montenegro?)

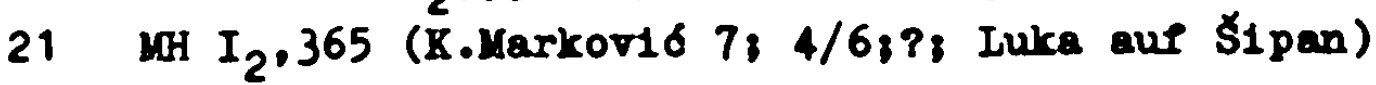

22 Bartok-Lord 12e (4/6, 24 V.8 Gacko)

23 Daridorib 196 (4/6; 15 V.; Boenien)

24 Petr.III 15 (4/6; 252 V.8Gegend von Sarajero)

25 Jastr.,50 (4/6, 14 V.8 Debarsko)

26 . Ikon.8 ( $4 / 6,14$ V.8 Debarako)

27 Zivaja star. XIV $1-2,181$ (4/6; 18 V.3 Debarsko)

$28 \quad 11.9(4 / 6 ; 31 \mathrm{~V} .8$ Prilep)

29 Mich.,195 (4/6, $30 \mathrm{~V} .3$ Masedonien)

30 Sapk.16 (4/6,74 V.3 Kostursko) 


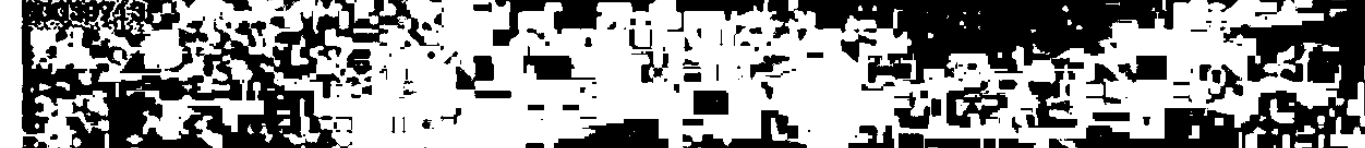

in

of

F

(4)

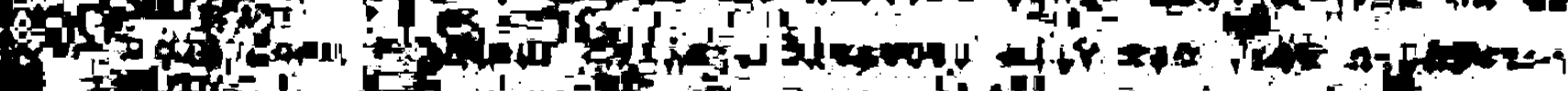

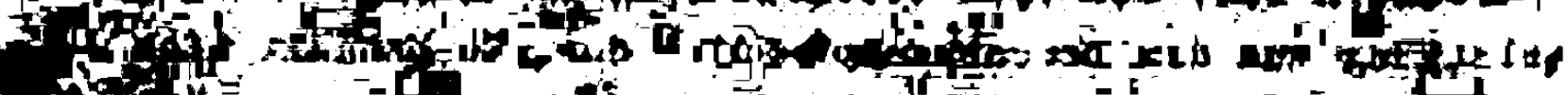

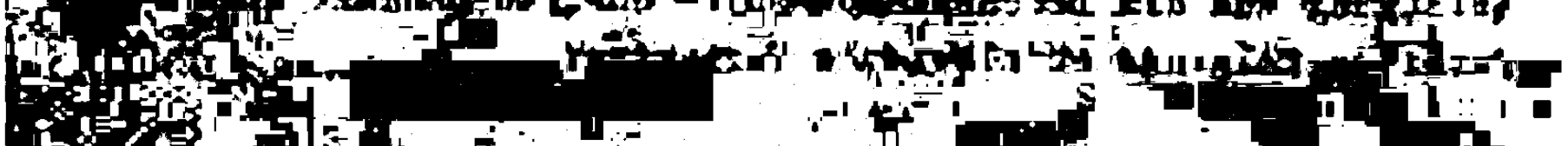

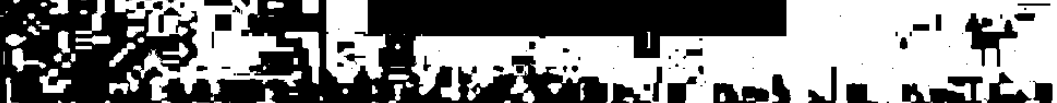

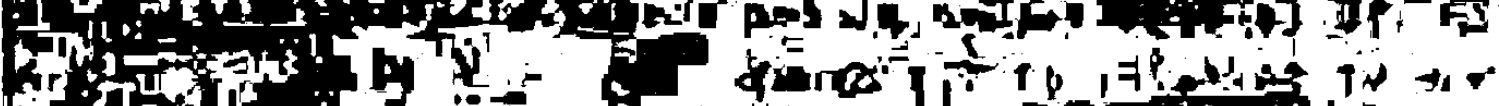

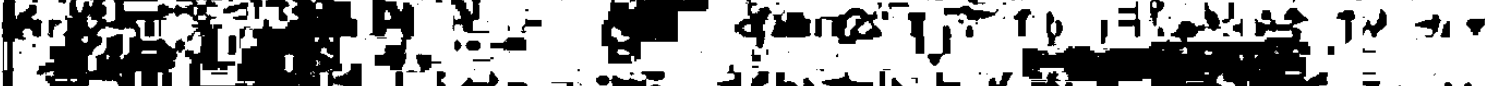

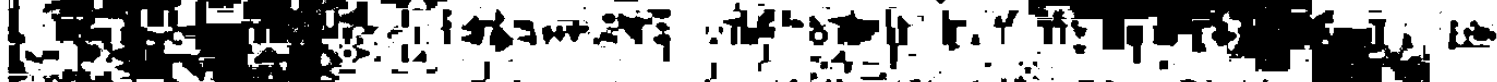

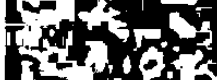

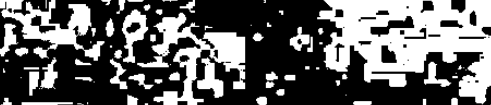

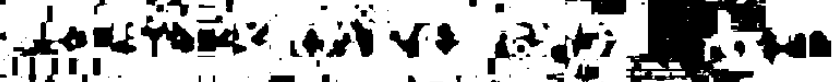

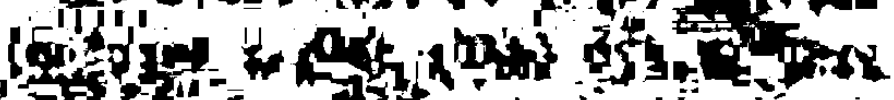

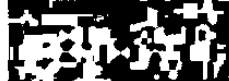

A

dy

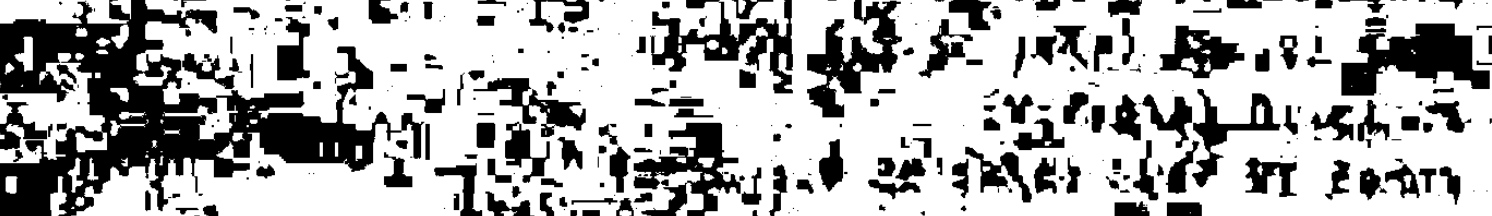

$145 ;=0$

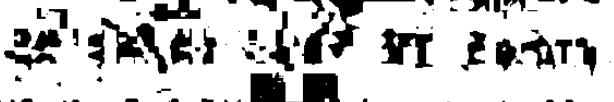

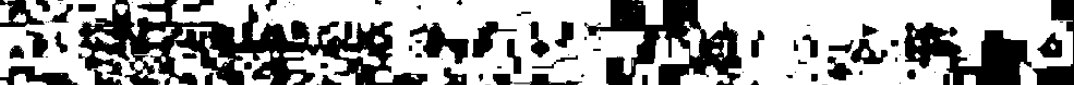

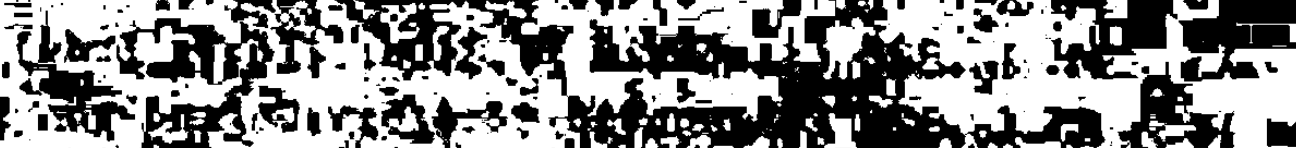

$\lim _{i \rightarrow 1}$

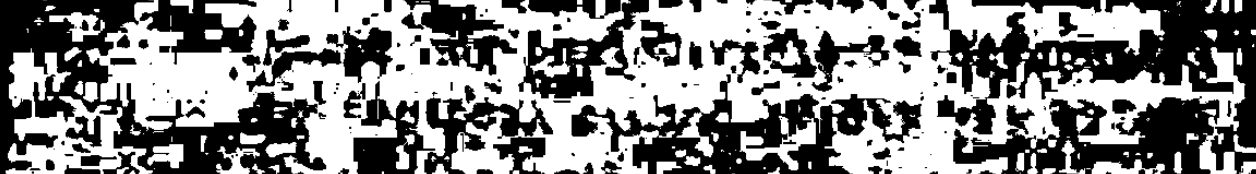

tits

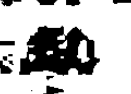

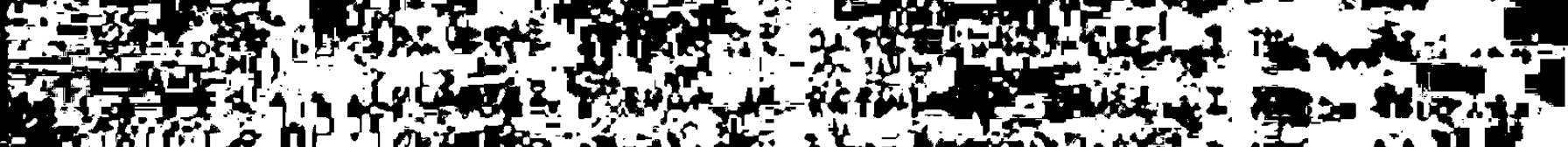

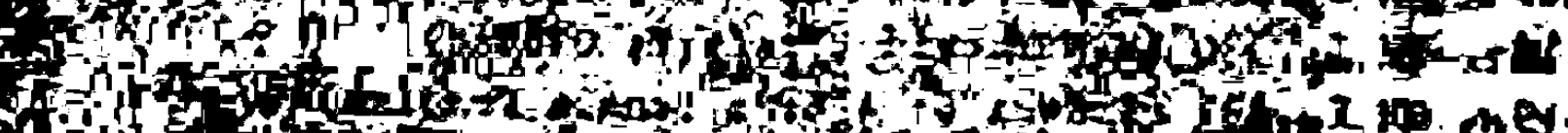

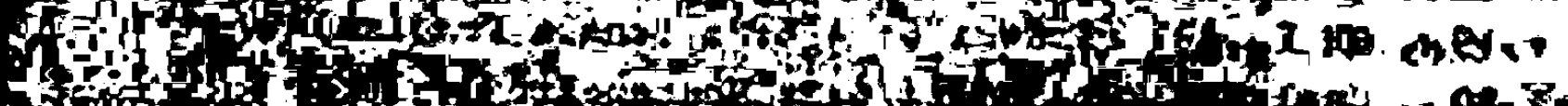

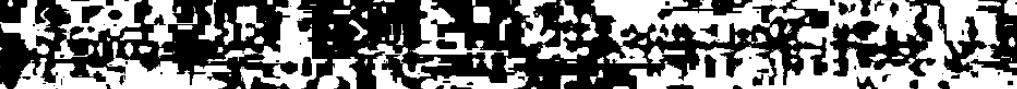

1 -

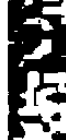

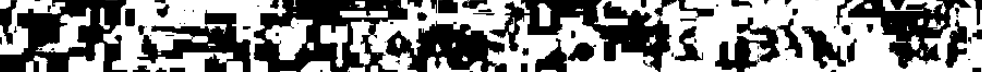

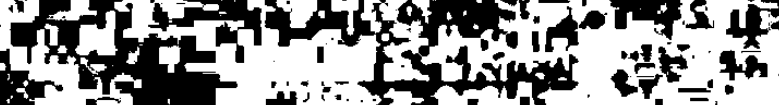

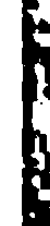

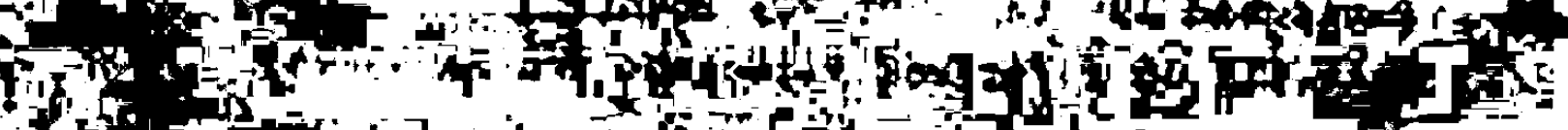

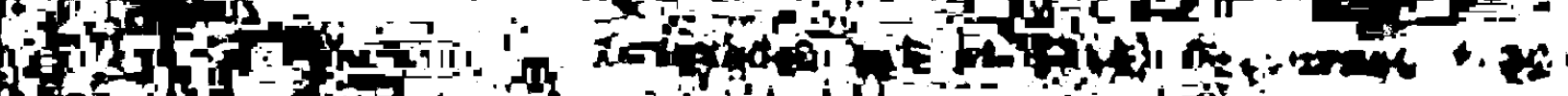

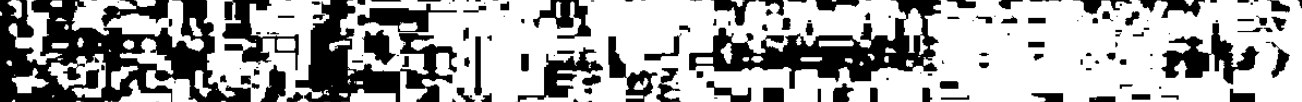

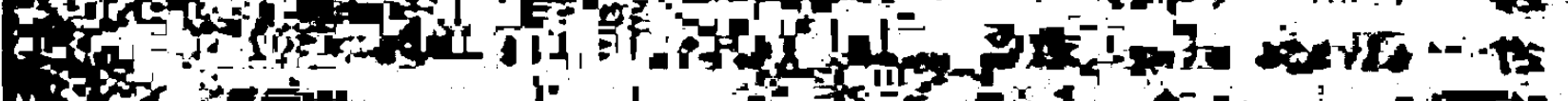

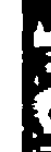

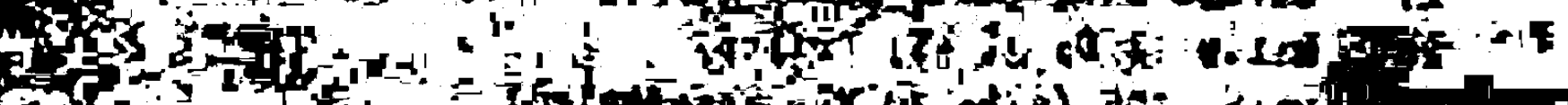

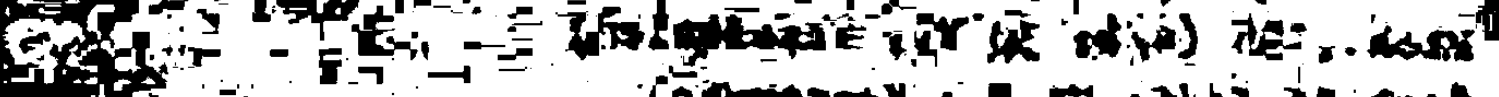

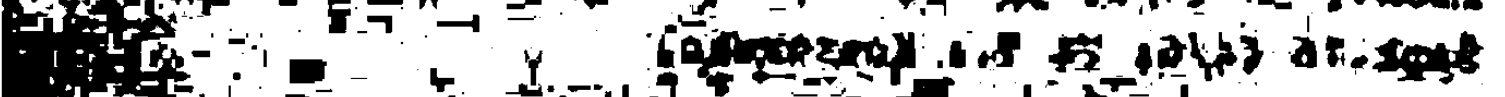

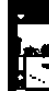

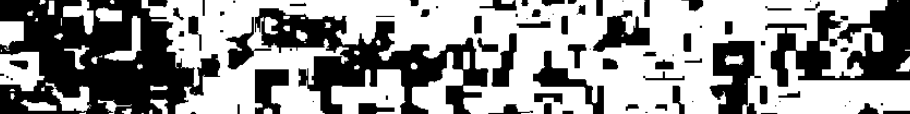

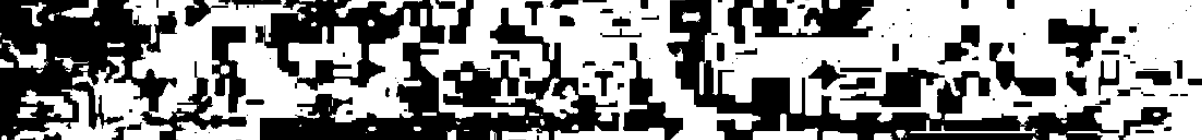




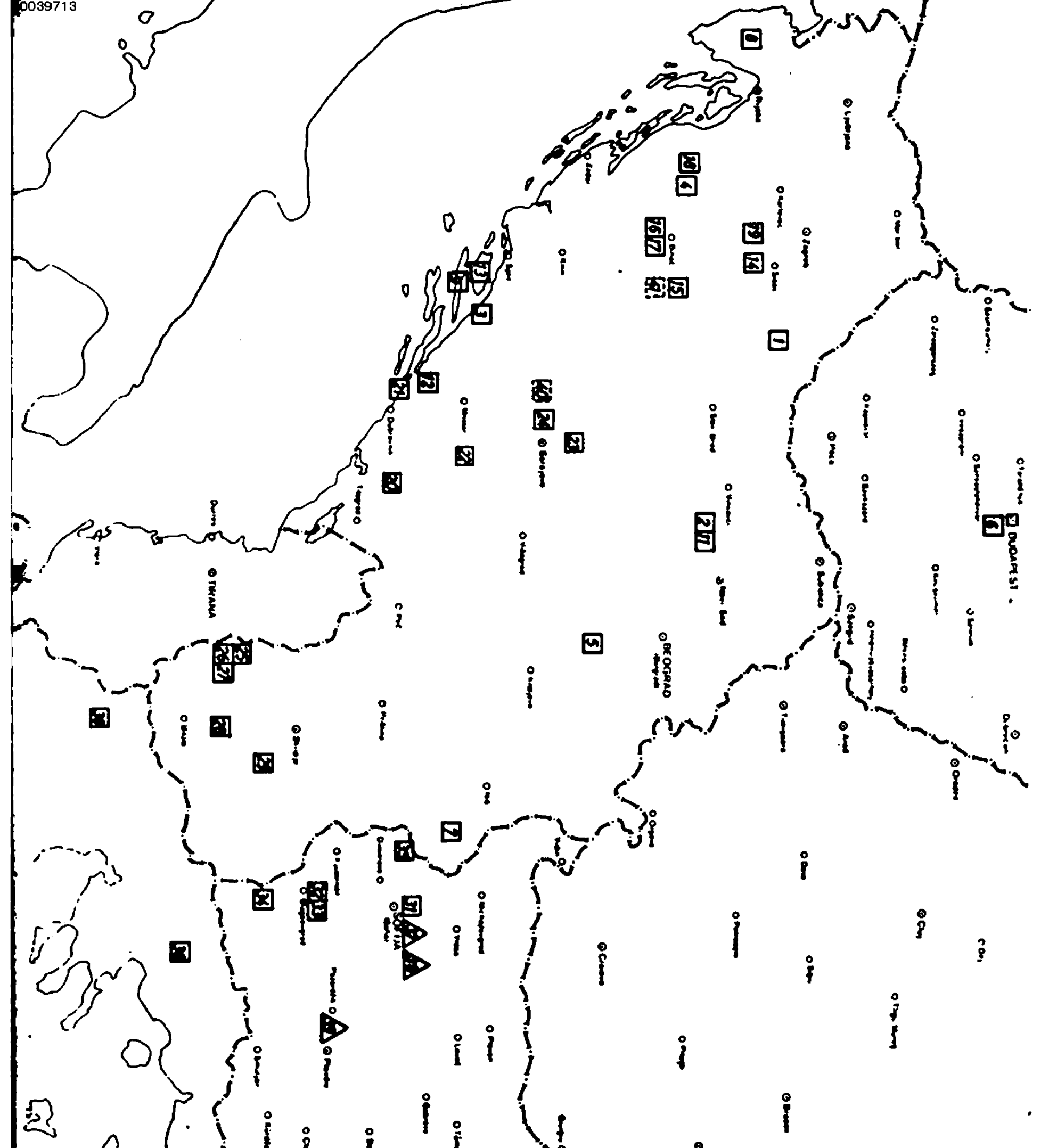




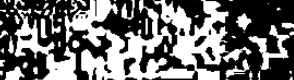

yit

$z^{2} t$

in

Th

Ant

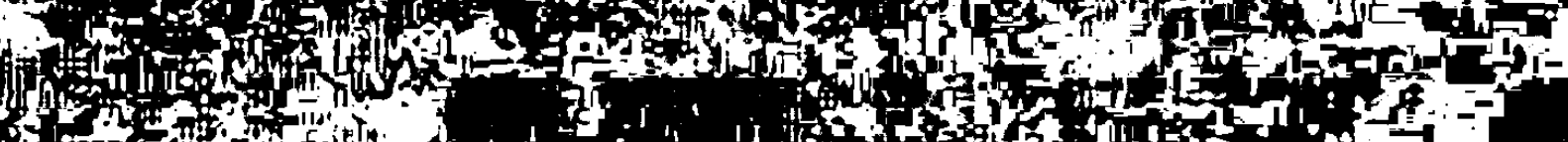

Sn

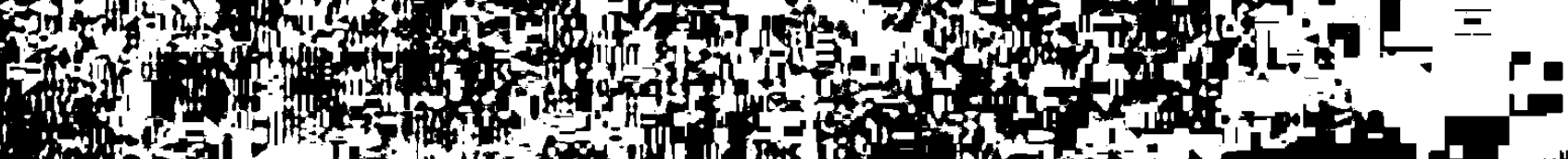

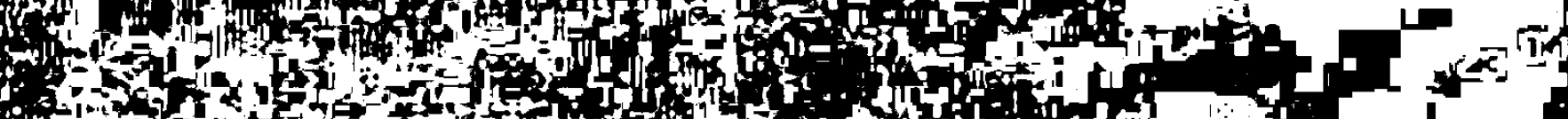
and

ond

F. . of

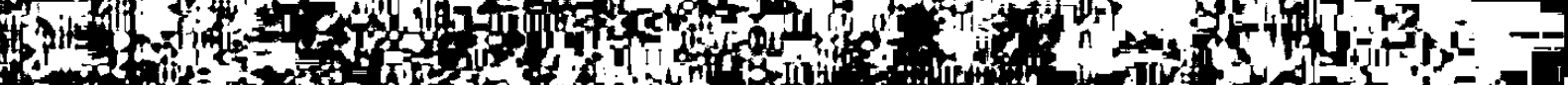

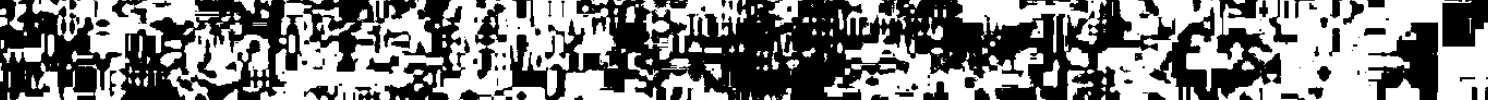

Len

W F r 4.

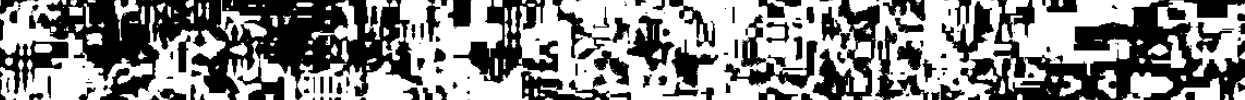

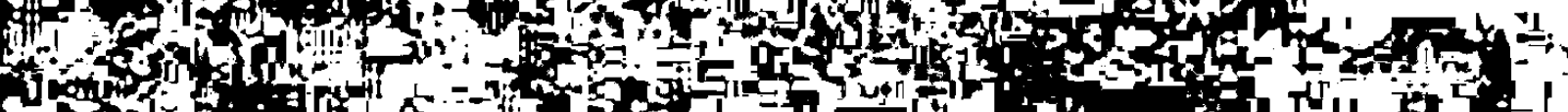
Q

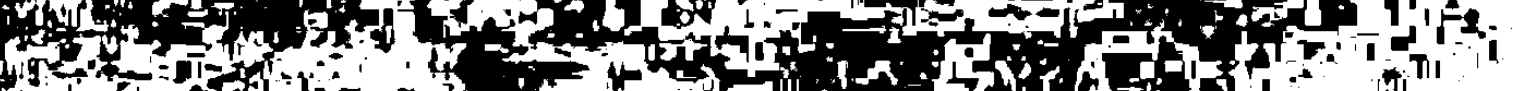

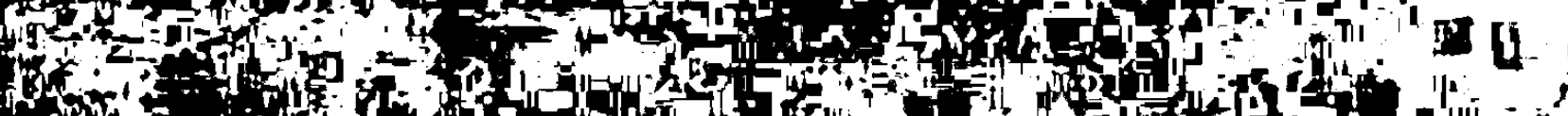

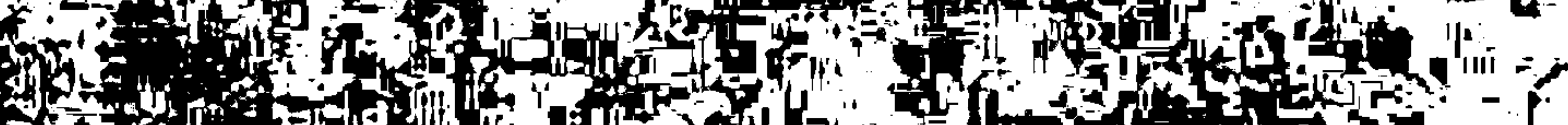

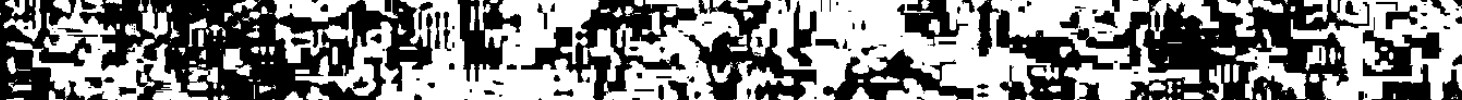

1-40

Af

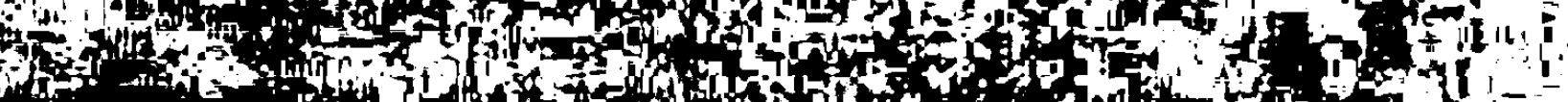

A

-7.

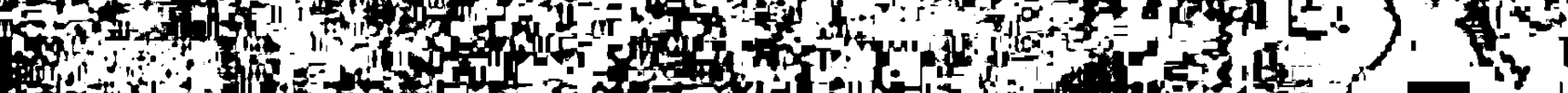

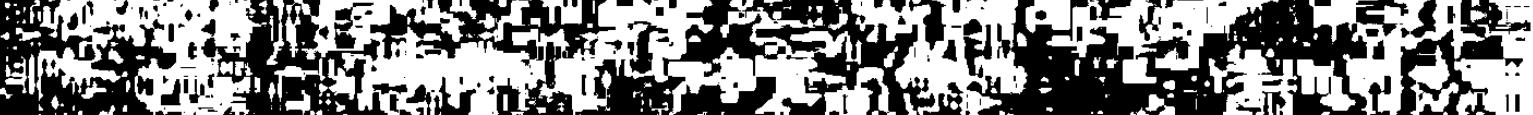

Ant

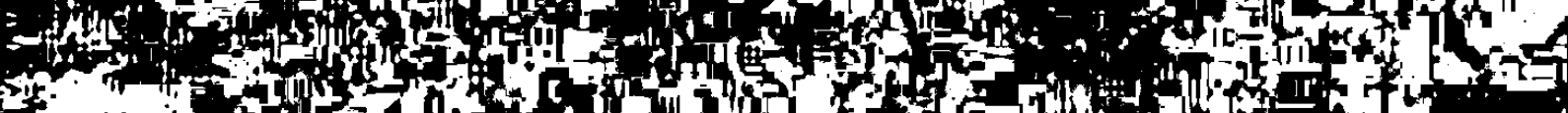

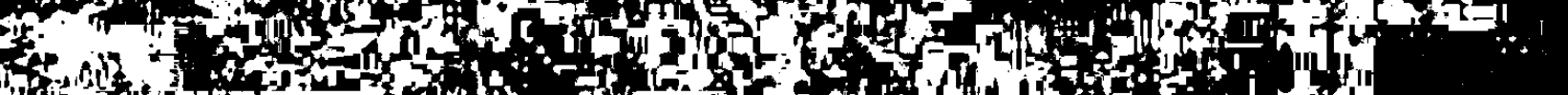

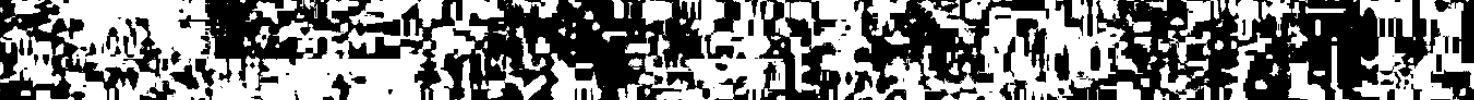

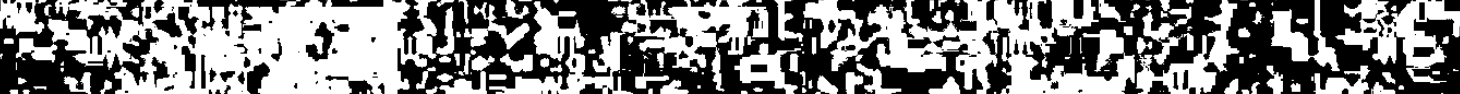

(150)

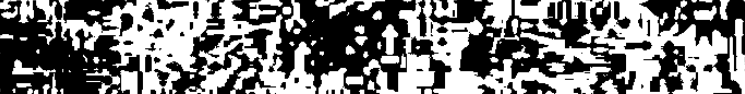

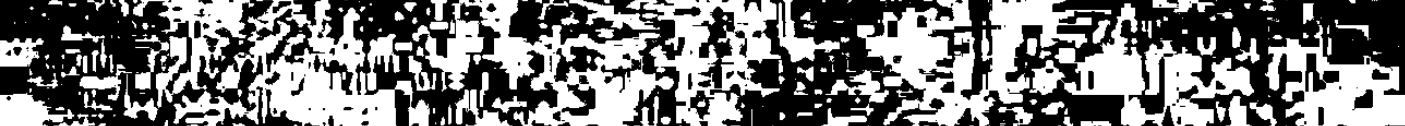

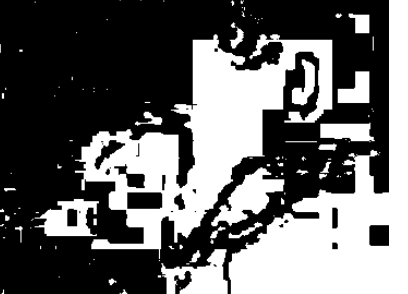

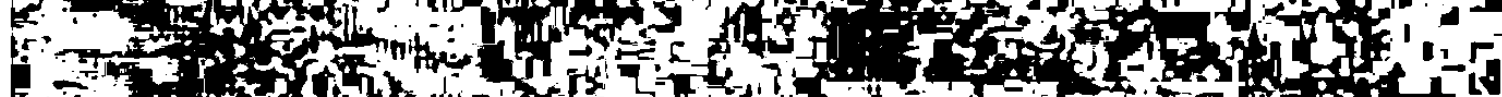

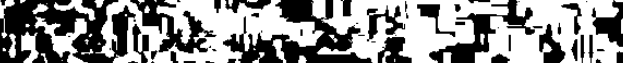

(1)

1)

(i)

15

I

(1)

and

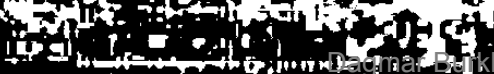

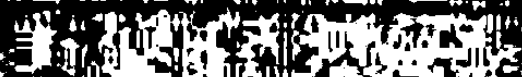

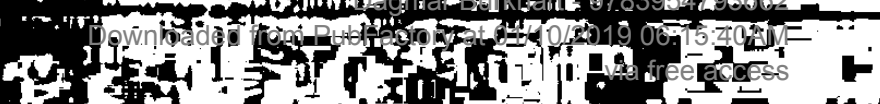




$$
\text { SbNU XIIII,95 (4/6; } 58 \text { V.3 Solijeko) }
$$

32 Stoll.II $3(4 / 6 ; 40 \mathrm{~V} . ;$ Blagoevgrad)

33 SbNU XIII, 18 (4/6; 42 V.; Blagoevgrad)

34 Maler.139 (4/6; 90 V.; Malerevo)

35 Kac.172 (4/6; 65 V.; Gegend von Turn)

36 Sto1l. Pokaz.I 413 ( $3 ; 127$ V.;Gegend von Serrai)

37 SbNU XIIV,61,Nr.45 (4/6; $40 \mathrm{~V}$.; Sol1j8ko)

38 SbNU XIIV,62,Nr.46 (4/6; $38 \mathrm{~V} . ;$ Sopijako)

39 SbNU XII.56 (5/5; $136 \mathrm{~V} . ;$ Plovdivako)

40 Fetr.III 27 (4/6;?; Bosnien)

41 WH $\mathrm{I}_{2} 40(4 / 6 ; 83 \mathrm{~V} \cdot ;$ Gornja Krajina)

Die Varianten 37-39 (echte Drachenkamplifeder) oind mit $\Delta$ in der Karte eingezeichnet.

Da auch hier nur der Variantenvergleich gewisse Rluckschluse ermöglicht, sollen zuerst die skr. und dann die maz.-wbulg. Lleder behandelt werden. - Var.1 fuhrt uns, was ihre Aufzelohnungszeit betrifft, immerhin in die ersten Jahrzehnte des 18. Jh. zurllck, wobel wahrscheinlich damit gerechnet werden darf, das das Lled in der vorliegenden Form schon im 17.Jh. in Umlauf war. Es hat folgenden Inhalt:

Kraljevid karko reitet durchs Gebirge, als ihn plotzlich heftiger Durst uberfalit. Er verflucht das Waldgebirge, weil es ihm kein Wasser gebe:

Bog te ubio, crna goro moja,

Kad u tebi ladne vode nema.

Gleichzeltig uberlegt er, ob er sein pferd schlachten und mit dessen Blut seinen Durst loschen solles

Da ja koljem konja lopod sebe,

Da pijem krveu od konjica.

Darauf antwortet das Waldgebirge, Marko solle es nicht verfluchen, denn es sei inm wohlgesinnt. Wenn er ein Stuck weitergehe, stoBe er auf kuhles Wasser, jedoch bewacht von der Vila Mandalina, die flir das Trinkwasser Kopfoteuer (harad) verlange: von dem Re1ter das Handpferd (konja povodnika) und von dem Wanderer eine weibe Hand (Arm?).- Marko macht sich nichts aus dieser Warnung, sondern begibt sich zu der Stelle, wo die Vila das kihle Wasser bewacht. Die Vila lot eingeschlafen, so das Marko ungestyrt selbst trinken und dann sein Pferd träken kann. Als er gerade auf- 
sitzt, um davonzureiten, erwacht die Fee und ruft den unbekannten Helden zurick, weil er ihr Tribut zu zahlen habe. Marko halt an und ruft der Vila zu, ele solle herkommen, dann werde er thr das Wasser zahlen:

Hod1, vilo, da t1 platim vodul

Als die Vile sich tzuschen lzBt und wirklich zu Marko hintritt, zieht dieser sein schwert und erschlagt sie, weil sie so schweren Wasserzoll (vodarina) eingehoben hat.

Wie wir sehen, handelt es sich hier um eine einfache und klare Motivkette, die aus folgenden Gliederm besteht: Durst des Helden und Verfluchung des wasserlosen Waldgebirges - Plan, das Pferd zu toten und dessen Blut zu trinken - Hinweis des Waldgebirges auf das von der Vila bewachte Waseer und Warnung vor ihrem Tribut - Brechen des Tabus durch den Helden, wahrend die Pee schlaft - Erwachen der V1la und ihr Verouch, den Wasserzoll einzutreiben - Bestrafung der grausamen Vila mit Tod. Hauptperson lot in diesem Sujet die $v 11 a^{271}$, ein dem Menschen hier bobsillig gesinntes naturdumonisches wesen, das die Wesserquelle sperrt bzw. nur gegen schweren Tribut ereigibt ${ }^{271 a .}$ Dese drel Hauptpunkte erinnem an den Drachen, der ebenfallo ein Pelndilches dimonisches Wesen darstellt, das Wasser operrt und diese Sperre nur gegen schweren Tribut aufhebt. De wir bereits in anderen Iledeujets eine Substitution des Drachen durch ein schon anthropomorpheres dumonisches Wesen, eben die Vila, feststellen konnten, liegt die Vermutung nahe, das es sich auch in diesem Pall um einen Ersetzungsvorgang handelt. Auch Chalanoklj 272 will die Rolle der Wasser-, Purt-, Grotten- bzw. Berglee so erklaren, wenn er segt:

Vila bardarica, brodarica, pezcerkinja, zagorkinja 111 gormaja samovila otdol'nymi certami ovoego eplCeskogo obraza eblizaetsja, 8 odnoj atorony, s babojjagoj, ved'moj-verticej, Maroj-Marenoj, Gol'doj-Bertoj elavjanskich 1 germanskich okazanij (po ovjazi s vodoj, otravlentju, pochisceniju 1 storozen ju vody, krovozadnost1), drugoj - so zmeem-drakonom-1z8usitelem.

Dieser Drache, der das Wesser versiegen labt, komet auch in der Indischen Mythologie vor und heibt hier Çushna - Kuyava - VritraAh1. Die Darre wird in indischen Erzählungen als Damon vorgestellt, der - ganz ahnlich wie die oludslavische Lamja - das Wasser in den Wolken zurlickalt. Der feindlich gesinnte Damon Vri- 
tra wird mit dem Epitheton "çushan" (austrockonend) belegt. 273 Ihn totet Indra und ermoglicht damit den Menschen wieder den Zugang zum lebensnotwendigen Wasser: Die verschlossenen Quellen offnen sich, die Plusse fullen sich mit Wrsser und Mensch und Tier drangen sich um das so lange entbehrte Lebenselement. Chalanekif spricht mit gewiseer Berechtigung sogar von einem alten indogermanischen Mythos, der hier seiner Melnung nach vorliegt:

Takim obrazom $v$ peanjach o bor'be geroja azdachoj 111 Marka 8 viloj-bardaricej, pezcerkinej, otkryrajutsja certy dremejzego indoevropejakogo mifa,ob-jasnjaviego atmosfericeskie javlenija smeny dozdja 1 zaouchi bor'boj boga-gromovnika ili narodnogo geroja demonom zasuchl, zmeem-8uchmennikom, - mifa, otrasiv8egosja $\nabla$ mogočlolennych skazanijach ariev Evropy 1 Azil 1 podvergbegoeja $v$ avoej istoriko-posticeskoj zizni raznoobraznym, inogda perekrestnym, viljaniem 1 vzaimodejotriem. 274

Matov 275 geht noch weiter, wenn er betont, aue eben diesen Mythos und auf die Iegende rom hl. Georg lieken sich auch die BoIen Dojein-Lieder, von denen im folgenden Kapitel zu oprechen sein wird, zurlickfuhren. Lord ${ }^{276}$ vergleicht die vila brodarica oogar mit Piamat, dem weiblichen Drachen des babylonischen Sohopfungemythos, bzw. mit Artemis, der griechischen Jagdgottin und Herrin des Waldes.

Nach dieser Abschweifung zuriack zu unserer Var.1. Dab Marko hier die Rolle des Helden splelt, der das damonische weibliche Wesen besiegt, 18t entweder aus den ulteren Drachenkamplifedern Ubernommen oder aber noch jungeren Datums. Die Fee wird Intereseanterwe1se mit Namen genannt ${ }^{277}$. Wie in den Liedern, wo Marko die drel Ketten Sklaven aus der Gewalt des ochwarzen Arabers beereit, opricht der Held auch in der obigen Var. mit dem Waldgeb1rge. So wie in dem einen Pall der Wald auf die Prage, warum er so verwelkt und verdorrt se1, antwortet, das dre1 Zuge Sklaven vorbelgetrieben worden seien, weist der Wald in dem anderen Pall - auf den Fluch Markos hin - dem Helden den Weg zu der Quel1e, wobel er gleichzeitig vor der drohenden Gelahr, d.h. vor dem von der Vila geforderten schweren Zoll warnt. - Var.2 unterscheidet sich durch einige Verinderungen von dem 150 Jahre ulteren Text der ersten Var. Statt des Waldgebirges gibt nun die Vila 
brodarlca selbst Antwort, als Marko das waseerlose Gebirge verflucht, und weist inn aus das Wasser hin, wobel ale aber glelohzeltig erklart, ele verlange schweren furtzoll (terka brodarina):

Od konj1ca uzmem povodnika,

Od perica oba oka Carna.

Marko Pindet die Wasserstelle und beginnt zu trinken, als auch achon die V1la angeflogen kommt und den Tribut verlangt. Da wendet Marko eine List an. Er fordert namlich die Vila auf, nach der Sonne zu eehen:

Ti pogledaj tome jarkom suncu, Kako Igra 1 gora 1 voda, Da ti istes brodarinu terku.

Nun folgt die Formel vom "brsen Ungluck", dessen Opfer die Pee wirds

Zla nesrecí vili priskodila.

whrend die Vila auf die Sonne blickt und damit abgelenkt 1st, nimmt Marko seinen Streitkolben und schiagt damit der vila derart zwischen die Schultern, das der Kolben zerspringt und die Vila tot zu Boden oinkt. Marko reitet nach Hause und singt dabei triumphierend:

Ko j'umoran, neka ee odmara,

Ko je mlado, neka ruzu bere,

Ko je zedno, neka vodu pije,

Od danaske brodarine nema,

Ja zagubih brodaricu vilu.

Verderbt wirkt hier die Stelle, daß die Vila selbst Antwort gibt statt des Waldgebirges, wie es aicher im urspringlichen lied hieB, dem EH 176 wohl, der einfachen, unkomplizierten und nicht kontaminierten Motivabfolge nach zu schlieBen, sehr nahe stehen durfte. Damit fult auch das Motiv der schlafenden vila weg, die erst durch das Trinken oder Hegreiten des Helden geweckt wird. Neu ist in diesem Lied der Trick des Helden, die Vila abzulenken, was uns aus anderen Heldeniledern bekannt ist, in denen der Gegner (Musa u.a.) auf diese oder unnliche Weise uberlistet wird. Jungeren Datums fot auch der Triumphgesang Markos am Liedende, der aus dem Sujet "Marko ukida svadbarinu"(Vuk II 67) ubernommen sein durfte, wozu ja die Ähnlichke1t der Situation in beiden Iledtypen - jedesmal befreit Marko die Bev8lkerung aus schwerer Not geradezu verfuhren muste. - Var.3 zeigt einen sehr ahnlichen Iledaufbau, nur dab hier nicht Marko, sondern ein Juranovic Mate der Hauptheld 18t: 
Statt des Waldes bzw. sekundur der V1la epricht "etwas" zu Mate und rit 1hm, slch umzusehen, dann werde or auf das rlible Wasser stoBen (das bier konkret al Dunaj-PluB berelohnet wird, womit wieder einmal der typische PluBname der sudslavischen Volksdiohtung eingesetet murde), an deseen Ufer die Vila vodarica schlafe. Nun folgt die Pormel rom Glucks

N' je Mat1 Bog 1 orica dala, Vodarica vila je raspala.

Bate trinkt, trankt sein peord und oingt dann triumphierend, or danke Gott, das or die Vila getluscht habe. D1e V1la erwacht jedoch und meint, Mate habe nicht ole, ondern sich selbst getluscht. Da wendet Mate die bekannte Iist mit der Ablenkmg (Blick auf die Sonne) an und schlagt der Vila den Kopl ab.

Der abschlieBende Triumphgesang fehlt hier. - Var.4 bringt ein neues sekundares Motivs

Als nimlich die Vila von Marko den Tribut (vom Helden belde Augen und vom Pferd allo vier Beine) fordert, bietet ihr Marko unermeBliche Schktzo (Jaepru nebrojenu) und noch nicht zugeschnittene selde (8viIu nekrojenu - Reiml) an, woraue die Vila neint, wenn ie Sohktze annzhme, konnte sie langet den See mit Silber auffulien, und wenn sie selde nihme, konnte 810 alle Bergo damit bedecken.

Damit 1st die Unbestechlichkeit des dimonischen Wesens unterotrichen, das keine Schktze ansammeln, sondern selne opfer verderben w111.

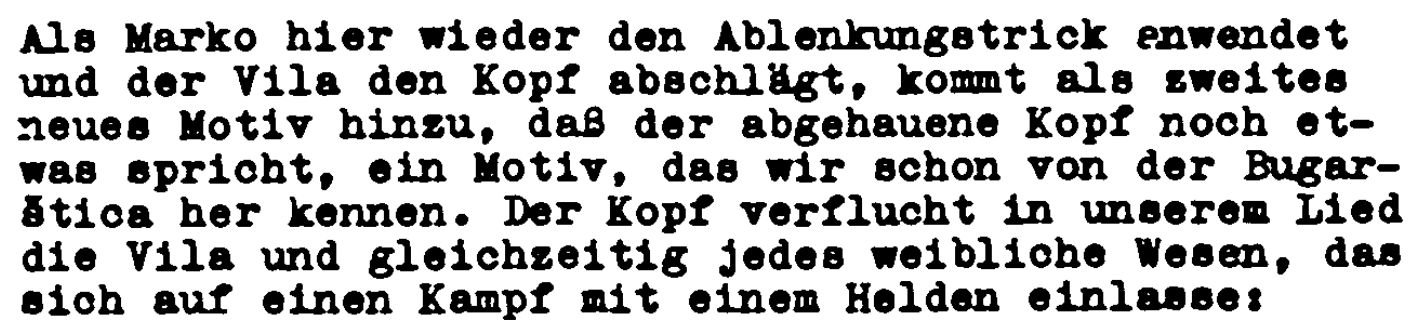
Aj prokleta evaka zeneka glava,

Ka se borl po gori Junakom.

Wharend in diesem lied niobt klar wird, wer anfango su den Helden epricht - es heibt einfach "Ter govorl Kraljevibu Marku" und in Var.2 die Wasserfee selbst dem Helden auf seinen Pluch antwortete, epricht in Var.5 eine dem Helden freundiloh gesinn. te ewelte Vila eu $1 \mathrm{hm}$, de thn vor der Vila brodarkinje warnt, weil diese ale Tribut vom Helden sme und Beine und vom Pferd alle vier Belne verlange. Wie wir noch sehen werden, wird die froundliohe Feo - wahrecheinlioh aus Differenzierungegrinden 
gegenlber der feindlichen Vila - in manchen Liedern durch einen Hirten ersetzt. Nun zum Inhalt von Var.5:

Marko Pindet den von der Preundlichen und warnenden Vila bezeichneten Brunnen mit kihlem Wasser, neben dem die Wasserfee unter eliler Tanne eingeschlafen 18t. Marko trinkt sich satt und zieht wieder weiter durch das Gebirge, als die Pee erwacht, dem Helden nacheilt und von inm den Tribut fordert, worauf der Held ihr Schatze anbietet, die die Fee ausschlagt mit den Worten:

Da ja ocu blaga uzimati, Carnu b' goru zlatom nakitila, I 8 biserom 1 a dragim kamenjem.

Als die Vila auf Markos listigen Hinweis auf die Sonne, die "Zeuge seiner Not se1", hereinfult:

Trze Marko zmiju od pojasa, Ya pogubi vilu brodarkinju.

Das Motiv, deb Marko eine Schlange am Gurtel tragt und mit ihr die Vila erschlagt, durfte wohl kaum wortlich zu nehmen sein. Mit Schlange ist eben das Messer gemeint, eine Umschreibung, die wir auch in den Marko-lhusa-Iledern zum Teil finden, wenn die Vila, Markos Wahlschwester, den Helden auf das im Gurtel versteckte Messer ("Schlange") aufmerksam macht. Das oblge Lied sohlleBt mit der Pestatellung, Marko habe die Wasserabgabe aufgehoben und es moge trinken, wer durstig sei, und eich erholen, wer mlude se1. - Var.6 fallt durch keine neuen Motive auf. Palach lat hier nur, daB die hilfreiohe vila Ravilojla am Liedende mit der brsen Wasservila dem Namen nach verwechselt wird. Als Marko die brawillige Pee abgelenkt hat und toten will, ruft er die freundliche vila (jetzt plotzlich Zagorkinja genanntl) an, die inm rat "Ia mani se guje od pojaea" und Marko so an sein verstecktee Messer erinnert. Nun schlagt Marko der Wasservila den Kopl ab, und der abgehauene Kopf meint, bishor eel os keinem Helden gelungen, die Pee zu uberlisten; wohl aber Narko habe dies vermocht. - Wenn in diesem Lied nur angedeutet murde, daß Marko sich auf der Jagd in Waldgebirge befand, was daraus hervorging, dab er fur alch, das Pferd und den "grauen Jagdfalken" Wasser oder Wein zum Trinken ouchte, so wird das in Var.7 klar formuliert:

Rano ran1 Kraljevicu Marko, Rano rani u evetu nedelju, Boga Marko nigde ne pominje, 
Rano rant u goru zelenu, Da ulovi atroga jelena,

Jal' jelena, jal' siva smdaka.

Marko befindet alch auf der Hirsch- und Rehbockjagd im Geblr8e, wobei ausdruckl1ch vermerkt wird, das dies am helligen

Sonntag geschleht; mit dieser Peststellung soll wahrscheinlich die erfolglose Jagd und vor allem die unhellvolle Begegnung mit der Wasserfee motiviert und als Strafe gedeutet werden.Das Motiv des Verstobes gegen die Sonntagshelligung kann als jungerer Zug betrachtet werden, den wir aus zahlreichen anderen Liedern kennen. Der Inhalt des Iiedes lautet weiter:

Marko verflucht das wasserlose waldgeblrge und erhalt von einer Vila den Hinwela, dab die V1la perterkinja, die Hohlenfee, in einem trockenen Baum, von dem nur der Wipfel grin sei, neun Brunnen mit neun Schlobsern verschlossen helte:

Ima dole jedno drvo suho,

Sve je suho, samo vrh mu zelen,

Tuka ima devet kladenaca,

I na njima deret katanaca.

Marko zerschlagt die neun Schloseer und labt dae Wasser frel, an dem er sich mit allen Lebewesen des Waldes glitilch tut. Da kommt die Wasservila herbel und fragt emport, wieso Marko sich erdreisten konnte, das gesperrte Wasser "aufzuschl1eBen". Marko bletet die ublichen Schitze an, die von der vila aber abgelehnt werden. Da nimmt der Held seine drelfache Peltsche (trostruku kandz1ju) und echlagt die vila 80, dab thr das Blut aus der Hand heraustritt. Sie lleht Marko um Gnade, bletet $1 \mathrm{hm}$ die Wahlbruderschaft an und vers1chert, nie mehr das Wasser sperren zu wollen.

Dieses Lied steht mit dem Motiv der neun in einem Baum eingeoperten Brunnen ganz in der maz.-wbulg. Tradition, der es ja geographisch praktisch angehort, da 88 aus der Umgebung von P1rot stamnt. Das Mot1v, daB die V1la bestimmte Abgaben fur das Wasser fordert, lot hier weggelassen. Neu und jlinger lot der Liedschlus, das Marko dié Pee nicht totet, sondern ele nur mit der Peitsche echligt, woraue die Vila thm die Wahlbruderschaft anbletet und Marko diese offensichtlich auch annimmt, wenn die Fee verspricht, das *aseer nie mehr zu sperren. Der urapringliche, aue den Drachenkampfliedern belbehaltene Iledechlus $18 t$ jedoch slcher der, das der Held das schkdliche, naturlich unerbittl1ch gedachte damonische Wesen (der Kulturheroe den Herro des Naturgutes Wasser) Uberwindet und totet und damit das lebenenot- 
wendige frieche Waseer wieder zuglinglich macht. Dadurch, das der Held Wahlbruderachaft mit der Pee schlleBt, wird deren drmoniecher und mythologischer Charakter abgeschwlichts Die vila wird gewisemaben in die menachliche Sphare einbezogen und wie ein mensohlicher Gegner des Helden behandelt. - Bel Var.8 lautet die nun bekannte Motivabfolge 80 :
Pluch Markoe im wasserlosen Gebirge - Hinweis der Pee auf die nahe Donau und die Vila vodarkinja am Ufor - Markoe Trinken, whrend die Waseervila ein- geschlafen 18t - Erwachen der V1la und Verfolgung des Helden - Anbieten von Schatzen und Ablehnung durch die Wasservila sowie die Forderung des Tributs (vom Helden beide Arme, vom Pford alle vier Beine) - Zweikampl zwischen Held und Vila - Ablenkung der V1- la durch Ilst - Totung der Waseorvila.

Nou lot an diesem lied nur, dab orwahnt wird, die vila habe olch beim Zweikampl mit weiBem Schaum, der Held aber mit weiBem und blutigem Schaum bedeckt. Diese formelhafte Wendung,der Auedruck fur die Uberlegenhelt des Ubernatiurlichen Gegners,der nur nit List get8tet werden kann, ist uns schon aus den prachenkampiliedern bekannt und wird auch spater (z.B. bel den Mu8a Kesedzija-Liedern) noch zu besprechen sein. - Var.9 unterscheidet sich vom vorhergehenden Iled durch das sekundure Mot1v, das die Waseervila nach dem Erwachen die ron ihr bewachte Donau trube findet, nun Marko nacheilt und sein Pferd festhklt, worauf der Held das Tier eraft, ob es mude oder durstig sel und deshalb nloht mehr weitergehe, und von dem plerd die Antwort bekommt, die vila halte es am 2urgel lest. De fordert Marko die Vila zum Loslassen und, als sie nioht gehorcht, zum Kampl auf. Der weitere Verlauf des Liedes 18t wie obens Trick der Ablenkung auf die Sonne, Trtung der V1la und Spreohen des abgehauenen Kopfes:

Ovako se ovakoj dogodilo,

Ka junaku rode zabranila.

Hier lot Ubrigens noch die altertumliche Form des Motive erhalten, das der Wald selbst aus Markoe Pluch antwortet. - In Var.10 (zitiert bel Chal.RPV 29,332 ohne Ortsangabe und Angaben aber Vers und Liedinge) 1at das Sujet so abgerandelts

Ein Hirte namen Jovan gibt auf Markoe Pluch hin die Antwort, ganz in der Nahe sel eine rahle quelle und dahinter ein griner See, aber or warne Marko davor, 
aus der quells zu trinken, denn dort habe man ein ungetauftes Kind bestattet. Marko schlagt die Warnung in den Wind, trinkt aus dem Seo und trankt auch sein prerd. Er reitet woiter. Da holt lihn die Vila brodarica in und verlangt als Bezablung flir das gotrunkene Wasser seinen Heldenkopf. Marko beginnt darauthin elnen Zweikampl mit der Vila und totet ole, nachdem or thre Aufmerksamke1t durch I1 at abgelenkt hat.

Hier lot durch eine jungere christliche Uberschichtumg des ursprungliche Liedsujet ziemlich verdorben worden. Der Hirte warnt Marko nicht davor, aus dem see zu trinken, weil dort elne vila wache, die schweren Tribut fur das Wasser verlange, sondern - in sekundarer Motivierming- weil dort eln ungetauftes und demit unreines Kind begraben, os deshalb am Seo nicht goheuer und das Wasser eventuell schadlich sel. Marko bricht das Tabu und trinkt. Von da an folgt das lied wieder den bekannten Sujetablaus VorPolgung durch die V1la - Forderung des Tribute - Zweikampl L18t - potung der Wasservila. Das Motiv des ungetauften KInds Im See scheint einer lokalen tberlieferung zu entetammen, weil es auch in Var.11 vorkommt:

Marko wird nach seinem Pluoh auf das wasserlose Gebirge von einer Vila su dem nahegelegenen Bumnen geruhrt, aber nicht gewarnt. Dio Warnung wird erst von elnem Schafhirten ausgesprochen, der zu Marko sagt, or hit to besser nicht getrunken, denn die V1len vergifteten das Wasser dadurch, das sio oin ungetauetes Kind darin badeten vielo hatten ihr Loben dadurch verloren, das ale von Vilenpleilen getroflen wurden, und auch Marko werde umkommen. Da ruft die Vila zagorkinja, der Schafer solle Gott danken, das ole gerade das schlafende Kind im Arm halte, sonst warde sio ihm seine SpaBe austrelben und thm die Schafe zerstuckeln (wortlichs "dreimal vertausendfachen"):

Ja b1 teb1 8alu odral1la, Trl put bi t1 11 jadila ovce.

Als Marko diese.Worte hört, ll1eht er auf seinem Schekken, wird aber von der Vila zurluckgerufen, weil or thr des Wasser noch zu zahlen habe; und zwar verlange sio weder Groschen noch Dukaten, sonderns

Vec ja iztem od junaka glava, Od konjica oba oka crna, I suvike noge sve cetiri.

Marko lenkt die Aufmerksamkeit der V11a auf den Himmel und schlagt ihr den Kopp ab, der sagt:

Ima dosad devet godin dana,

Od kako sam u goriol vila, 
Jost me junak nije prevario,

Ka to me je Kral jevicu Marko.

Diesem Iied let die Motivanreicherung nicht zum Vorteil gerelcht. Mehrere Motive sind sinnlos verdoppelt: Vila u $n$ d Hirte sprechen mit Marko, bevor er mit der Bergfee zusammenot8Bt; der Hirte warnt Marko sowohl vor dem vergifteten Wasser wie auch vor den ffeilen der Vila; die Vila sagt hier von 81ch aus, sie wolle keine Schatze, was oie erst antworten durfte, wenn der Held sie lhr vorher angeboten hatte. Die Vila tut dem vorlauten Schafer nichts zuleide, weil sie das ochlafende Kind nicht wecken will. Es ist also ziemlich unverstandlich, warum Marko, der sich schon auf der plucht befand, zurlickkehrt und das Risiko des Kamples mit der Vila eingeht, obwohl ihn doch vorher schon die Drohung der Vila an den Hirten in die Flucht jegte und er ungehindert hatte fliehen kơnnen. Die Beziehung der Vila zu dem ungetauften Kind scheint mit dem Aberglauben zusammenzuhangen, dab die vilen ungetaufte Kinder rauben und manchmal durch Wechselbrlge ersetzt haben.- Sehr interessant 18t Var.12 mit folgendem Inhalts

Marko reitet durch das wasserlose Waldgebirge und verflucht es. Er uberlegt, ob er das Pferd und den Palken schlachten solle, um deren Blut zu trinken. Da opricht "etwas" aus dem Wald zu ihm und rit ihm davon ab, denn ganz in der Nahe oel eln griner See, aus dem Marko trinken könne, wenn er nur das Wasser nicht trube, denn dann erwache die schlafende Vila brodarica und verlange schweren Zoll: vom Helden beide Augen und rom Pferd alle vier Beine. Marko trinkt trotz dieser Warnung am See und zieht singend weg. Da erwacht die Wasserfee und zischt wie eine grimme Schlange.Sie glutet sioh mit zwel Schlangen, und das wilde Getier des Waldes sammelt sich um sie. Sie bestelgt als Reittier einen Hirsch, nimmt als Zaumzeug eine Schlange, als zlugel zwel weitere Schlangen und elne vierte als Poitoche. Nlo olo Marko faot oingoholt hat, ruft elo ihm zu, er solle sich umsehen. Sie stelgt ab und schlest sechs pfeile auf Marko ab, die dessen Blurenfell aber auffingt und die der Held zerbricht. Als auch Marko abgestiegen ist, kommt die michtige Herrin des Waldes und Wassers ("Brodarica silna, od gorice banica gospoja") herbel und beginnt mit Marko zu ringen. Sie ringen bis Mittas miteinander, ohne das einer die oberhand gewinnen kann. Da lat $8 \mathrm{chl} 1 \mathrm{eBl}$ lch die Vila mit weiBem, Marko aber ait weiBem und blutigem Schaum bedeckt. Als Marko endlich in die Knie zu oinken beginnt, fingt die Vila an aus voller Kehle zu lachen, und es blitzt durch die klare luft, als ob der 
Himmel elch gerfenet hatte. In diesem gefahrlichen Augenblick ruft Marko selne Wahlechweeter an, die Vila, die $1 \mathrm{hm}$ versprochen hat, sie verde $1 \mathrm{hm}$ in jeder felahr helfen. Die hilfreiohe Vila erscheint und macht Marko Vorwlarfe, daB or nicht auf thre Warnung gehort habe, er solle nicht von dem Wasser trinkens Es war namlich thre Stimme, die su Marko aus den Wald oprach. Sie erinnert ihn gleichseitig an sein verstecktes Messer (od potaje nozi). Die Waseervila bliokt aue, mit wem Marko spreche, woraue Marko das Messer zleht, die Vila todilch verletzt und ihre Bingeweide den Berg hinunterstreut. Nun verflucht ihn die sterbende Vila, daB or die Herrin des Waldes und Seer, wo Enten und Schwine nisten, Wolf und Schafe gut Freund oind und Hirsche geritten werden konnen, getotet habe. Marko hort nicht auf den Fluoh, oondern erschlagt die Schlangen und labt den H1rsch frel.Dann bestelgt or sein Pferd und reitet weg, wobel or eeine Helcentat besingt:

Blago tome, ko jos ima koga,

Da ga brani 1 za njega mari.

Hajd, putnice, sad slobodno gorom,

Brodarine, dok je Marka, nemal

A.B. Lord, der sich mit diesem lied eingehender besohaftigt 278 hat, fuhrt zuerst den babjlonischen Schopfungsmythas an, wo Marduk die jungeren Gotter auf seiner Selte und magische Weffen sowie die Hilfe der Winde zur Verfugung hat, un den weiblichen Drachen Tlamat zu toten, d.h. In zwei relle su telien, aus denen er Himmel und Frde formt. Diese narrativen Elemente zieht Lord in Betracht, wenn or Uhnliche Zuge in der balkanischen Volksepik zeigen w111:

We might first seek a female supernatural creature which has a retinue of "monsters". Then we might seek a hero who overcomes this female ith a special weapon and with outside assistance. We shall notise if that hero 18 himself "special". With supernatural affliations of some sort. Finelly, we shall seok sone trace of the eplitting or dismemberment of the slain fonalo supernatural being.

All diese Elemente findet Iord in unserem Iled (= Var.12)s ein ubernaturliches welbliches Wesen, des Zuge elnes Ungeheuers hat, eben die Vila broderica; sie lat die Herrin der wilden Tieres 1hre As8oziation mit Schlangen 18t deutlich ausgepragt; sio zeigt glelohzelt18 Ihnlichkelt mit Tiamat und Artemis; der besondere Held lot Marko, geskugt von der Vila und mit auserordentlicher Kraft begabt; d1e besondere Waffe lat das versteckte Messeridie Hilfe von außen kommt von der Wahlechwester V1la, die dieselbe 
Rolle spielt wie die babylonischen oder griechischen Gbtter, die an der Seite ihrer Schutzlinge kamplen, d.h. Markos Vila hat eine annliche Funktion wie Odyseeus' Athene. Das letrte vergleichbare Element ist das Aufschlitzen der Vila und das Verstreuen ihrer Eingeweide, wenn auch hier kein Schbpfingsakt daraus folgt. Die Vila hat gigantische Zuge; sie lacht ein "kosmisches" Lachen, das klingt, als ob der Himmel sich 8pene. Lords Vergleich, den er selbst als "suggestive" bezeichnet,ist zwar verlockend, meiner Meinung nach aber nicht ganz zutreffend. Lord hatte wohl besser Drachenkamplifeder, aus denen die Vilabrodarica-Ileder nur abgeleitet und innerhalb der Ableitung wieder eine der letzten Stufen darstellen, mit dem Tiamat-MardukMythos verglichen. In diesem Fall konnten wir von typologischer Ähnlichkeit sprechen, denn dann hatten wir ein ubernaturliches weibliches Wesen mit kosmischen Zugen: die mehrköpfige Lamja b2w. Ala; einen auberordentlichen Heldens ein Heldenkind, einen Nachgeborenen, Bastard oder Zwilling; einen Helfer des Helden: das Pferd, den Palken, spater die Vila; auBergewrhnliche Wafen: das vom Vater geerbte Schwert, die goldene Keule, das versteckte Messer, den Wirbelwind, den die tanzende Vila erzeugt; das "dismemberment" des weiblichen Drachen l6st einen Schöpfungsakt im kleinen ausz es flieBen Ströme von Milch, Wein und Honig. Die Gestalt der Vila brodarica in unserem lied durfte wohl in dieser reich ausgeschmllckten Form eine splte Erscheinung oein, whrend die "einfache" bbsartige Vilengestalt in Var.1 eher dem urspringlichen Bild der menschenfeindlichen Pee nahezukommen scheint. Die Pee als Wahlochwester lot ebenfalls eine jungere Version des dem Helden hilfreichen Wesens, dessen Stelle wohl ursprunglich von dem sprechenden Heldenros eingenommen wurde ( $\nabla$ gl. die Lieder von Marko und dem Turken mit den drei Ketten Skleven, in denen das Pferd auf das versteckte Messer aufmerksam macht,oder die hilfreiche Rolle des Pferdes in den 4.13- und 4.22-Iiedern). - Die ersten beiden als Var. zu MH $\mathrm{I}_{2} 2$ angefuhrten Lieder bringen nichts Neues. Var.13 zeigt die bekannte Motivkette:

Marko verflucht das wasserlose Gebirge - Die Vila planinkinja (Gebirgsfee) hört inn und zeigt ihm einen Brunnen, der von der schlafenden vila vodarica be- 
wacht wird - Marko trinkt von dem Wasser und reitst weg - Die Waseervila erwacht, ellt Marko nach, halt sein Pferd am Zligel fest und fordert als Tribut von Marko die Augen und den sabel, vom Plerd die vier Beine - Marko lenkt die Aufmerksamkelt der Pee auf die Sonne und totet die V1la - Der abgehauene Kopl opricht.

In Var.14 spricht "etwas" aus dem Wald zu Marko. Der Held bietet der Waseervila Schatze an, die von dieser aber spottisch abgelehnt werden. Des List-Motiv fehlt hier. - Ein neues Element kommt mit den folgenden Liedern ins Spiel. Be handelt oioh um das Motiv, das Marko die V1la im Zweikampl (durch Ablenkung ihrer Aufmerksamke1t) Uberlistet, sie aufschlitzt und in ihrem Korper drel Herzen eindets Das erste we1B noch wentg vom Kampl ("malo za boj znade"), das zwelte 18t ermudet ("drugo a "srce samo umor110") und das dritte weib gar nichts ("nista 1 ne wnade"), dooh auf thm liegt eine geflugelte Schlange ("zmija krilafica"), die Marko versichert, wenn sie, die Blende, eher aufgewacht ware ("da 80 budem jadna poprenula"), hatte sle ihm lebend die Augen ausgerissen ("zivu bih t1 oxt 1skopala")279, oder die Stelle lautet in anderer Versions

Tri je aroa u njojzi nasao. Jedno mi se samo umorilo, $A$ drugo se samo razigrava, A na trecem Gara zmija apava.

Die bunte Schlange, die aue dem dritten Herzen liegt, oagt auch hier, whre sie eher erwacht, hatte sie Marko die Augen herausgeriseen, so das or blind durch die Welt gehen mabte. 280

Dieses Motiv von den drel Herzen im Korper der Vila findet eich in Var.15-18, wobel Var.18 als Besonderheit mit dem Mot1 "He1mkehr des Gatten zur Hochzelt seiner Prau" kontaminiert ist (die Vila benutzt in diesem Iled Ubrigens eine grine ungletige Sohlange, "guža zelenoga", als Reittier und eine kleine bunte Sohlange, "Garenu zmiffcu", als Reltpeitsche), und auch in Var.19-20. Das Motiv der drei Herzen im Korper des Ubernaturlichen Gegners soll nicht hier, sondern bel den Liedern von Marko und Musa Kesedzifa in Kap.5.1 besprochen werden. - Wie Var.18 mit dem "OdyseeusMotiv" kontaniniert war, so sind die beiden nachsten V1la brodarica-Lieder mit dem "Schwanenfungfrau-Mot1 hat folgenden Inhalt: 
Marko wird auf der Jagd von Durst Uberfallen und verllucht das grine Waldgebirge, das es in thm kein Wasser gebe. "Etwas" apricht aus dem Wald zu Marko und oagt, er solle nur ein paar Schritte weitergehen, dann otose er auf drel Brunnen, von denen elner von einer Vila bewacht werde, die von jedem Helden ala Zoll belde Augen und von eelnem Pferd alle vier beine verlange. Marko nimmt der Wasservila die Plugel und das Gefleder ("krila 1 uzglavlje") weg. Alo er der Pee trotz ihres Plehens das Plugelkleid nicht mehr zurlakgibt, geht sie mit Marko nach Prilep und bittet 1hn, er moge nlemandem verraten, das ale eine Bergfee se1.- Nach einem Jahr Iinden an Markos Hol glelchzeltig drel Peote statts Das erste 18t Markos Taufnamensest, das zweite findet anlablich der Geburt eines Sohnes Markos und der Vila statt und das dritte $18 t$ das Hochzeltsfest von Markos Schwester mit elnem Adligen aus Budim. Marko labt drel Pestafeln bereitens eine Tafel aus purem Gold flur die Gaste aus Budim, elne zwelte Tafel aus Marmor flur die Pamilie Markos und eine dritte, eine Elchenholztafel, fur die "vlahe ol romahe". Marko erzahlt beim Wein, das er eine Vila zur Prau habe. Die Vila hort dies mit Bedauern, das Marko ntumlich sein Schweigegelobnis gebrochen hat. S1e bittet, whirend sie Markos Schwester brlutlich schmlackt und inr Ratschlage fir die Reise glbt, das MAdchen, es moge von Marko die plugel und das Gefieder der Vila verlangen, damit die Gaste einmal sahen, wie eine Vila tanze. Marko labt sich tuuschen und gibt der Vila das Plibelkleid. Sie tanzt damit zweimal im Reigen, fliegt aber beim drittenmal hoch in die Wolken empor. Marko versucht sie zurlickzurue en, die V1la aber versichert, ole werde zwar ihr sobnchen besuchen, flur Marko aber unsichtbar blelben.- Zwel Wochen nach diesem Vorfall geht Marko mit Jagdhund und Palken aue die Jagd. Er verepricht dem Palken, er werde thm Beine und Flugel vergolden, wenn der Vogel the das Plugelkleld der Vila herbeihole. Dem Palken gelingt das, und die Vila zieht num wohl oder lubel wieder mit Karko, der das Plugelkleid der Fee dieses Mal verbrennt.

In Gegensatz zu den anderen Iledern mit dem Schwanenjungfrau-Motiv endet das Iled hier mit happy end, whinend es sonst mit dem Tanz und Abelug der Vila ochlieBt 281 . Var.22 iat ein kurzes, oohmuok$108 e 8$ Iled mit thnlicher Motivabfolges

Fluch Alibegs auf das wasserlose Waldgebirge - "Etwas" aus der Wolko weist ihm den Weg zu elnem grinen See, bewacht von elner Vila, die or fangen oolle - Nlibeg fangt die Vila - Er bringt ole zum Sultan, der aie zur Frau nimmt - Die Vila schenkt ihrem Gatten zwe1 Trchter und vier Sbhne - Bel oinem Pest tanzt sie morgens und pliegt am Nachmittag davon.

Das wichtige Motiv des weggenommenen Plugelkleids fehlt in diesem verotummelten Lled. Das der Held die gefangene Pee nicht selbat 
heiratet, 18t natlurlich ein sekundurer Zug. - Noch mehr verderbt wirkt Var.23, deren ganzer Inhalt elgentlich darin besteht, das eln "unbekannter Held" (neznanl dellja) das waseer1080 Romanifa-Gebirge (also Lokallelerung bei Sarajevo) verflucht und elne V1la aus den Wolken 1hm zuruet, er solle nicht das Gebirge verfluchen, sondern zu der grlinen Tanne weitergehen; unter der Tanne gebe es kluhles Wasser, daneben ungemintes Gras (nekoßena) und darin eln ungefreites (neproßena,- Reiml) Mrdchens or moge das pferd an einen Baum binden und grasen lassen, ruhles Waseer trinken und dann das ungefrelte Madchen riseen. Nur der Volletandigkelt halber sel alo 24. und letete skr. Var. das Iled Petr.III 15 erwahnt, obwohl - wie schon mehrfach betont - die Sammlung Petr.III, vor allem die Lieder "Ispod Javorine", Pragulirdis sind. Der Iledinhalt von Var.24 lautet 808

Marko steht frah auf in seiner stadt Prilep und glbt seinem Diener den Auftrag, den Schecken zu sattein, denn or beabsichtige, nach Prizren zun Zaren Stepan und zu seinem Wahlbruder Miloy Obilib zu reiten. Alo das peord bereltsteht, bricht Marko aue, uberquert vier Gobirgezuge und ubernachtet im Prolog-Gobirgo. Am nachsten Morgen oetzt Marko seinen Ritt fort. Mitten Im Gebirge wird Marko - und noch mehr seln Pford von heftigem Durat gequalt. Da Marko keine Quelle Indet, beschliebt or schon, sein Pford zu schlaohten, ala the eln Palke von elner Tanne herab den Weg zu elnen See welets Wahlbruder Marko oollo, wenn or ein Held se1, eln Stuck veitergehen, dann stose or auf elnen Tannenbaum mit trockenem Wiplel; darunter ae1 -in Soe mit kllhlem Waseer und an seinem Ufor eine Wascerfee (negorkinja vila bardarioa), die den seo bewache und echweren Tribut (1jutu bardarinu) verlango: rom Holden belde Augen, rom Pferd die Vorderbelne und vom Vogel die Plugel, um das Nasser herum selen vier Torbogen aus stoin gebaut, drel davon geschloseon und - iner gobemet, dooh konne nlemand Waseer trinken wogen der schweren Abgabe, die die Vila verlange: alle Tiere des Waldes iltten Durst und wagten nioht zu trinken; Marko solle num, wenn or wirkl1ch der berluhmte Held sol, Nir den ihn die Loute hielten, als orater aus den Soe trinken.- Marko roltet woiter und findet alles co, wie der Vogel es beschrieben hat. Er reltet in den Seo hinein und last Sarac olch. eatt trinken. Als Marko soinon Becher horaunzioht und gorade trinken w111, orwaoht d1e Pee, erkennt Marko und verlangt Tr1but. Marko trinkt oln paar Becher Waseor und eagt, or werde in nachhinein bezahlon. Wahrend Marko nooh beim Trinken 18t, vorlangt die Vila zun zweltenial Bezahlung. Obwohl Marko noch duratig iat, hofft or durch Plucht entkommen su können und reitet davon. DIe V1la 
jedoch breitet thre Pligel aus und holt Marko iliegend ein. Sie entwindet Marko das gezlickte Schwert, zleht ihn vom Pferd und beginnt mit lihm zu ringen. D1e beiden kamplen volle vier Stunden. Nlo die funete Stunde anbricht, lot die Vila mit weiBem, Marko aber mit blutikem Schaum bedeckt. Marko, von Durst geschwlicht, erkennt. das er die Vila mit normalen Mitteln nicht besiegen kann. Mlso greift er zu einer L18t. Er segt zu der V1la, er sehe zwel wolfe heranschlelchen, die ole und thn zerreiseen wirden. Die Vila blickt sich um und lockert dabel ihren Griff.Da benutzt Marko die Gelegenhe1t, drlakt die Vila zu Boden und sucht nicht lange nach oeinem Schwert, sondern beiBt der Vila die Kehle durch und schneidet ihr anschlieBend den Kopf ab. Er kehrt zum See zurlick, trinkt sich satt und pllanzt den Vilenkope auf einer stange an Ufer auf. Dann verklindet er lautstark allen Lebewesen des Waldes, er habe die Vila getotet und fir alle den Wasserzoll bezahlts nun durfe slch sattrinken, wer wolle. Da kommen alle Tiere des Waldes zum Trinken herbel, Marko aber reitet aingend nach Prizren weiter.

Naoh diesem auBer Diskussion stehenden Lied sind nun die wbulg.maz. Varianten zu behandeln. Var.25-27 eind alle drel Weihnachtelieder aus der Gegend von Debar; sle brechen an der Stelle ab, als das Waldgebirge auf Markos Pluoh hin antwortet, Marko moge nicht den Wald verfluchen, sondern lleber die Samovila Stojna, die zwolf Brunnen sammelte und Ins Gebirge hinaufschaffes

So posobra dranajeset Eerml,

I odnela gore u planina

bzw. die zwolf Brunnen verschloß:

Bog ja ubil Stojna samovila,

Sto zakl judi dvanaest Cerma.

Das anscheinend typisch maz. Mot1v des Brunnen-Zuschl1eBens durch die Samovila findet slch auch in Var.28 mit folgendem Inhalt:

Marko ist drel Tage und drel Nkchte im grinen Waldgeb1rge unterweg8, ohne Wasser zum Trinken oder Erfrischen zu finden. Da verflucht er das wasserlose Gebirge, das wie vom wind ausgetrocknet und von der Sonne ausgebrannt se1. Dor Wald antwortet, Marko solle nicht des Waldgebirge verfluchen, sondern die alte Samovila, die siebzig Brunnen sammelte, auf den Gipfel des Berges schaffte und nun flur einen Krug Wasser ein Paar Augen verlange. Darauf fragt Marko sein Pferd, ob es in der Lage se1, thn auf den Berg hinaufzutragen, damt er die Samovila tote und die siebzig Brunnen yefne. Das Pferd sagt, Marko solle lhm die zwolf Gurten festzlehen, dann konnten sie beide ihr Gluck versuchen. Marko zieht die Riemen fest, und das pferd tragt ihn auf den Berggipfel, damit er die alte Samovila tote und die siebzig Brunnen niederrels8e: 
Da otepa stara samovila,

I rasturi sedumdeset kla'enci.

Atertumlich mutet in diesem Iled an, dab das Waldgebirge auf Markos Fluch selbst Antwort glbt. Statt der Vila-Wahlschwester - der Helferin des Helden in neueren Iledern - 18t hier das Pferd der Berater und Helfer des Helden, eln sicherlich altes kotiv. Die Begegnung mit der Fee lot in diesem 0sterlied ausgelaseen. Sie wird geschildert, allerdings mit sekundar negativem Ausgang fur Marko, in Var.29, deren Inhalt lautet.

Marko ist drel Tage ohne Waseer im Waldgeblrge unterwegs und verflucht es, weil er "keinen Tropfen Wasser" finden kann. Da antwortet der Wald, nicht er sel daran schuld, sondern die Samovila Vela, die neun Brunnen sammelte und num hinter elsernen Toren mit silbernen Schlosiern unter Verschlus halte. Er, Marko, solle s1ch etwas nach rechts wenden, dann sehe er eine hohe Tanne mit vergoldetem Gipfel.- Marko indet die Tanne, zieht selne Keule, zerschmettert die Elsentore und sefnet die neun Brunnen. Nachdem er und das Pferd getrunken haben, will Marko fliehen, damit die Samovila dem Plerd nicht die goldenen filigel und thr selbst nicht die schwarzen Augen nehme. Da erblickt Vela die beiden und nimmt von Marko die Augen und von den peerd die Flagel als Bezahlung.

In dieser Var. mit marchenhaften Zligen (goldener wipfel, Elsentore, silberne Schlos8er, goldene Flugel) 18t bel der Antwort des Waldgebirges die Warnung vor dem von der Samovila verlangten Tribut weggelassen. Auch der Zweikampe zwischen Vila und Held, wie thn das skr. Iied auszumalen liebt, fehlt. Statt dessen ist die Samovila als das Ubermichtige dumonlache Wesen gezelchnet, das seinem Opfer ohne viel Federlesen die Augen bzw. die Flugel wegnimmt. Wie sich aus dem Variantenvergleich erglbt, durfte der fur den Helden negative Ausgang eine sekundure Erscheinung sein, die vielleicht aus anderen, alteren maz. Samovilen-Iiedern ubernommen warde. - wahrend den bloher genannten maz. Varlanten die den skr. elgene Nelgung zur epischen Ausmalung fehlte, lot num ein sludmaz. Iled zu besprechen, das den verglelchbaren okr.Iledern sehr ahnlich 18t. Es handelt sioh un Var. $30^{\circ}$ mit folgendem Inhalt:

Marko Kralevil ist im grinen Waldgebirge unterwegs, un einen graubräunlichen Hirsch (sur1 elen) zu jagen. Nach dre1 Tagen und dre1 Nachten erfolgloser Jagd plagt thn heftiger Durst, und er verflucht das Waldgeblrge, das Peuer moge es verbrennen, well es der 
Heldenkehle weder Wasser noch Wein zu bieten habe. Daraup antwortet Gjurg'a Samovila, nicht der Wald sel schuld daran und zu verfluchen, sondern V1da Samovila, die zwolf Quellen aue dem Berg. in elnem Baum mit trockenem Stamm und verdorrten Ästen, aber grinem Wipfel verschloseen halte. Marko durchstreift den Fald und findet den bezeichneten Baum. Er nimmt oeinen echweren Streitkolben, zerechlagt den Baum Stluck fur Stuck, zerbricht die zwolf Schloseer und labt die zwolf Quellen frel. Da wird die Samovila Vida aufmerksam, bestelgt einen Hirsch als Reittier, nimmt zwel Schlengen als Zaumzeug und elne dritte als Peitsche und reitet Marko nach. Sie holt ihn ein, packt ihn und will ihm die Augen auskratzen. Marko sagt, sie solle von thm ablassen; wenn sie Bezahlung flir das Wasser verlange, so mbge sle schwarze Groschen und gelbe Taler nehmen. Die Samovila lehnt das Geld ab und beharrt aus ihrer Porderung: Sie will die Augen dee Helden. Da kommt Gjurg'a Samovila herbel und meint, Marko solle "dlese Hure" nicht lange betteln, sondern zum heldischen Zwelkampl auffordern. Marko packt Vida bel den Haaren, bindet oie dem Pferd an die Beine und schwingt seinen Stroitkolben. Die Samovila fleht um Sohonung, doch Marko erklart, ole habe auf seinen Vorschlag auch nicht gehort, zieht sein Schwert und zerstuckelt die Samovila, damit sein Pferd Blut sehe und Lust verspare, in die wolken hinaufzufliegen.

Auch in diesem Iled hat die Samovila die Quellen in einem Baum verschloseen. Statt des Waldes gibt hier, genau wie in den ekr. Lledern, sekundar die Wahlochweeter Gjurg'a die Antwort aue Markos Pluch, ohne thn jedoch vor dem schweren Tribut zu warnen. Die Ausrustung der feindlichen Sanovila als Herrin des Waldes und des wilden Getiers entepricht etwa der in Var.12 beschriebenen. Die Schilderung eines Zweikamples der beiden Gegner fehlt. Marko 1at der klar uberlegene und grausame Held, der die Samovla trotz ihres Plehens totet. Der Ablenkngstrick, der in den okr. Varianten alo Erwelterungomotir hingugekommon let, lehit In den altertumlichen maz. Iledern, weil ja keine Kampebeschreibung gegeben wird, die in der skr. tberlieferung einen so wesentlichen Bestandtell der epischen Ileder ausmacht. Der zweite Teil dee Vila brodarica-Sujets scheint in der maz.-wbulg. tberlieferung flu verknderungen otarker anfullig gewesen zu sein als in der skr. Wie wir bel drel maz. Iledern sahen, fehlte der zweite Tell ganz, oder aber er marde zu elnem Sieg der Samovila oder, wie es im nucheten Iled der Pall 18t, zu threr Begnadigung 
ungestaltet. Es handelt sich um Var.31 mit folgendem Inhalts

Marko otrelft durch das Dospat-Gebirge und findet kein Wasser. Er fragt einen Schafer nach einer Quelle. Der Hirte we1st ihm den Weg zu zwel grthen Tannen, zwischen denen ein groBer see liegt, den die Vila-Samovila durch Sammeln des gansen Gebirgowaosers entatehen l1ek. Dorthin, meint der Sohrfer, wage sich niemand, weil die Samovila keinen Vogel lebend passieren, geschweige denn einen Menschen trinken lasse. Marko kommt zum See und findet die Pila ochlafend, oo daB or ungehindert trinken und soln Pferd trunken kann. Br reitet weiter. Die Vila orwacht, findet den Wasserspiegel ewel Spannen ( dve pedi) gesunken und fllegt empor, un den tbeltater ausindig zu machen. Sie sieht Marko und sohieBt drel Pfelle auf $1 \mathrm{hn} a b$, die dieser mit der Hand auffringt. Er zieht sein Damaszenerschwert und will die Vila toten. Sie aber bittet den Helden um Gnade, worauf Marko die Pee verschont und frellabt.

Der Pluch auf das waseerlose Gebirge, das hier konkret in sudweetbulgarien lokallalert wird, fehlt in dem oblgen lied.Statt der hilfrelchen Samovila zeigt ein Schafer den Weg, ohne aber etwas von einem Tribut zu erwahnen. Aus den Drachenkampfliedern bekannt lot das Motivs

Nikoj smee tamo da otide, Pa ne dava pile da proleti, A to nell covek da ol pije.

Wie der Drache hat hier die Samovila den Weg so grindlich veroperrt, daß "nicht einmal ein Vogel durchsohlupien kann". W1eder folgt das typisch maz.-wbulg. Motiv, das die Samovila das ganze Wasser des Gebirges an einer Stelle gesammelt und gesperrt hat. Der versohnliche IledschluB - Marko laBt die un Gnade Plehende Vila frel - lot naturlich sekundar.- Die nkohsten dre1 Lleder, Var.32-34, haben ein Motiv gemeinsam?

Nachdem Marko vor Duret schon sein Pferd schlachten will, das Waldgebirge inm - mit einer Warnung vor dem Tribut - den Weg zu dem Baum gezeigt hat, worin die Samovila neun plllse mit neum Schlossern (brw. 17 Pluses, 17 Rohrenbrunnen und zahllose endere Brunnen) verschlossen halt, und Marko die Schlosser zertranmert und Wassergllsee freigelassen hat, nimmt die SamoFila $\mathrm{hm}$ als Bezahlumg beide Augen (und dem Pferd die Beine). Marko bittet die Pee listig um Rlackgabe eines halben Auges (bzw. In Var.34 belder Augen), damit or sein Pferd noch einmal sehen könne. Die furchtbare vila flult auf die list herein, denn:

Ele ol Eena dirgokosa, Ona 81 e kratkouma. 
Marko packt seinen Streitkolben und schlagt die Fee damit vom Scheitel bis zur Sohle. Voller Angst bittet die Vile ihn um Einhelt, gibt ihm die Augen und dem Pferd die Beine zurlick und kommt dedurch frel.

Mit diesem Abschlus enden die Var.32-33. Die dritte Var.,Nr.34, ist etwas ausfuhrlicher und durch neue Motive bereichert:

Marko, gewarnt durch das Waldgeblrge, reitet zu der Samovila Vela, die die Brunnen und Wasserluufe mit "nemski katanci" verschlosien hilt, und fordert von ihr zwel Krige Wasser, einen zum Trinken und den anderen zum Waschen. Die Samovila bringt das gewlinschte Wasser und nimmt Marko glelchzeitig das Augenlicht:

Zatrori mu diete crni odi.

Marko redet Vela als "Schwester" an und bletet ihr die Ruckgabe der beiden Kruge Wasser an, wenn sie thm das Sehvermögen wiedergabe. Vela labt sich tuuschen:

Ele bese pusta Zenska strana,

Drigokose, ame krapouma, (1)

Izlaga 8e, voda 81 isturi

und erstattet Marko das Augenlicht zurlick. Kaum ist das geschehen, da fesselt Marko die Samovila mit Ketten an den Pferdeschwanz, reitet uber neun Berge und hilt dann an. Die Pee fleht ihn un Gnade an und veropricht ihm drei Krauter: eines, damit er sohne bekomme, ein zweltes, damit er Geld gewinne, und ein drittes, damit thn kein Unheil treffe.- Marko lehnt die Krauter ab mit der Begrindung, mannliche Nachkommen habe er schon, Geld gewinne er uberall und dem Unhell, das inm bestimmt sel, konne er nicht enteliehens er werde jetzt noch neun weitere Berge luberspringen und dann Vela freilassen. Marko hult jedoch sein Versprechen nicht. Er labt die Fee nicht 108, sondern stobt sie bls zum Knie in die Erde, schlygt sie drel Stunden lang mit der Keule und vierteilt sie schlieblich mit dem Schwert. Nachdem er das Wasser im Wald freigelasien hat, kehrt Marko nach Hause zurlick.

Wie in den skr. Var. als Erweiterungsmotiv die Iist mit der Ablenkung eine Rolle spielte, so wurde in diesen maz. Iledern die Pee auf andere Art getzuscht. Der positive Schlus bei var.32-33 lot wohl junger, der Abschluß mit dem Tod der Pee, der in Var. 34 allerdings mit Preude am grausamen Detall ausgespornen 1at, vermutlich die urspringliche Version. Das sekundar elngefuhrte Veroprechen der Vila, drei Zauberkruuter zu liefem, durfte ein spater eingedrungenes Marchenmotiv sein.- Dieses letztgenannte Motiv taucht auch in var.35 auf, die im ubrigen in ihrem Aufbau von den anderen Iiedern dieses Sujets absticht:

Marko will das Abendmahl in der Klosterkirche Ravanica 
nehmen, findet aber die Kirche versohlossen. Drinnen hort er die ronche den St1fter Marko verfluchen, der die Klosterkirche gebaut habe, ohne je dorthin zurlickzukehren, und der die grobe Bracke errichtet habe, an der jetzt die Samovila Kripa oitze und Tribut (bazdarlak) verlange.- Marko macht kehrt und reitet zu der Brlucke, wo die Pee ihn erblickt und sofort Tribut verlangt: von Marko das rechte Auge unc vom Pferd das rechte Vorderbein. Marko glbt se1nem Pferd die Sporen und greift schweigend zu den Waffen ("za pusaci derz1"). Die V1la verflucht ihn und beschimpet thn als "Hurenbastard". Als sie aber sieht, das Marko nicht einzuschlichterm 18t, sonderm wieder schweigend zu den Waffen ereift, verspricht ihm Kripa angstvoll drel Zauberkruuter:

Ja cu tebe tri bil'tja arizam.

Das elne bewirke, daB er dort alles sehe, in welche Richtung er auch immer blicke, das zweite, das er dorthin gelange, wohin er $81 \mathrm{ch}$ winsche, und das dritte, das ihm ein Sohn geboren werde. Marko lehnt das Geschenk ab, denn das alles gelinge thm auch ohne die Krauter, wenn es Gottes Wille sei. Dann schlagt er ihr zur strafe fur den eingehobenen Tribut den Kopf $a b$ und wirft diesen in den Futtersack. AnschlieBend geht er in die Kirche, um das Abendmahl zu nehmen. Danach eragt er die Mónche, warum oie die Kirche geschloseen hitten. Die Monche fragen ihn, ob er Marko Kralevic sel, was der Held bejaht. Nun erst wird Ibm das Abendmahl gereicht. Marko bittet die Monche, sein Pferd zu futtern. Sie finden den Vilenkopf im Puttersack, atmen befreit aur und veranstalten fur Marko zum Dank ein neuntagiges Gostmahl.

In diesem Iled ist der Handlungsablauf ganz offensichtlich wegen der Afeinjtzt des Handlungskerns - Befreiung von einem schweren Joch - dem Sujet angeglichen, wonach Marko auf dem Weg zum Abendmahl drei Ketten Sklaven aus der Gewalt eines Arabere, Tataren oder Turken befreit. Das urgpringliche Motiv des Duretes im wasserlosen Waldgebirge ist aus diesem Grunde weggefallen. Geblieben lst von dem urspringlichen Sujet nur noch die Bindung der Vila an das Wasser (wobel sie hier wahrscheinlich Bruckenzoll, und nicht mehr Bezahlung fur Trinkwasser verlangt), ihre grausame Tributforderung und Markos Sieg uber das damonische Wesen. Das Marchenmotiv von den drel Zauberkrautern 1 at dem der vorhergehenden Var. ganz Ghnlich. Es wurde sicher deshalb mit diesem Sujet verbunden, weil die vilen in sudslavischen Volksglauben als kräuter- und daher heil- und zauberkundig gelten. - Var.36 18t im zweiten Teil erweitert und auBerdem beim 


\section{Liedausgang verandert:}

Krali Marko ist drei Tage mit seinem schnellen RoB im Gebirge unterwegs und findet kein Wasser. Er verlangt von dem Wald, er moge ihm sofort den Weg zu einer frischen Quelle weisen, andernfalls möge die Samovila erscheinen, die Buume samt den Wurzeln ausreissen und ein machtiges Peuer entfachen. Das Waldgebirge weist die ungerechten Vorwlirfe zurlick und erklkrt, es habe zwar zwolf Brunnen, die aber die Samovila Gjurgja verschlossen halte, so das niemand daraus trinken konne.- Marko findet die Stelle, zerschlagt die Schlosser mit dem Schwert, labt das Wasser erei und trinkt sich - zusammen mit seinem pferd - satt. Dann reitet er weg und beschwort sein Pferd, moglichst schnell zu sein, damit die vila ihn beim Erwachen nicht mehr sehe. Gjurgja hat ihn aber schon erspant und holt ihn ein. Harko bittet die Samorila, sie moge ihn ziehen lassen, ohne den Tribut - vom Helden die Augen und vom Pferd die Beine - zu fordern er werde sie flur das getrunkene Wasser entichadigen. Die Samovila erklurt, wenn sie Geld annuhme, hatte sie das Gebirge langst vergolden konnen: sie verlange aber Markos Augen. Da betet der Held zum hl.Georg, er möge ihm zu Hilfe eilen und ihm beistehen, damit er die Vila tóten und das Wasser ereilasien konne. Der Heilige erscheint. Mit seiner Hilfe zwingt Marko Gjurgja zu Boden, um sie mit dem Schwert zu toten. In diesem Augenblick fleht die Pee um Gnade und bietet liarko die Wahlbruderschaft an. Marko nimmt das Angebot unter der Bedingung an, dab Gjurgja inm die Herzen der neun Helden gibt, die sie getbtet hat. Sie gibt sie ihm, woraus Marko die neun Herzen nimmt und in der Klosterkirche bestattet, damit sie die ewige Rube inden.

Der ganze zweite Teil dieses urapringlichen Vila brodarica-Lieds lat sekundar dazugekommen und mutet stark verchristlicht an. DaB der Held den hl.Gecrg herbeiruft, damit mit seiner Hilfe das damonische Wesen besiegt werden kann und das gesperrte Wasser wieder erei wird, erinnert natlurlich an die Drachenkampelieder und dirfte wohl von dort - vermutlich wegen der Sujetaffinitut ubernommen sein. Ein weiteres christliches Anhangsel ist das Erweiterungsmotiv von der Bestattung der neun Heldenherzen in geweihter Erde.

Wie schon am Kapitelanfang betont warde, ist das Vila brodaricaSujet m.E. durch Substitution (Drache durch Vila ersetzt) aus dem Drachenkanpfoujet entstanden, dessen verschiedene Spielarten (Lamja als Wolke bringt Durre uber das Land; Drache sperrt das fissser und verlangt taglich Menschenopfer; Drache im Brunnen) 
wir ja besonders auf maz.-wbulg. Boden beobachten konnten. Die Vermutung, daß unser Vila brodarica-Sujet - im Zuge der stufenweise fortschreitenden Entmythologisierung - aus einer Spielart des Drachenkamplaujets abgeleitet 18t, findet tatsachlich ihre Bestatigung in mehreren wbulg. Iiedern, die nun zu besprechen sind. Der skr. Iledschatz hilft uns nicht weiter, weil dort das Drachenkamploujet - auBer in den Georgsl1edern - nur mehr indirekt in Porm von Ableitungen und Substitutionen existiert, wahrend die maz.-wbulg. Volksepik die archaische Stufe mit stark mythologischen Zugen gut bewahrt hat. Das erste Iled der genannten Gruppe, Var.37, hat folgenden Inhalt:

Marko Kralevina ist drel Tage im Waldgebirge unterwegs und findet kein Wasser. Als er schon entschlossen 18t, sein Pferd zu erstechen und mit dessen Blut seinen Durst zu 18schen, da erbarmt sich Gott seiner und schickt ihm zwel engel, die inm den Weg zum Wasoer weisen sollen. Die beiden Engel fliegen zu Marko auf die Erde und sagen inm, er solle auf den Berggipfel steigen; dort seien in einem Pelsen zwolf Brunnen elngeschlosien, bewacht von einer dreiköpligen Chala, die niemanden trinken las8e; wenn sie gerade abwesend sei, solle Marko sich satt trinken und sein peerd tranken.- Marko reitet zu der bezelchneten Stelle, findet sie unbewacht, die eisernen Tore aber verschlossen. Da holt Marko mit dem PuB aus, zertrlimmert die Tore, trinkt und reitet weg. Die dreikbpfige Chala kommt bald daraue zurlick, findet die Tore zerochmettert und jagt Marko nach. Sie ereilt inn mitten auf dem weiten Feld und springt dem Pferd auf die Kruppe. Marko packt die Chala mit der einen Hand und ersticht sie mit der anderen.

Statt des Waldgebirges, das Marko den Weg zur Wasserstelle weisen sollte, wurde hier sekundär das christliche Element der Fntsendung zweier hilfreicher Engel eingesetzt. Das alte Drachenkamplmotiv ist daneben aber relativ gut erhalten. Eine Besonderheit besteht darin, daß Marko die Elsentore mit dem FuB, und nicht mit der Keule zerschmettert. Typisch maz.-wbulg. ist das Motiv der an einem Punkt konzentrierten und verschlosienen Brunnen, dem in den skr. Iledern das Motiv des von der Vila bewachten Waldsees entspricht. - Altertumlicher mutet noch Var.38 an, die jedoch leider unabgeschloseen lot:

Harko reitet drel Tage lang durch das Waldgebirge und sucht vergeblich nach Wasser. Weil er weder eine Quelle noch einen Brunnen findet, verflucht er das Waldgebirge, worauf dieses ihm antwortet, es besitze sehr 
wohl Quellen, doch seien diese von einer Ala "gefangen" (zaptisala), die niemanden trinken lasse; Marko habe nur zwel bis drei Giplel zu Uberqueren, dann stoBe er auf das Wasser.- Marko findet die Quellen unbewacht, trinkt und gibt auch seinem pferd zu trinken. Da kommt die dreikopfige und neunzingige Ala herbei und fragt Marko, wie er wagen konnte, an der verbotenen vuelle zu trinken. Marko bietet inr darauf Groschen und Goldstlucke als Bezahlung an, die die Ala aber ablehnt, weil, wenn sie Geld wollte,sie das Gebirge schon lingst versilbern und vergolden konnte. Sie fragt Marko, ob sie ihn toten oder lieber dem Pferd die Augen nehmen solle.

Bei diesem Iied liegt die schon bekannte Motivfolge vor: Fluch auf das angeblich wasserlose Waldgebirge - Rechtfertigung des Gebirges und Hinweis auf die von der Ala gesperrten Quellen Trinken aus der Quelle - drohendes Auftauchen der Ala - Anbieten von Schatzen und deren Ablehnung - Forderung der Ala. Der SchluB, Markos Sieg luber den Drachen, fehlt in diesem unvollendeten Iled. - Var.39 lot mit zwei anderen Liedoujets kontaminiert, die unser Kernmotiv umrahmen:

Petŭr, der Hirte (dx́lepin), bespricht mit seiner jungen Frau Elka, daB sie beide zwar arm geheiratet hat. ten, daB Gott sie alle Arten von Besitz erwerben lie und aie wohlhabend machte; nur ein Kind habe er thnen bisher versagt; darum wolle er sich am nichsten Morgen mit Schrtzen auf den Weg ins walachische Land machen, wo er hoffe, Heilkräuter erstehen zu konnen, die ihnen endlich das ersehnte Kind schenken wurden.- Petur bekreuzigt sich am nuchsten Tag und macht sich auf den Weg. Als er nach zwei Tagerelsen noch kein Wasser gefunden hat, fragt er eine am Wege aitzende Alte nach einer quelie. Die Frau erklart 1hm, es gebe zwar Wasser in einem nahen See, doch werde dieser von elner gelbgrlinen Schlange ("zult zilen smoka") bewacht, die nicht einmal ein Voglein passieren, geschweige denn einen Menschen trinken lasse.- Trotz dieser Warnung reitet Petur zu dem See, steigt ab und trinkt. Sofort kommt die Sohlange herbel, um Petir zu vereohlingen. Petir jedoch zieht sein walachisches Messer und zerschneidet die Drachenschlange "lukma po Iukma" (turk. lokma 'Stluckchen'). Darauf wird der Held krank und liegt zwolf Tage lang am Seeufer, ohne zu essen und zu trinken. Am dreizehnten Tag erhebt er sich, besteigt sein Pferd und schlät den Weg nach der Walachei ein. Da begegnet inm eine dreikgpeige Juda. Petur zieht wieder sein Messer, un die Pee zu toten. Diese aber bietet inm, wenn er Gnade walten las8e, die ersehnten "bilki za rozba" (Heilkruuter flr Kindersegen) und rat petír außerdem, er moge schnellstens nach Hause zurluckkehren, denn Filip Madzarin sei dort eingedrungen und werde seine Prau rauben und heiraten, weil das Ge- 
rlucht umgehe, daß Petur belm Kampl mit der Schlange ungekommen se1. Petur labt die Juda an Iaben. nimmt die Zauberkruuter und kehrt rasch nach Hause zurlick, wo er gerade rechtzeitig zun Beginn der Hochzeltsfelerlichkeiten kommt. Als Monch verkleidet gibt er vor, das Brautpaar trauen zu wollen, macht aber dann die Svaten und Filip Madzarin mit seinem Messer nieder.

In diesem komplexen Liedgebilde 18t der erste Bestandtell die Ballade von der kinderlosen Prau $281 a$, der zweite das Sujet rom wasserlosen Gebirge und der dritte das Lied von der Heimkehr des Gatten zur Hochzeit seiner Prau281b. Von diesem durch Kontamination entotandenen Lied interessiert uns hier nur der mittlere Te1l. Die Rolle des Antwort gebenden Waldgebirges hat sokundar eine alte Prau ubernomen, eine "stara babicka", die im Märchen wie im Lied gleichermaßen beliebte Figur zur Auskunftertellung. Die weibliche Drachengestalt scheint in diesem Lied in zwei damonische Wesen aufgespalten zu sein, namlich in die gelbgrine Schlange und die dreikoppige Juda ( $\nabla g l$. die dreiköpPige vila in den kroat. Liedern vom tberfall der Fee auf einen Hochze1tezug). Die Erkrankung des Helden lst nicht begrindet, es konnte aber sein, daB damit die Schwierigkeiten der Uberwindung der Drachenschlange angedeutet werden sollen. Das Motiv der Kindersegen bewirkenden Krauter erinnert an die Var.34 und 35. wo ebenfalle die Pee, um Gnade zu erwirken, Zauberkrauter angeboten hat.

Damit aind die wbulg. Varianten behandelt, die zum Beweis der Ableitung des Vila brodarica-Sujets aus dem Drachenkampleujet dienen sollten. - Zuletzt sel noch als Var.40 der Vollotandigkelt halber das bosnische lied Petr.III 27 (zitiert bel Chal. RFV $29_{2} .333$ ff.) angefuhrt, das Jedoch, weil die Sammlung Petr. III als unzuverlassig gilt, nichts an der Tatsache andert,daB ung nur maz.-wbulg. Drachenkanpflieder (auBer den erwahnten Goorgeliedern) zur Verfugung stehen. Der Inhalt von Var.40 lautets Ein Palke klagt im Jastrebac-Gebirge; dab es kein Waseer mehr gebe. Fruher, als noch der Beschlutzer des Gebirges, der Peurige Zmaj, am Leben war, den Zar Lazar durch Verrat tötete, herrochte muntereo Leben im Waldgebirges Alle Tiere tranken Wasser, badeten oder tummelten sich an der Wasserstelle. Doch nun sei ein Drache (azdaha) in See aufgetaucht, der nlemanden ans Wasser heranlasse und Mensch und Tier 
verschlinge. Die Vila sel geflohen. Nur ein Held sei noch in der Lage, den Drachen zu besiegen, numlich Marko Kraljevic. Der jedoch aitze den ganzen Tag ipats Schenke und trinke Wein. Also seien alle Iebewesen des Waldes dem Drachen schutzlos ausgeliefert.- Auf diese Klage hin kommt die Vila herbeigeflogen und versichert dem grauen Falken, noch ein zweiter Held, nbmlich der von ihr geskugte Milos, sei zum Kampl mit dem Drachen befahigt.- Die Vila schreibt einen Brief und schickt ihn mit dem Falken zu Milos. Als Milor die Nachricht gelesen hat,zieht er ins Kalpak-Gebirge, findet den grinen see und in ihm die "bunte Schlange", die gerade einen Hirsch verschlingt, dessen Kopf mit dem muchtigen Geweih noch aus ihrem Maul ragt. Miloz, von der vila in den Wolken ermutigt, t8tet den Drachen, befreit den Hirsch und singt triumphierend, die wilden Tiere des Waldes mogen nun alle zum See kommen, denn der Drache sel get8tet. Da kommen alle Tiere des Waldes herbel, um Milos zu danken. Die Vilen aber klusen ihn "ins weiBe Antlitz".

Wie sonst bei Petranovie III ist zwar auch dieses Lied aus Elementen der Volksuberlieferung zusammengesetzt, das Ergebnis ist aber trotzdem kein Volkslied, weil der des Lesens und Schreibens kundige sanger nicht mehr in der echten mundlichen Tradition steht. Das Lied wirkt geklinstelt, aberleden und fur den skr. Iiedraum unglaubwirdig mythologisch.

Wie schon bel anderen Iledoujets eine Ersetzung des Drachen durch die Plgur des Arabers festzustellen war, so ist dies auch bel unserem Vila brodarica-Sujet der Pall. Es handelt sich allerdings nur um eine Var., nfmlich Nr.41, mit folgendem Inhalt:

Marko wird von seiner alten Mutter beim Abendessen gefragt, worliber er laches luber das bescheidene Esien oder uber ihr hohes ilter. Marko verneint beides und erzahlt dann, es sel inm gerade eingefallen, wie er mit 300 anderen Helden in Gefangenschaft war und die Reihe an $1 \mathrm{hn}$ zum Waseerholen gekommen se1; da habe man ihn mit einem rostigen Schwert und einem abgesohundenen Gaul ausgestattet und zur Wasserstelle ins Gebirge geschickt. Nls er das Wasser geschopft hatte und sich noch das Gesicht habe waschen wollen, sel ein "Turdin Nrapina" herangeritten und habe als Bezahlung (harac) entweder den Kopl oder den rechten Arm oder aber 100 Golddukaten von Marko verlangt. Marko habe ihm erklart, das or kein Geld bel 81ch habe. Darauf habo der Nraber oein Schwert gezogen und Marko dreimal damit geschlagen, se1 dann aber von Markos rostigem Schwert todlich vermundet und $8 \mathrm{chlieBlich}$ in zwei Telle gehauen worden. Marko habe anschlisBend die Klelder des Arabers angezogen, dessen Pferd und Waf- 
fen genommen und den Lelchnam sum Sultan geschafet. Auf die witende Prage des Sultans, warum Nerko se1nen 28liner getbtet habe, antwortete lhm Marko, er bitte auch 1hn, den Sultan, getotet, wenn er 1hn angegriffen hatte. Dann sel or dem Sultan Immer nuher gerluckt, 80 das dieser Angst bekommen und ihm 100 Dukaten flur Wein geschenkt habe.

In dicsem Iled lot des alte Vila brodarioa-Sujet (in abgewandelter Form) nur als Episode eingebaut. Das Iled gehbrt sonst in den Kreis der Varianten, in denen Marko einen im Dienste des Sultans stehenden Turken (Schatzmeister u.g.) tötet oder ein Gebot des Sultans ubertritt, dem Sultan durch drohendes Auftreten Furcht einjagt und zum Schlus noch Geld erhelt, damit er den Sultan urbehelligt las8e. Wir haben also in diesem Iied wieder einen Beleg dafur, daB das urspringliche felndlich gesinnte damonische Wesen durch den politischen Peind abgelost warde.

Wie wir die Vila brodarica-Iieder von dem Draohenkamplaujet herzuleiten verouchten, konnte man an elne weitere Ableitung, von den Vila brodarica-liedern ausgehend, denken, die durch die Var. Bog.89; Vuk VI 17; Milut.6; MH I233; Jastr..281; Sapk.370; II. 262; Kax.132,133,138-142; SbNU I,55; VIII,98; XII,54; XIII, 14; und XIII, 18 (vgl. ISSP VIII Nr.301 und 302) vertreten 18t, deren Inhalt etwa folgendermaßen lautet:

Marko und sein Bruder Andreas wollen ihre Krafte messen. Statt eines Zweikampls schlagt Marko vor, sie beide sollten ins wasserlose Waldgebirge reiten una sehen, wer es langer, obne gu trinken, aushalte. Andreas nimmt den vorschlag an, und die Brider reiten tagelang durch den Wald, ohne ein Getrink bei sioh zu haben. Andreas wird zuerst von heftigem Durst geplagt und beschliebt, sein Pferd zu erstechen, um das Tierblut zu trinken. Im letzten Augenblick hrlt ihn Marko davon ab und rat ihm, statt deseen zu der nahen Schenke zu reiten und $81 \mathrm{ch}$ von der Schenkwirtin Wein herausbringen zu laseen, aber ja nicht in die Schenke hineinzugehen, weil die sicher voller Hajduken sei.- Andreas reitet zur Schenke und will $81 \mathrm{ch}$ von der Wirtin Wein an den Zaun bringen lassen. Als die Wirtin in das Haus geht, un den Wein zu holen, wird sie von den Gasten gefragt, wer drauben sei.Sie beschrelbt den unbekannten Helden, worauf die Hajduken sie drangen, ihn hereinzuholen. Die Wirtin lockt Andreas ins Haus, wo die Rkuber uber thn herfalien und thm den Kopf abschlagen.- Marko, der lange im Wald gewartet hat, macht olch schlieBlich auf den Weg zur Schenke, um nach oeinem Bruder zu sehen. Im Wirtshaus sieht er die Rluber mit dem Kopl seines Bruders 
Ball spielen. Auf die Prege, wessen Kopl das sel, antwortet ihm die Wirtin hohnisch, wenn ihm Gott nicht helfe, konne dasselbe auch mit seinem Kopl geschehen. Da gerat Marko in Wut, zieht seinen sabel und macht die Ruuberbande nieder, die Wirtin aber teert und verbrennt er.

Das Zentralmotiv in diesem Iled, der Durst im wasserlosen Gebirge, der Plan, das Pferdeblut zu trinken, und die drohende Gefahr an dum Ort, wo es etwas zu trinken gibt, ist im Prinzip das gleiche wie in den Vila brodarica-Iiedern. Die Schankwirtin, die vielleicht eine Pigur mit Resten dumonischer zuge verkorpert, wenn sie ihre negative Rolle spielt (es gibt auch den Typ der hilfreichen Wirtin, analog der Vila posestrima), konnte aus der Vila brodarica-Gestalt abgeleitet sein. Es gibt nurlich mehrere $\mathrm{Falle,}$, wo die Schankwirtin entweder vilenzlge tragt oder die Stelle der Vila eingenommen hat. In dem $326 \mathrm{~V} .(4 / 6)$ langen kontaminierten wbulg. Iied SbNU XIII, 14 bildet den letzten Bestandteil (S.17-18) das Sujet von den Bridern Marko und Andreas, ihrer Wette im wasserlosen Gebirge und der verraterischen Wirtin Mara. Hier hat die Schankwirtin offenbar vilenzizge; ale uhnelt numlich der Vila in den Iledern, wo zwel Wahlbruder durchs Gebirge reiten, einer davon singt, von der vila mit dem Pfell getroffen und von ihr, gezmangen durch die drohende Haltung des anderen Wahlbruders, mit Hellkrăutern wieder belebt und gehellt wird. In unserem Iled bietet nun die Wirtin die Heilung des von den oechzig in der Schenke versammelten Hajduken getóteten Andreas an, als Marko sie mit dem Schwert bedroht:

Nemoj mene, Marko, da pogubiz,

Ce lekuram mlado Andrease,

Ce lekuvam, $\chi_{e}$ go izlekuvaml-

Lekovea mlado Andrease,

Lekovaa, izlekovaa go.

Den gleichen Iiedschlus finden wir auch in Kac.132.- In dem 166 V.(4/6) langen wbulg. Iled SbNU XIII,18, das ebenfalls kontaminiert ist, versucht die heimtilckische Wirtin im zweiten Teil (S. 20) das durstende Bruderpaar zu verderben. Sie mischt nkmlich heimlich Wein und Schnaps, dant Marko betrunken werde und sie den webrlosen Andreas fangen könne:

Itra bila Mara mehandzijkja,

Ta izmesa vino 1 rakija,

Da opoi Marko te junaka,

Da mu zeme brata Andreaša. 
In den $48 \mathrm{~V} .(4 / 6)$ langen maz. Iled MAch.,194, das dem Aufbau nach oin V1la brodarica-Iled darstellt, lat die Vila brodarica durch eine junge Schankwirtin oubetituierts

Marko lat dre1 Tage in Waldgebirge unterwege und 11ndet kein Wasser. Als or schon entschlossen 1st, das Blut seines Pferdes zu trinken, zelgt $1 \mathrm{hm}$ die Semovila Vela den Weg zu oiner hohen Tannes

vizeto 1 u virnoto nebo, Granjeto 1 erebro podreseno, Sumjata 1 se kara grošre, Rozbata 1 se blagi jabuk1, Koreno 1 se po carska zemja.

An den Wurzeln dieses Wunderbaumes entepringe eine klihle Quelle, deren Wasser ein Madchen (odna malka moma) teuer verkaufes

Studna voda skapo preprodavas Edna kapka, oden altún zima, Vtora kapka, vtori al tín zima, Trekja kapka, troki al tín 21 ma Bardak dava, junaka zal jubva.

Marko findet alles, wie von der Samovila beschrelbend vorhergesegt, und rauft fur olch und das Pferd fur rins Goldotlucke einen Krug (bardak) Wasser.

Abechliebend sel nooh das $57 \mathrm{~V} .(4 / 6)$ lange 1otrioche Lied Iotarske,44 (Nr.9) angefuhrt, dessen Inhalt lautets

Kral Jer16 Marko reltet in Geb1rge und findet kein Wasoer. Br verflucht das wasserlose Waldgeb1rge und orhelt von diesem die intwort, or solle nur nooh otwas welter relten, dann stoBe or auf zwe1 Ahormberume;darunter befinde olch oin Brunnen, an dem ein radchen von der Insel Pasman - neben lhr oitre der junge Rade, "dit te mlado" - Wein verkaufo. Marko Iindet die bezelchnote Stelle und Iragt das Mrdchen, welchen der belden Manner sie lieber nahme, den jungen Rade oder 1hn, Marko. Das Madchen ontscheidet sioh fur Rade, woraus Marko in seiner Wut dem Jungen den Kopf abschlagt. De flungt der abgehauene Kopf zu reden an, opricht Marko m1t "Bruder" ("braj1le","brate") an und fragt $1 \mathrm{hn}$, wos er num ohne bruderliche Hilfe im Kampl gegen Tlirken und Hajduken maohen und was er agen werde, wenn die Mutter lhn frage, ob den jungen Rade die Turken oder Hajduken getrtet hatten.- Nach diesen vormurfevollen Worten wird Marko von solcher Reue erfaBt, daB or olch selbet seln Schwert ins Herz strBt. Als das MBdchen bolde Helden tot liegen sieht, verflucht os die "mage und Jahre" selnes Lebens sowle seine sutter, die lhm das Leben geBchenkt habe.

Das Lied lat eindeutig aus zwel Liedem kontaminiert, die natur11ch in bestimmtem Ausmas verstummelt werden mubten, damit der Kantaminationevorgang moglich murde. Der erste Bestandtell ist 
ein Vila brodarica-Lied mit Marko Kraljevic und einer zur Schenkwitin entmythologiaierten Pee als Protagonisten. Der zwelte Bestandtell behandelt das Sujet von der Entzwelung zweier Brual durch die Pee 282 , erweltert um Motive aus anderen Bruderzwist-Liedern (oprechender Kopf; Sorge um den Bruder in kinftigen Kumplen; Auftrag an die Mutter), wobel die Pee jedoch zu einen gewohnlichen Madchen, elner Weinhandlerin, entmythologisiert wurde. Diese entnythologisierte Fee ist das Bindeglied, der Angelpunkt zwischen beiden Teilen des kontaninierten Iledes. Weil im ersten Tell, in dem Vila brodarica. Lied, nur ein einzelner Held, im zweiten Teil aber ein Bruderpaar gebraucht wird, hat der sanger an der Nahtstelle zwischen den beiden Teilen willkirlich die Pigur des jungen Rade,der der Weinhandlerin Gesellschaft lefstet, eingefunrt, ohne dab gesagt wird, in welchem Verhältnis er zur Schankwirtin steht.Marko und Rade werden von da an plotzlich wie ein Bruderpaar behandelt, weil das zweite Iledsujet es so verlangt. DLe Schankwirtin lst m.E. - das 8011 nochmals betont werden - in beiden Iledbestandtelien eine entmythologisierte Vila.

Abschließend läßt sich sagen, daß das Vila brodarica-Sujet sowohl im skr. wie auch im maz.-wbulg. Iledraum verbreitet ist, wobel in beiden Pallen, starker jedoch im okr. Raum, eine Nelgung zur Motivanrelcherung besteht. Lokale Sonderformen zeigen sich darin, daß in den skr. Iledern die Pee einen See oder eine Quelle bewacht, whinrend sie in den maz.-wbulg. Iledern eämtliche Wasserstellen des Waldgebirges an einem Punkt (in einem Baum oder Pelsen) konzentriert und abgeschlossen hat. Die Vermutung, daB die Vila brodarica-Ileder aus dem Drachenkamploujet absuloiton oind, fand ibre Bestatigung in mohroren wbulg. Drachenkampliledern. Weiter konnte eine Iledentwicklung im Zuge der fortschreitenden Annuherung an die Realitat festgeotellt werden: Die Vila brodarica-Pigur lat in manchen Iiederm durch die negative Gestalt der Schankwirtin (krcmarica) ersetzt. Es liebe Bich also folgende Substitutions- und Entmythologisierungsrelhe aufstellen:

Drache im see bzw. Brunnen $\rightarrow$ Vila brodarica $\rightarrow$ Schankwirtin, 
wobei abermals zu bemerken 18t, daB wir annliche Entmythologisierungsreihen bereits fur andere Lledoujets aupstellen konnten, z.B. die Reihe dreikbpfiger Drache $\rightarrow$ ochwarzer Araber mit $\rightarrow$ Araber, Turke, dermonischen Zugen Hajduke bzw. Vila

fur das Sujet vom Hochzeltszug mit tberfall; oder eventuell die Reihe Drache $\rightarrow$ Vila $\rightarrow$ Hajduke pur das Sujet, in dem einer von zwel Wahlbrüdern bzw. eine mit ihrem Mann reitende junge Frau im Wald singt; oder aber schlleBlich die Reihe Drache $\rightarrow$ Vila,Juda $\rightarrow$ Riesenfisch $\rightarrow$ Pingierter Riesenfisch $\rightarrow$ vorgetkuschte日 Ertrinken

pur das Sujet, in dem ein Held ein Gewksser uberschwimmt, um ein Madchen zu gewinnen.

\subsection{BOLEN DOJXIN-LIEDER}

Uns interessieren hier nicht die Lieder, in denen Dojzin aus Solun als Wahlbruder von Kraljevib Marko (vgl. Vuk II 64, M1lut.68, Mil.156, Sapk.338) auftritt, sein Name mit dem Motiv der untreuen Frau oder verrateriochen Mutter verbunden 1 st (vgl.Stoin TV 2973; Sapk.334 und 422; Males.149; SbNU XIV,75; XIII,242) oder in dem Sujet von der Wegmarkierung mit Blut (vgl.Sapk.407 und 454) auftaucht, sondern nun stehen nur die al teren Bolen Dojein-Lieder zur Erorterung, deren Hauptthema der Kampp des kranken Helden mit einem schwarzen Araber darstellt. Die neueste und umpassendste Arbeit zu diesem Thema stammt von A. Fochi 283 , der die Priher erschienenen Beiträge fast alle $e^{284}$ berlucksichtigt und num zum erstenmal das gesamte rumbnische, bulg., maz., skr. und albanische Variantenmaterial auf die thematische Morphologie, dichterische Gestaltung und kulturelle Umwelt des Lieds hin untersucht. Er ruhrt 44 rumbnische und 2 albanische Varianten an, die hier, da es um sladslavische Probleme geht, nicht wiederholt werden sollen. Zu nennen aind jedoch die folgenden (von mir noch etwas ergunzten) maz., bulg. und skr. Varianten: Mil.88,154,155,261;Kac. 185-188; Sapk.392,407,431,454; Doz.40; Beze.I 1; Jastr.,62; 
SbNU III,97; VI,61; XIV,74; XXVI, 18; XXVI, 162; XXV, 18; XXVII,126; XXVII,556; XXXV,256; XIII, 106; XIII, 108; XIIII, 206; XIV,91; XIVI, 9; XIVI, 99; XIVII Nr.12; XIVII, 13; XIVIII.53; Stoin TV 2864,2961; Cirmuăanov 459; Vúrb.269; Iranov BNP,237 und 239 (Pragment); Bond.,71; Il.251; Jank. 4; Mich.,204; Dras.9 und 10; Col.I 10; Males.147; Radov.12; PPNP V,283; SbNU XXXV,9 (Erwăhnung einer Var.); XXXVI,84 (Erwahnung von 2 Var.); Sapk.VIII-IX 161 (Prosavariante); Vuk II 77; UH I,64; MH II, 16; Ietareke 15; EH 110; MH I $I_{6}$; Delorko NLP 130; NH $I_{1}, 576$ (B.Grgic 12): MH $I_{1}, 576$ (Ivan¿ic 25); MH $I_{1}, 576$ (Kacid 84); MH $I_{1}, 577$ (Mikulidic 31); MH $I_{1}, 577$ (Nalis 56); MH $I_{1}, 577$ (Pavlinovid 28); MH $I_{1}, 577$ (Smidiklas 9); WH $I_{1}, 578$ (Šestic 18); MH $I_{1}, 578$ (Trmsk1 8); Maz.,187; Delorko,0.8 Narodne pjesme s nekih 8ibenskih otoka, 1957/58 ( = Rukopiana zbirka Instituta za narodnu umjetnost u Zagrebu Nr.154).

Nach der grindlichen Arbelt von Pochl erlabigt es alch,hier elnen sukzessiven Variantenvergleich anzustellen, obwohl dieser vielleicht die Sujetentwicklung besser aufzeigen konnte, als es die von Fochi gebrauchte Methode tut. Fochi gliedert das Dojzin-Iied in flinf Eploodens

1. Das durch die Ankunft des sohwarzen Arabers hervorgerufene Ungluck,

2. Benachricht1gung des Helden und verzweifelter Ruf nach se1ner Hilfe,

3. Vorbereitung des Helden fur den Kampf,

4. Kampl und Sieg,

5. Tod und Apotheose des Helden,

von denen wioder jode ihrorselts in oinzelne "Themen" aupgotelit wird, und untersucht nun Eplsode fur Episode, wobel er die jeweils relevanten nationalen Varianten in Fubnoten angibt. Hier soll nur der allgemeine Handlungsgang des Liedes gezelgt werden, um das Verstandnis der folgenden Erbrterungen zu erleichterns

In Solun (sekundar ruman. farigrad, skr.Solin u.a.) ist ein ochwarzer Araber aufgetaucht, der der Stadt schweren Tribut auferlegt (in den alban. Varianten steht statt des ochwarzen Arabers "baloz", laut f̧abej 'Riese', den Pochi mit 'Drache' Ubersetzt; in dem 
Text Visaret e Komb1t I, Tirane 1937, S.215,Nr.1, V.13-14, 18t von elnem "schwarzen Baloz, der aus dem Meer entstiegen 18t", die Rede: "balor 1 zl â dalë prej det1t"). Der Unterdrlucker fordert tkgl1ch riesige Mengen zu essen und zu trinken, ein Madchen flur den Tag und eine junge Frau flur die Nacht und manchmal noch einen jungen Mann zur Befrledigung selner Mordlust.- Nun lat die Rethe an Angelina (8ekundar auch andere Namen), die Schwester des kranken Dojein (sekundir auch Namen wle Georgi, Privan, Ivo usw.), gekommen, als Opfer zu dem grablichen schwarzen Araber zu gehen. Sie seufzt, ringt die Hande und vergiebt helBe, bittere Tranen uber dem Geelcht 1hres Bruders, die diesen aus seiner Lethargle wecken und inn zu der Prage veranlassen, was der Grund fur den Kummer der Schwester sei. Als er die wahre Ursache erfahren hat, beschliest er, die Schwester und die Stadt zu retten, indem er gegen den Unterdrucker in den Kampl zieht. Dojzin labt seine Schwester das plerd holen und gibt thr den Auftrag, es bel seinem Freund (bzw. Wahlbruder), dem Hufschmied, "auf Heldentreue", d.h. auf Borg, beschlagen zu lassen. Das madchen kehrt unverrichteter Dinge zurlick, well der Hufschmied ihre schwarzen Augen (bzw. Ihr we1Bes Geoicht) als "Bezahlung" verlangt. Die gleiche Erfahrung macht die Schwester beim Schwertschm1ed. Als der kranke Held sleht, dab er mit unbeschlagenem Pferd und ungeschliffenem stuel in den Kampl ziehen muB, entsendet er die Schwester zum Tuchhlindier, wo sie Ie1nen zum Verbinden seiner Wunden auf Borg holen soll, was auch gelingt. In manchen bulg. Varianten wird das kadchen noch zum Barbier geschickt, der den Bruder auf Heldentreue rasieren soll; als er aber die bekannten unannehmbaren Bedingungen stellt, kehrt das Ykdchen ohne ihn zum Bruder zurlick. Whinrend in den albanischen Varianten der Zwelkampl des kranken Helden mit dem schwarzen Meeresilesen nach einer schriftl1chen Aufforderung erfolgt, reitet der Held in der Mehrzahl der anderen Varianten einfach zun Zelt des Arabers und fordert ihn zum Kampl. Entweder besiegt DojCin den Gegner nun mittels einer Iist (in den muman. Iiederm) oder aber (in den bulg., skr. und alban.I1edem) In einem ritterlichen Zweikampf, der zuerst mit dem Streitkolben, dann mit dem Schwert gefuhrt wird und mit der Enthauptung des Arabers endet. Nlo die Bewohner der Stadt das Kamplergebnls erfahren, jubeln sie dem Helden zu. Dieser racht sich nun noch an dem untreuen Huf- und Waffenschmied (bzw. Barbier), Indem er die beiden herausruft und totet, und kehrt dann nach Hause zurluk, un nach erfulter uise1 on zu sterben. In den alban. Varianten etirbt auch die Schwester.

Das Brgebnis der Untersuchungen Poch1s otellt eine Skizze ${ }^{285}$ dar, die auf Uberzeugende Welse Ursprung und Verbreitung des Sujets in Sudosteuropa widerspiegelt: 


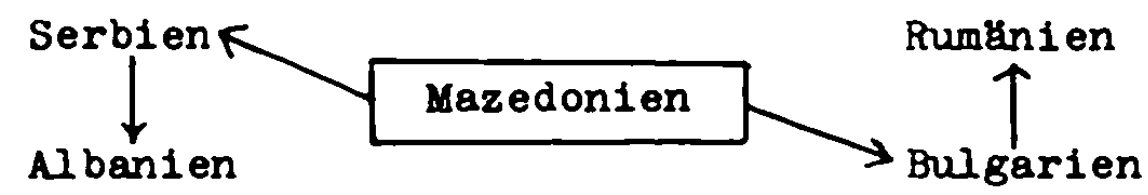

Wie aus dieser Skizze hervorgeht, konnte Pochi Mazedonien, woher allein etwa 20 Varianten stammen, als Ursprungsgebiet der Ballade feststellen, als deren genauerer Entstehungsort wohl die Stadt Thessalonike (Solun) bzw. die unmittelbar benachbarte Zone gelten darf. Dafir spricht gerade auch die vorwiegende Lokalisiserung des Iiedes in Solun, woraus sich schon fír das 17./18.Jh. (Beweis: EH 110) die skr. Ubertragung nach dem lautlich nahestehenden Solin an der jugoslavischen Adria verfolgen labt. Ubrigens waren in Thessalonike noch bis in die ersten Jahrzehnte des 20.Jh. mehrere an Dojcin geknupfte Sagen in Umlauf. Man zeigte sein Haus und sein Grab, und die slavische Bevolkerung felerte bis 1912 jedes Jahr im Mal die Erinnerung an Dojlin. AuBerdem vermutete man der Legende nach am Puß eines riesigen Nhormbaums in einem Stadtpark von Thessalonike das Grab des schwarzen Arabers, hangte am Westtor der Festung einen riesigen Knochen auf, den man flur eine Rippe des Arabers hielt, und verband den Namen "Araplija" eines Dorfes nordwestlich von Thessalonike mit dem Ort des legenduren Zweikampfes (Mil.155 ist eigentlich eine atiologische Iegende in Iiedform, in der der Dorfname Araplia durch des Dojein-Iied erklart wird!) ${ }^{286}$. Eine historische Persönlichkeit ist Dojein aber keinesfalls. Darin sind sich die Pachleute einig 287 .

Erstaunlicherweise macht sich Fochi keine Gedanken darluber,wer dieser Dojein sein konnte und ob das Motiv seiner langjuhrigen Krankheit und die Hufschmied- und Schwertfeger-Episoden in dem Sujet notwendig und ursprunglich sind. Zuerst zur zweiten Prage: Meines Erachtens sind die Eplsoden mit den untreuen Freunden (bzw. Wahlbridern) nicht urspringliche Bestandteile des Dojein-Sujets. In 80 gelungenen, altertumlich wirkenden und elnfachen Varianten wie Ml.155 und KaC.187 fehlen namlich die genannten Episoden, die wohl erst jungeren Detums sein durften und als retardierendes Element zur Spannungssteigerung bzw. zur 
Intensiviemung der qualenden liedstimmung eingefugt murden. Dadurch, daB der ohnehin schon durch langjahriges Siechtum kampfunfähig gewordene Dojein nun auch noch mit vollig unzulanglichen Waffen und unbeschlagenem Pferd in den Zweikampl mit dem riesenhaften schwarzen Araber zieht, wird der antithet1sche Charakter des Geschehens noch verscharft, die DavidGoliath-Situation noch mehr zugunsten des Unterdruckers verschoben, so daB der vorher unmbglich scheinende Sieg Dojlins umso groberes Gewicht erhalt. Dies zu errelchen, durfte der Sinn der spater eingebauten Episoden sein.

Die Prage, ob DojCin von Anfang an der Typ des jahrelang siechenden Helden war, lot schwer zu beantworten. Es stehen mehrere sludslavische ( $\mathrm{ggl}$. SbNU XIII,210; PPNP V,283; Radov.12) und rumänische ( $\nabla$ gl. G.D.Teodorescu: Poezil populare române, Bukarest 1885,S.577-581; Foch1,S.250) Iieder zur Vereugung, in denen die Ursache fur Dojlins Siechtum genannt wird : Er wurde auf Grund eines Verbrechens oder schweren Vergehens von Gott, einer Heiligen oder seiner eigenen Mutter dazu verdammt, jahrelang in schwerer Krankheit liegen zu mussen und erst nach $A b-$ lauf einer bestimmten Frist sterben zu konnen. Damit ricken die DojXin-Iieder in die Nabe der Iieder vom Typ ISSP V,330-34 (Nr.252 a-m) "Grešnik nakazan s dülgogodiłna bolest", in denen ein jahrelang Siechender von seiner lutter oder vom Popen nach der Uraache seiner Krankheit befragt wird, von seinem schweren Verbrechen berichtet bzw. seine sunden belchtet und dann entweder zu weiteren Jahren Siechtum verflucht wird bzw. endlich erlobst sterben kann. - In den Dojlin-Iiedern scheint der Gedanke zugrunde zu liegen, dab der zur strafe fur ein Vergehen oiechende Held erst durch selne Heldentat suhne leistet und nun seinen Geist aufgeben darf,- ein Motiv, des stark verchristlicht wirkt. Oder aber der siechende, halbtote Held als Kumper gegen den riesenetarken Araber wurde allein aus Grinden einer moglichst wirkungovollen Antithetik gewählt ( $\nabla g l$. den Typ des "verkannten Dummlings" oder des scheinbar schwachen, eben erst geborenen Heldenkinds als Gegner eines meist dimonischen Widersachers ().

Matov ${ }^{288}$, der das Bolen Dojein-Lied auf die Georgslegende zuruckfluren mochte, betont, auch der hl.Georg sel vor seinem 
munderbaren Kampl mit dem Drachen durch Martern kbrperlich v8111g geschwacht und gebrochen ("suisipan 1 izpotrosen") gewesen. Matov hat aber ubersehen, das der christliche Märtyrer von Gott jewe1ls immer wiederhergestellt marde, bevor man inn einer neuen Marter unterzog.

Mit der Behandlung der von Pochl nicht gestellten Frage, wer sich hinter dem Helden Dojoin verbergen konnte, kommen wir zum Kermpunkt des Problems. Ich mochte mit Matov 289 annehmen, daB der sonst nicht gebruchliche PN Dojein 290 in wirklichkeit ein Possessivadjektiv darstellt, und zwar eine Ableitung von trdoi$\delta_{\text {in }}=$ vdovidin (ein), 'Witwensohn' (zu bulg.,maz. vdorica 'Witwe') 1at. Mator engt jedoch die Frage m.E. zu sehr ein, wenn er den Namen Dojzin nur als Epitheton des hl.Georgs, der Waise war, ansehen mbchte. Man kbnnte vielleicht allgemeiner sagen, daß dieser Dojlin urspringlich zu den Heldenkindern zu rechnen ist, von denen wir bereits wissen, dab sie mit Vorliebe als Witwensbhne, Nachgeborene, Waisen und unehelich Geborene bezeichnet werden (in der griech. Volksdichtung lat der "Witwensohn" der fast atereotype Liedheldl). AuBerdem haben wir die Heldenkinder als beliebte Drachentrter kennengelernt. Fochi tut also das Problem vermutlich zu lelcht ab, wenn er mehrmals ( 5.487 1..510 f.) jede Beziehung des Bolen Dojzin-Sujets zun Motiv AaTh 300 bzw. zur Georgelegende leugnet und meint, die Ballade sel "infolge einer aus dem konkreten Leben stammenden Anregung entstanden, welche in klinstlerischer form vorbestehende Elemente und neue, aus dem Uberfluß des wirklichen Lebens entsprungene Elemente verschmolzen hat." Meiner Meinung nach ist jedoch das Bolen DojeinSujet aus dem Drachenkampf-Sujet unter Ersetzung des Drachent8tere duroh den oleohen Helden und doe Draohen duroh den echwarzen Araber sowie unter Einbeziehung neuerer Episoden und Elemente des Alltagslebens entstanden. Fur diese Ansicht oprechen sich auch Dzurinskif, Dinekov und Ivanov mehr oder wenlger deutlich aus. Die Sujetparallelen aind wirklich zu aufallend: Es erscheint ein Dracne bzw. als Substitution eln noch teilweise mit dimonischen Zugen ausgestatteter schwarzer sraber und unterdruckt eine ganze Stadt; er fordert taglich Menschen-, vor allem Jungfrauenopfer; endlich findet sich ein Held, der zu dem Kudchen, 
das gerade als Opfer an der Reihe 18t, in einer besonderen Beziehung steht, und rettet sie und die Stadt vor dem Ungeheuer. - Es wăre durchaus denkbar, daß der "besondere" drachentotende Held, der viellelcht urspringlich durch ein Heldenkind verkörpert wurde, später durch einen anderen Typ des scheinbar schwachen Helden, namlich den Siechenden, ersetzt wurde. Iroglicherwelse lot auch das kein Zufall, das in einer ganzen Anzahl Lieder unseres Sujets otatt des Namens "bolen Dojzin" der Name "bolen Georgi" oder "bolen G'ero", also Georg (vgl. Col.10; Sapk.431; Doz.40; ISSP VIII,475 unter "Bolen Georgi"), steht. DaB der schwaree Araber in vielen pallen oine Substitution des Drachen darstellt, wissen wir bereits aus anderen Sujets. Wenn er im Bolen Dojzin-Sujet melst sehr zurlickhaltend entweder gar nicht näher beschrieben oder nur als "dicklippig" (oder hyperbolisch: "Selne Oberlippe reichte bis zur Stim, die Unterlippe bis zum Nabel") bezelchnet wird, so lot dies eine Polge der fortschreitenden Entmythologisierung 291. Seine drmonischen zuge dokumentieren sich eher in seinem Verhalten. Auffallend sind jedoch gewisse Einzelheiten in Bolen Dojoin-Liedern, die deutlich an Drachenkampplieder erinnern.So he1Bt es z.B. in dem maz. Lied Radov.12z

Napadnala jedna tema megla Pod seloto, dolu livadjeto. Ne mi bila taja tema megla, Tok je bila orna Arapina.

Der schwarze Araber wird also hier, genau wie der Drache in einer Anzahl maz.-mbulg. Lieder, mit einem aich niedersenkenden dunklen Nebel verglichen. Oder aber der Araber wird - gleich dem Drachen - von den Heiligen aup die sundige Erde bzw. zu dem sündigen Helden gesandt, Vgl. PPNP V,283,

Ima vrome ova da se platit,

Zarto bo dojdi edna tezina,

Na Soluna od crna Arapina.

Ovoj jumak Arapa de zgubi,

Toga da ma se platat greojte.

Erwahnenswert lat vielleicht nooh die Tatsache, das z.T. auch Drachenkanpelleder (z.B. Sapk.15, Verk.-Lavr.86) in Solun oder sogar in Araplia (Stoil.II 13) lokalisiert sind. Abschliebend sel nooh angefuhrt, daB - analog zu den Lledern, in denen ein Held den Hoohreltszug statt ror elnem Drachen oder 
Araber vor einem Baren beschützt bzw. eine Stadt statt aus der Gewalt eines Drachen von einem Buren befreit - auch das Bolen Dojein-Motiv in der Form abgeandert existiert (vgl. Bezs.I 20 und 21; Vũrb.305: SbNU XXII,74 usw.), daB ein Bar jeden Tag ein Madchen PriBt und, als die Reihe an Stojans Schwester gekommen ist, von diesem getotet wird.

\subsection{ARAPIN-LIEDER}

Wie im letzten Kapitel versucht wurde, die Bolen DojCin-Lieder auf das Drachenkampl-Sujet zurlickzufunren, wobel der Drache durch die Gestalt des schwarzen Arabers eine Substitution erfahren hat, sollen nun auch die Haupttypen der Arapin-Iieder unter dem Aspekt einer möglichen Herleitung vom DrachenkamplSujet behandelt werden. Wegen der Materialfulle konnen die Iieder nicht der Reihe nach und ausfuhrlich besprochen werden. Dies ist auch nicht notig, denn es geht uns hier vor allem darum, in den Arapin-Liedern eine Abzweigung aus dem großen Kreis der Drachenkampflieder nachzuweisen.

Das erste Sujet warde bereits in Kap.4.41 angedeutet und konnte schon dort in direkte Beziehung zum Drachenkampfoujet gebracht werden. Es handelt sich um folgendes Handlungsschema:
Bin Held, entweder der stereotype Stojan oder - im Zeichen der Historisierung - der Königssohn Marko, reitet durch das Waldgebirge und findet dieses ver- welkt und verdorrt. Auf selne Prage, ob der Wald durch Feuer oder Reif so verwlistet worden sel, er- halt der Held die Antwort, weder Feuer noch Reif hat- ten ihm geschadet, sonderm ein Mohr (crni Arapin) ha- be drei Ketten Sklaven ( $t r i$ oindzira robi, tri verigi rob1), Junge manner, junge Prauen und Madchen, vorbe1- getrieben. Der Held läßt sich beschreiben, wo der Sklavenzug aich augenblicklich befindet, eilt ihm nach, totet den Sklaventreiber und befreit die Gefan- genen.

Dieses kurze Sujet komnt ausschlieBlich in Mazedonien und Bulgarien vor. Fur die skr. Epik im dinarischen Kerngebiet war es in dieser Form anscheinend nicht "liedfahig"; es lehlt daher in dem genannten Iledraum.

Als Argument fur die Herleitung aus dem Drachenkamploujet mogen. 
folgende Hinweise dienens In Kap.4.41 konnte ein Iiedsujet angefürt werden, in dem die Lamja, also der weibliche Drache, drei Ketten Sklaven treibt, die von Marko befreit werden. AuBerdem wurde die Weiterentwicklung dieses Handlungeschemas in Form des Sujets gezelgt, in dem Marko drel Ketten Sklaven aus der Gewalt der Samovila, also der Substitution des Drachen, befreit. Die dritte Stufe dieser Entmythologisierungsreihe ware nun das vorliegende sujet, in dem der crni Arapin, der Mohr, als Sklaventreiber fungiert. Auffallend 18t auch die Tatsache, daß der Wald dort, wo der schwarze Araber (bzw. die Samovila) vorbeigezogen ist, verwelkt und verdorrt. Dies durfte ein weiterer Beweis fur die Herkunft des Mohren vom Irachen sein, denn aus verschiedenen Drachenkampfliedern wissen wir, dab die Spur des Ungeheuers an verwelkten oder verdorrten waldern und Wiesen zu erkennen ist:

Deka mine, se povechne,

Deka stapi, se isachne (SbNU II,8).

Auch im HDA (s.v. "Drache") heiBt es, daß "die Tatsache des Feuerspeiens, das alles zerstort, das die Drachenbahn durch Funkenregen, die Drachenspur durch welke Blatter, ausgebrannte Rasenflecke, verwlistete Landatriche kennzeichnet" fur den Drachen typisch sei.

Wie schon in Kap.4.41 betont, wurde die Gestalt des Mohren nicht von ungefuhr in die Rolle des Sklaventrelbers gedrangt. Denn wir wissen, daß "Araber im Sklavenhandel eine wichtige Rolle spielten"292 . Der schwarze Araber, einerseits Symbol des brsen Prinzips (wie thn auch die griech. und alban. Volksdichtung kennt) und andererseits die typische Pigur des Sklavenhädlers, wird als nächste Stufe durch den Tirken oder Tataren, also den durch grausame zuge ausgezeichneten vertreter der unterdruckermacht, ersetzt ${ }^{293}$, die Liedhandlung aber im ubrigen beibehalten. Zu diesem einfachen Liedsujet gibt es folgende Varianten; Mil.148; Doz.36; Drag.7; KaX.126; Vurb.201; Jank.24; Kar.BNP 84 (und 1 Var.): Stoin TV 2869-2871 (verstlummelt); Stojk.,186,Nr.64a (hier kauft Marko als sekundures Motiv die Sklaven frei); Stoil.II 2 (hier ubersendet eine der Sklavinnen Marko durch einen Vogel die Botschaft, er möge die Gefangenen befreien). 
Dieeee kmappe Sujet wird nun im maz. Raiv vom ProzeB der Epielerwng und auoh Verchrietlichung erfaBt und erfahrt auf diese Welse verschledene Erwelterungen.

Zunkchst wird ein bescheldener Kahmen um die einfache Handlung gelegts Am Lledenfang helBt es, Krall Marko befinde olch auf dem Heg zur Kirche (zum Abendmahl). Dabel trifft er den Hald verwelkt an usw. Die Lledor ochlleBen damit, daB der Held nach der Befrelung der Sklaven sein urspringliohes Vorhaben ausfunrt und zur Kirche welterreltet. Nach diesem Schema sind folgende Varianten aufgebauts Kad.127-129; Jastr.,103; Ikon.24; .Z1vaja St.XIV,196; SbNU II,16; III,27.

Aus diesen Ansutzen folgt dann des erwelterte Sujet, in dem der urepranglioh bescheldene Rahmen zu ausfuhrliohen Anfangs- und Schlußepisoden ausgebaut murde, die folgendermaßen lautens
Marko hat langere Ze1t gefastet und s1ch 80 aup das Abendmahl am 0stersonntag vorbereitet. Br unterrich- tet Lutter und Gattin von seinem Vorhaben, zur Klo- oterkirche (Gradan1ca, Ravan10a, Dedan1, Athos) zu reiten, und laBt olch das Pferd satteln.Marko fragt seine Mutter, ob or Waffen mitnehmen solle. Die Mut- ter verneint mit der Begrindung, Narko gehe ja nicht zum Kampl, sondern reite aus einem frommen AnlaB weg. Bevor Marko aufbricht, fragt Ihn seine Gattin, wes- halb or keine Waffen trage, worauf Marko erklkit, die Mutter habe inm davon abgeraten. Dle kluge und weit- sichtige Prau jedoch, die sich der auoh auf den Weg zur K1rche lauernden Gefahren bewust 1st, versteckt in Markos Ausrlietung ein Messer und gibt dem Pferd die Anwelsung, es solle seinen Herrm darauf eufmerk- sam maohen, wenn dieser in Not 801 und elne Waffe brauche.- In manchen Varianten - und dies scheint ein sekumdärer Zug zu sein - nimmt Marko von sich aus keine Waffe mit und lat dann vor dem Kampl nit dem Sklaventrelber gezmugen, mit Hilfe selnes Pfer- des dem Araber seine Waffe gu entrelseen.

Das Mitteletulk des Sujete verluuet dann in weeentliohen wio in der genannten kurzen Fassung, nur das jetzt der Sklavenzug und die Binzelhelten des Kamples, den Marko auf Anraten des Pferdes mit Hilfe des versteckten Messers fuhrt, nkher beschrieben werden. In menchen Varianten will Marko die Sklaven zuerst loekaufen, wird aber von dem Mohren verhbhnt, b1s schlieblich das Pferd auf die in seiner mbhne versteckte Waffe aufmerksam macht und so seinen Herrn zum Kampl ermutigt. Dann folgt die Schlubepleode: 
Nach der Uberwindung des schwarzen Arabers und der Befrelung der Gelangenen setzt Marko seinen Weg zu der Klosterkirche fort. Dort angekommen, wagt or nicht, die Kirche su betreten, well or Blut vergossen hat. Nachdem Marko auf die Fragen des Abteo, warum or nicht in die Kirche eintrete, den Hergang der Sklavenbefrelung erzihlt hat, trostet ihn der Abt und meint, Narko habe kein Verbrechen, eandern eine gute Tat begangen. Daraufhin nimmt Marko das Abendmahl und kehrt nach Hause surlick.

In anderen Varianten reitet Marko mit dem abgesoblagenen Haupt des Mohren zur Kirohe, wo die versammelten Konige bzw. Monche herbelelien und thn za selner Befrelungstat begluckwinschen. Marko wirft darauf den blutigen Kopf auf den Opfertisch, lkBt aloh und den Sklaven das Abendmahl relchen, etiftet der Iirche die Halfte des erbeuteten Schatzes und kehrt mit den Befreiten nach Prilep zurluck, wo er sio spelst, beschenkt und denn elehen 1 ist. Oder aber Marko wird, als er mit den Sklavon zu der Kirche kommt, von den versammelten Glaubigen gerugt und gefragt, ob er denn gerade den Sonntag sum Sklaventrelben whilen musse. Auf diese Verdachtigung hin erzahlt Marko die Geschichte seines Kamples und des Sieges Uber den Gewalt tyter (eulumlfar), woraus alle Anwesenden einmitig erkluren, das sel keire Sinde, ondern Marko habe recht gehandelt. Der Held empfangt das Abendmahl, bekleidet und beschenkt dis beereiten Sklaven, labt ele ihres Weges siohen und kehrt selbst nach Prilep zurlick.

Zu diesem durch jüngere und christliche Zutaten erweiterten epischen Sujet gehrren folgende maz. und bulg. Variantens Jastr.,261; Jastr.,269; Tomit 4-6; Males.134; Sapk.340 und 401: Stoin SSB 315-317; SbNU II,102; II,135; XI,25; XIII,99; XIII, 5; XIIII,8; XIIII,9.

Dieses erweiterte Sujet scheint vom SO nach NW in den skr.Raum gewandert zu sein, wo es meines Wiseens nur in vier Paesungen aufgezelchnet 18t. Diese vier Ileder machen - Im Gegensatz zu den maz. und bulg. Varianten - alle elnen verderbten urd verotumelten Bindruck und gehoren damit sohr wahrecheinlich zu den Im skr. Iledraum sekundkren Sujets. In dem serb.Iled Stojk. $65 a$ (Brada Jovanovic 33, ohne Ortsangabe) ist das Sujet $8 . B$. folgendermaben abgeknderts

Marko w11l am 0stersonntag auf das Kosovofeld in dio K1rche zur Kommunion gehen. Auf don Rat oeiner Huttor hin nimmt er keine Waffen mit. Seine Gattin indelija, die Ihm das pferd sattelt, befestigt aber heimlich ein Schwert am Sattelknopl, das 810 mit oinem grauen Barenfell bedeckt. Bevor Marko aufbricht, oagt Ante- 
lija zu ihm, er solle hinter sich greifen, wenn er sich in Not befinde. Marko kỉmmert sich nicht um diese Worte und reitet davon. Auf dem Kosovofeld begegnen ihm 30 Turken, die drei Ketten Sklaven fuhren. Darunter befindet sich auch eine Wahlochwester Markos, die ihn durch ihre Tränen ruhrt. Marko, der sich ohne Waffe glaubt, will die Sklaven zunkchst loskaufen. Als er aber von den Turken verspottet wird, gerät er in Wut, greift hinter sich und ertastet das Schwert, mit dem er die 30 Turken alle totet. Er labt die Sklaven frel und reitet zur Kirche, die Hände bis zum Ellbogen blutig. Die Mónche wolien ihn so nicht einlessen, als Marko aber sein Erlebnis erzahlt, loben inn die Monche ob seiner guten Tat, geleiten inn in die Kirche und reichen ihm das Abendmahl.

Das lied wirkt sekundur verundert. Der fur die archaischeren maz. und bulg. Iieder so typische Auftrag an das redebegabte und ratgebende Pferd, es solle seinen Herrn im Notfall auf die versteckte Waffe hinweisen, ist hier - wie auch in den folgenden drei Varianten - weggefallen. Geblieben sind nur die von Narko zunkchst nicht beachteten Worte seiner Prau, er moge in Not hinter sich greifen. Ausgelassen ist auch das so wichtige Gesprach mit dem verdorrten Wald. Statt des (dumonischen) Mohren sind hier 30 Turken die Sklaventreiber. - In der Var. MH $I_{2} 65$ aus Banja Iuka feblt die Waffenepisode uberhaupt. Hier t8tet der bewafinete Marko auf dem Weg zum Kloster 60 Mohren und Ihren Anfuhrer, den "aga Arap-aga", und befreit die drel Ketten Sklaven. Anschließend folgen Belchte und Kommunion in der Kirche. Der Dialog mit dem Waldgebirge ist auch in diesem Fall weggefallen. - In der dritten Var. $\mathrm{MH} \mathrm{I}, 436$ (Pletikosic 4) aus Klis in Dalmatien geht die Motiveranderung schlieblich 80 weit, daß Marko barfub, waffenlos und ohne Pferd zur Kirche unterwegs ist. Er trifft 30 Turken. die zwolf Sklavinnen, darunter seine Wahlschwester, fuhren. Als er ihnen zuerst Geld bietet und darauf von den Turken verspottet wird, eilt er rasch nach Hause, kehrt bewafinet und beritten zurluck und metzelt die: 30 purken nieder, um die Gefangenen zu befreien. Als er dem Abt der Klosterkirche beichten will, erklart ihm dieser, Marko sei sundenfrei, täte aber besser daran, heimzukehren und in $\mathrm{Zu}-$ kunft nur noch zu pelugen. Der nun folgende liedteil otellt offensichtlich eine Kontamination mit dem "Marko als Pfluger"_ 
Sujet ( hort Marko nicht auf den Rat seiner yutter, Yferd und Warfen mit zur Kirche zu nehmen. Verfolgt von 100 Turken, den Treibern von drei Ketten Sklaven, muB Yarko zu PuB und unbewaffnet nach Hause fliehen, wo seine Mutter ihn schon mit Pferd und Waffen erwartet. Marko kehrt zurluck, totet die Halfe der purken, jagt die andere Hulfte in die Flucht und befreit die Sklaven.

Diese einer Uberwiegenden Nehrheit maz. und bulg. Varianten gegenuberstehenden vier skr. Lieder, die eindeutig einen verstummelten Eindruck erwecken, geben AnlaB zu der Vermutung, das das Sujet von der Befreiung dreier Ketten Sklaven aus der Gewalt eines Mohren maz.-bulg. Uroprungs und im okr. Raum sekundar 1st. Obwohl der Mohr in diesem Sujet nioht ausdricklich (wie es aber in vielen Hochzeitszugliedern wohl der Pall 1ot) als Wesen mit dumonischen Zügen beschrieben wird, konnte doch auf Grund der Sujetkhnlichkeit seine Herleitung aue dem Drachenwesen wahrscheinlich gemacht werden. In einem nahestehenden Sujet wird der von Marko beklumpte ochwarze Araber zwar auch nicht mehr ausdrlicklich mit dimonischen zlugen ausgestattet,jedoch sehr aufachluBreich als "ala-aletina ourna arapina"(Kioh. 346) und als "ala-arapina"(Mich.347) bezeichnet. In Stoin TV 2864 verlangt der Mohr nicht nur taglich ein urdchen als Geliebte, sondern fribt seine Opfer nach Drachenmanier sogar aue. Die Vermutung, daB es eich bel dem schwarzen Araber urapringlich um eine Ersetzung des Drachen handelt, scheint so gut wie bestatigt, doch kann sich die Gestalt des Mohren von der Drachenfigur mehr oder weniger entfermen.

Dem Drachenkampf-Sujet schon ziemlich fern oteht z.B. das Sujet, worln Marko die Bewohner des Kosovofeldes von dem sie unterdruckenden Mohren befreit, der den Leuten eine so hohe Heiratssteuer (skr. ovadbarina, bulg. ovatbina, ovatben danuk) auferlegt hat, dab die jungen heiratofuhigen Madchen und Manner unverheiratet altern. Hierzu sind folgende oldslavische varianten zu nennen: Vuk II 68; Maz.,21; MH I 7 ; MH I, $I_{2}, 338-344 ;$ SbNU VII, 95; XIIII,28; XIIII,57; Yer.Sp18.XXXVII-XXXVIII,248; Rod.Napr. VIII $_{2}, 54 .-$ Hier ist die schwere, fur die Unterdruckten unerschwingliche Heiratssteuer anscheinend ale eln sehr abgeschwäch- 
ter Ersatz flr die ursprunglich verlangten taglichen Menschenopfer Im Drachenkamploujet aufzufassen. Dieses Sujet von der durch Yarko "beglichenen" Heiratseteuer, womit Ironisch der Tod des Mohren umschrieben 18t, wird noch weiterentwickelt, 80 dab in den jungeren Varianten, die melat schon in Hajdukenmilieu fuhren, trotz deo Verbots des Mohren eine Iingierte Hochzelt veranstaltet wird und ein alo Braut verkleideter junger Held (melot Gruj1ca) den Mohren totet, vgl. die Ileder Vuk III 4; MIch.347; MIl.126; Šapk.418; SbNU X,84; XIIV,52; XIIV, 54 usw.

Dem Drachenkampl naher steht jedoch folgendes Handlungsechema: Ein ochwarzer Araber taucht auf und baut am Meer elnen prachtigen Wohnturm. Als er damit fertig 1st, achlckt er dem Sultan (Murad, Bajazid, Selim; oder Zar Kostadin, Sizman) einen Brief und fordert darin drohend deseen Tochter zur Prau. Er werde mit 1000 Svaten, lauter Mohren, kommen und die Braut abholen. In selner Not wendet olch der Sultan an Marko un HilPe (oder aber zuerst ochreibt der Sultan, dann die Sultanin, Marko antwortet aber erst auf den Brief der Sultanotochter). Marko antwortet, der Sultan oolle selne Tochter ruhis abholen lassen; er, Marko, werde ole dem Mohren auf dem Ruckweg rauben.- Der ochwarze Araber macht oich mit einem großen Hochzeitazue aup den Weg nach Konotantinopel, zieht durch die Straßen der Stadt, wo die Blarger vor Anget alle penoterladen eeschloseen haben, zum Palast und holt oeine Braut ab.- Bevor der Mohr elntrifet, begegnet Marko, alo er sein Pferd zur Wasoerstelle funrt, einem weinenden Mridchen, das dem see sein le1d klagt und sich ertrinken will, well ein Mohr es gefreit habe und nun abholen wolle. Marko erkennt die Sultanstochter, gibt sich thr zu erkennen und veropricht thr baldige Rettung. Die Szene kann sich auch am Meeresstrand aboplelen.- Auf dem Kuckweg ziehen die "Svaten" durch Prilep, wo ebenfalls alle Hauser verschlossen olnd und nur Marko mit seinem Schecken sich in der offenen Schenke aufhalt (oder aber der Zug kommt an der offenen Schenke schon in Konotantinopel vorbe1). Der Hohr labt anhalten und provoziert Marko zum Kampl. Marko totet den Bchrecklichen Gegner im Zwe1kampl, ochlugt die Ubrigen Mohren in die Flucht (oder totet sie ebenfallo), befreit die Sultanstochter und gibt ole threm Vater zurlick, von dem er dafur hohen lohn erhalt.

Ungefahr diesem Schema entoprechen folgende Varlanten: SbNU III, 1003 Drag.6; Sapk.VIII-IX,285 (e1n in Prosa aufgelöstes Iledl); SbNU XIII,72; KaX.124; Vuk II 65; Yaz.,37; M1lut.137; M1lut. 150 (sekundär verandert, aber in Kern noch deutlich zu erkennen); 
MH I $I_{2} 412$ (0otoj16 II 225; hier 18t der echwarze Araber oogar dreiköpfig!): MH I $I_{2} 414$ (Trmsk1 9); Iotareke,21 (etatt dee jultans bittet hier die Konlgin von Ungarn den Helden "Ive Kvadratine" brieflich, Ihr zu Hilfe zu ellen). Das gelungenste, Hethetioch wertvollete Iled dieser Gruppe ist zwelfellos Vuk II 65, gesungen von dem Meleterabnger Podrugovic, der sich auch un eine Yeychologiolerung der handlung bemunte:

ver Araber lot alo ausgesprochener whotling und. Gewalttuter gekennzelchnet. Er verlangt flur jede Nacht ein echones Mudchen, besiegt eine Reihe von Zwe1kumpfern und tritt echlieblich mit der drohenden Aufforderung an den Sultan heran, er moge $1 \mathrm{hm}$ oeine Tochter zur Prau geben. Meloterhaft geotaltet let denn der prophet1eche Traum der Sultanin, die Marko von Prilep alo Retter oleht. Wirkungovoll 1 et auch die dreimalige Stelgerung der an Marko gerlchteten Briefe, von denen erst der letzte, worín die Sultanetochter Marko ale Wahlbruder um H1lfe b1ttet, von Marko beantwortet wird. Alo Marko in pridcht1ger Ausrlistung nach Stambul reitet und nachte seinen Schecken im See trinken lubt, folgt die uuberst poet18che szene, wo die sultanstochter den grunen see anspricht, ihm ihr loid klagt und oloh ertrinken will, was aber durch Markos rasches Eingrelfen verhindert wird. Am nkchoten Tag verletzt Marko das vom Mohren erlaseene Verbot, die Sohenken offen zu halten, und totet auberdem noch den Brautfuhrer und Gevatter des Mohren, womit die Provokation zum Zwe1kampl gegeben 18t, der fur Marko olegrelch endet. Soerensen 294 halt dieses vollendete lled fur den Ausgangspunkt der bulg. Ileder Kac. 124 und SbNU III, 100, die oeiner Meinung nach nur elnen Abklatech davon darstelien. In dieser rigorosen Art kann jedoch die Frage der Beziehungen zwischen den maz.. bulg. und okr. Varianten nicht gelost werden. Vor allem wiesen wir heute, daß die kethetische Qualitut eines Iledes keinen Beweis fur dessen hohes Alter. darstellt. Gerade das Gegentell $18 t$ hulufig der Pall.

Berechtigt echeint indes die Vermutung, daß das im elldolaviechen Raum in relativ zahlreichen Varianten vertretene Iledeujet vom Drachenkampl-Sujet herzuleiten 1et 295 . Erotens iot der Mohr hier offenbar wieder die Substitution eines vrachen, der eine stadt unterdrlickt und Jungfrauenopfer verlangt. Zweltene halte $1 \mathrm{ch}$ die Szene flur aufechlubrelch, wo die sultanstochter sum see (oder Meer) geht, ihm weinend ihr Leid klagt und aloh ertranken will. 
Diese Stelle erinnert namlich an die Drachenkampflieder (z.B. Vuk V 249, ein Georgslied), worin die Königstochter, an die die Reihe als Opfer des Drachen gekommen ist, weinend an den See geht, in dem der Drache haust, un das Auftauchen des Ungeheuers abzuwarten, dort von dem Helden oder Heiligen nach inrem Kummer befragt und ochlieblich gerettet wird. Jordanov 296 mochte nach Art der historischen Schule das liedsujet auf das geschichtliche Ereignis der im Jahre 1353 erfolgten Heirat zwischen dem turkischen Emir Orhan und Theodora, der Tochter des Kantakuzenos, zurlickfunren. Es lat nicht von der Hand zu weisen, dab ahnliche historische Geschehnisse etwas zur Entwicklung eines Sujets beitragen können. Hier jedoch ocheint das alte Drachenkamploujet in der Weise "aktualisiert" worden zu sein, daß ein legendurer Herrscher und seine Tochter durch den türkischen Sultan und dessen Tochter,der heldenhafte Retter durch Marko (wobel vielleicht dessen Vasallenverhaltnis zum Sultan eine Rolle spielte) und der Drache durch den am Meer hausenden damonischen Mohren ersetzt wurden. Das legendure Element ist in diesem Sujet jedenfalls starker als das historische.

Zu erwahnen sind noch die drei Lieder SbliU XI,40, Kac.193 und Kad.218 aus Mazedonien und Viestbulgarien, in denen ein schones Madchen (nur in einem Fall handelt es sich um die Sultanstochter) einen Helden (Dete Malełkovo; Gruica detence; Serbin) um Hilfe anfleht, weil es dem im Hettbewerb siegreichen Hohren in die Hande fallen soll. Der Held besiegt den Unhold im Zweikamp 1 und rettet das Madchen.- Aupfallend an diesen sorst verderbt wirkenden Liedern ist die Tatsache, dab jedesmal ein Heldenkind (auch Surbin gehört unseren Erfahrungen nach dazu!) den schwarzen Araber besiegt, was vielleicht als welterer Hinweis - das Heldenkind als beliebter Drachentöterl - auf die Herkunft dieses Sujets vom Drachenkampfoujet zu werten ware. Eine Reminiszenz an die Rolle des Heldenkindes als Drachentöter ist vielleicht auch noch in den Liedern zu sehen, wo ein vom Sultan gegen Marko (wegen eines nichterlaubten Klosterbaus) entsandter Mohr elne Reihe von Helden, die alle Marko zu Hilfe eilen wollen (darunter Helden wie Debeli Novak, Gru- 
1ca, Tatomirce, Jankula, Milor Ogrjanin; Tadija od Senja, Ivan kapetan, serdar Wrkonjid, Ill ja Cmiljanib u.a.), nacheinander in Ketten legt, schlieblich aber von einem Heldenkind (Sekula detence; Sekul banovie, Gruica) ubermunden und getbtet wird. Dazu zahlen die Varianten Mil.143; Kad.164 und 165. SbNU XIII,118 und Delorko NEP I 32 (worin der schwarze Araber sogar dreikbpfig genannt wird).

\subsection{ERGEBNIS}

Der zentrale Tell der vorliegenden Arboit (Kap.4) behandelte ein Sujetfeld, bel dem sowohl die Sekundur- als auch die Primärschicht in der sudslavischen Volksepik nachgewiesen werden konnte. Zur Erorterung atanden zwel große thematische Pole, das Brautgewinnungsoujet auf der einen und das Drachenkampeoujet auf der anderen Selte, also die belden "Zentralthemen des epischen Schaffens in der Epoche des Zerfalls der urspringlichen Sippenordnung", wie Meletinaki j 297 die Yol-Themen "gerolCeskoe ovatovitro" und "bor'ba cudovidzami" nennt. Bei der Analyse dieser Themen stellte sich heraus, daB der umfangreiche Komplex des Drachenkamploujets mit seinen zahlreichen Abwandlungen (Kampl mit dem Drachen im See; Kampl mit dem Drachen im Brunnen; Vila brodarica-Lieder; Bolen Dojein-Lieder; Arapin-Lieder; in Verquickung mit dem Hochzeitezugaujets Kampp mit den Lamien im Yeer; Uberfall des Drachen oder drachenartigen Arabers auf den Hochzeitszug; liberfall durch die Vila; Kampf mit dem Drachen im Brunnen auf dem Hinweg zur Braut) eindeutig der archaischen maz.-wbulg. Primarschicht angehbrt, wahrend das andere Pol-Thema, das historisierte Sujet der exogamen Hochzeit nach dem Bestehen heldischer Preiersproben (sowie die Kombination dieses Themas mit dem (berfall-Motiv), zu der Sekundarschicht in der maz.-wbulg. Volksepik gehört. Dabei konnten im Laufe der Untersuchung mehrmals Entmythologioierungsreihen autgestellt werden, ausgehend vom Drachen (Lamja, Ala; Azdaja) Uber den damonischen Mohren und die brsgesinnte Pee (Samovila, Juda; Vila) zur Gestalt des Turken, Tataren oder Hajduken, wobei sich die Erkenntnis von Meletinskij 298 be- 
wahrheltete, daB die uraprunglichen mythischen Ungeheuer zunuchot einen jymkretismus mit den politiochen Peinden des Stammes elngehen und schlieblich ganz durch ole ersetzt werden. Als bevorzugter vrachentoter konnte der "besondere" Held, der Zmaj oder Zmej, der Vaterlose, Nachgeborene, Bastard,Zw1lling, durch besondere Geburt Ausgezelchnete, das Heldenkind festgestellt werden.

AuBerdem zelgte alch, daB - neben dem maz.-wbulg. Kaum als Beharrungogeblet des urchulschen Erbes - nach dem Gesetz der Peripherie auch das lebiet der dalmatinischen Inseln und der kroatiochen Kuste altertumlichere Zuge aufwe1st, als ole im dinarischen \%entralgebiet mit seiner olch oturmisch weiterentwickelnden, psyohologiolerenden und Bsthet1sch anspruchovolien Heldeneplk, die das Mythologieche nur noch rudimentur enthalt, anzutreffen waren. Die eplochen Isleder aus dem konservativeren Adriaraum sind aber durch den dinarischen liedraum hindurchgegangen und daher aut eine andere Art altertumlich alo die primar archaischen maz.-wbulg. Heldenlieder.

Interessante libereinstimmungen in Thematik und Motivgestaltung ergaben sich zwischen der an altertiumlichen mythologischen Themen ebenfallo reichen (oputer melot mit historischen Namen verbrimten) grlech. Volkseplk und den maz.-wbulg. Heldenliedern, so daB die Vermutung nahellegt, daB die griech. und maz.-wbulg. sanger aus elner alten gemeinsamen, nach Gattungen noch nicht differenzierten Grundschicht folkloristischen Materialo (die wohl auch der Marchendichtung uber die ethnischen Grenzen hinweg zur verfugung stand) geschbpet haben.

Abschließend soll elne schematioche Darstellung zur Veranschauliohung des in diesem Kapitel untersuchten oldolavischen Iiedmatortalo vorhelfen. 


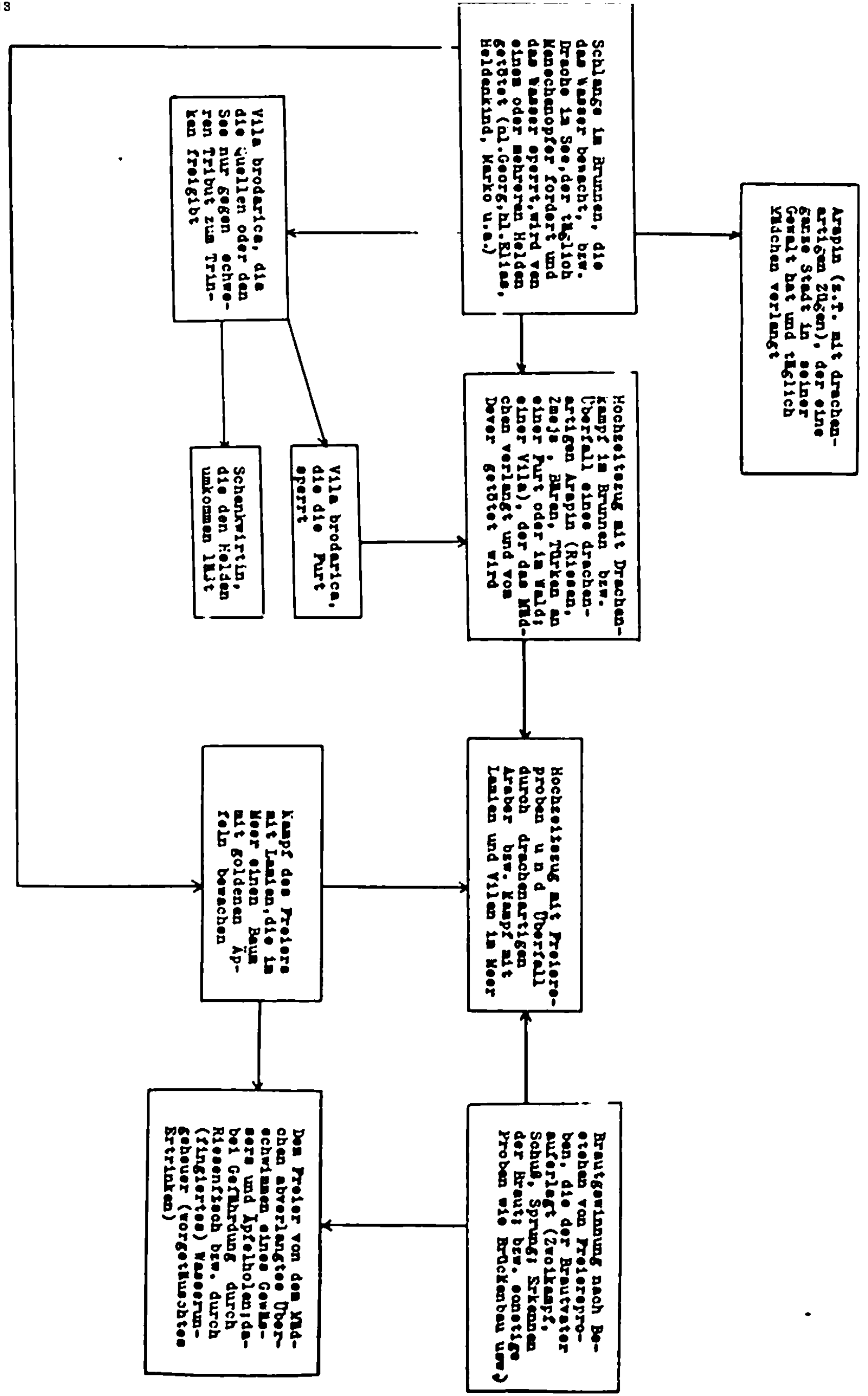


Nachdem in Kap.2 die zur Sekundurschicht gehorenden historischen Namen, die aus der skr. Volksepik zugewandert sind, und in Kap.3, 4.11 und 4.3 einige im ganzen ubernommene und nun zur maz.-bulg. Sekundarschicht gehorige Sujets untersucht wurden, sollen in diesem letzten Kapitel einige filr den urspringlichen maz.-bulg. Liedbestand typische Sujets, also Sujets der Primarschicht, besprochen werden. Bei diesen Themen handelt es sich um eine Auswahl, weil die Behandlung aller Sujets, die der maz.-bulg. primären liedschicht angehören, hier unmbglich wäre. Wie sich z.B. die Bolen Dojtin-Iieder (Iiedlokalisierung vorwiegend in Solun) als auf maz. Boden entstanden zeigten, so könnte man diesen Beweis vielleicht auch fur die Minja von Kostur-Lieder (Typ Vuk II 61; ISSF VIII,449 und 4801.: Liedlokalisierung in Kastoria!) 299 und ebenso fur die temo Brdanin-Iieder (Typ Vuk II 67; ISSF VI,184,Nr.27: Liedlokalisierung in Ohrid!) 300 fuhren. Zu dieser Primarschicht gehoren weiter auch die von $R$. Medenica 301 untersuchten Lieder von Banovic Strahinja, der untreuen Frau und dem Entfuhrer vlah Alija, Lieder, bei deren vergleichender Analyse sich herausstellte, dab die maz. Varianten, die noch nicht an Strahinja und die Jugoviti gebunden sind, der altesten Liedschicht (verglichen mit den jüngeren sliddalmatinischen und jungsten dinarischen Varianten!) angehoren. Ein Sonderfall ist mit den Mombilo-Liedern gegeben. Obwohl der historische Momil aus der ersten Halfte des 14.Jh. sicher in seiner bulg. Heimat (in den Rhodopen) in das Lied eingegangen sein durfte, tragen die heutigen bulg. und maz. Mombilo-lieder eindeutig sekundare Züge, wobei das Sekundärlied "nicht etwa auf eine altere Uberlieferung aufgepfropft, sondern mehr oder minder fertig geformt in seine alte Heimat zurlickgekehrt" 302 ware, d.h. der Liedstoff hat wahrscheinlich eine $\mathrm{N}-\mathrm{NW}$-Wanderung erlebt, erfuhr in nördlichen Liedgebieten seine volle epische Entfaltung und ist dann in seine urspringliche Heimat zurlickgewandert. 
Besonders charakteristisch fur den alten maz.-wbulg. Iledbestand aind Ileder mit mythologischem Gehalt. So konnte schon das groBe und fast zentral zu nennende Drachenkampl-Thema als zur Primarschicht im maz.-bulg. Iledraum gehoris nachgewiesen werden. EIne Auswahl weiterer thnlicher Themen 1 st in den nun folgenden Kapiteln zu erortern.

\subsection{KMMPF MIT EINEY UBERNATURIICHEN, ANTHROPOMORPHEN GEGNER}

Ein wichtiger anthropomorpher Gegner mit demonischen Zugen,namIIch die Gestalt des Mohren (curni Arapin), wurde bereits behandelt und in seinem Wesen als Substitution des Drachen erklart. Weitere anthropomorphe Gegner mit ubernaturlichen Zugen sind Musa Keeedzija mit mehreren Herzen, der zur Halfte oder ganz aus Stein bestehende Jude und das mit ubermenschlichen Kraften ausgestattete Riesenmadchen (Arvatka devojka).

In den $M \quad u \quad a \quad K$ e 8 e $z$ i $j$ a-Iiedern kumpet, verallgemeinermd gesagt, der Konigssohn Marko gegen einen weit uberlegenen Gegner, eben Musa. Der 2weikampl, der zuerst zu Pferd mit Streitkolben und Schwert, dann aber in Form eines Ringkampfes ausgetragen wird, dauert - nach epischer Schablone - drei Tage und drei Nachte, bis Marko schließlich mit blutigem, kusa aber nur mit weiBem Schaum (ein Beweis seiner Ubernaturlichen Braftl) bedeckt 18t. Marko droht zu unterliegen. In diesem Augenblick hochster Gefahr weist inn sein Pferd (dies ist die altere Version, vgl. die gleiche Rolle des Pferdes in den Arapin-Iiedern, in denen Marko an 0stern waffenlos zur Birche reitet und unterwegs drel Ketten Sklaven befreit) auf das von Marko ganz vergessene versteckte Messer hin (z.B. virb.285) oder aber - und dies lot die gelkufigere, aber jungere Form - Marko ruft seine Wahlschwester, die Pee 302 , zu Hilfe, die Marko entweder auf sein im Zopf oder Glutel verstecktes Messer hinweist bzw. Ihm selbst eine Waffe zusteckt, mit dem Marko den machtigen waffenlosen Gegner, der sich durch die Stimme der Samovila ablenken laBt oder dessen Aufmerksamkeit von Marko mit Iist auf die Wolken gelenkt wird (vgl. die Vila brodarica-Iieder!), totet und aufschlitzt. Im Korper Musas Iindet Marko mehrere $(2,3,9,12)$ Her- 
zen: Das eine von den zwel Herzer kamplte und hatte eloh bereite mude gekampft, das andere fing erst an eich zu erwarmen (KaC.168); oder zwel von drei Herzen waren schon mude vom Kampl, das dritte erwachte gerade (Tomic 3); oder das eine kamplte unermildich, das zwelte erwachte gerade und das dritte schlief noch (VIrb.285; SbNU XIII,52; Per.Spie.XCXIIXXXVIII, 243); oder das erste war schon ermidet, das zweite mit Schaum bedeckt und das dritte schlief noch (Kar.BNP 75); oder das erste hitte, nach Aussage der Pee, Markos Herz, das zweite Markos Gesicht und das dritte Markos Augen gefressen (Sapk.423); oder Musa besitzt neun Herzen (Kar.BNP 77), von denen eines schon ermudet war, das zwelte gerade erwachte und sieben noch schliefen (SbNU VIII, 100; er hat neun Herzen, we1l er von neun Ammen gestillt warde); oder aber von zwolf Herzen lot erst eines wach (Jastr.,60), was Marko dankbar zur Kanntnis nimmt, denn bel zwolf wachen Herzen ware es thm schlecht ergangen; oder Marko findet atatt eines Herzens neun Schlangen, von denen elne wach 1st, und totet ale auf Anjaten der Samovila (Mich.346). In den skr. Varianten hat Musa durchwes drel Herzen, von denen das erste schon ermudet, das zwej.te noch nicht kamplbereit und das dritte von einer geflugelten Schlange besetzt 1et, die Marko erklart, es ware ihm schlecht ergangen, wenn sie schon fruher aufgewacht ware.

DaB wusa mehrere Herzen besitzt, lst ein weiterer Bewe18, sogar der Hauptbewe1s flir seine tbernaturlichke1t. Hier liegt alcher die Vorstellung zugrunde, das ein Wesen mit mehreren Herzen, wobel das Herz als Sitz der Lebenskraft gedacht 18t, natlurich starker lot als ein normales Lebewesen mit einem Herzen. Aus einem ahnlichen Grund werden wahrscheinlich Hexen und Vampire im slavischen Volksglauben bfter mit zwei Herzen vorgestellt. Bezelchnend 18t, daß auch der Gigant Peloros, der von Ares todlich verwundet wird, aber erst beim Anblick des sterblichen Herakles sein Leben verliert, drei Seelen hat 303 . Wie Maretic (NNE,26i) vermutet, bedeuten die drei Herzen bel Musa eigentlich die Ixistenz dreier Eraftprinzipien, dreier Leben, d.h. der Besitzer dreier Herzen muB dreimal "eetotet" werden, bis er endlich "st1rbt." Dieser urapringliche Gedanke sel den Ilederm verlorengegangen, finde sich aber $z \cdot B$. in einer Erzahlung bel 
Vuk Karadzic (SNPr, 2.Ausgabe,S.185). An dieser Stelle sei an Vergils Aeneis erinnert, worin im 8. Buch Konig Euandrus berichtet, wie er in seiner Jugend Konig Erulus tötete und wie er ihn dreimal habe erschlagen mussen, weil Erulus drei Seelen besaß:

Et regem hac Erulum dextra sub Tartara misi, nascenti cui tri animas Feronia mater (horrendum dictu) dederat, terna arma movenda (ter leto sternendus erat; cui tum tamen omnis abstulit haec animas dextra et totidem exuit armis).

In der Var.Kad.169 ist zwar nicht von mehreren Herzen im Körper Musas die Rede, dafur wurde sekundar - als adaquate Entsprechung - das Motiv eingesetzt, daß der Leichnam Musas auf Marko fullt, unter dem sich Marko, wahrscheinlich weil Musa so riesig war, drei Tage nicht hervorarbeiten kann, bis er schlieblich von Fuhrleuten darunter hervorgezogen wird.

Daß dieser mit ubernaturlichen Zugen ausgestattete Gegner mehrere Herzen besitzt und von Marko nur mit Iist luberwäligt und getötet werden kann, diese Tatsachen rucken Musa in die unmittelbare Nahe des maz.-wbulg. Heldenkindes Dukadince. Auch dieses ist weitaus stärker als Marko, besitzt mehrere Herzen (drei Herzen in Kad.151; drei Herzen und auf dem dritten eine Schlange in Stojk.23; sieben Herzen in Drag.22; neun Herzen und auf dem neunten eine Schlange in SbNU XIII,86 und XIV,95; acht Herzen und eine Schlange in SbNU XII, zit.nach Marinov, SbNU XXVIII, 162) 304 und kann von Marko nur durch gemeine list von hinten getótet werden. Dieses Liedsujet ist vermutlich sehr alt, und der Name Marko fur den Gegner des Uberlegenen Heldenkindes wurde wohl erst spater eingesetzt. Ähnlich muß man sich wahrscheinlich die Entwicklung der kusa Kesedzija-Lieder vorstellen. Zugrunde liegt möglicherweise ein altes Sujet, in dem ein mit ubernaturlichen Zugen ausgestatteter Held, ein Heldenkind, von einem an sich unterlegenen Helden nur durch auBere Hilfe oder eine List getotet werden kann. Das lied war vermutlich urspringlich so angelegt wie die Dete Dukadince-Iieder, daß numlich die Sympathien auf Seiten des uberlegenen Heldenkindes lagen. Dafur zeugen noch Reste in manchen Musa-Liedern: Marko schlagt $2 . B$. dem Schmied, der ihm ein Schwert schmiedet, die Hand ab, weil er sagt, er habe bisher nur 
einem besseren Helden, nämlich Musa, ein besseres Schwert geschmiedet; oder Marko beklagt (am Iiedende) sein Schicksal, weil er einen Helden, besser als er selbst, getötet habe 305. Als aber das Sujet in der Feudalzeit mit den Namen Marko und Musa Kesedžija verbunden wurde, konnte dies deshalb geschehen, weil sich die Vorstellung des Ubernatülichen Gegners offenbar vom Positiven zum Negativen gewandelt hatte und aus dem Heldenkind mit dämonischen zugen nun fast ein Ungeheuer geworden war, das Wege und Schluchten sperrte (nach Art des Drachen ${ }^{306}$; vgl. SbNU XIVI, $5, N r .4$ ) und gegen das der Herrscher (der Sultan) zum Kampl aufrief. Marko, der positive Held, wurde nun im Dienste des Herrschers zum Retter in der Not, indem er einen sieg uber Musa erfocht. Das Sujet erfährt noch dadurch eine Erweiterung, daB der Sultan zuerst Wesire ausschickt, die von Musa entweder getotet oder ans Pferd gebunden und zurluckgesandt werden. Ein weiterea Ergänzungsmotiv (international? vgl. Zirmunskij, Vgl. Epenforschung, S.62 ff.) besteht darin, das Marko schon seit Jahren im Kerker des Sultans schmachtet, von diesem fur tot gehalten, aber auf Anraten einer dritten Person herausgeholt wird. Er beantwortet die Frage, ob er gegen Musa kamplen wolle, positiv unter der Bedingung, das man ihn und sein peerd zuerst monatelang pllege und wieder zu Kräten kommen lasse. Am Stamm einer verdorrten Eiche, aus der Marko Wasser zu pressen versucht, mibt erdie Zunahme seiner Kraft.- Ein durch Liedkontamination entstandenes Erweiterungsmotiv durfte (in den skr. Liedern) die Episode von Marko und dem Schmied Novak sein.

Da wir alle Entwicklungsphasen des Sujets, angefangen von den einfachen Handlungsschema des Zusammentreffens von Marko und Musa und ihrem Kampl Uber das Sujet vom Kamplaufruf des Sultans gegen den Wegelagerer Musa, der alle Wege und Schluchten sperrt, und der Meldung Markos zum Kampf bis hin zu dem um die Gefangenschafts- und Schmiedepisode erweiterten Liedern, deren prächtigste Vertretung im Lied Vuk II 66 gegeben ist, in den sudslavischen Varianten widergespiegelt finden, ist wohl anzunehmen, das das Sujet sich erst allmahlich aus bescheidenen Anfangen, die wir höchstwahrscheinlich im maz.-wbulg. Raum (wegen der Heldenkindtradition) suchen mussen, zu dem ästhetischen Niveau des Podrugovic-Liedes (Vuk II 66) aufschwingen mußte. 
Das Sujet hat, fur alle Entwicklungsphasen zusammengenommen, folgende Variantens Per.Sp18.XXXVII-XOXVIII,243; Karav.BNP 77 ; KaC.168; SbNU XXVII, 121; XXXIX, 25 XVI-XVII, 170; XIII,42; XII, 508 ZIII, 101; XXVI,76; XXXVII,88; XIII,52; VIII, 100; Drag.20; Sapk.423; Karav.BNP 75 (mit einem Entfuhrungsiled kontaminiert); Mich.346 (Nusa durch Arapin ersetat; Kontamination mit einem Entfuhrungsiled); Tomic 3 (mit dem Arapin-Sklaventrelber-Motiv kontaminiert); Vurb.285 (Musa durch Arapin ersetzt); Jastr..60 (Musa durch Korun ersetzt); Kac.169 (Musa durch Arapin ersetzt); Vuk II 66; Maz..34; Tomic,41; ParryLord 7: Saulic 24; $\mathrm{MH} \mathrm{I}_{2} 42 ; \mathrm{MH} \mathrm{I}_{2} 43 ; \mathrm{MH} \mathrm{I}_{2}, 415$ (Il1c 6); $\mathrm{MH} \mathrm{I}_{2}$ ' 415 (Ivandic 14); MH $I_{2}, 415$ (J.Klarie 17); $\mathrm{MH} \mathrm{I}_{2}, 415$ (Lovretic 5): MH $I_{2}, 416$ (Strohal I 53); art $I_{2}, 416$ (Vrbanic 7): Vuk VI 33 (Handlungsschema verandert; Musa durch Turken ersetzt; statt Narko drel Wahlbrider); $\mathrm{MH} \mathrm{I}_{2} 2$ (Musa durch Vila brodarica ersetzt) und die Varianten MH $\mathrm{I}_{2}, 328$ (Delic 46); MH $\mathrm{I}_{2}, 329$ (Marj. 5 und 6): $M H I_{2}, 330$ (M.Markovic 21); und MH $I_{2}, 331$ (Trnski 6), wobel die Beobachtung interessant 18t, das das Gefuhl fur das Ubernaturliche Wesen Musas bzw. seines uns unbekannten Vorgangers beim sanger anscheinend lebendig gewesen sein mus, denn sonst hatte er an dessen Stelle nicht eine andere ubernatirliche Gestalt - namich die Vila mit drei Herzen - gesetzt, ein Vorgang, der aus der Affinitat der beiden Iiedfiguren erklart werden kann.

Hinter Musa vermutet man entweder die historische Gestalt des Sohnes von Sultan Bajazid, eines kahnen und grausamen Abenteurers, der nach der Schlacht von Ankarra 1402 in den Thronkampfen eine wichtige Rolle spielte, bis er 1413 getotet und sein Bruder Mehmed I. Alleinherrscher uber das osmanenreich wurde. Oder hinter Musa verbirgt sich die Gestalt des Albaners Mojsej oder Mojsija, eines Vojvoden des Turkenkumplers Skenderbeg, der zeitweise auf Seiten des Sultans Mehmed II. kämpfte und von diesem wegen seines Abfalls um das Jahr 1464 gefoltert und getotet wurde 308 . Von diesem Musa ist schon bel Kacic-Miosic, der sich auf Barletius und Sagredo stutzt, die Rede:

I povede od Dibre viteza, Od starine plemica 1 kneza,

Po imenu Mojsiju vojvodu,

Srbski, pobre, Musu Arbanasa 309. 
Ruvarac 310 nimmt an, das der Masa der bulg. Ileder eine andere historische Gestalt sel als der Masa der skr. Ileder. hinter dem er den Vojvoden in Dienste Skenderbegs eleht. Diese 311 Melnung wird von Jordanov getellt, der flu den Musa der bulg. Ileder ausschlieBlich den Sultanssohn Musa in Anspruch nehmen mbichte. Dieser zweitellung der Iledgestalt lusa widerspricht aber m.E. die einheltliche, fur den skr. und bulg. Raun glelchermaben gultige Iieduberliefermg des thas-Sujets, Tur die sich vermutlich nicht mehr rekonstruteren $188 t$, welcher der beiden fur die kusa-Iledgestalt ausschlaggebenden historlschen Peroonen die Prloritat bzw. die Alleinvertretung zukommt. Wahrscheinlich handelt es sich un elne Verschmelzung der historischen Gestalten, deren Resultat eben unser Hasa in Iied sein durete.

Das Motiv des ubernatirlichen Gegners mit drel Herzen marde die Herzen zu Schlangen abgewandelt - anscheinend aus der skr. in die albanische Volksepik ubernommen. Hier findet der Held Im Le1b des erstochenen Gegners "drel Schlangen (tre gjarp1j). zwel schlafend, eine wach. Mujl bedauerts hatte er das friber gemubt, hatte er inm sogar das Toten des Bruders halll verziehen. Der Held mit den drel Schlangen im Bauch war etwas ganz GroBes. Ult thm besiegt man alle: 'Zusammen hitten wir Turken und Christen beherrschtl" ( Auch das Motiv der L18t in Zweikampl taucht Im albanischen Heldenlied auf: Mujl lenkt den Blick des Gegners zur Sonne und holt indessen das vergiftete yesser aus seiner Tasche, das die Ora 1hm zugesteckt hat ( $\nabla$ gl. Lambertz, Volksep1k,S.160).

Eine weitere mit Musa und dem damonischen Araber verwandte anthropomorphe Gestalt mit ubernaturlichen zugen ist der "zult evrein, zulta Cifutina, zúlta bazirgjana", also der $b$ e l b e $J$ u d e oder $g$ e $l$ b e $H$ \& $n d e r$, der den bl.Berg Athos mit Gewalt ausrauben oder mit Geld kaufen will und von Marko Kralevic getbtet wird. Das Iled ist in Solun lokalisiert und offenbar maz. Ursprung8. Es kommt in folgenden maz.-wbulg. Varianten vor: SbNU V,88 ( SbNU XIII,94; Per.Sp18.XXI-XXII,544; KaC.162; Rod.Napr.VIII ${ }^{\circ}$ 898 Bond.5 (nur der Anfang). 
Dieses Liedsujet wurde von $K$. Teodorov 312 in seinem Aufsatz "Naslojavanija v edna bilgarska narodna epiceska pesen" so grindlich behandelt, daß seine Ergebnisse hier summarisch wiedergegeben werden sollen. Eine nochmalige Untersuchung des Sujets erubrigt sich nach dieser vorbildlichen Arbeit, die höchstens noch durch einige Erganzungen vervollstandigt werden könnte. Nun zum Inhalt des Sujets:

Der Ausgangspunkt in diesem Lied (SbNU $V, 89$ ) ist die Tatsache, daß der "zullta Barirgjana", der Solun terrorisiert, $70 \mathrm{Könige}$ und 80 Bane getötet und aus deren Kopfen neun Turme mit Portalen aus Heldenarmen gebaut hat, dem alten Abt Slava des Athosklosters Hilendar einen Brief sandte, worin er ihn auffordert, inm den hl.Berg fur Geld zu verkaufen; weigere er sich, dann willden Äbte und rónche getötet, die Kloster ausgeraubt und verbrannt und mit ihnen die Evangelienbucher zerstört werden, so daß "vsicki narod bez zakon Ce stane"! Nach Beratung mit den Mönchen schickt der Abt zuerst Briefe in alle Welt, um Hilfe zu erbitten.Als dieser Versuch erfolglos bleibt,labt er drei Tage und drei Nächte Herolde durch Solun ziehen und alle Helden zum Kampf aufrufen,- doch es meldet sich niemand. Schlieblich scheint es unausweichlich zu sein, daß der Jude den hl.Berg mit seinen Schatzen kauflich erwirbt. Er schliebt mit dem Abt einen mundichen Kaufvertrag ab:

Suro dve dumi pazar napravili,

und der Abt erhalt von dem Händler so viel Geld versprochen, wie er nur transportieren könne; aber es dürfe nichts, vor allem keine Bucher, aus den Klostern entfernt werden. Da verbreitet sich das Gerlucht, der gelbe Jude werde die Athoskloster verbrennen; dies kommt auch Kralevid Marko zu Ohren. Marko beschlieBt nach einer Beratung mit seiner kutter, den Athos zu befreien, weil er durch eine solche Tat unsterblichen Ruhm erlange:

Ce otŭvnem Xista Sveta gora,

Ce ostarim spomen na zemjata.

Sollte er dabei umkommen, dann sei er fur seinen Glauben und im Kampf fur sein Volk gestorben. Marko sendet also dem Juden einen Brief, worin er ihm den Kampf ensagt:

Ne ti davam Xista Sveta gora.

Ne ti davam Ilindar munastirl

Ce ti secem nodze do kolena,

Ce ti sečm ruce do ramena.

Der Gegner antwortet, nur ein Zweikampl könne den erbitterten Streit um den hl.Berg entscheiden: Siege Marko, sei der Athos frei, siege der Jude, 80 werde er Marko an seine Eingangstür schmieden, um allen die 
Niederlage des berihmten Helden zu zeigen.- Am nuchsten Morgen macht Bich Marko auf den Weg nach Solun und sieht, wie der Jude gerade seinen Hof verlabt, um mit Marko zu klmplen. Da wird Marko von Purcht erfaßt ("uplasi se Marko Kralevike"), denn er erkennt die Uberlegenheit des Gegners:

te e gorko, junak nad junaci.

Das Pferd rit Marko zur Flucht, doch der Held ermannt sich und beginnt mit seinem Gegner zu kamplen. Zuerst schleudert der Jude seine Keule gegen Marko, der indes unverletzt bleibt, weil sein Pferd in die Knie geht. Als Marko nun die Keule gegen den Juden schleudert und ihn auf die Stirn trifft, wird nicht etwa der Kopf des Gegners, sondern die Waffe zerschmetterts

Razcapi se topuz na cetiri, A na junak ne Cue, ne ae!

Danach messen die beiden Helden auf Vorschlag des Juden ihre Kräte im Steinwurf: Marko wirft den Stein drei stunden weit, der Jude aber weit uber das weibe Meer. Da flurchtet sich Marko sehr ("virlo se e Marko uplasilo"). Schlieblich schlagt der Jude vor, uber seine Wohnturme zu springen. Marko schafft den Sprung nur mit groBer vihe, der Jude aber springt hoher und weiter als erforderlich. Marko gibt seine Niederlage im Dreikampl zu und soll folglich an das Portal des Juden geschmiedet werden. Er bittet aber den Sieger, er möge inn noch vorher von seiner Mutter Abschied nehmen lassen, was der Jude tatsachlich erlaubt. Als Markos Mutter den Hergang des Kamples erfahren hat, rat sie ihrem Sohn, den Juden dadurch zu toten, das Marko als Bettler verkleidet morgens zum Brunnen in Solun gehe und dem Juden die Beine durshschneide, wenn dieser sich zum Trinken niederbeuge; in die Brust zu stechen, sel sinnlos, denn der Jude hebs ein Herz aus Stein:

Ne moj udrja prez polovinata -

Kamenito e negovoto surce,

Ne ce moze pa da go pogubir -

Nalo machaj dole prez nozete,

Otreci mu nodze do kolena,

Ta pa begaj, kolko ¿e si mozes.

Marko halt sich im Morgengrauen verkleidet in der NGhe des Brunnens auf, als der schreckliche Jude kommt:

To e bila strasna chaletina ( 1 ).

Er druckt acht von den neun öfenungen des Brunnens $z u$, damit genligend Wasser herauslauft, und wäscht sich an der neunten:

Osưm Bopki bazirgjan zationa,

Na deveta voda $\measuredangle e$ si mie,

$\mathrm{Ce}$ e bilo junak nad junaci.

Da eilt Marko herbei und schneidet ihm die Beine unter 
dem Knie durch, flieht zu Pferd und wird von dem Leichnam noch drei Stunden verfolgt. Marko leidet nach diesem Erlebnis solche Angst, daB er drei Wochen lang zittert.

Das Iied schliebt mit der Verherrlichung des Nationalhelden Marko, der den hl.Berg befreit und die Iiturgieblucher gerettet habe, damit das Volk nicht "ohne Gesetz bleibe".

In diesem Lied hat Teodorov verschiedene Schichten festgestellt. DaB Marko hier als Glaubenskampfer und Verteidiger der nationalen Ehre auftritt, ist ein junger Zug, den man fur die Zeit der bulg. Wiedergeburt (18./19.Jh.) mit ihrem Kirchenkampl und dem beginnenden Nationalgefuhl ansetzen muß, denn zu der Zeit, als Marko vermutlich in dieses Iiedsujet einging (etwa im 15. Jh.), konnte von einem klar ausgepragten Nationalgeflihl noch keine Rede sein.- Der altertumlicher wirkenden, kurzen Variante SbNU V,88 fehlt Ubrigens die religiös-nationale Kamplmotivierung noch $\nabla 811$ ig:

Hier entscheidet kein Dreikampf uber das Schicksal des $h l$. Berges, der von dem Juden mit Gewalt eingenommen werden soll, sondern der Jude zieht mit 3000 Mann gegen Marko, die dieser mit Hilfe seines pferdes tötet oder in die Flucht jagt. Marko schlagt dem Juden den Kopf $a b$, der jedoch auf den Schultern sitzen bleibt. Da flieht Marko, verfolgt von dem enthaupteten Juden, und ruft seinen Gefahrten (Reijo u.a.) zu, sie soliten dem Juden Hindernisse in den Weg werfen, damit er stolpere und ihm der Kopl herunterfalle. Dies geschieht. Marko ersticht den Gegner und findet bei ihm drei Herzen,- ein Motiv, das aus den Musa-Liedern ubernommen sein durfte.

Ein jüngerer $\mathrm{Zug}$ durfte auch das kommerzielle Element in dem Lied SbNU V,89 sein, in dem der Handler um jeden Preis den hl. Berg kluflich erwerben will, whyrend die angedrohte Einnahme mit Gewalt einen alteren Eindruck macht (SbNU V,88). Sie ist ubrigens auch in den Liedern Mil.48 und Jastr.,208 gegeben, worin Sultan Murad bzw. Suleiman die Athosschatze fordert. Darin mochte Teodorov eine Widerspiegelung der zahlreichen Plunderungen sehen, denen der Athos im Laufe der Jahrhunderte ausgesetzt war. Jordanov313 fuhrt an, daB zur Zeit Selims I. und II. im 16.Jh. "e stanala prodažba na currkí i manastiri". - Zur Gestalt des Juden, der in dem glteren Lied SbNU V,88 noch "zŭlta cifutina" (gelber Jude) und in SbNU XIV, 35 "solunsko evrejze" (kleiner Jude aus Solun) heibt, bemerkt Teodorov, dab die jungere Bezeich- 
nung "bazirgjana" (Hündler ( pers. bazar gian, türk. bezirgân) erst durch die Turken vermittelt worden sei. Das Wort "zült", gelb, als Epitheton des judischen Handlers sei wohl darauf zuriuckzuführen, dab whhrend der Kreuzzluge (1096-1492) in mehreren wellen deutsche Juden nach Thessalonike gekommen seien, die wahrscheinlich wegen ihres blonden Aussehens AnlaB zu dem Wort "zult" gaben und wegen ihrer Gewand theit im Handel zum Prototyp des Handlers, des "bazirgjanin", wurden. Teodorov mochte die Ausbildung der Gestalt des "Zülta bazirgjana" auf die zeit nach 1387 ansetzen und als obere zeitliche Grenze fur die Einfuhrung dieser Gestalt in unser Sujet das Ende des 15. Jh. annehmen. Der "gelbe Jude" ist aber nicht die urspríngliche negative Iiedfigur in dem Handlungsschema, sondern er hat einen viel ulteren Riesen ersetzt, der, laut I. Burin ${ }^{314}$, m8glicherweise noch aus der heidnischen leit stammt. Feststeht, daB der Gegner Markos, vor dem dieser in Furcht erzittert, riesenhafte Ubersaturliche zuge besitzt und sich durch unermeBliche Kraft auszeichnets Er hat 70 konige und 80 Bane get8tet und aus den kypfen und Armen Turme gebaut; beim Trinken muB er von neun Brunnenrohren acht zuhalten, damit aus dem neunten genügend Wasser strömt; als sein Leichnam auf Marko fallt, kann dieser sich nur mit Hilfe seines Pferdes oder einer Gruppe Fuhrleute befreien (vgl. KaX.162; Jord.,LXXXVII; dieser Zug ist auch in das Musa-Lied Kad.169 ubernommen worden!); im athletischen Dreikampf (der ahnlich wie im Nibelungenlied aus Keulenschleudern, Steinwurf und Sprung besteht und altertimliche zuge aufweist, aber sicher nicht urspringlich zu dem beinschwachen Riesen gehörte), wird die Uberlegene Starke des Juden offenbar. Dieser heldische Dreikampf past naturlich nicht zu dem Hundler und gehort somit wohl einer alteren schicht an (von Teodorov dem 11.-13.Jh. zugeordnet). Der rieserhafte Gegner ist nicht ein Mensch aus Fleisch und Blut, sondern ein steinernes Wesen: die Keule zerschmettert an ihm, sein Herz ist aus Stein 315. Seine schwache Stelle aber sind die Beine. Man muß sie inm unter den knien durchschneiden oder ihn zum Stolpern bringen, dann kann er sich nicht mehr erheben. Seine enorme Lebensenergie beweist sich darin, daß er auch mit abgehauenen Beinen oder geköpft (der Kopf bleibt zunachst auf dem Rumpf sitzen und fallt 
erst beim Stolpern herunter, - ein Motiv, das an die Dete Dukadince-Lieder erinnert, in denen Marko das Heldenkind in der Mitte durchtrennt, die beiden Halften aber so lange aneinander haften, bis Dete Dukadince von Marko zum Bucken aufgefordert wird) den Gegner verfolgt.- Teodorov (S.223) verweist auf die Ähnlichkeit unseres Juden, hinter dem sich deutlich die Gestalt eines Riesen (zitovec, Zid, zidovina) verbirgt, mit dem Riesen Hrangnir der germanischen Mythologie, der ein dreieckiges steinemes Herz, einen steinemen Kopf und einen Schild aus Stein besaB ( $\mathrm{J}$. Grimm, Deutsche Mythologie I,499). Teodorov gibt zwar Erzählungen aus verschiedenen Gegenden Bulgariens und Mazedoniens an (SBNU I,119; SbNU II,161,164,165; III,191,202; IX,127), worin von stolpernden und danach sterbenden Riesen (zidove, in Mazedonien "elimi") die Rede ist, fuhrt das Motiv der Verwundbarkeit an den Beinen auf die zeit der Ritterrilstungen wăhrend der Kreuzzüge zurlick, verskumt es aber, einen Blick auf die Volksluberlieferung der benachbarten Griechen zu werfen, die in diesem $\mathrm{Fall}$ von groBem Interesse sein durfte. B.Schmidt ${ }^{316}$ erwahnt, als er uber die Riesen des neugriech. Volksglaubens spricht, die Ubertragung eines Zuges der jungeren Achilles-Sage auf diese Gestalten:

Denn auch das weib man von ihnen zu berichten, dab sie nur an einer Stelle ihres Leibes, nämlich am Knöchel, tödlich getroffen werden konner: gleich nach ihrer Geburt, erzlhlt man, tauchen ihre Mutter sie in einen Plus, wodurch sie am ganzen Korper unverwundbar werden mit einziger Ausnahme des Fußgelenkes, an welchem jene sie beim Eintauchen fassen und das in Folge dessen von jem stahlenden Wasser nicht benetzt wird (..). tubrigens war auch der die Insel Kreta bewachende eherne Talos nur unten am Knöchel verwundbar (..), und nach der spateren Sage auch Telamon's Sohn Alas nur an einer Stelle seines Körpers (..), wie Siegfried in der deutschen Heldensage.

Wir durfen also annehmen, daB das Motiv der unter dem Knie durchgeschnittenen Beine ${ }^{316 a}$ des Riesen in unserem erstgenannten Lied in Beziehung zur griech. Uberlieferung steht. Doch auch zu dem fur den Riesen todbringenden Stolpern gibt es griech. Belege bei Schmidt ${ }^{317}$ :

In Thessalien und Böotien erzäinlt man von ihnen [den Riesen], sie seien so groB gewesen wie die hochsten Pappeln und hatten sich, wenn sie niedergefallen, nicht wieder aufrichten können (vgl. Fauriel, Chants popul., Vorwort S.IXXXXI). 
Hier ist von den "Hellenen" (in Mazedonien und sudbulgarien in der Form "elimi, elini" mit der Bedeutung 'Riesen; Heiden' ubernommen), im neugriech. Volkgglauben allgemein ein untergegangenes Riesengeschlecht der Vorzelt ${ }^{318}$, die Rede. Schmidt will die

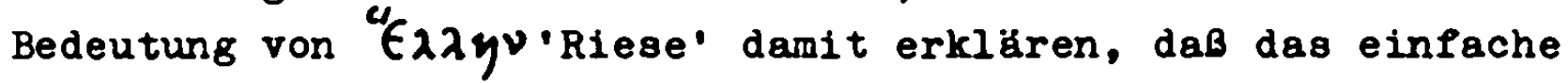
neugriech. Volk die Schopfer der riesenhaften antiken Bauwerke eben als Ubernaturlich große und starke Wesen auffabte, so wie die ungeheuren Bauten der pelasgischen Vorzeit von der hellenischen Nachwelt als "kyklopiache" bezeichnet wurden 319. Die Prage, warum in unserem Sujet vom "zülta bazirgjana" der urspringliche Riese durch die Gestalt des Juden ersetzt murde, beantwortet Teodorov so, daB der Riese - als Gestalt des heidnischen Mythos - und der Heide - als Peind des Christentums - in den Volksliedern einander angenăhert warden und zusammenfielen; auch Solun als "Aktionsbereich" sowohl des einen als auch des anderen könnte "edna vrizka po mjasto" geschaffen haben. Das wichtigste Argument Teodorovs ( 5.226 f.) aber 18t die Tatsache, daB das Wort "zid, zitovec, zidovin" in der Bedeutung 'Riese' (von altgriech. gigas; im Skr. auf Grund der phonetischen Gesetze und bei möglichem romanischem EinfluB, vgl. ital.gigante, franz.géant, Uber ${ }^{+} \mathrm{dzig}$ zu dzid ${ }^{320}$, die Unterscheidung zid und dzid im Skr. Lst laut Matl das Ergebnis eines Differenzierungsprozesses, um den Hebrăer und den Riesen auseinanderzuhalten) mit dem Wort "zid, zidin, zidovin" in der Bedeutung "Jude' (latein. iudaeus, ital. giudeo), dessen Verwendung schon fir altbulg. Denkmaler des 10.Jh. bezeugt ist, zusammenfiel. Aus dem Zusammenfall dieser beiden Gestalten in unserem lied resultieren die widersprichlichen Zuge der Gestalt des "gelben Juden". Der Zusammenfall, meint Teodorov, erfolgte etwa im 15.Jh. Doch auch der Gegner des Riesen war, nicht von Anfang an Marko Kralevid, sondern sicher einer jener uns namentlich nicht bekannten liedbelden aus der Zeit, als der byzantinische Diplomat Nikephoros sregoras 1325-1326 bei seiner Reise durch Mazedonien und Serbien seine Begleiter in der waldreichen Struma-Gegend verschiedene ihm unbekannte Helden besingen hörte. Dieser Vorganger Markos wurde im Kampl mit dem Riesen besiegt und bediente sich schließlich anderer Mittel, un den Gegner doch zur strecke zu bringen. Einst war aber zweifellos der Riese die Hauptfigur des Iiedes; 
deshalb erleidet der sprter als Gegner eingesetzte Marko Angst und Niederlage, die Schicksal seines namenlosen Vorgangers waren, den er möglicherweise im Laufe des 15.Jh. ersetzte.

Eine weitere Riesenfigur, diesmal in weiblicher Gestalt, ist die $A v a t k a$ a $v$ a j $k$ a (Zlata ot Arvata) der maz.wbulg. Lieder. Die riesenhafte Amazone gehört in den Kreis solcher Iledgestalten wie Musa, Dete Dukadince und Zülta bazirgjana, die dem "Normalhelden" auf Grund Ubermenschlicher Eigenschaften Uberlegen sind und deshalb nux mit Hilfe listiger Praktiken besiegt werden können. Wegen der Affinitut dieser Gestalten kommt es naturlich zu gewissen Motiventlehnungen von einem Sujet zum anderen. So hat der "gelbe Jude", der riesenhafte Gegner Markos, z.B. in einem Iied drei Herzen, ein Motiv, das aus den Musa-Liedern abernommen warde und auch in die Arapin-, Vila brodaricaund, was uns hier besonders interessiert, in die Lieder von dem Riesenmadchen (vgl. Marj.3) eingedrungen ist. Weiter wurde das Motiv, daB Narko sich von dem Leichnam des Riesen nur mit fremder Hilfe befreien kann, auch in die Musa-Iieder eingefuhrt. Oder aber der flur die Dete Dukadinđe-Lieder typische Zug, daß das von Markos Schwert durchgetrennte Heldenkind noch weiterreitet und erst nach einem von Marko veranlaBten Blicken in zwe 1 Teile auseinanderfallt, hat auch in die Riesenmadchen- und Züta bazirgjana-Lieder Eingang gefunden.

Wegen der Namensuhnlichkeit (Arvatka - Arapka) oder aber wegen der Affinit der mit übernatürlichen Zugen ausgestatteten Liedgestalten Arapin und Arvatka kam es zu einer Namenslubertragung in mehreren Arapka-Liedern (z.B. Kad.132 und 171). Statt Arapka, also an Stelle des Mohrenmadchens, das den im Gefangnis schmachtenden Marko befre1t, von 1hm aber nicht, wie versprochen, zur Trauten genommen, sondern wegen seiner abstoBenden HaBlichkeit getstet wird (vgl. Lieder wie Mil.54, Vuk II 63 usw.) steht nun der Name Arvatka devojka. Umgekehrt findet sich in dem Lied BNTv I,692 ( x Archiv Rakovski I B 1-344), das das Arvatka-Sujet behandelt, statt Arvatka der Name Arapka.

Zu dem eigentlichen Arvatka-Sujet, also den Liedem von dem nur durch List besiegbaren Riesenmädchen, gibt es folgende Varianten: SbNU I,62 (= Sapk.398); II, 100 (hier: "neznajna devojka");II, 107 (hier: devojka Rusanta); X,80; XIII, 11 (hier: Zlata ot Arvata); 
XIII,78; XIII,86 (hier: Voinka devojka); XIV Nr.26,38,43; Sapk.6 (hier: Rusalka); Romanska BNPTv,94; Kac.170; SbNU XIX, 37; BNTv I,692 (hier: Arapka).

Von dem alten, urspringlich sicher einheitlichen Sujet bestehen mehrere Variationen. In SbNU I,62 verlkuft die Handlung so: Marko sitzt mit seiner Mutter beim Abendessen und wird von seiner stolzen Mutter wegen seines Heldenmutes gerunmt. Marko damplt inre Begeisterung, Indem er erklurt, es gebe andere Helden, die ihm wohl uberlegen seien. Als die Mutter vor Enttkuschung weint, tröstet sie Marko und sagt, da sel z.B. das ihm luberlegene Mudchen Arvatka gewesen, das er dennoch besiegt habe. Das sei damals so gewesen: Es versammelten sich 30 Helden, darunter Marko, in der Nkhe der stadt Arvat an einem Brunnen. Dort erblickten sie einen an einer Kiefer hangenden Muhlstein. Auf die verwunderte Frage der Helden, was das zu bedeuten habe, antwortete ihnen ein Hirte, der Baum sel die Spindel und der Mhlstein das Spindelrad von Arvatka. Neugierig, dieses Madchen zu sehen, zogen die Helden nach Arvat, forderten am Hof des Madchens EinlaB und behaupteten, sie wollten Milos mit Arvatka verheiraten. Eine Sklavin hies sie warten, bis Arvatka zurlickgekehrt sei. Die Helden stiegen vom Pferd und warteten bis Mitternacht. Da kam von ferne ein leuchtender Stern auf den Hof zu; das war aber kein Stern, sondern Arvatka. Die Helden begribten sie und erklurten, sie wollten sie als Braut flr Milos freien. Arvatka willigte freudig ein und lud die Helden zum Trinken ein. Marko Jedoch zog heimlich sein Schwert, un das Riesenmadchen zu toten. Arvatka bemerkte seine Absicht und trieb die Helden witend mit ihrer Peitsche (troostra kamdijja) in das Verlieb, wo sie sie einsperrte und bis osterm schmachten ließ: Zum Reigentanz der Mädchen fehlten aber Tanzer, worauf Arvatka ihre 30 Gefangenen aus dem Kerker freilieb und sie zum Mittanzen aufforderte. Weil die Helden aber nicht fuhig waren, Arvatka beim Oro zu fuhren, trieb sie die Manner mit der Peitsche ins Gefangnis zurlick und kehrte allein zum Tanz zurlick. Da rief ein Kuckuck und verriet den Helden, wie sie sich befreien konnten, und flihrte alle, bis auf Marko, mittels eines Hares heraus:

Site 81 gi na vilakmo izvede.

Arvatka kam zurlick und war witend, als sie alle Helden bis auf einen geflohen fand. Whinrend sie sich zur Verfolgung auf den Weg machte, verlieb Marko, der das Geheimnis des Schlosses nun kannte, das Verlieb, verkleidete $81 \mathrm{ch}$ als Mónch und ritt dem Mädchen nach, das inn zu einem Wettrennen aufforderte. Marko entschuldigte sich damit, daB sein perd noch unerfahren sei, und machte das Mudchen darauf aufmerksam, daB sich angeblich - sein Stiefel gelockert habe. Arvatka lieB sich tiuschen, beugte sich nieder und wurde in dem 
Augenblick von Markos Streitkolben getroffen, so daB sie in zwei Halften auseinanderfiel:

Ot ednogo dvamina stanala.

Marko holte seine Gefkhrten ein und verkundete ihnen, daB Arvatka besiegt und getotet sei.

Wie mir scheint, liegt hier folgendes, fur alle Arvatka-Iiedder gultige Sujet zugrunde, das wir sonst nur noch in Marchen finden, das sich aber im Iied allein in dem durch archaische Zuge gekennzeichneten maz.-wbulg. Raum in dieser ausgeprägten Form erhalten hat:

Eine Gruppe Helden gelangt in die Nhe einer fremden Stadt, wo sie durch ein Zeichen auf die Anwesenheit eines Riesenwesens aufmerksam gemacht werden. Durch ihre Neugierde fallen sie in die Hunde des Ungeheuers und werden von ihm eingesperrt. Alle Helden bis auf einen wagen die Flucht (mittels magischer Hilfsmittel), und nur der letzte, der starkste Held, mochte das Ungeheuer toten. Da er sich der eigenen Unterlegenheit bemubt ist, greift er zu einer list und uberwaltigt das Ubermenschliche Wesen auf diese Weise.

Das Motiv von dem Ungeheuer, das Helden gefangen halt, schlieblich aber von einem besonders ausgezeichneten Helden mit list getotet wird, ist uns als Marchenmotiv mit ausfuhrlicher und spielerischer Ausmalung wohlbekannt.

DaB die Riesin mit einer gewaltigen Spindel spinnt, ist ein altes Sagenmotiv, das sowohl in den nordischen Sagen (vgl. Grimm, Deutsche Mythologie, S.517 f.) wie auch in der griech. Uberlieferung vorkommt:

Ihre [d.h. der Giganten] Weiber, ihnen selbst gleich an Wuchs, spinnen am Rocken, ihre Spindeln sind von gewaltiger Grobe und Schwere. Als einst die Riesen gegen einen Konig Krieg flurten, schleuderten deren Prauen ihre Spindeln auf die Feinde und erschlugen so Tausende von ihnen. 320 a

Auch die Plucht mit magischen Hilfsmitteln 1 st uns aus dem Marchen bekannt. In dem oben erwahnten lied handelt es sich bei der Plucht "na vlakno" sicher un das Motiv, daB ein Schlob nur mit Hilfe eines Haares geoffnet werden kann (im alban. epischen Lied offinet ein Zauberkraut verschlossene Kullen, vgl. Lambertz, Volksepik, S.154). In anderen Varianten, und das scheint weniger altertumlich zu sein, bricht einer der Gefangenen das Schlob mittels eines im Stiefel versteckten Messers auf; oder aber einer der Helden (Relja) ist geflugelt und tragt seine Gefuhrten nach- 
einander zur Kaminoffnung hinaus ins Preie.- Dazu ist zu sagen, daB Relja vermutlich erst dann, als er in der sudslavischen Volksdichtung allgemein als geflugelter Held vorgestellt wurde, fur ein wohl urspringlich theriomorphes geflugeltes Lebewesen (vielleicht: Motiv der dankbaren Tiere?) eintrat.

Das alte märchenhafte liedoujet marde dadurch im Sinne der sludslavischen epischen Volksdichtung verändert, daß man später die beliebten "Heldenkataloge" (Jankula, Sekula, Mombil, Gruica, Relja, Pavel u.a.) mit Marko an der Spitze einsetzte, einen gewissen epischen Rahmen schuf (Marko erzahlt die Begebenheit seiner Mutter beim Abendessen; drei Heldenmutter unterhalten sich uber ihre Sohne; Marko wird brieflich von den Bewohnern der Stadt Arvat zum Kommen aufgefordert), das Sujet durch zahlreiche Motivubertragungen erweiterte (Arvatka terrorisiert ein ganzes Land und labt keine Hochzeiten stattfinden, vgl. die Arapin-Lieder; Arvatka fordert von Marko einen Stern vom Himmel, doch Marko trifft statt des Sterns absichtlich das Mädchen, vgl. die in Kap.4.12 behandelten Viła gurkinja-Lieder; beim Zweikampp pließt aus Marko Blut, aus dem Riesenmadchen aber spriht Feuer, vgl. die Zúlta bazirgjana-Lieder; das von Marko zweigeteilte Madchen klagt nur uber Herzschmerzen und fullt erst beim Bucken auseinander, vgl. die Dete Dukadince-Lieder; das Riesenmadchen besitzt mehrere Herzen, vgl. die Musa- und Dete Dukadince-Lieder usw.) und durch Brauchtumselemente "aktualisierte" (Arvatka tanzt an 0stern Oro; sie geht an 0stern zum Abendmahl; Arvatka bringt den eingesperrten Helden, um sie uber die Jahreszeit zu informieren, an Ostem ein rotgefurbtes Ei, am Georgstag ein Lamm, am Peterstas einen "Petersapfel" - petrova jabuka -, am Nikolaustag einen Karpfen und am Johannistag "Johanniswasser"). Die Riesenstarke von Arvatka zeigt sich darin, daB sie Utensilien von gewaltigen Ausmaßen besitzt: eine Riesenspindel, einen Riesenhut und eine Riesenfeder (diese wird von den Helden der Reihe nach - in epischer Steigerung - immer ein Stluckchen weiter hochgehoben, wobei natiurlich Marko sich als der Sturkste erweist), womit - pars pro toto - die gewaltigen MaBe der Riesengestalt angedeutet werden. In einem Lied (SbNU $X, 80$ ) fliegt Arratka sogar durch die luft, ein Zug, der wahrscheinlich aus den vilen-Iiedern ubernommen wurde. Ihre Riesenkraft wird vor allem 
darin offenbar, daß Arratka ein ganzes Heldenteam opielend băndigt, dab sie sogar ein ganzes Land terrorisieren kann. Solch eine Gegnerin ist naturlich mit gewöhnlichen Waffen nicht zu schlagen, sondern kann nur mit Hilfe listiger Praktiken uberwaltigt werdens Marko, als monch verkleidet und ohne plerd und Waffe, erklart dem Riesenmädchen, es sei zwar ein "junak nad junaci", konne aber als Prau doch nicht richtig nach Mannerart reiten und den Sabel schwingen; als Arvatka sich täuschen läßt und Marko lembegierig Pferd und Waffe Uberlabt, besteigt Marko das pferd und totet die nun unbewafnete Gegnerin. Oder aber Marko totet sie, nachdem er ihre Aufmerksamkeit listig auf ihren Schuh oder auf den Himel gelenkt hat. Oder Marko, als hungernder Bettler getarnt, soll von der mitleidigen Arvatka in der Stadt Madzar (stereotyp statt Arvat) Essen erhalten; er labt Arvatka vor sich reiten (vgl. die Dete Dukadince-Lieder) und totet sie von hinten. In einem anderen lied ruft Marko, der im 2weikampf mit dem feuersprihenden Riesenmädchen zu unterliegen droht, seine Schwester (sein Bruder hat sich geweigert, ihm Hilfe zu leisten, weil ein Kampl von zwei Mannern gegen ein Madchen unehrenhaft se1) zu Hilfe, die inn auf das in Stiefel versteckte Messer hinwelst, mit dem er die waffenlose Gegnerin ersticht, ein Motiv, das an die Musa-lieder erinnert, nur dab die hilfreiche Samovila durch die Schwester ersetzt marde. Oder aber der Held (hier Relja) behauptet betrugerisch, er wolle nicht mit der Riesin kämpfen, sondern sie zur prauten nehmen, nur wage er das nicht wegen ibres schweren Mantels; das Mädchen läbt sich tauschen, schlagt zu Pferd den Mantel auseinander und entblobt damit seine schwache Stelle, die Taille (tank'i polovini), worauf es von Relja erstochen wird.

Die Frage lat nun, wie es zu dem in den Lledern uberwiegonden Namen Arvatka und dem davon abgeleiteten Arvat grad ( $\mathrm{g} g$. Madzar grad, Legen grad usw. als Ableitungen aus einem Ethnikon) kam. Dinekov 320 meint, es sei sehr schwierig, wenn nicht unmoglich, Arvatka devojka als eine historische Gestalt zu erklaren. Jordanov 321 dagegen vermutet, das den "stidslavischen Amazonen" Gestalten der Realitat zugrunde liegen. Die Arratka devojka unserer Lieder möchte er von "avrat-alan" (turk. avrat 'Prau'; alan 'Peld, Ebene, Iichtung'), wie Koprivatica in einem Perman von 1453 be- 
zeichnet wird, ableiten; durch Metathese sei aus "avrat" Arvat(ka) geworden. Dieser Ferman wurde von einer relchen Zugewanderten aus Rila erwirkt, die 1453 nach Edime zum Sultan ging und von ihm die Herrichaft luber Koprivitica sowie groBe Privilegien (2.B. daB kein turk. Reiter ihr Territorium betreten durfte) zugesichert erhielt. Banakevid $321 \mathrm{a}$ uusert berechtigte Bedenken dariber, ob die türk. Bezeichnung Avratalan aus dem Ferman auch wirklich im Volk bekannt und verbreitet war. Denn durch Jirecek (GAB,S.453) wissen wir, daB die Bewohner von Koprivłtica ihre herrin "gultanija" und deren Abkommlinge "sultanekovci" genannt haben. Wahrscheinlicher als diese zwar nicht uninteressante, aber doch zu mechanische Ankonlipfung an eine historische Person scheint mir der Erklürungsweg des Namens Arvatka durch ein Ethnikon. Chalanskij 322 hat aber vermutlich nicht recht, wenn er Arvatka von der griech. Bezelchnung fur die Albaner (op $\beta<v<\tau \alpha \zeta)$ ableiten mochte. Das -t- in Arvatka kann sicher nicht aus "arvanit" erklart werden. Ich möchte mich lieber fur eine Ableitung des Wortes Arvatka bzw. Arvatska devojka (wie es in SbNU $X, 80$ heiBt) von dem Ethnikon Hrvat bzw. Hurvat 'Kroate' entscheiden, von dem es im skr. und bulg. Raum die Sonderformen Harvat(in) bzw. Charvat und Arvat (Adjektiv "arvataki") gibt 323 (vgl. das Akademieworterbuch und die worterbucher von kladenov urd Gerov). Wie es zu dieser Ableitung gekommen sein mag, ist schwer zu erklaren. Auf jeden Fall entstand die Gestalt des "kroatischen Madchens" sicher nicht in Kroatien, sondern vielmehr in einiger Entfernung, eben im maz.-wbulg. Raum. Haufig ist es so, daß man die politischen Feinde und Eroberer der Vergangenheit später uberdimensioniert und mit Riesen gleichsetzt,wie dies z.B. bei den Hunnen (niederdeutsch Hune, russisch chyn 'Riese'), den Avaren ('echisch obr, polnisch olbrzym 'Riese'), Ungarn (franzbsisch ongre 'Ungeheuer, das Kinder verschlingt') und Spalen (aksl. spolin; bulg., russisch 18polin; polnisch stolin, stoIym 'Riese') ${ }^{324}$ der Pall war. Die Kroaten waren aber im Laufe der Geschichte nie Unterdrucker der Bulgaren, so dab die obige Erklurung hinfullig wird. Möglicherweise hat aber die Vorstellung eines fernen Volkes, das noch dazu einer anderen Konfession angehorte, zur Benennung der Riesengestalt beigetragen. Banasevic $324 a$ versucht eine Erklarung auf dem Weg, daB er die "Arvatka 
devojka" der maz.-wbulg. Iieder aus der "Hrvatka devojka" des Langzeilenliedes Bog. 38 bzw. Ghnlicher, uns vielleicht nicht erhaltener Iieder herleiten möchte. Er halt es für möglich, daß die Iiedgestalt dieses Madchens, das in dem erwähnten lied einen als Kaufmann verkleideten Turken, der es zu Pferd entfuhren will, luberlistet und in dessen Kleidern und auf dessen Pferd zurickkehrt, nach suden wanderte ("kao sto su dosle pesme o Janku, Sekulu i drugim junacima sa severa, koji su narocito popularni u macedonskim pesmama") und, auf Grund der Ähnlichkeit der Rolle ("junak-devojka"), in den maz.-wbulg. Riesenmad.chen-Liedern der Riesin den Namen gab.

Befriedigend ist bisher keine Erklarung, auch wenn fast jeder Erklärungsversuch etwas fur sich hat.

Das "kroatische Mrdchen", eine kriegerische Riesin, steht natürlich der Gestalt der $H$ e $l$ d e $n$ j u $n$ f $r$ a u 325 nahe, wie wir sie in den altgriech. Amazonen, den Schildmaiden und Walkuren der germanischen Epen, den "kuhnen Heldenjungfrauen" (udalye polenicy) der russischen Bylinen, der Maximo des Digenis Akritas-Epos und den orientalischen Marchen und Epen vertreten finden. Dennoch ist unsere Arvatka eher eine Riesin, die erst mit Kampfereigenschaften und -attributen belegt wurde, nachdem sie "liedfuhig" geworden war. Pfeil, Bogen, Streitkolben und Pferd waren sicher nicht von Anfang an ihre Ausristung, wharend diese Attribute mit der Heldenjungfrauengestalt untrennbar verbunden sind. Ein echt heldischer Zweikampl, wie er zwischen Heldenjungfrau und Preier statfindet, fehlt zwischen arvatka und ihrem Gegner. Statt dessen spielt die List eine groBe Rolle, d.h. eine Praktik, wie man sie weniger einem gleichwertigen heldischen Gegner, sondern eher einem Ubermachtigen Ungeheuer bzw. ubermenschlichen Wesen gegenuber anwendet.

Den besprochenen Varianten aus dem maz.-wbulg. Raum stehen drei skr. Lieder gegenuber, zwei davon aus der Gornja krajina und eine aus der Gegend von Makarska, d.h. es handelt sich nicht um Iieder aus dem dinarischen Kerngebiet, sondern von der kroat. Peripherie, die ja haufig archaische Sujets bewahrt hat (Gesetz der Perpherie!), zwar nicht in dem Ausmaß wie der maz.-wbulg., aber doch viel mehr als der dinarische Raum.- Die ersten beiden 
Lieder, $M \mathrm{IH}_{2} 49$ und Marj.3, tragen beide die Überschrift "Kral jevic Marko i dzidovka djevojka", d.h. das "kroatische Mädchen" heiBt hier einfach "Riesenmadchen", was fur den kroat. Raum verständich ist, weil dort die Bezeichnung "kroatisches Mädchen" im Sinne von 'Riesin' undenkbar wäre. In $\mathrm{MH} \mathrm{I}_{2} 49$, das einen verstummelten Eindruck macht, erzahlt Marko seiner Mutter folgendes Erlebnis:
Marko reitet mit seinen Gefuhrten Relja von Pazar und Milos od Pocerja durch das Waldgebirge. Sie Pin- den einen Straußenflugel, den Rel ja bis zur Schulter, Milos bis zum Gurtel und Marko nur bis zum Knie hoch- heben kann. Auf dem ebenen Feld treffen sie das Rie- senmädchen, das sie Pragt, ob sie Marko kennten, wor- auf alle drei einen falschen Schwur leisten. Die Rie- sin schlagt ein Zelt auf und legt sich zur Ruhe. Re- lja geht hin und schlagt die Schlafende mit dem Kol- ben, worauf die Riesin erwacht. Als auch noch Milos zuschlägt, wird die Riesin whtend und verfolgt die drei Helden. Als sie die Fluchtenden fast schon ein- geholt hat, schleudert Marko seine Keule und trifft die Verfolgerin tödlich, deren abgeschlagenes Haupt den Helden noch versichert, sie habe Marko nicht ge- sucht, um mit ihm einen Zweikampl auszutragen, son- dern um inm treue Liebste zu sein.

In diesem lied fehlen die wichtigen Szenen der Gefangennahme und Befreiung der Helden. Die riesige StrauBenfeder gehört,wie wir aus den maz.-wbulg. Liedern wissen, der Riesin; das wird jedoch in der kroat. Var. nicht gesagt. Einzusehen ist auch nicht, warum Marko, der sich beim Heben des plugels als der Schwächste erwies, ausgerechnet bei der Tötung der verfolgerin der Starkste sein soll. Es fehlt auch das Motiv der bei der Uberwindung der Riesin angewandten List. Nach all diesen Verstummelungen zu schließen, durfte das Lied wohl im Zuge einer NW-Wanderung nach Kroatien gelangt und dort sekundar sein. Marj.3 behandelt das gleiche Motiv, ist aber etwas breiter ausgesponnen:

Eingangs steht die Szene, daB sich die Mutter der drei Helden Uber ihre Söhne unterhalten, Marko dazukommt und das Erlebnis mit dem Riesenmadchen berichtet. Der Straußenflugel ist hier so uberdimensional, dab inn die Helden weder aus dem Weg schaffen noch mit dem Pferd uberspringen können, sondern an dem Plügel vorbei einen Weg flir sich und die pferde graben mussen. Als die Helden in der Weinschenke sitzen, kommt Didovka mit einem goldenen Spinnrocken und 
einer silbernen Spindel herein, den Straußenflugel hintere Ohr gesteckt, und Pragt, wobei sie die Spindel auf Markos Stiefel aufstutzt und dem Helden dadurch groBen Schmerz bereitet, die beiden Gefknrten Relja und kiloz, ob sie Marko kennten, was die zwei schworrend verneinen. Die Riesin geht, gefolgt von Marko. Als er ihr erklkrt, er sei Marko, will sie inn mit ihrer Spindel erschlagen, worauf Marko in die Kirche flieht. Von dort aus erschieBt er Dzidovka mit einem Pfeil und findet, als er inren Korper offnet, drei Herzen darin und auf dem einen eine dreiköplige Schlange, von der Marko erfuhrt, es ware ihm schlecht ergangen, wenn sie ihn eher bemerkt hatte.

AufachluBreich ist hier die Betonung der Spindel als Wafe der Riesin. Die riesige Feder ist nun in richtige Beziehung zu ihrer Besitzerin gebracht. Markos Flucht in die Kirche ist naturlich ein sekundares christliches Element. Das Motiv der drei Herzen stamm aus den Musa-Liedern.

Das einzige kroat.Iied (Bozk.NEP II 19), worin das Madchen Ervatka bzw. Arvatka divojka und seine Burg Ervat bzw. Arvat grad genannt werden, gehort deshalb nicht hierher, weil das sujet vollig umgestaltet warde und Ervatka statt einer Riesin hier eine richtige Heldenjungfrau darstellt:

In Mannerkleidem und Kriegerausristung tritt sie unerkannt unter dem Namen Hervo barjaktar (Bannertrager) in den Dienst ihres vom Sultan zum Heeresdienst berufenen Verlobten Valjen Becir-aga, besiegt die anderen Helden im Steinwurf und Wettrennen, Perner den Herausforderer des Sul tans, Diliki ja Luka, im 2weikampf mit der Lanze. Als ihr Verlobter nach Beendigung des Feldzuges seine Leute nach Ervat schickt, um die Verlobte abholen zu lassen, reitet Ervatka mit der Truppe. Es gelingt inr aber, vorauszureiten und sich umzukleiden. Als der Brautigam traurig nach dem Verbleib des Ervo Pragt, klart sich alles auf.

Wir haben hier also ein der Realitat mehr angenghertes verkleidetes Heldenmudchen vor uno, das von dor urspringliohen Riesin nur noch den Namen bewahrt hat und auch diesen z.T. schon verändert trägt: aus Arvatka wurde Ervatka, was sicher wieder aus dem im kroat. Raum verstandlichen Bemluhen resultiert, statt "kroatisch" ein anderes Wort zu wahlen.

Zusammenfassend labt sich sagen, daB das Arvatka-Sujet wahrscheinlich aus dem maz.-wbulg. Raum stammt, dort vielleicht unter griech. Einflub entstand und nach $N W$ wanderte, wo es in wenigen kroat. Liedem in verstlumelter Form erhalten $18 \mathrm{t}$. 
Wegen der Affinitut der besprochenen Ubernaturlichen, anthropomorphen Liedgestalten Musa, Zulta bazirgjana und Arvatka untereinander, aber auch gegenüber dem Drachen, der Vila und dem ochwarzen Araber konnten wir zahlreiche Verquickungen und Motiventlehnungen beobachten, z.B. was die Totung durch Anwendung einer list anbelangt.

Die Lieder, deren Sujet den Kampl mit einem Ubernatirilichen, anthropomorphen Gegner beinhaltet, können wir nach dem Gesagten wohl zu Recht der maz.-wbulg. primaren Iiedschicht zuordnen.

\subsection{HELDENKIN D-LIEDER}

Den Typ des $\mathrm{H}$ e $l$ d e $\mathrm{n}$ k $\mathrm{n}$ d e 8 , d.h. des Helden, der nach seiner Geburt mit Ubernaturlicher Schnelligkeit heranwächst. gibt es in den Mythen. Sagen und Epen vieler volker. Volch Vseslav'evid, der Held der russischen Byline, last sich, genau wie Mger im armenischen Epos "David von Sasun" oder Jung-Roland in der 18lundischen "Karlmagnus-Saga", nicht in Windeln wickeln, sondern fordert schon anderthalb Stunden nach seiner Geburt eine Stahlrustung, elinen goldenen Helm und eine 300 Pud schwere Streit. keule aus Blei 326 . Auch bei den Griechen, den nachsten Nachbarn der slidlichen Sludslaven, finden wir eine sehr alte Heldenkindtradition. Wir haben bereits Zeugnisee fur die altgriech. Zeit, 2.B. In der Gestalt des Herakles, der als Kind in der Wiege zwei von Hera gesandte entsetzliche Schlangen, die sich ihm um den Hals wanden, am Genick packte und mit einem einzigen Druck erstickte 327 . Doch auch die griech. Nkritenlieder (ein von Polites fur die heroischen Lieder, die vielfach Grenzkämpe zum Thema haben, gepragter Name: Akritika tragoúdia) bieten uns Beispiele für die Beliebtheit der Heldenkinder. Da lat z.B. der zweite groBe Sagenkreis (nach den Digenis Akritas-Iiedern) der neugriech. Heldenlieder, die die Abenteuer des Kostandàs behandeln, der oft auch durch Porphyrios, Proseyrkas, Kroseyrkas, Theophylaktos $u$. a. ersetzt wird oder an Digenis' Stelle steht. Wir kennen eine ganze Reihe von Liedern (deren schönste Varianten vor allem aus Zypern stammen), worin die Kindheit des Helden geschildert wird, der "sofort nach seiner Geburt seine Kraft durch ungeheure PreBgier zeigt, am ersten Tage schon den Backofen leerfribt und 
nachher gar tausend Schweine, ein Kamel am Spieb usw. verzehrt" oder, kaum geboren und getauft, schon Schwert und Lanze verlangt und prahlt, er sei ein großer Held ${ }^{328}$. Weiter gehört zu diesen "akritischen Liedern, deren Entstehung man im IX.Jh. wahrscheinlich machen kann"329, das alteste uns textlich erhaltene Lied, nämlich die aus dem 16.Jh. stammende Textaufzeichnung des AmurisLiedes, dessen Held, der Sohn des Amuris, mit Ubernaturlicher Schnelligkeit heranwächst, mit der Ausrlistung des Vaters (nach mehreren Kraftproben vor seiner Mutter) in den Kampf zieht, den Euphrat luberquert und allein ein ganzes Sarazenenheer niedermetzelt, worauf der Emir den gefangenen Amuris freigibt und sich dessen Heldensohn als Schwiegersohn erbittet. Ein weiteres hierher gehörendes Lied, dessen Inhalt "ohne Zweifel eine Episode des Akritenzyklus "330 bildet, hat ebenfalls ein Heldenkind als Protagonisten:

Die von Sarazenen und Raubern geraubte Gattin des Andronikos gebiert einen Sohn, der, ganz ahnlich wie Digenis, ungewöhnlich schnell heranwachst, nach einem Jahr schon das Schwert fuhrt, nach zwei Jahren die Lanze schwingt und nach drei Jahren bereits als Held geachtet wird:

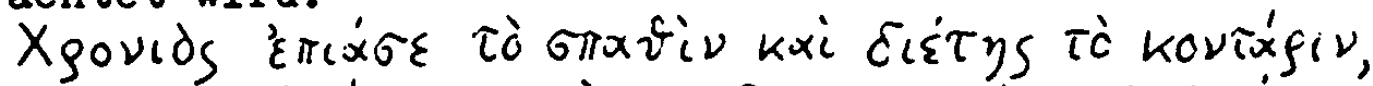

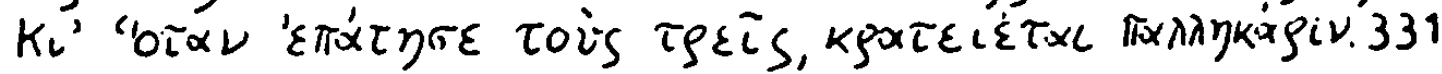
Er l\&Bt sich von den Sarazenen, die seiner Meinung nach schlecht im Sprung abschneiden (er beobachtet sie bei Wettspielen), mit Ketten und Fesseln binden, sprengt dann die Bande, Uberspringt neun Pferde und setzt sich auf das zehnte. Es gelingt ihm, zu seinem Vater zu fliehen. Er gibt sich ihm als Sohn zu erkennen und fei ert mit seinem Vater das Wiedersehen.

Mag diese akritische Heldenkindtradition auch - was sehr wahrscheinlich ist - auf die Volksdichtung der sudslavischen Nachbarn eingewirkt haben, so hat der maz.-wbulg. Liedraum doch die Entwicklung entscheidend weitergefinrt und etwas hervorgebracht, was wir sonst meines Wissens nirgends finden, nämich einen zur regelrechten Kategorie erhobenen Typ des Heldenkindes. Diese Heldenkinder, deren Alter zwischen einigen Stunden und mehreren Jahren schwanken kann, kommen haufig durch ubernatürliche Empfangnis oder Geburt (vgl.S.Thompson, Motif-Index: T 510 "Miraculous conception" und T 540 "Miraculous birth") zur Welt, ein Motiv, das nach Meinung von Veselovskij (Istoriceskaja poétika, S.533-538) in seinen altesten Formen wahrscheinlich mit der Vor- 
stellung der Parthenogenese zusammenhängt, die auf die Zeit des Matriarchats zurlickgehen dürte. Das Motiv zeigt in maz.-wbulg. Raum folgende Variationen: Ein Engel oder Heiliger haucht der Mutter in den Mund, und sie wird schwanger davon ( $\nabla g l$. SbNU XI, 30; XVI-XVII, 147; also eine verchristlichte Version der ubernaturlichen Empfängnis); sie wird schwanger durch Anstecken zweier Hyazinthen (Kax.113), durch Tragen eines Buchsbaumzweiges auf dem Kopf (SbNU VII,116) oder durch den Genuß eines Apfels, einer Fischflosse oder -schuppe (Bog.Kn.43); oder aber eine Prau trăgt neun Monate lang eine Steinplatte im Gürtel, und die Platte verwandelt sich entweder selbst (vgl. Marinov, SbNU XXVIII,161) oder durch göttliches Eingreifen (Mil.67) in ein Kind; oder das Kind bleibt, drei Jahre im Mutterleib und läbt sich bei der Geburt nicht helfen (Stoil.II 13); das Neugeborene erweist sich als Zmej-Abkömmling mit Flugeln und Schweif (Naurno Spis.III,12), vgl. den albanischen "drangue", einen geflugelten Helden, der die "kulsheüra" tötet (Çabej, Albanische Volkskunde,S.368); bei der Geburt des Wunderkindes donnert es mitten im Winter (Karav.BNP 95), vgl. ähnliche Vorzeichen bei der Geburt des russischen Bylinenhelden Volch Vseslav'evit, des kirgisischen Zauberrecken Almambet usw. (Žirmunskij, Vergleichende Epenforschung,S.58 f.); das Kind ist ein Nachgeborener, Sohn einer Witwe (Mil.40,50a,59; Stoil.II 13; Karav.BNP 137), ein Bastard (Stoin TV 1401) oder ein 2willing (I1.54;SbNU IX,6;Virb.440).

Das Heldenkind ist durch besondere $z$ e $i$ c $h$ e $n$ als ungewöhnlich hervorgehoben: Es trägt kleine goldene Flügel an den Schultern (Mil.50a; KaX.113; Karav.BNP 137), auf der Stim einen goldenen Stern oder ein Kreuz (Mil.50b; Kad.113) und besitzt mehrere Herzen (drei in KaC.151 und Stojk.23; sieben in Drag.22; neun in SbNU X,73; XIII,86; XIV,95; zw8IP in Mil.122 und Karav.BNP 78) ${ }^{332}$.

Die Frage ist nun, wie man die Erscheinung der Heldenkinder erklären soll. Popov 333 spricht zwar von zwei Kategorien Helden, deren eine die Heldenkinder, die "junaci nad junaci", die in enger Beziehung zur "mythischen Periode" stehen, die andere aber die von inm als "prosti junaci" (mit Marko an der Spitze) bezeichneten Helden darstellen; er aubert aber keine Vermutung dariber, wie es wohl zu dem rätselhaften Typ des heldenhaften Kindes gekommen 
eein konnte. Chalanskij334, der in der slavischen Volksdichtung immer und uberall deutsche Einflusee sucht, meint auch hier,das Wort "dete" als Bezeichnung fur einen jungen Helden sei die Ubersetzung des deutschen "kint" in der Bedeutung 'junger Ritter'. Hier lat einzuwenden, daß "dete" keine Lehnubersetzung der deutschen Bezeichnung fur 'junger Ritter' sein kann, denn die Heldenkinder im maz.-bulg. Raum gehören bestimmt schon der vorfeudalen Zeit an und sind uberdies wirklich als kleine Kinder im Alter von wenigen Stunden bis zu mehreren Jahren gemeint, und nioht etwa "junge Helden", wie Chalanskij sie sehen mochte. Penco slavejkov335 dagegen will die Heldenkinder damit erklaren, das er sagt, das Volk habe Marko "in seinem gekrinkten Herzen begraben und den Blick in die Zukunft, auf die Kinder gerichtet". Penev 336 wlederholt (ohne slavejkov zu nennen) diese symbolischidealistische Erklaringsweise, wenn er meint, im Bewubtsein des Volkes sei Marko entthront und durch neue Helden ersetzt worden, durch neue Inkarnationen seiner Ideale und Truume, eben durch die Heldenkinder. Der schopferische Geist des Volkes blicke in die ferne Zukunft, erfulit vom Glauben an die kommenden Generationen, an die Kinder, die starker sind als Marko und inn besiegen. Diesem Erk'tungaversuch ist entgegenzuhalten, daB die Heldenkinder ja viel altere Liedfiguren als Marko sind und das Marko erst nachtraflich mit ihnen in Verbindung gebracht warde. Die naivate Meinung kuBert wohl Jordanov"337, wenn er agt:"Bez vojako armnenie tezi deca-geroi $v$ juznoslavjanskata epika se javjavat kato ekvivalentni na crergite, no ne sa crergi, a malki deca". Die Heldenkinder sind also seiner Ansicht nach ein äquivalent zu unseren zwergen, doch sel die Ausbildung des Typs Heldenkind wahrscheinlich auch durch die Tatsache gefordert worden, daB in der Drin-Gegend tatskohlich nackte Kinder anzutreffen seien, wie Hahn in seiner Reisebeschrelbung berichte.- Amaudov 338 dagegen hat m.E. recht mit der tberlegung, das die Gestalt eines Dete Dukadince nicht nach Krali Marko entstanden se1, sondern $2 u$ den altesten Gestalten der Volksdichtung (Marchen, Iied) oder des Mythos gehore: "Dete Dukadince 1 dete Golomere 8 a navjarno prastari narodno-poeticni ili prikaznilni obrazi, koito edva pokrono se vmurvat $\nabla$ poemite $2 a$ Marko".- Angelov und Vakarelski 339 kuBern widerspruchliche Meinungen, wenn sie einerseits betonen. 
die Heldenkinder seien alte mythische Gestalten, die zum Teil später historisiert marden, andererseits aber die Ansicht vertreten, mit "dete" sei - gemas der Wortbedeutung in maz. Dialekten - ein junger Mann zwischen 20 und 25 Jahren gemeint; in den wenigen Pullen, wo es sich wiklich um Kinder handle, namlich bei Dete Malexkovo und Dete Golomere, kbnne man von rein stil1stischer Hyperbolisierung reden.- Dagegen ist einzuwenden, das es sich urspringlich eindeutig um Kinder handelt, die erst im Zuge der Rationalisierung und Historisierung opsterer Zeiten zum Teil zu jungen Helden murden, zum groberen Tell aber ausdrucklich als kleine Kinder geschildert werden.- Burin 340 , der sich nicht wie Teodorov 341 der Gleichsetzung "dete" = "momce" anschliest oder wie Dinekor" 342 von einer Zweitbedeutung "dete" = "momce, momưk" spricht, ist der wohl berechtigten Meinung, die ubernaturlichen Eigenschaften der Heldenkinder lieben auf uralte mythische und halbmythische Gestalten schlieBen, die das Bemastsein des Volkes erst spater mit Krali Marko in Beziehung gesetzt habe; es handle sich um Heldenkinder von hochstens drei oder sieben Jahren, und, damit wir daran nicht zweifeln, schildere sie uns der Sänger haufig als Wickelkinder, als skuglinge in der Wiege usw. Klar sei, daB es sich bel dem Typ des Heldenkindes um eine uralte Gestalt handle, die den ubrigen Heldengestalten, die - wenn auch oft nur in ihren Namen - manche historischen Zluge zeigen, chronologisch vorangehe.

Ich möchte mich der Meinung von Arnaudov und Burin anschlieBen und die Heldenkinder als eine auf maz.-rbulg. Boden (vielleicht unter griech. Einflus) entwickelte Kategorie von Volksdichtungshelden bezeichnen, die in sehr alte, auf jeden Fall betrichtlich altere Zeiten als die Zeit des historischen Marko (14.Jh.) zuruckweisen. AuBerdem glaube ich, bei der Betrachtung des gesamten "Heldenkindmaterials" drei Hauptgruppen feststellen zu können: 1. die aus dem Zmej entwickelten Drachentoter,

2. die "Wunderkinder", die den Zarenthron erobern, 3. die den Riesengestalten nahestehenden Heldenkinder.

Zu der ersten Gruppe ist zu sagen, das wir in den maz.-wbulg. Liedern vom Hochzeitszug mit einem Uberfall durch einen Drachen oder drachenkhnlichen Mohren und bei den Drachenkampeliedem mit all ihren Variationen vorwiegend Heldenkinder als Protagoniaten 
Panden, die die Rolle des Drachenkämpfers spielten, whrend in einer Reihe von Drachenkampliliedern der Zmej diese Stelle einnahm. Wie wir wissen, ist der Zmej (vgl. den albanischen Drangue) der pradestinierte Drachentoter. Also stehen Heldenkinder als Drachentöter und Zmejs als Drachenkampler in ganz enger Beziehung, wenn man sie nicht sogar als identisch bezeichnen darf. Tatsachlich wird z.B. das Heldenkind in Stoil.II 13 "zmejze" und in SbNU XVI-XVII, 147 "zmej" genannt. Zu diesen Drachenkämpferm gehbren vor allem Dete Golomese (von maz. golem 'groß'), Dete Maleðkovo (von maz. maleðkav 'klein'), Sekula detence und Gruica detence. Auch daß die Heldenkinder haufig mit einer Schlange im Korper geboren werden, deutet wohl auf ihre Zmej-Natur hin. Bei den "Wunderkindern" der zweiten Gruppe handelt es sich um Ubernatirlich emplangene oder geborene Kinder mit einem goldenen Mal auf der Stirn und goldenen Flugeln an den Schultern, wodurch sie zum Zmej in Beziehung gesetzt werden bzw. als zu Ungewöhnlichem bestimmt erscheinen, und hăufig einem Brief in der Hand (ein Legenden- und Marchenmotiv!), worin geschrieben steht, daB das Kind den Zarenthron erobern werde.

Böse Nachbarn oder Boten des Zaren horen, wie die Mutter dem Kind in der Wiege sein prachtiges Schicksal singend vorhersagt bzw. wie das Kind selbst seiner Mutter von seiner kinftigen Bestimmung erzkhlt, und benachrichtigen den Herrscher, der das Wunderkind in den Kerker werfen labt, wo es auf wunderbare Weise (haufig mit Hilfe von Engein oder Heiligen, - ein sekundär aus der Hagiographie oder religibsen Liedern labernommenes Legendenmotiv) Uberlebt. Als der Zar in den Kerker hinuntersteigt, wird er entweder von dem Heldenkind uberwaltigt und entthront, bzw. tritt der Herrscher angesichts der wunderbaren Errettung des Kindes diesem freiwillig den Thron ab.

Das das Heldenkind hier den Zarenthron einnimmt, ist schon das Zeichen einer gewissen Historisierung. Von diesem Sujet gibt es folgende Varianten: Mil.50 a; Mil.50 b; Mil.67; KaX.113 und 114; II.76; Sapk.299; SbNU V,11; V,17; VII,10; X,74; XIII,65; Øol.57; Karav.BNP 95 und 137; Verk.-Lavr.144; Vurb.288; Stoin TV 82;Stoin Pesnop.47; Brilg.kn.I (1859),211. Wie Schmaus 3428 gezeigt hat, findet sich dieses Motiv auch in einem weitschweifigen mohammedanischen Lied der bosnischen Krajina, nur hat es hier seine mythologischen zuge verloren und dient lediglich noch als Exposition zur Beschreibung einer glän- 
zenden militurischen Karriere im Dienste des Sultans. Es handelt sich um das Iied $\mathrm{MH} \mathrm{I}_{2} 4$ "Hasanpasa Predojevic osvaja Bihac", wo das Motiv des Wunderkindes folgendermaBen gestaltet ist:

Einer von den Leuten des Sultans trägt einen Permen nach Bosnien und trifft unterwegs einen Hirtenknaben, der singt, wenn der Sultan in Stambul uber ihn Kenntnis erhielte, wirde er, der knabe, Bihad flir ihn erobern.- Nachdem der Sultan dies erfahren hat, labt er den Knaben an seinen Hof holen und ausbilden. Na Hasanpasa erobert dieser schlieBlich Bihac.- Diesem Teil des Liedes geht ein symbolischer Traum der Tochter des Bans von Bihac voraus, die von einer "zmija sarovita" unter einer Rose trisumts

Kako zmija pigti sarovita, Prevrže se Bißcu do bedena.

Der Vater des Mädchens deutet diesen Traum sos

To se carev rodi prijatelju,

Ceri moja, u turskoj krajini;

dieser Preund des Sultang werde nach Stambul gehen, ein Heer sammeln und "na nas Bihac udariti".

Die magische Geburt und die Throneroberung des Heldenkindes sind hier weggefallen. Nur das lied des Hirtenknaben erinnert noch an das prophetische Schlaflied der Nutter in den maz. Iiedern dieses Sujets. Schmaus sieht wohl sehr richtig in der symbolischen bunten Schlange des Traumes eine mythische Identitut mit dem Heldenkind; selbst in dieser Form zeuge sie noch von der Zmaj-Natur des Helden. DaB wir das Motiv sogar noch in einem breit epiaierten, historisch konkretisierten und kuBerlich rationalisierten mohammedanischen Iled, das sich schon weitgehend der "Splelmannstechnik" bedient, antreffen, sei ein Beweis fur die Zahigkeit,mit der sich Relikte mythischer Vorstellungen behaupten.

Mit den in der dritten Gruppe genannten, den Riesen nahestehenden Heldenkindern ist vor allem Dete Dukadince (oder Dukatinde) gemeint. In dem Dete Dukadinbe-Sujet einden wir ja auch die meisten Parallelen zu den ubrigen Riesenkampl-Sujets, deren Protagonisten Helden wie Musa, Zülta bazirgjana und Arvatka daratellen.Máchal 343 bestutigt diese Meinung, wenn er schreibts "V bulharskfch planfch jmenuje se místo džidovina dfte Dukadinse". Der Inhalt des Dete Dukadince-Sujets ist im allgemeinen folgender:

Marko streift durch die walder und Gebirge. Es ist auf der Suche nach einem ihm Uberlegenen Gegner und fragt schlieblich den Abendstern, $O b$ es einen Helden gebe, der starker sei als er. Marko erfahrt, dab in einem Pa- 
last aus Eisen, Marmor, Gold und Silber in der Stadt Dukat ein siebenjuhriges (bzw. dreijuhriges) Kind lebe, das siebenmal (dreimal) Marko an Heldenkraft ubertreffe. Von Neugierde und beleidigtem Ehrgeiz getrieben, eilt Marko zu Dete Dukadince, von dem er freundlich bewirtet wird (epische Pormel: Sie trinken drei Tage und drei Nachte Wein miteinander). AnschlieBend schlagt Marko einen Steinwurf als Kraftprobe vor, wobei Marko eine schwere Niederlage erlebt: er schleudert den Stein drei Stunden weit, Dete $D$. aber so weit, daB man thn nicht mehr finden kann. Als Marko nun die Uberlegenheit des Dete $D$. erfahren hat, beschlieBt er, den kindlichen Gegner durch List zu töten. Er schl甘gt vor, weitere Kraftproben in Form von Schwerterkampp und Wettrennen auszutragen, und läbt zu dem 2 weck Dete D. sein pferd wenden und ihn vor sich herreiten. In diesem Augenblick zieht Marko sein Schwert und schlagt Dete D. von hinten den Kopf ab (bzw. haut inn mitten durch). Zu Markos groBem Schrecken bleibt der Kopf auf dem Rumpe (bzw. die eine Körperhalfte an der anderen) haften, und Dete D. klagt nur uber einen stechenden Schmerz im Herzen. Marko veranlast das Heldenkind listig, sich niederzubeugen bzw. sein pferd zu tummeln, worauf erst Dete $D$. auseinanderfallt.- Hufig findet Marko mehrere Herzen in der Brust des Heldenkindes.(In Var. Kad.151 verfolgt der halbe Leichnam Marko vgl. Zuila bazirgjana -, holt inn in einer engen Schlucht ein und kympft drei Tage und Nachte mit Marko, der sich nur mit Hilfe der Samovila des halben Leichnams erwehren kann; dann aber fullt der Leichnam - wie in manchen Züla bazirgjana-Liedern - auf ihn, und Marko kann sich erst nach drei Tagen von ihm befreien. Mit einem im Stiefel versteckten Messer - vgl. die Musa-Lieder - offnet er den Körper und findet drei Herzen darin. Die Samovilen begraben Dete $D$. , das siebenmal starker als Marko und der einzige Sohn seiner Mutter war, aus Bewunderung und witleid mit der christlichen Begrilindung:

Ono može svetija da stane,

Ot1 se e na sedim godini.)

Es handelt sich bei diesem Sujet um folgende Varianten: Mil.121; Kar.151-153 und 155; Sapk.463; SbNU I.55; I,66; VII,101;VII,102; XIV,93; XIII,85; XVI-XVII,165; XVI-XVII,162; XXXV,249; XIIII,11; Mich.,190; Pam.0br.,331; Jastr.,66; Radov.3; SbNU XXVI,22; XIIV, 9; XXVI,22 (dete KadinCanZe); IX,84 (dete Tatuliðe); Drag.21 und 22; KaX.156 (dete sedmomeže 'sieben Monate alt'); Karav.BNP 78 (dete Belezito 'mit einem Geburtszeichen versehen'). Marko ersetzt in diesem Sujet zweifellos wieder einen zlteren, wohl namenlosen Helden. Es lat anzunehmen, das eine urspringliche Riesengestalt, deren Namen wir nicht kennen, sich dem anziehungs- 
krätigen Typ des Heldenkindes beugen mußte, wobei sicher die affinitut der in beiden Fullen Ubernaturlichen Wesen eine groBe Rolle spielte. Erstaunlicher noch lat die Tatsache, daB die Kategorie der Heldenkinder, die vermutlich von dem drmonischen Zmej hergeleitet werden können, opkter sogar historische Gestalten in ihren Bannkreis zogen. So darf man wohl mit gewleser Berechtigung hinter Dete Dukadinde eine historische Gestalt des 14.Jh., numlich den Albaner Leka Dukagjin, den Herm von prizren 344 , vermuten, wenn nicht einfach, was auch mbglich ware, der an der serb.-maz.-bulg. Grenze liegende Berg "Dukat" zu der Namensbildung Dukatince gefuhrt hat. Teodorov 345 möchte das Dete Dukadinde-Sujet auf die historische Begebenheit der (ca. 1016 erfolgten) hinterlistigen Ermordung von Jovan Vladimir, einem Herracher der Zeta im 10./11.Jh., durch Ivan vladislav, den Sohn des Aron und Neffen Samuils, zuruckfuhren, eine Tat, die sowohl in der Chronik des Dokleaten wie auch in der "Iotorija Slavjanobolgarskaja" des Paisij Chilendaraki bezeugt 18t.- Teodorov geht aber weder auf den Namen Dete Dukadinze noch auf den Heldenkindcharakter der Lledfigur naher ein; sein Erklarungoversuch Uberzeugt m.E. nicht, denn das Hauptmotiv der Totung durch List lot eines der ganz archaischen Elemente, das in allen Sujets vom Kamp eines Helden mit einem uberlegenen ubernaturlichen Gegner vorkommt.

Bemerkenswerterwelse hat der Heldenkindtyp wohl im 16./ 17.Jh. noch elne so starke Anziehungskraft besessen, das sogar sekmdar zugewanderte Helden wie Sekula, Gruica, Zmaj-ognjeni Vuk und vielleicht auch Jankula in den "Sog" dieser Kategorie gerieten und einen AdaptionsprozeB zum Heldenkindtyp durchmachten. Von Sekula und Grutca detence ("Kindlein") war (vgl. Kap.4.13) schon mehr oder wentger ausfuhrlich die Rede. Zmaj-ognjeni Vuk wurde sehr wahrscheinlich als heldenkind in maz.-wbulg. Liedern in 0 gnjan $\left(z_{0}\right)$ bzw. Ognen umbenannt. Auch Soerensen 346 ist der Meinung, daB sich hinter Ognjan, dem Neffen Markos im Lied, der historische Zmaj Despot Vuk (Brankovic) verberge. Moglicherweise 18t auch Jankula, der - als der altere des Paares Sekula-Jankula - sonst meist die Oheimrolle opielt, von dem Heldenkindtyp "aufgesogen" worden. Anlab zu dieser Vermutung gibt uns das ratselhafte Dete Maliande in dem Lied Per.Spie.XIV,459, dessen Name 
sicher nicht von dem Wort fur "klein" (wie Dete Maleckovo) abgeleitet werden kann, sondern, wie Matov 347 vorschlugt, in "mali" und "Jance" aufgelöst werden kann und somit 'kleiner Janko' bedeuten durfte. Auch in SbNU II,133, Drag. 31 und Ikon.,135 spielt Jankula die Heldenkindrolle, wenn er als Neffe seinen Oheim Marko besiegt. Sogar Marko ist manchmal als Heldenkind, meist als Neffe von Jankula, aufgefabt ( $v$ gl. Rod.Napr.VIII 3,89 ; SbNU XXVII, 124; XLVI 2,11 ; Bezs.I 5).

Erwăhnenswert ist noch die Tatsache, dab die Heldenkinder sehr häufig in den beliebten $0 \mathrm{~h}$ e $\mathrm{i} \mathrm{m}-\mathrm{N}$ e $f \mathrm{f}$ e-Paaren die Rolle des Neffen (Schwestersohns) spielen. Die Oheim-Neffe-Konstellation gehort wohl, wie auch von dem Motiv der Ubernatülichen Empfängnis vermutet wurde, der dem Patriarchat vorangegangenen Zeit des Matriarchats an, als der Oheim (Mutterbruder) den Kinderm naherstand als ihr eigener Vater, der Mutterbruder - neben der Mutter - als Beschilzer der Nachkommenschaft mit allen Rechten und Pflichten des Familienoberhauptes fungierte, der Neffe den Oheim beerbte und auch für die Blutrache am Oheim zustandig war 348 . Wie wir heute wissen, ist dem patriarchalen Seniorat bei den Slaven auf jeden Fall eine Periode des Avunkulats vorausgegangen 349 . Darauf also dürften die Oheim-Neffe-Paare und das so innige Verhältnis zwischen dem Liedhelden und seiner Mutter (wobei von einem Vater fast nie die Rede ist) 350 in der sudslavischen epischen Volksdichtung zurlickzuführen sein, während die Vater-Sohn-Konstellation meist nur einen spateren Ersatz fur die urspringliche Oheim-Neffe-Verbindung darstellt.- Die beliebtesten Oheim-Neffe-Paare sind Marko-Sekula, Jankula-Sekula, Marko-Gruica und Marko-Ognjan, doch sind diese Namen sicher auf ein alteres, uns namentlich nicht bekanntes Paar aufgepfropft, das sich zur Zeit des Matriarchats formlerte, zeitlich aber wohl erst nach dem Typ des zunachst allein agierenden Heldenkindes entstand. Die Oheim-Neffe-Beziehung ist meist positiver Natur, wie wir z.B. in den Liedern vom Typ 4.11,4.13 und 4.3 gesehen haben, kann aber auch unbewubt (wie in den liedern Stoil.II 1 und Per.Spis.XIV,459, in denen Oheim Marko und Heldenkind unerkannt miteinander kämpfen und das Heldenkind siegt) oder bewuBt (wie z.B. in Jastr.,66 und SbNU IX,84, worin Marko wissentlich seinen Neffen bekrmpft) feindschaftlich sein. Diese Oheim-Neffe- 
Paarbildung war so produktiv, dab sie nicht einmal vor den Heiligen haltmachte. So ist z.B. in Jastr.,254 der hl.Sava der Neffe (Schwestersohn) des hl.Elias, mit dem er gemeinsam zwolf Drachen totet.

Diese typischen Oheim-Neffe-Paare und uberhaupt die maz.-wbulg. Heldenkinder haben m.E. auf den skr. Raum eingewirkt. So ist Markos Neffe Ognjan in Vuk II 51, an desgen Stelle in der alteFen Var.Bog.46 noch Sekula, der Neffe Jankos, steht, sicher nur so zu erklaren, das der in den maz. Raum abgewanderte und dort in Ognen (Ognjan) umgewandelte Zmaj-ognjeni Vuk in den dinarischen Raum zurlickgewandert ist und nun dort auch als Ognjan auftritt. In einem anderen Lied aus dem dinarischen Raum, namlich Vuk VI 19, das in seinem Sujet dem oben erwähnten Stoil.II 1 entspricht (Zweikampl zwischen Oheim und Neffen), ist Ognjan als Neffe Markos anscheinend wieder in Ognjeni Vuk zurluckerwandelt worden. Dieses Sujet ist wohl im skr. Raum sekundar. In den maz. Var. Stoil.II 1 und Per.Spis.XCV,459 lautet die Motivfolge so:

Dialog Markos mit seinem nach Heldenfleisch hungrigen Sabel - Zusammentreffen und von Marko provozierter Kampl (ohne gegenseitiges Erkennen) mit dem Heldenkind-Neffen, der auf dem Weg zu Marko ist, um sich von ihm als Oheim taufen zu lassen - Sieg deg Neflen Uber den Oheim und Anbinden des Besiegten an den Pferdeschwanz - Ankunft des Heldenkindes vor Markos Hof Empfang durch die Tante - heimliches Losbinden Markos durch seine Frau - freundschaftliche Begrabung awischen Marko und Neffen - Taufe und Heimkehr des Heldenkindes.

Dagegen beweigen die skr. Var. MH $I_{2} 68$ ("Marko Kraljevic 1 necak Marijan"), Istarske,40 ("Kraljevic Marko i mlado momðe") und Vuk VI 19 ("Marko Kraljevic i Ognjanin Vuk"; alt ist hier das Motiv, daB aus Marko Blut fließt, aus dem Jungling aber Feuerfunken schlagen) ihren sekundyren Charakter dadurch, dab sie von der urspringlichen Motivfolge nur noch folgende Bruchatucke erhalten haben:

Markos Dialog mit dem nach Heldenfleisch hungrigen Skbel - Markos Zusammentreffen mit einem unbekannten jungen Mann und Provokation durch Marko - Kampf mit dem Jlingling und Sieg des Unbekannten - freudige Begrubung, als der junge Mann sich als Markos Neffe vorstellt.

Aus "dete", also einem echten Heldenkind, ist hier ein "mlado momce" oder "momak", also ein junger Bursch, geworden, weil die okr. Epik im Zeichen der Rationalisierung die Vorotellung "Hel- 
denkind" richt zulassen kann. Das Motiv, daß das Heldenkind sich auf dem Weg zu seinem Oheim befindet, um sich von diesem taufen zu lassen, ist in den skr. Var. ebenso weggefallen wie das Anbinden des Besiegten an den Pferdeschwanz und das gutgespielte Tkuschungsmanöver an Markos Hof, als nämlich Marko und seine Frau Markos Schande geschickt uberspielen. Das Sujet endet in den skr. Iiedern schon damit, dab Oheim und Neffe einander gleich nach dem Kampf freudig erkennen.

Diskutierenswert ist auch die mögliche Annahme, daB es sich bei den im zweiten großen epischen Ballungsraum, namlich in sudun: garn, formierten Liedern vielleicht um maz. Einflub handelt, wenn in einer so auffallend großen Zahl von Liedern (Bog.18,19,21, 22, $31,46,76,78,88,100)$ von einem "mlado djete" die Rede ist. Allerdings wurde in diesen am sturksten historisierten sudslavischen Liedern die fast mythische Heldenkindvorstellung "normalisiert" und in ihrem Sinn mit "mlado momxe" (vgl. Bog.10,40,46,88) gleichgesetzt, was auch Formuliemungen wie "djeca jagniCari" (Bog.100) und "djeca soldatini" (Bog.87) beweisen. Auch in den jungeren Liedern des dinarischen Raumes wird "dete(nce)", wenn es verwendet wird, immer in der Bedeutung 'junger Bursch' gebraucht.

Welch ein weiter Weg von den halbmythischen namenlosen Heldenkindern ("dete samotvorle", "dete neznajko", "sedemgodiono dete" usw.) der maz.-wbulg. Volksdichtung bis zu den heldenhaften jungen Mannern der Lieder aus dem sludungarischen oder dinarischen

Raum! Dieser weitgespannte Bogen spiegelt das ganze Spektrum der sudslavischen Volksepik wider.

Abschliekend soll ein zitat noch einmal zurikckiuhren in die Welt der maz. "Wunderkinder", der Zmej-Abkömmlinge, der goldgeflugelten Heldenkinder aus uralter Zeit:

Poduchnal mi tich, běl větŭr,

Ta e duchal tǔkmo tri dni,

Tưkmo tri dni $i$ tri nosti;

Ta izduchal medno gumno,

Na gumnoto zlaten stožer,

Za stozera vrana konja,

I na konja sine sedlo;

Juzdata mu jasna zvězda,

Do d.vě zmil, dvě zengii,

I sedloto nanizano,

Nałareno, izpisano.

I na nego mữzo dète. 


\subsection{ZMEJ - LIEDER}

Bevor wir zur Besprechung der Zmej-Iieder Ubergehen, seien noch einige grundsätzliche Bemerkungen zur Zmej-bzw. ZmajVorstellung vorangestellt.

Im sildslavischen Volksglauben wird der Zmej vorwiegend als anthropomorphes Wesen, aber mit (goldenen) Flügeln in der Achselhöhle und scnuppigem Schwanz gedacht. Zmejs können fliegen und sind so stark, daB sie Buume mit der Wurzel auszureissen vermögen. Sie leben auf den Bergen in Höhlen, wo sie sogar Frauen ("zmeici") und Kinder ("zmejčta") haben. Sie verursachen Donner und Blitz und sind flur Regenfalle verantwortlich. Wenn sie durch die iuft fliegen, spruhen Funken, die die Umgebung entzlinden oder versengen; daher werden sie mit dem Epitheton "feurig" (ognjan, ognjen) belegt. Sie sind unsichtbar, kbnnen sich aber sichtbar machen und in Jünglinge verwandeln. Der Zmej entsteht aus einer vierzigjährigen Schlange, indem dieser Flugel und Beine wachsen. Der Zmej wird manchmal auch als Ungeheuer, als riesige Schlange mit Schuppen, Flugeln und vier Beinen - ähnlich einer Riesenechse (Verwechslung mit der Lamja?) - vorgestellt, doch Uberwiegt die anthropomorphe Vorstellung. Die wichtigste und den Menschen der unter seinem Schutz stehenden Gegend nutzlichste Eigenschaft des Zmejs besteht darin, daß er gegen den Gewitterdrachen ("chala, ala, hala, lamja, lamnja, azder, aždaja") kampft, Durre und Hagel 351 a abwendet und das von ihn beschutzte Gebiet vor MiBernten bewahrt.- Der Zmej hat eine Vorliebe für schöne junge Madchen, die er raubt, durch die luft in seine Hohle tragt und dort mit ihnen lebt. Die aus dieser Verbindung stammenden Zmej-Abkommlinge werden elf oder mehr Mona.te im Mutterleib getragen und als Zmej oder Zmeica mit Flugeln und Schuppenschwanz oder halb Zmej, halb Mensch geboren. Hat sich der Zmej statt eines Madchens eine Frau zur Geliebten auserwahlt, so raubt er diese nicht, sondern besucht sie in Abwesenheit ihres Mannes. Von einem Zmej geliebte Madchen oder Frauen erkennt man daran, daB sie immer bleicher und menschenscheuer werden. Analog zum Zmej sucht sich auch die Zmeica einen menschlichen Geliebten, den sie meist in der Gestalt eines einsamen Schufers findet. Sie besucht inn aus Angst vor ihrem Zmej- 
Gatten heimlich und versteckt die dieser Verbindung entsprossenen Kinder sorgfultig vor dem Zmej352. Genau wie der Vampir, den man sich bei den sudslaven präanimistisch (d.h. körperlich; Korper und Seele noch als Einheit vorgestellt) oder animistisch (die seele verlabt den wie tot daliegenden Korper und nimmt die Gestalt eines Seelentiers an) agierend vorstellt, kann auch der Zmej, der aber meist in der alteren prăanimistischen Weise vorgeht, manchmal auf animistische Art mit dem weiblichen Gewitterdrachen kämpfend vorgestellt werden: Den mit Flügeln geborenen Zmej, sei er noch ein kind oder schon erwachsen, verlabt im Schlaf ein "Geist", erhebt sich in die Lufte und krmpet mit dem "Geist" der Lamija um den Emtesegen, wobei meist der Zmej siegt; wahrend des Kamples ist von der Erde aus heftiges Donnern und Blitzen zu beobachter. Dreht man den "schlafenden" Zmej-Körper um oder verlagert ihn, solange seine Seele mit der Lamija kämpft, erkennt die zuruckkehrende seele den korper nicht mehr, und der Zmej stirbt 353 . Dieses Verhaltnis zwischen Lamija und Zmej ahnelt demjenigen zwischen dem Vampir und dem "krstnik, karsnik, kresnik"354, wobei der Krsnik die dem Zmej entsprechende positive Gestalt ist, meist ein Wiedergänger oder ein mit einer Gluckshaube Geborener, der den Menschen im Kampl gegen Hexen und Vampire beisteht. Bei den Slovenen allerdings ist der "kresnik" oder "obilnjak" ein wohlwollender Lokalgeist. Kampft ein Kresnik mit dem des Nachbargebiets, so wird die unter dem Schutz des Siegers stehende Gegend durch reiche Ernten gesegnet, das Gebiet des Unterlegenen aber durch MiBernten heimgesucht. Dem entspricht in Montenegro und BH der "stuhac, stuva, zduhac, zduha(C)", dessen Name vermutlich aus griech. FToLXETov 'Orts-, Schutzgeist. (nach Jokl uber albanische Vermittlung) hergeleitet werden kann, vgl. "stihi, stihjo", bei den Albanern Siziliens ein Plammenspeiender Drache mit Flügeln und menschlichen Zügen, und "stuhi", wie der sturmwind bei den Gegen heiBt 355 . Moglicherweise sind diese lokalen Schutzdămonen aus urspringlich manistischen Stammes- oder Sippenschutzgeistern hervorgegangen. Im skr.,maz. und bulg. Raum hat sich aus der wahrscheinlich urspringlichen Polarisation nach dem Ergebnis des Kamples von gleichwertigen Lokaldumonen (Sieg bedeutet Emtesegen, Niederlage des Lokaldamons 
MiBernte fur sein "Revier") eine Polarisation in guten und bösen Dłmon, eben in Zmej, Zmaj und Lamja, Ala usw., entwickelt. Wăhrend vorher zwei Lokaldamonen miteinander kämpften, die dem eigenen Schutzgebiet wohlgesinnt, dem des Gegners aber ubelgesinnt, nach außen hin jedoch weder gut noch böse waren, werden nun zwei Antipoden einander gegenubergestellt, wovon der eine als prinzipiell gutartig, der andere aber als bosartig betrachtet wird. Diese Entwicklung ist ein sudslavisches Spezifikum. denn bei den Neugriechen, die den Sudslaven sicher gerade hier ein nicht zu unterschatzendes $\mathrm{MaB}$ an Volksglaubensvorsteilungen vermittelt haben, gibt es zwar den Kampe verschiedener Ortsgeister ( $\sigma$ TolXEl $(\dot{\alpha})$ gegeneinander mit entsprechenden Folgen fur das Gebiet des Siegers bzw. Unterlegenen 356 , nicht aber die der sudslavischen Gegenuberstellung Lamja-Zmej entsprechende Polarisation Lamia-Drakon, weil die Entwicklung der damonischen Gestalten auf griech. und sudslavischem Boden verschiedene Wege ging. wahrend die griech. Lamia zu der Zeit, als sie den sudslaven vermittelt wurde, wohl noch ein dem Wasser verbundenes Ungeheuer war, was ja die slidslavische Lamja-Vorstellung beweist, hat sie sich im heutigen neugriech. Volksglauben eher den Riesinnen (im Marchen), Neraiden und Sirenen (Im Lied) angenghert. Daraus erklärt sich auch die Tatsache, daß in neugriech. Volksliedern dort der Drakon erscheint, wo sudslavische Sunger Lamja, Ażaja usw. setzen (z.B. beim Drachenkampf des hl.Georg, beim Kampf mit dem Drachen im Brunnen). Die Volksglaubensvorstellung der Albaner entspricht der der Sudslaven, wenn sie dem weiblichen Gewitterdrachen Kulshedra den durch besondere Geburtszeichen (Flugel unter den Achseln, Gluckshaube) hervorgehobenen Drachentöter Drangue gegenuberstellen 357 .

Der neugriech. Drakos, Drakon oder Drakontas, dem - wie die maz. und bulg. Zmeica dem Zmej - eine Drak(ont)issa zur Seite steht (was vermutlich eine jungere Erscheinung ist),gehort eindeutig zu den Ortsgeisterm und Lokaldamonen, dę rrolxeló. Sie hausen in tiefen Höhlen. Schluchten, Felsspalten, hohlen Baumen, Sumplen, Quellen und Brunnen. Uber die Gestalt des Drachen schwankt die Volksvorstellung: "bald werden sie als große Schlangen, bald als menschlich gebildete Geschöple, wenn auch mit dem oder jenem thierischen Zusatz, gedacht"358. Dieses Schwanken in 
der Vorstellung der Drachengestalt geht schon bis in das frïhe

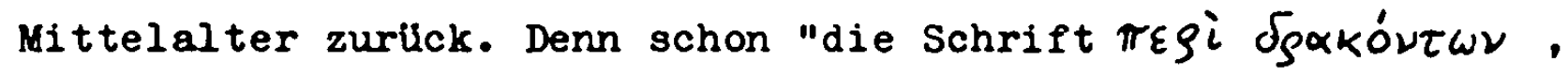
die dem Johannes von Damaskos (7.Jh.n.Chr.) beigelegt wird, berichtet: Man stellt sich die Drachen teils als Schlangen,kleine und große, vor, teils-als zu Menschen geworden, die mit Menschen umgehen, kommen und Frauen rauben und mit ihnen verkehren.- So ist der Drache auch in dem byzantinischen Roman Kallimachos und Chrysorrhoe, der sich deutlich aus Marchenelementen zusammensetzt. geschildert"359. Im Digenis-Epos, das bereits erwăhnt wurde,tritt der Drache als Quellenbeschlitzer, mehrkbpig und verwandlungsfähig (als Jungling) auf. Seine Eigenschaft als Frauenräuber wird auch hier schon offenbar.

Außerhalb Griechenlands findet man diese menschlich vorgestellten Drachen fast ausschlieblich in der Nachbarschaft der Griechen, auf deren Einfluß sie wohl deshalb zurluckgehen. "So ist auch der albanische Drangria, dessen Namen G.Meyer trotz des auffallenden Nasals wohl richtig auf lat. draconem oder ital.dragone zurlickfuhrt, ein menschlich gestalteter Riese, mit dem die Helden Ringkampfe bestehen"360. Wie slavisch Zmej, Zmaj etymologisch mit "zmija" 'Schlange' verwandt ist, bedeutete ja Drakon ursprünglich 'Schlange', hat diese Wortbedeutung aber heute verloren bzw. nur mehr ausnahmsweise bewahrt 361 . Wahrscheinlich geht der ganze Drakon-Glaube auf den Kult der als Schutzdamon fungierenden H a u s s c h $l$ a $\mathrm{n}$ e zurlick. Diesen Kult kennen wir nicht nur bei den Neugriechen, sondern auch schon aus der hellenischitalischen Antike, aus dem gesamten slavischen und auch deutschen Raum. Oder aber man könnte - wie Kretschmer ${ }^{362}$ - die Drachen des neugriech. Volksglaubens auf die schlangenfubigen $G$ i $g$ a $n$ t $n$ des Altertums zurlickfihren. Die Vorstellungen ahneln sich sehr, denn die Schlangen, die chthonischen Tiere, und die erdentsprossenen Giganten sind ja nur verschiedene Darstellungsformen derselben Erdmachte. Tatsachlich geht die Ähnlichkeit der neugriech. Drachen mit den Riesen des Marchens oft so weit, dab sie sich geradezu als identisch erweisen 363 .

Der Drache gilt in Griechenland sprichwortlich als Vorbild mannlicher Tapferkeit, so daß man von "Drachenmut" und "Drachenstarke" spricht. Schon fur das 15.Jh. ist uns bezeugt, dab tapfere Helden den B e i n a m e n "Drakos" erhalten ${ }^{364}$. Dazu paBt auch, daß 
der sudslavische Liedheld Momilo bereits in der turkischen Verschronik des Umur Pascha (Mahmud Pascha gewidmet, dessen Antszeit bis 1465 dauerte) als "ojdeha" (Drache) bezeichnet wird 365 . Wie wir wissen, kennt auch das sudslavische Heldenlied verschiedene Recken, die "Drachen(söhne)" sind. So heiBt es z.B. in dem Lied Petr.III 24:

Sto god ima Srbina junaka,

Svakoga su odgojile vile,

Mogoga su zmajevi rodili.

Dann werden Miloß Obilic, Zmaj Ognjeni Vuk, Relja

Bosnjanin, Banovic Sekula, Banovic Strahilo, Ijutica

Bogdan und Marko Kraljevic als Drachensöhne aufgezuhlt:

A sedmoga Kraljevica Marka,

I njemu je zmaj ognjeni babo.

Svaki ima zmajevu biljegu. 366

Alle sieben tragen also ein Drachenzeichen am Körper.

Wie wir noch sehen werden, ist dieses Motiv, was die Gestalt des Zmaj-ognjeni Vuk betrifft, alt und geht wahrscheinlich auf ein von mythologischen und totemistischen Vorstellungen erfulltes Heldenmarchen zurluck, das erst nachtraglich auf die historische Gestalt des Despoten Vuk Brankovic ubertragen wurde. Der Beiname 'Drache, Drachensohn' wurde dann bestimmten Helden zugelegt und schlieblich als heldisches Attribut verallgemeinert, um die hel dische Kraft der Recken aus alter Zeit zu erklären 367 . Chalanskij fuhrt als Parallele die altrömischen Sagen von der Abstammung eines Helden "von einem Laren oder einem Hausgeist, der in Gestalt einer Schlange auftritt", an. "Von einer solchen Schlange stammten Scipio und Augustus ab" 368 .

Doch nun zum sudslavischen Liedmaterialt wahrend wir im maz. und bulg. Raum eine große Zahl von Zmej-Liedern zur Verfugung haben, beläuft sich die Zahl der Zmaj-Iieder im skr. Raum nur auf etwa zwanzig, was wieder die schon bekannte Tatsache unterstreicht, daB die Iieder im maz.-bulg. Bereich mehr Archaisches als die skr. Epik bewahrt haben. Die maz.-bulg. Zmej-Lieder lassen sich in folgende Gruppen gliedern:

1. Kampl des Zmej gegen die Iamja,

2. Kampf des Helden gegen den Zmej,

3. Verwandlung des Helden in einen $Z$ mej,

4. Liebesbeziehung zwischen Zmej (bzw.Zmeica) und Mădchen oder Prau (bzw. Hirte). 
Von diesen vier Gruppen ist nur die erste im skr. Raum nicht vertreten. Auch die Zmeica fehlt im skr. Lied.

Die erste Gruppe wurde schon in Kap.4.41 uber den Drachenkampf besprochen. Hier handelt es sich um das alte Motiv des Kampfes um den Erntesegen, wobei sich der Zmej als Schutzdămon der Felder seines Bereiches, die Lanja aber als Emtevernichterin erweist. Während in Doz.,133 eine Gruppe von 300 Zmejs gegen eine Lamja käppt, werden in anderen Liedern (z.B. SbNU X,9; IX,7; XVI-XVII,54) menschliche Helden und - als Folge der Verchristlichung - sogar Heilige hinzugezogen, die auf der Seite der Zmejs kampfen. Interessant ist der Vergleich zwischen den als "Blitz" (umschrieben durch "Pfeil, Pfeilchen") bezeichneten Zmej-Bridern in SbNU IX,7 und dem dem Drakon im Brunnen furchtlos entgegentretenden Mädchen, der "Schönen" des Jannis (in den griech. Liedern Kind $X I ; X I V)$, die sich selbst als Abkömmling von Blitz und Donner bezeichnet. - Weitere Lamja-Kämpe (unabhängig von dem "agrarischen" Element) werden im maz.-bulg. Heldenlied von den wahrscheinlich aus der Zmej-Vorstellung abgeleiteten Heldenkindern ausgetragen. Zur Gruppe 2 gehören kurze, meist Brauchtumslieder (vor allem Koleda-Lieder), worin vom Kampf eines Helden mit einem Zmej berichtet wird. - In SbNU $X V, 6$ besiegt Bogdan einen kleinen Zmej ("mlado zmejદe") im Zweikampf, worauf der lang ersehnte Regen fallt. Den gleichen Effekt erzielt der hl.Elias in SbNU IV, 6 und ein Held in SbNU XV,111. In Bond.110 laBt sich ein namenloser "chrebri junak" in einen dreitägigen Kampp mit einem Zmej ein; schlieblich will der Held die Entscheidung herbeifuhren, hebt den 2mej hoch "bis zu den Sternen" und stoBt inn mit aller Kraft tief in die Erde; daraufhin fallt in dem Bereich so lange kein Regen mehr, bis die Bewohner den Zmej endlich ausgraben und Preilassen. - In diesen altertumlichen Liedern wird noch die Verantwortlichkeit des Zmej flur das Fallen der Niederschlage betont, whrend in den folgenden Liedern dieser Zug verlorenging und der Zmej fast wie ein menschlicher Gegner behandelt wird. In dem Lied SbNU XVI-XVII,171, das in den Bolen Dojein-Kreis gehört, wird von bolen Georgi gesagt, er liege tagsuber krank und pflege seine Wunden, nachts aber kampfe er mit Helden und Zmejs. Wharend in SbNU $\mathrm{XVVI}_{2}, 51$ der heldische Zweikampf zwi- 
schen Pavel und dem kleinen gelben Zmej ("žlüto zmejðe") unentschieden verlauft, besiegt der Held Dimiturr in SbNU $\mathbf{X}, 10$ eine Gruppe von 77 Zmejs bei der EB- und Trinkprobe, beim Ringkampf und im Steinwurf, worauf die Zmejs ihn als gröBeren Helden anerkennen und sich mit inm verbrudern. In Mil.12 ist die Rede von Prodan, dem heldenhaften Witwensohn, der unbesiegbar im Ringkampf, Steinwurf und Sprung ist; zwei Zmej-Brider hören von ihm und kämpfen drei Tage und drei Nachte mit ihm. Unter Nebel- und Taufall, unter Blitzen und Donner wird Prodan endlich von den Zmejs in den Himmel entfuhrt. In Stoin SSB, 117 schließen ein Held und ein "zmejce" eine Wette ab: Siegt das Zmejče im Zweikampf, erhălt es das Pferd des Helden, siegt jedoch der Held, darf er das Zmej-Reich einnehmen.

Auch die ukrainische Volksdichtung, die der balkanischen in vielen Zligen ahnlich ist, ist - wie bereits erwähnt wurde reich an Kämpfen zwischen Helden und Zmejs.

Die Lieder der dritten Gruppe, worin eine Zmej-Verwandlung geschildert wird, gehört dem Liederkreis mit familiğrer Thematik an. Im Gegensatz zum skr. Lied verwandelt sich im maz.-bulg. der Held nicht selbat in einen Zmej,sonderm er wird von seiner Mutter durch zauberische Praktiken dazu gemacht:

Ein junger Mann heiratet das Madchen, das er liebt, nicht aber das von seiner Mutter ausgewăhlte, worauf die Mutter ihren ungehorsamen Sohn mit einem schweren Pluch verwinscht. Von Zigeunerinnen erhält sie ein Pulver bzw. Zauberkräuter ("omrazni bilki" = $\mathrm{HaB}$ erzeugende Krauter), woraus sie (bei Vollmond, in einem neuen Topf usw.) einen Absud herstellen und damit die unliebsame Schwiegertochter besprengen soll, was zur Trennung der Ehepartner fihre.- AnschlieBend wird die Schwiegertochter aber von denselben Zigeunerinnen davon unterrichtet, dab ihre Schwiegermutter einen zauberischen Anschlag auf sie plane; sie solle deshalb in der Nacht mit ihrem Mann den Platz tauschen.- Dies geschieht, und die Schwiegermutter besprengt statt der Schwiegertochter ihren eigenen Sohn, worauf dieser von der Taille abwarts sich in einen grinen Zmej verwandelt, vor dem Menschen und Tiere fliehen. Entweder verschwindet der so verwandelte Sohn auf Nimmerwiedersehen in den Wald, oder aber er wird auf Betreiben der Schwiegertochter zurluckverwandelt in einen jungen Mann, schoner als vorher, und die Schwiegermutter wird geteert und verbrannt.

Hierher gehören die Varianten SbNU IX,48; XXII-XXIII,86; XUVI ${ }_{2}$, 
50; X, 19; XXXVIII Nr.213; XIIV Nr.889; XLVII Nr.53 und 56; XIIII Nr.121 und 122. - Dieses Sujet gehört in den großen Kreis der maz.-bulg. Lieder, die von Metamorphosen handeln (vgl. die Verwandlung eines von der Mutter verfluchten Liebespares in Hirsch und Reh; die Verwandlung der trauernden Frau in einen Kuckuck; die Verwandlung toter Iiebender in symbolische Pflanzen usw.); es macht einen nicht sehr altertllmlichen Eindruck.

Am umfangreichsten ist die vierte Gruppe, worin Liebesbeziehungen zwischen Zmejs und Madchen oder Frauen $368 \mathrm{a}$ bzw. Zmeicas und jungen Mannern behandelt werden. Aus der großen Zahl von Zmej-Iiedem dieser Gruppe, die nicht einzeln besprochen werden können, seien nur einzelne interessantere sujeta hervorgehoben, z.B.:

Ein Madchen erklät seiner Nutter, diese suche umsonst einen passenden Schwiegersohn, denn sie, die Tochter, werde schon seit drei Jahren von einem Zmej geliebt, der sie zur Braut nehmen wolle; die Mutter moge nicht erschrecken: Abends kbumen die Zmejs auf weiBen Pferden, die Zmeicas in goldenen Kutschen und die Zmej-Kinder in goldenen Wiegen, um die Braut abzuholen; im Wald sei es dann ganz windstill und das Dorf werde wie in Feuerglanz erstrahlen.-Die Mutter fragt, warum die Tochter ihr nicht friher davon erzahlt habe, denn dann hatte sie ihr ein Zaubermittel gegen den Zmej gegeben. In dem Augenblick trifft die Voraussage der Tochter ein, und sie wird entflunrt.

In diese:- Sujet (vgl. die Var. Col.2; Doz.9; SbNU XXV,132; XII, 6; XXVII, 168; Jank.35 u.a.) ist also die "einfache" Entfuhrung durch den Zmej, wie sie in vielen Liedern besungen wird, schon in eine prächtige, in märchenhafter stil gehaltene Brauteinholung umgestaltet. Viele andere Lieder handeln davon, daB ein von einem Zmej geraubtes Mädchen versucht, den miBlisbigen Fntfuhrer und Iiebhaber wieder loszuwerden:

Die Zmej-Braut fragt eines Tages den Zmej, ob er, da er doch feurig sei, nicht Heu- und Strohhaufen in Brand setzen konne. Der Zmej antwortet, Stroh durfe er in Brand stecken, nicht aber Heu, denn darin befunden sich "bilki omrazni" ( $\mathrm{HaB}$ erzeugende Kräuter), und wenn diese verbrennten, mllsse er sich von seiner Geliebten trennen.- Das Mädchen setzt daraufhin das Heu in Brand und befreit sich 80 von dem Zmej.

Dieses Sujet (vgl. die Var.Bont.99; SbNU I,21; XXVII,168;XXVII, 
170; XoI.28; SbNU X,21; XXXVIII Nr.5 und 57; Stoin TV 1407 , 1409 und 141C; Spis.BAN XXII,162 u.a.) erinnert deutlich an das alte (Marchen-)Motiv, wonach das Ungeheuer (Drache, Riese) den Sitz seiner Lebenskraft oder Stärke verrat und dadurch Uberwaltigt werden kann.

In anderen Liedern möchte ein von einem Zme $J$ geraubtes Mädchen zur Hochzeit seines Bruders gehen:

Domit auch der Zmej daran teilnehmen kann, verwandelt er sich in eine Nelke oder einen Gurtel, das ZmejKind aber wird zu einer Feder. Im Hause des Bruders angelangt, wirft das Madchen die Nelke bzw. den Gurtel und die Feder in das Feuer und befreit sich auf diese Weise von dem Zmej und seinem Abkömmling.

Vgl. hierzu die Var. Col.27; SbNU XIVI Nr.50; XLVIII Nr.4 u.a. Entsprechende Sujets die oft genug an Samovilen-Lieder erinnern, gibt es auch hinsichtlich der Liebesbeziehung Zmeica-Hirte:

Der Hirte, den die Zmeica durch ihre nachtlichen Besuche schon ganz geschwacht hat, erfahrt durch listige Fragen von der Zmeica selbst, welche Krauter eine Trennung bewirken können, und lost so die unheilvolle Beziehung.

Zu diesem Sujet sind Var. wie Per.Spis.XI-XII,164; Joz.7; Jank. 36; SbNU XVI-XVII,50; XVI-XVII,53;XXVII,170;X,22; XXV,3;XIIII Nr.278 u.a. zu nennen.

Seltsamerweise erscheint die Zmeica in manchen Liedern dem Hirten in Gestalt einer Barin:

Erst seine Mutter klärt den Hirten uber das wahre Wesen dieser Bärin auf und weiB gleichzeitig Rat, indem sie dem Sohn "bilki razdelni" (Trennung bewirkende Kräuter) mitgibt, die diesen von der Zmeica befreien. Hierzu gehören Var. wie Bond.16; Stoin TV 1420 und 1423; SbNU XIII Nr.56; XIIV Nr.109; XLVII,50; XIVII,519 u.a.- Wie wir bereits aus den vorhergehenden Kapiteln wissen, ist der Bar in den bulg. Liedern ein dämonisches Wesen, das sogar den Drachen ersetzen kann.

Zum Vergleich sollen noch die skr. Zmaj-Lieder in ihren Grundzuggen besprochen werden. Lieder der ersten Gruppe fehlen - wie bereits erwähnt - in der skr. Volksdichtung, obwohl die Vorstellung vom Zmaj-Ala-Kampf im skr. Volksglauben besteht. Die zweite Gruppe Jedoch (Kampp eines Helden mit einem Zmaj) ist durch mehrere interessante skr. Heldenlieder vertreten. Das Lied $\mathrm{MH} \mathrm{I}_{2} 50$ 
"Marko Kraljević i zmaj" warde bereits in Kap.4.21 erwähnt:

Hier ist Marko Kraljević der Brautfuhrer bei der Hochzeit des Sibinjanin Janko. ier Hochzeitszug wird von einem dreiköpfigen und sechsflugeligen Zmaj uberfallen, und Marko beweist seinen Heldenmut dadurch, daB er als einziger dem Ungeheuer entgegentritt und es tötet.

Offensichtlich ersetzt hier der Zmaj die aus den maz. und bulg.

Varianten bekannte dreiköpfige und mehrflugelige Lamja, also einen regelrechter Drachen, während der Zmaj coch sonst immer anthropomorph vorgestellt wird, was auch Vuk Karadzic betont, wenn er in seinem Rjednik (s.v. "ala") schreibt:

Za zmaja pak misli se da je kao ognjeni junak, od kojega u lecenju oganj odskace i svijetli.

Um solch einen Zmaj handelt es sich in dem beruhmten Lied Vuk II 42 "Carica Milica i Zmaj od Jastrepca", dessen Inhalt so lautet:

Zar Lazar fragt seine Gattin Milica nach dem Grund ihrer traurigen Stimmung und ihres bleichen Aussehens: ob sie etwa Mangel leide? Milica verneint und berichtet schlieBlich die Wahrheit: Seit einem Jahr erhalte sie oben im Wohnturm den nuchtlichen Besuch des Zmajs von Jastrebac, der jeweils bis zum Morgengrauen bei inr bleibe.- Zar Lazar trăgt Milica auf, sie solle den Zmaj in dieser Nacht fragen, ob er außer Gott noch einen Helden auf Erden flurchte.- Als abends der Zmaj vom Jastrebac-Gebirge geflogen komnt und sich auf den weichen Polstern in Milicas Wohnturm niedergelassen hat, stellt ihm die Zarin die Frage:

"Bojiz li se jos koga do boga, Ja na zemlji kakoga junaka?"

Der Zmaj heibt sie schweigen, denn diese Frage habe ihr der Zar aufgetragen. Als ihm Milica versichert, dab dem nicht so sei, läbt sich der Zmaj uberlisten und gesteht, er furchte auf der Welt niemanden außer Zmaj-despot Vuk in Kupinovo im Lande Srem; er icenne Vuk schon lange, schon aus seiner Kindheit, als Vuk ihn immer auf dem hohen Jastrebac im Spiel besiegt habe.- Nach diesen Worten muß der Zmaj wegfliegen, weil der Morgenstern aufgeht. Milica berichtet inrem Gatten von der Unterredung mit dem Zmaj und ihrem Ergebnis, worauf der Zar Zmaj-ognjeni Vuk in Srem brieflich bittet, er möge kommen und den Zmaj von Jastrebac töten. Nach einiger Ưberlegung macht sich der Held auf den Weg nach Krusevac und schlägt dort im Feld vor dem $\mathrm{Za-}$ renhof sein Zelt auf. Nachdem die Zarin den Helden erkannt hat, soll Vuk in den Palast zum Mahl geholt werden. Vuk bleibt aber lieber auf dem Feld und labt der Zarin sagen, sie solle die Ture zu ihrem Turmgemach nicht verschlieben und den Zmaj wie immer erwarten, ihm aber nichts von der Anwesenheit Vuks verraten.Als es Nacht wird, kommt der Zmaj geflogen und sucht 
Milica wie immer auf. In diesem Augenblich ruft Vuk den Zmaj heraus:

Ko se ljubi na bijeloj kuli.

Nek izlazi iz bijele kule,

Zar ne vidi le je poginuo?

Nun wirft der Zmaj Milica vor, sie habe ihn bei Lazar verraten, und flieht ins Freie, doch nicht zum Jastrebac, sondern hoch in die Wolken, wo ihn aber Zmajdespot Vuk erreicht:

Pa ne bjezi Jastrepcu planini,

Vec poojeze nebu pod oblake,

A Cera ga Zmaj-despote Vuce.

Vuk bricht dem Zmaj mit der Keule die Plügel, worauf der Zmaj niederstürzt. Vuk fliegt herbei und ochlugt inm den Kopf ab, den er Lazar bringt, worauf dieser voll Furcht zu zittern beginnt.- Reich belohnt zieht Vuk nach Hause zurluck.

Varianten dazu sind $\mathrm{MH} \mathrm{I}_{1} 54$ und 55; MH I, 570; Ähnlichkeit besteht auch mit Vuk VI 4, doch wird in diesem liedgestaltigen Märchen die Zarentochter von einem Adler besucht, der oich nach Ablegen des Gefieders in einen schönen Jïngling verwandelt. Das obige Sujet gehört sowohl der Gruppe 2 wie auch der Gruppe 4 an, weil es einerseits den Kampl eines Helden gegen einen Zmaj, andererseits aber auch die Liebesbeziehung eines Zmajo zu einer irdischen Schönen enthăt. Moglicherweise handelt es sich um eine Kontamination des im maz. und bulg. Kaum so stark verbreiteten und wahrscheinlich von dort zugewanderten Themas der vierten Gruppe mit dem alten totemistischen Thema der Abstammung eines Helden aus Wolfs- oder Zmaj-Geschlecht. Die Ungereimtheiten in dem Lied als Folgen einer verderbten Ableitung aus dem Georg-Drachenkampf-Sujet zu erklären, wie es in der Anmerkung (S.704) zu Vuk II 42 geschieht, scheint mir doch etwas zu vereinfachend. Zirmunskij 369 dagegen erwagt die Moglichkeit, daB den Liedern von Zmaj-ognjeni Vuk - Ehnlich wie der Byline uber Volch Vgeslav'evic - ein altes Heldenmarchen zugrunde liege. Meiner Ansicht nach handelt es sich bei Vuk II 42 einerseits um ein durch den Bezug auf die historischen Geotalten von Furat Lazar (gest.1389) und seiner Gattin Milica historisiertes Sujet der vierten Gruppe. Andererseits trat dazu das Motiv des aus Drachengeschlecht stammenden Helden (Vuk war in seiner Jugend mit dem Zmaj zusammen; Vuk Pliegt wie der Zmaj usw.), der allein als ebenburtiger Gegner einen Zmaj bekbupfen kann. Diese Vor- 
stellung erinnert an die Lieder vom Hochzeitszug mit Uberfall, worin der dämonische Araber bzw. Balacko ebenfalls den alegreichen Gegner schon aus seiner Jugendzeit kennt und furchtet. Hier scheint eine fast mythisch zu nennende Bekanntschaft oder Verwandtachaft zwischen Drachen und Drachenkämpfer vorzuliegen, die sicher auf ganz altertumliche Vorstellungen zurlickreicht; wir finden sie auch im neugriech. Heldenlied 370 . Im sudslavischen Volksglauben (und auch bei den Albanern und Aromunen) herrscht die Meinung, das nur Vampirsobne als Vampirtoter fungieren können 371 , was vollig zu der These der mythischen Verwandtschaft zwischen Held und Ubernatirlichem Gegner passen wurde. DaB der Zmaj von Jastrebac sich Uberlisten läBt und selbst verrat, wie man ihn unschadlich machen konne, ist wieder das alte Motiv AaTh 300 (von dem oben schon die Rede war), dessen Wesen darin besteht, dab dem Ungeheuer durch list das Geheimnis seiner Stärke oder Lebenskraft entlockt wird. DaB Despot Vuk, der rund 150 Jahre spater gelebt hat, hier zum Zeitgenossen von Lazar und Milica gemacht wurde, erklart sich m.E. vor allem durch die Kontamination mit einem Sujet, worin Zmaj-ognjeni Vuk bereits als Abkömmling eines Drachengeschlechts fixiert war. Der erste Hinweis auf eine Beziehung des Vuk Grgurović zu einem Zmaj findet sich in dem Langzeilenlied Bog.16 (davon abgeleitet Milut.104). In diesem Iied wird der todkranke Vuk Ognjeni heimlich von einem Zmaj und einer Vila (diese wahrschelnlich sekundär) gepflegt und stirbt, als seine mundertatigen Helfer ihn verlassen, weil Vuks Gattin das Tabugebot gebrochen und die dämonischen Wesen im Gemach ihres Gatten beobachtet hat. - In dieser Bugarstica steht das Leben Vuks offensichtlich in totemistiecher Beziehung zur Gestalt des Zmajs: sobald der Zmaj lhn verläBt, muß Vuk sterben, - ein Motiv, das wir aus den totemistischen Seelentiervorstellungen der al ten Jagerkulturen kennen.- Bereits in $\mathrm{EH}$, also schriftlich belegt fur das erste Drittel des 18.Jh., wird Vuk "Zmaj despote VuCe", also Zmaj genannt, in der etwas jungeren Tronosa-Chronik ${ }^{372}$ wird Vuk als "Zmaj 1 Vuk ognjeni" bezeichnet.- DaB "Zmaj-ognjeni" eine Ehrenbezeichnung fur einen überragenden Helden bedeutet, ist aus dem Vorhergehenden klar geworden. Und Vuk Grgurović war eben ein hervorragender Held und Turkenkampfer im Dienste des ungarischen 
Königs Mathias. Daher ist es wohl nicht richtig, wenn man wie Kostic 373 versuchen will, den heldischen Beinamen "Zmaj" aus dem 1408 vom ungarischen König eingeführten Ritterorden gle1chen Namens ("viterki orden 'Zmaj"") abzuleiten, den Helden wie Vuk Grgurovic, der walachische Vojvode Vlad, Szckely, der Despot Stefan Lazarevic u.a. erhielten. Die Gleichsetzung eines uberragenden Helden mit einem Zmaj bestand naturlich bereits vor der Schaffung des erwahnten Ordens, d.h. sie ist die Voraussetzung dafir. - In jingeren liedern wie Milut.122, und Petr.III 24 wird Vuk dann als Abkömmling eines Zmajs und einer Vila bezeichnet oder kommt mit seltsamen Geburtszeichen (Wolfshaarbuschel, Mal in Form einer Waffe, "zmajevo kolo pod pazuom", Flammen aus Mund und Nase) zur Welt, die ihn nicht nur als Zmaj, sondern gleichzeitig auch als (Wer-)Wolf ausweisen (vgl.Petr.II 40 und 41; Vuk Rjeznik s.v. "zmajognjeni": Krauss, Slav.Volksf., S.333; Vila 1867,S.454 u.a.) 374 . Volch Vseslav'eviC der Byline, den Jakobson 375 unter Heranziehung der Nestorchronik und des Igorlieds uberzeugend als den historischen russischen Teilfursten aus Polock namens Vseslav Brjacislavovic gedeutet hat, wird (laut Chronikbericht) durch einen Zauber empfangen und mit einer Geburtahaube (jazveno) geboren und kann sich (laut Igorlied und Byline) in verschiedene Tiere, unter anderem auch in einen Wolf, verwandeln. Es handelt sich hier aber sehr wahrscheinlich nicht (wie Jakobson annimmt) un die Widerspiegelung eines "gemeinslavischen epischen Sujets", das auf einem "gemeinsamen mythologischen Erbe" beruht und mit dem "Wolfskult" der slaven in Beziehung steht 376 , sondern man könnte wohl eher vermuten, daß die russische Byline und das okr. Heldenlied, bei aller Verschiedenheit der Sujets, aus einem alten Reservoir totemistischer Vorstellungen der Jagerkulturzeit schøpften. Die Byline verwendet das Werwolfmotiv im Marchenstil als eine Verwandlung unter mehreren möglichen; beim skr. Heldenlied erhebt sich die Prage, ob das Werwolfmotivinicht vielleicht jungeren Datums ist und erst spater, als Vuk Grgurovic schon zum Zmaj-ognjeni geworden war, zusktzlich zur Betonung des ZmajMotivo angefugt bzw. nur aus dem Namen Vuk (Wolf) des Helden hergeleitet wurde. In den alteren Aufzeichnungen ist jedenfalls von einem Werwolfszeichen am Korper des Vuk noch keine Rede. 
In dem langatmigen und sicher jungen Lied Petr.II 19 "Lov cara Lazara" kommt ebenfalls der Zmaj von Jastrebac vor, allerdings als Wahlbruder des Milos. Analog zu den Vilenliedern mit dem "Schwanenjungfraumotiv" wird in diesem Lied dem Zmaj sein Flïgelkleid (!) weggenommen und ihm von Miloł wieder zuruckgegeben, der den Zmaj vor Lazar und seinen Verwandten (Jugovici, Vuk Brankovic) schutzt. Das ganze Sujet scheint aus der Konstellation eines alteren Liedes vom Typ Vuk II 42 abgeleitet und mit dem Jagdmotiv zusammen breit ausgesponnen zu sein. Zu der dritten Gruppe (Verwandlung eines Helden in einen Zmaj) gibt es im skr. Iiedraum das interessante Beispiel von der Verwandlung des Sekula in einen Zmaj, das in den Varianten Bog.19, Vuk II 84 und 85, Petr.II 37, Saulic $I_{1} 39$ und 44 sowie MH I 78 vorliegt. In diesen Liedern ist die zweite Kosovoschlacht (gegen das Heer von Sultan Murad II.) von 1448, in der Székely (Sekula) den Tod fand, behandelt. Kombiniert mit dieser historischen sujetgrundlage ist ein altes totemistisches und schamanistisches Motiv, das auf Sekula Ubertragen wurde. Der Inhalt lautet in allen Varianten etwa folgendermaßen:

Janko und Sekula sind auf das Kosovofeld geritten, um mit den Turken zu kămpfen. Janko will den jungen, unerfahrenen Sekula davon abhalten, allein ins turkische lager zu reiten, doch Sekula labt sich nicht von seinem EntschluB abbringen und reitet zum Zelt des Sultans. Er holt aus seinem Busen eine gefligelte Schlange ("zmiju krilaticu" in Bog.19) bzw. verwandelt sich in eine sechsflugelige Schlange ("zmijom sestokrilom" in Vuk II 84, "zestokrila guja" in Vuk II 85) oder einen Zmaj (Petr.II 37), wahrend der Sultan sich in einen Falken verwandelt. Miteinander in der luft kämpfend nahern sich Falke und Flugelschlange bzw. Zmaj dem Zelt Jankos. Janko nimmt Pfeil und Bogen und erschieBt die Schlange, obwohl ihm Sekula vorher geasgt hatte, er solle den Falken schieBen, weil er, der Neffe Sekula, sich in eine Schlange verwandle (in Vuk II 84 und 85 ) bzw. er solle beide Tiere nicht erschießen, weil Sekula den Sultan lebend herbeischaffen wolle (in Petr.II 37).- In beiden Vukschen Iiedern erschieBt Janko deshalb die Schlange, weil er (unter christlichem Einflub: Schlange = Teufel, das Böse) in ihr die Verkơrperung des Turken sieht, der aus Schlangengeschlecht stamme, während Janko und Sekula dem Falkengeschlecht angehörten.- Sekula fuhlt die schlage bzw. den Pfeil des Oheims am eigenen Körper und kehrt vollig entkraftet zu Janko zuruck, wo er, unrettbar verioren, bald darauf stirbt. 
Hie wir sehen, handelt es sich hier offenbar um ein altes schamanistisches Motiv, nämich um die Aussendung der Seele in Gestalt eines Tieres. Wird das Seelentier getstet, stirbt unweigerlich auch der, für den es als Seelenträger fungiert 377 . Hier liegt das totemistische Prinzip der alten Jagerkulturen zugrunde, seine Seele in bestimmten Gegenständen oder Tieren zu verbergen und damit sein Leben zu schutzen.

DaB Sekula seine Außenseele in Gestalt einer Plugelschlange bzw. eines Zmajs aussendet, ist wohl ein Beweis fur die heldenhafte Zmaj-Natur Sekulas und daher keinesfalls negativ zu werten, wie das der Sänger nachträglich Janko (oder turo, seinem Ratgeber im Iied) in den Mund gelegt hat. Interessant ist die Vorstellung im Volksglauben der Sumadija-Bewohner, die Turken seien "ale", die Serben aber "zmajevi"378.

Obwohl das Motiv rom Kampl zweier Seelentrager (Plugelschlange gegen Falke) in der maz. und bulg. Volksepik nicht ausdrlacklioh im lied vorkommt, könnten wir vielleicht doch anlablich der maz. Lieder Tomic, 181 und Sapk.15 (vgl. deren Besprechung in Kap.4.41 S.346 1.) die Vermutung auBern, daB es sich dort bei dem Kampl der Palken Markos gegen die Lamja möglicherweise um ein knnliches Motiv handelt, wobei der Falke als Seelentier des Helden aufzufassen ware. Uberhaupt verdiente der Falke als mogliches Seelentier in der südslavischen volksdichtung grindlicher untersucht zu werden.

Sekula wird schon in Bog.21 mit dem heldischen Beinamen "Drakulovic" (Drachensohn) belegt. In jungeren Liedern kommt es vor, daB Sekula als Zmaj eine Vila verfolgt (MH $I_{1} 75$ ) oder von einer Vila in einen 2 maj verwandelt wird (MH $I_{1} 74$ ). In Petr.III 24 ist Sekula als Zmaj-Abkömmling erwähnt. Es nimmt also nicht wunder, daB gerade die als .Zmaj oder Zmaj-Abkömmling aufgefaBten Helden Sekula und Despot Vuk (Zmaj-ognjeni) nach ihrer Wanderung in den Sủden im maz.-wbulg. Raum als "dete Sekula" und "Ognjan detence" in den Kreis der Heldenkinder aufgenommen wurden, denn die Heldenkinder konnten wir als Ableitung aus der Zmej-Vorstellung bezeichnen. Die mit historischen Namen belegten Helden aus Zmaj-Geschlecht murden sozusagen ihrer historischen Umkleidung wieder beraubt, und die archaische Heldenkindvorstellung siegte. 
Das Lied MH II 12 "Ubio mater pretvorenu u zmaja" durfte wohl ein jungeres und verderbtes sujet sein. Hier verwandelt sich nämlich die böse Schwiegermutter in einen Zmaj, um ihre miBliebige Schwiegertochter zu erschrecken und zu qualen. Der Sohn verwundet den Zmaj tödlich, worauf die Alte sich mit unheilbaren und todbringenden Wunden ins Bett legt, sich als Zmaj zu erkennen gibt und schließlich stirbt, nachdem ihr Sohn sie verflucht hat.- Wir kennen das Motiv der Verwandlung von (meist alteren) Frauen in Hexen und Werwolfe aus den sidslavischen Volkssagen, und von dort her scheint das Motiv, aller‘dings nun gedankenlos mit dem Zmaj in Verbindung gebracht,letzten Endes zu stammen.

Als skr. Beispiele fur die vierte Gruppe (Liebesbeziehung zwischen einem Zmaj und einer irdischen Schönen), zu der ja auch das bereits besprochene Iied Vuk II 42 gehort, sind sonst nur einige wenige (Prauen-)Lieder zu nennen. Vuk I 239 (und als Var. Vuk V 250) "Ljuba zmaja ognjenoga" aus Dubrovnik hat folgenden Inhalt:

Ein Zmaj fliegt vom Meer zur Donau und trägt unter dem einen Flügel ein schönes Mädchen, unter dem anderen die Ausstattung des Madchens. Da wird der Zmaj von heftigem Durat befallen, labt das Madchen 108 und schickt es ins Waldgebirge um Wasser. An der Quelle halten sich aber drei Junggesellen auf, die das Madchen belastigen. Der erste sagt "Lijepe djevojke!", der zweite meint "Da je upitamo!" und der dritte schlagt sogar vor "Da je obljubimol" Da bittet das Madchen um Schonung, denn sie sel Tochter des Zaren und treue Traute des feurigen Zmaj.- Nach dieser Erklärung fliegt sie uber das Feld "wie ein Stern Uber den klaren Himmel". - In Vuk V 250 sagt das Mädchen sogar:

Ja sam seja Zmaj-ognjena Vuka,

A ljubovca ognjevita zmaja.

Einen wesentlich älteren Eindruck macht das Lied MH II, 11 (und dazu Varianten $\mathrm{MH} \mathrm{II}_{1}, 417$ f.) "Travoberica Mare $i$ zmaj" aus der Gegend von Makarska:

Ein Madchen, das im Freien arbeitet, sieht einen "grimmen Zmaj" auf sich zukommen und flieht darauf nach Hause. Der Zmaj holt die Schöne jedoch ein und trägt aie in eine tiefe Höhle, wo er ein Jahr lang mit ihr lebt und sie inm ein kind zur Welt bringt. Nach einem weiteren Jahr bittet sie den feurigen Zmaj, nach Hause gehen zu durfen, um ihre Mutter zu besuchen. Der Zmaj meint, er wirde sie gehen lassen, 
wenn er sicher sein könnte, daß sie wieder zurukckkehre. Als Mara schwört, sie werde bestimmt wiederkommen, labt der Zmaj sie gehen, tragt ihr aber zum Abschied auf, sie solle ihm allerlei bunte Blumen mitbringen, nur nicht "odolina cvica" (odoljen 'gemeiner Baldrian; Hexenkraut, dessen man sich nicht erwehren [ odoleti] kann'), denn davon erkranke er schwer und schmerze inn der Kopf.- Mara macht einen kurzen Besuch zu Hause und kehrt rasch zu dem Zmaj zurlick, nachdem sie allerlei Blumen, am meisten aber von dem verbotenen Hexenkraut, gesammelt hat. Der Zmaj erkrankt sofort und mus wehrlos zusehen, wie Mara mit ihrem Kind nach Hause entflieht.

In diesem Sujet ist das bereits aus dem maz.-bulg. Iiedraum bekannte altertumliche Motiv der Zauberkräuter erhalten, mit deren Hilfe sich das Mädchen von dem Zmaj befreit. Das Mudchen entlockt inm das Geheimnis hier allerdings nicht durch listiges Fragen, wie es eigentlich zur alteren Version des Motivs gehört, sondern der Zmaj verrät es selbst. Aus den "bilki omrazni" bzw. "bilki razdelni" der maz.-bulg. Iieder ist hier der Krankheit erzeugende Baldrian, das Hexenkraut "odolin", geworden.

Es stellt sich nun die Prage, ob das Motiv aus dem bulg.-maz. Raum zugewandert, durch den Pilter des dinarischen Raumes gegangen (in Vuk I 270 z.B. sind die Zauberkrauter nicht mehr erhalten; hior labt der Zmaj das Madchen auf Ehrenwort gehen) und heute noch in seiner altertümichen Form in dalmatinischen Var. (Gesetz der Peripherie!) erhalten ist, oder ob es sich um gröBere oder geringere Reste einer alten gemeinsamen Uberlieferung handelt. Diese Prage durfte sehr schwer zu beantworten sein.

\section{4 (SAMO-) VILA-, SAMODIVA- UND JUDA-LIEDER}

Die alteste Bezeichnung für die schönen, bekränzten, weiß gekleldeten und geflugelten feenartigen Wesen im Volksglauben der Slaven iat $V i l$ a. Sie ist bei den Sudslaven seit dem 13.Jh., bei den Russen schon se1t dem 11.Jh. bezeugt. Schneeweis 379 hat neuerdings den Versuch gemacht, die bis dahin ungeklarte Etymologie des Wortes Vila mit idg. 'ueja 'Wind', 'uxeięti 'es weht'. dazu litauisch vếjas, altind. vayú 'Iuft' zu verbinden und die vilen als urspringliche Luft- und Sturmgeister manistischen Ur- 
sprungs, nämich aus den Seelen zu früh verstorbener Mădchen, zu erklaren ( $v g l$. litauisch veles 'Totengeister'). Nach maz.bulg. Volksvorstellung sind die Samovilen die Schwestern der "vichri" (Windgeister).- Die Bezeichnungen "samovila" (in Mazedonien und Westbulgarien) und "samodiva" (vor allem in 0stbulgarien) sind jungeren Datums. Das Wort "diva" kann wahrscheinlich von dem pers.-turk. dev, def 'böser Geist, Teufel' oder von der slavischen Wurzel div- (vgl. bulg. div 'wild', diven 'wunderbar, erstaunlich', divja se 'sich wundern,staunen') abgeleitet werden ${ }^{380}$. Die Wortzusammensetzung mit samo- wird meist als Analogiebildung $z u$ anderen bulg. Wörtern wie samovolen, samoglav, samoživ usw. erklärt. Die "juda" oder "samojuda", die mit der "samodiva" identisch ist, vertritt häufig den Typ der bösartigen Pee. Ableitungen des Wortes Juda von dem PN Judas oder von latein. unda 'Welle, Woge' sind nicht aufrechtzuerhalten. Einleuchtender dagegen ist die bei Madenov aufgestellte Etymologie, wonach "juda" von der idg. Wurzel mit der Bedeutung 'kämpfen, in unruhiger Bewegung sein' abgeleitet wäre, vgl. sanskrit yúdhati, yodhati 'kämpfen', ud-yodhati 'sich aufregen', litauisch judù, judé'ti 'gereizt werden, sich streiten', judus 'zänisisch' und judra 'Wirbelwind', lettisch jauda 'Kraft, Stärke', latein. iubeo 'befehle', dazu bulg. judja 'verlocken', litauisch jauda 'Verlockung' und polnisch judzić 'reizen, ärgern'.

An dieser Stelle kann das Wesen des Vilenglaubens und seine Manifestation in Sagen und Liedern nicht ausfihrlich behandelt werden. Darüber informiert eine reiche Literatur ${ }^{381}$. Die Ähnlichkeit der sudslavischen (Samo-)Vilen mit den albanischen Zanen 382 und den griech. Neraiden 383 ist wohl als Ergebnis der Balkangemeinschaft aufzufassen. Inwiefern die griech. Neraiden zur Vilenoder Zanen-Vorstellung beigetragen haben, wäre eine eigene Untersuchung wert.

Aus dem überaus reichen skr., maz. und bulg. Liedmaterial, worin der zwiespältige Charakter der Vilen deutlich zum Ausdruck kommt, kann hier nur eine begrenzte Auswahl von Themen besprochen werden, wobei vor allem auf unterschiedliche Züge im skr. und maz.bulg. Kaum geachtet werden soll. Folgende Sujets, die sowohl durch skr. wie auch maz.-bulg. Lieder vertreten sind, seien nur 
erwahnt: Die Vila wird die Frau eines Helden, der ihr das Plugelkleid und damit ibre damonische Macht geraubt hat, doch nach Wiedergewinnung des Flügelkleids erfolgt die Flucht der Fee 384 - Die Vila entzweit zwei Bruder und sturzt sie ins Verderben 385 - Die Pee tritt als Herrin des Waldes auf: sie reitet auf einem Hirsch, trägt Schlangen als Gurtel, Peitsche und Zaumzeug, und die Tiere des Waldgebirges folgen ihr 386 - Die Vila brodarica, vodarica oder vodarkinja sperrt das Wasser und gibt es nur gegen schweren Tribut frei - Die Vila totet Markos singenden Wahlbruder aus Neid wegen seiner schönen Stimme oder aus Ärger wegen der Störung; sie wird von Marko gezwungen, den vom Pfeil Getroffenen mit Heilkräutern wieder zu beleben - Die Vila verbietet dem Helden, auf dem Vilentanzplatz sein zelt aufzuschlagen, und wird von dem Helden bezwungen - Die Vila vermittelt dem Helden magische kräte, indem sie ihn mit ihrer Milch nährt 387 - Die Vila als Wahlschwester steht dem Helden im Kampf mit einem Uberlegenen Gegner bei - Die Vila baut eine Burg aus Menschenknochen - Die Vila weiB die Zukunft voralis 388 u.a. Wie wir bereits aus der Behandlung des maz.-wbulg. Liedmaterials, das gleichzeitig alte und jungere Entwicklungsstadien widerspiegelt, wissen, ersetzt die Samovila einerseits in mehreren Sujets den weiblichen Drachen ( nämlich in folgenden Sujets: Die Samovila sperrt das Wasser - Die Samovila totet den singenden Helden - Die Samovila fuhrt drei Ketten Sklaven - Die Samovila uberfallt den Hochzeitszug und verschlingt den Bräutigam; im skr. Raum zum VilenschuB gemildert), andererseits als hilfreiche Wahlschwester den urspringlichen Helfer des Helden, namlich das pferd (z.B. in folgenden Sujets: Kampf des Helden mit der Lamja im Brunnen - Markos Kampf mit Musa).

während in den skr. Liedern der Held die Vila immer durch Wegnahme des magischen Flügelkleides gewinnt, erringt der Held im maz. und bulg. Lied die Samovila außerdem hăufig deshalb, weil er sie im Wettbewerb besiegt hat (die Samovila tanzt, der Held spielt auf der Flöte und hält länger durch als die Fee). Hierzu vgl. die Var. SbNU II,29; I,29; V,7; VI,5; VIII,167; Mil.2; II. 273; Sapk.9 und 680; Verk.20. Dieses in maz. und bulg. Var. verxörperte Motiv des Wettstreits zwischen Samovila und Hirten $388 a$ erinnert an die neugriech. Lieder (z.B. Passow 524; Lüdeke 117; 
Kind 18; Lubke,249), in denen Jannis die Lamia des Meeres durch sein flotenspiel hervorlockt und mit ihr eine Wette abscinliebt: Siegt er im Spiel, darf er die Lamia zur Frau nehmen, siegt jedoch die Lamia im Tanz, dann gehören ihr entweder die Herden des Jannis, oder aber Jannis ist ihrer Gewalt und Willkur ausgeliefert; in beiden Fullen verliert Jannis die Wette. In dem Lied Lubke, 248 versprechen die Flußneraiden Jannis, er durfe sich die schönste aus inren Reihen auswählen, wenn er nur immer weiter auf der Flotte spiele; Jannis schlagt jedoch das Angebot aus mit der Begründung, inm liege nur die schöne Eudokia im Sinn.- Dieses den Griechen und sudlichen Sudslaven gemeinsame Wettbewerbsthema fehlt in der skr. Volksepik. Es ist höchstens rudimentar in dem Sujet erhalten, worin die Vila aus Neid Uber die schönere Stimme des Helden den singenden Wahlbruder Markos erschiebt. Wie in den oben besprochenen 2 mej-Liedern trennt sich auch in den maz. und bulg. Samovilen-Liedern, die die Liebschaft zwisehen einem Hirten und einer Samovila schildem, der Held mit Hilfe von "omrani bilki" von seiner Geliebten (vgl. die Var. Col.66; Rod.Napr.VI,76; VIII,57 u.a.). Die Liebesbeziehung einer Samovila zu einem Hirten ist das Thema vieler maz.-bulg. Lieder, die meistens zum Choro (Reigentanz) gesungen werden (vgl. SbNU VIII,23; Mil.7; Sapk.2; Doz.7; Doz.Suppl.5 usw.);im skr. Liedraum aber ist dieses Thema allein in Form des "Schwanenjungfrau-Motivs" anzutreffen. Von den maz. Liedern dieser Gruppe ist am interessantesten das altertumliche Lied Mil.7. Hier erzünt die um ihren von der "morska samovila" (Meeresfee) geliebten Bruder besorgte Schwester, die den Bruder durch (magisches) Lachen und Anreden der Fee mit "Schwägerin" retten könnte, die Samovila durch Weinen und die Anrede "Judo samovilo" (statt "Snaho samovilo") so sehr, daß diese inren Geliebten totet.- Eine Spur dieses magischen Lachens, des Lachens wider den Tod, findet sich auch in dem serb. Lied Vuk VI 14 "Smrt Cara Uroßa", woruber Cajkanovid 389 geschrieben hat. - Interessant ist auch in Mil.7 wieder das Motiv der magischen Verwandtschaft, das darin zum Ausdruck kommt, daB die Schwester die Samovila mit "Schwagerin" anreden soll, um den Bruder zu retten. Ein typisches maz.-bulg. Liedsujet, das im skr. Raim unbekannt 
ist, lautet so:

Zu Stojan kommen seine zehn Schwestern zu Besuch. Neun davon sind Koniginnen, die zehnte ist Zarin Rada. Radas Kind verlangt um mitternbchtliche Stunde Wasser zu trinken, und Stojan bleibt nichts anderes Ubrig, als zum Samovilensee oder -brunnen zu gehen. Dort trifft er drei Samovilen, drei "brodnici", die inm raten, noch vor Hahnenschrei nach Hause zu eilen, die schutzende Turschwelle zu erreichen und sich von seiner Mutter "heilen" zu lassen.- Stojan kehrt sofort nach Hause zurlick, stirbt aber bald darauf.

In manchen Var. dieses Sujets sind die drei Samovilen Stojans Gevatterin (kumica) oder GroBmutter (baba) bzw. Tanten (lelja, strina), d.h. hier liegt wieder der Gedanke der magischen Verwandtschaft zwischen Held und Ubernatiulichem Wesen zugrunde.

Hierzu gehören Lieder wie Mil.61; Bond.37; Jank.32; Sapk.13; Mich.247: Per.Spis.XI-XII,150; XXIX,463; SbNU IX,19; vürb.221; Verk.4; Karav.BNP 1. Erneut zeigt sich hier die Samovila deutlich als unheilvolles damonisches Wesen, das denjenigen ins Verderben sturzt, der zu unerlaubter zeit (um Mitternacht, vor Hahnenschrei) in den Bereich der Herrin des Waldes und der Gewssser eindringt. Der Mensch in derartigen mythologischen Schicksalsballaden ist der damonischen Macht wehrlos ausgeliefert; er ist der durch die unheilvolle Begegnung mit dem ubernaturlichen Wesen Gezeichnete, dem Tod Geweihte, ein schicksalhaft Berinhrter, wie wir inn auch aus unseren deutschen Sagen kennen (Rudolf otto spricht von dem Einbruch des "Ganz Anderen", des Numinosen, das er als "mysterium tremendum et fascinosum" bezeichnet, vgl.seine Abhandlung "Das Heilige", Breslau 1917). Erst der Held der epischen Lieder wagt den Kampl mit dem mythischen Wesen und siegt (vgl. Sujets wie "Marko zwingt die Vila, den von ihr getöteten Helden wieder lebendig zu machen"; "Der Held klummert sich nicht um das Verbot, auf dem Vilentanzplatz sein Zelt aufzuschlagen"; Mil.1: Jovan Popov, der die Samovila durch Brechen des sonntkglichen Arbeitgverbots erzurnt nat, uberwindet die Pee, bindet sie an den Schweif seines Pferdes und schleift gie nach Hause). Bestrebt, das Heldentum seiner Iieblingsgestalten moglichst zu betonen, labt der epische Sänger seine Helden den vilen schlieblich nicht nur ebenburtig, sondern sogar so uberlegen werden, daB die Helden den vilen zu Hilfe eilen und sie retten mulssen bzw. die Vila dem Helden die Hand kist oder ihn bedient $389 a$, 
vgl. dazu Petr.II,247 und 390, Vuk II 86, VeK II 2 u.a. Ein typisch maz.-bulg. Zug ist die Tendenz zur Verchristlichung mancher Samovila-Iieder. So schützt die Samovila, ähnlich der 8v.Nedelja (hl.Sonntag) im skr. Lied, schlieblich sogar die Sonn- und Feiertagsmuhe (vgl. Mil.1,5,20; SbNU IV, 16 u.a.).

Weit verbreitet im sudslavischen Raum ist das Motiv der Samovila, die in den Wolken eine $B$ u $r$ aiss toten Menschen verschiedenen Geschlechts und Alters bzw. aus Menschenknochen baut $389 \mathrm{~b}$. Dieses Sujet ist in folgenden Var. vertreten: Jastr., 133; Mich.244 und 245; Ikon.247; Bulg.Kn.I,162; Verk. 1 und 3; Mil.3 und 10; SbNU VII.9; Stoin TV 135; Radov.1 (Die Samovila will Markos sonnchen fur ihre Burg rauben; als sie von Marko bedroht wird, entfesselt sie heftigen Wind, der Marko in das Meer blast); und aus dem skr. Liedraum: Vuk VII 47; MH II,38; MH II $1.435 \mathrm{f.;} \mathrm{Vuk} \mathrm{V} 252$ (Als der "car" mit 300 soldaten die Burg stirzen will, erschlagt die Vila das ganze Heer mit Knochen und Steinen); Vuk I 226 und Milut.1 (Sekundar besteht in diesen beiden Liedern das Baumaterial aus Gold. Perlen und Edelsteinen). - Im maz.-bulg. Raum murde das Motiv des Burgbaus auch auf Gott ("gospod"), den Herm Uber Leben und Tod, Ubertragen, der in den Wolken oder im Paradies ein Kloster bzw. eine Kirche aus toten Menschen baut, unterstutzt von Samovilen, der "Cuma"(Pest) oder Zmeicas, die ihm das "Baumaterial" liefern, vgl. Var. wie SbNU III,37; IV,21; XIV,13; Doz. 5; Karav.BNP 66; SbNU XIII, 15; XXVI Nr.368; XXII-XXIII, 121 und 133: KaX.47.

Das Motiv ist vermutlich aus der griech. Volksdichtung ubernommen, wo Charos (der Tod) einen Garten bzw. ein Haus aus toten Menschenlelbern buut (vgl. Kind 5; Lubke,262 usw.): N1e z1tronenbaume sind Mudchen, die Zypressen Jünglinge, Kinder pelanzt er als Basilikum in Topfe und Greise verwendet er zu Gartenzaunen; oder aber Charos verwendet fur sein haus Junglinge als Balken, Greise als Fundament, kleine Kinder als Turmzinnen, Heldenarme als Pfosten, Madchenzöpfe als Taue und Kinderkopfe als Stangenknaufe 390 . Wie Dieterich 391 betont hat, ist diese seltsame Allegorie höchstwahrscheinlich orientalischen Ursprungs. In "einem Teil des großen indischen Epos Mahâbharâta 
heiBt es z.B., daB der Held Visna das Feindesland zum Garten machte und abgehauene Königsköple als Wassermelonen, Büuche als Kürbisse und Arme als Peigenbăume einpflanzte". Diese Vorstellung gelangte vermutlich in byzantinischer zeit zu den Griechen und wurde nun an die Gestalt gebunden, der der Umgang mit Leichen und Leichenteilen am adaquatesten ist, eben Charos. De den Südslaven eine dem Charos entsprechende Gestalt fehlt, setzte man an seine Stelle ein annhernd uhnliches, grausam mordendes Wesen, namlich die Samovila. - Ob auch zwischen dem als berittenen Jäger auftretenden griech. Charos,der die jungen Leute vor sich hertreibt, die Kinder reihenweise am Sattel fuhrt und die Greise hinter sich nachzieht, und der sklaventreibenden Juda der maz. Lieder eine Beziehung besteht, ware erst zu untersuchen.

Die skr. Heldenepik, in der sich mythologische zuge nur noch rudimentar finden, hat auch die vilen vollig ihren epischen Gesetzen unterworfen und sogar eigene epische Schablonen bzw. Kompositionsschemata geschaffen, ngmich den sog. F e e r a

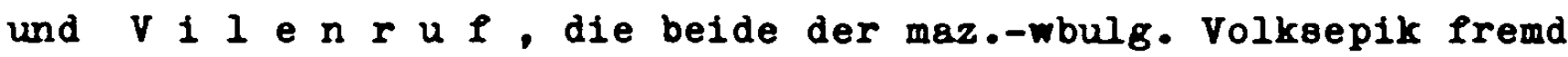
sind. Unter "Feenrat" verstehen wir die Einberufung einer Versammlung der Feen durch die Feenalteste, wobei eine der Vilen für die Erfullung einer bestimmten Aufgabe ausgewählt wird ( $\nabla g l$. z.B. die Entzweiung der Brluder in Bog.43, EH 132, MH I $I_{1} 45$, Petr. II 6; die ErschieBung des Brautigams im Hochzeitszug in Maz.,81, Bozk.NEP II 15 und Var.S.270; Plug der Vila zum Meer, ohne dem Zmaj in die Hande zu fallen in MH $I_{1} 75$ u.a.). Schmaus 392 sieht mit Recht in der Ausbildung des Feenrats, "der nach dem Vorbild der Heldenversammlung mit Erteilung und Ubernahme eines heldischen Auftrags gestaltet ist" und "an die "Tafelmunde' der Helden erinnert", einen Ausdruck des Hanges zur "Episierung", die die Entwicklung des Liedes im Westen des sudslavischen Gebiets bestimut hat.- Eine grindliche Untersuchung der anderen epischen Schablone verdanken wir Gesemann 393, der "die Stilisierung einer Geschichte im Rahmen des Feenrufes, wie er etwa fur eine Stadtbelagerung und -eroberung verwendet wird", als "eines der pragnantesten Kompositionsschemata" (neben anderen Schemata wie "Rabenbotschaft", "Traum und Traumdeutung") bezeichnet hat. 
Die Funktion des "Vilenrufs" besteht meist darin, daB ein Held (auf verantwortlichem Posten) von der Vila uber eine unmittelbar bevorstehende Gefahr (Herannahen von Feinden, drohende Belagerung u.a.) unterrichtet wird, wobei die Vila selbstverstandlich mit ihrer Vorhersage immer recht behalt. Die meisten Iieder benutzen den Feenruf jedoch nur als epische Einleitung. Sie "fuhren die Stilisierung nicht streng bis zum Schlus durch, sondern gehen, die einen fruher, die andern spater, in die einfache epische Erzahlung luber und schlieBen dann das lied auch nicht mit dem Schlubrup der Pee oder der SchluBantwort des Heldell an diese" 394. 'Am haufigaten wird das Schema des Vilenrufs ubrigens in Montenegro verwendet. Hierher gehören Lieder wie EH 89 und $90 ;$ Bog.116; Vuk IV 38,4C,43,46,49; Vuk II 94; Vuk VI 73; Vuk VII 47; Vuk VIII $25,39,42,47,52,54$; IX. 4,27; Milut.8,12,47,49,134,171,174; KacicMioric 33 u.a.

Abschließend laBt sich sagen, daB die Menschenfreundlichkeit der Pee, wie sie z.B. in dem gemeingldalavischen Iiedmotiv der Pflege eines kranken Helden durch die (Samo-)Vila bzw. der Unterstützung des kämpfenden Helden durch die Vila als Wahlochwester zum Ausdruck kommt, sehr wahrocheinlich einen jungeren Zug darstellt. Ursprïnglich war die Vila nämlich sicher als böswilliges mythisches Wesen gedanht, und von dieser archaischen Vorstellung zeugt gerade eine betrachtliche zahl maz. und bulg. Iieder. Auch die Substitution der negativen dämonischen Gestalt Lamja durch die Fee spricht fur diese Annahme. 
Eine der vordringlichsten Aufgaben der slavischen Folkloristik besteht, wie Bogatyrev 395 betont, in der vergleichenden Erforschung des slavischen Heldenepos, wobei vor allem die russischen Bylinen, ukrainischen Dumen und ostslavischen historischen lieder einerseits und die skr., bulg. und maz. Heldenlieder andererseits zuerst untereinander vergleichend zu untersuchen waren.

Die letzte Forderung zu erfullen, namlich die sudslavischen epischen Volkslieder - wenigstens fur einen bestimmten Ausschnitt - komparativ zu betrachten, war ziel der vorliegenden Arbeit, fur die solche, die engen nationalen sudslavischen Grenzen uberschreitenden Untersuchungen von Epenforscherm wie Chalanskij, Kravcov, Zirmunskij, Ibrovac, Medenica, Arnaudov, Dinekov, Soerensen, Jakobson, Lord und Schmaus als Vorbilder dienten.

6.1 Jnter systematisch sichtender Heranziehung des sudslavischen (und zum Teil auch griech., albanischen und rumanischen) Heldenliedmaterials warde versucht, mittels der "mikroskopischen" 396 Analyse eines bestimmten Sektors der Volksepik Aussagen uber die Verteilung der sudslavischen Heldenlieder in Zeit und Raum zu machen, d.h. die $C h r \circ n \circ l \circ g i$ und $S t r a t i f i k$ a $t i \circ n$ wenigstens in einigen Punkten $z u$ durchleuchten.

6.11 Um in das sonst unubersichtliche und verwirrend vielfaltige Material eine gewisse ordnung zu bringen, wurden zwei groBe Themenkreise, numlich das Sujet der heldischen Brautgewinnung und das Drachenkampfoujet, in den Mittelpunkt gerickt. Es handelt sich hierbei um zwei archaische Sujets, un die "Zentralthemen des epischen Schaffens in der Epoche des Zerfalls der urspringlichen Sippenordnung", wie Meletinskij397 - in Anlehnung an Propp 398 - die Themen "geroiceskoe svatovstvo" und "bor'ba 8 CudoviłCami" bezeichnet. Bei der Unterauchung der einander polar gegenuberstehenden Hauptthemen, die mit ihren zahlreichen Ableitungen ineinandergreifen, kam es vor allem darauf an, gewisse 
Kriterien fir eine chronologiache Schichtung, fur eine zeitliche und raumiche Verteilung der Liedvarianten zu finden. 6.12 Als Voraussetzung der "mikroskopischen Untersuchung" murden am Anfang eines jeden Kapitels Variantenverzeichnisse aufgestellt und dann die einzelnen Liedvarianten des jeweiligen Sujets der Reihe nach besprochen, wobei die besser erhaltenen, urspringlicheren, archaisch wirkenden und noch nicht erweiterten Varianten an den Anfang gestellt wurden. Eine solche Art der Liedbesprechung, auch wenn sie dem Vorwurf der Langatmigkeit ausgesetzt sein sollte, findet meiner Meinung nach darin ihre Rechtfertigung, daB eigentlich nur auf diese Weise ein Eindruck von der inneren Entwicklung eines Sujets, der Variantenbildung, der graduellen Entmythologisiemung und Historisierung, der Auflösung, Erweiterung und Kontamination, kurz ein Bild von dem wirklichen Leben der Volksdichtung und ihrer historischen Entwicklung vermittelt werden kann.

6.13 Zur Verdeutlichung der Liedentwicklung wurden, wenn möglich, an Kapitelende schematische Darstellungen des (mittels Pfeilen markierten) Abhangigkeitsverhaltnisses der Varianten untereinander angefugt oder zumindest Entmythologisierungsreihen aufgestellt.

6.14 Die răuliche Verteilung der Liedvarianten sollte in den beigefugten Ubersichtskarten zum Ausdruck kommen. Hierbei lieB sich (zum Teil mit Hilfe verschiedengestaltiger Markierungszeichen) zeigen, wie weit sich das Verbreitungsgebiet eines Sujets erstreckt, wo sich Variantenballungsraume feststellen lassen und woher die archaischeren (d.h. noch starker mythologisch gefärbten) Liedvarianten stammen. Wahrend die meisten Sujets im ganzen suldslavischen Raum verbreitet sind, wobei allerdings die archaischeren Varianten durchweg in Mazedonien und Westbulgarien und zum Teil auch im kroat. Klistengebiet und aup den dalmatinischen Inseln aufgezeichnet sind, gibt es daneben auch Sujets mythologischen Gehalts (vgl. Typ 4.13 und 4.22), die in ihrer "Reinform" ausschlieblich im maz.-wbulg., nicht jedoch im dinarischen Raum verbreitet sind.

6.2 In Laufe der Erörterung stellte sich heraus, dab die archaischsten Erzanllieder der maz.-wbulg. Zone entstammen und 
in engem Zusammenhang mit den Akritenliedern der benachbarten Griechen gesehen werden mussen, mit denen sie einen beträchtlichen Motiv- und Formelschatz gemeinsam haben. An zweiter Stelle sind, was die Altertümlichkeit betrifft, die Erzăhllieder des kroat. Küstenlandes und vor allem der Inseln zu nennen, wo oich nach dem Gesetz der Peripherie ( man vergleiche die russischen Bylinen im auBersten Nordenl) epische Iieder mit tellweise archaischen Zügen erhalten haben, die aber ihren Durchgang durch das Gebiet der dinarischen Zone nicht verleugnen können. Die jungste Liedstufe wird in den fast voillig entmythologisierten, dafur aber voll historisierten und psychologisierenden Heldenliedern des dinarischen Raums sichtbar. Diese wurden von vielen Forschem bisher als die allein maßgebenden sudslavischen epischen Lieder, die "klassischen" Heldenlieder, betrachtet, wăhrend man die für die Geschichte der Epik so aufschlubrelchen maz.-wbulg. und inselkroat. Erzăhllieder deshalb meist als mehr oder weniger uninteressant abtat, weil sie sich weder den Grad der Historisierung (also die "Geschichte in der Epik") noch die ksthetische Selte betreffend mit den Heldenliedern des dinarischen Raumes messen können, deren schönste Beispiele die Iledsammlung von Vuk St. Karadzic enthalt. Wenn in der vorliegenden Arbeit das Hauptgewicht auf den an archaisch-mythologischen Elementen reichen maz.-wbulg. Erzählliedern lag, so geschah dies allein deshalb, um Einsichten in die entwicklungsgeschichtliche Problematik der sudslavischen Volksepik gewinnen zu können, keineswegs aber aus Geringschatzung gegenuber den voll historisierten dinarischen Heldenliederm. Es muß an dieser Stelle ausdrucklich betont werden, daß der Yroze $B$ der Entmythologisierung als Voraussetzung fur die grundliche Historisierung der Erzähllieder des dinarischen Kerngebiets notwendig war und daß die skr. Heldenlieder; hatten sie nicht das alte mythologische Erbe durch neue rationalere und realistischnationale Elemente ersetzt, nie die im Lied des dinarischen Raumes so ausgeprägte "ideologische steigerung" 399 der heroischen Wirklichkeit erreicht hätten, die auf das Werden des nationalen Selbstbewußtseins und der damit verbundenen Unabhangigkeitsbestrebungen einen so bedeutenden Einflub ausubte. 
6.21 Wenn Zirmunskij400 den Drachenkampf des slidslavischen Liedhelden Marko Kraljevic generell als "ein neues Motiv" ansieht, "des, wie auch 80 viele andere Motive, aus Marchen und Liedern relativ spat auf diesen beliebten Volkshelden Uibertragen worden ist", so urteilt er wohl allzu sehr vom Standpunkt des Bylinenforschers aus, denn in den Bylinen sind bekanntlich eine Reihe phantastischer Elemente vermutlich erst in jüngerer Zelt aus dem Marchen Ubernommen worden. Ähnlich wie aber fur eine Anzahl von Bylinen des Kiever Zyklus eine auf vorstartliche Verhaltnisge zurückverweisende Liedschicht mit archaischschamanistischen Zugen bestimmt werden kann ( $\nabla g l$. die Arbeiten von Meriggi, Propp u.a.), existiert auch im sudslavischen Liedraum eine Zone, innerhalb derer Erzahllieder mit besonders archalschen Schichten festgestellt werden können. Es handelt sich um den maz.-wbulg. Iiedraum, dessen Volksepik eine Reihe sehr altertumlicher Iiedsujets - trotz veränderter Umweltsbedingungen - bis in die neueste Zeit bewahrt und in sogenannten voroder subhistorischen Liedschichten "konserviert" hat. Dieser archaiachen maz.-wbulg. P $r$ i $\ddot{a} r$ c h 1 c $h t$ gehören meines Erachtens folgende Sujets an: alle Arten von Drachenkampeliedern und ihre Ableitungen in Form der Samovila brodnica-, Bolen Dojcin- und Arapin-Lieder; Lieder, die den Kampl eines Helden gegen einen Ubernatürlichen, anthropomorphen Gegner (Musa Kesedzija mit mehreren Herzen, den steinernen Riesen Zülta bazirgjana und das Riesenmädchen Arvatka) behandeln; HeldenkinderIleder; Zmej-Lieder und Samovilenlieder. Das Pferd apielt dabei als archalscher Helfer und Ratgeber des Helden eine wichtige Rolle. - Abgesehen von den (auch im skr. und griech. Bereich vertretenen) wohl auf hagiographische Vorlagen zurluckgehenden Liedern, worin der hl. Georg einen Drachen tötet und damit die Königstochter und die ganze stadt rettet, ist das Drachenkampfthema im maz.-wbulg. Iledraum in folgenden Sujets vertreten: Kampl eines meist durch besondere Herkunft ausgezeichneten Helden - unter Umständen unterstutzt von einem Heiligen oder Zmej mit einem Drachen, der das Wasser sperrt, die Ernten vernichtet oder Menschen verschlingt; Befreiung von drei Ketten Sklaven aus der Gewalt eines Drachen; Kampl mit dem Drachen im Brunnen; Kampf mit einem Drachen, den das Singen der Frau des Helden ge- 
stort hat; Kampl des Brautfuhrers mit einem Drachen, der den Hochzeltszug Uberfallt; und schlieblich Kampl des Freiers,der alo Freiersprobe drei goldene Äpfel von einem Baum im Meer holen soll, mit einem oder mehreren Wasserdrachen.

Dabel konnte relativ haufig eine Substitution des Drachen durch die böswillige Fee (vgl. die Samovila brodnica-Lieder lieder, in denen der Held im Meer mit Samovilen kämpfen muB; Uberfall der Samovila auf einen Hochzeitszug und Verschlingen des Brautigams; die Samovila-Juda als Sklaventreiberin) oder den däonischen Mohren ( $v g l$. die Bolen Dojzin-Lleder; Arapin-Lieder;der Mohr als Sklaventreiber; tberfall eines drachenartigen ochwarzen Arabers auf den Hochzeltszug) lestgestellt werden.

Der bevorzugte Drachentöter ist in diesen Liedern ein an den archaischen "Kulturheros" (Meletinskij) erinnernder Mensch von besonderer Herkunft (ein auf wunderbare Weise empfangenes Heldenkind, oft mit mehreren Herzen, flugeln usw., ein Bastard, ein Nachgeborener, ein Zwilling) oder aber ein Zmej (der anthropomorphe, aber mit Drachenattributen ausgestattete prädestinierte Bekampfer des weiblichen Gewitterdrachen Lamja, Ala). 6.22 Diese an mythologischen Elementen reiche maz.-wbulg.primäre Liedochicht, die wir als vor- oder subhistorisch bezeichnen wollen, erfuhr vom 14.Jh. an - ahnlich wie schon eruher die griech. Akritenlieder - eine erete $H_{1}$ s t 0 r 1 s 1 e r u durch Aufnahme einheimischer liedhelden wie Marko, Relja, Momcilo usw. In eine bis dahin von wahrocheinlich namenlosen, archaisch-primitiv gestalteten Helden beherrschte Lieddichtung. Im Laufe dieser Phase einer ersten Historisierung durfte auch der UmformungaprozeB begonnen haben, in dessen Verlauf die in den alten Erzahlliedern bekłmpften mythischen Ungeheuer zum Teil durch die historischen Feịde (Turken, "schwarze Araber", "Tataren") ersetzt wurden.

Binschrankend mis gesagt werden, das es neben den alten MarkoLiedern im sludslavischen Raum eine Uberwiegende Mehrheit von liedern gibt, in denen der inzwischen zum typischen positiven Helden und Turkenkkmpfer gewordene Marko in jungerer zeit mehr. oder minder mechanisch in altertímlichere Sujeto mit friher nanenlosen oder auch historischen liedhelden eingesetzt murde. Relativ jung sind aicher die beliebten (Dreier-)Gruppierungen 
von Helden oder ganze "Heldenkataloge", in denen die "Beimischung" Glterer Helden oft rein "ornamentale" Bedeutung haben durfte.

6.23 Uber die primare Liedschicht maz.-wbulg. Provenienz legte sich vermutlich vom 16.Jh. an eine $S$ e $k$ u $n d \ddot{a} r-$ s c h $i c h$ t zugewanderter Elemente, die vor allem aus Heldennamen oder geographischen Bezeichnungen bestanden. Gleichzeitig und in den folgenden Jahrhunderten müssen der maz.wbulg. Volksepik auch ganze skr. Sujets zugeflossen sein, die von den maz. und bulg. Sangern mehr oder weniger verandert, d.h. inrer episch-heroischen zuge zum Teil entkleidet und dafur haupig "verbauerlicht" und mit familiaren und Brauchtumselementen ausgestattet wurden. In dieser Form fanden sie in die Lieduberlieferung der Mazedonier und Bulgaren Aufnahme, wo sie zum Teil auch Verbindungen mit der einheimischen Primärschicht eingingen. $2 u$ den $u$ testen im ganzen zugewanderten Liedsujets gehören wohl "Der prophetische Traum vom Pall Budims" und "Petur ban und Kral Mateja". Themen wie "Kosovo" und "Brautgewinnung nach dem Bestehen dreier Preiersproben" gelangten in mehreren zeitlich aufeinanderfolgenden "Schuben" nach Mazedonien und Westbulgarien, in ihrer letzten Phase anscheinend ziemlich spat, so wie auch das "Todor von Stalać-Sujet wohl zu einem der erst im vorigen Jahrhundert zugewanderten Sujets gehoren dürte.

Die aus dem Donauraum, wo die skr. Volksepik im 15./16.Jh. zu einer ersten Blüte gelangte, zugewanderten ugrisch-serbischen Heldennamen wie Jankula (János Hunyadi), Sekula (János Székely) Kral Matiał bzw. Matlija, Mateja, Matias (Mathias Corvinus), Gjuro Smederevec (Despot turad Brankovic), Ognen bzw. Ognjan (Despot Vuk Grgurovic, der Zmaj-ognjeni Vuk der skr. Lieder) und Toponyma wie Budim, Temiłvar, Slankamen, Srem usw. leiteten eine zweite Historisierungswelle in der maz.-wbulg. Volksepik ein.

6.24 Dieser HistorisierungsprozeB blieb aber in seinen Anfungen stecken und warde von der eigenstandigen maz.-wbulg. Liedschicht, die ihre archaisch-mythologischen Elemente mit groBer zahigkeit bewahrt hat, aufgefangen. Sekula und Ognen z.B. wur- 
den von der Heldenkind-Kategorie "absorbiert"; Jankula dagegen wurde zu einem stereotypen Liedhelden in der Art von Marko und Stojan; Budim wurde der typische stadtename.

6.3 Das Hauptinteresse dieser Arbeit galt, nachdem die sog. Sekundärschicht abgehoben war, den damanterliegenden archaischen, $v$ o h 1 s $t$ or 1 s $\mathrm{c}$ e $\mathrm{n}$ Liedschichten, deren Beziehung zum. Mythos und Märchen an mehreren Stellen kurz beleuchtet wurde. Wahrend Zirmunskij 401 das Helden- und Zaubermarchen als Zwischenstufe zwischen Mythos und Heldenepos ansieht und Propp 402 von einer "vorstaatlichen Form" (dogosudarstvennaja forma) des Heldenlieds und einer "Koexistenz der Genres" (sosuscestvovanie zanrov) 403 in fruher Zeit spricht, ist fur Meletinskij 404 das Auftreten der Gestalt des "kul'turnyj geroj", der die Kollektivkrafte des Stammes verkörpert, symptomatisch fur eine archaische Stufe des Heldenepos, das in diesem Fall dem Mythos und "Urmurchen" (praskazka) sehr nahe steht. Man kann wohl diesen drei Epenforschern zustimmen und zu dem SchluB kommen, daB, je weiter wir in die Vergangenheit zurluckgehen, die Differenzierung in einzelne Gattungen immer schwieriger und undeutlicher wird und dab wir vermutlich fur die alteste Periode einen festen Bestand an mehr oder minder streng strukturierten Glaubensvorstellungen mythologischer Art, von Lied- und Erzählmotiven und einfachen Sujets annehmen durfen, aus dem dann die Lied- und Karchenschöpfer gleichermaBen ihren Teil entnahmen, woraus sich die z.T. alten Motivubereinstimmungen in Mythos, Marchen und Erzahllied erklaren lassen 405. Wie jedoch die ukrainischen Dumen zeigen, muß ein Heldenlied nicht unbedingt aus vorepischen Elementen, also Mythen, entspringen, sondern kann, wie Kirdan ${ }^{406}$ meint, in Inhalt, Thematik und Liedgestalten durchaus der unmittelbaren historischen Wirklichkeit entnommen sein.

6.4 Der ir dieser Arbeit besonders betonte und in den Mittelpunkt gerluckte Aspekt der archaisch-mythologischen Primarschicht in der maz.-wbulg. Volksepik ist nur einer von vielen möglichen Gesichtspunkten, unter denen die sudslavischen Erzahllieder betrachtet werden können. Andere Möglichkeiten, eine Untersuchung 
anzustellen und damit das "Forschungsmosaik" auf diesem Gebiet zu vervollständigen, waren $z . B$. die Erforschung der in einem hohen Grad historisierten skr. Volksepik und ihrer Beziehung zur realen geschichtlichen Wirklichkeit, der Frage der Iiedtypologie, der Kontinuitatsproblematik sowie der Periodisierung und Iiedeinteilung. Daruber hinaus verdienten Fragen der Iiedstruktur und Poetik auch in Zukunft - trotz vieler Arbeiten gerade auf diesem Gebiet - gesteigerte Beachtung. Auch die sozialen Gegebenheiten im Verhältnis von Sanger und Gemeinschaft, das Problem der "Sångerschulen" , Pragen der Improvisationstechnik, der Variantenbildung, Aktualisierungsversuche uberlieferter stoffe sowie die Prage der Wechselwirkungen zwischen christlichem und moslimischem Liedraum sollten weiterhin erforscht und diskutiert werden.

Obwohl sich die vorliegende Untersuchung auf einen relativ eng begrenzten und damit besser Uberschaubaren Bereich beschränkte, wollte sie doch einen bescheidenen Beitrag auf dem umfangreichen Sektor der vergleichenden Epenforschung, der Erforschung der Epenbildung und -entwicklung und vor allem der Verteilung der sudslavischen Erzähliieder in Zeit und Raum leisten. 


\section{A N M E R K U N G E N}

Eine typische Formulierung stammt z.B. von Soerensen: "Zum Wesen der Heldendichtung und ihrer höheren Entwicklungsstufe, des Epos, gehört, daB sie auf historischer Grundlage beruht. Eine Ansicht, welche diese historische Grundlage leugnet und der epischen Dichtung eine wesentlich oder gar ausschlieblich mythische Grundlage vindiciren will (..), mussen wir als unwissenschaftlich zurluckweisen. Mogen auch mythische Elemente, die Ubrigens thatsächlich hinter Märchenstoffen nicht mythischen Charakters zuriaktreten, auch in die serbische Heldendichtung eingedrungen sein, ja manchmal die historische Grundlage uberwuchert haben, so bleibt doch die Thatsache dieser historischon Grundlage stehen. Jede Forschung uber die Entstehung, die Entwickelung und das Wesen der epischen Dichtung hat daher, wo dies anders möglich ist, diese Grundlage aufzusuchen und von derselben auszugehen" (ASIPh XIV,566 f.).

Karadzic, 0 srpskoj ..; Miklosich, Beiträge..; Soerensen, Beitrag zur Geschichte..; ders., Entstehung der kurzzeiligen..; Jagic, Grada..; ders., Die sudslavische Volksepik..; Máchal, 0 bohatýrském epose..; Chalanskij, Juźnoslavjanskie skazanija..; Maretic, NNE; Gavrilovic, Istorija..; Vaillant, Les chants épiques..; Subotic, Yugoslav Popular Ballads; Kravcov, Serbskij épos; Kostie, Starost..: Gesemann, Studien..; Banasevic, Ciklus Marka Kraljevica..; Grgec, Razvoj...; Muric, Narodna knjizemost; ders., Srpskohrvatska narodna epika; ders., Postanak 1 razvoj..; Murko, Tragom..; Schmaus, Studi je..; Zirmunskij, Epiceskoe tvorcestvo..; ders., Vergleichende Epenforschung; Latkovic, Narodna književnost; Lord, The Singer of Tales; Braun, Das skr. Heldenlied; Matic, Nas narodni ep...; Popovic, Narodna knjizevnost, in: Pregled..., 49-110; Enc.Jug.VI (1965),204-20: Narodna knjižvnost.

3 Vgl. vor allem: Jirecek, GdS; Jir.-Rad., Istorija..; Novakovic, Poslednji Brankovici..; Ivic, Istorija Srba..; ders., Srbi u Vojvodini; Radonic, Histoire..; ders., Srbija $i$ Ugarska..; Stanojevic, Le role des Serbes..;ders., Istorija..; Salamon, Ungarn..; Domanovsky, Geschichte Ungarns; Praknoi, Die Hohenzollern..; ders., Königswahl in Ungarn; Stadtmiller, Geschichte Sudosteuropas.

4 Besonders in den Volksliederm und Sagen der Slovenen,hier aber stark mythisiert und damit enthistorisiert, spielt Kralj Matjaz eine grobe Rolle. Um die Mitte des 16.Jh. berichtet der Friauler Historiker Nicoletti von den Görzer Slovenen un Tolmein, dab sie "Mathias, den König von Ungarn, und andere Personen dieser Nation" in ihrer Sprache besingen, vgl. Murko, reschichte... 205. Mathias

In den Anmerkungen werden Kurztitel oder die in der Bibliographie angegebenen Abiurzungen verwendet. 
kommt aber auch in der übrigen südslavischen sowie der slovakischen, ungarischen und ukrainischen Volksdichtung vor, vgl. Kuzelja, Uhors'kyj korol'..; Grafenauer, Slovenske ljudske pesmi..; ders., Slovenske pripovedke..; Komorovský, Poznámky..; ders., Král' Matej Korvín..; Matl, Österreichische Herrscher und Heerführer..;Kretzenbacher, Die Volksdichtung...

Kilibarda, Teren za stvaranje...

Miklosich, Die Volksepik der Kroaten..; Soerensen,ASIPh XIV-XV; Bog. Einleitung, 1-142; Jagic, Grada..; ders., Die sludslavische Volksepik..; Petrovskij,0 socinenijach P.Hektorovica; Milas, O narodnim pjesmama...; Maretic, NNE, vor allem S.11; Rjeenik JAZU I s.v."bugariti, bugarstica"; Chalanskij, K voprosu o proizchoždenii...; Siłmanov, Znacenieto i zadacata..; ders., Kriticen pregled..; Popovic, Pregled...55-58; Scherzer, Bugarstice.

Miletid, Kŭm vŭprosa..; Budimir, Bugarski, bugariti..; Lalevic, Prilog proučavanju..; ders., Odnos i veze ...; ders., Bugarłtiçe i umetniCka..; Grgec, Razvoj..,97-112; Murko, Tragom..,219 f.; Matic Ant.,15 1.,23 f.; Schmaus, Bugarstica-Studien. Verdoppelung..; ders., Stilanalyse und Chronologie..; ders., Bugarłtica-Studien. Der Gebrauch.; ders., Dvostruki epitet...; ders., Skr. Lang- und Kurzzeilenepik..; ders., Formel und metrisch-syntaktisches Modell..; Hraste, üder die Heimat..; Ivanov, BNP,70-73; Dinekov, BF, 425-29.

Maretic, NNE, 6.

Soerensen, ASIPh XIV,580,583.

Kravcov, Serbakij épos, 56-59.

Lalevic, Bugarłtice $i$ umetnicka pesma.

Vgl. auch Bog. Einleitung,78 ff.; Jagic, Die sludslavische Volksepik..,209.

Hraste, Uber die Heimat der Langzeilenepik...

Jagic, Die sludslavische Volksepik..,242.

Schmaus, Die balkanische Volksepik.., $147 \mathrm{f}$.

Dieser Versuch, den beliebten ungarischen Turkenkämpfer Janko als Abkömmling des serb. Despoten Stefan Lazarevic (1389-1427) hinzustellen, kann nur relativ jung sein und den ugrophilen serb. Kreisen in Sudungarn entstammen.Vgl. zu diesem Motiv (Var.: Milut.160; Petr.II 28 und Vuk Rjeðnik 8.v."Sibinjanin Janko") die Aufsätze: Wollner, Einige Spuren des Einflusses.., und Redep, Motiv o rodenju...

Vgl. KiBling, Turkenfurcht...

Soerensen, ASIPh XV,30 ff., vor allem S.32 und S.34. Petravic, Juraj Barakovic o turdu...

20 Jagic, Die sudslavische Volksepik..,216 1 .

21 Banovic, Oko Kraljevica Marka.., $29 f$. 
Daruber unterrichten an besten Jagic, Grada..,i26 ff. und Albrecht, Das Turkenbild...

23 Dazu vgl. Banał̌evic, Andrija Kacić-Miołic...; Banović, "Glasovitiji" junaci...; Gesemann, Studien..,36-39; Setka, Fra Andrija Kacić-Miobić...

Steinmeyer, Die jungeren HS...

Berneker, Bericht uber...

Gesemann, Jedno književno istorijsko otkriće...

Gesemann, EH.

Zivanovic, Erlangenski rukopis...; Xajkanović, Erlangenski rukopis..; Kostič, Zbornik za istoriju..; Šm knjiga starih..; Prohaska, Najstariji rukopis...; Prodanovié, Zbornik za istoriju..: Zeltner, Die EH; Popović, Ko je autor..; Latkovic, Dusan J.Popovic...; Valjavec, Ko je autor..; Marinković, Wer war Ludwig..; Matesić, Die Erlanger skr. Liederhandschrift..; Reiter, Zur Erlanger..; ders., Einiges uber den Schreiber...

vgl. Simlik, "Oliva" izvor...

Schmaus, Beiträge zur suldslavischen Epenforschung, 157 11.; ders., Die Fruge einer "Martolosen"-Epik. Schmaus, Ima li bugarstica... Kostic, Starost..,4,Anm.7; ders., Jos jedna bugarštica... Schmaus, Stilanalyse und Chronologie..; ders., Dvostruki epitet...

Uber Hajduken und Uskoken in der EH vgl. Nazexí, Iz nałe narodne epike.., vor allem S.143 19 .

Soerensen, ASlPh XVI, 117.

Vgl. Soerensen, ASIFh XVII, $199 \mathrm{ff.}$ Schmaus, Das "Seelentier"...

Schmaus, Probleme und Aufgaben..,15.

Gesemann, Zur Erforschung...

Polenakovic, 0 makedonskoj...; Nedeljkovic, oblici maleSevske...; ders., Rasmatranja..; Sikora, Epika..; Gesemann, Nova istraživanja..; Bulat, Prilog za izuXavanje..; vlahovic, 0 slepim guslarima..; ders., Gusle i junacke pesme...; ders.. Stanje epske pesme...; ders.. 0 guslama $i$ guslarima..; Pilipović, Epska pesma..; Kiselinović, Narodne umotvorine..; Amaudov, Narodnata pesen $v$ Sofijsko.. Slavejkov, Bülgarska literatura II, 16.

Dinekov, BP, 435.

Darluber unterrichten vor allem Slavejkov, Bülgarska literatura II, 15; Ivanov, BNP, 220 ff.; Dinekov, BP, 216 f1.; Kusic, Prilepski gusiar..; ders. und Schmaus, Guslar Vandel..: Murko, Tragom.., vor allem S.206-14; Schmaus und vlaho- 
vic, 0 epskoj pesmi..; Schmaus, Neki oblici...

45 Mil.,40.

46 Schmaus, Die balkanische Volksepik.., 140.

47 Darluber informiert z.B. Ivanov, BNP, 52-78 (Kap.V).

48 Jagic, Die suldslavische Volksepik.., 223,230.

49 Die Beispiele sind aus Tosev, 38; SbNU XII,70; XVI, 178; V,89; Il.,126; Males.,190,216; Sapk.372; Jastr.,50,55, 79; KaC.412; BNTV I,435.

50 Schon $X_{i}$ manov hat in seiner umfangreichen Arbeit "Pesenta $2 a$ mürtvija brat..", SbNU XV,583 $\%$., die Vermutung geäußert, der asymmetrische epische Zehnsilber $(4 / 6)$ sei aus dem älteren Achtsilber (4/4) durch Einschieben meist einsilbiger Fullwörter entstanden, allerdings - wie Siłmanov glaubt - unter EinfluB des westeuropäischen Zehnsilbers.

51 Karadzic, Dodatak..,48.

52 Zitiert nach Ivanov, BNP,215.

53 Soerensen, ASlPh XVI,95 19.

54 Jagic, Die sudslavische Volksepik..,230.

55 Zur Rolle des sprechenden, hilfreichen, ratgebenden und mitfuhlenden Pferdes im Heldenlied vgl. Bowra, Heldendichtung...171 ff.; Lambertz, Volksepik der Albaner, $116 \mathrm{ff}$. und Zirmunskij, Vergleich. Epenforschung, $25 \mathrm{ff}$.

56 Schmaus, Die balkanische Volksepik..,140 f.; ders.,Probleme und Aurgaben..,24.

57 Dinekov, BF, 442 P1.

57a Uber die bulg. Hajdukenlieder vgl. Arbeiten wie Septunov, Bolgarskie chajdutskie..; Romanska, Die Haiduken..; dies., Bülgarskata narodna pesen.

58 Schmaus, Die balkanische Volksepik.., $133 \mathrm{ff.}$

59 Vor allem in den beiden Aufsätzen: Die balkanische Volksepik..; und Probleme und Aufgaben...

60 Romanska, Bulgarische und mazedonische Heldenlieder...

61 Ivanov, BNP,214 $1 f_{\text {; }}$ Dinekov, BF, 504 f1.; Vakarelski, Bülgarskata istorideska..,25 f.,613; Burin, Narodni jat junałki epos, 25,670,683.

62 Bödey, Les échos des guerres...

63 Banasević, Ciklus.., 156.

64 Werner, Die männlichen PN..,10.

65 Die Lieder mit historischen Reminiszenzen werden vor allem in Kap. 3 behandelt.

66 Die Zahl der Indexnummern ist geringer als die Anzahl der Lieder, weil unter einer Indexnummer jeweils mehrere Var. angefuhrt sind. 
Arnaudov, Baladni motivi...

68

Dinekov, BP,442, Schmaus, Die balkan.Volksepik..,140 f. Entwistle, European Balladry, 3331. Vgl. Jirecek, GdS,250 f.; Maretic, NNE, 127. Zirmunskij, Vergleich. Epenforschung, 87. Gesemann, Studien.., $79 \mathrm{ff}$. Vgl. Jirecek, GdS, 265.

In dem maz. Lied Verk.-Lavr.27 ist zwar die Personenkonstellation sehr ähnlich (Sirbina devojka träumt und Jankula bzw. sein Neffe Stojan deutet den Traum), das Traummotiv aber anders (vor Jankulas Hof flieBt ein truber Sturzbach, was auf eine schlimme Nachricht hinweist) und die Handlung anscheinend Uberhaupt verderbt (der serb. König ruft Jankula zur Schlacht auf das "sirbinsko ramno pole", womit Kosovo gemeint sein durfte,- zieht aber eingeschúchtert wieder ab, als er Jankulas viele Zelte erbilickt).

Ivanov, BNP, 282-84 . Trifonov, Bülgarski pesni s istori Zeski spomeni..,80 ff. Romanska, Bulg. und maz. Heldenlieder.., 341. Vgl. Stoilov, Predveetie za padane...

Vgl. hierzu auch Vuk II 45 "Propast carstva srpskoga". worin es an Anfang heiBt, ein Falke trage eine Schwalbe in den Fängen und fliege her von Jerusalem; diese Erscheinung wird aber dann als der von der Muttergottes zu Furst Lazar gesandte hl. Elias erklürt, der einen Brief in Handen halte, in dem Furst Lazar zu einer Entscheidung zwischen dem "carstvo nebesko" und dem "carstvo zemaljsko" aufgefordert wird. Veröffentlicht bei Novakovic, Narodna predanja o boju... Safarik, J. (Hrsg.): Rodoslovie serbskoe (Tronoski rodoslov).- In: GIDSS V (1853), 17-112. Racki, Boj na Kosovu... Novakovic, Die serb. Volkslieder Uber die Kosovo-Schlacht. Maretić, Kosovsiki junaci i dogadaji... Chalanskij, 0 serbskich narodnych. pesn jach... Soerensen, ASlPh XV,225-45. Kostic, Iva kosovska cikla. Popovic, Pregled.., 63-68. Schmaus, Iz problematike istorijskog razvoja... Vgl. Jirečk, GdS,191 If.; Kostic, Opis vojske... Soerensen, ASIPh XV,234 ff. Vgl. Krstic, Prorocanstva o Kosova. 
Vgl. BNTv III,613, Anm. zu S.186.

Vgl. BNTv III,608, Anm. zu S.137.

Dinekov, BF, 494 .

Vgl. BNTr III,612, Anm. zu S.173.

Soerensen, ASIPH XV, $18 \mathrm{ff}$.

Zirmunskij, Vergleich. Epenforschung, 38.

In der russischen Byline fehlen (laut Frings-Braun, Brautwerbung, 30) eigentliche Brautraublieder.

Balladen Nr.3: Brautwerbung (Hildesage); Seemann, Die Zekuloballade... vor allem S.60 ff.; Frings und Braun, Brautwerbung, $24 \mathrm{ff.;} \mathrm{Chalanskij} \mathrm{RFV} \mathrm{31,} 117 \mathrm{ff.;} \mathrm{Stoi-}$ lov Pokaz. I 384 und II 384; Zirmunskij, Vergleich. Epenforschung, 39; Maretić, NNE, 228 f.; Boßković-Stulli, Sižei narodnih bajki...; Delorko, o nekim nałim...

$\mathrm{Vgl}$. Chal. RFV 31, $117 \mathrm{ff}$.

103

104

105

106

107

108

109

110

111

112

113

114

115

116

Zirmunskij, vergleich. Epenforschung, 40.

Kravcov, Idejnoe soderžanie..,348.

Loboda, Russkie byliny..; Geissler, Brautwerbung...

Zirmunskij, Vergleichende Epenforschung, 39.

Schneeweis, Skr. Volkskunde.., 66.

Volkov, Svadbarskite obredi.., 156.

Schneeweis, Skr. Volkskunde.., 68 P.

Piprek, Slavische Brautwerbungs- und Hochzeitsgebr.,129.

Vgl. dazu auch Horálek, Zum Problem der sủdslavischen

Volksballade, wo auch auf westslavische Parallelen verwiesen wird.- Die "männliche Entsprechung" zu diesem Foltermotiv finden wir in Vuk III 51, worin der Held Mali Radojica Martern mit glühender Kohle, einer Schlange und Holzstiften regungslos erträgt, beim Anblick des Reigentanzes mit der verfiuhrerischen Hajkuna an der Spitze aber ein Lächeln und Augenöffnen nicht unterdruicken kann.

Vgl. Thompson, Motif-Index H 310-359 (Suitor Tests) und T 50-69 (Wooing); AaTh 850-869 (The Princess's Hand Is Won).

Vgl. HDM I, 316-20 s.v. "Brautwerbungsmärchen". HDM I, 318 .

Zirmunskij, Vergleich. Epenforschung, 42.

Zum Problem der Wettkämpfe in den bulg. Heldenliedern vgl. Teodorov, süstnost i proizchod...

Eine Schußprobe ist uns bereits in der Odyssee uberliefert, wo die um Penelope werbenden Freier mit Odysseus' Bogen einen Pfeil durch zwölf Axtringe schießen sollen.

Zum Teil angerührt in Seemann, Die Zekulo-Ballade,43 ff.; ISSF VI,178 (12) "Junak ispülnjava trudni uslovija"; Stoil.Pokaz.434; Žirmunskij, Vergleich.Epenforschung, 43. 
117 Vgl. Jirecek, GdS, 192; Soerensen, ASIPh XV, 30; auch Bog. 10 verweist auf die Tatsache, daB Janko von Durad gefangengehalten wurde.

118 Vgl. Jirecek, GdS, 204; Novakovic, Poslednji Brankovici..,8; Soerensen, ASIPh XV,32. Banovic, Oko Kraljevica Marka..,29, möchte aus der im Lied zum Ausdruck kommenden Antipathie gegen Durad Brankovic aup eine Liedentstehung außerhalb Serbiens, namlich unter den katholischen Kroaten im Westen, schlieBen. Diese These labt sich aber nicht ohne weiteres aufrechterhalten. Die Lieder der ungar-serb. Gruppe sind nämlich allgemein durch ungarnfreundliche und dem Despotenhof in Smederevo gegenuber feindliche Stimmung ausgezeichnet, eben weil sie in den serb. Kreisen entstanden, die auf ungarischer Seite gegen die Turken kämpften und mit der Hunyadi-Partel sympathisierten.

119 Dies hat hier sicher weniger mit einem Ethnikon zu tun, sondern muB eher sozial verstanden werden: Sekula kleidet sich nach Art der Hirten, die meist dicke bulgarioche Pilzmäntel trugen, vgl. Sefterski, Jamurlukǔt..: zur Bezeichnung bugarin = Cobanin 'Hirte' vgl. Schmaus, Prezime "Bugarin".

120 Seemann, Die Zekulo-Ballade...51, Meletinskij,Geroj vol8ebnoj skazk1, 257; Thompson, Motif-Index I 100-199 (Unpromising Hero); Zirmunskij, Vergl.Epenforschung, 91,20.

$121 \quad V_{g l}$ Stoil.Pokaz.277

122 Vgl. ISSP VIII/IX,479.

123 Jireðek, GdS, 163.

124 Jiređek, GdS, 251.

125 Ivic, Istorija Srba..,33.

126 Diese Wamung des Gastgebers, gewisse Personen nicht zum Pest mitzubringen, scheint Wandergut zu sein, das auch in anderen skr. Iiedern wiederkehrt, vgl. Marj.10.

127 MH II $91 .-V_{\text {gl }}$. "Latini su stare varalice", Vuk Posl. 3242.

128 Vgl. Vuk III,712.

129 Vgl. Seemann, Die Zekulo-Ballade..,40 $\mathrm{fe}$.

130 Milcetic erklärt in seinen "Sitniji prilozi", worin er Vuk II 28, Kacic-Miosic 43 und Strekelj I 245 miteinander vergleicht, (S.11) das rätselhafte sloven. "svakojake rege sobriase" mit "svakojake కege podavałe, zametake, izvotase".

131 Jirecek, GdS, 1501.

132 Braun, Das skr. Heldenlied, 30.

133 Maretic, NNE, 169 P.

134 Kostic, Latinski (ledanski) kralj Mihailo, 21 fe; zu Novak (und seinem Sohn Gruica - im Lied) vgl. Banovic, 0 nekim historickim licima..,86-88. 
Kravcov, Serbskij épos, 601, Anm.250.

Jastr., 452 .

Vgl. Zirmunskij, Vergleich. Epenf..44 f.; Simonovic, Beiträge zu einer Untersuchung..., 92-98.

138 Vgl. Jirecek, GdS, 234-37; Maretic, NNE, 124-26.

139 Wir finden inn in den Liedern Bog.76, Vuk II 88 und 89; Milut.70, Vuk VI 36 und 45 ; in bulg. Liedern wie Il.88, Kad.198, Mich.365; Drag.,72-74; SbNU XLIII, 190-92,vgl. ISSP VIII/IX, 490 .

139a Einer Mitteilung von D.Theodoridis (Munchen) zufolge ware das bulg. "ð̌ejli" uber. cilli von tïrkisch çil (vgl. griech. $\tau \sigma i \lambda \iota K O$ ) 'Geldatuck' abzuleiten.

Werner, Die mannlichen PN, 13,124; vgl. Skaljit,. Turcizmi..,530: "Ramàdan, hipok. Rámo (ar.), musl. muško ime. Nadijeva se obieno djetetu koje se rodi u mjesecu posta ramazana."

141 Werner, Die männlichen PN, 68.

141 a Vgl. Maretic, NNE, 169 f.; ISSF VIII/IX, 476-79; Banovic, 0 nekim historizkim...

142 Werner, Die männlichen PN, 102.

143 HDM I, 318 (2b).

144 Ebda.

145 Z.B. in SbNU XIVI, 15 (Preier muB eine Brlicke Ubers Meer, eine Säule in den Himmel und ein Seil aus Sand bauen); SbNU III,19 (Freier muB einen Brunnen, eine Muhle und einen Turm bauen); Il.71 - SbNU X,6 - XV,4 IX,10 - VII, 10 usw. (Freier muß die von dem Mádchen erbaute Stadt oder Burg zerstören); Sapk.499 - SbNU XLVI 2 , 186 - XLVI ,15 - Mil.141 - Mich.87 und 88 - SbNU XIIX, 243 (Mädchen nimmt denjenigen zum Bräutigam, der Uber einen hohen Baum werfen oder dessen Blätter zählen kann), vgl. ISSF V, $14(\mathrm{Nr} .6), 15(\mathrm{Nr} .7), 536$ ( $\mathrm{Nr} .491)$. Uber die südslavischen Wettbewerbsballaden vgl. auch Horálek, Zum Problem..,14 ff.; ders., Studie..,99 11.; Budimir, Der Agon..; Braun, Zum Problem...

$146 \mathrm{Vgl}$. die bulg. und maz. Lieder, in denen das Mădchen immer neue Aufgaben (z.B. Pflanzen und Ernten von Trauben und Quitten im Meer, Herstellung eines Selles aus Sand, Uberschwimmen des Meeres u.ä.) stellt und zuletzt vom Freier verlangt, er solle auch noch einen Stern am Himmel mit dem pfeil treffen, und statt dessen vom Freier erschossen wird: Bezs.I 10; Ziva st.I.85; Vürb.302; Jank.250; Stoin TV 74; Mil.164; Sapk.489 und 490; SbNU $X V, 12 ;$ VI ,5; XXXVI, 42; XXV, 124 uv ; Bulg.kn. (1858) 2,33 ; Jank.250 uv. usw.- Stoil.Yokaz.317; ISSF v,536(4913,15 (7).- Vgl. hierzu Schillers Romanze "Der Handschuh", wo dieses alte Motiv behanaelt wird.

147 Vgl. Jagic, Dunav-Dunaj... 
Vgl. Jirecek, GdS, 193; ISSF VIII/IX,510; Skender beg; Noli, George Castrioti... Schmaus, Der Skenderbeg-Zyklus..; bei Kacic-Mioric ist "Kastriotic" der gepriesene Vorkampfer der Christenheit gegen die "heidnischen" Turken.

149 Vgl. Hiltbrunner,208,214; Schwab, 129 1.; Ranke-Graves II, 138-46.

$150 \quad \mathrm{Vgl}$. ISSP V,57 (163); VI,175 (5b); VI, 174-5 (5a) die SchluBvariante; VI,178 (12) die drittietzte Var.;VIII, 442 (223),454-56,476; Sto1l.Pokaz.II,255-56 (964); Jordanov, Krali-Marko...XCII-XCVI, XCIX-C; Dinekov, $\mathrm{BP}, 511,516$

151 Vgl. Herakles, der eine Keule aus dem Stamm eines wilden Ölbaums besaß, den er auf dem Helikon angetroffen und samt den Wurzeln ausgerissen hatte, 8. Schwab, 120.

152 Vgl. Ranke-Graves II, 102-105; Hiltbrunner, 208; Schwab, $121 \mathrm{f}$.

153 Zu diesem Punkt vgl. den Aufsatz Burkhart, Vampirglaube und Vampirsage...,225.

154 Vgl. Vuk Rječnik s.v. "ala" und "aždaha"; Marinov,SbNU XXVIII,210 f.; SbNU IV,112 (= Prikazki za zli duchove i dr. ot Demir-Chisarsko); Schneeweis, Skr. Volkskunde, 12 f.; Vakarelski, Etnografia..,224; Chal.RPV 29,.336 f.: Stojk., 314 ; Amaudov in BNTr IV,33-37; Dinekov, BP, 386-88; Karanov, Zmejat..,129 $\mathrm{fe.}$

155 Vgl. Kind,XVIII $f .3$ Lawson, Modern Greek Folklore.., 171-176; Schmidt, Das Volksleben der Neugriechen..., 130; Wachsmuth, Das alte Griechenland..,30 f.,55 f.

156 Zum antiken und neugriech. Lamia-Glauben vgl. PaulyWissowa, 23. Halbbd.,Sp.544-60; Roscher II ,Sp.1818-21; Ranke-Graves I, 184 ; Schmidt, Das Volksleben..,131 ff.; Lawson, Modern Greek..,171-76; Wachsmuth, Das alte..,56. "..Neu pransae Lamiae vivum puerum extrahat alvo". Schwab, 38; Hiltenbrunner, 377; Ranke-Graves I,214-16.

Vgl. dazu Schneeweis, Skr.Volkskunde,6-8; Vakarelski, Etnografia, 222-24; Marinov, SbNU XXVIII,201-206; Arnaudor in BNTr IV, 16-27; Dinekov, BF, 363-76.

Auf diesen Ersatz der Drachengestalt durch Vila, Araber oder Musa Kesedzija hat unabhängig von mir $A$. B. Lord hingewiesen, $\nabla$ gl. sein noch ungedrucktes Referat "Some Common Themes..". Bei Bynum, Kult dvaju..,68 wird der dreiköpfige Araber als Ableitung aus der klassischen Hydra aufgefaßt; Crjetko (Heneza motyva..) dagegen halt die Iamja fir eine solche Ableitung.

161 Schwab, 130-32; Ranke-Graves II, 146-51.

162 Schwab, 38-42; Ranke-Graves I,215-21.

163 . Schwab, 121-22; Ranke-Graves II, 102-05.

164 Vgl. Schwab, $121 \mathrm{f}$ : Ranke-Graves II, 1031. 
165 Vgl. Stanojević, Iz srpske proßlosti..,79-82; Maretic, NNE, 129 f.; Kravcov, Serbskij épos,599, Anm. 188; Kostić Tumac.,80-91; Jirecek, GdS, 143; Ivanov, BNP, 268 ff.- Jordan ov (Krali-Marko..,XCIII f.) hält Pilip Madzarin für den bayerischen Pfalzgrafen Philip, den Verteidiger Wiens 1529 bei der ersten Belagerung durch die Turken. Diese Meinung wird auch in ISSP VIII, 496 f. Ubernommen, außerdem aber ein Protovestiar namens Pilip $(1385 / 6)$ am Hofe der Balsici genannt.-Vgl. auch Romanska, Slavjanski folklor..,84, die sich Jordanovs Meinung anschilebt.

166 Vgl. Seemann, Die Zekulo-Ballade..,62 f.

167 Gine ist nämlich (laut Werner, Die männlichen PN..,70) eine aus $\mathrm{Ge}(0) \mathrm{rgin}$ abgeleitete Namensform.

168 Vgl. Jirecek, GdS,110; Jir.-Rad.,243,248; ISSP VIII/IX, $480 \mathrm{f.;}$ Jordanov, Krali-Marko.., LXXIV $\mathrm{ff}$.

169 Vgl. Teodorov, Projzchod na pesenta...

$170 \mathrm{Vgl}$. Tomie, Istorija u narodnim..,26; s. auch $\mathrm{kH} \mathrm{I}_{2}{ }^{2}$, worin Marko ebenfalls durch das versteckte Messer gerettet wird, auf das ihn seine Wahlschwester, die vila, hinweist.

171 Zum Ringkampf vgl. Teodorov, Sứtnost i proizchod..,66.

172 Vgl. Medenica, Problematik und Methodik..,149.

173 Vgl. Thompson, Motif-Index H 331.1.5 (Suitor Contest: riding through fire); vgl. die Junglinge im Feuerofen.

174 Vgl. AT, Buch der Richter 13-16, wo Samson seiner listigen Gattin Delilah verrät, dab seine Stärke in seinen Haaren liegt, worauf Delilah inm diese abschneidet.Es handelt sich hier um das alte Motiv "Körper ohne Seele", vgl. Prenzel,586; vgl. auch AaTh 300 .

175 Zu Rajko vojvoda bzw. Rajko Boßkovic (Bołkoik) vgl. ISSF VIII/IX,497; Vuk III,591, Anm. zu Nr.10; Jir.-Rad., 417-19.

176 Als Schicksalsfrauen-Lieder vgl. Mil.17; SbNU VI, 110; XXII-XXIII, 108; VII, 154; Prosa: Sapk.VIII/IX die Nrn. 107,131,138,195 u.a.- Vgl. auch Dinekov, BF, 388 .

177 Vgl. Ranke-Graves I,39 1 .

178 Dazu vgl. Teodorov, Sustnost 1 prodzchod..,58 1.,140 1.; S.165.

179 Vgl. Mat. Kritika, $30 \rho$.

179a Vgl. Banovic, Planine Kunara...

180 Vgl. hierzu Maretic, NNE,221-23 unter "Internacionalni motivi".- Als Marchenmotiv ist AaTh 590 auf dem Balkan mit 19 skr., 6 sloven., 4 griech. und AaTh 315 mit 6 sloven.,5 skr. und $48 \mathrm{griech}$. bekannten Var. vertreten. Das Motiv im Lied durfte in diesem Pall aus dem Märchen Ubernommen sein. Hahn $(\mathrm{S} .52)$ bezeichnet das Motiv mit dem Schlagwort "Schwester- oder Mutter-Verrat" bzw. "Skyllaformel", weil es an die Geschichte von Skyllas 
Verrat an ihrem Vater anklingt, vgl. Ranke-Graves I, 279-82.- Bei dem Iiebhaber der Mutter bzw. Schwester handelt es sich urspringlich un einen vertreter von einer Gruppe Riesen oder Drachen, der als einziger beim Kampf mit dem Helden Uberlebt hat; erst im Zeichen der Entmythologisierung wird das mythische Wesen durch einen Menschen ersetzt. Dazu vgl. Kretschmer, 325: "Den Drachen entsprechen auBerhalb Griechenlands fast durchweg Räuber", vgl. die Hajduken in den bulg. Var.

181 Vgl. Meletinskij, Proischoždenie..,21-94, 423-48.

181a Hierzu vgl. Köhler, Kleinere Schriften..I,469-72,Nr. 31: "Ne frapper qu'un seul coup", wo Beispiele fír die internationale Verbreitung dieses Motivs gebracht werden; vgl. auch Cajk.SNP,501.

182 Zur Jenseitsreise vgl. Pauly-Wissowa, 20.Halbbd., Sp. 2359-2449 s.v. "Katabasis".

183 Vgl. Schmaus, Milos Obilic..,43.

184 Vgl. Schmaus, Beiträge zur sudslavischen..,155 f.; Maretic, NNE,135 (Kaica), 159 ff. (Obilic).

185 Vgl. Rjeðnik JAZU s.v. "filjev" bzw. "viljev"; von Seemann (Die Zekulo-Ballade..,46) falschlich als 'Vilenhäupter' ubersetzt.

Lord, Some Common Themes...9 1 f.

Penev, Istorija... I, 124 .

Burin, Junak jasno..,16 ff.

Burin in der Einleitung zu BNTv $I, 22$.

190 Trem, 84 .

191 Kretschmer, VIII-IX; vgl. auch Leyen, Die Welt der Marchen II, 96 .

192 Wachsmuth, Das alte Griechenland...57.

193 Vgl. Jirecek, GdS,119.

194 Werner, Die mannlichen PN, 57.

195 Nodilo, Religija Srba... Rad 77,99 und Rad 79,197.

196 Chal.RPV 31,1421 .

197 Ruvarac, Dve studentske rasprave..,30 $\mathrm{f}$.

198 Vgl. Fochi, Das Doitschin-Lied..,243,263, und Çabej, Albanische Volkskunde, 368: "buloza, eine Art Drache".

199 Vgl. Dict.

$200 \quad V_{\text {gl }}$. Rjexnik JAZU

201 Von Werner (Die männlichen $P N, 58$ ) fälschlich zu rumän. balaur 'Herbstzeitlose' gestellt.

202 Soerensen, Die Entstehung...104.

203 Vgl.Maretic,NNE, 166 f.;Vuk III,629 1.; Banovic, Tko je bio..; ders., 0 nekim historickim... 
Vgl. Vuk II,771.

Vgl. Maretic, NNE, 5 .

206

Vgl. Ruvarac, Dve studentske rasprave..,66.

Vgl. Maretic, NNE, 180 l.; Gesemann, Clanci 1 rasprave..,145 ff.

208

Vgl. Maretić, NNE, $184 \rho$.

209

Vgl. Maretic, NNE, 17

210

211

Vgl. Maretic, NNE, 128; Jirecek, GdS,250;V. Corovic, in Nar.Enc.SHS s.v. "Perzelez Alija"; Novakovic, Poslednji Brankovic1..., IMS 148,28-36; Marjanovic, Problem...; Olesnicki, Tko je zapravo..; ders., Jos o licnost1..; Mirkovic, Mesto rodenja...

Vgl. Schwab, 37; Ranke-Graves I, 215.

$\mathrm{Vgl}$. Dinekov, BF, 512-14,

Vgl. ISSF V,335 (490b).

Bordevic, Priroda..,259-60 ("Medved"); Schneeweis, Skr. Volkskunde..,109; Bülg. Enc.s.v."mexkin den"; Vasil'ev, Medvezij prazdnik; Marinov, SbNU XXVIII,80 f.: "V Cest na mexkata ima ustroen prazdnik, Meckin den, na kojto den $v$ nejna cest se izvursat obredi i religiozni obicai".

Zur "external soul" vgl. Hirschberg s.v. "AuBenseele" und "Alter ego"; Beit, Ein Beitrag..; Frazer, Der goldene Zweig, Leipzig 1928,969 ff.; BP KHM III, 424 ff., $440 \mathrm{ff}$; Leyen, Die Welt der Marchen, I, 140,171,179, II, $14,68,105$.

Vgl. Curic, Nepoznata legenda..,417-19.

Vgl. Trautmann, Die Volksdichtung..,129 ff.

Vgl. ISSF V.58 (165) und VI, 197 (49).

Vgl. ISSF V,60 (172) und VI, 184 (26b).

Werner, Die männlichen PN..,135.

$\mathrm{Vgl}$. ISSF VIII/IX,467 $\mathrm{f}$; Romanska in BNPTv,94.

Vgl. AaTh 300 "The Dragon Slayer" und Thompson, MotifIndex D 1978.2. "Waking from magic sleep by letting tear fall on slesper".

223 Vgl. Xajkanovic, Donji svet..; Uber Unterwelt und Unterweltseingange vgl. Pauly-Wissowa s.v. "Katabasis", $\mathrm{Sp} .2359-2449$, vor allem Sp.2377 $\mathrm{ef}$.

$224^{*} \mathrm{Vgl}$. ISSF VIII/IX,213 (79b.2).

225 Vgl. Maretic, NNE, 170-76.

226 In PPNP $I_{1-2}(1934), 5-12$.

227 Vgl. Kostic, Latinski...,21 ff.

- $224 \mathrm{a}$ Vgl. Iudeke 115 und 116, wo der Drache in Gestalt eines schönen Madchens Jünglinge in den Brunnen lockt. Dieses 
Motiv findet sich in abgewandelter Form (der Wasserdrache - scorpia - labt seinen Sohn in Gestalt eines Junglings oben am Brunnenrand als "Lockvogel" sitzen und verschlingt die Helden, die nach der Aufforderung des Drachensohnes in den Brunnen steigen) auch in der rumbinischen Volksdichtung, vgl. Vrable, Balada populara..,144-73 (2.Scorpia). ZNŽo 9 (1904), 1-22, davon vor allem S.6-11. RPV 31 (1894), 177-216. Maretic, NNE, 206-208. Simonovic, Beitrăge zu einer Untersuchung..,92-98. Zirmunskij, Vergleich. Epenf., 44 l.,84 1 .

Vgl. RFV 31 (1894), 112-16, und die Untersuchung "O nekotorych geografiCeskich nazvanijach v russkom i juznoslavjanskom geroǰceskom épose", in: RPV 45 (1901), 327-28, zit. nach 乙̌irmunskij, Vergl.Epenf.,85.

Vgl. die wichtigate Literatur dazu bei Popovic, Pregled..(1913), 304 l., und Bortević, Letan - Ljes.

235 Religija Srba 1 Hrvata.., Rad 79, 199.

236 Xajk.15 SNP, 104.

237 Soerensen, ASIPh XV, 33.

238 Novakovic, Uber Legjan-grad..; ders., Letan grad 1 po1 jaci...

239 NNE, 181 .

240 Stoilov, Legen ġrad.., vor allem S.245.

$241 \mathrm{Vgl}$. Dve studentske rasprave..,32,42 1 .

242 Vgl. Andrija KaCic Miosic. Slovinski pesnik..,LMS 172, 9-10.

243 Hartland, The Legend of Perseus; Rystenko, Legenda o ...; Krumbacher, Der hl. Georg...; Novakovic, Legenda o sv. Gjurgju..; Kirpicnikov, Svjatoj Georgij..; Derzavin, Kral jevic Marko...; Loorits, Der hl. Georg...; Jagic, Ein Textbeitrag..; Ivanov, Starobǔlgarski razkazi (Nr.24: Sv. Georgij i lamjata; Nr.25: Svetec Michail voin ot Potuka); Ploss, Siegfried - Sigurd...; Vajs, Starohrvatske duhovne..,260-62; Veselovskij, Razyskanija v oblast1...; Novakovic, Apokrif1...36-92; Kostov, Izobrazenieto na sv. Georgi..; Alpatov, Obraz Georgija-voina..; Maretic, NNE, 195-99; Dinekov, BP, 386-88; Arnaudov in BNTV IV (Miticeski pesni), 33-37; Stoilov, Lamite i zme jovete... 159-74; Cajkanović, o srpskom vrhovnom bogu, 66-69: Kap. IX. Sveti Đorde.

244 Leyen, Die Welt der Marchen, I,64,II, 58,255; BP KHM I, 528-56 ("Die zwei Bruder"), vor allem S.534 und 547; Ranke, Die zwei Bruder...

245 Als wichtigste Quellen seien hier genannt: HDA s.v. "Drache"; HDM 8.v. "Drache", "Kampe mit dem Ungeheuer"; Vgl. Vuk II 36: "Milor u Latínima". 
F\&W 8.v. "dragon", "dragon cult", "dragon-fight or dragon-slaying theme", "dragon's blood"; Jobes s.v. "Draco", "Dragon", "Dragon blood", "Dragon king", "Dragon slayer", "Tiamat"; The Mythology of All Races V: Semitic (by S.H. Iangdon), vor allem S.91 f.,288 f., 294-98 und 302 f. Uiber "Tiamat"; Beitl s.v. "Drache", "Georg"; Buchb. 8.v. "Georg,hl."; Priedrich, Der geschichtliche Heilige Georg; Aufhauser, Das Drachenwunder..; HDA s.v. "Georg,hl."; Kriss und Kriss-Heinrich, Volksglaube im Bereich des Islam..., 154 ff.; Schmidt, Die Volkserzählung..,41-47 ("Sichelheld und Drachenzunge" ).

246 vgl. Proischozdenie..,25 ff.,423 ff.

247 Rystenko, Legenda..,288 f1.,336; Mat. Kritika,31; Krumbacher, Der hl. Georg...,103 ff.,197, $243 f$.

248 Vgl. hier die m.E. nicht sehr uberzeugende Arbeit von Bynum, Kult dvaju junaka... worin Verf. den "Kult zweier Helden" in kontinuierlicher Tradition auf den Mitr:ras-Kult zurluckführen möchte. Vgl. dazu auch Wenzel, A Medieval Mystery ...

249 Apostol(ov) ist allerdings im maz. und bulg. Raum auch ein männlicher Vor- bzw. Zuname.

250 Vgl. Schneeweis, Skr. Volkskunde, 136 f.; Vakarelski, Etnografia...295 f.; Schmaus, Sudosteuropa, 232 f.; Drobnjakovic, Etnologija..I,206-10; Marinov, SbNU XXVIII, 439-464.

251 Vgl. Skr. Volkskunde..,142, und Marinov, SbNU XXVIII, 509-11.

252 Vgl. Das alte Griechenland...23.

253 Vgl. Meletinskij, Proischozdenie..,27,430.

254 Vgl. Dinekov, BF, 514; ISSP VI,142 (86).

$254 a$ Vgl. Vrabie, Balada populară.., Kap.3 (CIntecul sarpe lui, 144-173), Motiv 1 "Blestenul".

$254 \mathrm{~b} V$ Vl. das Georgsmotiv in der rumän. Volksdichtung bei Vrabie, Balada populara... Kap.3, Motiv 3 (hier allerdings ist nicht der Heilige, sondern der Held Jovan Jorgovan der Toter des Wasserdrachen - hala, balaur -; nachdem der Held im Schob des Madchens in einen magischen Schlaf gesunken ist, wird er beim Nahen des Ungeheuers durch die Tranen des Madchens geweckt, uberwindet den Drachen und nimmt die Gerettete zur Prau).

255 HDA "Drache",372, vgl. auch s.v."Georg,hl.",647.

256 Krumbacher, Der hl.Georg..,296; Buchb.s.v."Georg,hl." .

257 Vgl. Sobranie socinenij III,101.

258 Cajkanovic, 0 srpskom vrhovnom..,66 ff.

253a Vgl. Kirfel, Die dreiköpige Gottheit; Usener, Dreiheit; Vyncke, Trojan...

259 Vgl. Boßkovic-Stulli, Narodna predaja..: Hier wird auch die Iiteratur uber Trojan diskutiert, vor allem 
Arbeiten wie Veselovgkij, Legendy..; Leger, La mythologie..,126-128; Cajkanovic, 0 srpskom vrhovnom..; Jagic, Historija knjizevnost..,283 f.; Vaillant, Le dieu slave...

259a Vgl. Mansikka, Die Religion der 0stslaven..,201,287288,397 .

260 Vgl. die Diskussion der verschiedenen Deutungsmbglichkeiten in folgenden Arbeiten: Slovo o polku Igoreve...; Iichacev, Slovo o polku..; Boldur, Trojan "Slova..", 7-35, wo Trojan als heidnische Gottheit gedeutet wird, die von Russen und Rumänen verehrt wurde (von letzteren als Gott des Winters); bei Boldur ist die wichtigste literatur uber Trojan zusammengestellt.

260 a Vgl. hier auch das bereits besprochene maz. Iied SbNU XVI-XVII, 177, in dem der Dever Marko ein dreik8pfiges Untier (dzveretina so tri glava) uberwältigt, köpft und drei Ketten Sklaven (junge Manner, Madchen, alte Leute) befreit.

261 Vgl. Proischoždenie..,432-34.

262 Vgl. Trautmann, Die Volksdichtung der GroBmssen..., $129 \mathrm{ff.,Nr.1:} \mathrm{"Dobrynjas} \mathrm{Kampf} \mathrm{mit} \mathrm{der} \mathrm{Schlange".-Die}$ Schlange Gorymcisce mit ihren zwolf Fungen wird auch in Nr.5: "Djuk Stepanovid" erwłhnt. In Nr.4 "Aljosa Popoviz und Tugarin" wird Tugarin, der Schlangensohn, von Aljosa dadurch getstet, dab der Held von Gott Regen erfleht und erhâlt, daß damit Tugarins plugel (!) aufgeweicht werden, Tugarin absturzt und $M$ josa dem auf der Erde liegenden Schlangensohn den Kopf abtrennt.

263 Vgl. Syrkin, Poéma o Digenise..,3.

264 Vgl. Syrkin, Poéma o Digenise..,4,34.

265 Kuz'mina, Devgenievo dejanie, 146; dem ersten rekonstruierten russischen Text liegt die vollständigste masische Fassung zugrunde, namlich die Version "Zitie Devgenija" aus der Samlung Tichonravov, einer auf das Jahr 1744 datierten HS.

266 Kuz'mina, Devgenievo...,173; dieser Rekonstruktion liegt die Fassung aus der Sammlung Titov, einer wahrscheinlich aus dem 18.Jh. stammenden HS, zugrunde, die fur den Anfang durch die Fassung aus der Sammlung Pogodin, einer HS aus dem letzten viertel des 17.Jh./ Anfang des 18.Jh., mit dem Titel "Dejanie preznich vremen $i$ chrabrych celovek. O derzosti i o chrabrosti $i$ o bodrosti prekrasnogo Devgenija" ergänzt wurde.

267 Vgl. Syrkin, Poéma o Digenise..,22,24; Rystenko,Legenda, $.412-17$.

268 Sathas und Legrand, Les exploits..,161-65.

269 Iord, Notes on Digenis Akritas...

270 Budimir, Digenis und Marko...

271 Zur Vila, Samovila vgl. Schneeweis, Skr. Volkskunde..., 
6-8; \#ortevic, Vestica i vila.., 57-119, Zusammenfassung S.121; Arnaudov in BNTV IV, 16-27; Maretic, NNE, 251-55; Prodanovic, NNK, 120-23; Uber die griech. Neraiden $\nabla$ gl. Kyriakides, Elliniki...,184-90; Schmidt, Das Volksleben..,98-130; zu den albanischen Zanen vgl. Cordignano s $\cdot \nabla$. "zanë"; Lambertz, Die Volksepik..,155157; Cabej, Żivot 1 obizaji..,303-19; ders., Albanische Volkskunde, 373.

$271 a$ Vgl. Bordevic, Vestica i vila..,91-92, die skr. Sage von der Vila, die belauscht wird und in einem Selbstgespräch verrät, dab sie 77 Quellen in ihrer Gewalt hat.

272 RPV $29_{2}, 333$.

273 RFV 29, 337; vgl, auch Vries, Forschungsgeschichte der Mythologie, vor allem $\mathrm{S} .267 \mathrm{\rho}$. - In einem irokesischen und austraisischen Mythos hat ein groBer Frosch alle Gewasser verschlungen.

274 RPV $29_{2}, 337$.

275 Mat.Kritika, 31.

276 Lord, Some Common Themes..,3.

277 Uber Feennamen vgl. Đorđevie, Vestica 1 vila..,85-86, und Marinov, SbNU XXVIII,205.

278 Lord, Some Common Themes..,1-4.

279 In Var.16.

280 In Var.15.

281 Dazu $\nabla$ gl. vor allem Krstic, Zenidba Coveka vilom.

281a Vgl. Dinekov, Probleme der bulg. Volksballade.

$281 \mathrm{~b} V$ Vl. Stoilov, Vojnik na svatbata..; Medenica, Muz na svadbi..; K8hler, Kleinere Schriften..III,229 19 . (Der heimkehrende Gatte); Żirmunskij, Vergl.Epenf.,14, Anm.1; Tolstoj, Vozvrascenie...

282 Vgl. hierzu Schmaus, Studien..2. Die ree entzweit...

283 Pochi, Das Doitschin-Lied...

284 Mat.Kritika, 31-32; Marinov, SbNU XXVIII,163; Ivanov, BNP, 235-42; Maretic, NNE, 127; Pavlovic, Bolani Dojein... Ergknzend sind zu nennen Dzurinskij, Bolgarskio pesni o Dojzine..,1-29; Popov, Bülgarski junaski pesni,274;Chalanskij, RFV 33,185-88; Dinekov, BP,499-502; zu den rumanischen und albanischen Beiträgen vgl. Pochi, Das Doitschin-Iied...230 1.- Maretic meint in seinem Aufsatz "Zivot i knjizevni rad.." (S.100), die These, dab die Bolen Doj飞in-Lieder von den Bulgaren zu den Serben gelangt seien, sei nicht aufrechtzuerhalten, da es sich bei dem Liedhelden Dojzin um den historischen Peter Dbczy, den ungarischen Vojvoden und Befehlshaber von Jajce und Varadin, handle.

285 Vgl. Fochi, Das Doitschin-Lied..,506. 
Vgl. Drag., 31 1.; Sapk.392 Anm.; Ivanov, BNP,235; Trem, 379; Dinekov, BP,499 1.; Maretic, NNE, 127.

287 Vgl. Maretic, NNE, 127; Chal.RFV 33,187; Dinekov, BF, 499; Dzurinskij, Bolgarskie pesni..,3; ISSF VIII/IX, 473; Poch1, Das Doitschin-Lied...,489.

288 Vgl. Mat.Kritika, $31 \mathrm{f}$.

289 Mat.Kritika, 31; vgl. Werner, Die mannl.PN,80 f.; ISSP VIII/IX,473.

290 Er 1st z.B. bei den PN in Mil.,653 nicht angefuhrt.

291 Džurinskij (Bolgarskie pesni..,12) zitiert, die Gestalt des schwarzen Arabers betreffend, Bezsonov (Épos serbskij 1 bolgarskij, Moskau 1855,S.42 und 45), der den Mohren absurderweise fur eine Substitution des "kara-vlach" halt und deswegen von Chalanskij (Zametki po..) kritisiert wird, der die Heimat des schwarzen Arabers am Sudufer des Schwarzen Meeres sucht.

292 Braun, Das skr. Heldenlied, 173; $\nabla g l$ a ach Jordanov, Krali-Marko..., IXXXII 1.; Tomic, 27; Dinekov, BP,463 1 .

293 Vgl. dazu die Bemerkungen von Burin, BNTv I, 35; Lieder sind angefuhrt be1 ISSF V,617 (661): "Turc1 karat robi".

294 Vgl. ASIPh XVII,216.

295 Vgl. auch die Anm. zu Vuk II 66, worin auf die Georgslegende verwiesen wird.

296 Vgl. Krali-Marko..,IIII ff.; vgl. auch Jir.-Rad.,224.

297 Vgl. Proischozdenie..,258: "central'nye temy épiZeskogo tvorlestra épochi razlozenija pervobytnoobscinnogo stroja".

298 Vgl. Proischożenie..,432.

299 In den maz. und bulg. Liedern heibt der Held Gine Arnautze, Gino Arbanas Bele ot Kostur, Bele Kostur'eto, Bele Kosturjande, Beljo junak, hinter dem man den Herrscher der Zeta, Balsa II., vermutet. Zu inm Ploh um 1375 die Gattin von König Marko und Ubergab inm die Stadt Kastoria, die bis dahin zu Markos Herrschaftsbereich gehörte. Vgl. Arnaudov, Ozerki...,306; Jordanov, Krali-Marko..,XVVI ff.; Jirecek, GdS, 105 f.(nach Orbini) : Maretic, NNE, 149 f.

300 Hinter Đemo, dem Lied nach Bruder von Musa Kesedzija, verbirgt sich wahrscheinlich Jegen- oder Jeđem-pasa, der "Hajduken-Pascha", ein gewalttätiger Rebell vom Ende des 17.Jh., der in den maz. und bulg. Liedern DinCe Amautce, Gine Budalina, Ginja Latince, Duko Ebasan${ }_{e}$ und Gino Amautce heiBt, vgl. ISSF VI, 184 (27); Popovic, Pregled..,70 1.; Vuk II 67 Anm.; Tomic.

301 Vgl. Medenica, Das Ilteste Zehnsilberlied..; ders.,Problematik und Methodik...

302 Schmaus, Die balkanische Volksepik..,140 f.; vgl. auch Dinekov, BF, 436-44, vor allem 442. 
302a Dieses Motiv, daB die Fee auf eine versteckte Waffe hinweist, das uns an die antiken Szenen erinnert, wo Götinnen ihren Iieblingshelden zu Hilfe eilen, finden wir auch in der neugriech. Volksepik, nur daß hier - stark verchristlicht - die Fee durch den Engel ersetzt ist.

303 Vgl. Schwab, 118.

304 Vgl. Marinov, SbNU XXVIII,162: "Takiva junaci imat ne edno surce, kakto obiknovenite Coveci, a njakolko sŭrca. Narodnata vjara $i$ poverieto $g i$ predstavljavat obiknoveno s tri sǔrca, no imalo i s poveče: osŭm, pa i deset (..). Tuk junałkoto sŭrce se predstavl java kato zmija usojnica. Tija sŭrca spjat i ne se probuzdat navednũz, a postepeno edno po edno. Ako trae borbata podŭlgo, sǔbuždat se vsickite sưrca; poslednoto se risuva kato ljuta zmija, t.e. naj-jako, naj-silno. I kogato se probuża tova posledno sürce, togava junakŭt stava nepobedim i neudưržim: togava izvărకsva svurrchcoveski podvizi".

305 Auch Braun (Das skr. Heldenlied, 194) macht sich Gedanken uber eine mögliche Umkehrung des Iiedes: "Das Iied könnte urspringlich zum Preise Musas gedichtet worden sein (..). Es braucht deswegen nicht mit seinem Siege zu enden - der Tod eines großen Helden ist ein dankbares episches Thema".

306 Iord, Some Common Themes..,8, fragt sich bei Vuk II 66: "Do we not here also have a dragon story?", was wir nach all dem Gesagten nur bedingt bejahen können.

$307 \mathrm{Vgl}$. Jirecek, GdS, $146 \mathrm{ff}$; Kostic Tumax., 102; Jordanov, Krali-Marko..,IXXXVII f.; Maretic, N'E, 155.

308 Ebda.

309 Kacie-Mioßic Nr.25 "Pisma, kako kralj ungarski pisa lonjigu Juri Kastrioticu na 1443" sowie S.303 in dem Prosaabschnitt "Turci ufatise velikoga viteza Musu i druge s njime".

$310 \quad V_{g l}$. Dve studentske rasprave...54 f.

311 Vgl. Krali-Marko...IXXIX.

312 Vgl. Naslojavanija $v$ edna..,203-40.

313 Vgl. Krali-Marko... I.XXXIX.

314 Vgl. Narodnijat junazki epos, 38.

315 Auch der für einen urspringlichen Riesen eingetretene Mihna Kosturanin in Bog. 86 ist nach Aussage der hilfreich herbeigeeilten Vila zur Halfte aus Stein; bei Schwertschlagen auf seinen Körper sprỉhen Funken.

316 Vgl. das Kapitel uber die Riesen (Giganten) in Schmidt, Das Volksleben der Neugriechen...

$316 a$ Zur magischen Unverwundbarkeit bzw. Verwundbarkeit nur an einer Stelle vgl. Zirmunskij, Vergleich.Epenf.,37, Anm.1; auch Sosruko in den Sagen der Narten ist nur un- 
terhalb des Knies verwundbar.

317 Vgl. Das Volksleben der Neugriechen..,205.

318 Bekanntlich nahmen die Griechen den Namen "Hellenen" erst zu Anfang des Unabhägigkeitskrieges wieder flur sich in Anspruch, nachdem sie sich vorher Tgaikoi oder 'Pwpatol genannt hatten, letzteres seit ihrer Bekehrung zum Christentum, der römischen Staatsreligion.

319 Dazu vgl, auch Iliev, Bülgarskite predanija za ispolini..: Palavestra, Narodna predanja..; Matl, Zur Bezeichnung und Wertung..; Zupanic, Der Name Grk...

$320 \quad V_{g l}$. Chal. RPV $30_{4}, 277$.

320a Vgl. Schmidt, Volksleben der Neugriechen..,201; zur sudslavischen Uberlieferung vgl. Palavestra, Narodna predanja.., vor allem S.59.

$320 \mathrm{~b}$ Vgl. BF, 475.

321 Vgl. Krali-Marko, IXXXIII .

321 a Banařevic, Ciklus..,156.

$322 \quad V_{g l} \cdot \operatorname{RFV~} 30_{4}, 276$.

323 Vgl. auch Esih, Bugarska pjesma...

324 Matl, Zur Bezeichnung und Wertung..,301-305.

324a Vgl. Ciklus.., 156 .

325 Dazu vgl. (mit Literaturangaben) Zirmunskij, Vergleich. Epenf., 14, Anm.2 und 4, und S.45-53;Boßk.NEP II, $270 \mathrm{f}$. (= Anm. zu Nr.16); Stoilov, Zeni cheroini..; AaTh $884 \mathrm{~B}$ "The Girl as Soldier" und AaTh 884 B "Girl Dressed as Man Deceives the King".

326 Vgl. Kirmunskij, Vergleich. Epenf.,59.

$327 \quad V_{g l}$. Schwab, 1121.

328 Iudeke, Griech. Volksdichtung, 206; Ellinika, 55( A $\left.^{\prime}\right)$, $56\left(B^{\prime}\right), 57\left(\Gamma^{\prime}\right)$.

329 Kyriakides, Neugriech. Volkskunde, 18.

330 Krumbacher, Geschichte der byzantin. Iitteratur, 833; vgl. auch Dieterich, Geschichte der byzantinischen... $101 \mathrm{f}$.

331 Kind, 2; Lubke, 273-75.

332 Vgl. dazu Marinov, SbNU XXVIII, 160-64.

333 Popov, Billgarskite junałki pesni, SbNU III,248 f.

334 Zit. nach Teodorov, Proizchod..,348.

335 Slavejkov, Bŭlgarska literatura, 31.

336 Penev, Istorija.., 128,135.

337 Jordanov, Krali-Marko, C.

338 Amaudov, ocerki..,306.

339 Trem, $203 \mathrm{f}$. 
340 Eurin, Junak jasno..,14-15 und in der Einleitung zu BNTV I, 30-34.

341 Teodorov, Proizchod...375 $\rho$.

342 Đinekov, BP, 476 zitiert Ivanov, J, Bulgarski starini iz Makedonija, Sofija 1931, 73: Belezka 26 ot 1813 g.: - dete, t.e.- junosa Trajce proimesíl propoved $\mathbf{v}$. Babcur, Kostursko'.

342a Schmaus, "Neomitologizam" i južnoslovenska narodna epika. 343 Máchal, 0 bohatýrském epose..,120.

344 Vgl. Trem, 134, 204; Gavrilovic, Istorija..,107; Jir.Rad., 319,330,402.

345 Teodorov, Proizchod...360 ff.; Nar.Enc.SHS I,384 s.v. "Vladimir, knez zetski".

346 ASIPh XV, 24.

347 Mat.Kritika, 301 .

348 Beth, uutterrecht; Schmidt, Das Wutterrecht, 29 f.,181; Kosven, Matriarchat.., 27,43; Chal.RFV 29, 120; Meletinskij, Geroj volłebnoj...77; Bastian, Die Rechtsverhaltnisse..,185; Starke, Die primitive Familie..,171 $f$.

349 Gasparini, Il matriarcato.., vor allem Kap.V,282-304.

$350 \mathrm{Zu}$ der Mutter-Sohn-Beziehung $\nabla g l$. Keremidziev, Rodstvenite otnołenija..,347.

351 Ang.-Arn. 20 (Nr.45).

351 a AuBer dem Zmaj konnen auch Menschen mit der Begabung, einen "Geist" auszusenden, der mit der Ala kampet (also eine animistische Vorstellung!), Hagelschlag verhindern. Zu diesen "zduhaci" oder "zmajeviti ljudi" vgl. Bordevic, Priroda u verovanju...99 $\mathrm{f}$.

352 Zum Zmej-Glauben vgl. Karanov, Zmejat.., 128-34; Sto1lov, Lamite 1 zmejovete...,158-74; Marinov, SbNU XVVIII,207210; Bozev, Prikazki...,112 f.; Vakarelski, Etnografia... $224 \mathrm{f.;}$ Amaudov, Zmej 1 zmeica, in BNTv IV,27-33;

Schneeweis, Skr. Volkskunde, 13; Drobnjakovi6, Etnologija...252; Cvjetko, Heneza motyva...; Zirmunskij, Vergleich. Epenf.,24, Anm.2.

353 Vgl. den Berioht aus Mazodonion bei Sapk.VIII/IX 258.

354 Vgl. Schneeweis, Skr. Volkskunde...,10.

355 Vgl. dazu ausfuhrlicher in Burkhart, Vampirglaube..., 224 fl.

356 Schmidt, Das Volksleben der Neugriechen..,189 $P$.

357 Vgl. Gabej, Sitten und Gebräuche..,218-34; ders., Zivot i obicaji..,303-29; ders., Albanische Volkskunde, 368; Lambertz, Gefl.Schw.,206,210.

358 Schmidt, Das Volksleben...190.

359 Kretschmer, VII. 
360 Kretschmer, VI; vgl. Kirdan, Ukrainskie narodnye dumy..., $18 \mathrm{ff..,} \mathrm{wo} \mathrm{von} \mathrm{Zweikamplen} \mathrm{zwischen} \mathrm{Helden} \mathrm{und}$ Zmejs in der ukrainischen Uberlieferung berichtet wird.

361 Kretschmer, VI.

362 Kretschmer, VIII.

363 Vgl. Schmidt, Das Volksleben..,191.

364 Kretschmer, VII.

365 Schmaus, Probleme und Aufgaben...,24; die zeitliche Angabe verdanke ich einer Mitteilung von D.Theodoridis, Munchen.

366 Zit. nach Chal. RPV 27, 119.

367 Vgl. Zirmunskij, Vergleich. Epenf.,28 1.; Máchal, 0 bohatýrském epose..,36 1 .

368 Zit. nach Zirmunskij, Vergleich. Epenf.,29; vgl. auch DerŽavin, Kralevic Marko..,213-33.

368a Vgl. Skripil', Povest' o Petre.. (1946 und 1949); Stoilov, Lamite 1 me jovete...

369 Zirmunskij, Vergleich. Epenf.,60 1 .

370 Z.B. Ellinikà, 69( $\left.A^{\prime}\right), 70\left(A^{\prime} \alpha\right)$ usw.

371 Vgl. Burkhart, Vampirglaube..,224 1 .

372 GISUD V,111.

373 Vgl. Kostic, Otkud Zmaj-0gnjanom..,95-98; ders.,Tumad., $66 \mathrm{f}$.

374 Vgl. Soerensen, ASIPh XV,14 f.; Zirmunskij, Vergleich. Epenf.,60 1.; Jakobson und Rużicic, The Serbian Zmaj Ognjeni Vuk...343-55.

Jakobson und Szeftel, The Vseslav Epos.

Op.c1t., 343 .

377

Zum Problem der "external soul" vgl. Anm.215; Uber den Schamanismus unterrichten Eliade, Le chamanisme..; ders., Traité d'histoire des religions; Harva, Die religiöse Vorstellung..; weitere Literatur bei Hirschberg s.v. "Schamanismus".

Zit. nach Cajkanovié, Sekula se u zmiju pretvorio,112; vgl. Krstic, Metamorfoze 1 okultni predmeti...

Schneeweis, Skr. Volkskunde...7.

Vgl. Arnaudor in BNTV IV,19 1 .

Angelov, Samovilite $v$ bülgarskata..; ders., Rulgarskata narodna balada..; Vakarelski, Za samovilite..,32 ff.; Il'inskij, Juda; Venedikov, Samodivite..; Marinov, SbNU XXVIII,201-206; Vakarelski, Etnografia..,222-25; Arnaudov in BNTv IV, 16-27; Dinekov, BP, 364-76; Maretic, NNE, 251-55; Prodanovic, NNK, 120-23; Bordevic, Vełtica 1 vila..,57-119; Schneeweis. Skr. Volkskunde..,6-8; Moszyriski, Kultura..II, 692 . 
Darluber informieren Lambertz, Die Volksepik..,155-57; Cabej, Zivot i obicaji..,303-19; ders., Albanische folkskunde, 373; Cordignano s.v. "zanë".

383 Dazu vgl. Schmidt, Das Volksleben..,98-130; Kyriakides, Elliniki laogr. I, 184-90.

$384 \quad Z u$ diesem internationalen "Schwanenjungfrau"-Motiv (AaTh 400) vgl. Thompson, Motif-Index D 361, I "SwanMaiden" und D 531; BP KHM II,347 A I und III Nr.193; Zirmunskij, Vergleich. Epenf., 29 (Anm.3), 30 (Anm.13).- Zirmunskij (op.cit.,29-32) deckt unter Heranziehung von vergleichend-ethnographischem Beweismaterial den totemistischen Ursprung des Motivs auf.-Vgl. auch Krstic, Zenidba Zoveka vilom.

Die Neraiden können vor allem dadurch zur the mit einem Helden gezwungen werden, dab der junge Mann ihnen ihr magisches Schleiertuch, seltener Ring, Kleider oder Flugel, wegnimmt ( $\mathrm{vgl}$. Schmidt, Volksleben der Neugriechen, 112 ff.). Wharend die Wegnahme des Flugelkleides die Vilen nur ihrer magischen Krafte beraubt, nicht aber ihr Leben gefährdet, ist in dem Lied $M H I_{2} 20$ und Var., worin das alte Motiv der Außenseele behandelt wird,das Leben (und die ewige Jugend) der Vila direkt an bestimmte Seelentiere gebunden, d.h. das erstgenannte Motiv von der Wegnahme des Flugelkleides wäre praktisch als Abschwächung des Außenseelen-Motivs aufzufassen. Vgl. hierzu Schmaus, Das "Seelentier" der Fee..; ders., Zlatoroge divokoze...

385 Dazu vgl. Schmaus, Studien..2. Die Fee entzweit die Brider.

386 Nur aus der balkanischen Peripherie bekannt, vgl. MH I 2 und Sapk.16.- Wie Seemann in seiner Untersuchung "Die Gestalt des kriegerischen Madchens.." mit einem

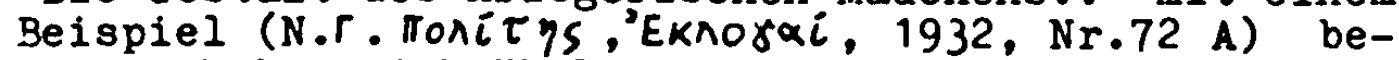
weist, haben sich ahnliche Vorstellungen auch im griech. Akritenlied gehalten, hier allerdings (sekundar?) aup ein Heldenmädchen bezogen: "Sie wirft sich in Mannerkleidung und ergreift ihre Waffen. Schlangen breitet sie auf inr ROB und beschlägt es mit Nattern. Ottern verwendet sie als Sporen.." (Seemann, op.cit.,201).

$387 \mathrm{Vgl}$. Hera, die Herakles durch ihre Gottermilch Unsterblichkeit verleiht. Auch im albaniochen Holdenlied heibt es, Zanenbrustmilch mache einen Helden stark wie einen Drangue.

388 Laut Schmidt, Das Volksleben..,106 $\mathrm{f}$. besitzen auch die Neraiden und Uberhaupt alle Nymphen der hellenischen Mythologie die "Gabe der Weissagung".

388a Vgl.Danckert, Das Volkslied..,146:"Der Spielmann im Dienst der tanzenden Fee ist eine sehr altertiumliche Figur", die z.B. im irischen Märchen häufig vorkommt.

389 Cajkanovic, Magi zni smej, 25 f1.

389a Vgl. Schmaus, Studien..2. Die Fee entzweit..,116 1.; Maretić, NNE,254; Prodanović, NNK, 121. 
389b Vgl. Danckert, Das Volkslied..,143: "Die balkanischen Vilen errichten ebenso wie die nordeuropäischen Feen gigantische Bauwerke in den Wolken."

Vgl. Kind, XV; Dieterich, Geschichte der byzantinischen..,142 f.

391 Op.cit.,142 1 .

392 Schmaus, Studien..2. Die Fee entzweit die Brider.

393 Gesemann, Studien..,70-78.

394 Gesemann, Studien..,76.

Bogatyrev, Nekotorye zadadi..,211 ff.

396 Schmaus, Probleme und Aufgaben..,19.

397 Meletinskij, Proischozdenie..,258.

398 Propp, Russkij geroileskij épos, 83 11.; ders., Osnovnye ètapy $\ldots, 304$.

399 Braun, Das skr. Heldenlied, $28 \mathrm{ff}$.

400 Zirmunskij, Vergleich. Epenf.,23.

401 Op.cit.,28.

402 Vgl. Russkij geroiðeskij épos, 83-246.

403 Vgl. Osnovnye étapy..,295.

404 Vgl. O genezise i putjach..,81 ff.; Anikin, Vozniknovenie..,28 $\mathrm{ff}$.

405 Vgl. die grundsätzlichen Bemerkungen hierzu von Vries, Betrachtungen zum Marchen..., der sehr richtig betont, "daB Márchen, Heldensage und Mythos mit einem im groBen und ganzen gleichartigen Motivenschatz arbeiten" (S.155) und daB "die motivische Gleichartigkeit" auf der "Verwendung gleichartiger "Archetypen" berunt(S.16i Weiter: "Es ist einfach unmöglich, von der stofflichen Seite her diese drei Literaturgattungen von einander scharf zu trennen, wie sehr wir dennoch immer wieder mit allem Nachdruck ihre Unterschiedlichkeit in Charakter und Funktion betonen mulssen. Ich zweifle nicht daran, dab der Mythos hier eine zentrale Stellung einnimmt" (S.171).

406 Vgl. Kirdan, Ukrainskie narodnye dumy..,265: "Proischoždenie i razvitie ukrainskogo geroiðeskogo éposa svidetel'struet $0^{\prime}$ tom, $Z$ to geroiceskij épos ne objazatel'no voznikaet iz proepiceskogo (iz mifov)". 
Hat

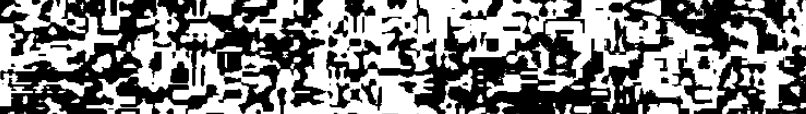

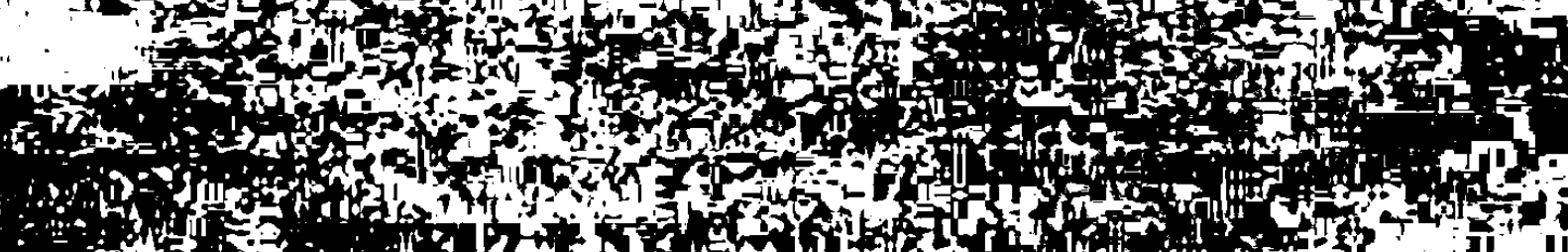

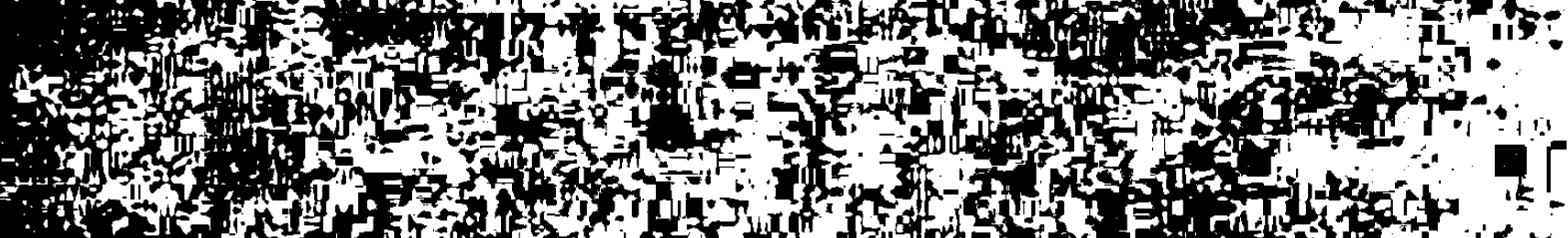

and

(10)

mate

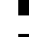
(1) (5) 6.

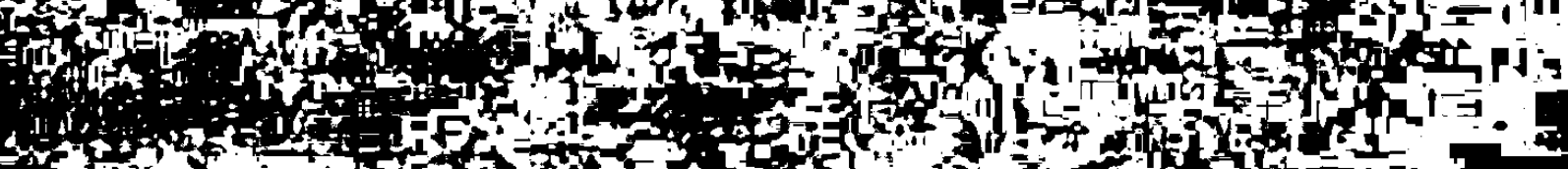
(n)

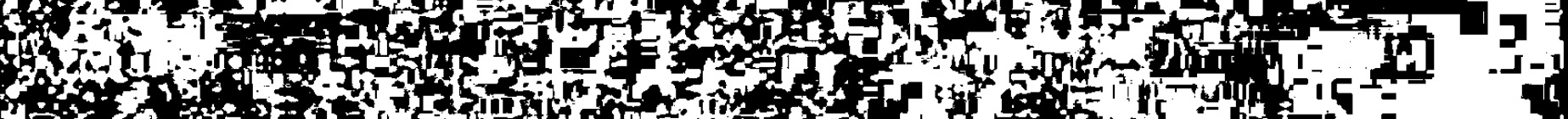

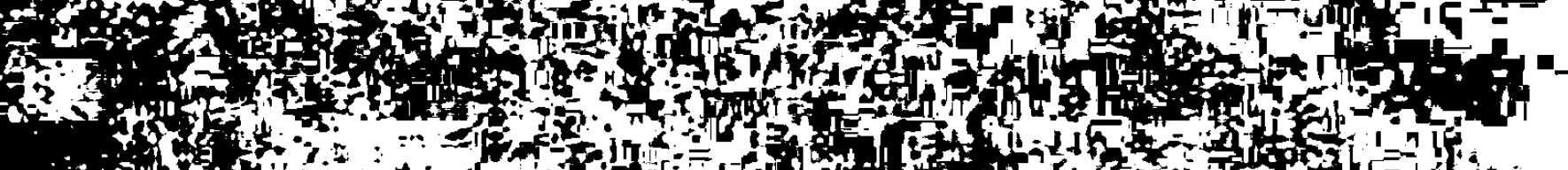

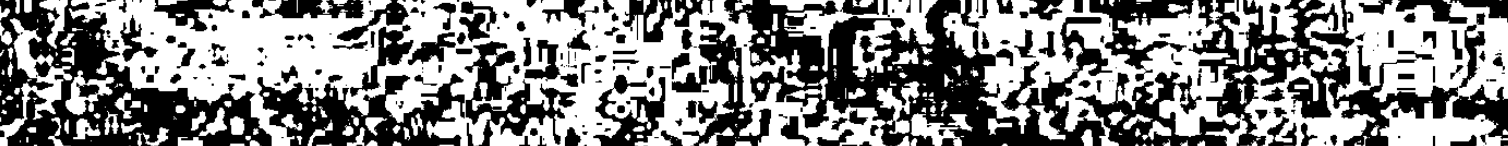

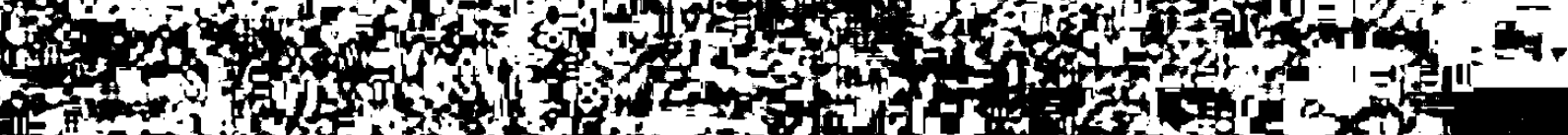
a

-

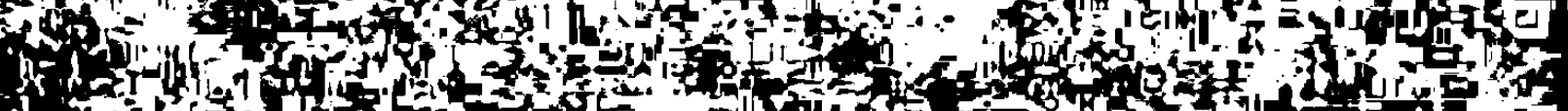

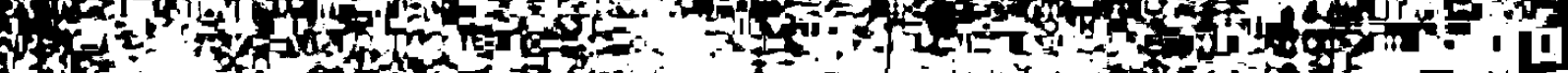

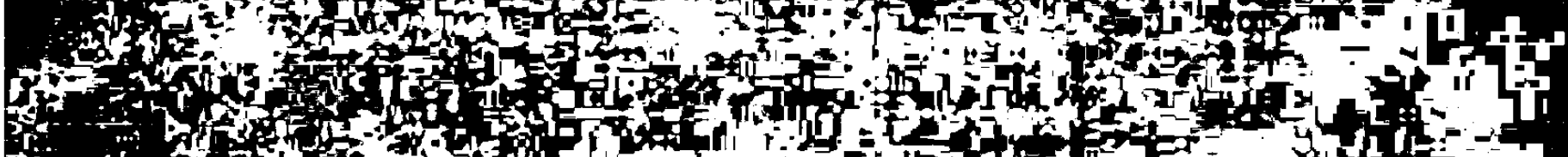

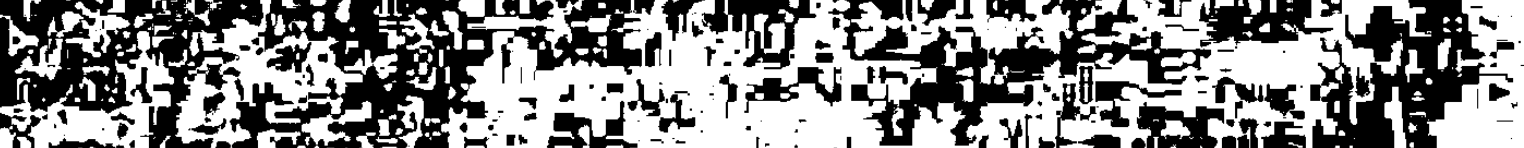
43 and .

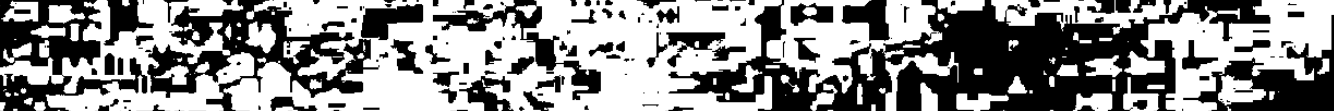




\section{A B X OR Z U N G E N}

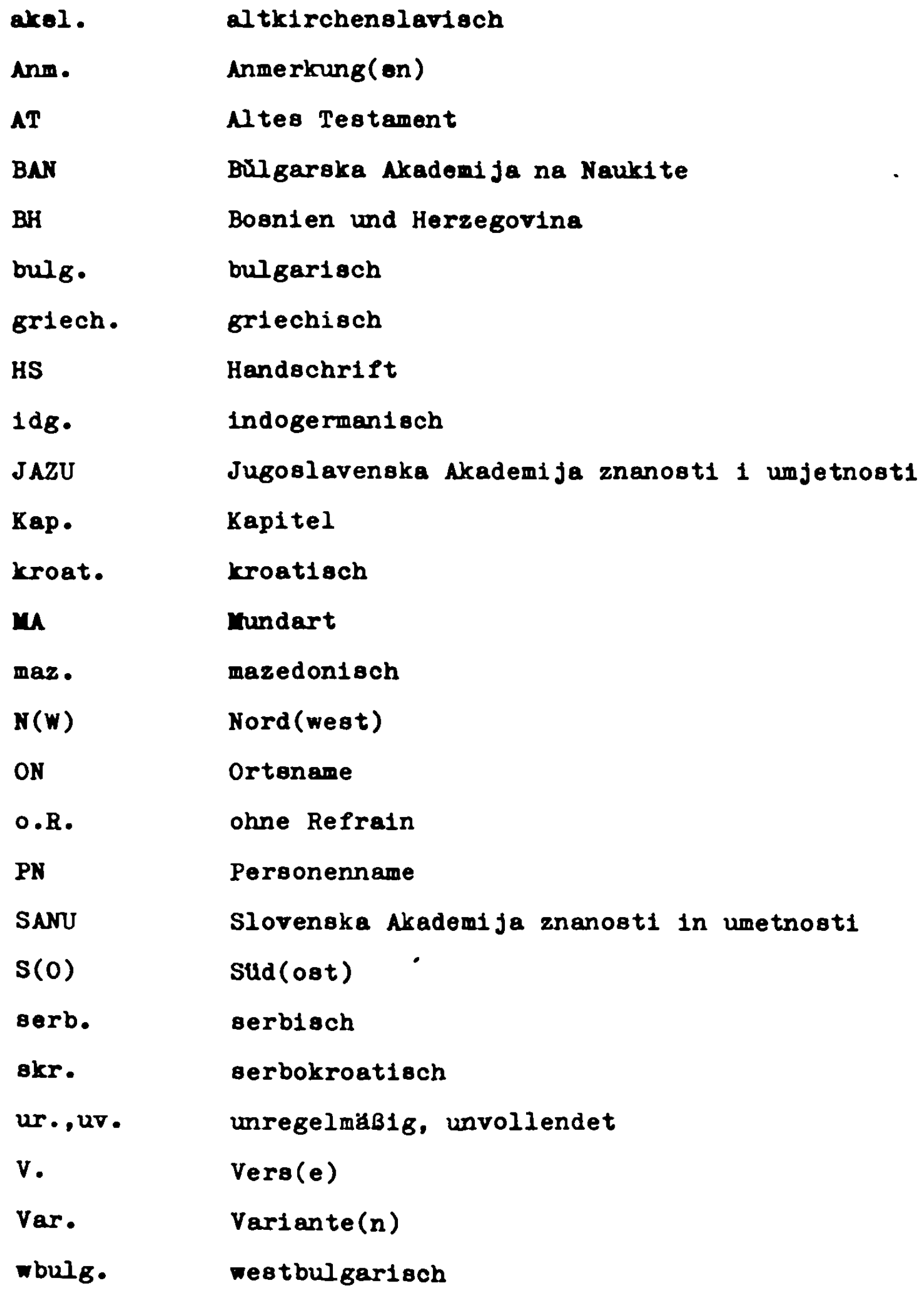




\section{A. ZEITSCHRI PTEN UND REIHEN}

APP

$\mathrm{ASIPh}$

$B \mathrm{Br}_{\mathrm{B}} \cdot \mathrm{km}$.

Byz.Z.

Caregr.veetn.

Pabula

PFC

GIDSS

GIEI SAN

GIEY

GISkND

GISUD

GI2X BH

God. BH

IEIM

IP

INEM

ISSP

JP

Iit.zbor.

IHS
Anal1 Piloloßkog Pakulteta, Beograd 1962 ff. Archiv flur Slavische Philologie, Berlin $1876 \mathrm{ff.}$ BuIgarski knizici, Konstantinopel $1858 \mathrm{f}$. Byzantinische Zeitschrift, Leipzig 1892 fe. Caregradski vestnik,I-XIII, Konstantinopel 1850-1862

Fabula. Zeitschrift flur Erzkhlforschung, Berlin 1957 ef.

Folklore Pellows Communications, Helsinkl 1910 ff. Glasnik Drustva Srpske Slovesnosti, Beograd 1847 fl.

Glasnik Etnografskog instituta Srpske Akademije Nauka, Beograd 1952 fe.

Glagnik Etnografskog muzeja u Beogradu, Beograd 1926 ef.

Glasnik Skopskog Naǔnog Drustra, Skopje 1925 ff. Glasnik Srpskog UCenog Društva, Beograd 1868 ff. Glasnik Zemaljakog Muzeja u Bosni 1 Hercegovint, Sarajevo 1889 ff.- Nova serija: Glasnik Zemaljskog Muzeja u Sarajevu, Sarajevo 1946 ff.

Godi knjak. Balkanolo8ki institut, Sarajevo 1956 f1. (Naucno Drubtro NR Bosne 1 Hercegovine)

Izvestija na Etnografskija institut 8 muzej. Solia 1953 ff.

Indogermanische Forschungen, Strabburg 1892 ff. Izvestija na Narodnija etnografski muzej, Solia $1921 \mathrm{ff}$.

Izvestija na Seminara po Slavjanska filologija pri universiteta $\nabla$ Sofija, Sofia $1904 \mathrm{ff}$.

Juźnoslovenski P1lolog. Povremeni spis za slovensku filologiju 1 lingvistiku, Beograd $1913 \mathrm{fl}$. Iiteraturen zbor. Spisanie na Drubtvoto za makedonski jazik 1 literatura, Skopje 1953/54 1 .

Letopis Mat1ce Srpske, Novi Sad (vorher Budim), 182511.

Ein Komma vor einer arabischen $\mathrm{zahl}$ bedeutet hier und im Text der Arbeit "Seite", während ein Punkt bzw.das Pehlen eines Satzreichens vor einer arabischen Zahl als "Nummer" zu lesen 18t."Band" bzw."Jahrgang" wird in römischen Zahlen ausgedruckt. 
Nar.etvar.

Nar.umj.

Nauéno op.

ob.tr.

Obzor

Per.spis.

PKJIP

PPNP

Rad

RÉSEE

RESI

$\mathrm{RP}$

RFV

RHC

RIÉB

Rod.napr.

Sb BAN

SBBKD

SbNO

SEZ b

SKGI

Slov.Etn. SOE Jb.

SOP

Sov.Etn.

Spia.BAN

Starine

Stud.Slav.
Narodno atvaralastvo, Beograd $1962 \rho 1$.

Narodna unjetnost, Zagreb 1962 p.

Zurnal. Naudno spisanie, I-X, Stara-Zagora

(dann Plovdiv und Turnovo) 1886-1897

Obzt trud. Povremenno knizerno opisanie, BolGrad 1863 (I-III)

Obzor, Zagreb 1916 fl.

PeriodiCesko spisanie na Bilgarskoto knizovno druzestro (fortgesetzt als Spis.BAN), Braila (dann Sofia) 1870 11.

Prilozi za knjizevnost, jezik, istoriju i folklor, Beograd 1920 If.

Prilozi proudavanju narodne poezije, Beograd 1934 11.

Rad JAZU, Zagreb $1867 \mathrm{\rho f}$.

Revue des Etudes sud-est europeénnes, Bukarest 1963 P1.

Revue des Etudes slaves, Par1s 1921 pl.

Russkij fol'klor, Moskau-Leningrad $1956 \mathrm{fP}$.

Russkij FilologiCeskij Vestnik, Warschau 187611.

Revue d'histoire comparée, Paris (Neue Serie) 1946 11.

Revue Internationale des ttudes Balkaniques, Beograd 1934 1 .

Rodopski napredulk. Meselno il justrovano episanie za nauka, obłtestreni znanija 1 narodni umotvorenija, I-X, Plovdiv (vorher Stanimaka) 1903-12

Sbornik na BAN, Solia 1913 ff.

Sbornik na Bulgarskoto Knizovno druzestvo $v$ Sopija, Sofia 1901 1f.

Sbornik za narodni umotvorenija, nauka 1 kniznina (dann Titelunderung: Sbornik za narodni umotvorenija i narodopia), Sofia $1889 \mathrm{ff}$.

Srpski Etnografoki zbornik, Beograd 1894 ff. Srpaki Knjizevni Glasnik, Beograd 1901 fl. Sloveneki etnograf, Ijubljana 1948 1. Slidosteuropa-Jahrblicher, minchen 1956 ff. Sudost-Forschungen, (Leipzig, dann) ab Bd.V ulinchen 1940 Pf.

Sovetskaja Ėtnografija, Moskau, $1938 \mathrm{fl}$.

Spisanie na BAN, Solia 1911 If.

Starine, Zagreb (JAZU) 1869 1.

Studia Slavica, Budapest 1955 ff. 
Stvar.

TIE

TODL

Z Baik

ZIJK

ZNZัo

ZR SAN

ZSIPh

Ziva st. Zivaja ot.

ZMNP
Stvaranje, Cetinje 1946/47 $\mathrm{fe.}$

Trudy Instituta etnografil, Moskau-Leningrad (Neue Serie) $1949 \mathrm{fl}$.

Trudy otdela drevnerusskoj literatury, LeninGrad $1934 \mathrm{fe}$.

Zeitschrift fur Balkanologie, Wunchen $1963 \mathrm{ff}$.

Zbornik za istoriju, jezik 1 knjlzemost erpskoga naroda, Beograd $1926 \mathrm{fe.}$

Zbornik za narodni zivot 1 obicaje juznih slavena, Zagreb $1896 \mathrm{ff}$.

Zbornik radova SAN. Etnografaki institut, BeoGrad 1949 ff.

Zeitschrift flir slawische Philologie, Leipzig $1925 \mathrm{ff}$.

Ziva starina, Ruse (spater Sofia) $1891 \mathrm{ff}$.

Zivaja starina. Periodiceskoe 1zdanie otdelenija Etnografil Imperatorskogo Geograficeskogo obzcestva, St.Petersburg, $1890 \mathrm{ff}$.

Zurnal Ministerstva narodnogo prosvezcenija, St.Petersburg $1851 \mathrm{ff}$.

\section{B. SAMAUUNGEN, INDIZES OND KOMNGNTARE}

AaTh

Aarne,A. und St.Thompson: The Types of the FolkTale, Helsinki 1961 (= PFC 184)

Abbot

Amzulescu

Abbot,G.F.8 Songs of Modern Greece,Cambridge 1900 Amzulescu, A.J.: Balade Populare Romineģt1, Bukarest 1964 ( 3 Bde.)

Andreev

Ukazatel' skazoßnych sjužetov po sisteme Aarne, hrs 88. von N.P.Andreev, Leningrad 1929

Ang-Arn .

Angelov, B. und H.Amaudor: Brilgarska narodna poezija (= Istorija na bŭlgarskata literatura v primer1 1 bibliografija I), Sofia 1922

Balladen Meier,John (Hrsg.) : Deutsche Volkslieder.Balladen I-II, Berlin 1935 und 1939

Bartok-Lord Bart6k, B.und A.B.Iord: Serbo-Croatian Folk Song8 (from the Milman Parry-Collection),New York 1951

Bez8.

Bezsonov,P.8 Bolgarskie pesni iz sborntkov Ju.I. Venelina, N.D.Katranova i drugich bolgar. I. Pesni junazk1-molodeckija, geroideskija ili êpiCeskija, Moskau 1855

Burskov sjakigo, Varna 1880 ff.-Bd.XV Elcha,Sumen 1887 
BNPTV

BNTV

Bog.

Bogkn

Bond.

BO\&k.NEP II

Bozev

BP KMM

Brlié HS

Burin

Cepenkov

Chal . RPV

curm.

Cajk.15 SNP

Cajk.SNP

Col.

David.

Dawkins

Delorko NEP I

Delorko NLP

Doz.
Romanska,Cv.: Bülgarsko narodno poeticno tvorCestro. Christomatija, Solia 1964

Bullgarako narodno tvorcestvo, I-XII, Sofia 1961-3 Bogizic,V.: Narodne pjesme iz starijih, najvike primorskih zapisa (= GISUD X), Beograd 1878

Bogorov,I.: Bulgarski narodni pesni. Iz Bogorovya knizatnik, Sofia 1879

Boncev,N.: Sbornik ot bŭlgarski narodni pesni, Varna 1884

Boßkovic-Stulli,M.: Narodne epske pjesme II (=Pet stoljeca hrvatake knjizevnosti 25), Zagreb 1964

Božev,S.D.: Prikazki za zli duchove i dr.-In: SbNU IV, 112-113

Bolte,J.und G.Pollvka: Anmerkungen zu den Kinderund Hausmärchen der Bruder Grimm,I-IV, Leipzig 1913-32

Zivaljevie,A.: Andrija Kacic Miołic slovinski pesnik.-In: IMS CIXXII (1892),1-43 (darin drei handschriftliche, von Brlic aufgezeichnete Var. besprochen)

Burin,I.: Junak jasno slúnce. Naroden epos, Sofia 1955

Cepenkov,M.K.: Makedonski narodni prikazni I, Skopje 1964

Chalanskij,M.: Juzno-slavjanskie skazanija o KraleviCe Marke $v$ ovjazi s proizvedenijami musskogo bylevogo éposa. Sravnitel nye nabljudenija $\checkmark$ oblasti geroiceskogo éposa južnych slavjan 1 russkogo naroda.-In: RFV Bde.27-34 (1892-1895)

Curmułanov,K.: Makedonaki narodni pesni, Sofia 1956

Cajkanovic,V.: Petnaest srpskih narodnih pesama, Beograd 1925

Cajkanovic,V.: Srpake narodne pripovetke I, Beograd 1927 (= SEZb XلII)

Colakov, .: Bŭlgarski naroden obornik I, Bolgrad 1872

DavidoviC,S.N.: Srpske narodne pjesme iz Bosne (Zenske), Pancevo 1884

Dawkins,R.M.: Modem Greek Folktales,0xford 1953

Delorko,0.: Narodne epake pjesme I (= Pet etoljeCa hrvatske lonjizevnosti 24), Zagreb 1964

Delorko,0.: Narodne lirske pjesme (= Pet stoljeéa hrvatske knjizemosti 23), Zagreb 1963

Dozon,A.: Bulgarski narodni pesni. Chansons populaires bulgares inédits, publiées et traduites par Auguste Dozon, Paris 1875 
Drag.

EH

Ellinikà

Pauriel

Filip.

Pranken

Hahn

Horm •

Horm.HS

Ikon.

Il.

ISSP V/VI

ISSP VIII/IX

Istarske

Ivan.

J ank.

Jastr.

Jowitsch

Ką.

Kacie-Miogic

Karav. BNP
Draganov,P.: Makedonsko-8lavjanskij sbornik, St.Petersburg 1894 (= Zapisk1 Imperatorskogo Russkogo GeografiCeskogo Obzcestva,otd.etn.XXII)

Gesemann,G.: Erlangenski rukopis starih srpskohrvatskih narodnih pesama, Sr.Karlovci 1925 ( = ZIJK Reihe Is Spomenici na srpskom jeziku 12) Ellinikà dimotikà tragoúdia (Ekloj1) I, Athen 1962

Pauriel,C.: Chants populaires de la Grece moderne I-II, Paris 1924-25

Pilipovic,I.: Kraljevic Marko u narodnim ptomama, Zagreb 1880

Pranken, A.: Rumänische Volkslieder und Balladen, Danzig 1889

Hahn,I :- Neugriechische und albanesische marchen I-II, Leipzig 1864

Hormann,K.: Narodne pjesme muslimana u Bosn1 1 Hercegovini I-II, Sarajevo 1933

Narodne pjesme muslimana u Bosni 1 Hercegovini. Iz rukopisne ostarstine Koste Hormanna, Red., uvod 1 komentari Benana Buturovic, Sarajevo 1966

Ikonomov, V.: Sbornik ot staronarodni pesni,1893 Illev,A.T.: Sbornik ot narodni umotvorenija,obiCa1 i dr., sǔbirani iz razni bulgargki pokrajnini.I. Narodni pesni, Solia 1889

Romanski,S.(Red.und Vorwort): Pregled na bülgarskite narodni pesni.-In: ISSP V (1925) und VI (1929)

Dimitrova,A.und M.Janakiev: Predanija za 18toriceski lica $v$ bulgargkite narodni umotvorenija.In: ISSP VIII/IX (1948),411-606

Iatarake narodne pjesme, Opatija ${ }^{2} 1924$

Ivanov,J.: Starobulgargki razkazi, Sof1a 1935 Jankov,G.: Brlgarski narodni pesni ot Elena $V$. Jankova, Plovdiv 1908

Jastrebov,I.S.: Obycai 1 pesni Tureckich serbov. Iz puterych zapisok, St.Petersburg 1889

Jowitsch,S.: Ethnographisches Gemahlde der slavonischen Militargranze, Wien 1835

Kacanovakij,V.: Pamjatniki bolgarskogo narodnogo tvordestva. Sbornik zapadno-bolgarskich pesen I, St.Petersburg 1882

Kacic-Miozic, Andrija: Razgovor ugodni naroda slovinskoga (Venedig 1756), Zagreb 1851

Karavelov,I.: Bolgarskie narodnye pesnt (Hrsg.P. A.Lavrov), Moskau 1905 
Kar.Pam.

Këngè

Kind

Kostic Tumad.

Kretschmer

Kuhad

Kurelac

Lambertz, Gell.Schw.

Lavr.-Pol.

Lubke

Iudeke

Maleð.

Marj.

Matic Ant.

Mat.Kritika

Maz.

MH

Mich.

Karavelov,L.: Pamjatniki narodnogo byta bolgar I, Moskau 1861

Këngë popullore legjendare, Tirana 1955

Kind,Th.: Anthologie neugriechischer Volkslieder, Leipzig 1861

Kostic,D.: Tumadenja druge knjige srpskih narodnih pjesama Vuka St. Karadżía. Dodatak Zetvrtom državnom izdanju, Beograd 1937

Kretschmer,P.: Neugriechische Märchen,Jena 1919

Kuhad,P.: Južno-slovjenske narodne popievke,I-IV, Zagreb 1879-83

Kurelac,F.: Jadke ili narodne pesme prostoga i neprostoga puka hrvatskoga po Zupah zoprunskoj, možonskoj i Zeležnoj na Ugrih, Zagreb 1871

Lambertz,M.: Die geflugelte Schwester. Albanische Volksmärchen, Eisenach 1957

Lavrov,P.A. und J.Pollvka (Hrsg.): Lidové povidky jihomakedonské ( 2 rukopisư St.VerkoviCových), Prag 1932 (= Rozpravy Ceské Akademie vẽd a umén 1 Jg.III, Nr. 70)

Lubke,H.: Volkslieder der Griechen, Berlin 21897 Neugriechische Volkslieder (Auswahl und Ubertragung ins Deutsche von Hedwig Ludeke), Teil II: Obertragungen, Athen 1964

Kostik,S.: Malezevski narodni pesni,Skopje 1959

Marjanovic,I.: Hrvatske narodne pjesme, sto se pjevaju u Gormjoj hrvatskoj krajini i u turakoj Hrvatskoj,I, Zagreb 1864

Matic,S.: Antologija narodnih pesama sa pregledom narodne knjizevnosti, Beograd o.J.

Mator, D.: Kritika, Dve novi abirki po zapadnobülgarakija folklor.-In: SbNU XIII,3-52

Mazuranic,S.: Hrvatske narodne pjesme (Xakavske), skupio ih po Primorju i po Granici, Crikvenica 1907

Hrvatske narodne pjesme (hrsgg.von der Matica Hrvatska) $I_{1-6}$ und II $_{1-4}$, Zagreb $1896 \mathrm{ff}$.

Michailov,Y.: Bügarski narodni pesni ot Makedonija, Sofia 1924

Miklos.(SB 103)Miklosich,F.: Uber Goethe's "Klaggesang von der edlen Frauen des Asan Aga".-In: Sitzungaberichte der Kaiserl. Akademie der Wissenschaften 103, Wien 1883,S.413-489

Mil.

Milic. Miladinovci,K. und $D_{.}:$Bülgarski narodni pesni, Sofia (4.Aufl.) 1961 Milićević,M.: Kraljevina Srbija,Beograd 1884 
Milut.

Moskova

Nametak

Nikolic

Novak.

ASIPh III

Pam.Obr.

Parry-Lord

Pask.

Passow

Petr.

Radov.

Sakellaridis

Schwab

Senk1

Slav.

Stoil.

Stoil. Pokaz .

Stoin

Pesnop.
Milutinovic,S.: Pjevanija Cernogorska i Hercegovacka I, Leipzig 1837

Moskova,D.: Pokazalec na obnarodvanite narodopiani $i$ folklomi materiali $v$ SbNU I-I.-In: SbNU I (1963), 418-490

Nametak, A.: 0 Hörmannovoj zbirci narodnih pjesama muslimana u Bosni i Hercegovini.-In: Nar. stvar. (1963), 447-455

Nikolic,G.A.: Srpske narodne pesme I, Novi Sad 1888

Novakovic,S.: Ein Beitrag zur Iiteratur der serbischen Volkspoesie.-In: ASIPh III (1879),640 ff.

Pamjatniki i obrazcy narodnago jazyka $i$ slovesnosti russkich i zapadnych slavjan,I-IV, St.Petersburg 1852-56

Srpskohrvatske junacke pjesme (skupio M.Parry, uredio A.B.Lord) II: Novi Pazar. Srpskohrvatski tekstovi, Beograd, Cambridge 1953

Paskalevski,P.: Narodni pesni od Egejska Makedonija, Skopje 1959

Passow,A.: Carmina popularia Graeciae recentioris, Athen (3.Aufl.) 1932

Petranovic,B.: Srpske narodne pjesme iz Bosne i Hercegovine,II-III, Beograd 1867 und 1870

Radovanovic,V.: Marijovci u pesmi, prici i zali. Nekoliko pregrsti iz riznici duhovnog blaga Juznosrbijanaca, Skoplje 1932 (= otztampano iz izdanja Skopskog naucnog drustva: Zbornik za etnografiju i folklor Južne Srbije i susednih oblasti I)

Sakellaridis,K.: To Nisyriko dimotiko tragoudia, Athen 1965

Schwab,G.: Sagen des klassischen Altertums, Minchen-Zlirich $0 . J$.

Angelov, B.und Chr.Vakarelski: Senki iz nevidelica. Kniga na bulgarskata narodna balada, Sofia 1936

Slavejkov,P.P.: Kniga na pesnite (Bügarski narodni pesni), Sofie 1961

Stoilov,A.P.: Sbornik ot bưlgarski narodni umotvorenija,I-II, Solia 1894 und 1895

Stoilov,A.P.: Pokazalec na pecatanite prez XIX. vek bŭlgarski narodni pesni, I(1815-1860) und II(1861-1878), Sofia 1916 und 1918

Stoin,V.: Narodna pesnopojka, Sofia 1930 
Stoin SSB

Stoin TV

Stojk.

Sapk.

Sapk.VIII/IX

Sapk.-Pol.

Saulic

Strekelj

Tach.

Thompson

Motif-Index

Tomic

Tommaseo

(1842)

Toß̌v

Trem

VeK

Verk.

Verk.-Lavr.

vien.uzd.

Vuk

(Karadżí)

Vuk Posl.

Vuk Prip.
Stoin,V.: Narodni pesni ot sredna severna Bülgarija, Sofia 1931

Stoin,V.8 Narodni pesni ot Timok do Vita, Sopia 1928

Stojkovic,S.: Kraljevic Marko, Novi Sad 1922

Sapkarev,K.A.: Sbornik ot bulgarski narodni umotvorenija, Teil 1-3, Sofia 1891-94

Sapkarev,K.A.8 Brilgarski narodni prikazki i verovanija, Solia 1892 (= Kniga VIII/IX des Sbornik ot bŭlgareki narodni umotvorenija, Teil 2)

Polivka,J.: Beležki kŭm prikazkite na Sapkarevija-"Sbornik ot bưlg.nar.umotvorenija" kn.8-9, 1892.-In: SbNU XVIII (1901),605-640

Saulic,N.: Srpske narodne pjesme I, Beograd 1929 Strekelj,K.8 Slovenske narodne pesmi, Ljubljana 1904-1907

Tachov,N.: Sbornik ot makedonski bưlgarski narodni pesni, Solia 1895

Thompson,St.8 Motif-Index of Folk-Literature, I-VI, Kopenhagen 1955-58

Tomić,J.N.: Istorija u narodnim epskim pesmama - Marku Kraljeviću. I.Pesme o Musi Kesedžiji 1 Demu Brdaninu, Beograd 1909

Tommaseo,N.: Canti popolari toscani, corsi, illirici, greci, I-IV, Venedig 1841-42

Toßev,K.und R.Ugrinova: Narodni umotvorbi ot PIringka Makedonija, Skopje 1950

Angelov, B.und Chr.Vakarelski: Trem na bulgarskata narodna istoričeska epika, Sofia 1939

Visaret e Kombit, I-IV, Tirana 1912-39

Verkovik,S.: Makedonski narodni pesni (red.K.Penusliski), Skopje 1961

Lavrov,P.A.: Sbornik VerkoviCa. I.Narodnyja pesni Makedonskich bolgar, Petrograd 1920 (= sbornik otdelen1ja russkogo jazyka 1 slovesnosti Rossijskoj Akademii Nauk XCV Nr.5)

Vienac uzdarja narodnoga 0 . Andriji Kacić-Mioziću na stolietni dan preminutja, Zadar 1861

Srpake narodne pjesme, I-IX (Staateausgabe), BeoGrad 1887-1902; die Lieder von I-IV werden zitiert nach der vierbändigen Ausgabe, Beograd 1958 (Nachdruck der 2.Ausg., Leipzig 1823-33)

Karadzic, Vuk St.: Srpgke narodne poslovice, Beograd 1900

Karadzic,Vuk St.: Srpske narodne pripovijetke 1 zagonetke, Beograd 1897 
varb.

$Z_{\text {ganec }}$

Be1tl

Buchb.

BSIg • Enc.

Cordignano

DIct.

Enc.Jug.

Frenzel

P\&W

Gerov

HDA

HDM

Heuser-

Şevket

Hiltbrunner

Hirschberg

Jobes

Mladenov

Nar . Enc . SHS
Vurbenski, A.: Pesnite na Berdjanskite bilgari, Nogejsk 1910

Zganec,V.: Hrvatske narodne pjesme kajkavake, Zagreb 1950

\section{NACHSCHLAGEVERKE}

Beitl,R.8 Wörterbuch der deutschen Volkskunde. Stuttgart 1955

Iexikon für Theologie und Kirche (begr. von $M$. Buchberger), 2.neu bearb.Aufl.von J.Hofer und K.Rahner, I-X, Preiburg 1957-65

Dancov,N.G. und I.G.: Bulgarska Enciklopedi ja, Solia 1936

Cordignano,P.: Dizionario alb.-ital. e ital.alb., Malland 1934

Dicţionarul limbil Romine literare contemporane, Bukarest (Akademieausg.) 1955

Enciklopedija Jugoslavije (Red.u.Krlež), Zagreb $1955 \mathrm{fe}$.

Frenzel,E.: Stoffe der Weltliteratur, Stuttgart 1963 (= Kröners Taschenausgabe Bd.300)

Funk \& Wagnall's Standard Dictionary of Folklore, Mythology and Legend, New York 1949

Gerov,N.8 Rečnik na bülgarski jazik a tŭlkuranie na bưlgarski i na ruski, I-VI,Plovdiv 1895-1904

Handworterbuch des deutschen Aberglaubens (Hrsg. Bächtold-Stäubli), I-X, Berlin 1927-42

Handwrrterbuch des deutschen Murchens (Hrsg.Lutz Mackensen, Joh.Bolte u.a.).I-II, Berlin-Leipzig 1930-40

Heuser-Sevket: Turkisch-Deutsches Worterbuch, Wiesbaden 1953

Hiltbrunner,0.: Kleines Lexikon der Antike, Bern 1961 ( = Sammlung Dalp Bd.14)

H1rschberg, w.: Worterbuch der v8lkerkunde, stuttgart 1965

Jobes,G.: Dictionary of Mythology, Polklore and Symbols, New York 1961

Madenov,St.: Etimologiceski i pravopisen recnik na bülgarakija knizoven ezik, Sofia 1941

Narodna enciklopedi ja srpeko-hrvatako-slovenacka (Hrog.St.Stanojevil), I-IV, Beograd 1929 
Pauly-Wissowa

Rjęnik JAZU

Roscher

Skal jic

Vuk Rječnik
Paulys Real-Encyclopädie der classischen Altertumswissenschaft (neubearbeitet von G.Wissowa), Stuttgart

Rjecnik hrvatskoga ili srpskoga jezika (begr. von ${ }$. Danilic, hrsgg. von der JAZU), Zagreb $1880 \mathrm{ff}$.

Roscher,W.H.: Ausfuhrliches Lexikon der griechischen und römischen Mythologie, Leipzig 18841937

Skaljie,A.: Turcizmi u srpskohrvatskom jeziku, Sarajevo 1966

Karadžic,Vuk St.: Srpski rjeðnik, istumacen njemaxkijem i latinskijem rijecima, Beograd (4.Aufl.) 1935

\section{ALLGEMEINE DARSTELLUNGEN UND MONOGRAPHIEN}

Albrecht, E.:

Anikin, B.P.:

Arnaudov, M.:

ders.:

Aufhauser, J :

Autran, $\mathrm{Ch} \cdot:$

ders.:

Banaševic, N.:

Bastian, A.:

Baudouin, Ch.:

Beit,H.v.:

Berthold,0.:

Boskovie-

Stulli, $\mathrm{M}$ :

Bowra, M.:
Das Turkenbild in der ragusanisch-dalmatinischen Literatur des 16.Jh., Munchen 1965 (= Slavist. Beiträge Bd.15)

Russkij bogatyrskij épos, Moskau 1964

Oxerki po bulgarski folklor, Sofia 1934

Baladni motivi $v$ narodnata pezija. I.Pesenta za delba na drama bratja, Sofia 1964

Das Drachenwunder des hl. Georg in der griechischen und lateinischen tberlieferung, Leipz.1911 Homère et les origines sacerdotales de l'épopée grecque, I-III, Paris 1943

L'épopée indoue, Paris 1946

Ciklus Marka Kraljevića i odjeci francusko-talijanske vitełke kmjizevnosti, skopje 1935 (= Knjige Skopskog Naucnog Druxtva III)

Die Rechtsverhältnisse bei den verschiedenen volkern. Berlin 1872

Ie triomphe du héros. Etude psychoanalitique sur le mythe du héros et les grandes épopées, Paris 1952

Symbolik des Märchens, I-II, Bern ${ }^{2} 1960$

Die Unverwundbarkeit in Sage und Aberglauben der Griechen, Giessen 1911

Narodna predaja o vladarevoj tajni, Zagreb 1967

Heldendichtung. Eine vergleichende Phänomenologie der heroischen Poesie aller völker und Zeiten, 1964 (= Úbersetzung des englischen Originals mit dem Titel: Heroic Poetry, London 1952) 
Braun, M.:

Carpenter,R.:

Chadwick, H.M. ders. und $N$. Chadwick:

Chalanskij, M.:

Culinovie, F.:

Danckert,W.:

Dieterich,K.:

Dinekov, P.:

Domanovsky, A.: Drobnjakovic, D.

Bordevic,T.:

ders.:

Durie,V.: ders.:

ders.:

Eliade, $\mathrm{M}_{\text {.: }}$

ders.:

$\checkmark$ Entwistle,W.:

Prakno1,W.: ders.:

Prazer,J.:

Priedrich,J.: Frings, Th. und M. Braun:
Das serbokroatische Heldenlied, Gottingen 1961 (= Opera Slavica I)

Folk-tale, fiction and saga in the Homeric epics Berkeley, 1946

The Heroic Age, Cambridge 1912

The Growth of Iiterature, I-III,Iondon 1932-40 Južno-slavjanskie skazanija o Kralevįe Marke v ovjazi s proizvedenijami russkogo bylevogo \&posa Sravitel'nye nabljudenija $v$ oblasti gero16eskogo éposa južnych glav jan 1 maskogo naroda.In: RPV $27,(1892), 82-143 ; 272(1892), 307-313 ; 28$, $(1892), 1-21 ; 28$ (1892),291- $343 ; 291(1893), 108^{3}$ $147 ; 29,(1893), 4308-352 ; 304(1893), 252-293 ; 31 / 2$ $(1894) \cdot 91-298 ; 32,(1894): 4175-249: 33_{1-2}(1895)^{2}$ $25-204: 343(1895): 1-73,164-168$

Narodno pravo. Zbornik pravnih misli iz naeih narodnin lmotvorina, Beograd 1938

Das Volkslied im Abendland, Berm-Munchen 1966 (= Sammlung Dalp Bd.98)

Geschichte der byzantinischen und neugriechischen Litteratur, Leipzif 1909

Bulgarski folklor I,Sofia 1959 (zit.als BF)

Die Geschichte Ungarns, Munchen-Leipzig 1923 Etnologija naroda Jugoslavije I, Beograd 1960 Vertica i vila u nasem narodnom verovanju i predanju.- Vampir i druga bica u nasem narodnom verovanju 1 predanju.-In: SEZb IXVI, Beograd 1953

Priroda u verovanju 1 predanju nasega naroda I.In: SEZb IXXI, Beograd 1958

Narodna knjizemost, Beograd 1949

Postanak 1 razvoj narodne knjizevnosti, Beograd (3.Aufl.) 1956

Srpakohrvatska narodna epika, Sarajevo 1955

Le chamanisme et les techniques archalques de l'extase, Paris 1951

Traité d'histoire dee religions, Paris 1959 European Balladry, Oxford ${ }^{2} 1951$

Mathias Corvinus, König von Ungarn,Preiburg 1891 Die Konigawahl in Ungarn, Wien 1920

The Golden Bough. A Study in Magic and Religion, I-XII, London (3.Aufl.) 1911-15

Der geschichtliche Heilige Georg, Munchen 1899

Brautwerbung. I, Leipzig 1947 ( = Berichte uber 
Gasparini, E.:

Gavrilovic,A.8

Geissler,P.:

Gesemann, G.:

Grafenauer,I.8

Grégoire,H.8

Grgec,P.:

Grimm, J \&

Hartland, E. 8

Harva, U. 8

Heusler,A.8

Hilferding,A.8 (Gil'ferding)

Horálek, K.8

Iro-Volkskunde:

Ivanov, J :

Ivic,A.:

Jagic, V. 8

Jako bson, R. :

dere.z

Jirecek,K.:

ders.:

ders . :

Jordanov, V.:

Jung, C.G.und $K$. Kerényi: die Verhandlungen der Sachaischen Akademie der Wissenschaften,phil.-hist.KI.,Bd.96,H.2)

Il matriarcato slavo, Mailand 1949

Istorija srpske 1 hrvatske knjizevnosti usmenoga postanka, Beograd 1912

Die Brautwerbung in der Weltilteratur, Halie 1955

Studien zur suldslavischen Volksepik, Reichenberg 1926 (= Veroffentlichungen der Slavist. Arbeitsgemeinschaft an der deutschen Universitat in Prag, 1.Reihe Untersuchungen, H.3, S.105 ff.)

Slovenske pripovedke o Kralju Matjaž, Ijubljana 1951

Ho Digenis Akritas, New York 1942

Razvoj hrvatskog narodnog pjeaniltva.Knjizevnopoviestne razprave, Zagreb 1944

Deutsche Mythologie, Berlin (4.Ausg.) 1875-78

The Legend of Perseus,I-III,London $1894 \mathrm{ff}$.

Die religibsen Vorstellungen der altaischen volker, Heloinki 1938 (= PPC 125)

Lied und Epos in germanischer Sagendichtung, Dortmund 1905

Sobranie sodinenij.- III: Bosnija,Gercegovina i Staraja Serbija, St.Petersburg 1873

Studie o slovangké IIdové poezil, Prag 1962

Europaische Lander. Beharrung und Wandel der europäischen Volkskultur in der Gegenwart (Hrsg. T.Gebhard und J.Hanika), wunchen 1963

Bulgarakite narodni pesni, Sofia 1959 (zit.BNP)

Istorija Srba u Vojvodini, Novi Sad 1929

Historija lonjizevnosti naroda hrvatakoga $i$ srpskoga (1867), Zagreb 1953 (= Djela IV)

Slavic Mythology, New York 1950 ( = in P\&W)

Slavic Epic Studios, Don Haag-Paria 1966 (- Bd. IV der Selected Writings)

Geschichte der Bulgaren, Prag 1876 (zit.GdB)

Geschichte der Serben II (bis 1537), Gotha 1918 (zit.GdS)

Iatorija Srba. Prva knjiga do 1537 godine (politiCka istorija), ubers. von J.Radonic, Beograd 1952 (zit.Jir.-Rad.)

Krali-Marko v bǔlgarakata narodna epika, Sofia 1901 ( $=$ SbBKD I)

Binfuhrung in das Wesen der Mythologie,Zurich 1951 
KaradziC,Vuk St.: Dodatak k sanktpeterburgakim sramiteljnim rjecnicima aviju jezika i narjeðija o osobitim ogledima bugargkog jezika, Wien 1822

ders.:

o srpskoj narodnoj poeziji, Beograd 1964

Ker,W.P.:

Epic and Romance. Essays on Medieval Literature, London 1897

Keremidziev,G.:

Narodnijat pevec djado Vico Bondev,Sofia 1954

Kirdan, B.P.:

Ukrainskie narodnye dumy (XV - nacalo XVII v.), Moskau 1962

Kirfel,W.:

KBhler,R.:

Koliqi,E.:

Die dreiköpfige Gottheit, Bonn 1948

Kleinere Schriften zur MHrchenforschung, IIII, Weimar 1898 (hrigg.von J.Bolte)

Komoroviký, I .:

Poesia popolare albanese, Florenz 1957

Král' Matej Korvín $v$ l'udovej prozaickej slovesnosti, Bratislava 1957

Kosven, Q:

$\checkmark$ Kraus8,F.:

Kravcov,N : :

Matriarchat. Istorija problemy, Moskau 1948

Slavische Volksforschungen, Leipzig 1908

Serbskij épos, Moskau-Leningrad 1933

$\mathrm{Kris8,R}$.und $\mathrm{H}$.

Krisg-Heinrich:Volksglaube im Bereich des Islam,I-II, Wiesbaden 1960 und 1962

Krumbacher,K.: Geschichte der byzantinischen Litteratur, Munchen 1897

ders.:

Der hl. Georg in der griechischen Uberlieferung Munchen 1911 (= Abhandlungen der Kgl.Bayer. Akademie der Wissenschaften,phil.-hiot.Kl.25 $)$

Kuz'mina,V.D.: Dergenievo Dejanie, Moskau 1962

Kyriakides,St.: Elliniki laographia I, Athen 1922

ders.:

Lambertz,M.:

Latković, V.:

Lawson, J . :

Leger,L.8

Leyen,F.v.d.:

Lichačev,D.S.:

Loboda, A.M.:

Loorits, 0.8

Neugriechische Volkskunde. Volksdichtung,Volksglaube und Volkskunst, Thessalonike 1936

Die Volksepik der Albaner, Halle 1958

Narodna knjizevnost, Beograd 1957

Modern Greek Folklore and Ancient Greek Religion. A Study in Survivals, Cambridge 1910

La mythologie slave, Paris 1901

Die Welt der Marchen,I-II, Dlisseldorf 1953

Slovo o polku Igoreve. Istoriko-literaturnyj ocerk, Moskau-Leningrad 1955

Russkie byliny o svatovstre, Kiev 1904

Der hl.Georg in der russischen Volksüberlieferung Estlands, Berlin 1955 (a Slavist. Veröpe. des 0steuropa-Instituts an der Freien Universität Berlin, Bd 7 ) 
Lord, A. B.:

Máchal, J : :

Mansikka,J.:

Maretic,T.:

Marinov, D.:

Mategic,J,:

Matic,S.:

Maticetov, M.:
The Singer of Tales, Cambridge,Mass. 1960

0 bohatýrském epose slovanském, Prag 1894

Die Religion der Ostslaven. I.Quellen, Helsinki 1922 (= PFC 43)

Naša narodna epika, Zagreb 1909 (zit. NNE)

Narodna vjara i religiozni narodni obicai ( $\mathrm{Kn}$. VII von Ziva st.).- In: SbNU XXVIII (1914)

Die Erlanger serbokroatische Liederhandschrift. Sprachliche Untersuchung, Minchen 1959

Nas narodni ep i nas stih, Novi Sad 1964

Kralj Matjaz $v$ luXi novega slovenskega gradiva in novih razinskovanj.- In: Razprave SAZU IV, Ijubljana 1958

MavrogordataJ.: Digenis Akritas, ed. with an introd.,transl. and commentary by J.Mavrogordato, oxford 1956

Meletinskij,E.:Geroj volłebnoj skazki. Proischozdenie obraza, Moskau 1958

ders.: Proischozdenie geroiceskogo éposa. Rannie formy i archaiceskie pamjatniki, Moskau 1963

Meriggi,B.: Le origine delle byline, Rom 1963

$V$ Miklosich,F.:

Beiträge zur slavischen Volkspoesie I. Die Volksepik der Kroaten, Wien 1870 (= Denkschriften der Kaiserl. Akad. der Wiss.,phil.-hist.Kl.,Bd.19)

Milicevic,M.: Knezevina Srbija, Beograd 1876 ders.:

Minkov, Cv : : Kraljevina Srbija. Novi krajevi, Beograd 1884 Misirkov, K.: Bülgaraka narodna poezija, Sofia 1935 Južnoslavjanskie épiceskie skazanija o zenit'be korolja Volkasina v svjazi a voprosom o pricinach populjarnosti korolja Marka sredi juźnych slavjan, Odessa 1909

Moszyriki,K.: Kultura ludowa Slowian, Krakau 1934

Murko,M.: Tragom srpako-hrvatske narodne epike, I-II, Zagreb 1951

ders.: Geschichte der literen süslavischen Literaturen, Ieipzig 1908

Mythology

The Mythology of All Races,I-XIII,New York 1964 (C.J.A. MacCulloch, ed.)

Nazecic, S.:

Iz nałe narodne epike. I.Hajducke borbe oko Dubrovnika i nał̧a narodna pjesma, Sarajevo 1959

Nodilo,N.:

Religija Srba i Hrvata na glamoj osnovi pjesama, prica i govora narodnoga.-In: Rad 77 (1885), 43-126; 79 (1886), 185-246

Noli, F.S.:

George Castrioti Scanderbeg, New York 1947

Novakovic, S.:
Posledni Brankovici u istoriji $i$ u narodnom pevanju (1456-1502).-In: IMS 146-148,Novi Sad 1886 
Otto,R.:

Palavestra,V.:

Penev, B.:

Petrovskij,N : : Piprek

PlOss,E.:

Polenakovic,H.:

Pollok,K.-H.:

Popinceanu, J.:

Popovic,D.:

ders.:

Popovic,P.:

Prodanovic,M.:

Propp,V.Ja.:

Putilov,B.N.:

Pypin,A.N.:

Racki,p.:

Radonic, J . :

ders.:

Raglan,F.:

Ralston, W.R.:

Ranke, K.:
Das Heilige, Breslau 1917

Narodna predanja o starom stanovnistru u dinarskim krajevima, Sarajevo 1966 (= Posebni otisak iz GIZM BH, Etnologija XX/XXI)

Istorija na novata bŭlgarska literatura,I-IV, Sofia 1930-36

O soXineni jach Petra Hektorovila,Kazan' 1901

Slavische Brautwerbungs- und Hochzeitsgebräuche, Stuttgart 1914

Siegfried - Sigurd, der Drachenkämpfer. Untersuchungen zur germanisch-deutschen Heldensage, zugleich ein Beitrag zur Entwicklungsgeschichte des alteuropäischen Erzăhlgutes, Kơln-Graz 1966 (= Beihefte der Bonner Jahrbicher Bd.17)

0 makedonskoj narodnoj književnosti.-In: Makedonska knjizevnost. Izdanje Srpske književne zadruge, Kolo LIV, $k \mathbf{j} \cdot 368$

Studien zur Poetik und Komposition des balkanischen lyrischen Volksliedes. I.Liebeslied, Gottingen 1964 (= Opera Slavica 5)

Religion, Glaube und Aberglaube in der mimanischen Sprache, Numberg 1964 (= Erlanger Beiträge zur Sprach- und Kunstwissenschaft 19)

Vojvodina u tursko doba, Novi Sad 1939 (= Vojvodina I, izdanje Istoriskog drustva u Novom Sadu, uredn.D.Popovic, S.144-300)

Srbi u Vojvodini,I-III, Novi Sad 1957

Pregled srpske knjižvnosti, Beograd ${ }^{8} 1927$

Naša narodna književnost, Beograd 1932 (zit.NNK) Russkij geroiceskij épos,Leningrad 1955 (zit.RGE) Slavjanskaja istoriceskaja ballada, Moskau 1965

Istorija slavjanskich literatur, I-II, St.Petersburg (2.Aufl.) 1879-81

Boj na Kosova. Uzroci i posljedice, Zagreb 1889 (= Rad 97)

Histoire des Serbes de Hongrie, Paris 1919

Srbija i Ugarska u srednjem veku, Novi Sad 1939 (= Vojvodina I, 128-143)

The Hero. A Study in Tradition, Myth and Drama, London 1936

The Songs of the Russian People as Illustrative of Slavonic Mythology and Russian Social Life. London 1872

Die zwei Bruder. Eine Studie zur vergleichenden Marchenforschung, Helsinki 1934 (= PPC 114) 
Ranke-Graves.R.v.: Griechische Mythologie. Quellen und Deutung, I-II, Reinbek b. Hamburg 1963/64

Romanska,Cv. : Slavjangki folklor.ocerki 1 obrazci, Sofia 196 dies.: Bülgargkata narodna pesen, Sofia 1965

Rystenko,A.V.s

Salamon, F.:

Legenda o ev.Georgij i drakone vizantijakoj 1 slavjano-russkoj literaturach,Odessa 1909

Ungarn im Zeitalter der Turkenherrachaft,Leip2181887

Sathas, C. und

E.Legrand:

Sbornik

Miletid 1912

Sbornik

Miletic 1933

Schell,0.8

Schmaus, A.:

Les exploits de Digénis Akritas, Paris 1875 Sbornik v Eest na prof. I. Miletic po elucaj na 25-godi snata mu knizovna dejnost (18861911) ot uxenicite mu, Sofia 1912

Sbornik $v$ ceet na prof. I. Miletic za bedemgodizninata ot rozdenieto mu, Sofia 1933

Das Volkslied, Leipzig 1908 (= Handblucher zur Volkskunde III)

Studije o krajinekoj epici, Zagreb 1953 ( = Rad 297)

ders.:

Schmidt,B.:

Suldoeteuropa, Munchen 1963 (= Sonderabdruck aus der Iro-Volkskunde)

Das Volksleben der Neugriechen und das hellenieche Alterthum I, Leipzig 1871

$\operatorname{Schmidt,I.8}$

Die Volkserzahlung. Marchen, Sage, Legende, Schwank, Berlin 1963

Schmidt,W.:

Schneeweie, E.:

Das Mutterrecht, Wien 1955 (= Studia Institut1 Anthropos $X$ )

Skend1,St.:

Serbokroatische Volkskunde. I.Volksglaube und Volksbrauch, Berlin 1961 (erschienen im GrundriB der Slavischen Philologie und Kulturgesch.)

Albanian and South Slavic Oral Epic Poetry, Philadelphia 1954 (= Memoirs of the American Folklore Society Bd.44)

Slave jkov,P.:

Bulgarska literatura (Red.B.Penev) II, Sofia 1923

Slovo

Soerensen, A.:

Slovo o polku Igoreve. Sbornik iesledovanij $i$ statej. Moskau-Leningrad 1950

Beitrag zur Geschichte der Entwickelung der serbischen Heldendichtung.-In: ASIPh XIV (1892),556-587; XV (1893), 1-36,204-245; XVI (1894),66-118; XVII (1895), 198-253; XIX(1897), 89-131; XX (1898),78-114 (zit.ASIPh XIV usw.)

$N$ ders.:

Entstehung der kurzzeiligen serbokroatiechen Liederdichtung im Kustenlande, Leipzig 1895

Sozonovid, I.:

Pesni o devuske-voine $i$ byliny o Starre Godinovide, Warschau 1896 
Sozonovid,I.:

Speranskij,M.:

$\checkmark$ stadtmuller,G.: Stanojević,St.: dere.:

ders.:

Starke,K.:

Stricker,W.:

$\checkmark$ Subotic,D.:

Syrkin, A.Ja.:

Sir̆manov,I.:

Teodorov,E.:

Tom18,J.:

Trautmann, R.:

Vaj8,I.:

Vakareloki,Ch.:

Veselovskij,A.:

ders.:

Vrabie,Gh.:

Vries,Jan des

dere.8

ders.:

Wachomuth, C.8
K voprosu o zapadnom vlijanil na slavjanskuju

i russkuju poéziju, Warschau 1898

Devgenievo dejanie. K istoril ego teksta $v$ starinnoj russkoj pis'mennoeti. Issledovanie 1 teksty, Petrograd 1922 ( = Sbornik Otdelenija russkogo jazyka 1 slovesnosti Akad. Nauk XCIX 7 )

Geschichte Sudosteuropas, Munchen 1950

Istorija erpokoga naroda, Beograd 1910

Le rôle des Serbes de Hongrie dans la vie nationale du peuple serb, Paris 1919

Iz sppoke proslost1. Istoriske Elanci, Beograd 1923

Die primitive Pamilie in inrer Entstehung und Entwicklung, Leipzig 1882

Die Amazonen in Sage und Geschichte, Berlin 1868 Yugoslav Popular Ballads, Cambridge 1932

Poéma o Digenlse Akrite, Moskau 1964

Pesenta za murtvija brat $v$ poezijata na balkanskite narodi.-In: SbNU XIII (1896),474 ff. und SbNU XV (1898), 449-600,1-186

Sü tnost 1 proizchod na bulgarsk1 te junazki 1 chajduăki pesn 1 vŭv vrŭzka s otraženite v tjach oŭstezanija, Sofia 1963

Istorija u narodnim epskim pesmama o Marku Kraljevicu. I.Pesme o Musi Kesedziji i Memu Brdaninu, Beograd 1909

Die Volksdichtung der GroBrussen. I.Die Byline, Heidelberg 1935

Starohrvateke duhovne pjesme, Zagreb 1905 (= Starine $X X X I$ )

Etnografia Bulgari1 (Etnografija na Bulgarija), Wroclaw 1965 (= Prace Etnologiczne VII)

Razyskanija $v$ oblasti russkich duchovnych st1chov II: Sv.Georgij $v$ legende, pesne 1 obrjade, Peterburg 1880 ( = Sbornik Otdelenija russkogo jazyka 1 elovesnoeti Imp.Akad. Nauk $\mathrm{XXI}_{2}$ )

Istoriceekaja poetika, Moskau 1940

Balada populara română, Bukarest 1966

Das Marchen, besonders in seinem Verhaltnis zu Heldensage und Mythos, Helsinki 1954 (= PPC 150)

Heldenlied und Heldensage, Bern-Munchen 1961 (= Sammlung Dalp Bd.78)

Porschungsgeschichte der Mythologie, Munchen 1961 Das alte Griechenland im neuen. Mit einem Anhang Uber Sitten und Aberglauben der Neugriechen bel Geburt, Hochzeit und Tod, Bonn 1864 
Wais,K.8

Werner,W.:

Zirmunskij,v.: ders.:
Frluhe Epik Westeuropas, Tubingen 1953

Die mannlichen Personennamen in den bulgarischen Volksliedern. Ein Beitrag zur bulgarischen Anthroponymie, Berlin 1965 (=Veröff.der Abt.f. slavische Sprachen und Literaturen des 0steuropaInstituts ar der Freien Univ.Berlin, Bd.33)

Vergleichende Epenforschung I, Berlin 1961

Narodnyj geroileskij épos. Sramitel'no-istoriCeskie oderki, Moskau-Leningrad 1962

\section{E. AUFSÄTZE}

Alpatov, M.:

Angelov, B.:

ders.:

Inikin, V.P.:

Lrnaudov, M.:

ders.:

ders : :

ders.:

Banałevic, N.:

Banovic, St.:

ders.:

ders.:

ders.:

ders : :

Beck,H.-G.:
Obraz Georgija-voina v iskusgtve Vizantii i drevnej Rusi.-In: TODL XII,292-311

Samovilite $v$ bŭlgargkata narodna poezija.-In: ISSP III (1911), 1-66

Bülgarskata narodna balada. Baladi z samovilisamodivi.-In: INEM XII (1936), 1-31

Vozniknovenie zanrov $v$ fol'klore (k opredeleniju ponjatija żanra i ego priznakov).-In: RP X,28 ff. Folklor ot Elensko. Nabljudenija i materiali.-In: SbNU XXVII (1913),; ff.

Kukeri i rusalii. Studii vurrchu bŭlgarskite obredi i legendi III.-In: SbNU XXXIV (1920), 1 ff.

Vgradena nevesta. Studii vürchu bŭlgarskite ob-

Narodnata pesen v Sofijsko. Belezki kŭm sbornika na d-r S. Vatev.-In: SbNU XLIII (1942),569-91

Andrija Kacic Miosić son orientation idéologique et politique.-In: KESI XL (1964), 16-25

Planine Kunara i Papuča u nasim narodnim pjesmama.-In: Rad 227 (1923),332-43

o nekim historickim licima nasih narodnih pjesama.-In: 7.N\% XXV (1924).57-104

Tko je bio Senjanin Ivan, glavni uskocki junak?In: Obzor IXXI (1930),232,2-3

"Glasovitiji" junaci, o kojima su se za Kaciceva Zivota u Dalmaciji pjevale narodne pjesme.- In: ZNZO XXXVIII (1954),75-132

Oko Kraljevića Marka i godine njegova rodenja.-In: ZNZO XIII (1964), 15-47

Formprobleme des Akritas-Epos.-In: Beiträge zur Südosteuropa-Forschung (anläBlich des I.Internat. Balkanologenkongresses in Sofia 26.8.-1.9.1966), Red.A.Schmaus, Munchen 1966, 137-46 redi i legendi IV.-In: SbNU XXXIV (1920),245 ff. 
$\operatorname{Be} 1 t, H \cdot \nabla \cdot 8$

Berneker,E.8

Beth,M.:

Bödey, J • \&

Bogatyrev, P.und

R.Jakobson:

Bogatyrev,P.:

ders.8

Boldur, A.8

Bołkovié-Stulli, M. 8

dies.8

$\checkmark$ Braun, M.:

ders. und

Th. Pringe:

ders.8

$\checkmark \operatorname{ders.8}$

$\sqrt{\operatorname{ders} \cdot 8}$

$\checkmark$ ders.:
Ein Beitrag zum Motiv der "Seele auBerhalb".In: Internat.Kongre $B$ der Volkserzahlungsforscher in Kiel und Kopenhagen (19.8.-29.8.59). Vorträge und Referate, Berlin 1961

Bericht uber die Erlanger Liederhandschrift (= Sitzungsberichte der Bayer.Akad.d.Wissenschaften, phil.-hist.Klasse vom 7.2.1914)

Mutterrecht.-Ins HDA VI (1935),Sp.706-13

Les échos des guerres turco-hongroises dans 18 poésie populaire bulgare.-In: RHC (1947).56-68

Die Polklore als eine besondere Porm des Schaffens.-In: Donum Natalicium Schrijnen, NijmegenUtrecht 1929

Nekotorye ocerednye voprosy sramitel'nogo 1zuCent ja éposa slavjan.-In: Osnowye problemy éposa vostornych slavjan. Moskau 1958

Nekotorye zadaci eravnitel'nogo izuXenija éposa slavjanskich narodov.-Ins Is8ledovanija po slavjanskomu literaturovedeniju 1 fol'kloristike. Doklady sovetskich uXenych na IV Mezdunarodnom 8-ezde slavistov, Moskau 1960, $211 \mathrm{ff}$.

Trojan "Slova o polku Igoreve".-In: TODL XV (1958' $7-35$

Sizel narodnih bajki u hrvatskosrpskim epskim pjeamama.-In: Nar.umj.I (1962), 15-36

Hrvetskosrpska narodna knjizevnost u gvjetlu nekih komparativnih proucavanja.-In: Nar.umj.II (1963).39-64

Zur Prage des Heldenliedes bel den Serbokroaten.-In: Paul Braunes Beiträge zur Geschichte der deutschen Sprache und Iiteratur 59 (1935). 261-88

Heldenlied.-In: Paul Brames Belträge 59 (1935). 289-313

Zum Themenbestand des serbokroatischen Heldenliedes:-In: Paul Braunes Beiträge 64(1940),83 $\mathrm{fe.}$

Beobachtungen zum heutigen Stand der epischen Volksdichtung in Jugoslavien.-In: Die Nachbarn II (1954), $36 \mathrm{ff}$.

Das Volkslied als philologisches Problem.-In: Welt der Slaven $\operatorname{III}_{1}$ (1958)

Zum Problem der serbokroatischen Volksballade.In: Slavist.Studien zum V.Internat.Slaviotenkongre $B$ in Sol1a 1963, Göttingen 1963,151-174 (= Opera Slavica IV) 
Budimir, M.:

ders.:

ders.:

Bulat,P.K.8

Burin, I :

Burkhart, $D$.

dies.:

Bynum, D. :

Chal anskij,M.:

ders.:

ders.:

ders.:

Cretkov, D.:

Cvjetko,S.:

Çabej,E.:

ders.:

ders.:

ders. 8

Cajkanovid,V.:

ders.:

ders.:
Bugarski, bugariti, bugarstica.-In: PPNP II $1-2$ (1935), $18 \mathrm{ff}$.

Digenis und Marko Kraljevic.-In: Izvestija na bưlgargkija archeologiceski Institut X (1936), 16-18 (= Actes du quatrieme Congres internationale des Etudes byzantines)

Der Agon in der klassischen und in der serbokroatischen Volksdichtung.-In: PPNP III(1936), 227-238

Prilog za izucavanje narodne poezije u južnoj Srbiji.-In: GISkND I $I_{1}(1925), 93-112$

Narodnijat junaski epos.-In: BNTv I,Sofia 1961

Vampirglaube und Vampirsage auf dem Balkan.-Ins Beiträge zur Sudosteuropa-Forschung (Red.A. Schmaus), Munchen 1966,211-52

Zum Drachenkampfthema. Motivparallelen in der sudslavischen und griechlschen Volksepik.-In: Z Balk V (1967)

Kult dvaju junaka u kultumoj istoriji Balkana.-In: AFP IV (1964),65-73

0 serbskich narodnych pesnjach kosovskogo cik1a, Warschau 1883 ( = Sonderdruck aus RFV 1881)

Zametki po slavjanskoj narodnoj poézii.II.Kogo nuzno razumet" pod imenem "Kernych arapov" $v$ serbskoj narodnoj poézii.-In: RPV VII,113 ff.

o bugarsticach.-In: RFV VII, 121-134

K voprosu o proizchozdenii atichotvornogo razmera i nazvanija "bugarstic".-In: Sbornik atatej posvjazcennych V.I.Lamanskomu,St.Petersburg 1907,I, 63-71

Beležki vŭrchu bŭlgargkija junaški epos.-In: Per.spie.61 (1900-1901)

Heneza motyva krylatoho zmija $v$ bolhars'kych narodnich pianjach.-In: Etnohraficnyj visnyk IX, Kiev 1930,3-30

Sitten und Gebrauche der Albaner.-In: RIÉB III $(1934-35), 556 \mathrm{ff}$.

Zivot 1 obi Xaji Arbanasa.-In: Knjiga o Balkanu I, Beograd 1936, 303-29

Albanische Volkskunde.-In: SOF XXV (1966),333-87

Die albanische Volksdichtung.-In: Leipziger

viertel jahresschrift fur Sudoeteurops III $_{3}$ (1939), 194-213

Studije iz religije i folklora.-In: SEZb XXXI (1924), drugo odelenje, Zivot i obicai narodni $\mathrm{knj} \cdot 13$

Donji svet u jami.-In: Studije..,135-138

Magikni smej.-In: Studije..,25-42 
Cajkanovic, v.: ders.:

ders.:

Ćurić,H.:

Davle tov, K. und V.Gacak:

Delorko,0.:

Deržavin,N.S.:

Dieterich,K.:

Dinekov,P.:

Đordevic,T.:

Dzurinskij, . :

Entwistle,W.:

Esih, I.:

Filipovic, M.: ders.:

Findeisen, H.:

$\checkmark$ Pochi,A.:

ders.:

Praknoi, V.:

Frings, T.:
Sekula se u zmiju pretvorio.-In:Studije..

Erlangenski rukopis starih srpskohrvatskih narodnih pesama, izdao G.Gezeman.-In: SKGI $18_{2}$ (1926), 147-8

0 srpskom vrhovnom bogu.-In: Srpska Kraljevska Akademija.Posebna izdanja CXXXII, Pilosofski i Piloloski spisi 34, Beograd 1941

Nepoznata legenda o hercegu Stjepanu.-In: Nar. stvar.VI (1963), 417-19

o proischoźdenil narodnogo geroiceskogo éposa.In: Russkaja literatura II (1962),76-86

0 nekim našim narodnim pjesmama a novelistickim osobinama.-In: Nar.umj.I (1962), 37-51

Kralevid Marko i Il' ja Muromec.-In: Spis.BAN 70 (1944),213-233

Die Volksdichtung der Balkanländer in ihren gemeinsamen Elementen.-In: Zeitschrift des Vereins für Volkskunde XII (1902),145 ff.,272 ff.,403 ff.

Probleme der bulgarischen Volksballade.-In: Aus der Geisteswelt der Slaven. Dankesgabe an Erwin Koschmieder Uberreicht vom Seminar fur Slav.Phil. der Univ.Munchen, Munchen 1967, 271-89

Leđan - Ljes.-In: Nas narodni Zivot VI, Beograd 1932,78-79 (Verfasser: T、Đordeví)

Bolgarskie pesni o Dojtine i Momcile.-In: Universitetskie izvestija $33_{4}$, Kiev 1893,1-29

Bride-snatching and the "Deeds of Digenis".-In: Oxford Slavonic Papers IV (1953),1-16

Bugarska pjesma o kralju Marku i "arvatskoj" djevojci.-In: Obzor LXX (1929), 329

Epska pesma u okolini Strumici.-In: PPNP (1934)

Volksglauben auf dem Balkan. Einige Betrachtungen.-In: SOF XIX (1960), 239-62

Sowjetwissenschaftliche Thesen uber das Schamanentum, Augsburg 1956 (= Abhandlungen und Aufsätze aus dem Institut fur Menschen- und Menschheitskunde $X X X)$

Paralleles folkloriques sud-est européens.-In: RÉSEE I (1963), 523 ff.

Das Doitschin- (Doicin-,Dojein-,Dojzin-) Lied in der ruldos teuropäischen Volksuberlieferung.-In: RESEE III (1965), H.1-2,229-68, H.3-4,465-511

Die Hohenzollem und Matthias Corvinus, Kön1g von Ungarn, Minchen 1916 (= Sonderdruck aus Ungarische Rundschau IV, 1915)

Europäische Heldendichtung.-In: Neophilologus XXIV (1938), 1-29 
Gasparin1,E.:

Geramb,V.V.:

Gesemann, G.:

ders.:

J dere.:

ders.8

Grafenauer,I.:

Horélek,K.8

dere.:

$J$ dere.:

Hraste, H:

Kyman, S . E. :

Ibrovac, $\mu .8$

Iliev,A.T.8

II'Inskij,G.:

Jagic, V . :

$V$ ders.8

$\checkmark$ ders.s

ders.:

Jakobeon, R. 8

Jakobson, R. und u.Szeftel:
Questioni di mitologia slava.-Ins Slov.Etn. XII (1960), $91 \mathrm{ff}$. und XIV (1961), $108 \mathrm{fl.}$

Zur Biologie des Volksliedes.-Ins Jahrbuch des boterreich. Volksliedwerkes II (1953)

Jedno knjizemo istorijeko otkrice. Erlangenski rukopis erpskih narodnih pesama.-In: SKGl Nova serija II 4 (1921),276-78

Nova istrazivanja o narodnom epu u Vardarskoj banovini.-Ins GISkND (1932), $11 \mathrm{fe}$.

Zur Erforschung der bulgarischen Volksepik.-In: Sbornik Miletic 1933,490-94

Clanci 1 rasprave o Banovicu strahinji.-In: PPNP II 2 (1935), 145-56

Sloveneke ljudske peemi o Kralju Matjazu.-In: Slov.Etn. III/IV (1950-51), 189-240

Zum Problem der sudelavischen Volksballade.-In: Welt der Slaven IX (1964),H.1,14 ff.

Ein Beitrag zur volkskundlichen Balkanologie.In: Pabula VII, (1964), 1-32

Kleine Beitrage zur belkanischen Marchenkunde.In: 2 Balk III (1965)

Uber die Heimat der Langzeilenepik auf Grund der 8prachlichen Analyse.-Ins Festschrift fiur E.Koschmleder, hrsgg.vom Sudost-Institut Munchen, Munchen 1958,57-67 (aus SOF XVII/1)

The ritual view of myth and the mythic.-In: Journal of Am. Polklore 68 (1955), 462-72

Les affinités de la poésie populaire serb et néogrecque.-In: God.BH I (1956), 389-455

Bulgarekite predanija $2 a$ ispolini, nareceni elini, zidove 1 latini.-In: SbNU III (1890), 179-205 und IV (1891),231-56

Juda. StraniCka iz slavjanskoj mifologil.-In: Sbornik Miletid 1933, 467-74

Grada za slovinsku narodnu poeziju.-In: Rad 37 (1876). 33-137

Dunar - Dunaj in der slavischen Volkspoesie.-In: ASIPh I (1876), 299-333

Die sudslavische Volksepik vor Jahrhunderten.In: ASIPh IV (1880), $192 \mathrm{fe}$.

Ein Textbeitrag zur Georgius-Legende.-Ins ASIPh IX (1886), 586-92

Studies in Comparative Slavic Metrics.-Ins Oxford Slavonic Papers III (1952), 21-66

The Veeslav Epos.-In: Russian Epie Studies. Memolrs of the Am.Polklore Soc.XIII(1948), 13-86 
Jakobson, R . und G.Ruzicić:

Jokl, N \&

Karanov,E.8

Keremidziev,G.:

Kilibarda,N \&8

KIrpi Cnikov,A.8

K18elinovic, $\boxplus .8$

KiBling, H.-J \&

Komorovikf, I \&

Kor8,P.8

Kost16,D.:

ders.8

ders.8

ders.8

ders.:

ders.8

ders.8

Kostic,M.8

Kostov,S.I.8
The Serbian Zmaj Ognjent Vuk and the Russian Veeslav Epos.-Ins Annualre de l'Institut de Philologie et d'Hlatoire Orientales et Slaves X (1950), Brilseel, S.343-55

Vulgarlateinisches im Albanischen.-Ins Ze1tschrift 1.Roman.Philol.XII (1921),228-33

Zmejat (azder) 1 eml jata (zímja) $\nabla$ bügarakata narodna poesija.-Ins Per.Spie.IX (1884). $129 \mathrm{IP}$.

Rodstrenite otnorenifa $\nabla$ naseto narodno trorEestvo.-In: ISSP VII (1931)

Teren $2 a$ straranje epskog Zmaj-ogajenog Vuka.In: Stvar. III (1964), 338-50

Sojatoj Georglf 1 Bgorlf Chrabryj.-Ins ZMNP $(1878)_{12}, 268-327$; $(1879)_{1}, 36-64 ;(1879)_{2} \cdot 175-278$ Narodne umotvorine u Juznoj Srbij1.-In: Spomenica dradesetipetgodirnjlce oelobouenja Juzine Srb1 je 1912-37, Skopje 1937

Turkenfurcht und Turkenhof fnung im 15./16.Jh. Zur Geschichte eines "Komplexes".-Ins SOP XXIII (1964), 1-18

Poznámky k l'udovej tradicil o kral'ovi Matejov1.-In: Slovensky národop18 II (1954),176 ff.

Vredenie v nauku o slavjanekom sticholozen11.In: Stat' 1 po slavjanoveden 1 Ju, Red.V.Iamanskij. 2.Ifg., St.Petersburg 1906, 300-78

Zbornik za 18torlju, jesik 1 knjizemost 8rpskog naroda.Prvo odeljenje knj.XII. Erlangenski Rukopie starih srpsko-hrvatskih narodnih pesama. Izdao D-r G.Gezeman, prof.Un1v.u Pra6u, 1925.-Ins JP VI (1926/27), 278-95

0ataja Rajakovic Ugardic. Prilog 1atorijl nageg narodnog epskog pesniftva.-Ins SKGI (1931). $611-19$

Starost narodnog epskog pjesnigtva naseg.-Ins JP XII (1933), 1-72

Jo8 Jedna bugargtica 1218 veka u Erlangenskom zborniku.- Ins JP XIII (1933/34),165-9

Latinski (ledanski) kralj Mihailo.-Ins PPNP IV (1937), $21 \mathrm{ff}$.

Dva kosoveka cikla.-Ins PPNP VI, (1939),1-18 Otkud Zmaj-Ognjanom Vuku taj nadimak.-In : PYNP VI,$(1939)$. 95-98

Opis vojske Jovana Hun jadija prl polasku u boj na Kosovo.-In: GISkND (1925)

Izobrazenieto na ov. Georgi v bưlgarsk1ja naroden nak1t.-In: Sbornik Mllet1d 1912,187 If. 
Kosven,M.:

Kravcov,N.:

ders.:

ders.:

ders.:

Kretzen-

- bacher,L.:

Krstic,B.:

ders.:

ders.:

Kuhn,H.:

Kuzelja,z.:

Kuz'mina,V.:

Kyriakidee,St.:

ders.:

Lalevic,M.:

ders.:

ders.:

Latkovic, V.:

Lord, A.B.:

$\checkmark$ ders.:
Amazonki. Istorija legendy.-In: Sov.Étn. (1947) $\mathrm{Nr} .2,33-59$ und $\mathrm{Nr} .3,3-32$

Južnoslovenski, srpskohrvatski i srpski epos.In: Nar.stvar.(1962), 179-85

Serbskij épos 1 istorija.-In: Sov.Ėtn. (1948), $\mathrm{Nr} \cdot 3,90-107$

Idejnoe soderžanie serbkogo éposa.-In: TIE XIII, 303-360

Istoriko-sramitel'noe izuXenie éposa slavjanskich narodov.-In: Osnovnye problemy éposa vostoxnych slavjan, Moskau 1958)

Die Volksdichtung im deutsch-slawischen Grenzraum Sủdosteuropas.-In: SOE Jb.VI (1962), 18-33 Zenidba Xoveka vilom.-In: PPNP IV (1937),99-118 Metamorfoze $i$ okultni predmeti u bugarłticama.In: PPNP V (1938), 86-96

Prorocanstva o Kosovu.-In: PPNP VI (1939),47-53 Zur Typologie mündlicher Sprachdenkmäler (=Sitzungsberichte der Bayer. Akad.d.Wiss.,phil.hist.Klasse Jg.1960, H.5, Minchen 1960)

Uhors'kyj korol' Matvij Korvin v slavjans'kij ustnij slovesnosty. Rozbir motyviv, zvjazanych 2 joho imenem.-In: Zapysky Naukovoho Tovarystva im. SevČenka Bd.67,1-55; Bd.68,55-82; Bd.69,3169; Bd.70,86-113, Lemberg 1905-1906

Novyj spisok "Devgenieva de janija".-In: TODL IX, 339-60

Forschungsbericht zum Akritas-Epos.-In: Berichte zum XI.Internat.Byzantin.KongreB, Munchen 1958, $\mathrm{II}_{2}$

Zur neugriechischen Ballade.-In: SOF XIX (1960), 326-43 Prilog proudavanju bugarstica.-In: PPNP II $1-2$

odnos i veze bugarstica i tuzbalica.-In: PPNP III (1936), 50-73 Bugarstice i umetnicka pesma.-In: PPNP $\mathrm{IV}_{2}$
(1937), 174-99

Duß̌an J.Popovic, Ko je autor, gde je i kada je nas tao Erlangenski rukopis? (Godisn jak muzeja grada Beograda,knj.1,1954, str.105-110).-In: PXJIF XXI $1-2$ (1955), $158 \mathrm{f1}$.

Notes on Digenis Akritas and Serbocroatian Epic.In: Harvard Slavic Studies II (1953),375 $\mathrm{ff}$.

Sommon Common Themes in Balkan Slavic Epic.Dragons ( = hektographiertes maschinengeschriebenes 
Lladeke, H.:

Mackensen,L.:

Maretic,T.:

ders.:

Marinkovic, B.:

Marjanovic, D.: $\checkmark$ Matl,J.:

ders.:

$\checkmark$ ders.:

Medenica,R.:

$\checkmark$ ders.:

$\checkmark$ ders.:

Meier,John:

Meletinskij,E.:

Meriggi,B.:

Miklosich, P.:

Milas,M.:

Mileetić,I.:

Miletid,L.:

Mirković,N.:

Nedeljkovic,D.: Oblici maleševske epike.-InsPPNP VI(1939), 18-34 Griechische Volksdichtung.-In: Archiv für Literatur und Volksdichtung I, 196-250

Brautwerbungsmärchen.-In: HDM I, 316-20

Kosovaki junaci 1 dogadaji u narodnoj epici.In: Rad 97 (1889)

Zivot 1 književni rad F.Mikloళica.-In: Rad 112 (1892), 41-153

Wer war Ludwig Franz Hack von Ancherau?- In: SOF XVII, 8-94

Problem 7. Alije.-In: PPNP (1936), 1-2,90-101

Die Entwicklungsbedingungen der epischen Volksdichtung bei den Slaven.-In: Jahrb.f.Kultur und Gesch.d.Slaven, N.F.V (Breslau 1929),57-76

Zur Bezeichnung und Wertung fremder volker bel den Slaven.-In: Festschrift fur Max Vasmer zum 70.Geb., Berlin 1956,293-306 (= Veroff.d.Abt. f.slav.Sprachen und Literaturen des 0steuropaInstituts an der Freien Universität Berlin IX)

Österreichische Herrscher und Heerfuhrer in der Volksmeinung und im Volkslied der sudslawen.In: Österreich.0sthefte $\mathrm{II}_{4}$ (Wien 1960), 258-72 Muz na svadbi svoje žene.-In: PPNP (1934),33 19. Das alteste Zehnsilberlied uber Banovic Strahinja.-In:Welt d.Slaven IX(1964),H.1,59-83

Problematik und Methodik der Variantenforschung. "Banovic Strahinja" im Kreise seiner Varianten.In: Z Balk III 1-2 (1965)

Volksliedwanderung und Volksliedforschung.-In: Archiv fur Literatur und Volksdichtung I (1949)

0 genezise 1 putjach differenciacii épireskich Zanrov.-In: RP V (1960), 81-101

Il Matrimonio di re Vulkašin.-In: Z Balk IV (1966), 89-99

Die Darstellung im slavischen Volksepos.-In: Denkschriften d.Kaiserl.Akad.d.Wiss.,phil.-hist. KI.XXXVIII, Wien 1890

0 narodnim pjesmama u "Ribanju" Petra Hektorovića, Nada, Sarajevo 1902

Sitniji prilozi.-In: ZNŽo 9 (1904), 1-22

Kŭm vŭprosa za tyj narecenite "bugarłtice".-

In: Bulgarski pregled I (1930), 321-35

Mesto rodenja Đerzeleza Alije.-In: PPNP (1936), H. 1-2, 117-18

Exemplar des beim I.Internat.Balkanologenkongre $B$ in Sofia $[26.8 .-1.9 .66]$ gehaltenen Referats) 
Nedeljkovic,D.: Rasmatranja na izvorima stare makedonske epike, I-III.-In: Zbornik radova SAN IV (1950)

Novakovic,st.8

ders.8

$\checkmark \operatorname{ders.8}$

$\checkmark \operatorname{ders} \cdot 8$

ders.:

ders.:

Olesnicki,A.:

ders.:

Pavlovic,I.:

Petravie,A.:

Plastis, E.8

Polenakovic, H.:

Popov, G.:

Poporic, D.:

Prodanovic,J.:

Prohaska, D.8

Propp,V.Ja.8
Apokrifi jednoga srpskog érilovekog zbornika XIV vieka.-In: Starine VIII (1876),36-92

Narodna predanja o boju kosovskom.-lns Starine $X(1878), 176-200$

Die serbischen Volkslieder Uber die KosovoSchlacht (1389). Eine kritische Studie.-In: ASIPh III (1878-79), 413-62

Uber Legjan-grad (Iedjan-Stadt) der serbischen Volkspoesie.-In: ASIPh III (1879), 124-30

Ledan-grad 1 poljacl u srpskoj narodnoj poezij1.-In: IMS 120 (1879)

Legenda o 8v. Gjurgju u staroj arpsko - 8lovenskoj i u narodnoj usmenoj literaturi.-Ins Starine XII (1880), 129-63

Tko.je zapravo bio berzelez Alija?- In: ZNŽo $\operatorname{XXIX}_{1}(1933), 18-37$

Jo8 o liCnosti Derzelez Alije.-In: zNZO XXIX (1934), 20-55

Bolani Dojtin u rumunskoj narodnoj pesmi.-Ins PPNP IV (1937), 88-89

Juraj Barakovic o Burdu Brankovicu.-InsPKJIF IX (1929), 123-28

Die neugriechische Volksdichtung.-InsSOE Jb VI $(1962), 42-57$

Kaciceve pesme u Makedonij1.-In: ZNZO XXXVIII (1954), 261-74

Bülgarskite junaski pesni.-InsSbNU III und IV (1890, 1891)

Ko je autor, gde je 1 kada je nastao Erlangensk1 rukopis?- In: Godión jak muzeja grada BeoGrada I (1954), 105-110

Zbornik za letoriju, jezik 1 knjizemost orpskog naroda. I.odelj.knj.XII.Srpska Kralj.Akad. Dr.G.Gezeman: Erlangenski rukopis otarih erpskohrvatskih narodnih pesama.Sr.Karlove1 1925.In: Glasnik Istoriskog drubtva u Novom Sadu I (1929), 120-21

Erlangenski rukopis otarih srpsko-hrvatskih narodnih pesama, izdao Dr.G.Gezeman. Zbornik za istoriju, jezik 1 knjizevnost srpskog naroda. Prvo odelj.,knj.XII.Srpska Kralj.Akad.,Sr.Karlove1 1925.-In: ASIPh 41 (1927), 307-13

Osnovnye etapy razvitija maskogo geroiceskogo éposa.-In: Is8ledovanija po slavjanskomu literaturovedeniju 1 Pol'kloristike. Doklady, Moskau 1960, 284-311 
Putilov, B.8

ders.8

Redep,J •:

$\checkmark$ Reiter,N.8

V ders.8

Repp,P.8

$\checkmark$ Romanska,CV.8

V dies.8

Rusic, Br.und

A. Schmaus :

Rusic, Br . 8

Ruvarac, I .8

Rybakov, B.8

Scherzer, I . :

Schmeus, A. und

U. Vlehovid:

Schmaus, A.:

ders.:

dere.8

dere.8

ders.8

dere.8

tere.:
Iz 18toril vengersko-8lavjangkich fol'klornych otnozenij.-In: Buropa et Hungaria.Congres8us ethnographicus in Hungaria.16.-20. X.1963 Budapest, Budapest 1965, S.301 ff.

Istoriceskie ballady $\nabla$ bornikach Vuka Stel. Karadzica.-In: APP IV (1964), 403 ff.

Motiv o rodenju Sibinjanin Janka u nasoj ataroj 1 narodnoj lonjizemosti.-In \& Godirnjak Pil. Pakul teta u Norom Sadu VIII (1964/5),189220

Zur Erlanger serbokroatischen Liederhandschrift. -In: ZSIPh XXV (1956), 368-81

Einiges über den Schretber der Erlanger Handschrift.-Ins SOP XXIV (1965), 221-34

Ortoja Rajakoric, ein Spielmann und Sippengenosse Könis Markos.-Ins ZSIPh XXIII(1955),39-59

Die Haiduken in der bulgarischen Volksdichtung.In: SOE Jb VI (1962), 34-41

Bulgarische und mazedonische Heldenlieder und historische Volkslieder uber Persönlichkelten aus der ungarischen Geschichte.-Ins Buropa et Hungaria, Budapest 1965, 333-43

Guslar Vandel iz Ohrida.-In\&PPNP III(1936),119133

Prilepeki guslar Apostol (= PPNP, Posebna 1zdanja 2, Beograd 1940)

Dve etudenteke rasprave. Prilog k ispitivanju 8rpakih junatkih pesama, Novi Sad 1884

Drevnye elementy $\nabla$ maskom narodnom trorkestre.In: Sov.Etn. (1948), 9019 .

Bugarstice.-InsRad 182 (1910), 181-224

O epskoj pesmi u Sremu.-InsGIEN VII(1932),1-16

Neki oblici epskog pevanja u proslosti.-Ins PPNP I (1934), 15-25

Ima 11 bugarbtica u Erlangenskom rukopisu?-Ins PPNP III (1936), 211-21

Obeležavanje puta krvlju.-In: PPNP III,(1936), 255-7

Kosovo u narodnoj pesmi muslimana.-In: PPNP V (1938), 102-21

Prezime "Bugerin".-Ins PPNP VI (1939),269-70

Philopappos Maximo-Szene und Kaiserepisode im altrussischen Digenis.-In: Byz.Z.44(1951),495 ef.

Beiträge zur suldslavischen Epenforschung.-Ins

Serta Monacensia (Hr8g.H.-J.KLBling und $A$. Schmaus), Leiden 1952 
Schmaus, A.:

$$
\begin{aligned}
& \checkmark \text { ders.: } \\
& \checkmark \text { ders.: } \\
& \checkmark \text { ders.: }
\end{aligned}
$$

ders.:

$\sqrt{d e r s .:}$

$v \operatorname{ders.:}$

ders.:

$V$ ders.:

\section{$\checkmark \operatorname{ders.:}$}

ders.:

$V$ ders.:

ders.:

ders.:

ders.:

$\checkmark$ ders . :

V ders.:
Episierungsprozesse im Bereich der slavischen Volksdichtung.-In: Veröf.d.0steuropa-Instituts Munchen IV (1953), Munchener Beiträge zur Slavenkunde. Pestgabe fur Paul Diels, 294-320

Ein epenkundliches Experiment.-In: Welt der Slaven I (1956), 322-33

Die Prage einer "Martolosen"-Epik.-In: Welt der Slaven III (1958)

Bugarłtica-Studien. Verdoppelung der Präposition.-In: Festschrift fur E.Koschmieder,hrsgg. vom Sudost-Institut Munchen (1958), 180-89

Gattung und Stil in der Volksdichtung.-In:Rad Kongreas Folklorista Jugoslavije u Varaždinu 1957, Zagreb 1959

Stilanalyse und Chronologie. Bugarstica und Zehnsilberepik.-In: Rad Kongresa Polklorista Jugoslavije VI, Bled 1959, 111-16

Bugarstica-Studien. Der Gebrauch des Deminutiv8.-In: Welt der Slaven IV, Wiesbaden 1959

Drostruki epitet u bugargtici.-In: Zbornik za filologiju i lingvistiku, Novi Sad 1959,58-73

Serbokroatische Lang- und Kurzzeilenepik. Epitheta als chronologisches Kriterium.-In: Munchener Studien zur Sprachwissenschaft XV (1959). 65-84

Formel und metrisch-syntaktisches Modell. Zur Iiedsprache der Bugarstica.-In: Welt der Slaven $(1960), 395-408$

Die albanische Volksepik.-In: Shêjzat VII,Rom 1963, 173-90

Die balkanische Volksepik. Typologie und Kontinuitätsproblem.-In: Z Balk $I_{1-2}$ (1963), 133-52

Iz problematike istorijakog razvoja kosovake tradicije. Pobratimi Miloza Obilića.-In: Zbornik Piloz. Pakulteta VIII, Beograd 1964, 617-24

Milor obilic u narodnom pesniftvu i kod Njegosa.-In: Rad Xog Kongresa Folklorista Jugoolavije, Cotinjo 1964, 43-54

Der Skenderbeg-Zyklus bei Andrija Kaxic Miosic.-In: Shejzat $x_{9-12}(1966), 320-35$

Probleme und Aufgaben der balkanischen Epenforschung.-In: Sudosteuropa-Schriften VII: Die Volksmusik Sudosteuropas. Beiträge zur Volkskunde und Musikwissenschaft anläBlich der I. Balkanologentagung in Graz 1964, Hrsg.W.Winsch, Munchen 1966, 14-28

Studien zu balkanischen Balladenmotiven.1.Wegmarkierung mit Blut.-In: Beiträge zur Sudosteuropa-Porschung (Red.A.Schmaus), Munchen 1966. 285-304 
V Schmaus,A.8

ders.8

ders.:

ders.:

Seemann, E.:

ders.:

Sefterski, R.:

Sikora, G.:

Simonovic,M.:

Skripil',M.:

ders : :

Sozonovid, I.:

Stanojevic,st.:

Stefanovic,s.:

Steinmeyer,E.:

Stojkova,st.:

Stoilov,A.P.:

ders.:

ders.:
Studien zu balkanischen Balladenmotiven.2. Die Pee entzweit die Bruder.-Insz Balk IV (1966), 100-38

"Neomitologizam" 1 južnoslovenska narodna epika.-In: Lit.zbor (1967)

Das "Seelentier" der Pee. Ein totemistisches Motiv in der Volksdichtung.-Ins Festschrift fur M.Woltner, Heidelberg 1967

Zlatoroge divokoze albanskin gorskih vila (zâna).-In: Jehona, Skopje 1967

Die Zekuloballade und die Ballade von der Brautwerbung. Eine Studie zu zwel Gottscheer. Liedern.-In: Jahrbuch flur Volkslledforschung VII (1941). 40-70

Die Gestalt des kriegerischen Madchens in den europisichen Volksballaden.-Ins Rheinisches Jahrbuch fur Volkskunde X (1959), 192-212

Jamurlukŭt $v$ Bülgari ja.-In:SbNU L(1963),369-403

Epika u Sopluku.-Ins PPNP $I_{2}(1934), 247-51$

Beitrăge zu einer Untersuchung uber einige der deutschen und serbischen Heldendichtung gemeinsame Motive.-In:ASIPh 36 (1915), 49-110

Povest' o Fetre 1 Fevrond1 1 épiceskie pesni juznych slavjan ob ognennom zmee.-In:liaucnyj bjulleten' Ieningradskogo gosudarstvennogo universiteta $\mathrm{Nr}$.11-12 (1946)

Povest' o Petre 1 Pevronil muromskich $\nabla$ ee otnołenijach k russkoj skazke.-In: TODL VII (1949) $131-67$

Tip amazonki $v$ evropejskoj literaturnoj tradicii $i$ poljanica voinstvennaja moskich bylin.In: Nauxno-literaturnyj sbornik Galicko-russkoj maticy $\mathrm{II}_{4}$. Lwow 1902, 137-53

O nekim motivima u nas
PPNP $I_{1-2}(1934), 511$.

Dva dogadaja ugarake istorije u nasoj narodnoj poezij1.-In: PPNP VI (1939), 35-45

Die jungeren Handschriften der Erlanger Universitätsbíblio thek, Erlangen 1913

Nabl judeni ja vurchu aǔvremennoto eŭstojanie na junaskata epiđeska tradic1ja $v$ Bulgarija.-In: Sbornik Slav janska filologija $\nabla$, Sofia 1963,22-3

Iegendata za Krall Marko.-In: Misŭl $X_{8}$ (1900). 53919 .

Legen-grad $v$ jugoslav janskata narodna poezija.In: Yer.Spis.64 (1903-04), 237-48

Lamite $i$ zmejovete $v$ narodnata poezija.-In: Spis.BAN XXII (1921) 
Stoilov,A.P.:

ders.8

ders •:

Šeptunor,I.:

Setka,J.:

Simcik,A.:

ders.:

Sismanov,I.:

ders.:

Teodorov,E.:

ders.:

Tolstoj,I.:

Trifonov,Ju.:

Usener,H.:

Vaillant,A.:

ders.:

ders.:

Vojnik na svatbata na zena si.- In: INEM I, (1921), 17-39

Zeni cheroin1.-In: INEM II $3-4$ (1922)

Predvestie $2 a$ padane na carstro (spored narodnite peeni).-In: INEM VII ${ }_{1-4}$ (1927)

Bolgarskie chajdutgkie pesni.-In: TIE XIII (1951), 251 Pf.

Pra Andrija Kadic Miozić i narodna pjesma.-In: ZNZO 38 (1954), 5-74

Nova knjiga starih jugoslovenskih narodnih pjesama.-In: Hrvatska prosvjeta XIV (1927), 69-70, 116-19

"Oliva" izvor pjesme broj 1 u Erlangenskom rukopisu.-In: Slavia VIII, Yrag 1929-30, 771-74

Znadenieto 1 zadacata na nazata etnografija.In: SbNU I (1889), 1-64

Kriti.ðen pregled na rüprosa za proizchoda na prabǔlgarite ot ezikovo glediste 1 etimologiite na imeto "bulgarin".-In: SbNU XVI-XVII (1900)

Naslojavanija $v$ edna büleErska narodna epiCeska pesen.-In: IEIM I (1953), 203-40

Proizchod na pesenta $2 a$ dete Dukadince.-In:IEIM II (1955), 347-87

Vozvrałcenie muža $\nabla$ "Odissee" 1 v rusekoj skazke.-In: Sbornik v rest' akad.S.P.01'denourga, Leningrad 1934, 509-22

Eügarski pesni s istoricesixi spomeni ot XVI v.In: INEM III 1-2 (1923), $80 \mathrm{Pl}$.

Dreibeit.-In: Kheinisches Museum fur Philologie 58 (1903), 1-47, 161-208, 321-62

Les chants épiques des Slaves du Sud.-In: Revrue des Cours et Confér. Jg.33,1.Serie (1932), Nr.4, $30 y-26 ; \mathrm{Nr} .5,431-47 ; \mathrm{Nr} .6,635-47$

Le Digénis slave.-In: PKJIF XXI (1955),197-228

Le dieu slave Trojan.-In: PKJIP XXII $3-4$ (1956),

Vakarelski,Ch.8 ders.:

Za samovilite - orisnici.-In: INEM XII (1936),321. Bulgarskata istorileska narodna pesen.-In: BNTV III, Sopia 1961

Val javec, F.:

Ko je autor, gde je, I kada je nastao Erlangensxi rukopis? (Wer ist der Autor der Erlanger Handschrift, wo und wann ist sie entstanden?). Sonderabdruck aus Godisn jak grada Beograda I (1954), 105-110.-In: SOF XVI (1957)

Vasil'ev,B.:

Venedikov,I.:

Medvezij prazdnik.-In:Sov.Ėtn. $(1948)_{4}, 78 \mathrm{lf.}$ Samodivite.-In: IEIM VI (1963) 
Veselovskij,A.: Legendy o vernom zide 1 ob imperatore Trajane.-In: ZMNP CCX (1880), 85-97

vlahovie,M.: $\quad$ O slepim guslarima u Južnoj Srbiji.-In:GlEM VI (1931), 100-106

ders.:

Stanje epske pesme u Istornoj Srbiji.-In: PPNP I (1934), 96-106

ders.:

Gusle $i$ junazke pesme u Istornoj Srbiji.-In: GIEM X (19,5), 100-107

ders.:

o guslama 1 guslarima u pirotskom kraju.-In: GIEM XI (1936), 142-60

Volkov,F.K.:

Svadbarskite obredi na slavjanskite narodi.In: SbNU III (1891)

Vyncke, P.:

Trojan. Pokusaj tumąenja.-In: APF IV (1964), 437-43

Wenzel,M.:

wollner,w.:

A Medieval Mystery Cult in Bosmia and Hercegovina.-In: Journal of the Warburg and Courtauld Institutes $\mathbf{X X I V}_{1-2}$. Iondon 1961

Einige Spuren des Einflusses der iranischen Heldensage auf die südslavische.-In: IF IV $(1894), 448$ ff.

Zeltner,H.:

Die Erlanger Handschrift.-In: Zentralblatt fur Bibliothekswesen Jg.64, H.1-2, Erlangen $1950,43-52$

Zganec,V.:

Metrika i ritmika u versifikaciji narodnog deseterca.-In: Nar.umj.II (1963),3-35

$Z_{i r m u n} \theta k i j, v_{.}:$

$\mathrm{K}$ voprosu o literaturnych otnoseni jach Vostoka i Zapada.-In: Vestnik Leningradskogo universiteta (1947)

ders.:

Epireskoe trorcestro slavjanskich narodor i problemy sravaitel'nogo izuénija éposa.-In: Issledovanija po slavjanskomu literaturovedeniju i fol'kloristike.Doklady, Moskau 1960

Zivanovic,J.s

Erlangenski rukopis starih srpsko-hrvatskih narodnin pesama. Izdao D-r GrGezeman.-In: Venac XI $(1925-26), 523-25$

Zupanie,N.:

Der Name Grk (Grieche) in der Bedeutung "Riese" bei den Belokranjei in Jugoslavien.-In: Izvestija na Bilg. ArcheologiCeski Institut $X$, Sopia 1936, 19-26 

3for the nof

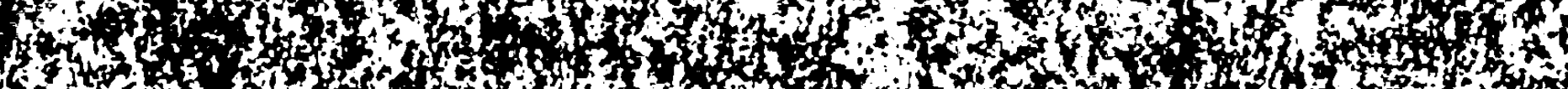

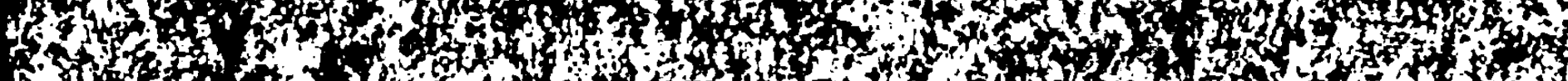

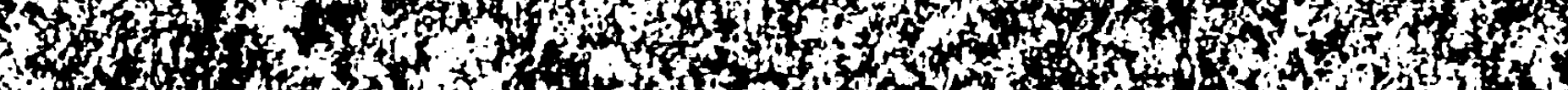

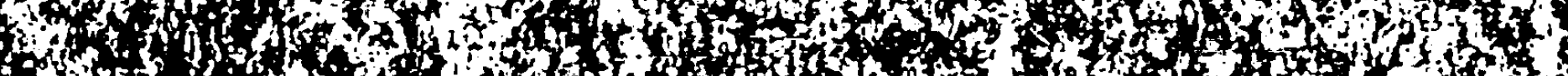

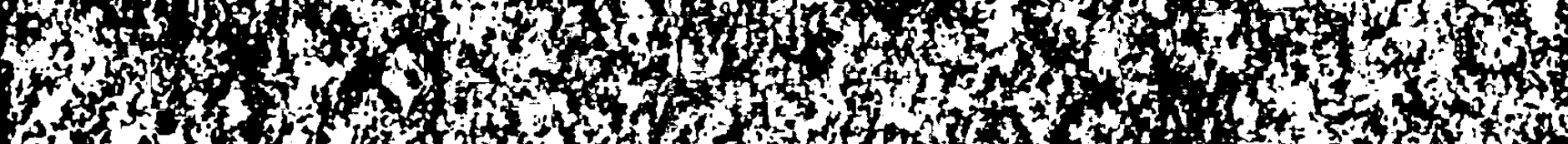
HNe

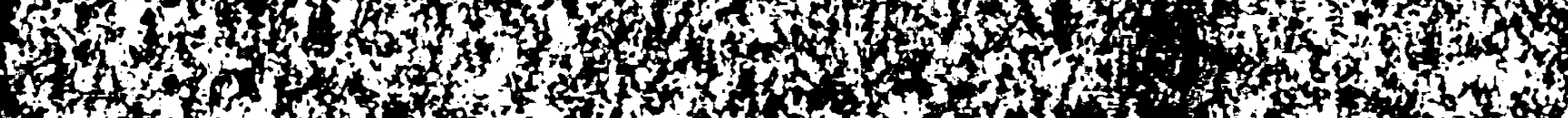

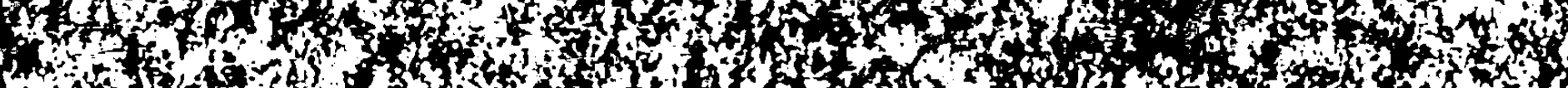

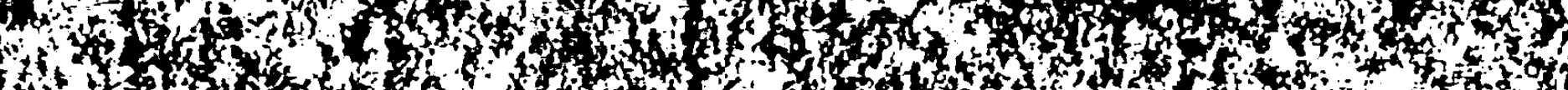
(tat whe

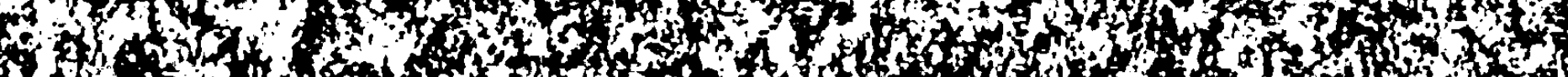

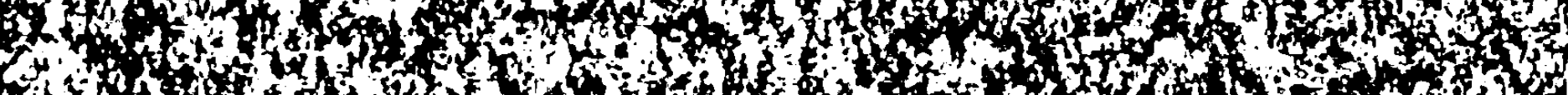

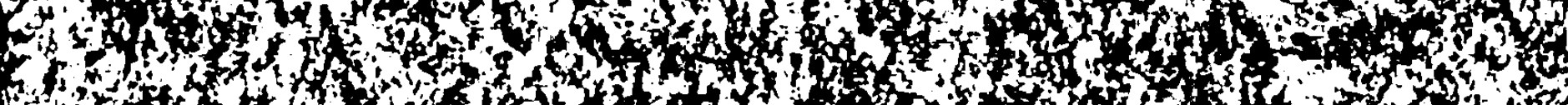
Hof

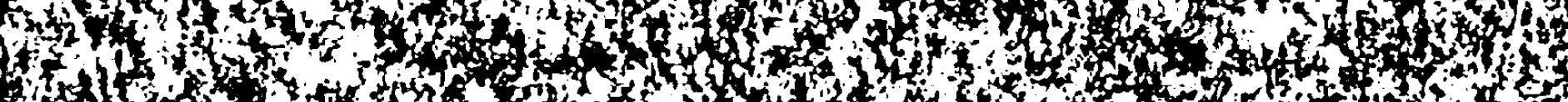

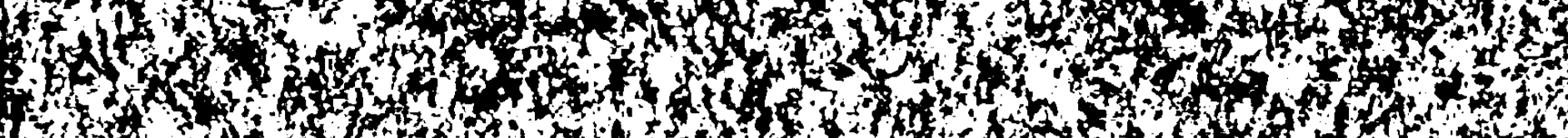

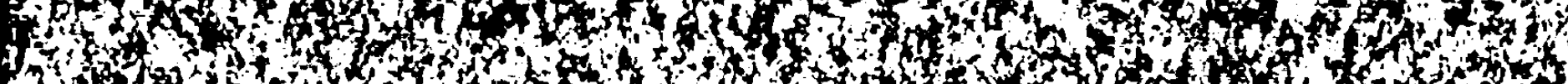
a 3. 1)

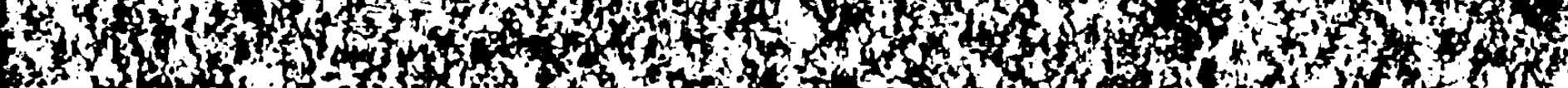
6.

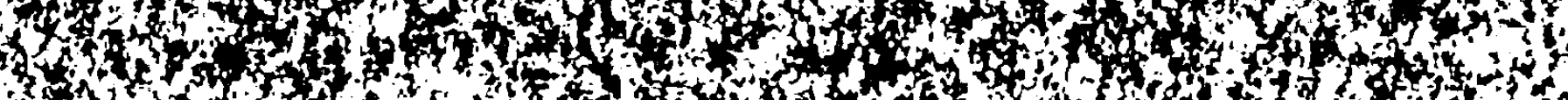

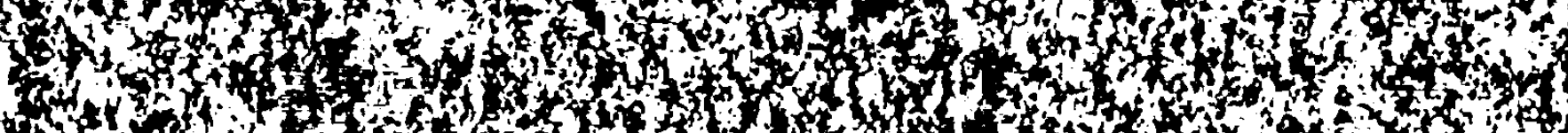

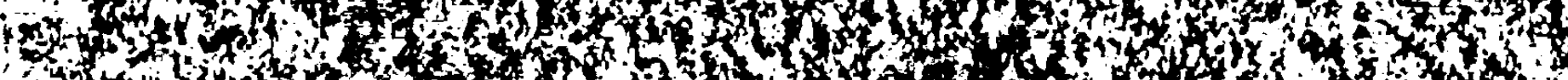
4 of

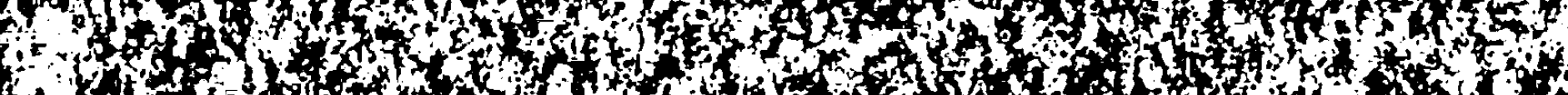

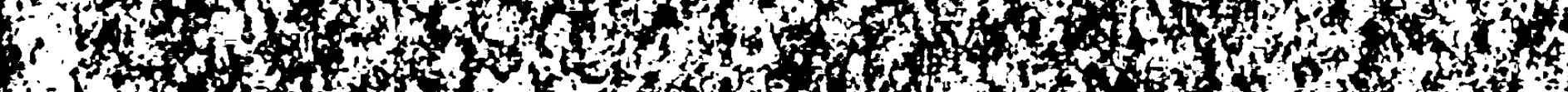

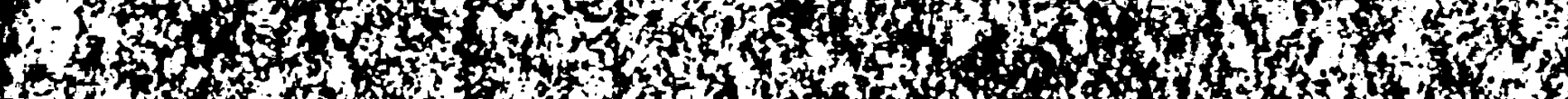

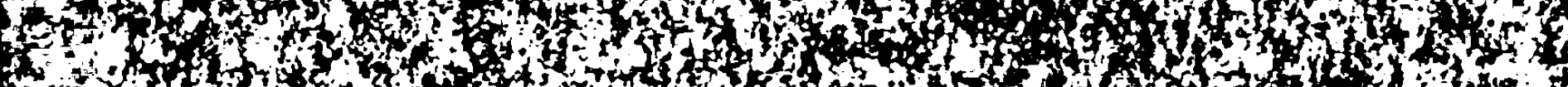

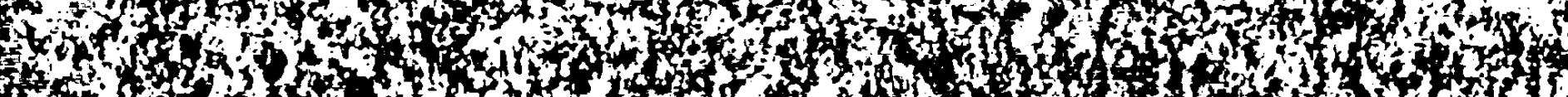

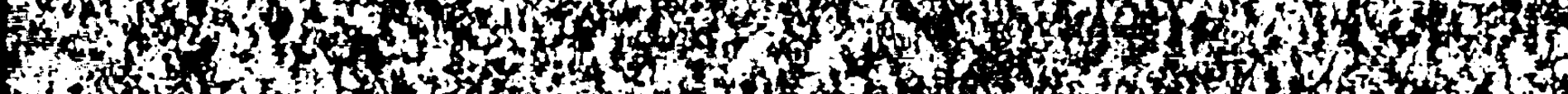

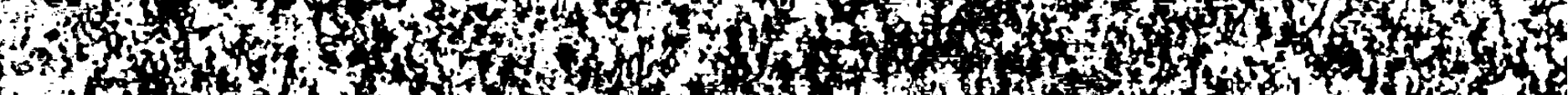

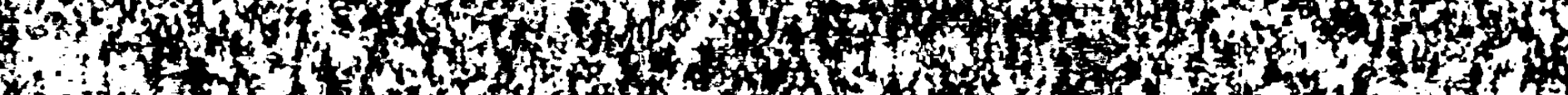

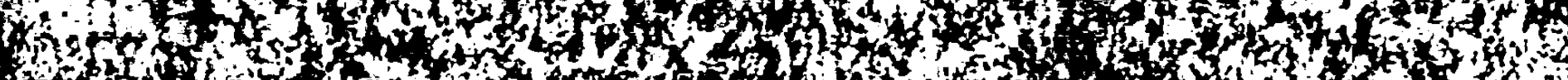

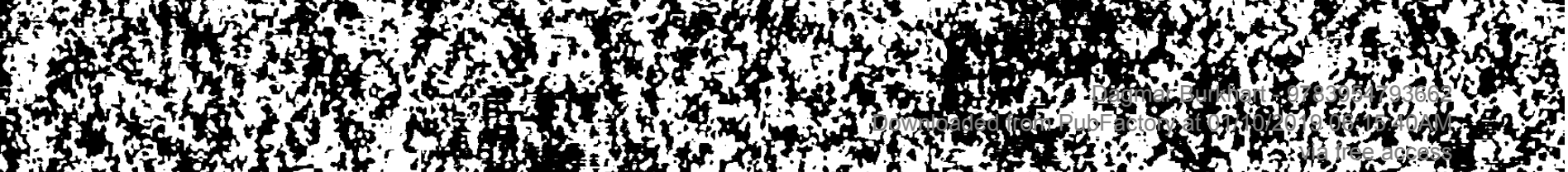

